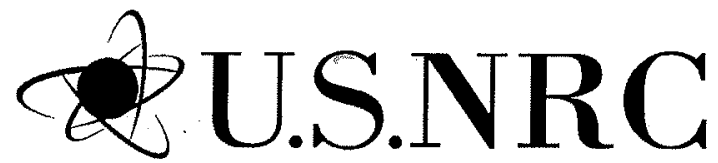

United States Nuclear Regulatory Commission Protecting People and the Environment

\title{
Cladding Embrittlement During Postulated Loss-of-Coolant Accidents
}




\section{AVAILABILITY OF REFERENCE MATERIALS IN NRC PUBLICATIONS}

\section{NRC Reference Material}

As of November 1999, you may electronically access NUREG-series publications and other NRC records at NRC's Public Electronic Reading Room at http://wnw.nrc.gov/reading $r \mathrm{rm}$.html. Publicly released records include, to name a few, NUREG-series publications; Federal Register notices; applicant, licensee, and vendor documents and correspondence; NRC correspondence and internal memoranda; bulletins and information notices; inspection and investigative reports; licensee event reports; and Commission papers and their attachments.

NRC publications in the NUREG series, NRC regulations, and Title 10, Energy, in the Code of Federal Regulations may also be purchased from one of these two sources.

1. The Superintendent of Documents

U.S. Government Printing Office

Mail Stop SSOP

Washington, DC 20402-0001

Internet: bookstore.gpo.gov

Telephone: 202-512-1800

Fax: 202-512-2250

2. The National Technical Information Service Springfield, VA 22161-0002

www.ntis.gov

1-800-553-6847 or, locally, 703-605-6000

A single copy of each NRC draft report for comment is available free, to the extent of supply, upon written request as follows:

Address: Office of Administration, Reproduction and Distribution Services Section

U.S. Nuclear Regulatory Commission

Washington, DC 20555-0001

E-mail: DISTRIBUTION@nrc.gov

Facsimile: $301-415-2289$

Some publications in the NUREG series that are posted at NRC's Web site address

http://mww.nrc.gov/reading-rm/doc-collections/nuregs are updated periodically and may differ from the last printed version. Although references to material found on a Web site bear the date the material was accessed, the material available on the date cited may

subsequently be removed from the site.

\section{Non-NRC Reference Material}

Documents available from public and special technical libraries include all open literature items, such as books, journal articles, and transactions, Federal Register notices, Federal and State legislation, and congressional reports. Such documents as theses, dissertations, foreign reports and translations, and non-NRC conference proceedings may be purchased from their sponsoring organization.

Copies of industry codes and standards used in a substantive manner in the NRC regulatory process are maintained at-

The NRC Technical Library

Two White Flint North

11545 Rockville Pike

Rockville, MD 20852-2738

These standards are available in the library for reference use by the public. Codes and standards are usually copyrighted and may be purchased from the originating organization or, if they are American National Standards, from-

American National Standards Institute

11 West $42^{\text {nd }}$ Street

New York, NY 10036-8002

unw.ansi.org

$212-642-4900$

Legally binding regulatory requirements are stated only in laws; NRC regulations; licenses, including technical specifications; or orders, not in NUREG-series publications. The views expressed in contractor-prepared publications in this series are not necessarily those of the NRC.

The NUREG series comprises (1) technical and administrative reports and books prepared by the staff (NUREG-XXXX) or agency contractors (NUREG/CR-XXXX), (2) proceedings of conferences (NUREG/CP-XXXX), (3) reports resulting from international agreements (NUREG/IA-XXXX), (4) brochures

(NUREG/BR-XXXX), and (5) compilations of legal decisions and orders of the Commission and Atomic and Safety Licensing Boards and of Directors' decisions under Section 2.206 of NRC's regulations (NUREG-0750).

DISCLAIMER: This report was prepared as an account of work sponsored by an agency of the U.S. Government Neither the U.S. Government nor any agency thereof, nor any employee, makes any warranty, expressed or implied, or assumes any legal liability or responsibility for any third party's use, or the results of such use, of any information, apparatus, product, or process disclosed in this publication, or represents that its use by such third party would not infringe privately owned rights. 


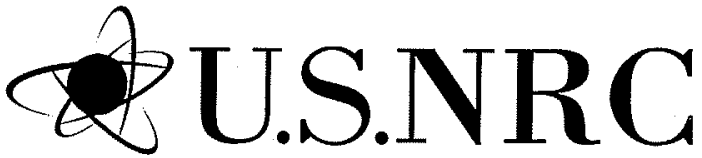

United States Nuclear Regulatory Commission

Protecting People and the Environment

\section{Cladding Embrittlement During Postulated Loss-of-Coolant Accidents}

Manuscript Completed: June 2008

Date Published: July 2008

Prepared by

M. Billone, Y. Yan, T. Burtseva, R. Daum

Nuclear Engineering Division

Argonne National Laboratory

9700 South Cass Avenue

Argonne, IL 60439

H. Scott, NRC Project Manager

NRC Job Code N6281

Office of Nuclear Regulatory Research 
This page is intentionally left blank. 


\section{Abstract}

The effect of fuel burnup on the embrittlement of various cladding alloys was examined with laboratory tests conducted under conditions relevant to loss-of-coolant accidents (LOCAs). The cladding materials tested were Zircaloy-4, Zircaloy-2, ZIRLO, M5, and E110. Tests were performed with specimens sectioned from as-fabricated cladding, from prehydrided (surrogate for high-burnup) cladding, and from high-burnup fuel rods which had been irradiated in commercial reactors. The tests were designed to determine for each cladding material the ductile-to-brittle transition as a function of steam oxidation temperature, weight gain due to oxidation, hydrogen content, pre-transient cladding thickness, and pre-transient corrosion-layer thickness. For short, defueled cladding specimens oxidized at 1000$1200^{\circ} \mathrm{C}$, ring compression tests were performed to determine post-quench ductility at $\leq 135^{\circ} \mathrm{C}$. The effect of breakaway oxidation on embrittlement was also examined for short specimens oxidized at $800-1000^{\circ} \mathrm{C}$. Among other findings, embrittlement was found to be sensitive to fabrication processes - especially surface finish - but insensitive to alloy constituents for these dilute zirconium alloys used as cladding materials. It was also demonstrated that burnup effects on embrittlement are largely due to hydrogen that is absorbed in the cladding during normal operation. Some tests were also performed with longer, fueledand-pressurized cladding segments subjected to LOCA-relevant heating and cooling rates.

Recommendations are given for types of tests that would identify LOCA conditions under which embrittlement would occur. 
This page is intentionally left blank. 


\section{Foreword}

Fuel rod cladding is the first barrier for retention of fission products, and the structural integrity of the cladding ensures coolable core geometry. In the early 1990s, new data from foreign research programs showed degraded cladding behavior for high-burnup fuel compared with low-burnup fuel in tests designed to simulate postulated accidents. Interim actions were taken, but it became clear that extrapolation from a low-burnup data base needed to be reassessed more carefully for regulatory purposes.

One of NRC's central regulations used in plant licensing deals with postulated loss-of-coolant accidents (LOCAs). A portion of that regulation in 10 CFR 50.46(b) specifies criteria that were derived from tests with unirradiated Zircaloy cladding, and these criteria limit the peak cladding temperature and the maximum cladding oxidation during the accident. These two limits are known as embrittlement criteria. Their purpose is to prevent cladding embrittlement during a LOCA, thus ensuring that the general core geometry will be maintained and be coolable.

In the mid-1990s, NRC sponsored a cooperative research program at Argonne National Laboratory to reassess these limits for the possible effects of fuel burnup. The program's industry partners included the Electric Power Research Institute, Framatome ANP (now AREVA), Westinghouse, and Global Nuclear Fuel; in general, the industry partners were responsible for providing precharacterized highburnup fuel rods and unirradiated archive tubing for testing. NRC also maintained coordination through the program with the U.S. Department of Energy, the Institute for Radiological Protection and Nuclear Safety in France, the French Atomic Energy Commission, the Japan Atomic Energy Agency, the Halden Reactor Project in Norway, and the Russian Research Center's Kurchatov Institute.

Because 10 CFR 50.46 applies to only two of the earlier cladding alloys, case-by-case reviews and frequent license exemptions have been required for two newer alloys. The research in this program has addressed the alloy-related effects as well as the burnup-related effects. This report thus provides test results that could be used to establish the technical basis for revision of 10 CFR 50.46(b) such that it accommodates the alloy and burnup effects. Other aspects of LOCA behavior, such as heat source redistribution and ballooning size, are also being investigated in this research program, but this report presents only those results that are relevant to cladding embrittlement.

Farouk Eltawila, Director Division of Systems Analysis Office of Nuclear Regulatory Research 
This page is intentionally left blank. 


\section{Contents}

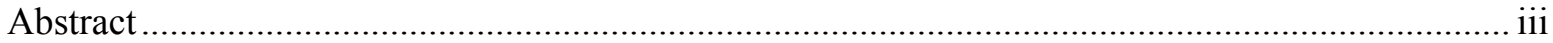

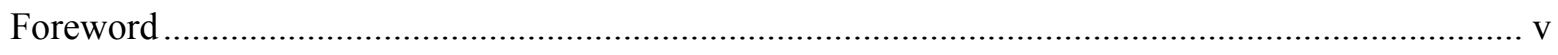

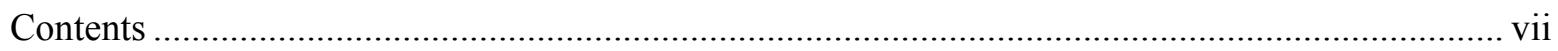

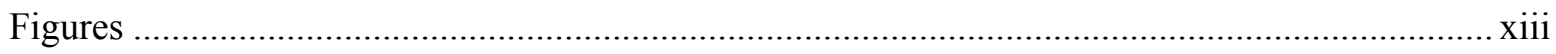

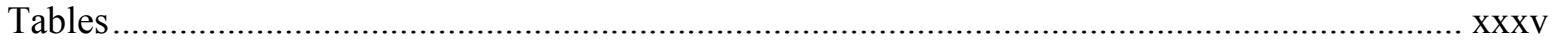

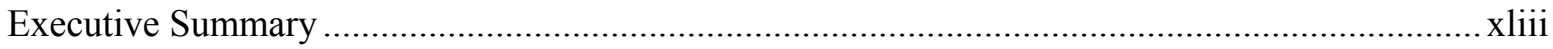

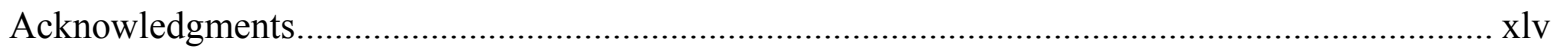

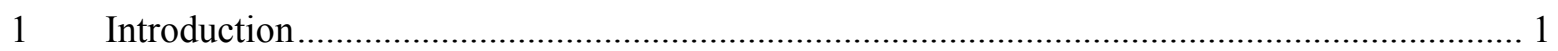

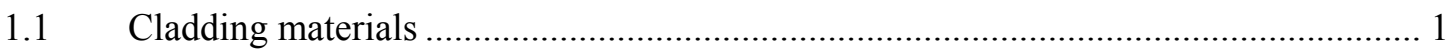

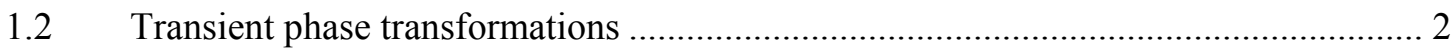

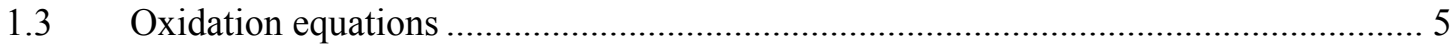

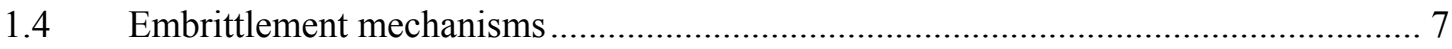

1.4.1 Beta-layer embrittlement by oxygen ................................................. 7

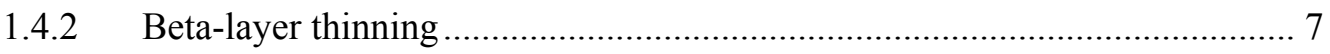

1.4.3 Localized hydrogen-induced embrittlement in the balloon region................ 7

1.4.4 Hydrogen-enhanced beta-layer embrittlement by oxygen .......................... 7

1.4.5 General hydrogen-induced embrittlement from breakaway oxidation ........... 7

1.4.6 Oxygen pickup from the cladding inner surface ...................................... 8

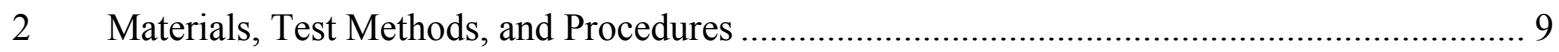

2.1 Description of cladding alloys and high-burnup fuel segments................................ 9

2.2 Oxidation and quench tests with short defueled cladding samples ........................... 12

2.3 Ductility determination using ring-compression tests.......................................... 23

2.4 LOCA integral tests with fueled-and-pressurized samples ...................................... 27 
3.1 Zircaloy-4.

3.1.1 Post-quench ductility of $17 \times 17$ Zry-4 oxidized at $1000^{\circ} \mathrm{C}, 1100^{\circ} \mathrm{C}$, and $1200^{\circ} \mathrm{C}$

3.1.2 Post-quench ductility of $15 \times 15$ Zry-4 oxidized at $1200^{\circ} \mathrm{C}$.

3.1.3 Breakaway oxidation time for $15 \times 15$ Zry-4 samples oxidized at 800 $1015^{\circ} \mathrm{C}$

3.2 Zircaloy-2

3.2.1 Post-quench ductility of $10 \times 10$ Zry-2 oxidized at $1000^{\circ} \mathrm{C}$ and $1200^{\circ} \mathrm{C}$

3.2.2 Breakaway oxidation time for $10 \times 10 \mathrm{Zry}-2$ samples oxidized at 970$1000^{\circ} \mathrm{C}$

3.3 ZIRLO

3.3.1 Post-quench ductility of $17 \times 17$ ZIRLO oxidized at $1000^{\circ} \mathrm{C}, 1100^{\circ} \mathrm{C}$, and $1200^{\circ} \mathrm{C}$

3.3.2 Breakaway oxidation time for $17 \times 17$ ZIRLO samples oxidized at 800 $1015^{\circ} \mathrm{C}$

3.4.1 Post-quench ductility of $17 \times 17 \mathrm{M} 5$ oxidized at $1000^{\circ} \mathrm{C}, 1100^{\circ} \mathrm{C}$, and $1200^{\circ} \mathrm{C}$

3.4.2 Breakaway oxidation time for $17 \times 17 \mathrm{M} 5$ samples oxidized at $1000^{\circ} \mathrm{C} \ldots . .115$

3.5 Effects of surface conditions on cladding performance

3.5.1 Effects of surface conditions on HBR-type Zry-4 and modern cladding alloys

3.5.2 Effects of surface conditions on E110 tubing and cladding.... 120

3.6 Effects of quench temperature on post-quench ductility. 138

3.6.1 Effects of quench temperature on post-quench ductility of $17 \times 17$ Zry-4......

3.6.2 Effects of quench temperature on post-quench ductility of $17 \times 17$ ZIRLO 
3.6.3 Effects of quench temperature on post-quench ductility of $17 \times 17$ M5 ..... 142

3.7 Summary of results for as-fabricated cladding …........................................... 143

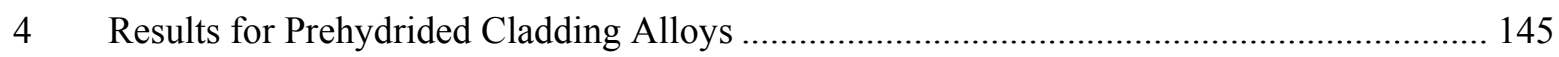

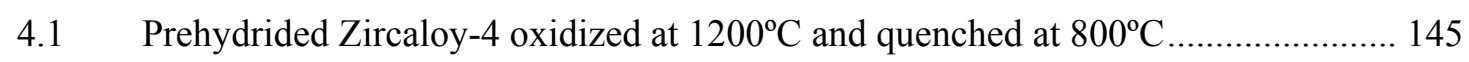

4.1.1 Post-quench ductility of prehydrided $17 \times 17$ Zry-4 oxidized at $1200^{\circ} \mathrm{C} \ldots .148$

4.1.2 Post-quench ductility of prehydrided HBR-type $15 \times 15$ Zry-4 oxidized

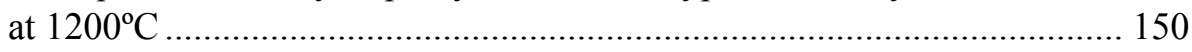

4.2 Effects of quench temperature on post-quench ductility..................................... 160

4.3 Discussion on cooling rate and quench temperature effects .................................. 168

4.4 Summary of post-quench ductility results for prehydrided Zry-4 ........................ 171

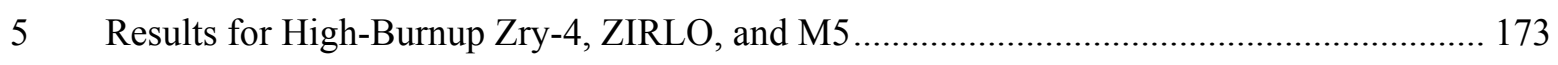

5.1 Results for high-burnup H. B. Robinson 15×15 Zry-4 …................................. 173

5.1.1 Characterization of high-burnup H. B. Robinson 15×15 Zry-4 ............... 173

5.1.2 Results of two-sided oxidation tests for high-burnup HBR $15 \times 15$

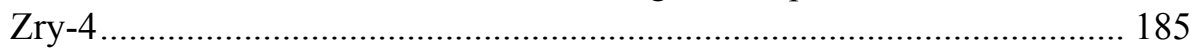

5.1.3 Results of one-sided oxidation tests for high-burnup HBR $15 \times 15$

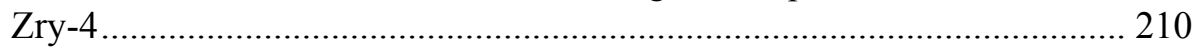

5.1.4 Discussion of high-burnup HBR 15×15 Zry-4 test results ....................... 226

5.2 Results for North Anna high-burnup 17×17 ZIRLO cladding............................... 227

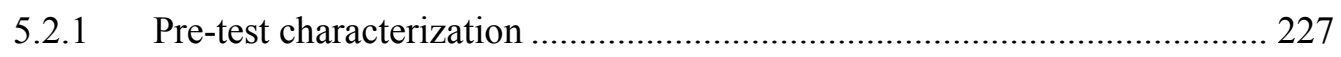

5.2.2 LOCA apparatus thermal and metallurgical benchmark tests for

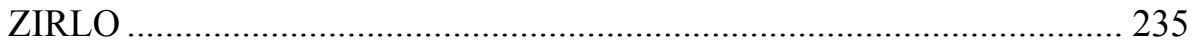

5.2.3 Ductility results for high-burnup North Anna ZIRLO ........................... 238

5.2.4 Discussion of high-burnup NA 17×17 ZIRLO test results........................ 256

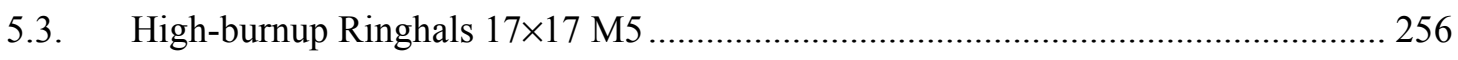

5.3.1 Characterization of high-burnup Ringhals M5 cladding ......................... 256 
5.3.2 LOCA apparatus thermal and metallurgical benchmark tests for M5 ....... 262

5.3.3 Ductility results for high-burnup Ringhals M5 cladding ........................ 262

5.3.4 Discussion of high-burnup Ringhals M5 results ...................................... 268

5.4 Summary of results for high-burnup cladding ....................................................... 286

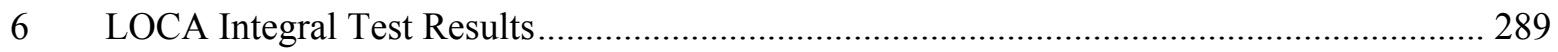

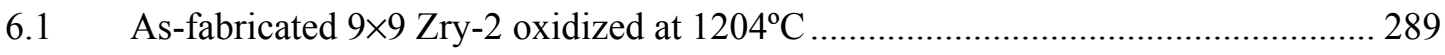

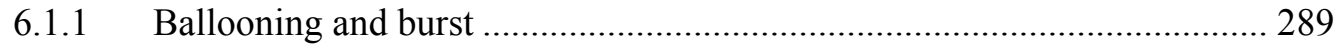

6.1.2 Oxidation and hydrogen pickup due to secondary hydriding.................... 296

6.1.3 Post-quench ductility for unirradiated LOCA integral samples ................. 300

6.2 High-burnup Limerick BWR 9×9 Zircaloy-2 oxidized at $1204^{\circ} \mathrm{C} \ldots \ldots \ldots \ldots \ldots \ldots \ldots \ldots . . . . . . . . . . . . . .303$

6.2.1 Ballooning and burst of high-burnup samples...................................... 303

6.2.2 Oxidation and hydrogen pickup due to secondary hydriding for highburnup samples................................................................................... 311

6.2.3 Post-quench ductility of high-burnup samples ...................................... 315

6.3 Cladding inner-surface oxygen pickup from fuel-cladding bond and fuel ............... 316

6.4 Summary of embrittlement implications of integral tests ..................................... 320

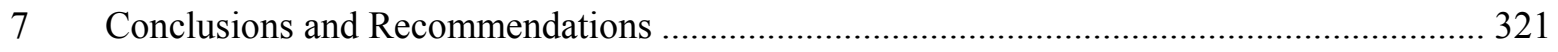

7.1 Beta-layer embrittlement of unirradiated cladding .............................................. 321

7.2 Beta-layer thinning of unirradiated cladding ...................................................... 323

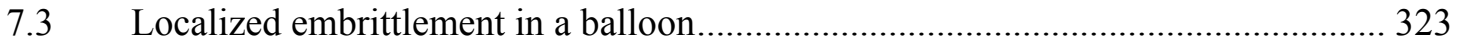

7.4 Hydrogen-enhanced beta-layer embrittlement.......................................................... 323

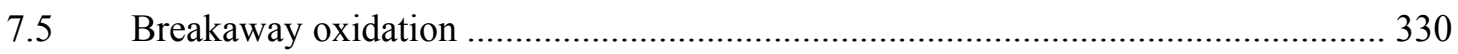

7.6 Oxygen pickup from the cladding inside diameter (ID) …................................. 330

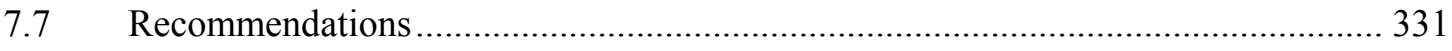

7.7.1 Circumferential and axial variations in hydrogen content.......................... 331 
7.7.2 Embrittlement oxidation level as a function of hydrogen content for high-burnup cladding

7.7.3 Effects of cooling rate and quench temperature on post-quench ductility and

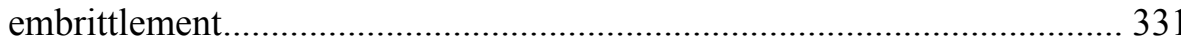

7.7.4 Assessment of prehydrided cladding as a surrogate for high-burnup

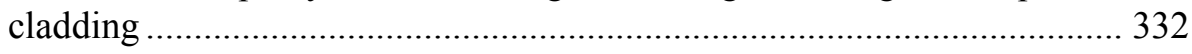

7.7.5 Sensitivity of breakaway oxidation to sample preparation and test

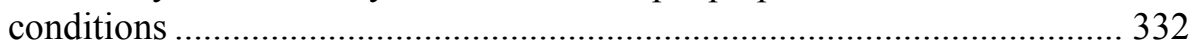

7.7.6 Performance-based tests for new cladding alloys................................... 332

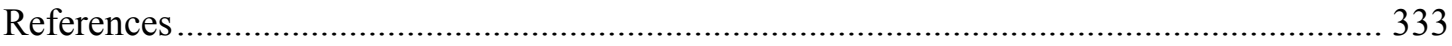


This page is intentionally left blank. 


\section{Figures}

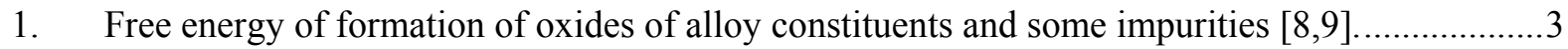

2. Schematic of cladding temperature during a LOCA................................................................

3. Qualitative diagram of oxygen concentration in Zircaloy cladding exposed at high temperature $\left(>980^{\circ} \mathrm{C}\right)$ to steam on the outside surface and cooled to room temperature. OD

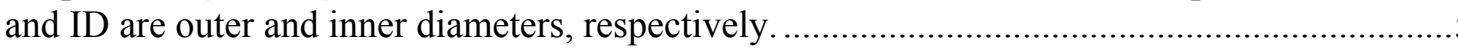

4. Unirradiated Zircaloy-2 after oxidation in steam at $1200^{\circ} \mathrm{C}$ for 600 seconds..........................5

5. Diffusion couple character of oxygen sources and cladding metal......................................... 8

6. Overview of the out-of-cell LOCA integral test apparatus. One in-cell unit was located at Workstation 6 of the Alpha-Gamma Hot Cell Facility (AGHCF) behind the hot-cell shield and seal windows. High-burnup Zry-4 oxidation/quench tests, as well as high-burnup Zry-2 oxidation and integral tests, were conducted in the AGHCF. Following closure of the AGHCF to programmatic work (January 2006), the out-cell apparatus was moved to a "cold" laboratory for testing nonirradiated cladding samples. This apparatus, equipped with a new furnace and a shorter $(610 \mathrm{~mm})$ test chamber, was moved in 2008 into Hot Cell \#4 of the Irradiated Materials Laboratory for performing oxidation-and-quench tests with highburnup ZIRLO and M5 cladding samples.

7. Schematic of oxidation kinetics, oxidation-quench, and LOCA integral test apparatus; test train and sample are shown for LOCA integral testing.

8. Test train for conducting one-sided steam-oxidation kinetics tests in-cell using $\approx 25$-mm-long Zircaloy cladding samples: a) test train within quartz tube; and b) enlarged view of sample region along the test train showing alumina spacers to inhibit Zircaloy-Inconel interaction and zirconia washers to minimize steam leakage to the sample inner surface.

9. Test train design for two-sided oxidation tests with four holes drilled into the Inconel holder below the sample (left) for steam ingress and four holes drilled into the holder above the sample for steam egress. Also shown are the three thermocouples permanently welded to the Inconel holder just above the sample. To improve strength and endurance, the number of holes was later reduced from four to three.

10. Thermal benchmark results from two tests, each with two TCs welded onto as-fabricated, HBR-type $15 \times 15$ Zry-4 cladding. Test HBRU\#20 had TCs welded onto the sample at $0^{\circ}$ and $120^{\circ}$, while test HBRU\#29 had TCs welded onto a new sample at $0^{\circ}$ and $240^{\circ}$. The sample hold temperature is $1204 \pm 10^{\circ} \mathrm{C}$, where $1204^{\circ} \mathrm{C}$ is the average of the three TC readings and $\pm 10^{\circ} \mathrm{C}$ is the standard deviation. 
11. Thermal benchmark results with as-fabricated $17 \times 17$ ZIRLO sample. Measured weight gains for $17 \times 17$ Zry-4, ZIRLO and M5 were inconsistent with each other and with CP-correlation prediction at 5\% CP-ECR due to possible differences in temperature overshoot (first peak) during the very rapid ramp to $1200^{\circ} \mathrm{C}$ followed by the temperature decrease and slower increase to $1200^{\circ} \mathrm{C}$.

12. Ring-compression load-displacement data at room temperature for Zry-4 oxidized to $20 \%$ CP-ECR $\left(20.3 \%\right.$ ECR based on measured weight gain) at $1100^{\circ} \mathrm{C}$. The sample fractured into four pieces. The offset strain $(0.455 \mathrm{~mm})$ is the distance along the displacement axis between the blue loading line (left) and the green unloading line (right).

13. Load-displacement results from RT compression and unloading of an 8-mm-long ring of HBR-type $15 \times 15$ Zry-4 cladding.

14. Photograph of ring compression sample supported by the fixed flat plate and loaded by the moveable, load-train platen for the Instron 8511. Not shown in the photograph is the control thermocouple which is located at the bottom inner surface of the ring. Also, thermocouples that rest against the side walls of the sample have been moved down to obtain a better image of the sample.

15. LOCA integral test train assembly and quartz tube. The $300-\mathrm{mm}$-long specimen is filled with zirconia pellets with a stack length of $\approx 270 \mathrm{~mm}$. The quartz tube has an outer diameter of $50 \mathrm{~mm}$, a wall thickness of $1.5 \mathrm{~mm}$, and a length of $686 \mathrm{~mm}$ (27 inches)

16. Schematic of the thermal history used for LOCA integral tests. Zirconia-filled, as-fabricated cladding samples are tested out-of-cell, and fueled high-burnup cladding samples are tested in-cell.

17. Thermal benchmark results for the $1000 \pm 10^{\circ} \mathrm{C}$ oxidation tests. The sample used was from the $0.57-\mathrm{mm}$-wall validation lot of $\mathrm{M} 5$, which has the same inner and outer diameter as $17 \times 17$ Zry-4 and ZIRLO. Quench at $800^{\circ} \mathrm{C}$ is not shown in this figure.

18. Thermal benchmark results for the $1100 \pm 2^{\circ} \mathrm{C}$ oxidation tests. The sample used was from the $0.57-\mathrm{mm}$-wall validation lot of M5, which has the same inner and outer diameter as $17 \times 17$ Zry-4 and ZIRLO. Quench at $800^{\circ} \mathrm{C}$ is not shown in this figure.

19. Post-test appearance of Zry-4 samples compressed at RT and $0.0333 \mathrm{~mm} / \mathrm{s}$ : (a) samples oxidized at $1000^{\circ} \mathrm{C}$ and (b) samples oxidized at $1100^{\circ} \mathrm{C}$. ECR values below each sample are calculated using the Cathcart-Pawel weight gain correlation.

20. Thermal benchmark results (Test Train \#1) for oxidation of $17 \times 17$ alloys at $1200 \pm 5^{\circ} \mathrm{C}$. The sample used for this benchmark was $17 \times 17$ Zry-4 with a wall thickness of $0.57 \mathrm{~mm}$. Quench is not shown in this figure.

21. Thermal benchmark results (later test train) for oxidation of $17 \times 17$ alloys at $1200 \pm 5^{\circ} \mathrm{C}$. The sample used for this benchmark was $17 \times 17$ ZIRLO with a wall thickness of $0.57 \mathrm{~mm}$. Quench is not shown in this figure. 
22. Offset (a) and permanent (b) strains vs. CP-ECR for $17 \times 17$ Zry-4 oxidized at $1200^{\circ} \mathrm{C}$, cooled at $\approx 13^{\circ} \mathrm{C} / \mathrm{s}$ to $800^{\circ} \mathrm{C}$, quenched, and ring-compressed at $\mathrm{RT}$ and $135^{\circ} \mathrm{C}$.

23. Thermal benchmark (HBRU\#5A) results for first test train used to oxidize HBR-type $15 \times 15$ low-tin Zry-4. The hold temperature based on two sample-welded TCs is $1200 \pm 17^{\circ} \mathrm{C}$

24. RT microhardness across prior-beta layer for $1200^{\circ} \mathrm{C}$-oxidized HBR-type $15 \times 15$ Zry- 4 .

25. Measured vs. predicted weight gain for two lots of HBR-type $15 \times 15$ low-tin Zry-4 oxidized at $1204 \pm 10^{\circ} \mathrm{C}$ and quenched at $800^{\circ} \mathrm{C}$.

26. Offset strain vs. CP-ECR and ring-compression test temperature for two lots of HBR-type $15 \times 15$ low-tin Zry-4 oxidized at $1204 \pm 10^{\circ} \mathrm{C}$, cooled at $\approx 11^{\circ} \mathrm{C} / \mathrm{s}$ to $800^{\circ} \mathrm{C}$, and quenched.

27. Thermal benchmark results for belt-polished $15 \times 15$ low-tin Zry-4 with a hold temperature of $\approx 1190^{\circ} \mathrm{C}$. Data-generating tests were conducted by increasing the holder control TC setting by $10^{\circ} \mathrm{C}$ to give a hold temperature of $1200^{\circ} \mathrm{C}$.

28. Offset strain vs. CP-ECR for $15 \times 15$ and $17 \times 17$ Zry- 4 samples oxidized at $1200^{\circ} \mathrm{C}$, cooled at $\approx 11^{\circ} \mathrm{C} / \mathrm{s}$ to $800^{\circ} \mathrm{C}$, and quenched. Ring compression tests were conducted at $135^{\circ} \mathrm{C}$ and $0.0333-\mathrm{mm} / \mathrm{s}$ displacement rate. Nominal offset strain for ductile-to-brittle transition ECR is $2 \%$.

29. Breakaway-oxidation time vs. oxidation temperature determined from the trend curves presented by Leistikow and Schanz $[19,20]$ for Zry-4 weight gain vs. time.

30. Results of thermal benchmark test with HBR-type $15 \times 15$ low-tin Zry-4. Measured weight gain was within $1 \%$ of the $\mathrm{CP}$-predicted weight gain. Hold temperature is $992 \pm 9^{\circ} \mathrm{C}$ at $78 \mathrm{~s}$ and $984 \pm 10^{\circ} \mathrm{C}$ at $1500 \mathrm{~s}$, beyond the temperature-ramp initiation.

31. Results of first thermal benchmark test with belt-polished $15 \times 15$ low-tin Zry-4. Measured weight gain was within $6 \%$ of the CP-predicted weight gain. Hold temperature is $1000 \pm 12^{\circ} \mathrm{C}$ at $95 \mathrm{~s}$ and $986 \pm 10^{\circ} \mathrm{C}$ at $1500 \mathrm{~s}$, beyond the temperature-ramp initiation.

32. Results of second thermal benchmark test with belt-polished $15 \times 15$ low-tin Zry-4. Initial overshoot temperature is $1012 \pm 7^{\circ} \mathrm{C}$, and long-time hold temperature is $986 \pm 12^{\circ} \mathrm{C}$. Results are based on the readings of three TCs welded to the sample $120^{\circ}$ apart.

33. Low magnification (left) of inner- and outer-surface oxide layers for HBR-type $15 \times 15$ lowtin Zry-4 oxidized at $\approx 1000^{\circ} \mathrm{C}$ for $159 \mathrm{~s}$; higher magnification (right) of the outer-surface oxide layer illustrating the smooth boundary between oxide and metal.

34. Low magnification (left) of inner- and outer-surface oxide layers for HBR-type $15 \times 15$ lowtin Zry-4 oxidized at $984 \pm 10^{\circ} \mathrm{C}$ for $3600 \mathrm{~s}$; higher magnification (right) of the outer-surface oxide layer showing the wavy boundary between oxide and metal, which is a precursor to breakaway. 
35. Low magnification (left) of inner- and outer-surface oxide layers for HBR-type $15 \times 15$ lowtin Zry-4 oxidized at $984 \pm 10^{\circ} \mathrm{C}$ for $5400 \mathrm{~s}$; higher magnification (right) of outer-surface oxide layer shows cracks in monoclinic oxide layer formed during the transition to breakaway oxidation.

36. Low magnification (left) of inner- and outer-surface oxide layers for belt-polished $15 \times 15$ low-tin Zry-4 oxidized at $\approx 1000^{\circ} \mathrm{C}$ for $135 \mathrm{~s}$; higher magnification (right) of outer-surface oxide layer shows the smooth boundary between oxide and metal.

37. Low magnification (left) of inner- and outer-surface oxide layers for belt-polished $15 \times 15$ low-tin Zry-4 oxidized at $986 \pm 12^{\circ} \mathrm{C}$ for $5400 \mathrm{~s}$ (BPZ4\#13); higher magnification (right) of outer-surface oxide layer shows wavy metal-oxide interface and initiation of breakaway oxidation.

38. Images of belt-polished $15 \times 15$ sample BPZ4\#18: (a) appearance of outer surface of sample showing local breakaway along a longitudinal strip; (b) inner and outer oxide layers showing pre-breakaway morphology of inner-surface oxide layer and post-breakaway morphology of outer-surface oxide layer; and (c) high magnification of outer-surface oxide layer.

39. Breakaway-oxidation data for HBR-type (0.3- $\mu \mathrm{m}$ surface roughness) and belt-polished (0.1$\mu \mathrm{m}$ surface roughness) $15 \times 15 \mathrm{Zry}-4$ oxidized in the same apparatus at $985 \pm 12^{\circ} \mathrm{C}$. Based on the ANL 200-wppm-hydrogen-pickup criterion, breakaway oxidation time is $\approx 3800 \mathrm{~s}$ for HBR-type $15 \times 15$ Zry-4 and $\approx 5000$ s for belt-polished (BP) $15 \times 15$ Zry-4.

40. Measured vs. CP-model-predicted Xi (oxide + alpha) layers after steam-oxidation tests $\left(300,600\right.$, and $1200 \mathrm{~s}$ at $\approx 1204^{\circ} \mathrm{C}$ ) with irradiated (LOI 6-8) and unirradiated (LOU 11-13) Zry-2..

41. Thermal benchmark results for $10 \times 10 \mathrm{Zry}-2$ at $1000^{\circ} \mathrm{C}$ target temperature. Average hold temperature is $1009 \pm 7^{\circ} \mathrm{C}$. Hold temperature after $2000 \mathrm{~s}$ from ramp initiation is $1005 \pm 8^{\circ} \mathrm{C}$. For oxidation tests, the control TC was lowered by $\approx 5^{\circ} \mathrm{C}$ to give a long-time hold temperature of $1000 \pm 8^{\circ} \mathrm{C}$.

42. Comparison of measured and CP-predicted weight gains for Zr-lined 10x10 Zry-2 and $17 \mathrm{x} 17$ Zry-4 oxidized at $1000^{\circ} \mathrm{C}$.

43. Micrographs of $10 \times 10 \mathrm{Zry}-2$ sample oxidized at $1000^{\circ} \mathrm{C}$ to $10 \% \mathrm{CP}$-ECR: (a) one of eight cross-sectional arc lengths, (b) outer Zry-2 surface, and (c) inner Zr-liner surface.

44. Thermal benchmark results for $10 \times 10$ Zry- 2 oxidation tests at $1200 \pm 6^{\circ} \mathrm{C}$. The raw data for the sample TC readings were corrected based on calibrating these TCs to an ANL NISTcalibrated TC. Also shown are the three TC readings for the holder TCs (Series 1-3).

45. Comparison of measured and CP-predicted weight gains for 10x10 Zry-2 and 17x17 Zry-4 oxidized at $1200^{\circ} \mathrm{C}$, cooled at $\approx 13^{\circ} \mathrm{C} / \mathrm{s}$ to $800^{\circ} \mathrm{C}$, and quenched at $800^{\circ} \mathrm{C}$. 
46. Metallographic images of $10 \times 10 \mathrm{Zry}-2$ sample oxidized at $1200^{\circ} \mathrm{C}$ to $10 \% \mathrm{CP}-\mathrm{ECR}$ :

(a) cross section (one of 8 orientations), (b) outer Zry-2 surface, and (c) inner Zr-lined surface.

47. Metallographic images of $10 \times 10 \mathrm{Zry}-2$ sample oxidized at $1200^{\circ} \mathrm{C}$ to $17 \% \mathrm{CP}$-ECR:

(a) cross section -- one of 8 orientations, (b) outer Zry-2 surface, and (c) inner Zr-lined surface.

48. Post-quench ductility (offset strain) vs. CP-ECR for Westinghouse $17 \times 17$ Zry-4, AREVA $15 \times 15 \mathrm{Zry}-4$, and GNF $10 \times 10 \mathrm{Zr}$-lined Zry-2, all oxidized at $1200^{\circ} \mathrm{C}$, cooled at $\approx 11-13^{\circ} \mathrm{C} / \mathrm{s}$ to $800^{\circ} \mathrm{C}$, and quenched at $800^{\circ} \mathrm{C}$. Ring-compression test temperature was $135^{\circ} \mathrm{C}$.

49. Comparison of Cathcart-Pawel model predictions to ANL sample weight gain data for irradiated (Limerick) Zry-2 after steam oxidation at $\approx 1000^{\circ} \mathrm{C}$ for test times of $1200 \mathrm{~s}$, $3600 \mathrm{~s}$, and $6000 \mathrm{~s}$

50. Comparison between weight gain data for ZIRLO and Zry-4 and weight gain predicted by the Cathcart-Pawel (CP) correlation for samples oxidized (two-sided) in steam at $1000^{\circ} \mathrm{C}$ (a) and $1100^{\circ} \mathrm{C}(\mathrm{b})$. Data correspond to CP-ECR values of $5,10,15,17$, and $20 \%$.

51. Post-quench ductility vs. measured (a) and CP-predicted (b) ECR for ZIRLO and Zry-4 oxidized at $1000^{\circ} \mathrm{C}$, cooled at $\approx 10^{\circ} \mathrm{C} / \mathrm{s}$ to $800^{\circ} \mathrm{C}$, and quenched. Ductility is based on offset strain determined from ring-compression data for tests conducted at RT and $0.0333-\mathrm{mm} / \mathrm{s}$ displacement rate.

52. Post-quench ductility vs. CP-predicted ECR for ZIRLO and Zry-4 oxidized at $1100^{\circ} \mathrm{C}$, cooled at $\approx 10^{\circ} \mathrm{C} / \mathrm{s}$ to $800^{\circ} \mathrm{C}$, and quenched. Ductility is based on offset strain determined from ring-compression data for tests conducted at RT and $0.0333-\mathrm{mm} / \mathrm{s}$ displacement rate.

53. Post-test appearance of ZIRLO ring-compression samples tested at room temperature and $0.0333 \mathrm{~mm} / \mathrm{s}$ : (a) samples oxidized at $1000^{\circ} \mathrm{C}$ and (b) samples oxidized at $1100^{\circ} \mathrm{C}$. ECR values are calculated using the Cathcart-Pawel weight gain correlation.

54. Metallography of as-polished Zry-4 (a) and ZIRLO (b) oxidized in steam at $1000^{\circ} \mathrm{C}$ for $\approx 3360 \mathrm{~s}$, cooled at $\approx 10^{\circ} \mathrm{C} / \mathrm{s}$ to $800^{\circ} \mathrm{C}$, and water quenched. Measured ECR values are $22.4 \%$ for Zry-4 and $18.0 \%$ for ZIRLO.

55. High-magnification images of etched ZIRLO sample following oxidation at $1000^{\circ} \mathrm{C}$ for 3360 $\mathrm{s}$ to $20 \% \mathrm{CP}$-ECR. The outer-surface oxide layer (a) is tetragonal, but the wavy oxide-metal interface indicates a precursor to breakaway oxidation. The inner-surface oxide layer (b) is thicker, has lateral cracks, appears to be monoclinic, and is in breakaway oxidation. The hydrogen pickup through the inner surface is $\approx 100$ wppm.

56. Metallography of etched Zry-4 (a) and ZIRLO (b) oxidized in steam at $1100^{\circ} \mathrm{C}$ for $\approx 1070 \mathrm{~s}$ to $20 \% \mathrm{CP}$-ECR, cooled at $\approx 10^{\circ} \mathrm{C} / \mathrm{s}$ to $800^{\circ} \mathrm{C}$, and water quenched. Measured ECR values are $20.3 \%$ for Zry-4 and $21.1 \%$ for ZIRLO. 
57. Comparison between weight gain data for ZIRLO and Zry-4 and CP-predicted weight gain for samples oxidized (two-sided) in steam at $1200^{\circ} \mathrm{C}$ and quenched at $800^{\circ} \mathrm{C}$.

58a. Offset strain vs. CP-ECR for $17 \times 17$ ZIRLO oxidized at $1200^{\circ} \mathrm{C}$, cooled at $\approx 13^{\circ} \mathrm{C} / \mathrm{s}$ to $800^{\circ} \mathrm{C}$, quenched, and ring-compressed at $\mathrm{RT}$ and $135^{\circ} \mathrm{C}$.

58b. Permanent strain vs. CP-ECR for $17 \times 17$ ZIRLO oxidized at $1200^{\circ} \mathrm{C}$, cooled at $\approx 13^{\circ} \mathrm{C} / \mathrm{s}$ to $800^{\circ} \mathrm{C}$, quenched, and ring-compressed at $\mathrm{RT}$ and $135^{\circ} \mathrm{C}$.

59. Offset strain vs. CP-ECR for $17 \times 17$ ZIRLO and Zry- 4 oxidized at $1200^{\circ} \mathrm{C}$, cooled at $\approx 13^{\circ} \mathrm{C} / \mathrm{s}$ to $800^{\circ} \mathrm{C}$, quenched, and ring-compressed at $135^{\circ} \mathrm{C}$.

60. Metallography of etched Zry-4 (a) and ZIRLO (b) oxidized in steam at $1200^{\circ} \mathrm{C}$ for $\approx 400 \mathrm{~s}$ and $\approx 440 \mathrm{~s}$, respectively, cooled at $\approx 13^{\circ} \mathrm{C} / \mathrm{s}$ to $800^{\circ} \mathrm{C}$, and quenched. Measured ECR values are $20.8 \%$ for Zry-4 and $22.3 \%$ for ZIRLO.

61. Metallography and microhardness indents across the radius of $17 \times 17$ Zry-4 (a) and ZIRLO (b) oxidized at $1200^{\circ} \mathrm{C}$ to $13 \% \mathrm{ECR}$, cooled at $\approx 13^{\circ} \mathrm{C} / \mathrm{s}$ to $800^{\circ} \mathrm{C}$, and quenched. The measured ECR values are $12.6 \%$ for Zry- 4 and $13.4 \%$ for ZIRLO.

62. Surface appearance and oxide layers of ZIRLO oxidized at $985^{\circ} \mathrm{C}$ for $3600 \mathrm{~s}$ with $270 \pm 165$ wppm hydrogen pickup in a ring including the yellow area: (a) outer surface with yellow area (440 wppm $\mathrm{H}$ under this layer) in black matrix; (b) outer- and inner-surface oxide layers (no breakaway) under black area; (c) outer-surface (breakaway) and inner-surface (no breakaway) oxide layers under yellow area; and (d) outer- and inner-surface oxide layers under yellow, both in breakaway.

63. Offset strain at $135^{\circ} \mathrm{C}$ vs. hydrogen pickup for $17 \times 17$ ZIRLO and $15 \times 15$ Zry-4 breakaway oxidation samples oxidized at $970-1000^{\circ} \mathrm{C}$ and cooled without quench.

64. Thermal benchmark results for $17 \times 17 \mathrm{M} 5$ oxidation tests at $1000^{\circ} \mathrm{C}$. The cladding OD is $9.50 \mathrm{~mm}$, and the wall thickness is $0.61 \mathrm{~mm}$. Quench at $800^{\circ} \mathrm{C}$ is not shown in this figure.

65. Thermal benchmark results for $17 \times 17 \mathrm{M} 5$ oxidation tests at $1100^{\circ} \mathrm{C}$. The cladding OD is $9.50 \mathrm{~mm}$, and the wall thickness is $0.61 \mathrm{~mm}$. Quench at $800^{\circ} \mathrm{C}$ is not shown in this figure.

66. Comparison between weight gain data for M5 and Zry-4 and weight gain predicted by the Cathcart-Pawel (CP) correlation for samples oxidized (two-sided) in steam at $1000^{\circ} \mathrm{C}$ (a) and $1100^{\circ} \mathrm{C}(\mathrm{b})$. Test times correspond to CP-ECR values of $\approx 5-20 \%$.

67. Post-quench ductility vs. measured (a) and CP-predicted (b) ECR for $17 \times 17$ M5 and Zry-4 oxidized in steam at $1000^{\circ} \mathrm{C}$, cooled at $\approx 10^{\circ} \mathrm{C} / \mathrm{s}$ to $800^{\circ} \mathrm{C}$, and quenched. Offset strain was determined from results of ring-compression tests conducted at RT and $0.0333-\mathrm{mm} / \mathrm{s}$ displacement rate. 
68. Post-quench ductility vs. CP-predicted ECR for $17 \times 17$ M5 and Zry-4 oxidized in steam at $1100^{\circ} \mathrm{C}$, cooled at $\approx 10^{\circ} \mathrm{C} / \mathrm{s}$ to $800^{\circ} \mathrm{C}$, and quenched. Offset strain was determined from results of ring-compression tests conducted at $\mathrm{RT}$ and $0.0333-\mathrm{mm} / \mathrm{s}$ displacement rate.

69. Post-test appearance of M5 ring-compression samples tested at room temperature and $0.0333 \mathrm{~mm} / \mathrm{s}$ : (a) samples oxidized at $1000^{\circ} \mathrm{C}$ and (b) samples oxidized at $1100^{\circ} \mathrm{C}$. ECR values are calculated using the Cathcart-Pawel weight gain correlation and $0.57-\mathrm{mm}$ wall. For $0.61-\mathrm{mm}$-wall M5, these values should be reduced to $4.7 \%, 9.3 \%, 14.1 \%, 16.0 \%$, and $18.8 \%$.

70. Metallography of as-polished Zry-4 (a) and M5 (b) oxidized in steam at $1000^{\circ} \mathrm{C}$ for $\approx 3360 \mathrm{~s}$, cooled at $\approx 10^{\circ} \mathrm{C} / \mathrm{s}$ to $800^{\circ} \mathrm{C}$, and water quenched. Measured ECR values are $22.4 \%$ for Zry-4 and $13.3 \%$ for M5.

71. High-magnification image of etched M5 outer-surface oxide and alpha layers following oxidation at $1000^{\circ} \mathrm{C}$ for $3360 \mathrm{~s}$. The outer-surface oxide layer is tetragonal, but the wavy oxide-metal interface is a precursor to breakaway oxidation.

72. Metallography of etched M5 (a) and Zry-4 (b) oxidized in steam at $1100^{\circ} \mathrm{C}$ for $\approx 1070 \mathrm{~s}$, cooled at $\approx 10^{\circ} \mathrm{C} / \mathrm{s}$ to $800^{\circ} \mathrm{C}$, and water quenched. Measured ECR values are $19.1 \%$ for M5 and $20.3 \%$ for Zry-4.

73. Thermal benchmark results for first test train for $17 \times 17 \mathrm{M} 5$ oxidation tests at $1203 \pm 8^{\circ} \mathrm{C}$. The cladding OD is $9.50 \mathrm{~mm}$, and the wall thickness is $0.61 \mathrm{~mm}$. Quench at $800^{\circ} \mathrm{C}$ is not shown in this figure.

74. Comparison between weight gain data for M5 and Zry-4 and CP-predicted weight gain for samples oxidized (two-sided) in steam at $1200^{\circ} \mathrm{C}$ and quenched at $800^{\circ} \mathrm{C}$

75a. Offset strain vs. CP-ECR for $17 \times 17 \mathrm{M} 5$ oxidized at $1200^{\circ} \mathrm{C}$, cooled at $\approx 13^{\circ} \mathrm{C} / \mathrm{s}$ to $800^{\circ} \mathrm{C}$, quenched, and ring compressed at room temperature $(\mathrm{RT})$ and $135^{\circ} \mathrm{C}$.

75b. Permanent strain vs. CP-ECR for $17 \times 17 \mathrm{M} 5$ oxidized at $1200^{\circ} \mathrm{C}$, cooled at $\approx 13^{\circ} \mathrm{C} / \mathrm{s}$ to $800^{\circ} \mathrm{C}$, quenched, and ring compressed at room temperature (RT) and $135^{\circ} \mathrm{C}$.

76. Offset strain vs. CP-ECR for $17 \times 17 \mathrm{M} 5$ and Zry- 4 oxidized at $1200^{\circ} \mathrm{C}$, cooled at $\approx 13^{\circ} \mathrm{C} / \mathrm{s}$ to $800^{\circ} \mathrm{C}$, quenched, and ring compressed at $135^{\circ} \mathrm{C}$.

77. Metallography of etched Zry-4 (a) and M5 (b) oxidized in steam at $1200^{\circ} \mathrm{C}$ for $\approx 400 \mathrm{~s}$, cooled at $\approx 13^{\circ} \mathrm{C} / \mathrm{s}$ to $800^{\circ} \mathrm{C}$, and water quenched. Measured ECR values are $20.8 \%$ for Zry-4 and $18.8 \%$ for M5.

78. Metallography and microhardness indents across the radius of $17 \times 17 \mathrm{Zry}-4$ (a) and M5 (b) oxidized at $1200^{\circ} \mathrm{C}$ to $12-13 \% \mathrm{CP}-\mathrm{ECR}$. The measured ECR values are $12.6 \%$ for Zry-4 and $13.1 \%$ for M5. Samples were quenched at $800^{\circ} \mathrm{C}$ following cooling at $\approx 13^{\circ} \mathrm{C} / \mathrm{s}$. 
79. Outer surface of belt-polished $15 \times 15$ Zry-4: (a) smooth exterior and (b) local region of surface abrasions.

80. Metallographic images in the scratched region of an HBR-type $15 \times 15$ Zry-4 sample (HBRU\#96) following oxidation at $985 \pm 12^{\circ} \mathrm{C}$ for $3600 \mathrm{~s}$. The top and bottom sectors are in breakaway oxidation, while the left and right sectors are not. The sample was prepared from a region of the cladding with scratches observed during pre-test and post-test characterization.

81. Cross section of ZIRLO cladding with machined scratch $\approx 20-\mu \mathrm{m}$ deep into outer surface.

82. Outer surface of scratched ZIRLO sample following oxidation at $985^{\circ} \mathrm{C}$ for $3400 \mathrm{~s}$. The local hydrogen pickup under the yellow surface is $440 \mathrm{wppm}$.

83. Outer surface of scratched ZIRLO sample following oxidation at $970^{\circ} \mathrm{C}$ for $2600 \mathrm{~s}$. The local hydrogen pickup under the yellow surface is $120 \mathrm{wppm}$.

84a. Outer surface of E1 10 tubing in the as-received condition $(0.35-\mu \mathrm{m}$ surface roughness). Axial direction is left to right.

84b. Outer surface of E110 tubing in the polished condition $(0.14-\mu \mathrm{m}$ surface roughness).

Axial direction is left to right.

84c. Outer surface of E110 tubing following etching in HF-containing pickling solution. Axial direction is left to right.

85. Thermal benchmark results for as-received E110 tubing and cladding oxidized in steam at $1000^{\circ} \mathrm{C}$. Ramp time is $75 \mathrm{~s}$.

86. As-fabricated E1 10 tubing oxidized in steam for a 75 -s ramp from $300^{\circ} \mathrm{C}$ to $1000^{\circ} \mathrm{C}$, followed by a 5-s hold at $1000^{\circ} \mathrm{C}$ and slow cooling: (a) low magnification of lustrous black outer surface oxide and (b) higher magnification of outer surface oxide showing white spots and streaks believed to be monoclinic oxide and oxide-instability initiation sites.

87. As-fabricated E110 thermal-benchmark (EU\#9) sample showing excessive monoclinic oxide formation around the welded thermocouple after 290 -s hold time at $1000^{\circ} \mathrm{C}$.

88. As-fabricated E1 10 sample oxidized in steam for a hold time of $290 \mathrm{~s}$ at $1000^{\circ} \mathrm{C}$ : (a) low magnification image of breakaway oxidation on the outer surface oxide of EU\#12 sample and (b) metallographic image of delaminated outer-surface oxide layer on EU\#13 sample.

89. EU\#11 sample oxidized for a hold time of $290 \mathrm{~s}$ at $950^{\circ} \mathrm{C}$. Breakaway oxidation is as extensive as for the EU\#12 sample oxidized for the same hold time at $1000^{\circ} \mathrm{C}$.

90. Hydrogen content distribution in E110 after oxidation Test EU\#38 with as-fabricated E110 exposed to steam at $1000^{\circ} \mathrm{C}$ for a hold time of $625 \mathrm{~s}(\approx 7 \% \mathrm{CP}-\mathrm{ECR})$. 
91. EU\#8 sample oxidized for a hold time of $1350 \mathrm{~s}$ at $1000^{\circ} \mathrm{C}$. Breakaway oxidation, delamination, and spallation are evident. The hydrogen pickup was $\approx 4200 \mathrm{wppm}$. 128

92. Room-temperature offset strain vs. CP-ECR for as-fabricated E110 tubing oxidized (twosided) in steam at $1000^{\circ} \mathrm{C}$ for hold times of $0-825 \mathrm{~s}$. Sample length is $8 \mathrm{~mm}$, and displacement rate is $0.0333 \mathrm{~mm} / \mathrm{s}$. Embrittlement is due to excessive hydrogen pickup (>200 wppm).

93. The effects of pickling (etching) E110 tubing prior to oxidation at $1000^{\circ} \mathrm{C}$ for $290 \mathrm{~s}$ :

(a) etched (180-s exposure to $\left.3.5 \% \mathrm{HF}+45 \% \mathrm{HNO}_{3}+51.5 \% \mathrm{H}_{2} \mathrm{O}\right)$ tubing sample;

(b) polished-and-etched E110 sample; and (c) etched-and-polished E110 sample.

94. Hybrid E110 sample (EU\#13) following oxidation at $1000^{\circ} \mathrm{C}$ for $290 \mathrm{~s}$. Machined-andpolished section is lustrous black, while as-fabricated E110 section is in breakaway oxidation.

95. Effects of polishing vs. machining-and-polishing on $\mathrm{E} 110$ oxidation at $1000^{\circ} \mathrm{C}$ for $290 \mathrm{~s}$

96. High magnification (200X) image of outer-surface oxide layers following oxidation at $1000^{\circ} \mathrm{C}$ for $290 \mathrm{~s}$ : (a) as-fabricated E110, (b) machined-and-polished E110, and (c) polished E110.

97. Machined-and-polished E110 sample (EU\#16) after 1025 -s hold time in steam at $1000^{\circ} \mathrm{C}$ :

(a) lustrous black oxide surface on one side of the sample and (b) extensive monoclinic oxide formation, delamination, and spallation evident on other side of the sample.

98. Hydrogen pickup vs. total test time for as-fabricated E1 10 tubing and ANL-modified machined-and-polished E110. The ramp time from $300^{\circ} \mathrm{C}$ to $1000^{\circ} \mathrm{C}$ is $75 \mathrm{~s}$ for the asfabricated tubing $(0.70-\mathrm{mm}$ wall) and $90 \mathrm{~s}$ for the machined-and-polished samples (0.6-mm wall).

99. Post-oxidation RT ductility vs. CP-ECR for ANL machined-and-polished (M-P) E110 samples and Bochvar-TVEL (BT) pickled E110 cladding following two-sided steam oxidation at $1100^{\circ} \mathrm{C}$.

100. Thermal benchmark test results for slow-cooled $17 \times 17$ Zry-4, ZIRLO, and M5 samples oxidized at $1200^{\circ} \mathrm{C}$.

101. Effects of quench vs. slow cooling on the post-oxidation ductility of $17 \times 17$ Zry-4 (0.57-mm wall) oxidized at $1200^{\circ} \mathrm{C}$, cooled at $\approx 13^{\circ} \mathrm{C} / \mathrm{s}$ to $800^{\circ} \mathrm{C}$, and either quenched at $800^{\circ} \mathrm{C}$ or slow cooled from $800^{\circ} \mathrm{C}$ to RT. Ring-compression tests were performed at $135^{\circ} \mathrm{C}$ and $0.0333-\mathrm{mm} / \mathrm{s}$ displacement rate

102. Effects of quench vs. slow cooling on the post-oxidation ductility of $17 \times 17$ ZIRLO $(0.57-$ $\mathrm{mm}$ wall) oxidized at $1200^{\circ} \mathrm{C}$, cooled at $\approx 13^{\circ} \mathrm{C} / \mathrm{s}$ to $800^{\circ} \mathrm{C}$, and either quenched at $800^{\circ} \mathrm{C}$ or slow cooled from $800^{\circ} \mathrm{C}$ to RT. Ring-compression tests were performed at $135^{\circ} \mathrm{C}$ and $0.0333-\mathrm{mm} / \mathrm{s}$ displacement rate. 
103. Effects of quench vs. slow cooling on the post-oxidation ductility of $17 \times 17$ M5 (0.61-mm wall) oxidized at $1200^{\circ} \mathrm{C}$, cooled at $\approx 13^{\circ} \mathrm{C} / \mathrm{s}$ to $800^{\circ} \mathrm{C}$, and either quenched at $800^{\circ} \mathrm{C}$ or slow cooled from $800^{\circ} \mathrm{C}$ to RT. Ring-compression tests were performed at $135^{\circ} \mathrm{C}$ and $0.0333-\mathrm{mm} / \mathrm{s}$ displacement rate

104. Uniform distribution of circumferential hydrides across the wall of HBR-type $15 \times 15$ Zry-4 prehydrided to 400 wppm $\mathrm{H}$.

105. Hydrogen concentration in a prehydrided HBR-type $15 \times 15$ Zry-4 sample before and after oxidation at $1200^{\circ} \mathrm{C}$ to $5 \% \mathrm{CP}$-ECR. Hydrogen contents after oxidation were corrected for sample weight gain to allow direct comparison with pre-test hydrogen contents.

106. Hydride morphology for prehydrided ( $435 \pm 50 \mathrm{wppm}$ ) HBR-type $15 \times 15$ Zry-4 showing a dense hydride rim $(\approx 46 \mu \mathrm{m})$ at the cladding inner surface.

107. Variation of post-quench ductility with pre-test hydrogen content for modern $17 \times 17$ Zry-4 oxidized at $1200^{\circ} \mathrm{C}$ to $7.5 \%$ and $10 \%$ CP-ECR (see 20 for temperature history), cooled at $\approx 13^{\circ} \mathrm{C} / \mathrm{s}$, quenched at $800^{\circ} \mathrm{C}$, and ring-compressed at $135^{\circ} \mathrm{C}$ and $0.0333 \mathrm{~mm} / \mathrm{s}$.

108. March 2006 thermal benchmark results for HBR-type $15 \times 15$ Zry-4 with a target oxidation temperature of $1200^{\circ} \mathrm{C}$.

109. June 2006 thermal benchmark results for HBR-type $15 \times 15$ Zry-4 with a target oxidation temperature of $1200^{\circ} \mathrm{C}$.

110. Variation of post-quench ductility with pre-test hydrogen content for HBR-type $15 \times 15$ Zry-4 oxidized to $5 \% \mathrm{CP}$-ECR with an end-of-heating temperature of $1180-1190^{\circ} \mathrm{C}$ (see Figures 10 and 108), cooled at $\approx 11^{\circ} \mathrm{C} / \mathrm{s}$, quenched at $800^{\circ} \mathrm{C}$, and ring-compressed at $135^{\circ} \mathrm{C}$.

111. Variation of post-quench ductility with pre-test hydrogen content for HBR-type $15 \times 15$ Zry-4 oxidized at $1204^{\circ} \mathrm{C}$ to $7.5 \%$ CP-ECR (see Figures 10,108 , and 109), cooled at $\approx 11^{\circ} \mathrm{C} / \mathrm{s}$, quenched at $800^{\circ} \mathrm{C}$, and ring-compressed at $135^{\circ} \mathrm{C}$.

112. Post-quench ductility vs. pre-test hydrogen content for modern $17 \times 17$ and HBR-type $15 \times 15$ Zry-4 oxidized at $1200^{\circ} \mathrm{C}$ to $7.5 \% \mathrm{CP}-\mathrm{ECR}$, cooled at $\approx 11-13^{\circ} \mathrm{C} / \mathrm{s}$, quenched at $800^{\circ} \mathrm{C}$, and ring-compressed at $135^{\circ} \mathrm{C}$

113. Metallographic images of HBR-type $15 \times 15$ Zry-4 following oxidation at $\approx 1200^{\circ} \mathrm{C}$ to $7.5 \%$ CP-ECR, cooling at $\approx 11^{\circ} \mathrm{C} / \mathrm{s}$ to $800^{\circ} \mathrm{C}$, and quench at $800^{\circ} \mathrm{C}$ : (a) as-received and (b) 600wppm hydrogen.

114. RT microhardness profiles across the prior-beta layer of two samples oxidized at $\approx 1200^{\circ} \mathrm{C}$ to $7.5 \% \mathrm{CP}$-ECR, cooled at $\approx 11^{\circ} \mathrm{C} / \mathrm{s}$ to $800^{\circ} \mathrm{C}$, and quenched at $800^{\circ} \mathrm{C}$ : as-received and 600 -wppm-hydrogen HBR-type $15 \times 15$ Zry- 4 . 
115. Measured RT microhardness and calculated oxygen-concentration profiles across the beta layers of HBR-type $15 \times 15 \mathrm{Zry}-4$ oxidized at $\approx 1200^{\circ} \mathrm{C}$ to $7.5 \% \mathrm{CP}$-ECR, cooled at $\approx 11^{\circ} \mathrm{C} / \mathrm{s}$ to $800^{\circ} \mathrm{C}$, and quenched at $800^{\circ} \mathrm{C}$ : (a) as-received and (b) 600-wppm hydrogen.

116. Effects of slow cooling vs. quench at $800^{\circ} \mathrm{C}$ on the post-test ductility at $135^{\circ} \mathrm{C}$ for HBR-type $15 \times 15$ Zry-4 oxidized to $5 \%$ CP-ECR at a peak temperature of $1180-1190^{\circ} \mathrm{C}$ prior to cooling. Plot includes data shown in Figure 110.

117. Effects of slow cooling vs. quench at $700^{\circ} \mathrm{C}$ and $800^{\circ} \mathrm{C}$ on ductility at $135^{\circ} \mathrm{C}$ for HBR-type $15 \times 15 \mathrm{Zry}-4$ oxidized to $7.5 \% \mathrm{CP}-\mathrm{ECR}$ at $1204^{\circ} \mathrm{C}$ prior to cooling. Plot includes data shown in Figure 110.

118. November 2006 thermal benchmark results for HBR-type $15 \times 15$ Zry-4 with a sample oxidation temperature of $1201 \pm 3^{\circ} \mathrm{C}$. Vertical lines indicate different quench temperatures for tests with prehydrided Zry-4 samples.

119. March 2007 thermal benchmark results for HBR-type $15 \times 15$ Zry-4 with a sample oxidation temperature of $1201 \pm 16^{\circ} \mathrm{C}$. Vertical line indicates quench at $800^{\circ} \mathrm{C}$

120. Embrittlement oxidation level (CP-ECR) vs. hydrogen content for $17 \times 17$ Zry-4 and $15 \times 15$ HBR-type Zry- 4 oxidized at $\leq 1200^{\circ} \mathrm{C}$, cooled at $11-13^{\circ} \mathrm{C} / \mathrm{s}$ to $800^{\circ} \mathrm{C}$ and quenched. Results for samples with large circumferential distributions in hydrogen content $( \pm 100 \mathrm{wppm})$ are not included in this because the limited database for these materials was insufficient to determine embrittlement CP-ECR

121. Gamma scan profile for segment $607 \mathrm{C}$ of HBR rod F07, from which samples were sectioned for hydrogen-content analysis, oxygen-content analysis, metallography, and two-sided oxidation tests.

122. Gamma scan profile for segment $608 \mathrm{C}$ of HBR rod G10, from which samples were sectioned for hydrogen- content analysis, oxygen-content analysis, metallography, and one-sided oxidation tests.

123. Sectioning diagram for characterization samples and two-sided-oxidation test samples. Eight 1.5-mm-long hydrogen-content samples were cut from 7H. A 13-mm-long sample (7D) was prepared for metallography, a 25-mm-long sample was cut for hydrogen and oxygen analyses (7E), and four 25-mm-long samples (7B, 7C, 7F, and 7G) were sectioned from near the core midplane for oxidation tests. C2 and C6 were used as metallography samples, and C3 and $\mathrm{C} 5$ were used as oxidation test samples.

124. Sectioning diagram for characterization samples and one-sided-oxidation test samples. Sample 7E was used for hydrogen and oxygen analysis. Sample 7D was used for metallographic analysis. Four 32-mm-long samples (7B, 7C, 7F, and 7G) were sectioned from near the core midplane for oxidation tests.

125. High-burnup HBR fuel morphology for the fuel midplane cross section of rod F07 showing indications of asymmetric power and temperature distributions relative to the center of the pellet. 
126. Fuel (dark), cladding (light), and fuel-cladding bond layer (gray) at the midplane of HBR rod F07. The image is a magnification of a small region from the fuel cross section shown in Figure 125.

127. High-magnification image of fuel-cladding bond layer at the fuel midplane of HBR rod A02.

128. Images of high-burnup Limerick BWR fuel-cladding bond at fuel-midplane location:

(a) prior to defueling in nitric acid and (b) after defueling in nitric acid.

129. Outer-surface corrosion layer for two-sided-oxidation test samples from HBR rod F07:

(a) midplane $(71 \mu \mathrm{m})$; (b) $320 \mathrm{~mm}$ above midplane $(74 \mu \mathrm{m})$; and (c) $650 \mathrm{~mm}$ above midplane $(95 \mu \mathrm{m})$.

130. Hydride distribution and morphology in HBR rod F07 cladding near locations used to section two-sided-oxidation test samples: a) fuel midplane (550-wppm H); b) $320 \mathrm{~mm}$ above midplane (550-wppm H); and c) $650 \mathrm{~mm}$ above midplane (740-wppm H).

131. Hydride distribution and morphology in HBR rod G10 cladding at the core midplane:

(a) typical hydride distribution across cladding wall and (b) atypical hydride distribution with a very dense hydride band near the outer surface and smaller dense hydrides across the wall.

132. Out-of-cell thermal benchmark results for as-fabricated cladding in the test train used to conduct in-cell two-sided oxidation tests with high-burnup HBR Zry-4 cladding. The results were used to plan oxidation times for two-sided tests with high-burnup HBR cladding samples.

133. Results of thermal benchmark test conducted after the in-cell oxidation tests with another test train and with TCs welded onto the outer surface of as-fabricated HBR-type Zry-4 cladding. Controller parameters were the same as those used to generate Figure 132 results.

134. Thermal benchmark results for pre-oxidized HBR-type Zry-4 with TCs welded onto barecladding outer surface and with steam-induced oxide layers of $37 \mu \mathrm{m}$ grown on the inner and outer surface of the cladding sample prior to the temperature ramp. Controller parameters were the same as those used to generate results in Figures 132 and 133

135. Temperature history used to calculate CP-ECR values and to interpret results for the in-cell two-sided oxidation tests conducted with high-burnup HBR Zry-4 cladding samples.

136. Measured average ([OD+ID]/2) alpha-layer thickness vs. CP-predicted value for high-burnup (550 \pm 100 wppm) HBR samples oxidized (two-sided) at $1100-1200^{\circ} \mathrm{C}$ and prehydrided $(600$ wppm) HBR-type Zry-4 sample oxidized at $\approx 1200^{\circ} \mathrm{C}$ to $7.5 \% \mathrm{CP}$-ECR.

137. High-magnification images of the outer surface of high-burnup HBR Zry-4 sample following oxidation (two-sided) at $1200^{\circ} \mathrm{C}$ to $7.4 \% \mathrm{CP}-\mathrm{ECR}$ and slow cooling to RT: (a) OM and

(b) SEM. 
138. High-magnification images of the inner surface of high-burnup HBR Zry-4 sample following oxidation (two-sided) at $1200^{\circ} \mathrm{C}$ to $7.4 \% \mathrm{CP}-\mathrm{ECR}$ and slow cooling to RT: (a) OM and

(b) SEM.

139. Optical microscopy images of the outer (a) and inner (b) surfaces of the high-burnup HBR Zry-4 sample oxidized (two-sided) at $\approx 1200^{\circ} \mathrm{C}$ to $9.3 \%$ CP-ECR followed by slow cooling to RT. The sample is in the as-polished condition.

140. Optical microscopy images of the outer (a) and inner (b) surfaces of the high-burnup HBR Zry-4 sample oxidized (two-sided) at $1200^{\circ} \mathrm{C}$ to $9.3 \% \mathrm{CP}$-ECR followed by slow cooling to RT. The sample is in the etched condition.

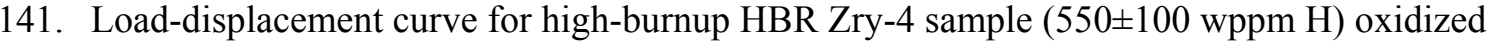
(two-sided) at $\mathrm{T} \leq 1110^{\circ} \mathrm{C}$ to $2.7 \% \mathrm{CP}$-ECR and slow cooled to RT. The ring-compression test was conducted at $135^{\circ} \mathrm{C}$ and $0.0333-\mathrm{mm} / \mathrm{s}$ displacement rate. The ring was intact after the test, indicating that ductility was $>45 \%$.

142a. Load-displacement curve for high-burnup HBR Zry-4 Ring \#1 (550 \pm 100 wppm H) cut from sample oxidized (two-sided) at $\mathrm{T} \leq 1169^{\circ} \mathrm{C}$ to $4.3 \% \mathrm{CP}-\mathrm{ECR}$ and slow cooled to RT. The ring-compression test was conducted at $135^{\circ} \mathrm{C}$ and $0.0333-\mathrm{mm} / \mathrm{s}$ displacement rate. The ring had a partial-wall crack after the first load drop, indicating that ductility was $>12 \%$.

142b. Load-displacement curve for high-burnup HBR Zry-4 Ring \#2 (550 \pm 100 wppm H) cut from sample oxidized (two-sided) at $\mathrm{T} \leq 1169^{\circ} \mathrm{C}$ to $4.3 \% \mathrm{CP}-\mathrm{ECR}$ and slow cooled to RT. The ring-compression test was conducted at $135^{\circ} \mathrm{C}$ and $0.0333-\mathrm{mm} / \mathrm{s}$ displacement rate. The ring had a single through-wall crack after $53 \%$ offset strain. Because it is not clear at what strain this crack occurred, the offset strain (37\%) corresponding to a $40 \%$ load drop is used to represent the ductility of the sample.

143. Load-displacement curve for high-burnup HBR Zry-4 (550 $\pm 100 \mathrm{wppm} H)$ sample oxidized (two-sided) at $\mathrm{T} \leq 1196^{\circ} \mathrm{C}$ to $6.4 \% \mathrm{CP}$-ECR and slow cooled to RT. The ring-compression test was conducted at $135^{\circ} \mathrm{C}$ and $0.0333-\mathrm{mm} / \mathrm{s}$ displacement rate. The ring had a single through-wall crack along the length of the sample at $4.0 \%$ offset strain, corresponding to the sharp load drop.

144. Load-displacement curve for high-burnup HBR Zry-4 (550 $\pm 100 \mathrm{wppm} \mathrm{H})$ sample oxidized (two-sided) at $1197^{\circ} \mathrm{C}$ to $7.4 \% \mathrm{CP}-\mathrm{ECR}$ and slow cooled to RT. The ring-compression test was conducted at $135^{\circ} \mathrm{C}$ and $0.0333-\mathrm{mm} / \mathrm{s}$ displacement rate. The ring had a single through-wall crack along the length of the sample at $4.0 \%$ offset strain, corresponding to the sharp load drop.

145. Load-displacement curve for high-burnup HBR Zry-4 (740 $\pm 110 \mathrm{wppm} \mathrm{H})$ sample oxidized (two-sided) at $1198^{\circ} \mathrm{C}$ to $7.5 \% \mathrm{CP}$-ECR and quenched at $800^{\circ} \mathrm{C}$. The ring-compression test was conducted at $135^{\circ} \mathrm{C}$ and $0.0333-\mathrm{mm} / \mathrm{s}$ displacement rate. The sharp load drop occurred essentially in the elastic deformation region and corresponded to a single through-wall crack along the length of the sample and no ductility. 
146. Load-displacement curve for high-burnup HBR Zry-4 (550 \pm 100 wppm H) sample oxidized (two-sided) at $1198^{\circ} \mathrm{C}$ to $9.3 \% \mathrm{CP}-\mathrm{ECR}$ and slow cooled to RT. The ring-compression test was conducted at $135^{\circ} \mathrm{C}$ and $0.0333-\mathrm{mm} / \mathrm{s}$ displacement rate. The ring had a single throughwall crack along the length of the sample at very low offset strain (brittle), corresponding to the sharp load drop.

147. Ductility at $135^{\circ} \mathrm{C}$ vs. CP-ECR for high-burnup HBR Zry-4 cladding following oxidation (two-sided) at $\leq 1200^{\circ} \mathrm{C}$ and either slow cooling to room temperature or quench at $800^{\circ} \mathrm{C}$. For the slow-cooled samples, the ductile-to-brittle transition CP-ECR is $\approx 8 \%$. For tests terminated prior to through-wall failure, arrows indicate that failure strains would be higher than end-of-test offset strains.

148. Permanent strain data from two-sided oxidation tests at $1200^{\circ} \mathrm{C}$ followed by slow cooling to RT for high-burnup and prehydrided (unirradiated) Zry-4 cladding samples.

149. Thermal-benchmark results for unirradiated, HBR-type Zry-4 exposed to one-sided (outersurface) oxidation: as-fabricated, pre-oxidized to $42-\mu \mathrm{m}$ outer-surface oxide layer; and preoxidized to $62-\mu \mathrm{m}$ outer-surface oxide layer. The temperature history for the $42-\mu \mathrm{m}$ oxide layer benchmark was used to plan and interpret the results from the one-sided oxidation tests with corroded $(68-\mu \mathrm{m})$, high-burnup HBR Zry-4.

150. Temperature histories for the one-sided and two-sided steam oxidation tests using highburnup HBR Zry-4 cladding samples

151. Sectioning diagram for high-burnup HBR Zry-4 samples after one-sided oxidation. Points of triangles indicate surfaces designated for metallographic characterization.

152. Comparison of measured and CP-predicted values for steam-induced outer-surface oxide layer thicknesses for high-burnup HBR Zry-4 samples oxidized at $1200^{\circ} \mathrm{C}$ to one-sided CP-ECR values of $4.9-9.7 \%$. Samples had a $68-\mu \mathrm{m}$ pre-test corrosion layer.

153. Outer surface of high-burnup HBR Zry-4 sample one-side oxidized at $1200^{\circ} \mathrm{C}$ for $174-\mathrm{s}$ test time to $4.9 \%$ CP-ECR: (a) contrast for viewing the oxide layer and (b) contrast for viewing the alpha layer.

154. Inner surface of high-burnup HBR Zry-4 sample one-side oxidized at $1200^{\circ} \mathrm{C}$ for 174 -s test time to 4.9\% CP-ECR: (a) normal contrast and (b) contrast and brightness adjusted for viewing the alpha layer in the central part of the micrograph.

155. High-burnup HBR Zry-4 sample one-side oxidized at $1200^{\circ} \mathrm{C}$ to $7.3 \% \mathrm{CP}$-ECR: (a) outer surface and (b) inner surface.

156. High-burnup HBR Zry-4 sample one-side oxidized at $1200^{\circ} \mathrm{C}$ to $8.5 \%$ CP-ECR: (a) outer surface and (b) inner surface.

157. Comparison of Zry-4 samples oxidized (one-sided) in steam at $1200^{\circ} \mathrm{C}$ to $5 \% \mathrm{CP}$-ECR: (a) as-fabricated HBR-type Zry-4 at $4 \mathrm{~mm}$ from sample midplane and (b) high-burnup HBR Zry-4 at $4 \mathrm{~mm}$ from sample midplane. 
158. Load-displacement curve for HBRI\#11 sample one-side oxidized to $4.8 \% \mathrm{CP}-\mathrm{ECR}$ at $1200^{\circ} \mathrm{C}$ and ring-compressed at $135^{\circ} \mathrm{C}$ and $0.0333 \mathrm{~mm} / \mathrm{s}$ displacement rate. The sample developed a tight through-wall crack along the 8-mm length at the support position, with the crack initiating from the inner surface. Offset displacement was $0.39 \mathrm{~mm}$, and permanent displacement in the loading direction was $0.27 \mathrm{~mm}$.

159. Load-displacement curve for HBRI\#12 sample one-side oxidized to $7.1 \% \mathrm{CP}-\mathrm{ECR}$ at $1200^{\circ} \mathrm{C}$ and ring-compressed at $135^{\circ} \mathrm{C}$ and $0.0333 \mathrm{~mm} / \mathrm{s}$ displacement rate. The sample developed a tight through-wall crack along the 8-mm length at the support position, with the crack initiating from the inner surface. Offset displacement was $0.1 \mathrm{~mm}$, and permanent displacement in the loading direction was $0.1 \mathrm{~mm}$.

160. Offset strain data at $135^{\circ} \mathrm{C}$ for high-burnup HBR Zry-4 samples with $\approx 550$-wppm hydrogen oxidized to a maximum temperature of $1200^{\circ} \mathrm{C}$ and slow cooled. Data are from two-sided and one-sided oxidation tests. Trend curve is based on two-sided-oxidation test results. .......225

161. Sectioning diagram for North Anna ZIRLO defueled cladding segments sent to ANL from Studsvik in second shipment. Corresponding ANL ID numbers are 648E, $648 \mathrm{~F}$ and $648 \mathrm{H}$ for Segments 5, 6, and 8, respectively.

162. Micrograph of polished metallographic sample at $\approx 2910 \mathrm{~mm}$ from rod bottom (Segment 6 in Figure 161) showing high-magnification image of ZIRLO corrosion layer.

163. High-magnification and high-contrast image of the ZIRLO fuel-cladding bond layer at $\approx 2910 \mathrm{~mm}$ from rod bottom (Segment 6 in Figure 161).

164. Images at eight locations around the circumference of etched ZIRLO cladding cross section at $\approx 2910 \mathrm{~mm}$ from the rod bottom showing radial and circumferential variation in hydride density. The thickness of the cladding metal wall $(544 \pm 2 \mu \mathrm{m})$, as well as the corrosion $(43 \pm 2$ $\mu \mathrm{m})$ and fuel-cladding-bond $(7 \pm 2 \mu \mathrm{m})$ layers, is relatively uniform.

165. Local cladding regions of high-burnup ZIRLO at $\approx 2910 \mathrm{~mm}$ from rod bottom showing (a) thickest ( $\approx 70 \mu \mathrm{m}$ equivalent) hydride rim and (b) thinnest $(\approx 40 \mu \mathrm{m}$ equivalent) hydride rim. The dashed line in the images was used to estimate equivalent (i.e., dense) thickness. The variation in hydride-rim thickness correlates quite well with the variation in LECOmeasured hydrogen content (500-840 wppm).

166. Comparison of thermal benchmark temperature histories for pre-oxidized ( $\approx 14-\mu \mathrm{m}$ OD and ID) ZIRLO (Test ZLU\#93B) and bare ZIRLO (Test ZLU\#98). ZLU\#93B temperatures were decreased by $12^{\circ} \mathrm{C}$ based on the decrease in holder temperature from the $\# 93 \mathrm{~B}$ test to the \#98 test and the TC reading correction based on comparison to NIST-calibrated TC.

167. Comparison of post-test offset strains at $135^{\circ} \mathrm{C}$ for high-burnup North Anna ZIRLO and H.B. Robinson Zry-4 cladding, oxidized at $\leq 1200^{\circ} \mathrm{C}$ and cooled with or without quench at $800^{\circ} \mathrm{C}$.

168. Load-displacement curve for high-burnup ZIRLO cladding oxidized to 6.3\% CP-ECR and cooled without quench: Ring \#1. 
169. Load-displacement curve for high-burnup ZIRLO cladding oxidized to $6.3 \%$ CP-ECR and cooled without quench: Ring \#2.

170. Load-displacement curve for high-burnup ZIRLO cladding oxidized to $8.1 \%$ CP-ECR and cooled without quench: Ring \#1.

171. Load-displacement curve for high-burnup ZIRLO cladding oxidized to 8.1\% CP-ECR and cooled without quench: Ring \#2.

172. Load-displacement curve for high-burnup ZIRLO oxidized to $10.2 \%$ CP-ECR and cooled without quench: Ring \#1.

173. Load-displacement curve for high-burnup ZIRLO oxidized to $10.2 \%$ CP-ECR and cooled without quench: Ring \#2.

174. Load-displacement curve for high-burnup ZIRLO oxidized to $6.3 \% \mathrm{CP}$-ECR and cooled with quench at $800^{\circ} \mathrm{C}$ : Ring $\# 1$.

175. Load-displacement curve for high-burnup ZIRLO oxidized to $6.3 \% \mathrm{CP}$-ECR and cooled with quench at $800^{\circ} \mathrm{C}$ : Ring $\# 2$.

176. Load-displacement curve for high-burnup ZIRLO oxidized to $4.0 \%$ CP-ECR and cooled with quench at $800^{\circ} \mathrm{C}$ : Ring $\# 1$.

177. Load-displacement curve for high-burnup ZIRLO oxidized to $4.0 \%$ CP-ECR and cooled with quench at $800^{\circ} \mathrm{C}$ : Ring $\# 2$.

178. Load-displacement curve for high-burnup ZIRLO oxidized to 5.1\% CP-ECR and cooled with quench at $800^{\circ} \mathrm{C}$ : Ring \#1 (7.4-mm long). The test was stopped due to displacement limitations prior to through-wall failure.

179. Load-displacement curve for high-burnup ZIRLO oxidized to 5.1\% CP-ECR and cooled with quench at $800^{\circ} \mathrm{C}$ : Ring \#1 (7.2-mm-long center ring). Partial through-wall side crack $\left(90^{\circ}\right.$ from loading direction) observed at $49 \%$ offset strain.

180. Load-displacement curve for high-burnup ZIRLO oxidized to 5.1\% CP-ECR and cooled with quench at $800^{\circ} \mathrm{C}$ : Ring $\# 1$ (5.5-mm-long end ring). Through-wall cracks occurred at the 10 and 12 o'clock positions after $9.5 \%$ offset strain.

181. Sectioning diagram for Ringhals M5 defueled cladding segments sent to ANL from Studsvik. From left to right, the segments were labeled by ANL as 645A, 645B, 645C, and $645 \mathrm{D}$.

182. Micrographs of corrosion layer (dark gray) on M5 cladding (light gray) outer surface at $\approx 2960 \mathrm{~mm}$ from bottom of high-burnup Ringhals Rod SUT3-00477. Based on images at eight circumferential locations, the corrosion layer thickness was determined to be $12 \pm 1 \mu \mathrm{m}$. 
183. Micrographs of fuel-cladding-bond oxide layer (dark gray) on M5 cladding (light gray) inner surface at $\approx 2960 \mathrm{~mm}$ from bottom of Ringhals Rod SUT3-00477. Based on images at eight circumferential locations, the corrosion layer thickness was determined to be $8 \pm 3 \mu \mathrm{m}$.

184. Metallographic image of high-burnup M5 cladding wall at one of eight circumferential locations. Based on data from all eight circumferential locations, the cladding wall thickness is $554 \pm 2 \mu \mathrm{m}(\approx 0.55 \mathrm{~mm})$. Short circumferential hydrides are observed across the wall.

185. Metallographic image of high-burnup M5 cladding wall at a second circumferential location (same axial location as shown in Figure 184). Hydride morphology consists of short circumferential and radial hydrides.

186. Comparison of post-test offset strains at $135^{\circ} \mathrm{C}$ for high-burnup $(110 \pm 20$ wppm hydrogen $)$ Ringhals M5 cladding cooled with or without quench at $800^{\circ} \mathrm{C}$ and for fresh M5 cladding cooled without or without quench at $800^{\circ} \mathrm{C}$. All samples were oxidized at a hold temperature of $1200^{\circ} \mathrm{C}$.

187. Comparison of post-test permanent strains at $135^{\circ} \mathrm{C}$ for high-burnup $(110 \pm 20 \mathrm{wppm}$ hydrogen) Ringhals M5 cladding cooled without quench and for fresh M5 cladding cooled with quench at $800^{\circ} \mathrm{C}$. All samples were oxidized at a hold temperature of $1200^{\circ} \mathrm{C}$.

188. Post-test offset strains at $135^{\circ} \mathrm{C}$ for high-burnup ( $110 \pm 20$ wppm hydrogen) Ringhals $\mathrm{M} 5$ cladding cooled with or without quench. Ductility limit for offset strains has been reset to $3.5 \%$ for oxidized M5 cladding. Curved lines are fit to average offset strains for slow cooling, quench excluding $1.9 \%$ data point (red solid line) and quench including all strain data (dashed black line).

189. Load-displacement curve for high-burnup M5 cladding oxidized to $13.4 \%$ CP-ECR and cooled without quench: Ring \#1.

190. Load-displacement curve for high-burnup M5 cladding oxidized to $13.4 \%$ CP-ECR and cooled without quench: Ring \#2.

191. Load-displacement curve for high-burnup M5 cladding oxidized to 15.1\% CP-ECR and cooled without quench: Ring \#1.

192. Load-displacement curve for high-burnup M5 cladding oxidized to 15.1\% CP-ECR and cooled without quench: Ring \#2.

193. Load-displacement curve for high-burnup M5 cladding oxidized to $17.0 \%$ CP-ECR and cooled without quench: Ring \#1.

194. Load-displacement curve for high-burnup M5 cladding oxidized to 17.0\% CP-ECR and cooled without quench: Ring \#2. 
195. Load-displacement curve for high-burnup M5 cladding oxidized to $18.1 \%$ CP-ECR and cooled without quench: Ring \#1.

196. Load-displacement curve for high-burnup M5 cladding oxidized to $18.1 \%$ CP-ECR and cooled without quench: Ring \#2.

197. Load-displacement curve for high-burnup M5 cladding oxidized to 16.1\% CP-ECR and cooled with quench: Ring \#1

198. Load-displacement curve for high-burnup M5 cladding oxidized to $16.1 \%$ CP-ECR and cooled with quench: Ring \#2

199. Load-displacement curve for high-burnup M5 cladding oxidized to 15.1\% CP-ECR and cooled with quench: Ring \#1

200. Load-displacement curve for high-burnup M5 cladding oxidized to 15.1\% CP-ECR and cooled with quench: Ring $\# 2$.......

201a. Load-displacement curve for high-burnup M5 cladding oxidized to 15.1\% CP-ECR and cooled with quench: Ring \#3. Test was interrupted after a displacement of $\approx 0.5 \mathrm{~mm}$ to compare offset $(2.3 \%)$ to permanent strain $(0.5 \%)$ for an intact ring. Ring length was 6.1 $\mathrm{mm}$.

201b. Determination of offset strains using linearized loading slope from second loading of highburnup M5 oxidized to 15.1\% CP-ECR and cooled with quench: Ring \#3. Ring length was $6.1 \mathrm{~mm}$.

202. Load-displacement curve for high-burnup M5 cladding oxidized to $13.4 \%$ CP-ECR and cooled with quench: Ring \#1

203. Load-displacement curve for high-burnup M5 cladding oxidized to $13.4 \%$ CP-ECR and cooled with quench: Ring \#2.

204. Load-displacement curve for high-burnup M5 cladding oxidized to $13.4 \%$ CP-ECR and cooled with quench: Ring \#3

205. Embrittlement oxidation level (CP-ECR) vs. hydrogen content for high-burnup $15 \times 15$ Zry-4 (550 $\pm 100 \mathrm{wppm}), 17 \times 17 \mathrm{ZIRLO}(540 \pm 100 \mathrm{wppm})$ and $17 \times 17 \mathrm{M} 5$ (110 $\pm 20 \mathrm{wppm})$ oxidized at $\leq 1200^{\circ} \mathrm{C}$, cooled at $11-13^{\circ} \mathrm{C} / \mathrm{s}$ to $800^{\circ} \mathrm{C}$, and either quenched or cooled without quench.

206. Temperature and pressure histories for full LOCA integral test sequence, including quench from $800^{\circ} \mathrm{C}$ to $100^{\circ} \mathrm{C}$. 
207. Images of the OCL $\# 8$ test sample after heating in argon to burst at $\approx 770^{\circ} \mathrm{C}$ (due to a maximum internal pressure of $8.62 \mathrm{MPa}$ [gauge] and an estimated pressure of $\approx 7.7 \mathrm{MPa}$ just prior to burst) and slow cooling: (a) low magnification of side view of sample, (b) higher magnification of side view of ballooned-and-burst region, and (c) higher magnification of frontal view of burst opening. Top of the sample, from which the thermocouples were inserted prior to welding, is to the left in these photographs.

208. Axial profile of the diametral ballooning strain at $0^{\circ}$ and $90^{\circ}$ relative to the burst opening for test sample OCL $\# 8$ heated under internal pressure in argon up to burst at $\approx 770^{\circ} \mathrm{C}$ and slow cooled to RT.

209. Cladding cross section at burst midplane for OCL\#8 sample (see Figure 208).

210. Ballooning strain profile for OCL\#22 test sample held for $1 \mathrm{~s}$ at $1204^{\circ} \mathrm{C}$, cooled to $800^{\circ} \mathrm{C}$, and quenched....

211. Ballooning strain profile for OCL\#17 test sample held for $120 \mathrm{~s}$ at $1204^{\circ} \mathrm{C}$, cooled to $800^{\circ} \mathrm{C}$, and quenched.

212. Ballooning strain profile for OCL\#13 test sample held for $300 \mathrm{~s}$ at $1204^{\circ} \mathrm{C}$, cooled to $800^{\circ} \mathrm{C}$, and quenched.

213. LECO oxygen and hydrogen content for OCL \#22 sample ramped in steam from $300^{\circ} \mathrm{C}$ to $1204^{\circ} \mathrm{C}$ at $5^{\circ} \mathrm{C} / \mathrm{s}$, held at $1204^{\circ} \mathrm{C}$ for $1 \mathrm{~s}$, cooled at $3^{\circ} \mathrm{C} / \mathrm{s}$ to $800^{\circ} \mathrm{C}$, and quenched.

214. LECO oxygen and hydrogen content for OCL\#17 sample ramped in steam from $300^{\circ} \mathrm{C}$ to $1204^{\circ} \mathrm{C}$ at $5^{\circ} \mathrm{C} / \mathrm{s}$, held at $1204^{\circ} \mathrm{C}$ for $120 \mathrm{~s}$, cooled at $3^{\circ} \mathrm{C} / \mathrm{s}$ to $800^{\circ} \mathrm{C}$, and quenched.

215. Data for OCL\#11 sample ramped in steam from $300^{\circ} \mathrm{C}$ to $1204^{\circ} \mathrm{C}$ at $5^{\circ} \mathrm{C} / \mathrm{s}$, held at $1204^{\circ} \mathrm{C}$ for $300 \mathrm{~s}$, cooled at $3^{\circ} \mathrm{C} / \mathrm{s}$ to $800^{\circ} \mathrm{C}$, and slow cooled from $800^{\circ} \mathrm{C}$ to RT: (a) LECO oxygen and hydrogen content and (b) ECR derived from LECO and metallography data and hydrogen pickup derived from LECO data.

216. Metallographic images at nine locations around the cross section of the midplane of the burst region of the OCL $\# 11$ test sample $\left(300 \mathrm{~s}\right.$ at $\left.1204^{\circ} \mathrm{C}\right)$. The cross-section-averaged ECR is $18.5 \%$. Locally, the oxidation level varies from $>36 \%$ to $13 \%$.

217. Bending test results for LOCA integral test sample OCL\#22: (a) pretest appearance with burst area on bottom, (b) post-test appearance with burst area on bottom, and (c) bending load vs. displacement (flexure extension) at the loading points.

218. Bending test results for LOCA integral test sample OCL\#17: (a) pretest appearance with burst area on bottom, (b) post-test appearance with burst area on bottom, and (c) bending load vs. displacement (flexure extension) at the loading points. 
219. Gamma scan profile for high-burnup Limerick rod F9 showing locations of LOCA integral samples ICL\#1 (labeled Phase A) and ICL\#2 (labeled Phase B). Fuel and cladding characterization were performed at the fuel midplane, at $0.7 \mathrm{~m}$ above the midplane, and at $\approx 1.1 \mathrm{~m}$ above fuel midplane.

220. Gamma scan profile for high-burnup Limerick rod J4 showing axial locations of LOCA integral samples ICL\#3 and ICL\#4.

221. Comparison of burst openings for (a) in-cell LOCA integral test ICL\#1 specimen from high-burnup Limerick rod F9 and (b) out-of-cell companion test OCL\#5 specimen from unirradiated Zry-2 cladding. Burst lengths are both $\approx 13$-mm long for these ramp-to-burst test samples.

222. Comparison of burst openings for (a) high-burnup Limerick ICL\#2 specimen and (b) unirradiated OCL\#11 Zry-2 specimen after 300 -s exposure to steam at $1204^{\circ} \mathrm{C}$, followed by slow cooling to RT.

223. Outer-diameter strain for in-cell test ICL\#1 sample (high-burnup Limerick fueled Zry-2) and companion out-of-cell test OCL\#5 sample (unirradiated Zry-2 filled with zirconia pellets). Both tests were ramp-to-burst tests in argon, followed by slow cooling to RT.

224. Outer-diameter strain for in-cell test ICL\#2 sample (high-burnup Limerick fueled Zry-2) and companion out-of-cell test OCL\#11 sample (unirradiated Zry-2 filled with zirconia pellets). Both samples were ramped to $1204^{\circ} \mathrm{C}$ in steam, held at $1204^{\circ} \mathrm{C}$ for $300 \mathrm{~s}$, and slow cooled to RT.

225. Comparison of ballooned-and-burst regions for four in-cell LOCA integral test samples

226. Sectioning diagram for ICL\#2 (300 s at $1204^{\circ} \mathrm{C}$, slow cooling to RT) sample. Locations A, $\mathrm{B}$, and $\mathrm{C}$ are metallography locations. $\mathrm{H}_{1}$ and $\mathrm{H}_{2}$ are locations for LECO hydrogen and oxygen measurements.

227. Sectioning diagram for ICL\#3 $\left(300 \mathrm{~s}\right.$ at $1204^{\circ} \mathrm{C}$, quench from $800^{\circ} \mathrm{C}$ to $460^{\circ} \mathrm{C}$, slow cooling to RT) sample. The sample fractured at locations A, B, and $\mathrm{C}$ during handling prior to the sectioning at D. LECO hydrogen and oxygen sample locations are not shown.

228. LECO oxygen-and hydrogen content for ICL\#2 and ICL\#3 test samples, both oxidized for $300 \mathrm{~s}$ at $1204^{\circ} \mathrm{C}$. Concentrations are referenced to the weight of the oxidized samples.

229. Axial distribution of ECR (based on LECO oxygen and metallographic data) and hydrogen pickup (based on LECO data in 228) for ICL\#2 and ICL\#3 test samples.

230. SEM fractography for ICL\#3 samples at axial location C in $179(\approx 20 \mathrm{~mm}$ above the burst midplane): (a) cladding cross section, (b) oxide layer, (c) oxygen-stabilized alpha layer, and (d) prior-beta layer. Interpolating from the results in Figure 229, the estimated hydrogen pickup is $\approx 3000 \mathrm{wppm}$, and the estimated measured ECR is $\approx 10 \%$ at this location. 
231. High-burnup Limerick oxidation sample following one-sided oxidation in steam at $1200^{\circ} \mathrm{C}$ for a 300 -s hold time.

232. Metallographic results for a circumferential location at the burst midplane of the ICL\#3 sample, oxidized for $300 \mathrm{~s}$ at $1204^{\circ} \mathrm{C}$. Fuel particles adherent to the cladding inner surface are shown in (c).

233. Fuel morphology for ICL\#2 LOCA sample: (a) as-irradiated, pre-test condition; (b) post-test condition $180 \mathrm{~mm}$ below burst midplane with $<2 \%$ creep strain; and (c) post-test condition at $50 \mathrm{~mm}$ above the burst midplane with $\approx 5 \%$ creep strain.

234. Evidence of local area on cladding inner surface of oxygen-stabilized alpha (left of B) for ICL\#2 sample at $50 \mathrm{~mm}$ above the burst midplane. The inner-surface region indicated by "A" does not have such an alpha layer and is more typical of what is observed for most of the inner surface at this axial location.

235. Offset strains for high-burnup Zry-4 (71-74 $\mu \mathrm{m}$ corrosion-layer thickness) and as-fabricated (fresh) HBR-type $15 \times 15$ Zry-4. Cladding samples were two-side oxidized at $\approx 1200^{\circ} \mathrm{C}$ and cooled at $\approx 11^{\circ} \mathrm{C} / \mathrm{s}$ to $800^{\circ} \mathrm{C}$. As-fabricated samples were quenched at $800^{\circ} \mathrm{C}$, while the high-burnup samples were slow cooled from $800^{\circ} \mathrm{C}$ to RT.

236. Embrittlement oxidation level (CP-ECR) vs. pre-test hydrogen content for high-burnup $15 \times 15 \mathrm{Zry}-4,17 \times 17 \mathrm{ZIRLO}$, and $17 \times 17 \mathrm{M} 5$ oxidized at $\leq 1200^{\circ} \mathrm{C}$, cooled at $11-13^{\circ} \mathrm{C} / \mathrm{s}$ to $800^{\circ} \mathrm{C}$, and either quenched or cooled without quench.

237. Embrittlement oxidation level (CP-ECR) vs. post-test hydrogen content for high-burnup $17 \times 17$ ZIRLO and pre-test hydrogen content for high-burnup $15 \times 15$ Zry-4 and $17 \times 17$ M5 oxidized at $\leq 1200^{\circ} \mathrm{C}$, cooled at $11-13^{\circ} \mathrm{C} / \mathrm{s}$ to $800^{\circ} \mathrm{C}$, and either quenched or cooled without quench.

238. Embrittlement oxidation level (CP-ECR) vs. hydrogen content for high-burnup HBR Zry-4 and prehydrided $17 \times 17$ Zry- 4 and $15 \times 15$ HBR-type Zry-4 oxidized at $\leq 1200^{\circ} \mathrm{C}$, cooled at $11-13^{\circ} \mathrm{C} / \mathrm{s}$ to $800^{\circ} \mathrm{C}$, and either quenched or cooled without quench. 
This page is intentionally left blank. 


\section{Tables}

1. Nominal Composition of Commercial Cladding Alloys....................................................2

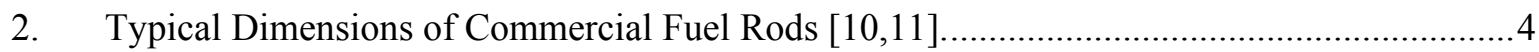

3. Dimensions and Chemistry of Zr-lined Zry-2 Used in the ANL Test Program (the " $<$ "

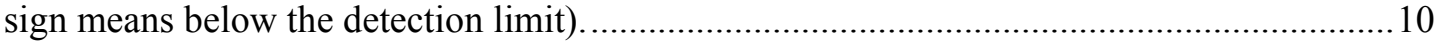

4. Dimensions and Chemistry of Zry-4 Used in the ANL Test Program (the " $<$ " sign means

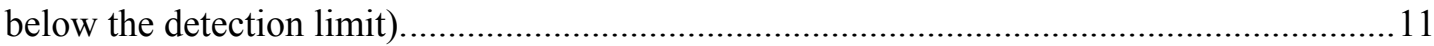

5. Dimensions and Chemistry of ZIRLO and M5 Used in the ANL Test Program (the " $<$ " sign means below the detection limit).

6. Dimensions and Chemistry of E110 Tubing and Cladding Used in the ANL Test Program (the " $<$ " sign means below the detection limit).

7. Characteristics of High-burnup Fuel Rod Segments and Defueled High-burnup Cladding for the ANL LOCA Test Program. Burnup values are rod averaged.

8. Weight Gain (Wg in $\mathrm{mg} / \mathrm{cm}^{2}$ ) and Measured ECR (\%) Values for $17 \times 17$ Zry-4 Oxidized in Steam at $1000^{\circ} \mathrm{C}$ and $1100^{\circ} \mathrm{C}$. ECR $=1.538 \mathrm{Wg}$ for $0.57-\mathrm{mm}$-wall cladding. Multiply weight gain results by a factor of 10 to convert to $\mathrm{g} / \mathrm{m}^{2}$. CP $=$ Cathcart-Pawel.

9. Ring Compression Test Results for $17 \times 17$ Zry-4 Samples Oxidized at $1000^{\circ} \mathrm{C}$ and $1100^{\circ} \mathrm{C}$, Cooled at $\approx 10^{\circ} \mathrm{C} / \mathrm{s}$ to $800^{\circ} \mathrm{C}$, and Quenched. ECR $=1.538 \mathrm{Wg}$ for $0.57-\mathrm{mm}$-wall cladding. Tests were performed on 8 -mm-long samples at RT and at $0.0333 \mathrm{~mm} / \mathrm{s}$ displacement rate. Displacements in the loading direction were normalized to the asfabricated outer diameter $(9.50 \mathrm{~mm})$ to calculate offset strain. A complete set of tests was performed with a Model 4505 Instron. A limited number of confirmation tests were performed with a Model 5566 Instron and rings cut from the same oxidation samples. .........35

10. Characterization Results for Highly Oxidized $17 \times 17$ Zry-4 Samples after Exposure to Steam at $1000^{\circ} \mathrm{C}$ and $1100^{\circ} \mathrm{C}$, Cooling at $\approx 10^{\circ} \mathrm{C} / \mathrm{s}$ to $800^{\circ} \mathrm{C}$, and Quench. CP-predicted ECR is $20 \%$.

11. Ring Compression Test (RCT) Results for $17 \times 17$ Zry-4 Cladding Oxidized at $1200 \pm 5^{\circ} \mathrm{C}$, Cooled at $\approx 13^{\circ} \mathrm{C} / \mathrm{s}$ to $800^{\circ} \mathrm{C}$, and Quenched. ECR $=1.538 \mathrm{Wg}$ for 0.57 -mm-wall cladding. Tests were performed on $\approx 8$-mm-long samples at RT and $135^{\circ} \mathrm{C}$ and at $0.0333-\mathrm{mm} / \mathrm{s}$ displacement rate. Displacements in the loading direction were normalized to the asfabricated outer diameter $(9.50 \mathrm{~mm})$ to calculate offset and permanent strains.

12. Characterization Results for $17 \times 17$ Zry-4 Samples after Exposure to Steam at $1200^{\circ} \mathrm{C}$ to $13 \%$ and $20 \% \mathrm{CP}$-ECR, Cooling at $\approx 13^{\circ} \mathrm{C} / \mathrm{s}$ to $800^{\circ} \mathrm{C}$, and Quench 
13. Ring Compression Test (RCT) Results for HBR-type $15 \times 15$ Low-tin Zry-4 Samples Oxidized at $1200 \pm 17^{\circ} \mathrm{C}$, Cooled at $\approx 11^{\circ} \mathrm{C} / \mathrm{s}$ to $800^{\circ} \mathrm{C}$, and Quenched. ECR $=1.1535 \mathrm{Wg}$ for 0.76 -mm-wall cladding. Tests were performed on $\approx 8$-mm-long samples at RT and $135^{\circ} \mathrm{C}$ and at $0.0333-\mathrm{mm} / \mathrm{s}$ displacement rate. Displacements in the loading direction were normalized to the as-fabricated outer diameter $(10.77 \mathrm{~mm})$ to calculate offset and permanent strains.

14. Oxide, Alpha, and Prior-Beta Layer Thicknesses at Four CP-ECR Values for HBR-type $15 \times 15$ Low-tin Zry-4 Oxidized at $1200 \pm 17^{\circ} \mathrm{C}$, Cooled at $\approx 11^{\circ} \mathrm{C} / \mathrm{s}$ to $800^{\circ} \mathrm{C}$, and Quenched.

15. Ring Compression Test Results for HBR-type $15 \times 15$ Low-tin Zry-4 Cladding Oxidized at $1204 \pm 10^{\circ} \mathrm{C}$, Cooled at $\approx 11^{\circ} \mathrm{C} / \mathrm{s}$ to $800^{\circ} \mathrm{C}$, and Quenched. ECR $=1.1535 \mathrm{Wg}$ for $0.76-\mathrm{mm}-$ wall cladding. Tests were performed on $\approx 8-\mathrm{mm}$-long samples at $\mathrm{RT}, 100^{\circ} \mathrm{C}$, and $135^{\circ} \mathrm{C}$ and at $0.0333-\mathrm{mm} / \mathrm{s}$ displacement rate. Samples from two lots were used to generate these data: 10.77-mm OD and 0.76-mm wall; and 10.76-mm OD and 0.77-mm wall. Displacements in the loading direction were normalized to the as-fabricated outer diameter to calculate offset and permanent strains.

16. Ring Compression Test (RCT) Results for Belt-polished $15 \times 15$ Zry-4 Cladding Oxidized at $1200^{\circ} \mathrm{C}$, Cooled at $\approx 11^{\circ} \mathrm{C} / \mathrm{s}$ to $800^{\circ} \mathrm{C}$, and Quenched. $\mathrm{ECR}=1.308 \mathrm{Wg}$ for $0.67-\mathrm{mm}$ wall cladding. RCTs were performed on $\approx 8$-mm-long samples at $135^{\circ} \mathrm{C}$ and $0.0333-\mathrm{mm} / \mathrm{s}$ displacement rate.

17. Breakaway Oxidation Time vs. Temperature for Zry-4 in Terms of Increase in Weight Gain Rate and Hydrogen-content Increase (200 wppm). References are: L-S = Leistikow and Schanz [19,20] and $\mathrm{M}=$ Mardon et al. [21].

18. Results of Breakaway Oxidation Tests at $984 \pm 10^{\circ} \mathrm{C}$ for HBR-type $15 \times 15$ low-tin Zry-4. The hydrogen content $\left(\mathrm{C}_{\mathrm{Hi}}\right)$ of the as-fabricated cladding is $22 \mathrm{wppm}$. The hydrogen content of the oxidized sample $\left(\mathrm{L}_{\mathrm{H}}\right)$ was measured with the LECO Hydrogen Determinator. Breakaway-oxidation time based on 200-wppm hydrogen pickup is $\approx 3800 \mathrm{~s}$.

19. First Set of Results for Breakaway Oxidation at $986 \pm 12^{\circ} \mathrm{C}$ (Figure 31) for Belt-polished $15 \times 15$ Low-tin Zry-4. The hydrogen content $\left(\mathrm{C}_{\mathrm{Hi}}\right)$ of the as-fabricated cladding is 26 wppm. The hydrogen content of the oxidized sample $\left(\mathrm{L}_{\mathrm{H}}\right)$ was measured with the LECO Hydrogen Determinator. Breakaway-oxidation time based on 200-wppm hydrogen pickup is $\approx 5000 \mathrm{~s}$.

20. Second Set of Results for Breakaway Oxidation of Belt-polished $15 \times 15$ Low-tin Zry-4 at Long-time Test Temperatures of $986^{\circ} \mathrm{C}$ (see Figure 32 ), $1000^{\circ} \mathrm{C}$, and $1014^{\circ} \mathrm{C}$. Hydrogen content $\left(\mathrm{C}_{\mathrm{Hi}}\right)$ of as-fabricated cladding is $26 \mathrm{wppm}$; hydrogen content of the oxidized sample $\left(\mathrm{L}_{\mathrm{H}}\right)$ was measured with the LECO Hydrogen Determinator; breakaway-oxidation time based on 200-wppm hydrogen pickup is $>5400 \mathrm{~s}$. 
21. Ring Compression Test (RCT) Results for $10 \times 10$ Zry-2 Cladding Oxidized at $1000^{\circ} \mathrm{C}$, Cooled at $\approx 10^{\circ} \mathrm{C} / \mathrm{s}$ to $800^{\circ} \mathrm{C}$, and Quenched. ECR $=1.328 \mathrm{Wg}$ for 0.66 -mm-wall cladding. Tests were performed on $\approx 8$-mm-long samples at RT and 0.0333 - $\mathrm{mm} / \mathrm{s}$ displacement rate. Post-test displacements in the loading direction were normalized to the as-fabricated outer diameter $(10.29 \mathrm{~mm})$ to calculate strains.

22. Ring Compression Test (RCT) Results for $10 \times 10$ Zry-2 Cladding Oxidized at $1200^{\circ} \mathrm{C}$, Cooled at $\approx 13^{\circ} \mathrm{C} / \mathrm{s}$ to $800^{\circ} \mathrm{C}$, and Quenched. ECR $=1.328 \mathrm{Wg}$ for $0.66-\mathrm{mm}$ wall cladding. Tests were performed on $\approx 8$-mm-long samples at $135^{\circ} \mathrm{C}$ and $0.0333-\mathrm{mm} / \mathrm{s}$ displacement rate. Displacements in the loading direction were normalized to the as-fabricated outer diameter $(10.29 \mathrm{~mm})$ to calculate strains.

23. Results for Breakaway Oxidation Studies of 10x10 Zry-2 Cladding. Test times are given from the beginning of the ramp from $300^{\circ} \mathrm{C}$ to the end of the hold time at temperature.

24. Weight Gain (Wg in $\mathrm{mg} / \mathrm{cm}^{2}$ ) and Measured ECR (\%) Values for $17 \times 17$ ZIRLO Oxidized in Steam at $1000^{\circ} \mathrm{C}$ and $1100^{\circ} \mathrm{C}$ and Quenched at $800^{\circ} \mathrm{C}$. $\mathrm{ECR}=1.538 \mathrm{Wg}$ for the $0.57-\mathrm{mm}$ - wall thickness. Multiply weight gain results by a factor of 10 to convert to $\mathrm{g} / \mathrm{m}^{2}$.

25. Ring Compression Test Results for $17 \times 17$ ZIRLO Samples Oxidized at $1000^{\circ} \mathrm{C}$ and $1100^{\circ} \mathrm{C}$, Cooled at $\approx 10^{\circ} \mathrm{C} / \mathrm{s}$ to $800^{\circ} \mathrm{C}$, and Quenched. ECR $=1.538 \mathrm{Wg}$ for $0.57-\mathrm{mm}$-wall cladding. Tests were performed on $8-\mathrm{mm}$-long samples at RT and $0.0333-\mathrm{mm} / \mathrm{s}$ displacement rate. Displacements in the loading direction were normalized to the as-fabricated outer diameter $(9.50 \mathrm{~mm})$ to calculate offset strain. A complete set of tests was performed with the Model 4505 Instron. A limited number of confirmation tests were performed with the Model 5566 Instron and rings cut from the same oxidation samples.

26. Characterization of Highly Oxidized (20\% CP-ECR) $17 \times 17$ Zry-4 and ZIRLO Samples after Exposure to Steam at $1000^{\circ} \mathrm{C}$ and $1100^{\circ} \mathrm{C}$, Cooling at $\approx 10^{\circ} \mathrm{C} / \mathrm{s}$ to $800^{\circ} \mathrm{C}$, and Quench.

27. Ring Compression Test (RCT) Results for $17 \times 17$ ZIRLO Cladding Oxidized at $1200^{\circ} \mathrm{C}$, Cooled at $\approx 13^{\circ} \mathrm{C} / \mathrm{s}$ to $800^{\circ} \mathrm{C}$, and Quenched. $\mathrm{ECR}=1.538 \mathrm{Wg}$ for $0.57-\mathrm{mm}$-wall thickness. Tests were performed on $\approx 8$-mm-long samples at $\mathrm{RT}$ and $135^{\circ} \mathrm{C}$ and at $0.0333-\mathrm{mm} / \mathrm{s}$ displacement rate. Displacements in the loading direction were normalized to the as-fabricated outer diameter $(9.50 \mathrm{~mm})$ to calculate offset and permanent strains.

28. Characterization of $17 \times 17$ Zry-4 and ZIRLO Samples after Exposure to Steam at $1200^{\circ} \mathrm{C}$ to $13 \%$ and $20 \% \mathrm{CP}$-ECR, Cooling at $\approx 13^{\circ} \mathrm{C} / \mathrm{s}$ to $800^{\circ} \mathrm{C}$, and Quenched.

29. Data Summary for ZIRLO Breakaway Oxidation Tests at $950-1015^{\circ} \mathrm{C}$ and $800^{\circ} \mathrm{C}$.

ZIRLO-2003 samples were quenched at $800^{\circ} \mathrm{C}$; ZIRLO-2006 samples were slow cooled to RT. 
30. Post-oxidation Ductility of ZIRLO with Significant Hydrogen Pickup during Breakaway Oxidation. ZIRLO-2006 samples summarized in Table 29 were oxidized at $985^{\circ} \mathrm{C}$ and $970^{\circ} \mathrm{C}$, then cooled without quench to $\mathrm{RT}$ and ring-compressed at $135^{\circ} \mathrm{C}$; average hydrogen values are reported for the $8-\mathrm{mm}$-long rings compressed at $0.0333 \mathrm{~mm} / \mathrm{s}$.

31. Weight Gain (Wg in $\left.\mathrm{mg} / \mathrm{cm}^{2}\right)$ and Measured ECR (\%) Values for $17 \times 17$ M5 Oxidized in Steam at $1000^{\circ} \mathrm{C}$ and $1100^{\circ} \mathrm{C}$ and Quenched at $800^{\circ} \mathrm{C}$. ECR $=1.437 \mathrm{Wg}$ for the $0.61-\mathrm{mm}$-wall thickness; multiply weight gain results by a factor of 10 to convert to $\mathrm{g} / \mathrm{m}^{2}$

32. Ring Compression Test Results for $17 \times 17 \mathrm{M} 5$ Samples Oxidized at $1000^{\circ} \mathrm{C}$ and $1100^{\circ} \mathrm{C}$, Cooled at $\approx 10^{\circ} \mathrm{C} / \mathrm{s}$ to $800^{\circ} \mathrm{C}$, and Quenched. ECR $=1.437 \mathrm{Wg}$ for 0.61 -mm-wall cladding. Displacements in the loading direction were normalized to the as-fabricated outer diameter $(9.50 \mathrm{~mm})$ to calculate offset strain. Tests were performed on 8-mm-long samples at RT and $0.0333-\mathrm{mm} / \mathrm{s}$ displacement rate in the Model 4505 Instron. Some confirmation tests were conducted in the new Model 5566 Instron with rings from the same oxidation samples.

33. Characterization of Highly Oxidized $17 \times 17$ Zry-4 and M5 Samples after Exposure to Steam at $1000^{\circ} \mathrm{C}$ and $1100^{\circ} \mathrm{C}$, Cooling at $\approx 10^{\circ} \mathrm{C} / \mathrm{s}$ to $800^{\circ} \mathrm{C}$, and Water Quench.

34. Ring Compression Test (RCT) Results for $17 \times 17$ M5 Cladding Oxidized at $1200^{\circ} \mathrm{C}$, Cooled at $\approx 13^{\circ} \mathrm{C} / \mathrm{s}$ to $800^{\circ} \mathrm{C}$, and Quenched. ECR $=1.437 \mathrm{Wg}$ for $0.61-\mathrm{mm}$-wall thickness. Tests were performed on $\approx 8$-mm-long samples at $\mathrm{RT}$ and $135^{\circ} \mathrm{C}$ and at $0.0333-\mathrm{mm} / \mathrm{s}$ displacement rate. Displacements in the loading direction were normalized to the as-fabricated outer diameter $(9.50 \mathrm{~mm})$ to calculate offset and permanent strains.

35. Characterization of $17 \times 17$ Zry-4 and M5 Samples after Exposure to Steam at $1200^{\circ} \mathrm{C}$ for Durations of 166 and $400 \mathrm{~s}$, Cooling at $\approx 13^{\circ} \mathrm{C} / \mathrm{s}$ to $800^{\circ} \mathrm{C}$, and Water Quench

36. Data Summary for ANL M5 Breakaway Oxidation Tests at $1000^{\circ} \mathrm{C}$; test times are from beginning of ramp at $300^{\circ} \mathrm{C}$ to the end of the hold time.

37. Effects of Pre-filming on the Breakaway Oxidation Time for ZIRLO. Hydrogen pickup values for as-fabricated (bare) ZIRLO samples are also listed. Samples were slow cooled from the hold temperature to RT and ring-compressed at $135^{\circ} \mathrm{C}$ and $0.0333 \mathrm{~mm} / \mathrm{s}$

38. Two-Sided Steam Oxidation Tests Conducted at $1000^{\circ} \mathrm{C}$ with As-received E110 Tubing. Cladding dimensions are 9.17-mm OD and 0.71-mm wall thickness; CP-ECR $=1.235 \mathrm{CP}$ $\mathrm{Wg}$; outer-surface roughness $=0.35 \mu \mathrm{m}$; and sample length $=\approx 25 \mathrm{~mm}$. Hydrogen samples were cut from center (C) and off-center (OC) sample locations. Note that Test EU\#11 was conducted at $950^{\circ} \mathrm{C}$.

39. Ring-Compression Test Results for E1 10 Samples Oxidized at $1000^{\circ} \mathrm{C}$ and Slow Cooled. Tests were performed on 8-mm-long samples at RT and $0.0333-\mathrm{mm} / \mathrm{s}$ displacement rate. 
40. Two-Sided Oxidation Tests Conducted on Modified E1 10 Cladding at $1000^{\circ} \mathrm{C}$. Samples had polished cladding outer diameter $(9.17 \mathrm{~mm})$, machined and polished inner diameter $(7.98$ $\mathrm{mm})$, and $0.6-\mathrm{mm}$ wall thickness.

41. Comparison of E110 Post-Oxidation RT Ductility between ANL Machined-and-Polished (M-P) Cladding Samples and Bochvar-TVEL (BT) Lots 2-4 Pickled Cladding Samples [26] Following Two-sided Steam Oxidation at $1100^{\circ} \mathrm{C}$.

42. Post-oxidation Ductility at $135^{\circ} \mathrm{C}$ for ANL Machined-and-Polished E110 Samples following Oxidation at $1200^{\circ} \mathrm{C}$ and Slow Cooling. Samples were fabricated from E110 cladding (etched and anodized): polished outer diameter $(9.07 \mathrm{~mm})$, machined-and-polished inner surface, and 0.6-mm wall thickness.

43. Ring Compression Test Results at $135^{\circ} \mathrm{C}$ and $0.0333 \mathrm{~mm} / \mathrm{s}$ for $17 \times 17 \mathrm{Zry}-4$ Cladding Oxidized at $1200^{\circ} \mathrm{C}$ and Slow Cooled (SC). ECR $=1.538 \mathrm{Wg}$ for $0.57-\mathrm{mm}$-wall cladding.

44. Ring Compression Test Results at $135^{\circ} \mathrm{C}$ and $0.0333 \mathrm{~mm} / \mathrm{s}$ for $17 \times 17$ ZIRLO Cladding Oxidized at $1200^{\circ} \mathrm{C}$ and Slow Cooled (SC). ECR $=1.538 \mathrm{Wg}$ for $0.57-\mathrm{mm}$-wall cladding.

45. Ring-Compression Test Results at $135^{\circ} \mathrm{C}$ and $0.0333 \mathrm{~mm} / \mathrm{s}$ for $17 \times 17 \mathrm{M} 5$ Cladding Oxidized at $1200^{\circ} \mathrm{C}$ and Slow Cooled (SC). ECR $=1.437 \mathrm{Wg}$ for $0.61-\mathrm{mm}$-wall cladding.

46. Ring Compression Test Results for Prehydrided $17 \times 17$ Zry -4 Cladding Oxidized at $1200^{\circ} \mathrm{C}$, Cooled at $\approx 13^{\circ} \mathrm{C} / \mathrm{s}$ to $800^{\circ} \mathrm{C}$, and Quenched. $\mathrm{ECR}=1.538 \mathrm{Wg}$ for $0.57-\mathrm{mm}$-wall cladding. Tests were performed on $\approx 8$-mm-long samples at $135^{\circ} \mathrm{C}$ and $0.0333-\mathrm{mm} / \mathrm{s}$ displacement rate.

47. Post-quench Ductility of Prehydrided HBR-type $15 \times 15$ Zry-4 Cladding Oxidized to $5 \%$ CP-ECR with $\mathrm{T}=1180-1190^{\circ} \mathrm{C}$ at End of Heating Ramp, Cooled at $\approx 11^{\circ} \mathrm{C} / \mathrm{s}$ to $800^{\circ} \mathrm{C}$, and Quenched (Q). Ring-compression tests were performed on $\approx 8$-mm-long samples at $135^{\circ} \mathrm{C}$ and $0.0333-\mathrm{mm} / \mathrm{s}$ displacement rate; $\mathrm{ECR}=1.1535 \mathrm{Wg}$ for $0.76-\mathrm{mm}$-wall and $1.1385 \mathrm{Wg}$ for $0.77-\mathrm{mm}$ wall; displacements were normalized to $10.77-\mathrm{mm}$ OD for $0.76-\mathrm{mm}$-wall and $10.76-\mathrm{mm}$ OD for $0.77-\mathrm{mm}$ wall.

48. Post-quench Ductility of Prehydrided HBR-type $15 \times 15$ Zry-4 Cladding Oxidized at $1200^{\circ} \mathrm{C}$ to $7.5 \% \mathrm{CP}$-ECR, Cooled at $\approx 11^{\circ} \mathrm{C} / \mathrm{s}$ to $800^{\circ} \mathrm{C}$, and Quenched (Q). Ring-compression tests were performed on $\approx 8-\mathrm{mm}$-long samples at $135^{\circ} \mathrm{C}$ and $0.0333-\mathrm{mm} / \mathrm{s}$ displacement rate. $\mathrm{ECR}=1.1535 \mathrm{Wg}$ for $0.76-\mathrm{mm}$ wall and $1.1385 \mathrm{Wg}$ for $0.77-\mathrm{mm}$ wall; displacements were normalized to $10.77-\mathrm{mm}$ OD for $0.76-\mathrm{mm}$ wall and $10.76-\mathrm{mm}$ OD for $0.77-\mathrm{mm}$ wall.

49. Comparison of Results for As-received and 600-wppm-prehydrided HBR-type $15 \times 15$ Zry-4 Samples after Exposure to Steam at $\approx 1200^{\circ} \mathrm{C}$ to $7.5 \% \mathrm{CP}$-ECR, Cooling at $\approx 11^{\circ} \mathrm{C} / \mathrm{s}$ to $800^{\circ} \mathrm{C}$, and Quench at $800^{\circ} \mathrm{C}$ 
50. Post-quench Ductility of Prehydrided HBR-type $15 \times 15$ Zry-4 Cladding Oxidized to $5 \%$ CP-ECR with $\mathrm{T}=1180^{\circ} \mathrm{C}$ at End of Heating Ramp, Cooled at $\approx 11^{\circ} \mathrm{C} / \mathrm{s}$ to $800^{\circ} \mathrm{C}$, and either Quenched (Q) at $800^{\circ} \mathrm{C}$ or Slow Cooled to RT. ECR $=1.1385 \mathrm{Wg}$; ringcompression tests performed on $\approx 8$-mm-long samples at $135^{\circ} \mathrm{C}$ and $0.0333 \mathrm{~mm} / \mathrm{s}$ displacement rate.

51. Post-quench Ductility of Prehydrided HBR-type $15 \times 15$ Zry-4 Cladding Oxidized to $7.5 \%$ CP-ECR at $1204^{\circ} \mathrm{C}$, Cooled at $\approx 11^{\circ} \mathrm{C} / \mathrm{s}$ to $800^{\circ} \mathrm{C}$, and Quenched (Q) at $800^{\circ} \mathrm{C}$, or Quenched at $700^{\circ} \mathrm{C}$, or Slow Cooled to $\mathrm{RT}, \mathrm{ECR}=1.1385 \mathrm{Wg}$; ring-compression tests performed on $\approx 8$-mm-long samples at $135^{\circ} \mathrm{C}$ and $0.0333-\mathrm{mm} / \mathrm{s}$ displacement rate.

52. Post-quench Ductility of Prehydrided HBR-type $15 \times 15$ Zry-4 Cladding Oxidized to $6 \%$ CP-ECR at $1200^{\circ} \mathrm{C}$, Cooled at $\approx 11^{\circ} \mathrm{C} / \mathrm{s}$ to $800^{\circ} \mathrm{C}$ and Quenched (Q) at $800^{\circ} \mathrm{C}$, Cooled from $800^{\circ} \mathrm{C}$ to $700^{\circ} \mathrm{C}$ at $3^{\circ} \mathrm{C} / \mathrm{s}$ and Quenched at $700^{\circ} \mathrm{C}$, Cooled from $700^{\circ} \mathrm{C}$ to $600^{\circ} \mathrm{C}$ at $2^{\circ} \mathrm{C} / \mathrm{s}$ and Quenched at $600^{\circ} \mathrm{C}$, or Slow Cooled from $600^{\circ} \mathrm{C}$ to $\mathrm{RT}$ at $<2^{\circ} \mathrm{C} / \mathrm{s}$. Thermal history is shown in Figure 118; CP-ECR is calculated from beginning of ramp to end of hold time; ring-compression tests performed on $\approx 8$-mm-long samples at $135^{\circ} \mathrm{C}$ and $0.0333-\mathrm{mm} / \mathrm{s}$ displacement rate.

53. Post-quench Ductility of Prehydrided HBR-type $15 \times 15$ Zry-4 Cladding Oxidized to 4.5$5.5 \% \mathrm{CP}$-ECR at $1200^{\circ} \mathrm{C}$, Cooled at $\approx 11^{\circ} \mathrm{C} / \mathrm{s}$ to $800^{\circ} \mathrm{C}$ and Quenched (Q) at $800^{\circ} \mathrm{C}$. Thermal history is shown in Figure 119; CP-ECR is calculated from beginning of ramp to end of hold time; ring-compression tests performed on $\approx 8$-mm-long samples at $135^{\circ} \mathrm{C}$ and $0.0333-\mathrm{mm} / \mathrm{s}$ displacement rate.

54. Comparison between ANL and CEA Test Samples, Test Conditions, and Results for Post-quench Ductility of Prehydrided Zry-4 as a Function of Quench Temperature

55. Corrosion Layer Thickness and Hydrogen Content Results for H. B. Robinson Rods F07 and G10 and for Rods A02 and R01. Axial locations are relative to the midplane of the 3658-mm-long fuel column

56. Summary of Cladding Characterization for HBR Fuel Rod Segments Used for Pre- and Post-test Analysis of Two-sided and One-sided Oxidation Tests

57. Thermal Benchmark Results for Test HBRU\#44 with As-fabricated Zry-4 (Figure 132), for Test HBRU\#73A with As-fabricated Zry-4 (Figure 133), and for Test HBRU\#73B with Pre-oxidized Zry-4 (Figure 135). Estimated temperatures for high-burnup test samples (HBRI) are given in column 3

58. Sample Characterization and Test Conditions for Two-sided Oxidation Tests Conducted with High-burnup HBR Zry-4 Cladding. SC is slow cooling, and Q is quench at $800^{\circ} \mathrm{C}$. 
59. Results of Quantitative Metallography for Two-sided-oxidized, High-burnup HBR Zry-4 following Steam Oxidation. Oxide layer thickness $\left(\delta_{\mathrm{ox}}\right)$ and measured ECR data are listed. Data are from optical microscopy (OM) images at eight circumferential locations around sample cross section (see Figures 137-139 for images from one-of-eight locations for HBRI\#4 and \#5 samples).

60. Results of Quantitative Metallography for Two-sided-oxidized, High-burnup HBR Zry-4 following Steam Oxidation. Oxygen-stabilized alpha layer thickness $\left(\delta_{\alpha}\right)$ data are listed, based on data from images at eight circumferential locations around sample cross section (see Figures 137 and 138 for OM images from one-of-eight locations for sample HBRI\#5).

61. Results of Ring-compression Tests for High-burnup HBR Zry-4 Cladding Samples Oxidized (Two-sided) at $1110-1198^{\circ} \mathrm{C}$ to $2.7-9.3 \%$ CP-ECR and Slow Cooled (SC) to RT or Quenched $(\mathrm{Q})$ at $800^{\circ} \mathrm{C}$. Tests were conducted on $\approx 8$-mm-long rings at $135^{\circ} \mathrm{C}$ and $0.0333-\mathrm{mm} / \mathrm{s}$ displacement rate; offset and permanent displacements were normalized to the cladding metal outer diameter $(10.6 \mathrm{~mm})$ to calculate strains.

62. Ductility Data from Two-sided Oxidation Tests at $1200^{\circ} \mathrm{C}$ followed by Slow Cooling for High-burnup and Prehydrided (Unirradiated) Zry-4 Cladding Samples.

63. Sample Characterization and Test Conditions for One-sided Steam Oxidation Tests (HBRI) Tests conducted with high-burnup HBR Zry-4 cladding. SC is slow cooling

64. Post-test Results for High-temperature Oxide Layer Thickness and Hydrogen Content for High-burnup HBR Zry-4 Samples (HBRI) Oxidized in Steam (One-sided) at $1200^{\circ} \mathrm{C}$

65. Post-test Results for Outer- and Inner-surface Alpha Layers Stabilized at $1200^{\circ} \mathrm{C}$ for High-burnup HBR Zry-4 Samples (HBRI) Oxidized in Steam (One-sided).

66. Ring-Compression Test Results for the Ductility at $135^{\circ} \mathrm{C}$ of High-burnup HBR Zry-4 Samples Oxidized (One-sided) in Steam at $1200^{\circ} \mathrm{C}$ and Slow Cooled to RT. CP-ECR values are based on outer-surface oxidation.

67. Post-oxidation Ductility Values for High-burnup HBR Zry-4 Cladding Samples Oxidized at $\leq 1200^{\circ} \mathrm{C}$ and Slow Cooled to RT. Test type is indicated by 2-S for two-sided oxidation and 1 -S for one-sided oxidation; tests were conducted on $\approx 8$-mm-long rings at $135^{\circ} \mathrm{C}$ and $0.0333-\mathrm{mm} / \mathrm{s}$ displacement rate; offset and permanent displacements were normalized to the cladding metal outer diameter $(10.6 \mathrm{~mm})$ to calculate strains

68. North Anna ZIRLO Characterization Results for Rod AM2-L17

69. Calculated Values for Hydrogen Content in Cladding Metal for North Anna ZIRLO Rod AM2-L17 Segments. The calculation assumes all measured $\mathrm{H}$ is in cladding metal. $\mathrm{EC}=$ eddy current. 
70. Calculated Hydrogen Pickup Fraction vs. Axial Location for North Anna ZIRLO Rod AM2-L17 Samples. The fuel-cladding bond thickness was assumed to be $7 \mu \mathrm{m}$, and the cladding metal wall thickness was calculated from $\mathrm{h}=544 \mu \mathrm{m}+\left(43 \mu \mathrm{m}-\delta_{\mathrm{c}}\right) / 1.56$.

71. Data Summary for Out-of-cell and In-cell Benchmark Tests Conducted with the New LOCA Furnace in Laboratory EL-208 (Out-of-cell), in the Irradiated Materials Laboratory (IML, Out-of-cell) and in IML Cell \#4

72. Post-Test Ductility Results for High-Burnup North Anna ZIRLO Cladding Oxidized at $\leq 1200^{\circ} \mathrm{C}$, Cooled with (ZLI\#4-6) or without (ZLI\#1-3) Quench at $800^{\circ} \mathrm{C}$, and RingCompressed at $135^{\circ} \mathrm{C} ; \mathrm{SC}=$ slow cooled without quench

73. Ringhals M5 Characterization Results for Cladding Segments from Rod SUT3-00477 ......258

74. Post-Test Ductility Results for High-Burnup Ringhals M5 Cladding Oxidized at $1200^{\circ} \mathrm{C}$, Cooled with $\left(800^{\circ} \mathrm{C}-\mathrm{Q}\right)$ or without Quench at $800^{\circ} \mathrm{C}$, and Ring-Compressed at $135^{\circ} \mathrm{C}$......

75. Summary of LOCA Integral Test Results for Out-of-cell Tests with Near-archival Asfabricated (Unirradiated) 9×9 Zry-2 Samples Filled with Zirconia Pellets. Outer diameter and wall thickness of as-fabricated cladding are $11.18 \mathrm{~mm}$ and $0.71 \mathrm{~mm}$, respectively.

76. Summary of In-cell LOCA Integral Tests (ICL) with High-burnup Fueled Cladding Specimens from Limerick BWR. Also shown are the results of companion out-of-cell tests OCL\#5 and OCL\#11 with non-irradiated Zry-2 cladding. 306

77. Embrittlement Threshold (CP-ECR) for As-fabricated Cladding Alloys Oxidized at $1200^{\circ} \mathrm{C}$, Cooled at $11-13^{\circ} \mathrm{C} / \mathrm{s}$ to $800^{\circ} \mathrm{C}$, Quenched at $800^{\circ} \mathrm{C}$ and Ring-compressed at $135^{\circ} \mathrm{C}$. For CP-ECR values $1 \%$ higher than the embrittlement threshold, the alloys are classified as brittle. Results are rounded off to the nearest whole-number percent. 322

78. Embrittlement Threshold (CP-ECR) for High-burnup Cladding Alloys Oxidized at $\leq 1200^{\circ} \mathrm{C}$, Cooled at $11-13^{\circ} \mathrm{C} / \mathrm{s}$ to $800^{\circ} \mathrm{C}$, and either Quenched (Q) at $800^{\circ} \mathrm{C}$ or Cooled without Quench. Ring-compression tests were performed at $135^{\circ} \mathrm{C}$. For CP-ECR values $1 \%$ higher than the embrittlement threshold, the alloys are brittle. Results are rounded off to the nearest whole-number percent. SC= slow cooling without quench. .326 


\section{Executive Summary}

One of NRC's central regulations used in plant licensing deals with postulated loss-of-coolant accidents (LOCAs). A portion of that regulation in 10 CFR 50.46(b) specifies criteria that were derived from tests with unirradiated Zircaloy cladding, and these criteria limit the peak cladding temperature and the maximum cladding oxidation during the accident. These two limits are known as embrittlement criteria. Their purpose is to prevent cladding embrittlement during a LOCA, thus ensuring that the general core geometry will be maintained and be coolable. This report documents the data needed to assess the effects of high-burnup operation on cladding embrittlement following a LOCA.

As-fabricated cladding alloys and high-burnup fuel segments for testing were provided by many industry organizations. Prehydrided cladding was prepared from as-fabricated Zry-4 to study the effects of hydrogen over a wide range of oxidation conditions and cooling scenarios. Because it was known that embrittlement increases rapidly above the peak cladding temperature limit in NRC's regulations $\left(2200^{\circ} \mathrm{F}\right.$ $=1204^{\circ} \mathrm{C}$ ), this research program focused on conditions leading to embrittlement at and below about $1200^{\circ} \mathrm{C}$. The primary testing method involved oxidation in steam at high temperatures and cooling with or without quench at $800^{\circ} \mathrm{C}$, followed by ring-compression ductility testing at room temperature and $135^{\circ} \mathrm{C}$ after cooldown.

Several embrittlement mechanisms were studied, and most were related to an equivalent-claddingreacted (ECR) parameter as calculated with the Cathcart-Pawel weight gain correlation (hence, CP-ECR). The use of this parameter, which is a measure of cladding oxidation, as a time- and temperaturedependent parameter is the same procedure that is commonly used in safety analyses to demonstrate compliance with 10 CFR 50.46. Among the important findings are the following.

As-fabricated cladding materials made with modern techniques exhibit an embrittlement threshold in the range of $17-20 \%$ CP-ECR. The exact value appears to be sensitive to manufacturing variables, but no significant effects of alloy constituents on embrittlement thresholds were observed for the alloys tested in this program. Also, these embrittlement thresholds are independent of quench temperatures at or below $800^{\circ} \mathrm{C}$.

Hydrogen, which enters the outer cladding surface during normal lifetime operation, reduces cladding ductility. Numerous LOCA embrittlement tests were conducted with prehydrided Zry-4 samples, and tests were also conducted with specimens of Zircaloy-4 (Zry-4), ZIRLO, and M5 cladding that had been sectioned from fuel rods with high burnups $(63-70 \mathrm{GWd} / \mathrm{t})$. Results are shown in the figure on the next page, in which best-linear-fit lines have been drawn as a guide for the reader. The range of hydrogen content up to $800 \mathrm{wppm}$ corresponds to a limit commonly used by fuel manufacturers. Results are shown for both cooling with quench at $800^{\circ} \mathrm{C}$ and cooling without quench, which represent upper and lower bounds, respectively, on calculated cladding wetting temperatures during a LOCA cooldown. For high-burnup Zry-4 and ZIRLO, post-LOCA embrittlement thresholds are bounded by 8-9\% (no quench) and $5 \%$ (quench at $800^{\circ} \mathrm{C}$ ). For high-burnup M5 with lower hydrogen content, the embrittlement threshold is bounded by $18 \%$ (no quench) and $14 \%$ (quench at $800^{\circ} \mathrm{C}$ ).

Hydrogen also enters the inner surface of the cladding during a LOCA in which the cladding experiences ballooning and burst prior to high-temperature steam oxidation. Steam that enters through the burst opening oxidizes the cladding inner surface within the balloon region. The hydrogen released from this oxidation is essentially trapped within the balloon region and absorbed by the cladding away from the burst opening. The hydrogen pickup is quite significant, and the hydrogen pickup rate is rapid. 


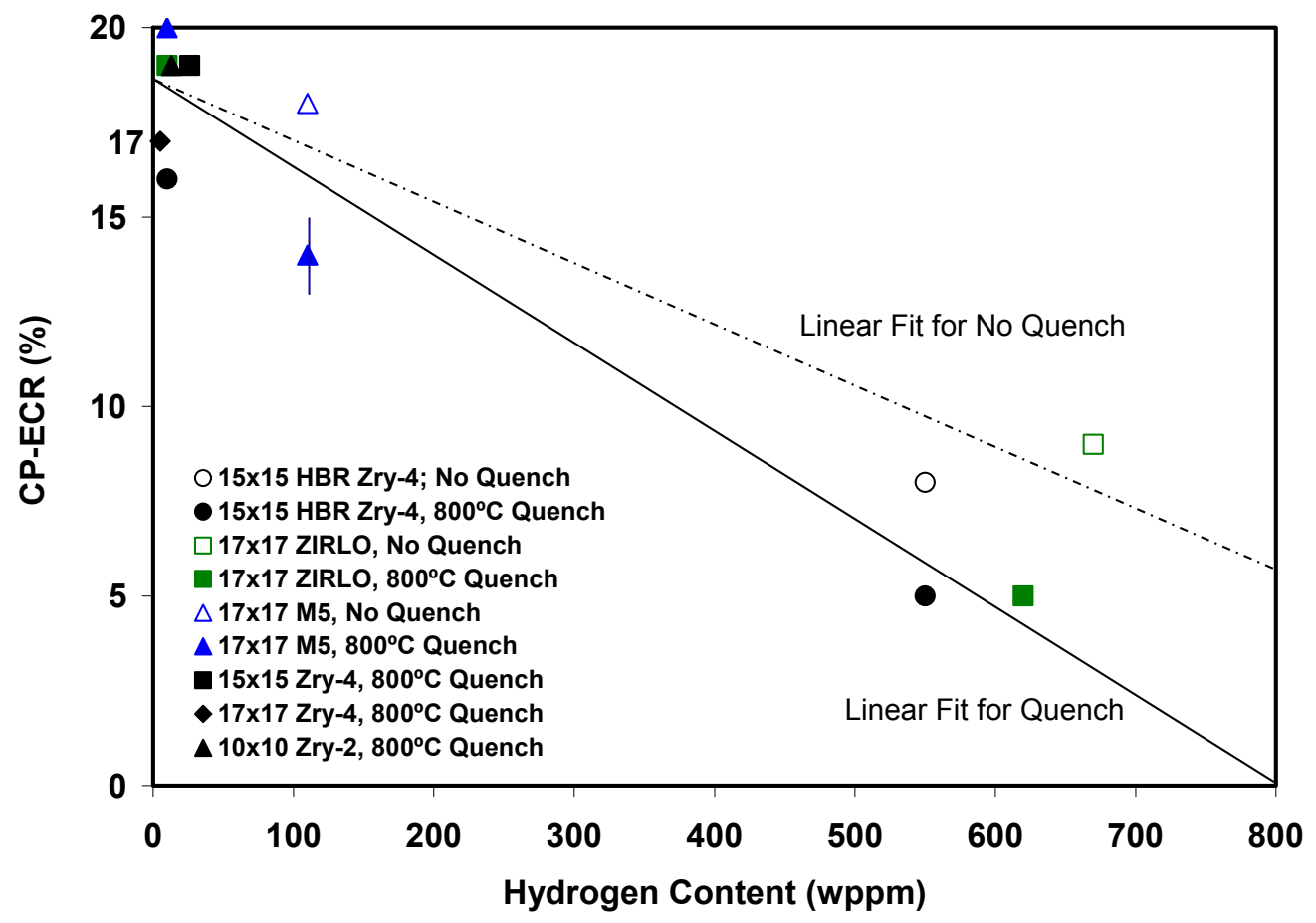

Embrittlement threshold expressed as an oxidation level (CP-ECR) vs. pre-test hydrogen content for as-fabricated cladding alloys and high-burnup Zry-4, ZIRLO, and M5 cladding, which were oxidized at $\leq 1200^{\circ} \mathrm{C}$ and either quenched at $800^{\circ} \mathrm{C}$ or cooled without quench.

This phenomenon was confirmed in the current work for high-burnup LOCA test segments. Because of rapid hydrogen pickup, no oxidation limit could be established for the balloon region such that ductility would be maintained. However, it was demonstrated that significant toughness is maintained up to about the current oxidation limit of $17 \%$ CP-ECR for cladding in the balloon region. Although clearly brittle, the cladding in the balloon region was highly resistant to fragmentation at oxidation levels $<17 \%$.

Zirconium dioxide can exist in several crystallographic forms, and a transformation can occur that results in an increase in oxidation rate; this transformation is referred to as "breakaway oxidation." Along with increase in oxidation rate, there is significant hydrogen pickup. Hydrogen that enters in this manner has the same effect on embrittlement as hydrogen from the normal burnup process. Minimum breakaway times were found in the range of $3000-6000$ seconds at $950-1000^{\circ} \mathrm{C}$, and these times can occur before reaching the CP-ECR oxidation limit for low-burnup fuel. Breakaway oxidation times may be important for some small-break LOCAs.

Although hydrogen produces the main burnup effect on embrittlement, it does so primarily as a catalyst by enhancing oxygen diffusion and solubility in the metal. For unirradiated cladding, the oxygen source is the zirconium dioxide layer that forms during high-temperature oxidation in steam. As burnup increases, there will also be an oxygen source on the inner surface of irradiated cladding that originates from the oxygen in the fuel pellets. Both outer and inner sources contain enough oxygen to embrittle the cladding. If the inner-surface oxygen source is well developed, then two-sided oxidation would have to be accounted for in LOCA calculations away from the balloon region. 
The authors would like to express their appreciation to the Office of Nuclear Regulatory Research for support and management of this program. We have been fortunate to have Harold Scott as our Project Manager for most of these years. His presence added stability and continuity to the program. We are particularly grateful to Ralph Meyer for his vision, leadership, expert knowledge of data needed for revision of the LOCA embrittlement criteria, technical expertise in pre-test planning and post-test data interpretation, and significant contributions to this report. In addition, he assembled an international group of uniquely talented experts from industry, licensing, and research to serve as participants in our LOCA program review meetings.

Many organizations, and individuals within those organizations, have contributed test materials, reviewed test plans, participated in program review meetings, shared experiences, and provided both guidance and technical expertise. The Electric Power Research Institute (EPRI), Global Nuclear Fuels (GNF), AREVA, and Westinghouse Electric Company (WEC) provided high-burnup commercial reactor fuel rods, as well as defueled M5 (Studsvik and AREVA) and ZIRLO (Studsvik and WEC) cladding from high-burnup fuel rods, to the program. These organizations, along with others, also supplied us with asfabricated cladding and tubing: Zry-2 (GNF), Zry-4 (WEC and AREVA), ZIRLO (WEC), M5 (AREVA), and E110 (Fortum).

We would like to thank those individuals who participated in pre-test planning and program review meetings. They shared their experience, data, and insights to help us better plan test matrices and to interpret test results. In addition to the organizations listed above, these individuals represent the following organizations: Anatech, Commissariat a l'Energie Atomique (CEA) at Saclay, Consejo de Seguridad Nuclear (CSN), Electricitie de France (EdF), Halden Reactor Project (HRP), Institute for Radiological Protection and Nuclear Safety (IRSN), Japanese Atomic Energy Agency (JAEA), Russian Research Center's Kurchatov Institute (RRC-KI), and VTT Technical Research Centre. In particular, we would like to acknowledge the contributions of Robert Montgomery and Y. R. (Joe) Rashid (Anatech), Jean-Paul Mardon and Bert Dunn (AREVA), Jean-Christophe Brachet (CEA), Nicholas Waeckel (EDF), Rosa Yang (EPRI), Gerald Potts (GNF), Erik Kolstad (HRP), Georges Hache and Claude Grandjean (IRSN), Fumihisa Nagase and Toyoshi Fuketa (JAEA), Larissa Yegorova (RRC-KI), and Mitchell Nissley and Robert Comstock (WEC).

The authors are particularly grateful for the dedicated and expert efforts of the technicians in our Irradiation Performance Section within the Nuclear Engineering Division at Argonne: Kevin Byrne, Jakub Dobrzynski, David McGann, David Pushis, and Gregory Quick. Without their efforts there would have been no tests conducted and no data to report.

Finally, the authors would like to acknowledge the pioneering efforts of former colleague Robert Strain who designed, built, and benchmarked the LOCA test apparatus used to generate the data presented in this report. 
This page is intentionally left blank. 
By the mid 1990s, it was well known that significant cladding oxidation (corrosion) takes place during extended periods of normal operation, and that some of the liberated hydrogen from the interaction with water is absorbed in the zirconium alloy cladding material. It thus seemed likely that an oxide layer on the surface and hydrogen in the metal would affect the cladding's behavior under conditions of a lossof-coolant accident (LOCA). Because cladding behavior under those conditions is important in reactor safety analyses, research was begun in 1997 to investigate any such burnup-related effects.

Several aspects of cladding behavior under LOCA conditions are involved in safety analyses: ballooning strains, flow area reduction, rupture conditions, axial distribution of heat sources, and cladding embrittlement. All are being investigated in a broad research program at Argonne National Laboratory (ANL), but only cladding embrittlement will be addressed in this report. The conditions under which cladding on high-burnup fuel loses its ductility and becomes embrittled are needed to assess, and perhaps revise, the embrittlement criteria in 10 CFR 50.46(b) of the NRC's regulations. These criteria are given as limits on cladding temperature and on oxidation level calculated as a percentage of cladding oxidized (equivalent cladding reacted [ECR]).

The current embrittlement criteria were based on tests with unirradiated Zircaloy cladding material and were adopted in 1973. The history of the development of these criteria is summarized in a paper by Hache and Chung [1]. The ductility tests themselves were of the ring-compression type, and the test results were evaluated at $135^{\circ} \mathrm{C}$, the saturation temperature during reflood. The ECR was calculated for these tests using the Baker-Just oxidation kinetics equations.

Although significantly improved testing techniques and oxidation kinetics equations are employed in the present study, the basis for the embrittlement criteria has remained the same. Most importantly, the materials tested in the current work include cladding from high-burnup fuel rods, which were taken from commercial reactors, and a variety of unirradiated cladding alloys, so that both burnup and alloy effects can be determined.

\subsection{Cladding materials}

Table 1 lists the nominal compositions of commercial cladding alloys that have been tested in this program. Zircaloy-2 cladding is used in boiling water reactors (BWRs). Zircaloy-4, ZIRLO, and M5 are used in pressurized water reactors (PWRs). The Russian E110 cladding is used in VVERs (Russian version of PWR) and was included in the study because it has a similar composition to M5 yet behaves very differently under LOCA conditions [2]. Specific dimensions and alloy compositions for the materials tested in this program are described in Section 2.1.

The traditional zirconium-based alloys used in the U.S. were variations of Zircaloy, which has tin as the major alloying element. In Russia, niobium was used as the major alloying element. Zirconiumniobium alloys tend to corrode less during normal operation than zirconium-tin alloys, so niobium has been added in recent years to alloys used in the U.S.

Niobium exhibits several differences compared with tin that affect the behavior of cladding under LOCA conditions. One is that the niobium solubility in zirconium is limited to about $0.5 \%$ at moderate temperatures such that about half of the niobium in the niobium-bearing alloys exists as precipitates or 
Table 1. Nominal Composition of Commercial Cladding Alloys.

\begin{tabular}{|c|c|c|c|c|c|}
\hline Element & Zircaloy-2 $^{\mathrm{a}}$ & Zircaloy-4 $^{\mathrm{a}}$ & ZIRLO $^{\mathrm{b}, \mathrm{c}}$ & $\mathrm{M}^{\mathrm{d}}$ & $\mathrm{E}^{\mathrm{a}}$ \\
\hline Sn,wt.\% & 1.45 & 1.45 & 1.1 & -- & -- \\
\hline Nb,wt.\% & -- & -- & 1.1 & 1.0 & 1.0 \\
\hline Fe,wt.\% & 0.14 & 0.21 & 0.1 & 0.038 & 0.009 \\
\hline Cr,wt.\% & 0.10 & 0.10 & -- & -- & -- \\
\hline Ni,wt.\% & 0.06 & -- & -- & -- & -- \\
\hline O,wt.\% & 0.125 & 0.125 & 0.120 & 0.135 & 0.06 \\
\hline Zr & Balance & Balance & Balance & Balance & Balance \\
\hline
\end{tabular}

${ }^{\mathrm{a} A S T M}$ B811 [3].

${ }^{\mathrm{b}} \mathrm{R}$. Comstock et al. [4].

${ }^{\mathrm{c}} \mathrm{W}$. Leech [5].

dJ-P. Mardon et al. [6].

${ }^{\mathrm{e}} \mathrm{P}$. V. Shebaldov et al [7].

${ }^{\mathrm{f}}$ Oxygen is considered an alloying element in these alloys.

second-phase particles. This is in contrast to tin, which goes into complete solution with zirconium in Zircaloy. The niobium precipitates affect phase changes during a LOCA (see Section 1.2). These changes are observable in metallography and may account for some of the differences in the behavior of these alloys.

Another difference is that niobium, like zirconium, has a strong affinity for oxygen - unlike tin. This can be seen in Figure 1, which shows the free energy of formation of oxides of alloy constituents and some impurities [8,9]. Additionally, the prevalent form of niobium oxide is $\mathrm{Nb}_{2} \mathrm{O}_{5}$. That is, niobium has a valence of +5 in the oxide, whereas zirconium has a valence of +4 . Taken together, these characteristics lead to the inclusion of niobium in the oxide layer, and it is present there as an aliovalent impurity, which can affect the behavior of the oxide.

Because many of the results described in the following depend on cladding thickness and diameter, typical dimensions of commercial fuel rods are given in Table 2 [10,11].

\subsection{Transient phase transformations}

During a LOCA transient, much of the coolant inventory would be lost during the blowdown, and the fuel cladding would begin to heat up. Around $800^{\circ} \mathrm{C}$ on the temperature rise, the pressurized cladding would reach its ultimate tensile strength, and a local instability would produce a large ballooning strain and a rupture in fuel rods with sufficient pressure and temperature increase. A modest temperature reduction would accompany this deformation in the vicinity of the balloon because of 


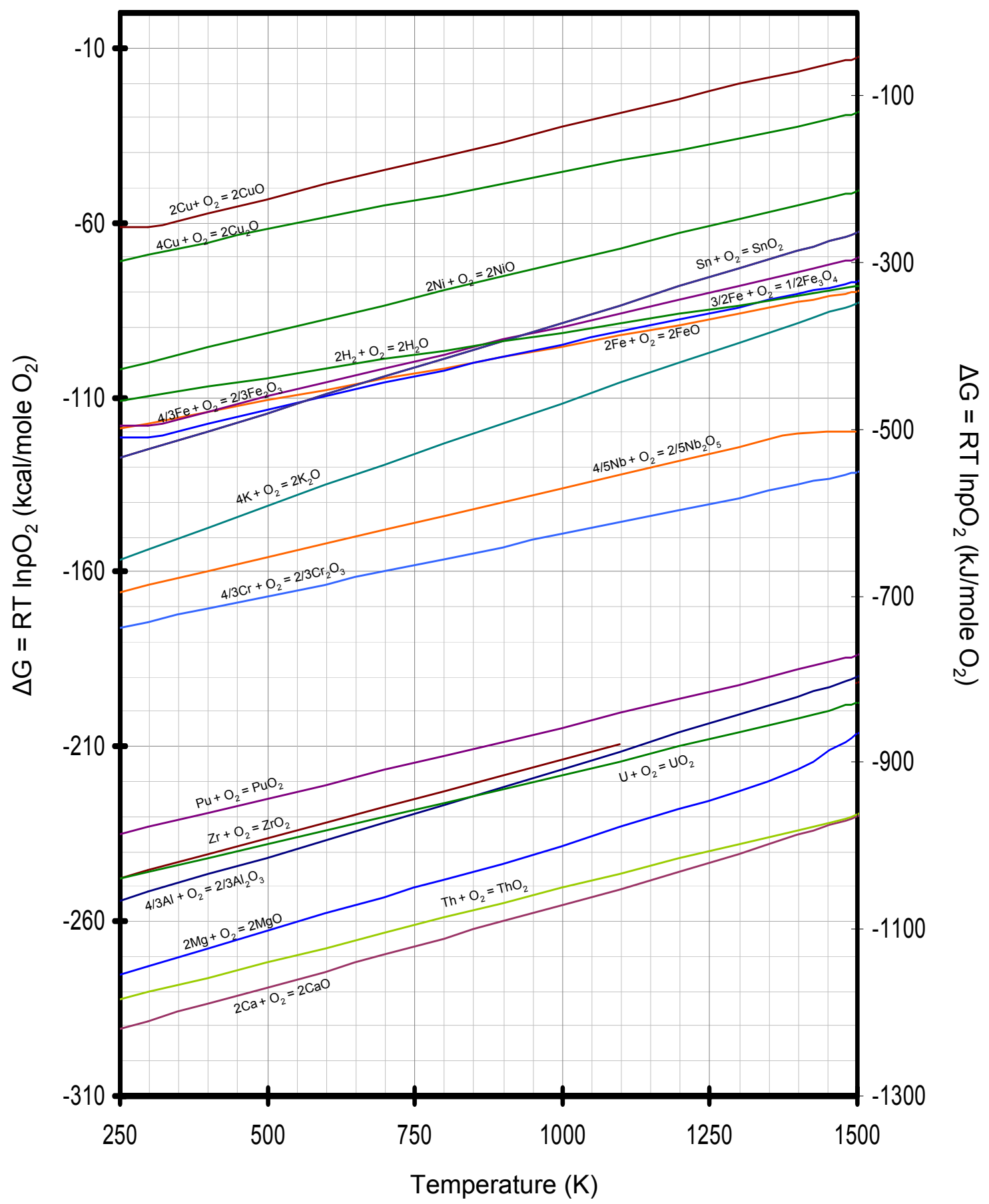

Figure 1. Free energy of formation of oxides of alloy constituents and some impurities $[8,9]$. 
Table 2. Typical Dimensions of Commercial Fuel Rods [10,11].

\begin{tabular}{|c|c|c|c|c|c|c|c|c|}
\hline $\begin{array}{c}\text { Cladding Type and } \\
\text { Dimensions }\end{array}$ & $\begin{array}{c}\text { BWR } \\
8 \times 8\end{array}$ & $\begin{array}{c}\text { BWR } \\
9 \times 9\end{array}$ & $\begin{array}{c}\text { BWR } \\
10 \times 10\end{array}$ & $\begin{array}{c}\text { PWR } \\
14 \times 14\end{array}$ & $\begin{array}{c}\text { PWR } \\
15 \times 15\end{array}$ & $\begin{array}{c}\text { PWR } \\
16 \times 16\end{array}$ & $\begin{array}{c}\text { PWR } \\
17 \times 17\end{array}$ & $\begin{array}{c}\text { VVER } \\
\text { Hex. }\end{array}$ \\
\hline Outside Diam. (mm) & 12.3 & 10.8 & 10.0 & 11.2 & 10.7 & 9.7 & 9.4 & 9.1 \\
\hline Thickness (mm) & 0.813 & 0.711 & 0.660 & 0.737 & 0.711 & 0.635 & 0.610 & 0.705 \\
\hline
\end{tabular}

enhanced cooling, but the temperature would then continue to rise. Eventually, the emergency cooling water would stop the temperature rise and begin to cool the cladding. When the temperature decreases to $400-800^{\circ} \mathrm{C}$, wetting of the cladding occurs and rapid cooling, or quenching, would take place. Such a temperature transient is shown schematically in Figure 2.

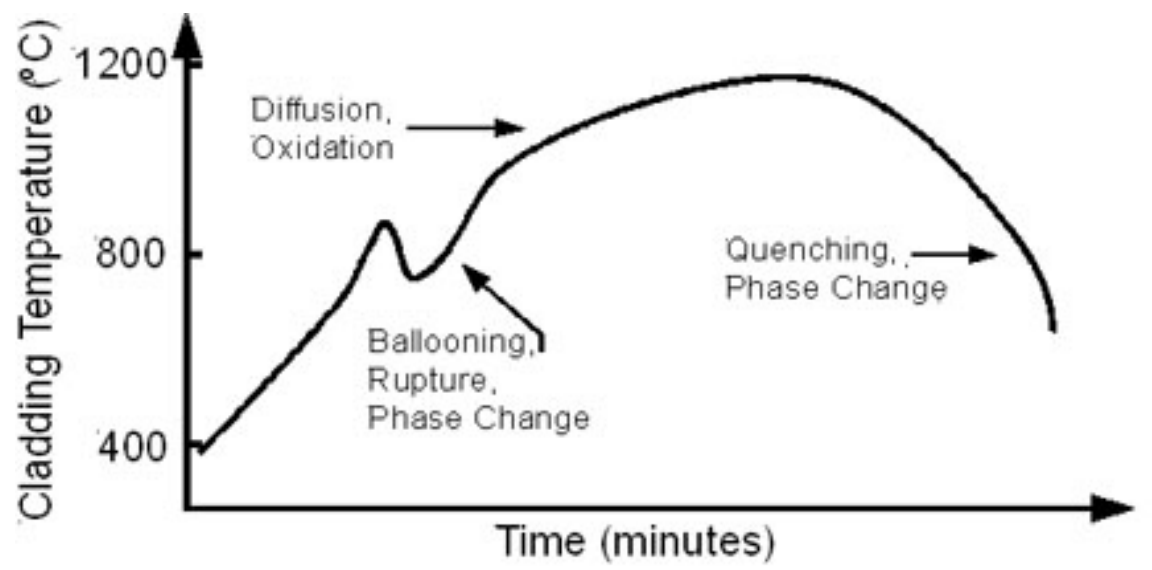

Figure 2. Schematic of cladding temperature during a LOCA.

From room temperature up to about $650-800^{\circ} \mathrm{C}$, the zirconium-based cladding alloys of interest have a hexagonal crystal structure, which is called the alpha phase. Above this temperature, which varies with alloy composition, there is a mixed-phase regime in which the crystal structure begins to change to a face-centered cubic geometry or beta phase. For Zry-4 with initial oxygen concentration of 0.11 wt. \%, the alpha to the mixed alpha-beta phase change temperature is $810^{\circ} \mathrm{C}$, and the alpha-beta to beta phase change temperature is about $980^{\circ} \mathrm{C}$. These values increase as the oxygen content increases, and they decrease with increasing hydrogen. They also decrease with the substitution of $\mathrm{Nb}$ for $\mathrm{Sn}$ because $\mathrm{Nb}$ stabilizes the beta phase at a lower temperature. The terms commonly used to describe these effects are: oxygen is an alpha-stabilizer and both hydrogen and $\mathrm{Nb}$ are beta-stabilizers.

Oxygen diffusion in $\mathrm{Zr}$ metal and in $\mathrm{ZrO}_{2}$ oxide becomes rapid enough above $800^{\circ} \mathrm{C}$ that measurable changes occur during a LOCA transient. Diffusion controls the oxidation process and other processes involved in cladding embrittlement. Thus, after the zirconium alloy changes from the alpha to the alpha + beta to the beta phase, the temperature becomes high enough that oxygen diffuses from the surface into the metal, quickly exceeding its solubility limit in the outer region of the cladding. Rather than precipitating some other phase or gas bubbles, this oxygen-rich metal transforms back to the alpha phase, where the oxygen solubility limit is much higher than in the beta phase. Upon cooling, the beta 
phase also converts back to the alpha phase, but the prior-beta region and the oxygen-stabilized alpha layer are easily distinguished at room temperature in metallographic sections. Figure 3 is a qualitative diagram of this situation for an oxidation temperature greater than the alpha-plus-beta to beta-phase temperature and for a location away from the balloon, where steam is not able to get inside the cladding.

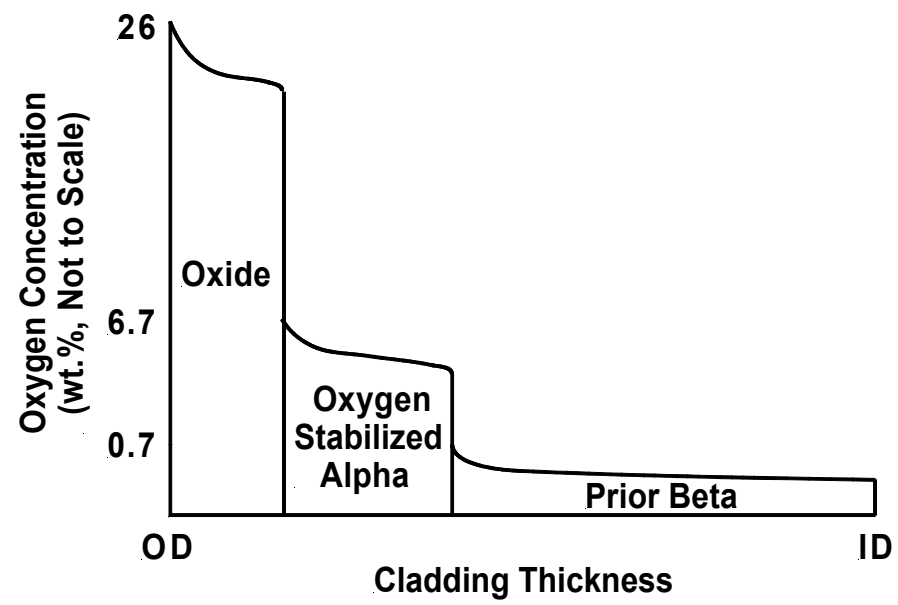

Figure 3. Qualitative diagram of oxygen concentration in Zircaloy cladding exposed at high temperature $\left(>980^{\circ} \mathrm{C}\right)$ to steam on the outside surface and cooled to room temperature. OD and ID are outer and inner diameters, respectively.

Figure 4 shows what these phases look like in a micrograph of an etched section of unirradiated Zircaloy-2 cladding after being oxidized (outside surface only) in steam for 600 seconds at $1200^{\circ} \mathrm{C}$.

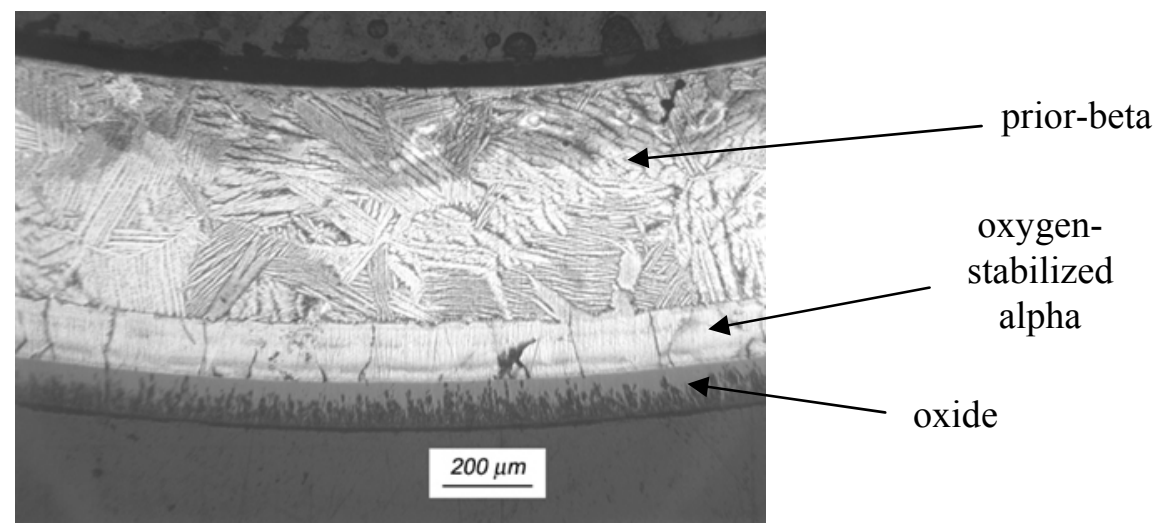

Figure 4. Unirradiated Zircaloy-2 after oxidation in steam at $1200^{\circ} \mathrm{C}$ for 600 seconds.

The presence of niobium in zirconium alloys alters this picture somewhat, with a more uneven boundary between the alpha and prior-beta layers, but the principle is the same. Within a ruptured balloon, steam will also enter through the rupture and produce a similar oxygen profile on the inside surface of the cladding.

\subsection{Oxidation equations}

Although the Baker-Just equations [12] have been used in many LOCA analyses, the CathcartPawel (CP) equations are more accurate for Zircaloys and will be used throughout this report. In their 
report [13], Cathcart et al. gave four related rate equations, one for each of the following: (a) the oxide layer thickness; (b) the alpha layer thickness; (c) the sum of the oxide-plus-alpha layer thickness; and (d) the total oxygen consumed, which was given as weight gain in grams per square centimeter of surface area. All of these obeyed parabolic kinetics. The rate equation for weight gain, $\mathrm{Wg}$ (Cathcart et al. called it $\tau$ ), is:

$$
\mathrm{d}(\mathrm{Wg}) / \mathrm{dt}=\left(\mathrm{k}^{2} / 2\right) / \mathrm{Wg}
$$

where $\mathrm{k}$ is a temperature-dependent coefficient (Cathcart et al. labeled it $\delta_{\tau}$ ). Under isothermal oxidation conditions, the integration of Equation 1 is simply

$$
(\mathrm{Wg})^{2} / 2=\left(\mathrm{k}^{2} / 2\right) \mathrm{t},
$$

or

$$
\mathrm{Wg}=\mathrm{k} \mathrm{t}^{1 / 2}
$$

which plots as a parabola.

The coefficient, $\mathrm{k}$, is an Arrhenius-type function of temperature:

$$
\mathrm{k}=\mathrm{a} \exp (-\mathrm{Q} /[\mathrm{RT}])
$$

where $\mathrm{R}$ is the universal gas constant, and the parameters a and $\mathrm{Q}$ are given by Cathcart et al. for each of the four rate equations reported. Using the Cathcart et al. (CP) values for "a" and "Q" for weight gain determined from metallographic results and the assumption of stoichiometric oxide, the isothermal CP equation becomes

$$
\mathrm{Wg}=0.602 \exp \left(-1.005 \times 10^{4} / \mathrm{T}\right) \mathrm{t}^{1 / 2},
$$

where $\mathrm{Wg}$ is given by Cathcart et al. in $\mathrm{g} / \mathrm{cm}^{2}$, $\mathrm{T}$ is temperature in $\mathrm{K}$, and $\mathrm{t}$ is time in $\mathrm{s}$. Thus, the weight gain increases as the square root of time at a given temperature, and the rate increases exponentially with temperature. The results of Equation 4 should be multiplied by a factor of 10 to convert to the SI units of $\mathrm{kg} / \mathrm{m}^{2}$. For convenience in the current work, the measured weight gain is expressed as $\mathrm{mg} / \mathrm{cm}^{2}$. In comparing the measured weight gain per unit surface area to the CP-predicted weight gain, the results of Equation 4 are multiplied by $10^{3}$ to give units of $\mathrm{mg} / \mathrm{cm}^{2}$.

A related parameter that is often used is ECR, or equivalent cladding reacted. ECR is defined as the percentage of the cladding thickness that would be oxidized if all the oxygen pickup stayed in the oxide layer as $\mathrm{ZrO}_{2}$. This is an artificial parameter because some of the oxygen diffuses into the metal, but it is useful and is directly related to weight gain by simple geometric factors, along with factors based on the density of $\mathrm{Zr}\left(6500 \mathrm{~kg} / \mathrm{m}^{3}=6.5 \mathrm{~g} / \mathrm{cm}^{3}\right)$, the atomic mass of $\mathrm{Zr}(91.2 \mathrm{~kg} / \mathrm{kg}$-mole), and the atomic mass of diatomic oxygen $(32.0 \mathrm{~kg} / \mathrm{kg}$-mole). The conversion is given in Equation 5 for one-sided oxidation and Equation 6 for two-sided oxidation.

$$
\begin{array}{ll}
\text { One-sided oxidation } & \mathrm{ECR}=43.9[(\mathrm{Wg} / \mathrm{h}) /(1-\mathrm{h} / \mathrm{Do})] \\
\text { Two-sided oxidation } & \mathrm{ECR}=87.8 \mathrm{Wg} / \mathrm{h},
\end{array}
$$

where $\mathrm{ECR}$ is in $\%, \mathrm{Wg}$ is in $\mathrm{g} / \mathrm{cm}^{2}, \mathrm{~h}$ is cladding thickness in $\mathrm{cm}$, and Do is cladding OD in $\mathrm{cm}$. 


\subsection{Embrittlement mechanisms}

Six embrittlement mechanisms are described below. Three of them were known before this research was initiated and three were not. Data relating to all of these mechanisms are presented in subsequent sections of this report.

\subsubsection{Beta-layer embrittlement by oxygen}

As temperature increases during a LOCA transient, the amount of oxygen that the beta phase can hold also increases. Above about $1200^{\circ} \mathrm{C}$, oxygen solubility in the beta phase becomes high enough in these cladding alloys that, after cooling, the prior-beta region will embrittle for relatively short oxidation times. This mechanism was understood in 1973 , and the $1204^{\circ} \mathrm{C}\left(2200^{\circ} \mathrm{F}\right)$ temperature limit in NRC's regulation precluded such embrittlement in unirradiated Zircaloy [1].

\subsubsection{Beta-layer thinning}

With increasing time, diffusion of oxygen into the metal will convert more and more of the beta phase to the oxygen-stabilized alpha phase - the alpha layer grows and the beta region shrinks. For long times at temperature, the ductile prior-beta region becomes so thin that the macroscopic specimen exhibits brittle behavior. This mechanism was also understood in 1973 and is accommodated by the 17\% ECR limit in NRC's regulation, provided oxidation is calculated with the Baker-Just correlation that was used in deriving the limit [1].

\subsubsection{Localized hydrogen-induced embrittlement in the balloon region}

Steam that enters through a rupture in a balloon causes oxidation inside the cladding. Hydrogen that is freed during this reaction is not swept away as it is on the outside of the cladding, but is absorbed in the metal. This absorption results in enhanced embrittlement in the balloon region or just beyond the necks of the balloon. This effect, which is neither burnup nor alloy dependent, was discovered earlier [1] and has been confirmed in the present research program.

\subsubsection{Hydrogen-enhanced beta-layer embrittlement by oxygen}

During normal operation, some hydrogen from the corrosion process is absorbed in the cladding metal. When that cladding is exposed to high-temperature LOCA conditions, the elevated hydrogen levels increase the solubility of oxygen in the beta phase and the rate of diffusion of oxygen into the beta phase. Thus, even for LOCA temperatures below $1204^{\circ} \mathrm{C}$, embrittlement can occur for times corresponding to less than $17 \%$ oxidation in corroded cladding with significant hydrogen pickup.

\subsubsection{General hydrogen-induced embrittlement from breakaway oxidation}

Zirconium dioxide $\left(\mathrm{ZrO}_{2}\right)$ can exist in several crystallographic forms (allotropes). The normal tetragonal oxide that develops under LOCA conditions is dense, adherent, and protective with respect to hydrogen pickup. There are, however, conditions that promote a transformation to the monoclinic phase - the phase that is grown during normal operation - that is neither fully dense nor protective. The tetragonal-to-monoclinic transformation is an instability that initiates at local regions of the metal-oxide interface and grows rapidly throughout the oxide layer. As this transformation results in an increase in oxidation rate, it is referred to as breakaway oxidation. Along with this increase in oxidation rate due to cracks in the monoclinic oxide, there is significant hydrogen pickup. Hydrogen that enters in this manner during a LOCA transient has the same effect on embrittlement as hydrogen from the normal burnup 
process. Although breakaway oxidation was known in 1973, a connection to embrittlement was not made at that time.

\subsubsection{Oxygen pickup from the cladding inner surface}

Figure 3 illustrates a situation where there is an oxygen source only on the cladding outer surface. For unirradiated cladding this oxygen source is the zirconium dioxide layer that forms during high temperature oxidation in steam. As burnup increases, normal corrosion will contribute to the outersurface oxygen source. There will also be oxygen sources on the inner surface of irradiated cladding due to gas-phase $\mathrm{UO}_{3}$ transport prior to gap closure, fuel-cladding-bond formation $\left(\mathrm{UO}_{2}\right.$ in solid solution with $\mathrm{ZrO}_{2}$ ), and the fuel bonded to this layer. Under LOCA conditions, oxygen can thus enter the cladding from the inner surface even away from the balloon location. The situation is like a multilayer diffusion couple as illustrated in Figure 5. The actual thicknesses of the OD and ID oxygen sources may be relatively unimportant at high burnup because they contain much more oxygen than will diffuse into the metal (see related tests by Hofmann and Politis [14]). This does not apply to the inner surface if the only oxygen source is the fuel-cladding bond layer, which would be completely reduced by the cladding metal during times required for high-temperature embrittlement. If the inner-surface oxide layer or the oxidebond-fuel layer is well developed, then two-sided oxidation would have to be accounted for in LOCA calculations away from the balloon region.

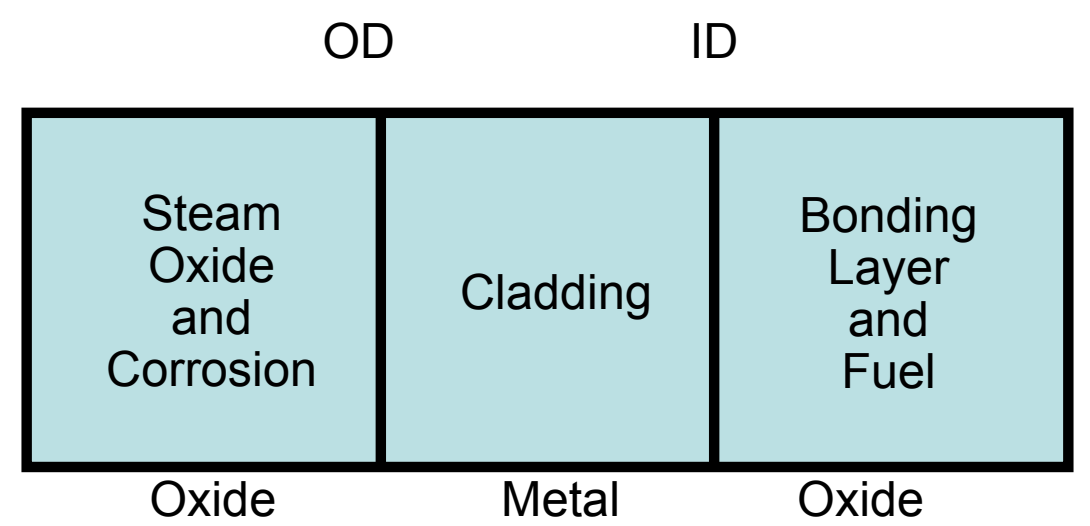

Figure 5. Diffusion couple character of oxygen sources and cladding metal. 


\section{Materials, Test Methods, and Procedures}

Interpretation and application of LOCA-relevant data require an understanding of cladding materials used for test samples, test methods, and test procedures. These are described in this section.

\subsection{Description of cladding alloys and high-burnup fuel segments}

As-fabricated cladding alloys were provided by Global Nuclear Fuels $(8 \times 8,9 \times 9$, and $10 \times 10$ Zry-2),

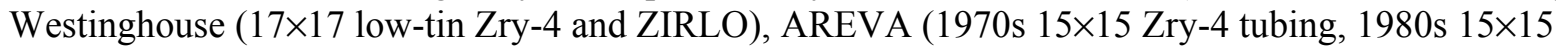
low-tin Zry-4, 15×15 low-tin Zry-4, 15×15 M5, and 17×17 M5), and Fortum (E110 tubing and cladding). Alloys, except for E110, that are listed without a decade are modern, belt- or wheel-polished cladding alloys. The $8 \times 8$ Zry- 2 was used for early thermal and metallurgical benchmark testing of the LOCA integral apparatus. The $9 \times 9$ Zry-2, although not archival cladding from the same lot, was fabricated by the same methods used to fabricate high-burnup Limerick fuel-rod cladding and has the same nominal composition and dimensions as the Limerick cladding. It has been used in this test program to generate baseline LOCA integral data and one-sided, high-temperature steam oxidation data. The 1970 s $15 \times 15$ Zry-4 tubing is close to being archive material for the high-burnup H. B. Robinson (HBR) cladding tested in this program. However, this tubing has $\approx 0.05$-mm larger outer diameter and $\approx 0.025$-mm thicker wall than the HBR cladding. The final finishing step after fueling the HBR tubing to convert it to cladding was an outer-surface pickling to remove $\approx 0.05 \mathrm{~mm}$ from the outer diameter. Because this tubing was not in final cladding form, it was not used to generate baseline data. Rather, the 1980 s $15 \times 15$ low-tin Zry-4 cladding, which has similar dimensions, oxygen content, and mechanical properties as the HBR cladding, was used in this work to determine baseline HBR oxidation and post-quench ductility properties. This cladding is referred to as "HBR-type Zry-4" to distinguish it from modern Zry-4 materials.

Some $15 \times 15$ and $17 \times 17$ M5 cladding was provided in 2002 by AREVA for benchmarking purposes but not for data generation. This $17 \times 17 \mathrm{M} 5(0.57-\mathrm{mm}$ wall) was characterized in terms of chemical composition and used to develop and benchmark the two-sided oxidation test train. At a later date, AREVA provided $17 \times 17 \mathrm{M} 5$ with $0.61-\mathrm{mm}$ wall thickness for the purpose of data generation. The postquench ductility of the $15 \times 15$ M5 and the $0.61-\mathrm{mm}$-wall $17 \times 17$ M5 was compared to confirm that postquench ductility correlated with extent of oxidation (ECR) at a given temperature independent of cladding wall thickness and outer diameter.

For the advanced-alloy post-quench ductility program, the primary alloys of interest are $10 \times 10$ Zry2, 17×17 low-tin Zry-4, 17×17 ZIRLO, and 17×17 M5 (0.61-mm wall). E110 was also added to the testing program to try to determine why its steam-oxidation behavior is so poor as compared to M5, even though its alloy composition is similar. E110 tubing and cladding were provided by Fortum (Finland). The tubing was pickled (etched) and anodized or autoclaved to convert it to cladding. In addition to the supplied forms of E110, ANL-modified E110 had several variants, which included surface modification (polished, etched, and etched-and-polished) and reduction in wall thickness to $\approx 61 \mathrm{~mm}$ (inner-surface machined and polished). The lessons learned from the E110 study regarding the destabilizing effects of surface roughness, surface scratches, and surface chemistry were used in planning the breakaway oxidation studies for all alloys.

For the breakaway-oxidation studies, the test plan called for the same alloys as used for the postquench-ductility studies. However, due to the limited supply of $17 \times 17$ low-tin Zry-4, belt-polished $15 \times 15$ and HBR-type (rough surface) $15 \times 15$ low-tin Zry-4 were used instead. This choice allowed the effects of surface roughness to be included in these studies for Zry-4 samples with similar geometry, tin content, and oxygen content. The other three alloys $(10 \times 10$ Zry-2, 17×17 ZIRLO, and 17×17 M5) used 
in the post-quench-ductility tests were also used in the breakaway oxidation tests.

For most of the cladding alloys received by ANL, measurements were performed to determine the OD, wall thickness, surface roughness, oxygen content, and tin content. Some of the alloys were sent to an outside organization to determine chemical composition. For ZIRLO cladding, Westinghouse also performed chemical analysis on a sample of the cladding sent to ANL. The ANL wall-thickness measurements were spot checks of this dimension at a few locations. More detailed characterization was performed for HBR archive and HBR-type Zry-4. Table 3 summarizes the dimensions, surface conditions, and chemical composition of the Zr-lined Zry-2 used in the ANL test program. The Zr liner is on the cladding inner surface $(\approx 10 \%$ of the wall thickness). Chemical composition data listed in Table 3 refer to the final cladding product $(\approx 90 \% \mathrm{Zry}-2$ and $\approx 10 \% \mathrm{Zr}$ liner). They should not be interpreted as the composition of standard Zry-2. The chemical composition listed in Table 1 for Zry-2 is closer to the composition of the Zry-2 alloys tested at ANL.

Table 3. Dimensions and Chemistry of Zr-lined Zry-2 Used in the ANL Test Program (the "<" sign means below the detection limit).

\begin{tabular}{|l|l|l|c|}
\hline \multicolumn{1}{|c|}{ Parameter } & $8 \times 8$ Zry-2 & $9 \times 9$ Zry-2 & $10 \times 10$ Zry-2 \\
\hline \hline OD, mm & 12.27 & 11.18 & 10.29 \\
\hline Wall Thickness, mm & 0.82 & 0.71 & 0.66 \\
\hline ID Liner Thickness, mm & $\approx 0.08$ & $\approx 0.07$ & $\approx 0.07$ \\
\hline OD Surface Roughness, $\mu \mathrm{m}$ & --- & 0.14 & 0.11 \\
\hline Sn, wt.\% & --- & 1.18 & --- \\
\hline Nb, wt.\% & --- & $<0.01$ & --- \\
\hline O, wt.\% & --- & 0.11 & --- \\
\hline Fe, wt.\% & --- & 0.20 & --- \\
\hline Cr, wt.\% & --- & 0.12 & --- \\
\hline Ni, wppm & --- & 550 & --- \\
\hline S, wppm & --- & 30 & --- \\
\hline C, wppm & --- & 250 & --- \\
\hline Hf, wppm & --- & $<100$ & --- \\
\hline Si, wppm & --- & $\leq 100$ & 13 \\
\hline N, wppm & --- & 45 & 6 \\
\hline H, wppm & --- & & \\
\hline
\end{tabular}

The dimensions and chemistry of the Zry- 4 used in the ANL test program are listed in Table 4. Included in Table 4 is near-archive HBR tubing. Pickling was used for the inner surface treatment of both near-archive HBR tubing and HBR-type cladding. Based on 24 measurements for adjacent segments of tubing for each of these materials, the wall thicknesses were determined to be $0.761 \pm 0.006 \mathrm{~mm}$ and $0.790 \pm 0.006 \mathrm{~mm}$, for the HBR-type cladding received in November 2004 and archival tubing, respectively. If the same approach had been used for the April 2003 batch of cladding, it is likely that (within statistical variation) the wall thickness of both batches would be $0.76 \mathrm{~mm}$. 
Table 4. Dimensions and Chemistry of Zry-4 Used in the ANL Test Program (the " $<$ " sign means below the detection limit).

\begin{tabular}{|c|c|c|c|c|}
\hline Parameter & $\begin{array}{c}15 \times 15 \text { Zry }-4 \\
\text { HBR } \\
\text { Archive } \\
\text { Tubing } \\
1977^{\mathrm{a}}\end{array}$ & $\begin{array}{l}\text { 15×15 Zry-4 } \\
\text { HBR-type } \\
\text { Cladding } \\
\approx 1980^{\mathrm{b}}\end{array}$ & $\begin{array}{c}\text { 15×15 Zry-4 } \\
\text { Cladding } \\
\text { Modern }^{\mathrm{c}}\end{array}$ & $\begin{array}{c}\text { 17×17 Zry-4 } \\
\text { Cladding } \\
\text { Modern }^{\mathrm{d}}\end{array}$ \\
\hline $\mathrm{OD}, \mathrm{mm}$ & 10.84 & $10.77,10.76$ & 10.91 & 9.50 \\
\hline Wall Thickness, mm & 0.80 & $0.76,0.77$ & 0.67 & 0.57 \\
\hline OD Surface Roughness, $\mu \mathrm{m}$ & 0.36 & $0.32,0.31$ & 0.10 & 0.14 \\
\hline Sn, wt. \% & 1.42 & 1.29 & $1.29 \pm 0.1$ & $1.29 \pm 0.1$ \\
\hline $\mathrm{Nb}, \mathrm{wt} . \%$ & $-\overline{--}$ & --- & $-\overline{---}$ & --- \\
\hline O,wt.\% & 0.137 & 0.136 & 0.124 & 0.120 \\
\hline Fe, wt.\% & 0.21 & --- & --- & --- \\
\hline Cr, wt.\% & 0.10 & --- & --- & --- \\
\hline Ni, wppm & $<35$ & --- & --- & --- \\
\hline S, wppm & --- & --- & --- & --- \\
\hline C, wppm & 140 & --- & --- & --- \\
\hline Hf, wppm & $<50$ & --- & --- & --- \\
\hline Si, wppm & 92 & --- & --- & $\begin{array}{ll}-- \\
--\end{array}$ \\
\hline N, wppm & 54 & --- & --- & --- \\
\hline H, wppm & 12 & 22 & 26 & 5 \\
\hline
\end{tabular}

${ }^{\mathrm{a}}$ Sandvik Special Metals Corp Certificate of Quality; based on tubing (H, N, O) and ingot; 06-30-77.

${ }^{\mathrm{b}}$ ANL data based on two AREVA lots received in April 2003 (0403) and November 2004 (1104).

${ }^{\mathrm{C}} \mathrm{ANL}$ data for AREVA cladding received in December 2004.

${ }^{\mathrm{d}}$ ANL data for cladding provided by Westinghouse.

The dimensions and chemistry for 17×17 ZIRLO, 17×17 M5 (validation lot), 17×17 M5 (data lot), and $15 \times 15$ M5 (validation lot) used in the ANL test program are listed in Table 5.

Fortum sent two types of E110 to ANL: tubing and cladding. The processing of tubing into the cladding ANL received involved pickling (etching) and anodizing to grow a fine $(<<1 \mu \mathrm{m})$ oxide layer on the outer tubing surface to harden it for protection against scratching and abrading during handling and loading fuel rods into assemblies. The ANL test program modified some of this tubing and cladding to study the effects of surface roughness and chemistry. The modifications are listed in Table 6 under the categories of "polished" and "machined-and-polished".

Irradiated materials used in the ANL test program are summarized in Table 7. The Electric Power Research Institute (EPRI) provided ANL with two fueled TMI-1 PWR rods at 48-50 GWd/MTU for validation of characterization and test methodologies, seven fueled Limerick BWR rods at 54-57 $\mathrm{GWd} / \mathrm{MTU}$ for LOCA data generation, and seven fueled H. B. Robinson PWR rods at 64-67 GWd/MTU. 
Table 5. Dimensions and Chemistry of ZIRLO and M5 Used in the ANL Test Program (the "<" sign means below the detection limit).

\begin{tabular}{|l|c|c|c|c|}
\hline \multicolumn{1}{|c|}{ Parameter } & $\begin{array}{c}17 \times 17 \\
\text { ZIRLO }^{\mathrm{a}}\end{array}$ & $\begin{array}{c}17 \times 17 \mathrm{M} 5^{\mathrm{b}} \\
(\text { Validation })\end{array}$ & $\begin{array}{c}17 \times 17 \mathrm{M}^{\mathrm{c}} \\
(\text { Data })\end{array}$ & $\begin{array}{c}15 \times 15 \mathrm{M}^{\mathrm{c}} \\
\text { (Validation) }\end{array}$ \\
\hline OD, mm & 9.50 & 9.50 & 9.50 & 10.91 \\
\hline Wall Thickness, mm & 0.57 & 0.57 & 0.61 & 0.64 \\
\hline OD Surface Roughness, $\mu \mathrm{m}$ & 0.11 & 0.12 & 0.12 & 0.11 \\
\hline Sn, wt.\% & 0.99 & 0.02 & --- & --- \\
\hline Nb, wt.\% & 0.98 & 1.02 & --- & --- \\
\hline O, wt.\% & 0.12 & 0.145 & 0.145 & --- \\
\hline Fe, wt.\% & 0.11 & 0.05 & --- & --- \\
\hline Cr, wt.\% & $<0.01$ & $<0.01$ & --- & --- \\
\hline Ni, wppm & $<100$ & $<100$ & --- & --- \\
\hline S, wppm & --- & $25 \pm 5$ & --- & --- \\
\hline C, wppm & 135 & 110 & --- & --- \\
\hline Hf, wppm & 40 & $<100$ & --- & --- \\
\hline Si, wppm & 53 & $<100$ & --- & --- \\
\hline N, wppm & 46 & 55 & --- & --- \\
\hline H, wppm & 5 & 6 & 5 & --- \\
\hline
\end{tabular}

${ }^{\mathrm{a} C h e m i c a l ~ d a t a ~ p r o v i d e d ~ b y ~ W e s t i n g h o u s e ~ a n d ~ C O N A M ~ M a t e r i a l s ~ A n a l y s i s ~ G r o u p ; ~} \mathrm{H}$ and $\mathrm{O}$ content confirmed by ANL.

${ }^{\mathrm{b}}$ Chemical data provided by CONAM Materials Analysis Group; $\mathrm{H}$ and $\mathrm{O}$ content confirmed by ANL.

${ }^{\mathrm{c}} \mathrm{ANL}$ data for AREVA M5 cladding.

EPRI and AREVA provided two high-burnup fueled M5 rods at 63 and $70 \mathrm{GWd}$ /MTU for LOCA integral testing of fueled-cladding samples. In addition, under agreements among NRC-Studsvik-AREVA and NRC-Studsvik-Westinghouse, high-burnup defueled M5 cladding from the European Ringhals PWR reactor and ZIRLO cladding from the North Anna PWR reactor, respectively, were supplied to ANL for post-quench ductility testing. Cladding materials from these high-burnup rods are characterized in sections $(5,6)$ relevant to the tests conducted.

\subsection{Oxidation and quench tests with short defueled cladding samples}

The LOCA integral apparatus was designed to perform both LOCA integral tests using long $(\approx 300$ $\mathrm{mm})$ fueled cladding samples and oxidation-quench tests using short $(25 \mathrm{~mm})$ defueled cladding samples. An out-of-cell unit was used for thermal-benchmarking purposes and for generating data for as-fabricated and prehydrided alloys. Two in-cell units have been used for testing high-burnup fueled and defueled cladding. The units share the same control and data acquisition systems. The main difference between LOCA- integral and oxidation-quench tests is the test train holding the sample in position within the quad-elliptical, radiant furnace and the connections required. Both use a quartz-tube steam chamber. 
Table 6. Dimensions and Chemistry of E110 Tubing and Cladding Used in the ANL Test Program (the "<" sign means below the detection limit).

\begin{tabular}{|l|c|c|c|c|}
\hline \multicolumn{1}{|c|}{ Parameter } & $\begin{array}{c}\text { E110 } \\
\text { Tubing }\end{array}$ & $\begin{array}{c}\text { E110 } \\
\text { Cladding }\end{array}$ & $\begin{array}{c}\text { E110 } \\
\text { E110 } \\
\text { (Polished) }\end{array}$ & $\begin{array}{c}\text { Machined- } \\
\text { and- } \\
\text { Polished) }\end{array}$ \\
\hline \hline OD, mm & 9.17 & 9.13 & 9.14 & 9.14 \\
\hline Wall Thickness, mm & 0.71 & 0.70 & 0.69 & $0.58-0.69$ \\
\hline OD Surface Roughness, $\mu \mathrm{m}$ & 0.35 & 0.19 & 0.14 & 0.14 \\
\hline Sn, wt.\% & 0.02 & --- & 0.02 & 0.02 \\
\hline Nb, wt.\% & 1.03 & --- & 1.03 & 1.03 \\
\hline O, wt.\% & 0.05 & --- & 0.05 & 0.05 \\
\hline Fe, wt.\% & $0.055 \pm 0.015$ & --- & $0.055 \pm 0.015$ & $0.055 \pm 0.015$ \\
\hline Cr, wt.\% & $<0.01$ & --- & $<0.01$ & $<0.01$ \\
\hline Ni, wppm & $<100$ & --- & $<100$ & $<100$ \\
\hline S, wppm & $25 \pm 15$ & --- & $25 \pm 15$ & $25 \pm 15$ \\
\hline C, wppm & 135 & --- & 135 & 135 \\
\hline Hf, wppm & 100 & --- & 100 & 100 \\
\hline Si, wppm & 100 & --- & 100 & 100 \\
\hline N, wppm & 46 & --- & 46 & 46 \\
\hline H, wppm & 5 & --- & 5 & 5 \\
\hline Chemical & & & \\
\hline
\end{tabular}

${ }^{\mathrm{a}}$ Chemical data provided by CONAM Materials Analysis Group; $\mathrm{H}$ and $\mathrm{O}$ content confirmed by ANL.

${ }^{\mathrm{b}}$ Pickled and anodized to harden the outer-surface layer.

${ }^{\mathrm{c}}$ Polishing done for about 2 minutes with $9-\mu \mathrm{m}$ and 3- $\mu$ m-grit $\mathrm{Al}_{2} \mathrm{O}_{3}$ paper.

${ }^{\mathrm{d}}$ Machining of inner surface and polishing of both outer and inner surfaces; a few test samples were prepared by machining $25 \mu \mathrm{m}$ off the outer surface followed by polishing of both surfaces.

The radiant-heating furnace has four vertical bulbs, reflecting inner surface, and 250-mm-high uniform heating zone. LOCA integral tests were conducted with 300-mm-long samples initially under high internal pressure $(\approx 8 \mathrm{MPa})$, which required connection to the high-pressure helium line, along with top and bottom pressure transducers. Oxidation-quench tests do not require the high-pressure connection or pressure transducers. Figure 6 shows a photograph of the out-of-cell apparatus. Figure 7 gives a schematic of the out-of-cell apparatus and in-cell apparatus. During initial studies, the quartz test chamber was purged with high-purity argon prior to the introduction of steam. This step was discontinued based on comparison studies with and without pre-test argon purging. Steam, at nearatmospheric pressure, flows up through the quartz-tube (47-48 $\mathrm{mm} \mathrm{ID)}$ test chamber at $0.32 \pm 0.05$ $\mathrm{g} / \mathrm{cm}^{2} /$ minute $(5.3 \mathrm{~g} /$ minute) and exits the chamber into a condenser. The quartz tube length was $686 \mathrm{~mm}$ for most tests and $610 \mathrm{~mm}$ for tests conducted in 2008 (see 5.2-5.3). Following oxidation and slowcooling phases, steam flow was turned off, and quench water was introduced through bottom flooding to give very rapid sample cooling to $80-100^{\circ} \mathrm{C}$ at the desired time and temperature during cooling. 
Table 7. Characteristics of High-burnup Fuel Rod Segments and Defueled High-burnup Cladding for the ANL LOCA Test Program. Burnup values are rod averaged.

\begin{tabular}{|c|c|c|c|c|c|c|}
\hline Parameter & TMI-1 & Limerick & $\begin{array}{c}\text { H. B. } \\
\text { Robinson }\end{array}$ & $\begin{array}{l}\text { North Anna } \\
\text { M5 }\end{array}$ & $\begin{array}{l}\text { North Anna } \\
\text { ZIRLO }\end{array}$ & $\begin{array}{l}\text { Ringhals } \\
\text { M5 }\end{array}$ \\
\hline Reactor & PWR & BWR & PWR & PWR & PWR & PWR \\
\hline $\begin{array}{c}\text { Enrichment, } \\
\text { wt.\% }\end{array}$ & 4.00 & $\begin{array}{c}3.95 \\
(3.40-3.95)\end{array}$ & 2.90 & 4.20 & $\approx 4$ & $\approx 4$ \\
\hline $\begin{array}{c}\text { Burnup, } \\
\text { GWd/MTU }\end{array}$ & $48-50$ & $54-57$ & $63-67$ & $63-70$ & 70 & 63 \\
\hline $\begin{array}{c}\text { Discharge } \\
\text { Date }\end{array}$ & 1997 & 1998 & 1995 & 2004 & 2001 & 2003 \\
\hline $\begin{array}{c}\text { Fast } \\
\text { Fluence, } \\
10^{25} \mathrm{n} / \mathrm{m}^{2}\end{array}$ & 9 & 11 & 14 & $\begin{array}{c}\text { Not } \\
\text { Provided }\end{array}$ & $\begin{array}{c}\text { Not } \\
\text { Provided }\end{array}$ & $\begin{array}{c}\text { Not } \\
\text { Provided }\end{array}$ \\
\hline Cladding & $\begin{array}{c}15 \times 15 \\
\text { Low-Sn } \\
\text { Zry-4 }\end{array}$ & $\begin{array}{c}9 \times 9 \\
\text { Zr-lined } \\
\text { Zry-2 }\end{array}$ & $\begin{array}{l}15 \times 15 \\
\text { Zry-4 }\end{array}$ & $\begin{array}{c}17 \times 17 \\
\text { M5 }\end{array}$ & $\begin{array}{l}17 \times 17 \\
\text { ZIRLO }\end{array}$ & $\begin{array}{c}17 \times 17 \\
\text { M5 }\end{array}$ \\
\hline $\begin{array}{c}\text { Initial Wall } \\
\text { Thickness, } \\
\text { mm }\end{array}$ & 0.69 & 0.71 & 0.76 & 0.57 & 0.57 & 0.57 \\
\hline $\begin{array}{c}\text { OD } \\
\text { Oxide, } \mu \mathrm{m}\end{array}$ & $\leq 30$ & $\begin{array}{c}\approx 10+ \\
\approx 10 \text { crud }\end{array}$ & $\leq 100$ & $<20$ & $\approx 20-50$ & $<20$ \\
\hline $\begin{array}{c}\text { Hydrogen } \\
\text { Pickup, } \\
\text { wppm }\end{array}$ & $\leq 300$ & 70 & $\leq 800$ & $<120$ & $<700$ & $\leq 110$ \\
\hline Fueled & Yes & Yes & Yes & Yes & No & No \\
\hline
\end{tabular}

The apparatus shown in the Figure 7 schematic was initially used for oxidation-kinetics tests of near-archive Limerick 9×9 Zry-2, high-burnup Limerick 9×9 Zry-2, and intermediate-burnup TMI-1 $15 \times 15 \mathrm{Zry}-4$ [15]. These one-sided oxidation tests, which were conducted in-cell, were performed without quench. Also, a slow-flowing argon purge was maintained inside the cladding and test train to minimize steam and hydrogen build-up. The test train used to conduct these in-cell tests is shown in Figure 8. Three Type $\mathrm{S}$ thermocouples are welded $120^{\circ}$ apart onto the Inconel sample holder just above the sample. One of these thermocouples is used to control the furnace power to achieve the desired hold temperature. The other two are for monitoring circumferential temperature distribution. For these tests, a fourth thermocouple is suspended within the sample to determine the circumferentially averaged temperature. Prior to conducting the in-cell tests, thermal and metallurgical benchmark tests were conducted out-of-cell with thermocouples welded directly onto the sample outer surface. The thermal benchmark results showed excellent agreement in the long-time hold temperatures among the thermocouples welded onto the sample, the three thermocouples welded onto the Inconel holder above the sample, and the thermocouple (TC) suspended inside the sample. Although not important for these longtime tests $(\geq 300 \mathrm{~s})$, the temperature rise of the suspended TC lagged the temperature rise of the holder TCs, which lagged the temperature rise of the TCs welded onto the sample. 


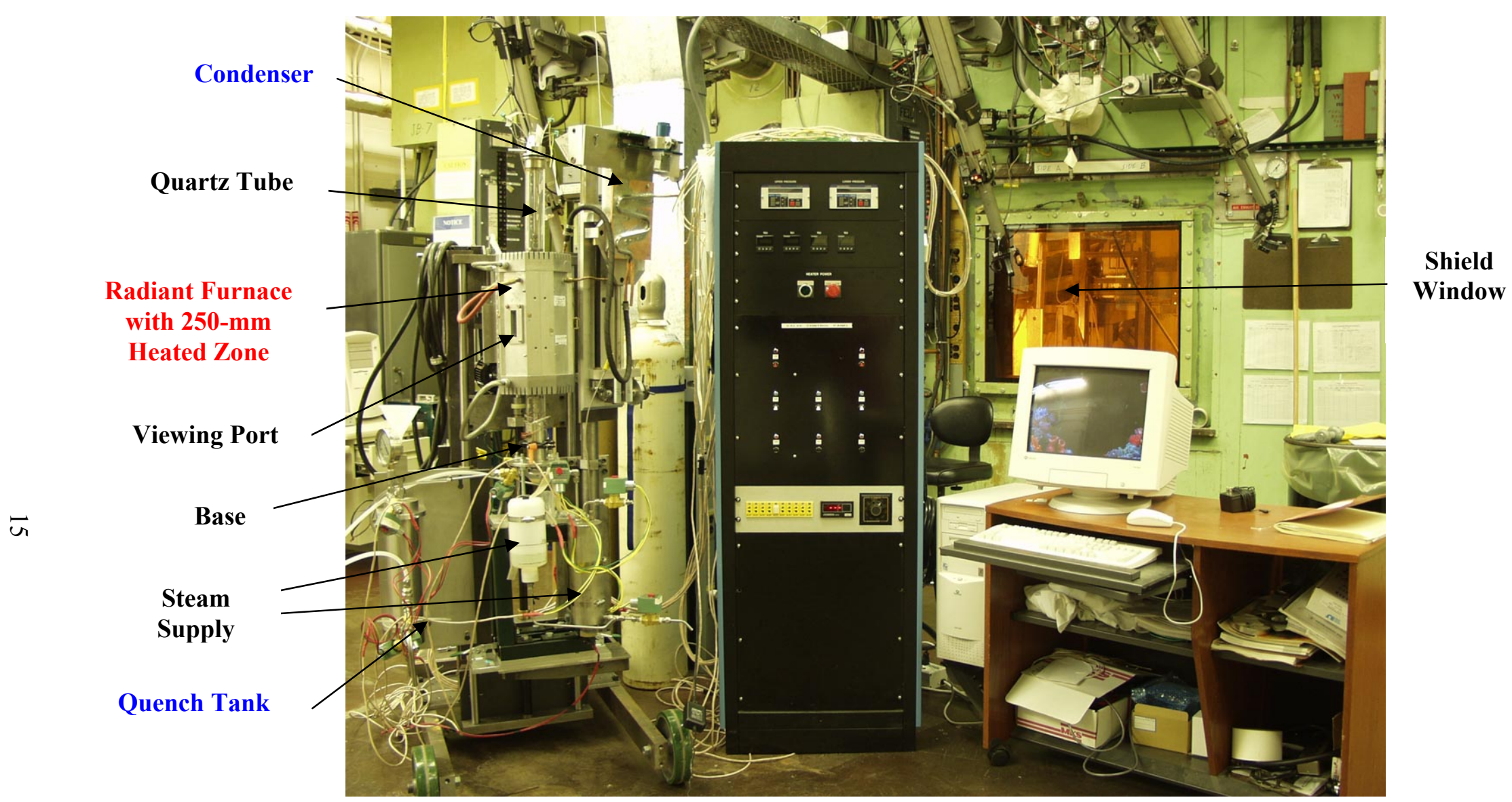

Figure 6. Overview of the out-of-cell LOCA integral test apparatus. One in-cell unit was located at Workstation 6 of the Alpha-Gamma Hot Cell Facility (AGHCF) behind the hot-cell shield and seal windows. High-burnup Zry-4 oxidation/quench tests, as well as high-burnup Zry-2 oxidation and integral tests, were conducted in the AGHCF. Following closure of the AGHCF to programmatic work (January 2006), the out-cell apparatus was moved to a "cold" laboratory for testing nonirradiated cladding samples. This apparatus, equipped with a new furnace and a shorter (610 $\mathrm{mm}$ ) test chamber, was moved in 2008 into Hot Cell \#4 of the Irradiated Materials Laboratory for performing oxidation-and-quench tests with highburnup ZIRLO and M5 cladding samples. 


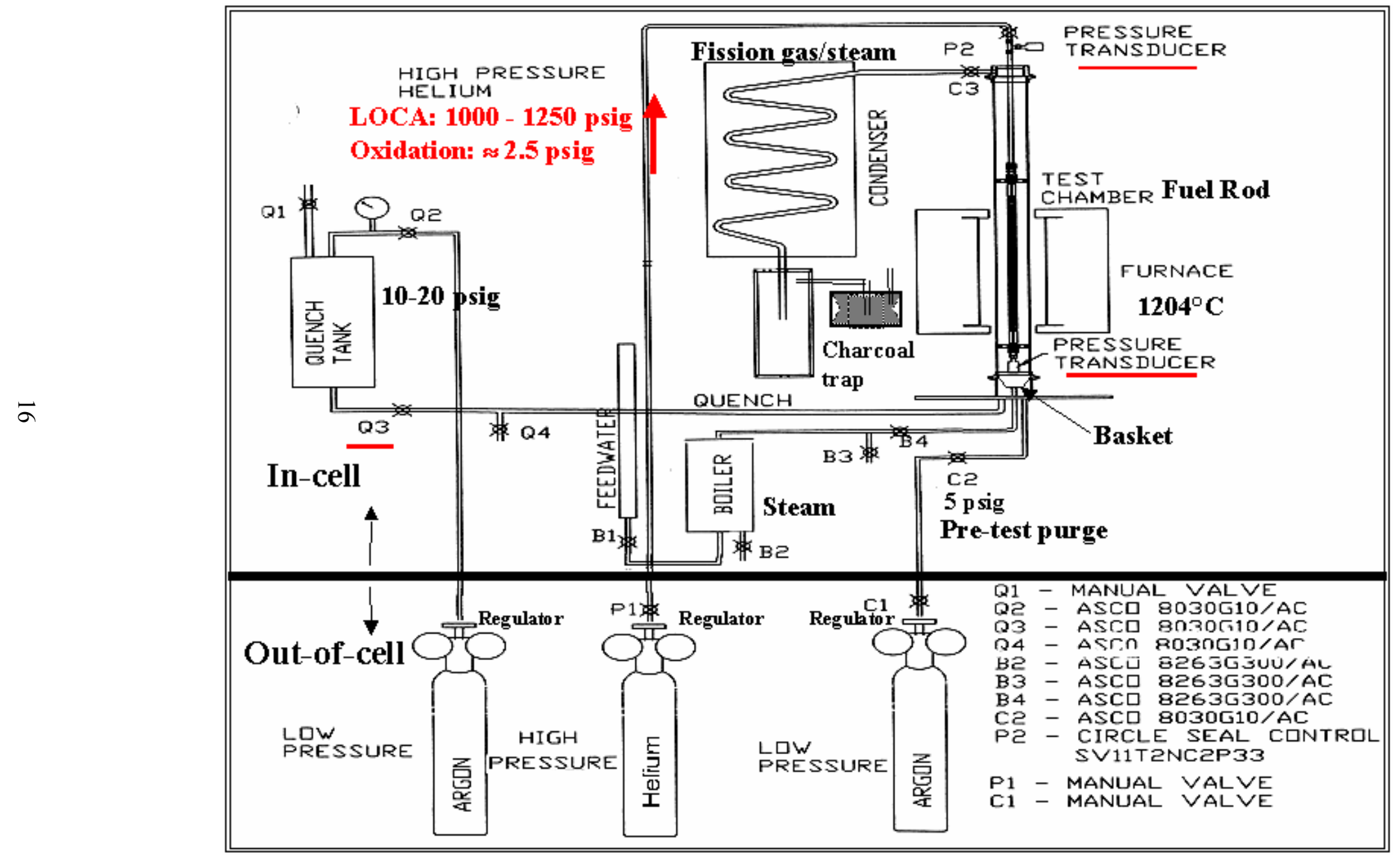

Figure 7. Schematic of oxidation kinetics, oxidation-quench, and LOCA integral test apparatus; test train and sample are shown for LOCA integral testing. 
The test train in Figure 8 was modified for the advanced-alloy post-quench ductility tests in order to conduct two-sided steam oxidation tests. The two-sided tests offered many advantages over the one-sided tests: better temperature control, uniform inner-surface oxidation, no change in sample hydrogen content due to inner-surface hydrogen pickup or hydrogen desorption to the purge gas, and a reliable and costeffective way to determine weight gain by simply weighing the sample before and after the test. Figure 9 shows the test train used for oxidizing and quenching the samples prior to conducting post-quench ductility tests. Holes were drilled into the hollow Inconel holder below and above the sample to allow adequate steam flow inside the cladding sample. Other changes were made to the Inconel holder wall thickness and outer-diameter to reduce the thermal mass and transient temperature lag of the holder.
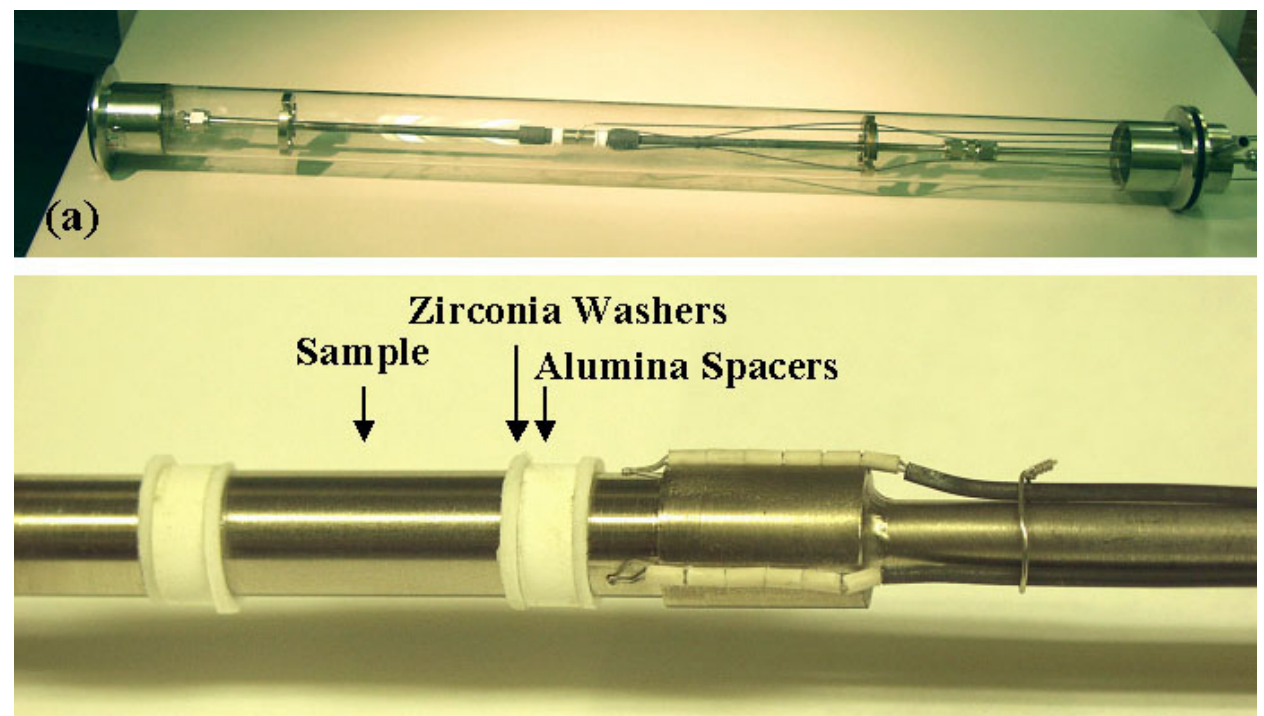

(b)

Figure 8. Test train for conducting one-sided steam-oxidation kinetics tests in-cell using $\approx 25$-mm-long Zircaloy cladding samples: a) test train within quartz tube; and b) enlarged view of sample region along the test train showing alumina spacers to inhibit Zircaloy-Inconel interaction and zirconia washers to minimize steam leakage to the sample inner surface.

Temperature control and monitoring are extremely important in conducting oxidation-quench tests, followed by post-quench ductility tests. As discussed in Section 1, the time-at-temperature for the transition between ductile and brittle behavior is a strong function of temperature. The furnace power and sample temperature are controlled by feedback from the designated TC output through a proportionalintegral-differential (PID) controller to the furnace power. Because the sample has such low thermal mass per unit length, it is important to ramp to the hold temperature at a relatively fast rate for these tests without temperature overshoot due to the initially rapid heat generation rate from cladding oxidation. In setting the controller parameters, the requirements are that the temperature overshoot during the ramp be $<20^{\circ} \mathrm{C}$ relative to the target hold temperature for a short period of time (few seconds), and that the average hold temperature be within $10^{\circ} \mathrm{C}$ of the target temperature. The $10^{\circ} \mathrm{C}$ is reasonable given the uncertainty in the Type $\mathrm{S}$ thermocouples - a few degrees - at the maximum oxidation temperature $\left(1204^{\circ} \mathrm{C}\right)$.

Temperature overshoot is not much of an issue for long-time oxidation temperatures $\leq 1100^{\circ} \mathrm{C}$, but it can have a significant embrittlement effect for higher oxidation temperatures. For tests conducted at $1200^{\circ} \mathrm{C}$, temperature overshoot was minimized by slowing down the heating rate at ramp temperatures within 50$100^{\circ} \mathrm{C}$ of the target temperature. 


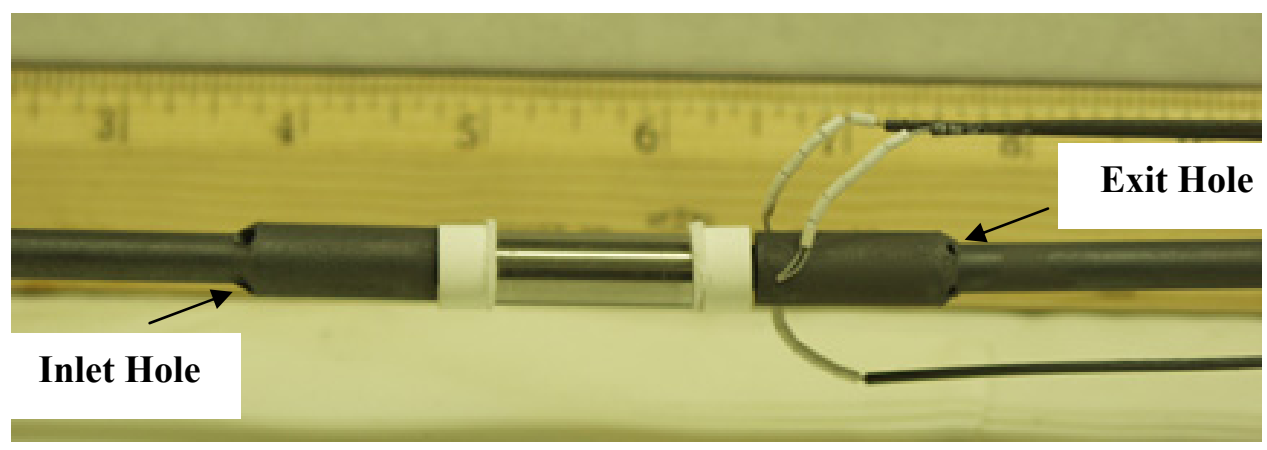

Figure 9. Test train design for two-sided oxidation tests with four holes drilled into the Inconel holder below the sample (left) for steam ingress and four holes drilled into the holder above the sample for steam egress. Also shown are the three thermocouples permanently welded to the Inconel holder just above the sample. To improve strength and endurance, the number of holes was later reduced from four to three.

The following benchmarking procedure was established for each test train:

a) Calibrate purchased TCs to ANL-owned, NIST-calibrated TC wire (introduced in January 2006).

b) Weld two calibrated Type S TCs onto sample outer surface at same orientation as holder control TC and another holder $\mathrm{TC} \pm 120^{\circ}$ from the control TC.

c) Use repeated testing with fresh samples and same orientation for TCs welded to sample to determine optimum controller parameters for desired temperature ramp and hold temperature.

d) For larger-diameter cladding (e.g., BWR $9 \times 9$ and PWR $15 \times 15$ ), repeat test with new sample, where one TC is welded on sample at same orientation as holder control TC, and one TC is welded on sample at same orientation as the third holder TC; this provides a good check of reproducibility of temperature results, as well as a better determination of circumferential variation.

e) Perform metallographic examination to determine oxide-layer thicknesses at eight circumferential locations; compare measured and predicted average values to Cathcart-Pawel (CP)-predicted values to ensure $<10 \%$ difference; compare circumferential variation to ANL criterion $(\leq \pm 3 \mu \mathrm{m})$.

f) Conduct oxidation test without TCs welded on the sample and compare measured sample weight gain at a time corresponding to $\approx 10 \% \mathrm{CP}$-ECR to weight gain calculated with CP-correlation; also perform metallographic examination to determine average inner- and outer-surface oxide layer thicknesses, as well as variation.

g) If temperature requirements are satisfied, measured weight gain is within $10 \%$ of predicted weight gain, average oxide layer thickness on inner and outer surfaces is within $10 \%$ of predicted thickness, and circumferential variation in oxide layer thickness is consistent with temperature variation, then begin oxidation testing with this test train.

h) Continue to run tests with the benchmarked test train and controller parameters for specific hold temperature until the measured weight gain and CP-predicted weight gain differ by $\geq 10 \%$; repeated quench will cause some warping of the test train, which moves the sample away from the furnace focal point; generally, a test train will be good for $\approx 15$ runs with quench and more without quench. 
Figure 10 shows thermal benchmark results for as-fabricated HBR-type $15 \times 15$ Zry- 4 cladding. In order not to obscure the results, the three holder temperatures for each of the two tests are not shown. For the controller parameters chosen, the hold temperature is $1204 \pm 10^{\circ} \mathrm{C}$, where the $\pm 10^{\circ} \mathrm{C}$ is the circumferential variation in temperature based on sample TC readings at $0^{\circ}, 120^{\circ}$, and $240^{\circ}$. On the average, there is no temperature overshoot. The highest reading of any one $\mathrm{TC}$ is $1220^{\circ} \mathrm{C}$ for a brief period of time. For this particular set of controller parameters, the temperature rise consists of a very fast $\operatorname{ramp}\left(\approx 75^{\circ} \mathrm{C} / \mathrm{s}\right)$ from $300^{\circ} \mathrm{C}$ to $\approx 1100^{\circ} \mathrm{C}$ and a slow ramp $\left(\approx 1.3^{\circ} \mathrm{C} / \mathrm{s}\right)$ from $1100^{\circ} \mathrm{C}$ to $1204^{\circ} \mathrm{C}$. At the end of the hold time, the furnace power is turned off, and the sample cools in steam at an average of $\approx 11^{\circ} \mathrm{C} / \mathrm{s}$ to the desired quench temperature of $800^{\circ} \mathrm{C}$. The actual cooling rate decreases exponentially with time, as would be expected for this zero-furnace-power phase of the transient. Part of the thermal benchmark testing is to determine the test time and temperature at which to stop the steam flow and initiate bottomflooding quench-water flow to induce very rapid cooling at the specified temperature. Rapid cooling $\left(\approx 150^{\circ} \mathrm{C} / \mathrm{s}\right)$ from the quench temperature to $100^{\circ} \mathrm{C}\left(80 \pm 10^{\circ} \mathrm{C}\right.$ for short samples) is fast enough for these tests, but not as fast as in-reactor cooling rates following wetting. This lower rate is due to the limited quench water supply that can be used in-cell ( $<3$ liters based on hot-cell criticality limitations). There is only enough quench water to fill the quartz tube chamber to an elevation just above the furnace.

As shown in Figure 10, the test is not an isothermal test. The significance of the weight gain during the initial heating ramp depends on the hold temperature and the hold time. For the temperature history shown in Figure 10, the CP-predicted weight gain is determined numerically by integrating Equation 1 over the time-dependent temperature profile $\mathrm{T}(\mathrm{t})$, which is recorded at an interval of $0.1 \mathrm{~s}$ :

$$
(\mathrm{Wg})^{2}=0.362 \int_{0}^{\mathrm{t}} \exp (-20100 / \mathrm{T}) \mathrm{dt},
$$

where $\mathrm{Wg}$ is in $\mathrm{g} / \mathrm{cm}^{2}, \mathrm{~T}$ is in $\mathrm{K}$, and $\mathrm{t}$ is in $\mathrm{s}$. Because of the parabolic nature of the weight gain correlation, the weight gain accumulated during the cooling ramp is usually insignificant. Also, the CP set of correlations was validated for $\mathrm{T} \geq 1000^{\circ} \mathrm{C}(1273 \mathrm{~K})$. However, the weight gain correlation appears to give results consistent with ANL data for $\mathrm{T} \geq 950^{\circ} \mathrm{C}$. For the ANL work, the integral in Equation 7 is converted to an integral with respect to temperature and the integration for the high-temperature oxidation tests (e.g., Figure 10) is usually performed for $\mathrm{T} \geq 1000^{\circ} \mathrm{C}$.

For oxidation and quench of as-fabricated and prehydrided samples used for post-quench ductility tests, the procedure is the same as the one used in the thermal and metallurgical benchmark tests:

a) Stabilize the system at $300^{\circ} \mathrm{C}$ in flowing saturated steam for $500 \mathrm{~s}$.

b) Initiate temperature ramp with feedback between the holder TC and the furnace power.

c) Hold at temperature for a predetermined time to achieve the desired CP weight gain and ECR.

d) Turn furnace power off while maintaining steam flow at the end of the hold time.

e) Stop steam flow and initiate bottom-flooding quench at a test time that will give rapid cooling at the desired cladding temperature. (Note: minimum temperature after quench is nominally $100^{\circ} \mathrm{C}$; for tests conducted after January 2006 , minimum temperature was reduced to $80 \pm 10^{\circ} \mathrm{C}$.) 


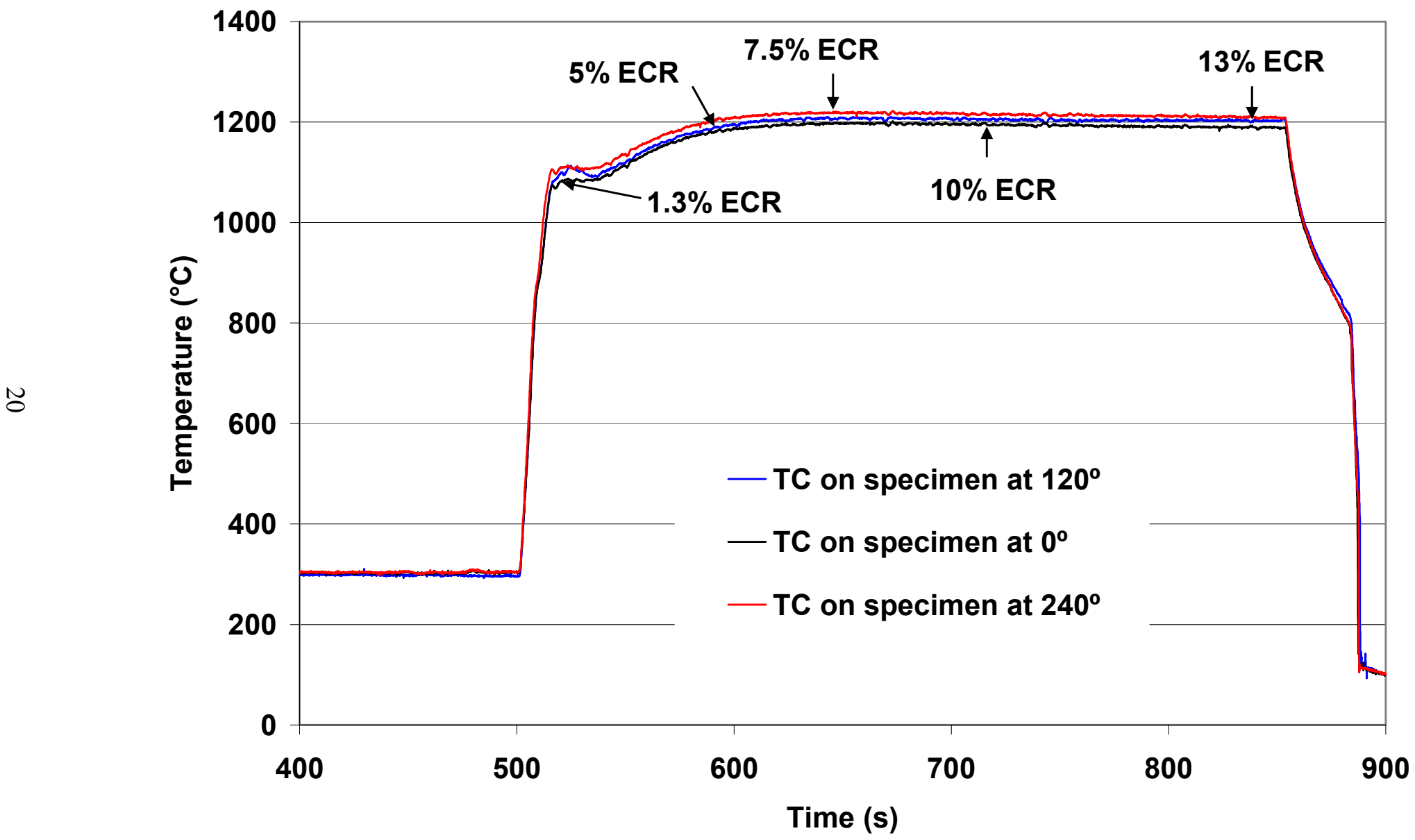

Figure 10. Thermal benchmark results from two tests, each with two TCs welded onto as-fabricated, HBR-type $15 \times 15$ Zry- 4 cladding. Test HBRU\#20 had TCs welded onto the sample at $0^{\circ}$ and $120^{\circ}$, while test HBRU\#29 had TCs welded onto a new sample at $0^{\circ}$ and $240^{\circ}$. The sample hold temperature is $1204 \pm 10^{\circ} \mathrm{C}$, where $1204^{\circ} \mathrm{C}$ is the average of the three TC readings and $\pm 10^{\circ} \mathrm{C}$ is the standard deviation. 
The procedure for conducting in-cell oxidation-quench tests with high-burnup cladding samples is similar to the one described above for out-of-cell tests with unirradiated cladding samples. However, the corroded, irradiated samples were not directly thermally benchmarked because ANL does not have the incell capability to locally remove the corrosion layer and spot-weld TCs to the cladding metal surface. With respect to the temperature history shown in Figure 10 for bare, unirradiated cladding, it is expected that pretest cladding corrosion would slow down the initial oxidation rate and the heating rate associated with the exothermic oxidation reaction. The presence of the corrosion layer would basically affect the peak temperature reached during the very rapid heating ramp. This effect has been confirmed in out-ofcell tests using the following procedure to determine the temperature profile for high-burnup Zry-4 cladding with a $70-\mu \mathrm{m}$-thick corrosion layer and an $11 \pm 4-\mu \mathrm{m}$-thick fuel-cladding bond layer:

a) With TCs welded onto bare as-fabricated cladding, conduct the thermal benchmark test for a hold time selected to grow $40-\mu \mathrm{m}$-thick oxide layers on the inner and outer surfaces of the cladding.

b) Cool to $300^{\circ} \mathrm{C}$ and repeat thermal benchmark test using the same controller parameters as were used in (a); compare the two sets of results with emphasis on the maximum temperature at the end of the rapid temperature rise (first peak), the time to reach the hold temperature, and the hold temperature.

c) If necessary, increase the holder control temperature to achieve the desired hold temperature for cladding with pre-transient oxide layers.

d) Install the calibrated test train in the in-cell furnace and conduct a metallurgical benchmark test with as-fabricated cladding without the TCs welded onto the cladding and with the hold time chosen to give a weight gain equivalent to $10 \%$ CP-ECR; if the out-of-cell and in-cell weight gains and converted ECR values are in good agreement, then the use of the test train in the in-cell furnace has been validated.

e) Use the results of the thermal benchmark in (b) and (c) - the one with oxide layers grown on the inner and outer surfaces prior to initiating the temperature ramp - to choose test times to give the desired CP-ECR values and to interpret the experimental results for high-burnup cladding.

The results of benchmark tests (a) and (b) indicated the following for HBR-type $15 \times 15$ Zry-4: the peak temperature at the end of the rapid heating rate was $40^{\circ} \mathrm{C}$ less for pre-oxidized cladding as compared to bare cladding; the time to reach the hold temperature was about the same for both cases; and the hold temperature for the pre-oxidized cladding was $\approx 8^{\circ} \mathrm{C}$ less than the hold temperature for the bare cladding. Knowing these effects helps to choose the optimum controller parameters for in-cell tests with highburnup cladding samples. For example, higher heating rates and desired hold temperatures for highburnup cladding can be achieved by selecting controller parameters to give rapid heating to the hold temperature for bare cladding and by repeating the test with the appropriate steam-grown oxide layer thicknesses chosen to match the effects of the corrosion and the fuel-cladding bond layers. For highburnup M5 with 20- $\mu \mathrm{m}$-thick corrosion and 10- $\mu \mathrm{m}$-thick fuel-cladding bond layers, the test time for the first benchmark would be chosen to grow $13-\mu \mathrm{m}$-thick oxide layers on the cladding inner and outer surfaces, and the hold temperature would be chosen to be higher $\left(\right.$ e.g., $1208^{\circ} \mathrm{C}$ ) than the hold temperature targeted for the high-burnup cladding. Following cooling to $300^{\circ} \mathrm{C}$, the same controller parameters would be used to conduct the thermal benchmark for the in-cell tests. A bare-cladding thermal history, which was considered for testing high-burnup ZIRLO and M5, is shown in Figure 11. However, this history was rejected because it did not give consistent weight gain results at low ECR values. 


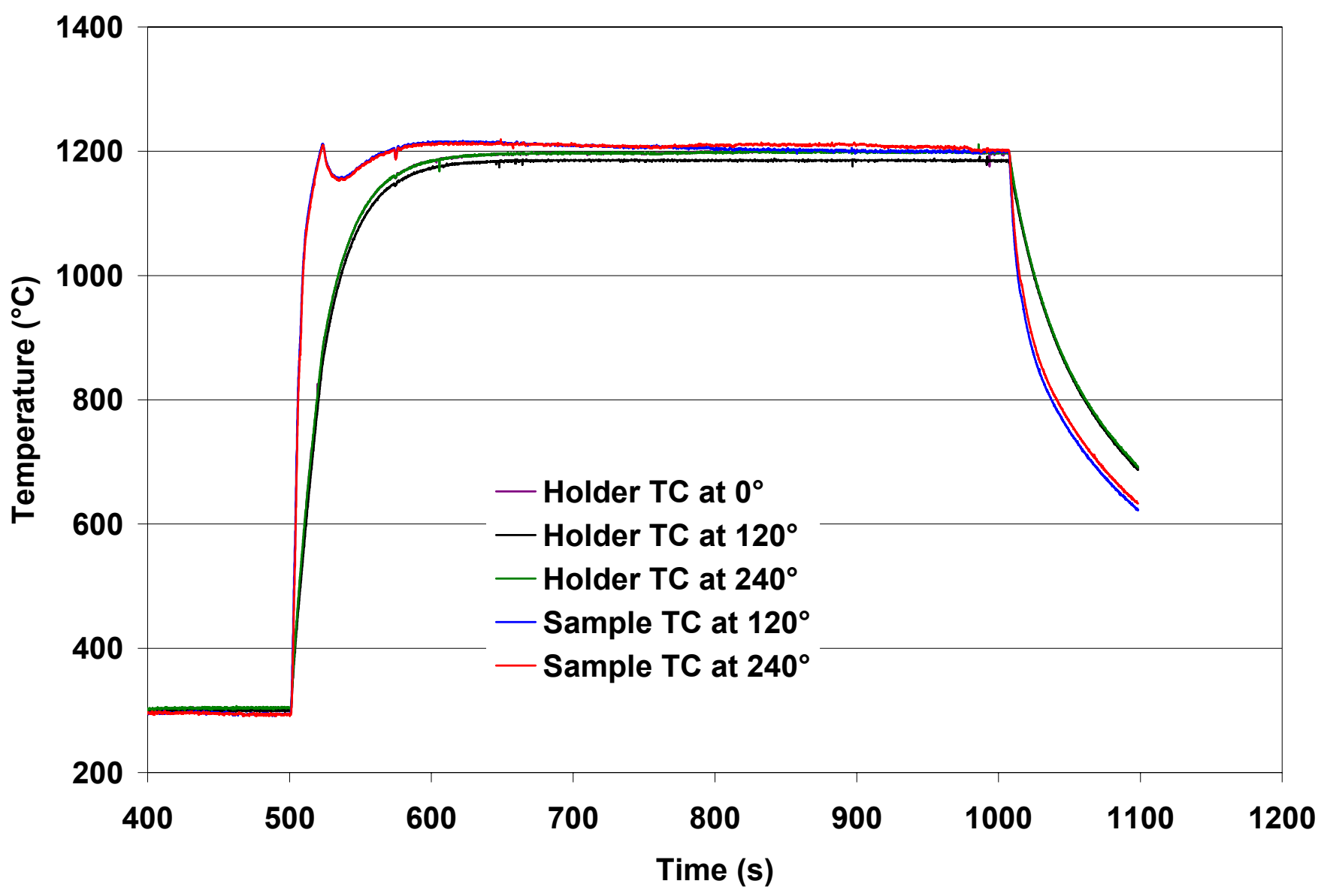

Figure 11. Thermal benchmark results with as-fabricated $17 \times 17$ ZIRLO sample. Measured weight gains for $17 \times 17$ Zry- 4 , ZIRLO and M5 were inconsistent with each other and with CP-correlation prediction at 5\% CP-ECR due to possible differences in temperature overshoot (first peak) during the very rapid ramp to $1200^{\circ} \mathrm{C}$ followed by the temperature decrease and slower increase to $1200^{\circ} \mathrm{C}$. 


\subsection{Ductility determination using ring-compression tests}

Hobson [16] and Hobson and Rittenhouse [17] performed low- and high-strain-rate ring compression tests, respectively, using two-sided oxidized Zry-4 cladding samples over a wide range of temperatures. The results of the low-strain-rate tests interpolated to $\approx 135^{\circ} \mathrm{C}\left(275^{\circ} \mathrm{F}\right)$ were used to formulate the $1204^{\circ} \mathrm{C}\left(2200^{\circ} \mathrm{F}\right)$ peak cladding temperature and $17 \%$ maximum oxidation level (Baker-Just ECR [12]). The ring-compression test is a good ductility screening test that is often used for near-brittle to brittle materials. However, the methods used by Hobson to determine oxidation temperatures and levels leading to brittle behavior were crude. Rings were crushed to complete failure - often four cracks at the $0^{\circ}$ (12 o'clock), $90^{\circ}$ (3 o'clock), $180^{\circ}$ (6 o'clock), and $270^{\circ}$ (9 o'clock) positions relative to the loading platen. The pieces were reassembled. If the cracked pieces formed a circular shape vs. an oval shape, they were classified as brittle. Load-displacement curves for these tests were never published and apparently not used.

In the current work, 8 -mm-long rings were compressed at a low-displacement rate $(0.0333 \mathrm{~mm} / \mathrm{s})$ in an Instron test machine. The load-displacement curves were analyzed by the following procedure: linearize the initial loading curve (see blue line on left in Figure 12), use the slope of the initial loading curve to mathematically unload the sample at the peak load before a significant load drop $(\approx 30-50 \%)$ indicating a through-wall crack along the length of the sample (see green line on right in Figure 12), and determine the offset displacement (distance along the displacement axis between loading and unloading lines). This offset displacement is normalized to the outer diameter of the pre-oxidized cladding to determine a relative plastic strain. The methodology is illustrated in Figure 12 for $17 \times 17$ Zry- 4 oxidized at $1100^{\circ} \mathrm{C}$ to $20 \% \mathrm{CP}-\mathrm{ECR}\left(20.3 \%\right.$ based on measured weight gain), quenched at $800^{\circ} \mathrm{C}$ and ringcompressed at room temperature $(\mathrm{RT})$. The offset displacement for this sample is $0.455 \mathrm{~mm}(\approx 0.46 \mathrm{~mm})$.

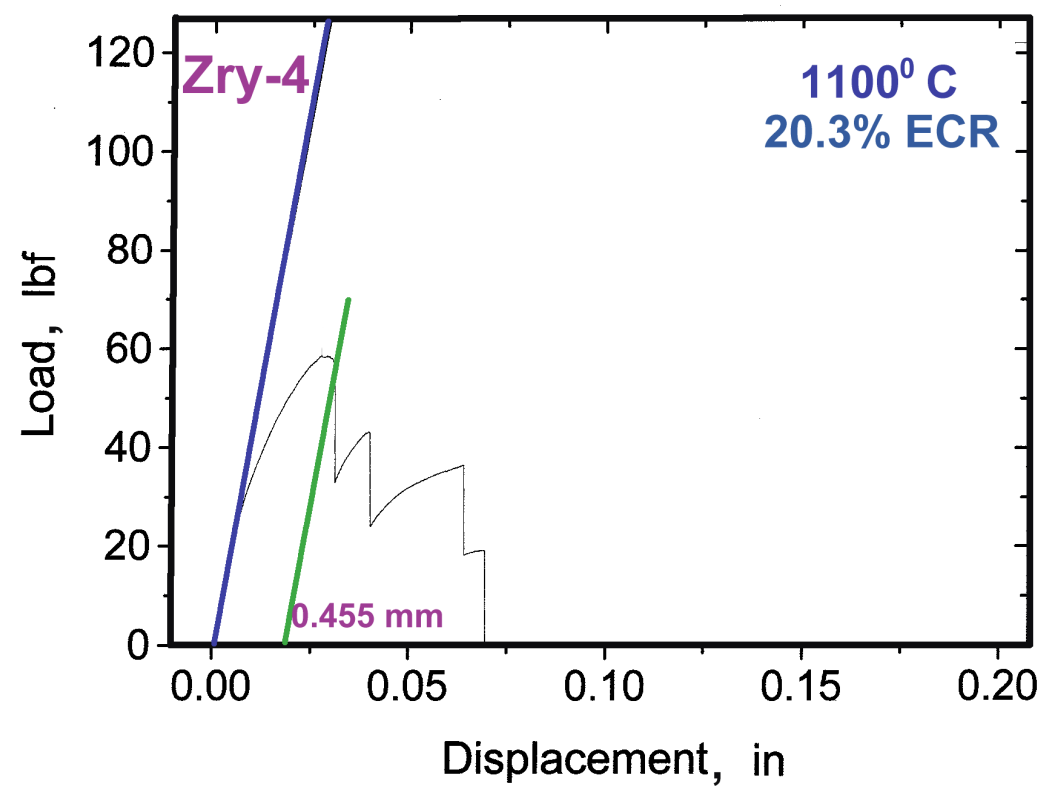

Figure 12. Ring-compression load-displacement data at room temperature for Zry-4 oxidized to 20\% CP-ECR $\left(20.3 \%\right.$ ECR based on measured weight gain) at $1100^{\circ} \mathrm{C}$. The sample fractured into four pieces. The offset strain $(0.455 \mathrm{~mm})$ is the distance along the displacement axis between the blue loading line (left) and the green unloading line (right). 
Normalizing this to the outer diameter of $9.50 \mathrm{~mm}$ for the pre-oxidized sample gives $4.8 \%$ offset strain. Cladding alloys (Zry-4, ZIRLO, M5, and E110) oxidized at $1000^{\circ} \mathrm{C}$ and $1100^{\circ} \mathrm{C}$ were tested and analyzed with this procedure. However, a few questions arose during this work regarding the methodology: would the ring actually unload prior to failure at the initial loading slope; what is the uncertainty in determining offset strain; and, given this uncertainty, what minimum value of offset strain should be used as the criterion for nil ductility?

To answer these questions, cladding alloys listed in Tables 3-6 were compressed at RT and 0.0333 $\mathrm{mm} / \mathrm{s}$ in the as-fabricated condition to a total displacement of $2 \mathrm{~mm}$. The samples were unloaded, and the post-test outer diameter for each ring was measured and compared to the pre-test outer diameter. The difference between these two diameters normalized to the initial diameter is called "permanent strain" in this work. It is a more direct measure of the ability of the material to deform plastically (i.e., exhibit ductility). It was found that the measured permanent displacement was $\leq 0.18 \mathrm{~mm}$ smaller than the offset displacement determined by the standard methodology shown in Figure 12. This converts to an overprediction of $\leq 2 \%$ by using the offset-displacement method. The logical explanation for this difference is that the unloading slope must be less than the loading slope. When the sample is loaded, it starts out circular with zero internal stress and behaves like an elastic spring with spring constant $\mathrm{k}_{\mathrm{s}}$. For the $17 \times 17$, $15 \times 15$, and E110 samples tested, the calculated and measured spring constants were in good agreement, ranging from 0.9 to $2.0 \mathrm{kN} / \mathrm{mm}$ for 8 -mm-long samples. The low value was for $17 \times 17$ Zry-4, ZIRLO and M5 with $0.57-\mathrm{mm}$ wall thickness. The high value was for thick-wall/small-diameter E110. The HBRtype $15 \times 15$ Zry-4 has an intermediate value of $1.4 \mathrm{kN} / \mathrm{mm}$. When the sample is unloaded, it is somewhat oval, has residual bending stresses from non-uniform plastic deformation, and has a lower unloading slope. This was confirmed both experimentally and analytically. The experimental confirmation is presented in the following.

The 8511 servo-hydraulic Instron was programmed for a compression displacement of $2 \mathrm{~mm}$ at $0.0333 \mathrm{~mm} / \mathrm{s}$, followed by unloading at a controlled rate of $0.0333 \mathrm{~mm} / \mathrm{s}$. The sample used was HBRtype $15 \times 15$ Zry-4. The results are shown in Figure 13. Clearly, the unloading slope is not as steep as the loading slope. The offset displacement $(1.32 \mathrm{~mm})$ based on mathematical unloading of the sample using the loading slope is larger than the true offset displacement $(1.19 \mathrm{~mm})$ based on the measured unloading curve. The difference $(0.13 \mathrm{~mm})$ is equivalent to $1.2 \%$ for this cladding geometry. The permanent displacement determined directly by measuring the pre-test and post-test diameter in the loading direction is in excellent agreement with the $1.19 \mathrm{~mm}$ determined from the full load-displacement curve, including unloading.

For oxidized samples, controlled unloading is not possible just prior to failure because the displacement at which failure will occur is unknown. Therefore, the standard procedure shown in Figure 12 is used to determine offset displacement and strain. To compensate for this over-estimation of offset strain, a limiting offset strain of $2 \%$ is set in the determination of the ductile-to-brittle transition. In other words, there is reasonable confidence that samples with $\geq 2 \%$ offset strain are ductile. For samples with offset strains $<2 \%$, it is not clear if they are ductile or brittle.

The $17 \times 17$ Zry-4, ZIRLO, and M5 samples oxidized at $1000^{\circ} \mathrm{C}$ and $1100^{\circ} \mathrm{C}$ to $5-20 \% \mathrm{CP}-\mathrm{ECR}$ and quenched at $800^{\circ} \mathrm{C}$ were initially compressed at RT and $0.0333 \mathrm{~mm} / \mathrm{s}$ to complete failure (three to four cracks) indicated by a load drop to zero. For samples that exhibited offset strains $<2 \%$ (e.g., one M5 sample at $1.8 \%$ ), the test was repeated with another $8-\mathrm{mm}$ ring from the same oxidation-quench sample by stopping the test after the first significant load drop (30-50\%). The sample was removed from the Instron and examined under a microscope to verify that a through-wall crack along the whole length of the sample had occurred. The post-test diameter was measured in the loading direction and compared to 


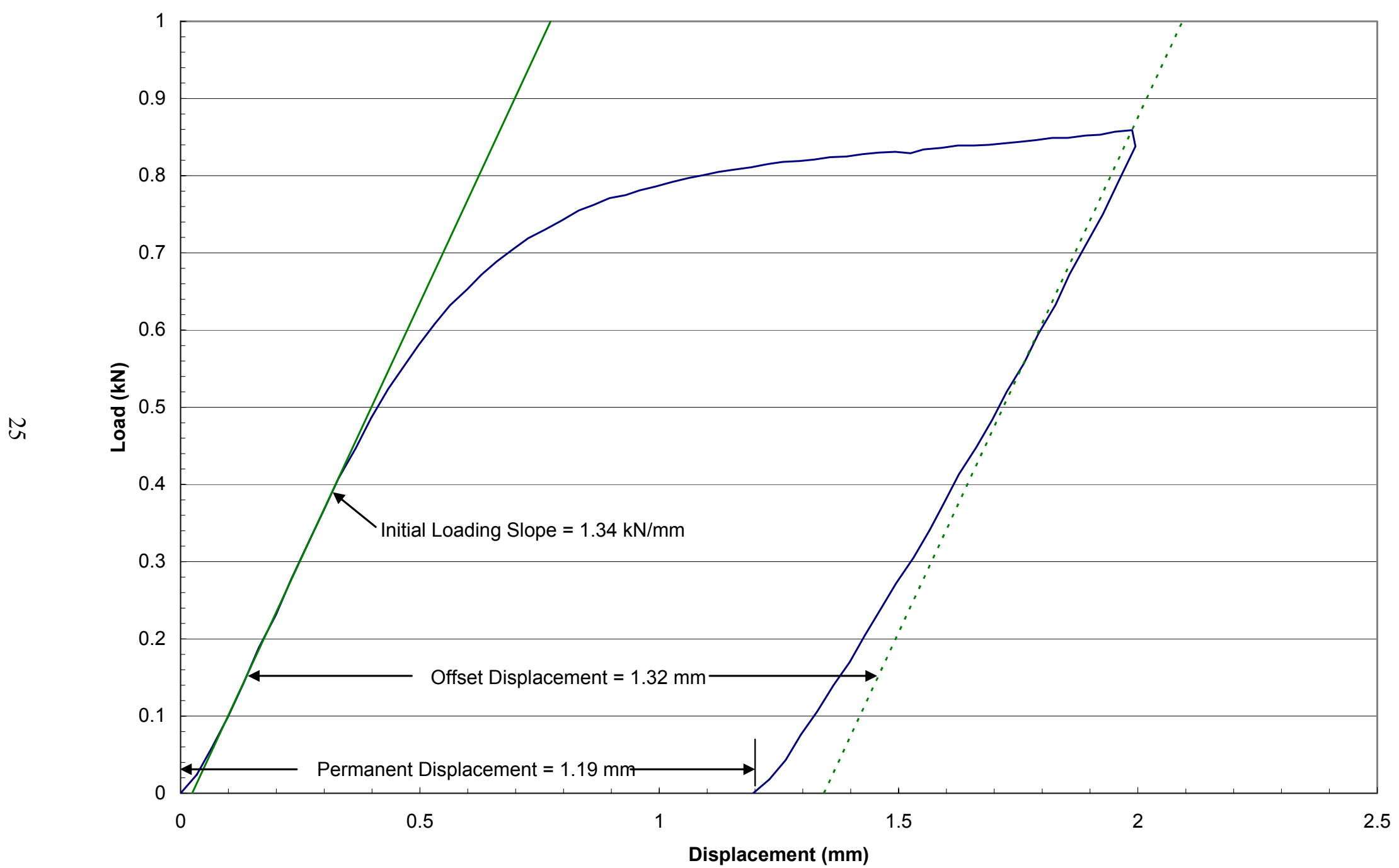

Figure 13. Load-displacement results from RT compression and unloading of an 8-mm-long ring of HBR-type $15 \times 15$ Zry-4 cladding. 
the pre-test diameter to determine permanent displacement and strain. If the measured permanent strain was $\geq 1 \%$, the sample was classified as ductile. The $1 \%$ permanent strain criterion is based on uncertainties in measuring the post-test diameter of a cracked ring to infer the permanent strain for the sample if it had been unloaded just prior to cracking. If the permanent strain were $<1 \%$ based on the RT test, a new sample with the same oxidation conditions would have been compressed at $135^{\circ} \mathrm{C}$. However, such was not necessary for the samples oxidized at $1000^{\circ} \mathrm{C}$ and $1100^{\circ} \mathrm{C}$.

The procedure of interrupting the test following the first load drop worked so well that it was adopted for all ring-compression tests of as-fabricated, prehydrided and high-burnup cladding oxidized at $1200^{\circ} \mathrm{C}$. The effects of hydrogen and high-temperature oxidation caused the cladding to embrittle at $<17 \% \mathrm{CP}$-ECR for RT tests. As samples under these conditions had to be retested at $135^{\circ} \mathrm{C}$ anyway, the RT tests were eventually eliminated for all rings sectioned from samples oxidized at $1200^{\circ} \mathrm{C}$.

The procedure for determining ductility and conditions (temperature, CP-ECR, H content, etc.) under which ductile-to-brittle-transition occurs is summarized in the following:

a) Section one or more 8-mm-long rings from the oxidation or oxidation-quench sample; measure and record the precise length and outer diameter of the oxidized sample; and mark the circumferential location corresponding to the minimum diameter that will be contacted by the loading platen.

b) Load ring into Instron 8511 (see Figure 14) with flat support and loading platens.

c) Compress at $\mathrm{RT}\left(1000^{\circ} \mathrm{C}\right.$ - and $1100^{\circ} \mathrm{C}$-oxidized samples $)$ or at $135^{\circ} \mathrm{C}\left(1200^{\circ} \mathrm{C}\right.$-oxidized samples $)$ and $0.0333 \mathrm{~mm} / \mathrm{s}$.

d) Interrupt test following first significant load drop ( $>30 \%)$; this is relatively easy to do as concurrent with the load drop is a loud cracking noise. Determine the offset strain from load-displacement data.

e) Remove the sample from the Instron, allow sample to cool to RT, and examine it under a microscope to determine if the sample failed with a single through-wall crack along the whole length of the sample or with multiple cracks; generally, load drops of 30-50\% imply a single crack, while larger load drops (80-100\%) imply two or three cracks.

f) If a single, tight, through-wall crack is found, measure the post-test diameter in the loading direction and determine the permanent displacement; normalize this displacement to the preoxidation-test outer diameter to determine the permanent strain; if the permanent strain is $<1 \%$, classify sample as brittle; if multiple cracks are found, the post-test diameter measurement is meaningless and this step is eliminated.

g) If multiple cracks are found, use the offset displacement and strain from the load-displacement curve; for samples with $<2 \%$ offset strain, classify samples as brittle; note: for M5 cladding oxidized at $1200^{\circ} \mathrm{C}$ and compressed at $135^{\circ} \mathrm{C}$, this transition had to be increased to $3.5 \%$.

h) Record both offset and permanent strains, along with pre-oxidation-test characterization (asfabricated, prehydriding $\mathrm{H}$ content, irradiated with a measured $\mathrm{H}$ content), oxidation temperature, CP-ECR, ECR determined from measured weight gain (i.e., measured ECR), quench temperature, ring compression test temperature, and number and location of cracks. 


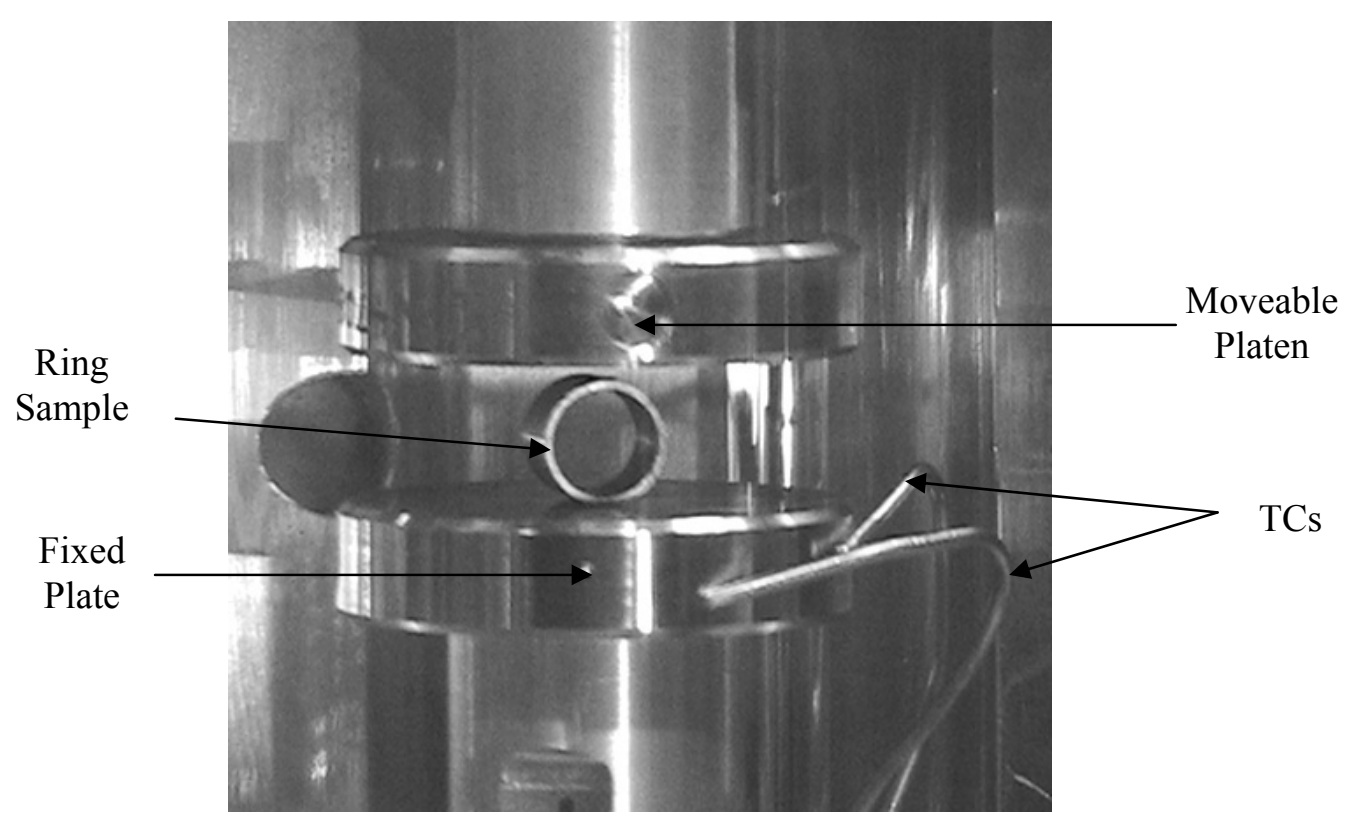

Figure 14. Photograph of ring compression sample supported by the fixed flat plate and loaded by the moveable, load-train platen for the Instron 8511. Not shown in the photograph is the control thermocouple which is located at the bottom inner surface of the ring. Also, thermocouples that rest against the side walls of the sample have been moved down to obtain a better image of the sample.

As a convenience for the reader, ductility data are plotted for each alloy using a consistent set of symbols and color scheme. In Section 3, black circles are used for used for Zry-4 data points, green squares are used for ZIRLO data points and blue triangles are used for M5 data points. In general, solid symbols are used for samples quenched at $800^{\circ} \mathrm{C}$ and open symbols are used for samples cooled without quench. This symbol-color scheme is also used in Sections 4 (prehydrided Zry-4) and Section 5 (highburnup alloys. However, in comparing high-burnup data to as-fabricated data for a single alloy, red is often used to indicate ductility data for rings sectioned from high-burnup samples.

\subsection{LOCA integral tests with fueled-and-pressurized samples}

Out-of-cell LOCA integral tests with as-fabricated cladding are relatively straightforward with regard to sample preparation and test conduct. Figure 15 shows the LOCA test train with as-fabricated cladding. For these tests the cladding sample is filled with $\approx 25$-mm-long zirconia pellets to simulate the heat capacity of the fuel. The stack length of these pellets is $\approx 270-\mathrm{mm}$ long. There is a clearance of $\approx 13$ $\mathrm{mm}$ between the top zirconia pellet and the top end fixture to prohibit contact during sample bending. The test train is supported at the top to minimize specimen bowing. The quartz tube encasing the test train provides an enclosed volume for steam flow and water quench, both of which are introduced through the bottom of the unit. The test train is centered within the quartz tube by means of two perforated spacer disks. Centering is very important as four vertical infrared lamps are focused within the furnace to heat the specimen. Swagelok fittings are used above the specimen to connect to the high-pressure gas line and top pressure gauge and below the specimen to connect to the bottom pressure-gauge line. The total gas volume above the fuel column is $10 \mathrm{~cm}^{3}$, most of which is outside the heated zone. Four Type $\mathrm{S}$ thermocouple lead wires are fed in through the top. Two of the thermocouples are spot-welded at the 


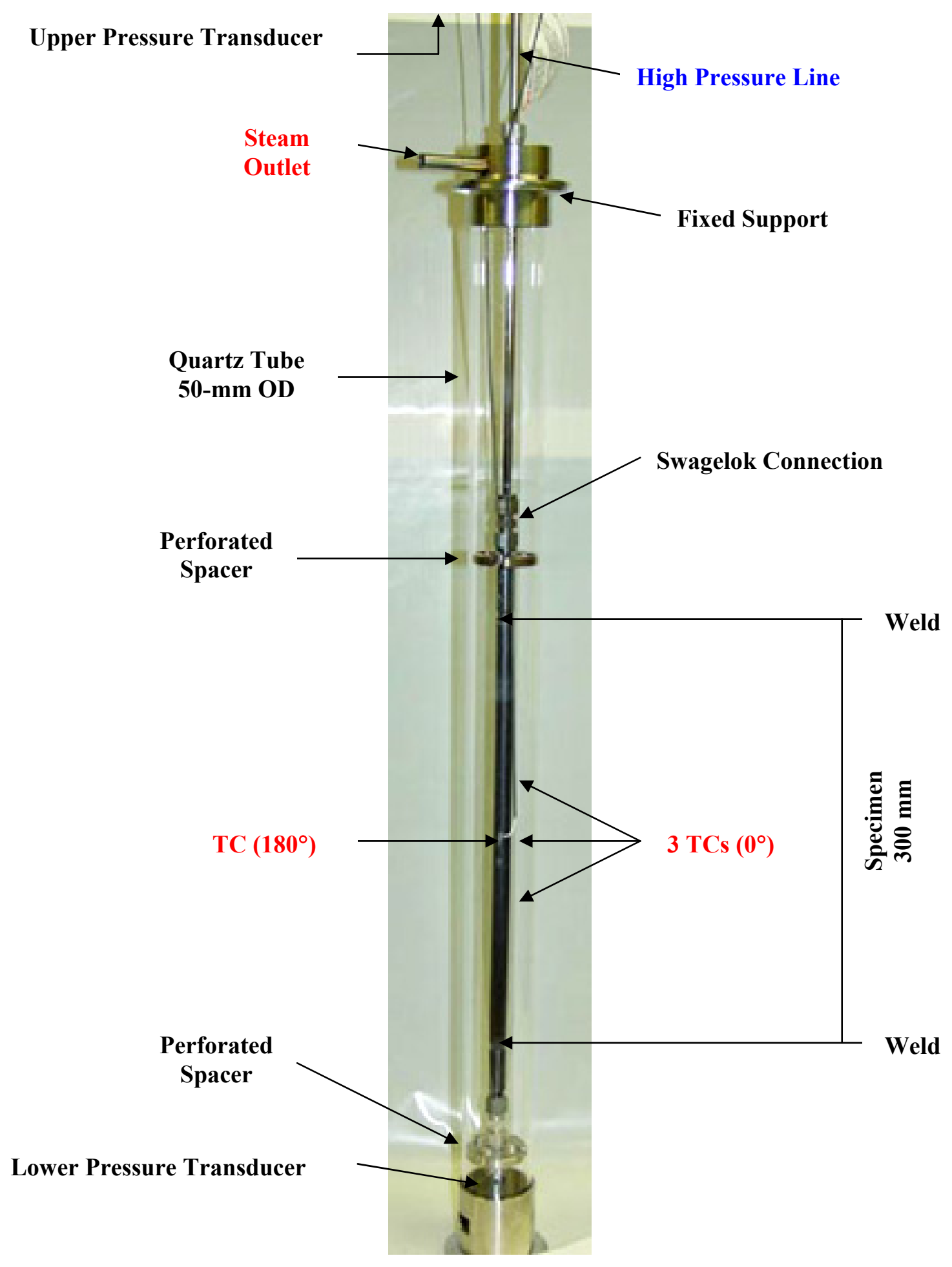

Figure 15. LOCA integral test train assembly and quartz tube. The $300-\mathrm{mm}$-long specimen is filled with zirconia pellets with a stack length of $\approx 270 \mathrm{~mm}$. The quartz tube has an outer diameter of $50 \mathrm{~mm}$, a wall thickness of $1.5 \mathrm{~mm}$, and a length of $686 \mathrm{~mm}$ (27 inches). 
specimen midplane, $180^{\circ}$ apart. The other two are spot-welded $50 \mathrm{~mm}$ above and $50 \mathrm{~mm}$ below the midplane at the same angular orientation as one of the midplane thermocouples. These thermocouples are accurate to $\pm 3^{\circ} \mathrm{C}$ at $1200^{\circ} \mathrm{C}$. The signal from the top thermocouple is used to control the furnace power to achieve the desired temperature ramp, hold temperature, and cooling rate prior to quench. Although the uniform heating zone of the furnace is $250-\mathrm{mm}$, the uniform temperature region of the undeformed sample is $\approx 100-125 \mathrm{~mm}$, centered about the midplane of the sample. The system is designed to allow switching of the control thermocouple in case the top one fails. For the out-of-cell tests, hands-on assembly is used, and bare-wire thermocouple beads are welded directly onto unirradiated tubing.

Because of the high thermal mass of the sample and the thermocouples welded (nonirradiated) or strapped (irradiated) directly on the LOCA integral sample, temperature control is much easier than for the short, defueled cladding oxidation samples. Figure 16 shows a schematic of the temperature history used for both out-of-cell and in-cell testing. The reference control parameters for BWR cladding are: 8.28-MPa (1200 psig) internal pressure with $\mathrm{He}$ at $\mathrm{RT}$ and $300^{\circ} \mathrm{C}, 5^{\circ} \mathrm{C} / \mathrm{s}$ heating rate, $1200^{\circ} \mathrm{C}$ hold temperature, variable hold time, $3^{\circ} \mathrm{C} / \mathrm{s}$ cooling rate from the hold temperature to $800^{\circ} \mathrm{C}$, and rapid cooling from bottom-flooding quench at $800^{\circ} \mathrm{C}$. As these parameters are controlled, they can be adjusted from test to test. The internal pressure $\left(8.28 \mathrm{MPa}\right.$ at $300^{\circ} \mathrm{C}$ and $8.62-9.10 \mathrm{MPa}$ peak pressure prior to burst) was chosen to ensure burst at $760 \pm 30^{\circ} \mathrm{C}$, which is below the alpha-to-(alpha + beta) phase change temperature for $9 \times 9$ Zry-2 cladding. This burst temperature also results in relatively large ballooning strains $(50 \pm 10 \%)$. Although many such tests were conducted with nonirradiated cladding during the development of the LOCA integral apparatus, the most important ones are those that provided a baseline for the in-cell tests: a) ramp-to-burst followed by slow cooling; b) ramp to $1200^{\circ} \mathrm{C}$, hold for $300 \mathrm{~s}$ at $1200^{\circ} \mathrm{C}$ followed by slow cooling; and c) the full LOCA sequence, including quench at $800^{\circ} \mathrm{C}$.

For high-burnup test rod specimens, a drill with both rotary and cyclic horizontal motion is used to remove $\approx 13 \mathrm{~mm}$ of fuel from the bottom of the specimen (space for end-cap welding) and $\approx 20 \mathrm{~mm}$ of fuel from the top of the specimen $(\approx 7 \mathrm{~mm}$ for end-cap welding and $13 \mathrm{~mm}$ for clearance). Following end-cap welding, the specimen is inserted into a holder for attaching the Swagelok fittings and for strapping two thermocouples $180^{\circ}$ apart to the specimen $\approx 50 \mathrm{~mm}$ above the midplane. Although a test train assembly device was designed and constructed to spot-weld TCs directly to the cladding metal following oxide removal, these operations were too challenging to perform remotely using manipulators. Comparisons between welded TCs and strapped TCs indicated less than a $10^{\circ} \mathrm{C}$ difference in readings. For the in-cell tests with high-burnup fueled cladding, internal axial gas flow rate is an important parameter. Prior to conducting the LOCA transient, the sample is pressurized rapidly at the top at RT and $300^{\circ} \mathrm{C}$. The time response of the pressure transducer below the fuel column is used to evaluate the axial gas flow rate.

Online data of interest include the time response of the bottom pressure transducer at RT and $300^{\circ} \mathrm{C}$, burst temperature, and burst pressure. Following a test, the sample was photographed (low quality) in-situ in the vertical position and moved to other workstations for non-destructive characterization in the horizontal position: photography (high quality), profilometry, and gamma scanning. Destructive examinations were performed on some of the samples to determine oxide and alpha layer thicknesses for inner- and outer-cladding surfaces (metallography), circumferential and axial distribution of oxygen (LECO), and circumferential and axial distribution of hydrogen (LECO). Prior to destructive examination, some of the nonirradiated samples were subjected to a four-point-bending test at room temperature to determine failure bending moment and ductility. The four-point-bending fixture was developed and tested with nonirradiated cladding in an out-of-cell Instron machine (Model 5566 table top Instron). This Instron was equipped with an oven for heating samples to $135^{\circ} \mathrm{C}$. 
All of the ductility tests for short, nonirradiated cladding samples oxidized at $1200^{\circ} \mathrm{C}$ and compressed at $135^{\circ} \mathrm{C}$ were conducted with the Model 5566 Instron. The control TC was located at the bottom inner surface for these tests. This Instron was also used to compress as-fabricated cladding samples to 2-mm total displacement in order to determine the relationship between offset strain derived from load-displacement curves and permanent strains that were measured directly.

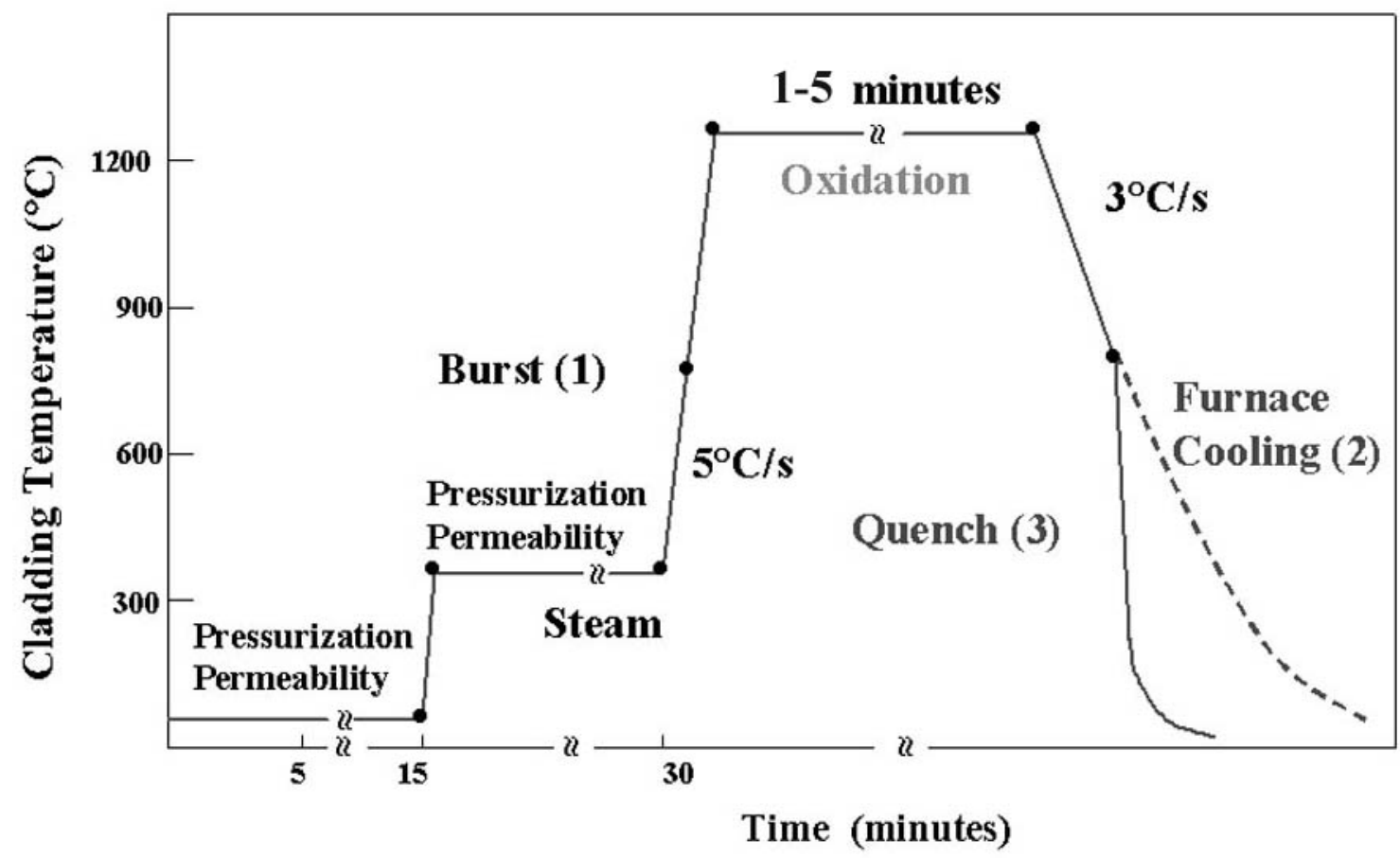

Figure 16. Schematic of the thermal history used for LOCA integral tests. Zirconia-filled, as-fabricated cladding samples are tested out-of-cell, and fueled high-burnup cladding samples are tested in-cell. 


\section{Results for As-fabricated Cladding Alloys}

In this section, the performance of as-fabricated $17 \times 17$ ZIRLO and M5 is compared to the performance of modern $17 \times 17$ low-tin Zry-4. Modern Zr-lined $10 \times 10$ Zry-2 is also included in the test matrix. These materials are described in Tables 3-5. In parallel to these tests, considerable testing of HBR-type $15 \times 15$ Zry-4 (see Table 4) was conducted to generate baseline data for the H. B. Robinson high-burnup cladding, as no high-burnup $17 \times 17$ low-tin Zry-4 was available to the program. Because the HBR-type $15 \times 15$ Zry-4 exhibited a lower post-quench-ductility transition ECR than $17 \times 17$ Zry-4, the post-quench ductility of modern (belt-polished) $15 \times 15 \mathrm{Zry}-4$ (see Table 4 ) oxidized at $1200^{\circ} \mathrm{C}$ was also studied. Oxidation kinetics studies were also conducted with as-fabricated $9 \times 9$ Zry-2 to generate baseline data for high-burnup Limerick Zry-2. In addition, breakaway oxidation studies at $800-1000^{\circ} \mathrm{C}$ were conducted with HBR-type and belt-polished 15×15 Zry-4, 17×17 ZIRLO, and 17×17 M5. Furthermore, E110 (see Table 6) was included in the breakaway oxidation studies to develop some fundamental understanding as to why this $\mathrm{Zr}-1 \mathrm{Nb}$ alloy exhibits such low breakaway-oxidation time as compared to another $\mathrm{Zr}-1 \mathrm{Nb}$ alloy, M5.

\subsection{Zircaloy-4}

\subsubsection{Post-quench ductility of $17 \times 17$ Zry-4 oxidized at $1000^{\circ} \mathrm{C}, 1100^{\circ} \mathrm{C}$, and $1200^{\circ} \mathrm{C}$}

This work was divided into two campaigns: characterization and RT-ring-compression testing of samples exposed to two-sided oxidization at $1000^{\circ} \mathrm{C}$ and $1100^{\circ} \mathrm{C}$ and quenched at $800^{\circ} \mathrm{C}$; and characterization and ring-compression testing $\left(\mathrm{RT}\right.$ and $\left.135^{\circ} \mathrm{C}\right)$ of samples exposed to two-sided oxidization at $1200^{\circ} \mathrm{C}$ and quenched at $800^{\circ} \mathrm{C}$. Characterization included weight gain, oxide- and alphalayer thickness (metallography), microhardness, and hydrogen pickup (LECO). All samples were oxidized in the same apparatus for test times corresponding to CP-predicted ECR values of 5, 10, 15, 17, and $20 \%$ for $0.57-\mathrm{mm}$-wall cladding. Additional tests were conducted at intermediate CP-ECR values for the $1200^{\circ} \mathrm{C}$-oxidized samples to better determine the ductile-to-brittle transition CP-ECR.

\section{$17 \times 17$ Zry-4 oxidized at $1000^{\circ} \mathrm{C}$ and $1100^{\circ} \mathrm{C}$}

Figures 17 and 18 show the thermal benchmark results for the $1000^{\circ} \mathrm{C}$ - and $1100^{\circ} \mathrm{C}$ - oxidation test trains, respectively. The ramp times to reach the hold temperature are short compared to the hold times at these temperatures. The average cooling rate to the $800^{\circ} \mathrm{C}$ quench temperature is $\approx 10^{\circ} \mathrm{C} / \mathrm{s}\left(10^{\circ} \mathrm{C} / \mathrm{s}\right.$ for $1100^{\circ} \mathrm{C}$ and $11^{\circ} \mathrm{C} / \mathrm{s}$ for $1000^{\circ} \mathrm{C}$ ). The temperature-time curves were used to calculate the $\mathrm{CP}$-predicted weight gain and ECR values. Table 8 lists the weight gain results for the oxidation tests at these temperatures. They are in very good agreement with the CP-predicted weight gains.

Table 9 gives the results of the RT post-quench ductility tests. It is clear from the results that $17 \times 17$ Zry-4 retains post-quench ductility up to $20 \%$ CP-ECR - the limit of the test matrix - at these oxidation temperatures. For the $1000^{\circ} \mathrm{C}$-oxidation tests, the offset strain levels off at $\approx 3 \%$, while for the $1100^{\circ} \mathrm{C}$-oxidation tests the offset strain levels off at $\approx 5 \%$. These results suggest that Zry-4 will retain ductility at higher CP-ECR values and higher test times (e.g., $>3400 \mathrm{~s}$ at $1000^{\circ} \mathrm{C}$ until breakaway oxidation occurs). For $1100^{\circ} \mathrm{C}$-oxidized samples, breakaway oxidation does not occur, and the beta layer does not appear to embrittle due to the low oxygen solubility $(\approx 0.4 \mathrm{wt} . \%)$ in the beta phase at $1100^{\circ} \mathrm{C}$. At much higher ECR values, beta-layer thinning would cause brittle behavior of compressed rings.

Photographs of the ring-compressed samples are shown in Figure 19. The 5\% CP-ECR samples were intact at the maximum Instron displacement for these samples. 


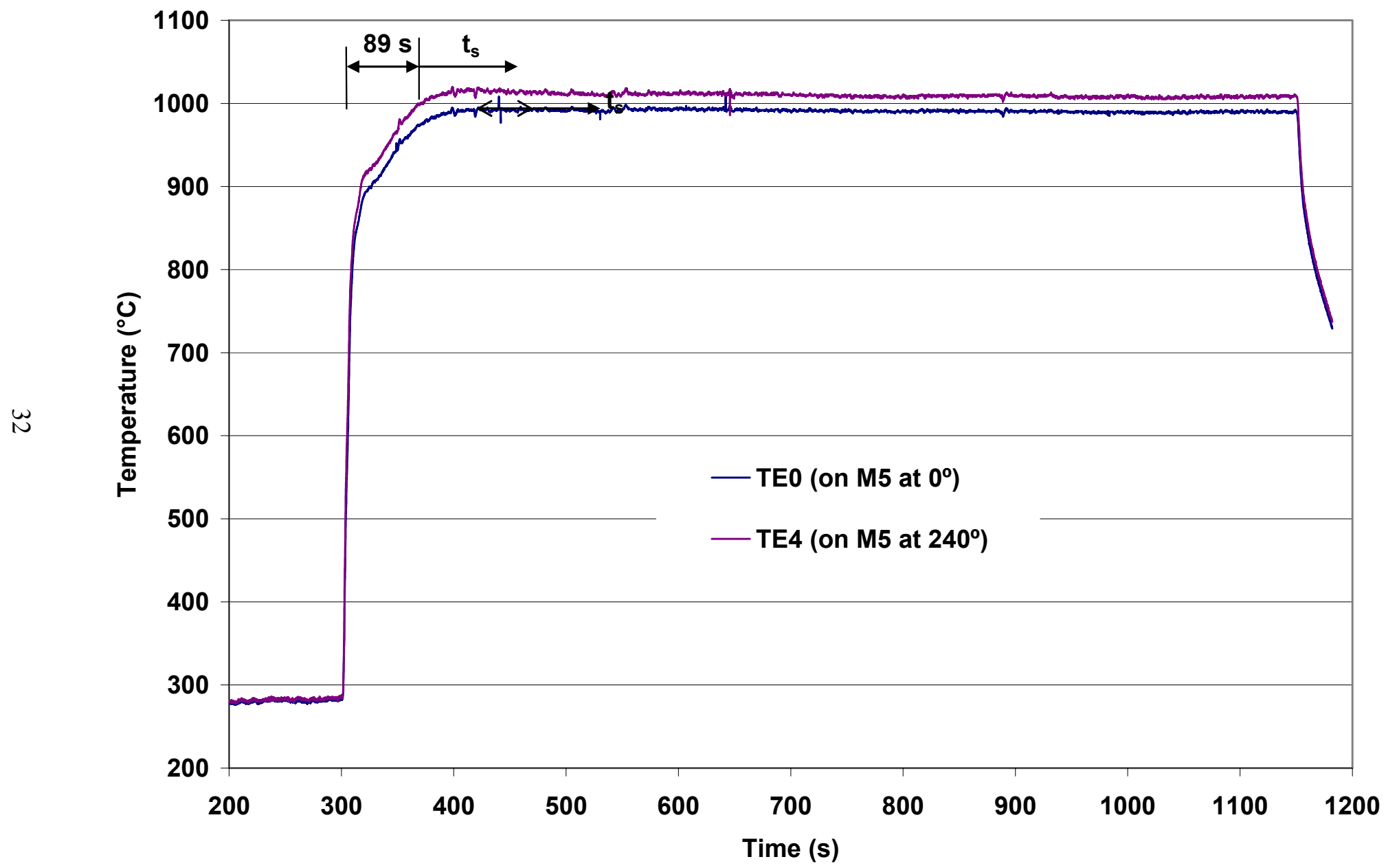

Figure 17. Thermal benchmark results for the $1000 \pm 10^{\circ} \mathrm{C}$ oxidation tests. The sample used was from the 0.57 -mm-wall validation lot of $\mathrm{M} 5$, which has the same inner and outer diameter as $17 \times 17 \mathrm{Zry}-4$ and ZIRLO. Quench at $800^{\circ} \mathrm{C}$ is not shown in this figure. 


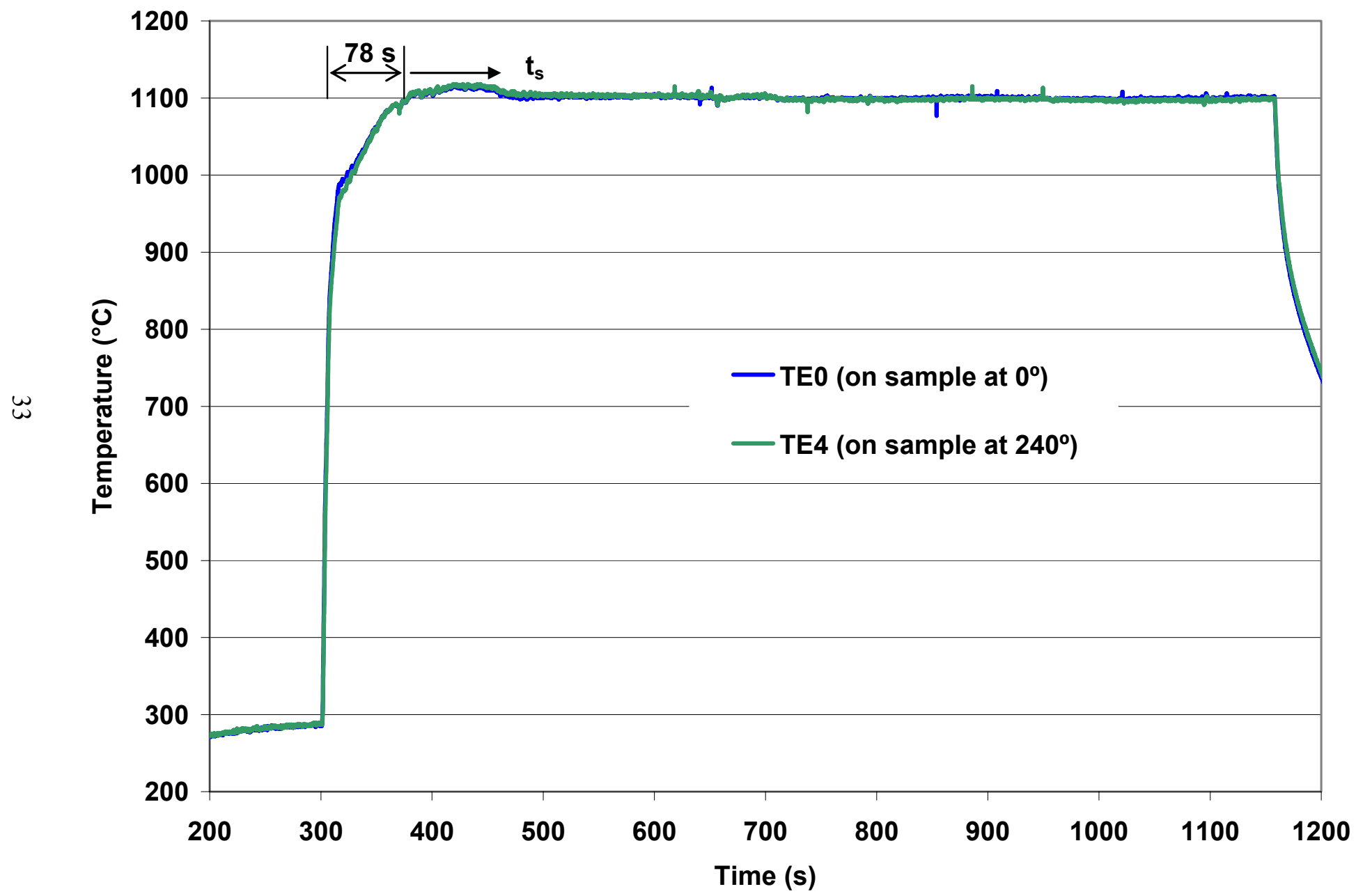

Figure 18. Thermal benchmark results for the $1100 \pm 2^{\circ} \mathrm{C}$ oxidation tests. The sample used was from the 0.57 -mm-wall validation lot of $\mathrm{M} 5$, which has the same inner and outer diameter as $17 \times 17$ Zry- 4 and ZIRLO. Quench at $800^{\circ} \mathrm{C}$ is not shown in this figure. 
Table 8. Weight Gain (Wg in $\left.\mathrm{mg} / \mathrm{cm}^{2}\right)$ and Measured ECR (\%) Values for $17 \times 17$ Zry-4 Oxidized in Steam at $1000^{\circ} \mathrm{C}$ and $1100^{\circ} \mathrm{C}$. ECR $=1.538 \mathrm{Wg}$ for $0.57-\mathrm{mm}$-wall cladding. Multiply weight gain results by a factor of 10 to convert to $\mathrm{g} / \mathrm{m}^{2}$. CP = Cathcart-Pawel.

\begin{tabular}{|c|c|c|c|c|}
\hline $\begin{array}{c}\text { Oxidation } \\
\text { Temperature, } \\
{ }^{\circ} \mathrm{C}\end{array}$ & $\begin{array}{c}\text { CP-Predicted } \\
\text { ECR, } \\
\%\end{array}$ & $\begin{array}{c}\text { CP-Predicted } \\
\text { Weight Gain, } \\
\mathrm{mg} / \mathrm{cm}^{2}\end{array}$ & $\begin{array}{c}\text { Measured } \\
\text { Weight Gain, } \\
\mathrm{mg} / \mathrm{cm}^{2}\end{array}$ & $\begin{array}{c}\text { Measured } \\
\text { ECR, } \\
\%\end{array}$ \\
\hline \hline 1000 & 5 & 3.25 & 3.9 & 6.1 \\
\hline 1000 & 15 & 9.75 & 11.0 & 11.0 \\
\hline 1000 & 17 & 11.05 & 12.5 & 19.3 \\
\hline 1000 & 20 & 13.00 & 14.6 & 22.4 \\
\hline 1000 & 5 & 3.25 & 4.0 & 6.2 \\
\hline \hline 1100 & 10 & 6.50 & 7.1 & 10.9 \\
\hline 1100 & 15 & 9.75 & 10.6 & 20.3 \\
\hline 1100 & 17 & 11.05 & 11.7 & 16.3 \\
\hline 1100 & 20 & 13.00 & 13.2 & \\
\hline 1100 & & & & \\
\hline
\end{tabular}

Table 10 summarizes the results of the metallography, microhardness and hydrogen pickup measurements. The low hydrogen pickup indicates that no breakaway oxidation occurred for these test times. The results in Table 10 are consistent with the post-quench ductility results. Metallographic images and graphical results for $17 \times 17$ Zry-4 are presented in the ZIRLO (3.3.1) and M5 (3.4.1) sections for purposes of comparison.

The post-quench ductility, as measured by offset strain, for Zry-4 oxidized at $1100^{\circ} \mathrm{C}$ decreased with ECR up to $\approx 15 \%$ and remained essentially constant at $\approx 5 \%$ offset strain from 15 to $20 \%$ ECR (see Table 10). As the ductility of the prior-beta layer decreases with increasing oxygen content, the results suggest that the oxygen content in the beta layer reaches the solubility limit $(0.38 \mathrm{wt} \%$ [18]) at $\approx 15 \% \mathrm{CP}$ ECR, which corresponds to an equivalent isothermal time of $\approx 600 \mathrm{~s}$. From $15 \%$ ECR $(600 \mathrm{~s})$ to $20 \%$ ECR $(1065 \mathrm{~s})$, the beta layer-thickness decreases to $\approx 300 \mu \mathrm{m}$, while the oxygen content and post-quench ductility of the prior-beta layer remain constant. Thus, neither oxygen- nor beta-layer-thinning-induced embrittlement was observed under these test conditions. As hydrogen pickup was negligible, hydrogeninduced embrittlement was also not observed. 
Table 9. Ring Compression Test Results for $17 \times 17 \mathrm{Zry}-4$ Samples Oxidized at $1000^{\circ} \mathrm{C}$ and $1100^{\circ} \mathrm{C}$, Cooled at $\approx 10^{\circ} \mathrm{C} / \mathrm{s}$ to $800^{\circ} \mathrm{C}$, and Quenched. ECR $=1.538 \mathrm{Wg}$ for $0.57-\mathrm{mm}$-wall cladding. Tests were performed on 8-mm-long samples at RT and at $0.0333 \mathrm{~mm} / \mathrm{s}$ displacement rate. Displacements in the loading direction were normalized to the as-fabricated outer diameter $(9.50 \mathrm{~mm})$ to calculate offset strain. A complete set of tests was performed with a Model 4505 Instron. A limited number of confirmation tests were performed with a Model 5566 Instron and rings cut from the same oxidation samples.

\begin{tabular}{|c|c|c|c|c|c|}
\hline $\begin{array}{c}\text { Oxidation } \\
\text { Temperature, } \\
{ }^{\circ} \mathrm{C}\end{array}$ & $\begin{array}{c}\text { Cathcart- } \\
\text { Pawel } \\
\text { ECR, \% }\end{array}$ & $\begin{array}{c}\text { Measured } \\
\text { ECR, } \\
\%\end{array}$ & $\begin{array}{c}\text { Offset } \\
\text { Displacement, } \\
\mathrm{mm}\end{array}$ & $\begin{array}{c}\text { Offset } \\
\text { Strain, } \\
\%\end{array}$ & $\begin{array}{c}\text { Confirmation } \\
\text { Tests } \\
\text { Model 5566 } \\
\text { Instron }\end{array}$ \\
\hline 1000 & 5 & 6.1 & $>4.4$ & $>46$ & --- \\
\hline 1000 & 10 & 11.0 & 2.74 & 29 & Yes \\
\hline 1000 & 15 & 16.9 & 0.71 & 7.5 & Yes \\
\hline 1000 & 17 & 19.3 & 0.48 & 5.1 & --- \\
\hline 1000 & 20 & 22.4 & 0.31 & 3.2 & --- \\
\hline \hline 1100 & 5 & 6.2 & $>5.5$ & $>58$ & --- \\
\hline 1100 & 10 & 10.9 & 1.9 & 20 & --- \\
\hline 1100 & 15 & 16.3 & 0.52 & 5.4 & --- \\
\hline 1100 & 17 & 18.0 & 0.47 & 4.9 & --- \\
\hline 1100 & 20 & 20.3 & 0.46 & 4.8 & --- \\
\hline
\end{tabular}

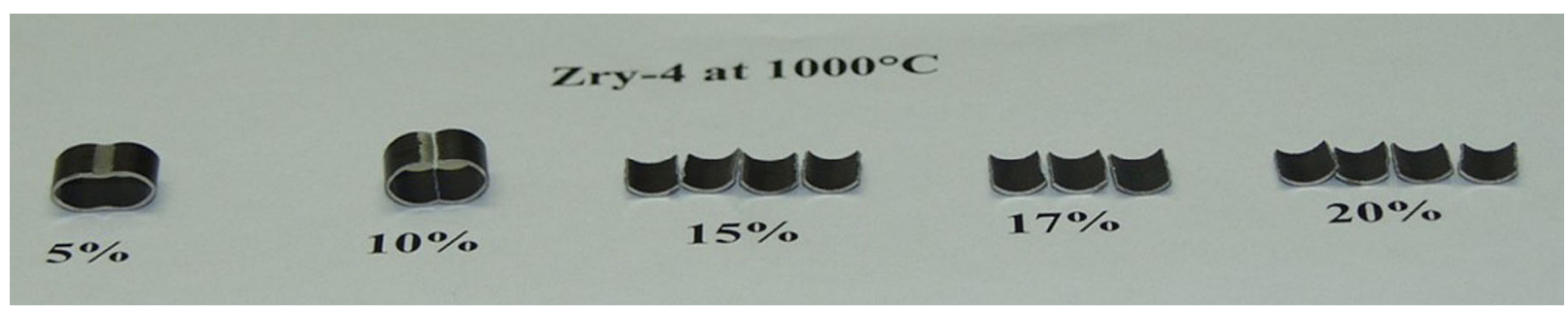

(a)

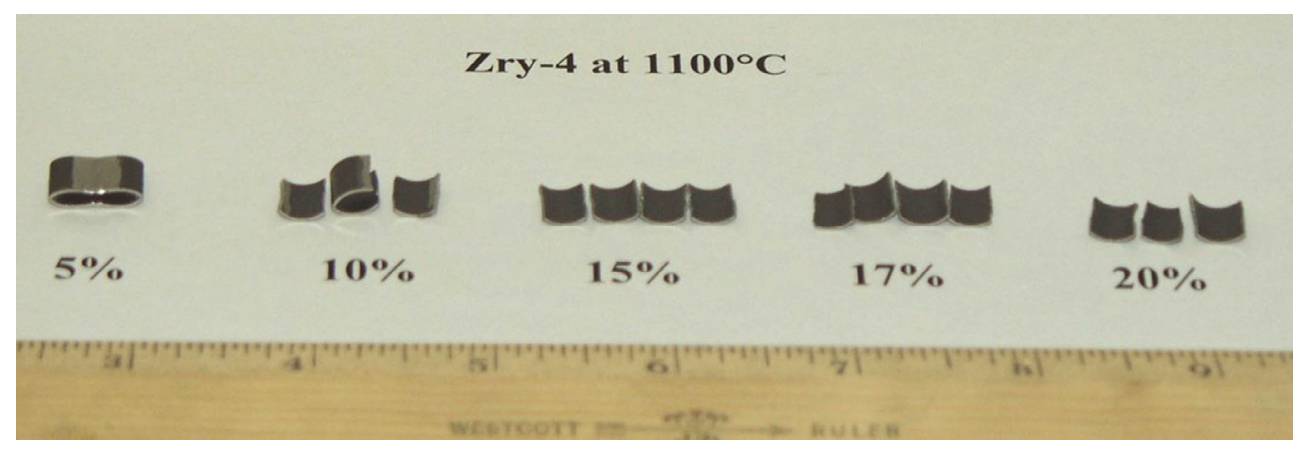

(b)

Figure 19. Post-test appearance of Zry-4 samples compressed at RT and $0.0333 \mathrm{~mm} / \mathrm{s}$ : (a) samples oxidized at $1000^{\circ} \mathrm{C}$ and (b) samples oxidized at $1100^{\circ} \mathrm{C}$. ECR values below each sample are calculated using the Cathcart-Pawel weight gain correlation. 
Table 10. Characterization Results for Highly Oxidized 17×17 Zry-4 Samples after Exposure to Steam at $1000^{\circ} \mathrm{C}$ and $1100^{\circ} \mathrm{C}$, Cooling at $\approx 10^{\circ} \mathrm{C} / \mathrm{s}$ to $800^{\circ} \mathrm{C}$, and Quench. CP-predicted ECR is $20 \%$.

\begin{tabular}{|c|c|c|}
\hline $\begin{array}{c}\text { Oxidation } \\
\text { Temperature, } \\
{ }^{\circ} \mathrm{C}\end{array}$ & & $17 \times 17$ Zry-4 \\
\hline \multirow[t]{9}{*}{1000} & Effective Oxidation Time, $\mathrm{s}$ & 3364 \\
\hline & Weight Gain, $\mathrm{mg} / \mathrm{cm}^{2}$ & 14.6 \\
\hline & Measured ECR, \% & 22.4 \\
\hline & RT Offset Displacement, mm & 0.31 \\
\hline & RT Offset Strain, \% & $\begin{array}{c}3.2 \\
\text { (ductile) }\end{array}$ \\
\hline & Hydrogen Content, wppm & 19 \\
\hline & Hydrogen Pickup, wppm & 15 \\
\hline & OD/ID Oxide Layer Thickness, $\mu \mathrm{m}$ & $83 / 82$ \\
\hline & Microhardness within Middle $0.2 \mathrm{~mm}$ of Prior-beta Layer, $\mathrm{DPH}^{\mathrm{a}}$ & $290-420$ \\
\hline \multirow[t]{9}{*}{1100} & Effective Oxidation Time, $\mathrm{s}$ & 1065 \\
\hline & Weight Gain, $\mathrm{mg} / \mathrm{cm}^{2}$ & 13.2 \\
\hline & Measured ECR, \% & 20.3 \\
\hline & RT Offset Displacement, mm & 0.46 \\
\hline & RT Offset Strain, \% & $\begin{array}{c}4.8 \\
\text { (ductile) }\end{array}$ \\
\hline & Hydrogen Content, wppm & 22 \\
\hline & Hydrogen Pickup, wppm & 19 \\
\hline & OD/ID Oxide Layer Thickness, $\mu \mathrm{m}$ & $70 / 68$ \\
\hline & Microhardness within Middle $0.2 \mathrm{~mm}$ of Prior-beta Layer, DPH & $240-470$ \\
\hline
\end{tabular}

${ }^{\mathrm{a}} \mathrm{DPH}=$ diamond pyramid hardness.

The variation of post-quench ductility with CP-ECR for $1000^{\circ} \mathrm{C}$-oxidized Zry-4 is similar to the variation for the $1100^{\circ} \mathrm{C}$-oxidized samples. The primary difference is the slow decrease in offset strain with ECR from $7.5 \%$ at $15 \%$ CP-ECR to $5.1 \%$ at $17 \%$ CP-ECR to $3.2 \%$ at $20 \%$ CP-ECR. The beta-layer oxygen-solubility at $1000^{\circ} \mathrm{C}$ is less $\left(0.24 \mathrm{wt} . \%\right.$ [18]) than it is at $1100^{\circ} \mathrm{C}$, so higher ductility would be expected. However, $1000^{\circ} \mathrm{C}$ is very close to the (alpha + beta) $\rightarrow$ beta phase transformation temperature. The oxidation temperature based on the thermal-benchmark history in Figure 17 is $1000 \pm 10^{\circ} \mathrm{C}$, which suggests that what is referred to as the beta layer may have contained a small fraction of alpha at the experimental oxidation temperature. Although it is not clear why $1000^{\circ} \mathrm{C}$-oxidized Zry-4 has lower postquench ductility at $20 \%$ CP-ECR than $1100^{\circ} \mathrm{C}$-oxidized Zry-4 at $20 \%$ CP-ECR (3\% vs. $5 \%$ ), the differences are rather small and ductility is retained at both oxidation temperatures. The higher measured weight gain of the $1000^{\circ} \mathrm{C}$-oxidized sample $(22.4 \%$ vs. $20.3 \%)$ does not explain the lower ductility. 


\section{$17 \times 17$ Zry-4 oxidized at $1200^{\circ} \mathrm{C}$}

Many tests were conducted with $17 \times 17$ Zry- 4 oxidized at $1200 \pm 5^{\circ} \mathrm{C}$ to determine the ductile-tobrittle transition $\mathrm{CP}-\mathrm{ECR}$ at $\mathrm{RT}$ and $135^{\circ} \mathrm{C}$. This required eight test trains and eight sets of thermal benchmark tests. Figures 20 and 21 show the thermal-benchmark results for the first test train and the most recent test train, respectively. Although the temperature ramps are different, these have little effect on the long-time tests used to determine the transition CP-ECR of $\approx 17 \%$ at $135^{\circ} \mathrm{C}$. Prior to quench, the sample cools at an average rate of $\approx 13^{\circ} \mathrm{C} / \mathrm{s}\left(1200^{\circ} \mathrm{C}\right.$ to $1000^{\circ} \mathrm{C}$ in $6 \mathrm{~s}$ and $1000^{\circ} \mathrm{C}$ to $800^{\circ} \mathrm{C}$ in $\left.23 \mathrm{~s}\right)$. Also, all ring-compression tests were stopped after the first significant load drop ( $>30 \%)$ to allow a measure of the permanent strain based on the diameter change in the loading direction.

The weight gain results (expressed in terms of measured ECR) and the post-quench ductility (PQD) results are summarized in Table 11. The PQD results are plotted in Figure 22. It is clear that $17 \times 17$ Zry4 embrittles at room temperature after oxidation to $\approx 9 \%$ CP-ECR and quench. This behavior is confirmed by both the offset strain criterion $(<2 \%)$ and the permanent-strain criterion $(<1 \%)$ for embrittlement, shown as horizontal dashed lines in Figure 22. The enhancement of ductility with the increase in ringcompression test temperature is quite pronounced. Based on the average of the permanent strain readings, the ductile-to-brittle transition CP-ECR is $\approx 18 \%$ at $135^{\circ} \mathrm{C}$. Based on the minimum values of permanent strain, $17 \% \mathrm{CP}-\mathrm{ECR}$ is a more conservative estimate. The ductility data for three rings oxidized at $1200^{\circ} \mathrm{C}$ and quenched at $800^{\circ} \mathrm{C}$ are $2.5 \pm 0.5 \%$ offset and $1.1 \pm 0.4 \%$ permanent strain. The " \pm " values represent one standard deviation. Using the conservative approach (average minus one standard deviation), the minimum offset and permanent strains are $2 \%$ and $0.7 \%$, respectively. Based on the ANL strain criteria, $17 \times 17$ Zry- 4 would be assessed as borderline ductile based on offset strain and brittle based on permanent strain following oxidation to $17 \%$ CP-ECR. However, three data points may not be enough for statistical significant. Given the absence of data between 13\% and 17\% CP-ECR, engineering judgment is used to select $17 \% \mathrm{CP}$-ECR as the ductile-to-brittle transition for $1200^{\circ} \mathrm{C}$-oxidized and $800^{\circ} \mathrm{C}$-quenched $17 \times 17$ Zry- 4 . The variations of offset and permanent strains with CP-ECR are shown in Figures $22 \mathrm{a}$ and $22 \mathrm{~b}$, respectively, for the RT and $135^{\circ} \mathrm{C}$ test conditions.

It is interesting to note that the oxygen solubility of the Zry- 4 beta phase at $1200^{\circ} \mathrm{C}$ is $0.57 \mathrm{wt} . \%$ [18]. The results in Table 11 suggest that oxygen saturation of the beta layer occurs at $\approx 17 \%$ CP-ECR for $1200^{\circ} \mathrm{C}$-oxidized Zry-4, and that an average oxygen content of $\approx 0.6 \mathrm{wt} . \%$ is enough to embrittle the Zry- 4 prior-beta layer following quench. As is shown in Section 3.3.1, the physical picture is more complicated than this because the post-quench prior-beta layer consists of alpha incursions ( $>0.6 \mathrm{wt} . \%$ oxygen) in an oxygen-depleted $(<0.6 \mathrm{wt} . \%)$ matrix due to precipitation of oxygen-stabilized alpha during cooling from $1200^{\circ} \mathrm{C}$ to $800^{\circ} \mathrm{C}$.

Table 12 summarizes the characterization results for $17 \times 17 \mathrm{Zry}-4$ oxidized at $1200^{\circ} \mathrm{C}$ to $13 \%$ and $20 \% \mathrm{CP}-\mathrm{ECR}$ and quenched at $800^{\circ} \mathrm{C}$. The hydrogen pickup is very low. Also, there is excellent agreement between the inner-surface and outer-surface oxide layer thickness, indicating adequate steam flow at the inner surface. The microhardness results support the post-quench ductility results. Based on the room-temperature microhardness values, one would expect ductility at $13 \% \mathrm{CP}$-ECR and embrittlement at $20 \% \mathrm{CP}-\mathrm{ECR}$ at $135^{\circ} \mathrm{C}$. Metallographic images and additional graphical results are presented for comparison purposes in the sections on ZIRLO (3.3.1) and M5 (3.4.1). Based on these results, the embrittlement observed at 17\% CP-ECR in Figure 22 is not hydrogen-induced or beta-layerthinning-induced ( $>300-\mu \mathrm{m}$ thickness at $17 \% \mathrm{CP}-\mathrm{ECR})$. 


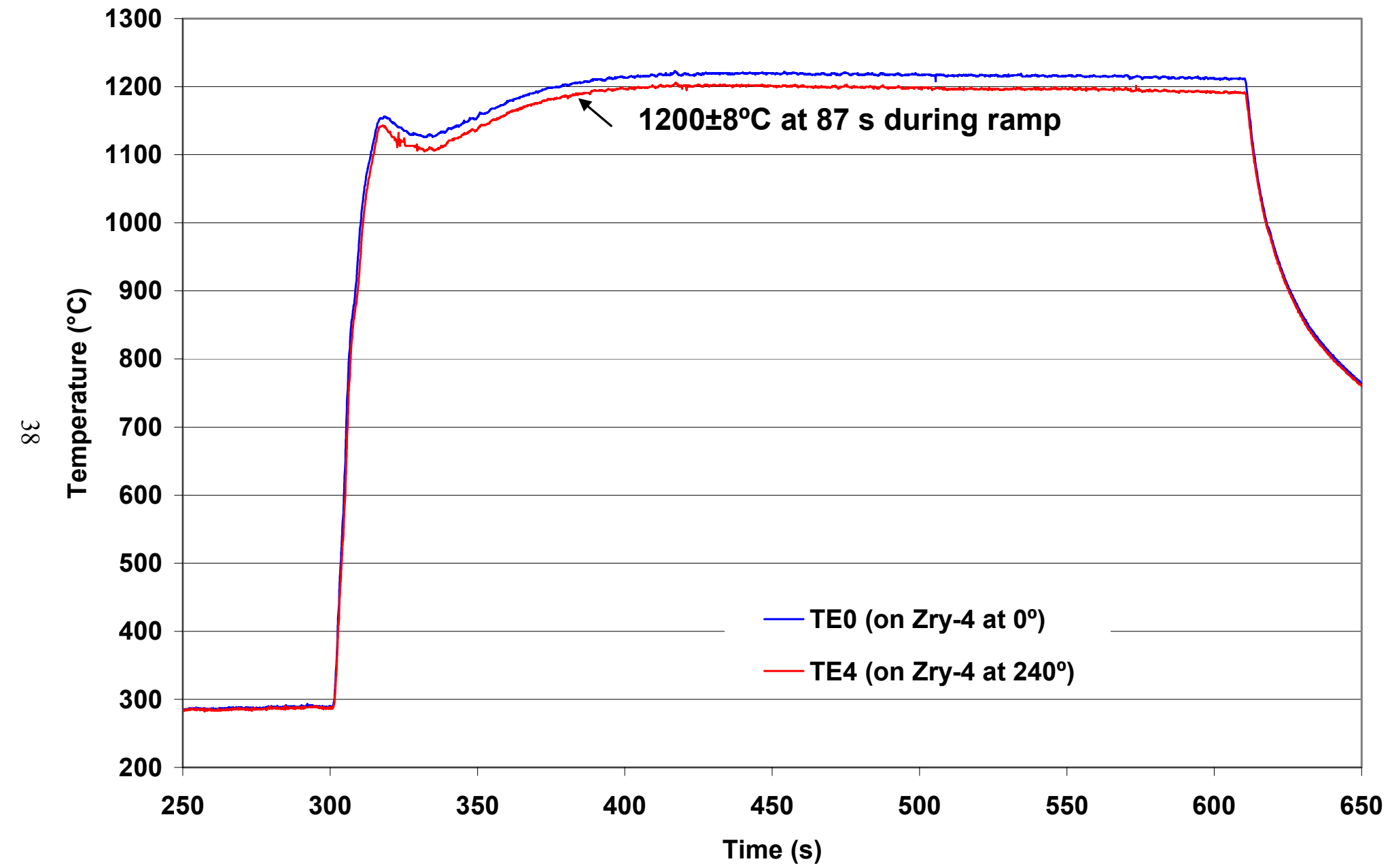

Figure 20. Thermal benchmark results (Test Train \#1) for oxidation of $17 \times 17$ alloys at $1200 \pm 5^{\circ} \mathrm{C}$. The sample used for this benchmark was $17 \times 17$ Zry-4 with a wall thickness of $0.57 \mathrm{~mm}$. Quench is not shown in this figure. 


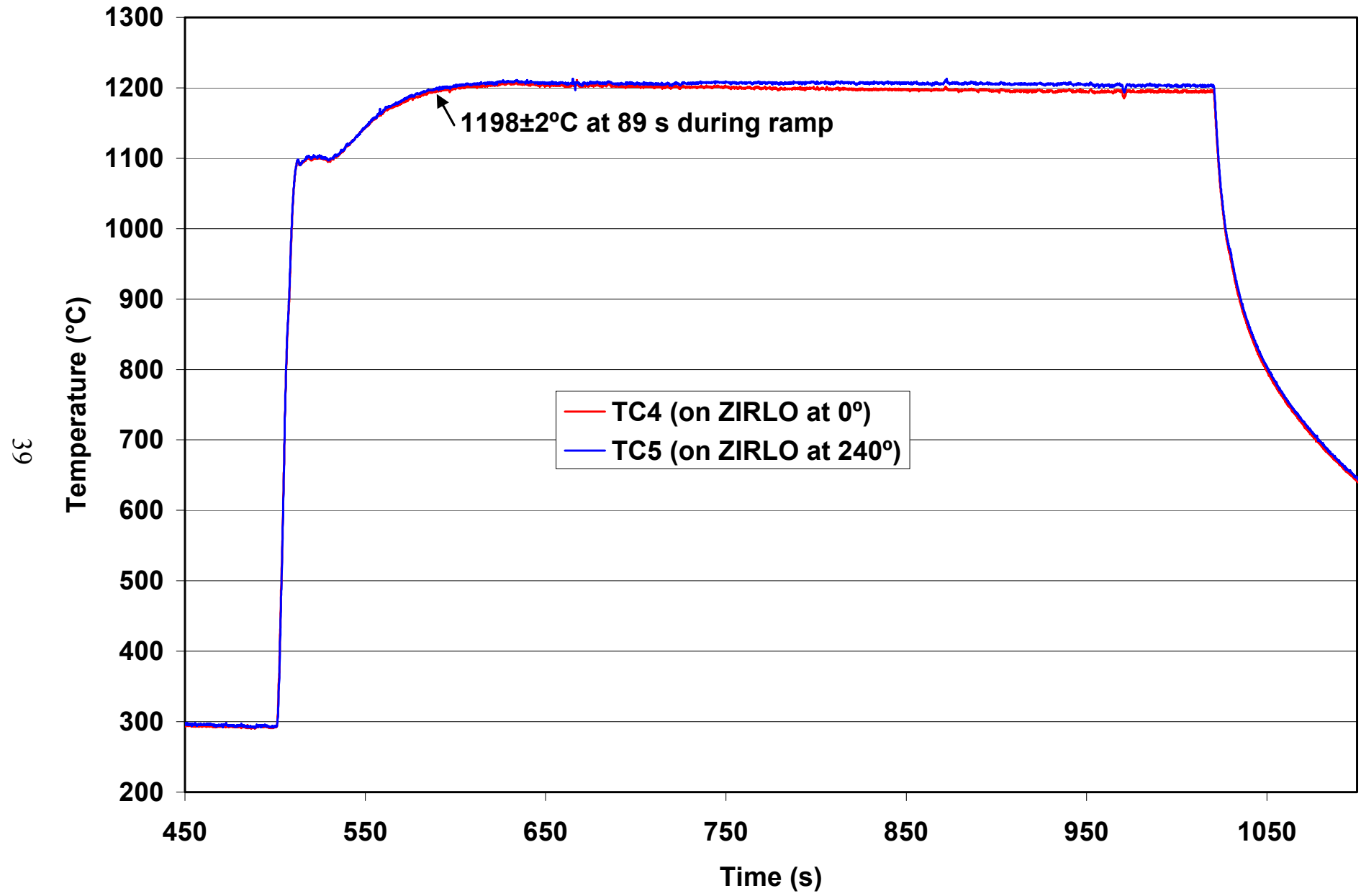

Figure 21. Thermal benchmark results (later test train) for oxidation of $17 \times 17$ alloys at $1200 \pm 5^{\circ} \mathrm{C}$. The sample used for this benchmark was $17 \times 17$ ZIRLO with a wall thickness of $0.57 \mathrm{~mm}$. Quench is not shown in this figure. 
Table 11. Ring Compression Test (RCT) Results for $17 \times 17$ Zry- 4 Cladding Oxidized at $1200 \pm 5^{\circ} \mathrm{C}$, Cooled at $\approx 13^{\circ} \mathrm{C} / \mathrm{s}$ to $800^{\circ} \mathrm{C}$, and Quenched. ECR $=1.538 \mathrm{Wg}$ for $0.57-\mathrm{mm}$-wall cladding. Tests were performed on $\approx 8$-mm-long samples at RT and $135^{\circ} \mathrm{C}$ and at $0.0333-\mathrm{mm} / \mathrm{s}$ displacement rate. Displacements in the loading direction were normalized to the asfabricated outer diameter $(9.50 \mathrm{~mm})$ to calculate offset and permanent strains.

\begin{tabular}{|c|c|c|c|c|c|c|c|}
\hline \multicolumn{2}{|c|}{$\begin{array}{c}\text { Test } \\
\text { Conditions }\end{array}$} & \multicolumn{2}{|c|}{$\begin{array}{c}\text { ECR, } \\
\%\end{array}$} & \multicolumn{2}{|c|}{$\begin{array}{c}\text { Plastic } \\
\text { Displacement, mm }\end{array}$} & \multicolumn{2}{|c|}{$\begin{array}{c}\text { Plastic } \\
\text { Strain, \% }\end{array}$} \\
\hline $\begin{array}{l}\mathrm{RCT} \\
\mathrm{T},{ }^{\circ} \mathrm{C}\end{array}$ & $\begin{array}{l}\text { Ox. Test } \\
\text { Time, }{ }^{a} \text { s }\end{array}$ & $\mathrm{CP}$ & Meas. & Offset & Permanent & Offset & Permanent \\
\hline RT & 0 & 0 & 0 & 6.3 & 5.9 & 66 & 62 \\
\hline $\begin{array}{l}\text { RT } \\
\text { RT }\end{array}$ & $\begin{array}{l}60 \\
60\end{array}$ & $\begin{array}{l}4.9 \\
4.9\end{array}$ & $\begin{array}{l}5.5 \\
5.5\end{array}$ & $\begin{array}{l}>3.5 \\
4.28\end{array}$ & $\begin{array}{c}>3.23 \\
---\end{array}$ & $\begin{array}{c}>37 \\
45\end{array}$ & $\begin{array}{c}>34 \\
---\end{array}$ \\
\hline RT & 100 & 7.8 & 8.2 & 0.38 & 0.21 & 4.0 & 2.2 \\
\hline RT & 136 & 10.0 & 10.9 & 0.10 & 0.05 & 1.0 & 0.5 \\
\hline RT & 151 & 10.8 & 11.9 & 0.08 & 0.05 & 0.8 & 0.5 \\
\hline 135 & 151 & 10.8 & 11.9 & 2.14 & --- & 23 & --- \\
\hline 135 & 151 & 10.8 & 11.9 & $>2.41$ & $>1.92$ & $>25$ & $>20$ \\
\hline RT & 203 & 13.0 & 12.8 & 0.09 & 0.07 & 1.0 & 0.7 \\
\hline RT & 203 & 13.0 & 14.6 & 0.08 & 0.06 & 0.8 & 0.6 \\
\hline 135 & 203 & 13.0 & 14.6 & 0.49 & 0.29 & 5.1 & 3.1 \\
\hline RT & 258 & 15.7 & 17.1 & $0.04-0.12$ & --- & $\approx 0.8$ & --- \\
\hline RT & 310 & 16.7 & 18.0 & 0.10 & 0.06 & 1.0 & 0.6 \\
\hline RT & 310 & 17.0 & 18.1 & 0.07 & 0.05 & 0.7 & 0.5 \\
\hline 135 & 310 & 17.0 & 18.1 & 0.26 & 0.14 & 2.8 & 1.4 \\
\hline $135^{b}$ & 318 & 17.0 & 18.5 & 0.26 & 0.12 & 2.8 & 1.3 \\
\hline $135^{b}$ & 318 & 17.0 & 18.5 & 0.19 & 0.07 & 2.0 & 0.7 \\
\hline $135^{b}$ & 390 & 19.0 & 20.3 & 0.29 & 0.10 & 3.1 & 1.1 \\
\hline $135^{b}$ & 390 & 19.0 & 20.3 & 0.18 & 0.08 & 1.9 & 0.8 \\
\hline RT & 428 & 20.0 & 20.7 & 0.05 & 0.04 & 0.5 & 0.4 \\
\hline
\end{tabular}

${ }^{\mathrm{a}}$ Includes ramp from $300^{\circ} \mathrm{C}$.

${ }^{b}$ Tests were conducted with current test train (see Figure 21 for thermal history).

Most other test results were conducted with the initial test train (see Figure 20 for thermal history). 


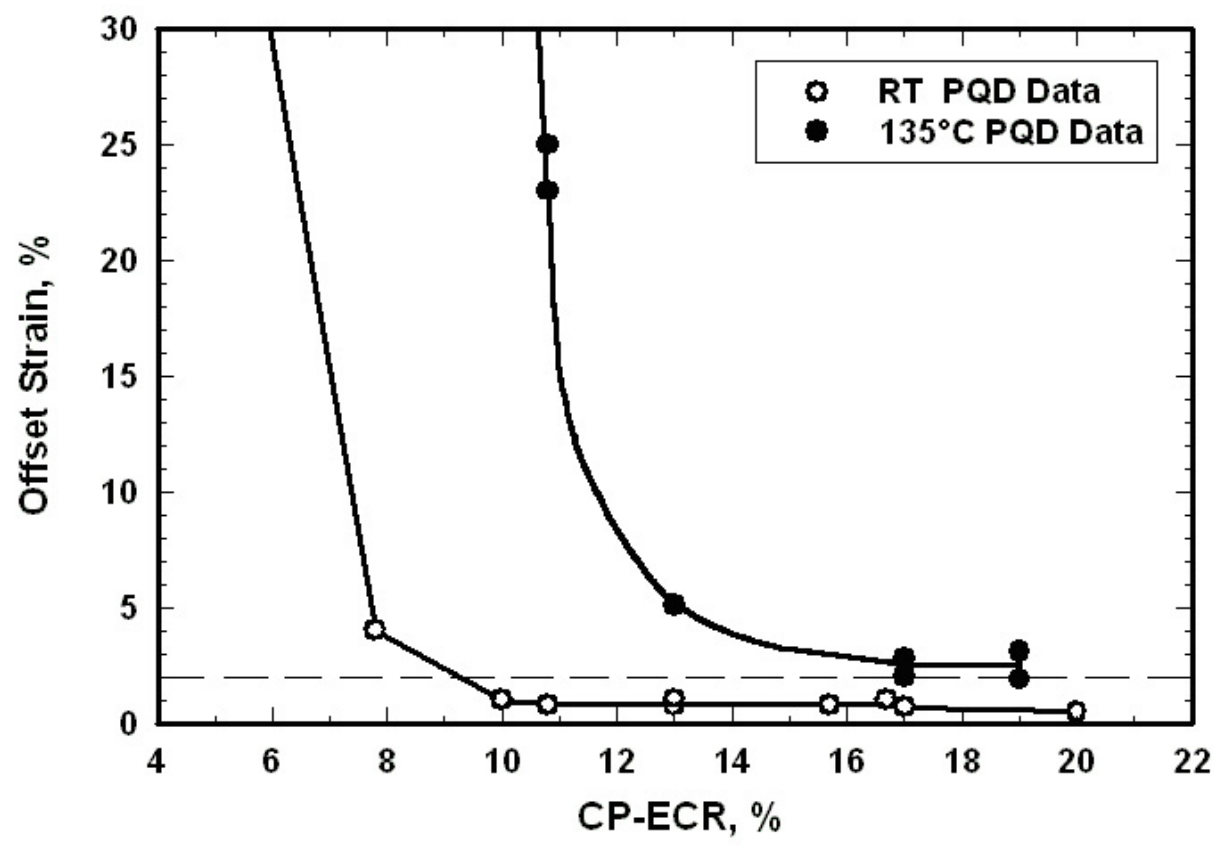

(a) Offset Strain

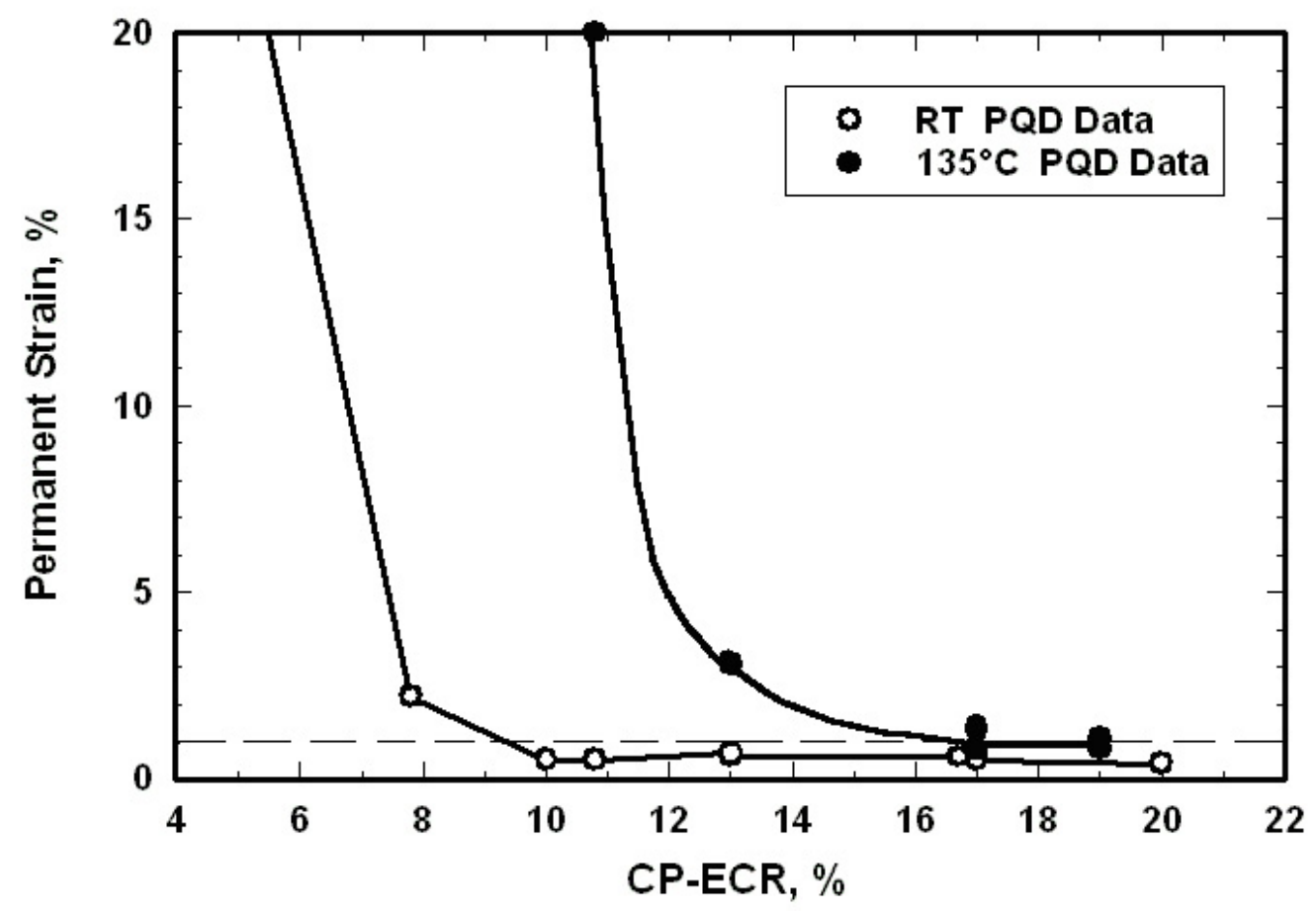

(b) Permanent Strain

Figure 22. Offset (a) and permanent (b) strains vs. CP-ECR for $17 \times 17$ Zry-4 oxidized at $1200^{\circ} \mathrm{C}$, cooled at $\approx 13^{\circ} \mathrm{C} / \mathrm{s}$ to $800^{\circ} \mathrm{C}$, quenched, and ring-compressed at $\mathrm{RT}$ and $135^{\circ} \mathrm{C}$. 
Table 12. Characterization Results for $17 \times 17$ Zry-4 Samples after Exposure to Steam at $1200^{\circ} \mathrm{C}$ to $13 \%$ and $20 \%$ CP-ECR, Cooling at $\approx 13^{\circ} \mathrm{C} / \mathrm{s}$ to $800^{\circ} \mathrm{C}$, and Quench.

\begin{tabular}{|c|c|c|}
\hline \multirow[b]{2}{*}{ Parameter } & \multicolumn{2}{|c|}{$17 \times 17$ Zry-4 } \\
\hline & $20 \% \mathrm{CP}-\mathrm{ECR}$ & $13 \% \mathrm{CP}-\mathrm{ECR}$ \\
\hline Effective Oxidation Time, s & 400 & 166 \\
\hline CP-Predicted Weight Gain, $\mathrm{mg} / \mathrm{cm}^{2}$ & 13.5 & 8.35 \\
\hline Measured ECR, \% & 20.8 & 12.8 \\
\hline Offset Displacement, mm & 0.049 & 0.090 \\
\hline RT Offset Strain, \% & 0.5 & 0.9 \\
\hline $\begin{array}{l}\text { RT Measured Permanent } \\
\text { Displacement, } \mathrm{mm}\end{array}$ & 0.04 & 0.07 \\
\hline RT Permanent Strain, \% & 0.4 & 0.7 \\
\hline RT Ductility, \% & $\begin{array}{c}\leq 0.4 \\
\text { (brittle) }\end{array}$ & $\begin{array}{c}\leq 0.7 \\
\text { (brittle) }\end{array}$ \\
\hline Hydrogen Content, wppm & 17 & low \\
\hline Hydrogen Pickup, wppm & 13 & low \\
\hline OD/ID Oxide Layer Thickness, $\mu \mathrm{m}$ & $68 / 66$ & $42 / 41$ \\
\hline Prior-Beta-Layer Thickness, $\mu \mathrm{m}$ & 266 & 419 \\
\hline $\begin{array}{l}\text { Microhardness, DPH } \\
\text { Oxide Layers } \\
\text { Alpha Layers } \\
\text { Prior-Beta Layer }^{\mathrm{a}}\end{array}$ & $\begin{array}{l}570-960 \\
530-730 \\
280-600\end{array}$ & $\begin{array}{l}600-770 \\
600-700 \\
260-360\end{array}$ \\
\hline
\end{tabular}

\subsubsection{Post-quench ductility of $15 \times 15$ Zry-4 oxidized at $1200^{\circ} \mathrm{C}$}

Baseline data were generated for the post-quench ductility of HBR-type $15 \times 15$ low-tin Zry- 4 oxidized at $1200^{\circ} \mathrm{C}$ and quenched at $800^{\circ} \mathrm{C}$. A parallel study was conducted using belt-polished $15 \times 15$ low-tin Zry-4 to determine if modern Zry-4 has higher post-quench ductility than 1980s Zry-4. Data were also generated for both types of Zry- 4 oxidized at $1000^{\circ} \mathrm{C}$ as part of the breakaway oxidation study. The breakaway oxidation results are reported in the Section 3.1.3.

The first dataset was generated for a test train with the thermal benchmark shown in Figure 23. Based on two TCs welded to the sample $120^{\circ}$ apart, the hold temperature was estimated to be $1200 \pm 17^{\circ} \mathrm{C}$. The oxidation and post-quench ductility results for HBR-type $15 \times 15$ low-tin Zry-4 exposed to the thermal history in Figure 23 are summarized in Table 13. For the samples compressed at RT, marginal ductility is indicated in the offset and permanent strains at 7.5\% CP-ECR. The RT ductile-to-brittle transition is estimated to be $8 \% \mathrm{CP}$-ECR. At $135^{\circ} \mathrm{C}$, the samples are ductile at $\approx 10 \% \mathrm{CP}$-ECR and brittle at $13 \% \mathrm{CP}$ ECR. The ductile-to-brittle transition CP-ECR at $135^{\circ} \mathrm{C}$ is $\approx 12 \%$. Additional samples were oxidized at $\approx 1188^{\circ} \mathrm{C}$ and $\approx 1176^{\circ} \mathrm{C}$ to $12-13 \% \mathrm{CP}$-ECR. These samples remained brittle at $\mathrm{RT}$ even 


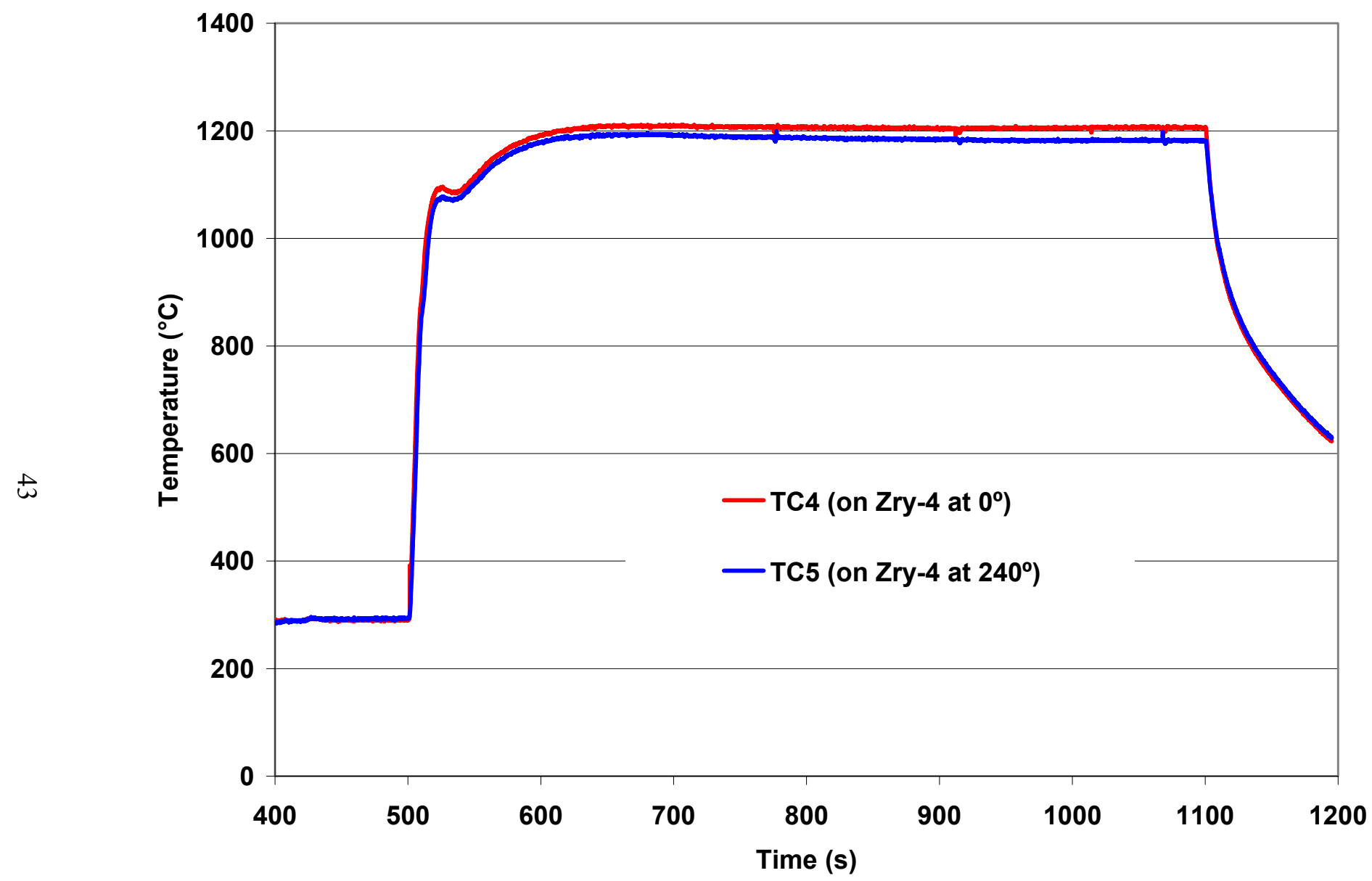

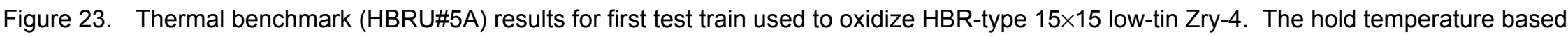
on two sample-welded TCs is $1200 \pm 17^{\circ} \mathrm{C}$. 
Table 13. Ring Compression Test (RCT) Results for HBR-type $15 \times 15$ Low-tin Zry-4 Samples Oxidized at $1200 \pm 17^{\circ} \mathrm{C}$, Cooled at $\approx 11^{\circ} \mathrm{C} / \mathrm{s}$ to $800^{\circ} \mathrm{C}$, and Quenched. ECR $=1.1535 \mathrm{Wg}$ for $0.76-\mathrm{mm}$ wall cladding. Tests were performed on $\approx 8$-mm-long samples at $\mathrm{RT}$ and $135^{\circ} \mathrm{C}$ and at $0.0333-\mathrm{mm} / \mathrm{s}$ displacement rate. Displacements in the loading direction were normalized to the as-fabricated outer diameter $(10.77 \mathrm{~mm})$ to calculate offset and permanent strains.

\begin{tabular}{|c|c|c|c|c|c|c|}
\hline \multirow{2}{*}{$\begin{array}{c}\text { RCT Test } \\
\text { Temperature, } \\
{ }^{\circ} \mathrm{C}\end{array}$} & \multicolumn{2}{|c|}{ ECR, \% } & \multicolumn{2}{|c|}{ Displacement, mm } & \multirow{2}{*}{$\begin{array}{l}\text { Offset } \\
\text { Strain, } \\
\%\end{array}$} & \multirow{2}{*}{$\begin{array}{c}\text { Permanent } \\
\text { Strain, } \\
\%\end{array}$} \\
\hline & $\mathrm{CP}$ & Meas. & Offset & Permanent & & \\
\hline RT & 0 & 0 & 7.0 & 6.8 & 65 & 63 \\
\hline $\begin{array}{l}\text { RT } \\
\text { RT } \\
--{ }^{\text {a }}\end{array}$ & $\begin{array}{l}4.9 \\
4.9 \\
4.9\end{array}$ & $\begin{array}{l}6.1 \\
6.1 \\
5.8\end{array}$ & $\begin{array}{c}1.77 \\
1.33 \\
---\end{array}$ & $\begin{array}{c}1.22 \\
0.67 \\
---\end{array}$ & $\begin{array}{l}16 \\
12 \\
---\end{array}$ & $\begin{array}{c}11 \\
6 \\
---\end{array}$ \\
\hline $\begin{array}{l}\text { RT } \\
\text { RT }\end{array}$ & $\begin{array}{l}7.5 \\
7.5\end{array}$ & $\begin{array}{l}8.0 \\
8.0\end{array}$ & $\begin{array}{l}0.22 \\
0.22\end{array}$ & $\begin{array}{l}0.01 \\
0.11\end{array}$ & $\begin{array}{l}2.0 \\
2.0\end{array}$ & $\begin{array}{l}0.9 \\
1.0\end{array}$ \\
\hline $\begin{array}{l}\text { RT } \\
135\end{array}$ & $\begin{array}{l}9.8 \\
9.8\end{array}$ & $\begin{array}{l}10.6 \\
10.6\end{array}$ & $\begin{array}{l}0.06 \\
0.31\end{array}$ & $\begin{array}{l}0.05 \\
0.19\end{array}$ & $\begin{array}{l}0.6 \\
2.9\end{array}$ & $\begin{array}{l}0.5 \\
1.8\end{array}$ \\
\hline $\begin{array}{l}\text { RT } \\
135\end{array}$ & $\begin{array}{l}12.8 \\
12.8\end{array}$ & $\begin{array}{l}13.9 \\
13.9\end{array}$ & $\begin{array}{l}0.05 \\
0.16\end{array}$ & $\begin{array}{l}0.03 \\
0.07\end{array}$ & $\begin{array}{l}0.5 \\
1.5\end{array}$ & $\begin{array}{l}0.3 \\
0.7\end{array}$ \\
\hline $\begin{array}{l}\text { RT } \\
135\end{array}$ & $\begin{array}{l}16.7 \\
16.7\end{array}$ & $\begin{array}{l}17.8 \\
17.8\end{array}$ & $\begin{array}{l}0.06 \\
0.14\end{array}$ & $\begin{array}{l}0.05 \\
0.05\end{array}$ & $\begin{array}{l}0.6 \\
1.3\end{array}$ & $\begin{array}{l}0.5 \\
0.5\end{array}$ \\
\hline
\end{tabular}

${ }^{a}$ Additional test performed for metallographic and microhardness measurements.

with the reduction in oxidation temperature. Table 14 summarizes the results of the post-test characterization, while Figure 24 shows microhardness profiles across the prior-beta layer at three CPECR values. The microhardness values are consistent with the post-quench ductility results. The RT post-quench ductility results appear to be consistent with those shown in Figure 22a for $17 \times 17$ low-tin Zry-4, but the $135^{\circ} \mathrm{C}$ data are not consistent as they indicate a ductile-to-brittle transition of only $\approx 12 \%$ CP-ECR, as compared to $17 \%$ CP-ECR for $17 \times 17$ low-tin Zry-4.

At the time the results were generated, it was not clear whether the HBR-type $15 \times 15$ low-tin Zry- 4 was inferior to the modern $17 \times 17$ low-tin Zry-4, or whether the large circumferential temperature gradient leading to local temperatures $\geq 1217^{\circ} \mathrm{C}$ was responsible for the low transition ECR. A new test train was built, and the thermal calibration was performed in two separate tests to give cladding temperatures at three circumferential locations: $0^{\circ}, 120^{\circ}$, and $240^{\circ}$. During the calibration effort, the sample was rotated within the quartz tube to determine the sensitivity of temperature to angular orientation. Great care was exercised to center the larger-diameter cladding with respect to the test train, 
Table 14. Oxide, Alpha, and Prior-Beta Layer Thicknesses at Four CP-ECR Values for HBR-type $15 \times 15$ Low-tin Zry-4 Oxidized at $1200 \pm 17^{\circ} \mathrm{C}$, Cooled at $\approx 11^{\circ} \mathrm{C} / \mathrm{s}$ to $800^{\circ} \mathrm{C}$, and Quenched.

\begin{tabular}{|l|c|c|c|c|}
\hline \multirow{2}{*}{ Parameter } & \multicolumn{4}{c|}{ CP-ECR, \% } \\
\cline { 2 - 5 } & $\approx 5$ & 7.5 & 9.8 & 12.8 \\
\hline \hline Outer Oxide Layer Thickness, $\mu \mathrm{m}$ & 26 & 35 & 61 & 80 \\
\hline Outer Alpha Layer Thickness, $\mu \mathrm{m}$ & 24 & 41 & 113 & 102 \\
\hline Prior-Beta Layer Thickness, $\mu \mathrm{m}$ & 690 & 636 & 513 & 453 \\
\hline Inner Alpha Layer Thickness, $\mu \mathrm{m}$ & 23 & 40 & 113 & 108 \\
\hline Inner Oxide Layer Thickness, $\mu \mathrm{m}$ & 24 & 36 & 62 & 79 \\
\hline Measured Weight Gain, $\mathrm{mg} / \mathrm{cm}{ }^{2}$ & 5.0 & 7.0 & 9.2 & 12.1 \\
\hline Measured ECR, $\%$ & 5.8 & 8.0 & 10.6 & 13.9 \\
\hline RT Offset Strain, $\%$ & $\approx 10 \%$ & $\approx 1.0$ & 0.3 & 0.5 \\
\hline $135^{\circ} \mathrm{C}$ Offset Strain, $\%$ & --- & --- & 2.9 & 1.5 \\
\hline
\end{tabular}

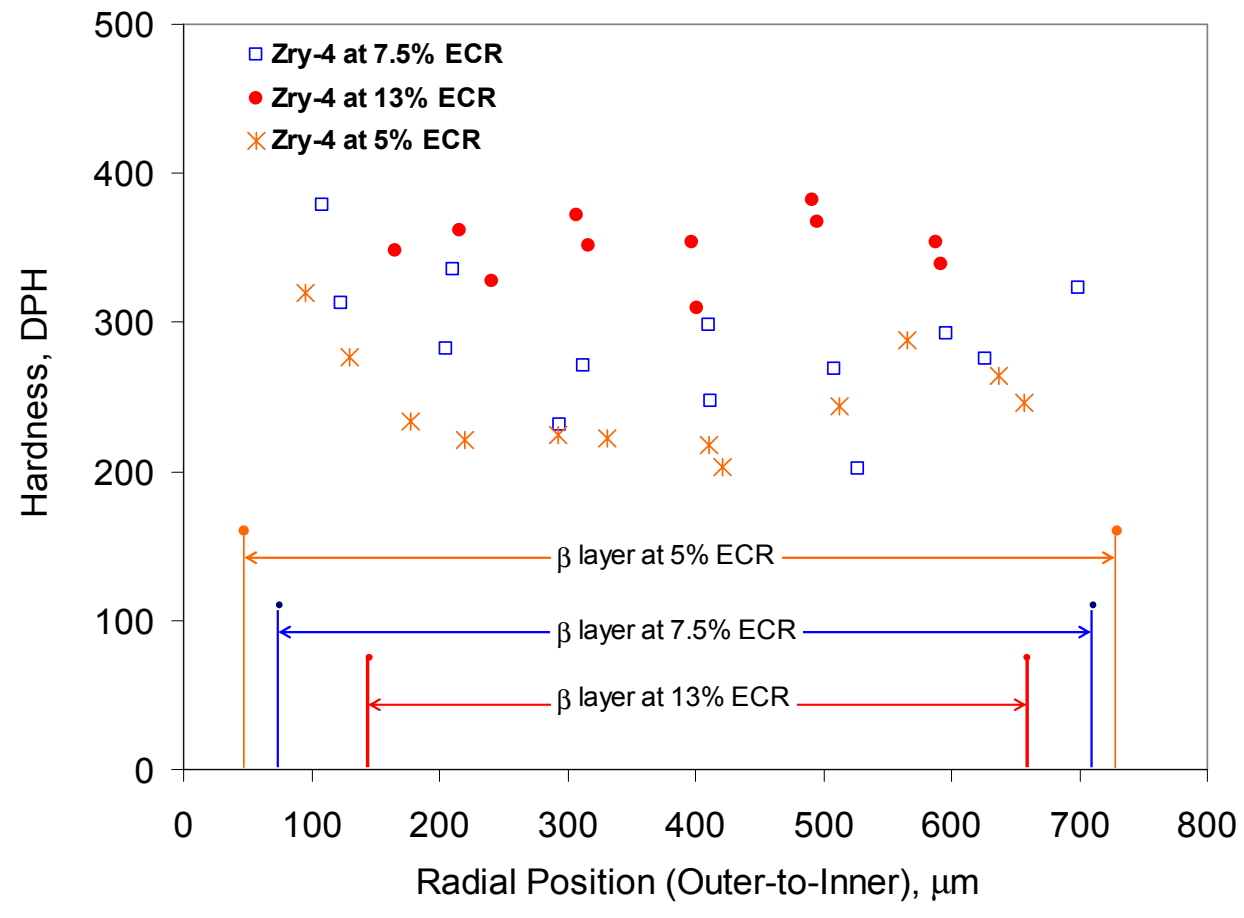

Figure 24. RT microhardness across prior-beta layer for $1200^{\circ} \mathrm{C}$-oxidized HBR-type $15 \times 15$ Zry- 4 . 
the quartz tube, and the furnace. The thermal benchmark results for the improved test train are shown in Figure 10. The hold temperature for this test train was $1204 \pm 10^{\circ} \mathrm{C}$.

Extensive testing was performed using the thermal history in Figure 10 because of the higher degree of confidence in the average hold temperature and circumferential temperature variation: $1204 \pm 10^{\circ} \mathrm{C}$. Each oxidized sample was sectioned into three $\approx 8$-mm-long rings, which were then compressed at $\mathrm{RT}, 100^{\circ} \mathrm{C}$, and $135^{\circ} \mathrm{C}$. The $100^{\circ} \mathrm{C}$ temperature is reasonable to assess long-term, postLOCA core coolability. Table 15 summarizes the oxidation results and the post-quench ductility results. Although samples from two lots were used in the testing, the agreement between these lots in terms of weight gain and post-quench ductility is excellent. Based on the data presented in Table 15 for permanent strains, the transition CP-ECR values are $7.5 \%$ at RT, $11.5 \%$ at $100^{\circ} \mathrm{C}$, and $14 \%$ at $135^{\circ} \mathrm{C}$.

Figure 25 shows a comparison between the measured weight gain and the $\mathrm{CP}$-predicted weight gain for HBR-type $15 \times 15 \mathrm{Zry}-4$ oxidized at $1200^{\circ} \mathrm{C}$. The agreement is excellent. Figure 26 shows the decrease in post-quench ductility (offset strain) with increasing CP-ECR and decreasing ring-compression temperature. The lines in the figure represent trend curves rather than "best fits" to the data.

Although the post-quench-ductility results with the newer test train (Figure 10) were better than the ones with the old test train, the ductile-to-brittle transition CP-ECR (14\%) was still lower for the older rough-surface HBR-type $15 \times 15$ Zry-4 than for the modern belt-polished $17 \times 17$ low-tin Zry-4 (17\%, Table 11). Several hypotheses were formulated and tested in an attempt to narrow down the reasons for these differences. The two alloys differ in surface roughness and possibly in surface chemistry, in OD and wall thickness, in as-fabricated oxygen content, and in test time to reach a given ECR. Modern beltpolished (BP) $15 \times 15$ low-tin Zry-4 was provided by AREVA (see Table 4) to determine if this cladding had comparable post-quench ductility to modern $17 \times 17$ low-tin Zry-4. As can be seen in Table 4, the modern alloys have comparable surface roughness and oxygen content. A new test train was constructed and benchmarked for the oxidation phase of the testing. The thermal benchmark results for this test train with TCs welded to the modern $15 \times 15$ Zry-4 are shown in Figure 27. The post-quench ductility results at $135^{\circ} \mathrm{C}$ are given in Table 16. The offset strains are compared in Figure 28 for belt-polished $17 \times 17$ and $15 \times 15$ Zry-4, as well as rough-surface HBR-type $15 \times 15$ Zry-4. Belt-polished $15 \times 15$ Zry-4 has a higher ductile-to-brittle transition CP-ECR (19\%) than belt-polished 17×17 Zry-4 (17\%) and rough-surface HBR-type $15 \times 15$ Zry-4 (14\%). As hydrogen pickup was insignificant for all three alloys and asfabricated oxygen contents are comparable (see Table 4), there appears to be fabrication differences in these Zry-4 lots, which result in differences in embrittlement threshold.

The prior-beta layer thickness of HBR-type $15 \times 15$ Zry- 4 is $\approx 420 \mu \mathrm{m}$ at the embrittlement CP-ECR of $14 \%$, while the prior-beta layer thickness of modern $17 \times 17$ Zry-4 is $\approx 320 \mu \mathrm{m}$ at the embrittlement CPECR of $17 \%$. The ductile-to-brittle transition appears to be controlled by the average oxygen content in the beta layer and is relatively insensitive to beta-layer thickness for thicknesses $>300 \mu \mathrm{m}$.

The selection of $14 \%$ transition CP-ECR for HBR-type $15 \times 15$ Zry-4 is primarily due to a single ring-compression data point at 15\% CP-ECR, which exhibited brittle behavior. Multiple oxidationquench tests were conducted in the narrow CP-ECR range of 13-16\% using both HBR-archive tubing and HBR-type $15 \times 15 \mathrm{Zry}-4$. Thirteen ductility data points were generated at $135^{\circ} \mathrm{C}$ following oxidation at $1200^{\circ} \mathrm{C}$ and $1204^{\circ} \mathrm{C}$ to $15.2 \%$ and $16.0 \% \mathrm{CP}-\mathrm{ECR}$ and quench at $800^{\circ} \mathrm{C}$. The results for permanent strain were $1.5 \pm 0.4 \%$ for $15.2 \% \mathrm{CP}$-ECR and $1.1 \pm 0.3 \%$ at $16 \% \mathrm{CP}$-ECR. By interpolation, the ductile-to-brittle transition CP-ECR would be $15.6 \%$, which rounds off to $16 \%$ CP-ECR. 
Table 15. Ring Compression Test Results for HBR-type 15×15 Low-tin Zry-4 Cladding Oxidized at $1204 \pm 10^{\circ} \mathrm{C}$, Cooled at $\approx 11^{\circ} \mathrm{C} / \mathrm{s}$ to $800^{\circ} \mathrm{C}$, and Quenched. ECR $=1.1535 \mathrm{Wg}$ for $0.76-\mathrm{mm}$ wall cladding. Tests were performed on $\approx 8$-mm-long samples at $R T, 100^{\circ} \mathrm{C}$, and $135^{\circ} \mathrm{C}$ and at $0.0333-\mathrm{mm} / \mathrm{s}$ displacement rate. Samples from two lots were used to generate these data: 10.77-mm OD and 0.76-mm wall; and 10.76-mm OD and 0.77-mm wall. Displacements in the loading direction were normalized to the as-fabricated outer diameter to calculate offset and permanent strains.

\begin{tabular}{|c|c|c|c|c|c|c|c|}
\hline \multicolumn{2}{|c|}{$\begin{array}{c}\text { Test } \\
\text { Conditions }\end{array}$} & \multicolumn{2}{|c|}{$\begin{array}{c}\text { ECR, } \\
\%\end{array}$} & \multicolumn{2}{|c|}{$\begin{array}{c}\text { Plastic } \\
\text { Displacement, } \mathrm{mm}\end{array}$} & \multicolumn{2}{|c|}{$\begin{array}{l}\text { Plastic } \\
\text { Strain, \% }\end{array}$} \\
\hline $\mathrm{T},{ }^{\circ} \mathrm{C}$ & $\begin{array}{c}\text { Test } \\
\text { Time, }{ }^{\mathrm{a}} \mathrm{s}\end{array}$ & $\mathrm{CP}$ & Meas. & Offset & Permanent & Offset & Permanent \\
\hline RT & 0 & 0 & 0 & 7.0 & 6.8 & 65 & 63 \\
\hline RT & 96 & 5.0 & 5.5 & 1.98 & --- & 18 & --- \\
\hline RT & 93 & 5.0 & 5.1 & 2.34 & --- & 20 & --- \\
\hline RT & 96 & 5.0 & 5.5 & $>5.5$ & $>4.9$ & $>51$ & $>45$ \\
\hline 100 & 93 & 5.0 & 5.1 & $>5.6$ & $>5.0$ & $>52$ & $>46$ \\
\hline 100 & 96 & 5.0 & 5.5 & $>5.6$ & $>5.1$ & $>52$ & $>47$ \\
\hline 135 & 93 & 5.0 & 5.1 & $>6.0$ & $>5.5$ & $>56$ & $>51$ \\
\hline RT & 154 & 7.5 & 8.1 & 0.25 & 0.11 & 2.3 & 1.0 \\
\hline RT & 145 & 7.4 & 7.6 & 0.23 & 0.14 & 2.1 & 1.3 \\
\hline 100 & 154 & 7.5 & 8.1 & $>3.9$ & $>3.4$ & $>36$ & $>32$ \\
\hline 100 & 145 & 7.4 & 7.6 & $>2.2$ & $>2.0$ & $>20$ & $>18$ \\
\hline 135 & 154 & 7.5 & 8.1 & $>4.7$ & $>4.3$ & $>43$ & $>40$ \\
\hline 135 & 145 & 7.4 & 7.6 & 5.53 & --- & 51 & --- \\
\hline $\mathrm{RT}$ & 230 & 10.0 & 10.4 & 0.08 & 0.04 & 0.7 & 0.4 \\
\hline RT & 230 & 10.3 & 10.7 & 0.06 & 0.05 & 0.6 & 0.5 \\
\hline 100 & 230 & 10.0 & 10.4 & 0.34 & 0.21 & 3.2 & 1.9 \\
\hline 100 & 230 & 10.3 & 10.7 & 0.26 & 0.16 & 2.4 & 1.5 \\
\hline 135 & 230 & 10.0 & 10.4 & 1.60 & 1.32 & 14.9 & 12.3 \\
\hline 135 & 230 & 10.3 & 10.7 & 1.45 & 1.10 & 13.5 & 10.2 \\
\hline 100 & 278 & 11.7 & 11.8 & 0.16 & 0.09 & 1.4 & 0.9 \\
\hline 135 & 278 & 11.7 & 11.8 & 0.31 & 0.19 & 2.9 & 1.7 \\
\hline RT & 353 & 13.0 & 13.2 & 0.04 & 0.03 & 0.4 & 0.3 \\
\hline $\mathrm{RT}$ & 353 & 12.8 & 13.2 & 0.07 & 0.05 & 0.6 & 0.5 \\
\hline 100 & 353 & 13.0 & 13.2 & 0.12 & 0.07 & 1.1 & 0.6 \\
\hline 100 & 353 & 12.8 & 13.2 & 0.10 & 0.05 & 0.9 & 0.5 \\
\hline 135 & 353 & 13.0 & 13.2 & 0.37 & 0.16 & 3.4 & 1.5 \\
\hline 135 & 353 & 12.8 & 13.2 & 0.22 & 0.13 & 3.1 & 1.2 \\
\hline 135 & 432 & 15.0 & 14.8 & 0.17 & 0.09 & 1.6 & 0.8 \\
\hline
\end{tabular}

${ }^{\mathrm{a}}$ Includes time for ramp from $300^{\circ} \mathrm{C}$ and hold time prior to cooling. 


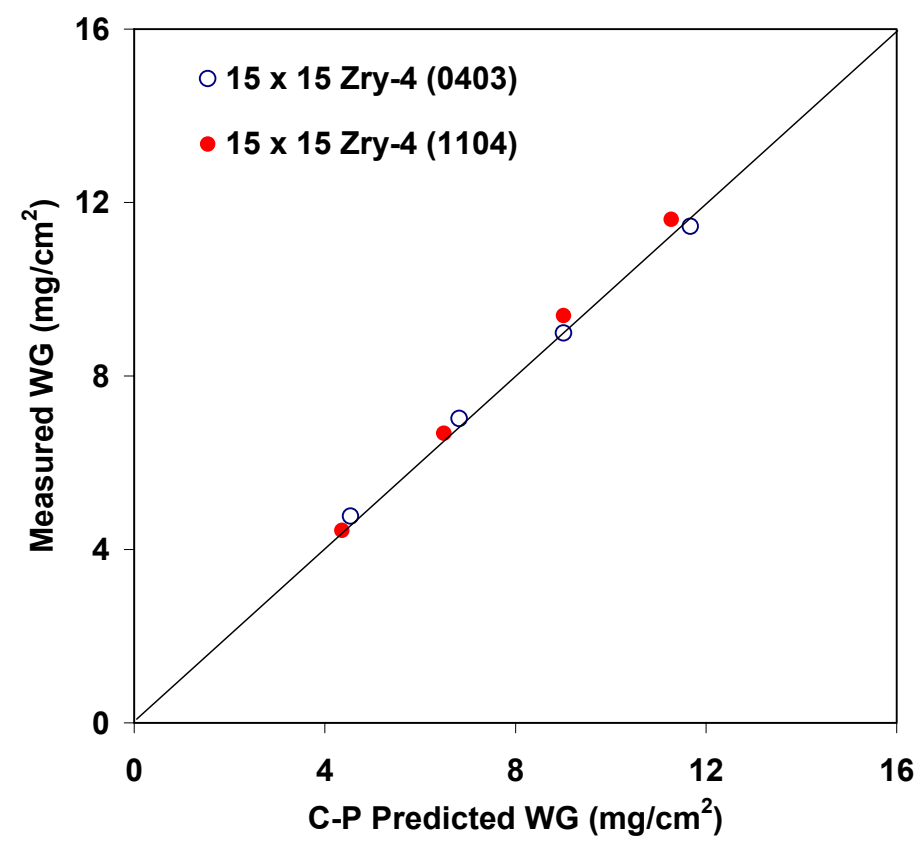

Figure 25. Measured vs. predicted weight gain for two lots of HBR-type $15 \times 15$ low-tin Zry-4 oxidized at $1204 \pm 10^{\circ} \mathrm{C}$ and quenched at $800^{\circ} \mathrm{C}$.

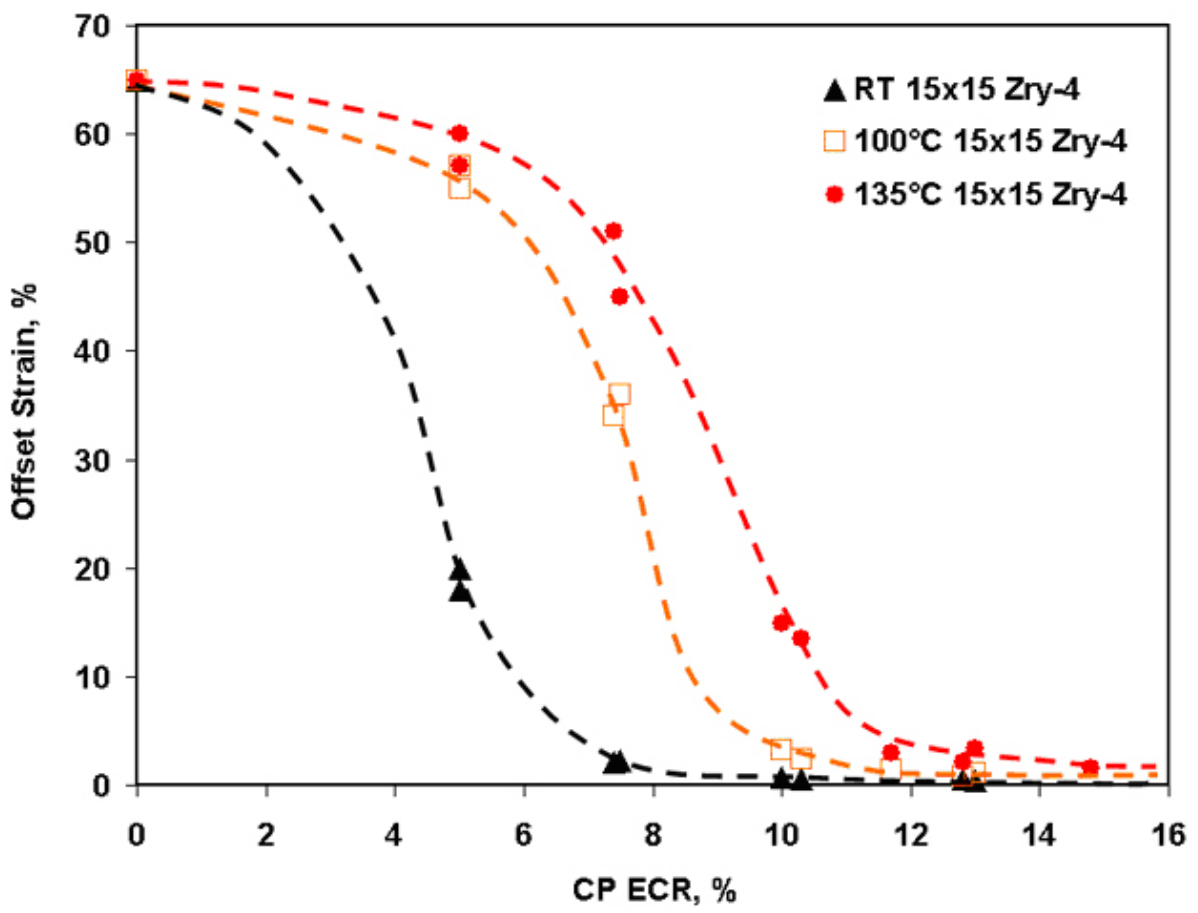

Figure 26. Offset strain vs. CP-ECR and ring-compression test temperature for two lots of HBR-type $15 \times 15$ low-tin Zry- 4 oxidized at $1204 \pm 10^{\circ} \mathrm{C}$, cooled at $\approx 11^{\circ} \mathrm{C} / \mathrm{s}$ to $800^{\circ} \mathrm{C}$, and quenched. 


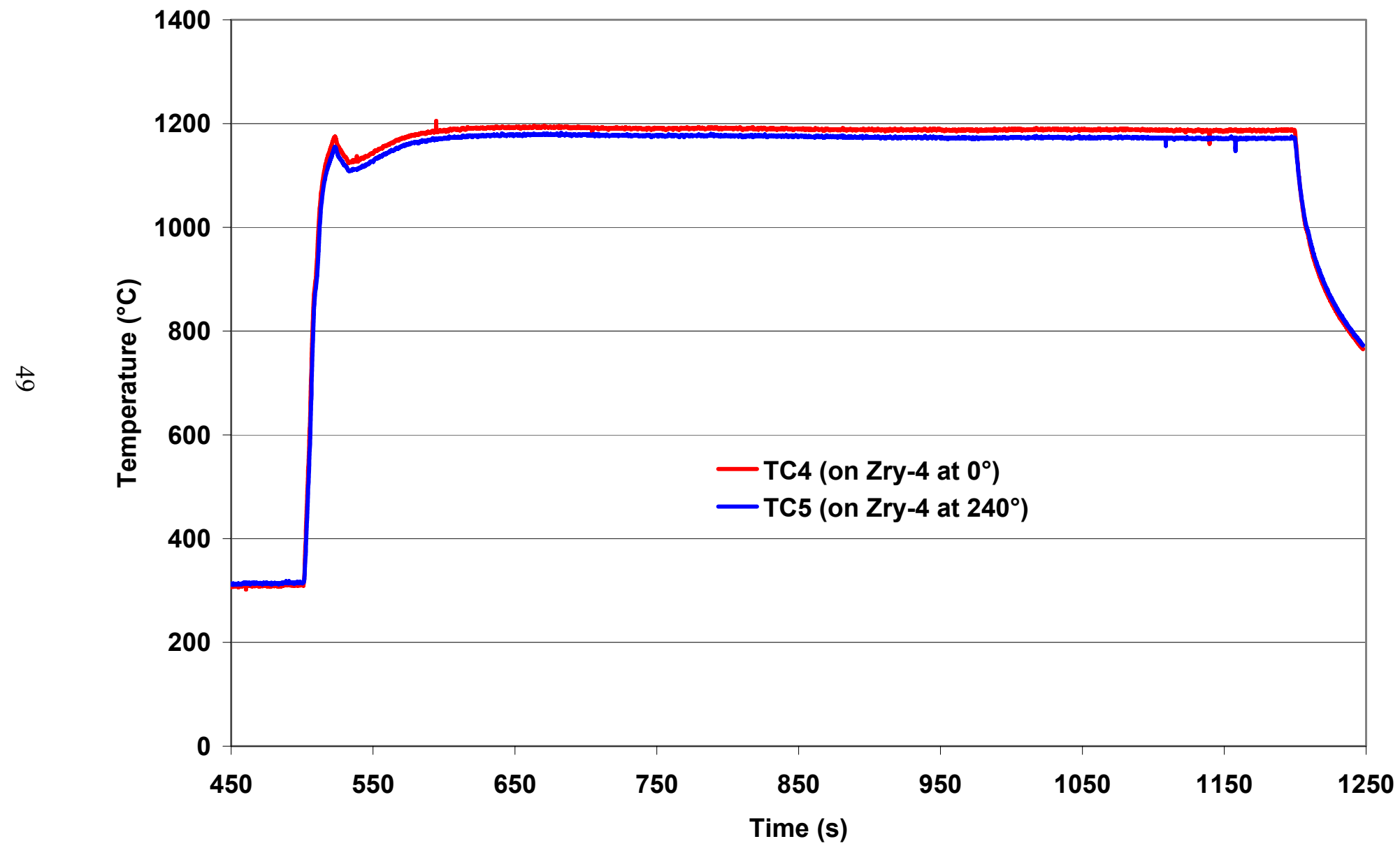

Figure 27. Thermal benchmark results for belt-polished $15 \times 15$ low-tin Zry-4 with a hold temperature of $\approx 1190^{\circ} \mathrm{C}$. Data-generating tests were conducted by increasing the holder control TC setting by $10^{\circ} \mathrm{C}$ to give a hold temperature of $1200^{\circ} \mathrm{C}$. 
Table 16. Ring Compression Test (RCT) Results for Belt-polished 15×15 Zry-4 Cladding Oxidized at $1200^{\circ} \mathrm{C}$, Cooled at $\approx 11^{\circ} \mathrm{C} / \mathrm{s}$ to $800^{\circ} \mathrm{C}$, and Quenched. ECR $=1.308 \mathrm{Wg}$ for $0.67-\mathrm{mm}$ wall cladding. RCTs were performed on $\approx 8-\mathrm{mm}$-long samples at $135^{\circ} \mathrm{C}$ and $0.0333-\mathrm{mm} / \mathrm{s}$ displacement rate.

\begin{tabular}{|c|c|c|c|c|c|c|c|}
\hline \multicolumn{2}{|c|}{$\begin{array}{c}\text { Test } \\
\text { Conditions }\end{array}$} & \multicolumn{2}{c|}{$\begin{array}{c}\text { ECR, } \\
\%\end{array}$} & \multicolumn{2}{c|}{$\begin{array}{c}\text { Plastic } \\
\text { Displacement, mm }\end{array}$} & \multicolumn{2}{c|}{$\begin{array}{c}\text { Plastic } \\
\text { Strain, \% }\end{array}$} \\
\hline $\begin{array}{c}\text { RCT } \\
\text { T, }{ }^{\circ} \mathrm{C}\end{array}$ & $\begin{array}{c}\text { Ox. Test } \\
\text { Time, }{ }^{\mathrm{a}} \mathrm{s}\end{array}$ & $\mathrm{CP}$ & Meas. & Offset & Permanent & Offset & Permanent \\
\hline 135 & 210 & 11.0 & 11.5 & $>3.6$ & $>3.2$ & $>33$ & $>29$ \\
135 & 210 & 11.0 & 11.5 & $>3.5$ & $>3.1$ & $>32$ & $>28$ \\
\hline 135 & 280 & 13.0 & 12.7 & 4.15 & 3.58 & 38 & 33 \\
135 & 280 & 13.0 & 12.7 & 2.60 & 2.35 & 24 & 22 \\
\hline 135 & 360 & 15.0 & 15.0 & 0.50 & 0.24 & 4.6 & 2.2 \\
135 & 360 & 15.0 & 15.0 & 0.35 & 0.17 & 3.2 & 1.6 \\
\hline 135 & 495 & 17.0 & 17.2 & 0.42 & 0.22 & 3.8 & 2.0 \\
135 & 495 & 17.0 & 17.2 & 0.30 & 0.16 & 2.7 & 1.5 \\
\hline 135 & 620 & 20.0 & 19.8 & 0.28 & 0.15 & 2.6 & 1.4 \\
135 & 620 & 20.0 & 19.8 & 0.23 & 0.09 & 2.1 & 0.8 \\
\hline
\end{tabular}

${ }^{\mathrm{a}}$ Includes ramp from $300^{\circ} \mathrm{C}$.

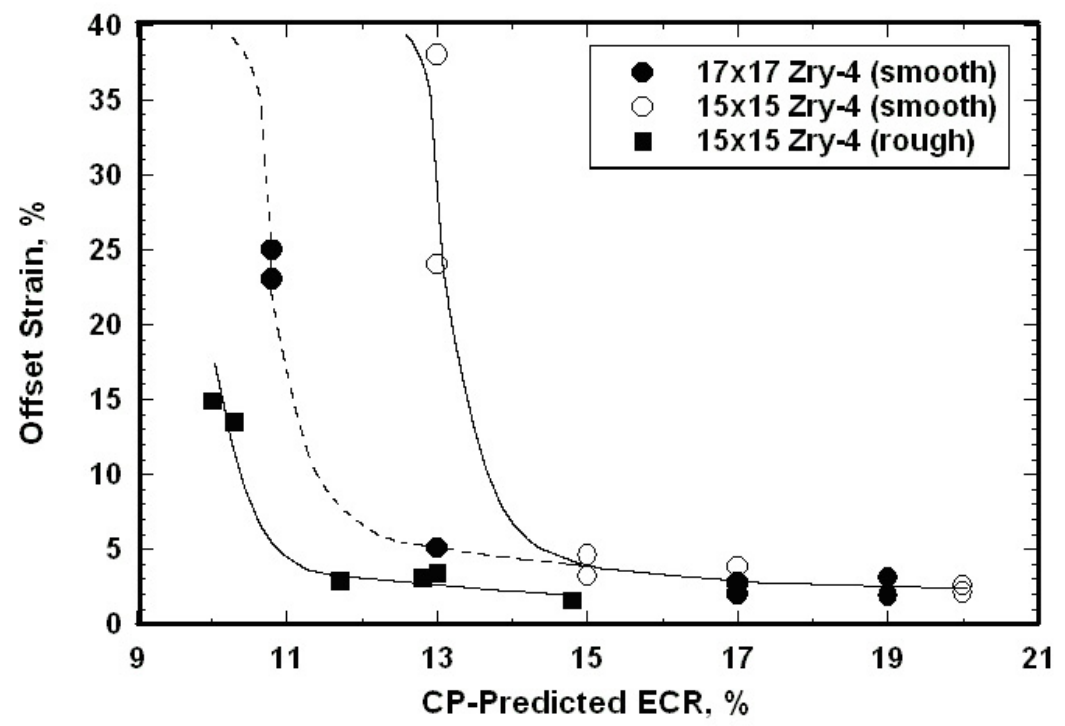

Figure 28. Offset strain vs. CP-ECR for $15 \times 15$ and $17 \times 17$ Zry-4 samples oxidized at $1200^{\circ} \mathrm{C}$, cooled at $\approx 11^{\circ} \mathrm{C} / \mathrm{s}$ to $800^{\circ} \mathrm{C}$, and quenched. Ring compression tests were conducted at $135^{\circ} \mathrm{C}$ and $0.0333-\mathrm{mm} / \mathrm{s}$ displacement rate. Nominal offset strain for ductile-to-brittle transition ECR is $2 \%$. 


\subsubsection{Breakaway oxidation time for $15 \times 15 \mathrm{Zry}-4$ samples oxidized at $800-1015^{\circ} \mathrm{C}$}

Breakaway oxidation has been investigated by Leistikow and Schanz [19,20] for Zry-4 and Mardon et al. [21] for Zry-4 and M5. Although the breakaway oxidation time is generally defined as the time corresponding to an increase in oxidation rate (i.e., weight gain rate), it is the associated hydrogen pickup that causes embrittlement. Leistikow and Schanz presented trend curves (see Figure 6 in Ref. 20) for weight gain vs. time at temperature and a data plot (see Figure 8 in Ref. 20) for hydrogen content vs. time at temperature for $650-1000^{\circ} \mathrm{C}$. They used an older vintage of standard Zry-4 with $1.6 \mathrm{wt} . \% \mathrm{Sn}, 0.12$ wt.\% O, and $0.725-\mathrm{mm}$ wall thickness. Typically the Zry-4 cladding of that vintage had $\approx 0.3-\mu \mathrm{m}$ outersurface roughness. Sample preparation included degreasing, pickling in a nitric-fluoric acid mixture, and cleaning in boiling water. Such treatment may leave a fine surface layer containing fluorine impurities. Both surface roughness and surface fluorine impurities can destabilize the oxide layer growth through early transformation from the tight tetragonal phase to the weaker monoclinic phase. Two-sided oxidation tests were performed in their study. Thus, the condition of the cladding inner surface may have influenced the breakaway oxidation times reported by Leistikow and Schanz.

Mardon et al. [21] presented hydrogen-concentration results vs. time at $1000^{\circ} \mathrm{C}$ for belt-polished $17 \times 17$ low-tin Zry-4 (1.29 wt.\% Sn, $0.12 \mathrm{wt} . \%$ O, and $\approx 0.1-\mu \mathrm{m}$ surface roughness). The oxidation was one-sided - outer-surface only. Thus, the condition of the cladding ID surface had no influence on the results.

The results of these two studies are compared in Table 17 in terms of breakaway time for weightgain rate increase and hydrogen content increase to $200 \mathrm{wppm}$. It is clear that the belt-polished Zry- 4 has a longer breakaway time at $1000^{\circ} \mathrm{C}$ than the pickled-and-cleaned, rough-surfaced Zry- 4 .

The results in Table 17 indicate that breakaway oxidation time is not a monotonic function of decreasing or increasing oxidation temperature. To illustrate this point, a trend curve is plotted in Figure 29 based on the Leistikow and Schanz results for breakaway-oxidation weight gain. Comparing the results for older cladding (pickled-and-cleaned, high surface roughness) to modern cladding (belt polished) indicated significant differences in breakaway oxidation time for Zry-4 at the same oxidation temperature. There may also be a difference in results for one-sided (OD surface) vs. two-sided oxidation tests because the inner surface usually has higher surface roughness and may have different surface chemistry as compared to the outer surface.

From the Leistikow and Schanz work, minimum times for breakaway oxidation in Zry-4 appear to occur at oxidation temperatures of $750-800^{\circ} \mathrm{C}$ and $1000^{\circ} \mathrm{C}$. In terms of hydrogen pickup, $1000^{\circ} \mathrm{C}$ oxidation gives the minimum breakaway time. However, no studies were found that explored the sensitivity of breakaway-oxidation time to temperatures within the range of $975-1025^{\circ} \mathrm{C}$. In ANL tests, breakaway oxidation time was determined within this temperature range by targeting average temperatures of $985^{\circ} \mathrm{C}, 1000^{\circ} \mathrm{C}$, and $1015^{\circ} \mathrm{C}$ for the two-sided oxidation tests. With circumferential temperature variations of $10-15^{\circ} \mathrm{C}$, local temperatures of $\approx 975-1025^{\circ} \mathrm{C}$ were included in the study. The alpha + beta $\rightarrow$ beta phase transition temperature $\left(\approx 980^{\circ} \mathrm{C}\right)$ for fresh Zry-4 is within this range.

Breakaway oxidation tests were not conducted with Zry-4 in the lower temperature range of 750$850^{\circ} \mathrm{C}$ because the Leistikow and Schanz results indicated that double the time was needed for 200-wppm hydrogen pickup at $800^{\circ} \mathrm{C}$ for the older cladding they tested. For modern cladding, which is belt- or wheel-polished on the outer surface and grit-polished on the inner surface, breakaway oxidation times at $800^{\circ} \mathrm{C}$ oxidation temperature should be much longer than the $3600 \mathrm{~s}$ reported by Leistikow and Schanz. 
Table 17. Breakaway Oxidation Time vs. Temperature for Zry-4 in Terms of Increase in Weight Gain Rate and Hydrogen-content Increase (200 wppm). References are: L-S = Leistikow and Schanz $[19,20]$ and $M=$ Mardon et al. [21].

\begin{tabular}{|c|c|c|c|c|c|}
\hline \multirow{2}{*}{$\begin{array}{c}\mathrm{T}, \\
{ }^{\circ} \mathrm{C}\end{array}$} & $\begin{array}{c}\text { Outer-Surface } \\
\text { Treatment }\end{array}$ & Oxidation & $\begin{array}{c}\text { Beight Gain } \\
\text { Rate Increase }\end{array}$ & $\begin{array}{c}\text { 200-wppm H } \\
\text { Content }\end{array}$ & \multirow{2}{*}{ Ref. } \\
\hline \hline 1050 & Pickled/Cleaned & 2-sided & $\approx 5700$ & --- & L-S \\
\hline 1000 & Pickled/Cleaned & 2-sided & $\approx 1560$ & 1800 & L-S \\
& Belt Polished & 1-sided & --- & 5400 & M \\
\hline 950 & Pickled/Cleaned & 2-sided & $\approx 3500$ & --- & L-S \\
\hline 900 & Pickled/Cleaned & 2-sided & $\approx 21,600$ & 50,400 & L-S \\
\hline 850 & Pickled/Cleaned & 2-sided & $\approx 6300$ & --- & L-S \\
\hline 800 & Pickled/Cleaned & 2-sided & $\approx 1980$ & 3600 & L-S \\
\hline 750 & Pickled/Cleaned & 2-sided & $\approx 2100$ & --- & L-S \\
\hline 700 & Pickled/Cleaned & 2-sided & $\approx 2640$ & --- & L-S \\
\hline 650 & Pickled/Cleaned & 2-sided & $\approx 11,400$ & 50,000 & L-S \\
\hline
\end{tabular}

${ }^{\mathrm{a}}$ For the L-S results, the hydrogen vs. time curve was used as a guide in determining breakaway oxidation time based on weight-gain-rate increase for curves with very gradual increase in slope.

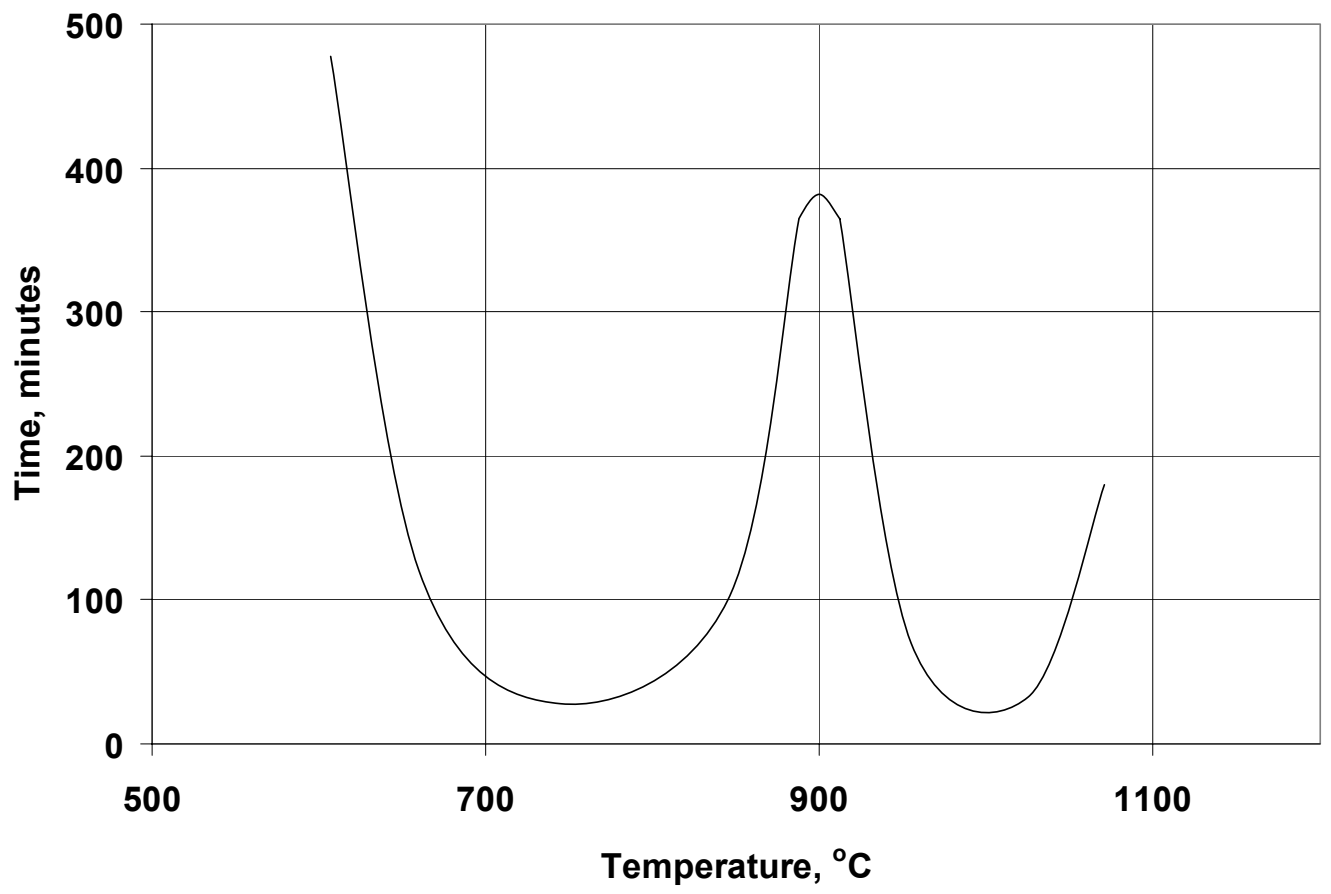

Figure 29. Breakaway-oxidation time vs. oxidation temperature determined from the trend curves presented by Leistikow and Schanz $[19,20]$ for Zry-4 weight gain vs. time. 
The classical view of the progression leading to breakaway oxidation is given by Leistikow and Schanz:

a) breakaway-oxidation instability initiates at the metal-oxide interface with local formation of monoclinic oxide;

b) the precursor to breakaway oxidation is the transition from a "flat" oxide-metal interface to a wavy interface (i.e., referred to as "rugosity");

c) the wavy surface creates alternating regions of tensile and compressive stresses in the near-surface oxide;

d) local regions under tensile stress transform first from tetragonal to monoclinic oxide;

e) the tetragonal-to-monoclinic oxide transition spreads from the inner surface to the outer surface; and

f) cracking of the weak monoclinic oxide increases the weight-gain rate and hydrogen pickup rate.

Applying this conceptual model to experimental procedures indicates that, by the time the outer surface is observed to turn from black (tetragonal) to gray (monoclinic), the weight-gain rate and hydrogen-pickup rate are such that the oxide is well into the breakaway regime, and the breakawayoxidation time is exceeded. As the furnace used for the ANL tests has a window for viewing a portion of the outer surface of the sample, it is relatively straightforward to turn off the furnace power and cool the sample at the oxidation time at which gray spots are observed on the outer surface of the cladding.

The thermal benchmark results for HBR and belt-polished $15 \times 15$ Zry- 4 are shown in Figures 30 and 31 , respectively, for a target hold temperature of $\approx 1000^{\circ} \mathrm{C}$. The test were conducted for a total test time of $1500 \mathrm{~s}$, including the ramp time from $300^{\circ} \mathrm{C}$ to $\approx 1000^{\circ} \mathrm{C}$ through the end of the hold time. Samples were cooled without quench, which is the standard test protocol for determining breakawayoxidation time. Excellent agreement was achieved between the CP-calculated and measured weight gain under these test conditions. For HBR-type Zry-4, the cladding temperature was $992 \pm 9^{\circ} \mathrm{C}$ at $78 \mathrm{~s}$ from temperature-ramp initiation and coasted down to a long-time temperature of $984 \pm 10^{\circ} \mathrm{C}$. Based on the flatness of the temperature profile, the cladding temperature is assumed to be $984 \pm 10^{\circ} \mathrm{C}$ for test times beyond $1500 \mathrm{~s}$. The breakaway-oxidation times reported in this work are referenced to zero time at the initiation of the ramp from $300^{\circ} \mathrm{C}$. As the ramp time is short $(78 \mathrm{~s})$ relative to the breakaway-oxidation time, the ramp time has no significant effect on the breakaway time.

For the belt-polished (BP) Zry-4 thermal history shown in Figure 31, the cladding temperature at 95 S was $1000 \pm 12^{\circ} \mathrm{C}$ and the long-time temperature was $986 \pm 10^{\circ} \mathrm{C}$. Thus, within experimental uncertainty, the long-time oxidation temperature for BP Zry-4 was essentially the same as the temperature for HBRtype Zry-4. Because of the large data scatter found for BP Zry-4 hydrogen pickup - due partly to scratches introduced during sample sectioning - the BP thermal benchmark was rerun for a longer time and with a controller setting designed to minimize overshoot (Figure 32). In addition, the test train length was decreased to adapt it to in-cell testing. The long-time temperature for this benchmark was $986 \pm 12^{\circ} \mathrm{C}$. Tests were also conducted at long-time temperatures of $1000 \pm 12^{\circ} \mathrm{C}$ and $1014 \pm 12^{\circ} \mathrm{C}$. The results are 


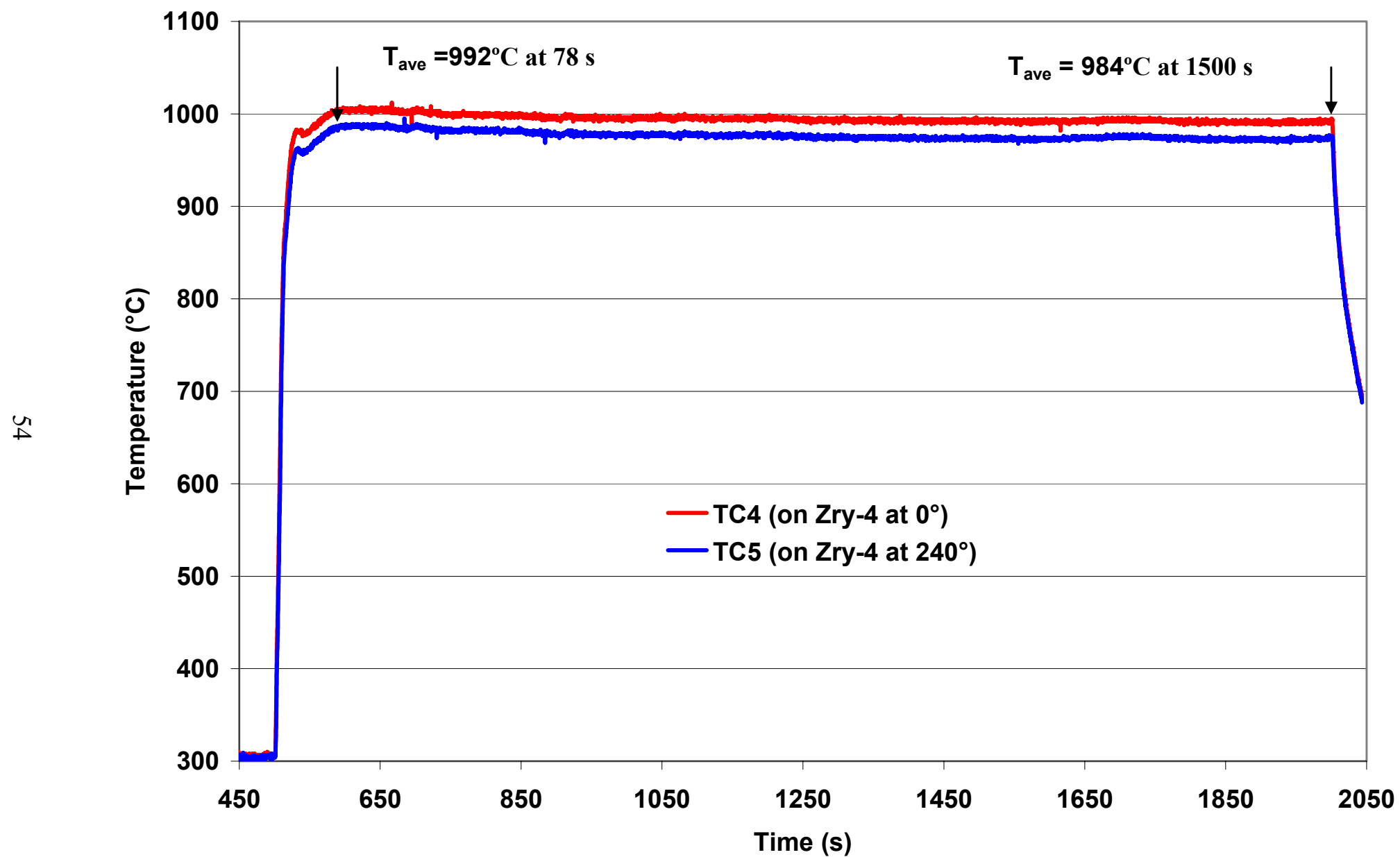

Figure 30. Results of thermal benchmark test with HBR-type $15 \times 15$ low-tin Zry-4. Measured weight gain was within $1 \%$ of the CP-predicted weight gain. Hold temperature is $992 \pm 9^{\circ} \mathrm{C}$ at $78 \mathrm{~s}$ and $984 \pm 10^{\circ} \mathrm{C}$ at $1500 \mathrm{~s}$, beyond the temperature-ramp initiation. 


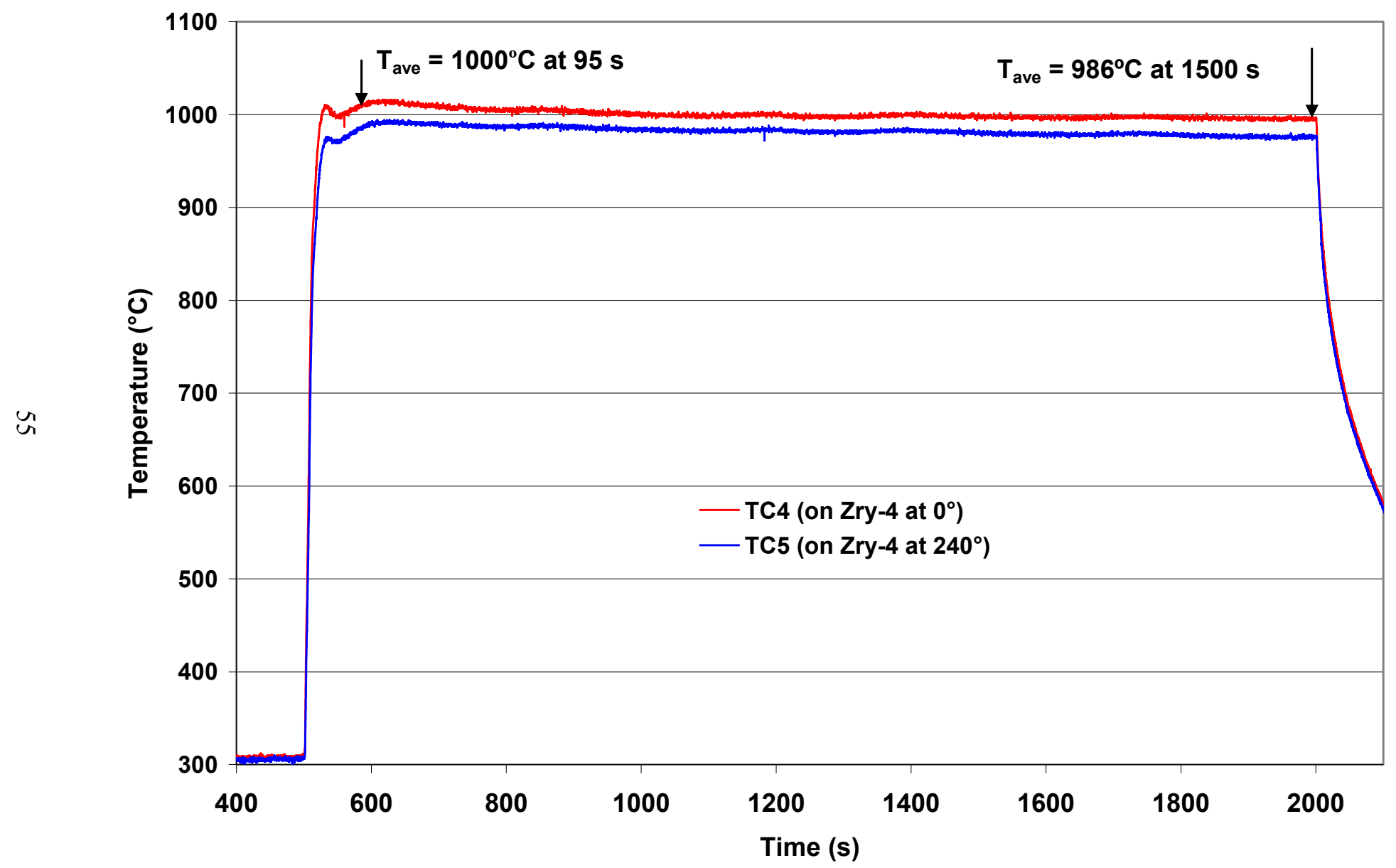

Figure 31. Results of first thermal benchmark test with belt-polished $15 \times 15$ low-tin Zry-4. Measured weight gain was within $6 \%$ of the CPpredicted weight gain. Hold temperature is $1000 \pm 12^{\circ} \mathrm{C}$ at $95 \mathrm{~s}$ and $986 \pm 10^{\circ} \mathrm{C}$ at $1500 \mathrm{~s}$, beyond the temperature-ramp initiation. 
shown in Figure 32. Because the $\pm 12^{\circ} \mathrm{C}$ was determined from three $\mathrm{TC}$ readings, it is also used for tests conducted at the temperatures shown in Figure 31.

Table 18 lists the breakaway-oxidation results at $984 \pm 10^{\circ} \mathrm{C}$ for HBR-type, low-tin $15 \times 15 \mathrm{Zry}-4$. Based on two tests at $3800 \mathrm{~s}$, the hydrogen pickup is $<200 \mathrm{wppm}$, and the breakaway time is $>3800 \mathrm{~s}$. Based on the 4000-s test result (1810-wppm H pickup), it was expected that a test time of $3900 \mathrm{~s}$ would give $\approx 200-400$ wppm H pickup. However, the H pickup after $3900 \mathrm{~s}$ was $1320 \mathrm{wppm}$. Given that considerable data scatter is expected for breakaway-oxidation time, no further testing was conducted for test times within 3800-3900 s, and $3800 \mathrm{~s}$ was identified as the breakaway-oxidation time. One sample (HBRU\#96) had pretest surface scratches introduced during sectioning. The sample was subjected to post-oxidation ductility testing because of the hydrogen pickup (170 $\pm 80 \mathrm{wppm})$. The offset and permanent strains for this sample at $135^{\circ} \mathrm{C}$ were $5.2 \%$ and $2.5 \%$, respectively. These results indicate that Zry-4 is ductile with $\approx 200$-wppm H pickup. However, because the sample was scratched prior to testing, the hydrogen-pickup results were not used to determine breakaway oxidation time (see 3.5.1).

Metallography was performed for HBR-type Zry-4 samples oxidized for 159 s, $3600 \mathrm{~s}$, and $5400 \mathrm{~s}$. Results for these times are shown in Figures 33-35 at two magnifications. The results support the Leistikow and Schanz description of breakaway oxidation evolution. In Figure 33, the oxide layers are clearly tetragonal with a black outer surface and smooth interface between the oxide layers and the metal. In Figure 34 - taken from the black non-scratched area of the HBRU\#96 test sample - the inner-surface and outer-surface oxide layers exhibit a wavy boundary at the oxide-metal interface. This is the precursor to breakaway oxidation. Both inner and outer oxides exhibit the same transition morphology, which suggests no preference for the inner surface to experience breakaway prior to the outer surface. In Figure 35 , the oxide layers are well beyond the breakaway transition. The outer and inner surfaces are gray, and significant cracking is observed on and within the oxide layers.

The results for belt-polished Zry-4 oxidized at $986 \pm 12^{\circ} \mathrm{C}$ (see Figure 31) are summarized in Table 19, followed by metallographic results in Figures 36-37. As expected, the breakaway oxidation time $(\approx 5000 \mathrm{~s})$ is longer for belt-polished Zry-4 as compared to the rough-surface Zry-4 $\approx 3800 \mathrm{~s})$. The BPZ4\#18 test sample, which was oxidized for $5000 \mathrm{~s}$, had a hydrogen pickup of $280 \pm 160 \mathrm{wppm}$. Although this is higher than the ANL 200 -wppm-H criterion, the sample did retain ductility $(\approx 6 \%$ offset and permanent strains) at $135^{\circ} \mathrm{C}$. The ductility results support the use of the ANL 200-wppm criterion for Zry-4 breakaway-oxidation time. Test sample BPZ4\#18 is particularly interesting because it experienced local breakaway at the outer surface. Figure 38a shows the sample discoloration along an axial strip, and Figure $38 \mathrm{~b}$ and $38 \mathrm{c}$ show the corresponding outer-surface oxide layer in this region. Tetragonal-tomonoclinic transition was observed only in this region. Also, the hydrogen concentration $(224,123,467$, and $352 \mathrm{wppm}$ ) at this axial location was highly non-uniform in the circumferential direction, indicating little time for hydrogen diffusion following local breakaway.

Because the test train used to generate the Table 18-19 results was at the end of its useful life, a new test train was built and benchmarked (see Figure 32). This shorter test train was used to examine the sensitivity of breakaway time to oxidation temperatures of $986-1014^{\circ} \mathrm{C}$ and to mild surface scratches (see 3.5.1). No breakaway oxidation was observed (Table 20) at $5400 \mathrm{~s}$ for $986^{\circ} \mathrm{C}, 1000^{\circ} \mathrm{C}$, and $1014^{\circ} \mathrm{C}$. Although the second test train gives longer breakaway oxidation times ( $>5400 \mathrm{~s})$, such variation is not surprising because breakaway oxidation is an instability phenomenon, which is sensitive to local surface conditions and temperature gradients, as well as other subtle differences in test conditions. Nevertheless, for LOCA-relevant times, it does not really matter whether the breakaway time for unscratched BP Zry-4 is $5000 \mathrm{~s}$ or $>5400 \mathrm{~s}$, as both times are very long. 


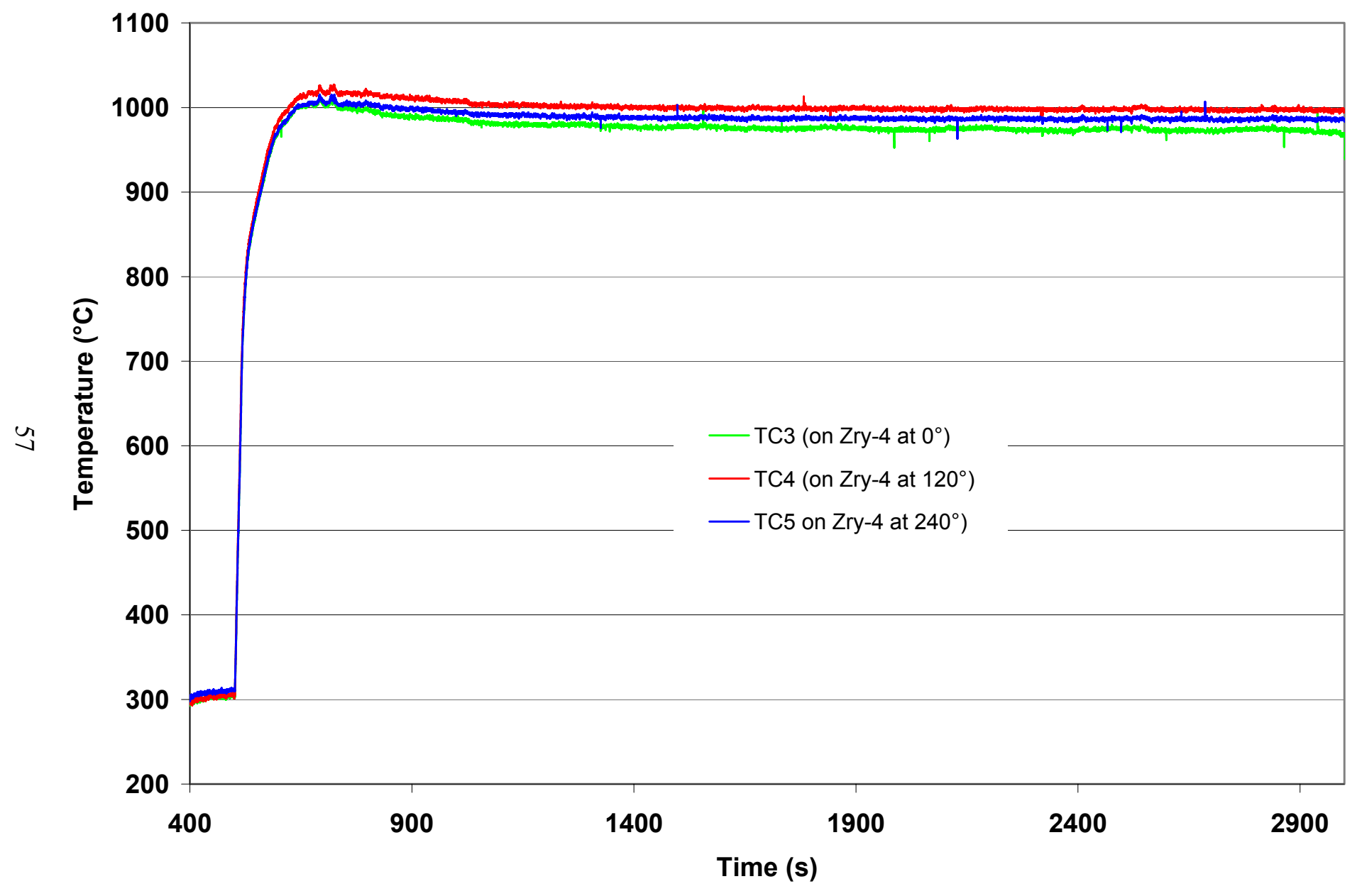

Figure 32. Results of second thermal benchmark test with belt-polished $15 \times 15$ low-tin Zry- 4 . Initial overshoot temperature is $1012 \pm 7^{\circ} \mathrm{C}$, and long-time hold temperature is $986 \pm 12^{\circ} \mathrm{C}$. Results are based on the readings of three TCs welded to the sample $120^{\circ}$ apart. 
Table 18. Results of Breakaway Oxidation Tests at $984 \pm 10^{\circ} \mathrm{C}$ for HBR-type $15 \times 15$ low-tin Zry- 4 . The hydrogen content $\left(\mathrm{C}_{\mathrm{Hi}}\right)$ of the as-fabricated cladding is $22 \mathrm{wppm}$. The hydrogen content of the oxidized sample $\left(\mathrm{L}_{H}\right)$ was measured with the LECO Hydrogen Determinator. Breakawayoxidation time based on 200 -wppm hydrogen pickup is $\approx 3800 \mathrm{~s}$.

\begin{tabular}{|c|c|c|c|c|c|c|}
\hline \multirow[b]{2}{*}{ Test ID } & \multirow[b]{2}{*}{$\begin{array}{c}\text { Test } \\
\text { Time, } \mathrm{s}\end{array}$} & \multicolumn{2}{|c|}{ Weight Gain, $\mathrm{mg} / \mathrm{cm}^{2}$} & \multirow[b]{2}{*}{$\begin{array}{c}\text { H Content, } \\
\text { wppm }\end{array}$} & \multirow[b]{2}{*}{$\begin{array}{c}\text { H-pickup, }{ }^{\text {a }} \\
\text { wppm }\end{array}$} & \multirow{2}{*}{$\begin{array}{c}\text { Offset } \\
\text { Strain } \\
\text { at } 135^{\circ} \mathrm{C} \text {, } \\
\%\end{array}$} \\
\hline & & $\mathrm{CP}$ & Measured & & & \\
\hline HBRU\#93 & 159 & 2.45 & 2.82 & Low & Low & --- \\
\hline HBRU\#90 & 1500 & 7.89 & 7.85 & Low & Low & --- \\
\hline HBRU\#84 & 3600 & 12.2 & 10.7 & 57 & 40 & --- \\
\hline HBRU\#96 ${ }^{b}$ & 3600 & 12.2 & 12.6 & 186 & 170 & 5.2 \\
\hline HBRU\#95 & 3800 & 12.5 & 10.6 & 61 & 40 & --- \\
\hline HBRU\#88 & 3800 & 12.5 & 10.7 & 42 & 20 & --- \\
\hline HBRU\#92 & 3900 & 12.7 & 16.4 & 1260 & 1320 & 0.9 \\
\hline HBRU\#91 & 4000 & 12.9 & 16.2 & 1723 & 1810 & --- \\
\hline HBRU\#87 & 4500 & 13.6 & 16.4 & 1581 & 1660 & --- \\
\hline HBRU\#81 & 5400 & 14.9 & 22.2 & 2111 & 2280 & --- \\
\hline HBRU\#82 & 7200 & 17.4 & 28.8 & 2769 & 3070 & --- \\
\hline
\end{tabular}

${ }^{a}$ The hydrogen pickup $\left(\Delta \mathrm{C}_{\mathrm{H}}\right)$ is referenced to the as-fabricated weight of the sample and is calculated from $\Delta \mathrm{C}_{\mathrm{H}}=\left(1+4 \times 10^{-3} \mathrm{Wg}\right) \mathrm{L}_{\mathrm{H}}-\mathrm{C}_{\mathrm{Hi}}$, where $\mathrm{Wg}$ is the measured weight gain in $\mathrm{mg} / \mathrm{cm}^{2}$.

${ }^{\mathrm{b}}$ Sample was scratched during pretest sectioning; see Section 3.5.1 for details.
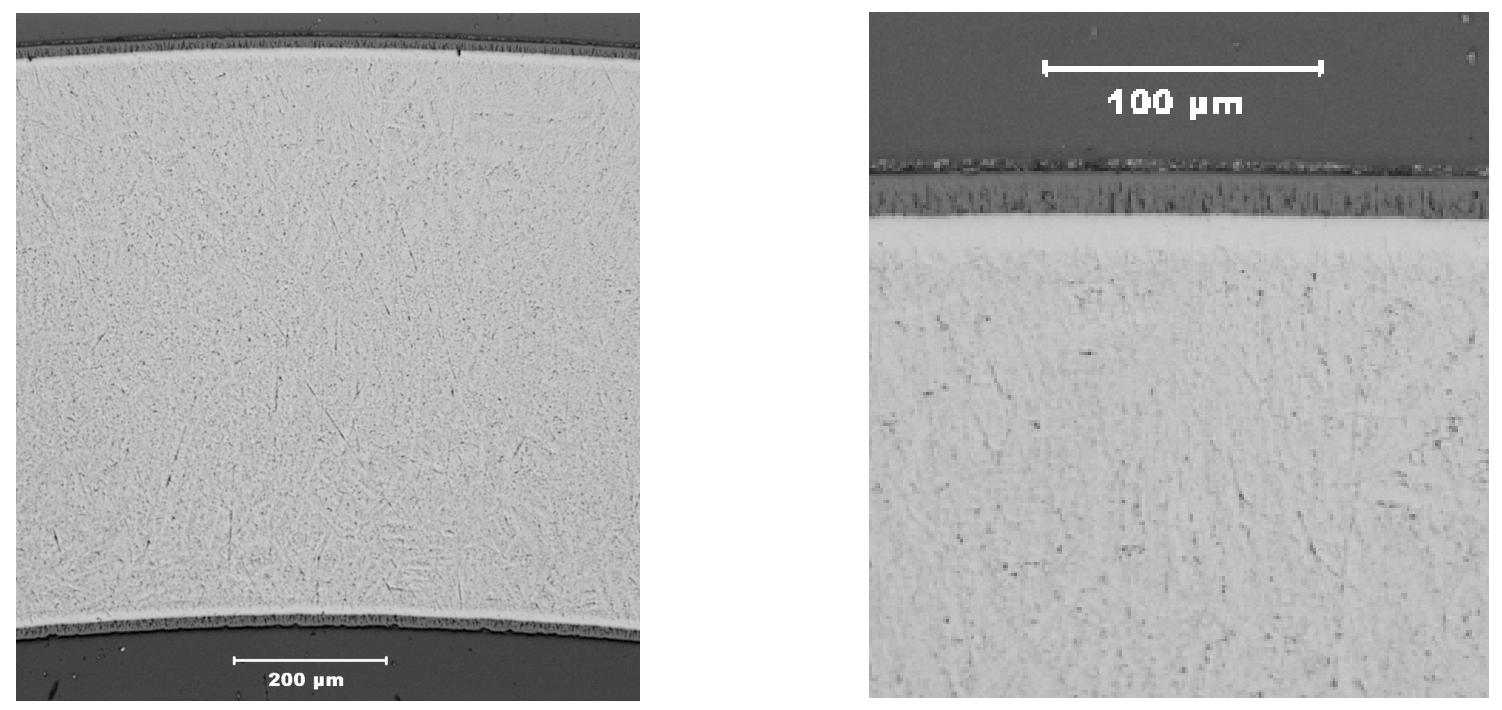

Figure 33. Low magnification (left) of inner- and outer-surface oxide layers for HBR-type $15 \times 15$ low-tin Zry-4 oxidized at $\approx 1000^{\circ} \mathrm{C}$ for $159 \mathrm{~s}$; higher magnification (right) of the outer-surface oxide layer illustrating the smooth boundary between oxide and metal. 

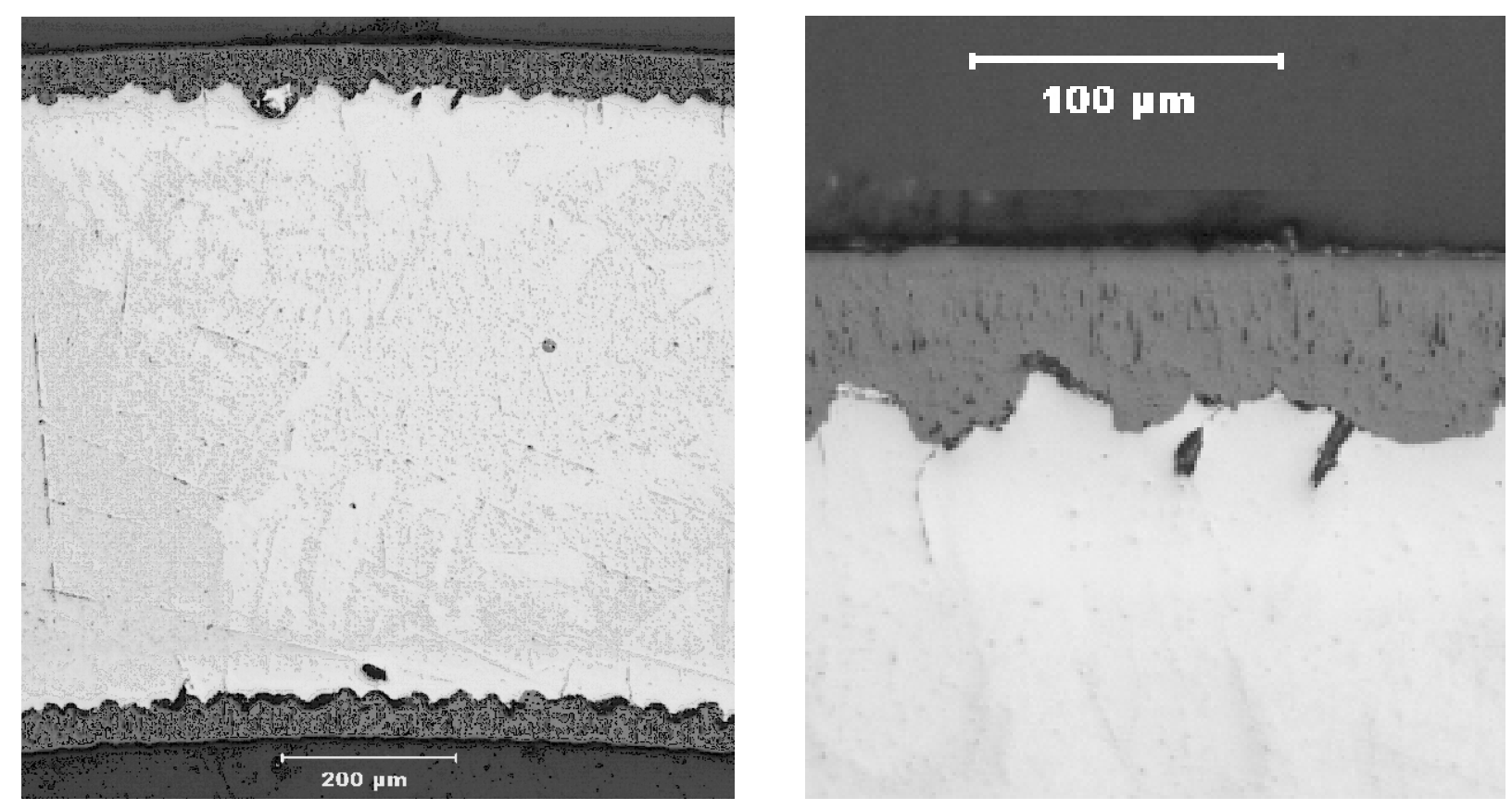

Figure 34. Low magnification (left) of inner- and outer-surface oxide layers for HBR-type $15 \times 15$ low-tin Zry-4 oxidized at $984 \pm 10^{\circ} \mathrm{C}$ for $3600 \mathrm{~s}$; higher magnification (right) of the outer-surface oxide layer showing the wavy boundary between oxide and metal, which is a precursor to breakaway.
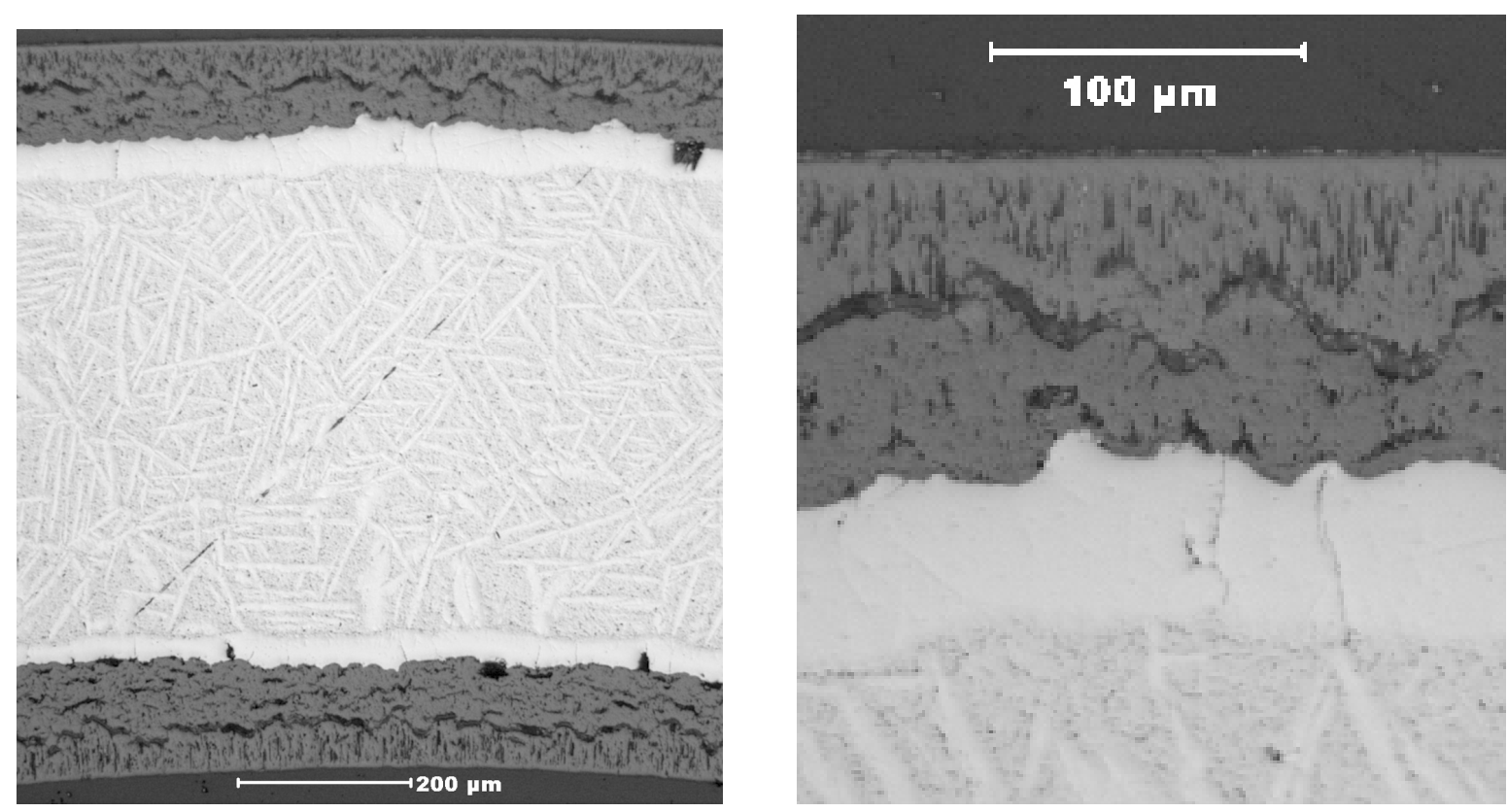

Figure 35. Low magnification (left) of inner- and outer-surface oxide layers for HBR-type $15 \times 15$ low-tin Zry-4 oxidized at $984 \pm 10^{\circ} \mathrm{C}$ for $5400 \mathrm{~s}$; higher magnification (right) of outer-surface oxide layer shows cracks in monoclinic oxide layer formed during the transition to breakaway oxidation. 
Table 19. First Set of Results for Breakaway Oxidation at $986 \pm 12^{\circ} \mathrm{C}$ (Figure 31) for Belt-polished $15 \times 15$ Low-tin Zry-4. The hydrogen content $\left(\mathrm{C}_{\mathrm{Hi}}\right)$ of the as-fabricated cladding is $26 \mathrm{wppm}$. The hydrogen content of the oxidized sample $\left(\mathrm{L}_{H}\right)$ was measured with the LECO Hydrogen Determinator. Breakaway-oxidation time based on 200-wppm hydrogen pickup is $\approx 5000 \mathrm{~s}$.

\begin{tabular}{|c|c|c|c|c|c|c|}
\hline \multirow[b]{2}{*}{ Test ID } & \multirow{2}{*}{$\begin{array}{c}\text { Test } \\
\text { Time, } \mathrm{s}\end{array}$} & \multicolumn{2}{|c|}{ Weight Gain, $\mathrm{mg} / \mathrm{cm}^{2}$} & \multirow{2}{*}{$\begin{array}{l}\text { H Content, } \\
\text { wppm }\end{array}$} & \multirow{2}{*}{$\begin{array}{c}\text { H Pickup, } \\
\text { wppm }\end{array}$} & \multirow{2}{*}{$\begin{array}{l}\text { Offset Strain } \\
\text { at } 135^{\circ} \mathrm{C}, \% \\
\left(\Delta \mathrm{C}_{\mathrm{H}}, \mathrm{wppm}\right)\end{array}$} \\
\hline & & $\mathrm{CP}$ & Measured & & & \\
\hline BPZ4\#16 & 135 & 2.45 & 2.85 & Low & Low & --- \\
\hline BPZ4\#15 & 1500 & 8.58 & 8.07 & Low & Low & --- \\
\hline BPZ4\#10 & 3600 & 12.7 & 10.8 & 20 & 0 & --- \\
\hline BPZ4\#18 & 5000 & 14.9 & 12.6 & 286 & 280 & $\begin{array}{c}6.0 \\
(280)\end{array}$ \\
\hline BPZ4\#13 & 5400 & 15.5 & 12.1 & 411 & 410 & $\begin{array}{c}5.9 \\
(260 \pm 180)\end{array}$ \\
\hline BPZ4\#12 & 7200 & 17.7 & 18.7 & 1798 & 1930 & --- \\
\hline
\end{tabular}

${ }^{a}$ The hydrogen pickup $\left(\Delta \mathrm{C}_{\mathrm{H}}\right)$ is referenced to the as-fabricated weight of the sample and is calculated from $\Delta \mathrm{C}_{\mathrm{H}}=\left(1+4.6 \times 10^{-3} \mathrm{Wg}\right) \mathrm{L}_{\mathrm{H}}-\mathrm{C}_{\mathrm{Hi}}$, where $\mathrm{Wg}$ is the measured weight gain.
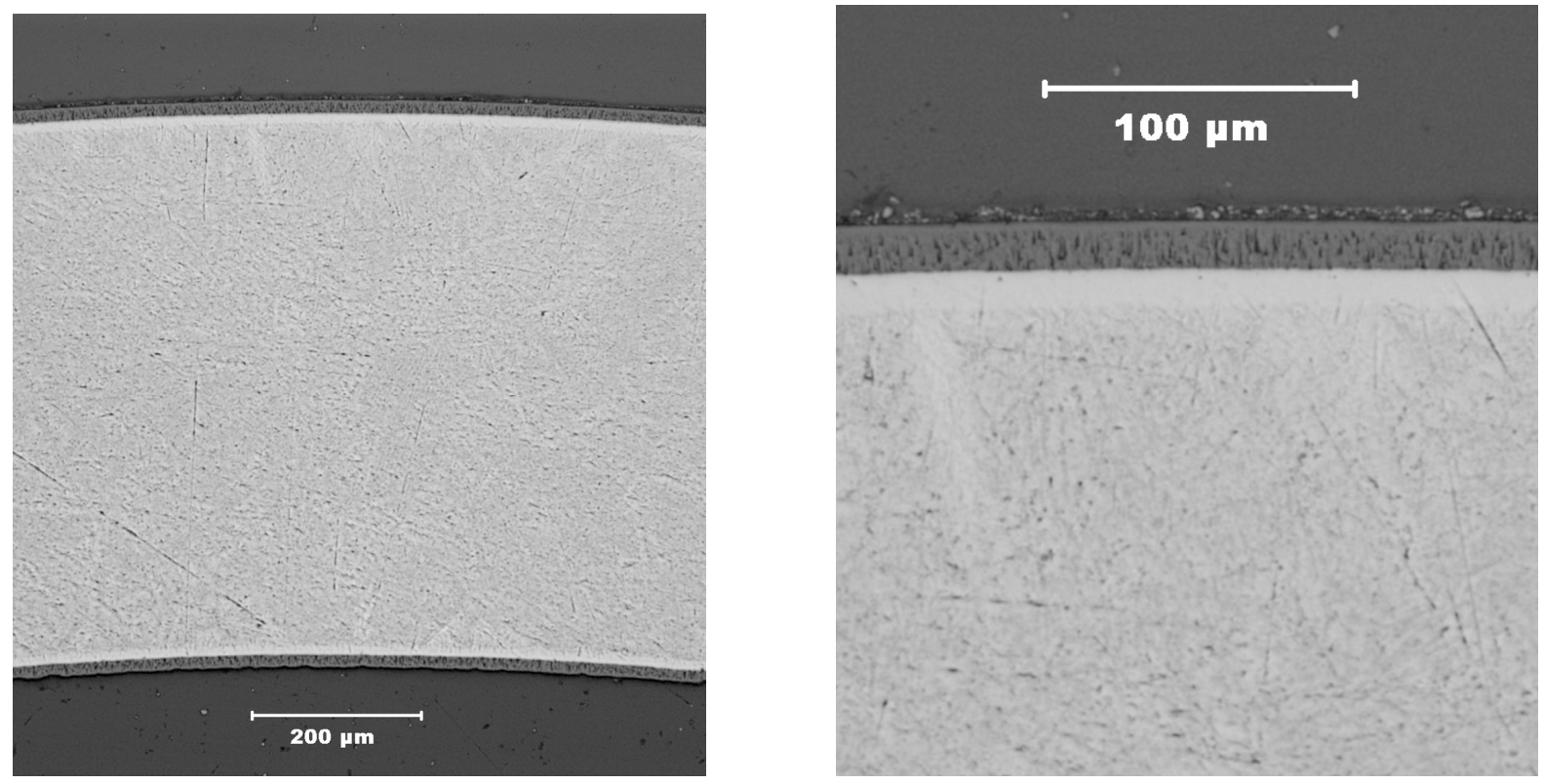

Figure 36. Low magnification (left) of inner- and outer-surface oxide layers for belt-polished $15 \times 15$ lowtin Zry-4 oxidized at $\approx 1000^{\circ} \mathrm{C}$ for $135 \mathrm{~s}$; higher magnification (right) of outer-surface oxide layer shows the smooth boundary between oxide and metal. 

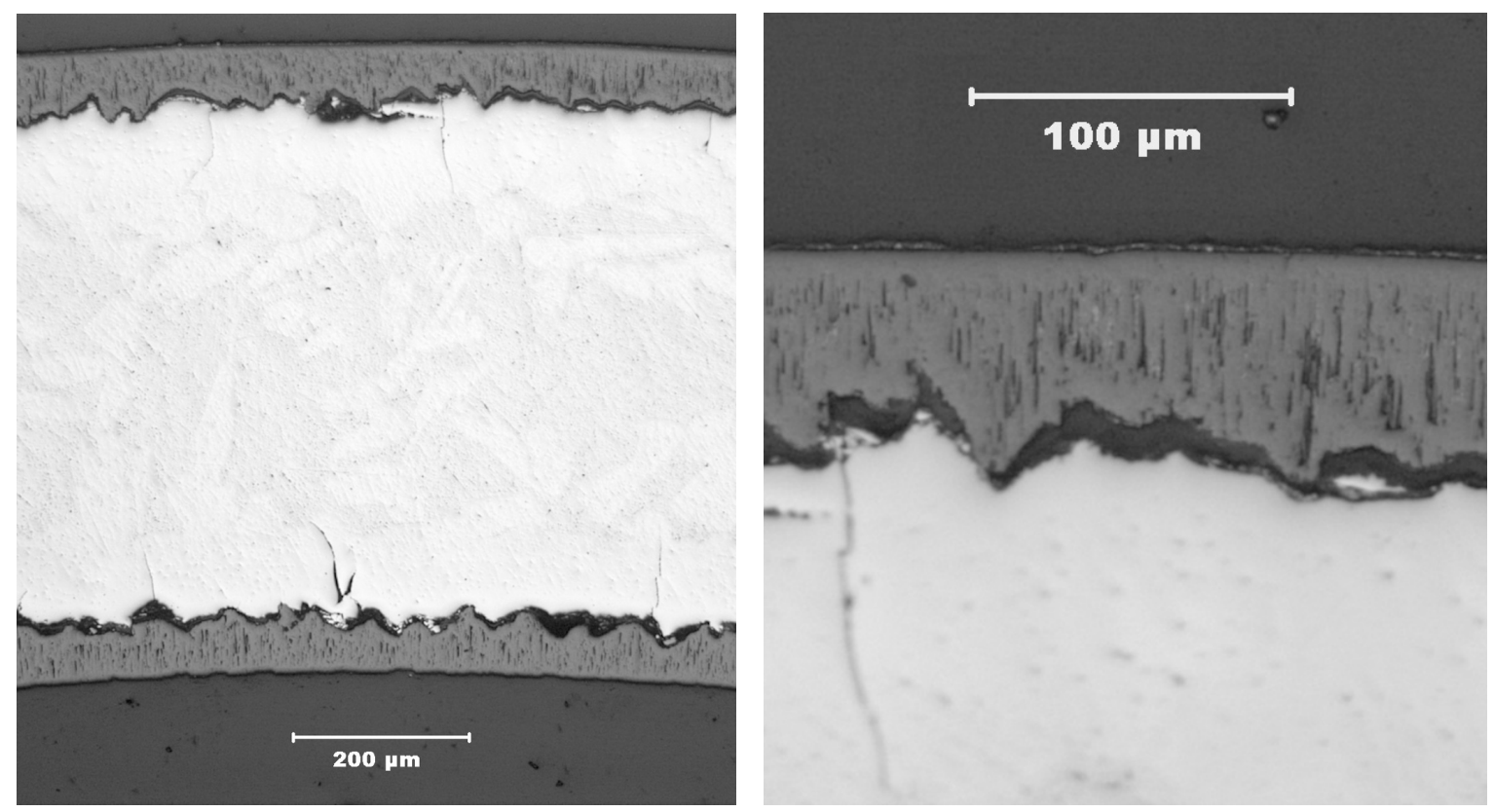

Figure 37. Low magnification (left) of inner- and outer-surface oxide layers for belt-polished $15 \times 15$ lowtin Zry-4 oxidized at $986 \pm 12^{\circ} \mathrm{C}$ for $5400 \mathrm{~s}$ (BPZ4\#13); higher magnification (right) of outer-surface oxide layer shows wavy metal-oxide interface and initiation of breakaway oxidation.

Table 20. Second Set of Results for Breakaway Oxidation of Belt-polished 15×15 Low-tin Zry-4 at Long-time Test Temperatures of $986^{\circ} \mathrm{C}$ (see Figure 32 ), $1000^{\circ} \mathrm{C}$, and $1014^{\circ} \mathrm{C}$. Hydrogen content $\left(\mathrm{C}_{\mathrm{Hi}}\right)$ of as-fabricated cladding is $26 \mathrm{wppm}$; hydrogen content of the oxidized sample $\left(\mathrm{L}_{\mathrm{H}}\right)$ was measured with the LECO Hydrogen Determinator; breakaway-oxidation time based on 200-wppm hydrogen pickup is $>5400 \mathrm{~s}$.

\begin{tabular}{|c|c|c|c|c|c|c|}
\hline & \multirow{2}{*}{ Test ID } & \multirow{2}{*}{$\begin{array}{c}\text { Test } \\
\mathrm{T},{ }^{\circ} \mathrm{C}\end{array}$} & $\begin{array}{c}\text { Test } \\
\text { Time, } \mathrm{s}\end{array}$ & $\mathrm{CP}$ & Weight Gain, mg/cm ${ }^{2}$ & \multirow{2}{*}{ H Content, } \\
\cline { 4 - 6 } wppm & $\begin{array}{c}\text { H Pickup, } \\
\text { wppm }\end{array}$ \\
\hline BPZ4\#30 & $986 \pm 12$ & 4000 & 13.1 & 11.6 & 18 & 0 \\
\hline BPZ4\#31 & $986 \pm 12$ & 4500 & 13.9 & 12.8 & 18 & 0 \\
\hline BPZ4\#33 & $986 \pm 12$ & 5000 & 14.7 & 12.2 & 18 & 0 \\
\hline BPZ4\#34 & $986 \pm 12$ & 5400 & 15.2 & 11.7 & 19 & 0 \\
\hline BPZ4\#38 & $1000 \pm 12$ & 5400 & 16.6 & 14.6 & 18 & 0 \\
\hline BPZ4\#41 & $1014 \pm 12$ & 5400 & 18.1 & 15.3 & 19 & 0 \\
\hline
\end{tabular}

${ }^{a}$ The hydrogen pickup $\left(\Delta \mathrm{C}_{\mathrm{H}}\right)$ is referenced to the as-fabricated weight of the sample and is calculated from $\Delta \mathrm{C}_{\mathrm{H}}=\left(1+4.6 \times 10^{-3} \mathrm{Wg}\right) \mathrm{L}_{\mathrm{H}}-\mathrm{C}_{\mathrm{Hi}}$, where $\mathrm{Wg}$ is the measured weight gain. 


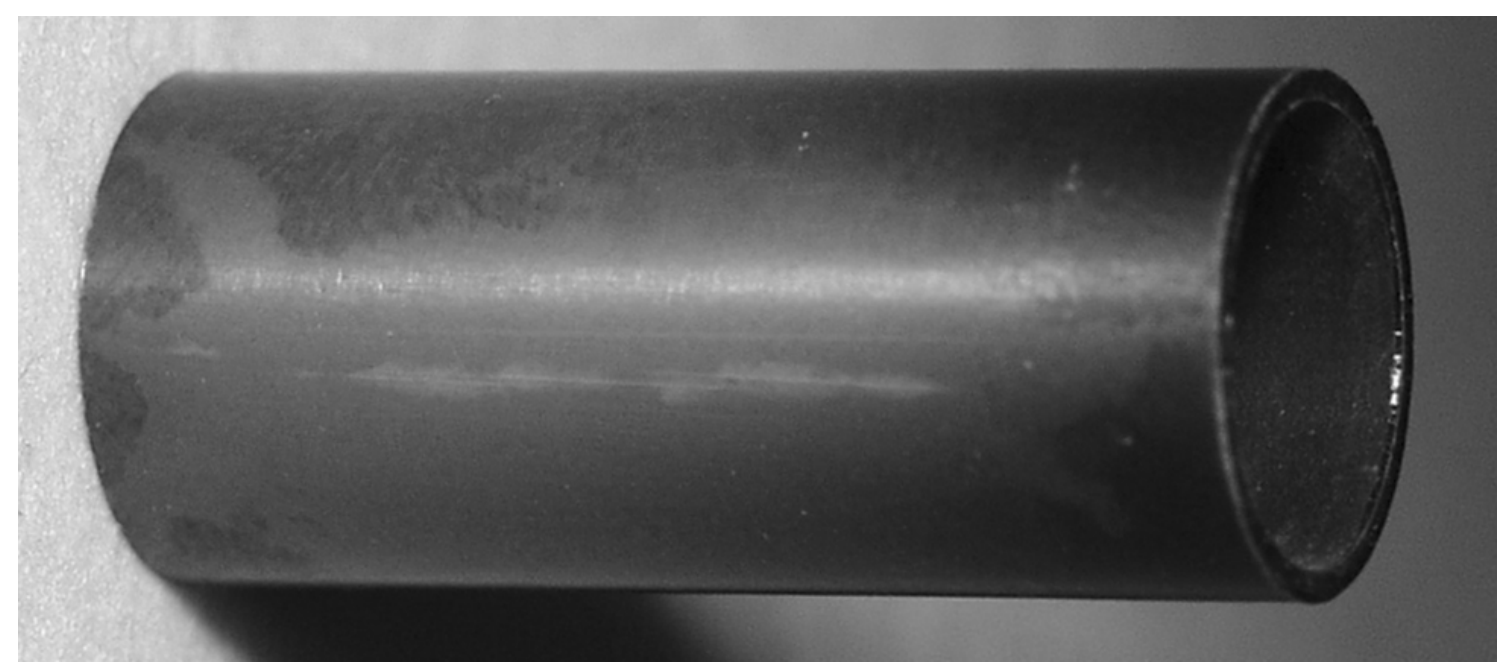

(a)

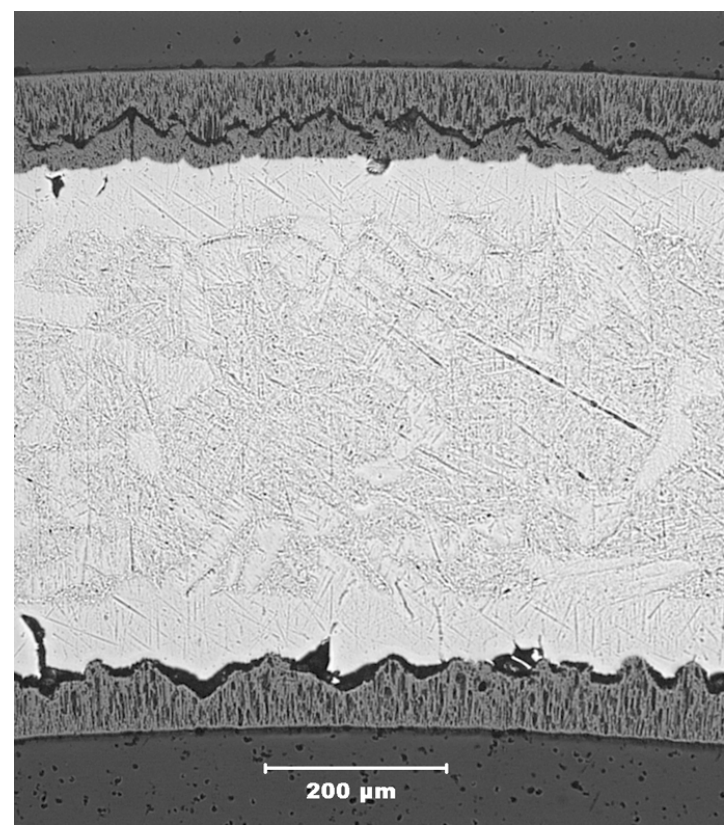

(b)

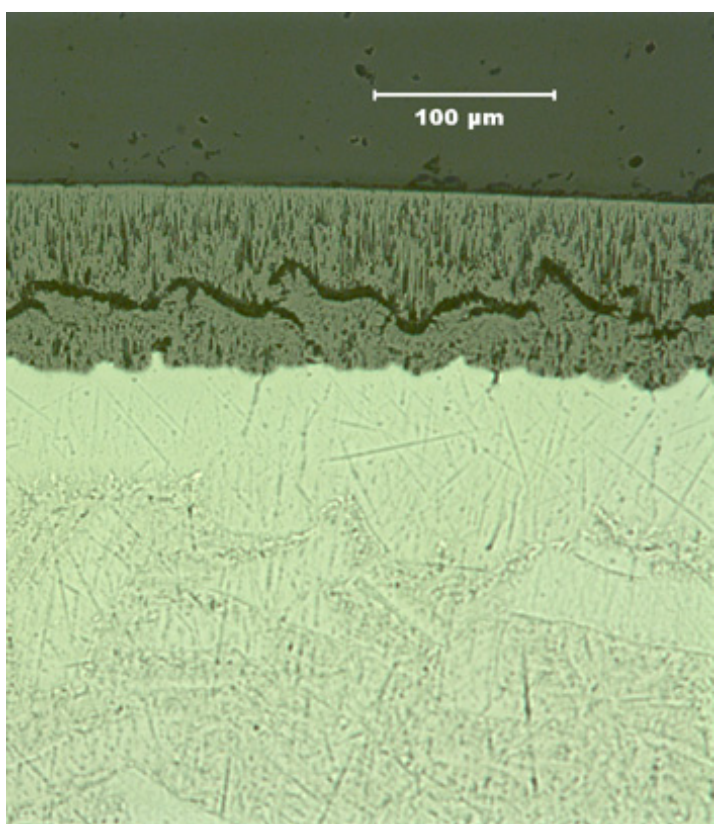

(c)

Figure 38. Images of belt-polished 15×15 sample BPZ4\#18: (a) appearance of outer surface of sample showing local breakaway along a longitudinal strip; (b) inner and outer oxide layers showing prebreakaway morphology of inner-surface oxide layer and post-breakaway morphology of outer-surface oxide layer; and (c) high magnification of outer-surface oxide layer.

The hydrogen pickup vs. oxidation time for rough-surface and belt-polished $15 \times 15$ Zry- 4 is plotted in Figure 39 based on the data in Tables 18 and 19. Both sets of results were generated by the same oxidation test train. The lower breakaway-oxidation time for the rough-surface HBR-type Zry-4 appears to be due to its higher surface roughness. However, the surface and near-surface chemistry (i.e., 


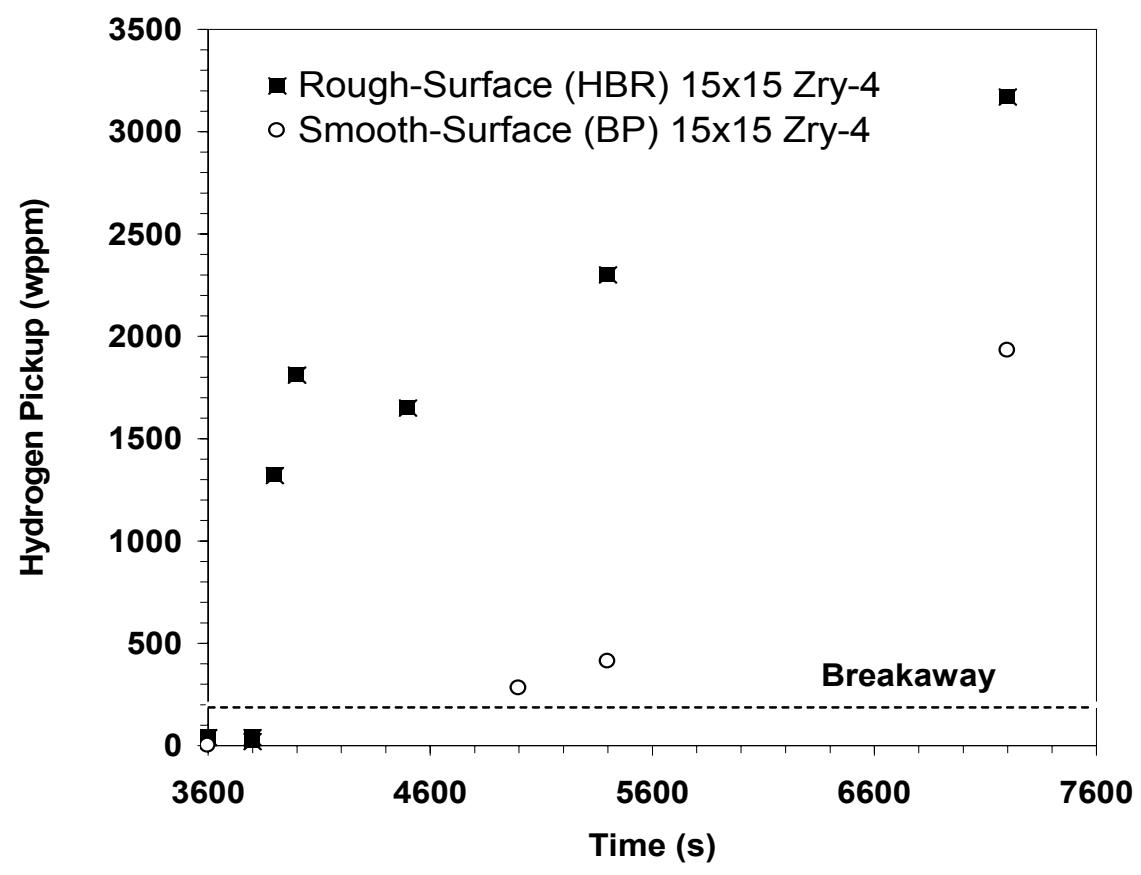

Figure 39. Breakaway-oxidation data for HBR-type (0.3- $\mu \mathrm{m}$ surface roughness) and belt-polished (0.1$\mu \mathrm{m}$ surface roughness) $15 \times 15 \mathrm{Zry}-4$ oxidized in the same apparatus at $985 \pm 12^{\circ} \mathrm{C}$. Based on the ANL 200 -wppm-hydrogen-pickup criterion, breakaway oxidation time is $\approx 3800 \mathrm{~s}$ for HBR-type $15 \times 15 \mathrm{Zry}-4$ and $\approx 5000 \mathrm{~s}$ for belt-polished (BP) $15 \times 15$ Zry-4.

impurities) and microstructure may be different for this cladding. Belt polishing removes surface impurities in the range of 0.1-0.3 $\mu \mathrm{m}$ and may result in some additional cold working of the near-surface metal. In terms of hydrogen content or hydrogen pickup, the HBR-type Zry-4 (1980s) has a much higher breakaway-oxidation time $(\approx 3800 \mathrm{~s})$ than the time $(\approx 1800 \mathrm{~s})$ determined by Leistikow and Schanz $[19,20]$ for 1970s Zry-4. The breakaway-oxidation time $(\approx 5000 \mathrm{~s})$ for modern AREVA $15 \times 15$ Zry-4 tested by ANL is comparable to the breakaway-oxidation time $(\approx 5400 \mathrm{~s})$ determined by Mardon et al. [21] for modern AREVA 17×17 Zry-4. Even though the Mardon et al. tests were one-sided with only outersurface oxidation, the ANL two-sided oxidation test results are comparable because the outer-surface oxide layer experienced breakaway oxidation earlier than the inner surface. 


\subsection{Zircaloy-2}

One-sided oxidation tests were conducted with as-fabricated and high-burnup 9×9 Zry-2 (see Tables 3 and 7 for material parameters) to determine the oxidation kinetics [15]. Tests were conducted at $1000^{\circ} \mathrm{C}(1200-6000 \mathrm{~s}), 1100^{\circ} \mathrm{C}(600-3000 \mathrm{~s})$, and $1204^{\circ} \mathrm{C}(300-1200 \mathrm{~s})$. Measured weight gain based on the increase in sample weight tended to be higher than CP-predictions due to some steam leakage causing inner-surface oxidation near the sample ends for all three oxidation temperatures. The weight-gain results based on metallographic images and analysis were in excellent agreement with the CP-predicted weight gains for the $1204^{\circ} \mathrm{C}$-oxidized samples. The measured oxide layer thicknesses were also in excellent agreement with the CP-predicted oxide layer (see page 74 of Ref. 13). However, the measured thicknesses of the oxygen-stabilized alpha layer were as much as $40 \%$ higher than the CP-predicted values. This is important in evaluating the use of the CP-correlations in deducing beta-layer thickness vs. time at temperature. In the ANL tests, the argon purge flowing through the inside of the samples minimized hydrogen pickup ( $<50 \mathrm{wppm})$ from partial inner-surface oxidation and allowed desorption of hydrogen from the beta layer to the purge. According to Cathcart et al. (Ref. 13, Appendix B, Table B1, page 166), samples oxidized (one-sided) at $1203^{\circ} \mathrm{C}$ for only $236 \mathrm{~s}$ picked up $250-450 \mathrm{wppm}$ hydrogen. Samples oxidized at lower temperatures for longer times picked up as much as 750 -wppm hydrogen. Hydrogen is a beta-stabilizer, which results in a decrease in alpha layer thickness and an increase in betalayer thickness. Figure 40 [22] shows the ANL measured (alpha + oxide)-layer thickness and the CPpredicted (alpha + oxide)-layer thickness. The higher measured values are due to the higher measured values for the alpha-layer thickness.

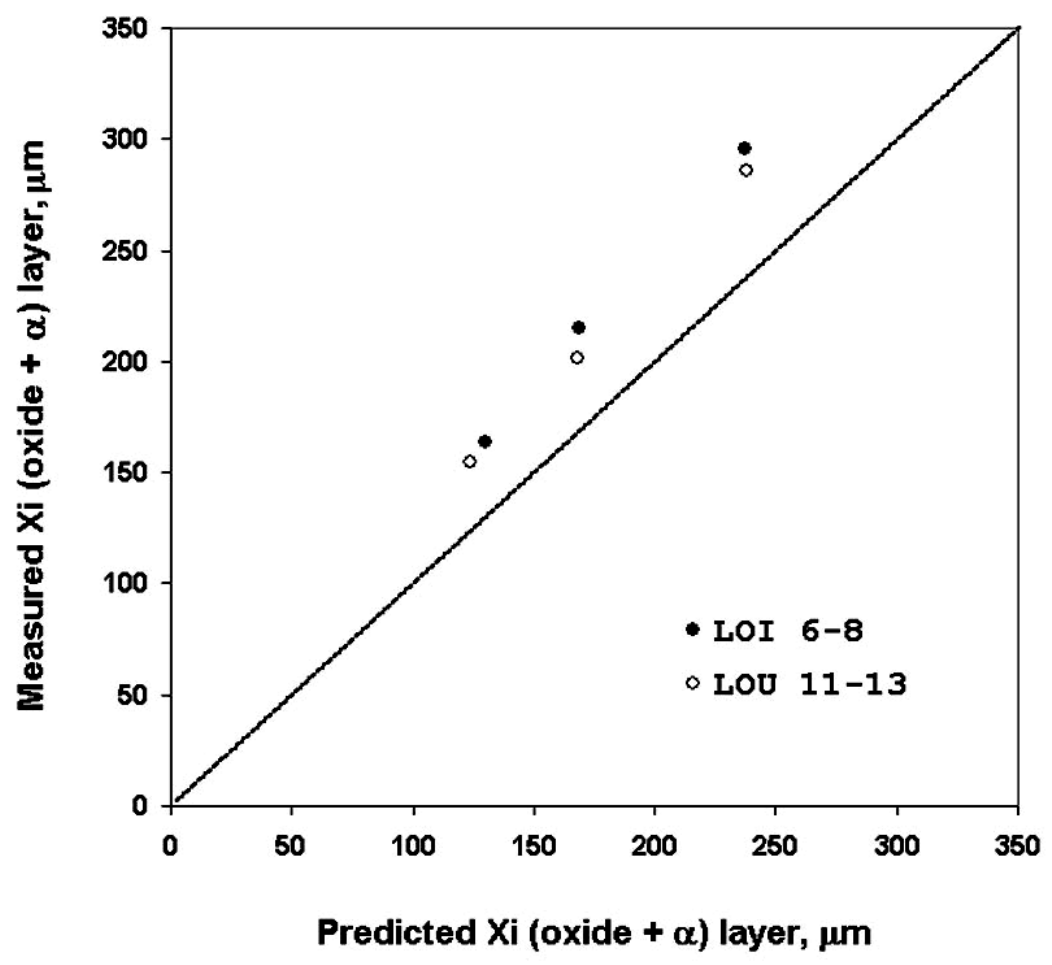

Figure 40. Measured vs. CP-model-predicted Xi (oxide + alpha) layers after steam-oxidation tests (300, 600 , and $1200 \mathrm{~s}$ at $\approx 1204^{\circ} \mathrm{C}$ ) with irradiated (LOI 6-8) and unirradiated (LOU 11-13) Zry-2. 


\title{
3.2.1 Post-quench ductility of $10 \times 10 \mathrm{Zry}-2$ oxidized at $1000^{\circ} \mathrm{C}$ and $1200^{\circ} \mathrm{C}$
}

\author{
$10 \times 10$ Zry-2 Oxidized at $1000^{\circ} \mathrm{C}$
}

$10 \times 10$ Zry-2 cladding samples were oxidized (two-sided) at $1000^{\circ} \mathrm{C}$ to $10 \%, 13 \%$, and $17 \% \mathrm{CP}$ ECR. Thermal benchmark results are shown in Figure 41. For the oxidation tests, the control TC was lowered by $5^{\circ} \mathrm{C}$ to give an average hold temperature of $1004 \pm 7^{\circ} \mathrm{C}$ up to $2000 \mathrm{~s}$ and a long-time $(\geq 2000 \mathrm{~s})$ hold temperature of $1000 \pm 8^{\circ} \mathrm{C}$. Following the heating phase, samples were cooled from $1000^{\circ} \mathrm{C}$ to $800^{\circ} \mathrm{C}$ at $\approx 10^{\circ} \mathrm{C} / \mathrm{s}$, quenched, and ring-compressed at RT. An additional test at $20.7 \% \mathrm{CP}$-ECR was performed without quench for the breakaway oxidation studies (see 3.2.2). The weight gain and post-test ductility for this sample are included in this section.

As-fabricated Zry-2 rings were compressed to 2-mm displacement and to maximum displacement. The thin-ring analytical solution for loading stiffness of a homogeneous Zry-2 wall is $1.06 \mathrm{kN} / \mathrm{mm}$. The stiffness determined from the load-displacement curve was $0.95 \mathrm{kN} / \mathrm{mm}$. The measured value is thus $\approx 10 \%$ lower than the predicted value. This difference is reasonable because the $\mathrm{Zr}$ liner may have a lower elastic modulus than Zry-2; an isotropic approximation for the elastic modulus of Zry-4 was used; and machine compliance may cause a reduction in stiffness. The difference between offset $(1.54 \mathrm{~mm})$ and permanent $(1.39 \mathrm{~mm})$ displacements was $0.15 \mathrm{~mm}$, which is consistent with other cladding alloys tested. The maximum offset strain that can be achieved with this cladding geometry is $60 \%$.

The weight gains listed in Table 21 for the $1000^{\circ} \mathrm{C}$-oxidized Zry-2 cladding are significantly lower than the CP-predicted weight gains and the measured weight gains for $17 \times 17$ Zry- 4 (see Table 8 for Zry- 4 results). Figure 42 shows the comparison. As indicated in Table 3, Zry-2 cladding has a Zr liner on the inner surface, which is about $10 \%$ of the wall thickness. Previous outer-surface oxidation tests conducted with $9 \times 9$ Zry-2 indicated excellent agreement between Zry-2 measured and predicted weight gains and oxide layer thicknesses. Quantitative metallography was performed for the Zry-2 sample used to generate the temperature history shown in Figure 41 (2000 s from ramp initiation to end of heating phase at $1000^{\circ} \mathrm{C} ; \approx 13 \% \mathrm{CP}$-ECR). The outer- and inner-surface oxide layers were $52 \pm 2 \mu \mathrm{m}$ and $31 \pm 2 \mu \mathrm{m}$, respectively. The circumferential uniformity of the oxide layer thickness indicates little temperature variation. More significantly, the decrease of $\approx 40 \%$ in the inner-surface oxide layer relative to the outersurface oxide layer and CP-predicted oxide layer thickness explains the lower-than-predicted weight gain. Figure 43 shows metallographic images of the sample oxidized to 10\% CP-ECR: (a) one of eight crosssectional arc lengths, (b) Zry-2 outer surface, and (c) the Zr-lined inner surface. The interface between the prior-beta-phase Zr-liner and Zry-2 is apparent in Figure 43c.

Ring-compression test results for the $1000^{\circ} \mathrm{C}$-oxidized Zry-2 cladding are also summarized in Table 21. The post-quench ductility of $10 \times 10 \mathrm{Zry}-2$ is higher than the ductility of $17 \times 17$ Zry-4 oxidized at $1000^{\circ} \mathrm{C}$ to $17 \%$ CP-ECR: $12 \pm 2 \%$ vs. $5.1 \%$ offset strain, respectively. Based on the $20.7 \%$ CP-ECR sample that was not quenched, Zry- 2 oxidized at $1000^{\circ} \mathrm{C}$ retains RT post-quench ductility at $>20 \% \mathrm{CP}$ ECR. Note that through-wall failure for two-sided-oxidized Zry-2 cladding rings appears as likely to initiate at the outer Zry-2 surface at $\pm 90^{\circ}$ from the loading direction as at the inner Zr surface along the loading direction. The $20.7 \%$ CP-ECR sample developed one through-wall crack at $90^{\circ}$ from the loading direction (side wall) and a second nearly-through-wall crack along the loading direction at the bottom surface. The results suggest that the oxygen-stabilized alpha layer formed within the $\mathrm{Zr}$ liner may not be as brittle as the oxygen-stabilized alpha layer formed within the Zry-2 cladding. 


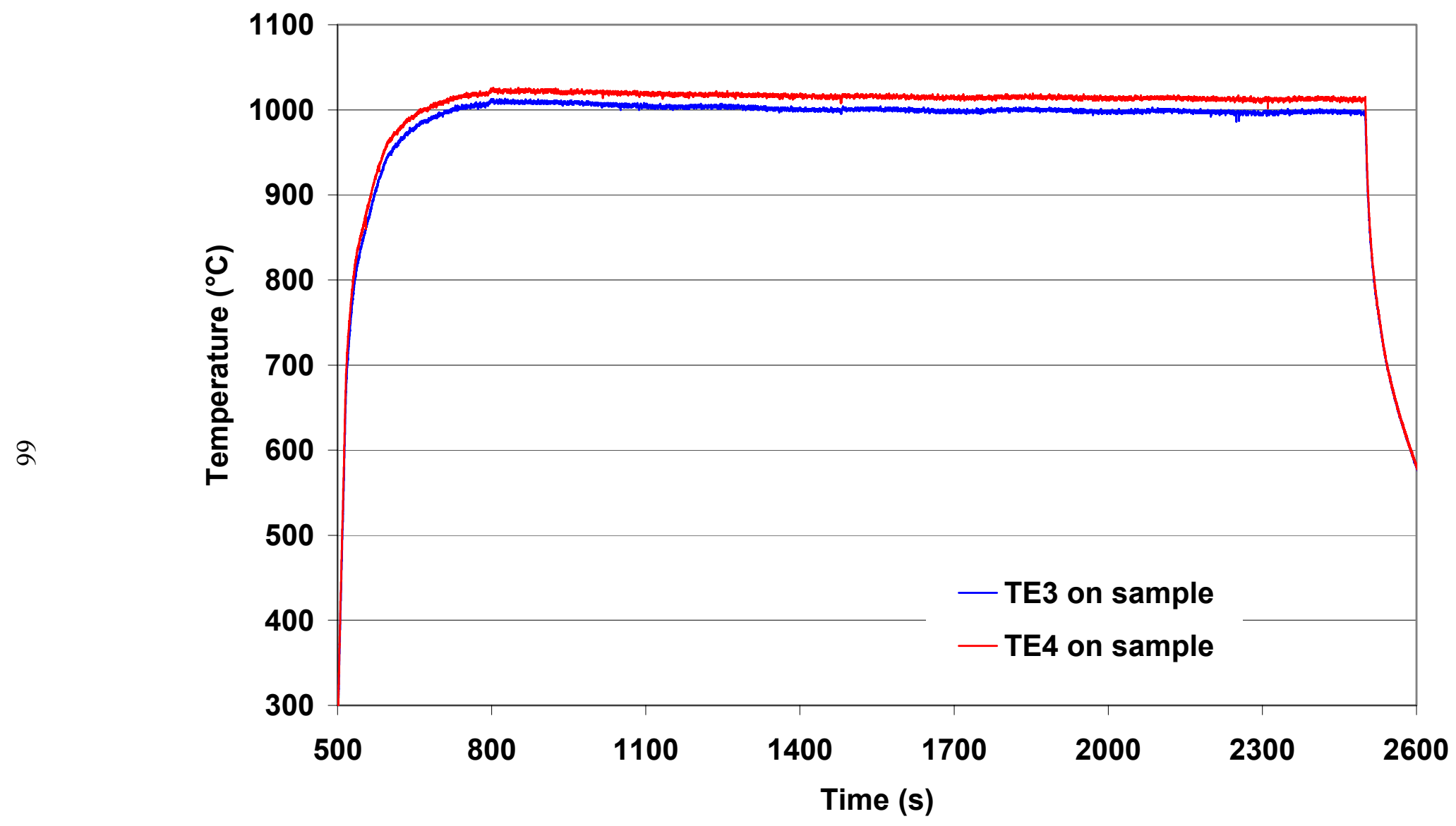

Figure 41. Thermal benchmark results for $10 \times 10 \mathrm{Zry}-2$ at $1000^{\circ} \mathrm{C}$ target temperature. Average hold temperature is $1009 \pm 7^{\circ} \mathrm{C}$. Hold temperature after $2000 \mathrm{~s}$ from ramp initiation is $1005 \pm 8^{\circ} \mathrm{C}$. For oxidation tests, the control TC was lowered by $\approx 5^{\circ} \mathrm{C}$ to give a long-time hold temperature of $1000 \pm 8^{\circ} \mathrm{C}$. 
Table 21. Ring Compression Test (RCT) Results for 10×10 Zry-2 Cladding Oxidized at $1000^{\circ} \mathrm{C}$, Cooled at $\approx 10^{\circ} \mathrm{C} / \mathrm{s}$ to $800^{\circ} \mathrm{C}$, and Quenched. ECR $=1.328 \mathrm{Wg}$ for $0.66-\mathrm{mm}$-wall cladding. Tests were performed on $\approx 8-\mathrm{mm}$-long samples at RT and $0.0333-\mathrm{mm} / \mathrm{s}$ displacement rate. Posttest displacements in the loading direction were normalized to the as-fabricated outer diameter $(10.29 \mathrm{~mm})$ to calculate strains.

\begin{tabular}{|c|c|c|c|c|c|c|c|c|}
\hline \multicolumn{3}{|c|}{$\begin{array}{c}\text { Test } \\
\text { Conditions }\end{array}$} & \multicolumn{2}{|c|}{$\begin{array}{c}\text { ECR, } \\
\%\end{array}$} & \multicolumn{2}{|c|}{$\begin{array}{c}\text { Plastic } \\
\text { Displacement, } \\
\mathrm{mm}\end{array}$} & \multicolumn{2}{|c|}{$\begin{array}{c}\text { Plastic Strain, } \\
\%\end{array}$} \\
\hline \multicolumn{2}{|c|}{$\mathrm{T},{ }^{\circ} \mathrm{C}$} & \multirow{2}{*}{$\begin{array}{c}\text { Test } \\
\text { Time, }^{\mathrm{a}} \\
\text { s }\end{array}$} & \multirow[b]{2}{*}{$\mathrm{CP}$} & \multirow[b]{2}{*}{ Meas. } & \multirow[b]{2}{*}{ Offset } & \multirow[b]{2}{*}{ Permanent } & \multirow[b]{2}{*}{ Offset } & \multirow[b]{2}{*}{ Permanent } \\
\hline Ox. & RCT & & & & & & & \\
\hline--- & $\mathrm{RT}$ & -- & 0 & 0 & 6.0 & --- & 60 & --- \\
\hline 1000 & $\mathrm{RT}$ & 1150 & 10.0 & 8.0 & $\begin{array}{l}\geq 5.1 \\
<6.6\end{array}$ & $\begin{array}{c}\geq 5.1 \\
---\end{array}$ & $\begin{array}{l}\geq 46 \\
<64\end{array}$ & $\geq 40$ \\
\hline 1000 & RT & 1930 & 13.0 & 10.4 & $\begin{array}{c}>1.16 \\
4.81\end{array}$ & $\begin{array}{c}>0.89 \\
3.46\end{array}$ & $\begin{array}{c}>11 \\
47\end{array}$ & $\begin{array}{l}>8.8 \\
34\end{array}$ \\
\hline 1000 & RT & 3420 & 17.0 & 13.6 & $\begin{array}{l}1.48 \\
0.95 \\
\end{array}$ & $\begin{array}{l}1.28 \\
0.55 \\
\end{array}$ & $\begin{array}{r}14 \\
9.2 \\
\end{array}$ & $\begin{array}{l}12 \\
5.3\end{array}$ \\
\hline $1000^{b}$ & RT & 5000 & 20.7 & 15.6 & 0.65 & $<0.5$ & 6.3 & $<5$ \\
\hline
\end{tabular}

${ }^{\mathrm{a}}$ Includes time for ramp from $300^{\circ} \mathrm{C}$ and hold time.

${ }^{\mathrm{b}}$ Breakaway oxidation test conducted with cooling from $1000^{\circ} \mathrm{C}$ to RT without quench.

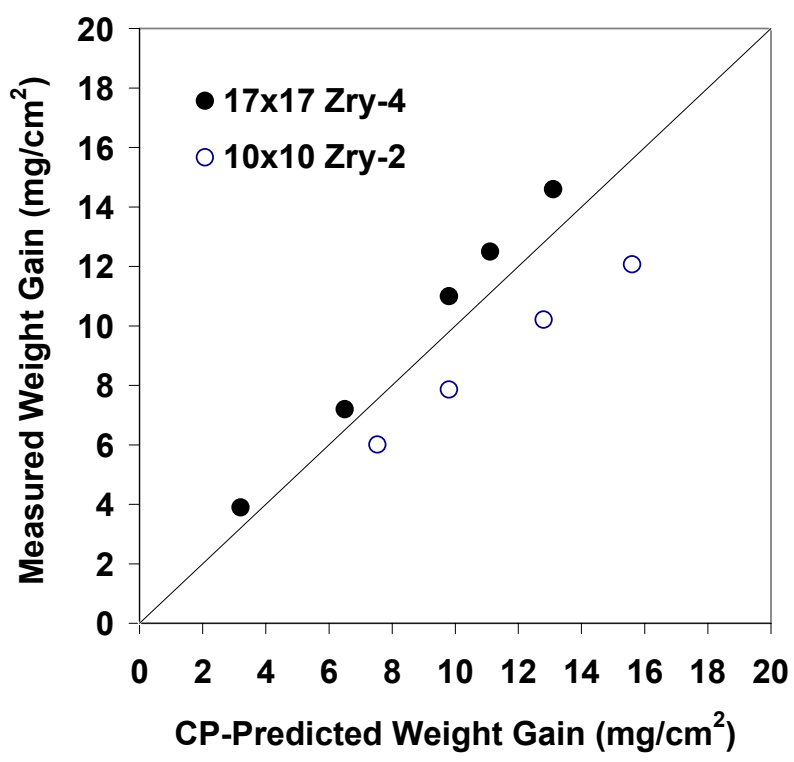

Figure 42. Comparison of measured and CP-predicted weight gains for Zr-lined 10x10 Zry-2 and 17x17 Zry-4 oxidized at $1000^{\circ} \mathrm{C}$. 


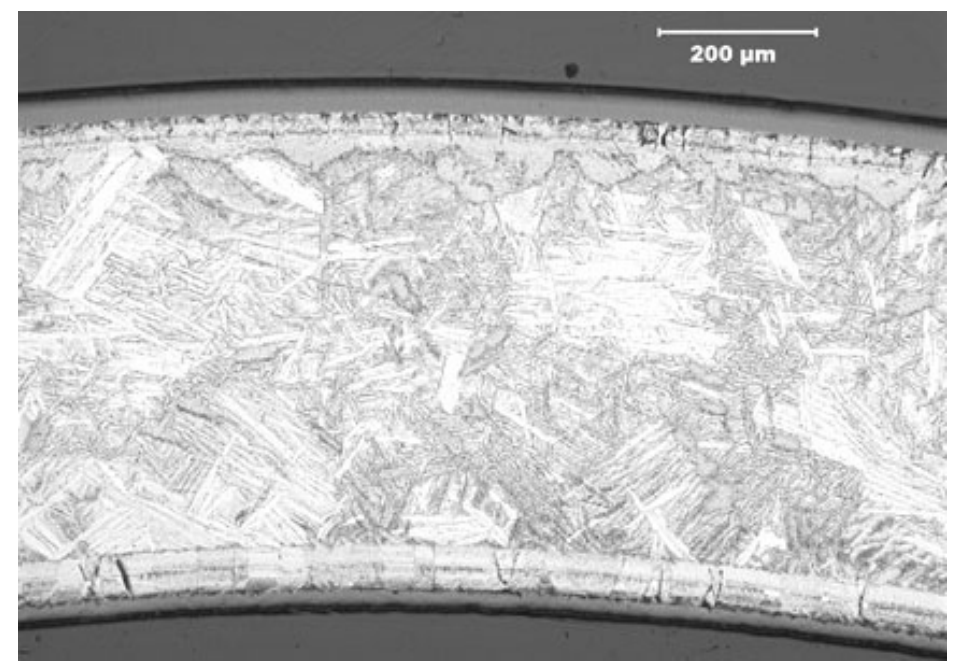

(a) Cross section

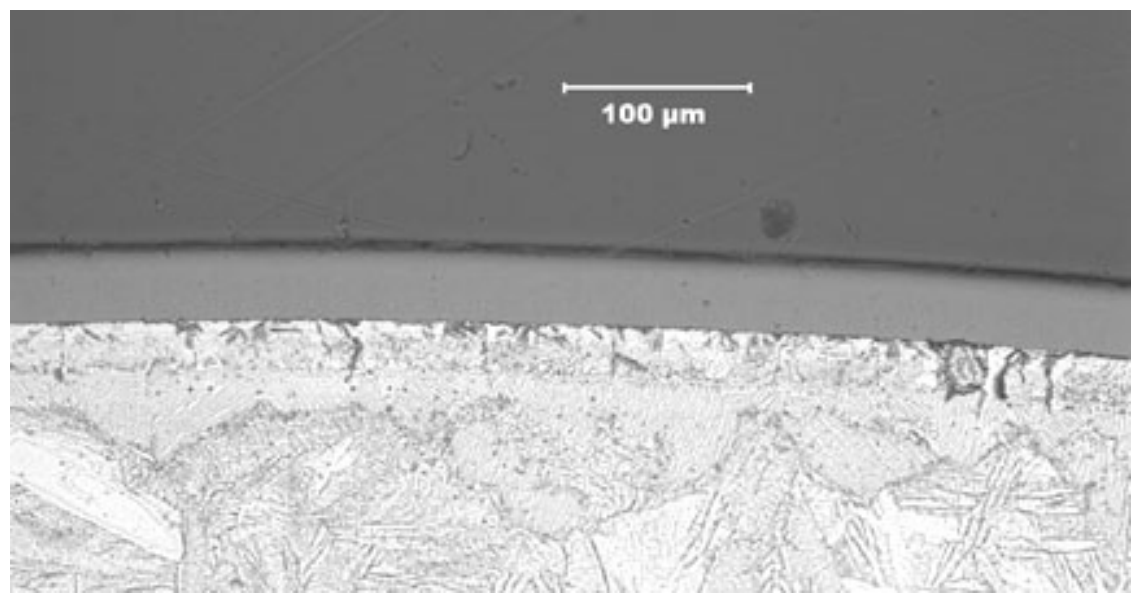

(b) Outer Zry-2 surface

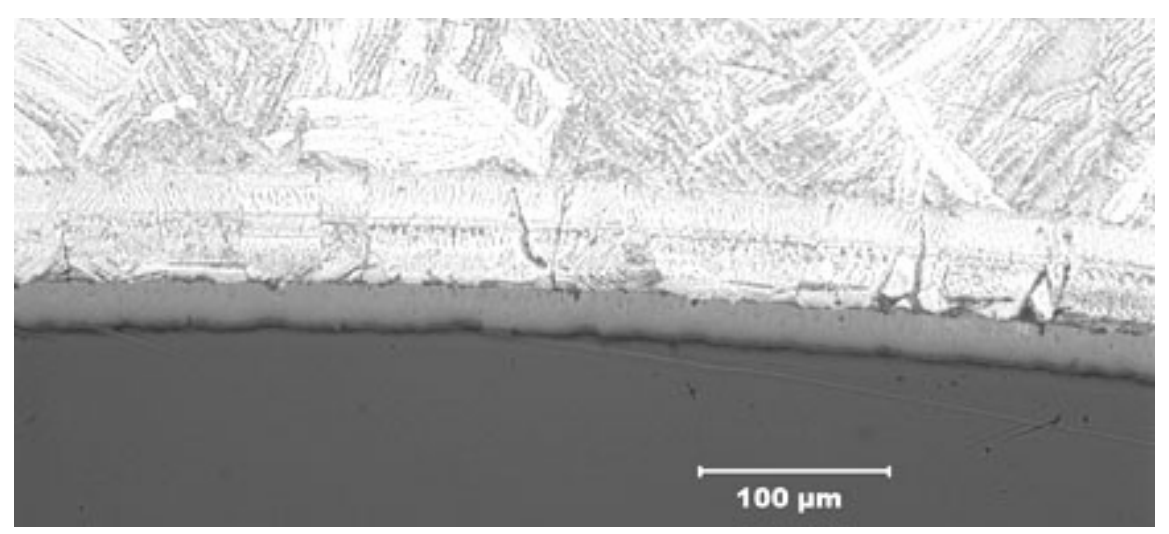

(c) Inner Zr-lined surface

Figure 43. Micrographs of $10 \times 10 \mathrm{Zry}-2$ sample oxidized at $1000^{\circ} \mathrm{C}$ to $10 \% \mathrm{CP}$-ECR: (a) one of eight cross-sectional arc lengths, (b) outer Zry-2 surface, and (c) inner Zr-liner surface. 
$10 \times 10$ Zry-2 cladding samples were oxidized (two-sided) at $1200^{\circ} \mathrm{C}$ to $10 \%, 13 \%, 17 \%$, and $20 \%$ CP-ECR. Thermal benchmark results are shown in Figure 44. Following the heating phase, samples were cooled from $1200^{\circ} \mathrm{C}$ to $800^{\circ} \mathrm{C}$ at $\approx 13^{\circ} \mathrm{C} / \mathrm{s}$, quenched, and ring-compressed at $135^{\circ} \mathrm{C}$.

As-fabricated Zry-2 rings were compressed at $135^{\circ} \mathrm{C}$ to $2 \mathrm{~mm}$ and to maximum displacement. The thin-ring analytical solution at $135^{\circ} \mathrm{C}$ for loading stiffness of a homogeneous Zry-2 wall is $0.98 \mathrm{kN} / \mathrm{mm}$. The stiffness determined from the load-displacement curve was $0.81 \mathrm{kN} / \mathrm{mm}$. The results suggest that the elastic modulus of the Zry-2/Zr composite may decrease more than the predicted $7.5 \%$ decrease for Zry-4 from RT to $135^{\circ} \mathrm{C}$. The difference between offset $(1.65 \mathrm{~mm})$ and permanent $(1.52 \mathrm{~mm})$ displacements was $0.13 \mathrm{~mm}$, which is consistent with the RT results. The maximum offset strain that can be achieved with this cladding geometry and the thermocouple on the inner surface of the cladding is $50 \%$.

The weight gains listed in Table 22 for the $1200^{\circ} \mathrm{C}$-oxidized $\mathrm{Zry}-2$ cladding are in good agreement with the CP-predicted weight gains and the measured weight gains for $17 \times 17$ Zry-4 (see Table 11 for Zry4 results). Figure 45 shows the comparison. Although the measured weight gains are in good agreement, the oxide layer on the $\mathrm{Zr}$ liner is $\approx 15 \%$ thinner than the oxide layer on the Zry-2 outer surface.

Quantitative metallography was performed on the Zry-2 cladding sample exposed to the temperature history shown in Figure $44(\approx 17 \%$ CP-ECR). The measured outer- and inner-surface oxide layers were $62 \pm 2 \mu \mathrm{m}$ and $53 \pm 2 \mu \mathrm{m}$, respectively. As with the $1000^{\circ} \mathrm{C}$-oxidized sample, the small circumferential variation in oxide thicknesses indicates good temperature uniformity. Micrographic images in Figures 46 (at $170 \mathrm{~s}$ and 10\% CP-ECR) and 47 (at $423 \mathrm{~s}$ and 17\% CP-ECR) show the differences in oxide layer thicknesses. Also, the oxygen-stabilized alpha layers, which are predicted to be about the same thickness as the oxide layers, are significantly thicker than predicted for both surfaces. Based on the results in Figures $46 \mathrm{c}$ and $47 \mathrm{c}$, the $\mathrm{Zr}$ liner $(\approx 66-\mu \mathrm{m}$ thick) has been consumed by oxidation and transformation to oxygen-stabilized alpha for $\geq 10 \% \mathrm{CP}$-ECR $\left(\geq 170\right.$-s test time) at $1200^{\circ} \mathrm{C}$.

Ring-compression test results for $1200^{\circ} \mathrm{C}$-oxidized Zry-2 cladding rings are also summarized in Table 22. The transition CP-ECR is $\approx 19 \%$ based on interpolation. Although the transition value falls within the range measured for two types of Zry-4, the decrease in ductility with increasing CP-ECR for Zry-2 is clearly more gradual than the trend curves for Zry-4. Comparison of the Zry-2 and Zry-4 postquench-ductility results is shown in Figure 48. This gradual decrease in ductility with CP-ECR may be due to the presence of the liner. For homogeneous Zry-4, the growth of the brittle oxide- and oxygenstabilized-alpha layers is expected to be the same at the inner and outer surfaces. Also, the rate of oxygen diffusion into the beta layer is expected to be the same from the outer and inner surfaces of the beta layer. As such, through-wall failure of the compressed ring should initiate at the cladding inner surface under the loading plate or above the support plate. For $1200^{\circ} \mathrm{C}$-oxidized Zry- 2 cladding at $10 \%$ and $13 \% \mathrm{CP}-$ ECR, through-wall failure was observed at the side of the sample, $90^{\circ}$ from the loading direction. At the side locations, the maximum tensile bending stress is located at the cladding outer surface. The $17 \% \mathrm{CP}-$ ECR samples failed with multiple through-wall cracks: top, $45^{\circ}$, and side for one sample; and bottom and $45^{\circ}$ for the second sample. The $20 \%$ CP-ECR samples failed in the traditional manner with a single through-wall crack at either the top or bottom of the ring.

Chung and Kassner [18] measured the oxygen content (2.5 wt.\%) needed to stabilize alpha in Zry-4 at $1200^{\circ} \mathrm{C}$. They also reviewed previous studies of zirconium, for which $2.1-2.2 \mathrm{wt} . \%$ oxygen is sufficient to stabilize alpha in $\mathrm{Zr}$ at $1200^{\circ} \mathrm{C}$. Based on these studies and on the ring compression results, the Zry-2 oxygen-stabilized alpha layer appears to be more brittle than the Zr-liner alpha layer, although both layers would be classified as brittle. 


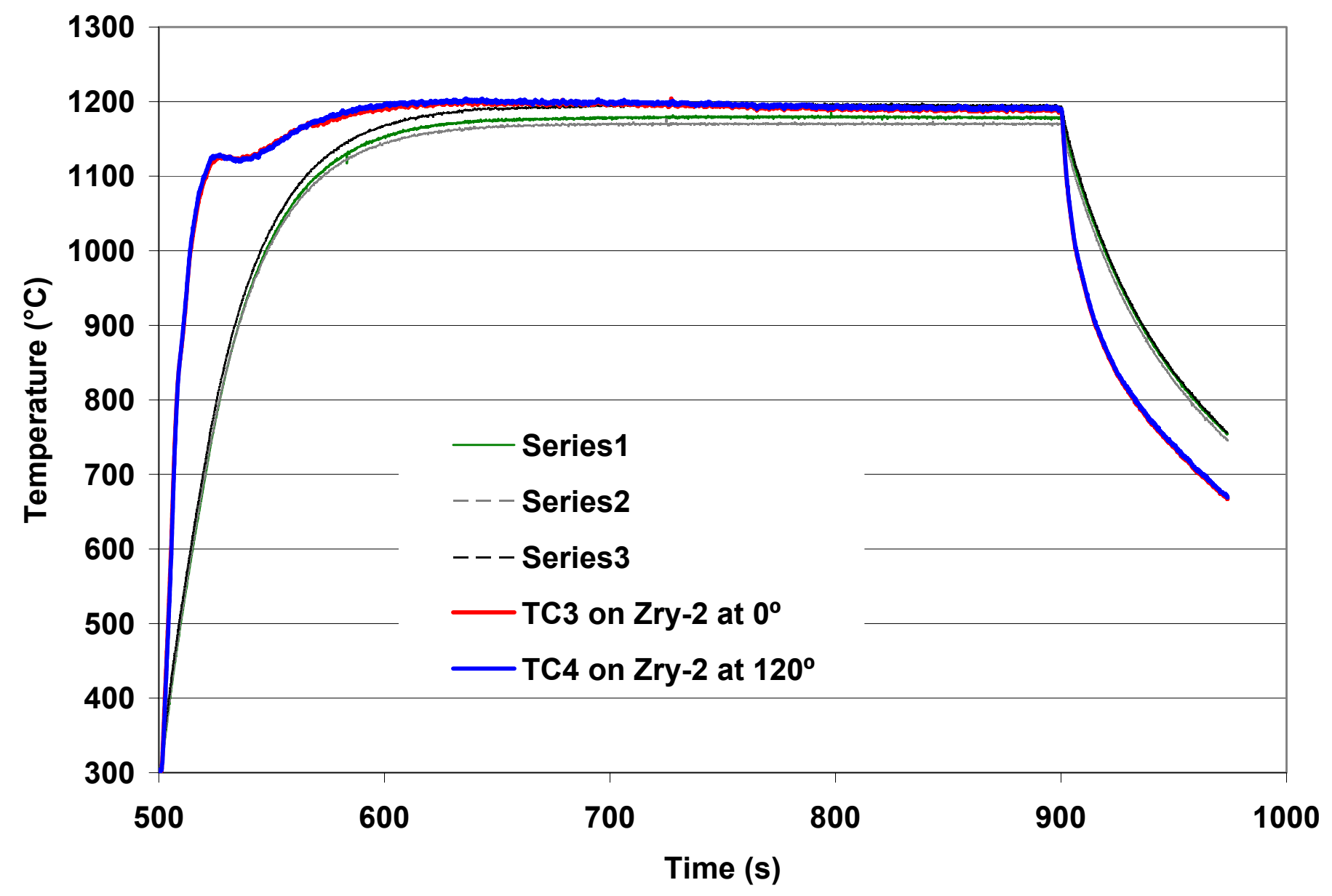

Figure 44. Thermal benchmark results for $10 \times 10 \mathrm{Zry}-2$ oxidation tests at $1200 \pm 6^{\circ} \mathrm{C}$. The raw data for the sample TC readings were corrected based on calibrating these TCs to an ANL NIST-calibrated TC. Also shown are the three TC readings for the holder TCs (Series 1-3). 
Table 22. Ring Compression Test (RCT) Results for $10 \times 10$ Zry-2 Cladding Oxidized at $1200^{\circ} \mathrm{C}$, Cooled at $\approx 13^{\circ} \mathrm{C} / \mathrm{s}$ to $800^{\circ} \mathrm{C}$, and Quenched. ECR $=1.328 \mathrm{Wg}$ for $0.66-\mathrm{mm}$ wall cladding. Tests were performed on $\approx 8-\mathrm{mm}$-long samples at $135^{\circ} \mathrm{C}$ and $0.0333-\mathrm{mm} / \mathrm{s}$ displacement rate. Displacements in the loading direction were normalized to the as-fabricated outer diameter $(10.29 \mathrm{~mm})$ to calculate strains.

\begin{tabular}{|c|c|c|c|c|c|c|c|c|}
\hline \multicolumn{3}{|c|}{$\begin{array}{c}\text { Test } \\
\text { Conditions }\end{array}$} & \multicolumn{2}{|c|}{$\begin{array}{c}\text { ECR, } \\
\%\end{array}$} & \multicolumn{2}{|c|}{$\begin{array}{c}\text { Plastic } \\
\text { Displacement, } \mathrm{mm}\end{array}$} & \multicolumn{2}{|c|}{$\begin{array}{l}\text { Plastic } \\
\text { Strain, \% }\end{array}$} \\
\hline \multicolumn{2}{|c|}{$\mathrm{T},{ }^{\circ} \mathrm{C}$} & \multirow{2}{*}{$\begin{array}{c}\text { Test } \\
\text { Time, } \\
\text { s }\end{array}$} & \multirow[b]{2}{*}{$\mathrm{CP}$} & \multirow[b]{2}{*}{ Meas. } & \multirow[b]{2}{*}{ Offset } & \multirow[b]{2}{*}{ Permanent } & \multirow[b]{2}{*}{ Offset } & \multirow[b]{2}{*}{ Permanent } \\
\hline Ox. & $\mathrm{RCT}$ & & & & & & & \\
\hline--- & 135 & --- & 0 & 0 & 5.11 & 5.18 & 50 & 50 \\
\hline 1200 & 135 & 170 & 10.0 & 10.8 & $\begin{array}{l}2.48 \\
2.60\end{array}$ & $\begin{array}{l}2.12 \\
2.27\end{array}$ & $\begin{array}{l}24 \\
25\end{array}$ & $\begin{array}{l}21 \\
22\end{array}$ \\
\hline 1200 & 135 & 260 & 13.0 & 13.7 & $\begin{array}{l}1.12 \\
1.44 \\
\end{array}$ & $\begin{array}{l}--- \\
1.34\end{array}$ & $\begin{array}{l}11 \\
14\end{array}$ & --- \\
\hline 1200 & 135 & 423 & 17.0 & 17.1 & $\begin{array}{l}0.75 \\
0.56\end{array}$ & $\begin{array}{l}-- \\
0.29\end{array}$ & $\begin{array}{l}7.3 \\
5.4 \\
\end{array}$ & --- \\
\hline 1200 & 135 & 575 & 20.0 & 19.9 & $\begin{array}{l}0.19 \\
0.15\end{array}$ & $\begin{array}{l}0.09 \\
0.10\end{array}$ & $\begin{array}{l}1.9 \\
1.5\end{array}$ & $\begin{array}{l}0.9 \\
1.0\end{array}$ \\
\hline
\end{tabular}

${ }^{\mathrm{a}}$ Includes time for ramp from $300^{\circ} \mathrm{C}$ and hold time.

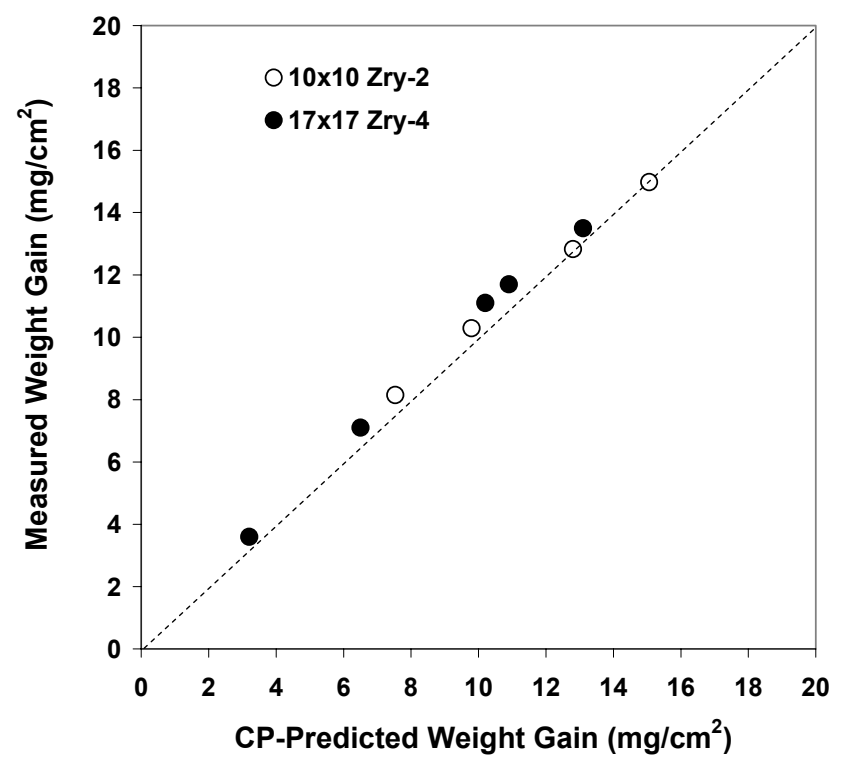

Figure 45. Comparison of measured and CP-predicted weight gains for 10x10 Zry-2 and $17 \times 17$ Zry-4 oxidized at $1200^{\circ} \mathrm{C}$, cooled at $\approx 13^{\circ} \mathrm{C} / \mathrm{s}$ to $800^{\circ} \mathrm{C}$, and quenched at $800^{\circ} \mathrm{C}$. 


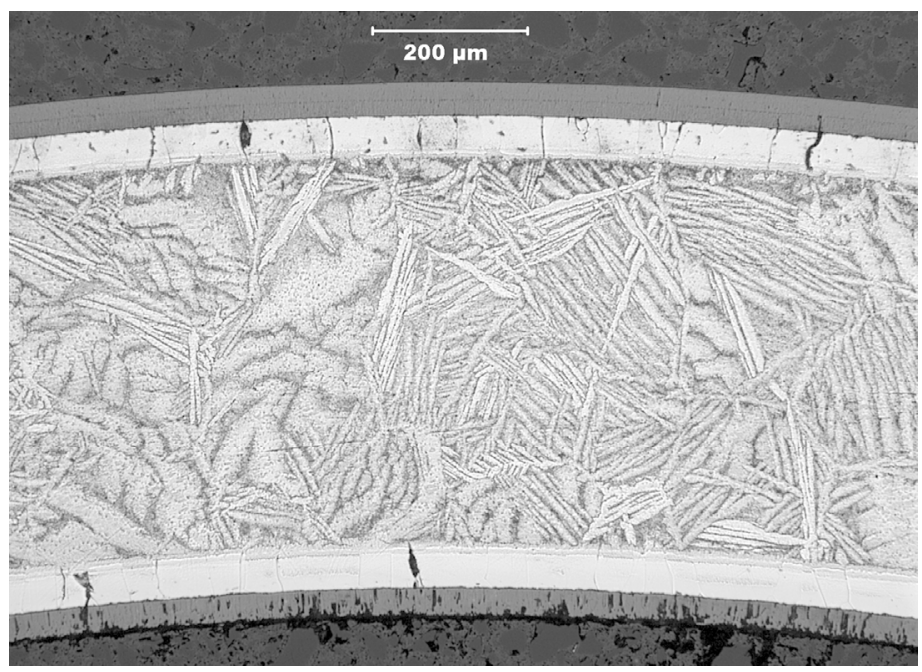

(a) Cross section

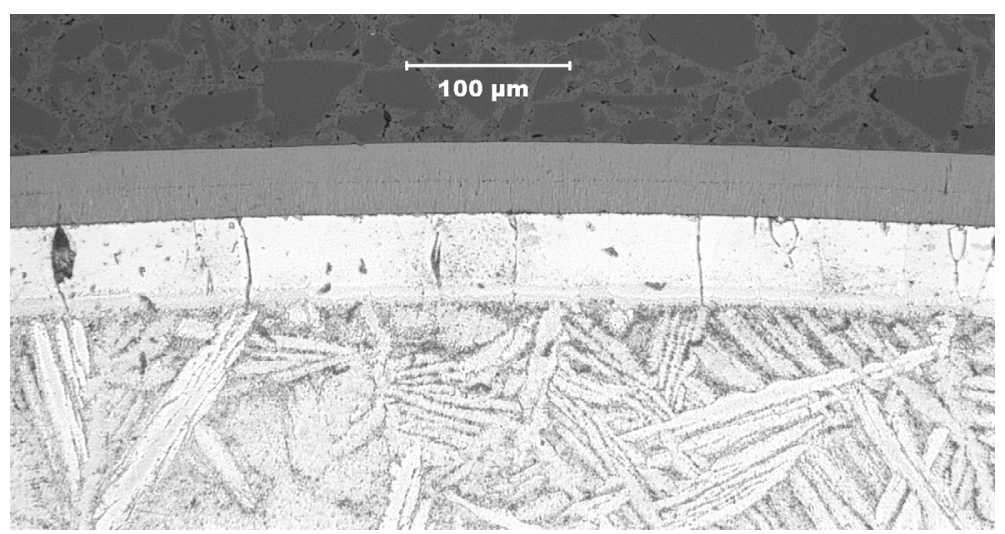

(b) Outer Zry-2 surface

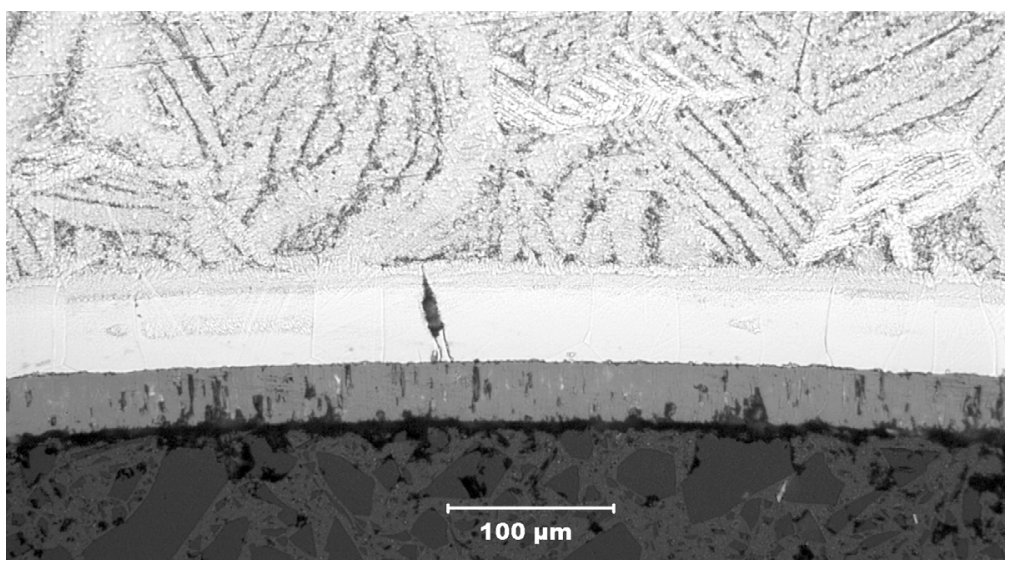

(c) Inner Zr-lined surface

Figure 46. Metallographic images of $10 \times 10 \mathrm{Zry}-2$ sample oxidized at $1200^{\circ} \mathrm{C}$ to $10 \% \mathrm{CP}$-ECR: (a) cross section (one of 8 orientations), (b) outer Zry-2 surface, and (c) inner Zr-lined surface. 


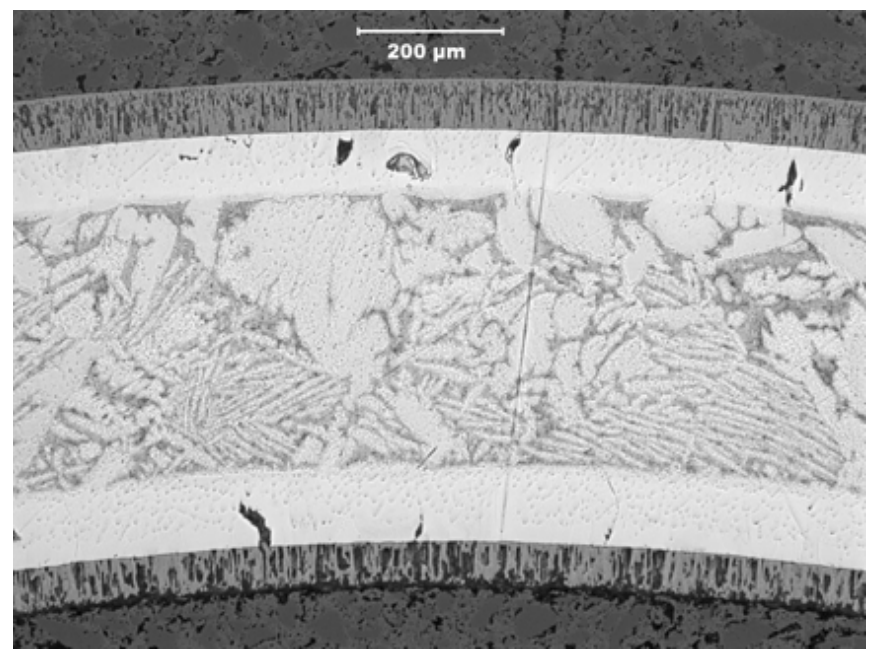

(a)

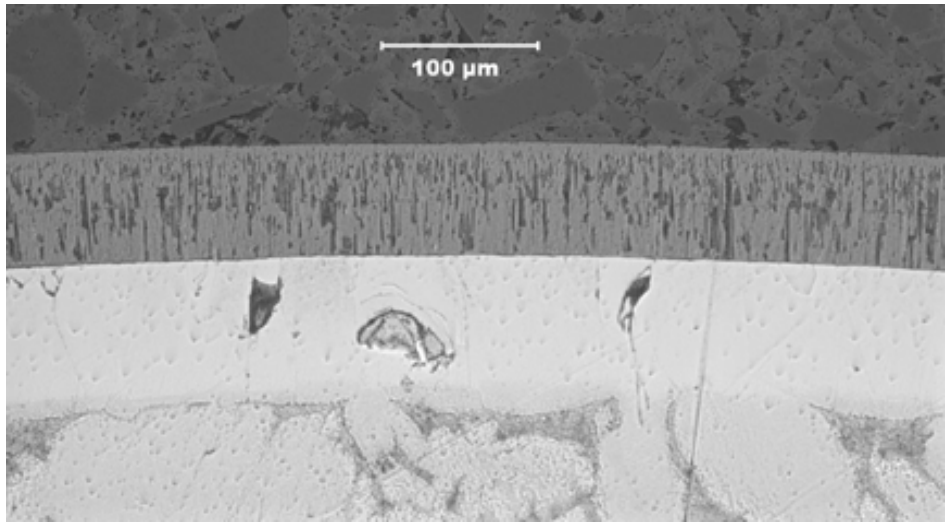

(b) Outer Zry-2 surface

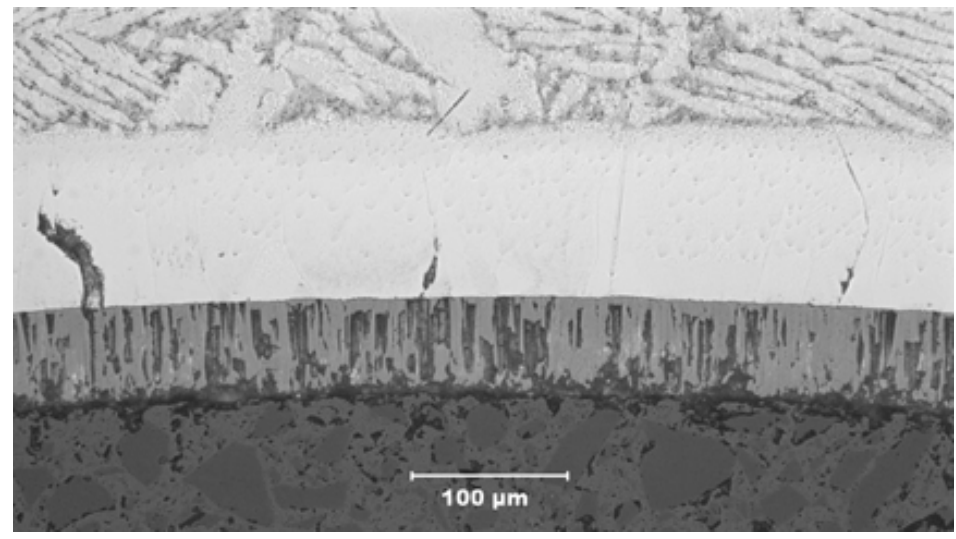

(c) Inner Zr-lined surface

Figure 47. Metallographic images of $10 \times 10$ Zry-2 sample oxidized at $1200^{\circ} \mathrm{C}$ to $17 \% \mathrm{CP}$-ECR: (a) cross section -- one of 8 orientations, (b) outer Zry-2 surface, and (c) inner Zr-lined surface. 


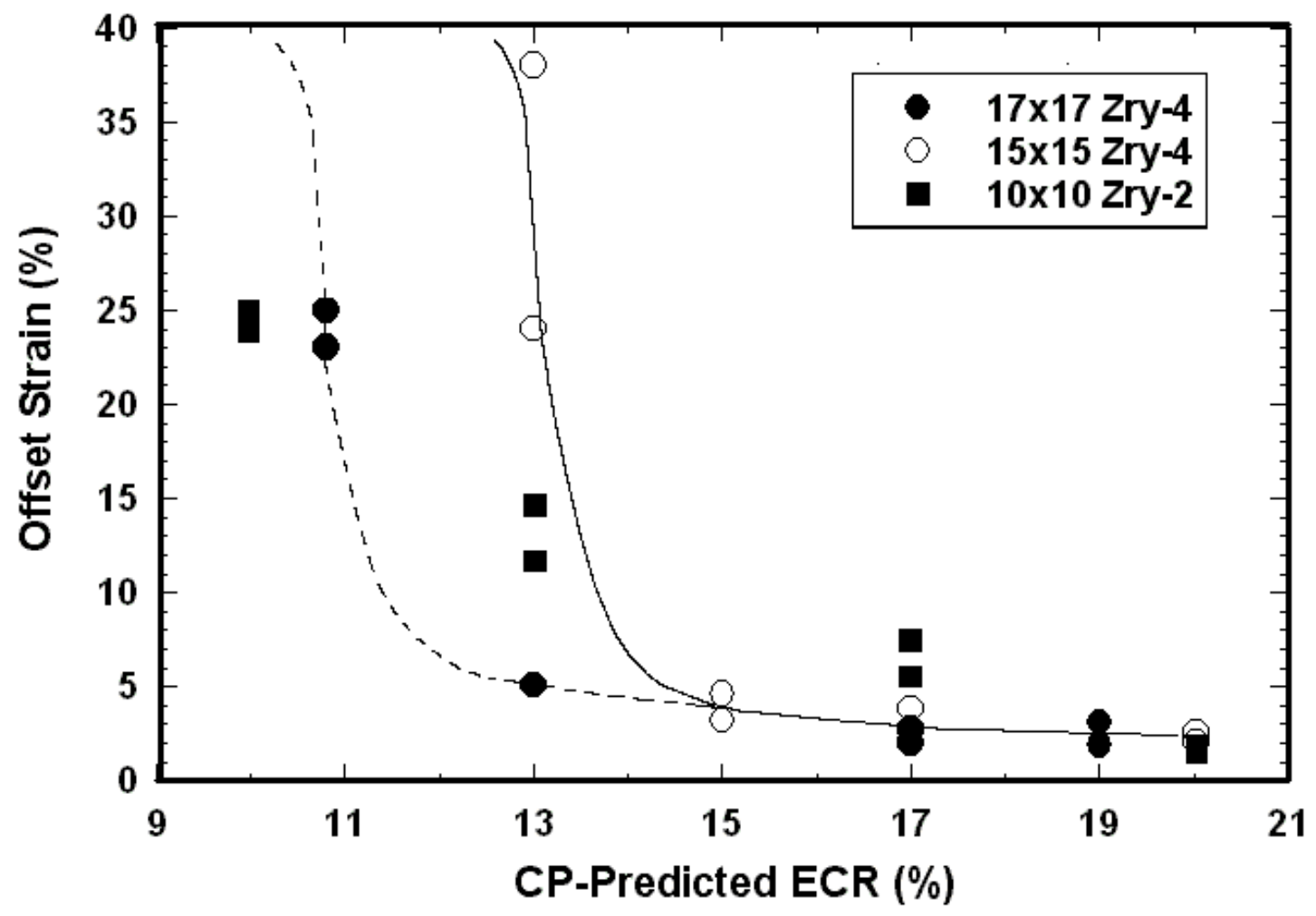

Figure 48. Post-quench ductility (offset strain) vs. CP-ECR for Westinghouse $17 \times 17$ Zry-4, AREVA $15 \times 15 \mathrm{Zry}-4$, and GNF $10 \times 10 \mathrm{Zr}$-lined Zry-2, all oxidized at $1200^{\circ} \mathrm{C}$, cooled at $\approx 11-13^{\circ} \mathrm{C} / \mathrm{s}$ to $800^{\circ} \mathrm{C}$, and quenched at $800^{\circ} \mathrm{C}$. Ring-compression test temperature was $135^{\circ} \mathrm{C}$.

\subsubsection{Breakaway oxidation time for $10 \times 10 \mathrm{Zry}-2$ samples oxidized at $970-1000^{\circ} \mathrm{C}$}

The breakaway oxidation time for $10 \times 10$ Zry-2 is expected to be about the same as the breakaway time for $9 \times 9$ Zry-2. One-sided oxidation tests using as-fabricated and high-burnup $9 \times 9$ Zry- 2 were conducted at $1000^{\circ} \mathrm{C}$ for hold times of $1200 \mathrm{~s}, 3600 \mathrm{~s}$, and $6000 \mathrm{~s}$. Although metallographic analysis of these samples was not conducted, sample weight gains were measured for the high-burnup samples. The results from Yan et al. [22] are presented in Figure 49. Even with the artifact of some inner-surface oxidation contributing to the measured weight gain, the 3600-s sample showed no evidence of breakaway oxidation. The 6000 -s sample had a weight gain $25 \%$ higher than the CP-predicted weight gain. At least $10 \%$ of this can be attributed to inner-surface oxidation near the ends of the sample. The remaining $15 \%$ may be a combination of breakaway oxidation and/or additional inner-surface oxidation for such a long test time. Based on the belt-polished $15 \times 15$ Zry- 4 results, the breakaway oxidation time is expected to be $\approx 5000 \mathrm{~s}$ for belt-polished $10 \times 10$ and $9 \times 9$ Zry-2.

Two-sided breakaway oxidation tests were conducted with $10 \times 10$ Zry-2 cladding samples. Tests were run for $5000 \mathrm{~s}$ at long-time hold temperature of $1000^{\circ} \pm 8^{\circ} \mathrm{C}$ (see Figure 41 ). Samples were cooled to RT without quench. The tests were repeated by lowering the control temperature by $15^{\circ} \mathrm{C}, 30^{\circ} \mathrm{C}$, and $200^{\circ} \mathrm{C}$ to give target temperatures of $985^{\circ} \mathrm{C}$ and $970^{\circ} \mathrm{C}$. The test matrix is given in Table 23, along with the results for weight gain, hydrogen content, and calculated hydrogen pickup. Within the temperature range of $\approx 960-1010^{\circ} \mathrm{C}$, the breakaway oxidation time for Zry-2 cladding is $>5000 \mathrm{~s}$. 


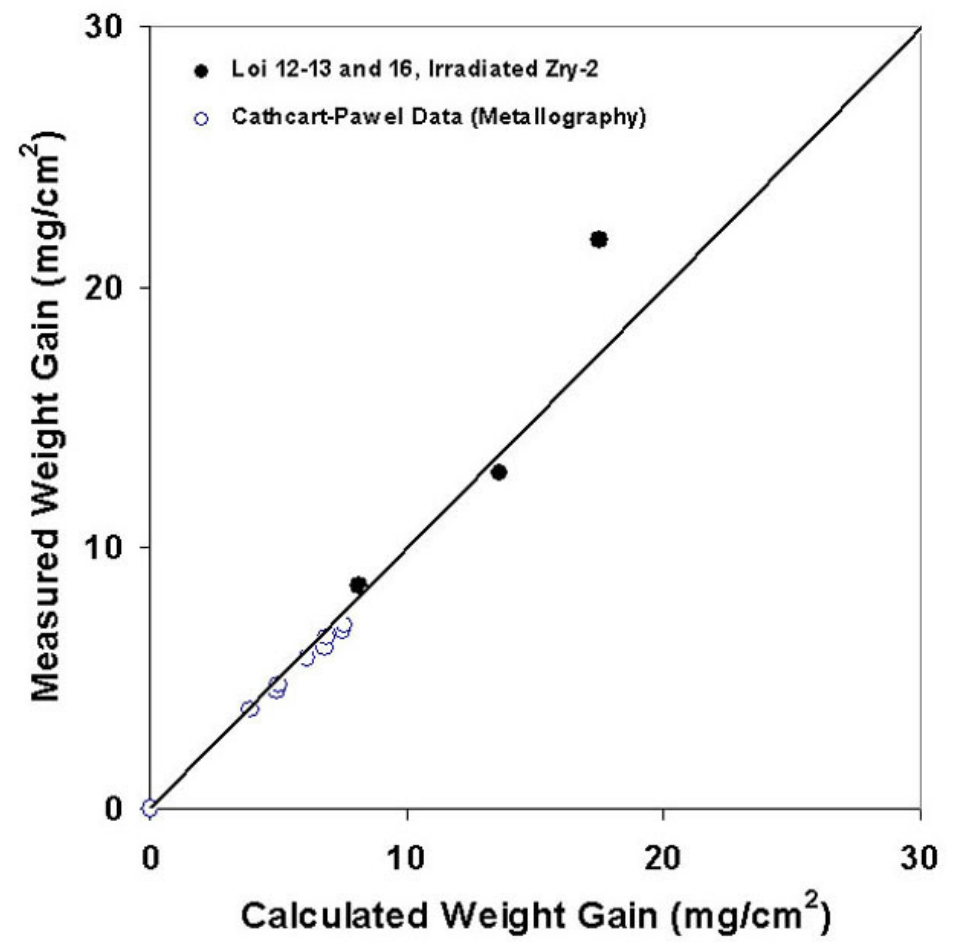

Figure 49. Comparison of Cathcart-Pawel model predictions to ANL sample weight gain data for irradiated (Limerick) Zry-2 after steam oxidation at $\approx 1000^{\circ} \mathrm{C}$ for test times of $1200 \mathrm{~s}, 3600 \mathrm{~s}$, and $6000 \mathrm{~s}$.

Table 23. Results for Breakaway Oxidation Studies of 10x10 Zry-2 Cladding. Test times are given from the beginning of the ramp from $300^{\circ} \mathrm{C}$ to the end of the hold time at temperature.

\begin{tabular}{|c|c|c|c|c|c|c|}
\hline \multirow{2}{*}{$\begin{array}{c}\text { Oxidation T, } \\
{ }^{\circ} \mathrm{C}\end{array}$} & \multirow{2}{*}{$\begin{array}{c}\text { Test } \\
\text { Time, } \mathrm{s}\end{array}$} & \multicolumn{2}{|c|}{ Weight Gain, $\mathrm{mg} / \mathrm{cm}^{2}$} & \multirow{2}{*}{$\begin{array}{c}\text { H Content, } \\
\text { wppm }\end{array}$} & $\begin{array}{c}\text { H Pickup, } \\
\text { wppm }\end{array}$ & $\begin{array}{c}\text { Outer } \\
\text { Surface }\end{array}$ \\
\cline { 3 - 4 } & 5000 & 15.6 & 12.1 & 16 & 4 & $\begin{array}{c}\text { Lustrous } \\
\text { Black }\end{array}$ \\
\hline $1000 \pm 8$ & $\mathbf{5 0 0 0}$ & $\mathbf{1 5 . 6}$ & $\mathbf{1 1 . 5}$ & $\mathbf{3 2}$ & $\mathbf{2 1}$ & $\begin{array}{c}\text { Lustrous } \\
\text { Black }\end{array}$ \\
\hline $985 \pm 8$ & 5000 & 14.4 & 9.8 & 27 & 15 & $\begin{array}{c}\text { Lustrous } \\
\text { Black }\end{array}$ \\
\hline $970 \pm 8$ & 5000 & 13.1 & 8.7 & 15 & 3 & $\begin{array}{c}\text { Lustrous } \\
\text { Black }\end{array}$ \\
\hline
\end{tabular}

${ }^{\mathrm{a}} \mathrm{Hydrogen}$ pickup $\left(\Delta \mathrm{C}_{\mathrm{H}}\right)$ is referenced to the as-fabricated weight of the sample and is calculated from $\Delta \mathrm{C}_{\mathrm{H}}=\left(1+4.7 \times 10^{-3} \mathrm{Wg}\right) \mathrm{L}_{\mathrm{H}}-\mathrm{C}_{\mathrm{Hi}}$, where $\mathrm{Wg}$ is the measured weight gain in $\mathrm{mg} / \mathrm{cm}^{2} . \mathrm{C}_{\mathrm{Hi}}$, is $13 \mathrm{wppm}$.

${ }^{\mathbf{b}} \mathrm{A} 20-\mu \mathrm{m}$-deep scratch was made along the length of the sample prior to testing. 


\subsection{ZIRLO}

\subsubsection{Post-quench ductility of $17 \times 17$ ZIRLO oxidized at $1000^{\circ} \mathrm{C}, 1100^{\circ} \mathrm{C}$, and $1200^{\circ} \mathrm{C}$}

This work was performed in sequence with the $17 \times 17$ Zry-4 testing and characterization. The same test trains, thermal-benchmark temperature histories (Figures 17, 18, 20 and 21), test times, and CP-ECR values were used, as the ZIRLO cladding has the same dimensions as the Zry-4 cladding. Results are also presented with the same subdivision as for Zry-4: characterization and RT-ring-compression testing of samples two-sided oxidized at $1000^{\circ} \mathrm{C}$ and $1100^{\circ} \mathrm{C}$ and quenched at $800^{\circ} \mathrm{C}$; and characterization and ringcompression testing (RT and $135^{\circ} \mathrm{C}$ ) of samples exposed to two-sided oxidization at $1200^{\circ} \mathrm{C}$ and quenched at $800^{\circ} \mathrm{C}$. Characterization included weight gain, oxide- and alpha-layer thickness (metallography), microhardness, and hydrogen pickup (LECO). All samples were oxidized to CPpredicted ECR values of 5, 10, 15, 17, and 20\%. Additional tests were conducted at intermediate CPECR values for the $1200^{\circ} \mathrm{C}$-oxidized samples to better determine the ductile-to-brittle transition CP-ECR value for this oxidation temperature.

\section{$17 \times 17$ ZIRLO oxidized at $1000^{\circ} \mathrm{C}$ and $1100^{\circ} \mathrm{C}$}

Table 24 shows the weight gain results for ZIRLO oxidized at $1000^{\circ} \mathrm{C}$ and $1100^{\circ} \mathrm{C}$. They are in very good agreement with the CP-predicted weight gains at these oxidation temperatures, except for the lower measured values for the $1000^{\circ} \mathrm{C}$-oxidation samples at $\geq 15 \% \mathrm{CP}$-ECR. Figures 50a and 50b show the measured weight gains for ZIRLO and Zry-4 oxidized at $1000^{\circ} \mathrm{C}$ and $1100^{\circ} \mathrm{C}$, respectively, as compared to the $\mathrm{CP}$-predicted weight gains.

Table 25 lists the results of the RT post-quench ductility tests for the $1000^{\circ} \mathrm{C}$ - and $1100^{\circ} \mathrm{C}$ oxidation samples. It is clear from the results that $17 \times 17$ ZIRLO retains post-quench ductility up to $20 \%$ CP-ECR - the limit of the test conditions - for these oxidation temperatures. The results are shown graphically in Figures 51 and 52 for $1000^{\circ} \mathrm{C}$ - and $1100^{\circ} \mathrm{C}$-oxidized samples, respectively. Because of the differences in weight gain between ZIRLO and Zry-4 oxidized at $1000^{\circ} \mathrm{C}$, offset strains are displayed as functions of measured ECR (51a) and CP-ECR (51b). For oxidation at $1100^{\circ} \mathrm{C}$, both alloys exhibit essentially the same weight gain for the same test time, so post-quench ductility results are plotted in Figure 52 as a function of CP-ECR only. For the $1000^{\circ} \mathrm{C}$ - and $1100^{\circ} \mathrm{C}$-oxidation tests, the offset strain leveled out at $\approx 3 \%$. These results suggest that ZIRLO will retain ductility at higher CP-ECR values and higher test times $\left(>3400 \mathrm{~s}\right.$ at $\left.1000^{\circ} \mathrm{C}\right)$ until breakaway oxidation or beta-layer thinning occurs. For $1100^{\circ} \mathrm{C}$-oxidation, breakaway oxidation should not occur, and the beta layer does not appear to embrittle due to the low saturation-level oxygen content. At much higher ECR values, the beta layer would thin enough to make the ring structure behave in a brittle manner. Photographs of the ring-compressed samples are shown in Figure $53 \mathrm{a}\left(1000^{\circ} \mathrm{C}\right)$ and $53 \mathrm{~b}\left(1100^{\circ} \mathrm{C}\right)$. The $5 \%$ and $10 \% \mathrm{CP}$-ECR samples oxidized at $1000^{\circ} \mathrm{C}$ were intact at the maximum Instron displacement. The $5 \% \mathrm{CP}$-ECR sample oxidized at $1100^{\circ} \mathrm{C}$ was also intact.

Table 26 summarizes the results of the metallography, microhardness, and hydrogen pickup measurements for ZIRLO as compared to Zry-4. The hydrogen pickup is very low for $1100^{\circ} \mathrm{C}$-oxidized ZIRLO samples. However, hydrogen pickup is $\approx 100 \mathrm{wppm}$ for ZIRLO oxidized at $1000^{\circ} \mathrm{C}$ for $3364 \mathrm{~s}$ (20\% CP-ECR). Metallographic images indicate that the inner-surface oxide is undergoing breakaway oxidation. Breakaway oxidation for ZIRLO oxidized at $800-1000^{\circ} \mathrm{C}$ is discussed in Section 3.3.2. The microhardness results in Table 26 are consistent with the post-quench ductility results.

Figure 54 shows metallographic images of ZIRLO and Zry-4 oxide layers following $1000^{\circ} \mathrm{C}$ oxidation to $20 \%$ CP-ECR. From these images, it is clear that the higher weight gain for Zry-4 oxidized 


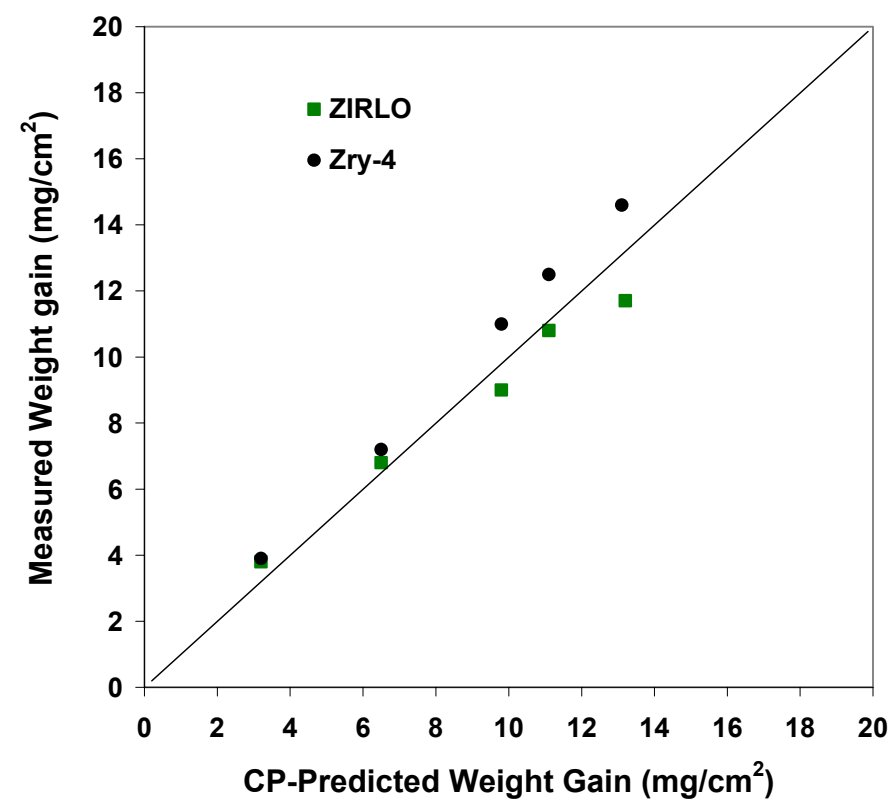

(a) $1000^{\circ} \mathrm{C}$

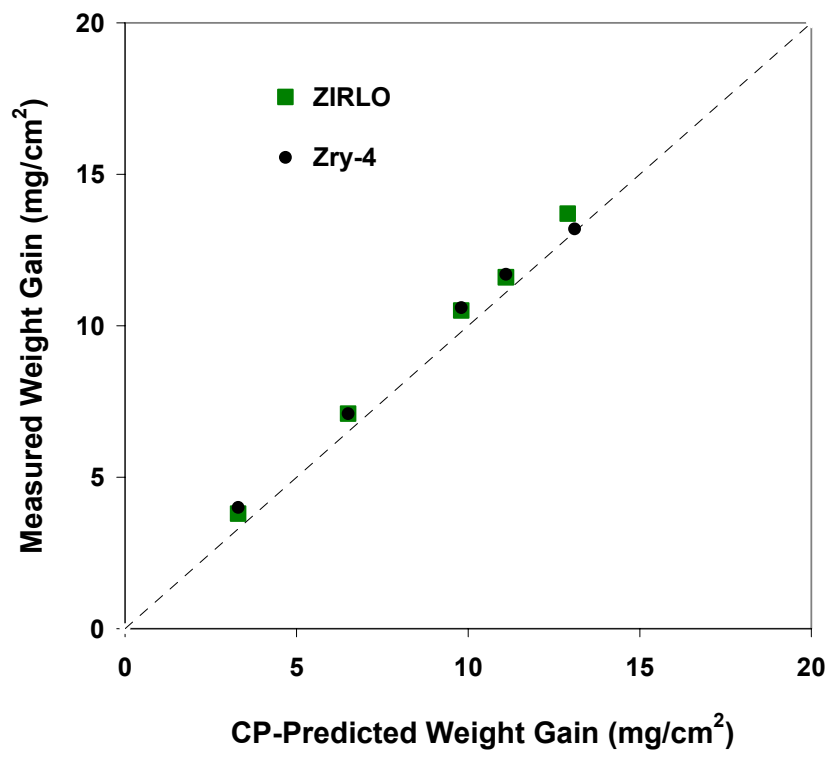

(b) $1100^{\circ} \mathrm{C}$

Figure 50. Comparison between weight gain data for ZIRLO and Zry-4 and weight gain predicted by the Cathcart-Pawel (CP) correlation for samples oxidized (two-sided) in steam at $1000^{\circ} \mathrm{C}(\mathrm{a})$ and $1100^{\circ} \mathrm{C}(\mathrm{b})$. Data correspond to CP-ECR values of $5,10,15,17$, and $20 \%$. 
Table 24. Weight Gain (Wg in $\left.\mathrm{mg} / \mathrm{cm}^{2}\right)$ and Measured ECR (\%) Values for $17 \times 17 \mathrm{ZIRLO}$ Oxidized in Steam at $1000^{\circ} \mathrm{C}$ and $1100^{\circ} \mathrm{C}$ and Quenched at $800^{\circ} \mathrm{C}$. ECR $=1.538 \mathrm{Wg}$ for the $0.57-\mathrm{mm}-$ wall thickness. Multiply weight gain results by a factor of 10 to convert to $\mathrm{g} / \mathrm{m}^{2}$.

\begin{tabular}{|c|c|c|c|}
\hline $\begin{array}{c}\text { Oxidation } \\
\text { Temperature, }{ }^{\circ} \mathrm{C}\end{array}$ & $\begin{array}{c}\text { Cathcart-Pawel } \\
\text { ECR, } \%\end{array}$ & $\begin{array}{c}\text { Measured } \\
\text { Weight Gain } \\
(\mathrm{Wg}), \mathrm{mg} / \mathrm{cm}^{2}\end{array}$ & $\begin{array}{c}\text { Measured } \\
\text { ECR, \% }\end{array}$ \\
\hline \hline 1000 & 5 & 3.8 & 5.9 \\
\hline 1000 & 10 & 6.8 & 10.5 \\
\hline 1000 & 15 & 9.0 & 13.8 \\
\hline 1000 & 17 & 10.8 & 16.6 \\
\hline 1000 & 20 & 11.7 & 5.9 \\
\hline 1100 & 5 & 3.8 & 10.9 \\
\hline 1100 & 10 & 7.1 & 16.1 \\
\hline 1100 & 15 & 10.5 & 21.1 \\
\hline 1100 & 17 & 11.6 & \\
\hline 1100 & 20 & 13.7 & \\
\hline
\end{tabular}

at this temperature is due to the thicker oxide layers grown on the Zry-4 surfaces. This is an alloy effect. Also, as is discussed in Section 3.3.2, the waviness of the ZIRLO oxide layers, particularly the innersurface oxide layer, is a precursor to breakaway oxidation and hydrogen pickup. Table 26 lists the innersurface oxide layer on ZIRLO as 9- $\mu \mathrm{m}$ thicker than the outer-surface oxide. These results suggest that the inner-surface is transforming from the stable tetragonal phase to the unstable monoclinic phase. Figure 55 shows higher magnification and better contrast for the outer- and inner-surface oxide layers grown on this ZIRLO sample. It is clear from Figure 55b that the inner-surface oxide layer is in transition from the tight tetragonal (dark) oxide phase to the cracked monoclinic (light) oxide phase. This supports the view that the ZIRLO hydrogen pickup is through the inner-surface oxide layer. Visual examination confirmed that the inner-surface oxide was gray, as compared to the black surface observed inside the Zry-4 sample oxidized under the same conditions.

Figure 56 shows metallographic images for ZIRLO and Zry-4 oxidized to $20 \%$ CP-ECR at $1100^{\circ} \mathrm{C}$. The Zry-4 prior-beta layer exhibits incursions of higher-oxygen alpha-phase material, which precipitated during cooling from $1100^{\circ} \mathrm{C}$ to $800^{\circ} \mathrm{C}$ prior to quench. The ZIRLO alpha and prior-beta layers are quite different in appearance from those of Zry-4. While oxygen is an alpha-stabilizer, $\mathrm{Nb}$ is a beta-stabilizer. The oxygen-stabilized alpha "layer" formed at high temperature in ZIRLO is not as uniform as the one formed in Zry-4, because $\mathrm{Nb}$ causes local regions of beta-stabilization even at higher oxygen contents. Precipitation of oxygen-stabilized alpha regions during cooling is also different in the ZIRLO prior-beta layer because of the presence of $\mathrm{Nb}$. Yet, even with these differences in microstructure and phase distribution, the post-quench ductility of the two alloys oxidized at $1000^{\circ} \mathrm{C}$ and $1100^{\circ} \mathrm{C}$ is remarkably similar.

The comparison between ZIRLO and Zry- 4 oxidized at $1000^{\circ} \mathrm{C}$ for up to $\approx 3360 \mathrm{~s}(20 \% \mathrm{CP}$-ECR) indicates that the weight gain for ZIRLO is $\approx 10 \%$ lower than predicted by the CP correlation, while the weight gain for Zry-4 is $\approx 10 \%$ higher than the CP-predicted correlation; the $20 \%$ difference in weight gain has no influence on post-quench ductility, as it merely reflects the differences in oxide-layer thickness rather than the oxygen content in the prior-beta layer; both alloys have adequate post-quench 
Table 25. Ring Compression Test Results for $17 \times 17 \mathrm{ZIRLO}$ Samples Oxidized at $1000^{\circ} \mathrm{C}$ and $1100^{\circ} \mathrm{C}$, Cooled at $\approx 10^{\circ} \mathrm{C} / \mathrm{s}$ to $800^{\circ} \mathrm{C}$, and Quenched. ECR $=1.538 \mathrm{Wg}$ for $0.57-\mathrm{mm}$-wall cladding. Tests were performed on 8-mm-long samples at RT and 0.0333- $\mathrm{mm} / \mathrm{s}$ displacement rate. Displacements in the loading direction were normalized to the as-fabricated outer diameter $(9.50 \mathrm{~mm})$ to calculate offset strain. A complete set of tests was performed with the Model 4505 Instron. A limited number of confirmation tests were performed with the Model 5566 Instron and rings cut from the same oxidation samples.

\begin{tabular}{|c|c|c|c|c|c|}
\hline $\begin{array}{c}\text { Oxidation } \\
\text { Temperature, } \\
{ }^{\circ} \mathrm{C}\end{array}$ & $\begin{array}{l}\text { Cathcart- } \\
\text { Pawel } \\
\text { ECR, \% }\end{array}$ & $\begin{array}{c}\text { Measured } \\
\text { ECR, } \\
\%\end{array}$ & $\begin{array}{c}\text { Offset } \\
\text { Displacement, } \\
\mathrm{mm}\end{array}$ & $\begin{array}{l}\text { Offset } \\
\text { Strain, } \\
\quad \%\end{array}$ & $\begin{array}{c}\text { Confirmation } \\
\text { Tests } \\
\text { Model } 5566 \\
\text { Instron }\end{array}$ \\
\hline 1000 & 5 & 5.9 & $>4.9$ & $>52$ & --- \\
\hline 1000 & 10 & 10.5 & $>2.35$ & $>25$ & Yes \\
\hline 1000 & 15 & 13.8 & 1.92 & 20 & Yes \\
\hline 1000 & 17 & 16.6 & 0.45 & 4.7 & --- \\
\hline 1000 & 20 & 18.0 & 0.27 & 2.9 & --- \\
\hline 1100 & 5 & 5.9 & $>5.0$ & $>52$ & --- \\
\hline 1100 & 10 & 10.9 & 2.1 & 22 & --- \\
\hline 1100 & 15 & 16.1 & 0.48 & 5.1 & Yes \\
\hline 1100 & 17 & 17.9 & 0.33 & 3.5 & --- \\
\hline 1100 & 20 & 21.1 & 0.32 & 3.3 & --- \\
\hline
\end{tabular}

ductility at 20\% CP-ECR; and the ZIRLO inner-surface oxide layer is in breakaway-oxidation transition at $3360 \mathrm{~s}$ based on hydrogen pickup and metallographic imaging. The differences in weight gain are attributable to alloy effects, particularly the $\mathrm{Nb}$ in ZIRLO. Better agreement for the offset strains of these two alloys is observed at high oxidation times in Figure 51b, where the offset strain is plotted as a function of CP-ECR. The results in Figure 51b clearly show that Zry-4 and ZIRLO have essentially the same post-quench ductility for equivalent isothermal oxidation times of $2430-3365 \mathrm{~s}$ at $1000^{\circ} \mathrm{C}$. The comparison between ZIRLO and Zry-4 oxidized at $1100^{\circ} \mathrm{C}$ for up to $\approx 1070 \mathrm{~s}$ ( $20 \% \mathrm{CP}$-ECR) indicates differences in microstructure and phase distribution but no significant differences in weight-gain kinetics and post-quench ductility. 


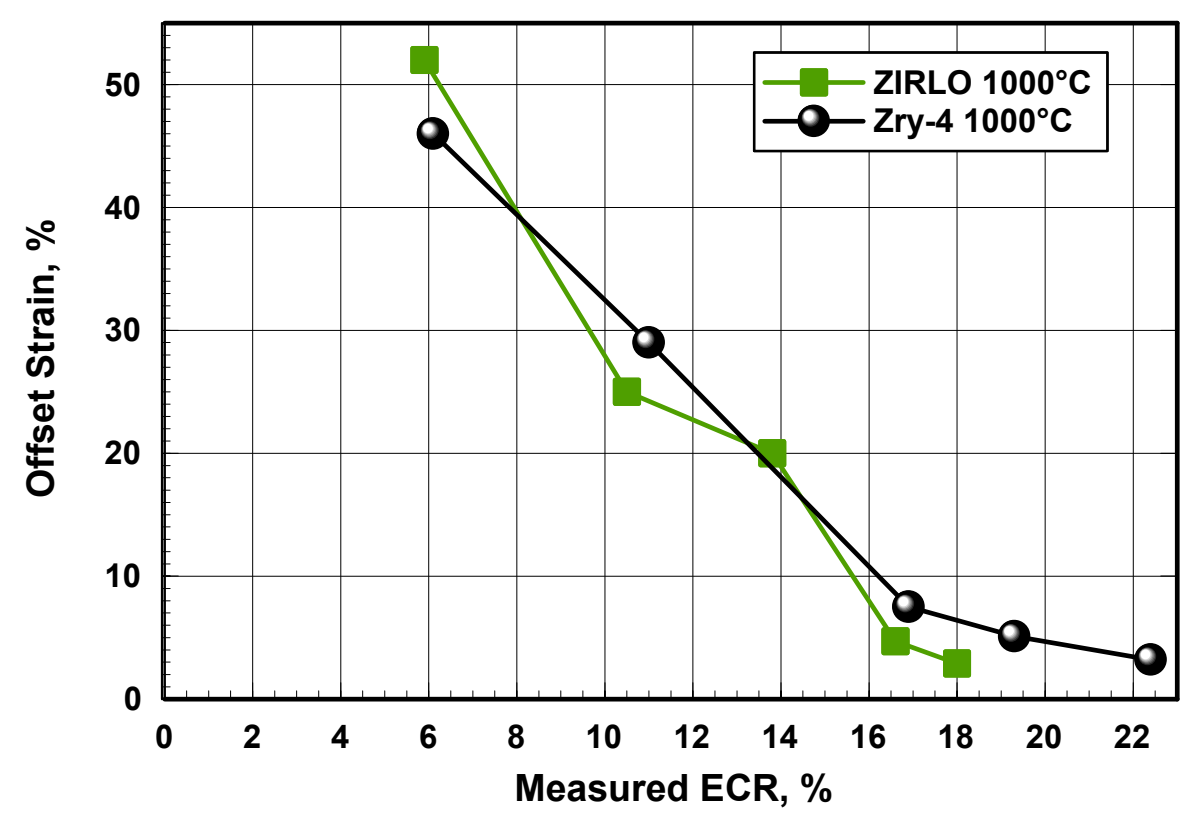

(a)

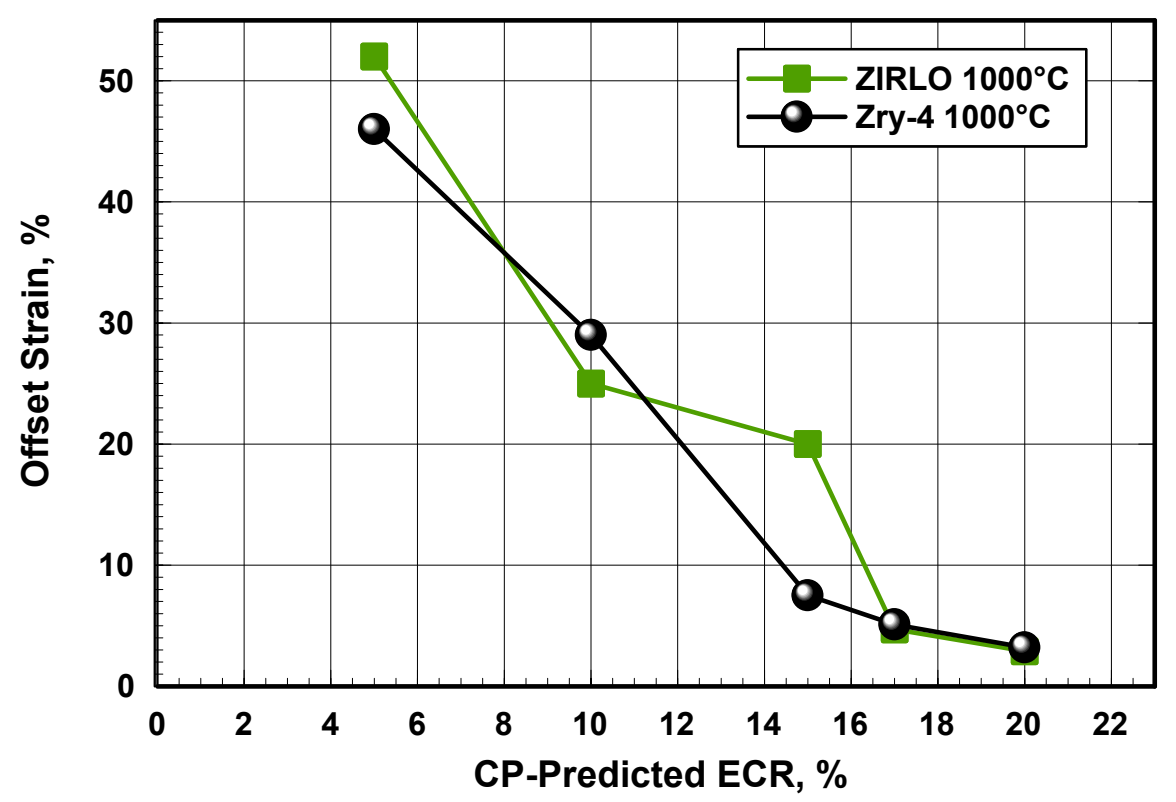

(b)

Figure 51. Post-quench ductility vs. measured (a) and CP-predicted (b) ECR for ZIRLO and Zry-4 oxidized at $1000^{\circ} \mathrm{C}$, cooled at $\approx 10^{\circ} \mathrm{C} / \mathrm{s}$ to $800^{\circ} \mathrm{C}$, and quenched. Ductility is based on offset strain determined from ring-compression data for tests conducted at RT and $0.0333-\mathrm{mm} / \mathrm{s}$ displacement rate. 


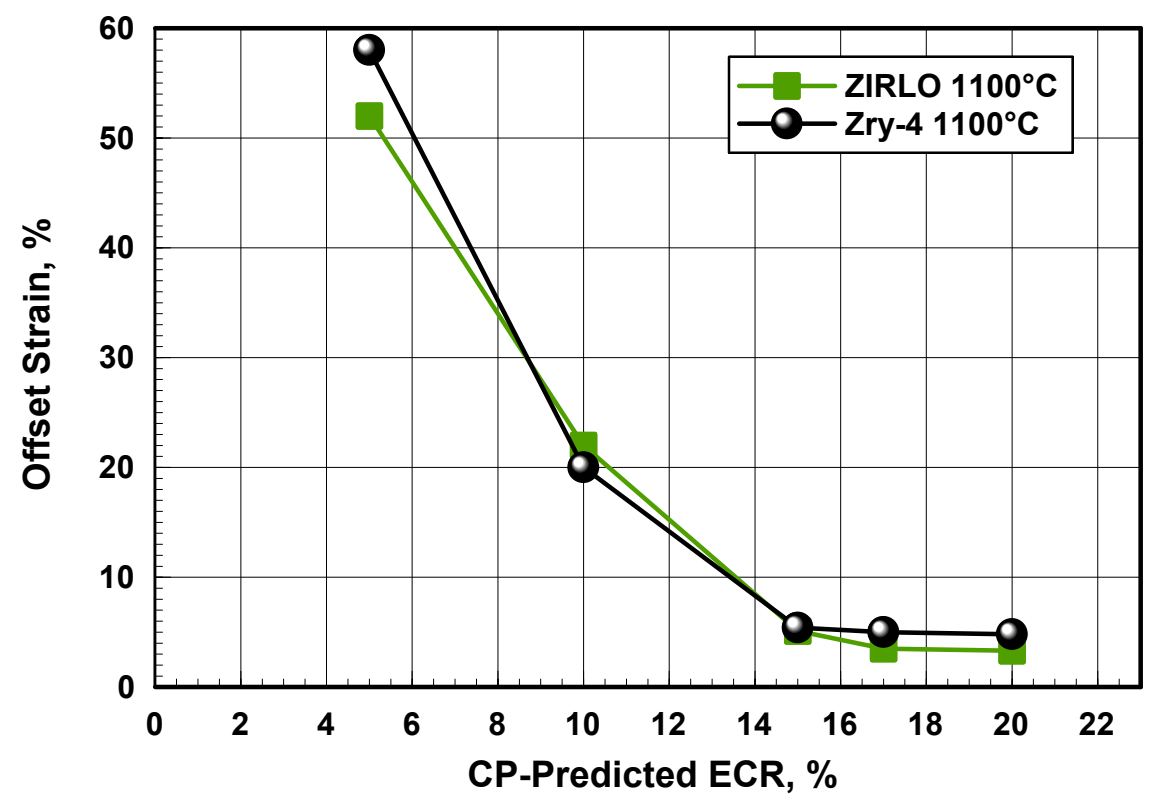

Figure 52. Post-quench ductility vs. CP-predicted ECR for ZIRLO and Zry-4 oxidized at $1100^{\circ} \mathrm{C}$, cooled at $\approx 10^{\circ} \mathrm{C} / \mathrm{s}$ to $800^{\circ} \mathrm{C}$, and quenched. Ductility is based on offset strain determined from ring-compression data for tests conducted at RT and $0.0333-\mathrm{mm} / \mathrm{s}$ displacement rate.

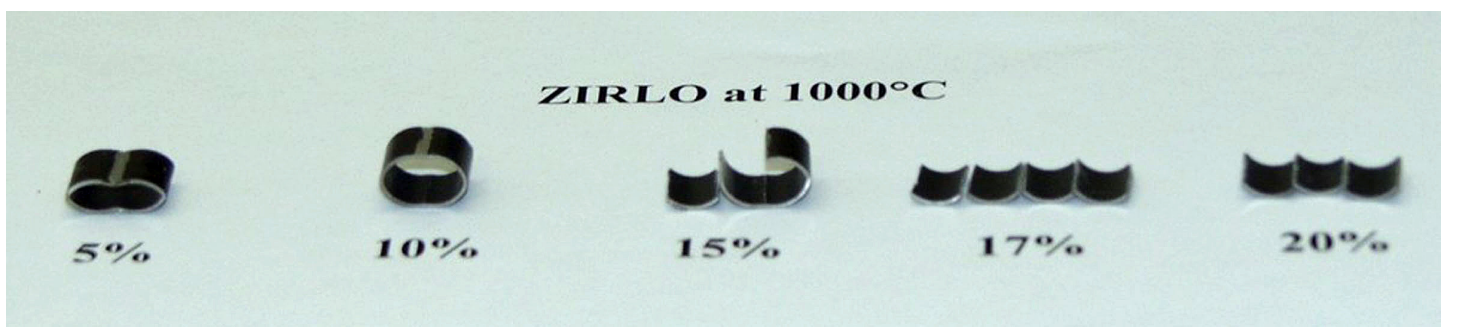

(a)

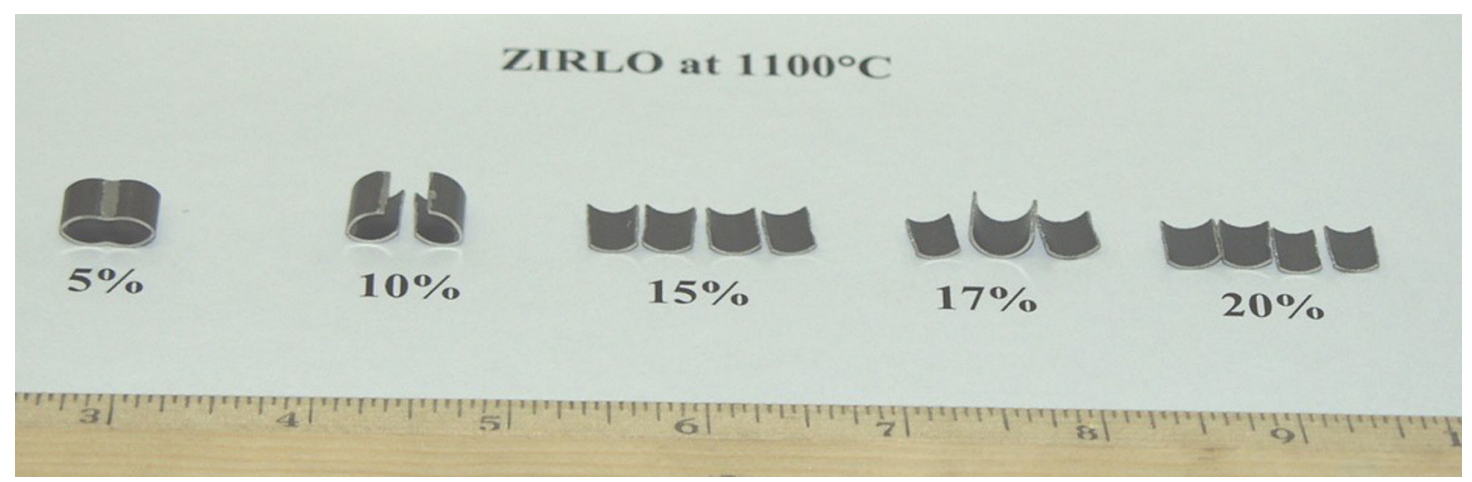

(b)

Figure 53. Post-test appearance of ZIRLO ring-compression samples tested at room temperature and $0.0333 \mathrm{~mm} / \mathrm{s}$ : (a) samples oxidized at $1000^{\circ} \mathrm{C}$ and (b) samples oxidized at $1100^{\circ} \mathrm{C}$. ECR values are calculated using the Cathcart-Pawel weight gain correlation. 
Table 26. Characterization of Highly Oxidized (20\% CP-ECR) $17 \times 17$ Zry-4 and ZIRLO Samples after Exposure to Steam at $1000^{\circ} \mathrm{C}$ and $1100^{\circ} \mathrm{C}$, Cooling at $\approx 10^{\circ} \mathrm{C} / \mathrm{s}$ to $800^{\circ} \mathrm{C}$, and Quench.

\begin{tabular}{|c|c|c|c|}
\hline $\begin{array}{c}\text { Oxidation } \\
\text { Temperature, } \\
{ }^{\circ} \mathrm{C}\end{array}$ & Parameter & Zry-4 & ZIRLO \\
\hline \multirow[t]{9}{*}{1000} & Effective CP Time, $\mathrm{s}$ & 3364 & 3364 \\
\hline & Weight Gain, $\mathrm{mg} / \mathrm{cm}^{2}$ & 14.6 & 11.7 \\
\hline & Measured ECR, \% & 22.4 & 18.0 \\
\hline & RT Offset Displacement, mm & 0.31 & 0.27 \\
\hline & RT Offset Strain, \% & $\begin{array}{c}3.2 \\
\text { (ductile) }\end{array}$ & $\begin{array}{c}2.9 \\
\text { (ductile) }\end{array}$ \\
\hline & Hydrogen Content, wppm & 19 & 102 \\
\hline & Hydrogen Pickup, wppm & 15 & 103 \\
\hline & OD/ID Oxide Layer Thickness, $\mu \mathrm{m}$ & $83 / 82$ & $57 / 66$ \\
\hline & Microhardness within Middle $0.2 \mathrm{~mm}, \mathrm{DPH}^{\mathrm{a}}$ & $290-420$ & $290-400$ \\
\hline \multirow[t]{9}{*}{1100} & Effective CP Time, s & 1065 & 1065 \\
\hline & Weight Gain, $\mathrm{mg} / \mathrm{cm}^{2}$ & 13.2 & 13.7 \\
\hline & Measured ECR, \% & 20.3 & 21.1 \\
\hline & RT Offset Displacement, mm & 0.46 & 0.32 \\
\hline & RT Offset Strain, \% & $\begin{array}{c}4.8 \\
\text { (ductile) }\end{array}$ & $\begin{array}{c}3.3 \\
\text { (ductile) }\end{array}$ \\
\hline & Hydrogen Content, wppm & 22 & 22 \\
\hline & Hydrogen Pickup, wppm & 19 & 18 \\
\hline & OD/ID Oxide Layer Thickness, $\mu \mathrm{m}$ & $70 / 68$ & $72 / 69$ \\
\hline & Microhardness within Middle $0.2 \mathrm{~mm}, \mathrm{DPH}^{\mathrm{a}}$ & $240-470$ & $330-460$ \\
\hline
\end{tabular}

${ }^{a}$ Includes oxygen-stabilized alpha needles (ZIRLO) and alpha incursions (Zry-4) in prior-beta layer. 


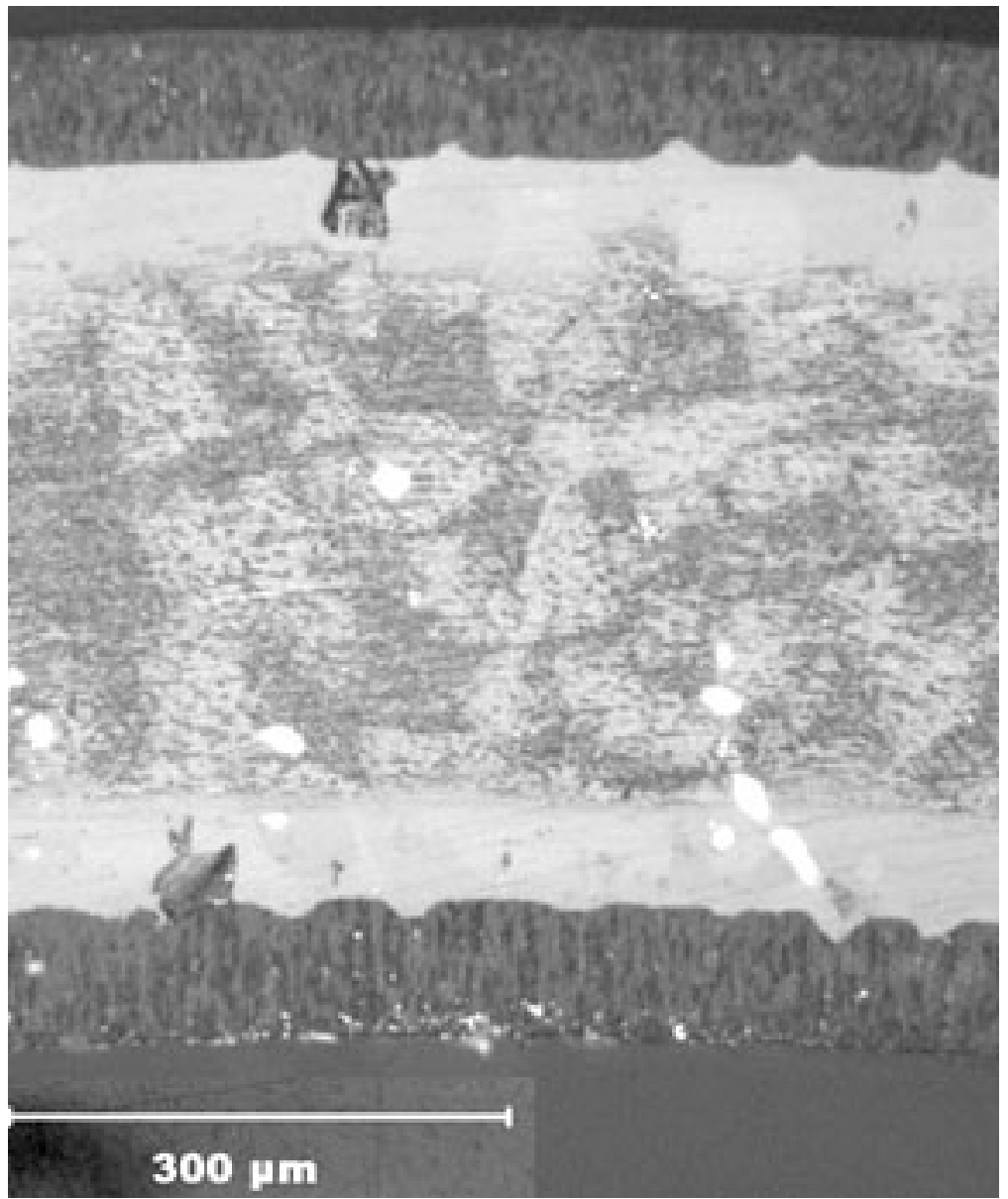

(a) Zry-4

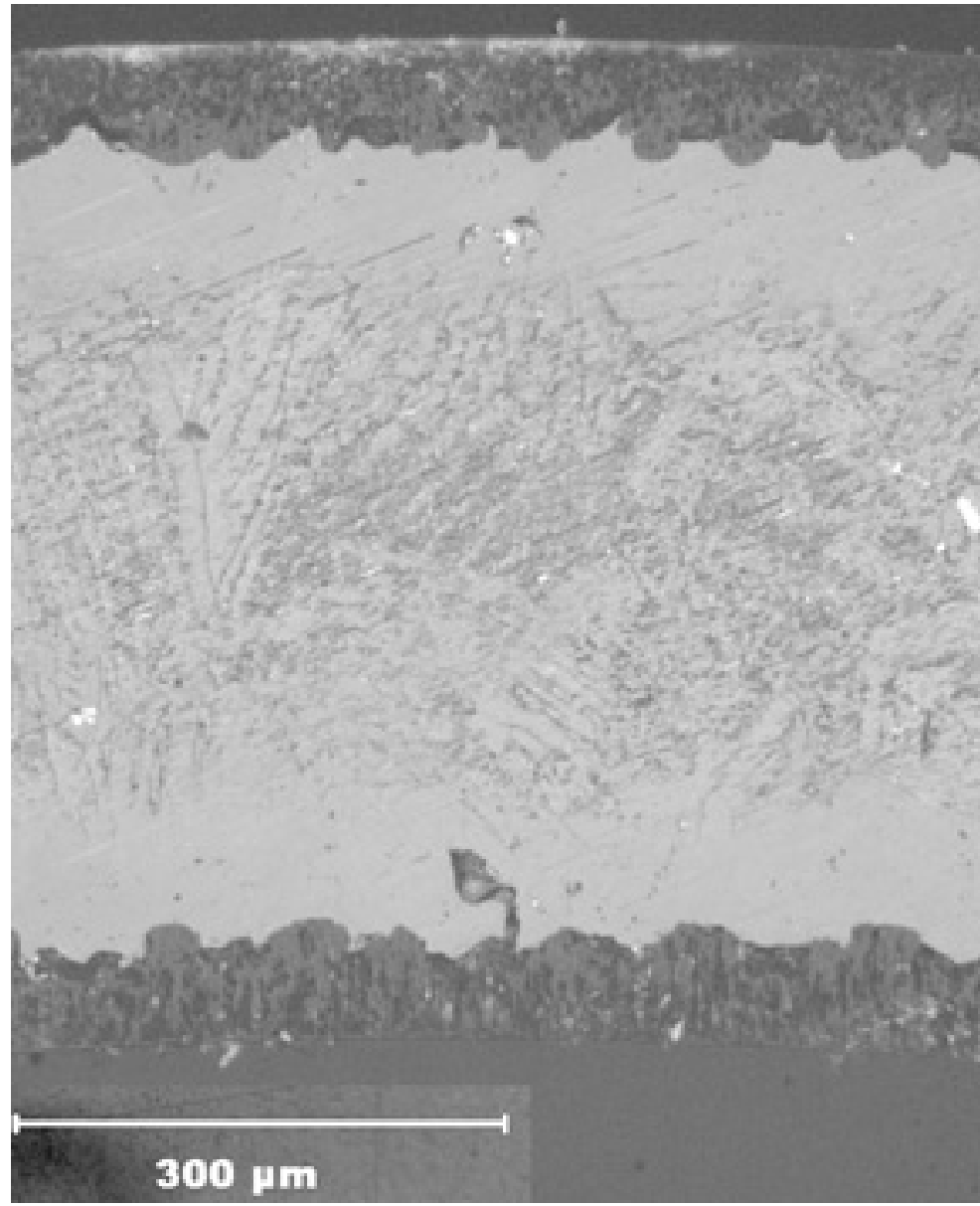

(b) ZIRLO

Figure 54. Metallography of as-polished Zry-4 (a) and ZIRLO (b) oxidized in steam at $1000^{\circ} \mathrm{C}$ for $\approx 3360 \mathrm{~s}$, cooled at $\approx 10^{\circ} \mathrm{C} / \mathrm{s}$ to $800^{\circ} \mathrm{C}$, and water quenched. Measured ECR values are $22.4 \%$ for Zry- 4 and $18.0 \%$ for ZIRLO. 


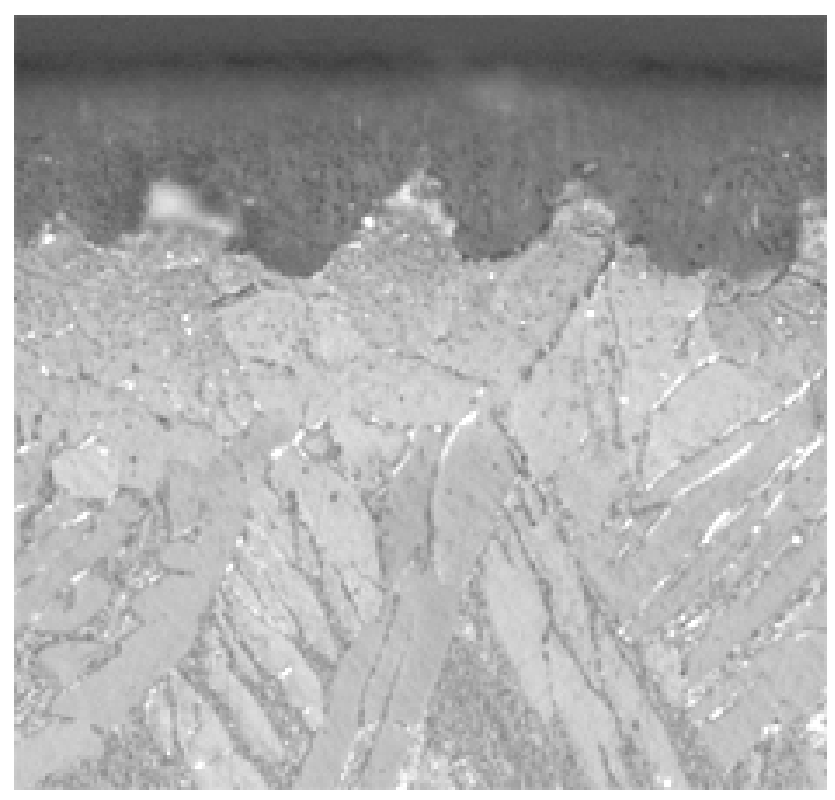

(a)

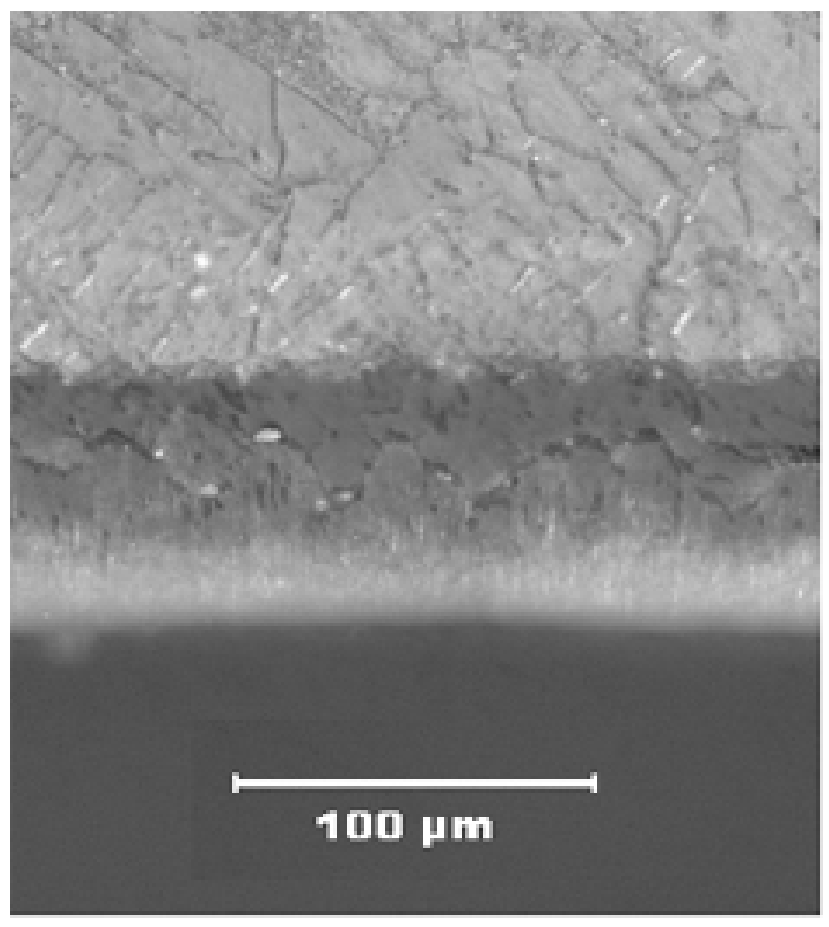

(b)

Figure 55. High-magnification images of etched ZIRLO sample following oxidation at $1000^{\circ} \mathrm{C}$ for $3360 \mathrm{~s}$ to $20 \%$ CP-ECR. The outer-surface oxide layer (a) is tetragonal, but the wavy oxide-metal interface indicates a precursor to breakaway oxidation. The inner-surface oxide layer (b) is thicker, has lateral cracks, appears to be monoclinic, and is in breakaway oxidation. The hydrogen pickup through the inner surface is $\approx 100$ wppm. 


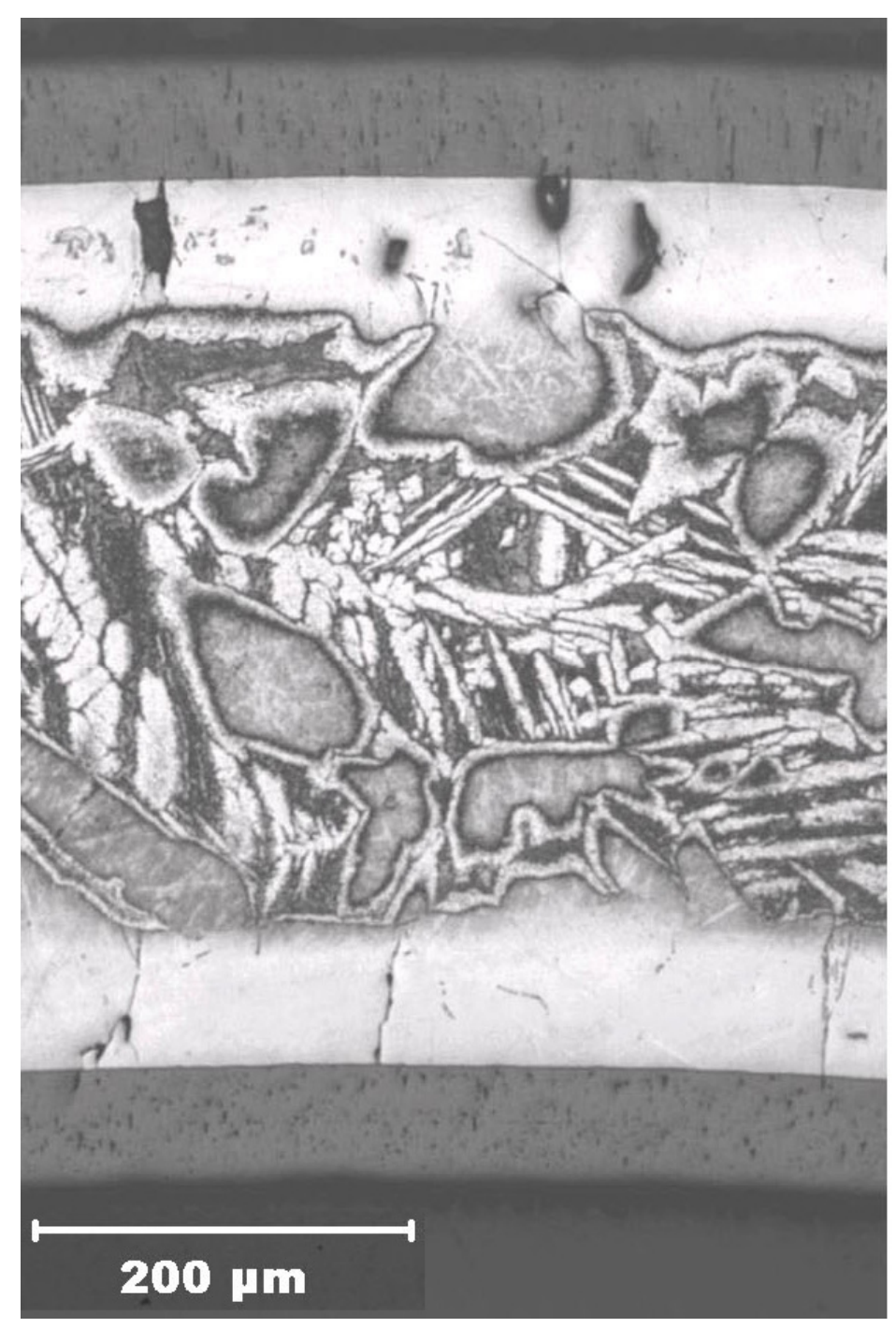

(a) Zry-4

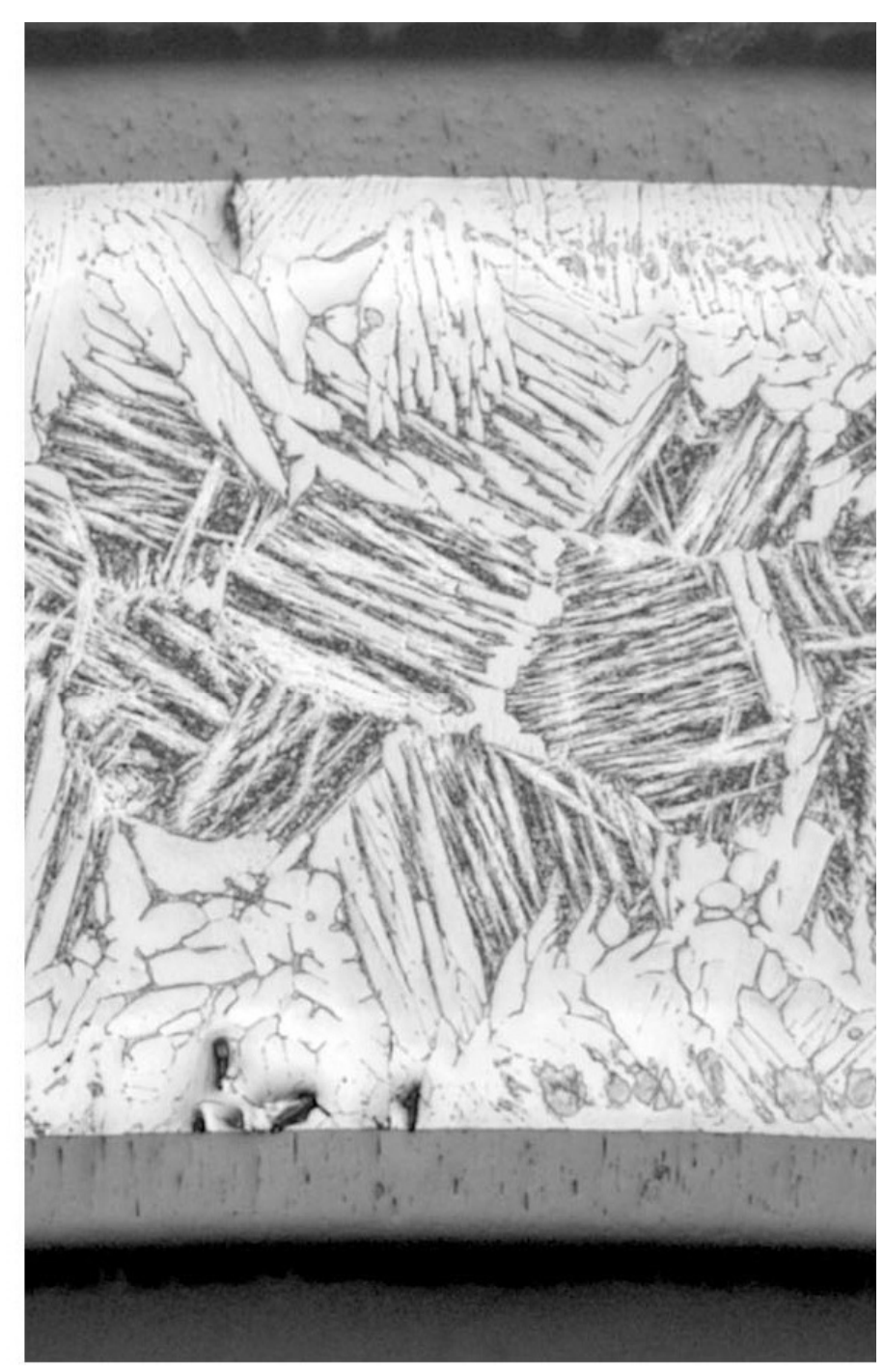

(b) ZIRLO

Figure 56. Metallography of etched Zry-4 (a) and ZIRLO (b) oxidized in steam at $1100^{\circ} \mathrm{C}$ for $\approx 1070 \mathrm{~s}$ to $20 \% \mathrm{CP}$-ECR, cooled at $\approx 10^{\circ} \mathrm{C} / \mathrm{s}$ to $800^{\circ} \mathrm{C}$, and water quenched. Measured ECR values are $20.3 \%$ for Zry- 4 and $21.1 \%$ for ZIRLO. 


\section{$17 \times 17$ ZIRLO oxidized at $1200^{\circ} \mathrm{C}$}

In parallel with the testing of Zry-4, numerous tests were conducted with $17 \times 17$ ZIRLO oxidized at $1200 \pm 5^{\circ} \mathrm{C}$ to determine the ductile-to-brittle transition CP-ECR at RT and $135^{\circ} \mathrm{C}$. Figures 20 and 21 show the thermal-benchmark results for the first and more recent test trains Although the temperature ramps are different, these have little effect on the long-time tests used to determine the high ductile-tobrittle transition CP-ECR for rings compressed at $135^{\circ} \mathrm{C}$. Also, all tests were stopped after the first significant load drop to allow a measure of the permanent strain based on the diameter change in the loading direction.

The weight gain (expressed in terms of measured ECR) and the post-quench ductility results are summarized in Table 27. As noted in Table 27, initial ring-compression scoping tests were performed at $135^{\circ} \mathrm{C}$ with relatively short $(\approx 5-\mathrm{mm}$ long) end pieces of oxidized-and-quenched rings. These results provided valuable qualitative information, but they may not be as quantitatively accurate as the results listed in bold type for $\approx 8$-mm-long sectioned from the center of the oxidation-quench samples or even rings sectioned from either side of the center sample. Figure 57 shows the ZIRLO and Zry- 4 measured weight gains, as compared to the CP-predicted weight gains. The experimental results for both alloys are in excellent agreement with each other and with the predicted values.

ZIRLO appears to embrittle at room temperature after oxidation to $\approx 11 \% \mathrm{CP}$-ECR and quench. This observation is confirmed by both the offset $(<2 \%)$ and the permanent-strain $(<1 \%)$ criteria for embrittlement. The enhancement of ductility with the increase in test temperature is quite pronounced. Based on the offset and permanent strain data, the ductile-to-brittle transition CP-ECR is $\approx 19 \%$ at $135^{\circ} \mathrm{C}$. The variations of offset strain and permanent strain with CP-ECR are shown in Figures 58a and 58b, respectively, for the RT and $135^{\circ} \mathrm{C}$ test conditions. Figure 59 is a comparison between the post-quench ductility (offset strain) at $135^{\circ} \mathrm{C}$ for ZIRLO and Zry-4 vs. CP-ECR following oxidation at $1200^{\circ} \mathrm{C}$ and quench at $800^{\circ} \mathrm{C}$. At CP-ECR values $<17 \%$, ZIRLO has significantly higher post-quench ductility than Zry-4. However, both alloys show low ductility at $\geq 17 \%$ CP-ECR for ring-compression test at $135^{\circ} \mathrm{C}$.

The higher ductile-to-brittle transition ECR for $17 \times 17$ ZIRLO (19\%) as compared to $17 \times 17$ Zry-4 $(17 \%)$ does not appear to be an alloy effect. Based on Figure 28, modern $15 \times 15$ Zry-4 and 10×10 Zry-2 have the same ductile-to-brittle transition ECR (19\%) as modern 17×17 ZIRLO. It appears that fabrication differences from lot-to-lot of Zry-4 have more of an effect on the embrittlement threshold for $1200^{\circ} \mathrm{C}$-oxidized cladding samples than alloy differences. 
Table 27. Ring Compression Test (RCT) Results for $17 \times 17$ ZIRLO Cladding Oxidized at $1200^{\circ} \mathrm{C}$, Cooled at $\approx 13^{\circ} \mathrm{C} / \mathrm{s}$ to $800^{\circ} \mathrm{C}$, and Quenched. ECR $=1.538 \mathrm{Wg}$ for 0.57 -mm-wall thickness.

Tests were performed on $\approx 8$-mm-long samples at RT and $135^{\circ} \mathrm{C}$ and at $0.0333-\mathrm{mm} / \mathrm{s}$ displacement rate. Displacements in the loading direction were normalized to the asfabricated outer diameter $(9.50 \mathrm{~mm})$ to calculate offset and permanent strains.

\begin{tabular}{|c|c|c|c|c|c|c|c|}
\hline \multicolumn{2}{|c|}{$\begin{array}{c}\text { Test } \\
\text { Conditions }\end{array}$} & \multicolumn{2}{|c|}{$\begin{array}{c}\mathrm{ECR}, \\
\%\end{array}$} & \multicolumn{2}{|c|}{$\begin{array}{c}\text { Plastic } \\
\text { Displacement, } \mathrm{mm}\end{array}$} & \multicolumn{2}{|c|}{$\begin{array}{c}\text { Plastic } \\
\text { Strain, \% }\end{array}$} \\
\hline $\begin{array}{l}\mathrm{RCT} \\
\mathrm{T},{ }^{\circ} \mathrm{C}\end{array}$ & $\begin{array}{c}\text { Test } \\
\text { Time, }{ }^{\mathrm{a}} \mathrm{s}\end{array}$ & $\mathrm{CP}$ & Meas. & Offset & Permanent & Offset & Permanent \\
\hline RT & 60 & 4.9 & 4.8 & $>5.55$ & $>5.24$ & $>58$ & $>53$ \\
\hline $\begin{array}{l}\mathrm{RT} \\
135 \mathrm{~b}\end{array}$ & $\begin{array}{l}136 \\
136\end{array}$ & $\begin{array}{l}10.0 \\
10.0\end{array}$ & $\begin{array}{l}10.3 \\
10.3\end{array}$ & $\begin{array}{l}0.26 \\
>4.8\end{array}$ & $\begin{array}{l}0.13 \\
>4.8\end{array}$ & $\begin{array}{c}2.7 \\
>51\end{array}$ & $\begin{array}{c}1.4 \\
>51\end{array}$ \\
\hline $\begin{array}{c}\text { RT } \\
\mathbf{1 3 5}^{\mathbf{c}} \\
\mathbf{1 3 5}^{\mathbf{c}}\end{array}$ & $\begin{array}{l}203 \\
203 \\
\mathbf{2 0 3}\end{array}$ & $\begin{array}{l}13.0 \\
13.0 \\
13.0\end{array}$ & $\begin{array}{l}13.4 \\
14.3 \\
14.3\end{array}$ & $\begin{array}{l}0.11 \\
1.96 \\
3.12\end{array}$ & $\begin{array}{c}0.07 \\
\mathbf{1 . 4 7} \\
\mathbf{>} \mathbf{2 . 4 6}\end{array}$ & $\begin{array}{c}1.2 \\
\mathbf{2 0 . 7} \\
\mathbf{3 3}\end{array}$ & $\begin{array}{c}0.7 \\
15.5 \\
>26\end{array}$ \\
\hline $\begin{array}{l}\mathrm{RT} \\
135^{\mathrm{b}}\end{array}$ & $\begin{array}{l}248 \\
248\end{array}$ & $\begin{array}{l}15.1 \\
15.1\end{array}$ & $\begin{array}{l}15.4 \\
15.4\end{array}$ & $\begin{array}{l}0.18 \\
1.73\end{array}$ & $\begin{array}{l}0.11 \\
1.28\end{array}$ & $\begin{array}{c}1.8 \\
18.2\end{array}$ & $\begin{array}{c}1.2 \\
13.4\end{array}$ \\
\hline $\begin{array}{c}\mathrm{RT} \\
135^{\mathrm{b}} \\
\mathbf{1 3 5}^{\mathbf{c}} \\
\mathbf{1 3 5}^{\mathbf{b}}\end{array}$ & $\begin{array}{l}310 \\
310 \\
\mathbf{3 1 8} \\
\mathbf{3 1 8}\end{array}$ & $\begin{array}{l}17.1 \\
17.1 \\
\mathbf{1 7 . 0} \\
\mathbf{1 7 . 0}\end{array}$ & $\begin{array}{l}17.8 \\
17.8 \\
\mathbf{1 8 . 4} \\
\mathbf{1 8 . 4}\end{array}$ & $\begin{array}{l}0.16 \\
0.66 \\
\mathbf{0 . 5 9} \\
\mathbf{0 . 3 6}\end{array}$ & $\begin{array}{c}0.06 \\
--- \\
0.27 \\
0.17\end{array}$ & $\begin{array}{l}1.0 \\
7.0 \\
6.2 \\
3.8\end{array}$ & $\begin{array}{l}0.6 \\
--- \\
2.8 \\
1.8\end{array}$ \\
\hline $\begin{array}{l}135^{c} \\
135^{b}\end{array}$ & $\begin{array}{l}390 \\
390\end{array}$ & $\begin{array}{l}19.0 \\
19.0\end{array}$ & $\begin{array}{l}21.2 \\
21.2\end{array}$ & $\begin{array}{l}0.29 \\
0.19\end{array}$ & $\begin{array}{l}0.11 \\
0.11\end{array}$ & $\begin{array}{l}3.1 \\
2.0\end{array}$ & $\begin{array}{l}1.2 \\
0.9\end{array}$ \\
\hline $\begin{array}{l}\mathrm{RT}^{\mathrm{d}} \\
135^{\mathrm{d}} \\
135^{\mathrm{d}}\end{array}$ & $\begin{array}{l}428 \\
448 \\
448\end{array}$ & $\begin{array}{l}21.2 \\
21.7 \\
21.7\end{array}$ & $\begin{array}{l}22.3 \\
23.4 \\
23.4\end{array}$ & $\begin{array}{l}0.11 \\
0.20 \\
0.20\end{array}$ & $\begin{array}{c}0.06 \\
0.11 \\
---\end{array}$ & $\begin{array}{l}1.1 \\
2.1 \\
2.1\end{array}$ & $\begin{array}{l}0.6 \\
1.2 \\
---\end{array}$ \\
\hline
\end{tabular}

${ }^{\mathrm{a}}$ Includes time for ramp from $300^{\circ} \mathrm{C}$ and hold time.

${ }^{\mathrm{b}}$ Short ( $\approx 5$-mm long) rings sectioned from end of oxidation-quench samples.

${ }^{\mathbf{c}}$ Tests were conducted with current test train (see Figure 21 for thermal history). Most other test results were generated with the initial test train (see Figure 20 for thermal history). ${ }^{\mathrm{d}}$ Control TC switched prior to runs; estimated cladding temperature is $\approx 1215^{\circ} \mathrm{C}$.

Table 28 summarizes the characterization results for $17 \times 17$ Zry- 4 and ZIRLO oxidized at $1200^{\circ} \mathrm{C}$ to $13 \%$ and $20 \% \mathrm{ECR}$ and quenched at $800^{\circ} \mathrm{C}$. As expected, hydrogen pickup is very low. Also, there is excellent agreement between the inner-surface and outer-surface oxide layer thickness, indicating adequate steam flow at the inner surface. The microhardness results support the post-quench ductility results. Based on the room-temperature microhardness values, one would expect ductility at $13 \% \mathrm{CP}$ ECR and embrittlement at $20 \% \mathrm{CP}-\mathrm{ECR}$ at the $135^{\circ} \mathrm{C}$ test temperature. The microstructures across the cladding wall are shown in Figure 60a for Zry-4 and Figure $60 \mathrm{~b}$ for ZIRLO oxidized at $1200^{\circ} \mathrm{C}$ to $\approx 20 \%$ CP-ECR. As with the lower oxidation temperatures, Zry-4 has well-defined oxygen-stabilized alpha layers grown at $1200^{\circ} \mathrm{C}$, while the presence of $\mathrm{Nb}$ in ZIRLO results in a less clear distinction of this layer. The microhardness indents for Zry-4 and ZIRLO oxidized to $\approx 13 \%$ CP-ECR are shown in Figures 61a and $61 \mathrm{~b}$, respectively. 


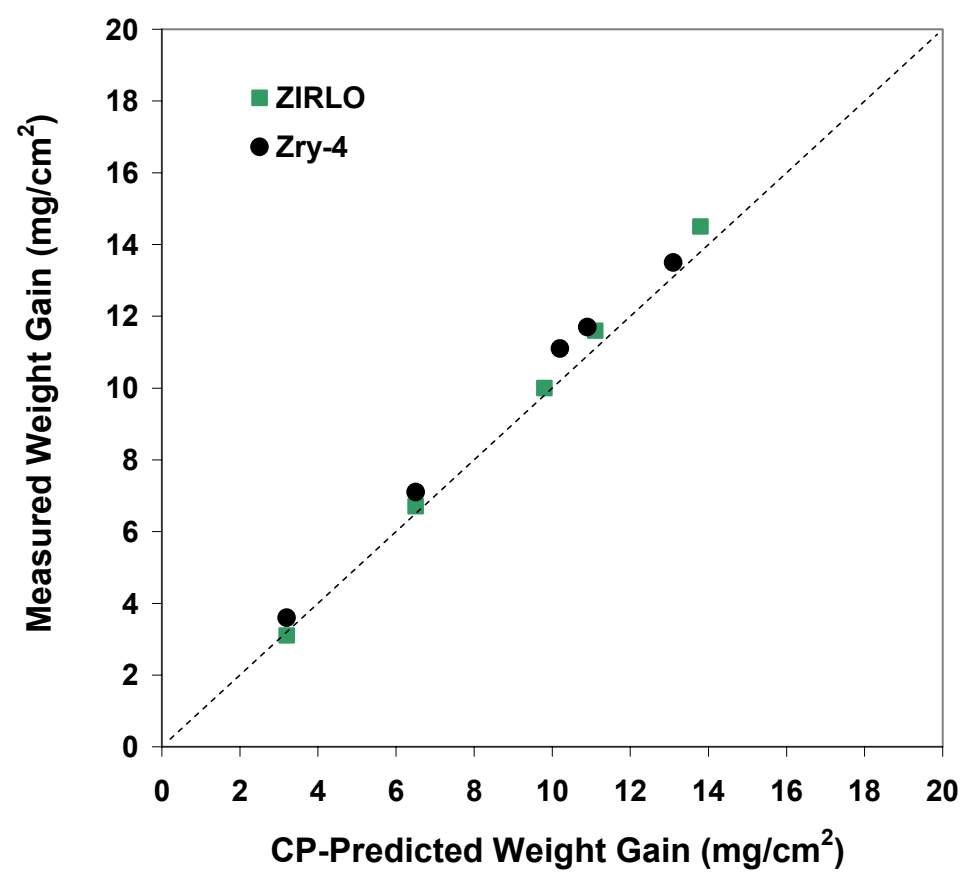

Figure 57. Comparison between weight gain data for ZIRLO and Zry-4 and CP-predicted weight gain for samples oxidized (two-sided) in steam at $1200^{\circ} \mathrm{C}$ and quenched at $800^{\circ} \mathrm{C}$.

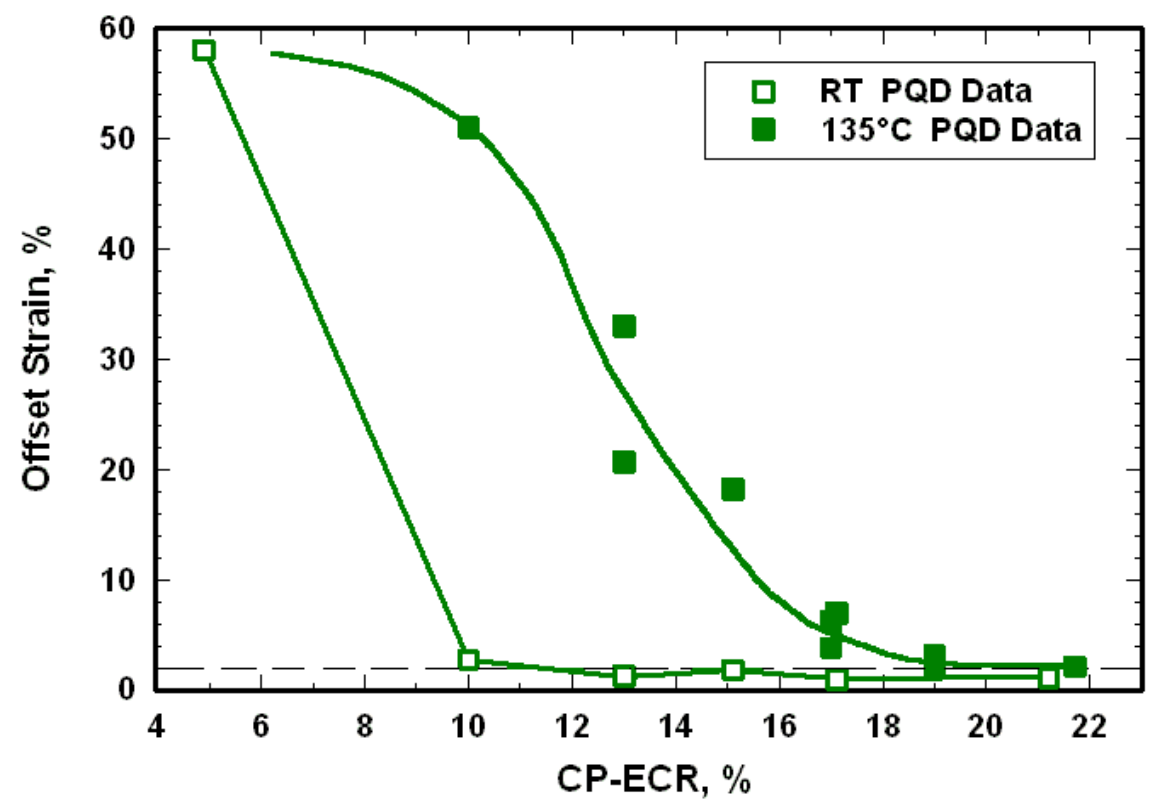

Figure 58a. Offset strain vs. CP-ECR for $17 \times 17$ ZIRLO oxidized at $1200^{\circ} \mathrm{C}$, cooled at $\approx 13^{\circ} \mathrm{C} / \mathrm{s}$ to $800^{\circ} \mathrm{C}$, quenched, and ring-compressed at RT and $135^{\circ} \mathrm{C}$. 


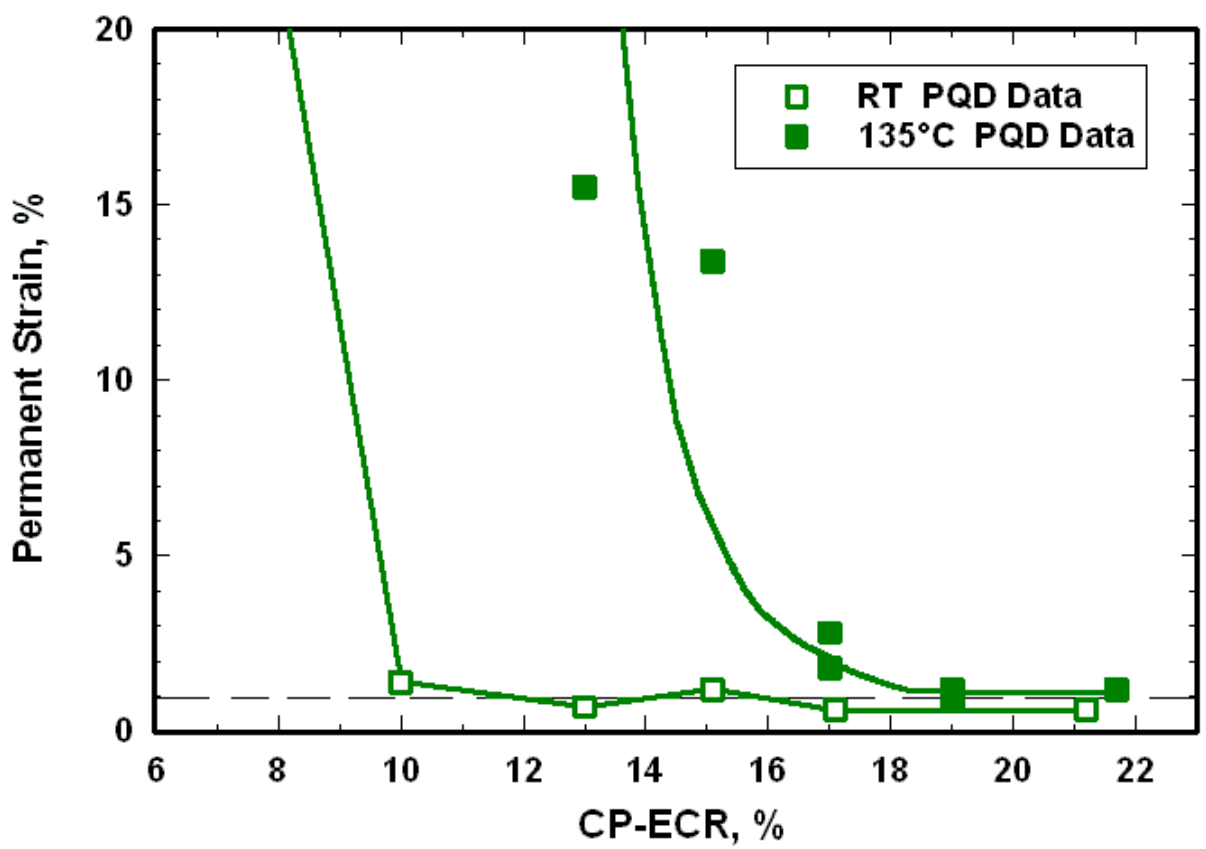

Figure 58b. Permanent strain vs. CP-ECR for $17 \times 17 \mathrm{ZIRLO}$ oxidized at $1200^{\circ} \mathrm{C}$, cooled at $\approx 13^{\circ} \mathrm{C} / \mathrm{s}$ to $800^{\circ} \mathrm{C}$, quenched, and ring-compressed at RT and $135^{\circ} \mathrm{C}$.

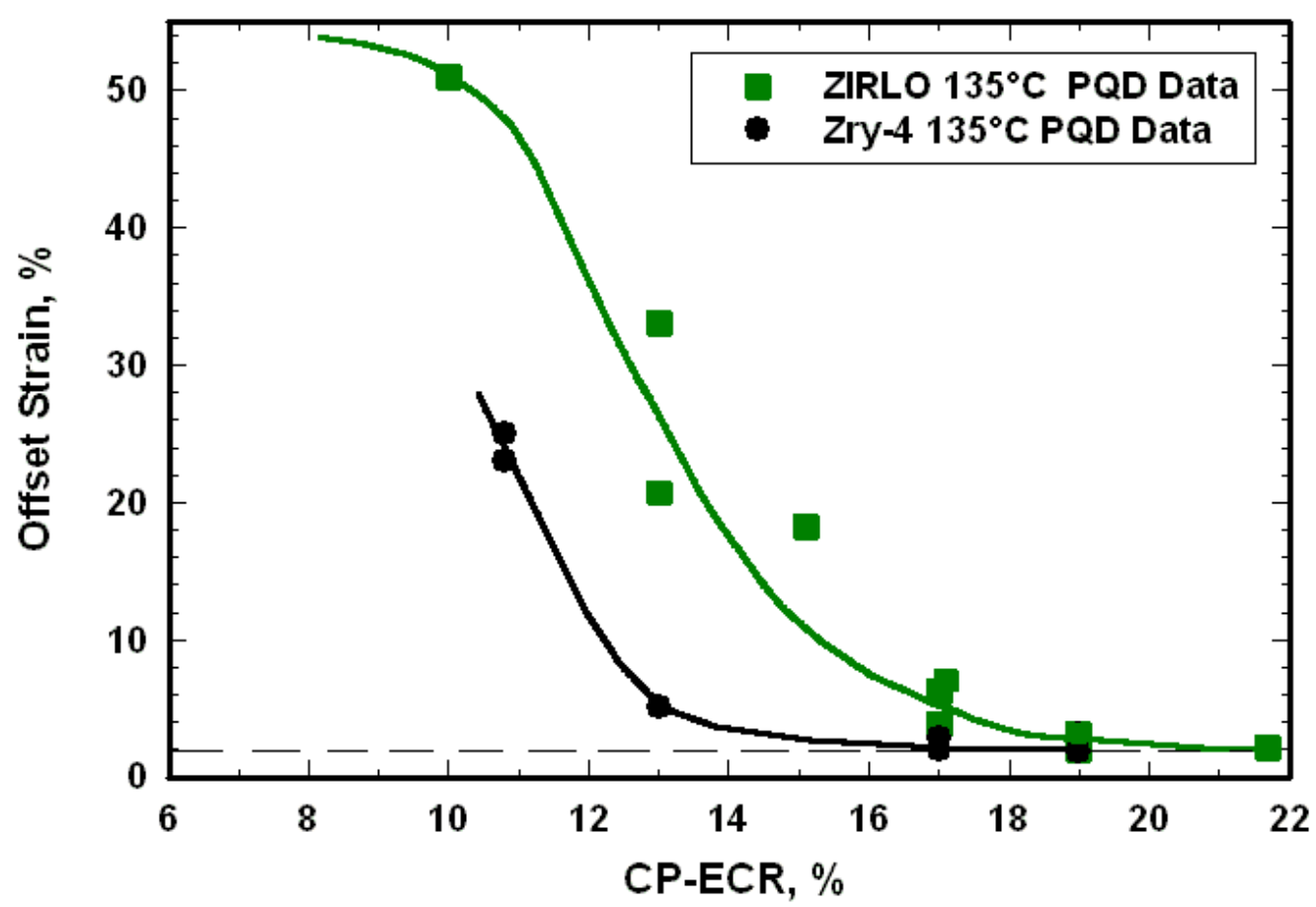

Figure 59. Offset strain vs. CP-ECR for $17 \times 17 \mathrm{ZIRLO}$ and Zry- 4 oxidized at $1200^{\circ} \mathrm{C}$, cooled at $\approx 13^{\circ} \mathrm{C} / \mathrm{s}$ to $800^{\circ} \mathrm{C}$, quenched, and ring-compressed at $135^{\circ} \mathrm{C}$. 
Table 28. Characterization of $17 \times 17$ Zry- 4 and ZIRLO Samples after Exposure to Steam at $1200^{\circ} \mathrm{C}$ to $13 \%$ and $20 \%$ CP-ECR, Cooling at $\approx 13^{\circ} \mathrm{C} / \mathrm{s}$ to $800^{\circ} \mathrm{C}$, and Quenched.

\begin{tabular}{|c|c|c|c|c|}
\hline \multirow[b]{2}{*}{ Parameter } & \multicolumn{2}{|c|}{ Zry-4 } & \multicolumn{2}{|c|}{ ZIRLO } \\
\hline & $20 \%$ ECR & $13 \% \mathrm{ECR}$ & $21.2 \% \mathrm{ECR}$ & $13 \% \mathrm{ECR}$ \\
\hline Effective $\mathrm{CP}$ time at $1200^{\circ} \mathrm{C}, \mathrm{s}$ & 400 & 166 & 444 & 166 \\
\hline Weight Gain, $\mathrm{mg} / \mathrm{cm}^{2}$ & 13.5 & 8.35 & 14.5 & 8.70 \\
\hline Measured ECR, \% & 20.8 & 12.8 & 22.3 & 13.4 \\
\hline RT Offset Displacement, mm & 0.05 & 0.09 & 0.11 & 0.11 \\
\hline RT Offset Strain, \% & 0.5 & 0.9 & 1.2 & 1.2 \\
\hline $\begin{array}{l}\text { RT Measured Permanent } \\
\text { Displacement, mm }\end{array}$ & 0.04 & 0.07 & 0.06 & 0.07 \\
\hline RT Permanent Strain, \% & 0.4 & 0.7 & 0.6 & 0.7 \\
\hline RT Ductility, \% & $\begin{array}{c}\leq 0.4 \\
\text { (brittle) }\end{array}$ & $\begin{array}{c}\leq 0.7 \\
\text { (brittle) }\end{array}$ & $\begin{array}{l}\leq 0.6 \\
\text { (brittle) }\end{array}$ & $\begin{array}{c}\leq 0.7 \\
\text { (brittle) }\end{array}$ \\
\hline Hydrogen Content, wppm & 17 & low & 17 & low \\
\hline Hydrogen Pickup, wppm & 13 & low & 14 & low \\
\hline OD/ID Oxide Thickness, $\mu \mathrm{m}$ & $68 / 66$ & $42 / 41$ & $74 / 71$ & $44 / 43$ \\
\hline Prior-Beta-Layer Thickness, $\mu \mathrm{m}$ & 266 & 419 & $\approx 150$ & $\approx 370$ \\
\hline $\begin{array}{l}\text { Microhardness, DPH } \\
\text { Oxide Layers } \\
\text { Alpha Layers } \\
\text { Prior-Beta Layer }^{\mathrm{a}}\end{array}$ & $\begin{array}{l}570-960 \\
530-730 \\
280-600\end{array}$ & $\begin{array}{l}600-770 \\
600-700 \\
260-360\end{array}$ & $\begin{array}{c}560-1160 \\
600-800 \\
350-530\end{array}$ & $\begin{array}{l}610-770 \\
650-860 \\
350-450\end{array}$ \\
\hline
\end{tabular}

${ }^{\mathrm{a}}$ Range includes microhardness values of oxygen-rich alpha needles (ZIRLO) and alpha incursions (Zry-4) in this layer. 


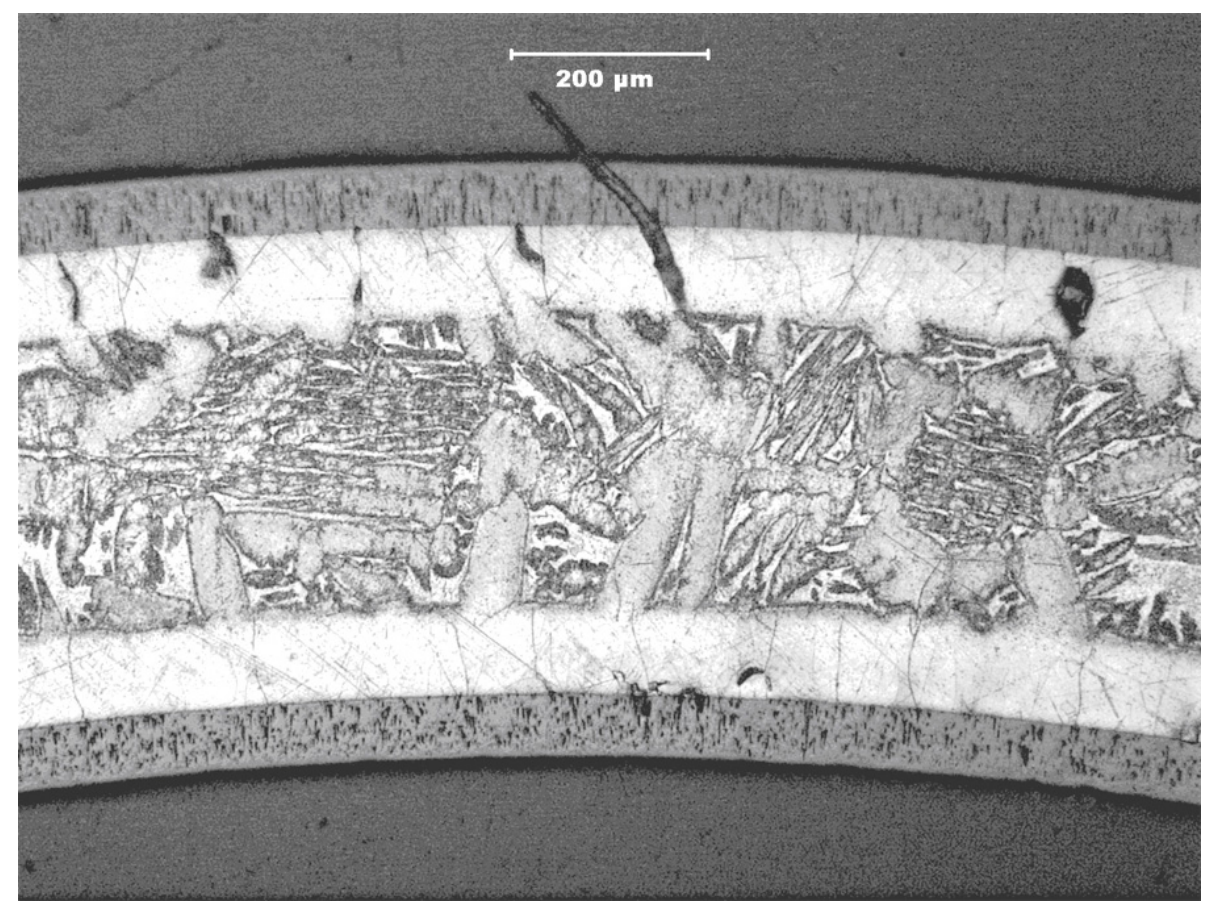

(a) Zry-4

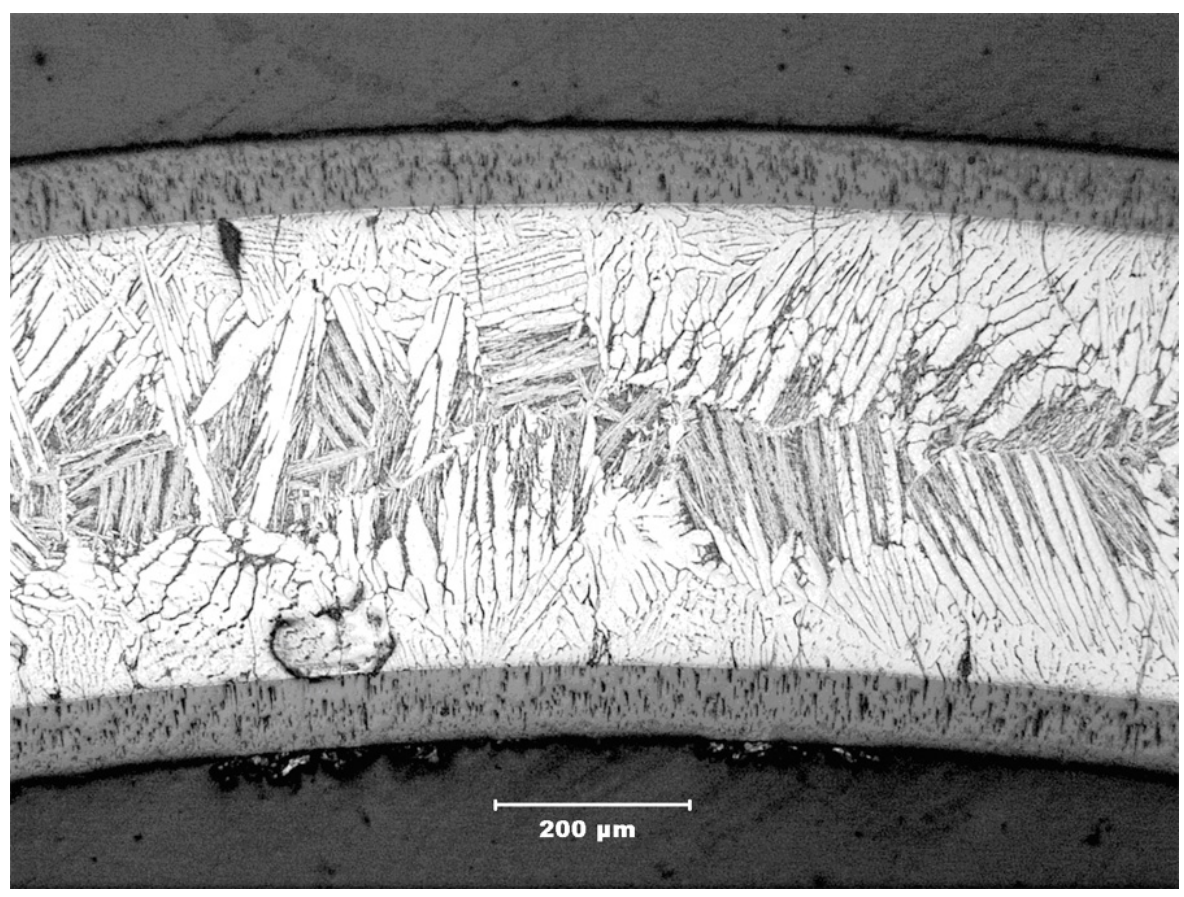

(b) ZIRLO

Figure 60. Metallography of etched Zry-4 (a) and ZIRLO (b) oxidized in steam at $1200^{\circ} \mathrm{C}$ for $\approx 400 \mathrm{~s}$ and $\approx 440 \mathrm{~s}$, respectively, cooled at $\approx 13^{\circ} \mathrm{C} / \mathrm{s}$ to $800^{\circ} \mathrm{C}$, and quenched. Measured ECR values are $20.8 \%$ for Zry-4 and $22.3 \%$ for ZIRLO. 


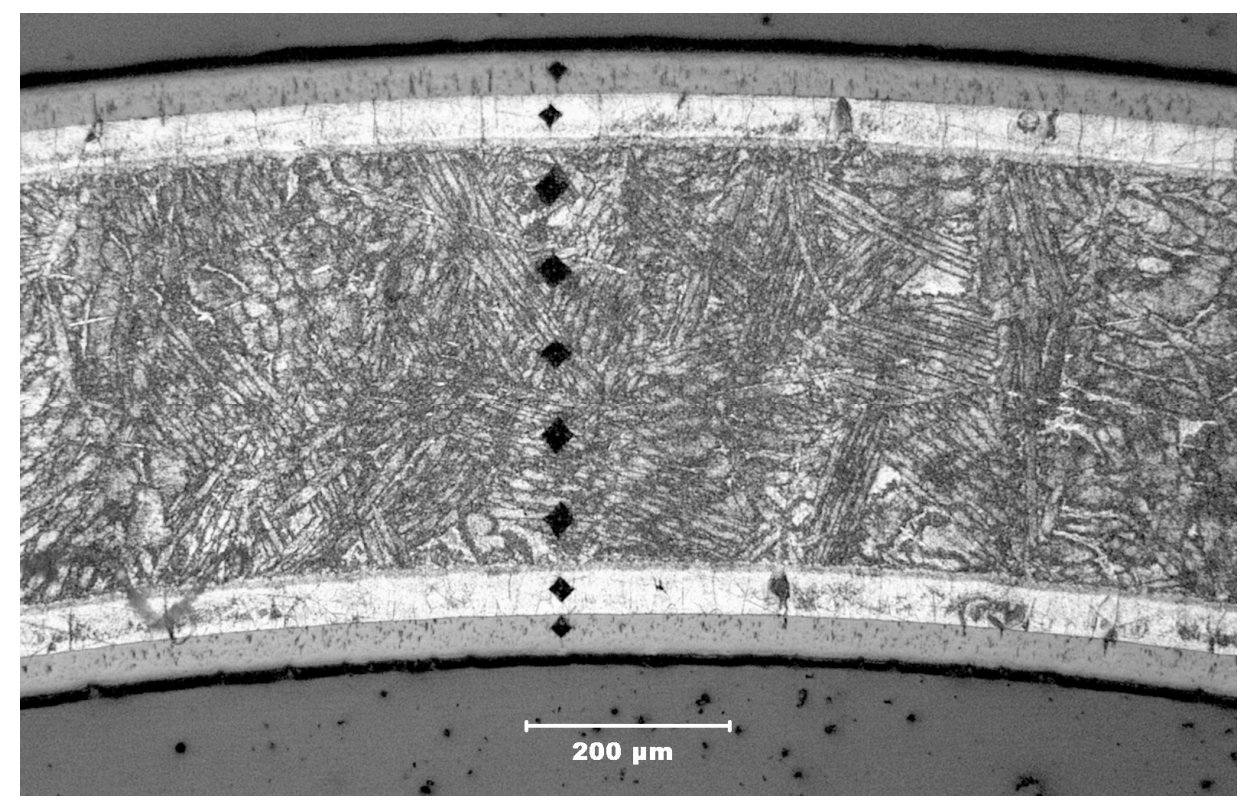

(a) Zry-4

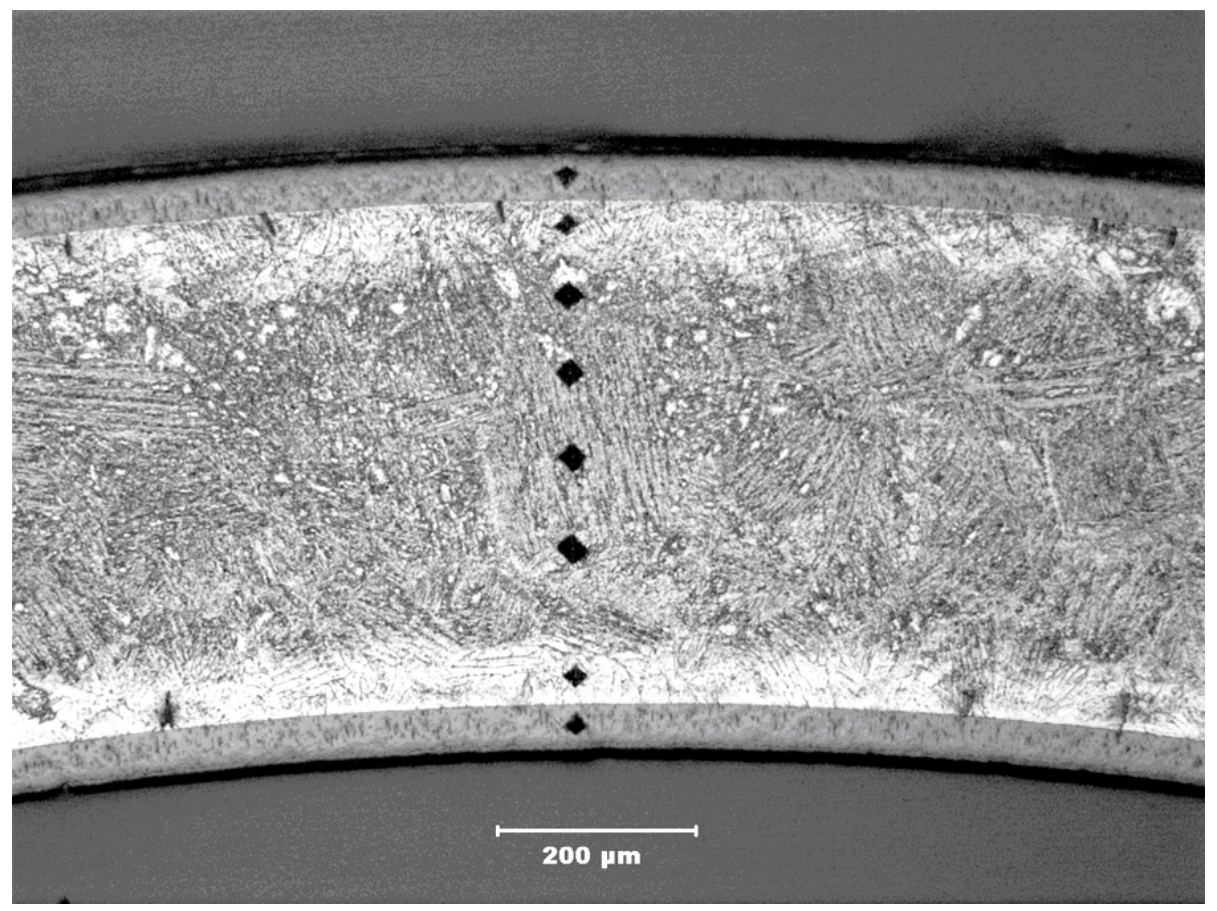

(b) ZIRLO

Figure 61. Metallography and microhardness indents across the radius of $17 \times 17 \mathrm{Zry}-4$ (a) and ZIRLO (b) oxidized at $1200^{\circ} \mathrm{C}$ to $13 \% \mathrm{ECR}$, cooled at $\approx 13^{\circ} \mathrm{C} / \mathrm{s}$ to $800^{\circ} \mathrm{C}$, and quenched. The measured ECR values are $12.6 \%$ for Zry-4 and $13.4 \%$ for ZIRLO. 


\subsubsection{Breakaway oxidation time for $17 \times 17$ ZIRLO samples oxidized at $800-1015^{\circ} \mathrm{C}$}

Unlike Zry-4, no published data were found for ZIRLO breakaway oxidation time vs. temperature. Thus, the approach adopted in this work was to explore breakaway oxidation times in the range of 950$1015^{\circ} \mathrm{C}$ to determine the minimum breakaway time. A test was also run at $800^{\circ} \mathrm{C}$ for a period greater than the minimum time for $950-1015^{\circ} \mathrm{C}$ to demonstrate that breakaway did not occur at earlier times at $800^{\circ} \mathrm{C}$. Based on the results shown in Figure 55b for ZIRLO received and tested in 2003 (ZIRLO-2003), the inner-surface oxide layer is already in breakaway following oxidation at $1000^{\circ} \mathrm{C}$ for $\approx 3400 \mathrm{~s}$. However, the breakaway oxidation time is relevant only to the cladding outer surface away from the balloon region. Given that ZIRLO may pick up hydrogen from the inner surface before the outer surface experiences breakaway oxidation, it was necessary to determine by visual inspection and metallography if the outer surface was in breakaway oxidation at the time corresponding to $\approx 200$-wppm hydrogen pickup. The outer-surface appearance and metallography are shown in Figure 62 for a sample oxidized for $3600 \mathrm{~s}$ at $985^{\circ} \mathrm{C}$, which is beyond the breakaway transition with hydrogen pickup of $270 \pm 165$ wppm.

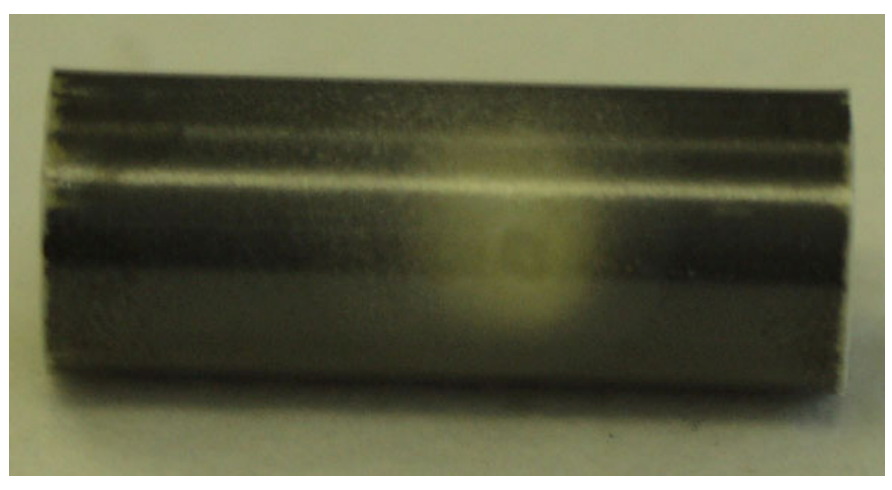

(a)

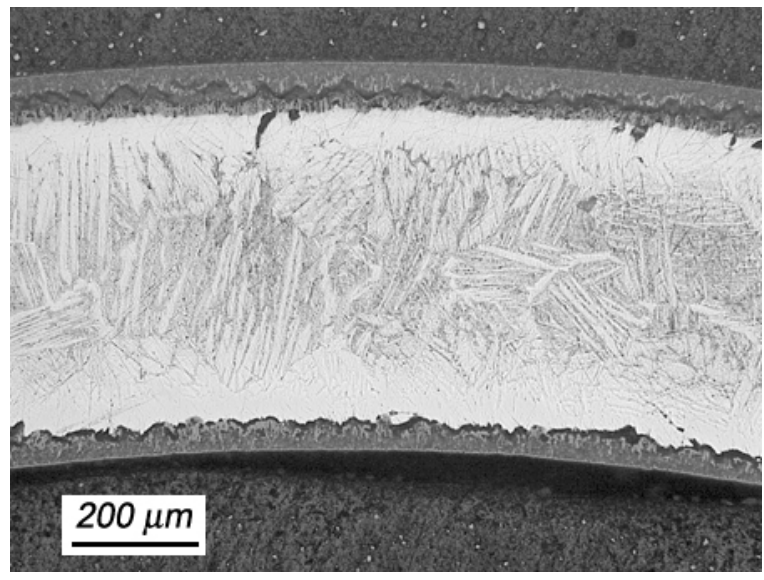

(c)

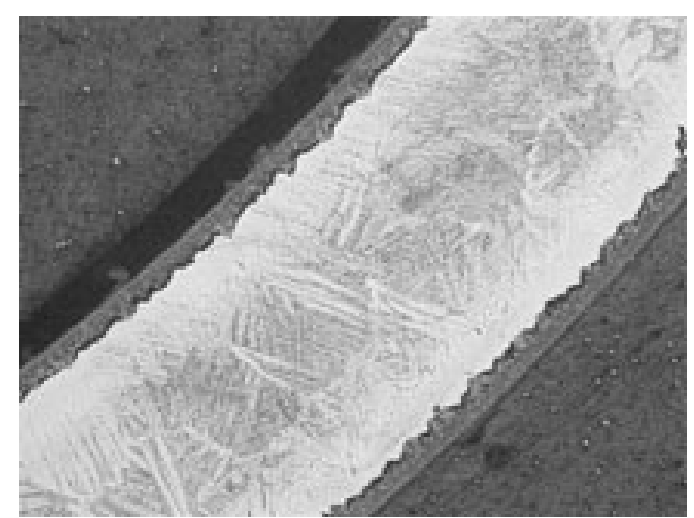

(b)

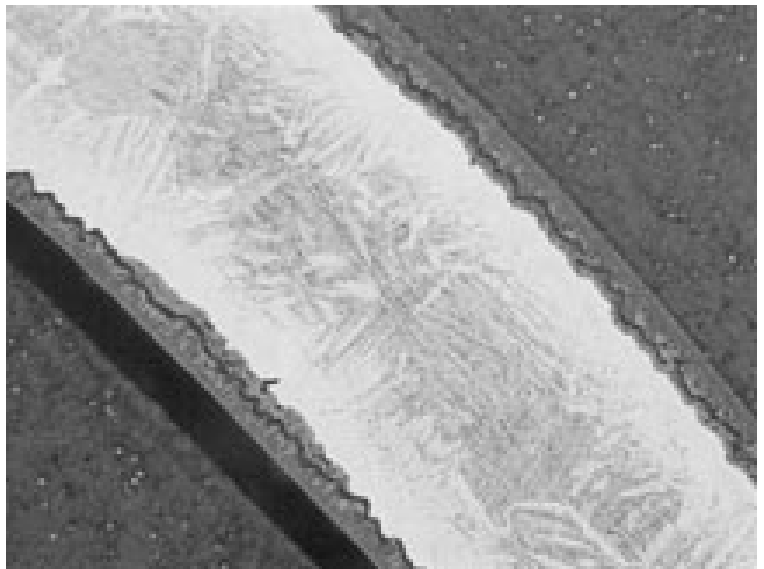

(d)

Figure 62. Surface appearance and oxide layers of ZIRLO oxidized at $985^{\circ} \mathrm{C}$ for $3600 \mathrm{~s}$ with $270 \pm 165$ wppm hydrogen pickup in a ring including the yellow area: (a) outer surface with yellow area (440 wppm $\mathrm{H}$ under this layer) in black matrix; (b) outer- and inner-surface oxide layers (no breakaway) under black area; (c) outer-surface (breakaway) and inner-surface (no breakaway) oxide layers under yellow area; and (d) outer- and inner-surface oxide layers under yellow, both in breakaway. 
ZIRLO tubing from a different lot was supplied to ANL by Westinghouse in 2006 for breakaway oxidation studies. Dimensions (9.49-mm OD, 0.57-mm wall), oxygen content (1164 wppm), and hydrogen content $(11 \mathrm{wppm})$ are comparable to those for ZIRLO-2003. The outer surface roughness of ZIRLO-2006 is a little higher $(0.17 \pm 0.03 \mu \mathrm{m})$ than the roughness of ZIRLO-2003 $(0.11 \pm 0.01 \mu \mathrm{m})$. Table 29 summarizes the ZIRLO breakaway oxidation results. Based on the ANL criterion of 200-wppmhydrogen pickup, the minimum breakaway time is $\approx 3000 \mathrm{~s}$, and it occurs at $970^{\circ} \mathrm{C}$. The breakaway oxidation times for higher $\left(985-1015^{\circ} \mathrm{C}\right)$ and lower $\left(800^{\circ} \mathrm{C}\right.$ and $\left.950^{\circ} \mathrm{C}\right)$ oxidation temperatures were $>3000 \mathrm{~s}$. The post-oxidation ductility at $135^{\circ} \mathrm{C}$ for samples with significant hydrogen pickup is summarized in Table 30 . ZIRLO is ductile at $135^{\circ} \mathrm{C}$ with a hydrogen pickup $\leq 440 \mathrm{wppm}$, and it is brittle with a hydrogen pickup $\geq 730$ wppm for oxidation temperatures in the range of $970-985^{\circ} \mathrm{C}$. The hydrogen data in Table 30 represent the average hydrogen content of the 8-mm-long rings and not the maximum hydrogen content of the sample. The results are presented to demonstrate the ductility of ZIRLO at the breakaway-oxidation time criterion of 200-wppm-hydrogen pickup. Because breakaway oxidation is an instability phenomenon, it is not advisable to use a higher hydrogen pickup for this criterion even if the alloy has some ductility with $>200$-wppm hydrogen.

Table 29. Data Summary for ZIRLO Breakaway Oxidation Tests at $950-1015^{\circ} \mathrm{C}$ and $800^{\circ} \mathrm{C}$. ZIRLO2003 samples were quenched at $800^{\circ} \mathrm{C}$; ZIRLO-2006 samples were slow cooled to RT.

\begin{tabular}{|c|c|c|c|c|c|c|}
\hline $\begin{array}{c}\text { ZIRLO } \\
\text { Lot }\end{array}$ & $\begin{array}{c}\mathrm{T}, \\
{ }^{\circ} \mathrm{C}\end{array}$ & $\begin{array}{c}\text { Test } \\
\text { Time, }^{\mathrm{a}} \\
\mathrm{s}\end{array}$ & $\begin{array}{c}\mathrm{CP} \mathrm{Wg,} \\
\mathrm{mg} / \mathrm{cm}^{2}\end{array}$ & $\begin{array}{c}\text { Measured Wg, } \\
\mathrm{mg} / \mathrm{cm}^{2}\end{array}$ & $\begin{array}{c}\text { Hydrogen } \\
\text { Content }\left(\mathrm{L}_{\mathrm{H}}\right), \\
\text { wppm }\end{array}$ & $\begin{array}{c}\text { Hydrogen } \\
\text { Pickup } \\
\left(\Delta \mathrm{C}_{\mathrm{H}}\right), \\
\text { wppm }^{\mathrm{b}}\end{array}$ \\
\hline 2006 & 1015 & 4000 & 15.6 & 15.1 & 30 & 21 \\
\hline 2006 & 1000 & 1500 & 8.63 & 8.68 & 15 & 5 \\
\hline 2003 & 1000 & 2440 & 11.1 & 10.8 & 36 & 30 \\
\hline 2003 & 1000 & 3480 & 13.0 & 11.7 & 102 & 100 \\
\hline 2006 & 1000 & 3600 & 13.5 & 11.4 & 68 & 60 \\
\hline 2006 & 1000 & 4000 & 14.2 & 12.6 & $131 \pm 12$ & 130 \\
\hline 2006 & 1000 & 4200 & 14.5 & 14.3 & $608 \pm 366$ & 630 \\
\hline 2006 & 1000 & 5000 & 15.9 & 16.9 & $1246 \pm 83$ & 1350 \\
\hline 2006 & 985 & 3400 & 11.9 & 9.6 & 46 & 37 \\
\hline $\mathbf{2 0 0 6}{ }^{\mathbf{c}}$ & $\mathbf{9 8 5}$ & $\mathbf{3 4 0 0}$ & $\mathbf{1 1 . 9}$ & $\mathbf{9 . 9}$ & $\mathbf{1 7 4 \pm 1 4 0}$ & $\mathbf{1 7 5} \pm \mathbf{1 4 5}$ \\
\hline 2006 & 985 & 3600 & 12.3 & 10.0 & $267 \pm 158$ & 270 \\
\hline 2006 & 985 & 4000 & 12.9 & 11.8 & $847 \pm 143$ & 890 \\
\hline $\mathbf{2 0 0 6}{ }^{\mathbf{c}}$ & $\mathbf{9 7 0}$ & $\mathbf{2 6 0 0}$ & $\mathbf{9 . 5}$ & $\mathbf{7 . 8}$ & $\mathbf{5 3}$ & $\mathbf{4 4}$ \\
\hline 2006 & 970 & 3000 & 10.2 & 8.1 & $199 \pm 150$ & 200 \\
\hline 2006 & 970 & 3400 & 10.8 & 8.6 & $565 \pm 85$ & 580 \\
\hline 2006 & 950 & 3000 & 8.9 & 6.8 & 31 & 20 \\
\hline 2006 & 800 & 4000 & --- & 2.62 & 14 & 3 \\
\hline
\end{tabular}

${ }^{a}$ Includes time from beginning of ramp at $300^{\circ} \mathrm{C}$ to end of hold time at oxidation temperature. ${ }^{b}$ Hydrogen pickup $\left(\Delta \mathrm{C}_{\mathrm{H}}\right)$ is referenced to the as-fabricated sample weight: $\Delta \mathrm{C}_{\mathrm{H}}=\left(1+5.4 \times 10^{-3} \mathrm{Wg}\right) \mathrm{L}_{\mathrm{H}}-\mathrm{C}_{\mathrm{Hi}}$, where $\mathrm{C}_{\mathrm{Hi}}$ is as-fabricated hydrogen content $(11 \mathrm{wppm})$.

${ }^{\mathrm{c}} \mathrm{Samples}$ with machined scratch, $\approx 20-\mu \mathrm{m}$ deep into the outer surface (see Section 3.5.2). 
Table 30. Post-oxidation Ductility of ZIRLO with Significant Hydrogen Pickup during Breakaway Oxidation. ZIRLO-2006 samples summarized in Table 29 were oxidized at $985^{\circ} \mathrm{C}$ and $970^{\circ} \mathrm{C}$, then cooled without quench to RT and ring-compressed at $135^{\circ} \mathrm{C}$; average hydrogen values are reported for the $8-\mathrm{mm}$-long rings compressed at $0.0333 \mathrm{~mm} / \mathrm{s}$.

\begin{tabular}{|c|c|c|c|c|c|}
\hline $\begin{array}{c}\text { Oxidation } \\
\mathrm{T}, \\
{ }^{\circ} \mathrm{C}\end{array}$ & $\begin{array}{c}\text { Test } \\
\text { Time, } \\
\mathrm{s}\end{array}$ & $\begin{array}{c}\text { H-Content } \\
\mathrm{L}_{\mathrm{H}}, \text { wppm }\end{array}$ & $\begin{array}{c}\text { H-Pickup } \\
\Delta \mathrm{C}_{\mathrm{H}}, \\
\text { wppm }\end{array}$ & $\begin{array}{c}\text { Offset } \\
\text { Strain, } \\
\%\end{array}$ & $\begin{array}{c}\text { Permanent } \\
\text { Strain, } \\
\%\end{array}$ \\
\hline $\mathbf{9 8 5}^{\mathbf{c}}$ & $\mathbf{3 4 0 0}$ & $\mathbf{1 7 4} \pm \mathbf{1 4 0}$ & $\mathbf{1 7 5} \pm \mathbf{1 4 5}$ & $\mathbf{5 . 1}$ & $\mathbf{5 . 1}$ \\
\hline 985 & 3600 & $214 \pm 120$ & $215 \pm 125$ & $>1.7$ & -- \\
\hline 985 & 4000 & $\begin{array}{c}731 \pm 112 \\
987 \pm 16\end{array}$ & $\begin{array}{c}765 \pm 120 \\
1040 \pm 20\end{array}$ & $\begin{array}{c}0.8 \\
0.8\end{array}$ & 0.2 \\
\hline 970 & 3400 & $416 \pm 100$ & $435 \pm 105$ & 4.8 & 2.1 \\
\hline
\end{tabular}

${ }^{a}$ Includes time from beginning of ramp at $300^{\circ} \mathrm{C}$ to end of hold time at oxidation temperature. ${ }^{b}$ Hydrogen pickup $\left(\Delta C_{H}\right)$ is referenced to the as-fabricated sample weight: $\Delta \mathrm{C}_{\mathrm{H}}=\left(1+5.4 \times 10^{-3} \mathrm{Wg}\right) \mathrm{L}_{\mathrm{H}}-\mathrm{C}_{\mathrm{Hi}}$, where $\mathrm{C}_{\mathrm{Hi}}$ is as-fabricated hydrogen content.

${ }^{\mathrm{c}}$ Samples with machined scratch, $\approx 20-\mu \mathrm{m}$ deep into the outer surface (see Section 3.5.2 for details).

As shown in Figure 63, both ZIRLO and Zry-4 maintain ductility for hydrogen pickup $\leq 440$ wppm and are brittle for hydrogen pickup $>700$ wppm. Thus, ductility is retained for $\leq 200$ wppm hydrogen pickup. The ductile-to-brittle transition hydrogen level for these oxidation temperatures is $\approx 500-700$ wppm.

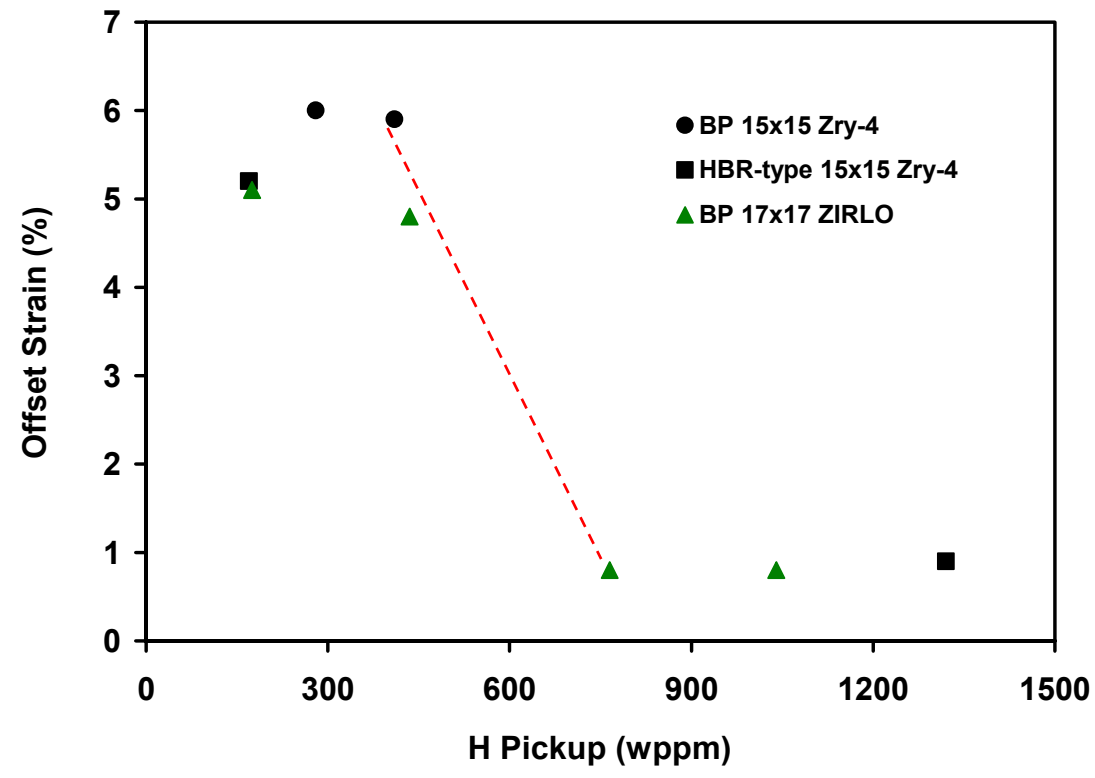

Figure 63. Offset strain at $135^{\circ} \mathrm{C}$ vs. hydrogen pickup for $17 \times 17 \mathrm{ZIRLO}$ and $15 \times 15 \mathrm{Zry}-4$ breakaway oxidation samples oxidized at $970-1000^{\circ} \mathrm{C}$ and cooled without quench. 


\section{$3.4 \quad$ M5}

\subsubsection{Post-quench ductility of $17 \times 17 \mathrm{M5}$ oxidized at $1000^{\circ} \mathrm{C}, 1100^{\circ} \mathrm{C}$, and $1200^{\circ} \mathrm{C}$}

This work was performed in parallel with the $17 \times 17$ Zry-4 and ZIRLO testing and characterization. Although the same test times were used for M5 as for Zry-4 and ZIRLO, the thicker M5 wall (0.61 mm) required new thermal benchmarks for each oxidation temperature. Also, the CP-ECR was reduced by a factor of $0.57 / 0.61=0.934$ for the M5 relative to Zry-4: ECR $=1.437 \mathrm{Wg}$. The M5 results are presented with the same subdivision of topics as used for Zry-4: characterization and RT-ring-compression testing of samples that were two-sided oxidized at $1000^{\circ} \mathrm{C}$ and $1100^{\circ} \mathrm{C}$ and quenched at $800^{\circ} \mathrm{C}$; and characterization and ring-compression testing (RT and $135^{\circ} \mathrm{C}$ ) of samples exposed to two-sided oxidized at $1200^{\circ} \mathrm{C}$ and quenched at $800^{\circ} \mathrm{C}$. Characterization included weight gain, oxide- and alpha-layer thickness (metallography), microhardness, and hydrogen pickup (LECO) measurements. The M5 samples were oxidized to CP-predicted ECR values of 4.7, 9.3, 14.1, 16.0, and 18.8\%. Additional M5 oxidation tests were conducted to 20-21\% CP-ECR to allow a direct comparison with the Zry-4 results in terms of CP-ECR. As with the Zry-4 tests, M5 tests were conducted at intermediate CP-ECR values for the $1200^{\circ} \mathrm{C}$-oxidized samples to better determine the ductile-to-brittle transition ECR value for this oxidation temperature.

\section{$17 \times 17 \mathrm{M} 5$ oxidized at $1000^{\circ} \mathrm{C}$ and $1100^{\circ} \mathrm{C}$}

The thermal benchmarks used for the thicker M5 cladding are shown in Figure 64 for $1000^{\circ} \mathrm{C}$ tests and Figure 65 for $1100^{\circ} \mathrm{C}$ tests. Table 31 lists the weight gain results for $\mathrm{M} 5$ at $1000^{\circ} \mathrm{C}$ and $1100^{\circ} \mathrm{C}$ oxidation temperatures. The results at $1100^{\circ} \mathrm{C}$ are in good agreement with both the Zry-4 results and the $\mathrm{CP}$-predicted weight gain. For $1000^{\circ} \mathrm{C}$ oxidation, M5 exhibits significantly lower weight gain than Zry-4 and the CP-predicted weight gain for the same oxidation time. The M5 and Zry-4 weight gains are plotted in Figure $66: 1000^{\circ} \mathrm{C}$ results in Figure $66 \mathrm{a}$ and $1100^{\circ} \mathrm{C}$ results in Figure $66 \mathrm{~b}$.

Table 32 lists the results of the RT post-quench ductility tests. It is clear that $17 \times 17$ M5 retains post-quench ductility up to $20 \% \mathrm{CP}-\mathrm{ECR}$ - the limit of the test conditions - at these oxidation temperatures. The results are shown graphically in Figures 67 and 68 for $1000^{\circ} \mathrm{C}$ and $1100^{\circ} \mathrm{C}$ oxidation temperatures, respectively. Because of differences in weight gain between M5 and Zry-4 oxidized at $1000^{\circ} \mathrm{C}$, offset strains are plotted as functions of measured ECR (Figure 67a) and CP-ECR (Figure 67b). For oxidation at $1100^{\circ} \mathrm{C}$, both alloys exhibit essentially the same weight gain for the same test time. Thus, post-quench ductility results are plotted in Figure 68 as a function of CP-ECR only. For the $1000^{\circ} \mathrm{C}$ - and $1100^{\circ} \mathrm{C}$-oxidation tests, the $\mathrm{M} 5$ offset strain levels out at $\approx 3 \%$. It appears that M5 will retain ductility at higher CP-ECR values and higher test times until breakaway oxidation $\left(>4100 \mathrm{~s}\right.$ at $\left.1000^{\circ} \mathrm{C}\right)$ or significant beta-layer thinning $\left(>20 \% \mathrm{CP}\right.$-ECR at $\left.1100^{\circ} \mathrm{C}\right)$ occurs. For $1100^{\circ} \mathrm{C}$-oxidation, breakaway oxidation should not occur, and the beta layer does not appear to embrittle due to the low saturation-level oxygen content.

M5 post-quench ductility results for $1000^{\circ} \mathrm{C}$-oxidized samples illustrate an important point. Postquench ductility is determined by the oxygen concentration distribution in the beta phase. Even if the growth rate of the oxide layer is slower for M5 than for Zry-4 at $1000^{\circ} \mathrm{C}$, sufficient oxygen is available in the oxide to transport oxygen from the oxide to the oxygen-stabilized alpha layer to the beta layer. The rate of diffusion into the beta layer is controlled by the alpha/beta boundary condition (i.e., solubility limit of oxygen in the M5 beta layer) and the oxygen concentration gradient in the beta layer. The excellent correlation between ductility loss and increasing CP-ECR is because both beta-layer oxygen pickup and CP-ECR are proportional to the square-root of time under isothermal conditions. 


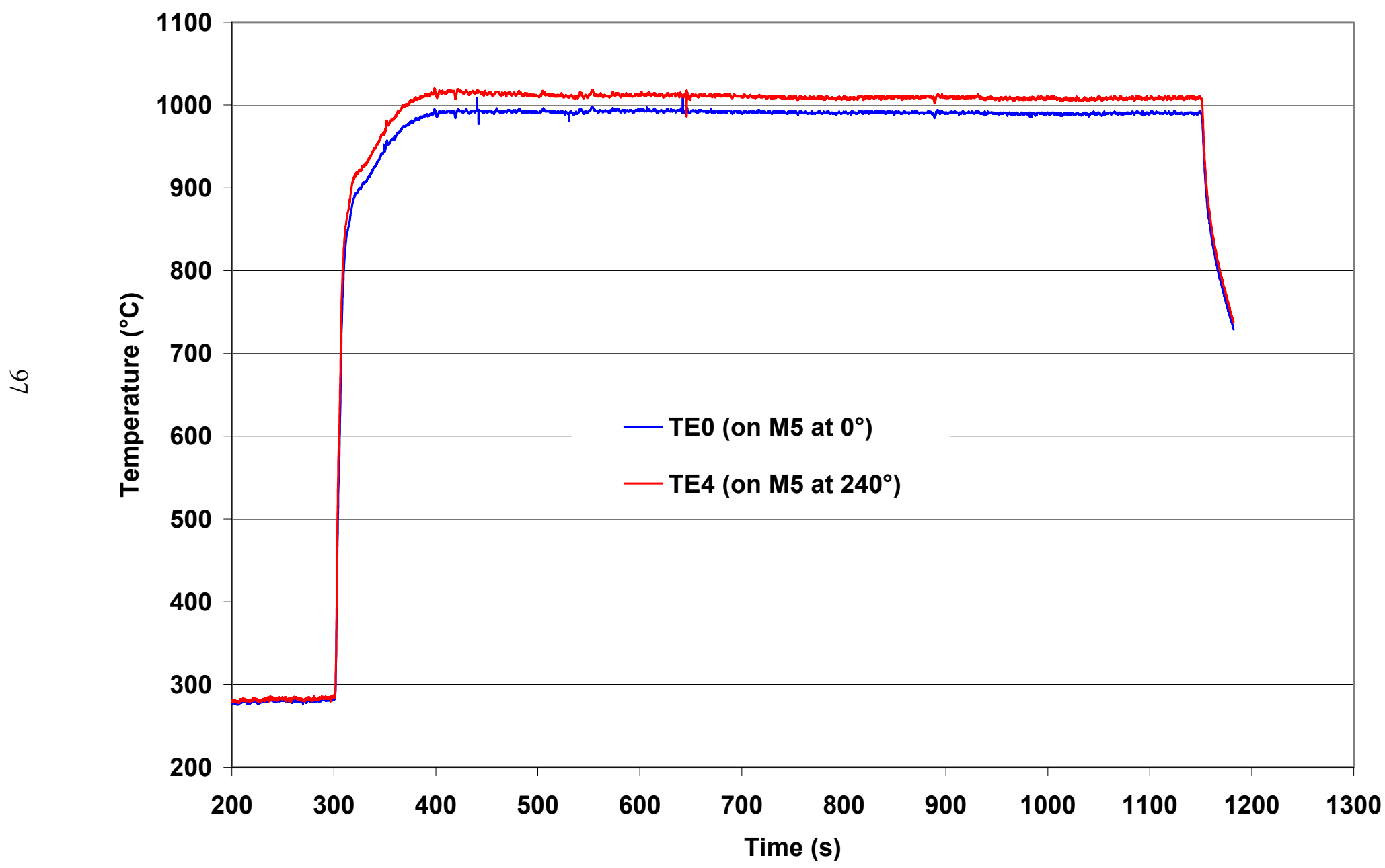

Figure 64. Thermal benchmark results for $17 \times 17 \mathrm{M} 5$ oxidation tests at $1000^{\circ} \mathrm{C}$. The cladding OD is $9.50 \mathrm{~mm}$, and the wall thickness is $0.61 \mathrm{~mm}$. Quench at $800^{\circ} \mathrm{C}$ is not shown in this figure. 


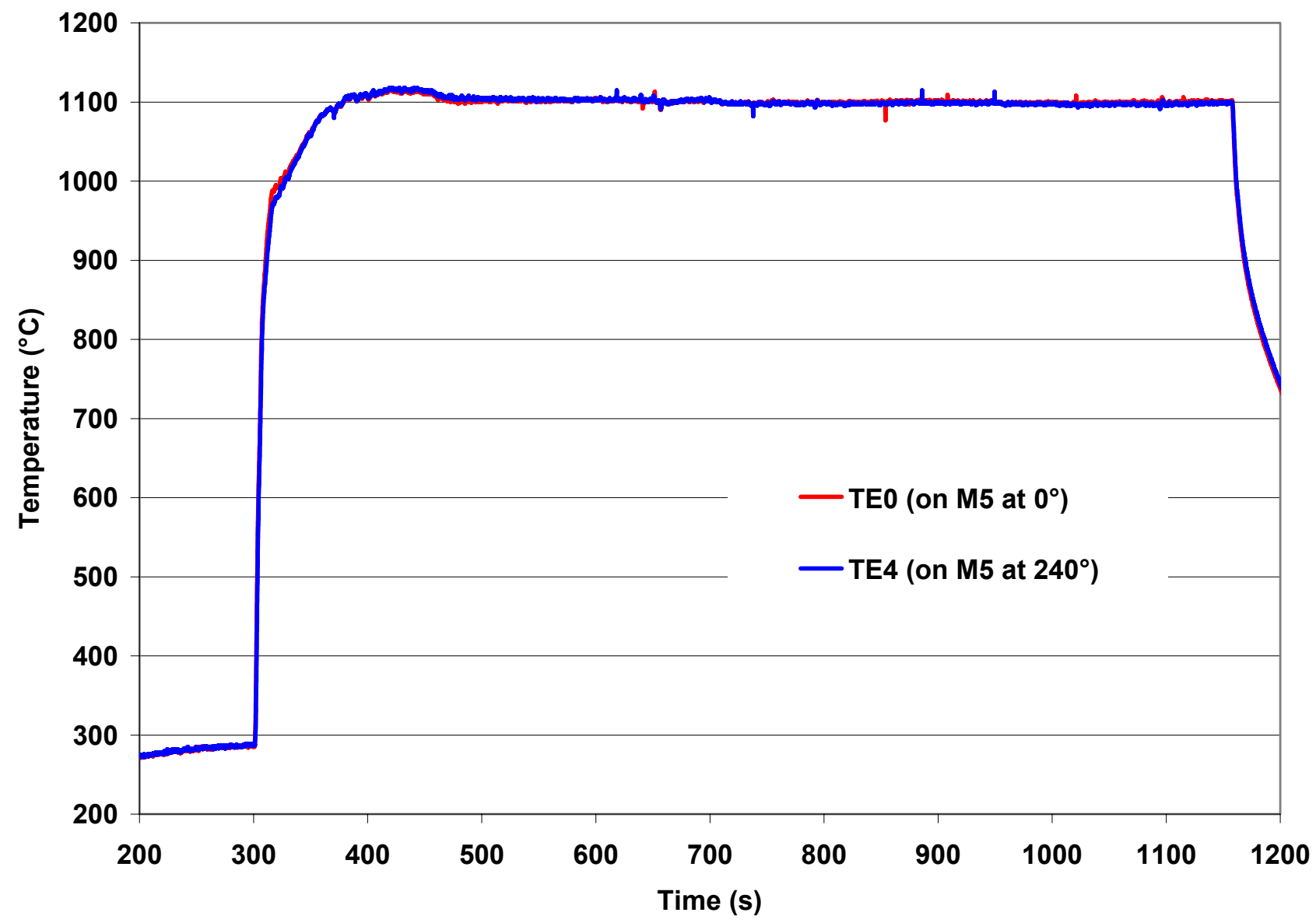

Figure 65. Thermal benchmark results for $17 \times 17 \mathrm{M} 5$ oxidation tests at $1100^{\circ} \mathrm{C}$. The cladding $\mathrm{OD}$ is $9.50 \mathrm{~mm}$, and the wall thickness is $0.61 \mathrm{~mm}$. Quench at $800^{\circ} \mathrm{C}$ is not shown in this figure. 
Table 31. Weight Gain (Wg in $\left.\mathrm{mg} / \mathrm{cm}^{2}\right)$ and Measured ECR (\%) Values for $17 \times 17 \mathrm{M} 5$ Oxidized in Steam at $1000^{\circ} \mathrm{C}$ and $1100^{\circ} \mathrm{C}$ and Quenched at $800^{\circ} \mathrm{C}$. ECR $=1.437 \mathrm{Wg}$ for the $0.61-\mathrm{mm}-$ wall thickness; multiply weight gain results by a factor of 10 to convert to $\mathrm{g} / \mathrm{m}^{2}$.

\begin{tabular}{|c|c|c|c|}
\hline $\begin{array}{c}\text { Oxidation } \\
\text { Temperature } \\
{ }^{\circ} \mathrm{C}\end{array}$ & $\begin{array}{c}\text { Cathcart-Pawel } \\
\text { ECR } \\
\%\end{array}$ & $\begin{array}{c}\text { Measured } \\
\text { Weight Gain } \\
\mathrm{mg} / \mathrm{cm}^{2}\end{array}$ & $\begin{array}{c}\text { Measured } \\
\text { ECR } \\
\%\end{array}$ \\
\hline 1000 & 4.7 & 3.0 & 4.3 \\
\hline 1000 & 9.3 & 5.3 & 7.6 \\
\hline 1000 & 14.1 & 7.4 & 10.7 \\
\hline 1000 & 16.0 & 8.0 & 11.6 \\
\hline 1000 & 18.8 & 9.2 & 13.3 \\
\hline 1000 & 20.7 & 8.6 & 12.4 \\
\hline 1100 & 4.7 & 3.2 & 4.6 \\
\hline 1100 & 9.3 & 6.4 & 9.2 \\
\hline 1100 & 14.1 & 9.6 & 13.8 \\
\hline 1100 & 16.0 & 11.3 & 16.2 \\
\hline 1100 & 18.8 & 13.3 & 19.1 \\
\hline 1100 & 20.4 & 14.3 & 20.6 \\
\hline
\end{tabular}

Photographs of the ring-compressed samples are shown in Figure $69 \mathrm{a}$ for $1000^{\circ} \mathrm{C}$-oxidized samples and Figure $69 \mathrm{~b}$ for $1100^{\circ} \mathrm{C}$-oxidized samples. The 5\% (actually $4.7 \%$ ) and $10 \%$ (actually 9.3\%) CP-ECR samples oxidized at $1000^{\circ} \mathrm{C}$ were intact at the maximum test displacement. The $10 \%$ (actually $9.3 \%$ ) CPECR sample oxidized at $1100^{\circ} \mathrm{C}$ was also intact.

Table 33 summarizes the results of the metallography, microhardness, and hydrogen pickup measurements for M5 as compared to Zry-4. The hydrogen pickup is very low for the $1000^{\circ} \mathrm{C}$ - and $1100^{\circ} \mathrm{C}$-oxidized samples. The results in Table 33 are consistent with the post-quench ductility results.

Figure 70 shows metallographic images of Zry-4 and M5 oxide layers following $1000^{\circ} \mathrm{C}$ oxidation for $3364 \mathrm{~s}$. From these images, it is clear that the higher weight gain for Zry-4 oxidized at this temperature is due to the thicker oxide layers grown on the Zry-4 surfaces. This weight gain difference is clearly an alloy effect. Also, as will be discussed in Section 3.4.2, the mild waviness of the M5 oxide layers is an early precursor to breakaway oxidation and hydrogen pickup. Table 33 shows that the outersurface oxide layer is only $4-\mu \mathrm{m}$ thicker than the inner-surface oxide. These results, along with the results for the sample oxidized for $4100 \mathrm{~s}$, suggest that the breakaway oxidation time for $\mathrm{M} 5$ oxidized at $1000^{\circ} \mathrm{C}$ may be significantly above $4100 \mathrm{~s}$. Figure 71 shows higher magnification and better contrast for the outer-surface oxide layer grown on the M5 sample oxidized for $\approx 3400 \mathrm{~s}$.

Figure 72 shows the metallography for M5 and Zry-4 oxidized at $1100^{\circ} \mathrm{C}$ for $1065 \mathrm{~s}$. The Zry- 4 prior-beta layer includes regions of higher-oxygen alpha-phase material - alpha incursions - which precipitated during cooling from $1100^{\circ} \mathrm{C}$ to $800^{\circ} \mathrm{C}$ prior to quench. The $\mathrm{M} 5$ alpha and prior-beta layers are quite different in appearance from those of Zry-4. While oxygen is an alpha-stabilizer, $\mathrm{Nb}$ is a 


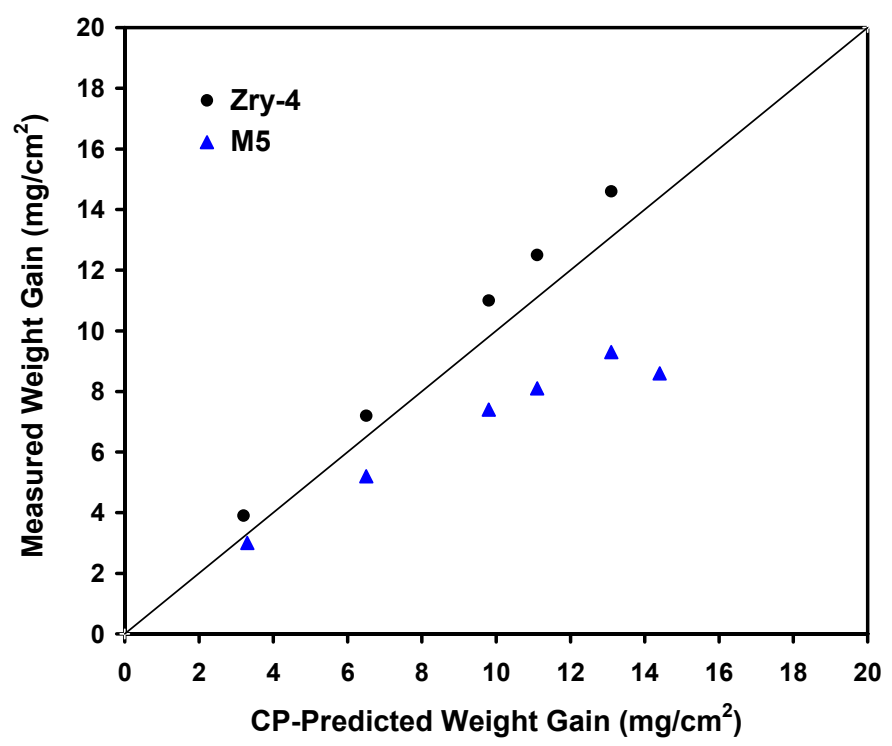

(a) $1000^{\circ} \mathrm{C}$

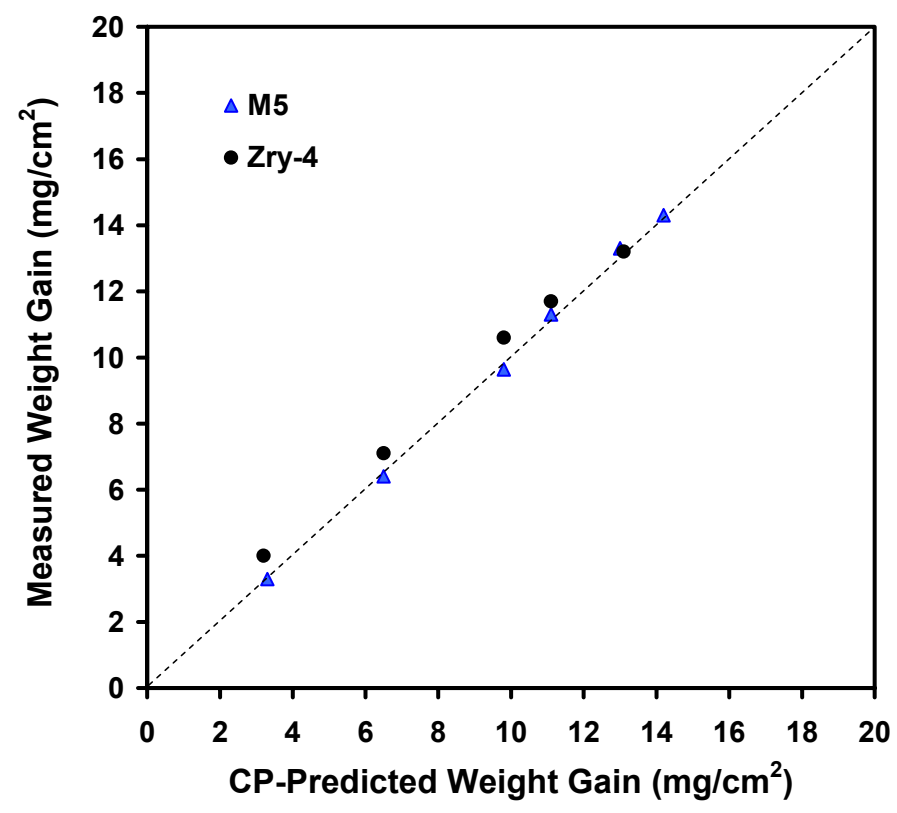

(b) $1100^{\circ} \mathrm{C}$

Figure 66. Comparison between weight gain data for M5 and Zry-4 and weight gain predicted by the Cathcart-Pawel (CP) correlation for samples oxidized (two-sided) in steam at $1000^{\circ} \mathrm{C}$ (a) and $1100^{\circ} \mathrm{C}(\mathrm{b})$. Test times correspond to CP-ECR values of $\approx 5-20 \%$. 
Table 32. Ring Compression Test Results for $17 \times 17 \mathrm{M} 5$ Samples Oxidized at $1000^{\circ} \mathrm{C}$ and $1100^{\circ} \mathrm{C}$, Cooled at $\approx 10^{\circ} \mathrm{C} / \mathrm{s}$ to $800^{\circ} \mathrm{C}$, and Quenched. ECR $=1.437 \mathrm{Wg}$ for 0.61 -mm-wall cladding. Displacements in the loading direction were normalized to the as-fabricated outer diameter $(9.50 \mathrm{~mm})$ to calculate offset strain. Tests were performed on 8-mm-long samples at RT and $0.0333-\mathrm{mm} / \mathrm{s}$ displacement rate in the Model 4505 Instron. Some confirmation tests were conducted in the new Model 5566 Instron with rings from the same oxidation samples.

\begin{tabular}{|c|c|c|c|c|c|}
\hline $\begin{array}{c}\text { Oxidation } \\
\text { Temperature, } \\
{ }^{\circ} \mathrm{C}\end{array}$ & $\begin{array}{l}\text { Cathcart- } \\
\text { Pawel } \\
\text { ECR, \% }\end{array}$ & $\begin{array}{c}\text { Measured } \\
\text { ECR, } \\
\%\end{array}$ & $\begin{array}{c}\text { Offset } \\
\text { Displacement, } \\
\mathrm{mm}\end{array}$ & $\begin{array}{c}\text { Offset } \\
\text { Strain, } \\
\%\end{array}$ & $\begin{array}{c}\text { Confirmation } \\
\text { Tests } \\
\text { Model } 5566 \\
\text { Instron }\end{array}$ \\
\hline 1000 & 4.7 & 4.3 & $>4.6$ & $>48$ & --- \\
\hline 1000 & 9.3 & 7.6 & $>4.9$ & $>51$ & Yes \\
\hline 1000 & 14.1 & 10.7 & 3.76 & 40 & Yes \\
\hline 1000 & 16.0 & 11.6 & $\leq 1.82$ & $\leq 19$ & --- \\
\hline 1000 & 18.8 & 13.3 & 0.302 & 3.2 & --- \\
\hline 1000 & 20.7 & 12.4 & 0.238 & $2.5^{\mathrm{a}, \mathrm{b}}$ & --- \\
\hline 1100 & 4.7 & 4.6 & 5.4 & 57 & --- \\
\hline 1100 & 9.3 & 9.2 & $>3.7$ & $>39$ & --- \\
\hline 1100 & 14.1 & 13.8 & 0.71 & 7.5 & Yes \\
\hline 1100 & 16.0 & 16.2 & 0.38 & 4.0 & --- \\
\hline 1100 & 18.7 & 19.1 & 0.17 & 1.8 & --- \\
\hline 1100 & 20.4 & 20.6 & 0.31 & $3.2^{\mathrm{a}}$ & --- \\
\hline
\end{tabular}

${ }^{a}$ Tests were interrupted after the first significant load drop to determine permanent strains of $2.1 \%$ and $1.2 \%$ for $2.5 \%$ and $3.2 \%$ offset strains, respectively.

${ }^{\mathrm{b}} \mathrm{A}$ ring compression test was also conducted at $135^{\circ} \mathrm{C}$ for a ring sectioned from this sample.

Offset and permanent strains increased from $2.5 \%$ to $5.3 \%$ and from $2.1 \%$ to $3.2 \%$, respectively.

beta-stabilizer. The oxygen-stabilized alpha "layer" formed at high temperature in M5 is not as uniform as the one formed in Zry- 4 because $\mathrm{Nb}$ causes local regions of beta-stabilization even at higher oxygen contents. Precipitation of oxygen-stabilized alpha regions during cooling is also different in the M5 priorbeta layer because of the presence of $\mathrm{Nb}$. Yet, even with these differences in microstructure and phase distribution, the post-quench ductility of the two alloys oxidized at $1000^{\circ} \mathrm{C}$ and $1100^{\circ} \mathrm{C}$ for the same duration is remarkably similar. 


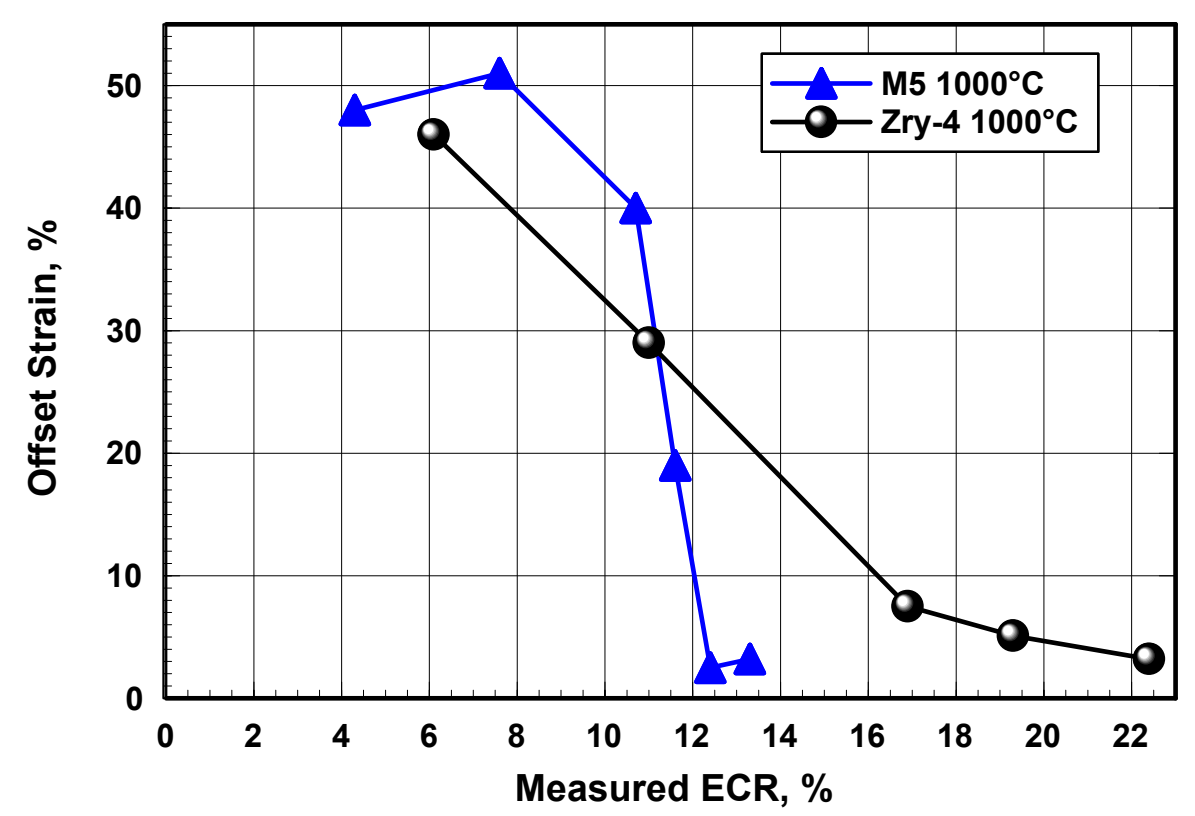

(a)

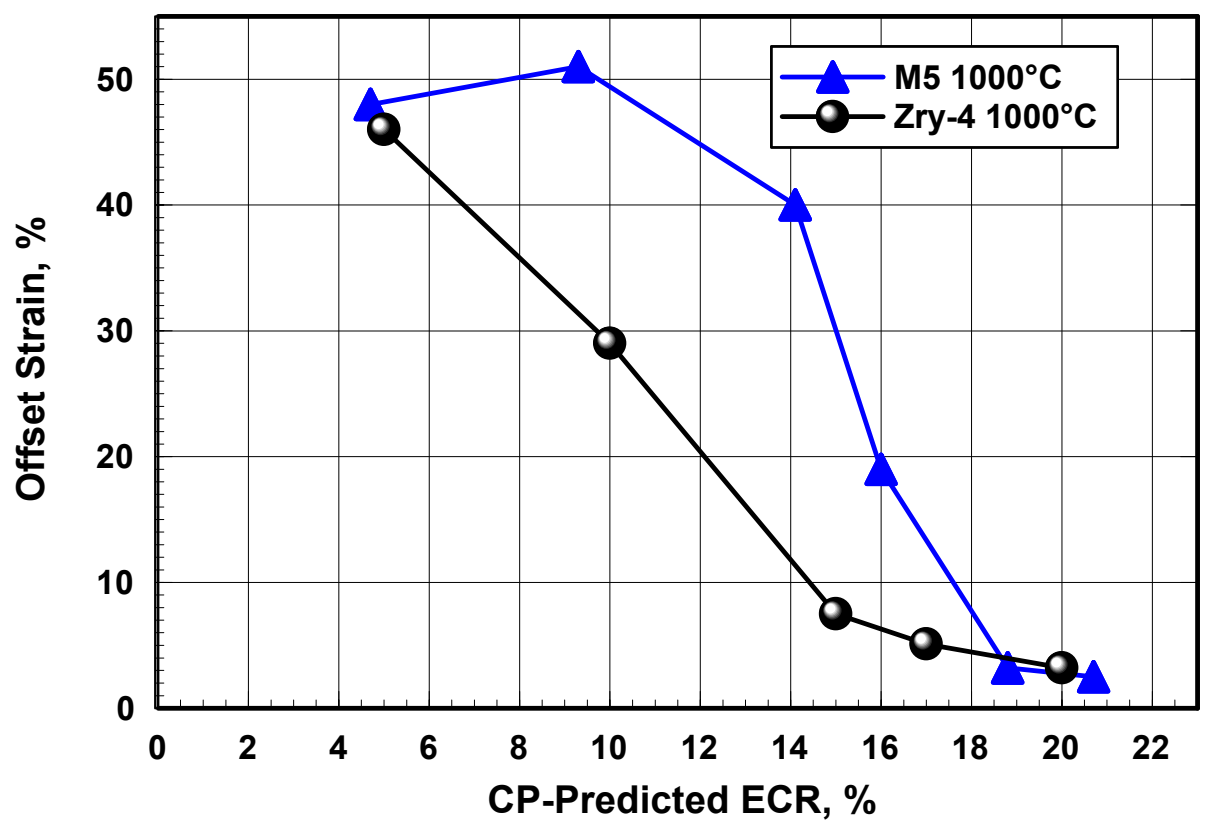

(b)

Figure 67. Post-quench ductility vs. measured (a) and CP-predicted (b) ECR for $17 \times 17 \mathrm{M} 5$ and Zry-4 oxidized in steam at $1000^{\circ} \mathrm{C}$, cooled at $\approx 10^{\circ} \mathrm{C} / \mathrm{s}$ to $800^{\circ} \mathrm{C}$, and quenched. Offset strain was determined from results of ring-compression tests conducted at $\mathrm{RT}$ and $0.0333-\mathrm{mm} / \mathrm{s}$ displacement rate. 


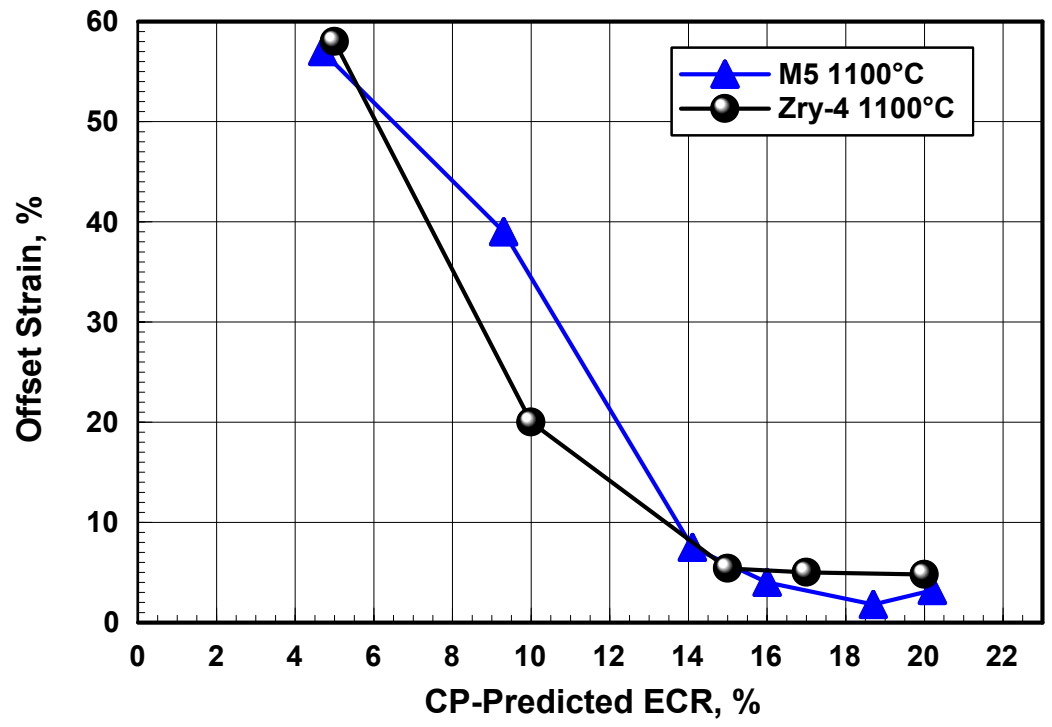

Figure 68. Post-quench ductility vs. CP-predicted ECR for $17 \times 17 \mathrm{M} 5$ and Zry-4 oxidized in steam at $1100^{\circ} \mathrm{C}$, cooled at $\approx 10^{\circ} \mathrm{C} / \mathrm{s}$ to $800^{\circ} \mathrm{C}$, and quenched. Offset strain was determined from results of ringcompression tests conducted at RT and $0.0333-\mathrm{mm} / \mathrm{s}$ displacement rate.

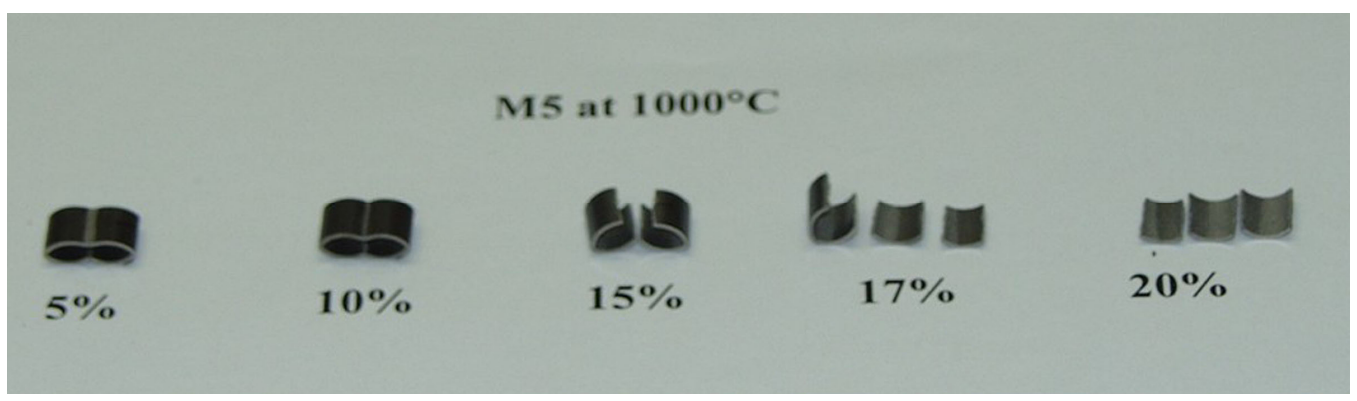

(a)

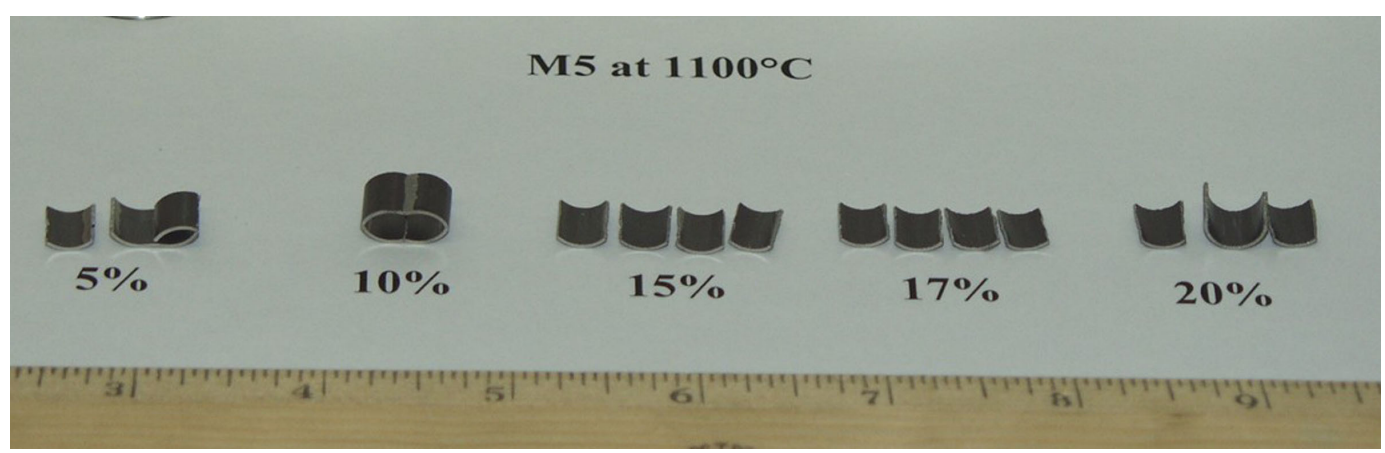

(b)

Figure 69. Post-test appearance of M5 ring-compression samples tested at room temperature and $0.0333 \mathrm{~mm} / \mathrm{s}$ : (a) samples oxidized at $1000^{\circ} \mathrm{C}$ and (b) samples oxidized at $1100^{\circ} \mathrm{C}$. ECR values are calculated using the Cathcart-Pawel weight gain correlation and $0.57-\mathrm{mm}$ wall. For $0.61-\mathrm{mm}$-wall M5, these values should be reduced to $4.7 \%, 9.3 \%, 14.1 \%, 16.0 \%$, and $18.8 \%$. 
M5 exhibits very slow oxide-layer growth and weight-gain increase at $1000^{\circ} \mathrm{C}$ as compared to Zry4. Also, above $\approx 10 \%$ CP-ECR ( $\approx 960$ s equivalent isothermal time), weight gain does not increase in a consistent manner with oxidation time or the square root of time. For example, the ECR based on weight gain was determined to be $10.7 \%$ at $1890 \mathrm{~s}, 11.6 \%$ at $2430 \mathrm{~s}, 13.3 \%$ at $3365 \mathrm{~s}$, and $12.2 \%$ at $4065 \mathrm{~s}$. The offset strain decreases very steeply ( $40 \%$ to $3 \%)$ with a small increase in measured ECR $(10.7 \%$ to $13.3 \%$ ) corresponding to a large increase in oxidation time (1890 s to $4065 \mathrm{~s})$. Based on fundamental considerations regarding oxygen increase in the beta layer, it appears more meaningful to express M5 post-quench ductility (offset strain) as a function of CP-ECR.

Table 33. Characterization of Highly Oxidized $17 \times 17$ Zry-4 and M5 Samples after Exposure to Steam at $1000^{\circ} \mathrm{C}$ and $1100^{\circ} \mathrm{C}$, Cooling at $\approx 10^{\circ} \mathrm{C} / \mathrm{s}$ to $800^{\circ} \mathrm{C}$, and Water Quench

\begin{tabular}{|c|c|c|c|}
\hline $\begin{array}{c}\text { Oxidation } \\
\text { Temperature, } \\
{ }^{\circ} \mathrm{C}\end{array}$ & Parameter & $\begin{array}{c}\text { Zry-4 } \\
20 \% \text { CP-ECR }\end{array}$ & $\begin{array}{c}\text { M5 } \\
18.8 \% \text { CP-ECR }\end{array}$ \\
\hline \multirow[t]{9}{*}{1000} & Effective CP time, $\mathrm{s}$ & 3364 & 3364 \\
\hline & Weight Gain, $\mathrm{mg} / \mathrm{cm}^{2}$ & 14.6 & 9.2 \\
\hline & Measured ECR, \% & 22.4 & 13.3 \\
\hline & RT Offset Displacement, mm & 0.31 & 0.31 \\
\hline & RT Offset Strain, \% & $\begin{array}{c}3.2 \\
\text { (ductile) }\end{array}$ & $\begin{array}{c}3.2 \\
\text { (ductile) }\end{array}$ \\
\hline & Hydrogen Content, wppm & 19 & 26 \\
\hline & Hydrogen Pickup, wppm & 15 & 22 \\
\hline & OD/ID Oxide Thickness, $\mu \mathrm{m}$ & $83 / 82$ & $36 / 32$ \\
\hline & Microhardness within Middle $0.2 \mathrm{~mm}, \mathrm{DPH}$ & $290-420$ & $300-430$ \\
\hline \multirow[t]{9}{*}{1100} & Effective CP Time, s & 1065 & 1065 \\
\hline & Weight Gain, $\mathrm{mg} / \mathrm{cm}^{2}$ & 13.2 & 13.3 \\
\hline & Measured ECR, \% & 20.3 & 19.1 \\
\hline & Offset Displacement, mm & 0.46 & 0.17 \\
\hline & RT Offset Strain, \% & $\begin{array}{c}4.8 \\
\text { (ductile) }\end{array}$ & $\begin{array}{c}1.8 \\
\left(\text { brittle }^{\mathrm{a}}\right)\end{array}$ \\
\hline & Hydrogen Content, wppm & 22 & 17 \\
\hline & Hydrogen Pickup, wppm & 19 & 12 \\
\hline & OD/ID Oxide Layer Thickness, $\mu \mathrm{m}$ & $70 / 68$ & $72 / 62$ \\
\hline & Microhardness within Middle $0.2 \mathrm{~mm}, \mathrm{DPH}^{\mathrm{b}}$ & $240-470$ & $260-400$ \\
\hline
\end{tabular}

${ }^{\mathrm{a}}$ New sample oxidized to higher EP-ECR (20.4\%) was ductile (3.2\% offset strain).

${ }^{\mathrm{b}}$ Includes oxygen-stabilized alpha needles (M5) and alpha incursions (Zry-4) in prior-beta layer. 


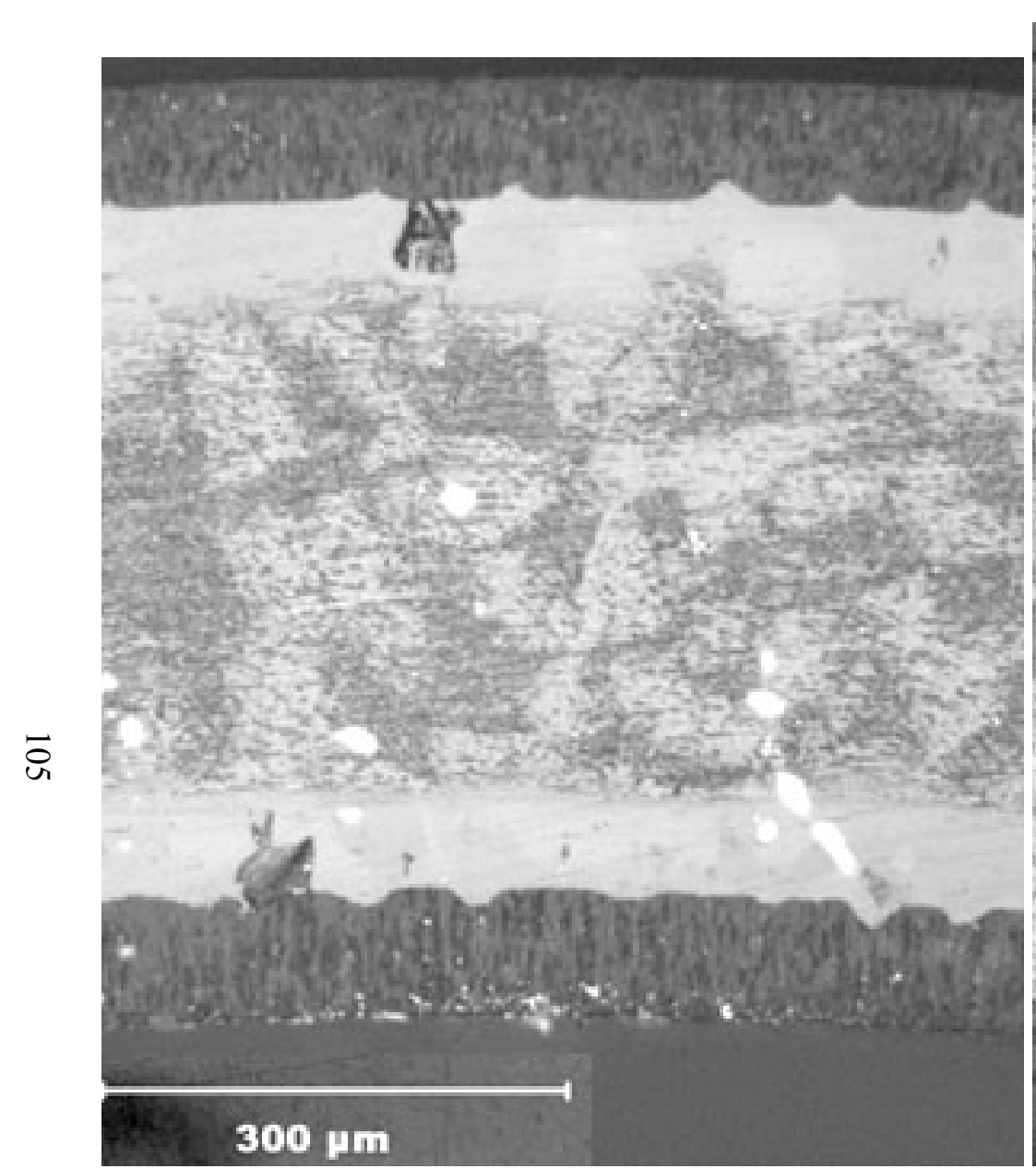

(a) Zry-4

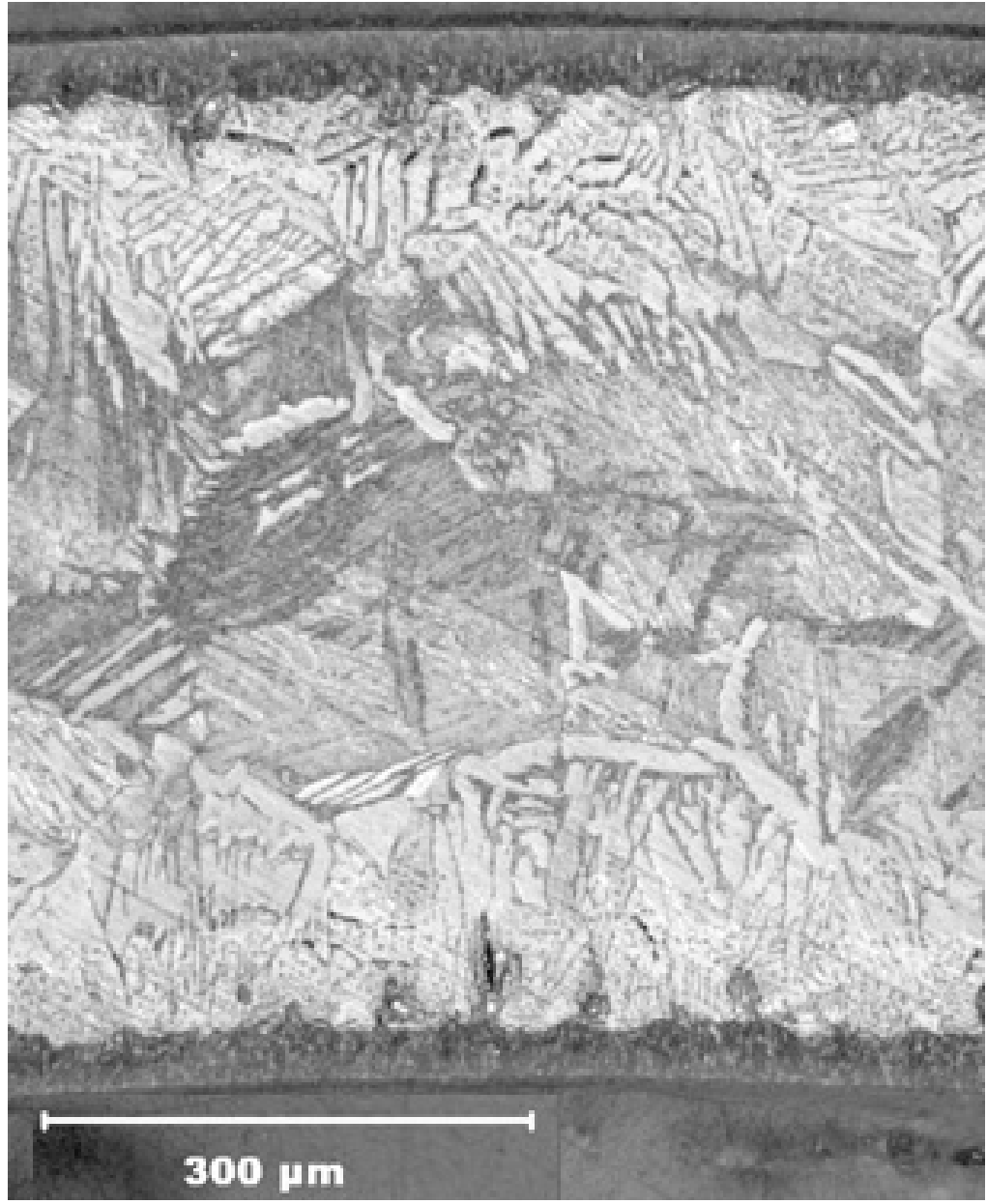

(b) M5

Figure 70. Metallography of as-polished Zry-4 (a) and M5 (b) oxidized in steam at $1000^{\circ} \mathrm{C}$ for $\approx 3360 \mathrm{~s}$, cooled at $\approx 10^{\circ} \mathrm{C} / \mathrm{s}$ to $800^{\circ} \mathrm{C}$, and water quenched. Measured ECR values are $22.4 \%$ for Zry-4 and $13.3 \%$ for M5. 


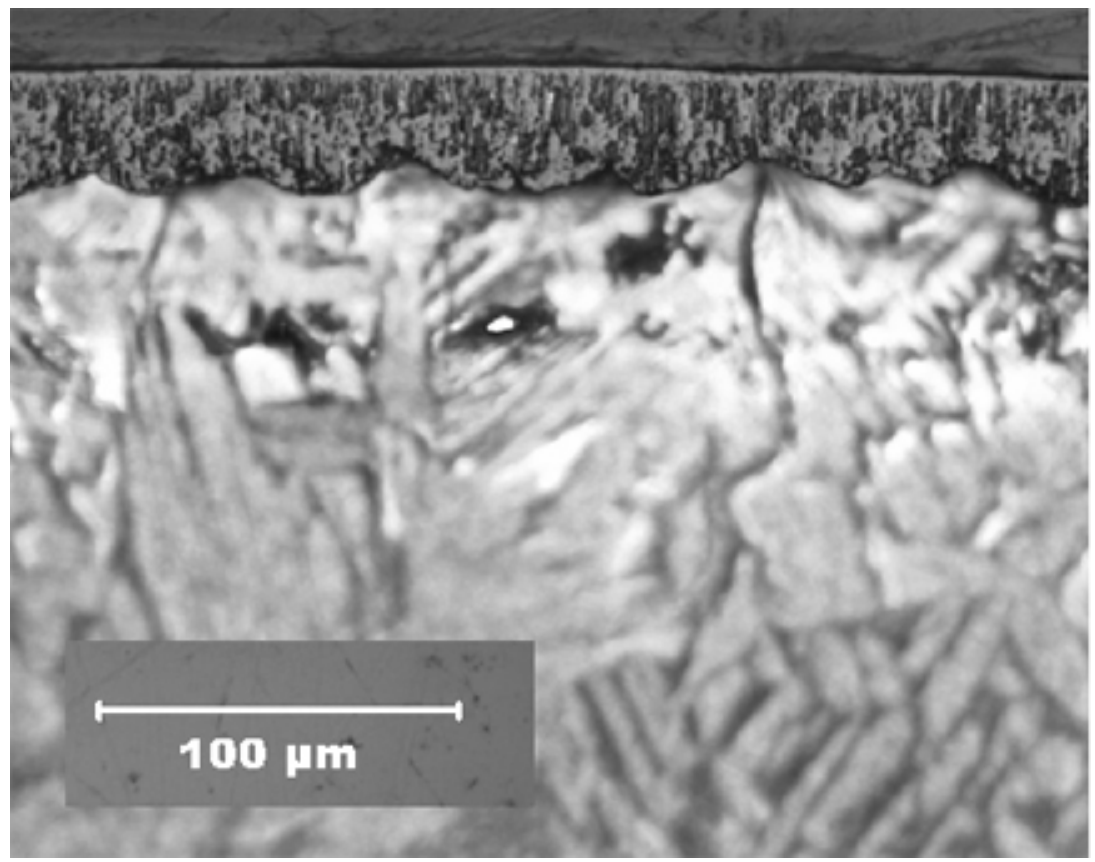

Figure 71. High-magnification image of etched M5 outer-surface oxide and alpha layers following oxidation at $1000^{\circ} \mathrm{C}$ for $3360 \mathrm{~s}$. The outer-surface oxide layer is tetragonal, but the wavy oxide-metal interface is a precursor to breakaway oxidation.

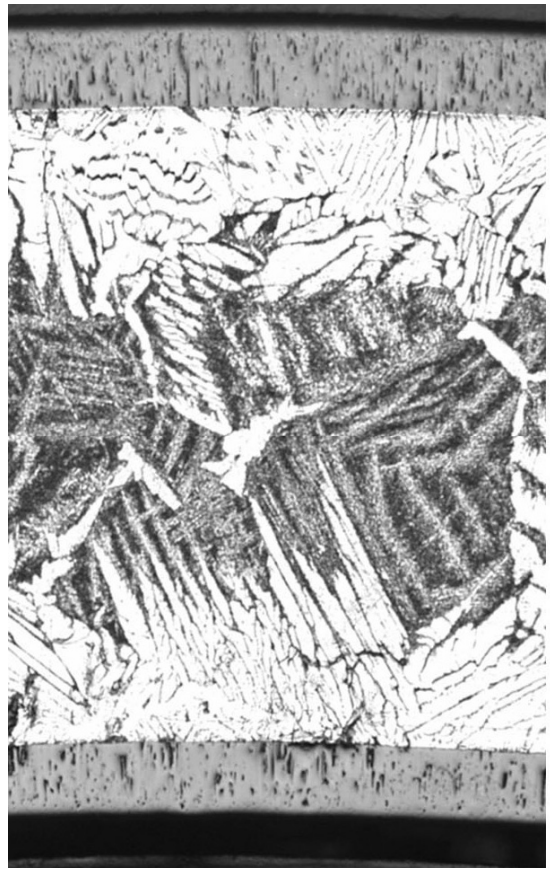

(a) M5

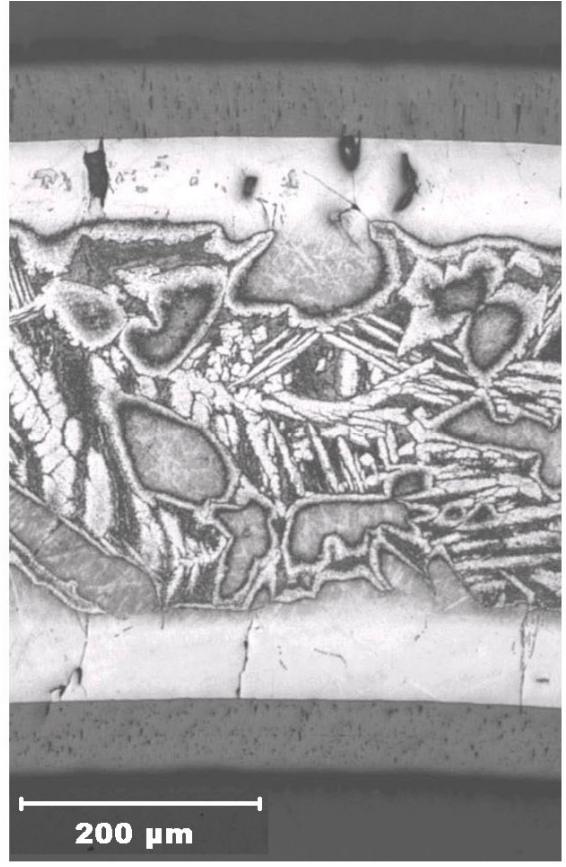

(b) Zry-4

Figure 72. Metallography of etched M5 (a) and Zry-4 (b) oxidized in steam at $1100^{\circ} \mathrm{C}$ for $\approx 1070 \mathrm{~s}$, cooled at $\approx 10^{\circ} \mathrm{C} / \mathrm{s}$ to $800^{\circ} \mathrm{C}$, and water quenched. Measured ECR values are $19.1 \%$ for M5 and $20.3 \%$ for Zry-4. 


\section{$17 \times 17$ M5 oxidized at $1200^{\circ} \mathrm{C}$}

In parallel with the Zry-4 testing, numerous tests were conducted with $17 \times 17 \mathrm{M} 5$ oxidized at $1200 \pm 5^{\circ} \mathrm{C}$ to determine the ductile-to-brittle transition CP-ECR at RT and $135^{\circ} \mathrm{C}$. Figure 73 shows the thermal-benchmark results for the first test train. Because the differences in ramp rates are small for the $0.61-\mathrm{mm}$ M5 vs. the $0.57-\mathrm{mm}$ Zry-4 and ZIRLO, the thermal benchmark results shown in Figure 21 were used for the more recent tests with M5. Although the temperature ramps are slightly different, these have little effect on the long-time tests used to determine the high transition CP-ECR at a ring-compression temperature of $135^{\circ} \mathrm{C}$. Also, all tests were stopped after the first significant load drop to allow a measure of the permanent strain based on the diameter change in the loading direction.

The weight gain results (expressed in terms of measured ECR) and the post-quench ductility results are summarized in Table 34. Figure 74 shows the measured M5 and Zry-4 weight gains, as compared to the CP-predicted weight gains. The experimental results for both alloys are in excellent agreement with each other and with the predicted values.

M5 appears to embrittle at room temperature after oxidation at $1200^{\circ} \mathrm{C}$ to $\approx 12 \% \mathrm{CP}$-ECR and quench. This observation is confirmed by both the offset $\operatorname{strain}(<2 \%)$ and the permanent-strain $(<1 \%)$ criteria for embrittlement. The enhancement of ductility with the increase in test temperature is quite pronounced. Based on permanent strain data, the ductile-to-brittle transition CP-ECR is $20 \%$ at $135^{\circ} \mathrm{C}$. The variations of offset and permanent strains with CP-ECR are shown in Figures 75a and 75b, respectively, for the RT and $135^{\circ} \mathrm{C}$ test conditions. Figure 76 is a comparison between the post-quench ductility (offset strain) at $135^{\circ} \mathrm{C}$ for M5 and Zry-4 vs. CP-ECR following oxidation at $1200^{\circ} \mathrm{C}$ and quench at $800^{\circ} \mathrm{C}$. At $<17 \% \mathrm{CP}-\mathrm{ECR}$, M5 has significantly higher post-quench ductility than Zry-4.

As was indicated in one of the footnotes for Table 32, the differences in offset and permanent strains were $\leq 2 \%$ for a few rings sectioned from $1000^{\circ} \mathrm{C}$ and $1100^{\circ} \mathrm{C}$ oxidation samples and compressed at RT. For one ring compressed at $135^{\circ} \mathrm{C}$, the difference was $2.3 \%$. As seen from the results in Table 74 , the average difference at the ductile-to-brittle transition CP-ECR is $2.5 \%$ for the samples oxidized at $1200^{\circ} \mathrm{C}$ and compressed at $135^{\circ} \mathrm{C}$. Thus, the $2 \%$ offset strain criterion does not guarantee $1 \%$ permanent strain and ductility for M5 oxidized and compression tested under these conditions. In particular, for $1200^{\circ} \mathrm{C}$-oxidized samples compressed at $135^{\circ} \mathrm{C}$, the offset strain corresponding ductility should be raised from $2 \%$ to $3.5 \%$.

Table 35 summarizes the characterization results for $17 \times 17$ Zry -4 and M5 oxidized at $1200^{\circ} \mathrm{C}$ for times equivalent to approximately $13 \%$ and $20 \%$ CP-ECR (based on $0.57-\mathrm{mm}$-wall cladding) and quenched at $800^{\circ} \mathrm{C}$. As expected, the hydrogen pickup is very low. Also, there is excellent agreement between the inner-surface and outer-surface oxide layer thickness, indicating adequate steam flow at the inner surface. The microhardness results support the post-quench ductility results. Based on the roomtemperature microhardness values, one would expect M5 to retain post-quench ductility at $\leq 20 \% \mathrm{CP}$-ECR at the elevated test temperature of $135^{\circ} \mathrm{C}$. The microstructures across the cladding wall are shown in Figure 77 for Zry-4 and M5 oxidized at $1200^{\circ} \mathrm{C}$ to $\approx 20 \%$ CP-ECR. As with the lower oxidation temperatures, Zry-4 has well-defined oxygen-stabilized alpha layers grown at $1200^{\circ} \mathrm{C}$, while the presence of $\mathrm{Nb}$ in M5 results in a less clear distinction of this layer. The microhardness indents for Zry-4 and M5 oxidized to $\approx 13 \%$ CP-ECR are shown in Figures $78 \mathrm{a}$ and $78 \mathrm{~b}$, respectively. 


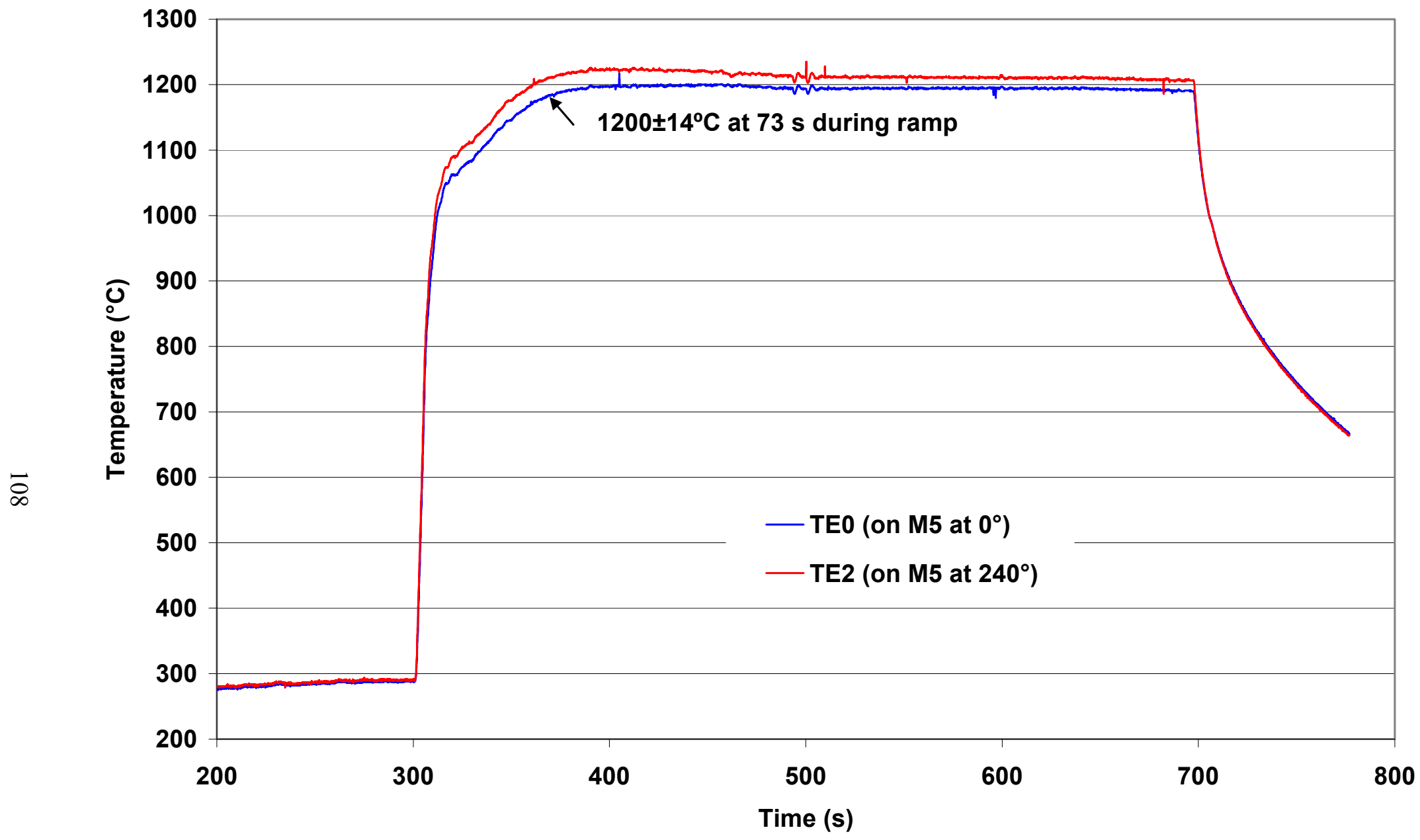

Figure 73. Thermal benchmark results for first test train for $17 \times 17 \mathrm{M} 5$ oxidation tests at $1203 \pm 8^{\circ} \mathrm{C}$. The cladding OD is $9.50 \mathrm{~mm}$, and the wall thickness is $0.61 \mathrm{~mm}$. Quench at $800^{\circ} \mathrm{C}$ is not shown in this figure. 
Table 34. Ring Compression Test (RCT) Results for $17 \times 17 \mathrm{M} 5$ Cladding Oxidized at $1200^{\circ} \mathrm{C}$, Cooled at $\approx 13^{\circ} \mathrm{C} / \mathrm{s}$ to $800^{\circ} \mathrm{C}$, and Quenched. ECR $=1.437 \mathrm{Wg}$ for $0.61-\mathrm{mm}$-wall thickness. Tests were performed on $\approx 8-\mathrm{mm}$-long samples at $\mathrm{RT}$ and $135^{\circ} \mathrm{C}$ and at $0.0333-\mathrm{mm} / \mathrm{s}$ displacement rate. Displacements in the loading direction were normalized to the as-fabricated outer diameter $(9.50 \mathrm{~mm})$ to calculate offset and permanent strains.

\begin{tabular}{|c|c|c|c|c|c|c|c|}
\hline \multicolumn{2}{|c|}{$\begin{array}{c}\text { Test } \\
\text { Conditions }\end{array}$} & \multicolumn{2}{|c|}{$\begin{array}{c}\text { ECR, } \\
\%\end{array}$} & \multicolumn{2}{|c|}{$\begin{array}{c}\text { Plastic } \\
\text { Displacement, } \mathrm{mm}\end{array}$} & \multicolumn{2}{|c|}{$\begin{array}{c}\text { Plastic } \\
\text { Strain, \% }\end{array}$} \\
\hline $\begin{array}{l}\mathrm{RCT} \\
\mathrm{T},{ }^{\circ} \mathrm{C}\end{array}$ & $\begin{array}{c}\text { Test } \\
\text { Time, }{ }^{\mathrm{a}} \mathrm{s}\end{array}$ & $\mathrm{CP}$ & Meas. & Offset & Permanent & Offset & Permanent \\
\hline RT & 58 & 4.5 & 4.0 & $>5.35$ & $>5.0$ & $>56$ & $>53$ \\
\hline $\begin{array}{l}\text { RT } \\
135\end{array}$ & $\begin{array}{l}132 \\
132\end{array}$ & $\begin{array}{l}9.1 \\
9.1\end{array}$ & $\begin{array}{l}9.1 \\
9.1\end{array}$ & $\begin{array}{r}0.32 \\
>4.8\end{array}$ & $\begin{array}{r}0.13 \\
>4.8\end{array}$ & $\begin{array}{c}3.4 \\
>51\end{array}$ & $\begin{array}{r}1.6 \\
>51\end{array}$ \\
\hline RT & 203 & 12.1 & 13.1 & 0.17 & 0.09 & 1.8 & 0.9 \\
\hline $\begin{array}{l}135^{b} \\
135^{b}\end{array}$ & $\begin{array}{l}226 \\
226\end{array}$ & $\begin{array}{l}13.0 \\
13.0\end{array}$ & $\begin{array}{l}13.6 \\
13.6\end{array}$ & $\begin{array}{l}1.43 \\
1.20\end{array}$ & $\begin{array}{l}1.13 \\
0.84\end{array}$ & $\begin{array}{l}15.0 \\
12.6\end{array}$ & $\begin{array}{c}11.9 \\
8.8\end{array}$ \\
\hline $\begin{array}{l}\text { RT } \\
135\end{array}$ & $\begin{array}{l}248 \\
248\end{array}$ & $\begin{array}{l}14.1 \\
14.1\end{array}$ & $\begin{array}{l}13.8 \\
13.8\end{array}$ & $\begin{array}{l}0.16 \\
1.73\end{array}$ & $\begin{array}{l}0.07 \\
1.25\end{array}$ & $\begin{array}{c}1.7 \\
18.2\end{array}$ & $\begin{array}{l}0.7 \\
13\end{array}$ \\
\hline $\begin{array}{c}\text { RT } \\
135 \\
\mathbf{1 3 5}^{\mathbf{b}} \\
\mathbf{1 3 5}^{\mathbf{b}}\end{array}$ & $\begin{array}{l}308 \\
308 \\
\mathbf{3 1 8} \\
\mathbf{3 1 8}\end{array}$ & $\begin{array}{l}16.0 \\
16.0 \\
\mathbf{1 6 . 0} \\
\mathbf{1 6 . 0}\end{array}$ & $\begin{array}{l}15.7 \\
15.7 \\
\mathbf{1 7 . 4} \\
\mathbf{1 7 . 4}\end{array}$ & $\begin{array}{l}0.13 \\
1.02 \\
\mathbf{0 . 5 2} \\
\mathbf{0 . 5 2}\end{array}$ & $\begin{array}{c}0.06 \\
--- \\
0.27 \\
---\end{array}$ & $\begin{array}{c}1.4 \\
10.7 \\
\mathbf{5 . 4} \\
\mathbf{5 . 4}\end{array}$ & $\begin{array}{c}0.6 \\
--- \\
2.8 \\
---\end{array}$ \\
\hline RT & 428 & 18.7 & 18.8 & 0.195 & 0.06 & 2.0 & 0.6 \\
\hline $\begin{array}{l}135^{b} \\
135^{b}\end{array}$ & $\begin{array}{l}480 \\
480\end{array}$ & $\begin{array}{l}19.9 \\
19.9\end{array}$ & $\begin{array}{l}21.4 \\
21.4\end{array}$ & $\begin{array}{l}0.36 \\
0.29\end{array}$ & $\begin{array}{l}0.10 \\
0.10\end{array}$ & $\begin{array}{l}3.8 \\
3.1\end{array}$ & $\begin{array}{l}1.0 \\
1.0\end{array}$ \\
\hline
\end{tabular}

${ }^{a}$ Includes time for ramp from $300^{\circ} \mathrm{C}$ and hold time.

${ }^{b}$ Tests were conducted with current test train (see Figure 21 for thermal history). Most other test results were generated with the initial test train (see Figure 73 for thermal history). 


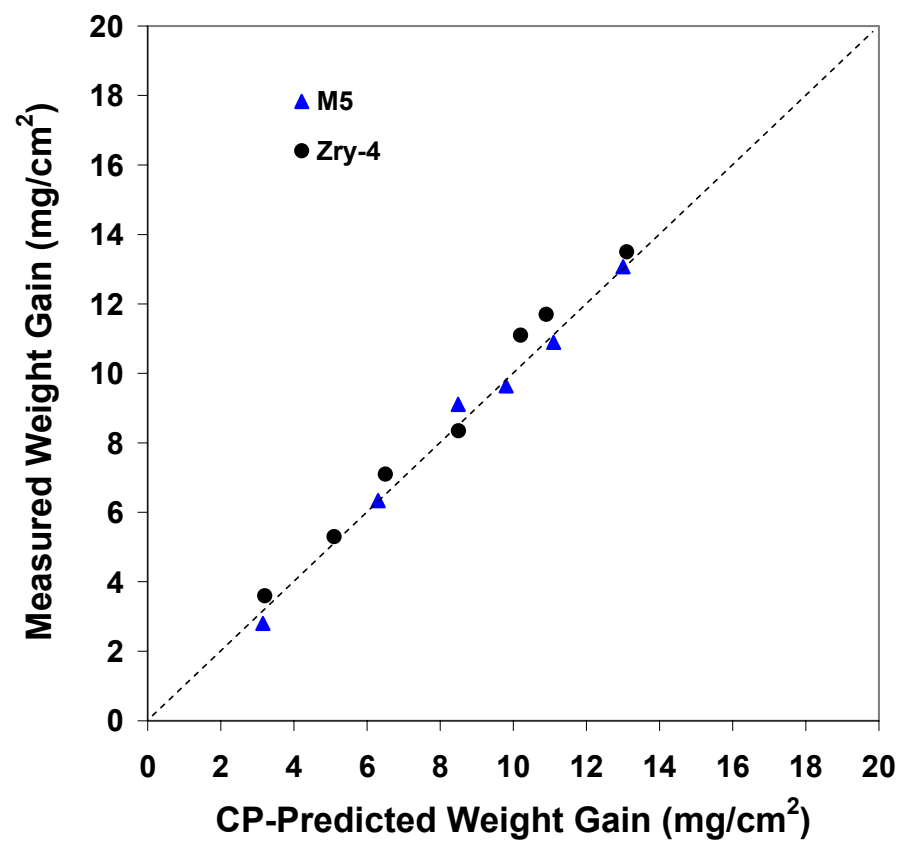

Figure 74. Comparison between weight gain data for M5 and Zry-4 and CP-predicted weight gain for samples oxidized (two-sided) in steam at $1200^{\circ} \mathrm{C}$ and quenched at $800^{\circ} \mathrm{C}$.

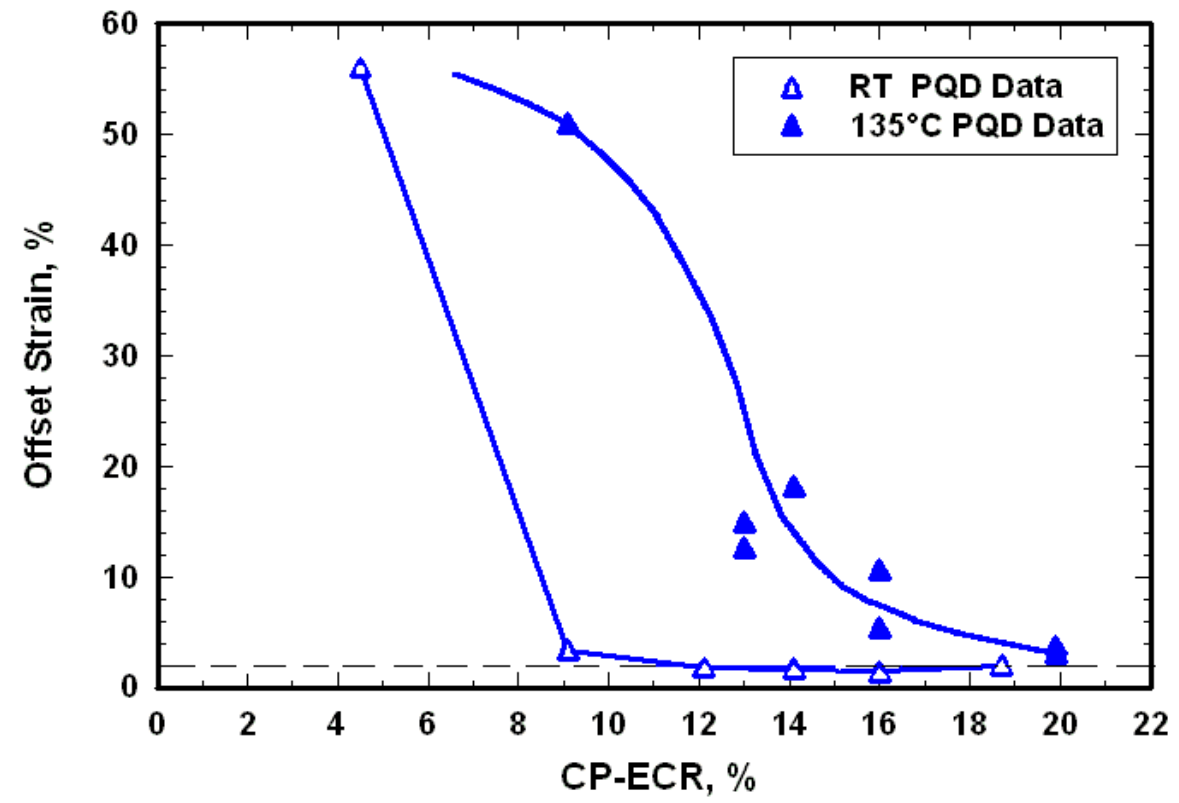

Figure 75 a. Offset strain vs. CP-ECR for $17 \times 17 \mathrm{M} 5$ oxidized at $1200^{\circ} \mathrm{C}$, cooled at $\approx 13^{\circ} \mathrm{C} / \mathrm{s}$ to $800^{\circ} \mathrm{C}$, quenched, and ring compressed at room temperature (RT) and $135^{\circ} \mathrm{C}$. 


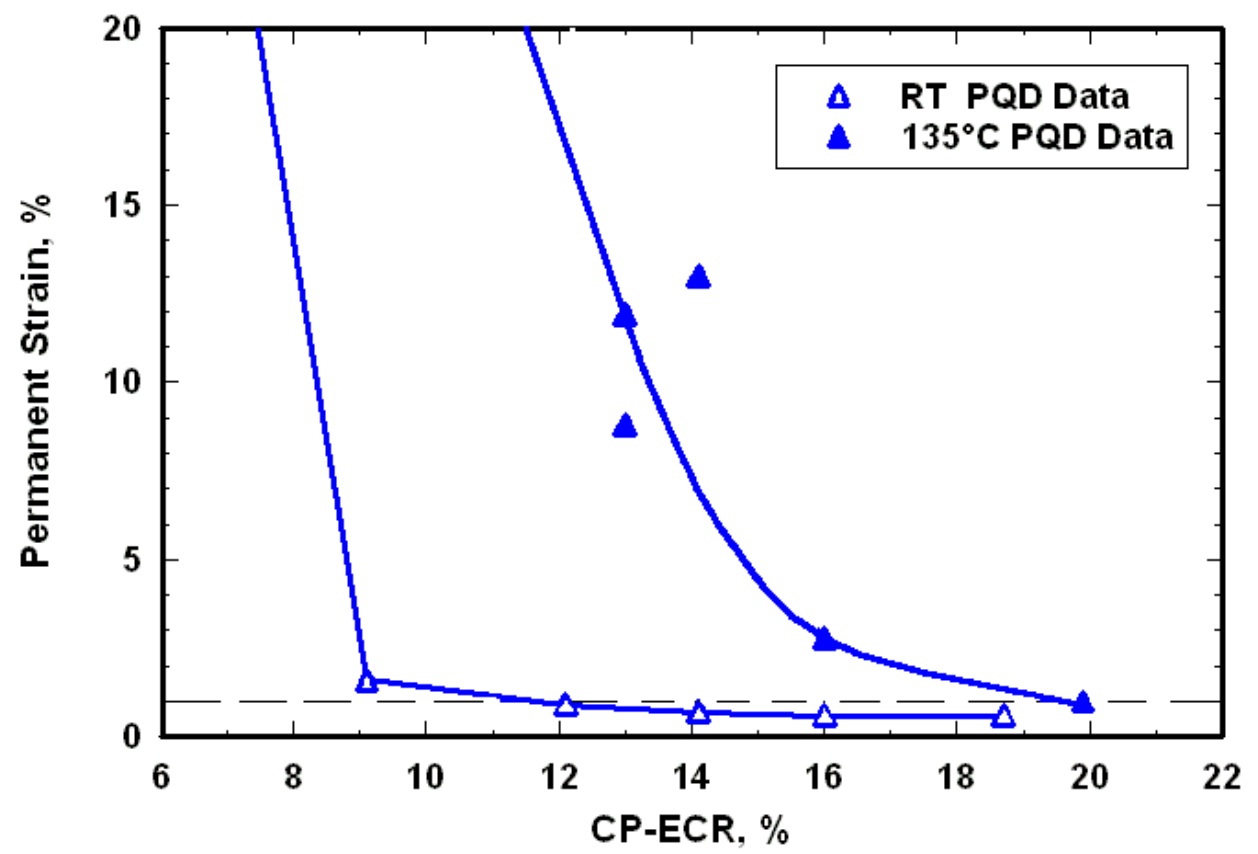

Figure $75 \mathrm{~b}$. Permanent strain vs. CP-ECR for $17 \times 17 \mathrm{M} 5$ oxidized at $1200^{\circ} \mathrm{C}$, cooled at $\approx 13^{\circ} \mathrm{C} / \mathrm{s}$ to $800^{\circ} \mathrm{C}$, quenched, and ring compressed at room temperature (RT) and $135^{\circ} \mathrm{C}$.

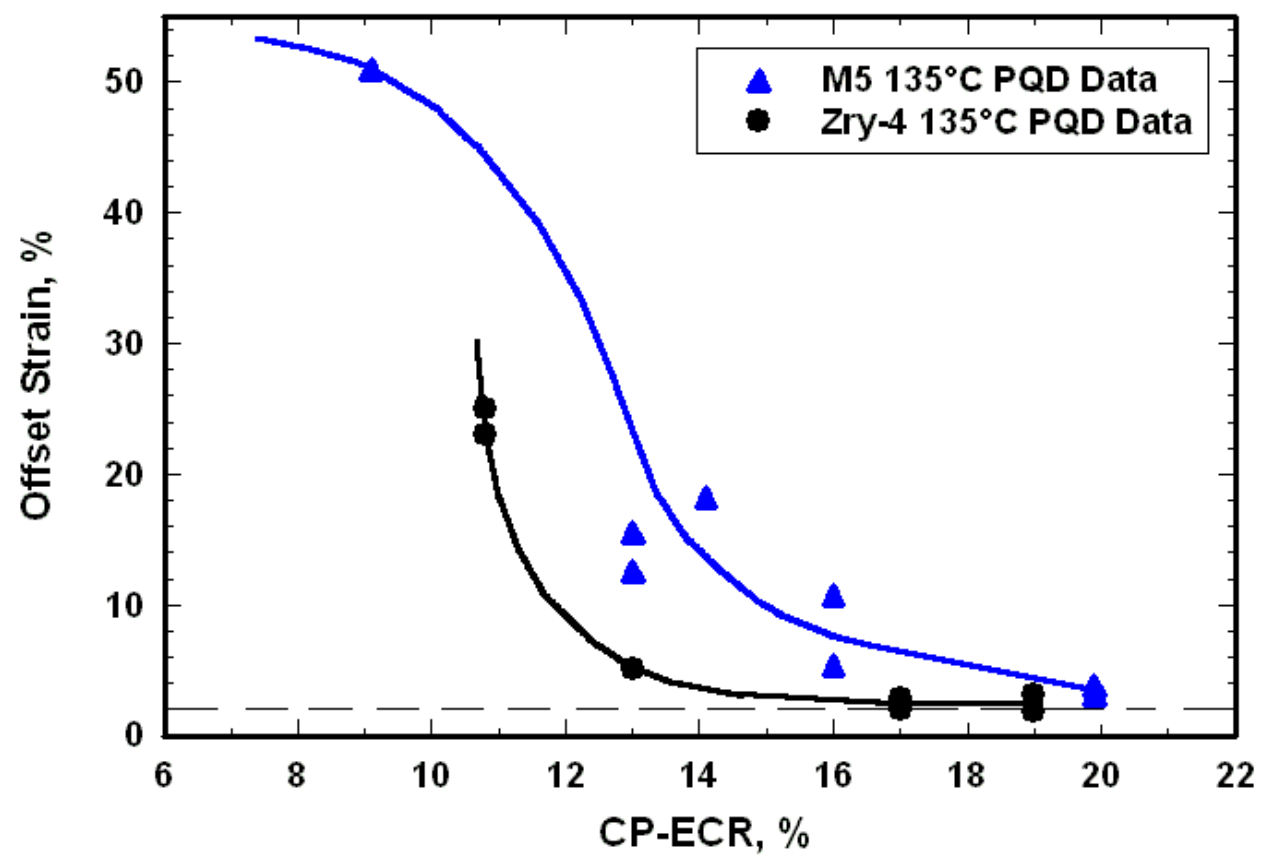

Figure 76. Offset strain vs. CP-ECR for $17 \times 17 \mathrm{M} 5$ and Zry-4 oxidized at $1200^{\circ} \mathrm{C}$, cooled at $\approx 13^{\circ} \mathrm{C} / \mathrm{s}$ to $800^{\circ} \mathrm{C}$, quenched, and ring compressed at $135^{\circ} \mathrm{C}$. 
Table 35. Characterization of $17 \times 17$ Zry-4 and M5 Samples after Exposure to Steam at $1200^{\circ} \mathrm{C}$ for Durations of 166 and $400 \mathrm{~s}$, Cooling at $\approx 13^{\circ} \mathrm{C} / \mathrm{s}$ to $800^{\circ} \mathrm{C}$, and Water Quench

\begin{tabular}{|c|c|c|c|c|}
\hline \multirow[b]{2}{*}{ Parameter } & \multicolumn{2}{|c|}{ Zry-4 } & \multicolumn{2}{|c|}{ M5 } \\
\hline & $20 \% \mathrm{ECR}$ & $13 \% \mathrm{ECR}$ & $18.7 \% \mathrm{ECR}$ & $12.1 \% \mathrm{ECR}$ \\
\hline Effective $\mathrm{CP}$ time at $1200^{\circ} \mathrm{C}, \mathrm{s}$ & 400 & 166 & 400 & 166 \\
\hline Weight Gain, $\mathrm{mg} / \mathrm{cm}^{2}$ & 13.5 & 8.35 & 13.1 & 9.11 \\
\hline Measured ECR, \% & 20.8 & 12.8 & 18.8 & 13.1 \\
\hline RT Offset Displacement, mm & 0.05 & 0.09 & 0.20 & 0.11 \\
\hline $\begin{array}{l}\text { RT Measured Permanent } \\
\text { Displacement, mm }\end{array}$ & 0.04 & 0.07 & 0.06 & 0.09 \\
\hline RT Permanent Strain, \% & 0.4 & 0.7 & 0.6 & 0.9 \\
\hline RT Ductility, \% & $\begin{array}{c}\leq 0.4 \\
\text { (brittle) }\end{array}$ & $\begin{array}{c}\leq 0.7 \\
\text { (brittle) }\end{array}$ & $\begin{array}{c}\leq 0.6 \\
\text { (brittle) }\end{array}$ & $\begin{array}{c}\leq 0.9 \\
\text { (brittle) }\end{array}$ \\
\hline Hydrogen Content, wppm & 17 & low & 19 & low \\
\hline Hydrogen Pickup, wppm & 13 & low & 14 & low \\
\hline OD/ID Oxide Thickness, $\mu \mathrm{m}$ & $68 / 66$ & $42 / 41$ & $68 / 61$ & $46 / 40$ \\
\hline Prior-Beta-Layer Thickness, $\mu \mathrm{m}$ & 266 & 419 & $\leq 360$ & $\approx 442$ \\
\hline $\begin{array}{l}\text { Microhardness, DPH } \\
\text { Oxide Layers } \\
\text { Alpha Layers } \\
\text { Prior-Beta Layer }^{\mathrm{a}}\end{array}$ & $\begin{array}{l}570-960 \\
530-730 \\
280-600\end{array}$ & $\begin{array}{l}600-770 \\
600-700 \\
260-360\end{array}$ & $\begin{array}{l}650-780 \\
580-850 \\
280-450\end{array}$ & $\begin{array}{l}580-680 \\
680-880 \\
300-410\end{array}$ \\
\hline
\end{tabular}

${ }^{a}$ Range includes microhardness values of oxygen-rich alpha needles (M5) and alpha incursions (Zry-4) in this layer. 


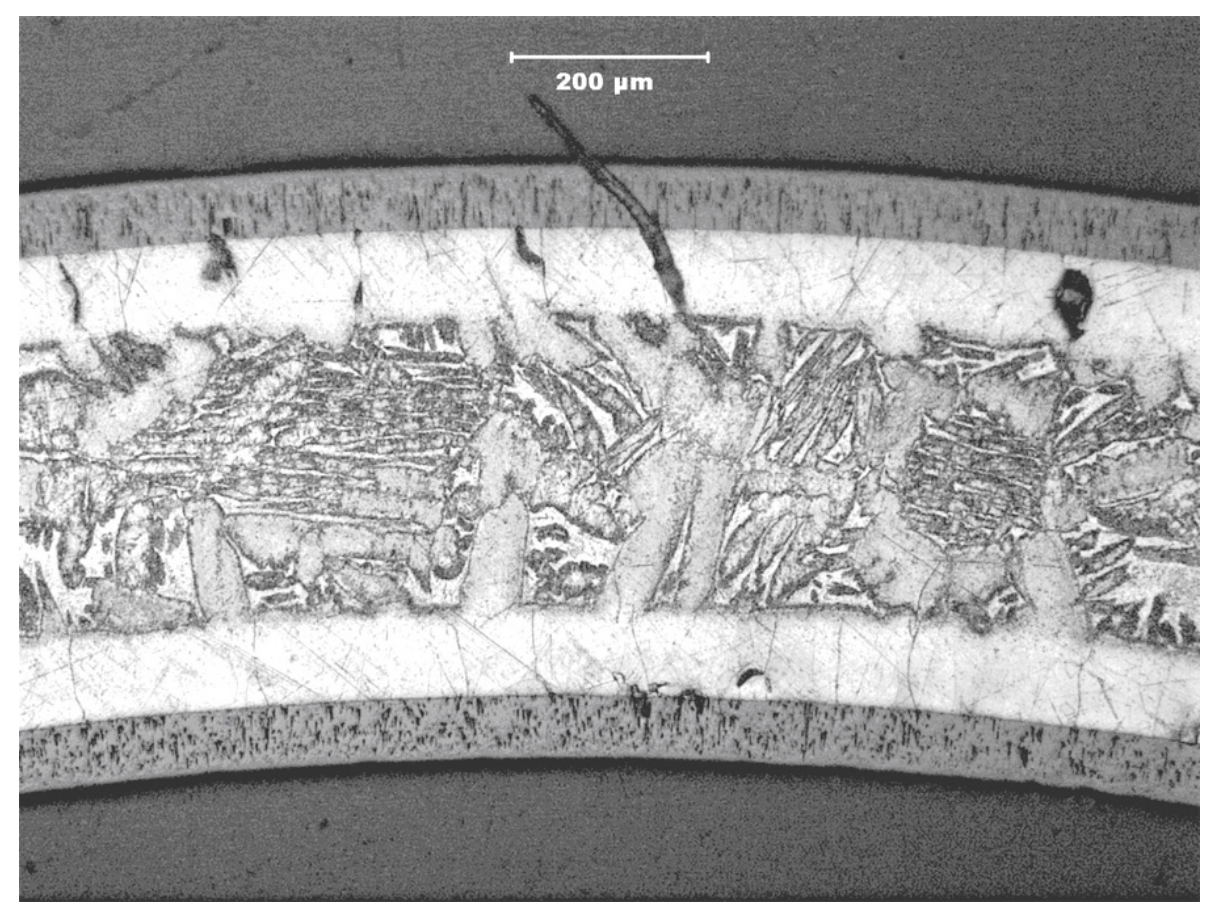

(a) Zry-4

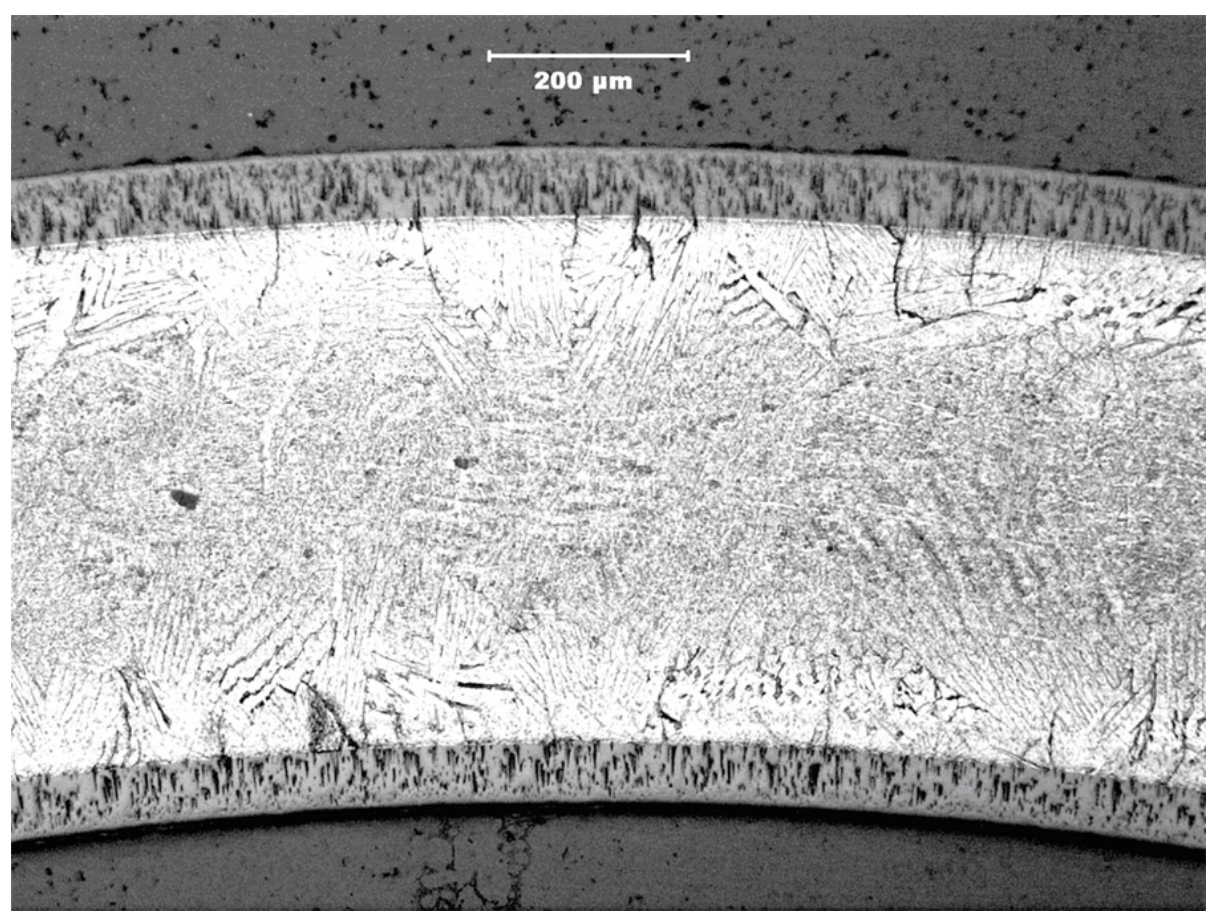

(b) M5

Figure 77. Metallography of etched Zry-4 (a) and M5 (b) oxidized in steam at $1200^{\circ} \mathrm{C}$ for $\approx 400 \mathrm{~s}$, cooled at $\approx 13^{\circ} \mathrm{C} / \mathrm{s}$ to $800^{\circ} \mathrm{C}$, and water quenched. Measured ECR values are $20.8 \%$ for Zry- 4 and $18.8 \%$ for M5. 


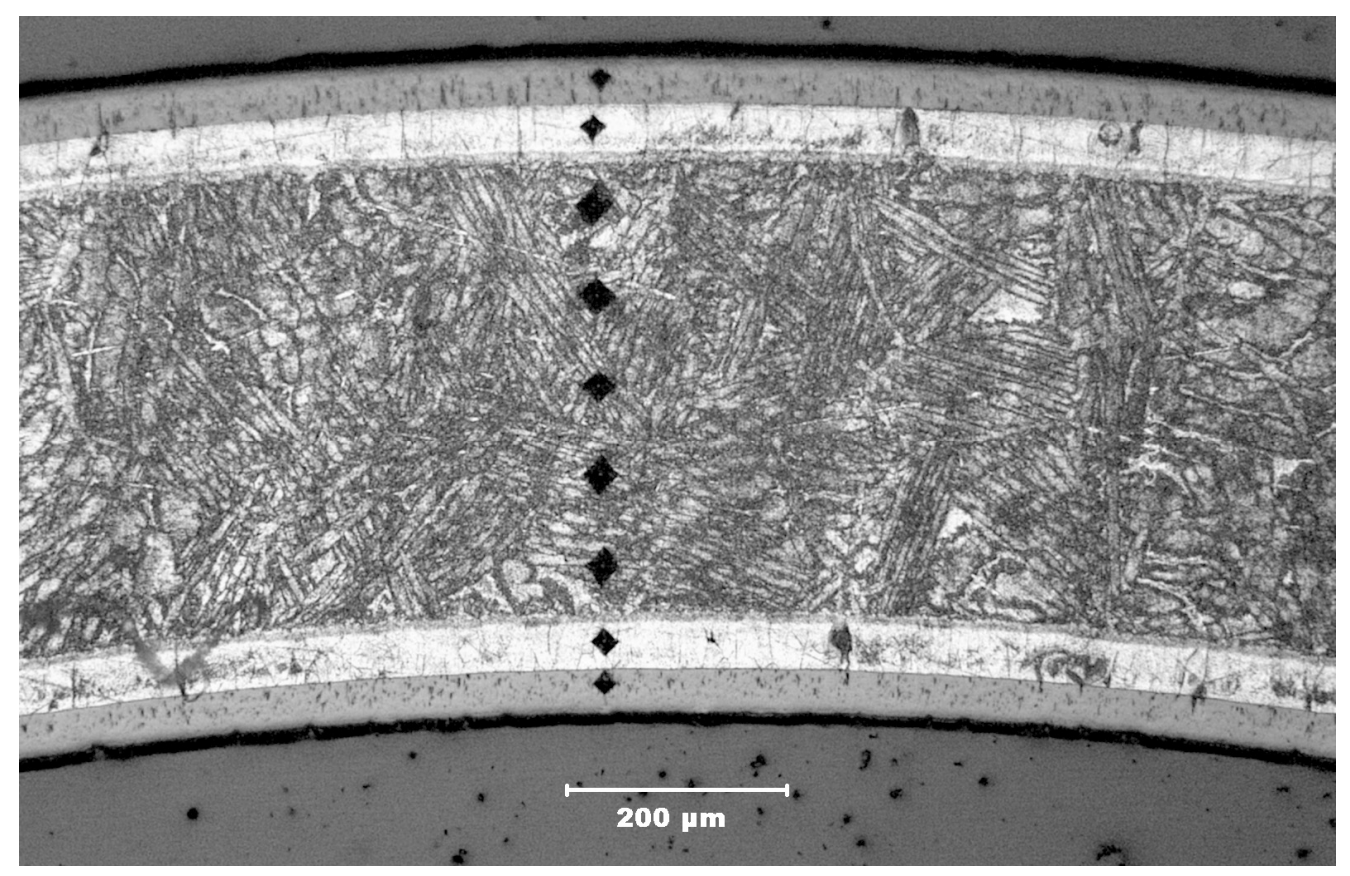

(a) Zry-4

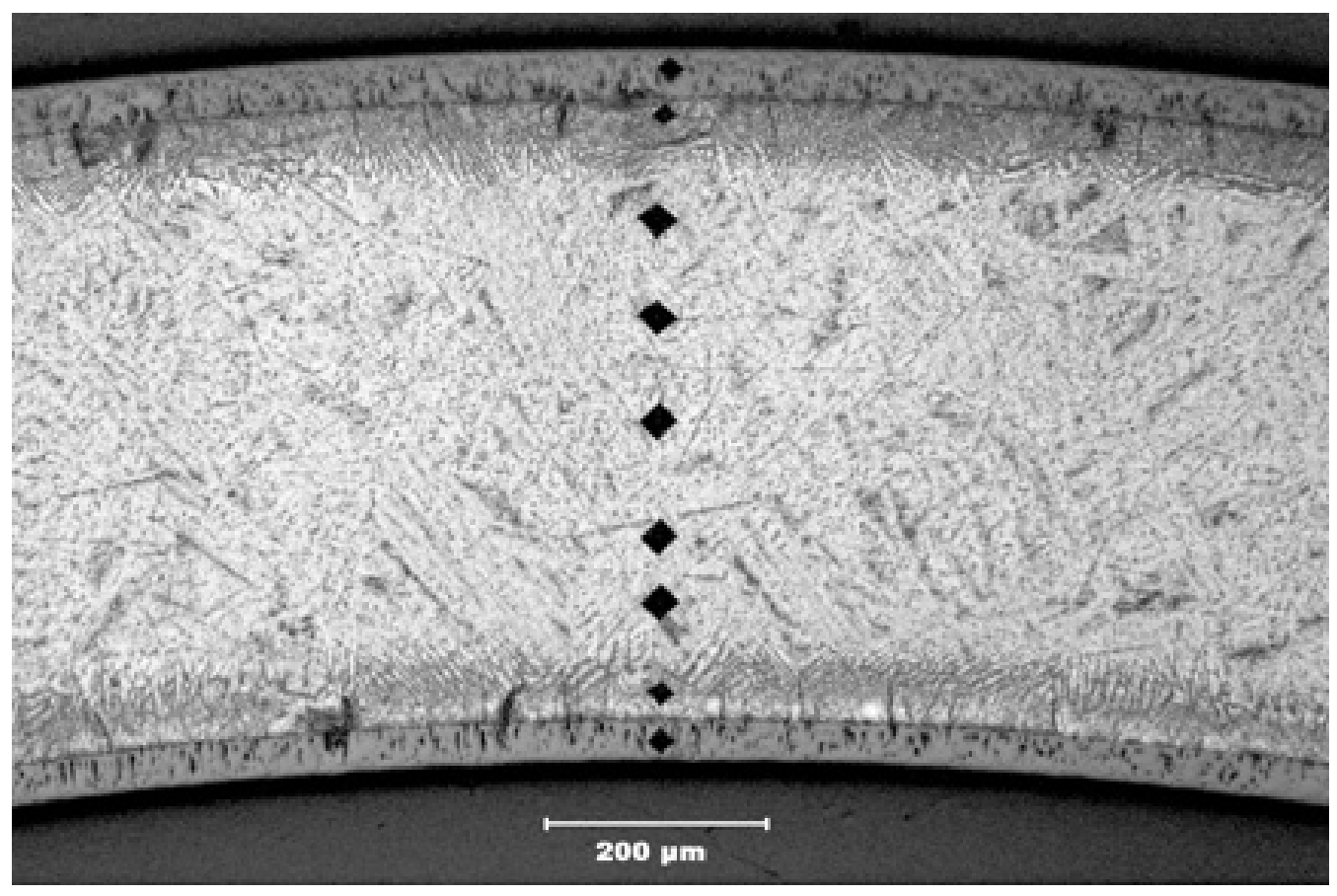

(b) M5

Figure 78. Metallography and microhardness indents across the radius of $17 \times 17$ Zry-4 (a) and M5 (b) oxidized at $1200^{\circ} \mathrm{C}$ to $12-13 \% \mathrm{CP}-\mathrm{ECR}$. The measured ECR values are $12.6 \%$ for Zry-4 and $13.1 \%$ for M5. Samples were quenched at $800^{\circ} \mathrm{C}$ following cooling at $\approx 13^{\circ} \mathrm{C} / \mathrm{s}$. 


\subsubsection{Breakaway oxidation time for $17 \times 17 \mathrm{M} 5$ samples oxidized at $1000^{\circ} \mathrm{C}$}

Based on the work of Mardon et al. [21] the breakaway oxidation time for M5 corresponding to $\approx 200$-wppm $\mathrm{H}$ pickup is $\approx 6400 \mathrm{~s}$ at $1000^{\circ} \mathrm{C}$. However, M5 exhibits very slow growth rate of inner- and outer-surface oxide layers at $1000^{\circ} \mathrm{C}$, which may prolong breakaway oxidation. Also, breakawayoxidation times at $975-1025^{\circ} \mathrm{C}$ or at lower temperatures have not been reported in the open literature. Based on limited ANL data, M5 does not undergo breakaway oxidation at $1000^{\circ} \mathrm{C}$ for test times of 3450 and $4100 \mathrm{~s}$.

Table 36. Data Summary for ANL M5 Breakaway Oxidation Tests at $1000^{\circ} \mathrm{C}$; test times are from beginning of ramp at $300^{\circ} \mathrm{C}$ to the end of the hold time.

\begin{tabular}{|c|c|c|c|c|c|c|}
\hline Cooling & $\begin{array}{l}\mathrm{T}, \\
{ }^{\circ} \mathrm{C}\end{array}$ & $\begin{array}{c}\text { Test Time, } \\
\mathrm{S}\end{array}$ & $\begin{array}{l}\mathrm{CP} \mathrm{Wg}, \\
\mathrm{mg} / \mathrm{cm}^{2}\end{array}$ & $\begin{array}{c}\text { Measured Wg, } \\
\mathrm{mg} / \mathrm{cm}_{2}\end{array}$ & $\begin{array}{c}\text { Hydrogen } \\
\text { Content }\left(\mathrm{L}_{\mathrm{h}}\right) \text {, } \\
\text { wppm }\end{array}$ & $\begin{array}{c}\text { Hydrogen } \\
\text { Pickup } \\
\left(\Delta \mathrm{C}_{\mathrm{H}}\right){ }^{\mathrm{a}} \\
\text { wppm }\end{array}$ \\
\hline $\mathrm{Q}$ at $800^{\circ} \mathrm{C}$ & 1000 & 3450 & 13.1 & 9.2 & 26 & 22 \\
\hline $\mathrm{Q}$ at $800^{\circ} \mathrm{C}$ & 1000 & 4100 & 11.1 & 10.8 & 13 & 8 \\
\hline
\end{tabular}

${ }^{a}$ Hydrogen pickup $\left(\Delta \mathrm{C}_{\mathrm{H}}\right)$ is referenced to the as-fabricated sample weight:

$\Delta \mathrm{C}_{\mathrm{H}}=\left(1+5.4 \times 10^{-3} \mathrm{Wg}\right) \mathrm{L}_{\mathrm{H}}-\mathrm{C}_{\mathrm{Hi}}$, where $\mathrm{C}_{\mathrm{Hi}}$ is as-fabricated hydrogen content.

\subsection{Effects of surface conditions on cladding performance}

Breakaway oxidation is an instability phenomenon that leads to transformation from the tighttetragonal-oxide phase (black) to the cracked-monoclinic-oxide phase (gray or yellow). The time-attemperature and temperature at which the breakaway occurs may be dependent on cladding surface conditions (roughness, scratches, and chemistry) and near-surface chemistry. The tetragonal oxide phase of $\mathrm{ZrO}_{2}$ is not thermodynamically stable at temperatures below $\approx 1150^{\circ} \mathrm{C}$. However, this black oxide phase is observed on cladding surfaces following steam oxidation at temperatures much less than $1150^{\circ} \mathrm{C}$. It is even observed as part of the tight sub-micron corrosion layer adherent to the cladding surface grown at normal reactor operating temperatures. Compressive stress and hypostoichiometry $\left[\mathrm{ZrO}_{(2-\mathrm{x})}\right]$ appear to stabilize the tetragonal phase at temperatures much lower than the phase-transition temperature. As the density of the oxide is lower than that of the cladding metal, the volume expansion during oxide formation leads to compressive stress in the oxide. Also, as oxidation progresses in steam at high temperature, oxygen continues to diffuse from the oxide to the oxygen-stabilized alpha layer, leaving an oxygen gradient in the oxide and hypostoichiometric oxide at the Zr-alloy surface. Conversely, irregularities in surface geometry can result in alternating regions of compressive and tensile stresses. According to Leistikow and Schanz $[19,20]$, such irregularities along the metal-oxide surface are a precursor to tetragonal-to-monoclinic transformation and breakaway oxidation.

Surface and near-surface chemistry can play a significant role in the breakaway oxidation phenomenon. Cladding impurities and/or alloy constituents can induce early monoclinic-oxide formation. They can also delay the transformation. In general, impurities and alloy constituents in the oxide layer with valences less than +4 (e.g., $\mathrm{Al}^{+3}, \mathrm{Cr}^{+3}, \mathrm{Ca}^{+2}, \mathrm{Mg}^{+2}$ ) help preserve hypostoichiometry, while elements with valences greater than +4 (e.g., $\mathrm{Nb}^{+5}$ ) tend to drive the oxide toward $\mathrm{ZrO}_{2}$ and the monoclinic phase. Also, fluorine surface impurities from pickling (i.e., etching) are known to induce early monoclinic oxide formation. Extensive studies have been performed by Cheng and Adamson [23] and Cheng et al. [24] on the effects of fluorine impurities on nodular corrosion in BWR cladding and early breakaway oxidation time. 
In this section, the effects on breakaway oxidation of surface roughness, surface scratches, and surface chemistry are examined. HBR-type Zry-4 and modern Western cladding alloys are discussed in Section 3.5.1, while E110 is discussed in Section 3.5.2.

\subsubsection{Effects of surface conditions on HBR-type Zry-4 and modern cladding alloys}

$\underline{\text { Surface roughness and chemistry }}$

The HBR-type $15 \times 15$ Zry-4 exhibited breakaway oxidation at $\approx 3800 \mathrm{~s}$ and $985^{\circ} \mathrm{C}$, while the beltpolished (BP) $15 \times 15 \mathrm{Zry}-4$ had a breakaway oxidation time of $\approx 5000 \mathrm{~s}$ at $985^{\circ} \mathrm{C}$. Also, the hydrogen pickup rate was much faster for HBR-type Zry-4. HBR-type Zry-4 roughness $(0.3 \mu \mathrm{m}$ for HBR vs. 0.1 $\mu \mathrm{m}$ for BP) appears to have contributed to early breakaway time for the outer surface, and pickling (vs. grit-polishing) appears to have contributed to early inner-surface breakaway and rapid hydrogen pickup.

\section{$\underline{\text { Surface scratches and abrasions }}$}

In the process of handling cladding during fueling, end-cap welding, insertion into the fuel assembly, and core loading, scratches and abrasions will occur on the cladding outer surface. Such scratches could reduce the breakaway oxidation time for fresh cladding in the reactor core. Vendors have a "design-basis" scratch depth, which is based on a stress criterion given that the scratch will locally thin the cladding wall and increase the hoop stress for a given pressure loading. For Western cladding alloys, the depth of the design-basis scratch is $<10 \%$ of the wall thickness, which is $<57 \mu \mathrm{m}$. Generally, vendors use $\approx 2$ mils $(\approx 50 \mu \mathrm{m})$ as the design-basis scratch depth.

The as-fabricated cladding segments received by Argonne did not have "normal" or "design-basis" scratches although they did have mild abrasions. Figure 79 shows images of the belt-polished $15 \times 15$ Zry4 outer surfaces: (a) smooth and (b) local abrasions. This smooth exterior is characteristic of most of the belt-polished $15 \times 15$ Zry-4 cladding segments received by Argonne, as well as the belt-polished $17 \times 17$ PWR and $10 \times 10$ BWR alloys.

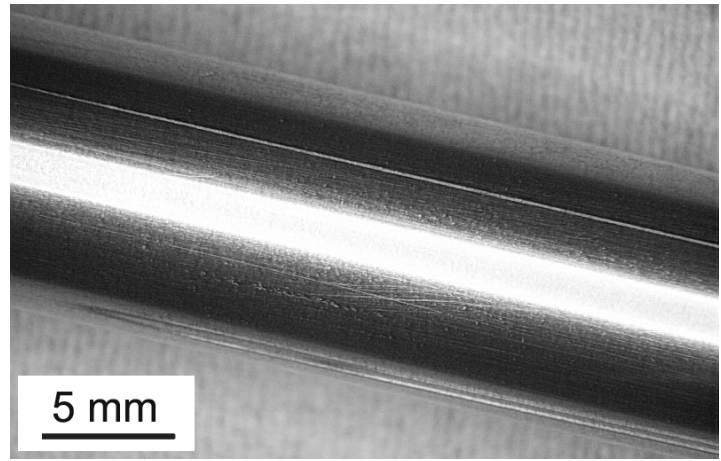

(a)

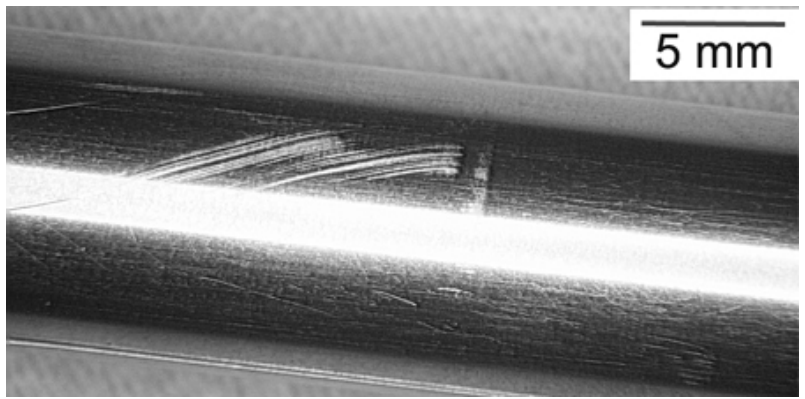

(b)

Figure 79. Outer surface of belt-polished 15×15 Zry-4: (a) smooth exterior and (b) local region of surface abrasions.

A sample was sectioned from the mildly abraded region and oxidized for $5000 \mathrm{~s}$ at $986 \pm 12^{\circ} \mathrm{C}$. The outer surface was lustrous black and the hydrogen pickup was negligible, indicating that mild abrasions do not have a significant effect on the breakaway oxidation time of Zry-4. 
One HBR sample (HBRU\#96) had visible outer-surface scratches prior to testing. Following oxidation at $985^{\circ} \mathrm{C}$ for $3600 \mathrm{~s}$, the measured weight gain was only $3 \%$ higher than the CP-predicted weight gain and the outer surface was black. However, the hydrogen content and pickup were $186 \pm 75$ wppm and $174 \pm 80 \mathrm{wppm}$, respectively. The oxidized sample was sectioned in the region of longitudinal scratches and examined by optical microscopy. The results at four circumferential locations of the cross section are shown in Figure 80. The $0^{\circ}$ (top) and $180^{\circ}$ (bottom) sectors are in breakaway oxidation, while the $90^{\circ}$ and $270^{\circ}$ sectors are not. Based on the appearance of the outer surface and on the metallographic results, local breakaway oxidation and hydrogen pickup occurred in the scratched region. The results suggest that the breakaway oxidation time could $b e \approx 200 \mathrm{~s}$ less at $\approx 1000^{\circ} \mathrm{C}$ for fuel rods clad in scratched HBR-type Zry-4 at the beginning of reactor operation.

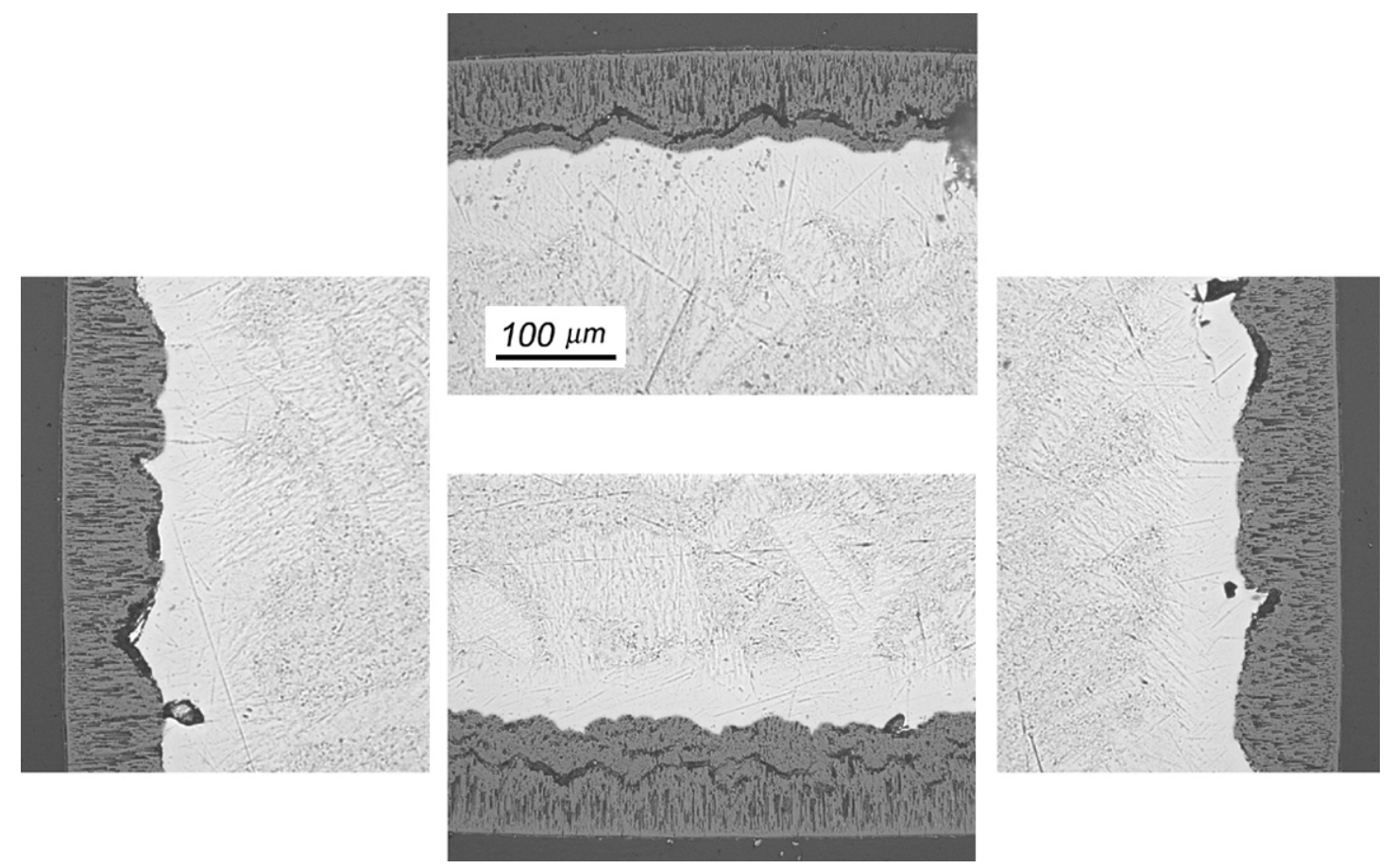

Figure 80. Metallographic images in the scratched region of an HBR-type $15 \times 15$ Zry-4 sample (HBRU\#96) following oxidation at $985 \pm 12^{\circ} \mathrm{C}$ for $3600 \mathrm{~s}$. The top and bottom sectors are in breakaway oxidation, while the left and right sectors are not. The sample was prepared from a region of the cladding with scratches observed during pre-test and post-test characterization.

A scratch depth of $\approx 20 \mu \mathrm{m}$ was machined into the outer surface of belt-polished $17 \times 17$ ZIRLO along a length of about 2 inches $(50 \mathrm{~mm})$. The scratch geometry is shown in Figure 81 for a cladding cross section. Scratched samples were oxidized at $985^{\circ} \mathrm{C}$ for $3400 \mathrm{~s}$ and at $970^{\circ} \mathrm{C}$ for $2600 \mathrm{~s}$ (see Table 29 for results). Breakaway oxidation did initiate along the scratched regions as shown in Figures 82 and 83. For the scratched sample oxidized at $985^{\circ} \mathrm{C}$ for $3400 \mathrm{~s}$, the midplane hydrogen pickup was $175 \pm 145$ wppm, as compared to only 37 wppm for the smooth sample oxidized under the same conditions. Underneath the yellow oxide shown in Figure 82, the hydrogen content was as high as $400 \mathrm{wppm}$. Given that the breakaway oxidation time is estimated to be $3500 \pm 100 \mathrm{~s}$ for smooth ZIRLO oxidized at $985^{\circ} \mathrm{C}$, the 20- $\mu \mathrm{m}$-deep scratch in the ZIRLO outer surface appears to reduce that time by only 100-200 s. For the scratched ZIRLO sample oxidized at $970^{\circ} \mathrm{C}$ for $2600 \mathrm{~s}$, the average hydrogen pickup at the midplane was only $44 \mathrm{wppm}$, with a local hydrogen pickup under the yellow oxide of $120 \mathrm{wppm}$. Again, the scratch appears to reduce the breakaway oxidation time by $\approx 200$ s relative to smooth cladding. 


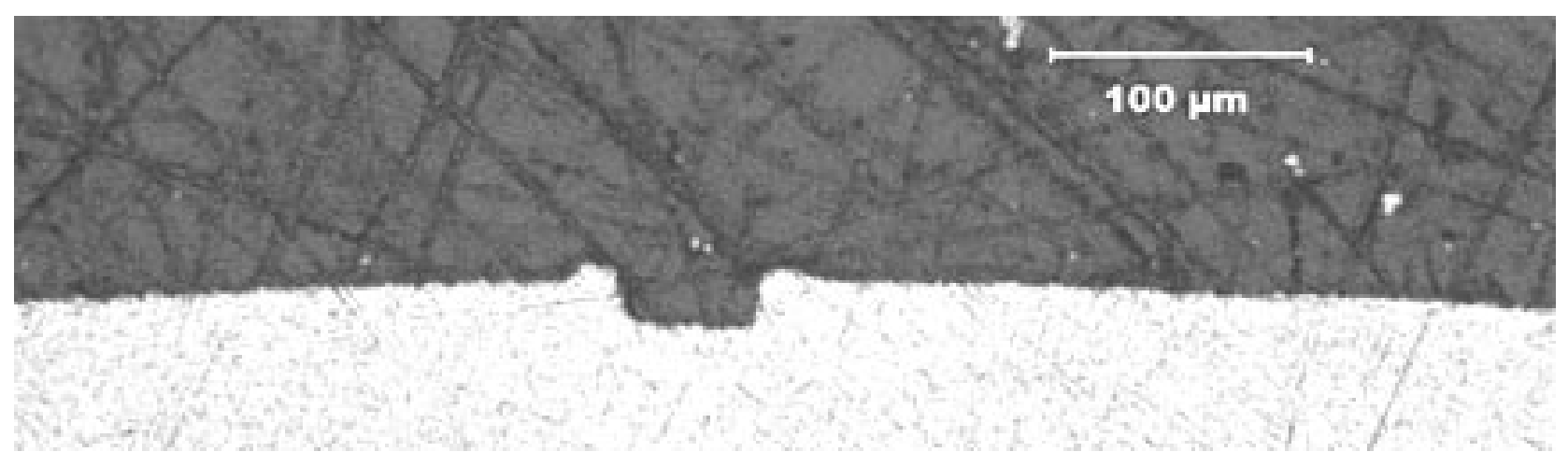

Figure 81. Cross section of ZIRLO cladding with machined scratch $\approx 20-\mu \mathrm{m}$ deep into outer surface.

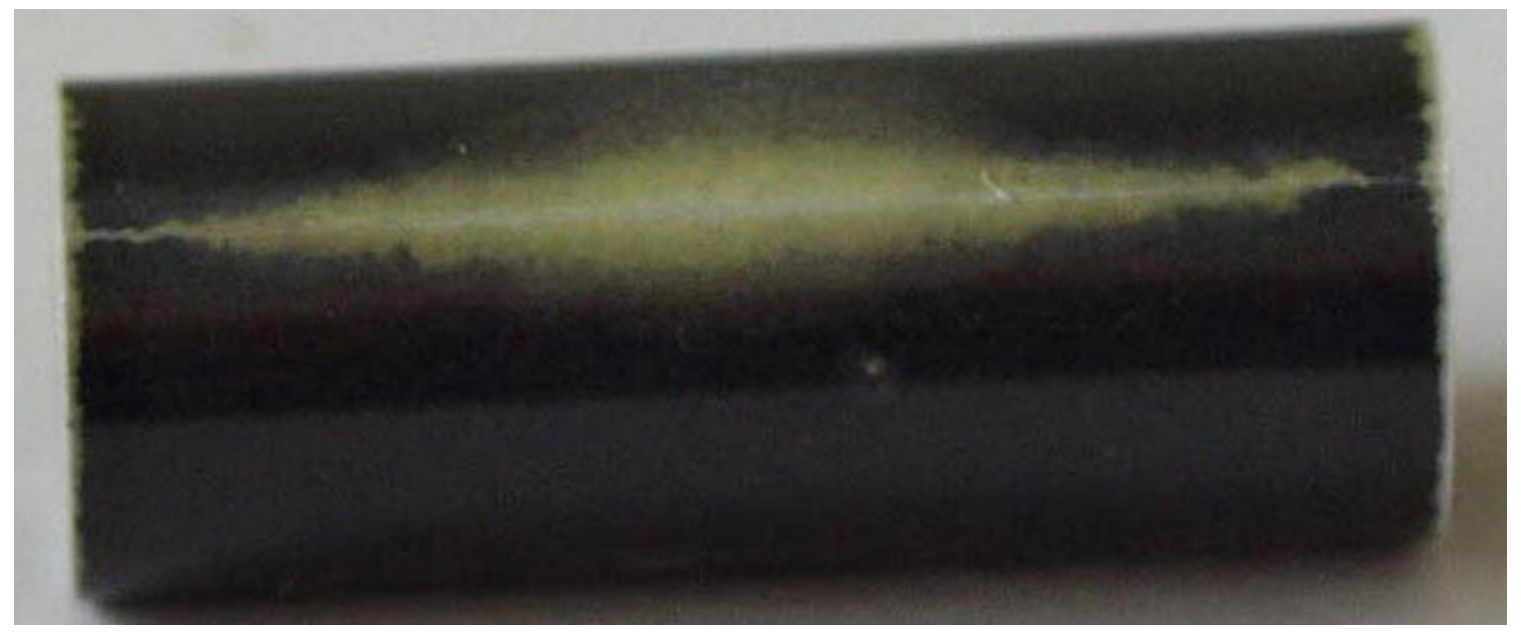

Figure 82. Outer surface of scratched ZIRLO sample following oxidation at $985^{\circ} \mathrm{C}$ for $3400 \mathrm{~s}$. The local hydrogen pickup under the yellow surface is $440 \mathrm{wppm}$.

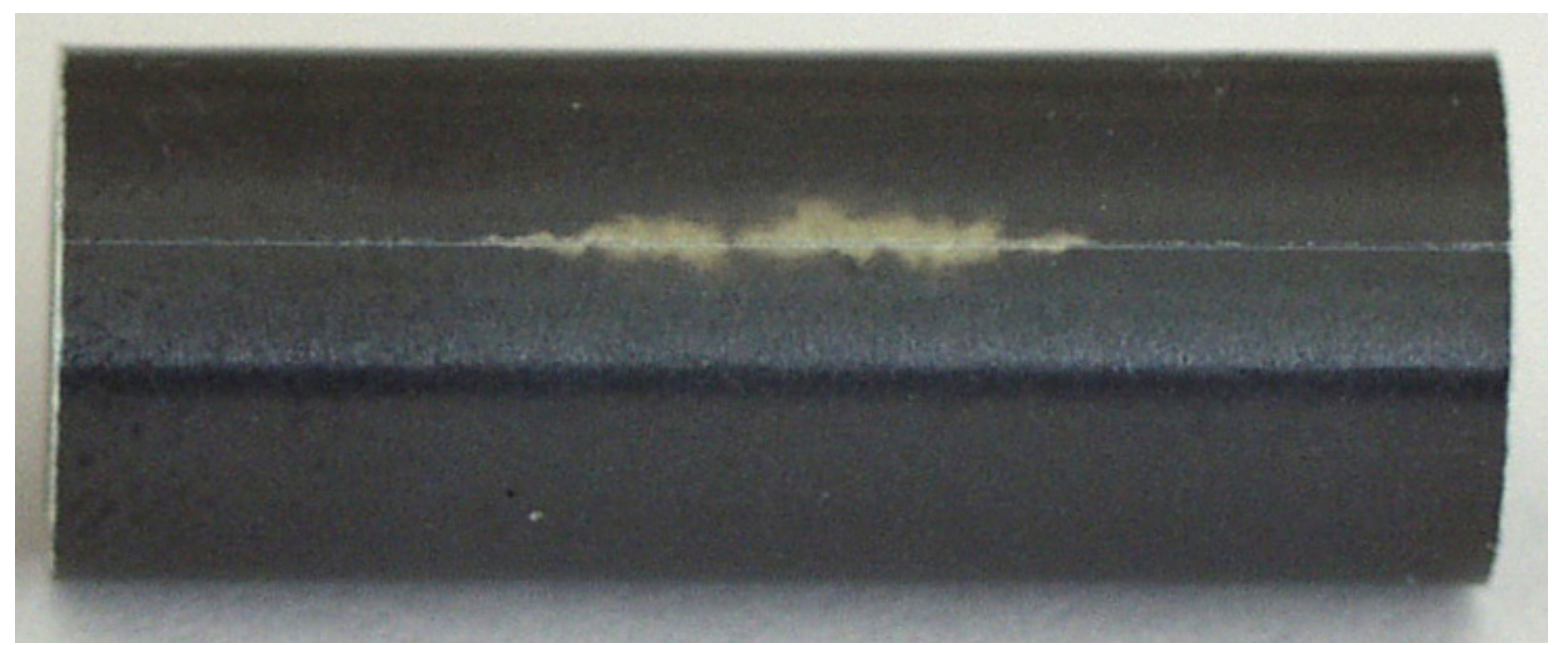

Figure 83. Outer surface of scratched ZIRLO sample following oxidation at $970^{\circ} \mathrm{C}$ for $2600 \mathrm{~s}$. The local hydrogen pickup under the yellow surface is $120 \mathrm{wppm}$. 


\section{$\underline{\text { Surface oxide films }}$}

During reactor startup, water-side corrosion will initiate. By the time the fuel has enough decay heat for temperature elevation during a LOCA, the cladding outer surface will have an oxide film. For softer cladding alloys (e.g., E110 with 500 wppm oxygen), the cladding is pre-filmed $(<1-\mu \mathrm{m}$ thick) through pickling-anodizing or autoclaving during fabrication to protect the cladding from excessive scratching during fuel loading. The effects of pre-filming or early in-reactor corrosion on breakaway oxidation time were studied for $17 \times 17$ ZIRLO. Westinghouse supplied ANL with pre-filmed $(<1-\mu \mathrm{m}$ thick) ZIRLO that had been exposed to $360^{\circ} \mathrm{C}$ water for 36 hours in an autoclave. The samples were preoxidized on inner and outer surfaces prior to breakaway oxidation testing (see Table 37 for results).

Table 37. Effects of Pre-filming on the Breakaway Oxidation Time for ZIRLO. Hydrogen pickup values for as-fabricated (bare) ZIRLO samples are also listed. Samples were slow cooled from the hold temperature to RT and ring-compressed at $135^{\circ} \mathrm{C}$ and $0.0333 \mathrm{~mm} / \mathrm{s}$.

\begin{tabular}{|c|c|c|c|c|c|c|}
\hline $\begin{array}{c}\text { Surface } \\
\text { Condition }\end{array}$ & $\begin{array}{c}\mathrm{T}, \\
{ }^{\circ} \mathrm{C}\end{array}$ & $\begin{array}{c}\text { Test } \\
\text { Time, } \\
\mathrm{s}\end{array}$ & $\begin{array}{c}\text { Measured Wg, } \\
\mathrm{mg} / \mathrm{cm}^{2}\end{array}$ & $\begin{array}{c}\text { Hydrogen } \\
\text { Content }\left(\mathrm{L}_{\mathrm{H}}\right), \\
\text { wppm }\end{array}$ & $\begin{array}{c}\text { Hydrogen } \\
\text { Pickup } \\
\left(\Delta \mathrm{C}_{\mathrm{H}}\right), \\
\text { wppm }\end{array}$ & Comment \\
\hline Bare & 975 & 3000 & 9.01 & $39 \pm 2$ & $30 \pm 2$ & $\begin{array}{c}\text { Small yellow } \\
\text { spot on OD }\end{array}$ \\
\hline Bare & 975 & 3500 & 8.65 & $108 \pm 46$ & $100 \pm 50$ & $\begin{array}{c}\text { Small yellow } \\
\text { area on OD }\end{array}$ \\
\hline Bare & 980 & 3000 & 11.8 & $352 \pm 118$ & $370 \pm 125$ & $\begin{array}{c}\text { Post- } \\
\text { breakaway }\end{array}$ \\
\hline Bare & 985 & 3000 & 9.10 & $104 \pm 40$ & $100 \pm 40$ & $\begin{array}{c}\text { Small yellow } \\
\text { area on OD }\end{array}$ \\
\hline Bare & 985 & 3400 & 9.43 & $303 \pm 164$ & $310 \pm 170$ & $\begin{array}{c}\text { Post- } \\
\text { breakaway }\end{array}$ \\
\hline \hline Pre-filmed & 985 & 3000 & 9.00 & $59 \pm 35$ & $50 \pm 40$ & $\begin{array}{c}\text { Small yellow } \\
\text { spot on OD }\end{array}$ \\
\hline Pre-filmed & 985 & 3400 & 9.28 & $259 \pm 138$ & $260 \pm 145$ & $\begin{array}{c}\text { Post- } \\
\text { breakaway }\end{array}$ \\
\hline Pre-filmed & 985 & 4000 & 11.9 & $1070 \pm 89$ & $1130 \pm 100$ & $\begin{array}{c}\text { Post- } \\
\text { breakaway }\end{array}$ \\
\hline Pre-filmed & 980 & 3200 & 8.67 & $125 \pm 116$ & $120 \pm 120$ & $\begin{array}{c}\text { Two yellow } \\
\text { spots on OD }\end{array}$ \\
\hline Pre-filmed & 980 & 3200 & 8.84 & $101 \pm 98$ & $100 \pm 100$ & $\begin{array}{c}\text { Yellow spots } \\
\text { on OD }\end{array}$ \\
\hline
\end{tabular}

${ }^{a}$ Includes time from beginning of ramp at $300^{\circ} \mathrm{C}$ to end of hold time at oxidation temperature.

${ }^{\mathrm{b}}$ Hydrogen pickup $\left(\Delta \mathrm{C}_{\mathrm{H}}\right)$ is referenced to the as-fabricated sample weight:

$\Delta \mathrm{C}_{\mathrm{H}}=\left(1+5.4 \times 10^{-3} \mathrm{Wg}\right) \mathrm{L}_{\mathrm{H}}-\mathrm{C}_{\mathrm{Hi}}$, where $\mathrm{C}_{\mathrm{Hi}}$ is as-fabricated hydrogen content $(11 \mathrm{wppm})$.

As shown in Table 37, pre-filming with thin $(<1 \mu \mathrm{m})$ oxide layers had only a small effect on breakaway oxidation time and temperature at which the minimum time occurred. The minimum 
breakaway oxidation time for pre-filmed ZIRLO oxidized at $980-985^{\circ} \mathrm{C}$ is $3300 \pm 100 \mathrm{~s}$. Combining the results in Table 29 for bare ZIRLO with and without machined scratches and the data in Table 37 for bare and pre-filmed ZIRLO, the minimum breakaway oxidation time at $970-985^{\circ} \mathrm{C}$ can be expressed as $3100 \pm 300 \mathrm{~s}$ for the range of ZIRLO surface conditions tested.

Westinghouse (W) has generated an independent data set [25] indicating that bare and pre-filmed ZIRLO samples do not experience breakaway oxidation for test times of $4400 \mathrm{~s}$ and $5400 \mathrm{~s}$ and oxidation temperatures in the range of $950-1000^{\circ} \mathrm{C}$. Some ZIRLO samples formed areas of tan oxide near end regions, resulting in hydrogen pickup $>200 \mathrm{wppm}$. Excluding end effects (breakaway due to geometrical discontinuity), Westinghouse results indicate significantly higher breakaway oxidation times for ZIRLO, as compared to the ANL results. Westinghouse also found that breakaway oxidation times for ZIRLO were greater than those determined for W $15 \times 15$ Zry-4 oxidized concurrently with $17 \times 17$ ZIRLO. Differences in ANL and W results highlight the importance of establishing standardized procedures for pretest surface cleaning, heating, temperature monitoring and control, and steam flow rates for breakaway oxidation tests.

\subsubsection{Effects of surface conditions on E110 tubing and cladding}

Although Russian E110 cladding is not used in the U.S., it was added to the ANL test program for the purposes of gaining some understanding as to why this particular $\mathrm{Zr}-1 \mathrm{Nb}$ alloy experiences such early breakaway oxidation time and ductility loss for steam-oxidation temperatures of $1000-1100^{\circ} \mathrm{C}$.

Breakaway oxidation times reported in the literature for E110 are as low as $500 \mathrm{~s}$ based on ductility loss, $>200$-wppm hydrogen pickup, weight-gain-rate increase, and/or visual appearance with correspondingly low CP-ECR values. However, in reviewing the literature for E110, we found it very difficult to compare data sets because oxidation test methods varied considerably (e.g., heating and cooling rates), as did E110 chemistry, thermomechanical treatment, and surface finish.

Concurrent with the ANL E110 study, an extensive study of E110 was conducted at the Russian Research Center "Kurchatov Institute" (RRC-KI) and the Research Institute of Atomic Reactors (RIAR). The RRC-KI/RIAR study was sponsored by NRC, Institute for Radiological Protection \& Nuclear Safety (IRSN), and TVEL (E110 vendor). Close collaboration was maintained between the ANL and Russian programs, particularly with regard to test-sample oxidation protocol and methodologies for post-oxidation ductility determination. The Russian program results are well documented in NUREG/IA-0211 [2]. In some cases, efforts were duplicated to confirm results. For most of the research, ANL concentrated on the evolution of E1 10 breakaway oxidation at $1000^{\circ} \mathrm{C}$ - particularly the effects of surface roughness, surface scratches, and surface chemistry - while the Russian program, which had access to numerous heats of E110, concentrated on the effects of alloying elements and impurities in the E110 bulk. In the Russian program, the following differences between Russian E110 and Western cladding alloys were considered and investigated: impurities in zircon ore, electrolytic refinement vs. Kroll process for reducing the ore to produce $\mathrm{Zr}$ ingots, variations in alloying elements (e.g., oxygen), and fabrication processes for making tubing from the ingot. The most substantial improvement in E110 behavior came from fabricating E1 10 cladding from a Western Zr ingot. These results suggest that electrolytic refinement removes impurities that may help stabilize the oxide layer grown on the surface.

Argonne had access to only one heat of E110 - the tubing and cladding provided by Fortum in Finland. Because the ANL study was restricted to this one heat, the focus of the ANL program was on the effects of surface finish, which could be modified by machining, polishing, and etching, as well as the effects of cladding thickness. 


\section{Characterization of E110 tubing and cladding}

Characterization of E110 tubing was performed by ANL to verify that the E110 received from Fortum was within specifications and to try to ascertain any differences that would explain the poor LOCA performance of E110 relative to the excellent performance of M5. The dimensional and chemical characterization results are listed in Table 6 for E110 and Table 5 for M5. For the alloying and impurity elements measured, materials used in the ANL test program are within specifications for E110 [7] and M5 [6]. Noticeable differences in materials are: thicker wall for E110 (0.71 mm vs. 0.57-0.61 mm for M5), higher surface roughness for E110 tubing $(0.34 \mu \mathrm{m}$ vs. $0.12 \mu \mathrm{m}$ for M5), and lower oxygen content for E110 (0.05 wt.\% vs. 0.145 wt.\% for M5). As Zry-4 cladding with thicker walls (0.67-0.77 mm) showed no adverse effects due to wall thickness, it appeared highly unlikely that wall thickness alone would contribute to E110 performance. The higher surface roughness could contribute directly or indirectly to early breakaway oxidation. However, breakaway oxidation time $\left(\approx 3800 \mathrm{~s}\right.$ at $\left.1000^{\circ} \mathrm{C}\right)$ determined by ANL for $0.32-\mu \mathrm{m}$-rough HBR-type Zry-4 was significantly higher than what is reported for E110 in the Russian program [2] for $1000^{\circ} \mathrm{C}$ oxidation temperature. Also, E110 cladding (etched and anodized) had a lower surface roughness $(0.19 \mu \mathrm{m})$ than the tubing, but the cladding also exhibited early breakaway oxidation times. It seemed more likely that high surface roughness could result in earlier initiation of breakaway oxidation for an alloy that is inherently unstable. It is also likely that negative effects of surface impurities would be exaggerated for materials with higher surface roughness and higher local surface areas, which provide more sites for initiation of instability.

With regard to the lower oxygen content of E110 as compared to M5, the Russian program found that E110 heats with oxygen content as high as $0.11 \mathrm{wt} . \%$ exhibited early breakaway oxidation. In a study performed by the Bochvar Institute and TVEL [26], E110 heats with as much as $0.13 \mathrm{wt} \%$ oxygen showed early breakaway oxidation and hydrogen pickup at oxidation temperatures as high as $1100^{\circ} \mathrm{C}$.

Argonne performed scanning electron microscopy (SEM) and transmission electron microscopy (TEM) with E110 and M5 samples to determine if there were significant differences in grain size, in $\mathrm{Zr}(\mathrm{Nb}, \mathrm{Fe}, \mathrm{Cr})$ precipitate size and distribution, and in $\mathrm{Zr}-\mathrm{Nb}$ precipitate size and distribution. E110 grain size was determined by SEM to be $4.7 \mu \mathrm{m}$, which is within specifications for M5 (3-5 $\mu \mathrm{m})$. E110 Nb-Ferich precipitates were found to be $>100 \mathrm{~nm}$, which is consistent with the 100-200 nm reported by Mardon et al. [6] for M5 and measured by ANL. E110 Nb-rich precipitates were determined to be $\approx 40 \mathrm{~nm}$, which is consistent with the $50 \mathrm{~nm}$ reported by Mardon et al. [6] for M5 and measured by ANL. A non-uniform cluster of precipitates was found in one location of an E110 TEM sample, while Mardon et al. [6] reported uniform distribution of such precipitates. However, given the very small size of the TEM sample area examined, such non-uniformity may not be characteristic of bulk E110 tubing and cladding.

Based on ANL characterization, no differences could be found to explain the differences in LOCA performance between E110 and M5. However, because early breakaway oxidation could be due to surface as well as bulk effects, ANL tested several surface-modified types of E110: as-received tubing, polished tubing, machined-and-polished tubing, tubing etched in an acid bath containing HF, and cladding that was etched and anodized. The outer surfaces of the as-received (a), polished (b), and etched (c) tubing samples are shown in Figure 84 at low magnification (50X). Figure 84a shows the rough surface of as-received tubing, as well as longitudinal and circumferential scratches. Figure $84 \mathrm{~b}$ shows the outer surface of polished and machined-and-polished E110 tubing with a reduced roughness of $0.14 \mu \mathrm{m}$. Polishing also removed some of the surfaces scratches. Figure $84 \mathrm{c}$ shows the outer surface of a sample etched in an HF-containing solution $\left(13.5 \% \mathrm{HF}+13.5 \% \mathrm{HNO}_{3}+40 \% \mathrm{C}_{3} \mathrm{H}_{6} \mathrm{O}_{3}+33 \% \mathrm{H}_{2} \mathrm{O}\right.$ for $\left.30 \mathrm{~s}\right)$. The surface roughness appears to have decreased, but the longitudinal and axial scratches are more readily observed. Preferential etching may have widened and deepened these scratches. 


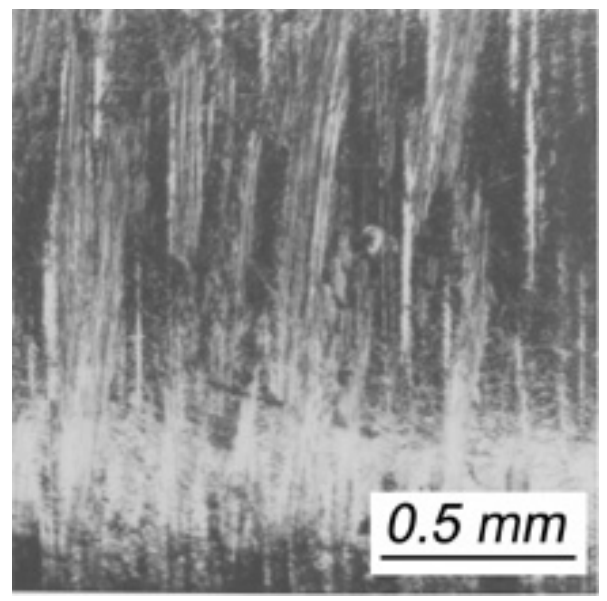

Figure 84a. Outer surface of E110 tubing in the as-received condition (0.35- $\mu \mathrm{m}$ surface roughness). Axial direction is left to right.

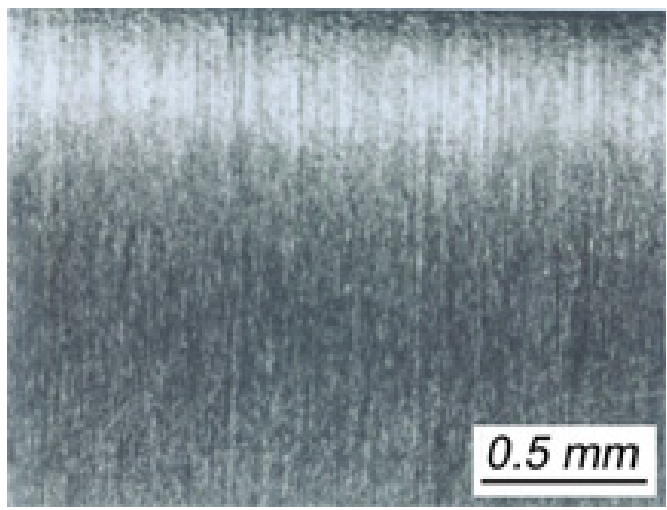

Figure $84 \mathrm{~b}$. Outer surface of E110 tubing in the polished condition $(0.14-\mu \mathrm{m}$ surface roughness). Axial direction is left to right.

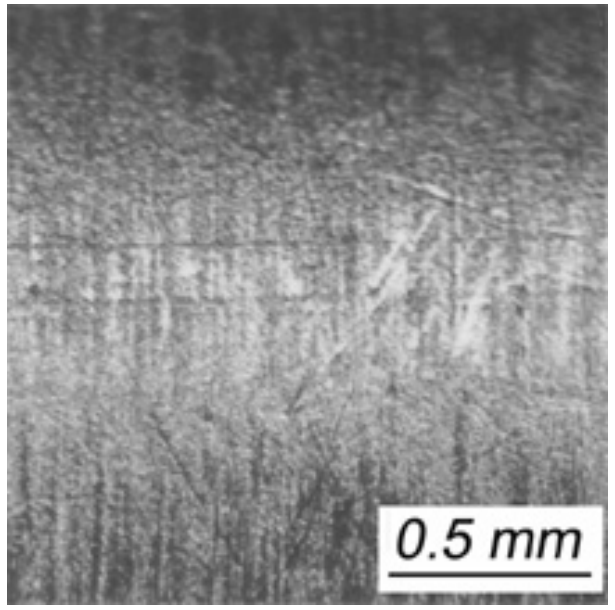

Figure 84c. Outer surface of E110 tubing following etching in HF-containing pickling solution. Axial direction is left to right. 


\section{As-fabricated E110 tubing and cladding oxidized at $1000^{\circ} \mathrm{C}$}

Because the results of the Russian program indicated very early breakaway at $1000^{\circ} \mathrm{C}$ oxidation temperature, testing at ANL focused on this temperature. The thermal benchmark for the $1000^{\circ} \mathrm{C}$ tests is shown in Figure 85 . The ramp time from $300^{\circ} \mathrm{C}$ to $1000^{\circ} \mathrm{C}$ is $75 \mathrm{~s}$. Hold times of $5 \mathrm{~s}$ to $1350 \mathrm{~s}$ were investigated. The reference hold time for most tests was $290 \mathrm{~s}$. Table 38 summarizes the test conditions and observations for the more interesting tests conducted with as-received E110 tubing.

Test EU\#10 was conducted to observe the behavior of the outer-surface oxide layer following the ramp to $1000^{\circ} \mathrm{C}$. The hold time at $1000^{\circ} \mathrm{C}$ was only $5 \mathrm{~s}$. Although the outer-surface oxide layer appeared to be lustrous black (see Figure 86a), higher magnification images revealed the presence of white or "gray" spots ( $\leq 50-\mu \mathrm{m}$ diameter) and streaks within the lustrous black matrix (see Figure $86 \mathrm{~b})$. It is assumed that these spots and streaks represent monoclinic oxide in a tetragonal matrix. Such behavior was not observed for any other cladding alloy tested. The white spots are not observed until much later times for polished E110 samples.

Test EU\#9 was the thermal benchmark test with thermocouples (TCs) welded directly onto the E110 tubing. The TCs resulted in an abrupt change in geometry - much like the change at the ends of the sample - at the cladding surface, which can alter the stress state and induce early breakaway oxidation. This sample had a larger area of gray monoclinic oxide on the outer surface (see Figure 87) than the EU\#12 sample (see Figure 88a), which had no welded TCs on the sample. Metallography of the cross section (see Figure $88 \mathrm{~b}$ ) shows that some of the oxide layer has already experienced delamination after only 290-s hold time for the companion EU\#13 sample. Breakaway oxidation is both local and extensive. Hydrogen appears to be absorbed locally into E110 at breakaway locations, but it does not have time to diffuse and homogenize during the short hold time at temperature. Sample EU\#11 was oxidized at $950^{\circ} \mathrm{C}$ for 290 -s hold time. Breakaway oxidation is evident in Figure 89.

Sample EU\#36 had a hold time of $395 \mathrm{~s}$ at $1000^{\circ} \mathrm{C}$. However, breakaway was less extensive than for the 290-s hold-time sample. Thus, the hydrogen pickup was low at the sample midplane and $<50$ wppm in the regions between the midplane and the ends of the sample. These results confirm that breakaway oxidation is an instability phenomenon with variation in the extent of breakaway vs. hold-time at temperature. At the longer hold time of $625 \mathrm{~s}$, sample EU\#38 picked up a significant amount of hydrogen. The midplane of the sample had local hydrogen readings ranging from very low values to $\approx 180$ wppm, with the low values occurring under black oxide and the higher values occurring under regions of gray oxide. At the off-center locations, the hydrogen pickup was much higher $(420 \pm 160$ wppm). Even for a longer hold time (625 s), hydrogen does not diffuse fast enough to homogenize the gradient. Figure 90 shows the axial variation of hydrogen content for the EU\#38 test sample.

Samples with hold times of 825 to 1350 s experienced significant oxide delamination and spallation, as well as significant hydrogen pickup. The hydrogen concentration was still highly nonuniform after $825 \mathrm{~s}$, but it was both high and uniform after a 1350 -s hold time at $1000^{\circ} \mathrm{C}$. The $1350-\mathrm{s}$ sample (EU\#8) is shown in Figure 91. Some of the $1000^{\circ} \mathrm{C}$-oxidized samples were sectioned into 8-mmlong rings and ring-compressed at RT. The results are summarized in Table 39. The ductile-to-brittle transition CP-ECR was in the range of 6-7\% (see Figure 92). The corresponding embrittlement hold time at $1000^{\circ} \mathrm{C}$ is $500 \pm 100 \mathrm{~s}$, with total test times including the ramp from $300^{\circ} \mathrm{C}$ of $575 \pm 100 \mathrm{~s}$. For E1 10 oxidized under these conditions, embrittlement occurs with hydrogen contents $>200 \mathrm{wppm}$. However, there was significant circumferential and axial variation in hydrogen content (25-560 wppm) for the embrittled sample at $\approx 7 \% \mathrm{CP}$-ECR. Thus, a precise determination between $\mathrm{H}$ content and embrittlement could not be made for these samples. 


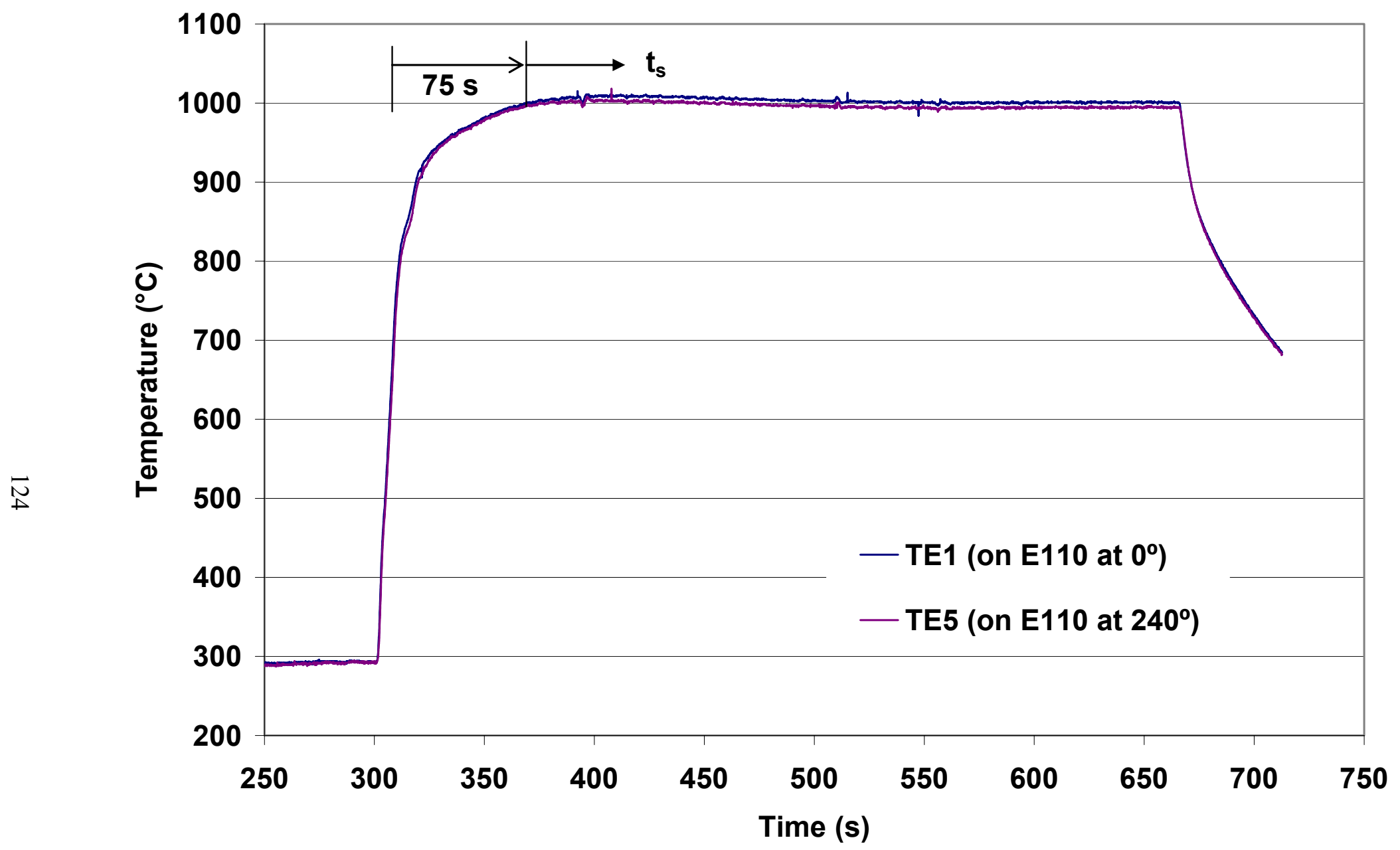

Figure 85. Thermal benchmark results for as-received E110 tubing and cladding oxidized in steam at $1000^{\circ} \mathrm{C}$. Ramp time is $75 \mathrm{~s}$. 
Table 38. Two-Sided Steam Oxidation Tests Conducted at $1000^{\circ} \mathrm{C}$ with As-received E110 Tubing. Cladding dimensions are 9.17-mm OD and 0.71-mm wall thickness; CP-ECR $=1.235 \mathrm{CP}$ $\mathrm{Wg}$; outer-surface roughness $=0.35 \mu \mathrm{m}$; and sample length $=\approx 25 \mathrm{~mm}$. Hydrogen samples were cut from center $(\mathrm{C})$ and off-center $(\mathrm{OC})$ sample locations. Note that Test EU\#11 was conducted at $950^{\circ} \mathrm{C}$.

\begin{tabular}{|c|c|c|c|c|c|}
\hline $\begin{array}{l}\text { Test } \\
\text { ID\# }\end{array}$ & $\begin{array}{l}\text { Hold } \\
\text { Time } \\
\text { s }\end{array}$ & $\begin{array}{l}\text { Total } \\
\text { Time } \\
\text { s }\end{array}$ & $\begin{array}{c}\mathrm{CP} \\
\mathrm{ECR} \\
\%\end{array}$ & $\begin{array}{c}\mathrm{H} \\
\text { Content } \\
\text { wppm }\end{array}$ & $\begin{array}{l}\text { Sample Condition } \\
\text { Observations }\end{array}$ \\
\hline EU\#10 & 5 & 80 & 1.8 & --- & $\begin{array}{l}\text { Black oxide layer (Figure 86a); } \\
\text { white spots } \leq 50 \mu \mathrm{m} \text { (Figure 86b) }\end{array}$ \\
\hline EU\#9 & 290 & 365 & 5.0 & --- & $\begin{array}{l}\text { Extensive monoclinic oxide } \\
\text { around welded TCs (Figure 87) }\end{array}$ \\
\hline EU\#12 & 290 & 365 & 5.0 & $120 \pm 45(\mathrm{C})$ & Nonuniform oxide (Figure 88a) \\
\hline EU\#13 & 290 & 365 & 5.0 & --- & $\begin{array}{l}\text { Half the sample was as-fabricated; } \\
\text { oxide delamination (Figure } 88 \mathrm{~b} \text { ) }\end{array}$ \\
\hline EU\#11 & $\begin{array}{l}290 \text { at } \\
950^{\circ} \mathrm{C}\end{array}$ & 365 & $<5$ & --- & $\begin{array}{l}\text { Oxide surface (Figure } 89 \text { ) may be } \\
\text { worse than EU\#12 sample }\end{array}$ \\
\hline EU\#36 & 395 & 470 & 5.8 & $\begin{array}{c}7 \pm 3(\mathrm{C}) \\
44 \pm 7(\mathrm{OC})\end{array}$ & Nonuniform oxide layer \\
\hline EU\#38 & 625 & 700 & 7.1 & $\begin{array}{c}80 \pm 40(\mathrm{C}) \\
90 \pm 90(\mathrm{C}) \\
420 \pm 160(\mathrm{OC})\end{array}$ & $\begin{array}{l}\text { Significant axial distribution } \\
\text { of hydrogen content (Figure 90) }\end{array}$ \\
\hline EU\#40 & 825 & 900 & 8.1 & $\begin{array}{c}540 \pm 80(\mathrm{C}) \\
1430 \pm 110(\mathrm{OC})\end{array}$ & $\begin{array}{l}\text { Delamination-spallation } \\
\text { from half the sample }\end{array}$ \\
\hline EU\#8 & 1350 & 1425 & 10.4 & $4230 \pm 250(\mathrm{C})$ & $\begin{array}{l}\text { Extensive delamination- } \\
\text { spallation (see Figure 91) }\end{array}$ \\
\hline
\end{tabular}


(a)
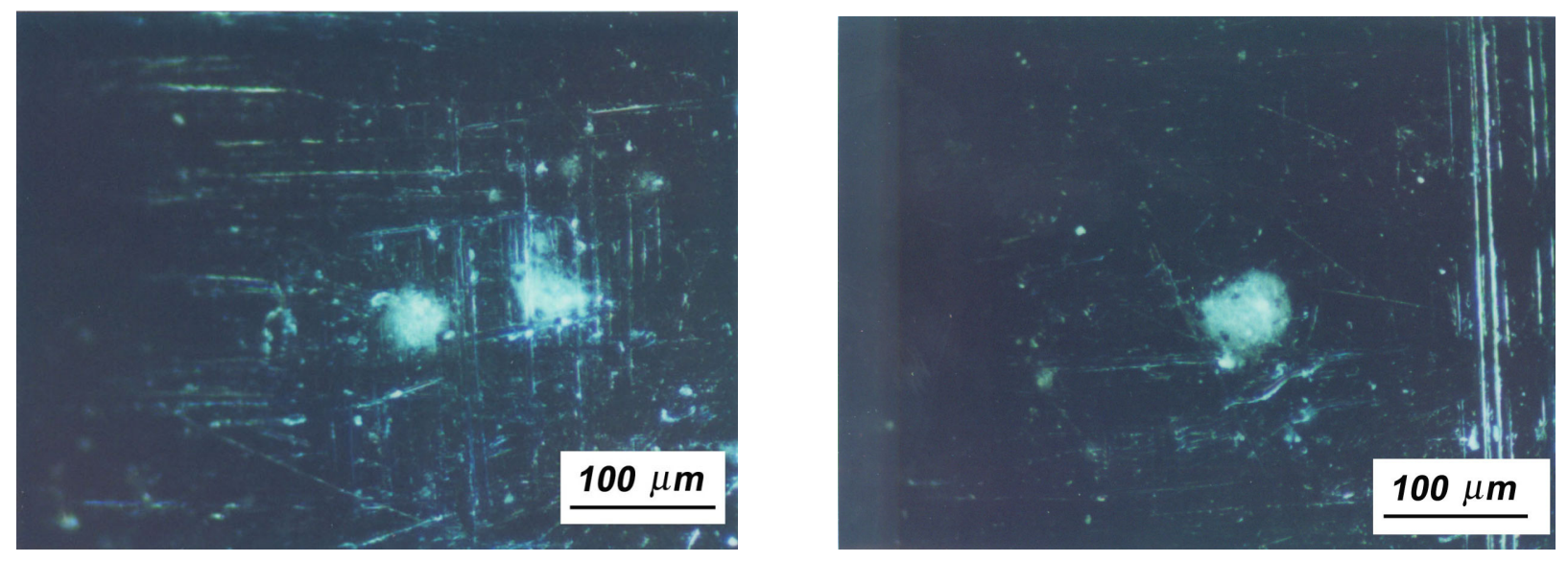

(b)

Figure 86. As-fabricated E110 tubing oxidized in steam for a 75 -s ramp from $300^{\circ} \mathrm{C}$ to $1000^{\circ} \mathrm{C}$, followed by a 5-s hold at $1000^{\circ} \mathrm{C}$ and slow cooling: (a) low magnification of lustrous black outer surface oxide and (b) higher magnification of outer surface oxide showing white spots and streaks believed to be monoclinic oxide and oxide-instability initiation sites.

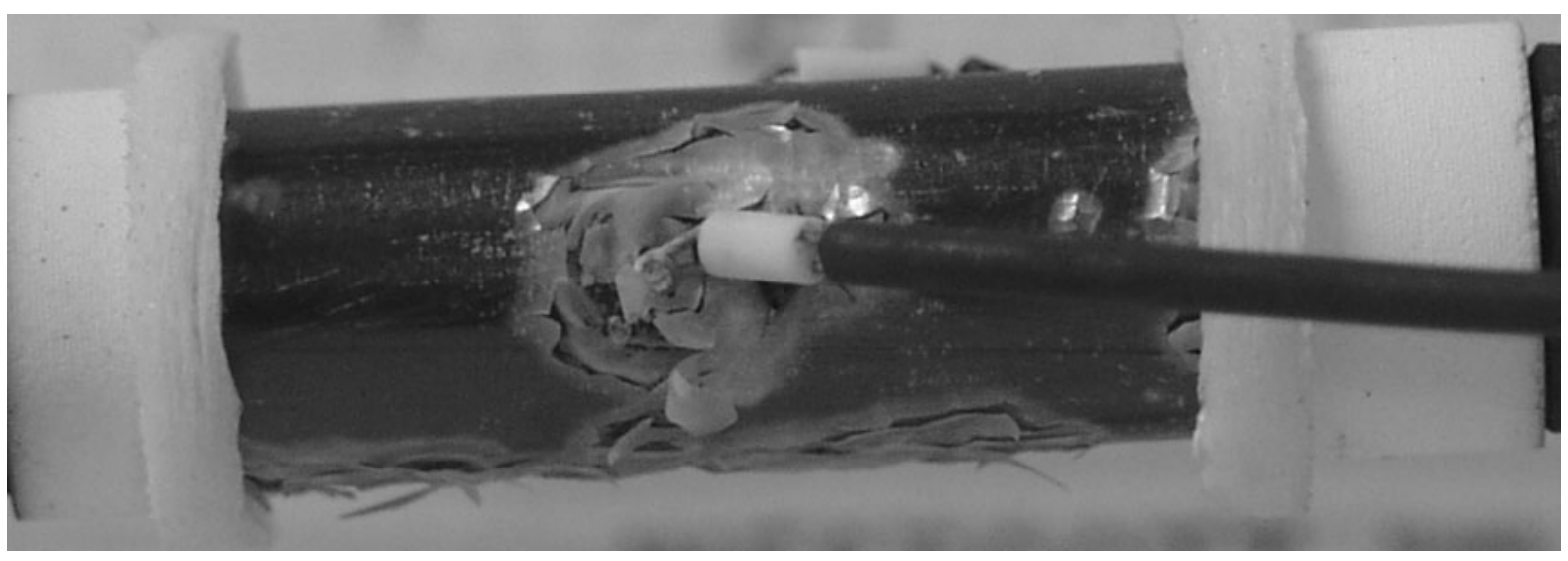

Figure 87. As-fabricated E110 thermal-benchmark (EU\#9) sample showing excessive monoclinic oxide formation around the welded thermocouple after 290 -s hold time at $1000^{\circ} \mathrm{C}$. 


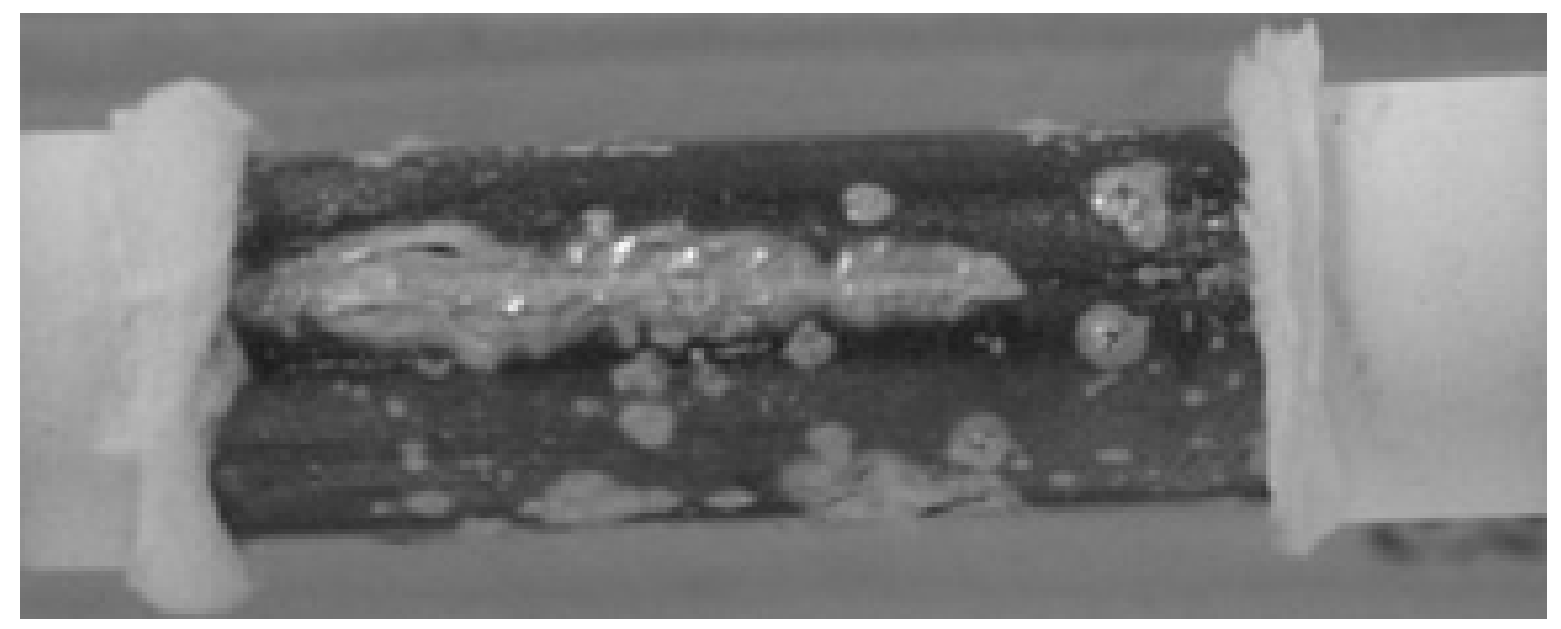

(a)

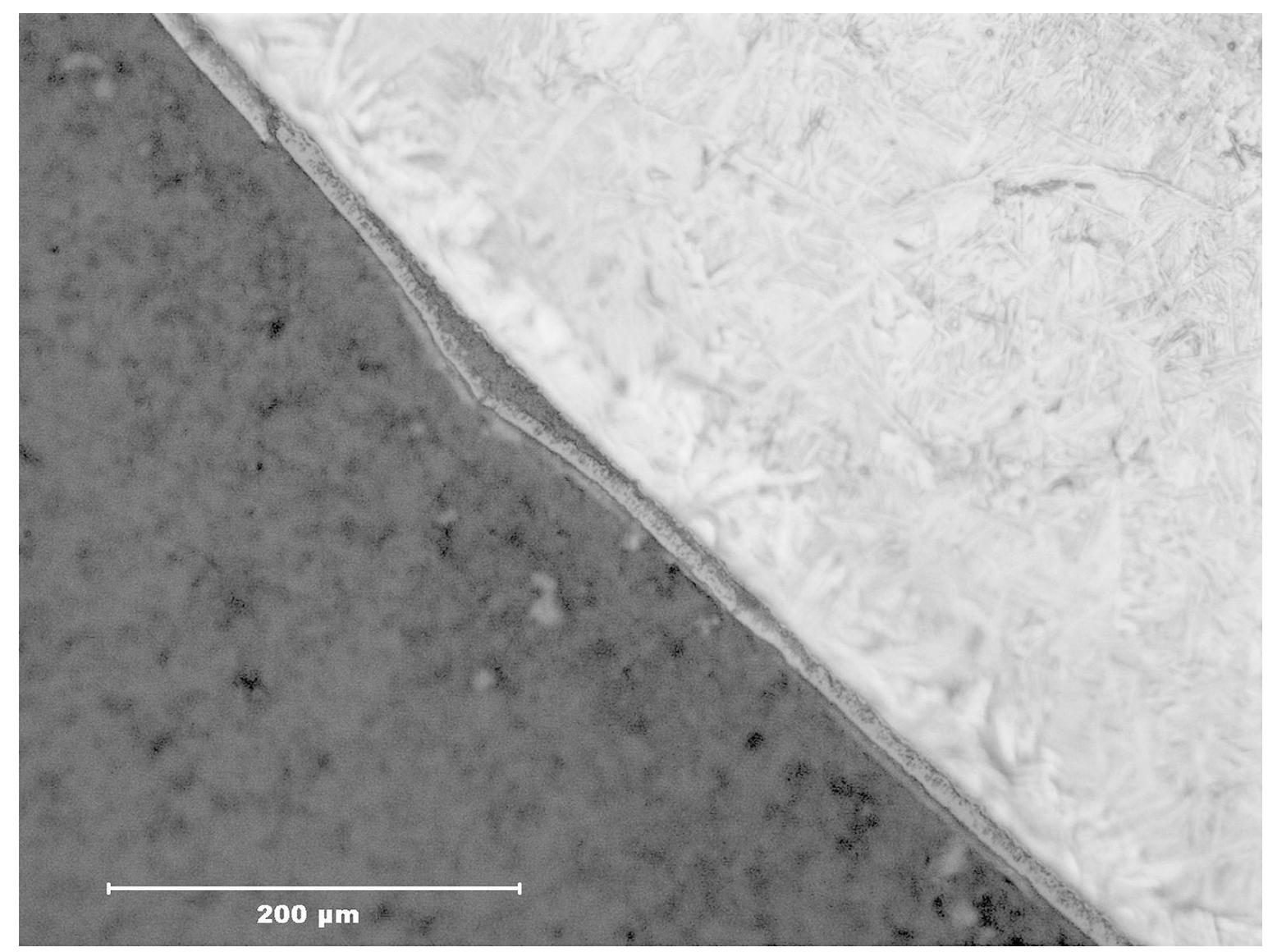

(b)

Figure 88. As-fabricated E110 sample oxidized in steam for a hold time of $290 \mathrm{~s}$ at $1000^{\circ} \mathrm{C}$ : (a) low magnification image of breakaway oxidation on the outer surface oxide of EU\#12 sample and (b) metallographic image of delaminated outer-surface oxide layer on EU\#13 sample. 


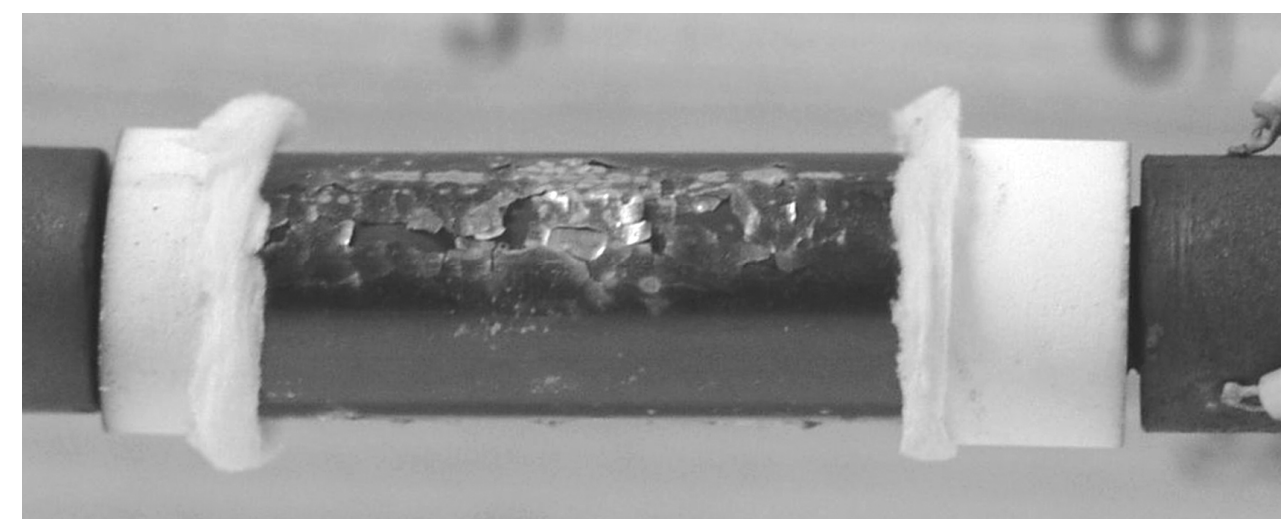

Figure 89. EU\#11 sample oxidized for a hold time of $290 \mathrm{~s}$ at $950^{\circ} \mathrm{C}$. Breakaway oxidation is as extensive as for the EU\#12 sample oxidized for the same hold time at $1000^{\circ} \mathrm{C}$.

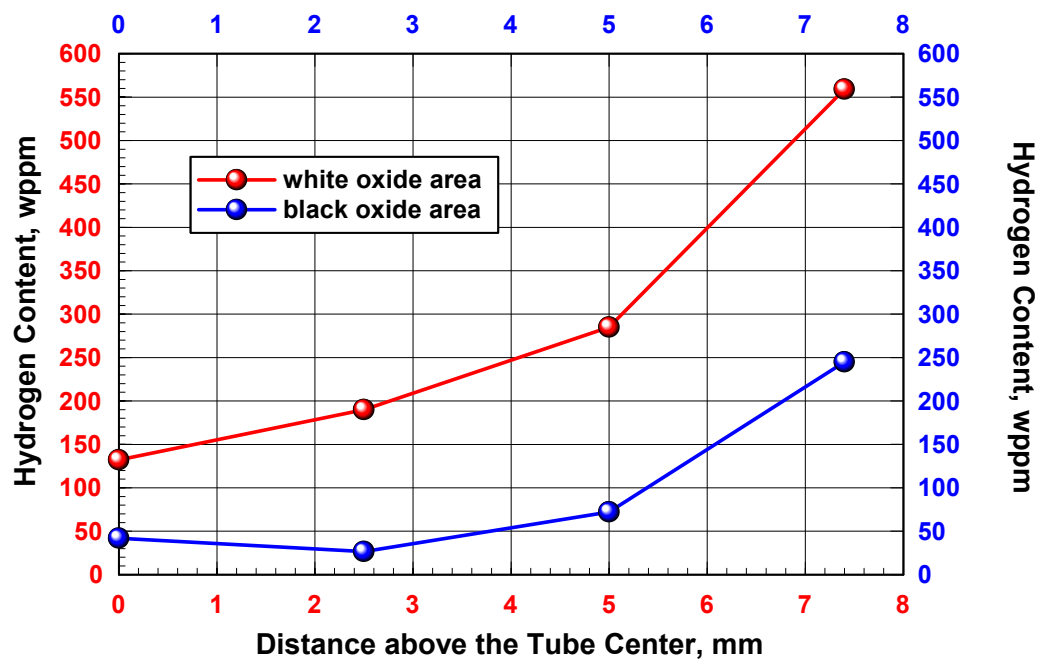

Figure 90. Hydrogen content distribution in E110 after oxidation Test EU\#38 with as-fabricated E110 exposed to steam at $1000^{\circ} \mathrm{C}$ for a hold time of $625 \mathrm{~s}(\approx 7 \% \mathrm{CP}-\mathrm{ECR})$.

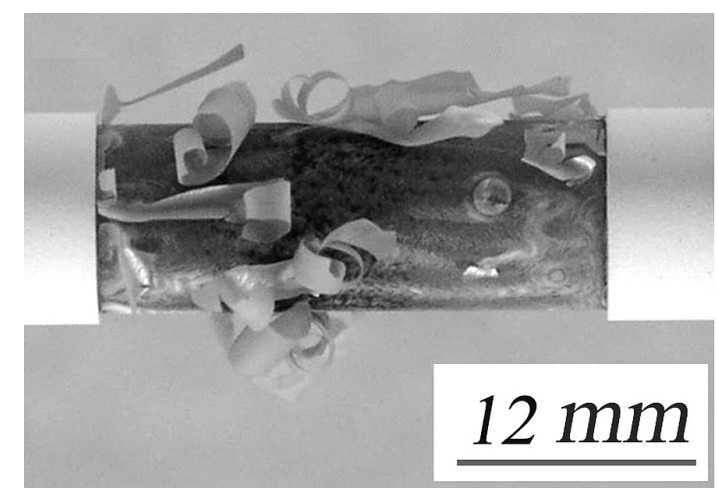

Figure 91. EU\#8 sample oxidized for a hold time of $1350 \mathrm{~s}$ at $1000^{\circ} \mathrm{C}$. Breakaway oxidation, delamination, and spallation are evident. The hydrogen pickup was $\approx 4200 \mathrm{wppm}$. 


\section{Effects of etching E110 tubing prior to oxidizing at $1000^{\circ} \mathrm{C}$}

The results in Figure 86 suggest that surface and substrate impurities may serve as initiation sites for E110 breakaway oxidation. E110 tubing is pickled and anodized to produce cladding with an increased surface hardness to make it more scratch resistant. The specific acid mixture and pickling time used by TVEL are proprietary. However, based on the Russian program tests and one test conducted by ANL with E1 10 cladding oxidized at $1100^{\circ} \mathrm{C}$ for $\approx 500 \mathrm{~s}$, the extent of outer-surface breakaway oxidation was comparable for the cladding and the tubing.

In an effort to determine the effects of pickling (etching) on breakaway oxidation, E110 tubing was exposed to two types of acid-bath mixtures prior to cleaning and oxidation: (a) a solution used by ANL to clean steel and vanadium surfaces (30-s exposure to $13.5 \% \mathrm{HF}+13.5 \% \mathrm{HNO}_{3}+40 \% \mathrm{C}_{3} \mathrm{H}_{6} \mathrm{O}_{3}+33 \%$ $\mathrm{H}_{2} \mathrm{O}$ ) and (b) a solution used to etch Zry-2 cladding in the 1980s (180-s exposure to $3.5 \% \mathrm{HF}+45 \%$ $\mathrm{HNO}_{3}+51.5 \% \mathrm{H}_{2} \mathrm{O}$ ). Samples were then cleaned (ultrasonic baths of RT ethanol and water) and oxidized at $1000^{\circ} \mathrm{C}$ for a hold time of $290 \mathrm{~s}$. Both (a) and (b) resulted in extensive monoclinic oxide formation and breakaway oxidation of the E110 outer-surface oxide. The results suggest that E110 oxidation behavior is very sensitive to sub-micron-deep F impurities. Figure 93a shows the silver-gray appearance of the outer surface following etching with solution (b) and oxidation. Figure 93b shows the partial, but extensive breakaway oxidation of polished-and-etched (b) E110. Figure 93c shows the lustrous black appearance of an E110-tubing sample that was etched with (b) and then polished. The results of this limited study suggest that pickling (etching) E110 with an acid solution containing HF can promote earlier and more extensive breakaway oxidation, while polishing the sample following etching appears to remove the sub-micron-deep layer containing F impurities.

Table 39. Ring-Compression Test Results for E110 Samples Oxidized at $1000^{\circ} \mathrm{C}$ and Slow Cooled. Tests were performed on 8-mm-long samples at RT and 0.0333- $\mathrm{mm} / \mathrm{s}$ displacement rate.

\begin{tabular}{|c|c|c|c|c|c|c|}
\hline Test ID & $\begin{array}{l}\text { Hold } \\
\text { Time, } \\
\text { s }\end{array}$ & $\begin{array}{l}\text { Total } \\
\text { Time, } \\
\text { s }\end{array}$ & $\begin{array}{c}\text { ECR, \% } \\
\text { CP- } \\
\text { Model }\end{array}$ & $\begin{array}{c}\text { H Content } \\
\text { (Variation), } \\
\text { wppm }\end{array}$ & $\begin{array}{c}\text { RT Offset } \\
\text { Displacement, } \\
\text { mm }\end{array}$ & $\begin{array}{c}\text { RT Offset } \\
\text { Strain, } \\
\%\end{array}$ \\
\hline E110 & 0 & 0 & 0 & 3 & 6 & 66 \\
\hline EU\#10 & 5 & 80 & 1.8 & --- & 6.05 & 66 \\
\hline EU\#9 & 290 & 365 & 5.0 & --- & --- & --- \\
\hline EU\#12 & 290 & 365 & 5.0 & $\begin{array}{c}120 \\
(70-170)\end{array}$ & 5.44 & 59 \\
\hline EU\#36 & 395 & 470 & 5.8 & $\begin{array}{c}32 \\
(4-84)\end{array}$ & 5.82 & 63 \\
\hline EU\#38 & 625 & 700 & 7.1 & $\begin{array}{c}275 \\
(25-560)\end{array}$ & 0.13 & $\begin{array}{c}1.4 \\
\text { (brittle) }\end{array}$ \\
\hline EU\#40 & 825 & 900 & 8.1 & $\begin{array}{c}925 \\
(440-1500)\end{array}$ & 0.04 & $\begin{array}{c}0.4 \\
\text { (brittle) }\end{array}$ \\
\hline
\end{tabular}




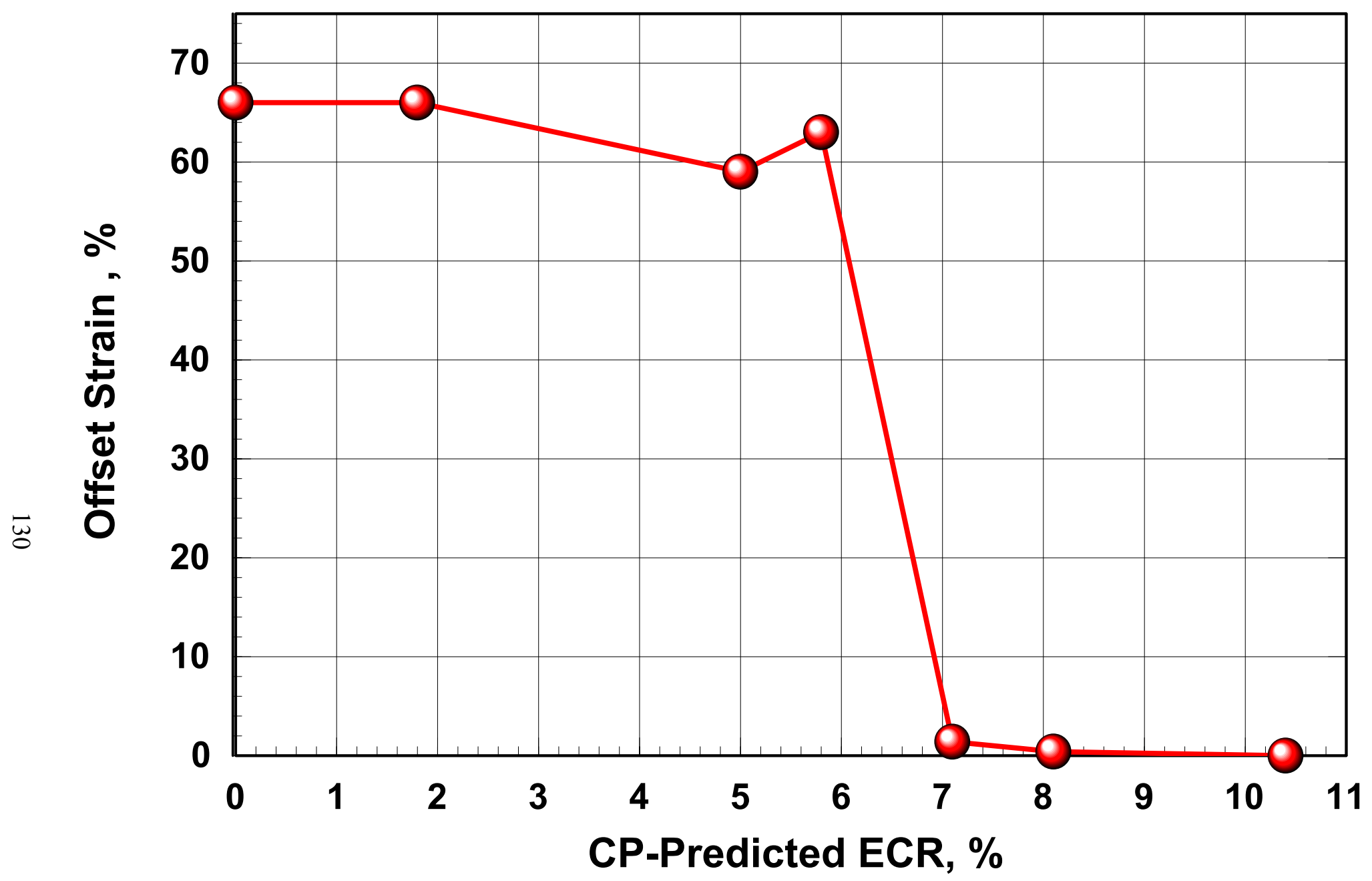

Figure 92. Room-temperature offset strain vs. CP-ECR for as-fabricated E110 tubing oxidized (two-sided) in steam at $1000^{\circ} \mathrm{C}$ for hold times of 0 $825 \mathrm{~s}$. Sample length is $8 \mathrm{~mm}$, and displacement rate is $0.0333 \mathrm{~mm} / \mathrm{s}$. Embrittlement is due to excessive hydrogen pickup (>200 wppm). 


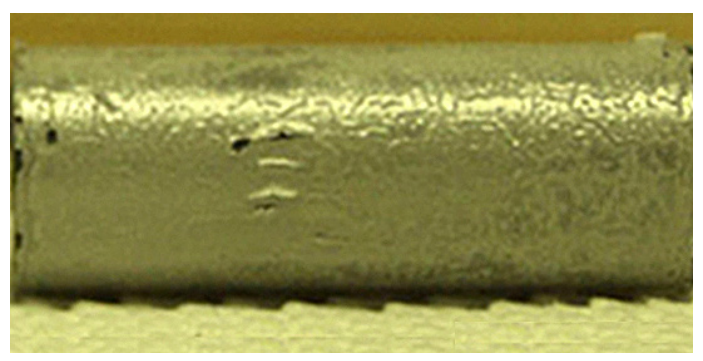

(a)

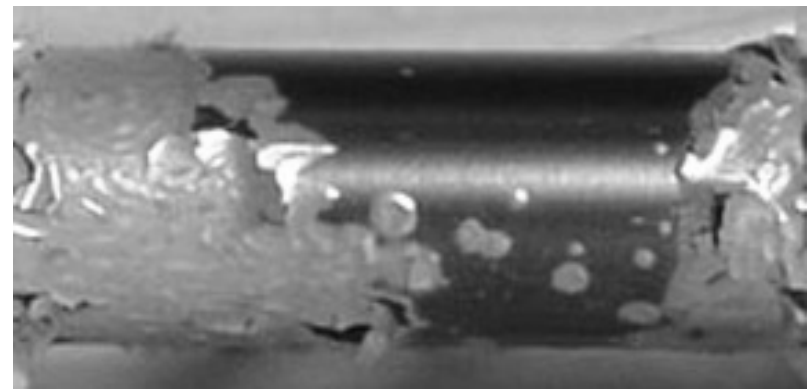

(b)

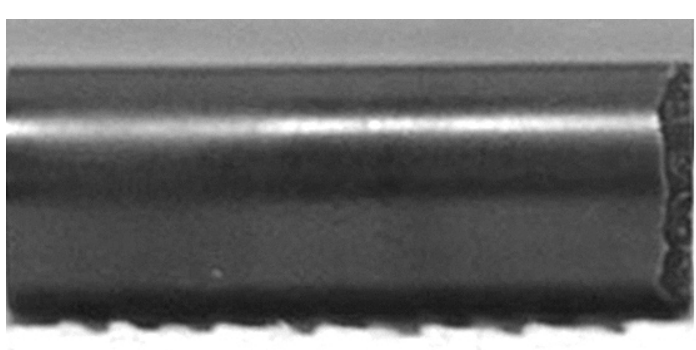

(c)

Figure 93. The effects of pickling (etching) E110 tubing prior to oxidation at $1000^{\circ} \mathrm{C}$ for $290 \mathrm{~s}$ : (a) etched (180-s exposure to $3.5 \% \mathrm{HF}+45 \% \mathrm{HNO}_{3}+51.5 \% \mathrm{H}_{2} \mathrm{O}$ ) tubing sample; (b) polished-and-etched E110 sample; and (c) etched-and-polished E110 sample.

\section{Effects of polishing and machining-and-polishing E110 tubing prior to oxidizing at $1000^{\circ} \mathrm{C}$}

In Test EU\#13, half of the sample was in the as-fabricated condition, and half the sample was machined on the outer surface ( $38 \mu \mathrm{m}$ removed) and polished. The hybrid sample was oxidized at $1000^{\circ} \mathrm{C}$ for 290 -s hold time. Based on visual inspection, the oxide on the machined-and-polished segment is lustrous black, while the non-treated segment shows the mix of grayish-white (monoclinic oxide) regions in a matrix of black (tetragonal) oxide observed in all other tests with as-received E110 (see Figure 94).

Test EU\#14 was conducted to determine the relative benefits of polishing vs. machining-andpolishing on E110 steam-oxidation performance. The hybrid sample consisted of three axial regions: a) one-half-segment prepared by machining ( $25 \mu \mathrm{m}$ removed) and polishing; b) one-quarter-segment prepared by polishing only; and c) one-quarter-segment of as-fabricated E110 tubing. This hybrid sample was also oxidized at $1000^{\circ} \mathrm{C}$ for 290 -s hold time. As shown in Figure 95, both the polished-only and the machined-and-polished regions of the sample exhibited lustrous black outer-surface oxides, while the asfabricated region exhibited breakaway oxidation. From Figure 95, it appears that polishing alone is sufficient to improve the behavior of E110. Polishing smoothes out the surface roughness by removing $<5 \mu \mathrm{m}$ of material and chemical impurities at the surface and in the substrate. 


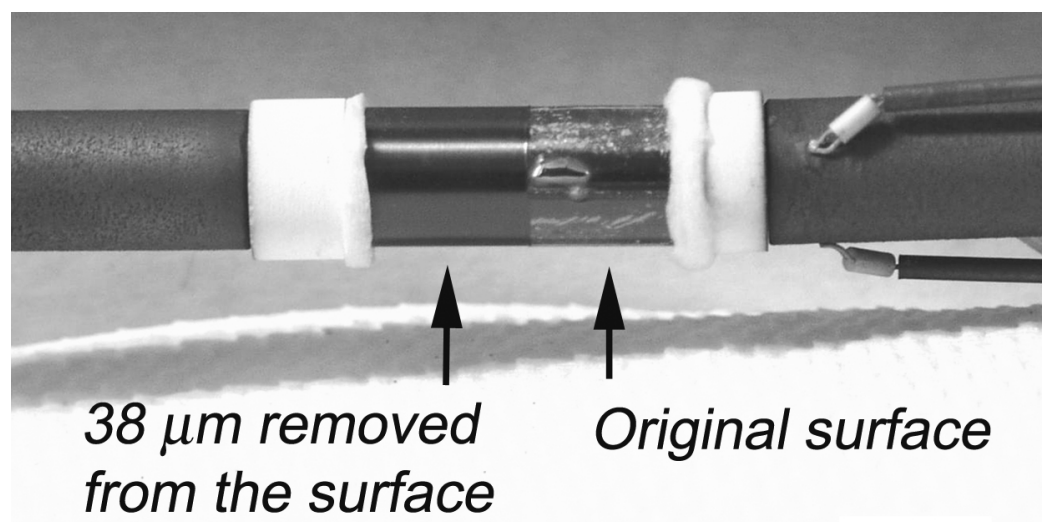

$10 \mathrm{~mm}$

Figure 94 . Hybrid E110 sample (EU\#13) following oxidation at $1000^{\circ} \mathrm{C}$ for $290 \mathrm{~s}$. Machined-andpolished section is lustrous black, while as-fabricated E110 section is in breakaway oxidation.

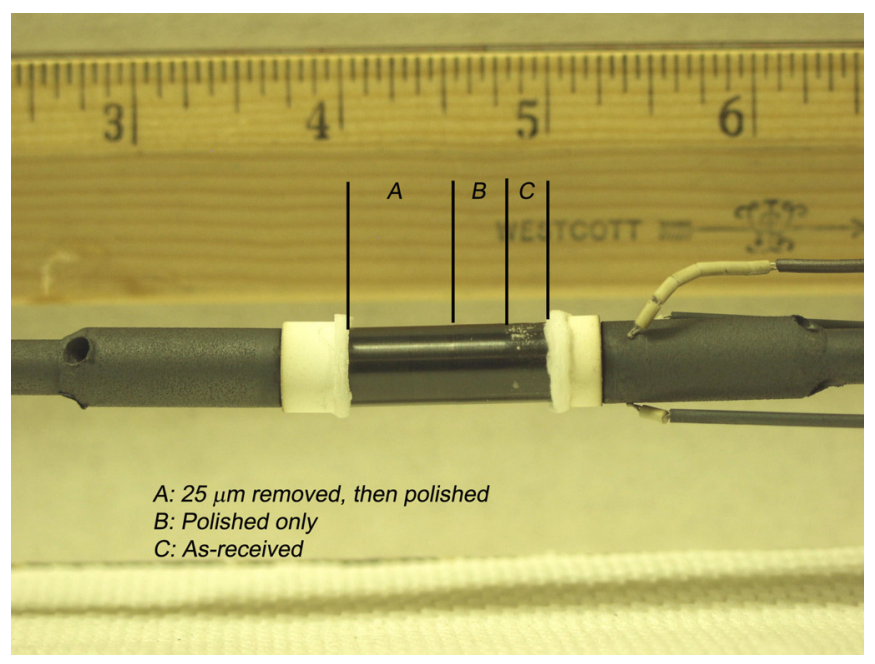

Figure 95. Effects of polishing vs. machining-and-polishing on E110 oxidation at $1000^{\circ} \mathrm{C}$ for $290 \mathrm{~s}$.

To further investigate the effects of polishing and machining-polishing, higher (200X) magnification photographs were taken of the surfaces of the three regions of the EU\#14 sample. Figure 96a shows the outer surface of the as-fabricated material after oxidation with large regions of monoclinic (light-colored) oxide. Figure 96b shows the same magnification of the machined-and-polished outer surface after oxidation with very small, isolated spots of monoclinic oxide. The largest spot diameter in the image is $\approx 25 \mu \mathrm{m}$. Figure $96 \mathrm{c}$ shows the same magnification of the polished outer surface after oxidation with small - compared to the as-received material - spots of monoclinic oxide. The largest spot diameter in Figure $96 \mathrm{c}$ is $\approx 75 \mu \mathrm{m}$.

It is clear that the quality of the oxide layer on the polished surface is much better than the asfabricated tubing surface. This observation suggests that the oxidation behavior of the E110 alloy is sensitive to some combination of surface roughness and surface chemistry. Further improvement may be made by removing some of the near-surface layer, as well as the surface itself. Worth noting is that the untreated inner surface of the whole sample had large regions of monoclinic oxide visible to the eye. 


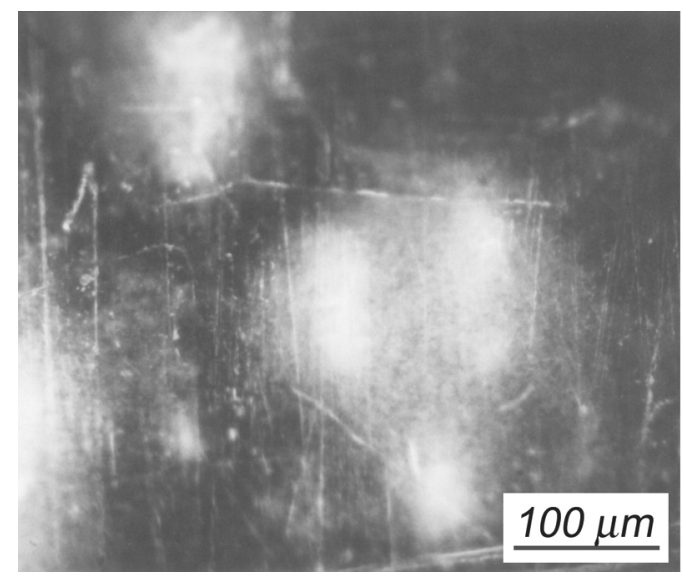

(a)

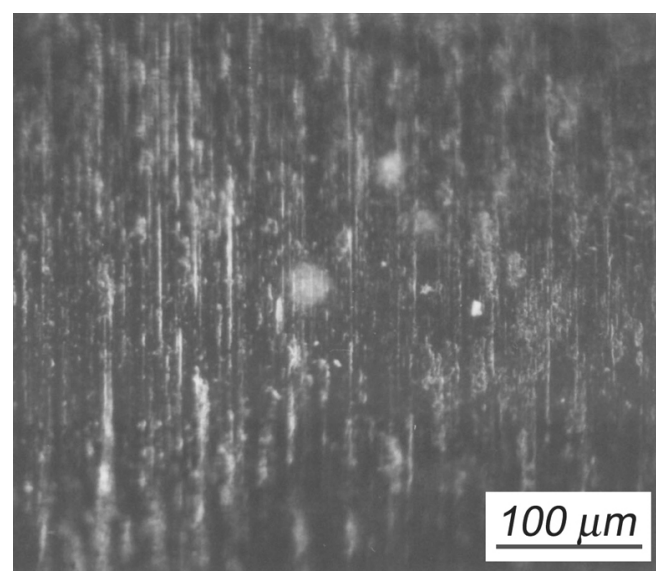

(b)

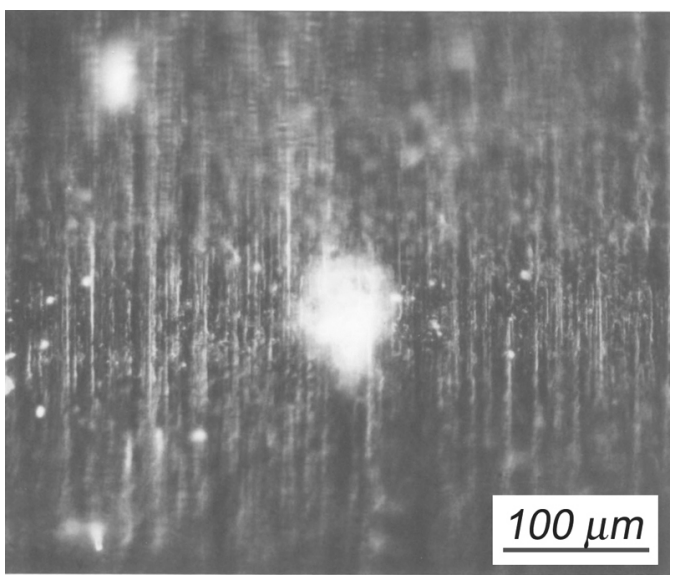

(c)

Figure 96. High magnification (200X) image of outer-surface oxide layers following oxidation at $1000^{\circ} \mathrm{C}$ for 290 s: (a) as-fabricated E110, (b) machined-and-polished E110, and (c) polished E110.

To better compare the E110 oxidation performance to the performance of Western alloys, E110 samples were modified to give the same wall thickness $(\approx 0.6 \mathrm{~mm})$ and comparable outer-surface roughness as M5 (see Table 5). The ANL-modified E1 10 was fabricated by machining about $100 \mu \mathrm{m}$ from the inner-surface wall, polishing the inner surface, and polishing the outer surface to a roughness level of $0.14 \mu \mathrm{m}$. Oxidation tests with these samples were designed to determine breakaway oxidation time in terms of outer-surface oxide appearance and hydrogen pickup. The thermal benchmark results for the M5 oxidation tests (see Figure 64) were used to plan and interpret the E110 tests. The E110 results are summarized in Table 40. Not included in Table 40 are tests conducted for 0 to 190 -s hold times for which the samples were lustrous black with no hydrogen pickup.

For the machined-and-polished samples, breakaway oxidation initiated at the ends of the sample and progressed towards the middle (Figure 97). Longer breakaway oxidation times could possibly have been achieved with longer, more continuous samples without abrupt changes in geometry (e.g., ends of 25-mm-long ANL samples). However, polishing of the E110 surfaces did significantly delay breakaway 
Table 40. Two-Sided Oxidation Tests Conducted on Modified E110 Cladding at $1000^{\circ} \mathrm{C}$. Samples had polished cladding outer diameter $(9.17 \mathrm{~mm})$, machined and polished inner diameter (7.98 $\mathrm{mm})$, and 0.6-mm wall thickness.

\begin{tabular}{|c|c|c|c|c|}
\hline $\begin{array}{c}\text { Test } \\
\text { ID\# }\end{array}$ & $\begin{array}{c}\text { Hold } \\
\text { Time, } \\
\text { s }\end{array}$ & $\begin{array}{c}\text { Total } \\
\text { Time, } \\
\text { s }\end{array}$ & $\begin{array}{c}\text { H } \\
\text { Content, } \\
\text { wppm }\end{array}$ & Outer-Surface Oxide \\
\hline \hline EU\#22 & 292 & 382 & --- & Lustrous black \\
\hline EU\#24 & 413 & 503 & $11 \pm 5$ & Lustrous black with white ends \\
\hline EU\#37 & 815 & 905 & $6 \pm 1$ & --- \\
\hline EU\#16 & 1025 & 1115 & 150 & See Figure 97 for variation in outer surface \\
& & & $(32-342)$ & oxide layer \\
\hline EU\#41 & 2025 & 2115 & $1280 \pm 100$ & --- \\
\hline
\end{tabular}

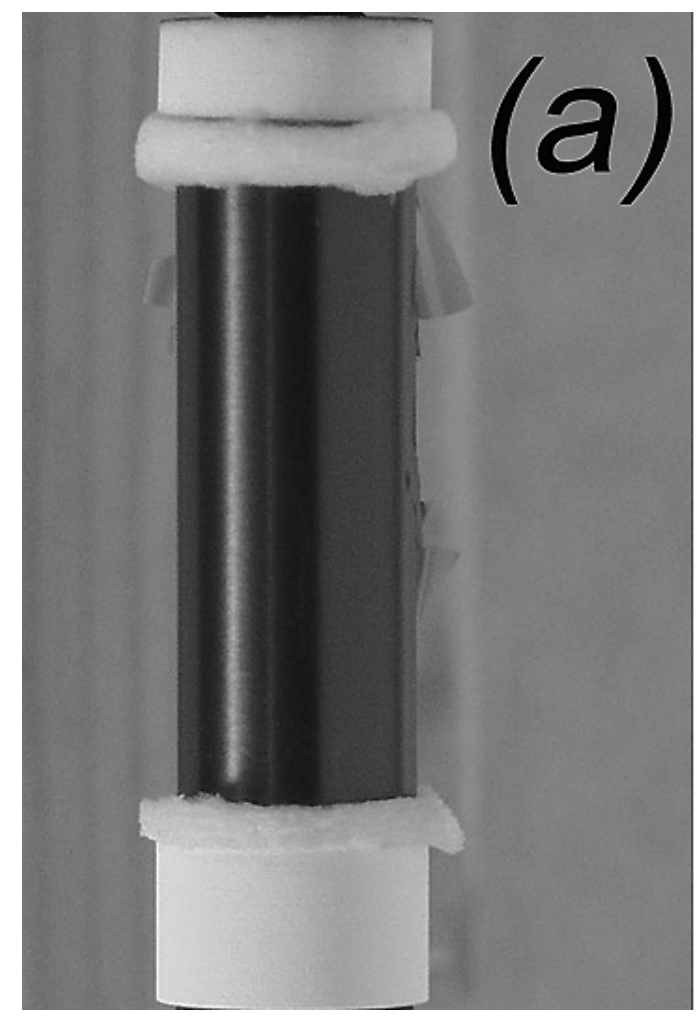

(a)

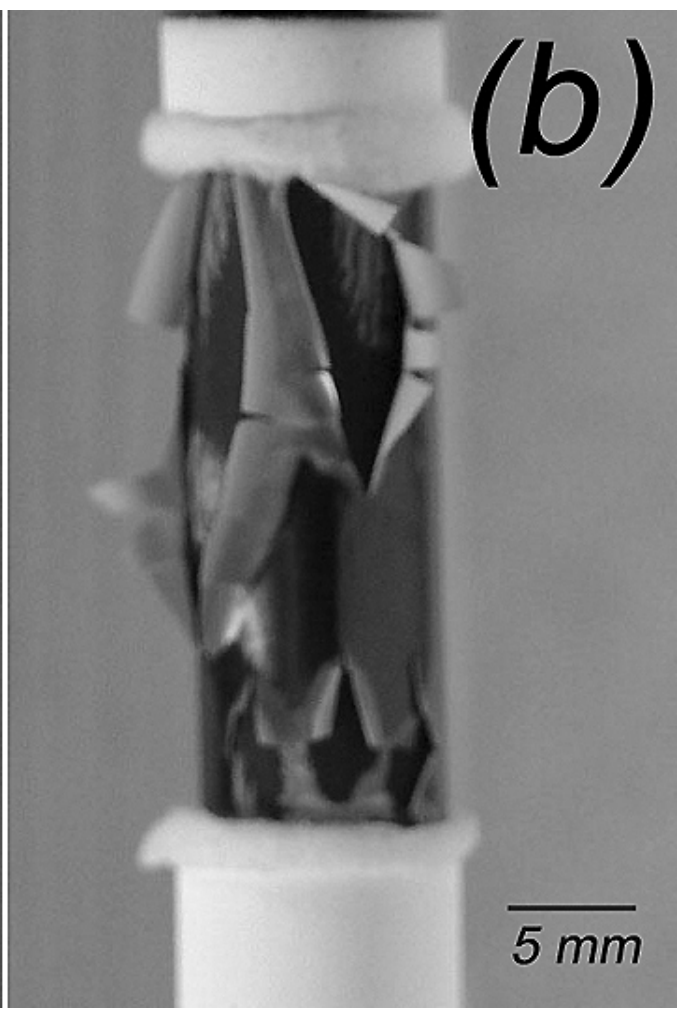

(b)

Figure 97. Machined-and-polished E110 sample (EU\#16) after 1025-s hold time in steam at $1000^{\circ} \mathrm{C}$ : (a) lustrous black oxide surface on one side of the sample and (b) extensive monoclinic oxide formation, delamination, and spallation evident on other side of the sample. 
oxidation time in terms of hydrogen pickup. Figure 98 shows the hydrogen pickup vs. time for asfabricated E110 samples vs. ANL-modified (OD polishing, ID machining-and-polishing) E110 samples. The breakaway oxidation time was essentially double for the polished E110 as compared to the asfabricated E110 tubing.

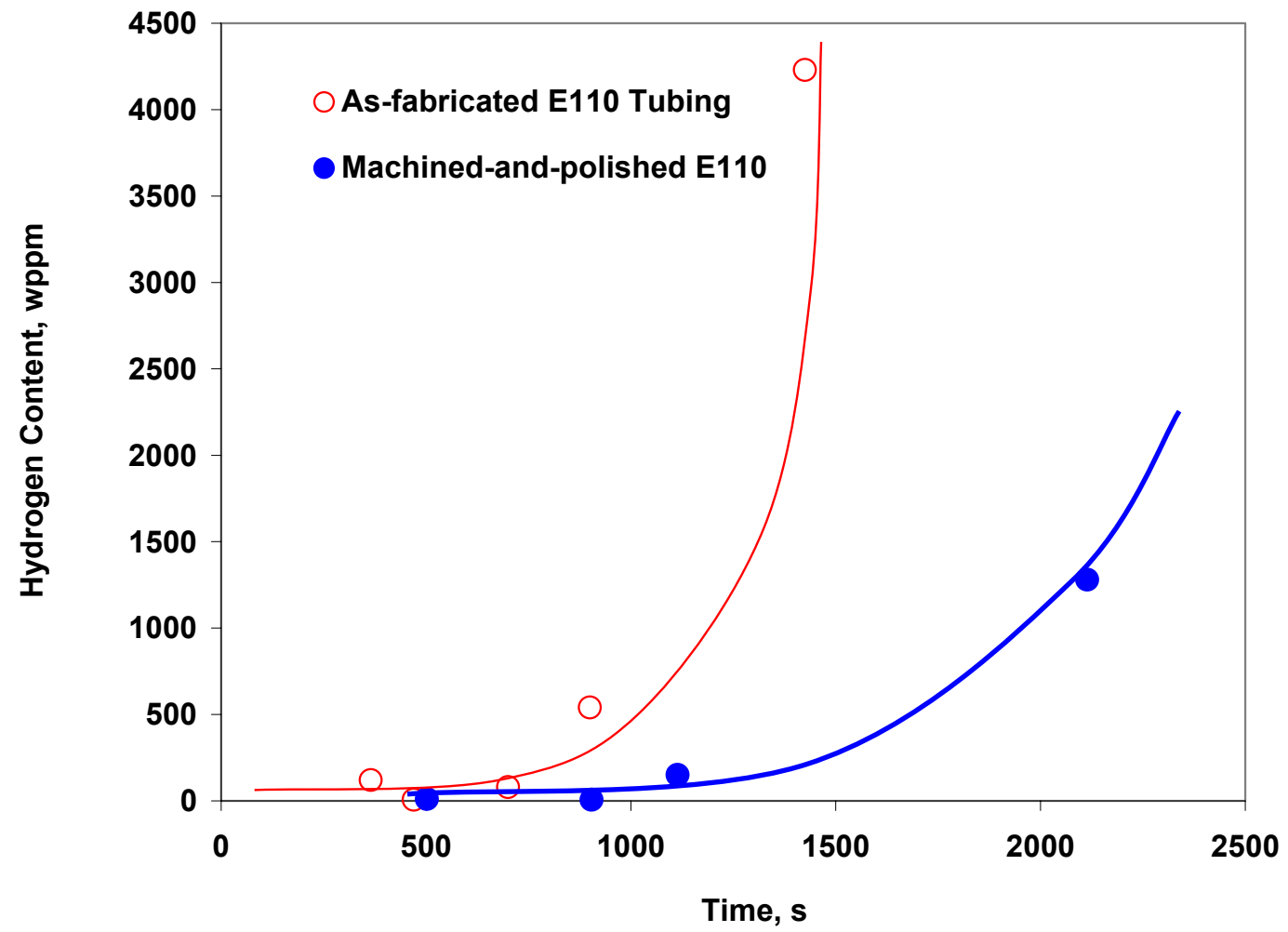

Figure 98. Hydrogen pickup vs. total test time for as-fabricated E110 tubing and ANL-modified machined-and-polished E110. The ramp time from $300^{\circ} \mathrm{C}$ to $1000^{\circ} \mathrm{C}$ is $75 \mathrm{~s}$ for the as-fabricated tubing (0.70-mm wall) and $90 \mathrm{~s}$ for the machined-and-polished samples (0.6-mm wall).

\section{Effects of machining-and-polishing E110 tubing prior to oxidizing at $1100^{\circ} \mathrm{C}$}

A series of tests was conducted with ANL machined-and-polished E110 samples oxidized at $1100^{\circ} \mathrm{C}$ to determine post-oxidation ductility vs. CP-ECR. The M5 thermal benchmark results for $1100^{\circ} \mathrm{C}$ (see Figure 65) were used to plan these E1 10 tests and interpret the results. All samples exhibited a lustrous black oxide layer up to the highest hold time $(1011 \mathrm{~s})$ at $1100^{\circ} \mathrm{C}$. At this hold time, small white spots were observed on the outer-surface oxide layer.

The investigation of ANL-modified post-oxidation ductility was motivated by the results of Bochvar-Institute/TVEL work [26] for the RT ring-compression ductility of seven lots of E110, with varying concentrations of $\mathrm{Hf}, \mathrm{Fe}$, and $\mathrm{O}$ (all within material specification ranges), as well as different combined impurity levels ( $\mathrm{Ni}, \mathrm{Al}, \mathrm{Si}, \mathrm{Ca}, \mathrm{K}, \mathrm{F}, \mathrm{Cl}, \mathrm{Na}$, and $\mathrm{Mg}$ ). The E110 tubing used in the Bochvar/TVEL study had an outer diameter of $9.13 \mathrm{~mm}$ after "pickling." Although not specified, the tubing wall thickness was assumed to be $0.71 \mathrm{~mm}$. It is not clear whether or not the tubing was anodized - standard procedure to convert tubing into cladding - following pickling. For these tests, 30-mm-long tubing segments were exposed to two-sided steam oxidation for $600 \mathrm{~s}$. Both heating $\left(300^{\circ} \mathrm{C}\right.$ to $1100^{\circ} \mathrm{C}$ in 
$\approx 2 \mathrm{~s})$ and cooling $\left(1100^{\circ} \mathrm{C}\right.$ to $300^{\circ} \mathrm{C}$ in $\left.15-20 \mathrm{~s}\right)$ rates were relatively high. The corresponding CP-ECR is $12 \%$ for $0.71-\mathrm{mm}$-wall cladding oxidized (two-sided) to $1100^{\circ} \mathrm{C}$ for $600 \mathrm{~s}$.

Four of the Bochvar-TVEL lots with a combined impurity level of 110-135 wppm exhibited outersurface breakaway oxidation, high hydrogen pickup (200-600 wppm), and low RT ring-compression ductility $(<5 \%)$. Three of the lots with combined impurity levels of $25-45$ wppm exhibited stable oxide growth (observed at low magnification), lower hydrogen pickup (60-200 wppm), and higher RT ringcompression offset strain (5-10\%). Based on ANL experience with the effects of surface finish (polishing vs. pickling), we hypothesized that the Bochvar-TVEL samples would have exhibited longer-time stable oxide growth, lower hydrogen pickup, and higher ductility if the surfaces had been polished rather than pickled. To test this hypothesis, ANL machined-and-polished (M-P) samples were oxidized at $1100^{\circ} \mathrm{C}$ and subjected to RT ring-compression tests. The results of these tests are compared to the best of the Bochvar-TVEL results (Lots 2-4) in Table 41 and Figure 99.

Table 41. Comparison of E110 Post-Oxidation RT Ductility between ANL Machined-and-Polished (M-P) Cladding Samples and Bochvar-TVEL (BT) Lots 2-4 Pickled Cladding Samples [26] Following Two-sided Steam Oxidation at $1100^{\circ} \mathrm{C}$.

\begin{tabular}{|c|c|c|c|c|c|}
\hline $\begin{array}{c}\text { E110 } \\
\text { Material }\end{array}$ & $\begin{array}{c}\text { Wall } \\
\text { Thickness, } \\
\text { mm }\end{array}$ & $\begin{array}{c}\text { CP } \\
\text { ECR, } \\
\%\end{array}$ & $\begin{array}{c}\text { Meas. } \\
\text { ECR, } \\
\%\end{array}$ & $\begin{array}{c}\text { Offset } \\
\text { Displacement, } \\
\text { mm }\end{array}$ & $\begin{array}{c}\text { Offset } \\
\text { Strain, } \\
\%\end{array}$ \\
\hline \hline ANL M-P & 0.61 & 7.5 & 7.0 & 5.47 & 60 \\
\hline ANL M-P & 0.69 & 10.5 & 9.2 & -86 & 31 \\
\hline BT Lot 2 & 0.71 & 12 & $\approx 10$ & --- & 6.6 \\
\hline BT Lot 3 & 0.71 & 12 & $\approx 10$ & --- & 4.4 \\
\hline BT Lot 4 & 0.71 & 12 & $\approx 10$ & & 21 \\
\hline ANL M-P & 0.58 & 14.4 & 12.7 & 1.94 & 6.3 \\
\hline ANL M-P & 0.58 & 19.4 & 16.0 & 0.58 & \\
\hline
\end{tabular}

Significantly higher post-oxidation ductility was achieved by machining the inner surface to give a wall thickness comparable to M5 and by polishing both inner and outer surfaces. The Bochvar-TVEL samples, which were pickled rather than polished, may have exhibited higher post-oxidation ductility if the surfaces had been polished following pickling or if the surfaces had not been pickled at all. Also, the machined-and-polished E110 post-oxidation ductility results for $1100^{\circ} \mathrm{C}$-oxidized samples are comparable to the results obtained for the modern $17 \times 17$ alloys (Zry-4, ZIRLO, and M5) used in U.S. reactors. 


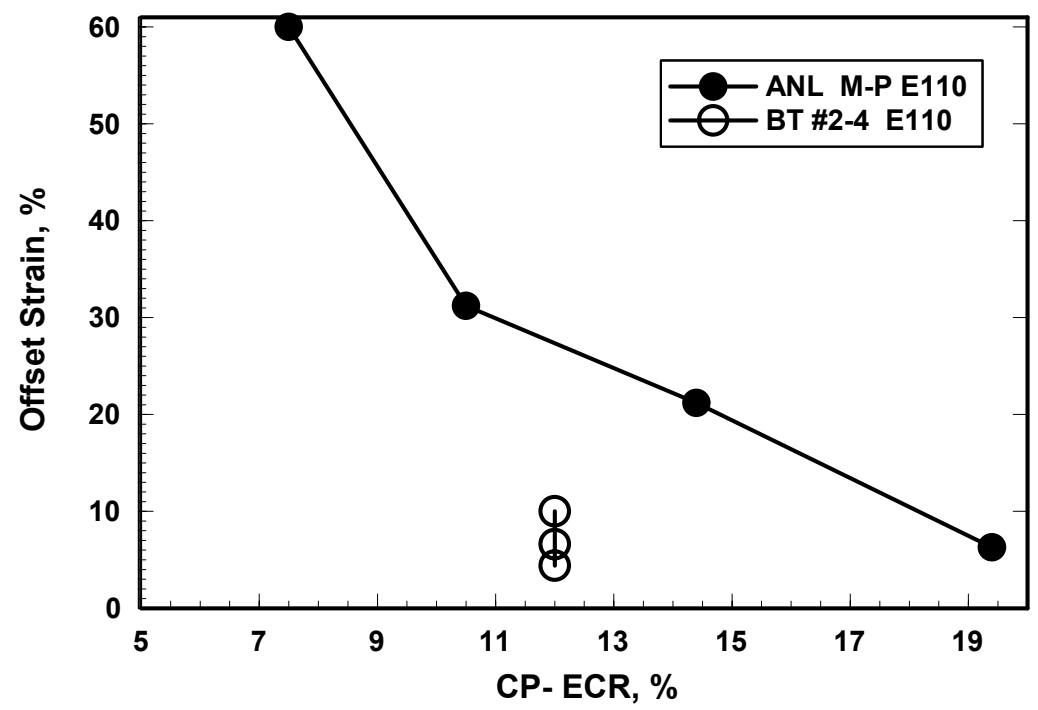

Figure 99. Post-oxidation RT ductility vs. CP-ECR for ANL machined-and-polished (M-P) E110 samples and Bochvar-TVEL (BT) pickled E110 cladding following two-sided steam oxidation at $1100^{\circ} \mathrm{C}$.

\section{Effects of machining-and-polishing E110 tubing prior to oxidizing at $1200^{\circ} \mathrm{C}$}

Machined-and-polished E1 10 samples were oxidized at $1200^{\circ} \mathrm{C}$, slow-cooled, and ring-compressed at $135^{\circ} \mathrm{C}$. Because the ductility of the ANL-modified E1 10 was so good following $1100^{\circ} \mathrm{C}$, the $1200^{\circ} \mathrm{C}$ oxidized samples were tested to see how they compared to the U.S. alloys. The $1200^{\circ} \mathrm{C}$ thermal benchmark results for M5 (see Figure 73) were used to plan the tests and interpret the results. Table 42 summarizes the results for oxidation levels and ring-compression offset strains for these E110 samples.

Table 42. Post-oxidation Ductility at $135^{\circ} \mathrm{C}$ for ANL Machined-and-Polished E110 Samples following Oxidation at $1200^{\circ} \mathrm{C}$ and Slow Cooling. Samples were fabricated from E110 cladding (etched and anodized): polished outer diameter $(9.07 \mathrm{~mm})$, machined-and-polished inner surface, and $0.6-\mathrm{mm}$ wall thickness.

\begin{tabular}{|c|c|c|c|c|c|}
\hline $\begin{array}{c}\text { E110 } \\
\text { Test \# }\end{array}$ & $\begin{array}{c}\text { Wall } \\
\text { Thickness, } \\
\mathrm{mm}\end{array}$ & $\begin{array}{c}\text { CP } \\
\text { ECR, } \\
\%\end{array}$ & $\begin{array}{c}\text { Meas. } \\
\text { ECR, } \\
\%\end{array}$ & $\begin{array}{c}\text { Offset } \\
\text { Displacement, } \\
\mathrm{mm}\end{array}$ & $\begin{array}{c}\text { Offset } \\
\text { Strain, } \\
\%\end{array}$ \\
\hline \hline EU\#53 & 0.60 & 7.5 & 8.6 & $>5$ & $>55$ \\
\hline EU\#51 & 0.60 & 10.0 & 10.4 & $>5$ & $>55$ \\
\hline EU\#52 & 0.61 & 13.0 & 13.8 & 1.47 & 16 \\
& 0.61 & 13.0 & 13.8 & 0.66 & 7 \\
\hline
\end{tabular}

The ductility of ANL-modified E110 oxidized at $1200^{\circ} \mathrm{C}$ is higher than that of HBR-type $15 \times 15$ Zry-4 and modern $17 \times 17$ Zry-4 cladding for $\leq 13 \%$ CP-ECR. The post-oxidation ductility of ANLmodified E1 $10(12 \%)$ is comparable to that of $17 \times 17$ M5 (14\%) at 13\% CP-ECR. The ductile-to-brittle transition CP-ECR for ANL-modified E110 was not determined in this program. 


\subsection{Effects of quench temperature on post-quench ductility}

The protocol for cooling oxidized samples prior to ring-compression ductility tests was the same for $17 \times 17$ Zry-4, ZIRLO, and M5: cooling in steam at $\approx 10-13^{\circ} \mathrm{C} / \mathrm{s}$ from the oxidation temperature to $800^{\circ} \mathrm{C}$; and rapid cooling (quench) from $800^{\circ} \mathrm{C}$ to $\leq 100^{\circ} \mathrm{C}$ (generally $80 \pm 10^{\circ} \mathrm{C}$ ). As $800^{\circ} \mathrm{C}$ is below the (alpha + beta) $\rightarrow$ alpha phase-transformation temperature for as-fabricated Zry-4, the quench temperature is low enough to allow the phase transformation to occur prior to "freezing" in the microstructure at $800^{\circ} \mathrm{C}$. While slower cooling from the oxidation temperature to the quench temperature could result in more redistribution of oxygen between oxygen-rich alpha incursions and low-oxygen beta, there is no clear evidence that this change would affect post-quench ductility. However, for as-fabricated M5 the (alpha + beta) $\rightarrow$ alpha phase-transformation temperature is $\approx 650^{\circ} \mathrm{C}$. For as-fabricated ZIRLO, this phase transformation temperature is expected to be between $650^{\circ} \mathrm{C}$ and $800^{\circ} \mathrm{C}$. Thus, the phase transformation for M5 and ZIRLO is not complete at the time of the $800^{\circ} \mathrm{C}$ quench (Q) used in the ANL test program. Additional tests were conducted with samples oxidized at $1200^{\circ} \mathrm{C}$. Following cooling at $\approx 13^{\circ} \mathrm{C} / \mathrm{s}$ to $800^{\circ} \mathrm{C}$, samples were further slow cooled (SC) to RT and ring-compressed at $135^{\circ} \mathrm{C}$.

\subsubsection{Effects of quench temperature on post-quench ductility of 17x17 Zry-4}

The post-oxidation ductility results for Zry-4 subjected to slow cooling are presented in Table 43 . The slow-cooled (i.e., no quench) samples were oxidized in a separate test train with the thermal history shown in Figure 100. The complete data set presented in Table $11(\mathrm{Q})$ is combined with the data set in Table 43 (SC) to generate the graphical results shown in Figure 101 for offset strain vs. CP-ECR.

Table 43. Ring Compression Test Results at $135^{\circ} \mathrm{C}$ and $0.0333 \mathrm{~mm} / \mathrm{s}$ for $17 \times 17$ Zry- 4 Cladding Oxidized at $1200^{\circ} \mathrm{C}$ and Slow Cooled (SC). ECR $=1.538 \mathrm{Wg}$ for 0.57 -mm-wall cladding.

\begin{tabular}{|c|c|c|c|c|c|c|c|}
\hline \multicolumn{2}{|c|}{$\begin{array}{c}\text { Test } \\
\text { Conditions }\end{array}$} & \multicolumn{2}{c|}{$\begin{array}{c}\text { ECR, } \\
\%\end{array}$} & \multicolumn{2}{c|}{$\begin{array}{c}\text { Plastic } \\
\text { Displacement, mm }\end{array}$} & \multicolumn{2}{c|}{$\begin{array}{c}\text { Plastic } \\
\text { Strain, \% }\end{array}$} \\
\hline $\begin{array}{c}\text { Ox. Test } \\
\text { Time, }{ }^{\mathrm{a}} \mathrm{s}\end{array}$ & Cooling & CP & Meas. & Offset & Permanent & Offset & Permanent \\
\hline 187 & SC & 13.0 & 13.2 & 1.03 & --- & 11 & --- \\
187 & SC & 13.0 & 13.2 & 0.61 & --- & 6.5 & -- \\
\hline 288 & SC & 17.0 & 18.5 & 0.30 & 0.16 & 3.2 & 1.7 \\
288 & SC & 17.0 & 18.5 & 0.12 & 0.05 & 1.3 & 0.5 \\
\hline
\end{tabular}

${ }^{\mathrm{a}}$ Includes time for ramp from $300^{\circ} \mathrm{C}$ and hold time.

At 13\% CP-ECR, the slow-cooled Zry-4 samples have an average offset strain of 9\% (6.5-11\%) as compared to $5.1 \%$ for quenched Zry-4. Although ductility apparently increases with slow-cooling at $13 \%$ CP-ECR, this effect may be due to data scatter as there is an abrupt decrease in ductility of Zry-4 in the range of $11-15 \%$ CP-ECR. At 17\% CP-ECR, the ductility strains of the slow-cooled and quenched Zry-4 samples are essentially the same : $2.3 \%(1.3-3.2 \%)$ average offset strain and $1.1 \%(0.5-1.7 \%)$ average permanent strain for slow-cooled Zry-4 samples; and 2.5\% (2.0-2.8\%) average offset strain and 1.1\% (0.7-1.4\%) permanent strain for quenched Zry-4. Thus, the ductile-to-brittle transition CP-ECR for $1200^{\circ} \mathrm{C}$-oxidized Zry-4 appears to be insensitive to quench at $\leq 800^{\circ} \mathrm{C}$. 


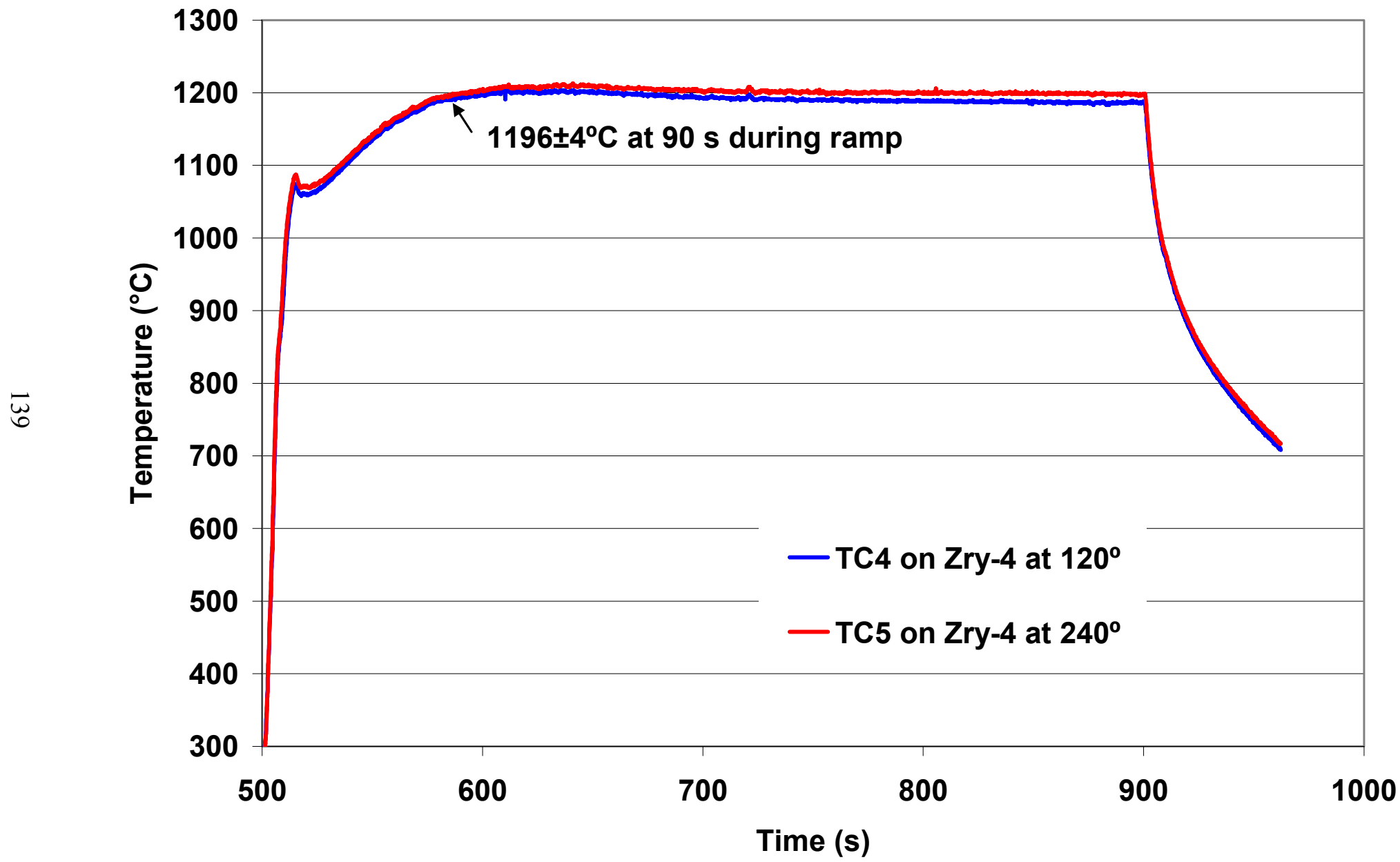

Figure 100. Thermal benchmark test results for slow-cooled $17 \times 17$ Zry-4, ZIRLO, and M5 samples oxidized at $1200^{\circ} \mathrm{C}$. 


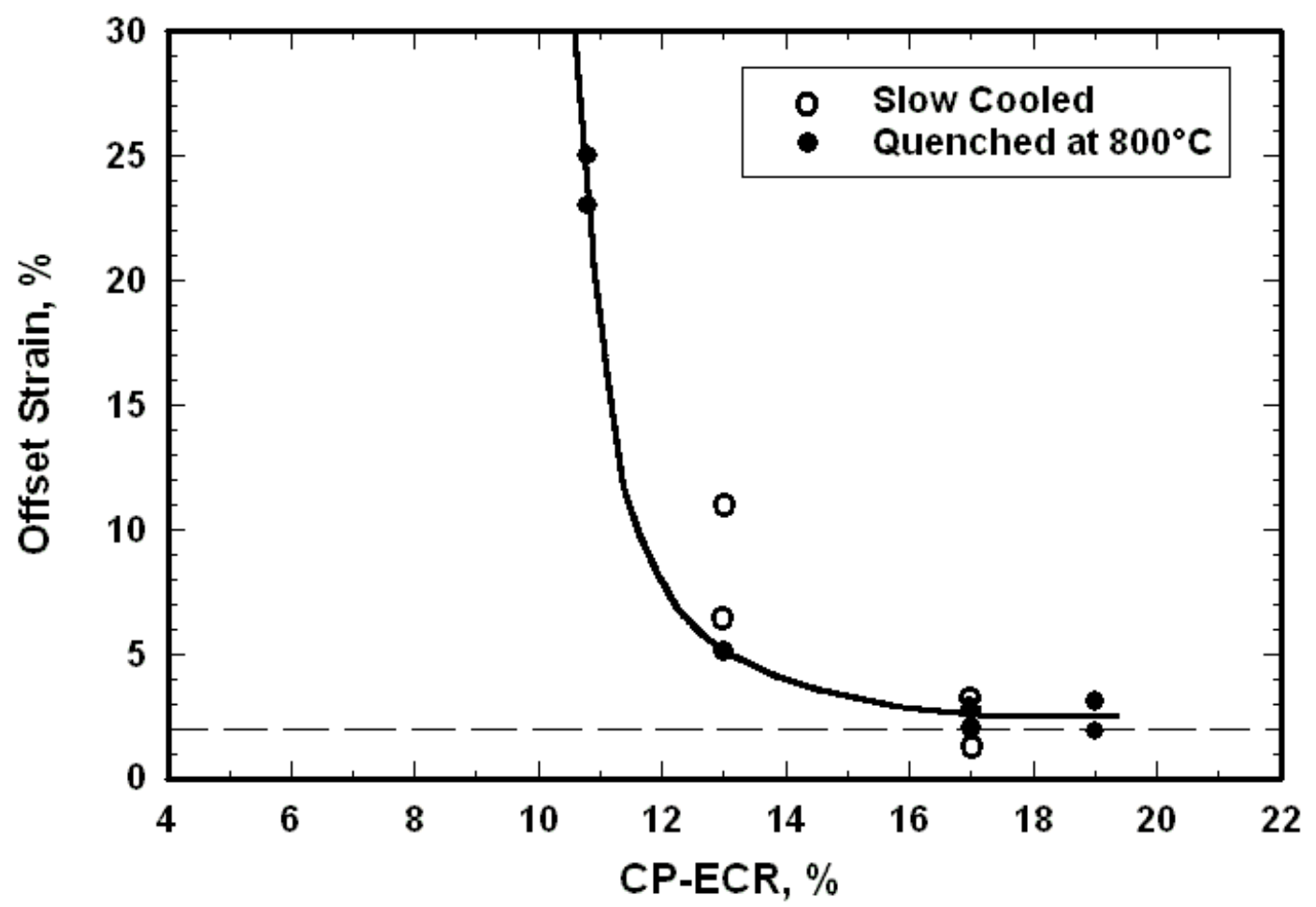

Figure 101. Effects of quench vs. slow cooling on the post-oxidation ductility of $17 \times 17$ Zry-4 (0.57-mm wall) oxidized at $1200^{\circ} \mathrm{C}$, cooled at $\approx 13^{\circ} \mathrm{C} / \mathrm{s}$ to $800^{\circ} \mathrm{C}$, and either quenched at $800^{\circ} \mathrm{C}$ or slow cooled from $800^{\circ} \mathrm{C}$ to RT. Ring-compression tests were performed at $135^{\circ} \mathrm{C}$ and $0.0333-\mathrm{mm} / \mathrm{s}$ displacement rate.

\subsubsection{Effects of quench temperature on post-quench ductility of $17 \times 17$ ZIRLO}

The post-oxidation ductility results for ZIRLO subjected to slow cooling are given in Table 44 . The slow-cooled samples were oxidized in a separate test train with the thermal history shown in Figure 100. The complete data set presented in Table $27(\mathrm{Q})$ is combined with the data set in Table 44 (SC) to generate the graphical results shown in Figure 102 for offset strain vs. CP-ECR.

At 13\% CP-ECR, the slow-cooled ZIRLO samples have an average offset strain of 9\% (8.1-9.3\%) as compared to $27 \%$ (21-33\%) for quenched ZIRLO. This factor of three reduction in ductility for slowcooled samples appears to be significant. However, at 17\% CP-ECR, the ductility of slow-cooled and quenched ZIRLO are within data scatter: $3.6 \%$ (2.0-5.5\%) average offset strain and 1.5\% (1.2-1.8\%) average permanent strain for slow-cooled ZIRLO samples; and 5.7\% (3.8-7.0\%) average offset strain and $2.3 \%(1.8-2.8 \%)$ permanent strain for quenched ZIRLO. Thus, the ductile-to-brittle transition CP-ECR for $1200^{\circ} \mathrm{C}$-oxidized ZIRLO appears to be relatively insensitive to quench at $\leq 800^{\circ} \mathrm{C}$. For $<17 \% \mathrm{CP}$ ECR, slow-cooled ZIRLO samples may have less ductility than quenched samples at the same CP-ECR (e.g., 13\%). However, considerably more data would need to be generated to establish such a trend. Also, data points plotted at $10 \%$ and $15 \%$ CP-ECR were obtained from shorter rings $(5-6 \mathrm{~mm})$ cut from the ends of the oxidation-quench sample. These data points may not be as reliable as the ones for 8-mmlong rings sectioned from within the middle $20 \mathrm{~mm}$ of the 25 - $\mathrm{mm}$-long oxidation-quench sample. 
Table 44. Ring Compression Test Results at $135^{\circ} \mathrm{C}$ and $0.0333 \mathrm{~mm} / \mathrm{s}$ for $17 \times 17$ ZIRLO Cladding Oxidized at $1200^{\circ} \mathrm{C}$ and Slow Cooled (SC). ECR $=1.538 \mathrm{Wg}$ for $0.57-\mathrm{mm}$-wall cladding.

\begin{tabular}{|c|c|c|c|c|c|c|c|}
\hline \multicolumn{2}{|c|}{$\begin{array}{c}\text { Test } \\
\text { Conditions }\end{array}$} & \multicolumn{2}{c|}{$\begin{array}{c}\text { ECR, } \\
\%\end{array}$} & \multicolumn{2}{c|}{$\begin{array}{c}\text { Plastic } \\
\text { Displacement, mm }\end{array}$} & \multicolumn{2}{c|}{$\begin{array}{c}\text { Plastic } \\
\text { Strain, \% }\end{array}$} \\
\hline $\begin{array}{c}\text { Ox. Test } \\
\text { Time, }{ }^{\mathrm{a}} \text { s }\end{array}$ & Cooling & CP & Meas. & Offset & Permanent & Offset & Permanent \\
\hline 187 & SC & 13.0 & 13.5 & 0.77 & --- & 8.1 & --- \\
187 & SC & 13.0 & 13.5 & 0.89 & --- & 9.3 & -- \\
\hline 288 & SC & 17.0 & 17.3 & 0.32 & 0.17 & 3.4 & 1.8 \\
288 & SC & 17.0 & 17.3 & 0.32 & 0.14 & 3.4 & 1.5 \\
288 & SC & 17.0 & 17.3 & 0.52 & --- & 5.5 & -- \\
288 & SC & 17.0 & 17.3 & 0.20 & 0.11 & 2.0 & 1.2 \\
\hline
\end{tabular}

${ }^{\mathrm{a}}$ Includes time for ramp from $300^{\circ} \mathrm{C}$ and hold time.

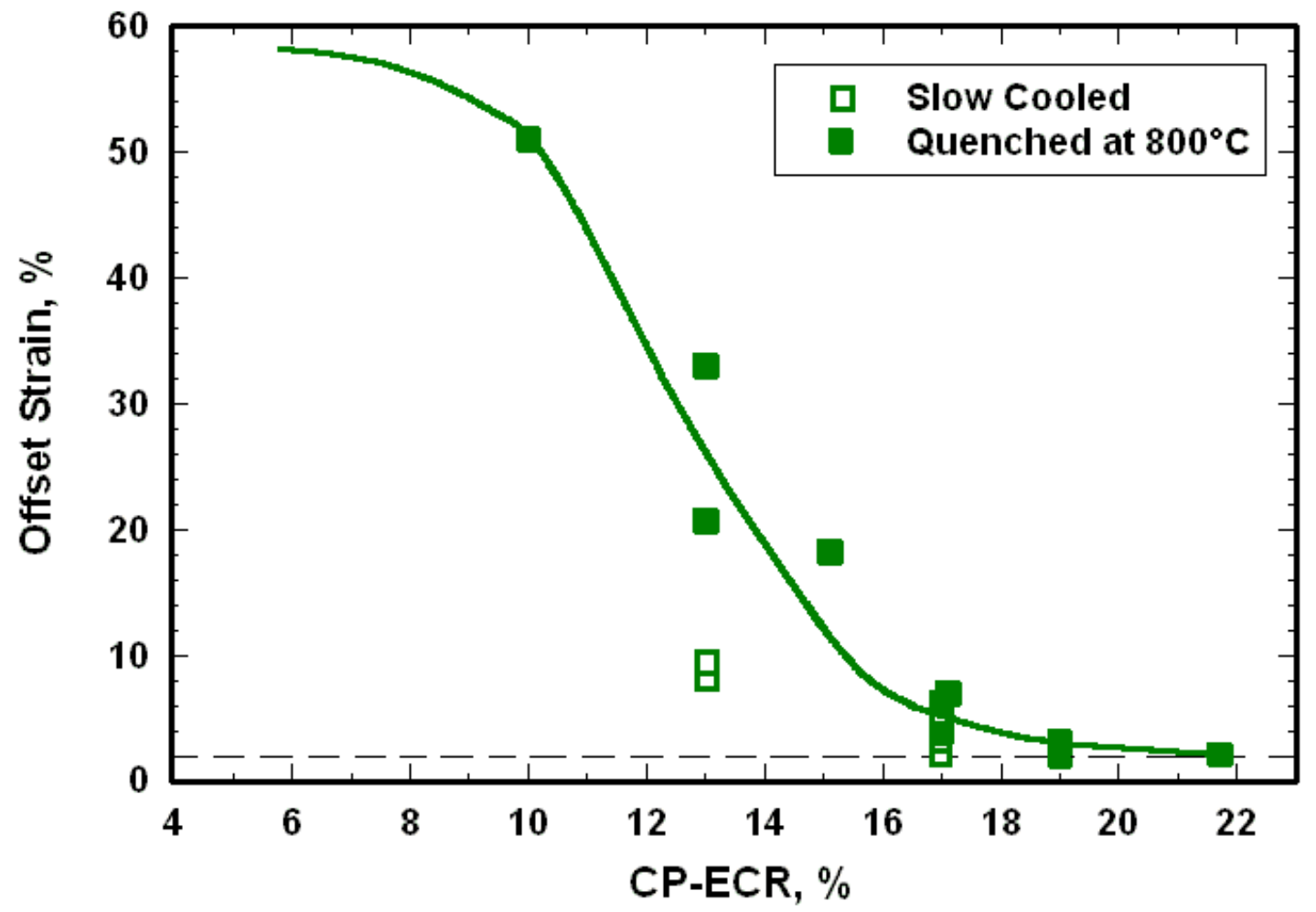

Figure 102. Effects of quench vs. slow cooling on the post-oxidation ductility of $17 \times 17$ ZIRLO (0.57-mm wall) oxidized at $1200^{\circ} \mathrm{C}$, cooled at $\approx 13^{\circ} \mathrm{C} / \mathrm{s}$ to $800^{\circ} \mathrm{C}$, and either quenched at $800^{\circ} \mathrm{C}$ or slow cooled from $800^{\circ} \mathrm{C}$ to RT. Ring-compression tests were performed at $135^{\circ} \mathrm{C}$ and $0.0333-\mathrm{mm} / \mathrm{s}$ displacement rate. 


\subsubsection{Effects of quench temperature on post-quench ductility of $17 \times 17$ M5}

The post-oxidation ductility results for M5 subjected to slow cooling are given in Table 45. The slow-cooled samples were oxidized in a separate test train with the thermal history shown in Figure 100. The complete data set presented in Table 34 (Q) is combined with the data set in Table 45 (SC) to generate the graphical results shown in Figure 103 for offset strain vs. CP-ECR. The post-oxidation ductility of M5 appears to be insensitive to quench temperatures $\leq 800^{\circ} \mathrm{C}$. The strain data for the slowcooled samples are within the scatter of the strain data for the samples quenched at $800^{\circ} \mathrm{C}$.

Table 45. Ring-Compression Test Results at $135^{\circ} \mathrm{C}$ and $0.0333 \mathrm{~mm} / \mathrm{s}$ for $17 \times 17 \mathrm{M} 5$ Cladding Oxidized at $1200^{\circ} \mathrm{C}$ and Slow Cooled (SC). ECR $=1.437 \mathrm{Wg}$ for 0.61-mm-wall cladding.

\begin{tabular}{|c|c|c|c|c|c|c|c|}
\hline \multicolumn{2}{|c|}{$\begin{array}{c}\text { Test } \\
\text { Conditions }\end{array}$} & \multicolumn{2}{c|}{$\begin{array}{c}\text { ECR } \\
\%\end{array}$} & \multicolumn{2}{c|}{$\begin{array}{c}\text { Plastic } \\
\text { Displacement, mm }\end{array}$} & \multicolumn{2}{c|}{\begin{tabular}{c} 
Slastic \\
\multicolumn{2}{|c|}{}
\end{tabular}} \\
\hline $\begin{array}{c}\text { Ox. Test } \\
\text { Time }\end{array}$ & Cooling $\mathrm{s}$ & CP & Meas. & Offset & Permanent & Offset & Permanent \\
\hline 192 & SC & 13.0 & 13.3 & 1.54 & --- & 16 & --- \\
192 & SC & 13.0 & 13.3 & 1.18 & --- & 13 & -- \\
\hline 292 & SC & 16.0 & 15.6 & 0.87 & --- & 9.1 & --- \\
292 & SC & 16.0 & 15.6 & 0.52 & --- & 5.1 & -- \\
\hline
\end{tabular}

${ }^{\mathrm{a}}$ Includes time for ramp from $300^{\circ} \mathrm{C}$ and hold time.

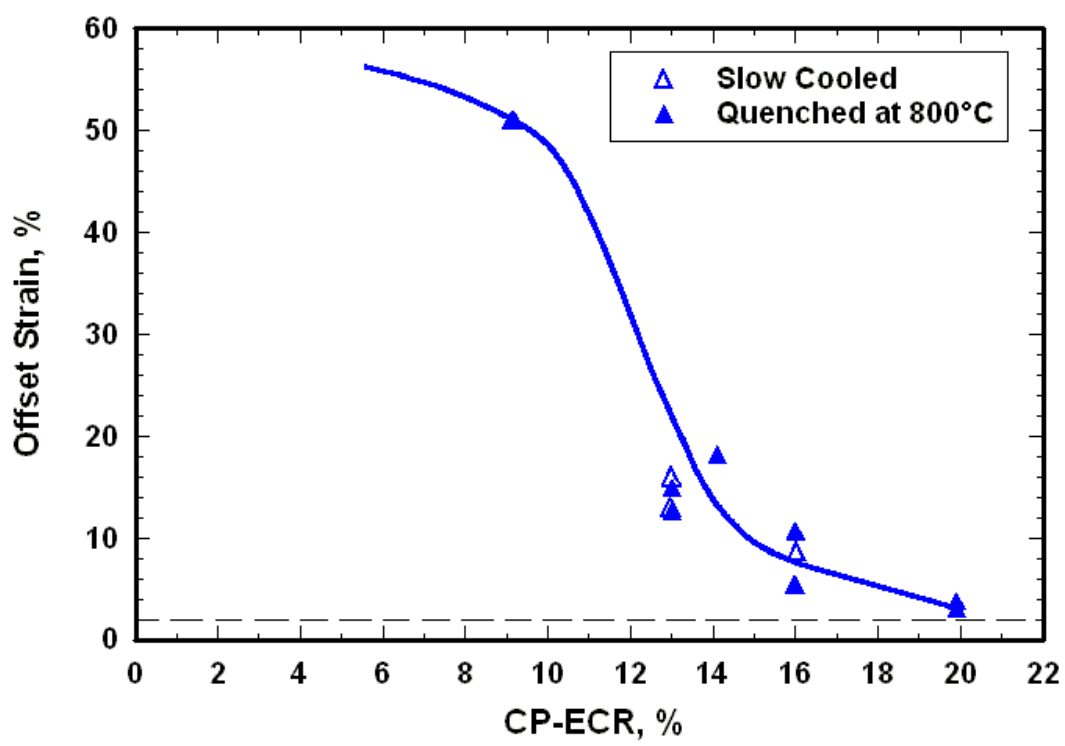

Figure 103. Effects of quench vs. slow cooling on the post-oxidation ductility of $17 \times 17 \mathrm{M} 5$ (0.61-mm wall) oxidized at $1200^{\circ} \mathrm{C}$, cooled at $\approx 13^{\circ} \mathrm{C} / \mathrm{s}$ to $800^{\circ} \mathrm{C}$, and either quenched at $800^{\circ} \mathrm{C}$ or slow cooled from $800^{\circ} \mathrm{C}$ to RT. Ring-compression tests were performed at $135^{\circ} \mathrm{C}$ and $0.0333-\mathrm{mm} / \mathrm{s}$ displacement rate. 


\subsection{Summary of results for as-fabricated cladding}

Modern PWR and BWR cladding alloys are belt- or wheel-polished on the cladding outer surface to reduce surface roughness to $\approx 0.1 \mu \mathrm{m}$. In addition to resulting in a smoother outer surface, the beltpolishing mechanically removes many surface and substrate impurities. The cladding inner-surface roughness is also reduced through a variety of techniques, including grit-blasting. Pickling (etching) with an acid mixture containing HF, which was used in the 1970s-1980s to remove surface impurities, is no longer used as a finishing step to convert tubing into cladding. This fabrication change has made the modern alloys more resistant to breakaway oxidation in the temperature range of $800-1000^{\circ} \mathrm{C}$. The modern alloys also retain post-quench ductility to higher CP-ECR values than their earlier counterparts.

These modern PWR and BWR cladding alloys retained ductility at room temperature up to the highest oxidation level investigated, $20 \% \mathrm{CP}-\mathrm{ECR}$, following oxidation at $1000^{\circ} \mathrm{C}$ and $1100^{\circ} \mathrm{C}$ and quenching at $800^{\circ} \mathrm{C}$. Hydrogen pickup for Zry-4, Zry-2, and M5 was very low ( $<25$ wppm), so hydrogen did not induce embrittlement in these samples. For ZIRLO, hydrogen pickup was low $(<20 \mathrm{wppm})$ for samples oxidized at $1100^{\circ} \mathrm{C}$ and $\approx 100 \mathrm{wppm}$ for samples oxidized at $1000^{\circ} \mathrm{C}$. Weight gain (i.e., total oxidation) at $1000^{\circ} \mathrm{C}$ oxidation temperature was lower for ZIRLO and M5 as compared to Zry-4, thus showing an alloy effect. Similar low weight gain, due to the Zr inner liner, was observed for Zry-2 cladding following oxidation at $1000^{\circ} \mathrm{C}$. The weight gain for each alloy correlated with the total (OD+ID) oxide layer thickness. Although variations in weight gain were observed, the post-quench ductility of the four alloys was essentially the same after long-time oxidation at these temperatures.

For oxidation at $1200^{\circ} \mathrm{C}$ and quenching at $800^{\circ} \mathrm{C}$, room temperature embrittlement of the modern alloys was observed at CP-ECR values significantly below 17\%. However, when these samples were tested at $135^{\circ} \mathrm{C}$, the ductile-to-brittle transition CP-ECR increased to $\geq 17 \%$. Some of the alloys were also tested after cooling from $1200^{\circ} \mathrm{C}$ with no quench. Slow cooling had no observable effect on the ductileto-brittle transition CP-ECR for $17 \times 17$ Zry-4, ZIRLO and M5, indicating that lower quench temperatures would not increase ductility and transition CP-ECR. Hydrogen pickup was very low for the alloys tested, and the prior-beta layer was thick enough to preclude embrittlement due to beta-layer thinning. Although the prior-beta-layer microstructures of ZIRLO and M5 were quite different from those of Zry-4 and Zry2 , post-quench ductility results were comparable and correlated quite well with CP-ECR.

Breakaway oxidation, hydrogen pickup, and resulting embrittlement occur for all Zr-based cladding alloys. However, there is considerable variability in the time-at-temperature needed to initiate this instability and to pick up enough hydrogen to embrittle the cladding. Previous studies have shown minimum breakaway oxidation times, based on weight gain, for Zry-4 oxidized at $750-800^{\circ} \mathrm{C}$ and $1000^{\circ} \mathrm{C}$. However, oxidation at $1000^{\circ} \mathrm{C}$ resulted in the shortest time to pick up hydrogen at the temperatures of interest, and hydrogen is the embrittlement catalyst. Thus a 200-wppm level was chosen as the ANL criterion for determining breakaway oxidation time, and it was confirmed that cladding alloys with 200wppm hydrogen retain ductility at $135^{\circ} \mathrm{C}$ for these oxidation temperatures.

In the ANL test program, two vintages of Zry-4 cladding were subjected to numerous oxidation tests to determine breakaway oxidation time: relatively old HBR-type low-tin Zry-4 and modern beltpolished low-tin Zry-4. The differences in the as-fabricated materials were outer-surface roughness $(0.32$ $\mu \mathrm{m}$ for HBR-type and $0.10 \mu \mathrm{m}$ for modern Zry-4) and inner-surface finishing (pickled for HBR-type and grit-polished for modern Zry-4). When oxidized in the same test apparatus, the breakaway oxidation time for HBR-type Zry-4 was $\approx 3800 \mathrm{~s}$, while the breakaway time for the modern Zry-4 was $\approx 5000 \mathrm{~s}$. On the other hand, the effects of surface scratches, inadvertently induced during sample sectioning of HBR-type Zry- 4 , resulted in the initiation of breakaway in the scratched region and only $\approx 200$-s reduction in the 
breakaway time. One Zry-2 sample with a 20 - $\mu$ m-deep axial scratch machined into the outer surface showed no signs of breakaway oxidation after $5000 \mathrm{~s}$ at $1000^{\circ} \mathrm{C}$. A ZIRLO sample with a $20-\mu \mathrm{m}$-deep axial scratch machined into the outer surface exhibited a breakaway oxidation time of $\approx 2800 \mathrm{~s}$ at $970^{\circ} \mathrm{C}$ compared with $3000 \mathrm{~s}$ at $970^{\circ} \mathrm{C}$ for a smooth ZIRLO sample. Thus, "normal" surface scratches that may form during handling and loading of rods into assemblies appear to have only a small influence on breakaway oxidation time for modern cladding alloys used in the U.S.

The Russian Zr-1Nb cladding (E110) was added to the ANL test program to determine why this cladding exhibited such short breakaway oxidation times $\left(500-700 \mathrm{~s}\right.$ at $\left.1000^{\circ} \mathrm{C}\right)$ compared with the $\mathrm{Zr}-$ $1 \mathrm{Nb}$ cladding (M5) used in the U.S. Within the limitations of what ANL could measure and vary, no significant differences were found in chemical composition or microstructure between E110 and M5. Differences in surface roughness, along with possible differences in surface impurities, were considered as plausible reasons for behavior differences. Argonne tests confirmed the poor performance of E110 at $1000^{\circ} \mathrm{C}$ and identified instability initiation sites on the E110 outer-surface oxide as early as $5 \mathrm{~s}$ at $1000^{\circ} \mathrm{C}$. ANL then modified the E110 cladding to be more similar to Western materials by polishing the outer surface to $0.14-\mu \mathrm{m}$ surface roughness and by machining-and-polishing the inner surface to give a thinner wall thickness $(\approx 0.6 \mathrm{~mm})$. The outer-surface polishing increased the breakaway time from $\approx 600 \mathrm{~s}$ to $\approx 1200 \mathrm{~s}$ at $1000^{\circ} \mathrm{C}$. For tests at $1100^{\circ} \mathrm{C}$ and $1200^{\circ} \mathrm{C}$ oxidation temperatures, breakaway oxidation was not observed, and post-oxidation ductility of the ANL-modified E110 was as good as Zry-4 and M5. On the other hand, etching the E110 tubing surface with HF-containing acid baths tended to exacerbate breakaway oxidation. These results support the contention that the combination of higher surface roughness and etching with HF-containing acid mixtures promotes early monoclinic-oxide formation, which can reduce breakaway oxidation time. Based on the combined work of the Russian and ANL test programs, it appears that E110 would be more stable if the Kroll process were used to refine the zircon ore as is done for Western alloys rather than using electrolytic refining as has been done in Russia. The less stable the alloy, the more significant the reduction in breakaway-oxidation time resulting from surface roughness and impurities. 


\section{$4 \quad$ Results for Prehydrided Cladding Alloys}

High-burnup operation results in cladding outer-surface corrosion (oxidation) and hydrogen pickup. Hydrogen can reduce significantly the ductile-to-brittle transition ECR, especially at high oxidation temperatures. Baseline data were needed on the effects of hydrogen on embrittlement. Such data were generated with non-irradiated cladding, which had been prehydrided prior to testing. As tests with nonirradiated cladding are much easier to conduct, a relatively large number of tests were conducted to map out embrittlement as a function of hydrogen content, oxidation temperature, oxidation level (e.g., CPECR), and quench temperature. The data generated using prehydrided cladding samples helped in both planning and interpreting the results of tests conducted with high-burnup cladding.

In this section, post-quench ductility data are presented for prehydrided Zry-4 cladding oxidized at $1200^{\circ} \mathrm{C}$ and either slow cooled to RT or quenched at $800^{\circ} \mathrm{C}, 700^{\circ} \mathrm{C}$, or $600^{\circ} \mathrm{C}$. The reference test conditions are the same as those for the as-fabricated alloys: oxidize $25-\mathrm{mm}$-long samples at $1200^{\circ} \mathrm{C}$ to the desired CP-ECR level, cool at $\approx 11-13^{\circ} \mathrm{C} / \mathrm{s}$ from $1200^{\circ} \mathrm{C}$ to $800^{\circ} \mathrm{C}$, rapidly cool (by means of bottomflooding quench water flow) from $800^{\circ} \mathrm{C}$ to $100^{\circ} \mathrm{C}$, slow cool from $100^{\circ} \mathrm{C}$ to $\mathrm{RT}$, section 8 -mm-long rings from the oxidation sample, and compress the rings at $135^{\circ} \mathrm{C}$ and $0.0333 \mathrm{~mm} / \mathrm{s}$.

\subsection{Prehydrided Zircaloy -4 oxidized at $1200^{\circ} \mathrm{C}$ and quenched at $800^{\circ} \mathrm{C}$}

Two methods have been used to introduce hydrogen into Zry-4 segments. During the period of June - October 2004, prehydriding was performed at $400^{\circ} \mathrm{C}$ in a closed quartz chamber (1.5-liter volume) with a gas mixture of $4 \% \mathrm{H}_{2}$ in argon at near ambient pressure. The 100 -mm-long segments were wrapped in aluminum foil to prevent oxide film buildup while allowing hydrogen atoms to permeate to the surface of the Zry-4 sample. The exposure times used to introduce 200-600 wppm of hydrogen into the segment were 1500 to $4500 \mathrm{~s}$. This simple procedure resulted in circumferential hydrides uniformly distributed through the wall of the Zry-4 segments (see Figure 104).

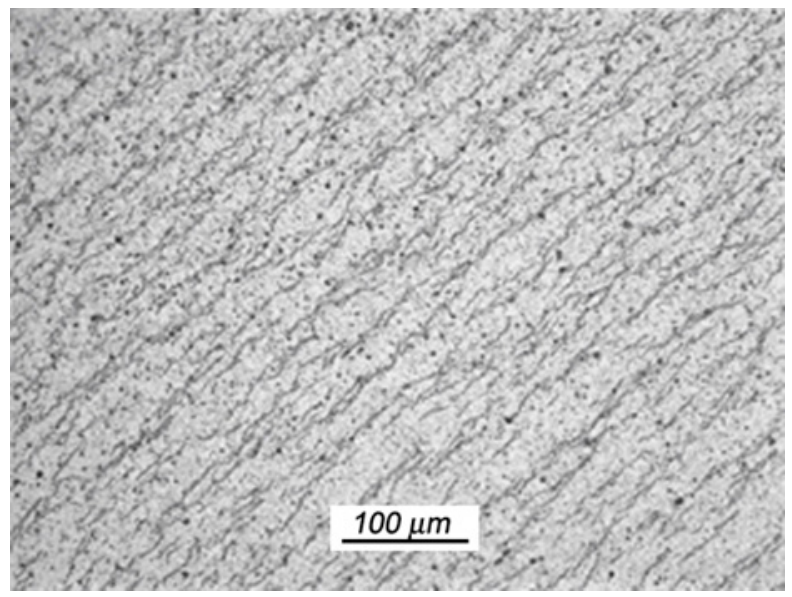

Figure 104. Uniform distribution of circumferential hydrides across the wall of HBR-type $15 \times 15 \mathrm{Zry}-4$ prehydrided to $400 \mathrm{wppm} \mathrm{H}$.

However, due to furnace temperature gradients and non-uniform cladding surface conditions, the hydrogen-concentration gradients in the axial and circumferential directions were significant. For a segment with a target hydrogen content of $500 \mathrm{wppm}$, the axial gradient was $\approx 4 \mathrm{wppm} / \mathrm{mm}$, and the circumferential gradient varied from $\approx 0.6$ to $6 \mathrm{wppm} / \mathrm{mm}$ for a $25-\mathrm{mm}$-long sample. The procedure for 
homogenization of the hydrogen calls for heating the sample to $400^{\circ} \mathrm{C}$ for $\leq 72$ hours in an inert atmosphere with temperature cycling between 300 and $400{ }^{\circ} \mathrm{C}$. However, even high-purity argon contains trace impurities of oxygen, moisture, and nitrogen, which would result in the growth of surface oxide layers and possible nitrogen-contamination of these layers. As it was desirable to avoid surface modification during sample preparation for steam-oxidation tests, this homogenization step was not used for the LOCA test samples. In planning the oxidation tests for prehydrided cladding alloys, we assumed that homogenization of hydrogen would occur during the oxidation heating ramp.

Early test results indicated that the circumferential and axial gradients in hydrogen content remained after the oxidation tests conducted at $1200^{\circ} \mathrm{C}$. It has been demonstrated that redistribution of hydrogen across the wall of the cladding is very rapid as the wall is thin $(0.57-0.77 \mathrm{~mm})$, and the beta layer has a very high affinity for hydrogen. However, it was surprising to discover that no significant redistribution of hydrogen occurred in the longer axial direction $(25 \mathrm{~mm})$ or the circumferential direction $(\approx 30 \mathrm{~mm})$. Figure 105 shows the hydrogen distribution for a prehydrided HBR-type Zry-4 oxidation sample before and after oxidation-quench testing. Prior to oxidation, hydrogen levels were measured for 2-mm-long rings cut from both sides of a 30-mm-long sample. Following oxidation of the remaining 25mm-long sample to $5 \%$ CP-ECR (92 s from beginning of ramp to the end of the $1200^{\circ} \mathrm{C}$ hold time), hydrogen readings were obtained from the center of the oxidized sample and from the 8-mm-long rings used in the ring compression tests. These post-oxidation hydrogen measurements were corrected for weight gain for comparison to pretest values.

\section{Post-Oxidation H, wppm}

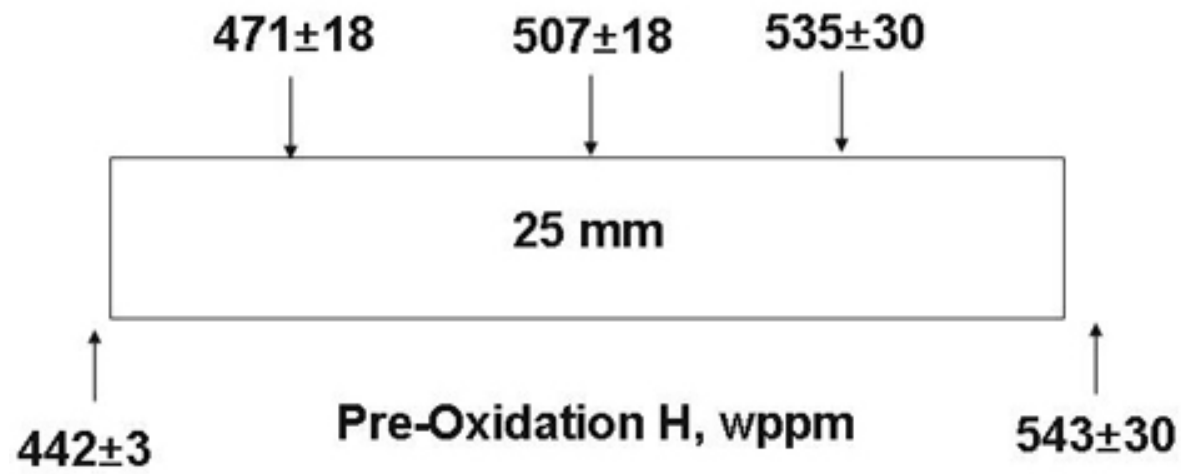

Figure 105. Hydrogen concentration in a prehydrided HBR-type $15 \times 15$ Zry-4 sample before and after oxidation at $1200^{\circ} \mathrm{C}$ to $5 \%$ CP-ECR. Hydrogen contents after oxidation were corrected for sample weight gain to allow direct comparison with pre-test hydrogen contents.

The gradients following high-temperature oxidation were comparable to the pretest gradients, indicating that hydrogen did not homogenize under these test conditions. Although gradients in hydrogen concentration are not desirable for controlled studies, the relative immobility of the hydrogen allowed ANL to study the local effects of hydrogen concentration on post-quench ductility for samples oxidized to the same CP-ECR levels. The approach is reasonable even for samples with more uniform distribution of hydrogen. As prehydriding Zry-4 is more of an art than a science, prehydrided Zry-4 used in other LOCA-relevant studies (e.g., CEA, JAEA) does have some axial gradient that leads to sample-to-sample variation in hydrogen for samples cut from the same prehydrided segment. 
Modern $17 \times 17$ Zry-4 and HBR-type $15 \times 15$ Zry-4 segments were prehydrided by the closed-system method. Due to limited material availability, more $15 \times 15$ Zry- 4 segments were prehydrided for oxidation tests. The baseline data generated for HBR-type $15 \times 15$ Zry-4 were used to plan the in-cell oxidation tests with high-burnup HBR cladding (see Section 5.1).

The improved and more recent method used for prehydriding cladding alloys utilizes a three-stage furnace for temperature control and flowing gas containing either $4 \% \mathrm{H}_{2}-96 \%$ Ar mixture, $30 \% \mathrm{H}_{2}$ $70 \%$ Ar mixture, or $100 \% \mathrm{H}_{2}$. Prehydriding was conducted at $350^{\circ} \mathrm{C}$ with this furnace. Segments of HBR-type $15 \times 15$ Zry-4 were 50 -to-100 mm long and prehydrided to $180-880 \mathrm{wppm}$. Because of the temperature uniformity in the new furnace, better homogenization of hydrogen was achieved in the axial and circumferential direction. It was difficult to control the final hydrogen content for segments prehydrided with $100 \% \mathrm{H}_{2}$, which was both flowing and at a slightly elevated pressure $(0.1113 \mathrm{MPa}$ absolute). Hydrogen uptake progressed very slowly for the first 4.5 hours of exposure, with hydrogen contents ranging from $\approx 70 \mathrm{wppm}$ at 2 -hours exposure to $\approx 180 \mathrm{wppm}$ at 4.75 -hours exposure. Within the test period of 5 to 8 hours, hydrogen uptake increased dramatically from $200 \mathrm{wppm}$ to $900 \mathrm{wppm}$, but duplicate tests conducted for the same time-temperature history did not result in the same hydrogen contents (e.g., for a 7-hour hold time at $350^{\circ} \mathrm{C}$, one sample picked up $140 \mathrm{wppm}$ while another sample picked up $730 \mathrm{wppm}$ ). Also, for $>200$-wppm-H pickup, a dense hydride rim formed on or near the inner surface of the cladding (see Figure 106), even though hydrogen flowed along both the inside and outside of the segment. As the HBR-type cladding inner surface had been pickled as a final fabrication step, this effect may explain why higher hydrogen pickup was observed at the inner surface. Several oxidation samples were prepared by this technique. The dense hydride rim near the inner-cladding surface was not considered to be an issue for oxidation tests because hydrogen redistribution across the wall of the cladding is expected to be rapid in the beta phase, and this phase has a high affinity for hydrogen. However, circumferential variation in hydride rim thickness led in some cases to significant circumferential variation in hydrogen content.

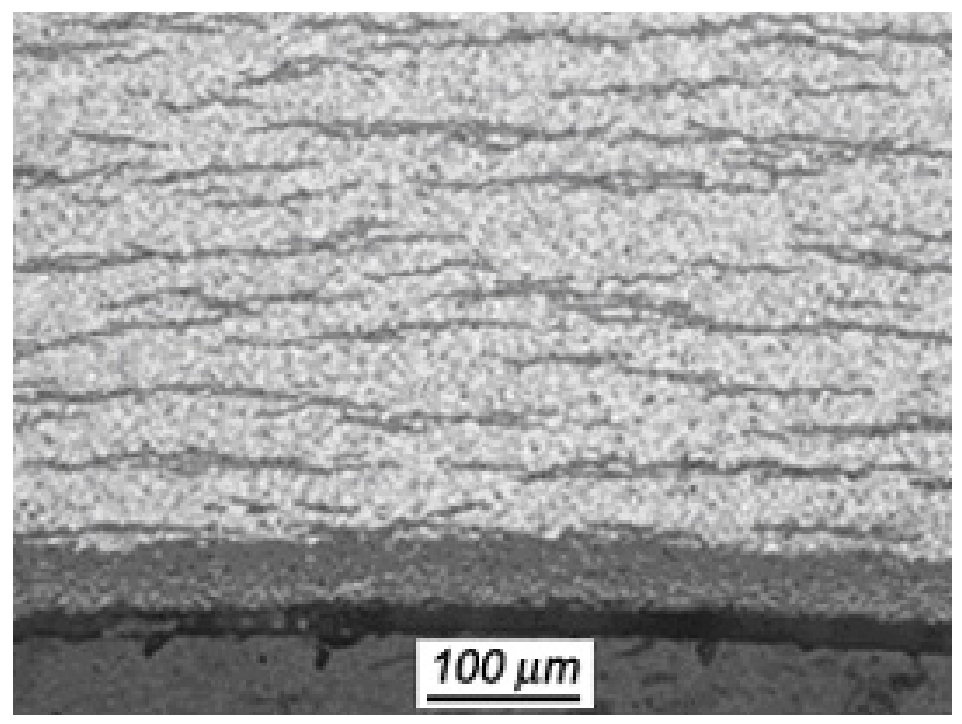

Figure 106. Hydride morphology for prehydrided (435 \pm 50 wppm) HBR-type $15 \times 15$ Zry-4 showing a dense hydride $\operatorname{rim}(\approx 46 \mu \mathrm{m})$ at the cladding inner surface. 
Better control was achieved by using the $4 \% \mathrm{H}_{2}-96 \%$ Ar gas mixture at the same hold temperature $\left(350^{\circ} \mathrm{C}\right)$ and absolute pressure $(0.1113 \mathrm{MPa})$. However, the segments had to be pre-wrapped in aluminum foil to reduce test time and to inhibit oxide buildup on the cladding segment surfaces. This process was used to generate prehydrided HBR-type Zry-4 samples for post-quench ductility studies.

\subsubsection{Post-quench ductility of prehydrided $17 \times 17$ Zry-4 oxidized at $1200^{\circ} \mathrm{C}$}

The ANL tests with prehydrided $17 \times 17$ Zry-4 samples were conducted during June-October 2004 with samples prepared by the old prehydriding method. Because of ANL's limited supply of $17 \times 17$ Zry- 4 and the old oxidation test train used, the results should be used more for scoping purposes to determine ranges of hydrogen contents and CP-ECR levels for which post-quench ductility was retained. There were informal communications from other researchers that hydrogen contents of 300-600 wppm were enough to completely embrittle Zry-4 after exposures to $1200^{\circ} \mathrm{C}$ for test times $<60 \mathrm{~s}$ and CP-ECR levels $<5 \%$. These test results were later published by Mardon et al. [21]. The results were generated by an approach using very rapid heating to $1200^{\circ} \mathrm{C}$, oxidation at $1200^{\circ} \mathrm{C}$ for various hold times, and direct quench at $1200^{\circ} \mathrm{C}$. Thus, it was important to conduct companion tests with the ANL test protocol (slow ramp from about $1150^{\circ} \mathrm{C}$ to $1200^{\circ} \mathrm{C}$, hold at $1200^{\circ} \mathrm{C}$ for various test times, cool at $\approx 13^{\circ} \mathrm{C} / \mathrm{s}$, quench at $800^{\circ} \mathrm{C}$, slow cool from $100^{\circ} \mathrm{C}$ to $\mathrm{RT}$, and ring-compress at $135^{\circ} \mathrm{C}$ ). Because of the axial gradients in the ANL prehydrided samples, the approach used was to study the effects of hydrogen on embrittlement at two target CP-ECR values: $7.5 \%$ and $10 \%$. The thermal history for the test train used for oxidation is given in Figure 20. However, because so many tests had been conducted with this test train, it was rebenchmarked during the testing of the prehydrided $17 \times 17$ Zry-4 samples.

Table 46 summarizes the post-quench ductility results for prehydrided $17 \times 17$ Zry- 4 oxidized at $1200^{\circ} \mathrm{C}$ to target CP-ECR levels of $7.5 \%$ and $10 \%$. Test times were selected based on the thermal history in Figure 20. Calculated CP-ECR levels were later corrected based on the thermal re-benchmarking for the old test train. The hydrogen contents listed in Table 46 were determined from 2-mm-long rings cut from prehydrided segments prior to oxidation and post-oxidation samples cut before and after ringcompression testing. For the post-oxidation hydrogen readings, the hydrogen concentration was corrected for weight gain to reference the hydrogen content to the pre-oxidized sample weight. The nominal CPECR values used for plotting trend curves are $7.5 \%$ and $10 \%$. The lower CP-ECR values for the prehydrided samples are 7.5-7.6\%. The 7.8\% CP-ECR for the as-fabricated sample (no prehydriding) is not significantly different from $7.5 \%$ because the ductility is so high. The higher CP-ECR values for the prehydrided samples are $9.4-10.1 \%$ and $10.8 \%$ for the as-fabricated sample (no prehydriding). Given the sparse data set, the variable hydrogen content along the samples, and the condition of the test train used, the CP-ECR groupings are reasonable.

The offset strain data and the trend curves are plotted in Figure 107. At 7.5\% CP-ECR, the ductileto-brittle transition occurs between 314-wppm and 412-wppm hydrogen. The ductile-to-brittle transition is interpolated to occur at $375 \pm 25 \mathrm{wppm}$ for $7.5 \%$ CP-ECR oxidation level. At 10\% CP-ECR, Zry-4 is ductile at 274-wppm $\mathrm{H}$ and brittle at 335-wppm $\mathrm{H}$. The ductile-to-brittle transition is interpolated to occur at $300 \pm 25 \mathrm{wppm} \mathrm{H}$ for $10 \% \mathrm{CP}$-ECR oxidation level. These results are not inconsistent with the results presented by Mardon et al. [21]. The hydrogen content for their samples was $600 \mathrm{wppm}$ (most likely $600 \pm 50 \mathrm{wppm}$ ) in $17 \times 17 \mathrm{Zry}-4$ with $0.57-\mathrm{mm}$-wall thickness. Their samples were oxidized (onesided) at $1200^{\circ} \mathrm{C}$ under isothermal conditions and were quenched at $1200^{\circ} \mathrm{C}$. 
Table 46. Ring Compression Test Results for Prehydrided $17 \times 17$ Zry-4 Cladding Oxidized at $1200^{\circ} \mathrm{C}$, Cooled at $\approx 13^{\circ} \mathrm{C} / \mathrm{s}$ to $800^{\circ} \mathrm{C}$, and Quenched. ECR $=1.538 \mathrm{Wg}$ for 0.57 -mm-wall cladding. Tests were performed on $\approx 8$-mm-long samples at $135^{\circ} \mathrm{C}$ and $0.0333-\mathrm{mm} / \mathrm{s}$ displacement rate.

\begin{tabular}{|c|c|c|c|c|c|c|c|}
\hline \multicolumn{2}{|c|}{$\begin{array}{c}\text { Test } \\
\text { Conditions }\end{array}$} & \multicolumn{2}{c|}{$\begin{array}{c}\text { ECR, } \\
\%\end{array}$} & \multicolumn{2}{c|}{$\begin{array}{c}\text { Plastic } \\
\text { Displacement, mm }\end{array}$} & \multicolumn{2}{c|}{ Strain, \% } \\
\hline $\begin{array}{c}\text { H Content } \\
\text { wppm }\end{array}$ & $\begin{array}{c}\text { Ox. Test } \\
\text { Time, }{ }^{\mathrm{a}} \mathrm{s}\end{array}$ & CP & Meas. & Offset & Permanent & Offset & Permanent \\
\hline 5 & 100 & 7.8 & 8.2 & 5.48 & 4.82 & 58 & 51 \\
\hline 247 & 95 & 7.6 & 8.5 & 3.30 & 3.02 & 35 & 32 \\
278 & 95 & 7.6 & 8.5 & 1.13 & -- & 12 & -- \\
314 & 95 & 7.6 & 8.5 & 1.95 & -- & 21 & -- \\
\hline 412 & 100 & 7.5 & 8.8 & 0.05 & 0.07 & 0.5 & 0.7 \\
438 & 100 & 7.5 & 8.8 & 0.06 & 0.08 & 0.6 & 0.8 \\
524 & 100 & 7.5 & 8.8 & 0.06 & --- & 0.6 & -- \\
\hline \hline 5 & 151 & 10.8 & 11.9 & 2.14 & --- & 23 & --- \\
5 & 151 & 10.8 & 11.9 & $>2.41$ & $>1.92$ & $>25$ & $>20$ \\
\hline 154 & 136 & 9.4 & 9.9 & 2.87 & 2.58 & 30 & 27 \\
209 & 136 & 9.4 & 9.9 & 0.52 & 0.31 & 5.5 & 3.3 \\
274 & 136 & 9.4 & 9.9 & 0.27 & -- & 2.8 & -- \\
\hline 335 & 141 & 10.1 & 12.8 & 0.06 & 0.04 & 0.6 & 0.4 \\
462 & 141 & 10.1 & 11.2 & 0.04 & 0.08 & 0.4 & --- \\
499 & 141 & 10.1 & 11.2 & 0.05 & 0.04 & 0.5 & 0.4 \\
\hline
\end{tabular}

${ }^{\mathrm{a}}$ Includes time for ramp from $300^{\circ} \mathrm{C}$ and hold time.

More data would be needed for modern $17 \times 17$ Zry-4 to map out combinations of hydrogen content, oxidation temperature, and CP-ECR leading to embrittlement; to determine the influence of heating rate on post-quench ductility; and to determine the influence of cooling rate and quench temperature on postquench ductility. The database for HBR-type $15 \times 15$ Zry- 4 oxidized at $1200^{\circ} \mathrm{C}$ is more extensive and is presented in Section 4.1.2 for quench at $800^{\circ} \mathrm{C}$ and in Section 4.2 for quench at $700^{\circ} \mathrm{C}$ and $600^{\circ} \mathrm{C}$ vs. slow cooling to RT. The HBR-type Zry-4 data base is important as it is used to aid in interpreting the results of tests with high-burnup HBR Zry-4. 


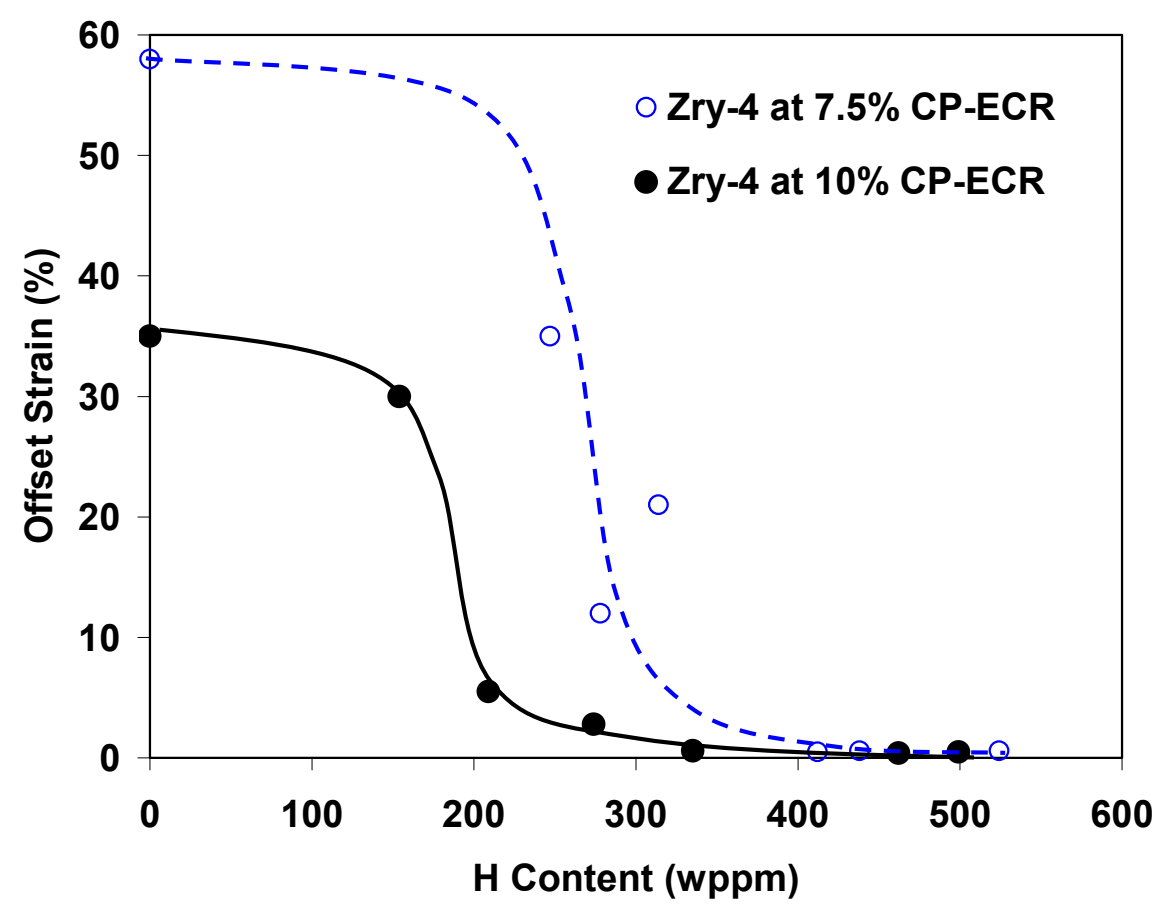

Figure 107. Variation of post-quench ductility with pre-test hydrogen content for modern $17 \times 17$ Zry-4 oxidized at $1200^{\circ} \mathrm{C}$ to $7.5 \%$ and $10 \%$ CP-ECR (see Figure 20 for temperature history), cooled at $\approx 13^{\circ} \mathrm{C} / \mathrm{s}$, quenched at $800^{\circ} \mathrm{C}$, and ring-compressed at $135^{\circ} \mathrm{C}$ and $0.0333 \mathrm{~mm} / \mathrm{s}$.

\subsubsection{Post-quench ductility of prehydrided HBR-type $15 \times 15$ Zry-4 oxidized at $1200^{\circ} \mathrm{C}$}

The tests with prehydrided $15 \times 15$ Zry-4 samples were conducted with well-benchmarked test trains. Tests conducted during June-December 2004 used the test train with the temperature history shown in Figure 10. Tests conducted from January-June 2006 used the thermal history presented in Figure 108, which is very similar to the one in Figure 10. Tests conducted during June-October 2006 are characterized by the thermal history shown in Figure 109, which has a faster ramp to $1200^{\circ} \mathrm{C}$ and a temperature overshoot of $16^{\circ} \mathrm{C}$ early in the transient. This temperature history resulted in earlier-thanexpected embrittlement due to the fast ramp and the temperature overshoot. Tests conducted after October 2006 used a thermal history more similar to the one in Figure 108. The test protocol for HBRtype Zry-4 was the same as the one used for oxidizing prehydrided $17 \times 17$ Zry- 4 . However, because asfabricated HBR-type Zry-4 exhibited low ductile-to-brittle-transition CP-ECR (16\%), the target CP-ECR values were reduced to $5 \%$ and $7.5 \%$. The $7.5 \%$ CP-ECR oxidation level allowed a direct comparison of the two data bases. In evaluating the ANL data, note that 5\% CP-ECR was reached for most samples during the slow part of the heating ramp with a peak temperature of $1190^{\circ} \mathrm{C}$ (Figure 10) or $1180^{\circ} \mathrm{C}$ (Figure 108) prior to cooling. The oxidation level of 7.5\% was achieved for most samples at the end of a 55 -s hold time at $1204^{\circ} \mathrm{C}$. Tables 47 and 48 summarize post-quench ductility results for prehydrided $15 \times 15$ Zry- 4 oxidized to target CP- ECR levels of 5\% and 7.5\%, respectively. The footnotes to Tables 47 and 48 identify the thermal history for the tests conducted in 2006. 


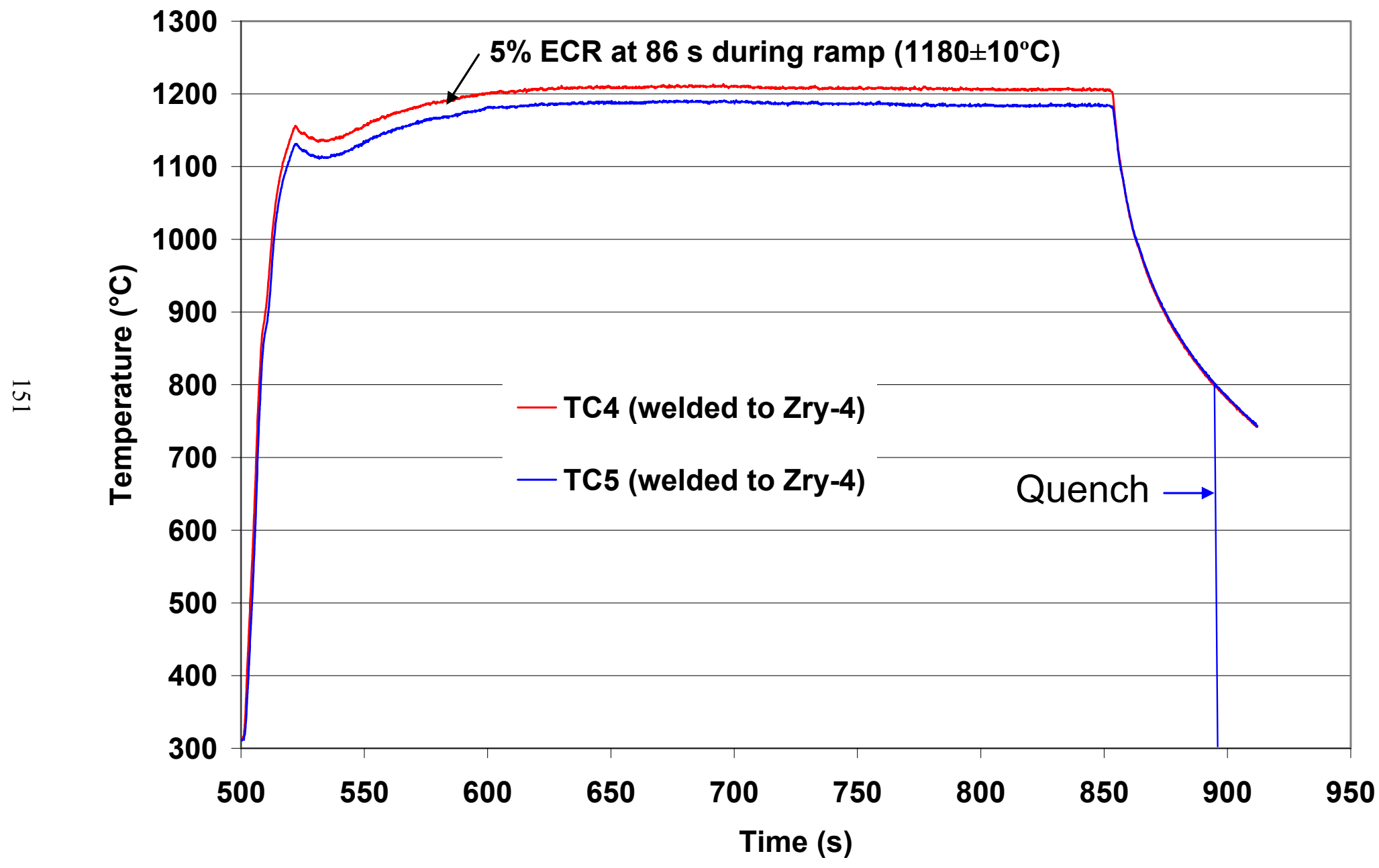

Figure 108. March 2006 thermal benchmark results for HBR-type $15 \times 15$ Zry-4 with a target oxidation temperature of $1200^{\circ} \mathrm{C}$. 


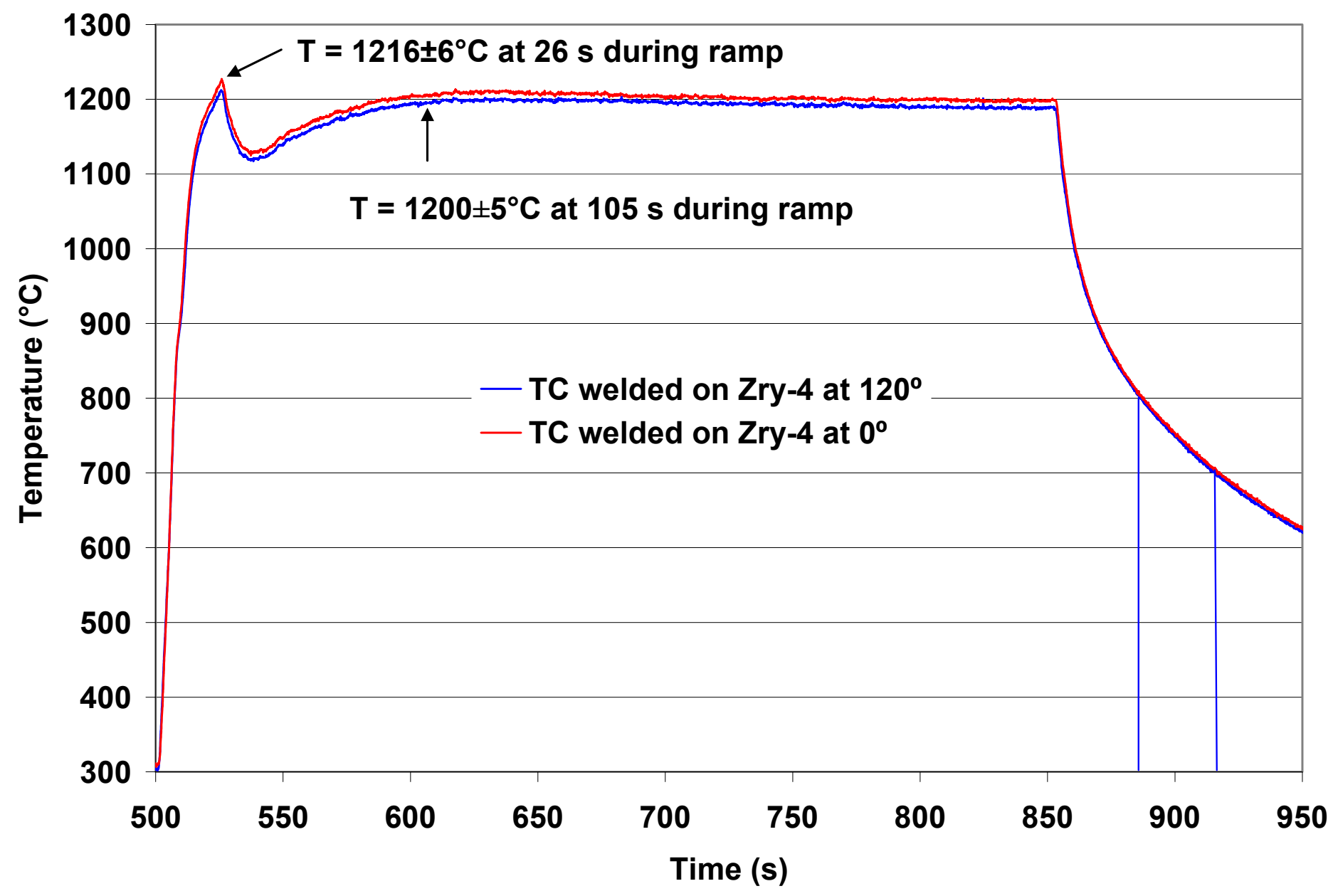

Figure 109. June 2006 thermal benchmark results for HBR-type $15 \times 15$ Zry-4 with a target oxidation temperature of $1200^{\circ} \mathrm{C}$. 
Data and trend curves for offset strain vs. pre-oxidation hydrogen content are given in Figures 110 and 111 for the 5\% and 7.5\% CP-ECR oxidation levels, respectively. For 5\% CP-ECR test conditions, Zry-4 exhibits post-quench ductility up to $\approx 550$-wppm hydrogen and is definitely brittle at $\approx 640$-wppm hydrogen. Although the ductile-to-brittle-transition hydrogen content at 5\% CP-ECR is not precisely determined, 600-wppm hydrogen appears to be a reasonable value based on interpolation. The transition CP-ECR and/or the hydrogen content would decrease for tests with faster heating ramps and longer hold times at $\approx 1200^{\circ} \mathrm{C}$.

For the $7.5 \%$ CP-ECR oxidation level, one Zry-4 sampled exhibited ductility at 400-wppm hydrogen. However, embrittlement occurred at 335-wppm hydrogen for the more aggressive temperature ramp shown in Figure 109. For lower heating rate (Figures 10 and 108), the ductile-to-brittle transition hydrogen level is $375 \pm 25 \mathrm{wppm}$. The HBR-type Zry-4 offset strains are lower than the strains for $17 \times 17$ Zry-4 at $<315 \mathrm{wppm} \mathrm{H}$, but the ductile-to-brittle transition hydrogen content appears to be the same $(375 \pm 25 \mathrm{wppm})$ at $7.5 \%$ CP-ECR for both types of Zry-4 (see Figure 112). Thus, within the data scatter, the higher transition CP-ECR for as-fabricated $17 \times 17$ Zry-4 does not appear to lead to higher transition values for prehydrided $17 \times 17$ Zry-4, as compared to HBR-type $15 \times 15$ Zry-4. .

Table 47. Post-quench Ductility of Prehydrided HBR-type 15×15 Zry-4 Cladding Oxidized to 5\% CPECR with $\mathrm{T}=1180-1190^{\circ} \mathrm{C}$ at End of Heating Ramp, Cooled at $\approx 11^{\circ} \mathrm{C} / \mathrm{s}$ to $800^{\circ} \mathrm{C}$, and Quenched (Q). Ring-compression tests were performed on $\approx 8$-mm-long samples at $135^{\circ} \mathrm{C}$ and $0.0333-\mathrm{mm} / \mathrm{s}$ displacement rate; ECR $=1.1535 \mathrm{Wg}$ for $0.76-\mathrm{mm}$-wall and $1.1385 \mathrm{Wg}$ for $0.77-\mathrm{mm}$ wall; displacements were normalized to $10.77-\mathrm{mm}$ OD for $0.76-\mathrm{mm}$-wall and 10.76 $\mathrm{mm}$ OD for $0.77-\mathrm{mm}$ wall.

\begin{tabular}{|c|c|c|c|c|c|c|c|c|}
\hline \multicolumn{3}{|c|}{$\begin{array}{c}\text { Sample and Test } \\
\text { Conditions }\end{array}$} & \multicolumn{2}{c|}{$\begin{array}{c}\text { ECR, } \\
\%\end{array}$} & \multicolumn{2}{c|}{$\begin{array}{c}\text { Plastic } \\
\text { Displacement, mm }\end{array}$} & \multicolumn{2}{c|}{ Plastic } \\
\hline $\begin{array}{c}\text { Q-T, } \\
{ }^{\circ} \mathrm{C}\end{array}$ & $\begin{array}{c}\text { Test } \\
\text { Time, }^{\mathrm{a}}{ }^{\mathrm{s}} \mathrm{s}\end{array}$ & $\begin{array}{c}\mathrm{H}, \\
\mathrm{wppm}\end{array}$ & CP & Meas. & Offset & Permanent & Offset & Permanent \\
\hline 800 & 93 & 22 & 5.0 & 5.1 & $>6.0$ & $>5.5$ & $>56$ & $>51$ \\
\hline 800 & 92 & 320 & 5.0 & 5.4 & 5.49 & --- & 51 & --- \\
\hline 800 & 92 & 375 & 5.0 & 5.4 & 3.38 & 3.36 & 31 & 30 \\
\hline 800 & 92 & 400 & 5.0 & 5.4 & 3.91 & 3.56 & 36 & 33 \\
\hline 800 & 92 & 400 & 5.0 & 5.4 & 2.98 & 3.02 & 28 & 28 \\
\hline 800 & 92 & 480 & 5.0 & 5.4 & 0.68 & --- & 6.3 & --- \\
\hline 800 & 92 & 517 & 5.0 & 5.4 & 0.57 & --- & 5.4 & --- \\
\hline 800 & 92 & 545 & 5.0 & 5.4 & 1.45 & --- & 13.5 & --- \\
\hline 800 & 92 & 636 & 5.0 & 5.6 & 0.06 & 0.04 & 0.5 & 0.4 \\
\hline $\mathbf{8 0 0}^{\mathbf{b}}$ & $\mathbf{9 6}$ & $\mathbf{7 1 0}$ & $\mathbf{5 . 0}$ & $\mathbf{5 . 7}$ & $\mathbf{0 . 0 6}$ & $\mathbf{0 . 0 7}$ & $\mathbf{0 . 5}$ & $\mathbf{0 . 6}$ \\
\hline $\mathbf{8 0 0}^{\mathbf{b}}$ & $\mathbf{9 6}$ & $\mathbf{7 3 0}$ & $\mathbf{5 . 0}$ & $\mathbf{5 . 7}$ & $\mathbf{0 . 0 5}$ & --- & $\mathbf{0 . 5}$ & --- \\
\hline $\mathbf{8 0 0}^{\mathbf{b}}$ & $\mathbf{9 6}$ & $\mathbf{7 6 0}$ & $\mathbf{5 . 0}$ & $\mathbf{5 . 7}$ & $\mathbf{0 . 0 3}$ & --- & $\mathbf{0 . 3}$ & --- \\
\hline 800 & 92 & 800 & 5.0 & 5.4 & 0.03 & --- & 0.3 & --- \\
\hline
\end{tabular}

${ }^{\mathrm{a}}$ From beginning of ramp at $300^{\circ} \mathrm{C}$ to end of hold time at $1204^{\circ} \mathrm{C}$ (see Figure 10 for thermal history).

${ }^{\mathrm{b}}$ See Figure 108 for thermal history of these tests conducted in 2006; ECR $=1.1385 \mathrm{Wg}$. 
Table 48. Post-quench Ductility of Prehydrided HBR-type $15 \times 15$ Zry-4 Cladding Oxidized at $1200^{\circ} \mathrm{C}$ to $7.5 \%$ CP-ECR, Cooled at $\approx 11^{\circ} \mathrm{C} / \mathrm{s}$ to $800^{\circ} \mathrm{C}$, and Quenched (Q). Ring-compression tests were performed on $\approx 8-\mathrm{mm}$-long samples at $135^{\circ} \mathrm{C}$ and $0.0333-\mathrm{mm} / \mathrm{s}$ displacement rate. $\mathrm{ECR}=1.1535 \mathrm{Wg}$ for $0.76-\mathrm{mm}$ wall and $1.1385 \mathrm{Wg}$ for $0.77-\mathrm{mm}$ wall; displacements were normalized to $10.77-\mathrm{mm}$ OD for $0.76-\mathrm{mm}$ wall and $10.76-\mathrm{mm}$ OD for $0.77-\mathrm{mm}$ wall.

\begin{tabular}{|c|c|c|c|c|c|c|c|c|}
\hline \multicolumn{3}{|c|}{$\begin{array}{l}\text { Sample and Test } \\
\text { Conditions }\end{array}$} & \multicolumn{2}{|c|}{$\begin{array}{c}\text { ECR, } \\
\%\end{array}$} & \multicolumn{2}{|c|}{$\begin{array}{c}\text { Plastic } \\
\text { Displacement, } \mathrm{mm}\end{array}$} & \multicolumn{2}{|c|}{$\begin{array}{l}\text { Plastic } \\
\text { Strain, \% }\end{array}$} \\
\hline $\begin{array}{l}\mathrm{Q}-\mathrm{T}, \\
{ }^{\circ} \mathrm{C}\end{array}$ & $\begin{array}{c}\text { Test } \\
\text { Time, } \\
\text { s }\end{array}$ & $\begin{array}{c}\mathrm{H}, \\
\text { wppm }\end{array}$ & $\mathrm{CP}$ & Meas. & Offset & Permanent & Offset & Permanent \\
\hline $\begin{array}{l}800 \\
800\end{array}$ & $\begin{array}{l}154 \\
145\end{array}$ & $\begin{array}{l}22 \\
22\end{array}$ & $\begin{array}{l}7.5 \\
7.5\end{array}$ & $\begin{array}{l}8.1 \\
7.6\end{array}$ & $\begin{array}{l}>4.7 \\
5.53\end{array}$ & $>4.3$ & $\begin{array}{c}>43 \\
51\end{array}$ & $>40$ \\
\hline $800^{b}$ & 144 & 185 & 7.4 & 8.1 & 1.41 & 1.2 & 13 & 11 \\
\hline $\begin{array}{l}800^{c} \\
800^{c}\end{array}$ & 132 & $\begin{array}{l}335 \\
335\end{array}$ & 7.4 & 7.7 & 0.08 & --- & 0.7 & -- \\
\hline 800 & 145 & 360 & 7.5 & 7.6 & 0.54 & --- & 5.0 & --- \\
\hline 800 & 145 & 386 & 7.5 & 7.7 & 0.20 & --- & 1.9 & --- \\
\hline 800 & 145 & 386 & 7.5 & 7.7 & 0.11 & 0.07 & 1.0 & 0.6 \\
\hline 800 & 145 & 386 & 7.5 & 7.7 & 0.06 & 0.04 & 0.6 & 0.4 \\
\hline 800 & 145 & 390 & 7.5 & 7.6 & 0.09 & --- & 0.8 & --- \\
\hline 800 & 145 & 400 & 7.5 & 7.6 & 0.23 & 0.11 & 2.1 & 1.0 \\
\hline $800^{b}$ & 144 & 435 & 7.4 & 8.0 & 0.05 & 0.03 & 0.5 & 0.3 \\
\hline $800^{b}$ & 144 & 435 & 7.4 & 8.0 & 0.05 & 0.03 & 0.5 & 0.3 \\
\hline 800 & 145 & 533 & 7.5 & 8.1 & 0.05 & --- & 0.5 & --- \\
\hline 800 & 145 & 600 & 7.5 & 8.1 & 0.04 & --- & 0.4 & --- \\
\hline
\end{tabular}

${ }^{a}$ From beginning of ramp at $300^{\circ} \mathrm{C}$ to end of hold time at $1204^{\circ} \mathrm{C}$ (see Figure 10 for thermal history).

${ }^{b}$ Tests conducted with thermal history shown in Figure 108; ECR $=1.1385$ Wg.

${ }^{\mathrm{c}}$ Tests conducted with thermal history shown in Figure 109; ECR $=1.1385 \mathrm{Wg}$. 


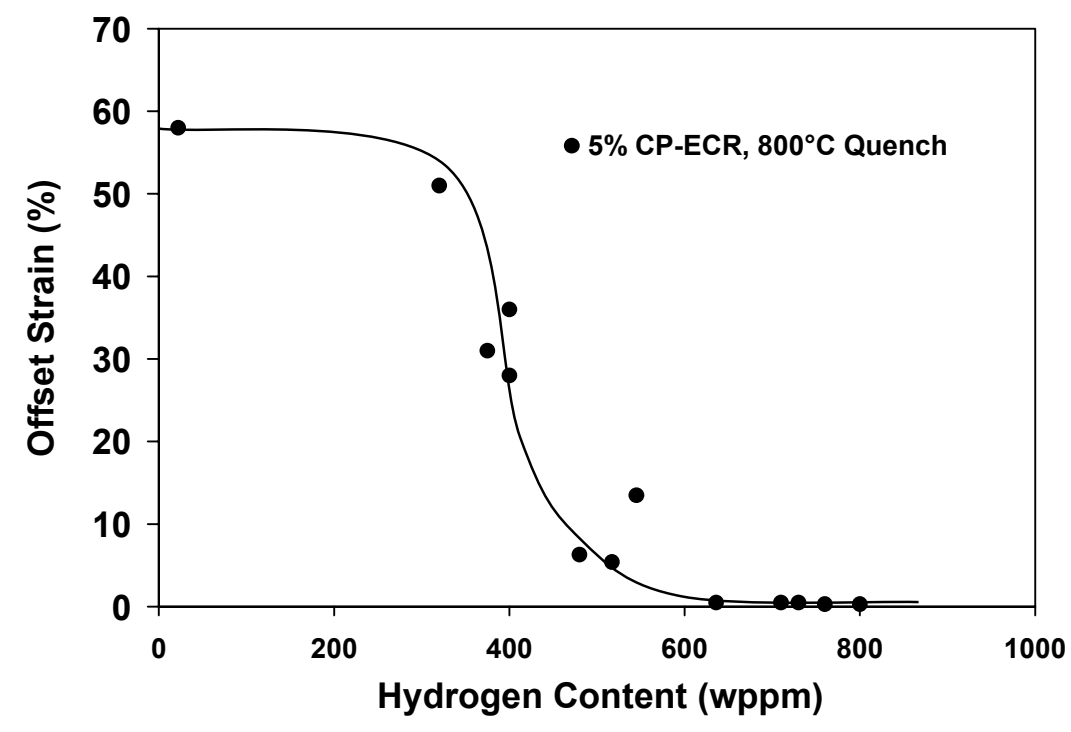

Figure 110. Variation of post-quench ductility with pre-test hydrogen content for HBR-type $15 \times 15$ Zry-4 oxidized to $5 \% \mathrm{CP}-\mathrm{ECR}$ with an end-of-heating temperature of $1180-1190^{\circ} \mathrm{C}$ (see Figures 10 and 108 ), cooled at $\approx 11^{\circ} \mathrm{C} / \mathrm{s}$, quenched at $800^{\circ} \mathrm{C}$, and ring-compressed at $135^{\circ} \mathrm{C}$.

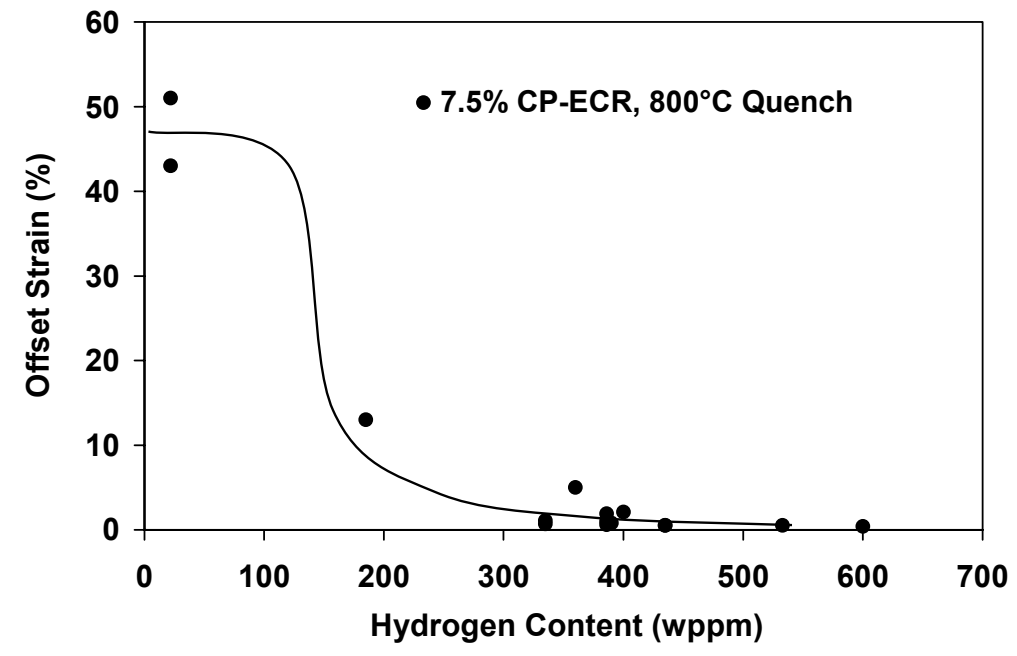

Figure 111. Variation of post-quench ductility with pre-test hydrogen content for HBR-type $15 \times 15 \mathrm{Zry}-4$ oxidized at $1204^{\circ} \mathrm{C}$ to $7.5 \%$ CP-ECR (see Figures 10,108 , and 109 ), cooled at $\approx 11^{\circ} \mathrm{C} / \mathrm{s}$, quenched at $800^{\circ} \mathrm{C}$, and ring-compressed at $135^{\circ} \mathrm{C}$. 


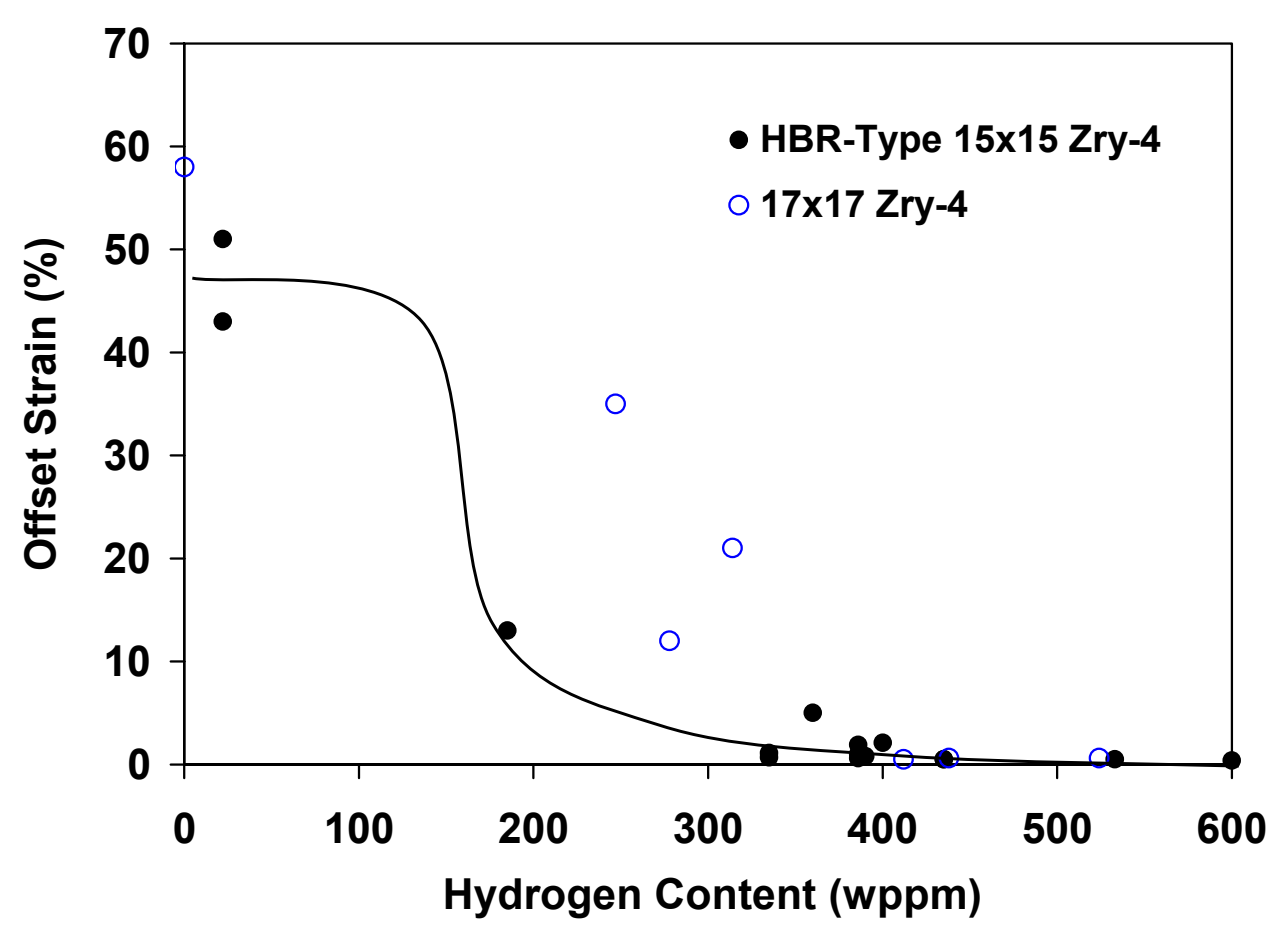

Figure 112. Post-quench ductility vs. pre-test hydrogen content for modern $17 \times 17$ and HBR-type $15 \times 15$ Zry-4 oxidized at $1200^{\circ} \mathrm{C}$ to $7.5 \% \mathrm{CP}$-ECR, cooled at $\approx 11-13^{\circ} \mathrm{C} / \mathrm{s}$, quenched at $800^{\circ} \mathrm{C}$, and ringcompressed at $135^{\circ} \mathrm{C}$.

To better understand the significant decrease in post-quench ductility with increasing hydrogen content, metallography and microhardness were performed on as-received HBR-type Zry-4 and prehydrided (600 wppm) HBR-type Zry-4, both oxidized at $\approx 1200^{\circ} \mathrm{C}$ to $7.5 \% \mathrm{CP}$-ECR. Figures $113 \mathrm{a}$ and $113 \mathrm{~b}$ show typical cross sections (at one out of eight circumferential locations) of the as-received and prehydrided samples, respectively, following oxidation and quench at $800^{\circ} \mathrm{C}$. Although both samples show evidence of alpha incursions precipitated during cooling in the prior-beta layer, these incursions appear to be larger and more pronounced in the as-received Zry-4. The layer thicknesses are comparable and do not suggest that one sample was highly ductile and the other sample was highly brittle. Table 49 summarizes measured sample weight gains, layer thicknesses determined from metallographic images, weight gains determined from the layer thicknesses, and post-quench ductility. The presence of 600wppm hydrogen resulted in embrittlement (nil-ductility) of Zry-4 oxidized to 7.5\% CP-ECR, whereas the as-received Zry-4 sample exhibited a very high offset strain $(>43 \%$, which is the limit of this particular test) at $135^{\circ} \mathrm{C}$ ring-compression temperature. The prior-beta-layer microhardness profiles shown in Figure 114 reveal significant differences between the two samples. The local and average microhardness values in the prior-beta layer for the prehydrided sample are significantly higher than the ones for the asreceived sample. These results are consistent with the post-quench ductility results: higher microhardness values correlate to lower post-quench ductility strains. 


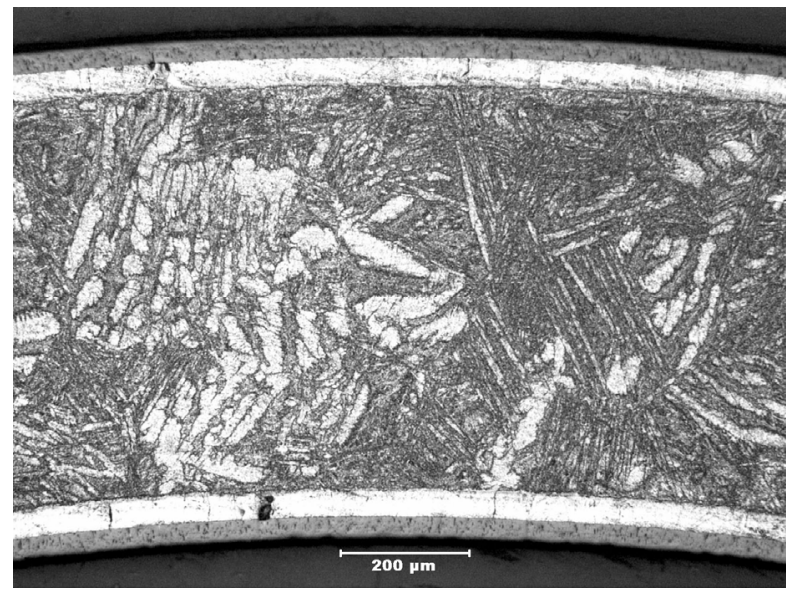

(a) As-received

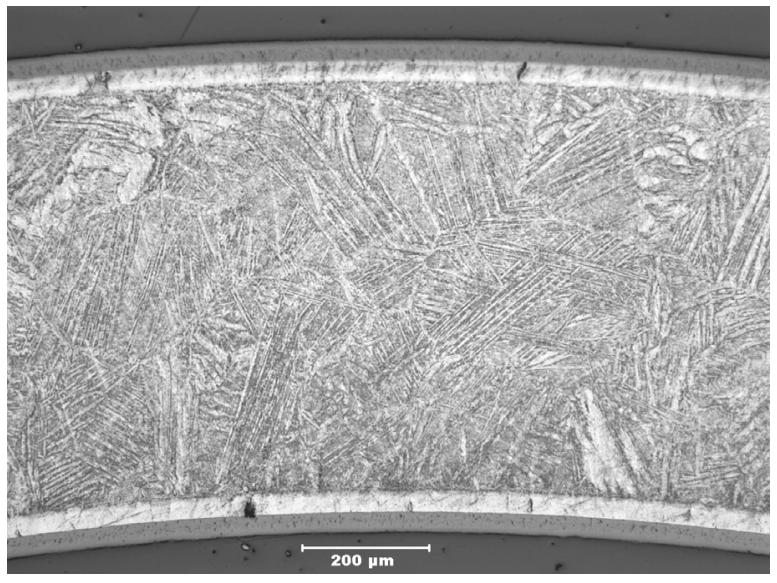

(b) 600-wppm hydrogen

Figure 113. Metallographic images of HBR-type $15 \times 15$ Zry-4 following oxidation at $\approx 1200^{\circ} \mathrm{C}$ to $7.5 \% \mathrm{CP}$ $\mathrm{ECR}$, cooling at $\approx 11^{\circ} \mathrm{C} / \mathrm{s}$ to $800^{\circ} \mathrm{C}$, and quench at $800^{\circ} \mathrm{C}$ : (a) as-received and (b) 600-wppm hydrogen.

Table 49. Comparison of Results for As-received and 600-wppm-prehydrided HBR-type 15×15 Zry-4 Samples after Exposure to Steam at $\approx 1200^{\circ} \mathrm{C}$ to $7.5 \% \mathrm{CP}$-ECR, Cooling at $\approx 11^{\circ} \mathrm{C} / \mathrm{s}$ to $800^{\circ} \mathrm{C}$, and Quench at $800^{\circ} \mathrm{C}$

\begin{tabular}{|c|c|c|}
\hline \multirow{2}{*}{ Parameter } & \multicolumn{2}{|c|}{ HBR-Type 15x15 Zry-4 } \\
\cline { 2 - 3 } & As-received & Prehydrided \\
\hline Hydrogen Content, wppm & $\approx 10$ & 600 \\
\hline Hold Temperature, ${ }^{\circ} \mathrm{C}$ & $1200 \pm 17$ & $1204 \pm 10$ \\
\hline CP-ECR, $\%$ & 7.5 & 7.5 \\
\hline CP Weight Gain, mg/cm ${ }^{2}$ & 6.5 & 6.5 \\
\hline $\begin{array}{c}\text { Measured Weight Gain based on } \\
\text { Change in Sample Weight, } \mathrm{mg} / \mathrm{cm}^{2}\end{array}$ & 6.94 & 6.75 \\
\hline Measured ECR, $\%$ & 8.0 & 7.8 \\
\hline Outer-surface Oxide Layer, $\mu \mathrm{m}$ & 35 & 33 \\
\hline Outer-surface Alpha Layer, $\mu \mathrm{m}$ & 41 & 38 \\
\hline Prior-beta Layer, $\mu \mathrm{m}$ & 636 & 640 \\
\hline Inner-surface Alpha Layer, $\mu \mathrm{m}$ & 40 & 39 \\
\hline Inner-surface Oxide Layer, $\mu \mathrm{m}$ & 36 & 34 \\
\hline Weight Gain Determined from & --- & 6.7 \\
\hline Metallography, mg/cm ${ }^{2}$ & & 0.4 \\
\hline $\begin{array}{c}\text { Post-Quench Ductility, } \% \\
\text { (Offset Strain) }\end{array}$ & $>43$ & \\
\hline
\end{tabular}




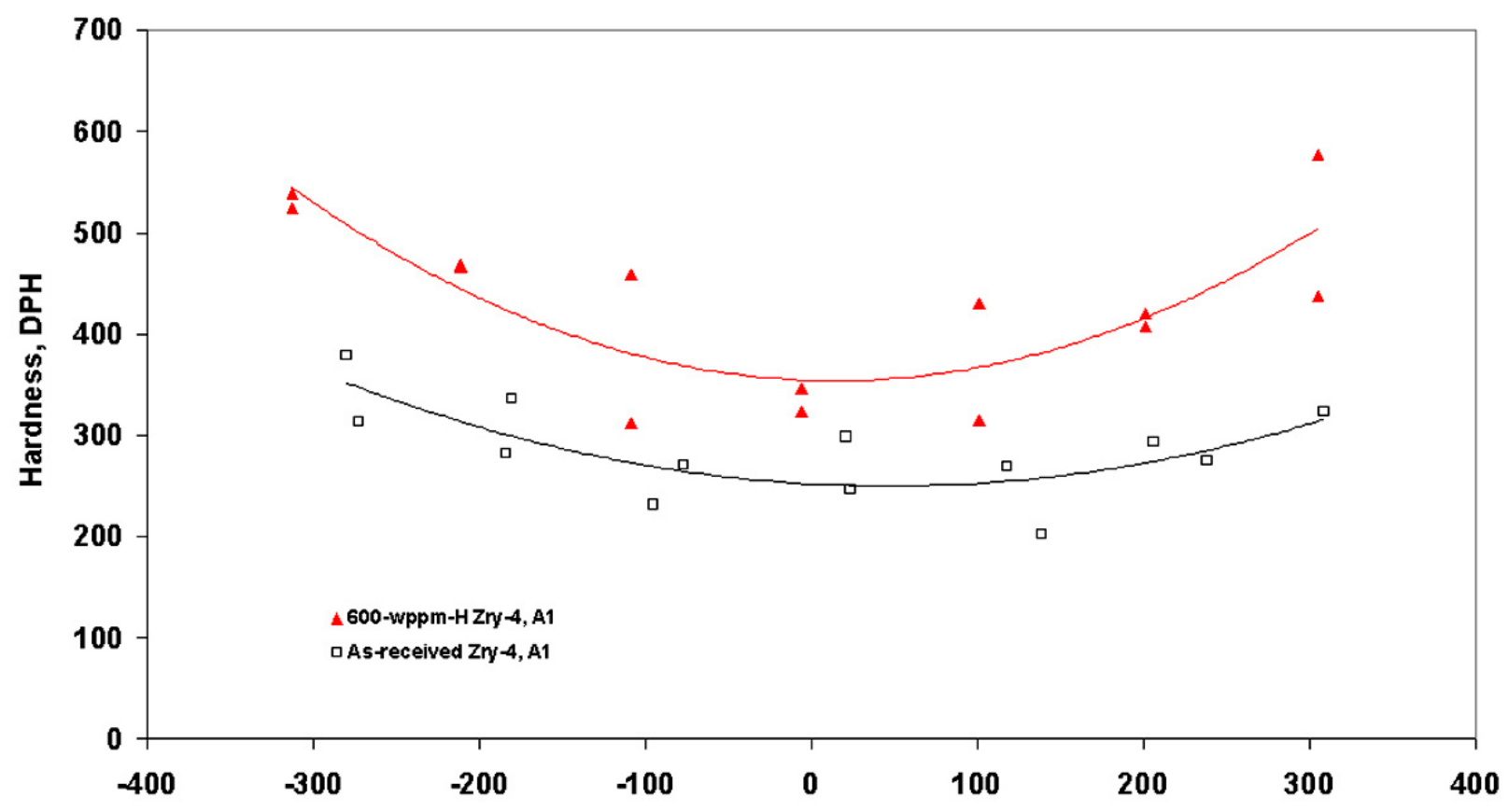

Distance from Mid-Radius, microns

Figure 114. RT microhardness profiles across the prior-beta layer of two samples oxidized at $\approx 1200^{\circ} \mathrm{C}$ to $7.5 \% \mathrm{CP}$-ECR, cooled at $\approx 11^{\circ} \mathrm{C} / \mathrm{s}$ to $800^{\circ} \mathrm{C}$, and quenched at $800^{\circ} \mathrm{C}$ : as-received and 600 -wppmhydrogen HBR-type $15 \times 15$ Zry-4.

The elevated RT microhardness for the prehydrided sample suggests that hydrogen increases the rate of oxygen diffusion into the beta layer during oxidation at elevated temperature, and/or that hydrogen has a direct effect on increasing hardness and embrittlement. Based on the results of Mardon et al. [21, Figure 16], $600 \mathrm{wppm}$ of hydrogen causes the solubility limit of oxygen in the prior-beta layer to increase by $0.4 \pm 0.1 \mathrm{wppm}$ relative to as-received material oxidized at $1200^{\circ} \mathrm{C}$. If the Chung and Kassner [18] solubility limit of 0.57 -wt. $\%$ oxygen at $1200^{\circ} \mathrm{C}$ were used for as-received Zry-4, then the oxygen solubility limit for 600-wppm-H Zry-4 would be $1.0 \pm 0.1 \mathrm{wt} . \%$. The oxygen concentration in the beta layer at the alpha-beta boundary would increase from $\approx 0.6 \mathrm{wt} . \%$ to $\approx 1.0 \mathrm{wt} . \%$. Using the oxygen diffusivity determined by Pawel et al. [27], the solubility limit for the oxygen concentration at the alphabeta boundary, the as-received oxygen concentration for the "zero-time" oxygen concentration across the beta layer, and the end-of-oxidation beta-layer thickness (approximation to bypass the more complicated moving-boundary problem), the oxygen profiles were calculated and compared to the microhardness profiles across the beta layer for as-received and 600-wppm-prehydrided Zry-4. The results are given in Figure 115 for as-received (a) and prehydrided (b) Zry-4 oxidized at $\approx 1200^{\circ} \mathrm{C}$ to $7.5 \% \mathrm{CP}$-ECR. These calculated oxygen concentrations do not agree very well with the microhardness vs. oxygen-content results of Mardon et al. [21, Figure 16]. The results of Mardon et al. show a linear relationship between microhardness and oxygen concentration for samples oxidized long enough at $1000-1200^{\circ} \mathrm{C}$ to approach the solubility limit. The non-linear relationships shown in Figures 115a and 115b suggest that the model and oxygen diffusivity used to calculate the oxygen profiles may need some improvement. 


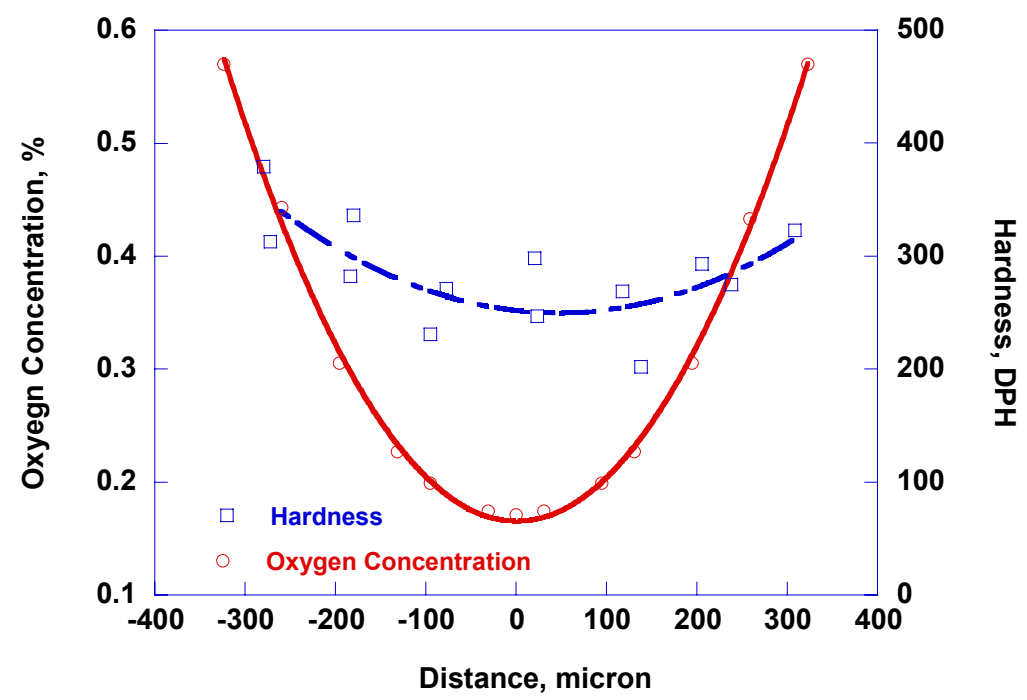

(a) As-received

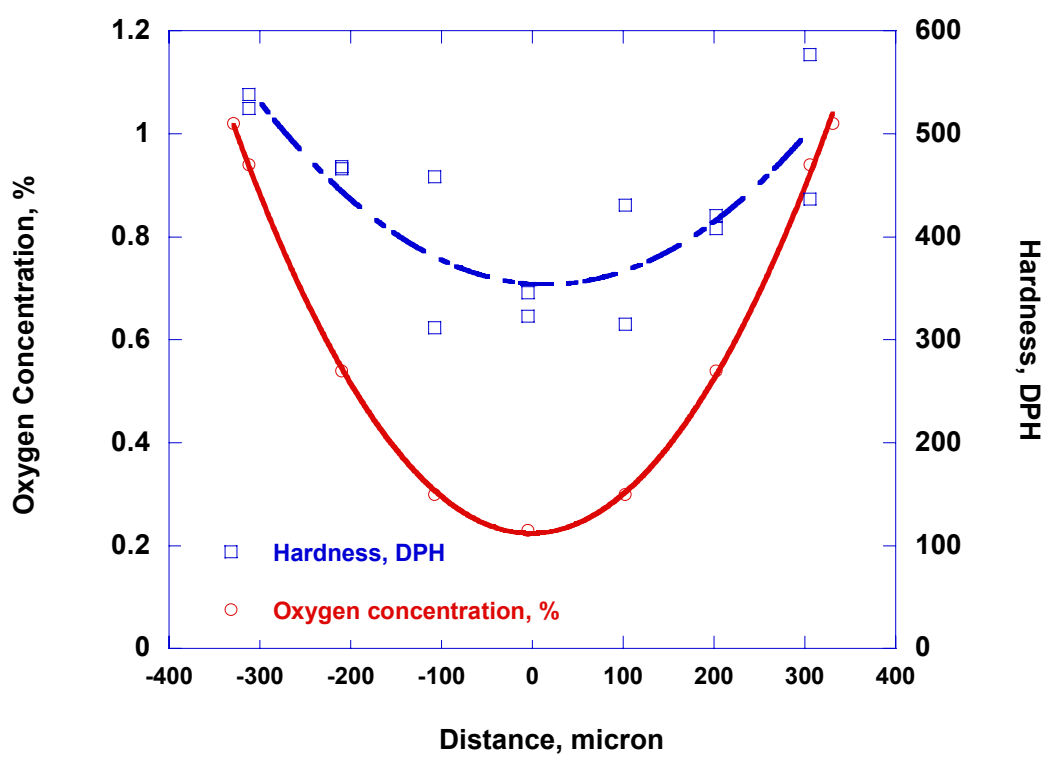

(b) 600-wppm hydrogen

Figure 115. Measured RT microhardness and calculated oxygen-concentration profiles across the beta layers of HBR-type $15 \times 15$ Zry- 4 oxidized at $\approx 1200^{\circ} \mathrm{C}$ to $7.5 \% \mathrm{CP}-\mathrm{ECR}$, cooled at $\approx 11^{\circ} \mathrm{C} / \mathrm{s}$ to $800^{\circ} \mathrm{C}$, and quenched at $800^{\circ} \mathrm{C}$ : (a) as-received and (b) 600-wppm hydrogen. 


\subsection{Effects of quench temperature on post-quench ductility}

Heating-rate effects on post-quench ductility and ductile-to-brittle transition CP-ECR are reasonably well understood qualitatively. However, systematic studies have not been performed to quantify the transition CP-ECR vs. temperature ramp rate. Also, modeling oxygen diffusion into the beta layer during transient heating is challenging because of the temperature-dependent increase in beta-layer oxygen concentration at the alpha-beta boundary. At a fixed CP-ECR, cladding oxidized at a low heating rate to $1200^{\circ} \mathrm{C}$ will exhibit higher post-quench ductility than cladding oxidized at a very high heating rate to $1200^{\circ} \mathrm{C}$. The rapidly heated sample would experience more time at $1200^{\circ} \mathrm{C}$ and would pick up more oxygen in the beta layer due to higher diffusivity and solubility at $1200^{\circ} \mathrm{C}$ as compared to lower oxidation temperatures. However, the effects of cooling rate and quench temperature on post-quench ductility are not well understood. In Section 3.6, it was shown that as-fabricated Zry-4, ZIRLO, and M5 samples quenched at $800^{\circ} \mathrm{C}$ after oxidation at $1200^{\circ} \mathrm{C}$ exhibited the same ductile-to-brittle-transition CP-ECR as samples cooled from $1200^{\circ} \mathrm{C}$ to RT without quench. The transitions occurred at $17-20 \% \mathrm{CP}$-ECR and corresponded to relatively long test times. For oxygen-induced embrittlement of as-fabricated cladding alloys, the cooling rate from $800^{\circ} \mathrm{C}$ to RT appears to be insignificant. However, tests needed to be conducted with prehydrided and high-burnup samples before conclusions could be drawn with regard to cooling-rate and quench-temperature effects on post-quench ductility.

In order to address these issues for prehydrided samples, tests were conducted with prehydrided HBR-type $15 \times 15$ Zry- 4 to determine the effects of quench temperature on post-quench ductility for samples oxidized at $1200^{\circ} \mathrm{C}$. Prehydrided samples were oxidized to the same CP-ECR level and, cooled at an average rate of $11^{\circ} \mathrm{C} / \mathrm{s}$ to $800^{\circ} \mathrm{C}$ and quenched (Q); or cooled at an average rate of $7.3^{\circ} \mathrm{C} / \mathrm{s}$ to $700^{\circ} \mathrm{C}$ and quenched; or slow cooled (SC) from $1200^{\circ} \mathrm{C}$ to RT. The relevant temperature histories for these tests are shown in Figures 108 and 109. Because of the significant database presented in Section 4.1.2 for HBR-type $15 \times 15$ Zry-4 at 5\% and 7.5\% CP-ECR, the same oxidation levels were used in this study. The results for Zry-4 oxidized to 5\% CP-ECR are listed in Table 50 and shown in Figure 116, along with the data in Table 47. The 7.5\% CP-ECR results are listed in Table 51 and shown in Figure 117, along with the data in Table 48.

The prehydrided (710-760 wppm) samples quenched at $800^{\circ} \mathrm{C}$ were brittle after oxidation to $5 \%$ CP-ECR. Slow-cooled samples with the same hydrogen content and oxidized to the same CP-ECR had marginally higher offset and permanent strains. Nevertheless, the difference is significant as all six samples exhibited low ductility (offset strain $\geq 2.0 \%$, permanent strain $\geq 1.4 \%$ ). Quenching at $800^{\circ} \mathrm{C}$ essentially "freezes" in the distribution of oxygen within the high-oxygen-containing alpha incursions precipitated during very rapid cooling from $800^{\circ} \mathrm{C}$ to $100^{\circ} \mathrm{C}$ and the low-oxygen-containing prior-beta matrix. For the slow-cooled samples, oxygen diffusion is very slow below $800^{\circ} \mathrm{C}$ and is not predicted to occur. However, most of the hydrogen is expected to be in solution in the low-oxygen-containing part of the prior-beta layer. Hydrogen has more mobility than oxygen at $<800^{\circ} \mathrm{C}$. It can move to the interfaces of these two regions and form small precipitates. If the oxygen concentration remains the same in the low-oxygen-containing prior-beta matrix and the hydrogen concentration decreases with slow cooling, the ductility results suggest that hydrogen causes a small amount of embrittlement beyond what is expected due to its enhancement of oxygen solubility in the prior-beta layer. If hydrogen is given time to migrate out of the low-oxygen prior-beta regions, then the ductility of these regions appears to be enhanced.

The results following oxidation to $7.5 \% \mathrm{CP}$-ECR are also interesting. These prehydrided samples were at $\approx 1200^{\circ} \mathrm{C}$ hold temperature for $\approx 60 \mathrm{~s}$. Depending on the heating rate (Figure 10, 108, or 109), 
embrittlement for $800^{\circ} \mathrm{C}$-quenched Zry-4 samples occurred in the range of 335-wppm (Figure 109 heating rate) to 400-wppm $\mathrm{H}$ (one sample with Figure 10 heating rate). However, slow-cooled samples exhibited low ductility for hydrogen contents up to $\approx 550 \mathrm{wppm}$, with one sample marginally brittle at $530 \mathrm{wppm}$ and another one ductile at $570 \mathrm{wppm}$. As with the prehydrided 5\% CP-ECR samples, the enhancement in offset and permanents strains is small but significant. For the aggressive heating rate in Figure 109, samples with $\approx 330$ wppm $\mathrm{H}$ were brittle following quench at $800^{\circ} \mathrm{C}$, brittle ( 2 out of 3 samples) following quenching at $700^{\circ} \mathrm{C}$, and marginally ductile following slow cooling to RT.

Table 50. Post-quench Ductility of Prehydrided HBR-type 15×15 Zry-4 Cladding Oxidized to 5\% CPECR with $\mathrm{T}=1180^{\circ} \mathrm{C}$ at End of Heating Ramp, Cooled at $\approx 11^{\circ} \mathrm{C} / \mathrm{s}$ to $800^{\circ} \mathrm{C}$, and either Quenched $(\mathrm{Q})$ at $800^{\circ} \mathrm{C}$ or Slow Cooled to RT. ECR $=1.1385 \mathrm{Wg}$; ring-compression tests performed on $\approx 8$-mm-long samples at $135^{\circ} \mathrm{C}$ and $0.0333 \mathrm{~mm} / \mathrm{s}$ displacement rate.

\begin{tabular}{|c|c|c|c|c|c|c|c|c|}
\hline \multicolumn{3}{|c|}{$\begin{array}{l}\text { Sample and Test } \\
\text { Conditions }\end{array}$} & \multicolumn{2}{|c|}{$\begin{array}{l}\mathrm{ECR}, \\
\%\end{array}$} & \multicolumn{2}{|c|}{$\begin{array}{c}\text { Plastic } \\
\text { Displacement, mm }\end{array}$} & \multicolumn{2}{|c|}{$\begin{array}{l}\text { Plastic } \\
\text { Strain, \% }\end{array}$} \\
\hline $\begin{array}{c}\text { Q-T, } \\
{ }^{\circ} \mathrm{C} \\
\text { or SC }\end{array}$ & $\begin{array}{l}\text { Test } \\
\text { Time, } \\
\text { s }\end{array}$ & $\begin{array}{c}\mathrm{H}, \\
\text { wppm }\end{array}$ & $\mathrm{CP}$ & Meas. & Offset & Permanent & Offset & Permanent \\
\hline 800 & 96 & 710 & 5.0 & 5.7 & 0.06 & 0.07 & 0.5 & 0.6 \\
\hline $\mathrm{SC}$ & 96 & 720 & 5.0 & 5.7 & 0.37 & 0.29 & 3.4 & 2.7 \\
\hline $\begin{array}{l}\text { SC } \\
\text { SC } \\
\text { SC }\end{array}$ & $\begin{array}{l}96 \\
96 \\
96\end{array}$ & $\begin{array}{l}720 \\
720 \\
720\end{array}$ & $\begin{array}{l}5.0 \\
5.0 \\
5.0\end{array}$ & $\begin{array}{l}5.6 \\
5.6 \\
5.6\end{array}$ & $\begin{array}{l}0.18 \\
0.22 \\
0.21\end{array}$ & $\begin{array}{l}0.14 \\
0.19 \\
0.17\end{array}$ & $\begin{array}{l}2.3 \\
2.1 \\
2.0\end{array}$ & $\begin{array}{l}1.4 \\
1.8 \\
1.6\end{array}$ \\
\hline 800 & 96 & 730 & 5.0 & 5.7 & 0.05 & --- & 0.5 & --- \\
\hline $\mathrm{SC}$ & 96 & 740 & 5.0 & 5.7 & 0.30 & 0.25 & 2.8 & 2.3 \\
\hline 800 & 96 & 760 & 5.0 & 5.7 & 0.03 & --- & 0.3 & --- \\
\hline $\mathrm{SC}$ & 96 & 760 & 5.0 & 5.7 & 0.32 & 0.17 & 3.0 & 1.6 \\
\hline
\end{tabular}

${ }^{\mathrm{a}}$ From beginning of heating ramp at $300^{\circ} \mathrm{C}$ to time at $1180^{\circ} \mathrm{C}$ (see Figure 108 for thermal history). 


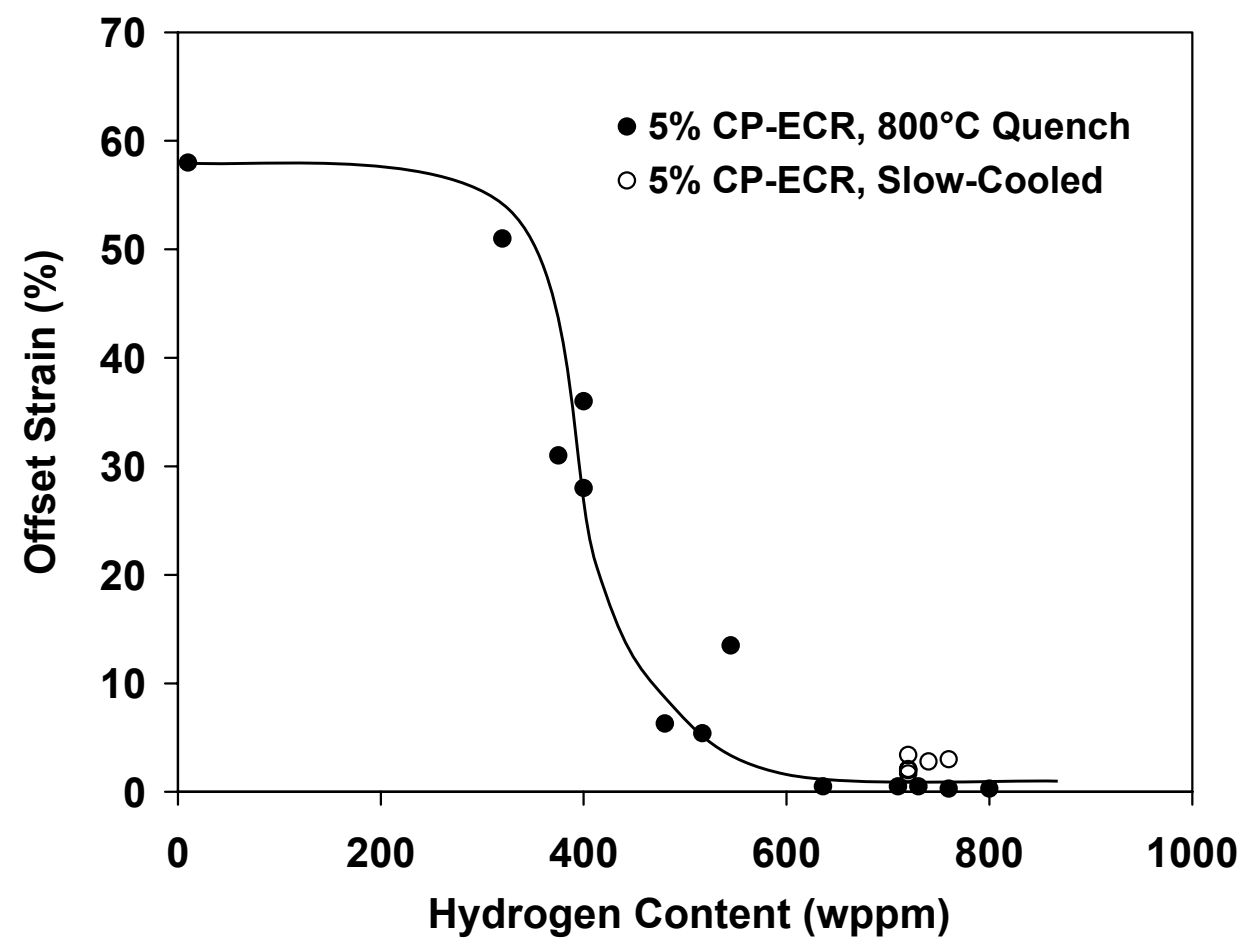

Figure 116. Effects of slow cooling vs. quench at $800^{\circ} \mathrm{C}$ on the post-test ductility at $135^{\circ} \mathrm{C}$ for HBR-type $15 \times 15$ Zry-4 oxidized to $5 \% \mathrm{CP}-\mathrm{ECR}$ at a peak temperature of $1180-1190^{\circ} \mathrm{C}$ prior to cooling. Plot includes data shown in Figure 110.

The CP-ECR values reported throughout Sections 3 and 4 are based on the integrated value up through the end of the heating phase. For the rapid cooling in the ANL experiments, oxygen diffusion into the beta layer is negligible during cooling. However, the calculated weight gain for the cooling phase does add a little to the CP-ECR value. The $\mathrm{CP}$ weight gain for the cooling phase from $1200^{\circ} \mathrm{C}$ to $800^{\circ} \mathrm{C}$ is $1.52 \mathrm{mg} / \mathrm{cm}^{2}$. Because of the parabolic nature of diffusion and weight gain, the contribution of the cooling weight gain is not linear. Let $(\mathrm{Wg})_{\mathrm{t}}$ be the total weight gain prior to quench at $800^{\circ} \mathrm{C},(\mathrm{Wg})_{\mathrm{h}}$ be the weight gain at the end of the heating phase, and $(\mathrm{Wg})_{\mathrm{c}}$ be the weight gain calculated from the cooling curve by ignoring the heating phase. Then, $(\mathrm{Wg})_{\mathrm{t}}=\left[(\mathrm{Wg})_{\mathrm{h}}{ }^{2}+(\mathrm{Wg})_{\mathrm{c}}{ }^{2}\right]^{0.5}=\left[(\mathrm{Wg})_{\mathrm{h}}{ }^{2}+2.3\right]^{0.5}$. Using the conversion factors for weight gain to ECR and the same notation for total, heating, and cooling, we can write $\mathrm{ECR}_{\mathrm{t}}=\left[\left(\mathrm{ECR}_{\mathrm{h}}\right)^{2}+\left(\mathrm{ECR}_{\mathrm{c}}\right)^{2}\right]^{0.5}$. For the $17 \times 17 \mathrm{Zry}-4$ results in Table 46 , the $7.5 \%$ heatingphase CP-ECR converts to a total CP-ECR of $7.9 \%$, and the $10 \%$ heating-phase CP-ECR lconverts to a total CP-ECR of $10.3 \%$. For the HBR-type $15 \times 15$ Zry-4 results in Tables 47, 48, and 50-52, the heatingphase CP-ECR values of 5\%, $6 \%$, and $7.5 \%$ convert to total CP-ECR values of $5.2 \%, 6.2 \%$, and $7.7 \%$, respectively. 
Table 51. Post-quench Ductility of Prehydrided HBR-type 15×15 Zry-4 Cladding Oxidized to 7.5\% CPECR at $1204^{\circ} \mathrm{C}$, Cooled at $\approx 11^{\circ} \mathrm{C} / \mathrm{s}$ to $800^{\circ} \mathrm{C}$, and Quenched (Q) at $800^{\circ} \mathrm{C}$, or Quenched at $700^{\circ} \mathrm{C}$, or Slow Cooled to RT, ECR $=1.1385 \mathrm{Wg}$; ring-compression tests performed on $\approx 8$ $\mathrm{mm}$-long samples at $135^{\circ} \mathrm{C}$ and $0.0333-\mathrm{mm} / \mathrm{s}$ displacement rate.

\begin{tabular}{|c|c|c|c|c|c|c|c|c|}
\hline \multicolumn{3}{|c|}{$\begin{array}{l}\text { Sample and Test } \\
\text { Conditions }\end{array}$} & \multicolumn{2}{|c|}{$\begin{array}{c}\text { ECR, } \\
\%\end{array}$} & \multicolumn{2}{|c|}{$\begin{array}{c}\text { Plastic } \\
\text { Displacement, mm }\end{array}$} & \multicolumn{2}{|c|}{$\begin{array}{l}\text { Plastic } \\
\text { Strain, \% }\end{array}$} \\
\hline $\begin{array}{l}\text { Q-T, }{ }^{\circ} \mathrm{C} \\
\text { or SC }\end{array}$ & $\begin{array}{c}\text { Test } \\
\text { Time, } \\
\text { s }\end{array}$ & $\begin{array}{c}\mathrm{H}, \\
\text { wppm }\end{array}$ & $\mathrm{CP}$ & Meas. & Offset & Permanent & Offset & Permanent \\
\hline $800^{\mathrm{b}}$ & 144 & 185 & 7.4 & 8.0 & 1.41 & 1.2 & 13 & 11 \\
\hline $\begin{array}{l}\mathrm{SC}^{\mathrm{b}} \\
\mathrm{SC}^{\mathrm{b}}\end{array}$ & $\begin{array}{l}144 \\
144\end{array}$ & $\begin{array}{l}180 \\
185\end{array}$ & $\begin{array}{l}7.4 \\
7.4\end{array}$ & $\begin{array}{l}8.1 \\
8.1\end{array}$ & $\begin{array}{l}1.40 \\
2.04\end{array}$ & $\begin{array}{l}1.2 \\
1.8\end{array}$ & $\begin{array}{l}13 \\
19\end{array}$ & $\begin{array}{l}11 \\
17\end{array}$ \\
\hline $\begin{array}{l}800^{\mathrm{c}} \\
800^{\mathrm{c}}\end{array}$ & $\begin{array}{l}132 \\
132\end{array}$ & $\begin{array}{l}335 \\
335\end{array}$ & $\begin{array}{l}7.4 \\
7.4\end{array}$ & $\begin{array}{l}7.7 \\
7.7\end{array}$ & $\begin{array}{l}0.12 \\
0.08\end{array}$ & $\begin{array}{c}0.08 \\
---\end{array}$ & $\begin{array}{l}1.1 \\
0.7\end{array}$ & $\begin{array}{l}0.7 \\
---\end{array}$ \\
\hline $\begin{array}{l}700^{\mathrm{c}} \\
700^{\mathrm{c}} \\
700^{\mathrm{c}}\end{array}$ & $\begin{array}{l}132 \\
132 \\
132\end{array}$ & $\begin{array}{l}335 \\
335 \\
335\end{array}$ & $\begin{array}{l}7.4 \\
7.4 \\
7.4\end{array}$ & $\begin{array}{l}7.6 \\
7.6 \\
7.6\end{array}$ & $\begin{array}{l}0.24 \\
0.11 \\
0.15\end{array}$ & $\begin{array}{l}0.11 \\
0.08 \\
0.09\end{array}$ & $\begin{array}{l}2.2 \\
1.0 \\
1.3\end{array}$ & $\begin{array}{l}1.0 \\
0.7 \\
0.8\end{array}$ \\
\hline $\begin{array}{l}S C^{c} \\
S C^{c}\end{array}$ & $\begin{array}{l}132 \\
132\end{array}$ & $\begin{array}{l}327 \\
327\end{array}$ & $\begin{array}{l}7.4 \\
7.4\end{array}$ & $\begin{array}{l}7.6 \\
7.6\end{array}$ & $\begin{array}{l}0.45 \\
0.31\end{array}$ & $\begin{array}{l}0.27 \\
0.23\end{array}$ & $\begin{array}{l}4.2 \\
2.8\end{array}$ & $\begin{array}{l}2.5 \\
2.1\end{array}$ \\
\hline $800^{\mathrm{b}}$ & 144 & 435 & 7.4 & 8.0 & 0.05 & 0.03 & 0.5 & 0.3 \\
\hline $800^{\mathrm{b}}$ & 144 & 435 & 7.4 & 8.0 & 0.05 & 0.03 & 0.5 & 0.3 \\
\hline $\mathrm{SC}^{\mathrm{b}}$ & 144 & 490 & 7.4 & 8.0 & 0.36 & 0.26 & 3.3 & 2.4 \\
\hline $\mathrm{SC}^{\mathrm{b}}$ & 144 & 530 & 7.4 & 8.0 & 0.15 & 0.10 & 1.4 & 0.9 \\
\hline $\mathrm{SC}^{\mathrm{b}}$ & 144 & 570 & 7.4 & 8.0 & 0.19 & 0.14 & 1.8 & 1.3 \\
\hline
\end{tabular}

${ }^{\mathrm{a}}$ From beginning of ramp at $300^{\circ} \mathrm{C}$ to end of hold time at $\approx 1200^{\circ} \mathrm{C}$.

${ }^{\mathrm{b}}$ Tests conducted with thermal history shown in Figure 108.

${ }^{\mathrm{c}}$ Tests conducted with thermal history shown in Figure 109. 


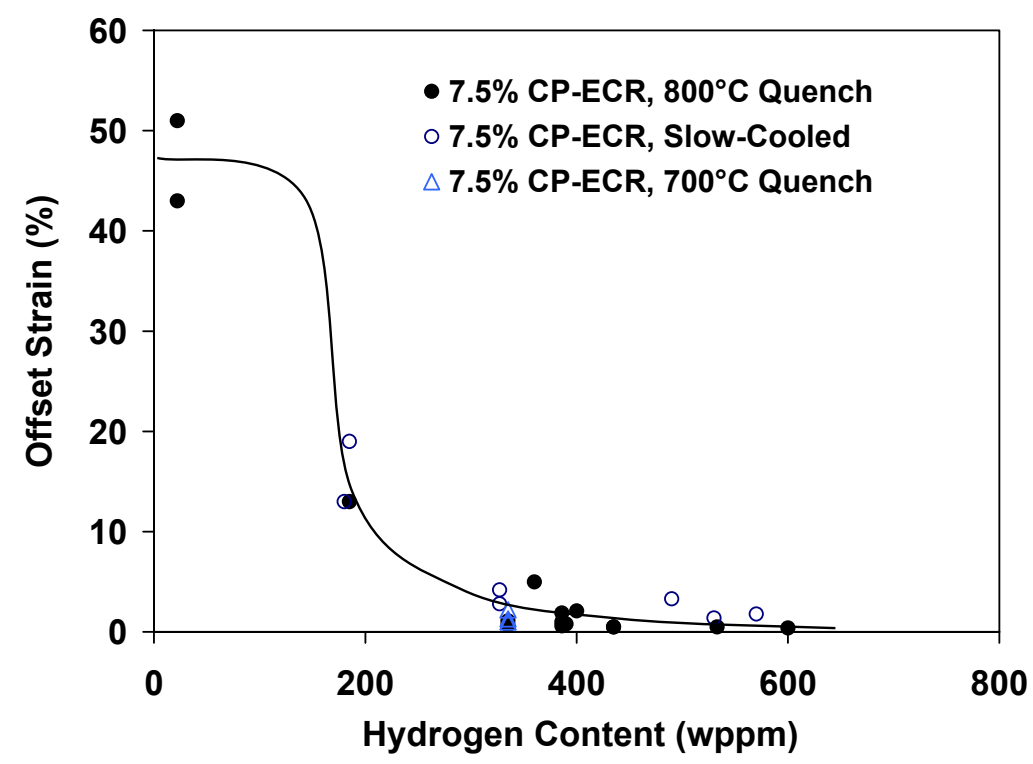

Figure 117 . Effects of slow cooling vs. quench at $700^{\circ} \mathrm{C}$ and $800^{\circ} \mathrm{C}$ on ductility at $135^{\circ} \mathrm{C}$ for HBR-type $15 \times 15$ Zry-4 oxidized to $7.5 \% \mathrm{CP}-\mathrm{ECR}$ at $1204^{\circ} \mathrm{C}$ prior to cooling. Plot includes data shown in Figure 110.

In order to better understand the effects of quench temperature on post-quench ductility, an additional set of tests was conducted with a heating rate comparable to the ones shown in Figures 10 and 108 , which were used to oxidize most of the prehydrided samples prior to conducting post-quench ductility tests. Figure 118 shows the thermal history for these additional tests. The lower heating rate to $1200^{\circ} \mathrm{C}$ is comparable to the heating rates shown in Figures 10 and 108 , as well as the ones used to oxidize high-burnup Zry-4 samples (see Section 5).

Previous data for prehydrided HBR cladding were generated for samples oxidized to $5 \%$ and $7.5 \%$ CP-ECR. Additional tests were conducted with Zry-4 samples containing 450-470 wppm hydrogen oxidized to $6 \% \mathrm{CP}-\mathrm{ECR}$. During the oxidation phase, the samples were at $1200-1204^{\circ} \mathrm{C}$ for $17 \mathrm{~s}$ and $>1180^{\circ} \mathrm{C}$ for $86 \mathrm{~s}$. The uniformity of hydrogen content from sample to sample allowed for a good comparison of ductility for Zry-4 quenched at $800^{\circ} \mathrm{C}(450 \pm 20 \mathrm{wppm} \mathrm{H}), 700^{\circ} \mathrm{C}(450 \pm 20 \mathrm{wppm} \mathrm{H})$, and $600^{\circ} \mathrm{C}(460 \pm 30 \mathrm{wppm} \mathrm{H})$, as well as the sample that was slow cooled to RT $(470 \pm 30 \mathrm{wppm} \mathrm{H})$. The post-test ductility results are given in Table 52 . The samples quenched at $600-800^{\circ} \mathrm{C}$ were all brittle by both the offset and permanent strain criteria. The slow-cooled samples were ductile with $3.5 \pm 1.4 \%$ offset strain and $2.7 \pm 1.0 \%$ permanent strain. Although the average cooling rates decreased from $11^{\circ} \mathrm{C} / \mathrm{s}$ $\left(1200^{\circ} \mathrm{C}\right.$ to $\left.800^{\circ} \mathrm{C}\right)$ to $3^{\circ} \mathrm{C} / \mathrm{s}\left(800^{\circ} \mathrm{C}\right.$ to $\left.700^{\circ} \mathrm{C}\right)$ to $2^{\circ} \mathrm{C} / \mathrm{s}\left(700^{\circ} \mathrm{C}\right.$ to $\left.600^{\circ} \mathrm{C}\right)$, it is only the very slow cooling at $<<2{ }^{\circ} \mathrm{C} / \mathrm{s}$ from $600^{\circ} \mathrm{C}$ to $\mathrm{RT}$ that resulted in ductility enhancement. Oxygen redistribution at $600^{\circ} \mathrm{C}$ to $\mathrm{RT}$ is highly unlikely due to the slow diffusivity of oxygen. The phase change from (beta + alpha) $\rightarrow$ alpha is complete by about $750^{\circ} \mathrm{C}$, so no further phase change is expected from $600^{\circ} \mathrm{C}$ to RT. However, hydrogen diffusivity is much faster than oxygen diffusivity. Thus, hydrogen can come out of solid solution and precipitate as very small hydrides during very slow cooling from $600^{\circ} \mathrm{C}$ to RT. 


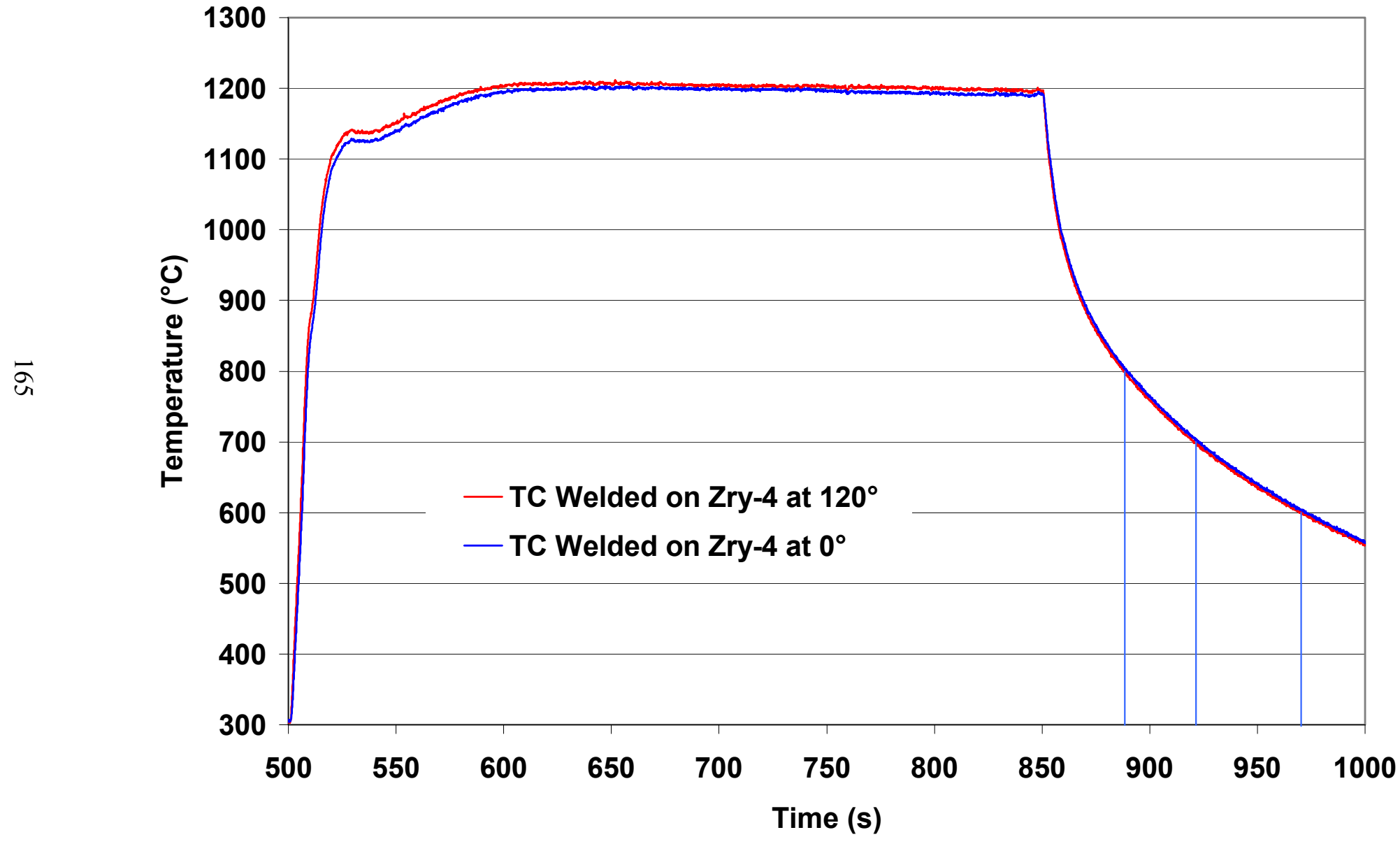

Figure 118. November 2006 thermal benchmark results for HBR-type $15 \times 15$ Zry-4 with a sample oxidation temperature of $1201 \pm 3^{\circ} \mathrm{C}$. Vertical lines indicate different quench temperatures for tests with prehydrided Zry-4 samples. 
Table 52. Post-quench Ductility of Prehydrided HBR-type 15×15 Zry-4 Cladding Oxidized to 6\% CPECR at $1200^{\circ} \mathrm{C}$, Cooled at $\approx 11^{\circ} \mathrm{C} / \mathrm{s}$ to $800^{\circ} \mathrm{C}$ and Quenched (Q) at $800^{\circ} \mathrm{C}$, Cooled from $800^{\circ} \mathrm{C}$ to $700^{\circ} \mathrm{C}$ at $3^{\circ} \mathrm{C} / \mathrm{s}$ and Quenched at $700^{\circ} \mathrm{C}$, Cooled from $700^{\circ} \mathrm{C}$ to $600^{\circ} \mathrm{C}$ at $2^{\circ} \mathrm{C} / \mathrm{s}$ and Quenched at $600^{\circ} \mathrm{C}$, or Slow Cooled from $600^{\circ} \mathrm{C}$ to RT at $<2^{\circ} \mathrm{C} / \mathrm{s}$. Thermal history is shown in Figure 118; CP-ECR is calculated from beginning of ramp to end of hold time; ringcompression tests performed on $\approx 8-\mathrm{mm}$-long samples at $135^{\circ} \mathrm{C}$ and $0.0333-\mathrm{mm} / \mathrm{s}$ displacement rate.

\begin{tabular}{|c|c|c|c|c|c|c|c|c|}
\hline \multicolumn{2}{|c|}{$\begin{array}{c}\text { Sample and Test } \\
\text { Conditions }\end{array}$} & \multicolumn{2}{c|}{$\begin{array}{c}\text { ECR, } \\
\%\end{array}$} & \multicolumn{2}{c|}{$\begin{array}{c}\text { Plastic } \\
\text { Displacement, mm }\end{array}$} & \multicolumn{2}{c|}{$\begin{array}{c}\text { Plastic } \\
\text { Strain, \% }\end{array}$} \\
\hline $\begin{array}{c}\text { Q-T, }{ }^{\circ} \mathrm{C} \\
\text { or SC }\end{array}$ & $\begin{array}{c}\text { Test } \\
\text { Time, } \\
\text { s }\end{array}$ & $\begin{array}{c}\text { H, } \\
\text { wppm }\end{array}$ & CP & Meas. & Offset & Permanent & Offset & Permanent \\
\hline 800 & 106 & 450 & 6.0 & 6.5 & 0.10 & 0.08 & 0.9 & 0.7 \\
800 & 106 & 450 & 6.0 & 6.5 & 0.09 & 0.07 & 0.8 & 0.7 \\
\hline 700 & 106 & 450 & 6.0 & 6.6 & 0.07 & 0.05 & 0.6 & 0.5 \\
700 & 106 & 450 & 6.0 & 6.6 & 0.10 & 0.05 & 0.9 & 0.5 \\
\hline 600 & 106 & 460 & 6.0 & 6.5 & 0.08 & 0.05 & 0.7 & 0.5 \\
600 & 106 & 460 & 6.0 & 6.5 & 0.13 & 0.08 & 1.2 & 0.7 \\
\hline SC & 106 & 470 & 6.0 & 6.4 & 0.22 & 0.18 & 2.1 & 1.7 \\
SC & 106 & 470 & 6.0 & 6.4 & 0.53 & 0.39 & 4.9 & 3.6 \\
\hline
\end{tabular}

${ }^{a}$ From beginning of ramp at $300^{\circ} \mathrm{C}$ to end of hold time at $\approx 1200^{\circ} \mathrm{C}$.

${ }^{\mathrm{b}}$ Total transient CP-ECR, including cooling phase, is $6.2 \%$.

The ductility enhancement with slow cooling to RT is important in data interpretation (see Section 5), but it may not be relevant to LOCA post-quench ductility for quench temperatures $\geq 600^{\circ} \mathrm{C}$.

Additional data for prehydrided HBR-type Zry-4 were needed to determine the embrittlement threshold within the narrow CP-ECR range of $4.5-5.5 \%$ for samples cooled with quench at $800^{\circ} \mathrm{C}$. The prehydrided samples included ones with small $(< \pm 30 \mathrm{wppm})$ and large $(\geq \pm 100 \mathrm{wppm})$ circumferential variations in hydrogen. A new test train was constructed and carefully benchmarked to generate these data. The thermal benchmark results shown in Figure 119 give the temperature history used to generate these results. Results of the additional tests are summarized in Table 53. The embrittlement threshold vs. hydrogen content derived from all the ductility data for prehydrided Zry-4 is shown in Figure 120 for samples cooled with or without (i.e., slow cooling [SC]) quench (Q) at $800^{\circ} \mathrm{C}$. Embrittlement results in Figure 120 are for the heating rates used in this study and are expressed in terms of the total transient CPECR, including oxidation during the heating ramp, the hold time and the cooling phase. The database used to determine embrittlement threshold is based on samples with relatively uniform hydrogen content in the circumferential direction $(< \pm 30 \mathrm{wppm})$. A few samples were tested with circumferential variations $( \pm 100 \mathrm{wppm})$ as large as anticipated for high-burnup Zry-4. Although these samples were predicted to be ductile based on average hydrogen content, they were brittle: $510 \pm 100 \mathrm{wppm}$ hydrogen oxidized to $5.2 \%$ CP-ECR and $610 \pm 100$ wppm hydrogen oxidized to $4.7 \%$ CP-ECR. To quantify embrittlement effects of large circumferential variations in hydrogen, a very extensive dataset would be needed with multiple oxidation-quench tests conducted at the same CP-ECR and hydrogen content. 


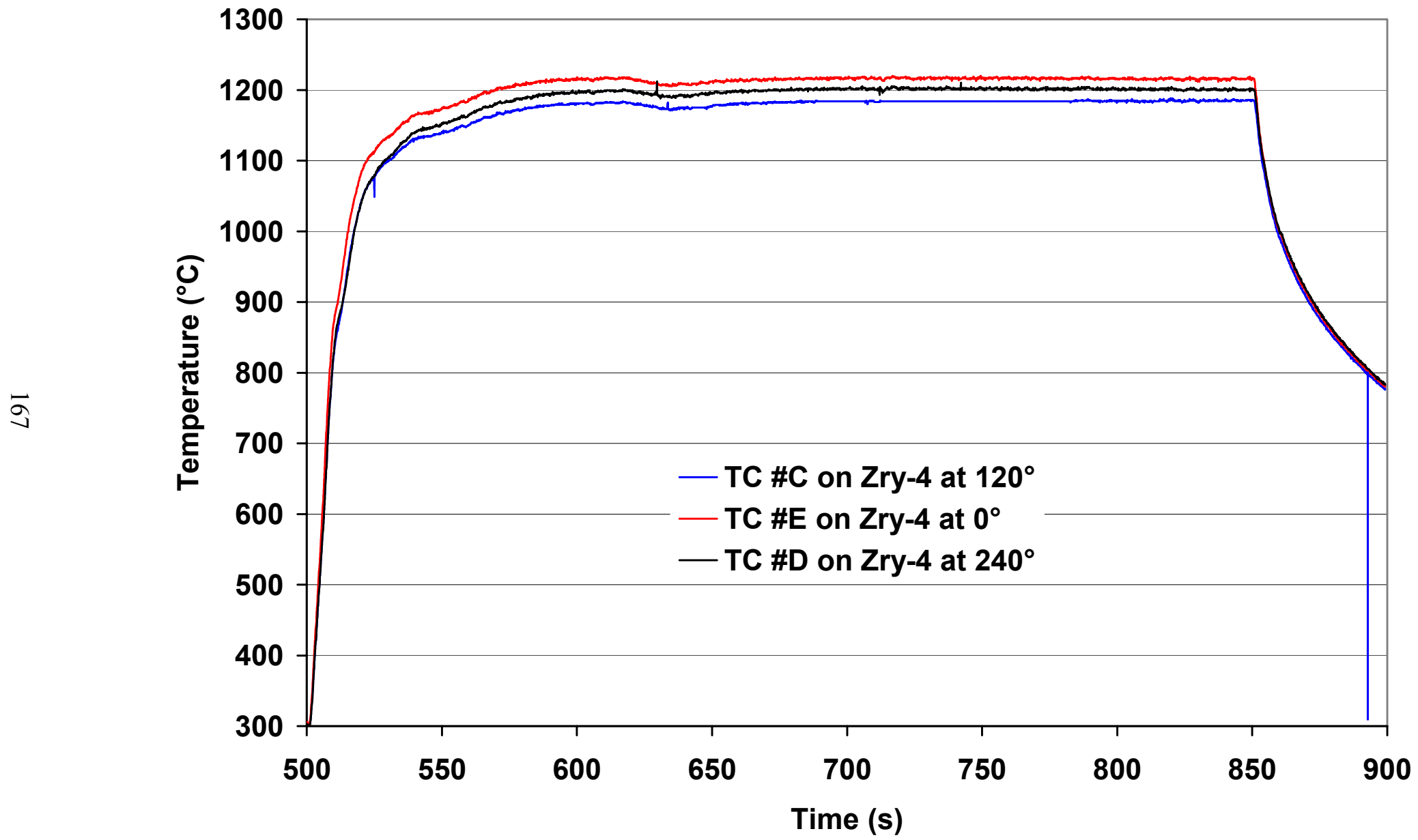

Figure 119. March 2007 thermal benchmark results for HBR-type $15 \times 15$ Zry-4 with a sample oxidation temperature of $1201 \pm 16^{\circ} \mathrm{C}$. Vertical line indicates quench at $800^{\circ} \mathrm{C}$. 
Table 53. Post-quench Ductility of Prehydrided HBR-type 15×15 Zry-4 Cladding Oxidized to 4.5-5.5\% CP-ECR at $1200^{\circ} \mathrm{C}$, Cooled at $\approx 11^{\circ} \mathrm{C} / \mathrm{s}$ to $800^{\circ} \mathrm{C}$ and Quenched (Q) at $800^{\circ} \mathrm{C}$. Thermal history is shown in Figure 119; CP-ECR is calculated from beginning of ramp to end of hold time; ring-compression tests performed on $\approx 8$-mm-long samples at $135^{\circ} \mathrm{C}$ and $0.0333-\mathrm{mm} / \mathrm{s}$ displacement rate.

\begin{tabular}{|c|c|c|c|c|c|c|c|}
\hline \multicolumn{3}{|c|}{$\begin{array}{l}\text { Sample and Test } \\
\text { Conditions }\end{array}$} & \multirow{2}{*}{$\begin{array}{c}\text { CP-ECR, } \\
\%\end{array}$} & \multicolumn{2}{|c|}{$\begin{array}{c}\text { Plastic } \\
\text { Displacement, mm }\end{array}$} & \multicolumn{2}{|c|}{$\begin{array}{l}\text { Plastic } \\
\text { Strain, \% }\end{array}$} \\
\hline $\begin{array}{l}\text { Test } \\
\text { Time, }^{\text {a }} \\
\text { s }\end{array}$ & $\underset{\max }{{ }^{\circ} \mathrm{C}}$ & $\begin{array}{c}\mathrm{H}, \\
\text { wppm }\end{array}$ & & Offset & Permanent & Offset & Permanent \\
\hline 74 & 1185 & $\begin{array}{c}610 \pm 100 \\
640 \pm 100 \\
630 \pm 80\end{array}$ & 4.5 & $\begin{array}{l}0.11 \\
0.03 \\
0.09\end{array}$ & 0.03 & $\begin{array}{l}1.0 \\
0.3 \\
0.8\end{array}$ & $\begin{array}{l}--- \\
0.4 \\
---\end{array}$ \\
\hline 83 & 1191 & $\begin{array}{l}490 \pm 20 \\
470 \pm 20 \\
460 \pm 20\end{array}$ & 5.0 & $\begin{array}{l}0.30 \\
0.33 \\
0.44\end{array}$ & $\begin{array}{l}--- \\
--- \\
---\end{array}$ & $\begin{array}{l}2.8 \\
3.1 \\
4.1\end{array}$ & $\begin{array}{l}--- \\
--- \\
---\end{array}$ \\
\hline 83 & 1191 & $\begin{array}{c}510 \pm 100 \\
>510 \pm 100 \\
>510 \pm 100\end{array}$ & 5.0 & $\begin{array}{l}0.11 \\
0.03 \\
0.09\end{array}$ & $\begin{array}{l}0.10 \\
0.04 \\
0.07\end{array}$ & $\begin{array}{l}1.0 \\
0.3 \\
0.8\end{array}$ & $\begin{array}{l}0.9 \\
0.4 \\
0.7\end{array}$ \\
\hline 93 & 1193 & $\begin{array}{l}470 \pm 20 \\
470 \pm 20 \\
490 \pm 20\end{array}$ & 5.5 & $\begin{array}{l}0.33 \\
0.21 \\
0.09\end{array}$ & $\begin{array}{l}--- \\
--- \\
---\end{array}$ & $\begin{array}{l}3.1 \\
2.0 \\
0.8\end{array}$ & $\begin{array}{l}--- \\
--- \\
---\end{array}$ \\
\hline
\end{tabular}

${ }^{\mathrm{a}}$ From beginning of ramp at $300^{\circ} \mathrm{C}$ to end of hold time at $\approx 1200^{\circ} \mathrm{C}$.

${ }^{\mathrm{b}}$ Total CP-ECR values, including cooling phase, are $4.7 \%, 5.2 \%$ and $5.7 \%$, respectively.

The test results show that slow cooling gives a small enhancement in ductility that increases the ductile-to-brittle transition CP-ECR for a given hydrogen content. At 7.7\% total transient CP-ECR, the hydrogen content needed to embrittle the cladding appears to increase from $\approx 370 \mathrm{wppm}$ to $\approx 550 \mathrm{wppm}$.

\subsection{Discussion on cooling rate and quench temperature effects}

Results similar to those in Table 52 were generated by CEA in collaboration with AREVA and EdF. Preliminary results were presented by Mardon [28] in July 2005, and additional results were presented by V. Maillot et al. [29] in June 2006. The tests were performed by CEA with prehydrided (600 wppm) $17 \times 17$ Zry-4 samples oxidized to $\approx 6.2 \%$ ECR based on the measured weight gain (i.e., measured ECR). A comparison between ANL and CEA test samples, test conditions, and results is given in Table 54. If the cladding materials and test conditions were the same, one would expect the ANL samples to be more ductile because of the lower hydrogen content. However, the cooling rate prior to quench appears to have a dominant effect on the post-quench ductility for samples quenched at 600$700^{\circ} \mathrm{C}$. The cooling time from $1200^{\circ} \mathrm{C}$ to $800^{\circ} \mathrm{C}$ is much longer $(\approx 1000 \mathrm{~s})$ for the CEA tests as compared to the ANL tests (38 s). However, both ANL and CEA data sets indicate the same results for Zry-4 samples quenched at $800^{\circ} \mathrm{C}$ : the samples were brittle. 


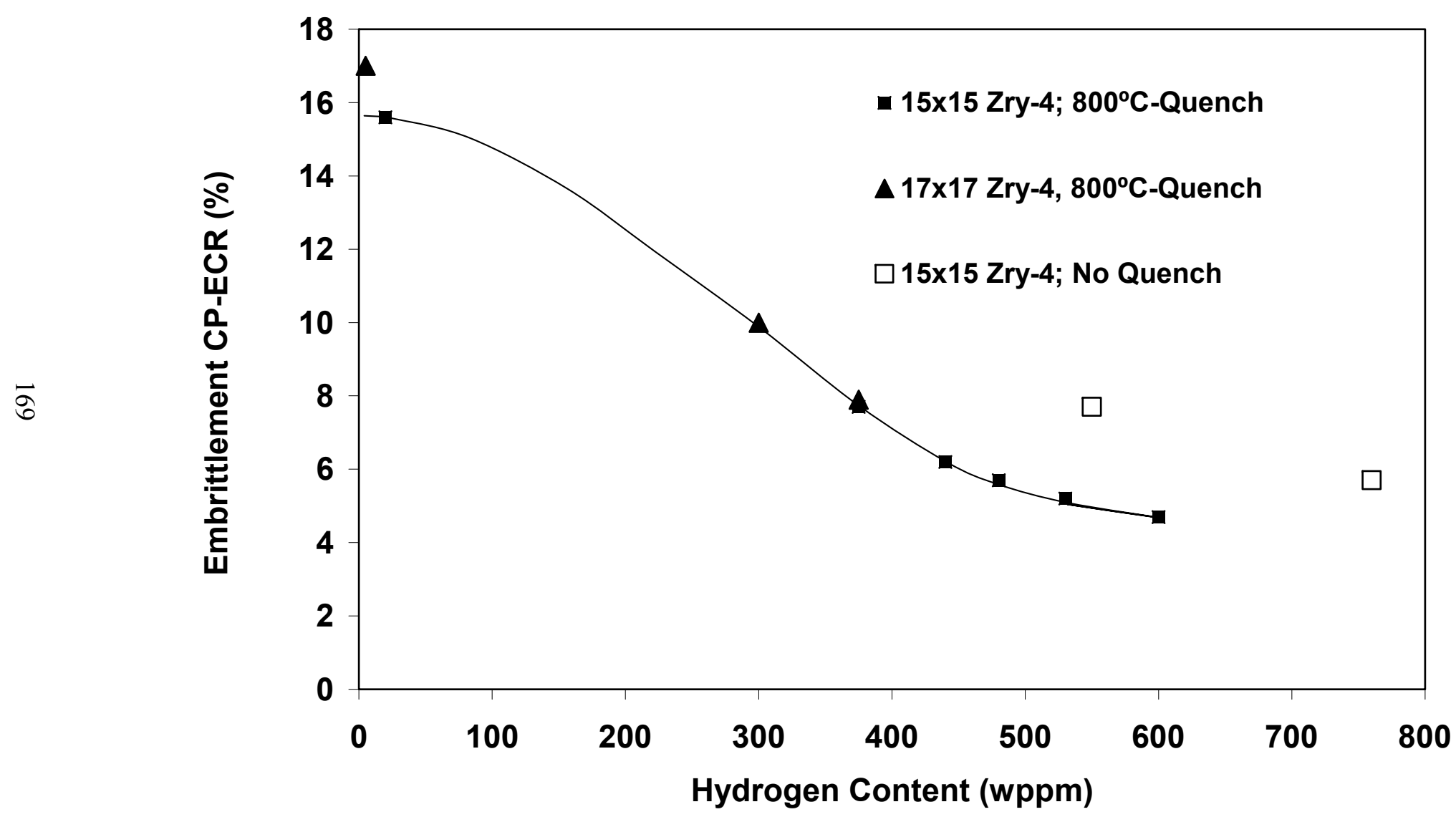

Figure 120. Embrittlement oxidation level (CP-ECR) vs. hydrogen content for $17 \times 17$ Zry- 4 and $15 \times 15$ HBR-type Zry- 4 oxidized at $\leq 1200^{\circ} \mathrm{C}$, cooled at $11-13^{\circ} \mathrm{C} / \mathrm{s}$ to $800^{\circ} \mathrm{C}$ and quenched. Results for samples with large circumferential distributions in hydrogen content ( \pm 100 wppm) are not included in this figure because the limited database for these materials was insufficient to determine embrittlement CP-ECR. 
Table 54. Comparison between ANL and CEA Test Samples, Test Conditions, and Results for Postquench Ductility of Prehydrided Zry-4 as a Function of Quench Temperature

\begin{tabular}{|c|c|c|c|}
\hline Parameter & ANL & CEA & Comment \\
\hline Cladding Test Samples & $\begin{array}{c}15 \times 15 \text { Zry-4 (low-tin) } \\
0.77-\mathrm{mm} \text { wall } \\
\approx 0.3-\mu \mathrm{m} \text { roughness } \\
1370 \text { wppm O } \\
460 \pm 10 \text { wppm H }\end{array}$ & $\begin{array}{c}17 \times 17 \mathrm{Zry}-4 \text { (low-tin) } \\
0.57-\mathrm{mm} \text { wall } \\
\approx 0.3-\mu \mathrm{m} \text { roughness } \\
\approx 1200 \text { wppm O } \\
600 \text { wppm H }\end{array}$ & \\
\hline Oxidation Test & Two-sided & One-sided (OD) & \\
\hline $\begin{array}{c}\text { Oxidation Time at } \\
1200^{\circ} \mathrm{C}, \mathrm{s}\end{array}$ & 17 & 50 & \\
\hline $\begin{array}{l}\text { Oxidation Time at } \\
\geq 1180^{\circ} \mathrm{C}, \mathrm{s}\end{array}$ & 86 & 90 & $\begin{array}{l}\text { Includes heating and } \\
\text { cooling ramps }\end{array}$ \\
\hline $\begin{array}{c}\text { Cooling Times, } \mathrm{s} \\
1200 \rightarrow 800^{\circ} \mathrm{C} \\
800 \rightarrow 600^{\circ} \mathrm{C} \\
600 \rightarrow 150^{\circ} \mathrm{C}\end{array}$ & 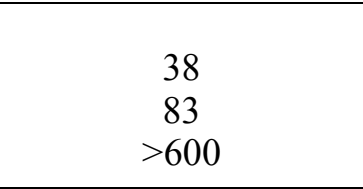 & $\begin{array}{l}1000 \\
1180 \\
9000\end{array}$ & $\begin{array}{c}\text { CEA values estimated } \\
\text { from average cooling } \\
\text { rates }\end{array}$ \\
\hline $\begin{array}{l}\text { Post-quench Ductility } \\
\text { Offset Strain, \% } \\
\text { (Permanent Strain, \%) }\end{array}$ & & & \\
\hline $800^{\circ} \mathrm{C}$ Quench & $\begin{array}{l}0.8 \\
(0.7)\end{array}$ & $\begin{array}{c}1.0 \pm 0.2 \\
(---)\end{array}$ & Brittle \\
\hline $700^{\circ} \mathrm{C}$ Quench & $\begin{array}{l}0.8 \pm 0.15 \\
\quad(0.5)\end{array}$ & $\begin{array}{c}10.4 \pm 0.9 \\
(---)\end{array}$ & $\begin{array}{l}\text { ANL Brittle } \\
\text { CEA Ductile }\end{array}$ \\
\hline $600^{\circ} \mathrm{C}$ Quench & $\begin{array}{c}1.0 \pm 0.2 \\
(0.6 \pm 0.1)\end{array}$ & $\begin{array}{c}13 \\
(--)\end{array}$ & $\begin{array}{l}\text { ANL Brittle } \\
\text { CEA Ductile }\end{array}$ \\
\hline No Quench & $\begin{array}{c}3.5 \pm 1.4 \\
(2.7 \pm 1.0)\end{array}$ & $\begin{array}{c}6.6 \pm 2.4 \\
(---)\end{array}$ & $\begin{array}{l}\text { Results remarkably } \\
\text { close (ductile) }\end{array}$ \\
\hline
\end{tabular}

The $38 \mathrm{~s}$ cooling time for the ANL tests is long enough for oxygen redistribution during the partial phase change from beta-to-(alpha + beta) in this temperature range. Based on the work of Brachet et al. [30], the beta-to-alpha phase transformation is expected to be $\approx 50 \%$ complete at $800^{\circ} \mathrm{C}$ for Zry- 4 with asfabricated levels of oxygen and with 300-600 wppm hydrogen. The ANL and CEA post-oxidation ductility data are also consistent for samples that were slow cooled from $1200^{\circ} \mathrm{C}$ to RT, even though the total cooling time from $1200^{\circ} \mathrm{C}$ to $150^{\circ} \mathrm{C}$ was much greater for the CEA samples. Both cooling scenarios appear to give hydrogen enough time to come out of solution and precipitate as fine hydrides outside the low-oxygen-content prior-beta material responsible for ductility.

The primary differences between the two sets of results are for quench temperatures of $700^{\circ} \mathrm{C}$ and $600^{\circ} \mathrm{C}$. The ANL results show no enhancement in post-quench ductility for quench at these temperatures for a cooling times of $33 \mathrm{~s}\left(800 \rightarrow 700^{\circ} \mathrm{C}\right)+50 \mathrm{~s}\left(700 \rightarrow 600^{\circ} \mathrm{C}\right)=83 \mathrm{~s}$, as compared to $\approx 1200 \mathrm{~s}$ for the CEA samples. Although the exponential-decay cooling curves for the ANL and CEA tests have the 
opposite curvature as compared to LOCA transients, the ANL cooling times appear to be more LOCA relevant. For the ANL cooling times, ductility is not increased by lowering the quench temperature from $800^{\circ} \mathrm{C}$ to $600^{\circ} \mathrm{C}$. The ductility enhancement observed for samples cooled with no quench implies that time-dependent phenomena (e.g., hydrogen diffusion and precipitation) do indeed occur for long cooling times below $600^{\circ} \mathrm{C}$. This enhancement is important in data interpretation for the ANL and CEA test results, but more data would be needed to establish the magnitude of this ductility enhancement for LOCA-relevant cooling rates and quench temperatures.

Vendor-predicted wetting (i.e., film boiling) temperatures - temperatures at which rapid cooling occur - are in the range of $400-800^{\circ} \mathrm{C}$. It is also possible that some small-break LOCAs are terminated without quench. Possible enhancement of ductility for quench temperatures in the range of $400-600^{\circ} \mathrm{C}$ could be investigated with LOCA-relevant cooling rates prior to quench.

\subsection{Summary of post-quench ductility results for prehydrided Zry-4}

Hydrogen has a significant effect on reducing post-quench ductility. As-received HBR-type $15 \times 15$ Zry-4 oxidized to $7.5 \% \mathrm{CP}$-ECR has a very high post-quench ductility following oxidation at $\approx 1200^{\circ} \mathrm{C}$ and quench at $800^{\circ} \mathrm{C}$, while the same material prehydrided to 600 -wppm hydrogen has essentially no post-quench ductility. In addition to performing ring compression tests at $135^{\circ} \mathrm{C}$, as-received and prehydrided samples were characterized and compared following oxidation and quench. The RT microhardness profile in the prior-beta phase was significantly higher for the prehydrided Zry-4 sample. These ANL results are consistent with the results presented by Mardon et al. [21], demonstrating that hydrogen increases the hardness and oxygen-solubility limit in the beta phase of Zry- 4 . This effect also results in higher oxygen concentration gradients and higher diffusion rates of oxygen into the beta layer.

Although the embrittlement CP-ECR of as-fabricated alloys oxidized at $1200^{\circ} \mathrm{C}$ was relatively insensitive to quench at $800^{\circ} \mathrm{C}$ vs. slow cooling to RT, the same was not true for prehydrided Zry- 4 . Slow cooling to RT resulted in a small, but significant, increase in ductility $(\approx 3 \%)$ compared with quenching. Further, based on two series of tests conducted with prehydrided Zry-4, lowering the quench temperature from $800^{\circ} \mathrm{C}$ to $700^{\circ} \mathrm{C}$ to $600^{\circ} \mathrm{C}$ had no further effect on post-quench ductility for hydrogen contents of 340 wppm and $450 \mathrm{wppm}$ and oxidation levels of $7.5 \%$ and $6.0 \%$, respectively. All quenched samples were brittle under these conditions, while the samples that were slow cooled from $1200^{\circ} \mathrm{C}$ to RT retained a small level of ductility. These results indicate that the ductility enhancement arises from slow cooling at $<<2^{\circ} \mathrm{C} / \mathrm{s}$ from $600^{\circ} \mathrm{C}$ to RT. During this interval, hydrogen would have time to diffuse short distances out of the matrix of prior-beta grains and precipitate as fine hydrides. If this were the case, then the results suggest a small intrinsic hydrogen embrittlement for hydrogen dissolved in the prior-beta matrix in addition to the indirect effects just mentioned.

It was also observed that the post-test ductility of prehydrided Zry-4 oxidized and quenched at $800^{\circ} \mathrm{C}$ was highly sensitive to heating rate, short-time temperature overshoot (above $1200^{\circ} \mathrm{C}$ ) at the end of the temperature ramp, average hydrogen content, and circumferential variation in hydrogen content. The ductility of similar samples that were slow cooled was not as sensitive to these parameters. For oxidation levels of $5.0 \%$ and $7.5 \%$ CP-ECR, slow-cooled Zry-4 samples remained ductile at average hydrogen contents $\approx 150 \mathrm{wppm}$ higher than the embrittlement hydrogen levels for samples quenched at $800^{\circ} \mathrm{C}$. In other limited testing with modern $17 \times 17$ Zry-4, the higher transition CP-ECR in the as-fabricated condition, compared to HBR-type $15 \times 15$ Zry-4, was not maintained for prehydrided samples. 
This page is intentionally left blank. 


\section{$5 \quad$ Results for High-Burnup Zry-4, ZIRLO, and M5}

Two-sided oxidation tests were conducted at $\leq 1200^{\circ} \mathrm{C}$ with Zry-4, ZIRLO, and M5 cladding samples sectioned from high-burnup fuel rods to determine the ductile-to-brittle transition oxidation level (CP-ECR) as a function of hydrogen content. Because of the limited number of these difficult tests that could be conducted, the goal in test planning was to select oxidation levels such that the transition CPECR could be determined to within $1 \%$ for samples cooled with or without quench at $800^{\circ} \mathrm{C}$. Three-tofive LOCA oxidation tests were conducted without quench to determine ductility vs. oxidation level. For each oxidation sample, two or three rings were sectioned for ring compression testing at $135^{\circ} \mathrm{C}$. Based on the behavior of prehydrided Zry-4, it was assumed that the ductility of high-burnup Zry-4 cooled without quench would be an upper bound to the ductility of samples cooled with quench at $800^{\circ} \mathrm{C}$. Although no data were generated in this program for prehydrided ZIRLO and M5, it was also assumed that highburnup ZIRLO and M5 would show the same qualitative sensitivity to quench. The data for high-burnup cladding samples cooled without quench were sufficient to determine the transition oxidation level under these conditions, as well as to guide in the selection of oxidation levels for samples cooled with quench.

Although the primary goal of such testing was the determination of oxidation embrittlement level as a function of hydrogen content, a secondary purpose was to determine the growth of oxide, alpha, and beta layers as a function of oxidation level and test time for high-burnup cladding. Extensive post-test metallography and scanning electron microscopy (SEM) were performed using post-test high-burnup Zry4 samples. Also, in order to determine such evolution for Zry-4 samples oxidized for longer periods of time at $1200^{\circ} \mathrm{C}$, one-sided oxidation tests were conducted with high-burnup Zry-4 samples exposed to steam on the cladding outer surface.

High-burnup Zry-4, ZIRLO, and M5 samples were obtained from fuel rods irradiated in the H. B. Robinson (HBR), North Anna (NA), and Ringhals reactors, respectively. HBR sectioning and defueling were performed by ANL in the AGHCF. Sectioning and defueling of the NA ZIRLO and Ringhals M5 cladding were performed by Studsvik. Fuel and cladding characterization data for HBR Zry-4 samples are presented in Section 5.1.1. ZIRLO and M5 cladding characterization data are presented in Sections 5.2.1 and 5.3.1, respectively. For two-sided oxidation tests, test conditions, ductility data, and embrittlement-threshold determination are presented for high-burnup Zry-4, ZIRLO, and M5 in Sections 5.1.2, 5.2.3, and 5.3.3, respectively.

\subsection{Results for high-burnup H. B. Robinson 15×15 Zry-4}

\subsubsection{Characterization of high-burnup H. B. Robinson $15 \times 15$ Zry-4}

Seven high-burnup HBR rods (64-67 GWd/MTU) were received by ANL in May 2001 for LOCArelevant testing. Ruzauskas and Fardell [31] and Van Swam et al. [32] give a detailed description of the as-fabricated cladding, the irradiation history, the nondestructive testing results (eddy current, profilometry, fission-gas release, etc.), and the fuel isotopic content for these rods. EPRI, in cooperation with Framatome ANP Richland (now AREVA ANP), arranged for the shipment of the rods from the Robinson plant to GE Vallecitos Nuclear Center (VNC) to ANL. The seven rods, along with five other HBR rods, were sectioned into $\approx 0.9$-m $(\approx 35$-in.) lengths by GE-VNC and shipped to ANL in DOE-owned T-2 casks.

Characterization was performed on HBR rod A02 (67 GWd/MTU) as part of the NRC spentnuclear-fuel program [33]. This rod was irradiated in an edge-next-to-corner position within the assembly. HBR rod R01 (67 GWd/MTU), also an edge-next-to-corner rod, was characterized for a spent- 
nuclear fuel program conducted by Sandia National Laboratories and sponsored by DOE, NRC, and international partners. Fuel ceramography, cladding metallography, and hydrogen concentration measurements for A02 and R01 indicated circumferential temperature variation in the fuel and cladding. The circumferential variation in hydrogen content at $0.5-0.9 \mathrm{~m}$ above the core midplane was $\pm 100 \mathrm{wppm}$ based on four quadrant measurements. Metallography of cladding cross sections showed local regions of very dense hydrides across the cladding wall. At most circumferential locations, dense hydride rims near the cladding outer surface were observed. The effective thickness of these rims varied circumferentially. The variation in hydride morphology and distribution is consistent with the LECO hydrogen-content results. Such variation may have a significant impact on the embrittlement threshold at a measured average hydrogen-content level. Experience with prehydrided Zry-4 (see Figure 105) indicated that hydrogen did not homogenize in the circumferential direction during oxidation at $1200^{\circ} \mathrm{C}$ for test times long enough to embrittle prehydrided Zry-4.

Interior rods F07 and G10 were selected for two-sided and one-sided oxidation tests, respectively. These rods were neither near assembly edges nor next to guide tubes. The expectation was that cladding sectioned from these rods would have more uniform hydrogen concentration and hydride morphology. Based on data for rods A02 and R01, cladding at the fuel midplane was expected to have a corrosion layer thickness of $\approx 70 \mu \mathrm{m}$ and a hydrogen content of $\approx 550 \mathrm{wppm}$. Results for prehydrided Zry-4 (see Figures 110 and 111) indicated that embrittlement would occur for samples with $>600$-wppm hydrogen oxidized at $1200^{\circ} \mathrm{C}$ to $5 \% \mathrm{CP}$-ECR. These were important factors in the decision to section oxidation samples primarily from near the core midplane.

The fuel midplane is located near the top of grid span \#3 and close to one end of the middle fuelrod segment. It is labeled in the gamma scanning profile for the middle segments of rods F07 (Figure 121) and G10 (Figure 122); the locations of grid spacer \#4 and grid span \#4 are also labeled. The gamma-scan results were used to select samples from uniform burnup regions along the fuel segments.

Figure 123 shows the sectioning diagram for characterization samples and test samples for twosided oxidation tests. Figure 124 shows a similar sectioning diagram used for the one-sided oxidation characterization and test samples. Characterization results for rods F07 and G10, along with those for rods A02 and R01, are summarized in Table 55. For short (1.5-mm-long) F07 cladding samples, the circumferential variation in hydrogen content was in the range of \pm 70 to $\pm 90 \mathrm{wppm}$ (standard deviation of four data points per location). Taking the average of the eight sets of hydrogen readings, the cladding hydrogen content is $550 \pm 100 \mathrm{wppm}$ for oxidation test samples sectioned from a span of $140 \mathrm{~mm}$ near the fuel midplane. This hydrogen level is consistent with the hydrogen measurement for the G10 near-

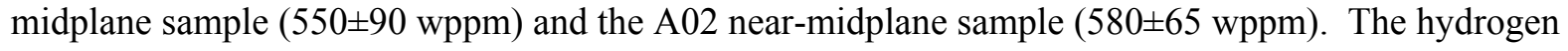
concentrations are referenced to the weight of the corroded cladding. If all the hydrogen were in the cladding metal, the metal would contain slightly higher hydrogen concentration. However, this correction was not made because of the uncertainties in the amount of corrosion layer lost during the cutting and snipping used to prepare samples for LECO hydrogen determination.

The F07 hydrogen measurement ( $545 \pm 90 \mathrm{wppm}$ ) taken at $320 \mathrm{~mm}$ above the fuel midplane is consistent with the R01 measurement $(550 \pm 80 \mathrm{wppm})$ taken at $360 \mathrm{~mm}$. The F07 measurement $(800 \pm 110$ wppm after high-temperature oxidation) taken at $650 \mathrm{~mm}$ above the fuel midplane is higher than A02 and R01 values with comparable corrosion-layer-thickness values. Based on the corrosion layer thickness (95 $\mu \mathrm{m})$ for the F07 sample, a hydrogen content of 730-750 wppm was expected. However, when corrected for sample weight loss due to spallation of the corrosion layer during the oxidation test, the hydrogen content would be reduced from $800 \mathrm{wppm}$ to $\approx 715 \mathrm{wppm}$. Given the uncertainty in this measurement, a hydrogen content of $740 \pm 110$ wppm was chosen on the basis of scaling the A02 and R01 results. 


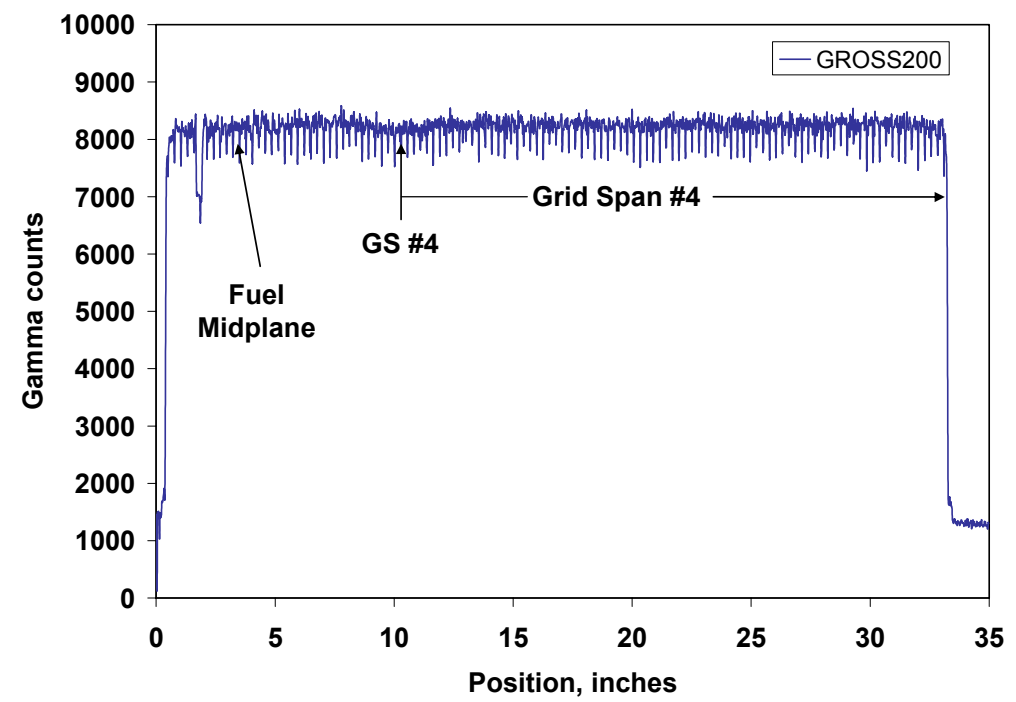

Figure 121. Gamma scan profile for segment $607 \mathrm{C}$ of HBR rod F07, from which samples were sectioned for hydrogen-content analysis, oxygen-content analysis, metallography, and two-sided oxidation tests.

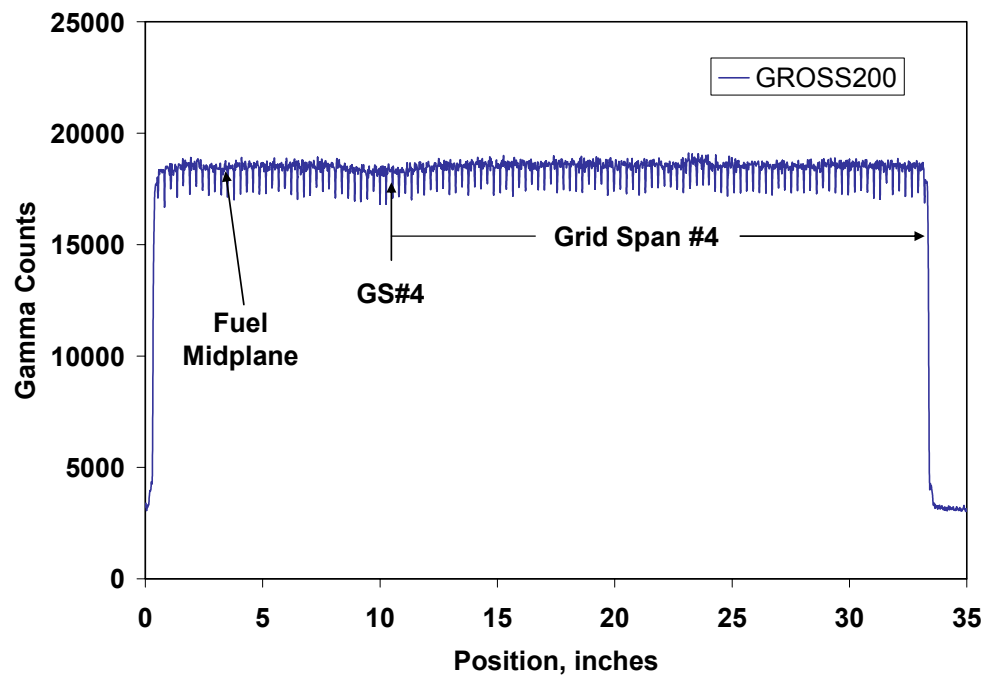

Figure 122. Gamma scan profile for segment $608 \mathrm{C}$ of HBR rod G10, from which samples were sectioned for hydrogen- content analysis, oxygen-content analysis, metallography, and one-sided oxidation tests. 

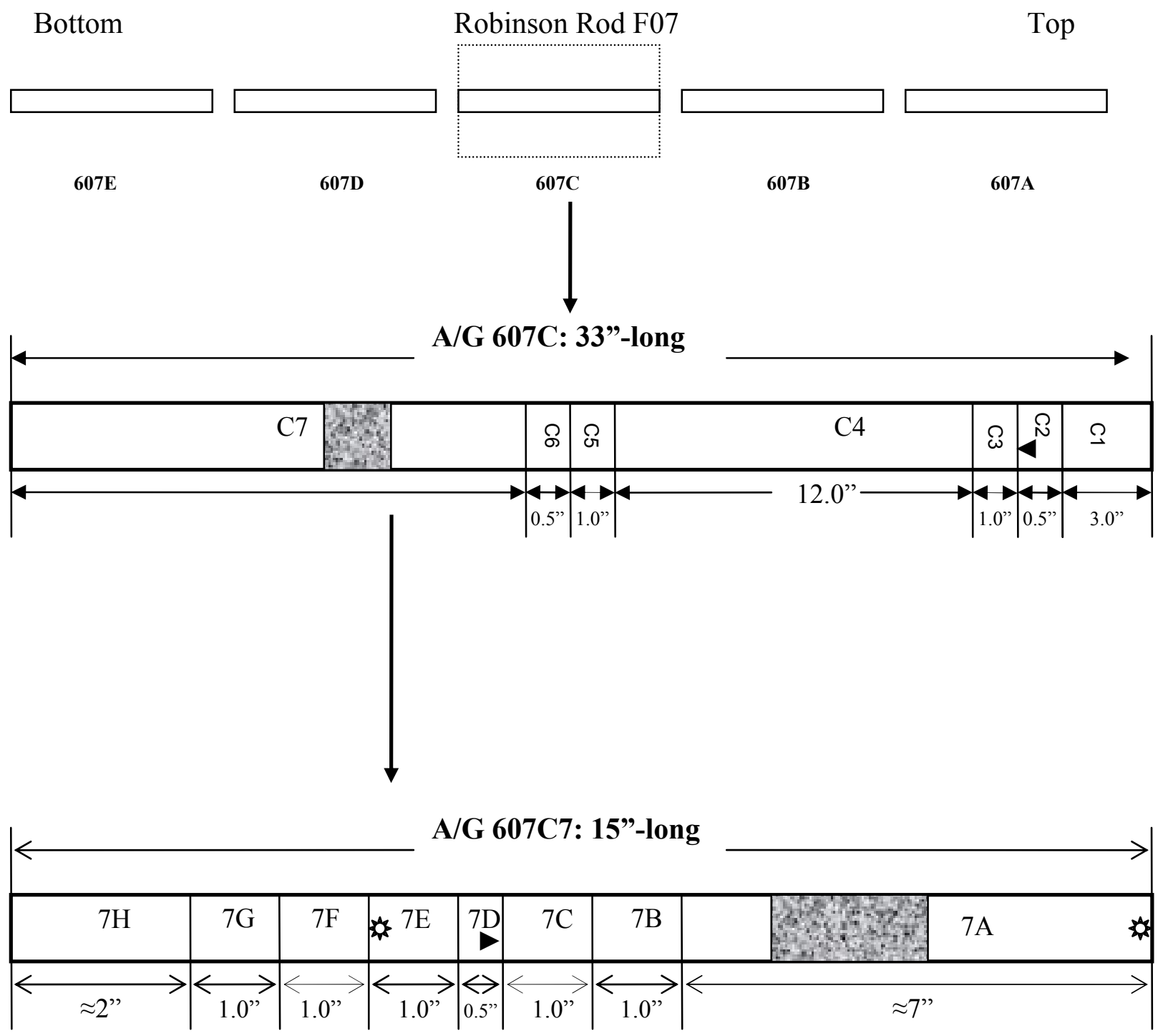

Grid Spacer

Figure 123. Sectioning diagram for characterization samples and two-sided-oxidation test samples. Eight 1.5-mm-long hydrogen-content samples were cut from $7 \mathrm{H}$. A 13-mm-long sample (7D) was prepared for metallography, a 25-mm-long sample was cut for hydrogen and oxygen analyses (7E), and four 25-mmlong samples ( $7 \mathrm{~B}, 7 \mathrm{C}, 7 \mathrm{~F}$, and $7 \mathrm{G}$ ) were sectioned from near the core midplane for oxidation tests. $\mathrm{C} 2$ and $\mathrm{C} 6$ were used as metallography samples, and C 3 and $\mathrm{C} 5$ were used as oxidation test samples. 

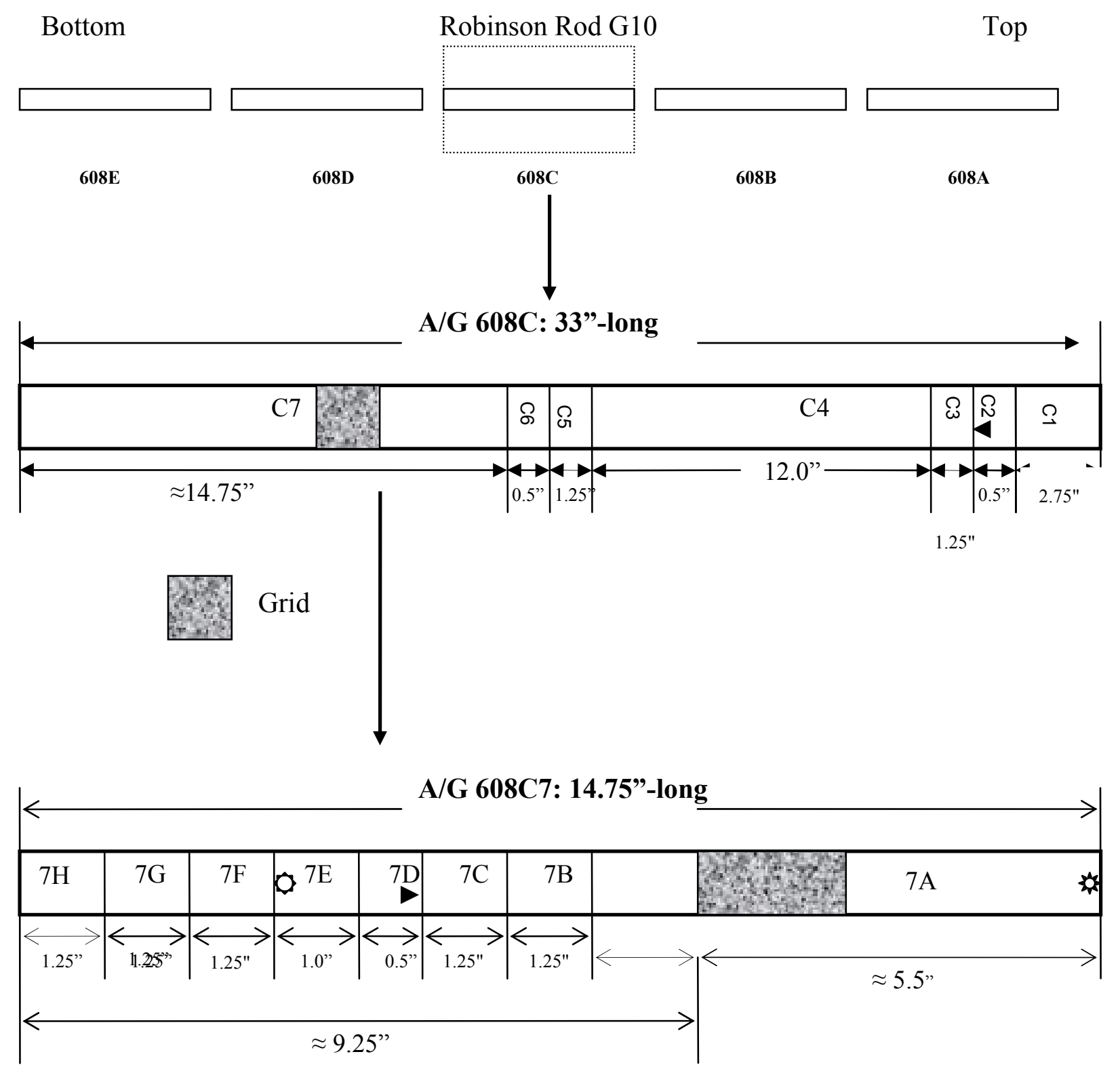

Grid Spacer 4

Figure 124. Sectioning diagram for characterization samples and one-sided-oxidation test samples. Sample 7E was used for hydrogen and oxygen analysis. Sample 7D was used for metallographic analysis. Four 32-mm-long samples (7B, 7C, 7F, and 7G) were sectioned from near the core midplane for oxidation tests. 
Table 55. Corrosion Layer Thickness and Hydrogen Content Results for H. B. Robinson Rods F07 and G10 and for Rods A02 and R01. Axial locations are relative to the midplane of the 3658-mmlong fuel column.

\begin{tabular}{|c|c|c|c|c|}
\hline $\begin{array}{c}\text { Axial Location } \\
\text { Relative to } \\
\text { Fuel Midplane. } \\
\text { mm }\end{array}$ & $\begin{array}{c}\text { Rod F07 } \\
\text { H Content } \\
\text { (Corrosion Layer) }\end{array}$ & $\begin{array}{c}\text { Rod G10 } \\
\text { H Content } \\
\text { (Corrosion Layer) }\end{array}$ & $\begin{array}{c}\text { Rod A02 } \\
\text { H Content } \\
\text { (Corrosion Layer) }\end{array}$ & $\begin{array}{c}\text { Rod R01 } \\
\text { H Content } \\
\text { (Corrosion Layer) }\end{array}$ \\
\hline-920 & & $\begin{array}{l}\approx 360 \mathrm{wppm}^{\mathrm{a}} \\
\left(\approx 40 \mu \mathrm{m}^{\mathrm{a}}\right)\end{array}$ & & \\
\hline-580 & & $\begin{array}{c}\approx 400 \mathrm{wppm}^{\mathrm{a}} \\
(44 \pm 2 \mu \mathrm{m})\end{array}$ & & \\
\hline \pm 50 & $\begin{array}{c}545 \pm 85 \mathrm{wppm} \\
530 \pm 80 \mathrm{wppm} \\
530 \pm 90 \mathrm{wppm} \\
535 \pm 85 \mathrm{wppm} \\
555 \pm 85 \mathrm{wppm} \\
575 \pm 80 \mathrm{wppm} \\
535 \pm 80 \mathrm{wppm} \\
\underline{565 \pm 70 \mathrm{wppm}} \\
550 \pm 100 \mathrm{wppm} \\
(71 \pm 5 \mu \mathrm{m})\end{array}$ & $\begin{array}{c}550 \pm 90 \text { wppm } \\
(68 \pm 2 \mu \mathrm{m})\end{array}$ & $\begin{array}{c}580 \pm 65 \text { wppm } \\
(70 \mu \mathrm{m})\end{array}$ & \\
\hline+320 & $\begin{array}{l}545 \pm 80 \text { wppm } \\
\quad(74 \pm 5 \mu \mathrm{m})\end{array}$ & & & \\
\hline+360 & & & & $\begin{array}{l}550 \pm 180 \mathrm{wppm} \\
\quad(77 \mu \mathrm{m})\end{array}$ \\
\hline+510 & & & & $\begin{array}{c}650 \pm 150 \mathrm{wppm} \\
(89 \mu \mathrm{m})\end{array}$ \\
\hline+650 & $\begin{array}{c}740 \pm 110 \mathrm{wppm}^{\mathrm{a}} \\
(95 \pm 4 \mu \mathrm{m})\end{array}$ & & & \\
\hline 700 & & & $\begin{array}{l}\text { 750 } \pm 90 \text { wppm } \\
\quad(98 \mu \mathrm{m})\end{array}$ & \\
\hline 740 & & & & $\begin{array}{l}770 \pm 125 \mathrm{wppm} \\
\quad(98 \mu \mathrm{m})\end{array}$ \\
\hline
\end{tabular}

${ }^{\mathrm{a}}$ Estimated by interpolation/extrapolation and scaling. Hydrogen measurements following oxidation and ring-compression tests were higher for rod F07 at $+650 \mathrm{~mm}(800 \pm 110 \mathrm{wppm})$ due to weight loss from corrosion-layer spalling and higher for rod G10 at $-920 \mathrm{~mm}(550 \pm 70 \mathrm{wppm})$ and at $-580 \mathrm{~mm}(570 \pm 70$ wppm) due to inner-surface hydrogen pickup during one-sided oxidation tests. 
The corrosion layer thicknesses measured for rods F07 and G10 are in good agreement with those measured for rods A02 and R01 at the axial locations examined. For the F07 and G10 samples oxidized and slow cooled, the corrosion layer thickness is $\approx 70 \mu \mathrm{m}(68-74 \mu \mathrm{m})$. The two-sided oxidation sample that was quenched had a corrosion layer thickness of $95 \mu \mathrm{m}$.

Half of sample 7E in Figure 123 was sectioned for LECO oxygen determination. The measured oxygen concentration $(2.08 \pm 0.19 \mathrm{wt} . \%)$ is in good agreement with the $\approx 70$ - $\mu \mathrm{m}$ corrosion layer thickness if the Pilling-Bedworth ratio (1.75) recommended by Van Swam et al. [34] is used for the HBR corrosion layer. The 1.75 ratio is consistent with $\approx 10 \%$ porosity in the HBR corrosion layer.

Detailed characterization was performed for the midplane region of the F07 rod to determine the fuel, fuel-cladding bond, corrosion layer, and hydride morphology. Figure 125 shows a low magnification image of the fuel morphology. The central darkened region is not symmetric with respect to the center of the pellet. This result indicates asymmetric power distribution and fuel temperature, as well as circumferential variation in cladding temperature.

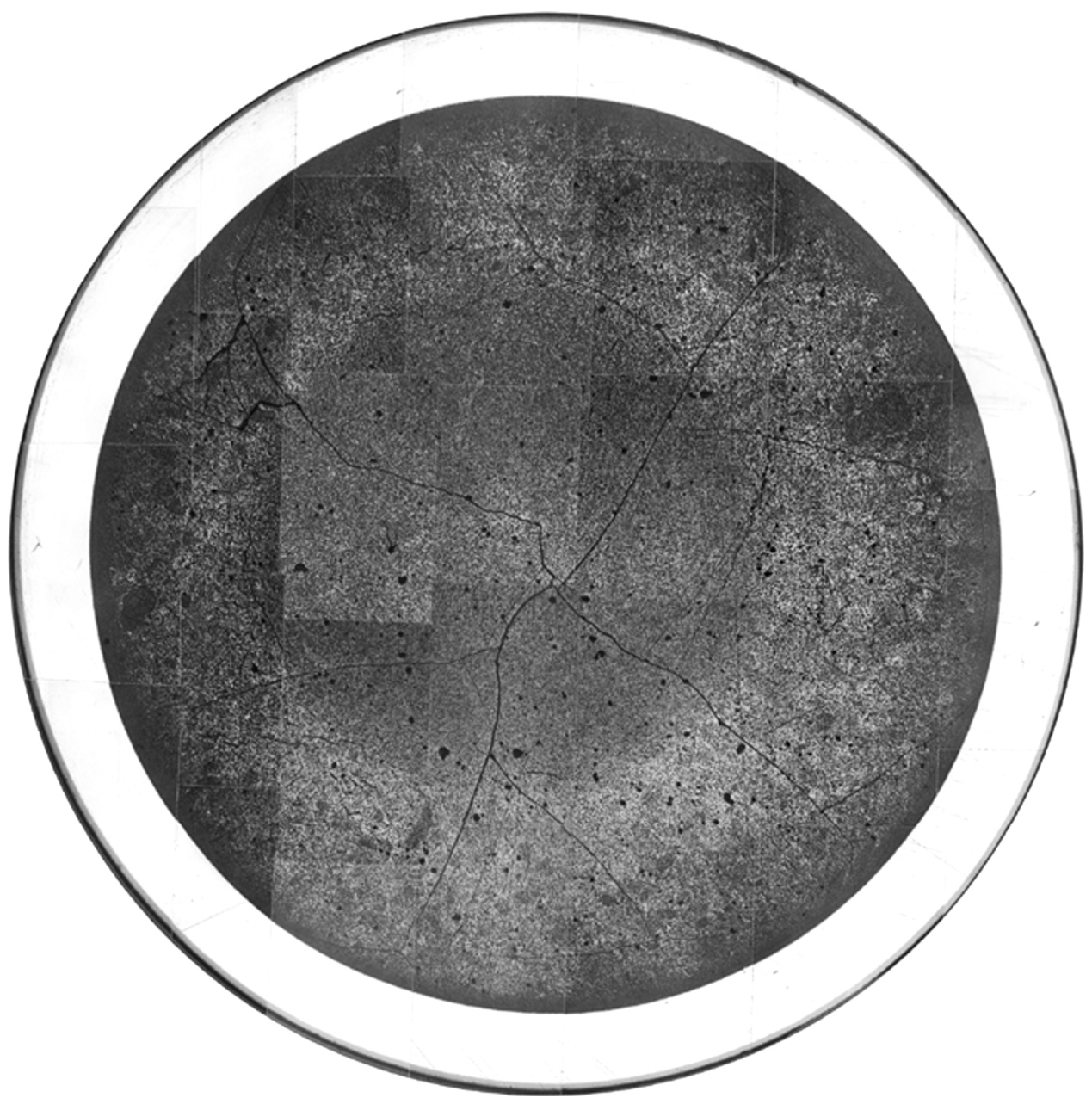

Figure 125. High-burnup HBR fuel morphology for the fuel midplane cross section of rod F07 showing indications of asymmetric power and temperature distributions relative to the center of the pellet. 
The fuel-cladding bond appears to be well developed at the F07 rod midplane. This finding is consistent with characterization results for the A02 and R01 HBR rods. Figure 126 shows the fuelcladding bond within one circumferential sector of the fuel shown in Figure 125. The bond thickness is $11 \pm 4 \mu \mathrm{m}$. A higher magnification image is shown in Figure 127 for the fuel-cladding bond in rod A02. This bond layer remains intact and adherent to the cladding inner-surface after nitric-acid defueling. Figure 128 shows the bond layer on the inner surface of high-burnup Limerick defueled cladding. It is an additional source of oxygen, beyond the oxygen from steam, during two-sided oxidation tests. For onesided (outer-surface) oxidation tests, it is the primary source of oxygen on the inner surface of defueled cladding. According to Une et al. [35], the bond layer is primarily $\mathrm{ZrO}_{2}$ with some $\mathrm{UO}_{2}$ in solid solution. Whether or not all of the $\mathrm{UO}_{2}$ in the bond remains following nitric-acid defueling is not clear.

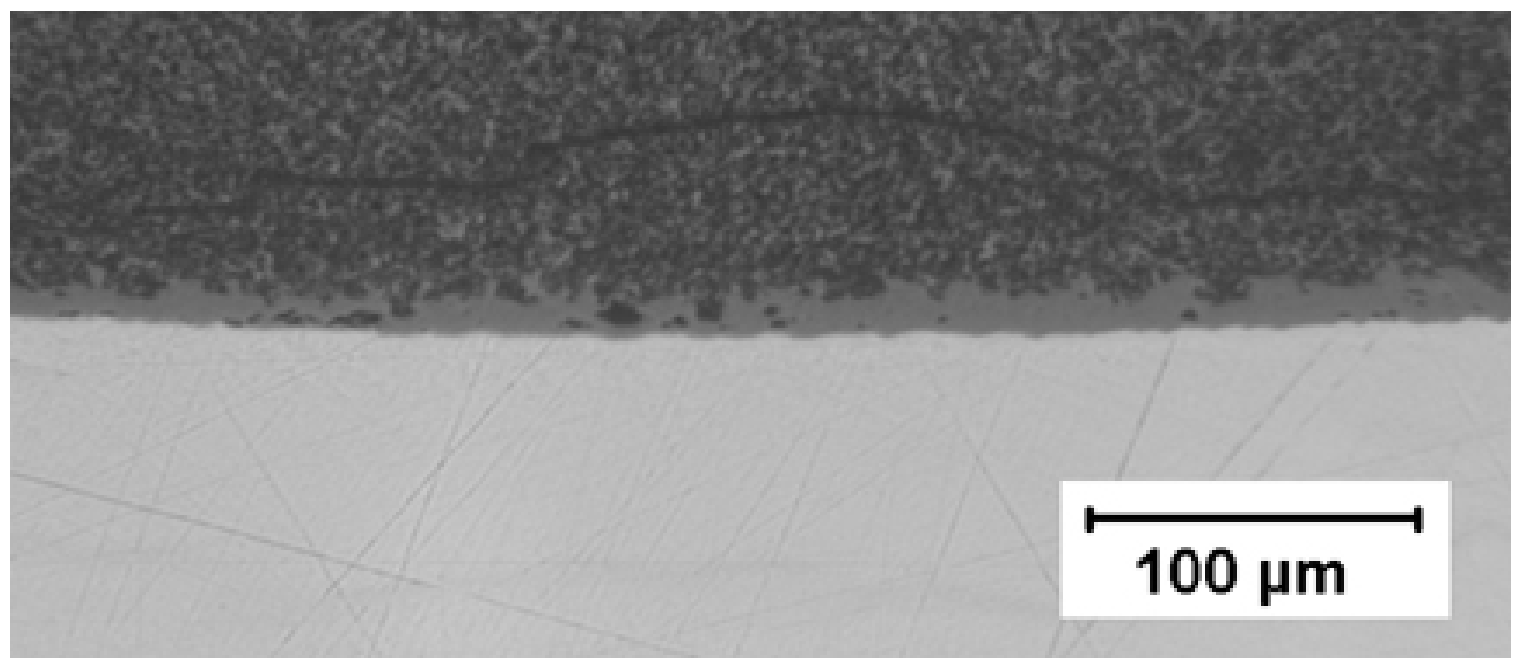

Figure 126. Fuel (dark), cladding (light), and fuel-cladding bond layer (gray) at the midplane of HBR rod F07. The image is a magnification of a small region from the fuel cross section shown in Figure 125.

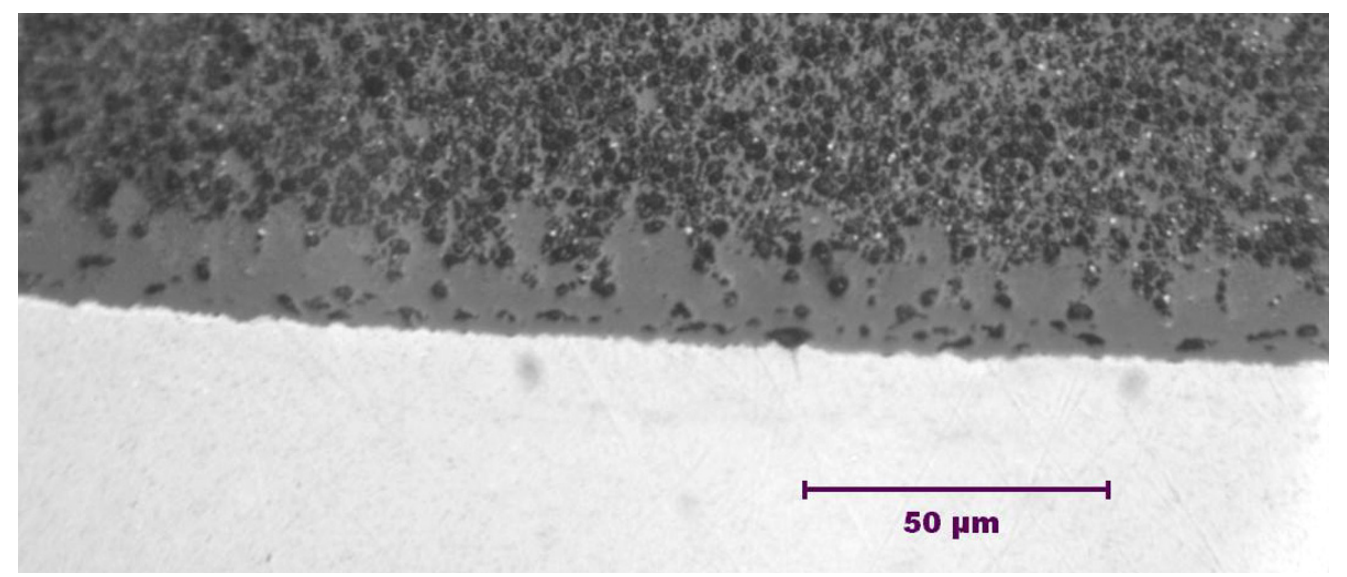

Figure 127. High-magnification image of fuel-cladding bond layer at the fuel midplane of HBR rod A02. 


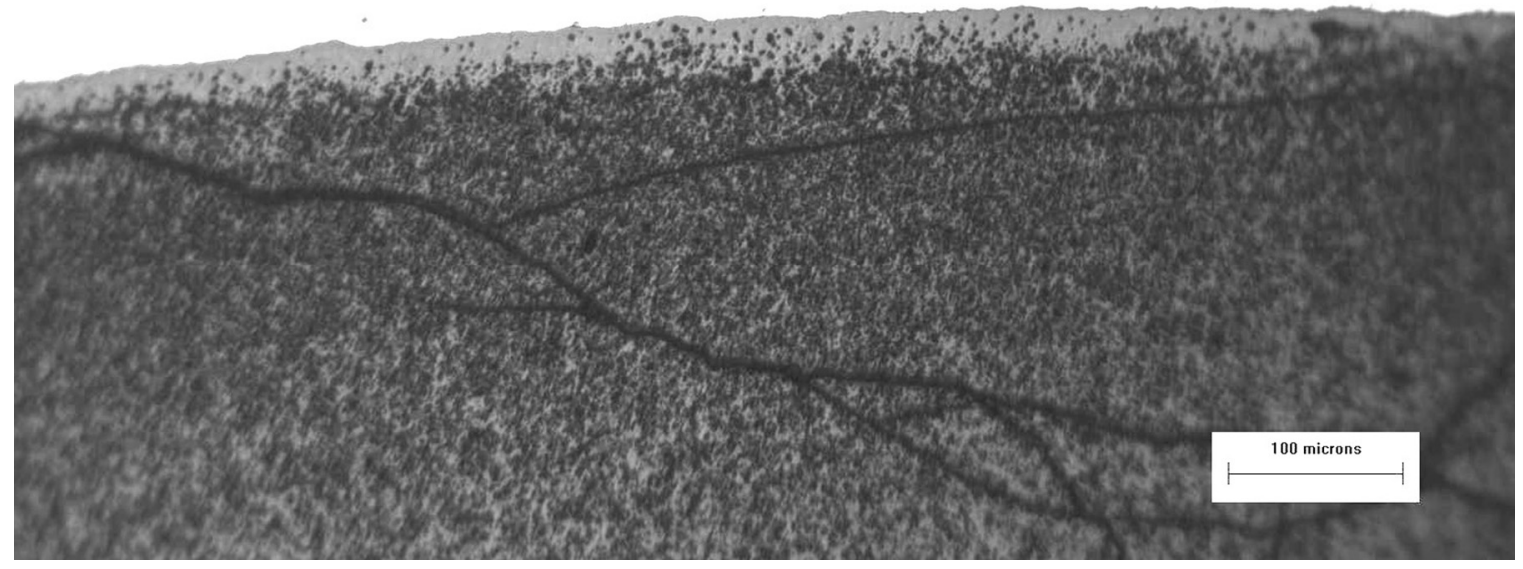

(a)

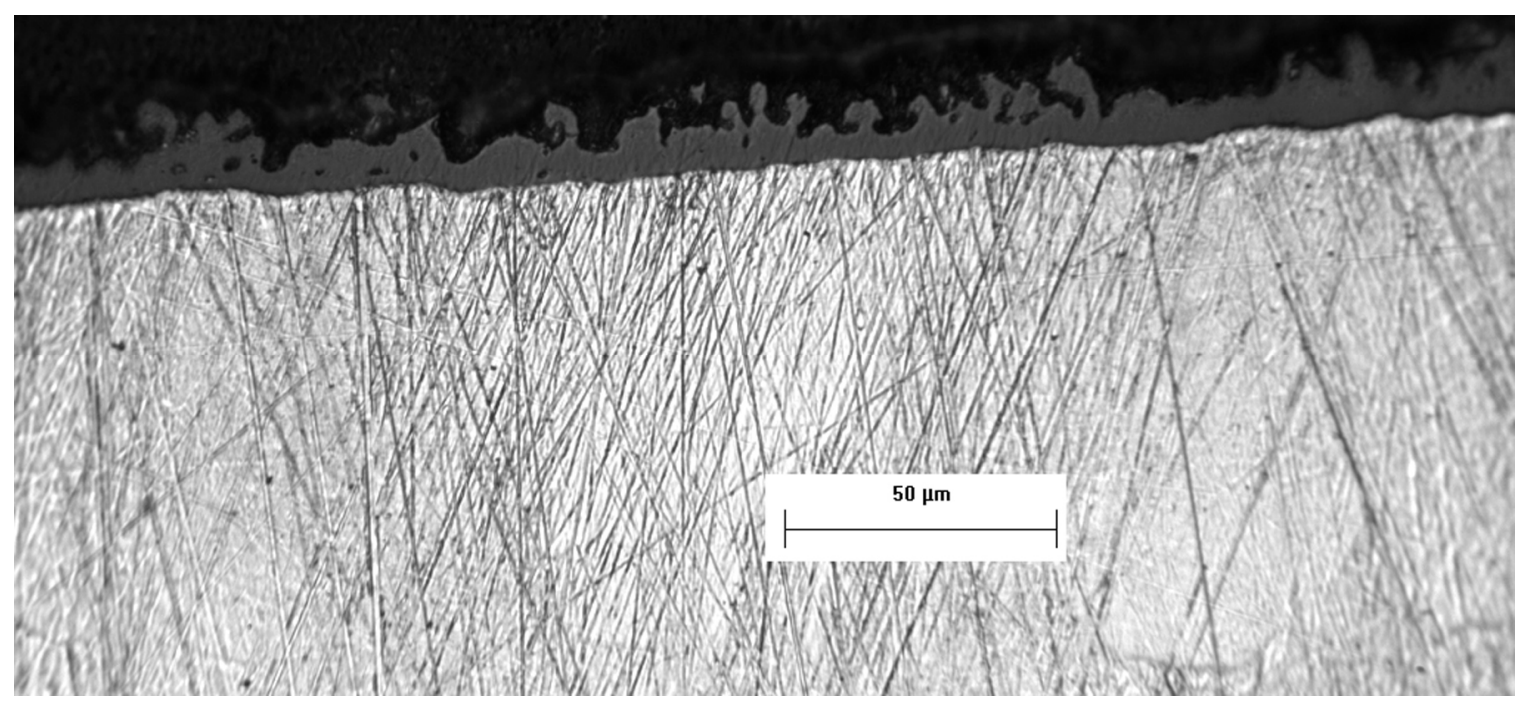

(b)

Figure 128. Images of high-burnup Limerick BWR fuel-cladding bond at fuel-midplane location: (a) prior to defueling in nitric acid and (b) after defueling in nitric acid.

High-magnification images were taken from three axial locations of HBR rod F07 to determine corrosion layer thickness, cladding metal thickness, and hydride distribution and morphology. At each axial location, eight circumferential regions were magnified to obtain the data. The corrosion layer thickness was measured to be $71 \pm 5 \mu \mathrm{m}$ at the midplane (in grid span \#3); $74 \pm 5 \mu \mathrm{m}$ at $320 \mathrm{~mm}$ above the midplane (in grid span \#4); and $95 \pm 4 \mu \mathrm{m}$ at $650 \mathrm{~mm}$ above the midplane (in grid span \#4). From the metallography, we determined that the average cladding wall thickness at the midplane was $0.712 \mathrm{~mm}$ for rod F07 and $0.720 \mathrm{~mm}$ for rod G10. These wall thicknesses were used in the determination of test times and CP-ECR values. Metallographic images of the corrosion layer at three relevant axial locations along rod F07 are shown in Figure 129. 


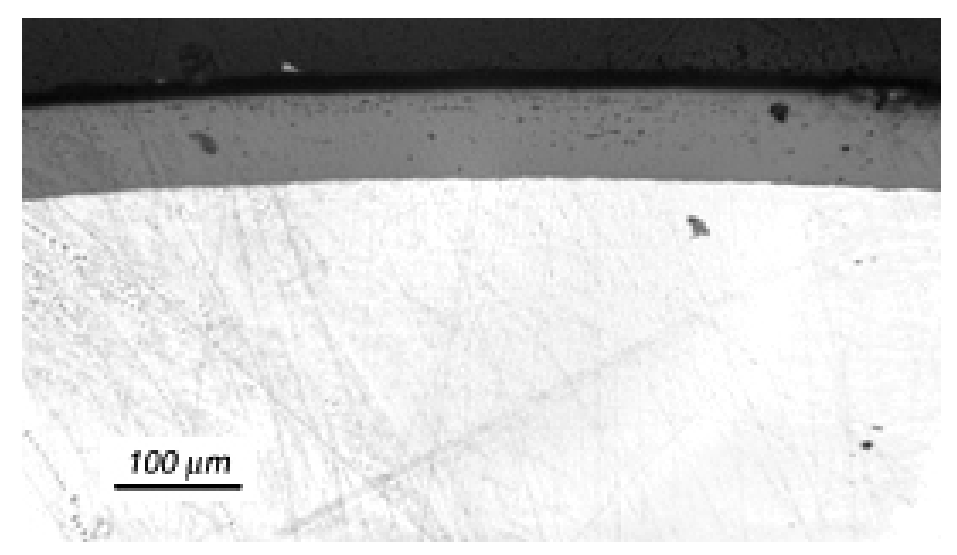

(a) Midplane

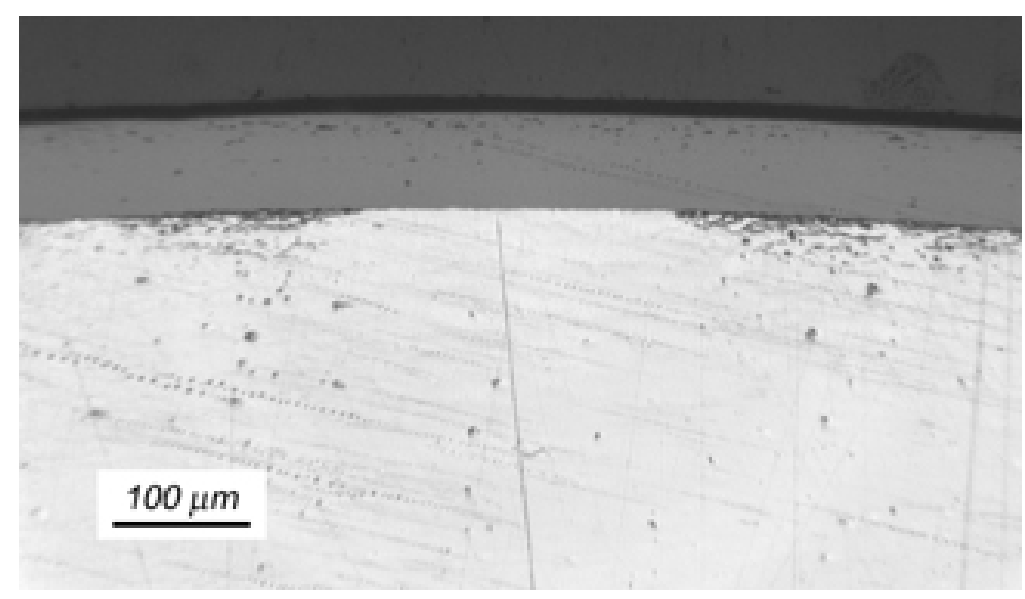

(b) $320 \mathrm{~mm}$ above midplane

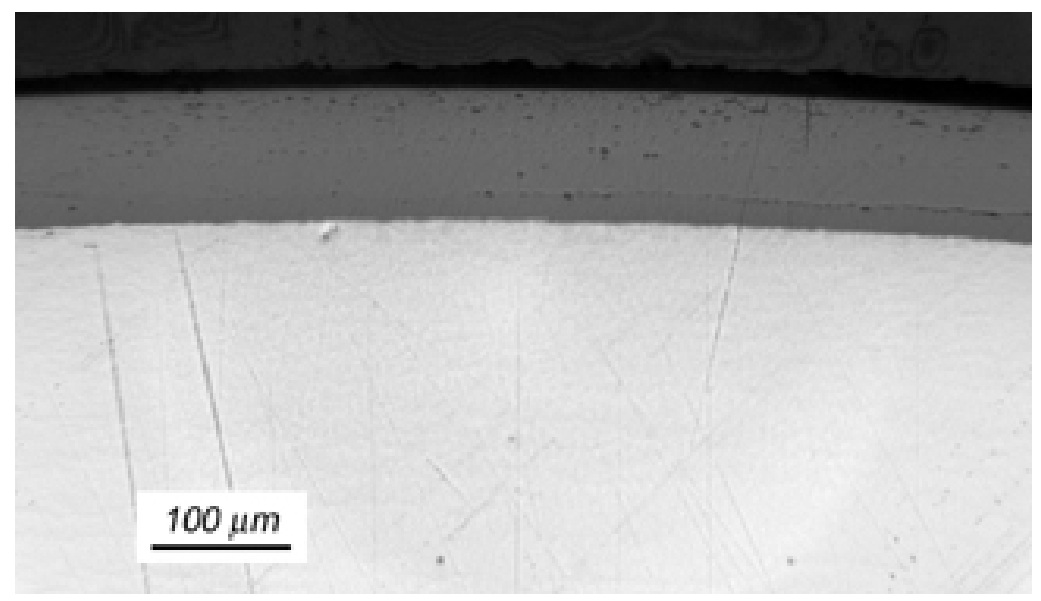

(c) $650 \mathrm{~mm}$ above midplane

Figure 129. Outer-surface corrosion layer for two-sided-oxidation test samples from HBR rod F07: (a) midplane $(71 \mu \mathrm{m})$; (b) $320 \mathrm{~mm}$ above midplane $(74 \mu \mathrm{m})$; and (c) $650 \mathrm{~mm}$ above midplane $(95 \mu \mathrm{m})$. 
Hydride distribution and morphology are important parameters for oxidation and post-oxidation ductility tests. Images of etched samples are shown in Figure 130 for three axial locations of interest for HBR rod F07. No unusual hydride morphology was observed in the eight arc segments imaged.

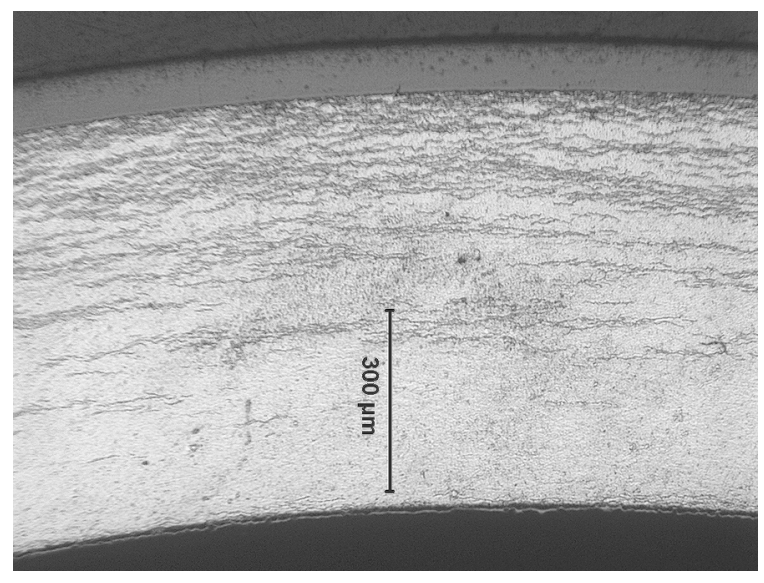

(a) Midplane

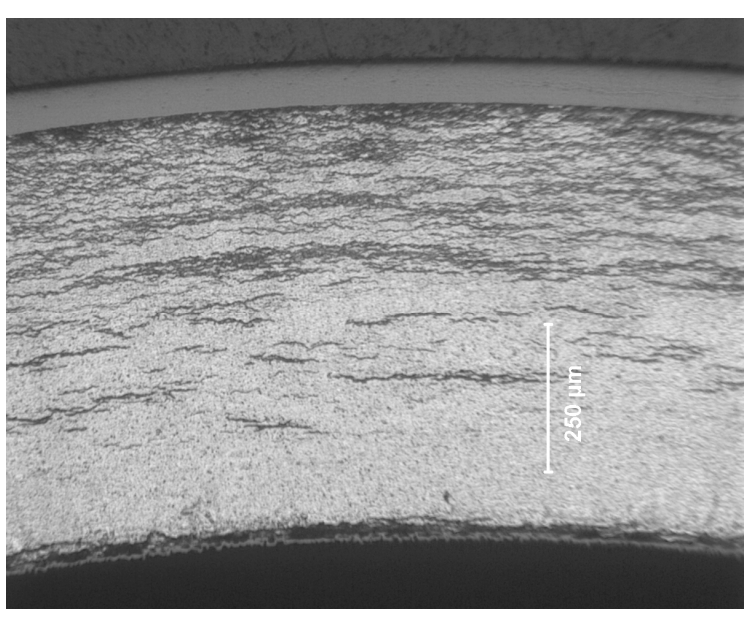

(b) $320 \mathrm{~mm}$ above midplane

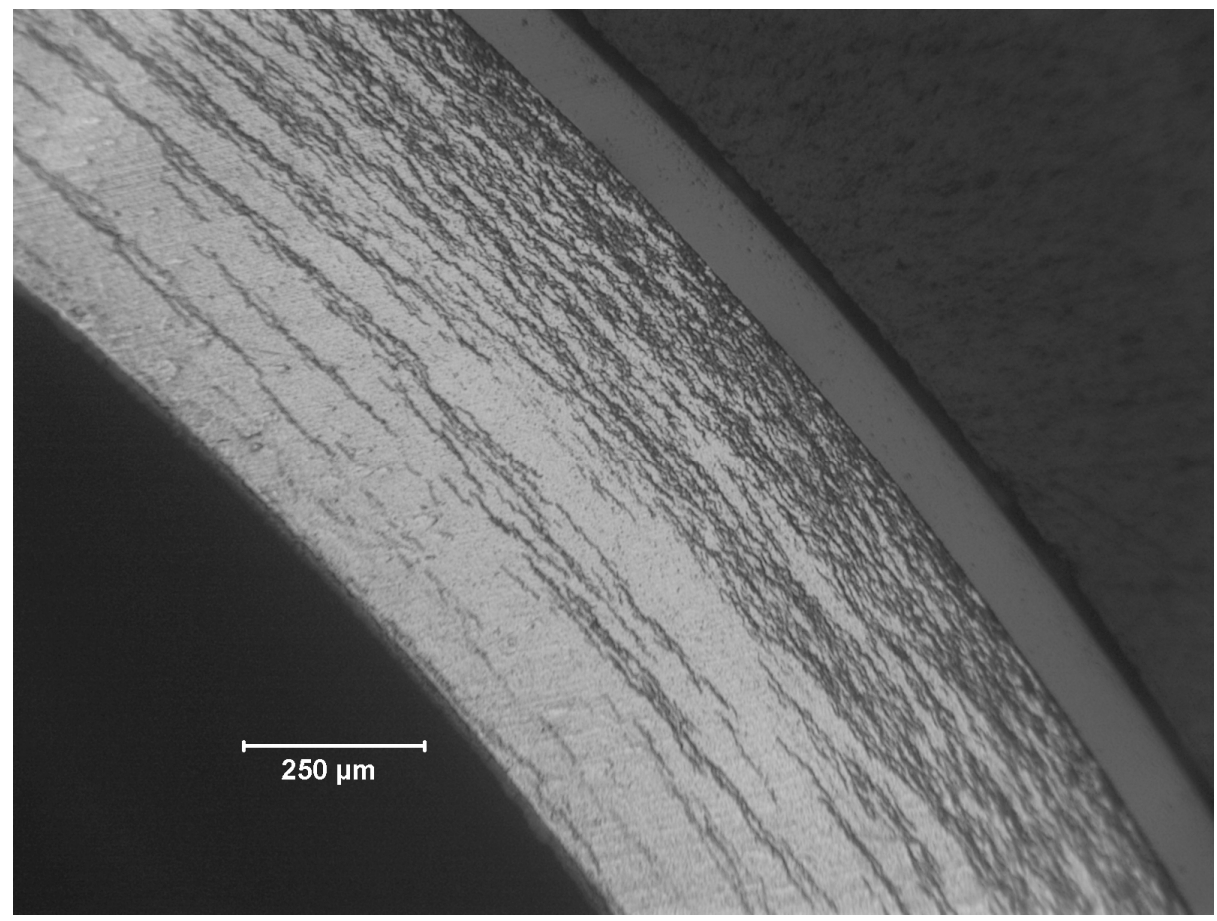

(c) $650 \mathrm{~mm}$ above midplane

Figure 130. Hydride distribution and morphology in HBR rod F07 cladding near locations used to section two-sided-oxidation test samples: a) fuel midplane (550-wppm H); b) $320 \mathrm{~mm}$ above midplane (550wppm H); and c) $650 \mathrm{~mm}$ above midplane (740-wppm H). 
For HBR Rod G10, from which one-sided oxidation samples were sectioned, metallographic images from etched cladding areas at the fuel midplane location revealed areas of typical (Figure 131a) and atypical (Figure 131b) hydride distribution and morphology. The hydrides in Figure 131b appear to be much denser across the cladding wall and appear to have more hydrogen than the region shown in Figure 131a. This observation was confirmed for rod R01, which had circumferential variations of 450770 wppm hydrogen with atypical hydride morphology within about $50 \%$ of the cross section.

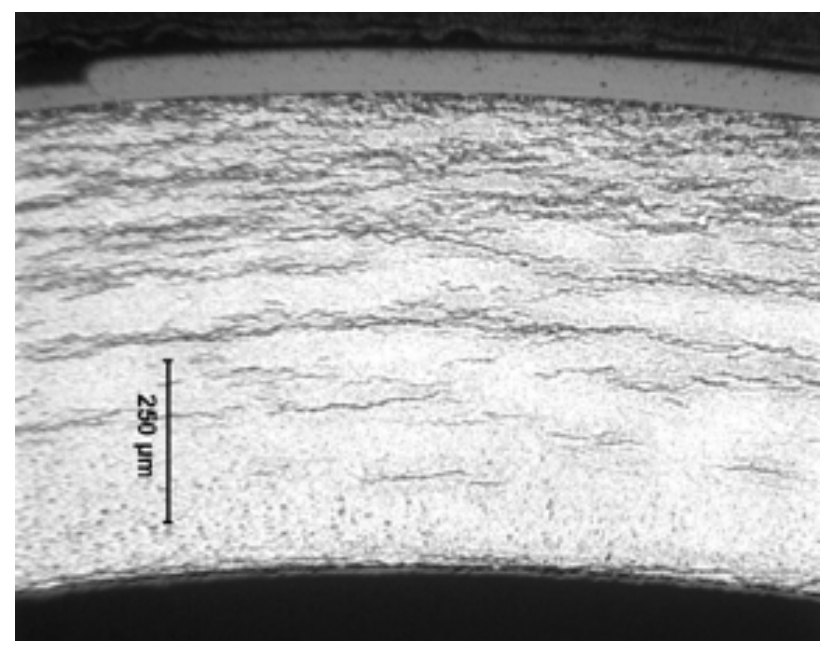

(a) Typical hydride morphology

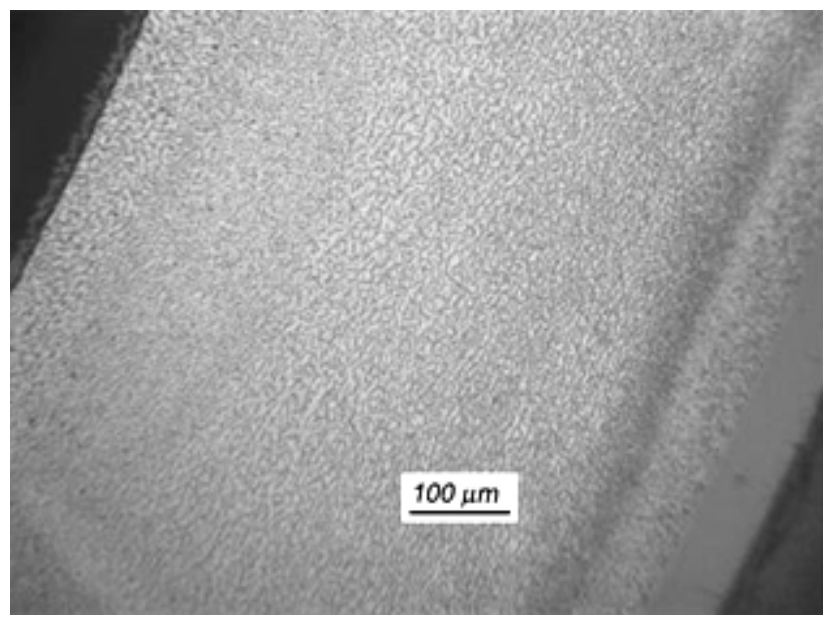

(b) Atypical hydride morphology

Figure 131. Hydride distribution and morphology in HBR rod G10 cladding at the core midplane: (a) typical hydride distribution across cladding wall and (b) atypical hydride distribution with a very dense hydride band near the outer surface and smaller dense hydrides across the wall.

Table 56 summarizes the data used to plan and interpret the test results for the two-sided and onesided oxidation tests. 
Table 56. Summary of Cladding Characterization for HBR Fuel Rod Segments Used for Pre- and Posttest Analysis of Two-sided and One-sided Oxidation Tests

\begin{tabular}{|c|c|c|c|c|c|c|}
\hline Test Type & Sample ID & $\begin{array}{c}\text { Corrosion } \\
\text { Thickness, } \\
\mu \mathrm{m}\end{array}$ & $\begin{array}{c}\text { Corrosion } \\
\text { ECR } \\
\%\end{array}$ & $\begin{array}{l}\text { Hydrogen } \\
\text { Content, } \\
\text { wppm }\end{array}$ & $\begin{array}{c}\text { Cladding } \\
\text { Thickness, } \\
\text { mm }\end{array}$ & $\begin{array}{c}\text { Cladding } \\
\text { OD, }{ }^{a} \\
\text { mm }\end{array}$ \\
\hline Two-sided & $\begin{array}{c}\text { Rod F07 } \\
\text { C7B, C7C } \\
\text { C7F, C7G }\end{array}$ & 71 & 5.4 & $550 \pm 100$ & 0.712 & 10.58 \\
\hline Two-sided & $\begin{array}{c}\text { Rod F07 } \\
\text { C5 }\end{array}$ & 74 & 5.6 & $550 \pm 100$ & 0.714 & 10.58 \\
\hline Two-sided & $\begin{array}{l}\text { Rod F07 } \\
\text { C3 }\end{array}$ & 95 & 7.1 & $740 \pm 110$ & 0.702 & 10.54 \\
\hline One-sided & $\begin{array}{c}\mathrm{G} 10 \\
\text { C7B, C7C } \\
\text { C7F, C7G }\end{array}$ & 68 & 5.1 & $550 \pm 100$ & 0.720 & 10.60 \\
\hline One-sided & $\begin{array}{l}\text { D3 } \\
\text { D5 }\end{array}$ & $\begin{array}{c}44 \\
\approx 40\end{array}$ & $\begin{array}{c}3.3 \\
\approx 3.0\end{array}$ & $\begin{array}{l}\approx 400 \\
\approx 360\end{array}$ & $\begin{array}{l}0.740 \\
0.742\end{array}$ & $\begin{array}{l}10.65 \\
10.65\end{array}$ \\
\hline
\end{tabular}

${ }^{a}$ Deduced from interpolation of outer diameters reported in Ref. 31 minus two times the corrosion layer thickness measured by ANL. A reasonable value to use for all these samples is $10.6 \mathrm{~mm}$ for normalizing the offset and permanent displacements to determine strains.

\subsubsection{Results of two-sided oxidation tests for high-burnup HBR 15x15 Zry-4}

Six two-sided oxidation tests were conducted during January-February 2005 in the in-cell LOCA oxidation-quench apparatus. Because of the limited availability of the Alpha-Gamma Hot Cell (AGHC) at ANL, the tests had to be planned carefully and conducted quickly. If time had permitted, these tests would have been conducted sequentially with a full post-test data set (metallography and post-oxidation or post-quench ductility) from the previous test used to plan the next test. A new test train was constructed; benchmarked in an out-of-cell test with non-irradiated cladding samples to determine the temperature history and verify that the measured weight gain and oxide-layer thickness were within 10\% of the CP predicted values; and benchmarked in an in-cell test with a nonirradiated cladding sample to demonstrate that the same weight gain results were obtained using the in-cell furnace. The weight gains measured following the out-of-cell and in-cell tests were in excellent agreement with the CP-predicted values. The thermal history for this test train is shown in Figure 132, along with times corresponding to CP-ECR values of 3 to $10 \%$ for the $0.77-\mathrm{mm}$ wall of the as-fabricated cladding. In planning and conducting the in-cell tests, we adjusted the test times corresponding to the target CP-ECR values for the difference in cladding wall thickness $(0.71 \mathrm{~mm}$ vs. $0.77 \mathrm{~mm})$.

As described below, the corrosion layer was found to be partially protective with regard to growth of the high-temperature oxidation layer with time. Thus, the rate of oxidation of the corroded highburnup cladding is somewhat lower than that of the as-fabricated cladding used to generate the temperature history in Figure 132. The lower oxidation rate corresponds to lower heat-generation rate and lower cladding temperatures during the fast ramp from $300^{\circ} \mathrm{C}$ to $\approx 1000^{\circ} \mathrm{C}$. Consequently, additional thermal benchmark tests were conducted after the in-cell tests were completed to better determine the temperatures to use for interpretation of the high-burnup test results. 


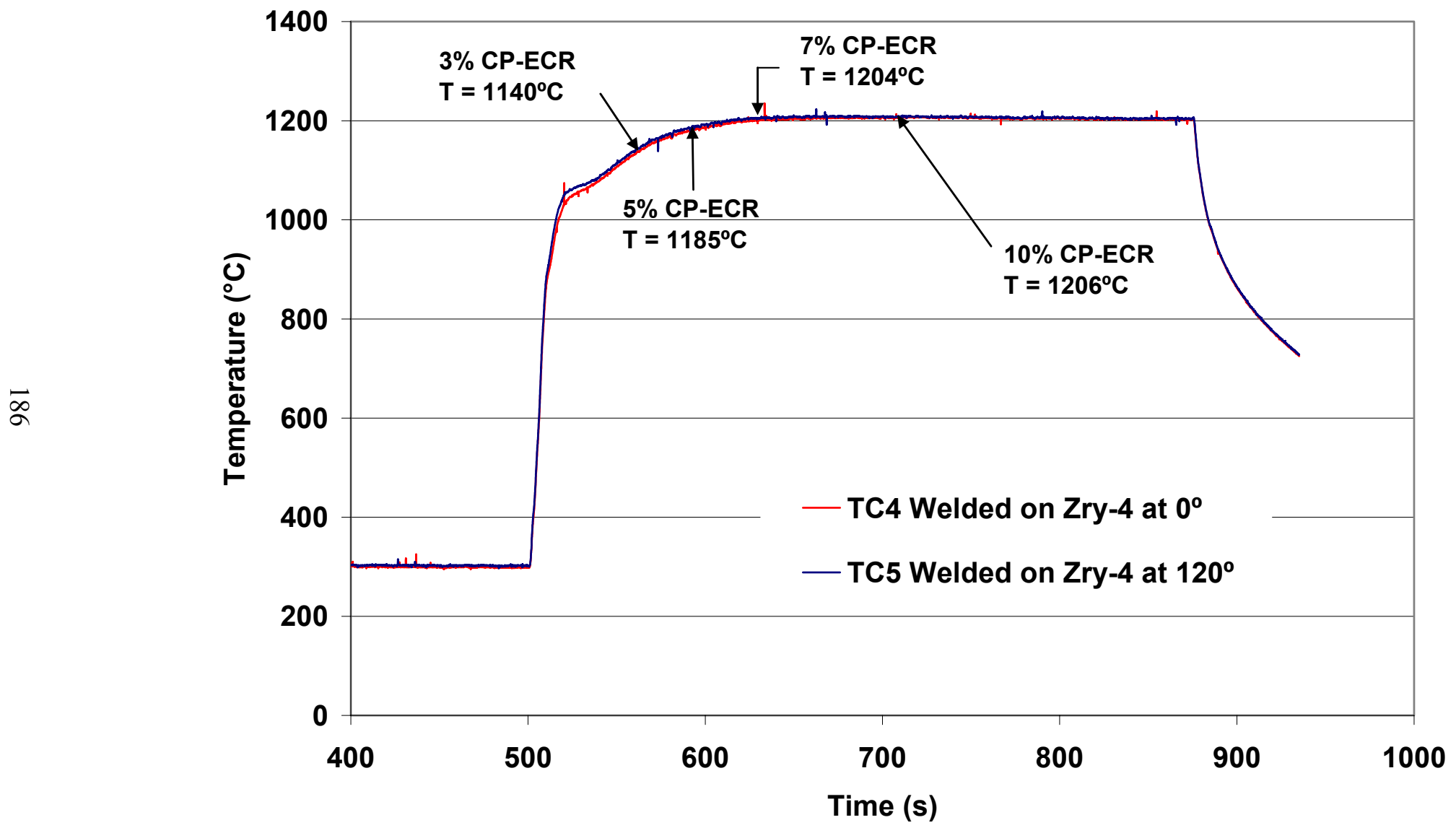

Figure 132. Out-of-cell thermal benchmark results for as-fabricated cladding in the test train used to conduct in-cell two-sided oxidation tests with high-burnup HBR Zry-4 cladding. The results were used to plan oxidation times for two-sided tests with high-burnup HBR cladding samples. 
Another test train was constructed after running the in-cell tests, and the thermal benchmark was conducted by using the same controller parameters as were used for the in-cell tests. Two tests were conducted in sequence with thermocouples welded to the cladding metal: ramp from $300^{\circ} \mathrm{C}$ to $1200^{\circ} \mathrm{C}$ and hold long enough to grow a 37- $\mu \mathrm{m}$ oxide on the cladding inner and outer surfaces and slow cool to RT, and repeat the ramp-and-hold test with the oxidized cladding. Figure 133 shows the temperature ramp-and-hold results for initially bare cladding, and Figure 134 shows results for cladding with initial oxide layers of $37 \mu \mathrm{m}$ on the inner and outer surfaces. By comparing the two figures, we determined that for pre-oxidized cladding, the temperature at the end of the rapid ramp is lower $\left(1017^{\circ} \mathrm{C}\right.$ vs. $\left.1060^{\circ} \mathrm{C}\right)$, the time to reach the hold temperature is about the same (140 s vs. $130 \mathrm{~s})$, and the hold temperature is slightly lower $\left(1193^{\circ} \mathrm{C}\right.$ vs. $\left.1201^{\circ} \mathrm{C}\right)$. Temperatures from these two benchmark runs are compared at relevant incell test times in Table 57 under the columns for the bare-cladding results (HBRU\#73A) and the preoxidized cladding results (HBRU\#73B). A small correction was then made to the temperature history for pre-oxidized cladding by accounting for differences in test trains used to conduct the in-cell

Table 57. Thermal Benchmark Results for Test HBRU\#44 with As-fabricated Zry-4 (Figure 132), for Test HBRU\#73A with As-fabricated Zry-4 (Figure 133), and for Test HBRU\#73B with Preoxidized Zry-4 (Figure 135). Estimated temperatures for high-burnup test samples (HBRI) are given in column 3 .

\begin{tabular}{|c|c|c|c|c|c|}
\hline $\begin{array}{c}\text { HBRI } \\
\text { Test } \#\end{array}$ & $\begin{array}{c}\text { Test } \\
\text { Time }, \\
\mathrm{s}\end{array}$ & $\begin{array}{c}\text { Deduced } \\
\text { HBRI } \\
\mathrm{T},{ }^{\circ} \mathrm{C}\end{array}$ & $\begin{array}{c}\text { HBRU\#44 } \\
\text { (Figure 132) } \\
\mathrm{T},{ }^{\circ} \mathrm{C}\end{array}$ & $\begin{array}{c}\text { HBRU\#73A } \\
\text { (Figure 133) } \\
\mathrm{T},{ }^{\circ} \mathrm{C}\end{array}$ & $\begin{array}{c}\text { HBRU\#73B } \\
\text { (Figure 135) } \\
\mathrm{T},{ }^{\circ} \mathrm{C}\end{array}$ \\
\hline 2 & 62 & 1110 & 1141 & 1136 & 1105 \\
\hline 1 & 93 & 1169 & 1186 & 1180 & 1163 \\
\hline 3 & 132 & 1196 & 1204 & 1196 & 1188 \\
\hline 5 & 155 & 1197 & 1206 & 1201 & 1192 \\
\hline 6 & 155 & 1197 & 1206 & 1201 & 1192 \\
\hline 4 & 206 & 1198 & 1206 & 1201 & 1193 \\
\hline
\end{tabular}

${ }^{\mathrm{a}}$ From beginning of ramp at $300^{\circ} \mathrm{C}$ to end of hold time.

tests and the bare vs. pre-oxidized cladding thermal benchmarks. Also shown in Table 57 (under the heading HBRU\#44) are the bare-cladding temperatures (see Figure 132) measured at relevant test times for the test train used to conduct the in-cell tests. The difference between the two test-train results for the same controller parameters and bare cladding samples is $\approx 5^{\circ} \mathrm{C}$. Thus, for interpretation of in-cell tests, the temperatures in Figure 133 were increased gradually during the ramp to give a $5^{\circ} \mathrm{C}$ increase in hold temperature. The results are plotted in Figure 135 and summarized in Table 58.

The temperature history in Figure 135 represents a lower bound during the temperature ramp for high-burnup samples tested in-cell. The heat of oxidation is proportional to the oxidation rate, which is proportional to the inverse of the oxide-layer thickness for dense oxide layers grown in steam at high temperature (see Equation 1). Even if the corrosion layer $\left(\delta_{\mathrm{c}} \approx 70 \mu \mathrm{m}\right)$ and the fuel-cladding-bond oxide layer $\left(\delta_{\mathrm{b}} \approx 10 \mu \mathrm{m}\right)$ grown at reactor temperatures were as protective as high-temperature-grown oxide layers, the initial heat generation would be proportional to $1 / \delta_{\mathrm{c}}+1 / \delta_{\mathrm{b}}=0.114 \mu \mathrm{m}^{-1}$. For the thermal benchmark test with pre-oxidized cladding, the initial heat generation rate is proportional to $2 /(37-\mu \mathrm{m})=$ $0.054 \mu \mathrm{m}^{-1}$. Therefore, the initial oxidation heating rate in the thermal benchmark test is $<50 \%$ of the initial heat generated by the corroded high-burnup cladding during the in-cell tests. 


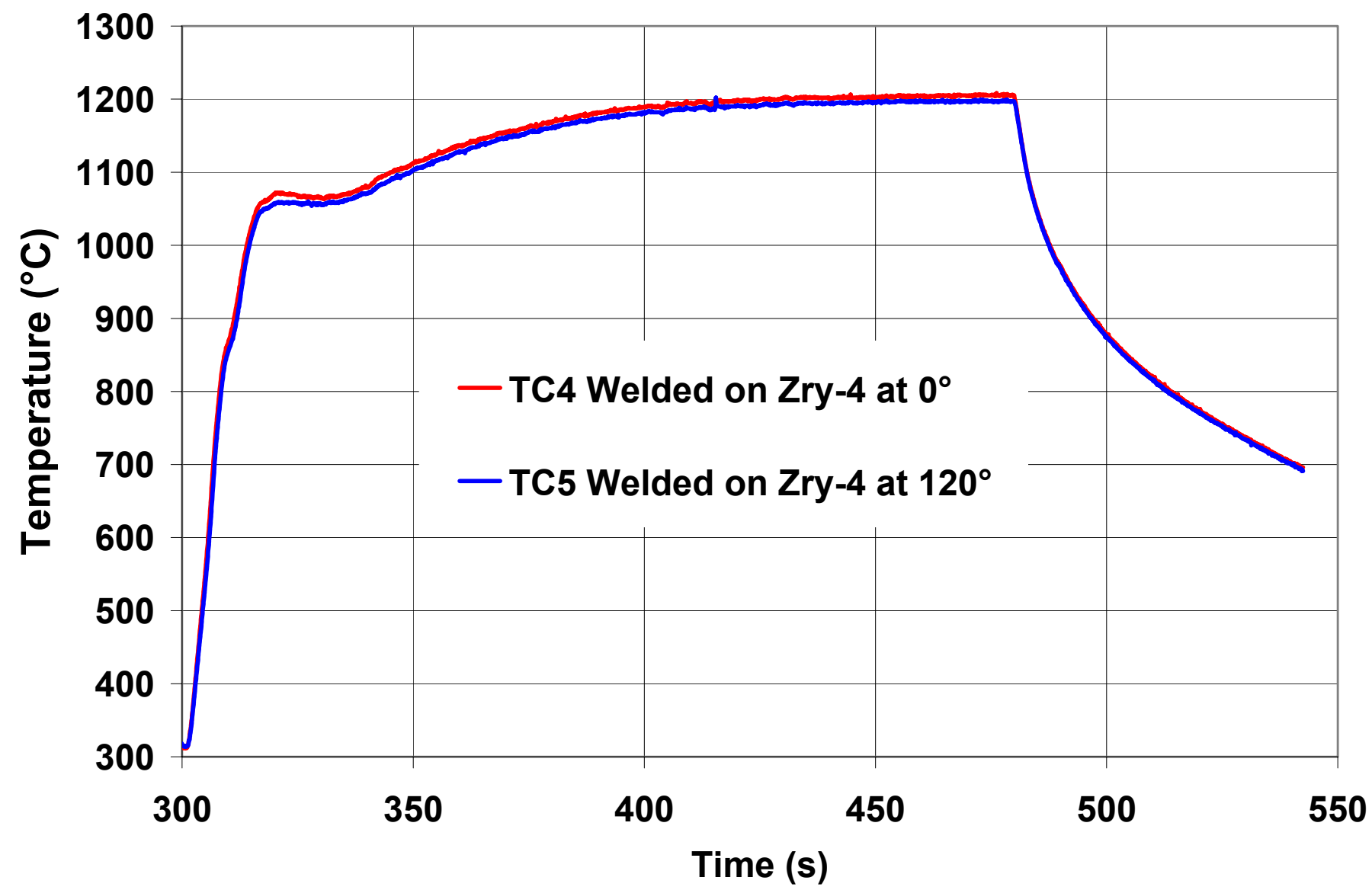

Figure 133. Results of thermal benchmark test conducted after the in-cell oxidation tests with another test train and with TCs welded onto the outer surface of as-fabricated HBR-type Zry-4 cladding. Controller parameters were the same as those used to generate Figure 132 results. 


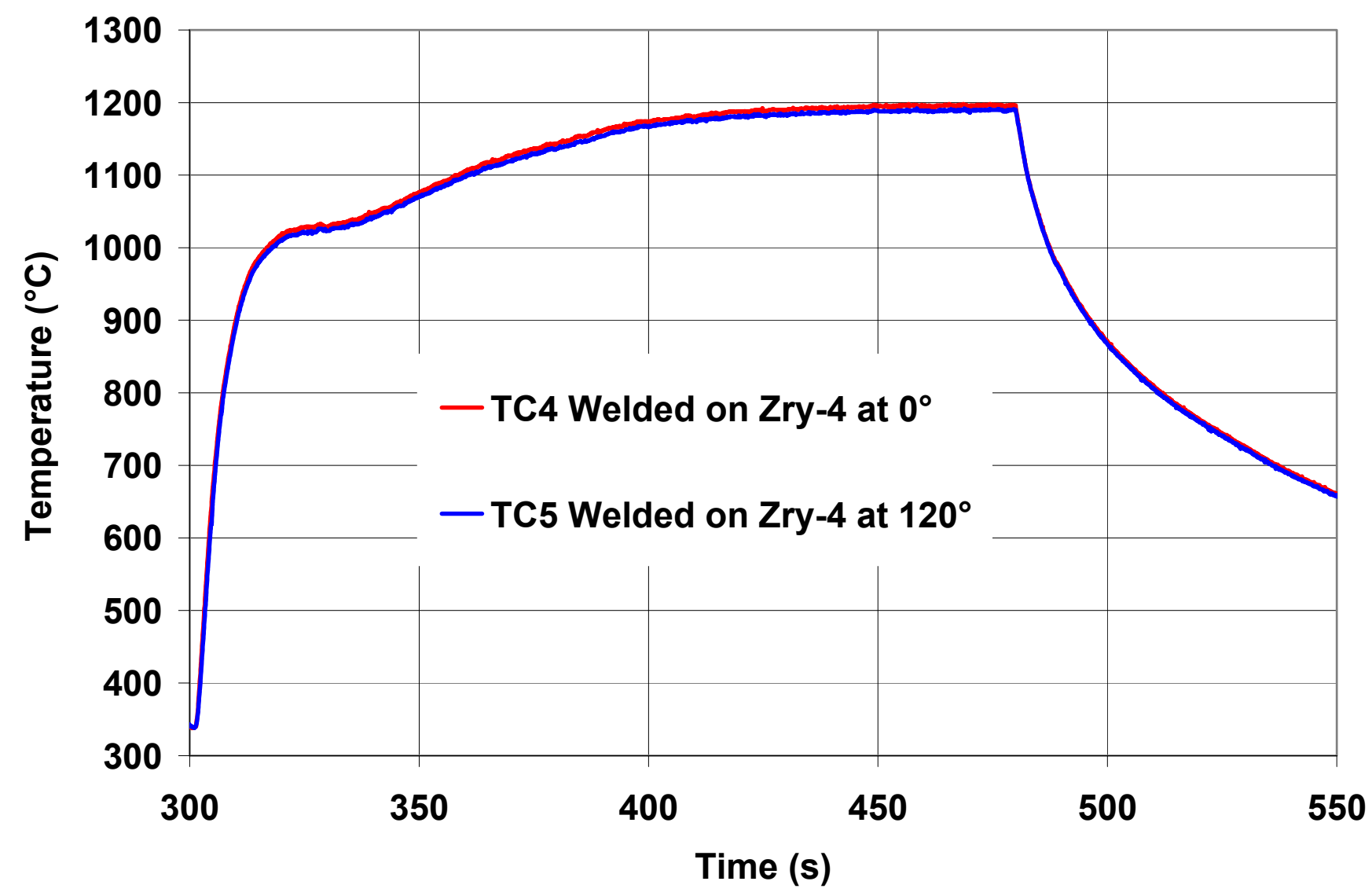

Figure 134. Thermal benchmark results for pre-oxidized HBR-type Zry-4 with TCs welded onto bare-cladding outer surface and with steaminduced oxide layers of $37 \mu \mathrm{m}$ grown on the inner and outer surface of the cladding sample prior to the temperature ramp. Controller parameters were the same as those used to generate results in Figures 132 and 133. 


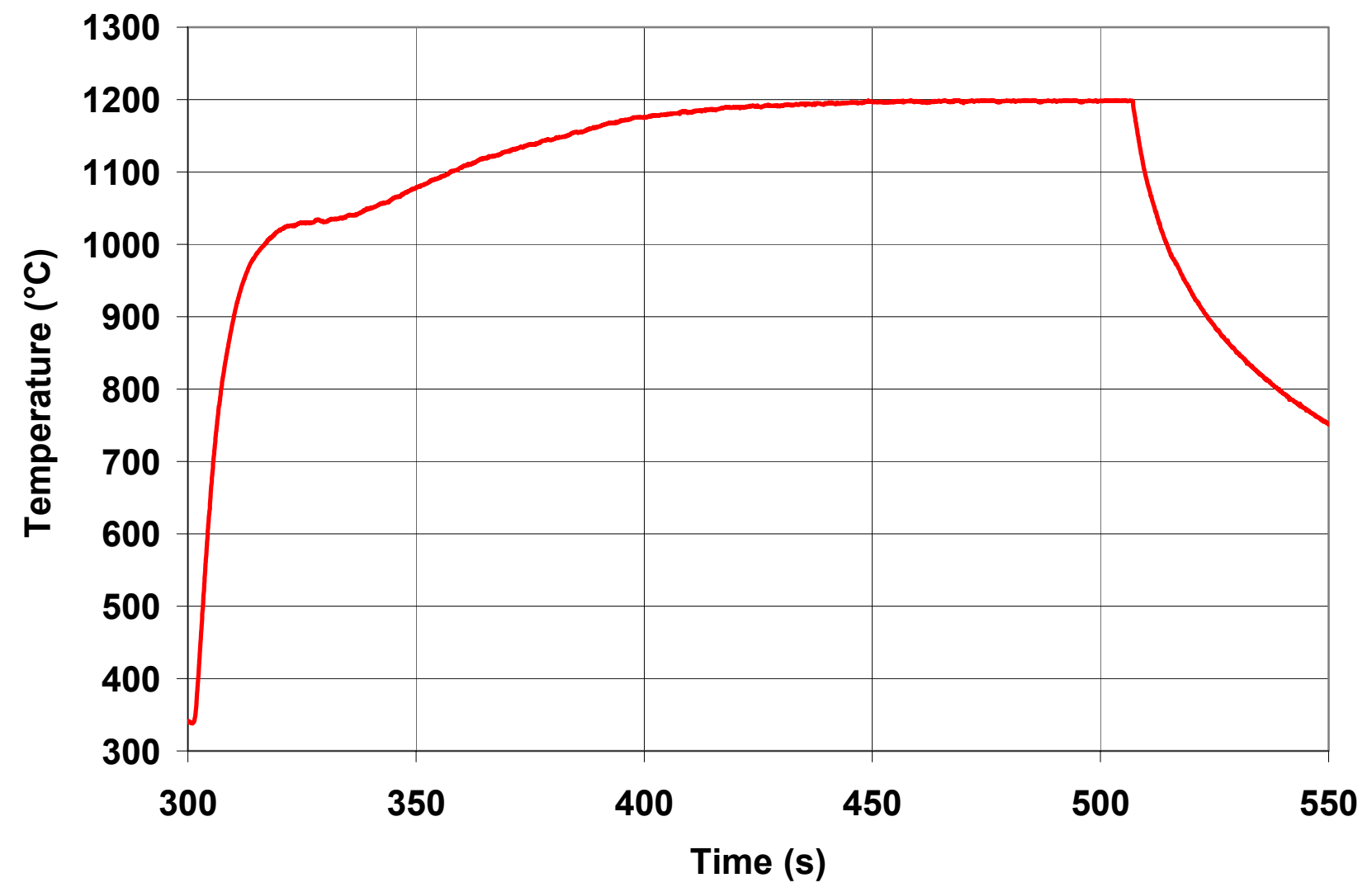

Figure 135. Temperature history used to calculate CP-ECR values and to interpret results for the in-cell two-sided oxidation tests conducted with high-burnup HBR Zry-4 cladding samples. 
However, the temperature history in Figure 135 should be a reasonable lower bound because beyond a certain oxide thickness $(\approx 10 \mu \mathrm{m})$ heat of oxidation is too small to have a significant effect on cladding temperatures during the heating ramp.

Table 58. Sample Characterization and Test Conditions for Two-sided Oxidation Tests Conducted with High-burnup HBR Zry-4 Cladding. SC is slow cooling, and Q is quench at $800^{\circ} \mathrm{C}$.

\begin{tabular}{|c|c|c|c|c|c|c|c|}
\hline $\begin{array}{c}\text { Test } \\
\text { ID \# }\end{array}$ & $\begin{array}{c}\text { Hydrogen } \\
\text { Content, } \\
\text { wppm }\end{array}$ & $\begin{array}{c}\text { Test } \\
\text { Time, } \\
\mathrm{s}\end{array}$ & $\begin{array}{c}\text { Target } \\
\text { CP-ECR, } \\
\%\end{array}$ & $\begin{array}{c}\text { Corrected } \\
\text { CP-ECR, } \\
\%\end{array}$ & $\begin{array}{c}\text { Maximum } \\
\mathrm{T}, \\
{ }^{\circ} \mathrm{C}\end{array}$ & $\begin{array}{c}\text { Time at } \\
\mathrm{T} \geq 1180^{\circ} \mathrm{C}, \\
\mathrm{s}\end{array}$ & Cooling \\
\hline \hline 2 & $550 \pm 100$ & 62 & 3 & 2.7 & 1110 & 0 & $\mathrm{SC}$ \\
\hline 1 & $550 \pm 100$ & 93 & 5 & 4.3 & 1169 & 0 & $\mathrm{SC}$ \\
\hline 3 & $550 \pm 100$ & 132 & 7 & 6.4 & 1196 & 27 & $\mathrm{SC}$ \\
\hline 5 & $550 \pm 100$ & 155 & 8 & 7.4 & 1197 & 50 & $\mathrm{SC}$ \\
\hline 6 & $740 \pm 110$ & 155 & 8 & 7.5 & 1197 & 50 & $\mathrm{Q}$ \\
\hline 4 & $550 \pm 100$ & 206 & 10 & 9.3 & 1198 & 101 & $\mathrm{SC}$ \\
\hline
\end{tabular}

${ }^{\mathrm{a}}$ Includes time for ramp from $300^{\circ} \mathrm{C}$ and hold time.

The target CP-ECR values were chosen based on the post-quench ductility results for prehydrided HBR-type Zry-4. From Figures 101 and 102, we estimated that high-burnup cladding with 550 wppm hydrogen would be brittle at $5 \%<\mathrm{CP}$-ECR $<7.5 \%$. The effects of slow cooling on ductility were not known at the time the high-burnup HBR tests were planned and conducted. Tests were planned at lower (3\% and 5\%) and higher (7\% and 10\%) CP-ECR levels in order to bracket the expected ductile-to-brittle transition CP-ECR. Additional tests were conducted at $8 \%$ target CP-ECR after data for the first set of tests showed that ductility had been retained up to 7\% target CP-ECR. Table 58 gives the test conditions for the two-sided oxidation tests, including the target CP-ECR values (based on Figure 132) and the corrected CP-ECR values (based on Figure 135).

Post-test measurements included sample weight, layer (corrosion, steam-oxide, and oxygenstabilized alpha) thicknesses, hydrogen concentration, and post-test ductility at $135^{\circ} \mathrm{C}$. All test samples decreased in weight, indicating that corrosion-layer spallation (probably during cooling) resulted in greater weight loss than the gain due to oxygen pickup. The metallographic results are particularly interesting in that they reveal information regarding fundamental phenomena that influence oxygen pickup, oxygen diffusion, and post-test ductility. Based on the results of the oxidation tests with highburnup Limerick BWR cladding (see Section 6.2 and Yan et al. $[15,36]$ ), we concluded that the corrosion layer was non-protective and "transparent" to steam oxidation. However, the Limerick-cladding corrosion layer was only $\approx 10-\mu \mathrm{m}$ thick $(\approx 3$-to-18 $\mu \mathrm{m}$ variation around the cladding circumference). Also, the one-sided oxidation tests with Limerick cladding were run for relatively long times (300-6000 s), which resulted in very thick outer-surface oxide layers. If the corrosion layer did have any effect on oxidation kinetics, it was not detectable for these sample and test conditions. In particular, the measured oxide layer thickness and the weight gain determined from layer thicknesses agreed quite well with CPpredicted values for as-fabricated and high-burnup cladding. 
Table 59 summarizes the results of the steam-oxide-thickness measurements taken from metallographic images. Only the 7.4\% and 9.3\% CP-ECR oxide thicknesses are given, along with the corresponding weight gains. Because of problems encountered in mounting the lower CP-ECR samples and the difficulty in distinguishing the steam-oxide layer from the corrosion layer, the uncertainty for these samples was too high to yield reliable data. For the higher CP-ECR samples, the measured steamoxide thickness on the outer surface of the cladding is clearly less than the inner-surface-oxide thickness and less than the CP-predicted thickness. The results indicate that the thick HBR corrosion layer is partially protective with respect to steam oxidation. The weight gains, determined from the metallographic results in Tables 59 and 60, are less than the CP-predicted weight gains. In terms of ECR based on these weight gains, the 7.4\% CP-ECR sample had a measured ECR of 5.6\%, and the 9.3\% CPECR sample had a measured ECR of $7.8 \%$. The difference in ECR is $1.5-1.8 \%$.

Table 59. Results of Quantitative Metallography for Two-sided-oxidized, High-burnup HBR Zry-4 following Steam Oxidation. Oxide layer thickness $\left(\delta_{\mathrm{ox}}\right)$ and measured ECR data are listed. Data are from optical microscopy (OM) images at eight circumferential locations around sample cross section (see Figures 137-139 for images from one-of-eight locations for HBRI\#4 and \#5 samples).

\begin{tabular}{|c|c|c|c|c|c|c|c|}
\hline $\begin{array}{c}\text { Test } \\
\text { ID \# }\end{array}$ & $\begin{array}{c}\text { Test } \\
\text { Time, } \\
\mathrm{s}\end{array}$ & $\begin{array}{c}\text { Maximum } \\
\mathrm{T}, \\
{ }^{\circ} \mathrm{C}\end{array}$ & $\begin{array}{c}\text { CP-ECR, } \\
\%\end{array}$ & $\begin{array}{c}\text { Measured } \\
\text { ECR, } \\
\%\end{array}$ & $\begin{array}{c}\text { CP- } \delta_{\text {ox }}, \\
\mu \mathrm{m}\end{array}$ & \multicolumn{2}{|c|}{$\begin{array}{c}\text { Measured } \delta_{\text {ox }}, \\
\mu \mathrm{m}\end{array}$} \\
\cline { 5 - 8 } & & 1110 & 2.7 & --- & 11 & --- & --- \\
\hline 1 & 92 & 1169 & 4.3 & --- & 18 & --- & --- \\
\hline 3 & 132 & 1196 & 6.4 & --- & 26 & --- & --- \\
\hline 5 & 155 & 1197 & 7.4 & $5.6 \pm 0.2$ & 30 & $19 \pm 2$ & 26 \\
\hline 6 & 155 & 1197 & 7.5 & --- & 30 & --- & --- \\
\hline 4 & 206 & 1198 & 9.3 & $7.8 \pm 0.4$ & 38 & $28 \pm 4$ & 38 \\
\hline
\end{tabular}

${ }^{\mathrm{a}}$ Includes time for ramp from $300^{\circ} \mathrm{C}$ and hold time.

The effect of the fuel-cladding bond on the oxidation growth rate at the inner surface is less clear. This bond layer is only $\approx 11 \pm 4 \mu \mathrm{m}$ thick, and like the thin corrosion layer on the Limerick cladding, its effect on oxide growth rate was not detectable. At 7-to-9\% CP-ECR, the measured ID oxide layer is in agreement with the $\mathrm{CP}$-predicted value, indicating that the thin fuel cladding bond is much less protective to steam oxidation than the thick corrosion layer.

Although it slows down the growth of the OD high-temperature oxide, the corrosion layer does not slow down the growth of the oxygen-stabilized alpha layer. Table 60 and Figure 136 show the measured OD and ID oxygen-stabilized alpha-layer thickness values, as compared to the CP-predicted values.

Unlike the oxide layers, the OD and ID alpha layers are comparable and agree reasonably well with the $\mathrm{CP}$-predicted values. The difference of 1-2 $\mu \mathrm{m}$ between measured and predicted OD alpha-layer thickness is not significant because of the uncertainty in the CP correlation due to the variable hydrogen pickup in the Cathcart et al. [13] samples. The slightly thicker $(2 \mu \mathrm{m})$ OD vs. ID alpha layer may or may 
not be significant. The results indicate that oxygen diffuses directly from the corrosion layer to the cladding metal, resulting in growth of the oxygen-stabilized alpha layer. Oxygen from this alpha layer is available for diffusion into the beta layer.

Table 60. Results of Quantitative Metallography for Two-sided-oxidized, High-burnup HBR Zry-4 following Steam Oxidation. Oxygen-stabilized alpha layer thickness $\left(\delta_{\alpha}\right)$ data are listed, based on data from images at eight circumferential locations around sample cross section (see Figures 137 and 138 for OM images from one-of-eight locations for sample HBRI\#5).

\begin{tabular}{|c|c|c|c|c|c|c|c|}
\hline $\begin{array}{c}\text { Test } \\
\text { ID \# }\end{array}$ & $\begin{array}{c}\text { Test } \\
\text { Time, } \\
\mathrm{s}\end{array}$ & $\begin{array}{c}{ }^{\mathrm{T}} \\
\end{array}$ & $\begin{array}{c}\mathrm{T}, \\
{ }^{\circ} \mathrm{C}\end{array}$ & $\begin{array}{c}\text { Maximum } \\
\%\end{array}$ & $\begin{array}{c}\text { CP-ECR, } \\
\%\end{array}$ & $\begin{array}{c}\text { Measured } \\
\text { ECR, }\end{array}$ & \multicolumn{2}{c|}{$\begin{array}{c}\text { CP- } \delta_{\alpha}, \\
\mu \mathrm{m}\end{array}$} & \multicolumn{2}{|c|}{$\begin{array}{c}\text { Measured } \delta_{\alpha}, \\
\mu \mathrm{m}\end{array}$} \\
\hline \hline 2 & 62 & 1110 & 2.7 & --- & 9 & 8.4 & 6.2 \\
\hline 1 & 93 & 1169 & 4.3 & --- & 16 & 14 & 12 \\
\hline 3 & 132 & 1196 & 6.4 & --- & 25 & 23 & 21 \\
\hline 5 & 155 & 1197 & 7.4 & $5.6 \pm 0.2$ & 29 & 27 & 25 \\
\hline 6 & 155 & 1197 & 7.5 & --- & 29 & --- & --- \\
\hline 4 & 206 & 1198 & 9.3 & $7.8 \pm 0.4$ & 37 & 35 & 33 \\
\hline
\end{tabular}

${ }^{a}$ Includes time for ramp from $300^{\circ} \mathrm{C}$ and hold time.

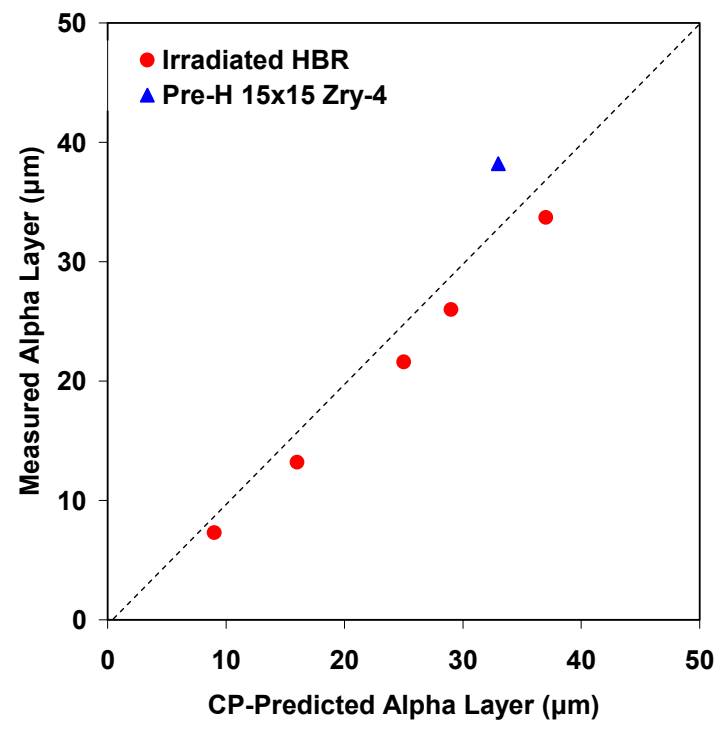

Figure 136. Measured average ([OD+ID]/2) alpha-layer thickness vs. CP-predicted value for high-burnup (550 $\pm 100 \mathrm{wppm}) \mathrm{HBR}$ samples oxidized (two-sided) at $1100-1200^{\circ} \mathrm{C}$ and prehydrided $(600 \mathrm{wppm}) \mathrm{HBR}-$ type Zry-4 sample oxidized at $\approx 1200^{\circ} \mathrm{C}$ to $7.5 \%$ CP-ECR. 
Metallographic (optical microscopy, OM) images were taken of the oxidized high-burnup HBR Zry-4 samples. Higher quality OM images were obtained for the $7.4 \%$ and $9.3 \%$ CP-ECR samples. In addition, SEM images were obtained for the $7.4 \%$ CP-ECR sample. Figure 137 a shows a partial cross section emphasizing the outer surface of the 7.4\% CP-ECR sample. The corrosion layer is visible, but its thickness is much smaller than the $71 \mu \mathrm{m}$ of the as-irradiated HBR Zry-4. Some of this layer was consumed during the oxidation test, and most of it was lost during cooling (spallation). Also shown in Figure 137a are the oxide layer formed at high temperature, the oxygen-stabilized alpha layer, and part of the prior (previous) beta layer. Because the corrosion layer was not fully protective (numerous microand macro-cracks), the high-temperature oxide grew underneath the corrosion layer, which remained visible. Figure $137 \mathrm{~b}$ shows the SEM image from another position along the $7.4 \%$ CP-ECR sample. The distinction between the corrosion layer and the high-temperature oxide layer is much clearer in the SEM image, which was then used to draw the boundary lines in Figure 137a.

Similar OM and SEM images were obtained for the inner-surface area of the 7.4\% CP-ECR sample. Figure 138a shows the OM image, in which the oxide layer, the oxygen-stabilized alpha layer, and part of the prior-beta layer are clearly visible. No boundary is observed between the fuel-cladding-bond oxide and the high-temperature oxide. Figure $138 \mathrm{~b}$ shows the SEM image for the $7.4 \%$ CP-ECR sample inner surface at another axial location.

The outer- and inner-surface oxide layers for the 9.3\% CP-ECR high-burnup HBR Zry-4 sample are better viewed by using polished samples for OM imaging. Figure 139a shows the outer-oxide layer. The unevenness of the outer boundary and the morphology of this region suggest the presence of corrosion oxide, although the thickness is small due to partial loss of this layer. Also, there was a small gap between the outer surface and the epoxy, which allowed room for some of the corrosion layer to spall and drop below the imaged surface during grinding and polishing. Figure 139b shows the inner-surface oxide layer in the as-polished condition. There is no indication of a fuel-cladding bond layer in this image. Based on readings taken from eight circumferential areas, the average high-temperature oxide layer thickness is $28 \pm 4 \mu \mathrm{m}$ for the outer-surface oxide and $38 \mu \mathrm{m}$ for the inner-surface oxide (see Table 59). The variation in the outer-surface high-temperature oxide thickness is due to uncertainties in determining the interface between the corrosion layer and the high-temperature oxide layer, as well as the circumferential variation in oxide layer thickness.

The oxygen-stabilized alpha layer and the prior-beta layer are better imaged from etched surfaces. Figures 140a and 140b show the outer- and inner-surface regions, respectively, of these layers. The contrast between the oxygen-stabilized alpha layer and the prior-beta layer is quite good and allows for an accurate determination of the alpha-layer thickness. Based on readings from eight circumferential areas, the average alpha-layer thickness values (see Table 60) are about the same near the outer surface (35 $\mu \mathrm{m})$ and the inner surface $(33 \mu \mathrm{m})$.

Ring-compression tests were conducted at $135^{\circ} \mathrm{C}$ and $0.0333-\mathrm{mm} / \mathrm{s}$ crosshead displacement rate with $\approx 8$-mm-long samples sectioned from the oxidation and oxidation-quench samples. Offset displacements were determined from load-displacement curves and normalized to the cladding metal outer diameter $(10.6 \mathrm{~mm})$ to calculate offset strain. In addition, the outer diameter of the oxidized cladding was measured in the loading direction prior to, and after, compression testing. As is standard protocol for the ANL ring-compression tests, the tests were stopped after the first significant load drop to determine if through-wall failure along the length of the sample had occurred. Table 61 summarizes the results of the ring-compression tests. 


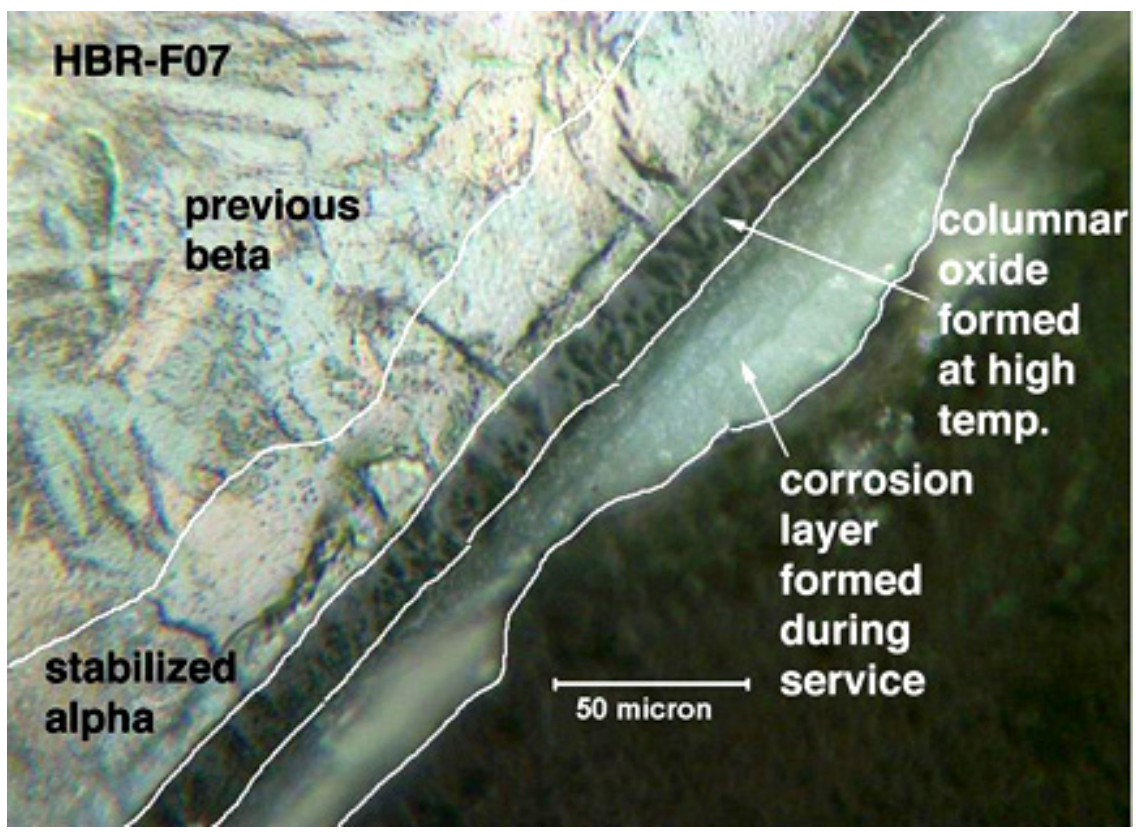

(a)

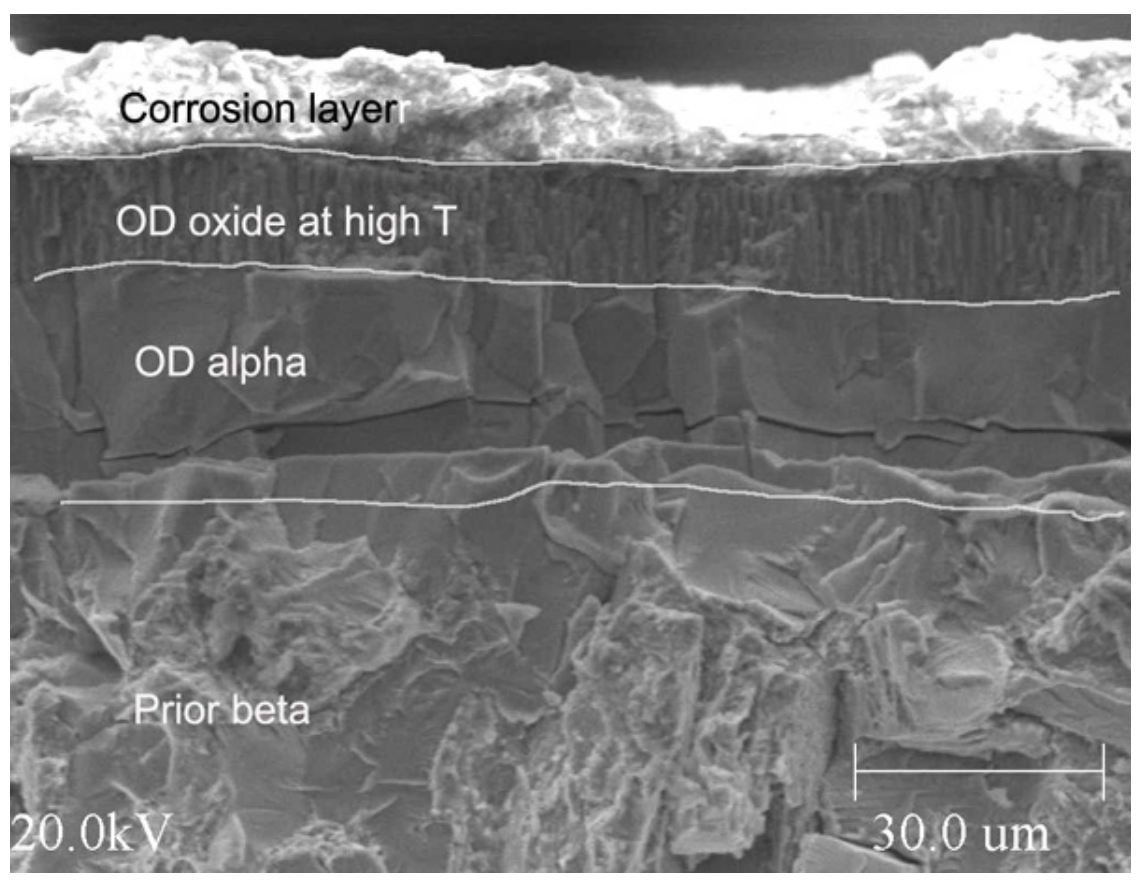

(b)

Figure 137. High-magnification images of the outer surface of high-burnup HBR Zry-4 sample following oxidation (two-sided) at $1200^{\circ} \mathrm{C}$ to $7.4 \% \mathrm{CP}-\mathrm{ECR}$ and slow cooling to RT: (a) OM and (b) SEM. 


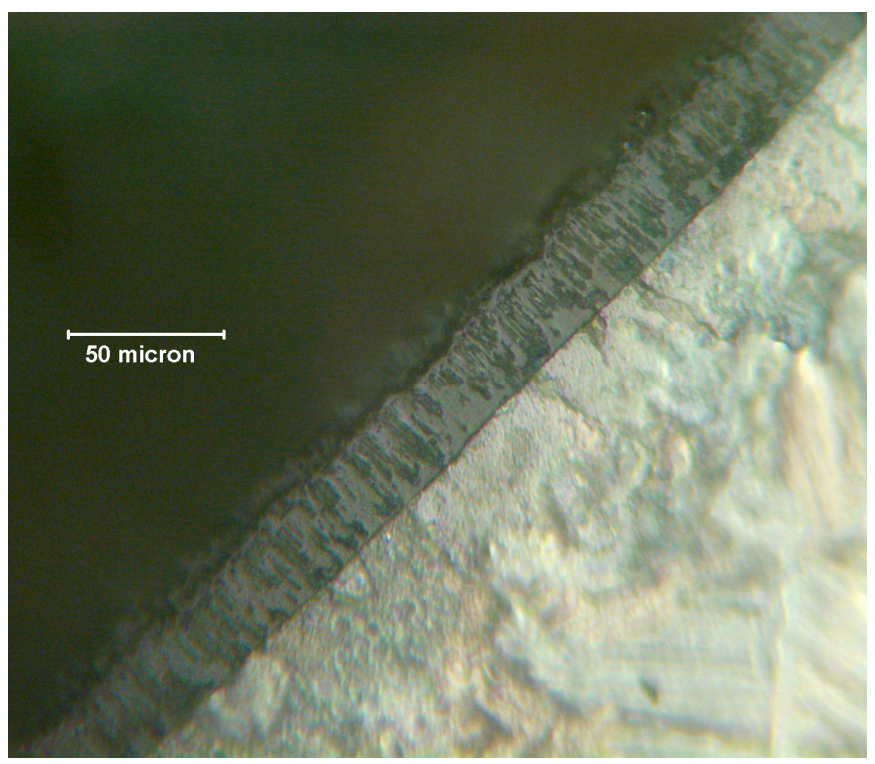

(a)

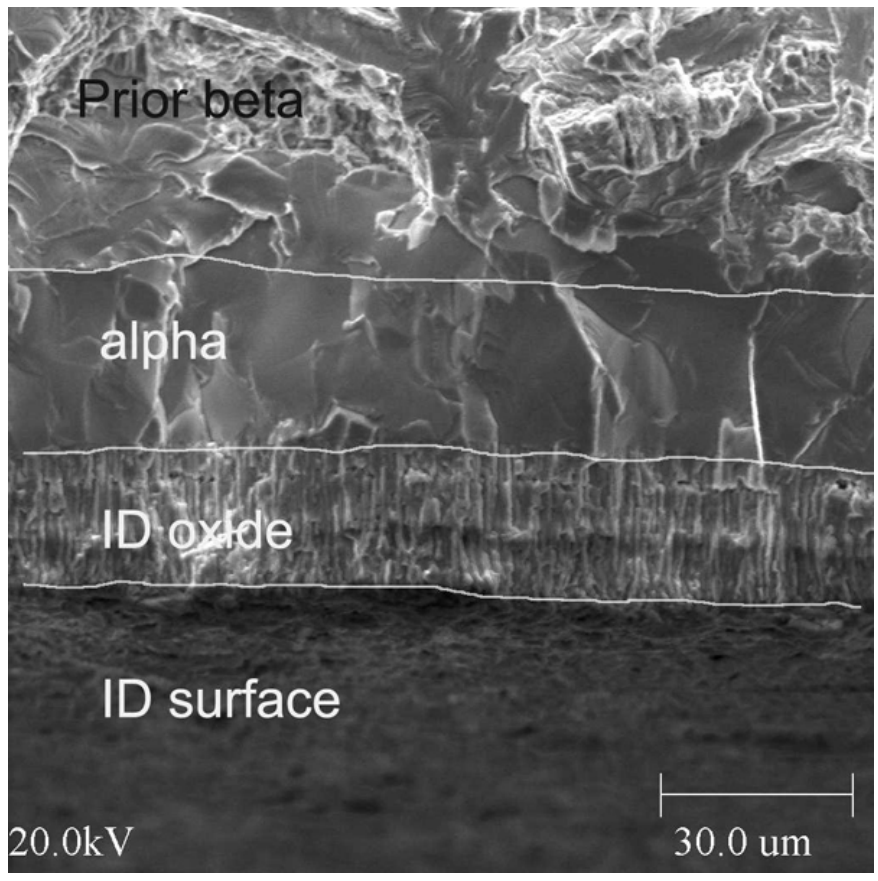

(b)

Figure 138. High-magnification images of the inner surface of high-burnup HBR Zry-4 sample following oxidation (two-sided) at $1200^{\circ} \mathrm{C}$ to $7.4 \%$ CP-ECR and slow cooling to RT: (a) OM and (b) SEM. 


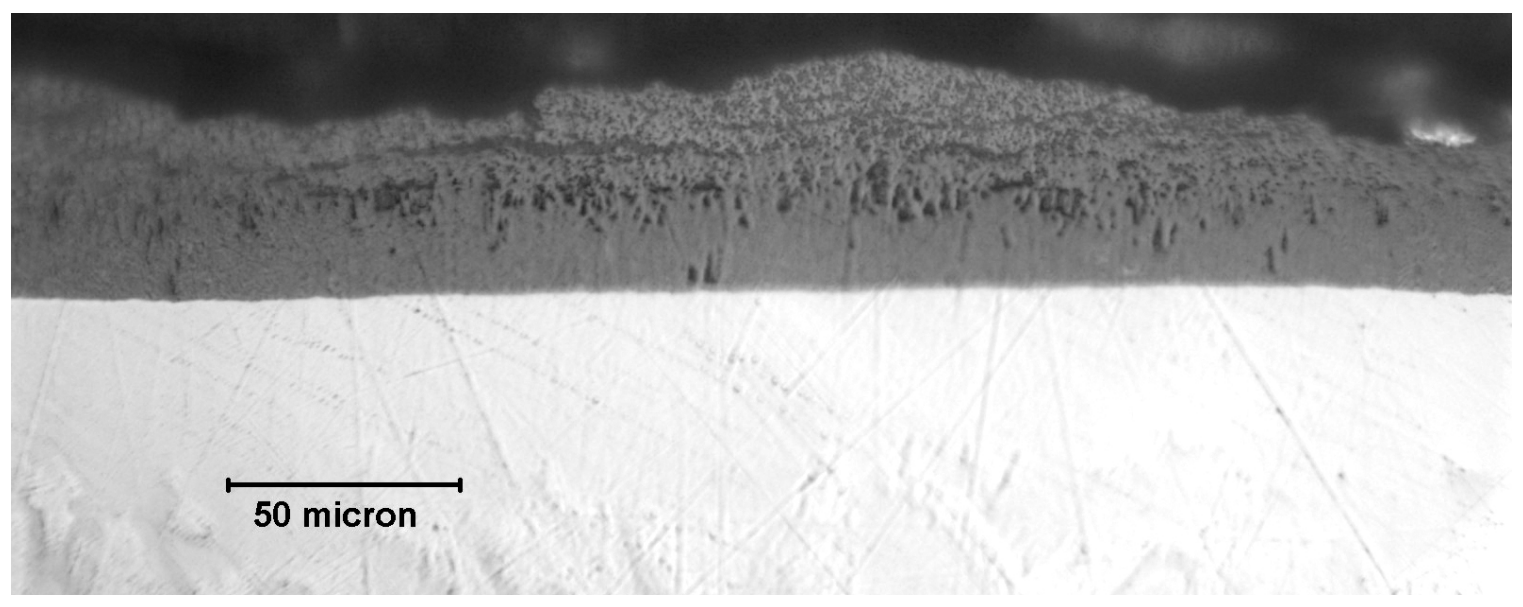

(a)

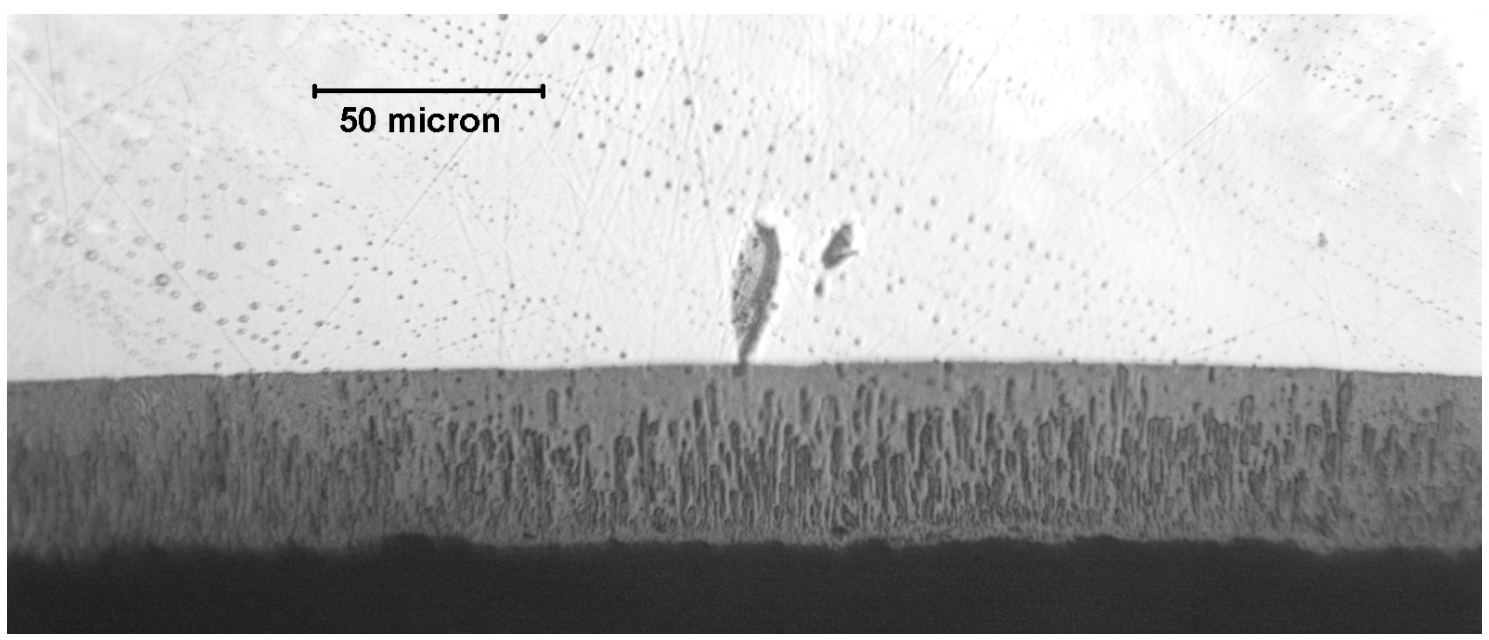

(b)

Figure 139. Optical microscopy images of the outer (a) and inner (b) surfaces of the high-burnup HBR Zry-4 sample oxidized (two-sided) at $\approx 1200^{\circ} \mathrm{C}$ to $9.3 \%$ CP-ECR followed by slow cooling to RT. The sample is in the as-polished condition.

The CP-ECR values in Tables 58-61 were calculated for the heating phase of the transient. The total ECR $\left(\mathrm{ECR}_{\mathrm{t}}\right)$ can be calculated from the relationship $\mathrm{ECR}_{\mathrm{t}}=\left[\left(\mathrm{ECR}_{\mathrm{h}}\right)^{2}+\left(\mathrm{ECR}_{\mathrm{c}}\right)^{2}\right]^{0.5}$, which yields total transient CP-ECR values of $2.9 \%, 4.5 \%, 6.6 \%, 7.6 \%$, and $9.4 \%$, respectively, for heating-phase CPECR values of $2.7 \%, 4.3 \%, 6.4 \%, 7.4 \%$, and $9.3 \%$. 


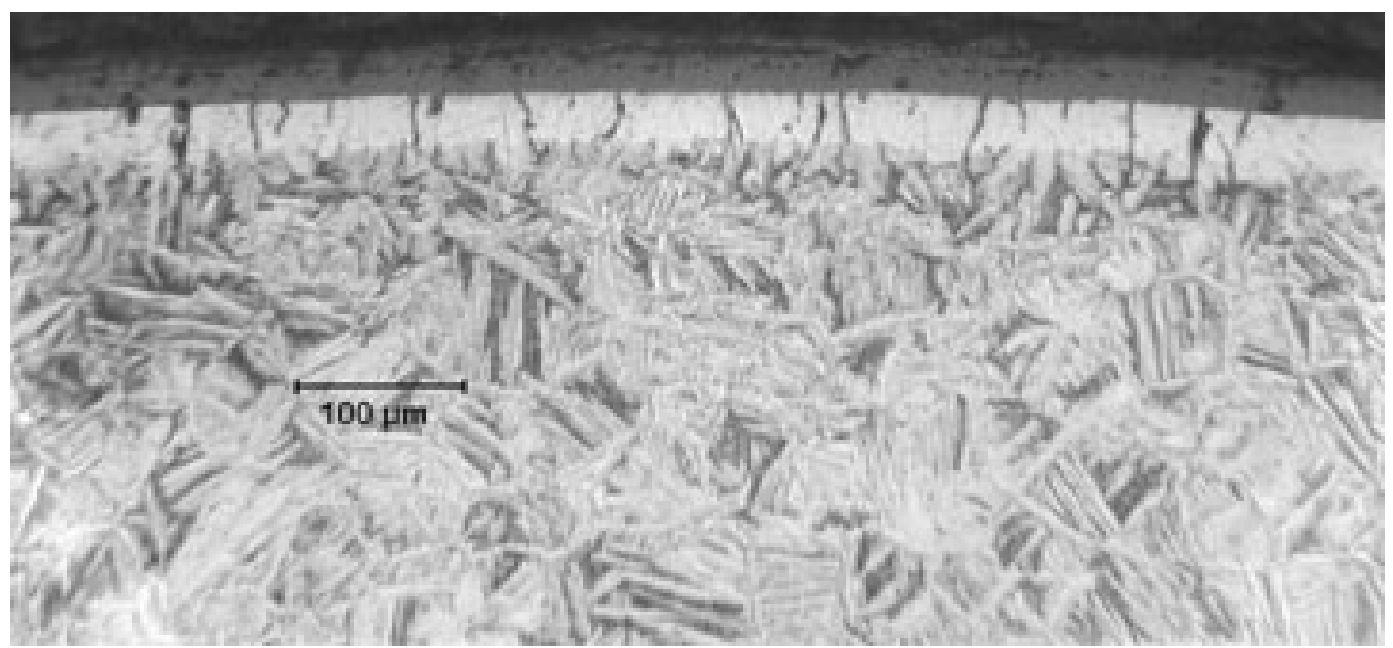

(a)

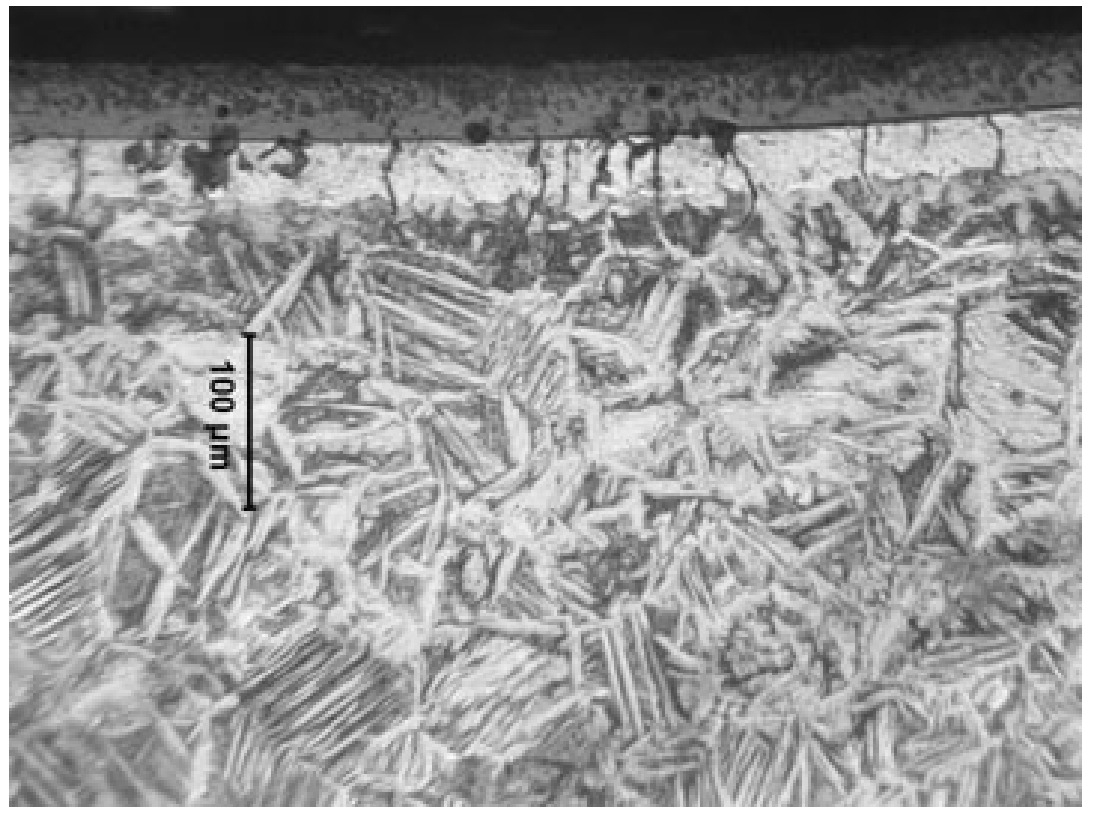

(b)

Figure 140. Optical microscopy images of the outer (a) and inner (b) surfaces of the high-burnup HBR Zry-4 sample oxidized (two-sided) at $1200^{\circ} \mathrm{C}$ to $9.3 \% \mathrm{CP}-\mathrm{ECR}$ followed by slow cooling to RT. The sample is in the etched condition. 
Table 61. Results of Ring-compression Tests for High-burnup HBR Zry-4 Cladding Samples Oxidized (Two-sided) at $1110-1198^{\circ} \mathrm{C}$ to $2.7-9.3 \%$ CP-ECR and Slow Cooled (SC) to RT or Quenched $(\mathrm{Q})$ at $800^{\circ} \mathrm{C}$. Tests were conducted on $\approx 8-\mathrm{mm}$-long rings at $135^{\circ} \mathrm{C}$ and $0.0333-\mathrm{mm} / \mathrm{s}$ displacement rate; offset and permanent displacements were normalized to the cladding metal outer diameter $(10.6 \mathrm{~mm})$ to calculate strains.

\begin{tabular}{|c|c|c|c|c|c|c|c|}
\hline \multirow{2}{*}{$\begin{array}{l}\text { Test } \\
\text { ID \# }\end{array}$} & \multirow{2}{*}{$\begin{array}{c}\text { Hydrogen } \\
\text { Content, } \\
\text { wppm }\end{array}$} & \multirow{2}{*}{$\begin{array}{c}\text { Test } \\
\text { Time, }^{\mathrm{a}} \\
\mathrm{s}\end{array}$} & \multirow[t]{2}{*}{ Cooling } & \multirow{2}{*}{$\begin{array}{c}\text { CP-ECR, } \\
\%\end{array}$} & \multirow{2}{*}{$\begin{array}{c}\text { Maximum } \\
\text { Oxidation } \mathrm{T} \text {, } \\
{ }^{\circ} \mathrm{C}\end{array}$} & \multicolumn{2}{|c|}{ Plastic Strains, \% } \\
\hline & & & & & & Offset & Permanent \\
\hline 2 & $550 \pm 100$ & 62 & $\mathrm{SC}$ & 2.7 & 1110 & $>45$ & $>43$ \\
\hline 1 & $550 \pm 100$ & 93 & $\mathrm{SC}$ & 4.3 & 1169 & $\begin{array}{l}>12 \\
\approx 37\end{array}$ & --- \\
\hline 3 & $550 \pm 100$ & 132 & $\mathrm{SC}$ & 6.4 & 1196 & 4.0 & 2.6 \\
\hline 5 & $550 \pm 100$ & 155 & $\mathrm{SC}$ & 7.4 & 1197 & 4.0 & 2.9 \\
\hline 6 & $740 \pm 110$ & 155 & Q & 7.5 & 1197 & 0.2 & 0.8 \\
\hline 4 & $550 \pm 100$ & 206 & $\mathrm{SC}$ & 9.3 & 1198 & 0.5 & 0.6 \\
\hline
\end{tabular}

${ }^{\mathrm{a}}$ Includes time for ramp from $300^{\circ} \mathrm{C}$ and hold time (see Figure 135 for temperature history).

The load-displacement curves are presented because they reveal more information (e.g., maximum load) than just the summary values in Table 61 . Figure 141 shows the load-displacement curve for the sample oxidized to $2.7 \% \mathrm{CP}$-ECR at a maximum temperature of $1110^{\circ} \mathrm{C}$ during the ramp. The test was stopped after an offset displacement of $4.75 \mathrm{~mm}$, which is close to the geometrical limit where the top and bottom ends contact the thermocouple across the sample. The sample was intact and had as much ductility as the as-fabricated HBR-type Zry- 4 cladding. The results are significant because the presence of $550 \pm 100 \mathrm{wppm}$ hydrogen had no effect on the ductility of the sample at such a low oxidation level. With a test time of only $62 \mathrm{~s}$ from $300^{\circ} \mathrm{C}$ to $1110^{\circ} \mathrm{C}$, there was not enough time at high temperature for significant oxygen diffusion into the beta layer to occur. Some of the increase in load at large displacements is due to the stiffness of two thermocouples in contact with the sides of the ring.

Based on the post-quench-ductility results for prehydrided samples (see Figure 110 ), the $4.3 \% \mathrm{CP}$ ECR sample was expected to have low ductility. Two 8-mm-long rings were sectioned from the oxidation sample. The first ring tested experienced a sharp $40 \%$ load drop after $12 \%$ offset strain (see Figure 142a). The load drop was accompanied by a sharp cracking noise. However, the post-test sample had a crack initiating on the inner surface that did not penetrate through the wall. The second ring was tested under the same conditions (see Figure 142b). The load decrease with displacement was gradual, indicative of a highly ductile ring, and the only sharp load drop observed (and cracking sound heard) was at the end of the test at very low load. After 53\% offset strain, the ring was in the shape of a bow tie (infinity symbol) with a single crack through the wall of the cladding across the length of the ring. Although a partial crack may have formed anywhere in the range of 18-53\% offset strain and developed into a through-wall crack at $53 \%$ offset strain, it is more likely that the slow-growing crack penetrated the wall at an intermediate strain. Based on judgment and experience, $37 \%$ offset strain is assumed to represent the ductility of this sample. It is much higher than offset strains measured for prehydrided samples, which were quenched at $800^{\circ} \mathrm{C}$ following oxidation to $5 \% \mathrm{CP}$-ECR. The lower peak oxidation temperature $\left(1169^{\circ} \mathrm{C}\right.$ vs. $\left.1180-1190^{\circ} \mathrm{C}\right)$, the lower CP-ECR (4.3\% vs. $\left.5.0 \%\right)$, and the cooling history (slow cooling vs. quench) all contributed to the relatively high ductility of this sample. 


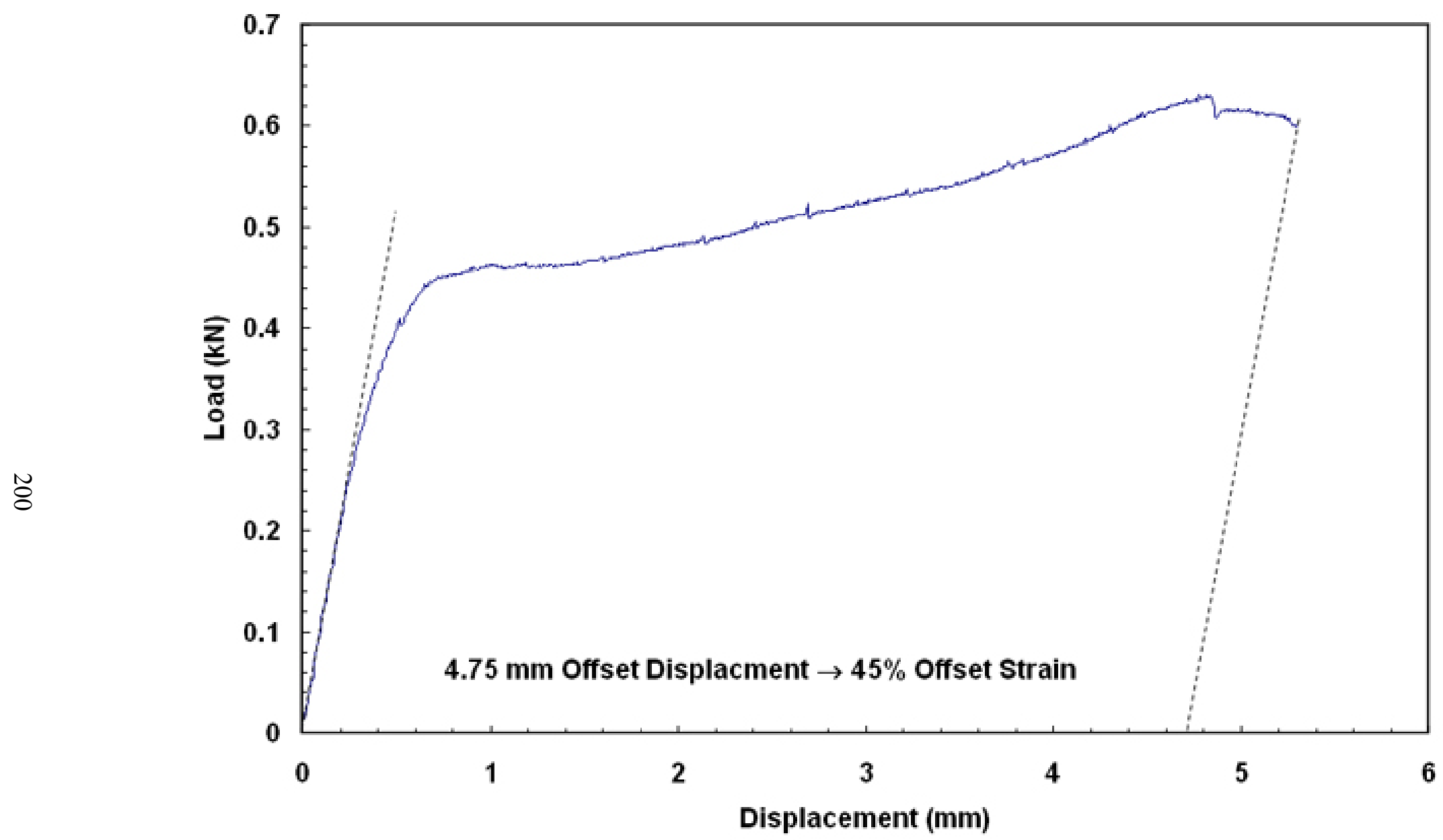

Figure 141. Load-displacement curve for high-burnup HBR Zry-4 sample $\left(550 \pm 100\right.$ wppm H) oxidized (two-sided) at $\mathrm{T} \leq 1110^{\circ} \mathrm{C}$ to $2.7 \%$ CP-ECR and slow cooled to RT. The ring-compression test was conducted at $135^{\circ} \mathrm{C}$ and $0.0333-\mathrm{mm} / \mathrm{s}$ displacement rate. The ring was intact after the test, indicating that ductility was $>45 \%$. 


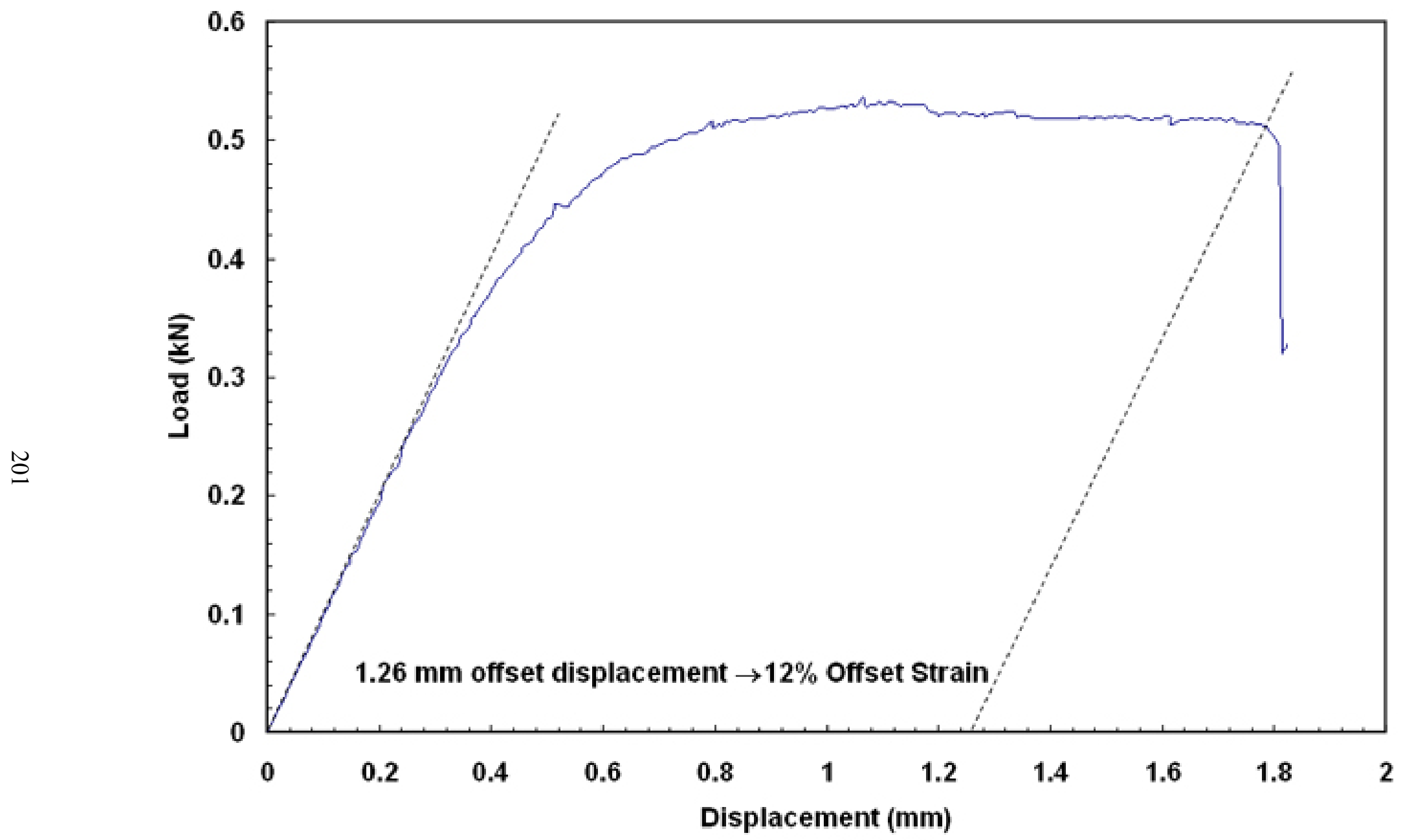

Figure 142a. Load-displacement curve for high-burnup HBR Zry-4 Ring \#1 $(550 \pm 100$ wppm H) cut from sample oxidized (two-sided) at T $\leq$ $1169^{\circ} \mathrm{C}$ to $4.3 \% \mathrm{CP}-\mathrm{ECR}$ and slow cooled to RT. The ring-compression test was conducted at $135^{\circ} \mathrm{C}$ and $0.0333-\mathrm{mm} / \mathrm{s}$ displacement rate. The ring had a partial-wall crack after the first load drop, indicating that ductility was $>12 \%$. 


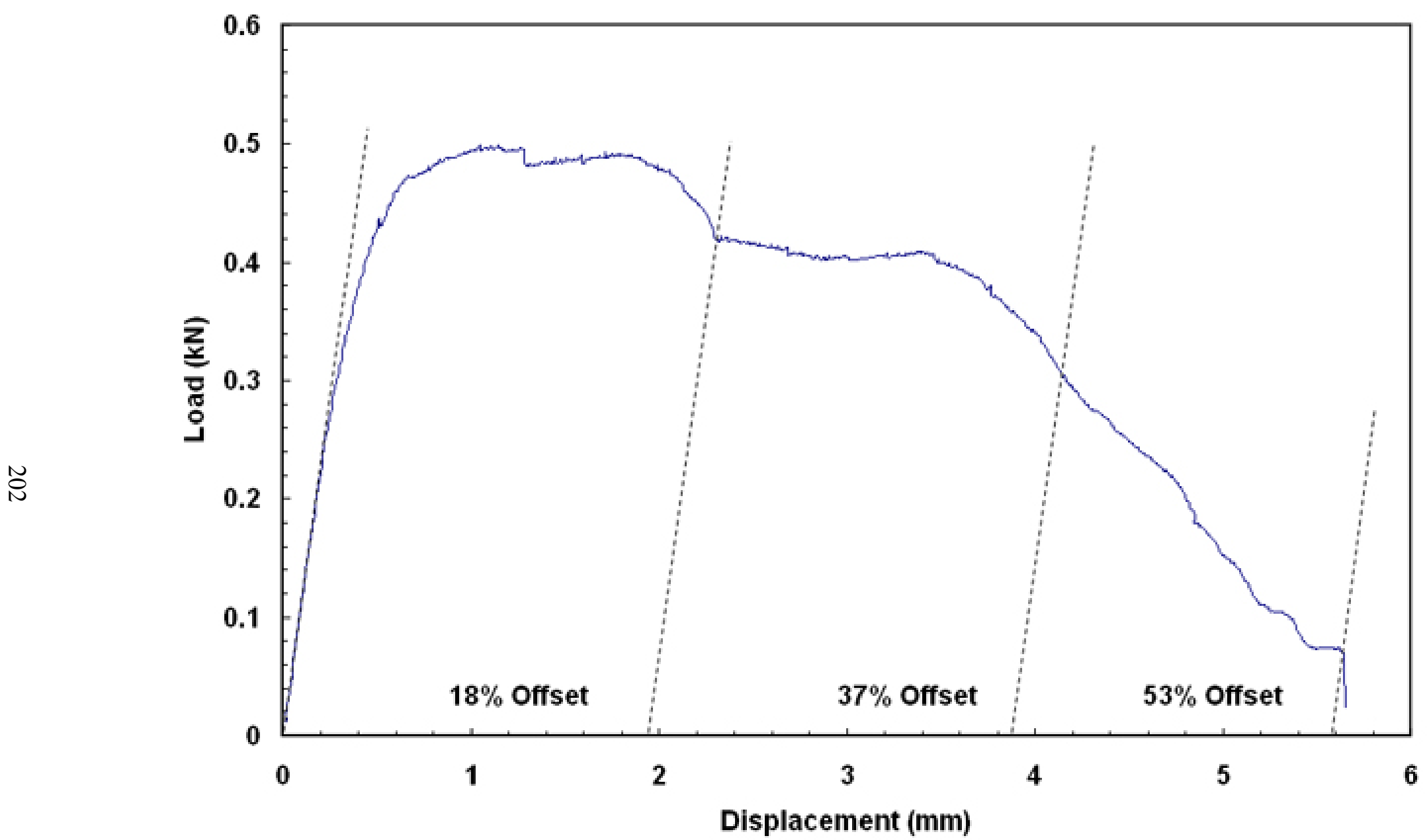

Figure 142b. Load-displacement curve for high-burnup HBR Zry-4 Ring \#2 (550 \pm 100 wppm H) cut from sample oxidized (two-sided) at T $\leq$ $1169^{\circ} \mathrm{C}$ to $4.3 \% \mathrm{CP}-\mathrm{ECR}$ and slow cooled to RT. The ring-compression test was conducted at $135^{\circ} \mathrm{C}$ and $0.0333-\mathrm{mm} / \mathrm{s}$ displacement rate. The ring had a single through-wall crack after $53 \%$ offset strain. Because it is not clear at what strain this crack occurred, the offset strain (37\%) corresponding to a $40 \%$ load drop is used to represent the ductility of the sample. 
Figure 143 shows the load-displacement curve for the high-burnup HBR Zry-4 sample with $550 \pm 100$ wppm hydrogen, which was oxidized to $6.4 \%$ CP-ECR at a peak oxidation temperature of $1196^{\circ} \mathrm{C}$. The sharp load drop corresponded to through-wall failure across the length of the ring. Offset $(4.0 \%)$ and permanent $(2.6 \%)$ strains for this sample are given in Table 61 . By ANL criteria ( $\geq 2 \%$ offset strain and/or $\geq 1 \%$ permanent strain), the sample is ductile. However, the low ductility indicates a significant decrease in ductility between $4.3 \%$ and $6.4 \%$ CP-ECR heating phase oxidation levels ( $4.5 \%$ to $6.6 \%$ total oxidation levels, including oxygen pickup during the cooling phase).

The 7.4\% CP-ECR test was conducted because it was estimated that embrittlement would occur at this oxidation level for Zry-4 with 550 100 wppm hydrogen. However, Figure 144 shows that the offset strain $(4.0 \%)$ was the same as for the $6.3 \%$ CP-ECR sample, and the permanent strain was comparable $(2.9 \%$ vs. $2.6 \%)$. The test was repeated with a high-burnup HBR Zry-4 sample with higher hydrogen content $(740 \pm 110 \mathrm{wppm})$ and with quench at $800^{\circ} \mathrm{C}$. The CP-ECR was slightly higher $(7.5 \%$ vs. $7.4 \%)$ because of the thinner metal wall. Consistent with prehydrided samples $(>400 \mathrm{wppm} \mathrm{H})$ oxidized at $1200^{\circ} \mathrm{C}$ to $7.5 \% \mathrm{CP}-\mathrm{ECR}$ and quenched at $800^{\circ} \mathrm{C}$, this high-burnup sample was highly brittle (see Figure 145). The 9.3\% CP-ECR test sample, which was slow cooled, was also highly brittle (see Figure 146).

Figure 147 shows the post-oxidation and post-quench ductility data plotted as a function of CPECR. A trend curve is also plotted for the slow-cooled samples with 550 100 wppm hydrogen. Using interpolation, we calculated that the ductile-to-brittle transition CP-ECR for these high-burnup samples is $\approx 8 \%$ following slow cooling to RT. Although oxidation tests with quench at $800^{\circ} \mathrm{C}$ were not conducted with 550-wppm high-burnup Zry-4 samples, engineering judgment and insights can be used to estimate the transition CP-ECR at this hydrogen level for quenched Zry-4. Notice in Figure 147 that the 4.3\% CPECR with 550-wppm hydrogen and cooled without quench exhibited $37 \%$ offset strain. From our experience with prehydrided Zry-4 (Figures 116 and 117) and irradiated ZIRLO (Figure 167 in 5.2.3), this sample would have retained ductility following quench. On the other hand the $6.4 \% \mathrm{CP}$-ECR, with 550-wppm hydrogen and cooled without quench, exhibited only 4\% ductility. Using the same judgment and insights, this sample would likely be brittle following quench. Thus, to the nearest percent CP-ECR, the ductile-to-brittle transition CP-ECR for high-burnup Zry-4 with 550-wppm hydrogen is estimated to be $\approx 5 \%$.

As shown in Figures 116 and 117, the embrittlement of prehydrided Zry-4 samples oxidized at $1200^{\circ} \mathrm{C}$ and quenched at $800^{\circ} \mathrm{C}$ is very sensitive to average hydrogen content. Based on the results of several quench tests, embrittlement of prehydrided Zry-4 is also sensitive to circumferential variations $( \pm 100 \mathrm{wppm})$ in hydrogen content. The same sensitivity is expected for irradiated Zry-4 oxidized and cooled with quench. However, embrittlement of prehydrided Zry-4 oxidized at $1200^{\circ} \mathrm{C}$ and cooled without quench exhibited less sensitivity to hydrogen content because of the slow decrease in ductility with increasing hydrogen content. This behavior of slow-cooled Zry-4 allows more latitude in comparing the ductility of oxidized prehydrided and high-burnup Zry-4 as a function of CP-ECR for hydrogen contents in the range of 470-720 wppm. Table 62 lists results for comparable prehydrided and irradiated Zry-4 samples cooled without quench. Figure 148 shows permanent strains for these samples as a function of CP-ECR. The results suggest that, for slow-cooled samples, the ductility of prehydrided Zry4 may be lower than the ductility of high-burnup Zry-4, but the results are certainly comparable within the data scatter. Also, for prehydrided Zry-4, all the hydrogen measured is in the metal, whereas for highburnup Zry-4 samples, the 550 $\pm 100 \mathrm{wppm}$ hydrogen value includes all hydrogen that is in the cladding and the corrosion layer $(71-74 \mu \mathrm{m})$, as well as the combined mass of cladding and corrosion layer. If all the hydrogen were in the metal, it would contain $\approx 600 \mathrm{wppm}$. If some of the hydrogen is in the corrosion layer, the metal hydrogen content could be as low as $\approx 500 \mathrm{wppm}$. These differences would have a more significant effect on Zry-4 samples quenched at $800^{\circ} \mathrm{C}$ as compared to slow cooled samples. 


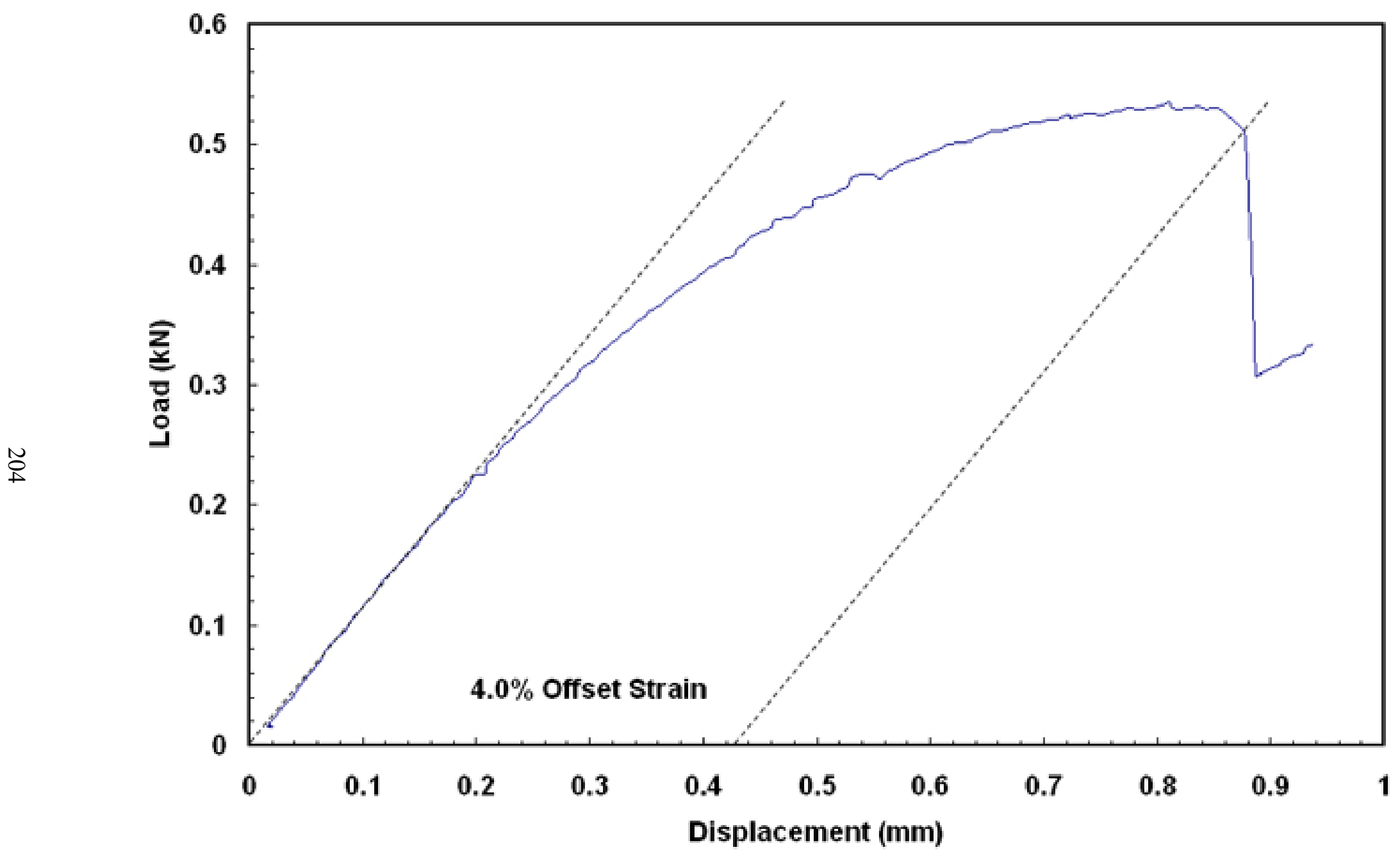

Figure 143. Load-displacement curve for high-burnup HBR Zry-4 (550 $\pm 100 \mathrm{wppm} \mathrm{H})$ sample oxidized (two-sided) at $\mathrm{T} \leq 1196^{\circ} \mathrm{C}$ to $6.4 \% \mathrm{CP}-\mathrm{ECR}$ and slow cooled to RT. The ring-compression test was conducted at $135^{\circ} \mathrm{C}$ and $0.0333-\mathrm{mm} / \mathrm{s} \mathrm{displacement} \mathrm{rate.} \mathrm{The} \mathrm{ring} \mathrm{had} \mathrm{a} \mathrm{single} \mathrm{through-}$ wall crack along the length of the sample at $4.0 \%$ offset strain, corresponding to the sharp load drop. 


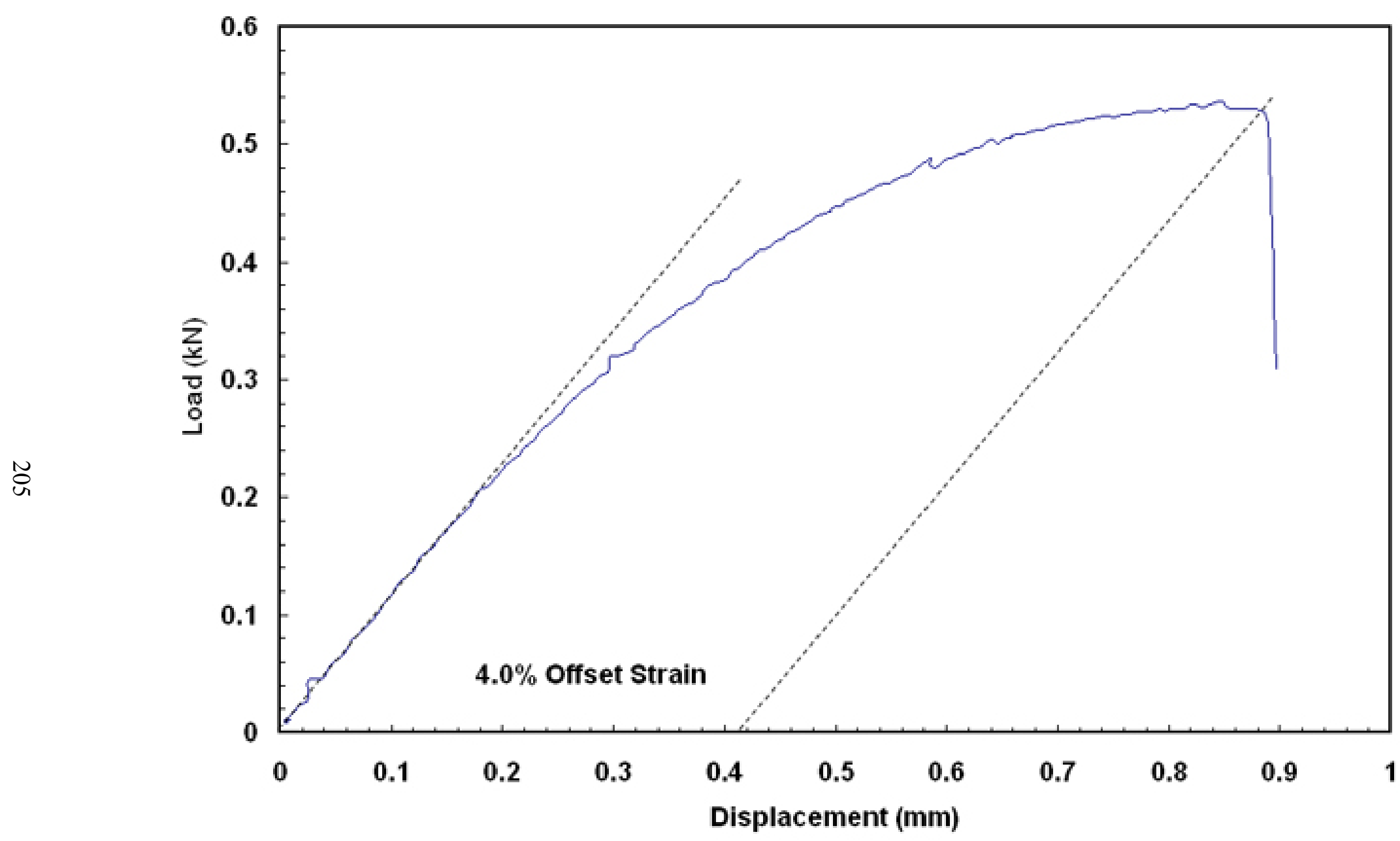

Figure 144. Load-displacement curve for high-burnup HBR Zry-4 $(550 \pm 100 \mathrm{wppm} \mathrm{H})$ sample oxidized (two-sided) at $1197^{\circ} \mathrm{C}$ to $7.4 \% \mathrm{CP}-\mathrm{ECR}$ and slow cooled to RT. The ring-compression test was conducted at $135^{\circ} \mathrm{C}$ and $0.0333-\mathrm{mm} / \mathrm{s}$ displacement rate. The ring had a single through-wall crack along the length of the sample at $4.0 \%$ offset strain, corresponding to the sharp load drop. 


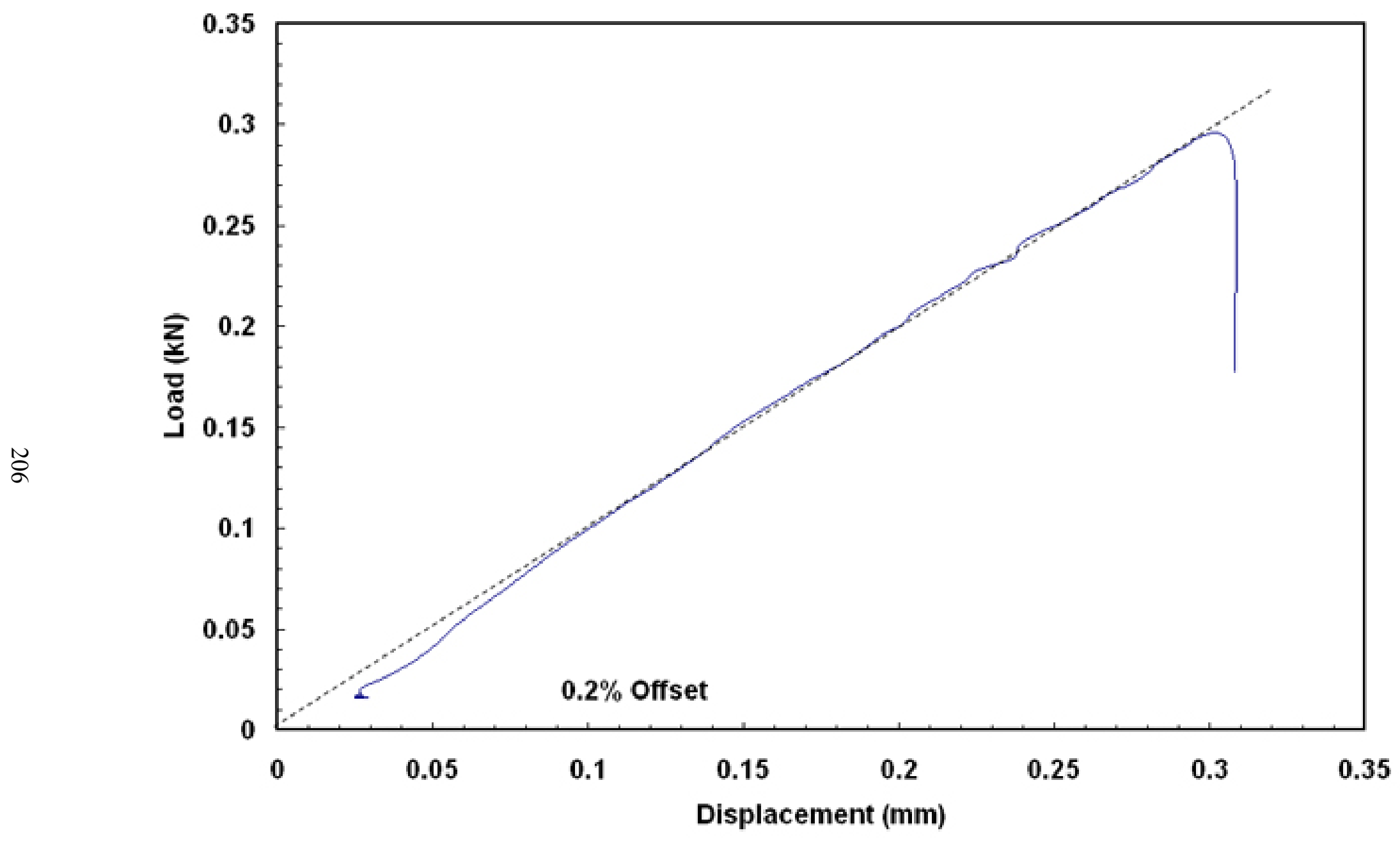

Figure 145. Load-displacement curve for high-burnup HBR Zry-4 $\left(740 \pm 110\right.$ wppm H) sample oxidized (two-sided) at $1198^{\circ} \mathrm{C}$ to $7.5 \%$ CP-ECR and quenched at $800^{\circ} \mathrm{C}$. The ring-compression test was conducted at $135^{\circ} \mathrm{C}$ and $0.0333-\mathrm{mm} / \mathrm{s}$ displacement rate. The sharp load drop occurred essentially in the elastic deformation region and corresponded to a single through-wall crack along the length of the sample and no ductility. 


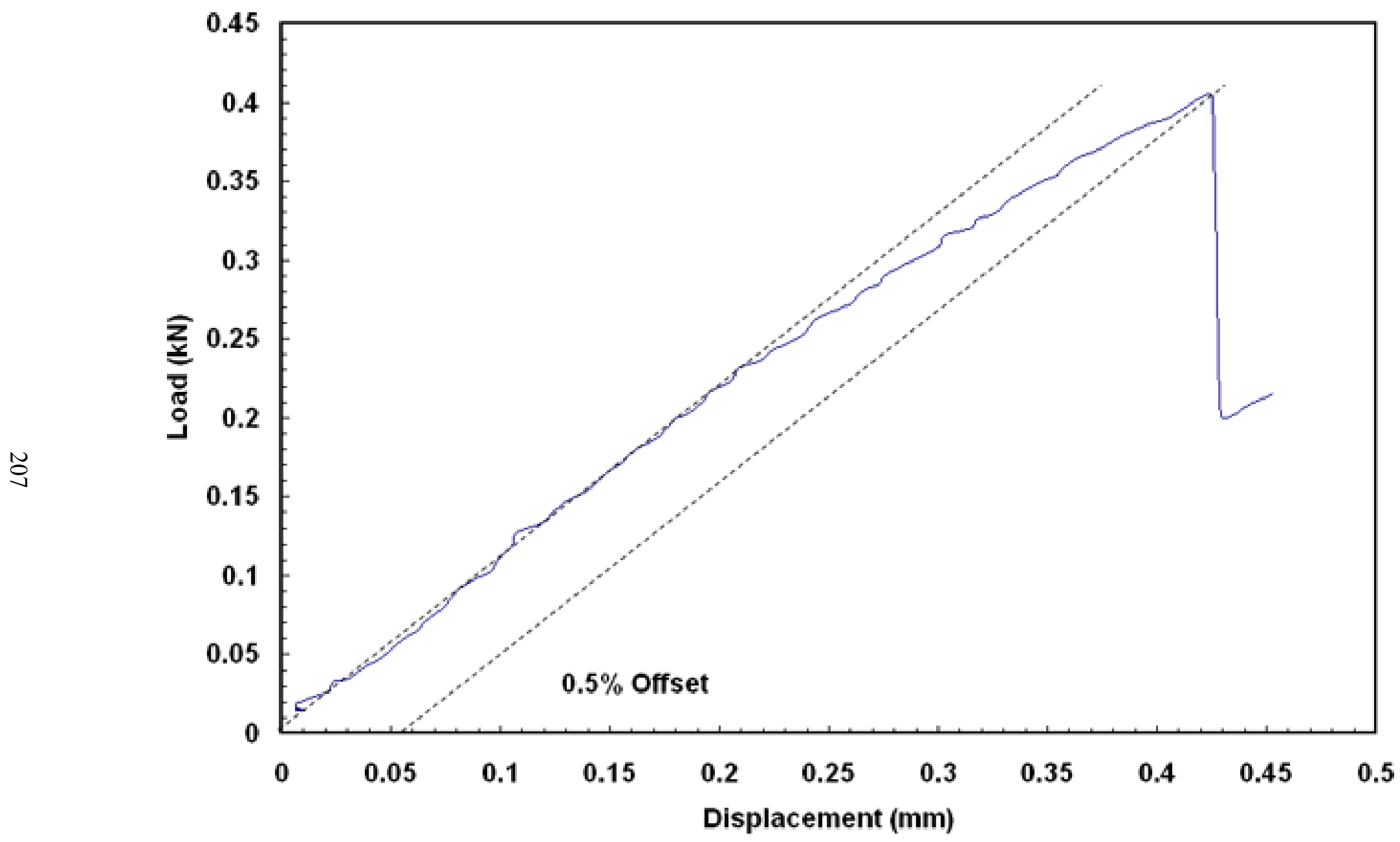

Figure 146. Load-displacement curve for high-burnup HBR Zry-4 $(550 \pm 100 \mathrm{wppm} \mathrm{H})$ sample oxidized (two-sided) at $1198^{\circ} \mathrm{C}$ to $9.3 \% \mathrm{CP}-\mathrm{ECR}$ and slow cooled to RT. The ring-compression test was conducted at $135^{\circ} \mathrm{C}$ and $0.0333-\mathrm{mm} / \mathrm{s}$ displacement rate. The ring had a single through-wall crack along the length of the sample at very low offset strain (brittle), corresponding to the sharp load drop. 


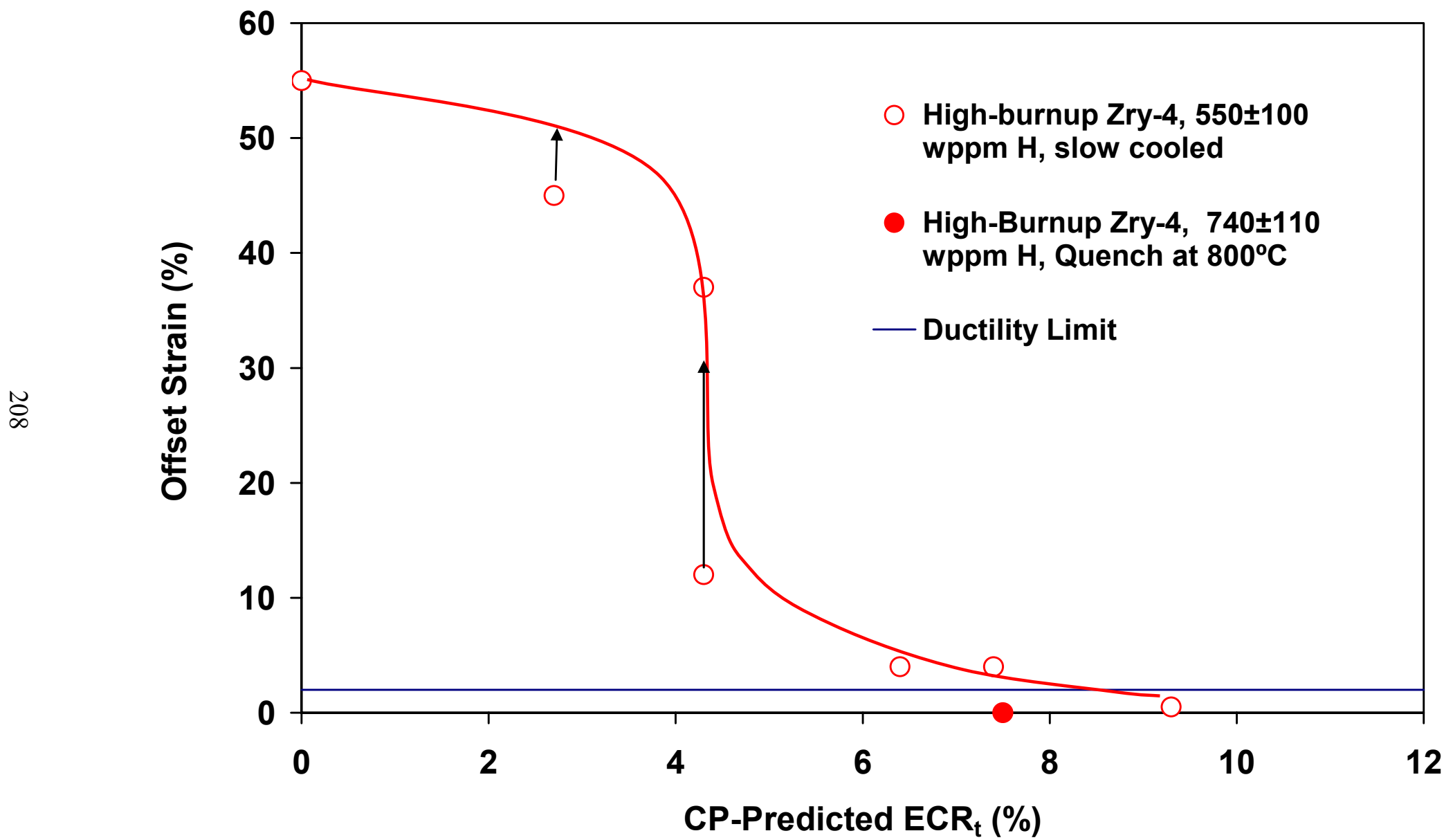

Figure 147. Ductility at $135^{\circ} \mathrm{C}$ vs. CP-ECR for high-burnup HBR Zry-4 cladding following oxidation (two-sided) at $\leq 1200^{\circ} \mathrm{C}$ and either slow cooling to room temperature or quench at $800^{\circ} \mathrm{C}$. For the slow-cooled samples, the ductile-to-brittle transition CP-ECR is $\approx 8 \%$. For tests terminated prior to through-wall failure, arrows indicate that failure strains would be higher than end-of-test offset strains. 
Table 62. Ductility Data from Two-sided Oxidation Tests at $1200^{\circ} \mathrm{C}$ followed by Slow Cooling for Highburnup and Prehydrided (Unirradiated) Zry-4 Cladding Samples.

\begin{tabular}{|c|c|c|c|c|}
\hline $\begin{array}{c}\text { Cladding } \\
\text { Condition }\end{array}$ & $\begin{array}{c}\text { H Content, } \\
\text { wppm }\end{array}$ & $\begin{array}{c}\text { CP-ECR, } \\
\%\end{array}$ & $\begin{array}{c}\text { Offset } \\
\text { Strain, } \\
\%\end{array}$ & $\begin{array}{c}\text { Permanent } \\
\text { Strain, } \\
\%\end{array}$ \\
\hline \hline Prehydrided & 720 & 5.0 & 3.4 & 2.7 \\
\hline Prehydrided & 470 & 6.0 & 2.1 & 1.7 \\
\hline Prehydrided & 470 & 6.0 & 4.9 & 3.6 \\
\hline High-burnup & $550 \pm 100$ & 6.4 & 4.0 & 2.6 \\
\hline Prehydrided & 490 & 7.4 & 3.3 & 2.4 \\
\hline Prehydrided & 530 & 7.4 & 1.4 & 0.9 \\
\hline Prehydrided & 570 & 7.4 & 1.8 & 1.3 \\
\hline High-burnup & $550 \pm 100$ & 7.4 & 4.0 & 2.9 \\
\hline High-burnup & $550 \pm 100$ & 9.3 & 0.5 & 0.6 \\
\hline
\end{tabular}

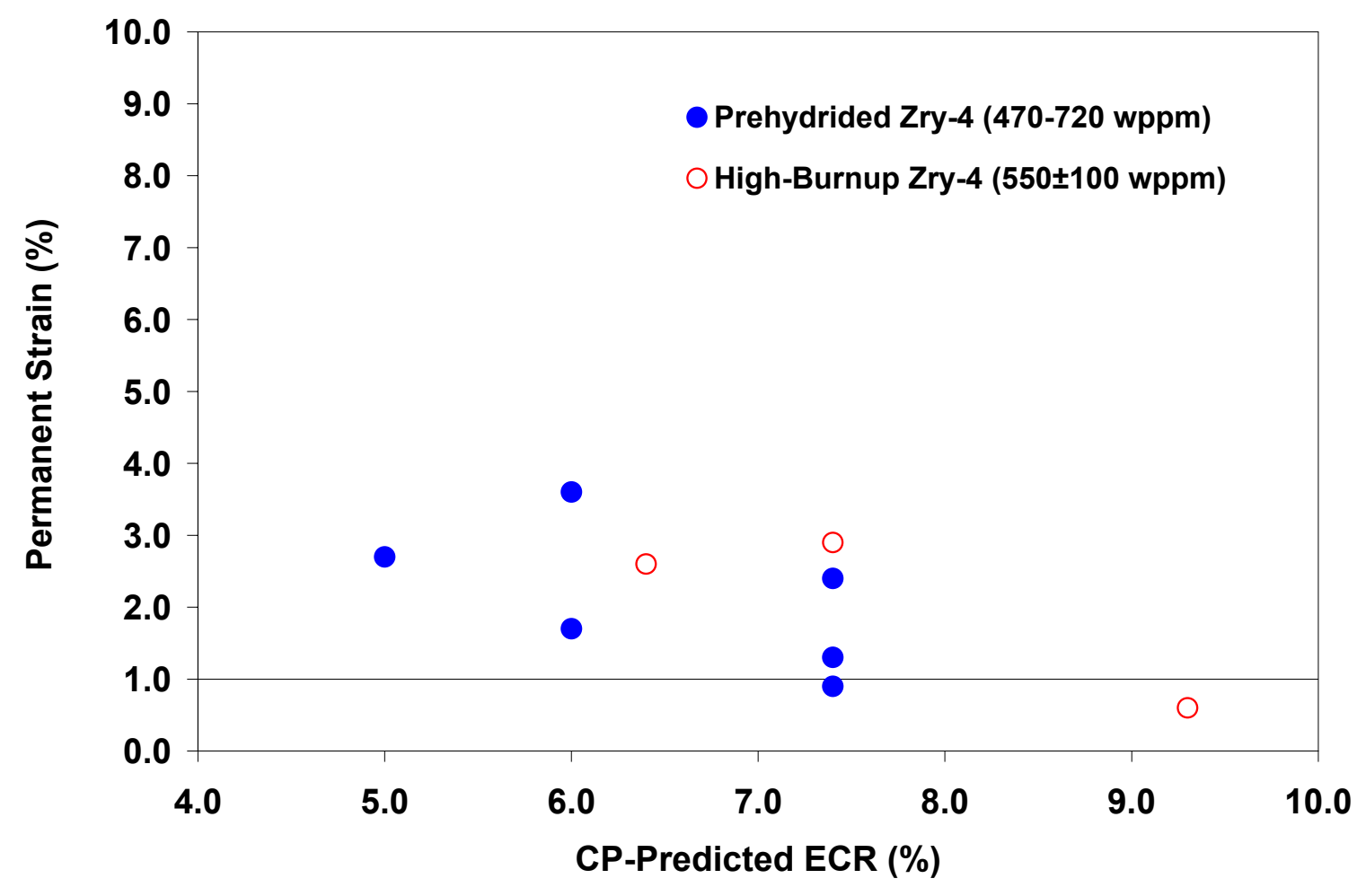

Figure 148. Permanent strain data from two-sided oxidation tests at $1200^{\circ} \mathrm{C}$ followed by slow cooling to RT for high-burnup and prehydrided (unirradiated) Zry-4 cladding samples. 


\subsubsection{Results of one-sided oxidation tests for high-burnup HBR 15x15 Zry-4}

The purposes of conducting one-sided oxidation tests were to investigate post-oxidation ductility of high-burnup Zry-4 cladding away from the balloon region (where there would be no inner-surface steam oxidation) and the influence of the outer-surface corrosion layer on steam-oxidation kinetics at $1200^{\circ} \mathrm{C}$. Test planning and initial data interpretation were based on the CP-ECR calculated for outer-surface steam oxidation of bare cladding, which is consistent with the manner in which LOCA embrittlement calculations are currently performed for licensing purposes. This calculation does not account for the oxygen source inside fueled cladding samples from the fuel-cladding bond and the fuel itself. Of these two internal sources of oxygen, only the fuel-cladding bond oxygen source could be investigated in these studies with defueled cladding. Differences in ductility vs. CP-ECR between the one-sided- and twosided-oxidized high-burnup samples, along with metallographic results, were used to infer the influence of the fuel-cladding bond oxide on embrittlement. The effects on ductility of oxygen in the fuel are discussed in Section 6.

The system used in 2001 to conduct oxidation kinetics studies with high-burnup Limerick Zry-2 was duplicated in 2005 to conduct these one-sided oxidation tests. The test train was essentially the same as the one shown in Figure 9 without the drilled holes. Steam leakage into the inner volume through the sample-gasket and gasket-spacer interfaces was a concern, but it was not a major problem with the tests conducted in 2001. The slow-flowing argon purge through the center of the samples was sufficient to minimize inner-surface oxidation at the ends of the sample to $<10 \%$ of the sample length. Hydrogen pickup through the inner surface of the cladding due to hydrogen generation from the small amount of steam leakage did not appear to be a significant issue in 2001 because the hydrogen content of the asirradiated Zry-2 cladding was $\approx 70 \mathrm{wppm}$, and the hydrogen content of the post-oxidation samples was $<100$ wppm. The $1200^{\circ} \mathrm{C}$ Zry- 2 samples were exposed to steam for $300-1200 \mathrm{~s}$ in the 2001 tests. The times for the 2005 tests with high-burnup Zry-4 were considerably shorter (174-534 s).

For the one-sided tests, the same test train was used for the out-of-cell thermal benchmarks and for the in-cell tests. Figure 149 shows the results of the thermal benchmark test using as-fabricated HBRType Zry-4 cladding. The controller parameters were chosen to ramp quickly to high temperature without temperature overshoot. Also shown in Figure 149 are the results of thermal benchmark tests with the starting cladding material pre-oxidized in steam at $1200^{\circ} \mathrm{C}$ to outer-surface oxide layer thicknesses of $42 \mu \mathrm{m}$ and $62 \mu \mathrm{m}$. Two thermocouples were welded directly to the Zry-4 metal prior to pre-oxidation for these tests. The average of the two thermocouple readings is plotted in Figure 149. The heat-of-oxidation effect on the cladding temperature appears to be negligible for pre-oxidized cladding with a $42-\mu \mathrm{m}$ oxide layer. The temperature history for the sample with the $62-\mu \mathrm{m}$ oxide layer is about the same as the one for the $42-\mu \mathrm{m}$ oxide layer. The $42-\mu \mathrm{m}$ pre-oxide-layer temperature history was used to plan and interpret test results for the one-sided high-burnup HBR Zry-4 tests. Figure 150 compares the faster-ramp temperature history for the one-sided oxidation tests to the slower-ramp temperature for the two-sided tests (see Figure 135).

Table 63 summarizes the test conditions for the one-sided oxidation tests. All samples were slow cooled from $1200^{\circ} \mathrm{C}$. The test chamber inlet port, which had been used to flood the chamber with quench water in two-sided oxidation tests, was used for the argon purge in these tests. As can be seen in Table 63 , all samples reached $1200^{\circ} \mathrm{C}$ oxidation temperature and were at $1200^{\circ} \mathrm{C}$ for substantial periods of time.

Figure 151 shows the cutting diagram for the oxidized high-burnup Zry-4 samples. Because of concern regarding inner-surface oxidation and hydrogen pickup away from the sample midplane, only one 8-mm-long ring $(\mathrm{C} 2)$ was sectioned from the midplane region for ring-compression testing. 


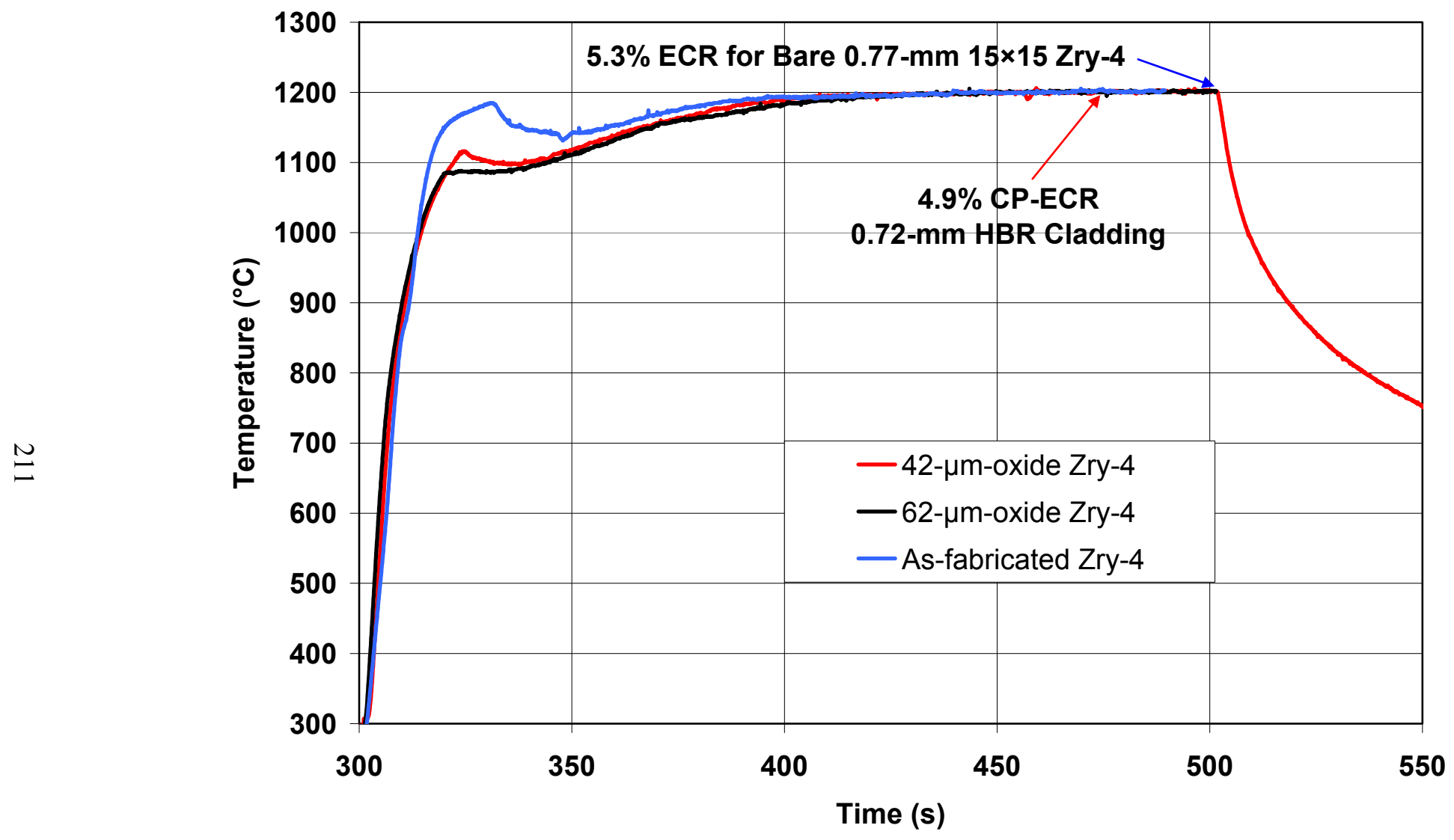

Figure 149. Thermal-benchmark results for unirradiated, HBR-type Zry-4 exposed to one-sided (outer-surface) oxidation: as-fabricated, preoxidized to 42- $\mu \mathrm{m}$ outer-surface oxide layer; and pre-oxidized to $62-\mu \mathrm{m}$ outer-surface oxide layer. The temperature history for the $42-\mu \mathrm{m}$ oxide layer benchmark was used to plan and interpret the results from the one-sided oxidation tests with corroded (68- $\mu \mathrm{m})$, high-burnup HBR Zry-4. 


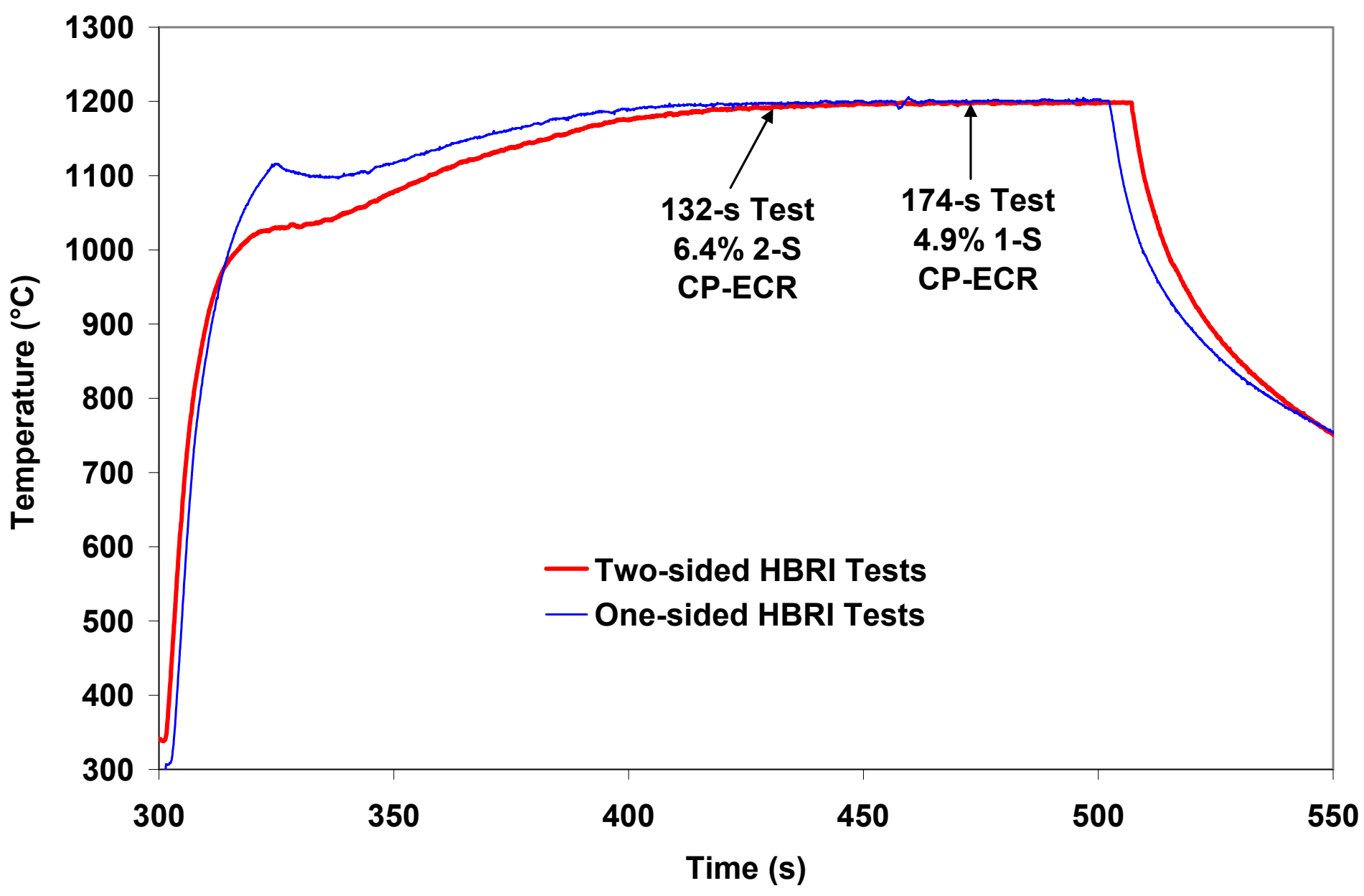

Figure 150. Temperature histories for the one-sided and two-sided steam oxidation tests using high-burnup HBR Zry-4 cladding samples. 
Hydrogen content was determined for the rings after ring-compression testing. The samples on either side of the 8-mm-long ring ( $\mathrm{C} 1$ and $\mathrm{C} 3)$ were used for metallographic examination.

Table 63. Sample Characterization and Test Conditions for One-sided Steam Oxidation Tests (HBRI) Tests conducted with high-burnup HBR Zry-4 cladding. SC is slow cooling.

\begin{tabular}{|c|c|c|c|c|c|c|c|}
\hline $\begin{array}{c}\text { HBRI } \\
\text { Test } \\
\text { ID } \#\end{array}$ & $\begin{array}{c}\text { Corrosion } \\
\text { Layer, } \\
\mu \mathrm{m}\end{array}$ & $\begin{array}{c}\text { Hydrogen } \\
\text { Content, } \\
\text { wppm }\end{array}$ & $\begin{array}{c}\text { Test } \\
\text { Time, } \\
\mathrm{s}\end{array}$ & $\begin{array}{c}\text { One-sided } \\
\text { CP-ECR, } \\
\%\end{array}$ & $\begin{array}{c}\text { Maximum } \\
\mathrm{T}, \\
{ }^{\circ} \mathrm{C}\end{array}$ & $\begin{array}{c}\text { Time at } \\
\mathrm{T} \geq \\
1180^{\circ} \mathrm{C}, \\
\mathrm{s}\end{array}$ & Cooling \\
\hline \hline 7 & 68 & $550 \pm 100$ & 174 & 4.9 & 1200 & 85 & $\mathrm{SC}$ \\
\hline 11 & 44 & $\approx 400$ & 174 & 4.8 & 1200 & 85 & $\mathrm{SC}$ \\
\hline 8 & 68 & $550 \pm 100$ & 323 & 7.3 & 1200 & 234 & $\mathrm{SC}$ \\
\hline 12 & $\approx 40$ & $\approx 360$ & 323 & 7.1 & 1200 & 234 & $\mathrm{SC}$ \\
\hline 10 & 68 & $550 \pm 100$ & 419 & 8.5 & 1200 & 330 & $\mathrm{SC}$ \\
\hline 9 & 68 & $550 \pm 100$ & 534 & 9.7 & 1200 & 445 & $\mathrm{SC}$ \\
\hline
\end{tabular}

${ }^{\mathrm{a}}$ Includes time for ramp from $300^{\circ} \mathrm{C}$ and hold time.

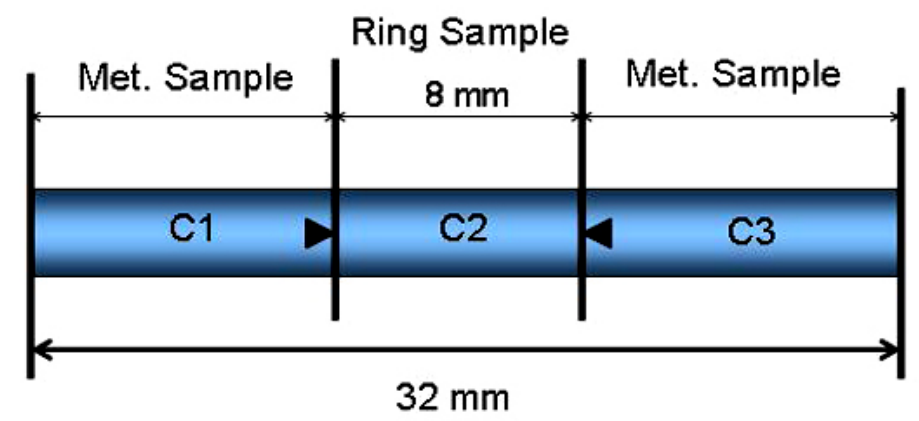

Figure 151. Sectioning diagram for high-burnup HBR Zry-4 samples after one-sided oxidation. Points of triangles indicate surfaces designated for metallographic characterization.

Table 64 summarizes the post-test results for the high-temperature oxide layer formed on the cladding outer surface and the hydrogen content of the samples. The post-test hydrogen analysis was performed on ring sectors cut from the oxidized-and-compressed rings. The hydrogen values were not corrected for weight gain due to oxidation. The weight of the post-oxidized samples was only slightly less than the weight of the pre-oxidized samples. Although the main purpose of the post-test hydrogen analysis was to determine if the samples picked up additional hydrogen due to steam leakage and innersurface oxidation near the ends of the sample, the results indicated that fuel-mid-plane samples oxidized for 174-419 s actually lost hydrogen. The last column in Table 64 indicates whether or not inner-surface oxidation was observed at the ends of the 8-mm-long ring used for ring-compression ductility tests. No inner surface oxide was observed for the HBRI\#7 (4.9\% 1-S CP-ECR) and the HBRI\#8 (7.3\% 1-S CPECR) test samples. For HBRI\#10 (8.5\% 1-S CP-ECR) about $15 \%$ of the inner surface exhibited some oxide-layer growth from steam leakage. For HBRI\#9 (9.7\% 1-S CP-ECR), over $80 \%$ of the cross section at $4 \mathrm{~mm}$ from the ring midplane had some degree of inner-surface oxide. These observations were made on the OM-sample cross section adjacent to the end of the ring. Although the HBRI\#11-12 samples were not imaged, both samples appeared to pick up $\approx 180 \mathrm{wppm} \mathrm{H}$. 
Table 64. Post-test Results for High-temperature Oxide Layer Thickness and Hydrogen Content for High-burnup HBR Zry-4 Samples (HBRI) Oxidized in Steam (One-sided) at $1200^{\circ} \mathrm{C}$.

\begin{tabular}{|c|c|c|c|c|c|c|c|}
\hline $\begin{array}{c}\text { HBRI } \\
\text { Test } \\
\text { ID } \#\end{array}$ & $\begin{array}{c}\text { Pre-test } \\
\text { H Content, } \\
\text { wppm }\end{array}$ & $\begin{array}{c}\text { Test } \\
\text { Time, }\end{array}$ & $\begin{array}{c}\text { One-sided } \\
\text { CP-ECR, } \\
\%\end{array}$ & \multicolumn{2}{|c|}{ OD High-T Oxide, $\mu \mathrm{m}$} & $\begin{array}{c}\text { Post-test } \\
\text { H Content. } \\
\text { wppm }\end{array}$ & $\begin{array}{c}\text { ID } \\
\text { Oxide } \\
\text { Layer }\end{array}$ \\
\hline \hline 7 & $550 \pm 100$ & 174 & 4.9 & 38 & $31 \pm 6$ & $335 \pm 31$ & None \\
\hline 11 & $\approx 400$ & 174 & 4.8 & -- & -- & $570 \pm 70$ & --- \\
\hline 8 & $550 \pm 100$ & 323 & 7.3 & 56 & $42 \pm 7$ & $190 \pm 12$ & None \\
\hline 12 & $\approx 360$ & 323 & 7.1 & -- & -- & $550 \pm 70$ & -- \\
\hline 10 & $550 \pm 100$ & 419 & 8.5 & 65 & $53 \pm 7$ & $318 \pm 44$ & $\begin{array}{c}15 \% \text { of Met. } \\
\text { Cross Section }\end{array}$ \\
\hline 9 & $550 \pm 100$ & 534 & 9.7 & 74 & $63 \pm 8$ & $767 \pm 59$ & $\begin{array}{c}>80 \% \text { of Met. } \\
\text { Cross Section }\end{array}$ \\
\hline
\end{tabular}

${ }^{\mathrm{a}}$ Includes time for ramp from $300^{\circ} \mathrm{C}$ and hold time.

Figure 152 compares the measured vs. CP-predicted values for the high-temperature oxide-layer thicknesses of the outer surface. The measured values are $\approx 11 \mu \mathrm{m}$ less than the predicted values. These results are consistent with the two-sided-oxidation test results, which show an average difference of 12 $\mu \mathrm{m}$. They confirm that the corrosion layer slows down the initial growth rate of the steam-oxide layer.

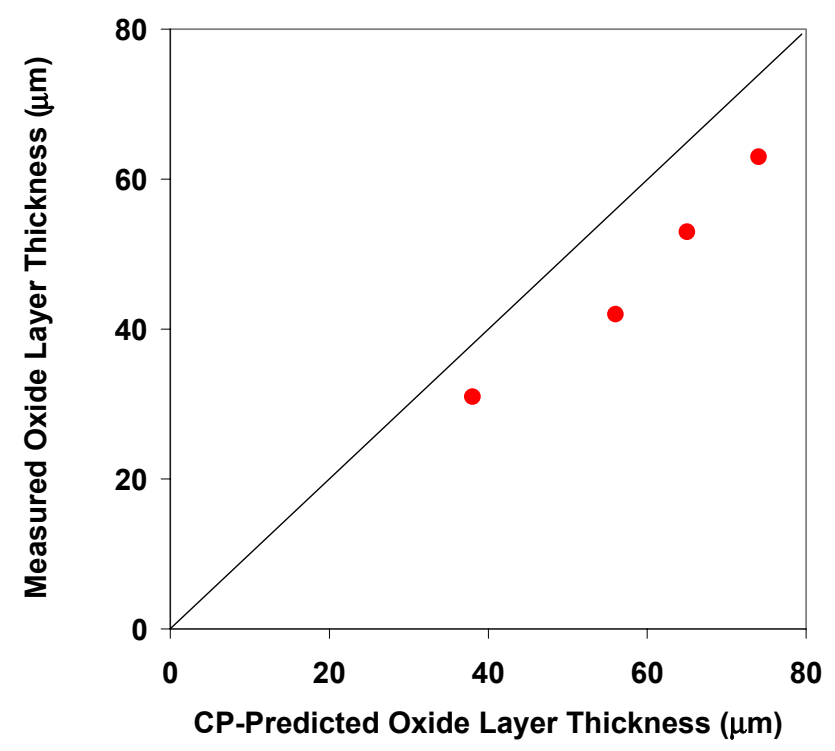

Figure 152. Comparison of measured and CP-predicted values for steam-induced outer-surface oxide layer thicknesses for high-burnup HBR Zry-4 samples oxidized at $1200^{\circ} \mathrm{C}$ to one-sided CP-ECR values of 4.9-9.7\%. Samples had a 68- $\mu \mathrm{m}$ pre-test corrosion layer. 
Table 65 shows the CP-predicted values for the oxygen-stabilized alpha layer formed under steam oxidation conditions. Also shown in Table 65 are the measured values at the inner and outer surfaces for the HBRI\#7 sample after a test time of 174 s prior to slow cooling to RT. Although there is no steam flow along the inner surface, the alpha layer formed from reduction of the fuel-cladding bond layer is comparable to the alpha layer formed at the corroded outer surface, which was exposed to steam flow.

Table 65. Post-test Results for Outer- and Inner-surface Alpha Layers Stabilized at $1200^{\circ} \mathrm{C}$ for Highburnup HBR Zry-4 Samples (HBRI) Oxidized in Steam (One-sided).

\begin{tabular}{|c|c|c|c|c|c|c|c|}
\hline $\begin{array}{c}\text { HBRI } \\
\text { Test } \\
\text { ID \# }\end{array}$ & \multirow{2}{*}{$\begin{array}{c}\text { Post-test } \\
\text { wpontent }\end{array}$} & $\begin{array}{c}\text { Test } \\
\text { Time, } \\
\text { ws }\end{array}$ & \multirow{2}{*}{$\begin{array}{c}\text { One-sided } \\
\text { CP-ECR, } \\
\%\end{array}$} & \multicolumn{3}{|c|}{$\begin{array}{c}\text { Alpha Layer Thickness, } \\
\mu \mathrm{m}\end{array}$} & $\begin{array}{c}\text { ID } \\
\text { Oxide } \\
\text { Layer }\end{array}$ \\
\cline { 5 - 8 } & & & $\begin{array}{c}\text { CP } \\
\text { OD }\end{array}$ & $\begin{array}{c}\text { Meas. } \\
\text { OD }\end{array}$ & $\begin{array}{c}\text { Meas. } \\
\text { ID }\end{array}$ & \\
\hline 7 & $335 \pm 31$ & 174 & 4.9 & 38 & $42 \pm 4$ & $36 \pm 5$ & None \\
\hline 11 & $570 \pm 70$ & 174 & 4.8 & 38 & --- & --- & --- \\
\hline 8 & $190 \pm 12$ & 323 & 7.3 & 57 & $58 \pm 7$ & $35 \pm 8$ & None \\
\hline 12 & $550 \pm 70$ & 323 & 7.1 & 57 & --- & --- & --- \\
\hline 10 & $318 \pm 44$ & 419 & 8.5 & 66 & $70 \pm 8$ & -- & $\begin{array}{c}15 \% \text { of Met. } \\
\text { Cross } \\
\text { Section }\end{array}$ \\
\hline 9 & $767 \pm 59$ & 534 & 9.7 & 76 & $77 \pm 7$ & --- & $\begin{array}{c}>80 \% \text { of } \\
\text { Met. } \\
\text { Cross } \\
\text { Section }\end{array}$ \\
\hline
\end{tabular}

${ }^{\mathrm{a}}$ Includes time for ramp from $300^{\circ} \mathrm{C}$ and hold time.

For each test sample, up to eight metallographic images at equally spaced circumferential locations were used to obtain the data in Tables 64 and 65. Examples of metallographic images used to measure the thicknesses of the high-temperature oxide layer and alpha layer are shown in Figures 153-156. The contrast has been adjusted in Figure 153b for the 174-s test sample (HBRI\#7) to allow distinction between the oxygen-stabilized alpha layer grown at $1200^{\circ} \mathrm{C}$ at the outer surface as compared to the alpha incursions precipitated during cooling. The outer-surface alpha layer stabilized at $1200^{\circ} \mathrm{C}$ is whiter in appearance and relatively uniform in thickness, while the alpha incursions at the outer surface are graywhite and exhibit a more uneven alpha-beta interface (see Figure 153b for outer surface). The alpha-layer thickness is more difficult to measure at the inner surface because the alpha-beta boundary is not as smooth and the color contrast is not as sharp between alpha stabilized at $1200^{\circ} \mathrm{C}$ and alpha incursions. Also, recall from Figures 126 and 127 that the fuel-cladding bond layer is not uniform in thickness $(11 \pm 4$ $\mu \mathrm{m})$. However, the measured alpha-layer thickness is consistent with the complete reduction of the fuelcladding bond oxide, which is estimated to occur at $\approx 100 \mathrm{~s}$ into the 174-s test. Assuming this estimated time, the inner-surface alpha layer would continue to grow from $100 \mathrm{~s}$ to $174 \mathrm{~s}$ at a lower rate than the outer-surface alpha layer, which essentially had an infinite source of oxygen to sustain the growth of the outer-surface layer. The observed difference in alpha-layer thicknesses is relatively small. For the twosided oxidation tests, the inner-surface alpha layer was $\approx 2-\mu \mathrm{m}$ thinner than the outer-surface alpha layer. Accounting for this difference, the inner-surface alpha layer grown from reduction of the fuel-cladding bond is only $\approx 4 \mu \mathrm{m}$ less than expected under flowing steam conditions. The results for the 323-s test sample (HBRI\#8) are also listed in Table 65. While the OD alpha layer continues to grow from $174 \mathrm{~s}$ to $323 \mathrm{~s}$, the ID alpha layer shows no increase in thickness within the precision of the measurements. The results are consistent with what one would expect following the complete reduction of the fuel-cladding bond at $\approx 100$ s during the test. 


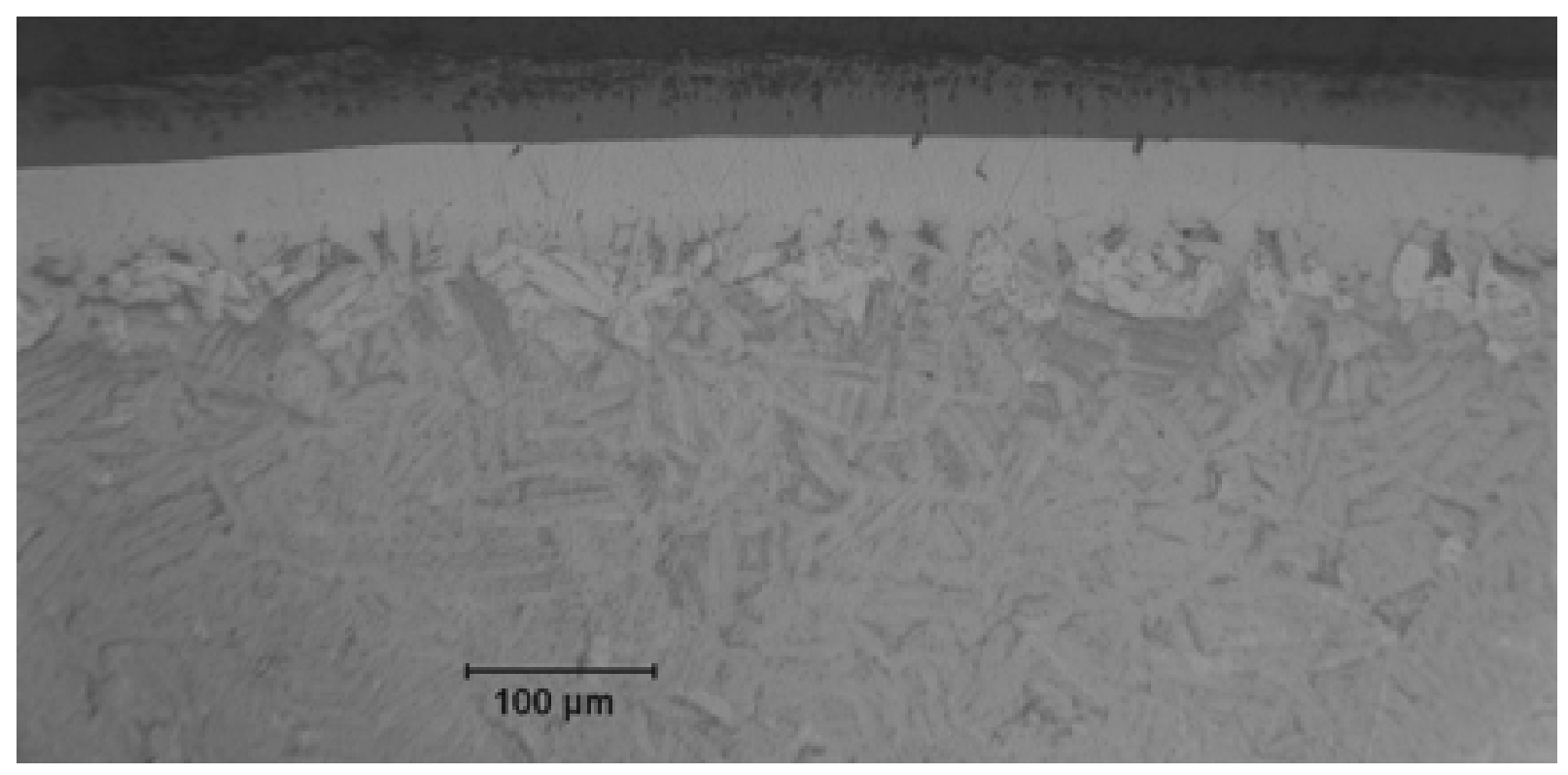

(a)

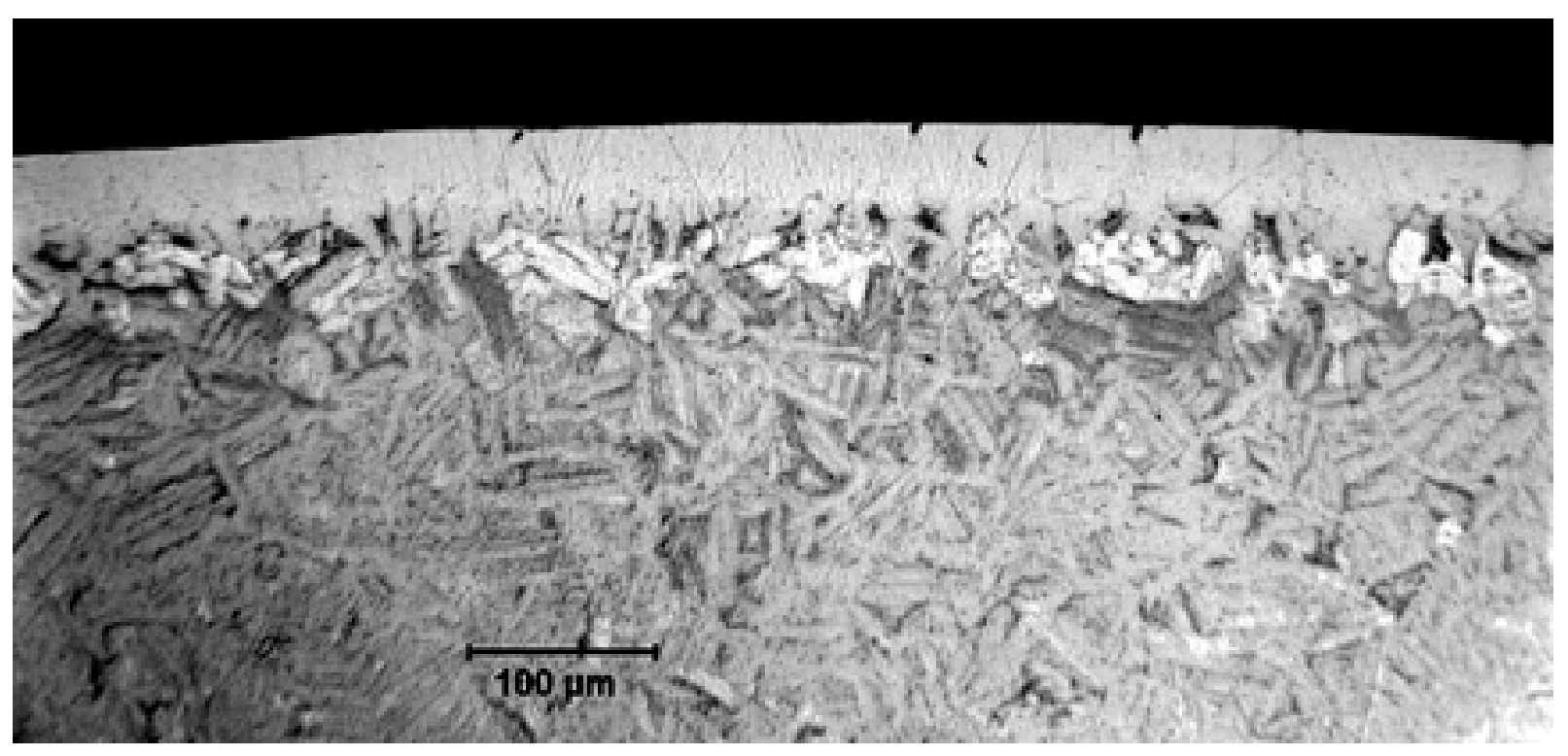

(b)

Figure 153. Outer surface of high-burnup HBR Zry-4 sample one-side oxidized at $1200^{\circ} \mathrm{C}$ for 174 -s test time to $4.9 \%$ CP-ECR: (a) contrast for viewing the oxide layer and (b) contrast for viewing the alpha layer. 


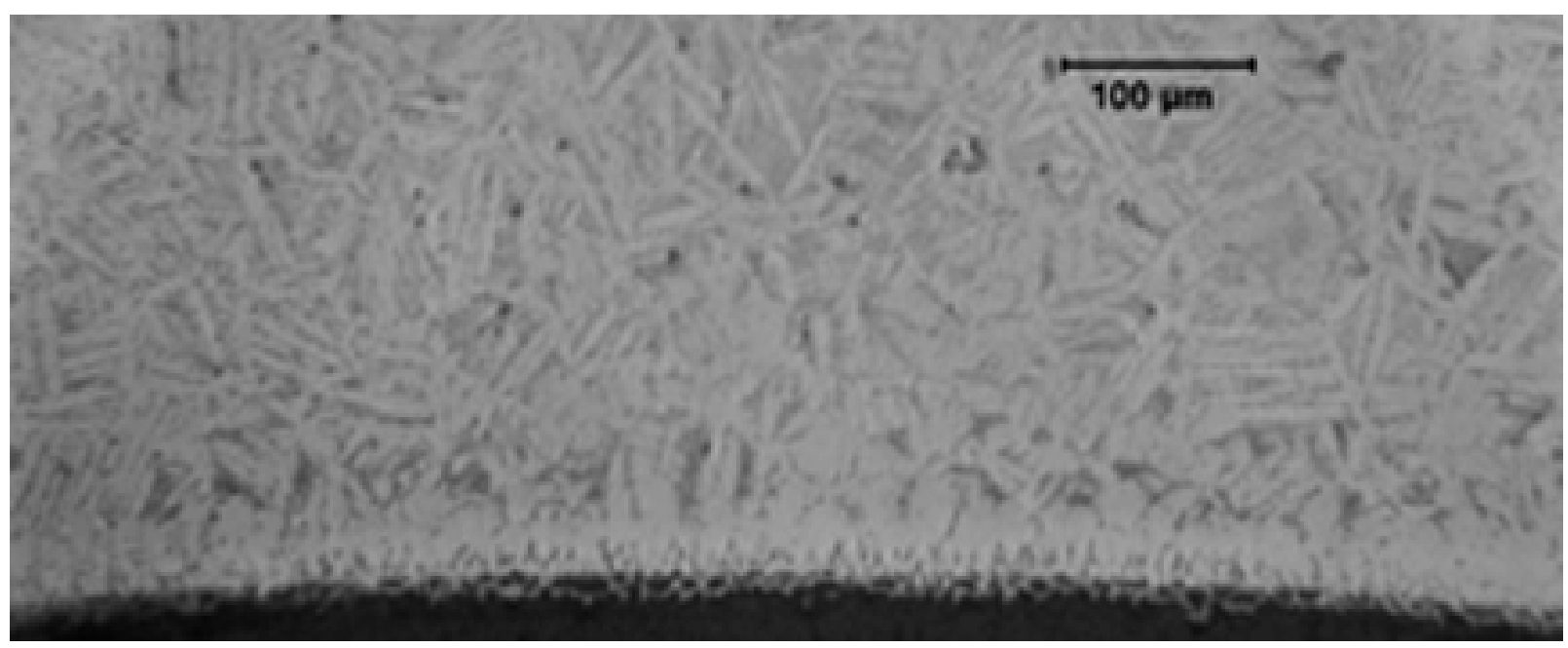

(a)

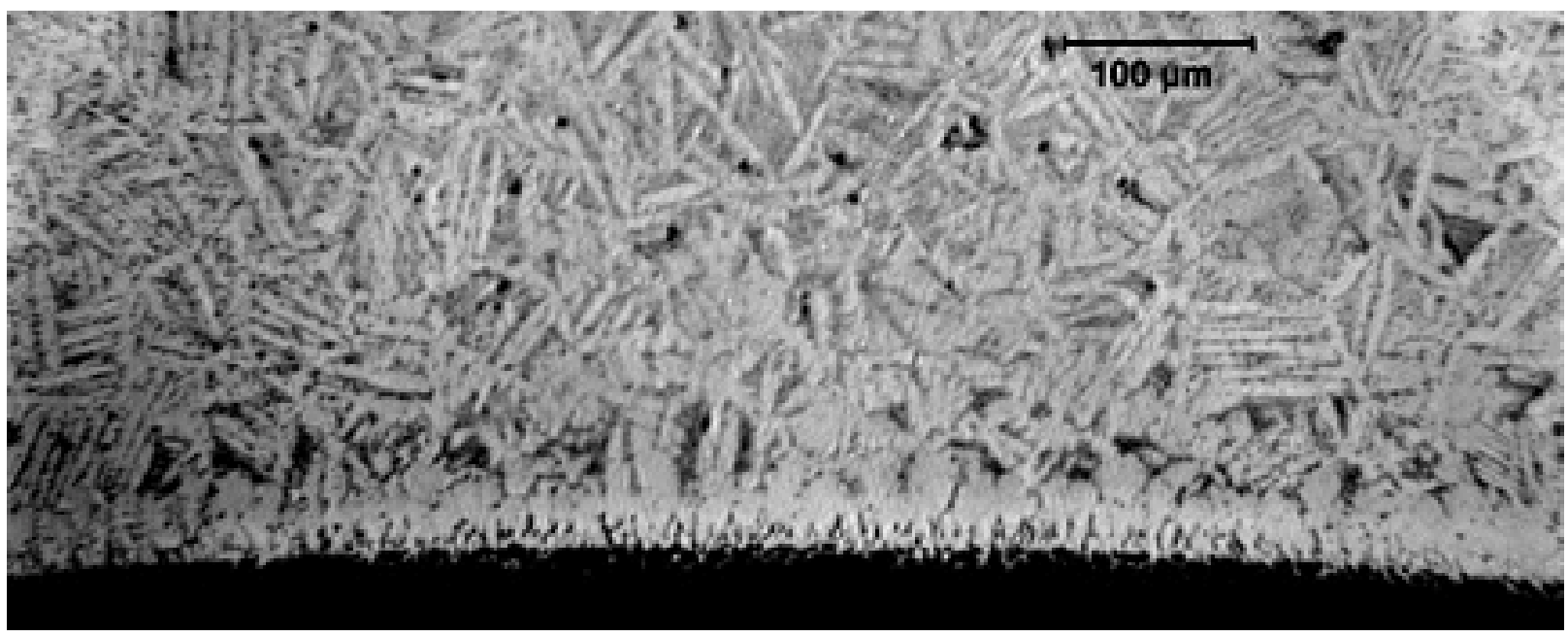

(b)

Figure 154. Inner surface of high-burnup HBR Zry-4 sample one-side oxidized at $1200^{\circ} \mathrm{C}$ for 174 -s test time to $4.9 \%$ CP-ECR: (a) normal contrast and (b) contrast and brightness adjusted for viewing the alpha layer in the central part of the micrograph. 


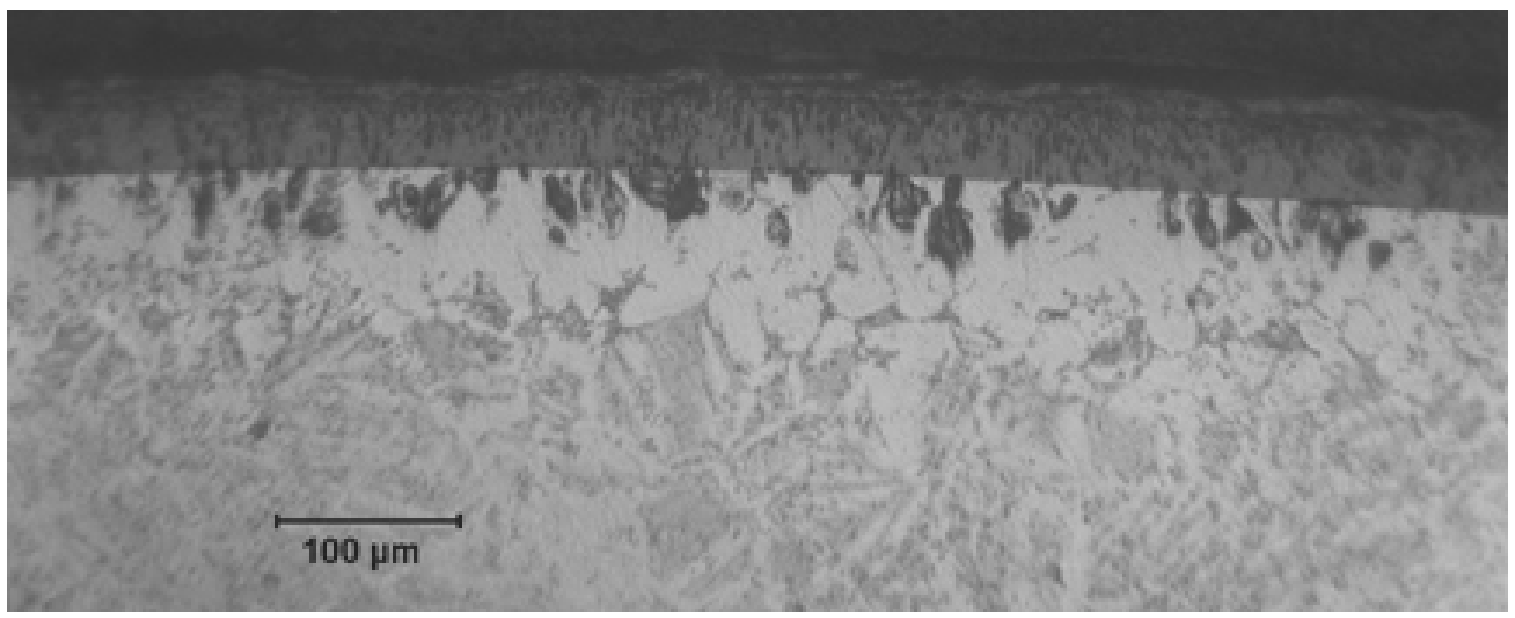

(a)

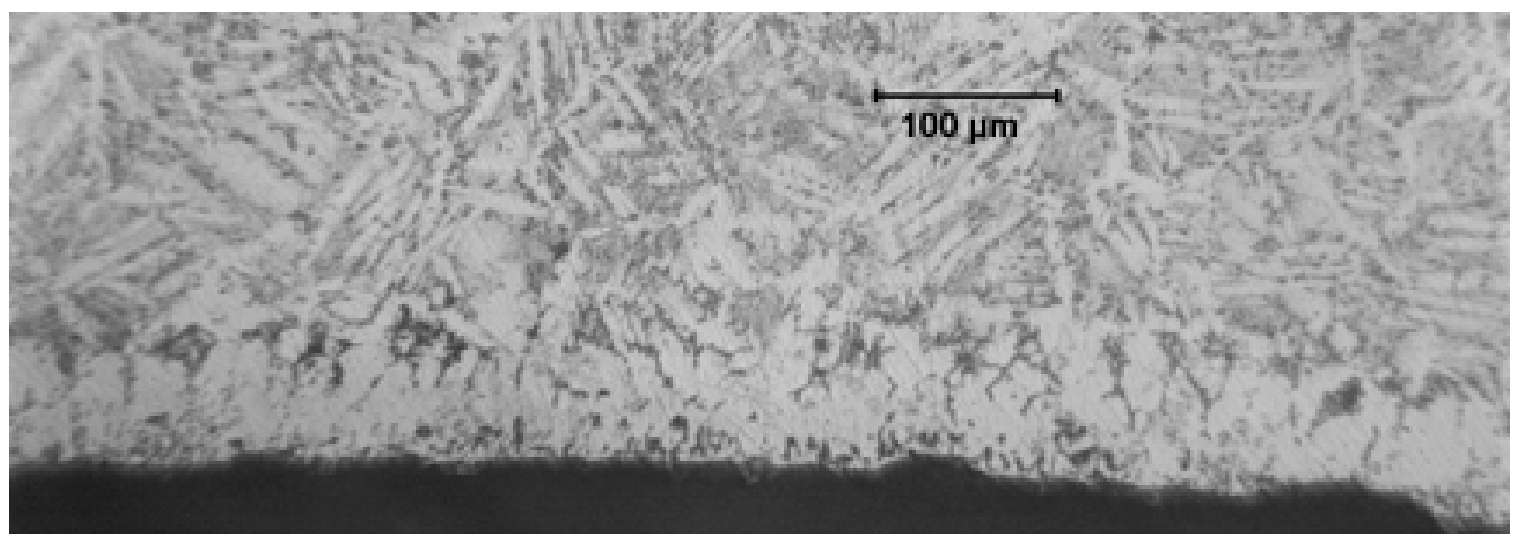

(b)

Figure 155. High-burnup HBR Zry-4 sample one-side oxidized at $1200^{\circ} \mathrm{C}$ to $7.3 \% \mathrm{CP}-\mathrm{ECR}$ : (a) outer surface and (b) inner surface. 


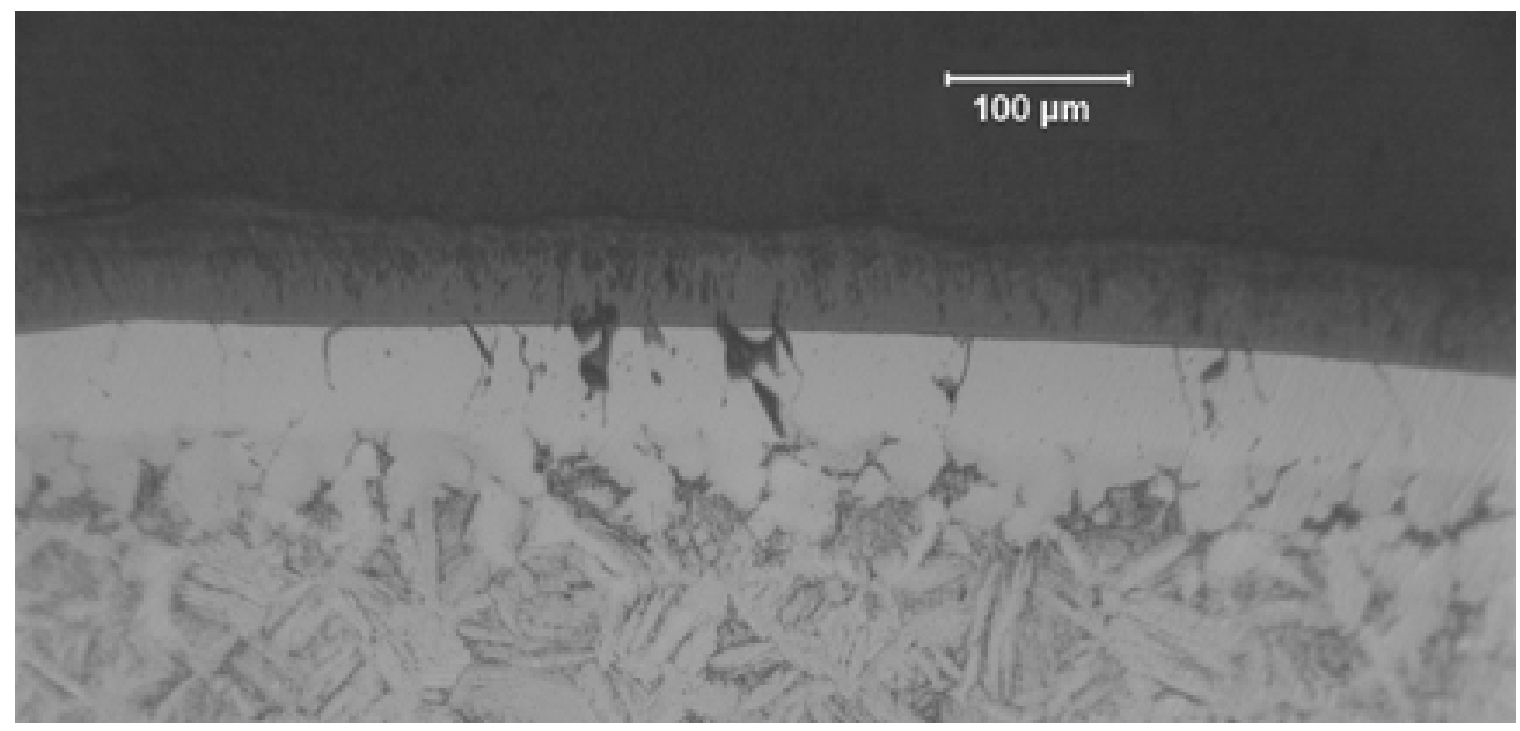

(a)

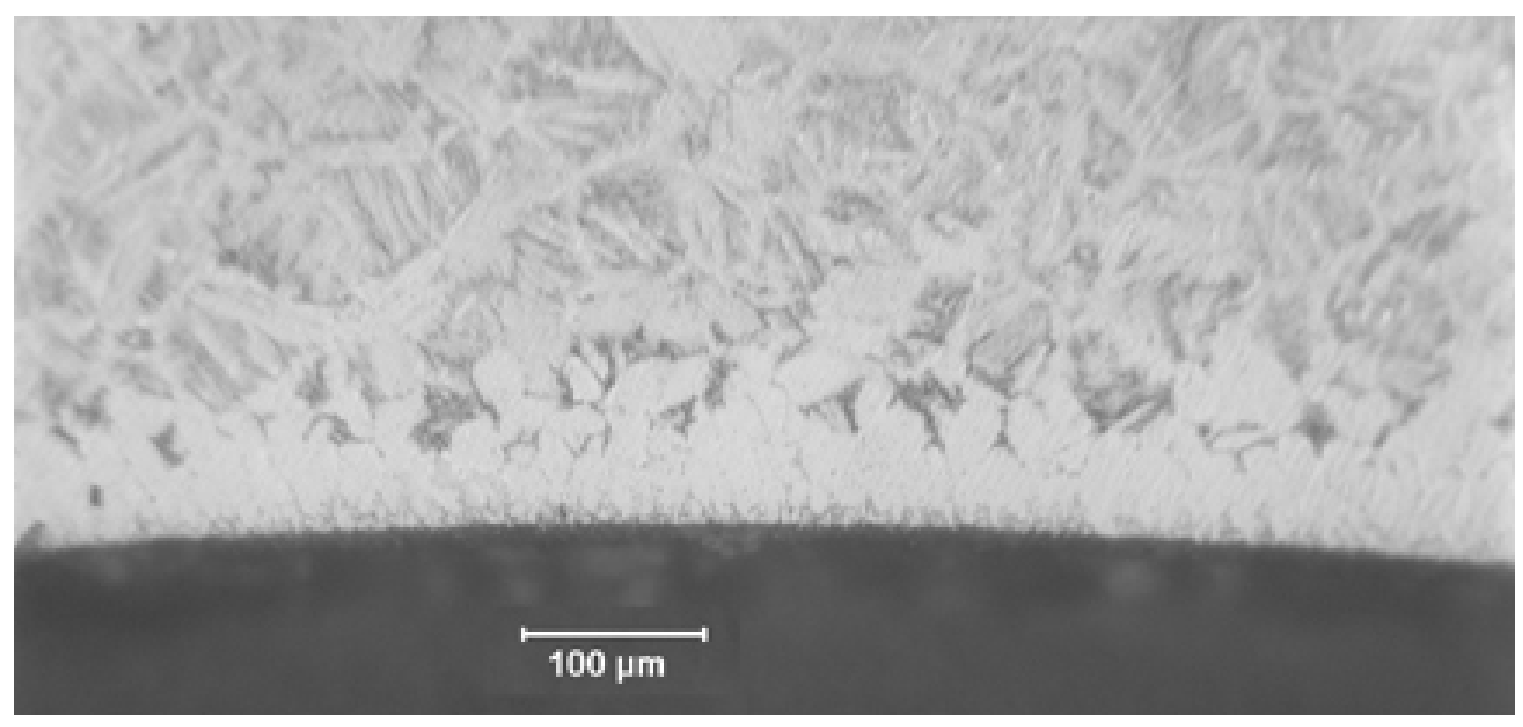

(b)

Figure 156. High-burnup HBR Zry-4 sample one-side oxidized at $1200^{\circ} \mathrm{C}$ to $8.5 \% \mathrm{CP}$-ECR: (a) outer surface and (b) inner surface. 
Post-oxidation ring-compression tests were performed with the six oxidized high-burnup HBR Zry4 samples. Ductility data are summarized in Table 66. The results are quite interesting even though the hydrogen content was not constant during these one-sided oxidation tests.

Table 66. Ring-Compression Test Results for the Ductility at $135^{\circ} \mathrm{C}$ of High-burnup HBR Zry-4 Samples Oxidized (One-sided) in Steam at $1200^{\circ} \mathrm{C}$ and Slow Cooled to RT. CP-ECR values are based on outer-surface oxidation.

\begin{tabular}{|c|c|c|c|c|c|c|c|c|}
\hline \multirow[t]{2}{*}{$\begin{array}{l}\text { Test } \\
\text { ID \# }\end{array}$} & \multirow{2}{*}{$\begin{array}{c}\text { Post-test } \\
\text { H } \\
\text { Content, } \\
\text { wppm }\end{array}$} & \multirow{2}{*}{$\begin{array}{c}\text { Test } \\
\text { Time, }{ }^{\mathrm{a}} \\
\text { s }\end{array}$} & \multirow{2}{*}{$\begin{array}{c}\text { One-sided } \\
\text { CP-ECR, } \\
\%\end{array}$} & \multicolumn{2}{|c|}{$\begin{array}{c}\text { Plastic } \\
\text { Displacement, mm }\end{array}$} & \multicolumn{2}{|c|}{$\begin{array}{l}\text { Plastic } \\
\text { Strain, \% }\end{array}$} & \multirow[t]{2}{*}{$\begin{array}{c}\text { ID } \\
\text { Oxidation }\end{array}$} \\
\hline & & & & Offset & Perm. & Offset & Perm. & \\
\hline 7 & $335 \pm 31$ & 174 & 4.9 & 0.89 & 0.65 & 8.4 & 6.1 & None \\
\hline 11 & $570 \pm 70$ & 174 & 4.8 & 0.39 & 0.27 & 3.7 & 2.5 & --- \\
\hline 8 & $190 \pm 12$ & 323 & 7.3 & 0.47 & 0.39 & 4.4 & 3.7 & None \\
\hline 12 & $550 \pm 70$ & 323 & 7.1 & 0.10 & 0.10 & 0.9 & 0.9 & --- \\
\hline 10 & $318 \pm 44$ & 419 & 8.5 & 0.40 & 0.33 & 3.8 & 3.1 & $\begin{array}{c}\approx 15 \% \text { at Ends } \\
\text { of Ring }\end{array}$ \\
\hline 9 & $767 \pm 59$ & 534 & 9.7 & 0.02 & 0.01 & 0.2 & 0.1 & $\begin{array}{c}>80 \% \text { at Ends } \\
\text { of Ring }\end{array}$ \\
\hline
\end{tabular}

${ }^{\mathrm{a}}$ Includes time for ramp from $300^{\circ} \mathrm{C}$ and hold time.

The ductility data for the 4.9\% (HBRI\#7) and 7.3\% (HBRI\#8) 1-S CP-ECR samples were evaluated because the rings used for these tests exhibited no evidence of inner-surface oxide formation.

Nevertheless, both samples had well-defined inner-surface alpha layers, which were formed primarily by diffusion of oxygen from the fuel-cladding bond oxide. This behavior can be demonstrated by comparing the OM cross-section images (see Figure 157) from unirradiated and high-burnup Zry-4 samples oxidized to $\approx 5 \% 1-\mathrm{S}$ CP-ECR. The unirradiated Zry-4 sample $(0.77-\mathrm{mm}$ wall $)$ was one-side oxidized for a test time of $190 \mathrm{~s}$. The outer-surface oxide and alpha layers were well developed, and the inner surface was free of oxide and alpha (see Figure 157a). By contrast, the high-burnup Zry-4 sample in Figure 157b had a well-developed alpha layer at the inner surface. Similar results were obtained for unirradiated $(7.5 \%$ CP-ECR) and high-burnup (7.3\% CP-ECR) samples one-side oxidized at $1200^{\circ} \mathrm{C}$.

The high-burnup Zry-4 rings from the one-sided oxidation tests failed due to crack initiation at the inner surface and propagation towards the outer surface. The failure location was under the loading platen or above the support platen where the maximum tensile bending stress occurs at the cladding inner surface. Thus, the oxygen-stabilized alpha layer at the cladding inner surface is brittle enough to initiate the crack. With increasing ring displacement and some plastic deformation, the crack grows through the prior-beta layer and the brittle outer-surface alpha layers. These results suggest that oxygen in the fuelcladding bond contributes to embrittlement of high-burnup cladding during a LOCA.

The test results for lower grid-span samples oxidized to $4.8 \%$ and $7.1 \% 1$-S CP-ECR are useful for quantitative comparison purposes because their end-of-test hydrogen contents are comparable to the hydrogen content of the two-side-oxidized HBR samples. The load-displacement curves for the one-sideoxidized samples are shown in Figures 158 (4.8\% CP-ECR) and 159 (7.1\% CP-ECR). The ductility data from Tables 61 (two-sided results) and 66 (one-sided results) are compared in Table 67 and Figure 160 for samples with $\approx 550$ wppm hydrogen, which were slow cooled. 


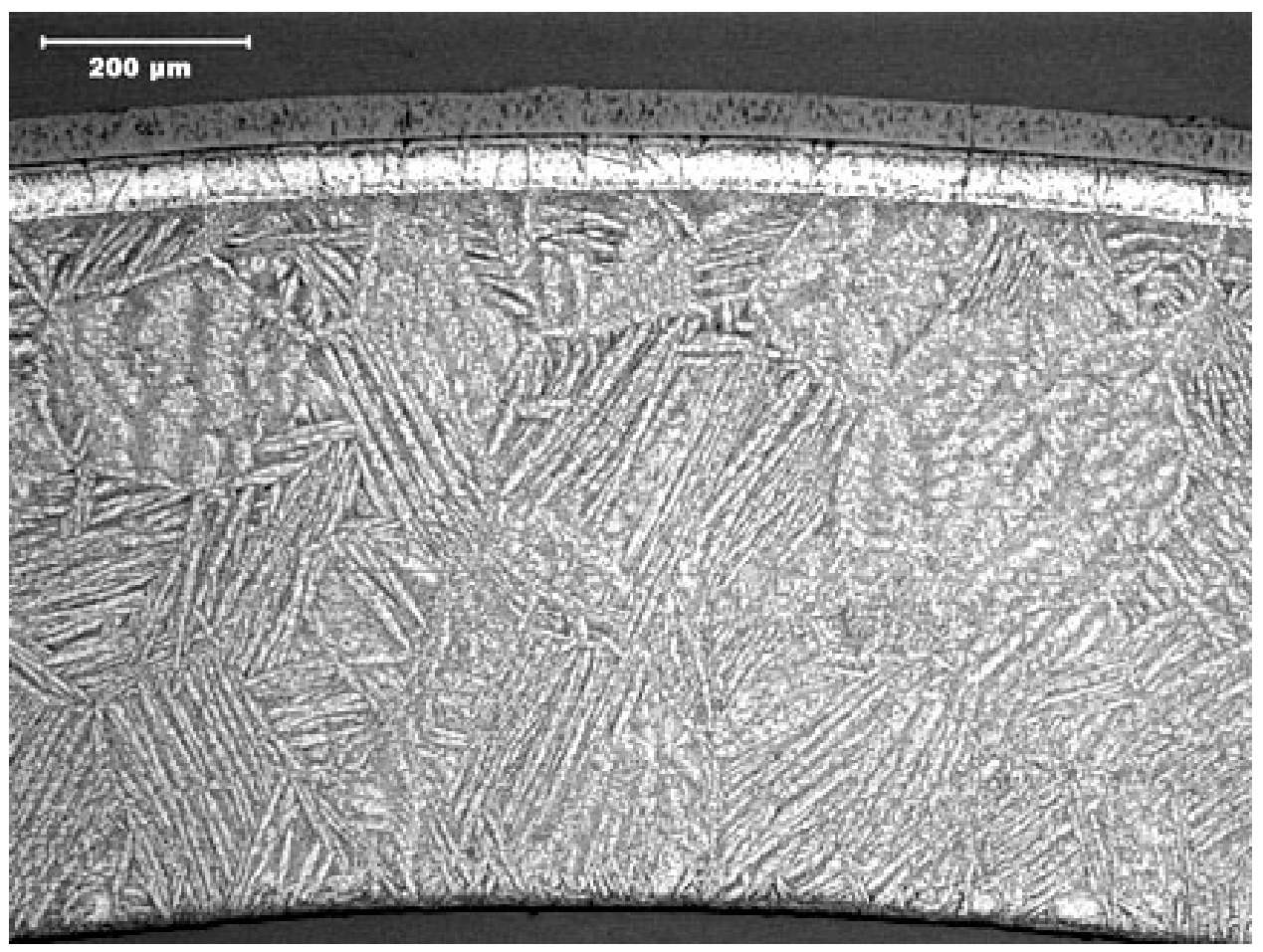

(a)

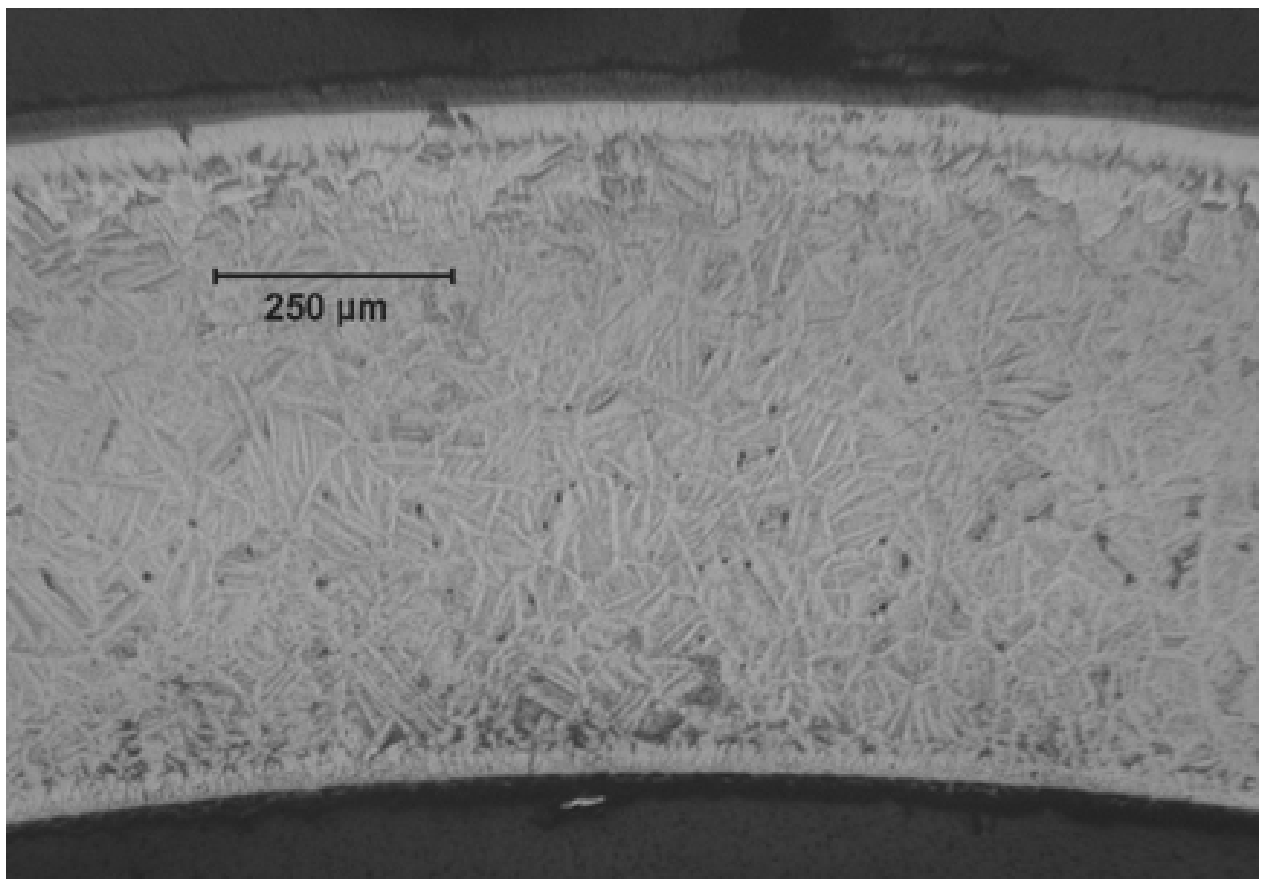

(b)

Figure 157. Comparison of Zry-4 samples oxidized (one-sided) in steam at $1200^{\circ} \mathrm{C}$ to $5 \% \mathrm{CP}$-ECR: (a) as-fabricated HBR-type Zry-4 at $4 \mathrm{~mm}$ from sample midplane and (b) high-burnup HBR Zry-4 at $4 \mathrm{~mm}$ from sample midplane. 


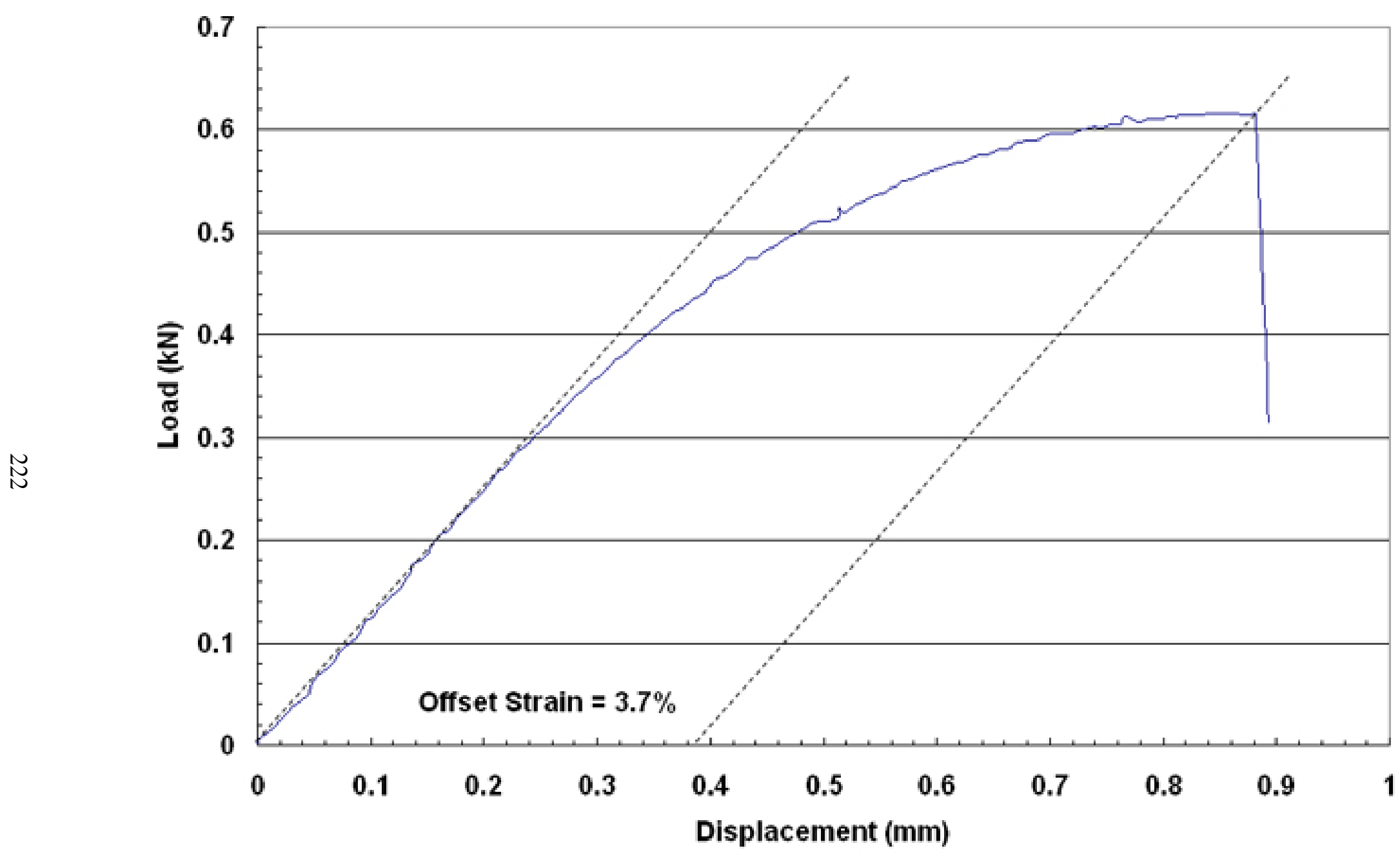

Figure 158. Load-displacement curve for HBRI\#11 sample one-side oxidized to $4.8 \% \mathrm{CP}$-ECR at $1200^{\circ} \mathrm{C}$ and ring-compressed at $135^{\circ} \mathrm{C}$ and $0.0333 \mathrm{~mm} / \mathrm{s}$ displacement rate. The sample developed a tight through-wall crack along the 8-mm length at the support position, with the crack initiating from the inner surface. Offset displacement was $0.39 \mathrm{~mm}$, and permanent displacement in the loading direction was $0.27 \mathrm{~mm}$. 


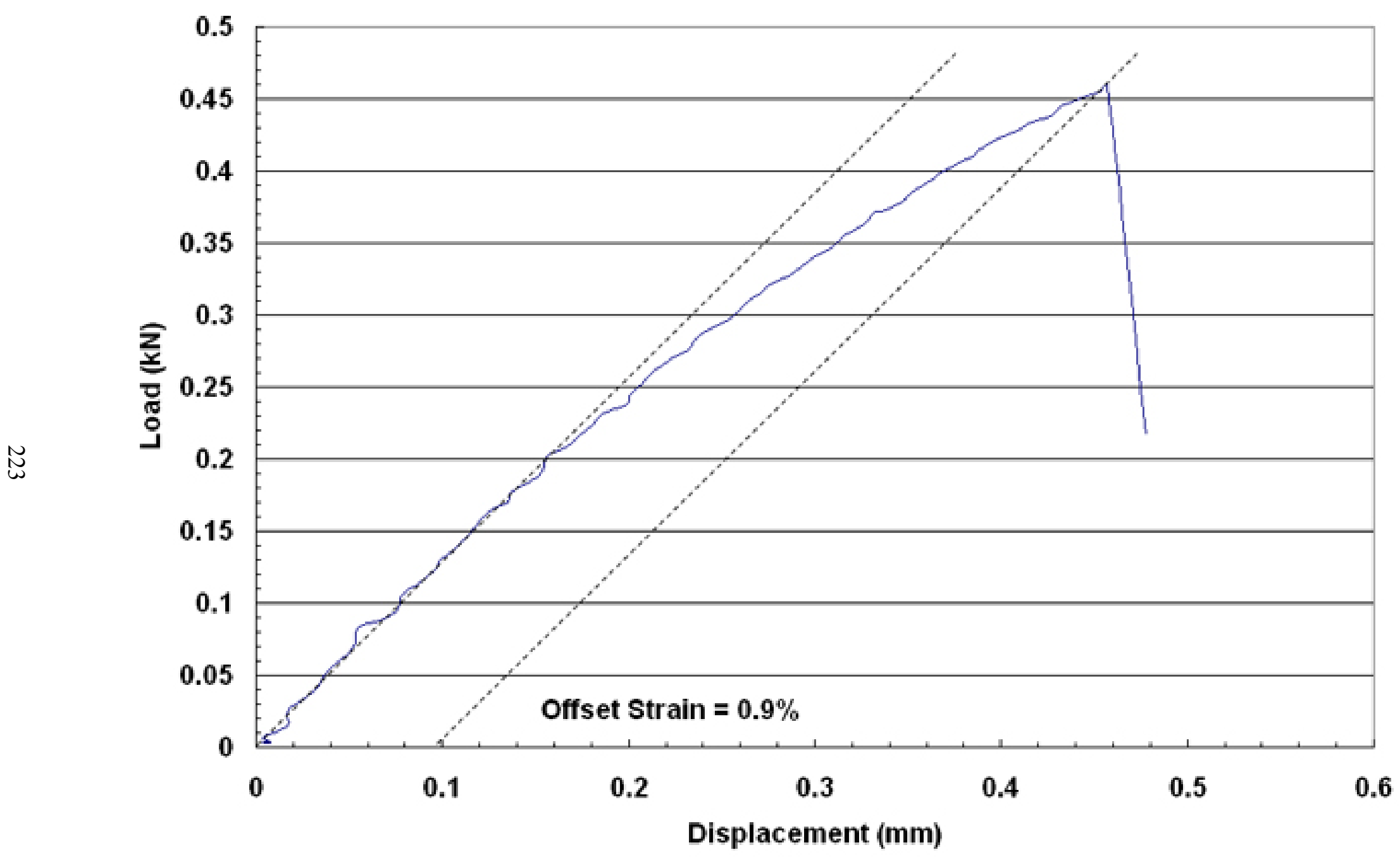

Figure 159. Load-displacement curve for HBRI\#12 sample one-side oxidized to $7.1 \% \mathrm{CP}$-ECR at $1200^{\circ} \mathrm{C}$ and ring-compressed at $135^{\circ} \mathrm{C}$ and $0.0333 \mathrm{~mm} / \mathrm{s}$ displacement rate. The sample developed a tight through-wall crack along the 8-mm length at the support position, with the crack initiating from the inner surface. Offset displacement was $0.1 \mathrm{~mm}$, and permanent displacement in the loading direction was $0.1 \mathrm{~mm}$. 
Table 67. Post-oxidation Ductility Values for High-burnup HBR Zry-4 Cladding Samples Oxidized at $\leq 1200^{\circ} \mathrm{C}$ and Slow Cooled to RT. Test type is indicated by 2-S for two-sided oxidation and 1$S$ for one-sided oxidation; tests were conducted on $\approx 8$-mm-long rings at $135^{\circ} \mathrm{C}$ and 0.0333 $\mathrm{mm} / \mathrm{s}$ displacement rate; offset and permanent displacements were normalized to the cladding metal outer diameter $(10.6 \mathrm{~mm})$ to calculate strains.

\begin{tabular}{|c|c|c|c|c|c|c|c|}
\hline $\begin{array}{c}\text { Test } \\
\text { ID \# }\end{array}$ & $\begin{array}{c}\text { Hydrogen } \\
\text { Content, } \\
\text { wppm }\end{array}$ & $\begin{array}{c}\text { Test } \\
\text { Time, } \\
\mathrm{s}\end{array}$ & $\begin{array}{c}\text { Test } \\
\text { Type, }\end{array}$ & $\begin{array}{c}\text { CP-ECR, } \\
\%\end{array}$ & $\begin{array}{c}\text { Maximum } \\
\text { Oxidation T, } \\
{ }^{\circ} \mathrm{C}\end{array}$ & & \multicolumn{2}{|c|}{ Plastic Strains, \% } \\
\cline { 6 - 8 } & & & & & & & \\
\hline 2 & $550 \pm 100$ & 62 & $2-\mathrm{S}$ & 2.7 & 1110 & $>45$ & $>43$ \\
\hline 1 & $550 \pm 100$ & 93 & $2-\mathrm{S}$ & 4.3 & 1169 & $>12$ & --- \\
\hline 11 & $570 \pm 70$ & 174 & $1-\mathrm{S}$ & $4.8^{\mathrm{b}}$ & 1200 & 3.7 & 2.5 \\
\hline 3 & $550 \pm 100$ & 132 & $2-\mathrm{S}$ & 6.4 & 1196 & 4.0 & 2.6 \\
\hline 12 & $550 \pm 70$ & 323 & $1-\mathrm{S}$ & $7.1^{\mathrm{b}}$ & 1200 & 0.9 & 0.9 \\
\hline 5 & $550 \pm 100$ & 155 & $2-\mathrm{S}$ & 7.4 & 1197 & 4.0 & 2.9 \\
\hline 4 & $550 \pm 100$ & 206 & $2-\mathrm{S}$ & 9.3 & 1198 & 0.5 & 0.6 \\
\hline
\end{tabular}

${ }^{\mathrm{a}}$ Includes time for ramp from $300^{\circ} \mathrm{C}$ and hold time.

${ }^{\mathrm{b}} \mathrm{CP}-\mathrm{ECR}$ values calculated for one-sided steam oxidation.

The results shown in Figure 160 have been plotted in the usual way vs. CP-ECR; i.e., one-sided values are used for the one-sided tests and two-sided values are used for the two-sided tests. When plotted in this manner, the one-sided-test ductility values fall significantly below the data and trend line for the two-sided-test ductility values. Three factors have been considered to understand the differences.

The first factor is the differences in heating rate and test time at $1200^{\circ} \mathrm{C}$ (see Figure 150). The relatively high ductility values for two-side-oxidized HBRI\#2 (2.7\% CP-ECR) and HBRI\#1 (4.3\% CPECR) can be rationalized by the oxidation temperatures being significantly below $1200^{\circ} \mathrm{C}$. However, for the remaining three two-sided tests and the two one-sided tests, equivalent times at temperature and CPECR levels are more comparable. However, differences in heating rate and hold time at $1200^{\circ} \mathrm{C}$ would not completely explain the differences in ductility levels observed in Figure 160.

The second factor considered is the additional oxygen source from slow steam leakage inside the cladding during the one-sided tests. Although no oxide layer was observed at the edges of the rings used for the ring compression tests, low-partial-pressure steam in a hydrogen atmosphere can grow an oxygenstabilized alpha layer without growing an oxide layer. For the 174-s and 323-s samples examined, no oxide layer was observed at the edges of the $8-\mathrm{mm}$ rings used to determine ductility, and the oxygen content in the fuel-cladding bond was sufficiently high to grow the alpha layers observed. For these two test times, steam leakage is not considered to be a significant source of oxygen for embrittlement.

The third factor considered is the effect of the fuel-cladding bond on embrittlement. For the twosided oxidation tests, the effects of the bond-layer oxygen could not be discerned in the presence of flowing steam. However, for the one-sided steam-oxidation tests, the fuel-cladding bond oxide is considered to be a significant source of oxygen for formation and growth of an alpha layer concurrent with diffusion of oxygen into the beta layer. The samples were brittle enough at the inner surface to initiate and propagate cracks through the wall of the cladding. Of the three factors considered, the 


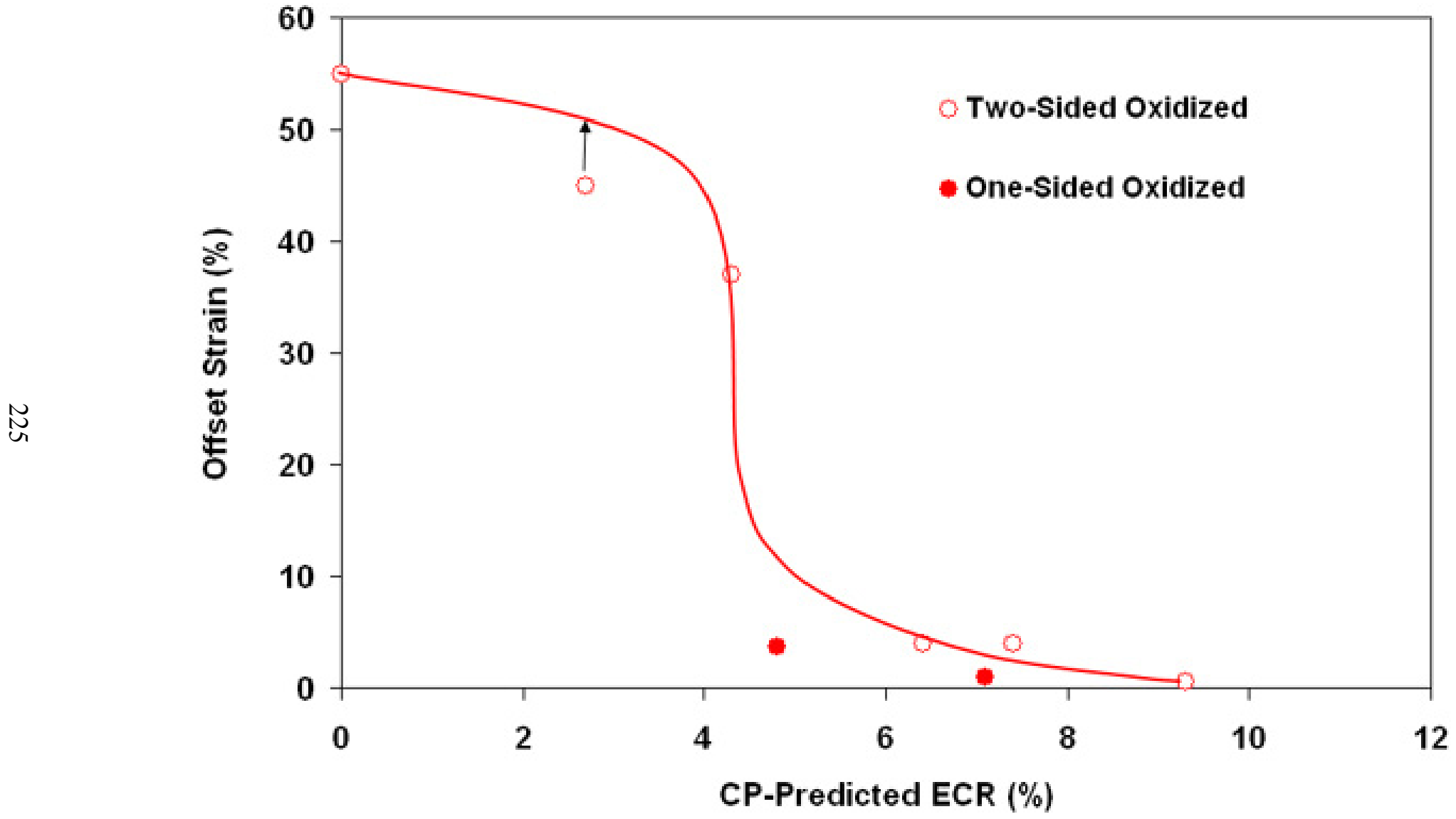

Figure 160 . Offset strain data at $135^{\circ} \mathrm{C}$ for high-burnup HBR Zry-4 samples with $\approx 550$-wppm hydrogen oxidized to a maximum temperature of $1200^{\circ} \mathrm{C}$ and slow cooled. Data are from two-sided and one-sided oxidation tests. Trend curve is based on two-sided-oxidation test results. 
fuel-cladding bond oxygen source, which is not accounted for in the one-sided CP-ECR calculation, is considered to be the dominant factor in reducing the ductility of the high-burnup Zry-4 samples from the one-sided tests. Additional embrittlement related to the presence of fuel bonded to the cladding is discussed in Section 6.

\subsubsection{Discussion of high-burnup HBR $15 \times 15$ Zry-4 test results}

The ductile-to-brittle transition CP-ECR for as-fabricated HBR-type Zry-4 oxidized at $1200^{\circ} \mathrm{C}$ is $16 \%$ following quench at $800^{\circ} \mathrm{C}$. Based on the behavior of modern $17 \times 17$ Zry-4, ZIRLO, and M5, this transition CP-ECR is expected to be independent of quench temperature for as-fabricated cladding alloys. For high-burnup HBR-type Zry-4 oxidized under the same conditions (two-sided) at $1200^{\circ} \mathrm{C}$ and slow cooled, this transition CP-ECR is reduced from $16 \%$ to $\approx 8 \%$. Based on limited results for high-burnup Zry-4 and ZIRLO (see 5.2.3) cladding and extensive results for prehydrided Zry-4 cladding (see Section 4 ), the transition CP-ECR is further reduced to $\approx 5 \%$ following quench at $600-800^{\circ} \mathrm{C}$. Hydrogen contents higher than $\approx 600$ wppm would cause a lower transition CP-ECR for Zry-4 following oxidation at $1200^{\circ} \mathrm{C}$ and quench at $600-800^{\circ} \mathrm{C}$. The high-burnup sample with 740-wppm hydrogen was brittle following oxidation to $7.5 \% \mathrm{CP}$-ECR and quench. Quench temperatures below $600^{\circ} \mathrm{C}$ may increase the transition $\mathrm{CP}-\mathrm{ECR}$ and/or transition hydrogen content if the cooling time is long enough at $<600^{\circ} \mathrm{C}$. With regard to cooling time, note that for a hypothetical LOCA the cooling rate increases with time between the maximum temperature and wetting temperatures, whereas for ANL and CEA experiments, the cooling rate decreases exponentially with time during this interval. The experimental results for slow cooling without quench or cooling with quench at $<600^{\circ} \mathrm{C}$ may result in ductility enhancement that would not occur during a LOCA.

For one-sided steam oxidation, which is relevant to cladding outside the balloon region, it was found that the fuel-cladding-bond oxide provides an additional source of oxygen for embrittlement beyond that calculated for single-sided steam oxidation. The ductile-to-brittle transition CP-ECR decreased from $\approx 8 \%$ to $\approx 6 \%$ for slow-cooled high-burnup Zry-4 samples exposed to outer-surface steam flow. The results suggest that the calculation method for determining CP-ECR away from the balloon region should be revised to account for additional oxygen sources (e.g., fuel-cladding bond and fuel) inside the cladding.

The calculated oxidation levels (CP-ECR values) reported in tables and shown in figures in 5.1.25.1.3 are for the heating phase of the LOCA transient. The increase in predicted weight gain and CP-ECR during the cooling phase is small $(\leq 0.2 \%$ in $\mathrm{CP}$-ECR) and insignificant relative to the determination of transition oxidation levels to the nearest percent. For the two-sided oxidation tests, the heating-phase CPECR values of $2.7,4.3,6.4,7.4,7.5$, and $9.3 \%$ correspond to $2.9,4.5,6.6,7.6,7.7$ and $9.4 \%$ total transient oxidation level $\left(\mathrm{CP}-\mathrm{ECR}_{\mathrm{t}}\right)$. The total transient CP-ECR is used for test planning and data reporting in Sections 5.2 and 5.3. 


\subsection{Results for North Anna high-burnup 17×17 ZIRLO cladding}

\subsubsection{Pre-test characterization}

Figure 161 shows the axial locations of North Anna ZIRLO Rod AM2-L17 from which Studsvik sectioned and defueled 80-mm-long cladding segments for ANL. Segment axial orientation relative to the bottom of the fuel rod was not maintained during defueling. Characterization results for LOCA pretest planning were generated for samples sectioned from segments labeled 5, 6, and 8 in Figure 161. Results for corrosion layer thickness and/or oxygen concentration were used to estimate the axial location of these characterization samples within the segments.

Table 68 summarizes the characterization results for corrosion-layer thickness, fuel-cladding-bond layer thickness, LECO-measured oxygen content, and LECO-measured hydrogen content. For LECO measurements, short cladding rings $(\approx 2$-mm-long) were sectioned and then snipped into four quarter rings. The hydrogen or oxygen content and mass were measured for each quarter ring. This mass included the masses of the corrosion layer, the cladding metal, and the fuel-cladding bond. The average hydrogen or oxygen content for a ring was determined from the total hydrogen or oxygen evolved from the four quarter rings normalized to the combined masses of the rings. The four measurements per ring were also used to determine the one-sigma circumferential variation in hydrogen or oxygen content. As shown in Table 68, there is considerable circumferential variation in hydrogen concentration at any one axial location within the uniform burnup region. If the data point at $2803 \mathrm{~mm}$ (from the rod bottom) is ignored because the location appears to be close to a grid spacer, the axial average of the remaining five sets of data points is $620 \pm 50 \mathrm{wppm}$. The circumferential variation for Segment 5 and 6 samples is more significant $(\approx \pm 150 \mathrm{wppm})$ than the axial variation along the segments. Metallographic results for a Segment 6 sample were consistent with LECO-hydrogen results: a dense hydride rim near the cladding outer surface, which varied in equivalent thickness from about 40 to $70 \mu \mathrm{m}$ around the circumference.

Figure 162 shows a high-magnification micrograph of the corrosion layer at $2909 \mathrm{~mm}$ from the rod bottom, as imaged from a polished met sample. Indications of circumferential and radial cracks may be due to sample mounting in epoxy - drying and contraction of epoxy may cause or exaggerate circumferential cracks - and/or the effects of grinding and polishing. The corrosion layer thickness ( $43 \pm 2$ $\mu \mathrm{m})$ was measured for eight such locations at this position. Figure 163 shows a high-magnification and high-contrast image of the fuel-cladding bond layer in the as-polished condition. Based on eight images around the circumference of the etched cross section, the bond-layer thickness was measured to be $\approx 7 \pm 2$ $\mu \mathrm{m}$. Because of the highly non-uniform bond-fuel interface, the reported bond thickness is that of an equivalent oxide bond with a smooth fuel interface. The cladding metal wall thickness was measured to be $544 \pm 2 \mu \mathrm{m}$. Figure 164 shows the composite of the eight images taken around the circumference of the etched cross section at the same axial location. The circumferential variation in hydride distribution and morphology is indicated. In Figure 165, high-magnification images are shown at circumferential locations with thickest $(\approx 70 \mu \mathrm{m})$ and thinnest $(\approx 40 \mu \mathrm{m})$ equivalent hydride-rim thicknesses. 


\section{C6-137 activity of rod AM2-L17}

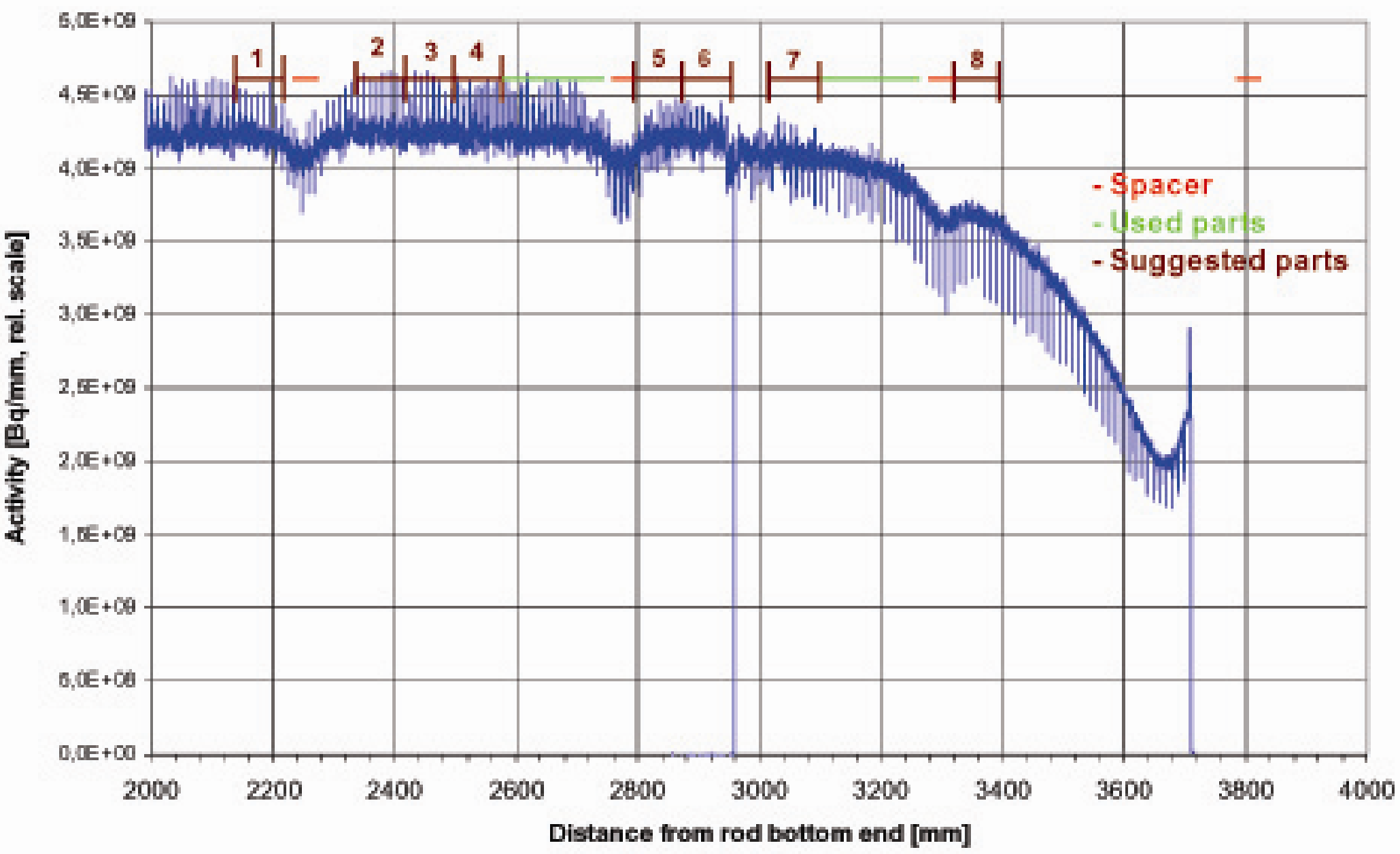

Figure 161. Sectioning diagram for North Anna ZIRLO defueled cladding segments sent to ANL from Studsvik in second shipment. Corresponding ANL ID numbers are 648E, 648F and 648H for Segments 5, 6, and 8, respectively. 
Table 68. North Anna ZIRLO Characterization Results for Rod AM2-L17

\begin{tabular}{|c|c|c|c|c|c|c|}
\hline $\begin{array}{l}\text { Sample } \\
\text { ID \# } \\
\text { W } \\
\text { (ANL) }\end{array}$ & $\begin{array}{l}\text { Location } \\
\text { from } \\
\text { Bottom, } \\
\text { mm }\end{array}$ & $\begin{array}{l}\text { Corrosion } \\
\text { Layer from } \\
\text { Eddy Cur. } \\
\text { (EC), } \mu \mathrm{m}\end{array}$ & $\begin{array}{c}\text { Corrosion } \\
\text { Layer from } \\
\text { Metallography } \\
\mu \mathrm{m}\end{array}$ & $\begin{array}{c}\text { Fuel-Clad } \\
\text { Bond Layer } \\
\text { from Met., } \\
\mu \mathrm{m}\end{array}$ & $\begin{array}{c}\text { LECO } \\
\text { Oxygen } \\
\text { Content, } \\
\text { wt. } \%\end{array}$ & $\begin{array}{l}\text { LECO } \\
\text { Hydrogen } \\
\text { Content, } \\
\text { wppm }\end{array}$ \\
\hline $\begin{array}{c}5 \\
(648 E)\end{array}$ & $\begin{array}{l}2800- \\
2880\end{array}$ & $38-42$ & --- & --- & $\begin{array}{c}1.31 \pm 0.24 \\
@ 2801 \\
---\end{array}$ & $\begin{array}{c}464 \pm 71 \\
@ 2803 \mathrm{~mm} \\
563 \pm 145 \\
@ 2855 \mathrm{~mm}\end{array}$ \\
\hline $\begin{array}{c}6 \\
(648 F)\end{array}$ & $\begin{array}{l}2880- \\
2960\end{array}$ & $43-48$ & $\begin{array}{c}41 \pm 3 \\
\text { @2,2900 mm } \\
--- \\
43 \pm 2 \\
\text { @ } 2909 \mathrm{~mm}\end{array}$ & $\begin{array}{c}--- \\
@ 2900 \mathrm{~mm} \\
--- \\
\\
7 \pm 2 \\
\text { @ } 2909 \mathrm{~mm}\end{array}$ & $\begin{array}{c}--- \\
1.72 \pm 0.01 \\
@ 2906 \mathrm{~mm}\end{array}$ & $\begin{array}{c}590 \pm 168 \\
@ 2899 \mathrm{~mm} \\
605 \pm 152 \\
@ 2901 \mathrm{~mm} \\
657 \pm 148 \\
@ 2908 \mathrm{~mm}\end{array}$ \\
\hline $\begin{array}{c}8 \\
(648 \mathrm{H})\end{array}$ & $3320-3400$ & $40-45$ & -- & -- & $\begin{array}{l}1.62 \pm 0.23 \\
@ 3999 \mathrm{~mm}\end{array}$ & $\begin{array}{c}670 \pm 40 \\
@ 3997 \mathrm{~mm}\end{array}$ \\
\hline
\end{tabular}

The LOCA post-quench ductility and embrittlement results are highly sensitive to hydrogen content in the metal. The upper-bound hydrogen content can be calculated by assuming that all the LECOmeasured hydrogen is in the metal. Metallographic results can be used to determine the factor $\left(\mathrm{f}_{\mathrm{H}}\right)$ needed to correct for the reduced mass of the metal relative to the LECO mass. Based on the thicknesses of the corrosion $\left(\delta_{\mathrm{c}}\right)$, metal $(\mathrm{h})$ and fuel-cladding bond $\left(\delta_{\mathrm{b}}\right)$ layers, along with oxide $\left(5.63 \mathrm{~g} / \mathrm{cm}^{3}\right)$ and metal $(6.54$ $\mathrm{g} / \mathrm{cm}^{3}$ ) densities, correction factors have been determined for corrosion layer thickness values in the range of 35-45 $\mu \mathrm{m}$. A linear approximation for the correction-factor variation with corrosion layer thickness $\left(\delta_{\mathrm{c}}\right.$ in $\mu \mathrm{m})$ is:

$$
\mathrm{f}_{\mathrm{H}}=1.069+1.7 \times 10^{-3}\left(\delta_{\mathrm{c}}-35\right)
$$




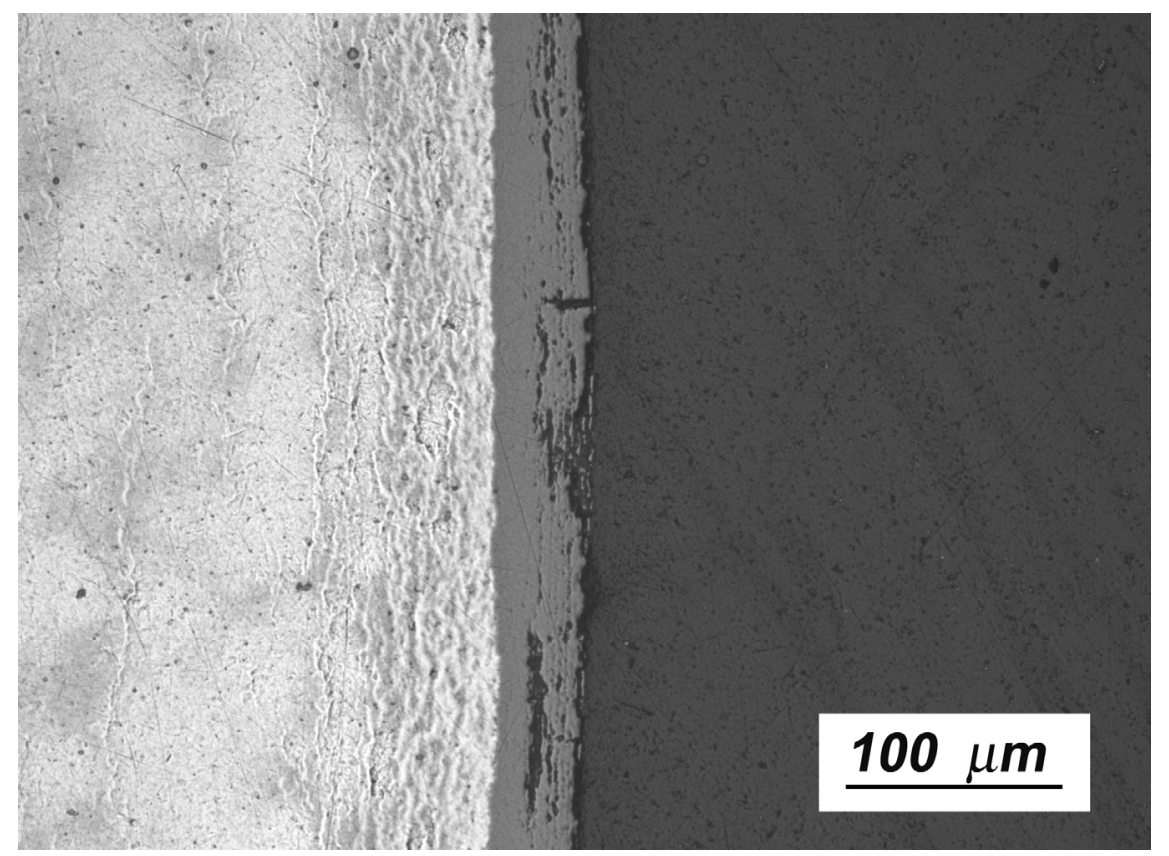

Figure 162. Micrograph of polished metallographic sample at $\approx 2910 \mathrm{~mm}$ from rod bottom (Segment 6 in Figure 161) showing high-magnification image of ZIRLO corrosion layer.

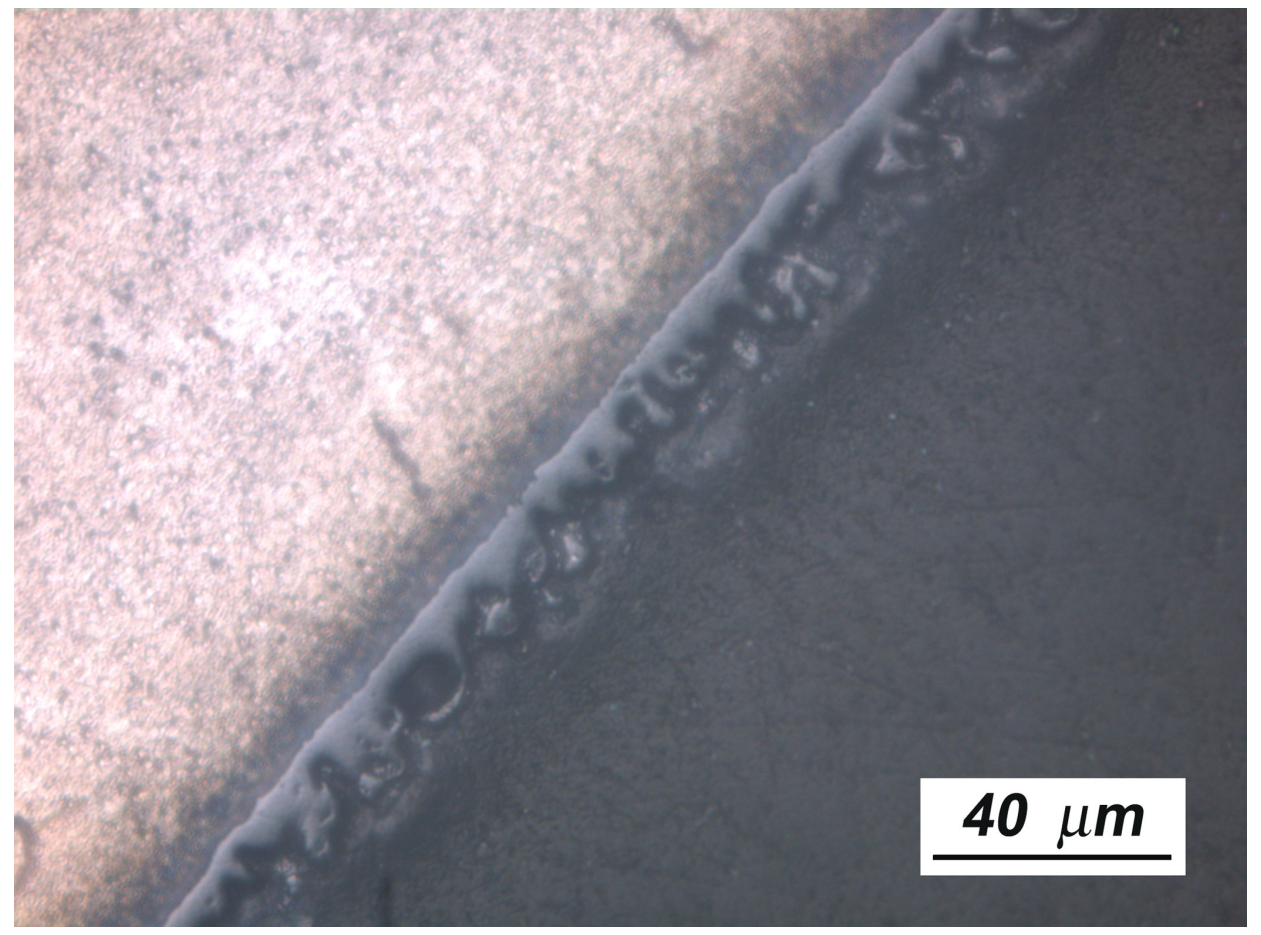

Figure 163. High-magnification and high-contrast image of the ZIRLO fuel-cladding bond layer at $\approx 2910$ $\mathrm{mm}$ from rod bottom (Segment 6 in Figure 161). 


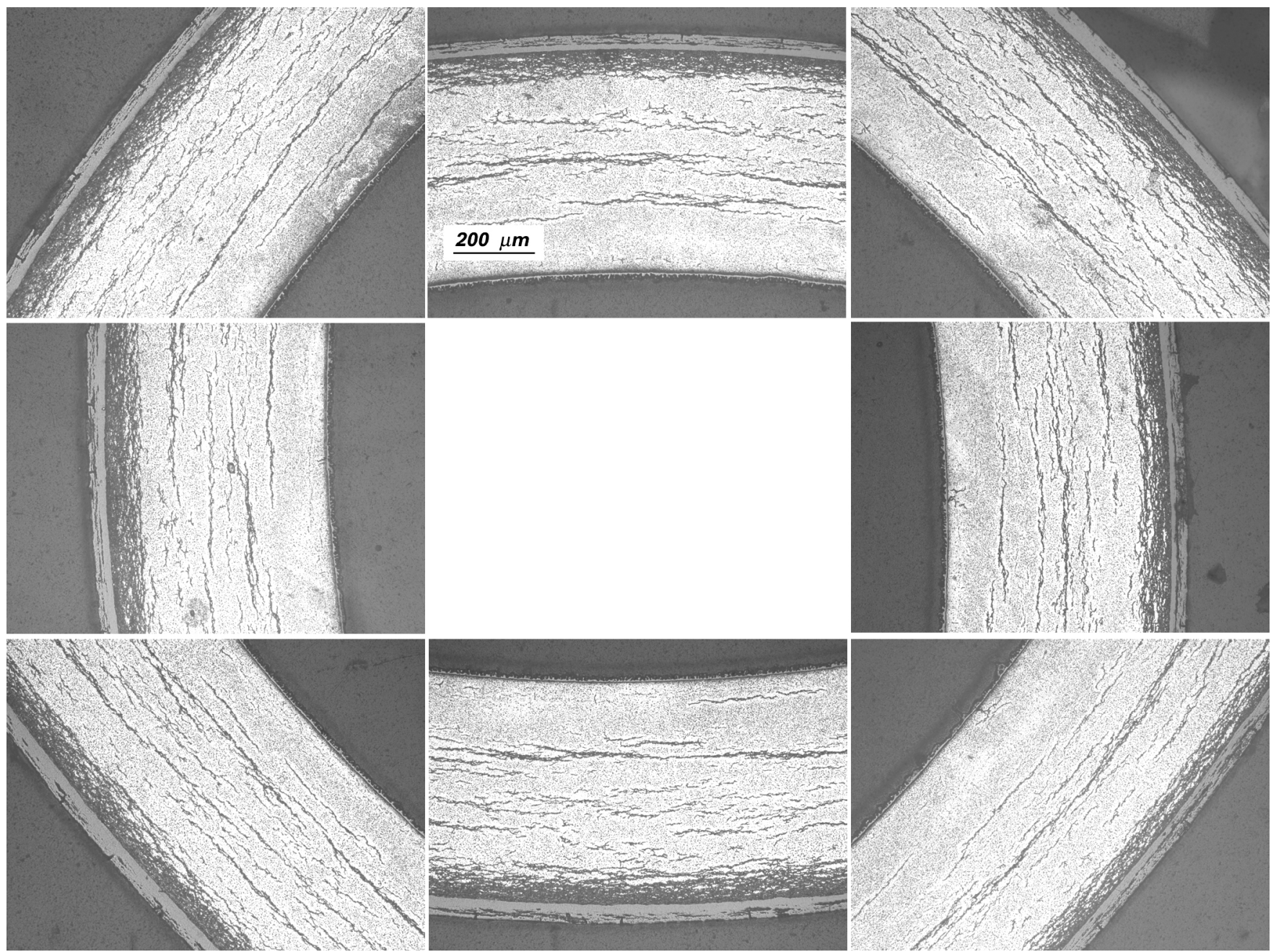

Figure 164. Images at eight locations around the circumference of etched ZIRLO cladding cross section at $\approx 2910 \mathrm{~mm}$ from the rod bottom showing radial and circumferential variation in hydride density. The thickness of the cladding metal wall ( $544 \pm 2 \mu \mathrm{m})$, as well as the corrosion $(43 \pm 2 \mu \mathrm{m})$ and fuel-cladding-bond $(7 \pm 2 \mu \mathrm{m})$ layers, is relatively uniform. 


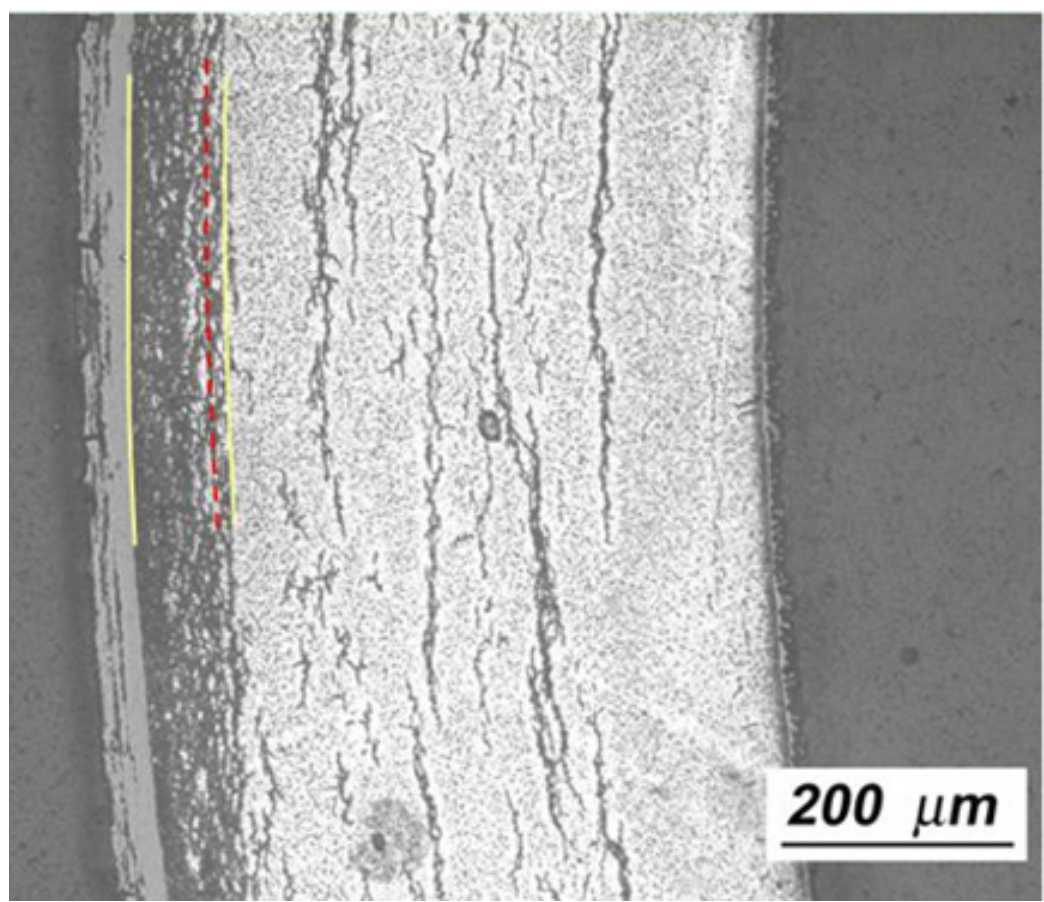

(a) Thick hydride rim

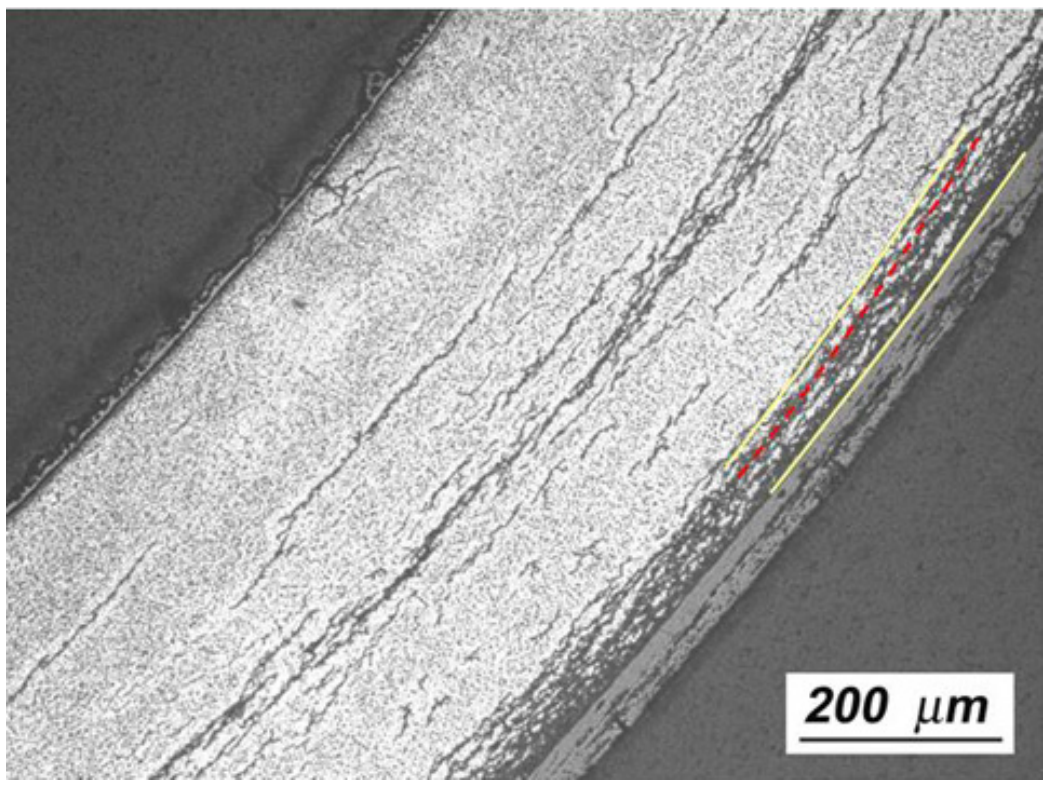

(b) Thin hydride rim

Figure 165. Local cladding regions of high-burnup ZIRLO at $\approx 2910 \mathrm{~mm}$ from rod bottom showing (a) thickest $(\approx 70 \mu \mathrm{m}$ equivalent) hydride rim and $(\mathrm{b})$ thinnest $(\approx 40 \mu \mathrm{m}$ equivalent) hydride rim. The dashed line in the images was used to estimate equivalent (i.e., dense) thickness. The variation in hydride-rim thickness correlates quite well with the variation in LECO-measured hydrogen content (500-840 wppm). 
Table 69 shows the results for the upper-bound hydrogen content in the cladding metal based on the correction factor determined from Equation 8. Also shown are metal hydrogen contents based on a correction factor from LECO-measured oxygen at three locations. The results are similar.

Table 69. Calculated Values for Hydrogen Content in Cladding Metal for North Anna ZIRLO Rod AM2$\mathrm{L} 17$ Segments. The calculation assumes all measured $\mathrm{H}$ is in cladding metal. EC $=$ eddy current.

\begin{tabular}{|c|c|c|c|c|c|c|}
\hline \multirow[b]{2}{*}{$\begin{array}{c}\text { Sample } \\
\text { ID \# } \\
\text { W } \\
\text { (ANL) }\end{array}$} & \multirow[b]{2}{*}{$\begin{array}{l}\text { Location } \\
\text { from } \\
\text { Bottom, } \\
\text { mm }\end{array}$} & \multicolumn{2}{|c|}{$\mathrm{f}_{\mathrm{H}}$} & \multirow[b]{2}{*}{$\begin{array}{l}\text { LECO } \\
\text { Hydrogen } \\
\text { Content, } \\
\text { wppm }\end{array}$} & \multicolumn{2}{|c|}{$\begin{array}{l}\text { Hydrogen Content in } \\
\text { Metal, wppm }\end{array}$} \\
\hline & & $\begin{array}{c}\text { Based } \\
\text { on EC } \\
\delta_{\mathrm{c}} \\
\end{array}$ & $\begin{array}{c}\text { Based } \\
\text { on Met. } \\
\delta_{\mathrm{c}}\end{array}$ & & $\begin{array}{c}\text { Using } \\
\text { Layer } \\
\text { Thicknesses }\end{array}$ & $\begin{array}{c}\text { Using } \\
\text { LECO } \\
\text { Oxygen }\end{array}$ \\
\hline \multirow{2}{*}{$\begin{array}{c}5 \\
(648 \mathrm{E})\end{array}$} & 2803 & 1.074 & --- & $464 \pm 71$ & $498 \pm 76$ & $482 \pm 74$ \\
\hline & 2855 & 1.078 & --- & $563 \pm 145$ & $607 \pm 156$ & --- \\
\hline \multirow{3}{*}{$\begin{array}{c}6 \\
(648 F)\end{array}$} & 2899 & --- & 1.079 & $590 \pm 168$ & $637 \pm 180$ & --- \\
\hline & 2901 & --- & 1.079 & $605 \pm 152$ & $653 \pm 163$ & --- \\
\hline & 2908 & --- & 1.083 & $657 \pm 148$ & $712 \pm 160$ & $704 \pm 159$ \\
\hline $\begin{array}{c}8 \\
(648 \mathrm{H})\end{array}$ & 3997 & 1.077 & --- & $670 \pm 40$ & $722 \pm 43$ & $712 \pm 42$ \\
\hline
\end{tabular}

Hydrogen pickup fraction (HPF) is a metric commonly used to estimate cladding hydrogen content from corrosion layer thickness. HPF represents the ratio of cladding hydrogen pickup and hydrogen generated in the formation of the corrosion layer. The corrosion layer thickness can be estimated from eddy-current measurements performed either poolside (most common) or in a hot cell. Metallographic results and/or LECO-oxygen results can be used to more precisely determine the hydrogen pickup fraction. The ANL method for performing this calculation is similar to the method used to determine the hydrogen correction factor $\left(\mathrm{f}_{\mathrm{H}}\right)$ : cylindrical geometry; layer thicknesses and densities used to determine masses per unit length for corrosion layer, metal, and bond layer; and subtraction of as-fabricated concentrations of hydrogen and oxygen.

However, a simple layer approach with no correction factors gave the same HPF results (within $\pm 0.5 \%$ absolute) as the detailed method within the relevant range of parameters. The correlation derived from the layer approach (based on mass per unit area) is: 


$$
\mathrm{HPF}=(2 \% \mu \mathrm{m} / \mathrm{wppm}) \mathrm{L}_{\mathrm{H}} / \delta_{\mathrm{c}}
$$

where $\mathrm{L}_{\mathrm{H}}$ is the LECO-measured hydrogen content in wppm and $\delta_{\mathrm{c}}$ is the corrosion layer thickness in $\mu \mathrm{m}$. Results from detailed ANL calculations are presented in Table 70 for five axial locations at which hydrogen was measured. For HPF values of $24 \%, 27 \%, 29 \%, 30 \%$, and $33 \%$, Equation 9 predicts $24 \%$, $27 \%, 28 \%, 31 \%$ and $34 \%$. Given the uncertainty in the density of the corrosion layer $\left(5.01 \mathrm{~g} / \mathrm{cm}^{3}\right.$ for $90 \%$-dense layer, $5.63 \mathrm{~g} / \mathrm{cm}^{3}$ for a Pilling-Bedworth ratio of 1.56 , and $5.8 \mathrm{~g} / \mathrm{cm}^{3}$ for $100 \%$-dense stoichiometric monoclinic oxide), Equation 9 gives a reasonable approximation for hydrogen pickup fraction for corrosion-layer thicknesses $\leq 50 \mu \mathrm{m}$. It has not been tested at higher corrosion-layer thicknesses for which the density of the layer decreases and curvature effects may become more significant.

Table 70. Calculated Hydrogen Pickup Fraction vs. Axial Location for North Anna ZIRLO Rod AM2-L17 Samples. The fuel-cladding bond thickness was assumed to be $7 \mu \mathrm{m}$, and the cladding metal wall thickness was calculated from $\mathrm{h}=544 \mu \mathrm{m}+\left(43 \mu \mathrm{m}-\delta_{\mathrm{c}}\right) / 1.56$.

\begin{tabular}{|c|c|c|c|c|c|}
\hline \multirow{2}{*}{$\begin{array}{c}\text { Sample } \\
\text { ID \# } \\
\text { W } \\
\text { (ANL) }\end{array}$} & \multirow{2}{*}{$\begin{array}{c}\text { Location } \\
\text { from } \\
\text { Bottom, } \\
\text { mm }\end{array}$} & \multicolumn{2}{|c|}{$\delta_{\mathrm{c}}, \mu \mathrm{m}$} & \multirow{2}{*}{$\begin{array}{l}\text { LECO } \\
\text { Hydrogen } \\
\text { Content, } \\
\text { wppm }\end{array}$} & \multirow{2}{*}{$\begin{array}{c}\text { Hydrogen } \\
\text { Pickup } \\
\text { Fraction, } \\
\%\end{array}$} \\
\hline & & $\begin{array}{l}\text { Based } \\
\text { on EC }\end{array}$ & $\begin{array}{c}\text { Based } \\
\text { on Met. }\end{array}$ & & \\
\hline 5 & 2803 & 38 & --- & $464 \pm 71$ & 24 \\
\hline$(648 E)$ & 2855 & 41 & --- & $563 \pm 145$ & 27 \\
\hline 6 & 2900 & --- & 41 & $600 \pm 150$ & 29 \\
\hline$(648 \mathrm{~F})$ & 2908 & & 43 & $657 \pm 148$ & 30 \\
\hline $\begin{array}{c}8 \\
(648 H)\end{array}$ & 3997 & 40 & --- & $670 \pm 40$ & 33 \\
\hline
\end{tabular}

The results in Table 70 were generated assuming that all of the measured hydrogen is in the cladding metal. It is possible that some of the hydrogen is in the corrosion layer. If so, this hydrogen would be driven off during the LOCA test temperature ramp, and it would not contribute to post-quench embrittlement. Hydrogen content has also been measured from the post-LOCA-test samples. The posttest hydrogen readings are presented in Section 5.2.3. These measured values are used to determine the concentration of hydrogen in the metal. As the samples described in 5.2.3 gained little-to-no weight during the LOCA tests, these post-test measurements are based on a comparable sample mass per unit length as compared to the mass per unit length of the pre-test hydrogen measurements. 


\subsection{2 . LOCA apparatus thermal and metallurgical benchmark tests for ZIRLO}

Thermal benchmark tests were conducted with two thermocouples welded onto fresh (as-fabricated) ZIRLO samples, in addition to the three TCs permanently welded to the Inconel holder just above the sample. Tests were repeated with fresh samples until furnace control parameters were established to give the desired temperature ramp and hold temperature. The output from the holder control TC is used to control furnace power during the temperature ramp and hold periods. For tests to be conducted using corroded high-burnup cladding, the thermal history for a pre-oxidized sample was determined. Preoxidation was conducted at $1000^{\circ} \mathrm{C}$ to grow inner- and outer-surface oxide layers that would result in about the same reduced heat of oxidation during the heating ramp to $1200^{\circ} \mathrm{C}$ as would be characteristic of high-burnup cladding with an outer-surface corrosion layer and an inner-surface oxide bond layer. Following thermal benchmarking, additional oxidation tests were conducted with no TCs welded to the samples. For these tests, weight gain and surface oxide layer thicknesses were measured and compared to Cathcart-Pawel (CP) predicted values. The ANL criterion for a successful metallurgical benchmark test is that the measured weight gain and average oxide layer thickness be within $10 \%$ of the CP-predicted values. Agreement between measured inner-surface and outer-surface oxide layers is also used to validate adequate steam flow to the cladding inner surface. The variation in oxide layer thickness (e.g. $< \pm 3 \mu \mathrm{m})$ is used to confirm that the temperature variation in the circumferential direction is small.

Thermal and/or metallurgical benchmark tests were conducted in three laboratory locations: coldlab EL-208, just outside IML Cell \#4 and inside IML Cell \#4. Table 71 summarizes the test locations, test conditions, and results of the seven benchmark tests conducted. Prior to conducting these tests, the old radiant-heating furnace, which has been used for over 8 years, was replaced with a new furnace. The old furnace was highly sensitive to relocation because of the design of the filaments within the vertical heating bulbs. The new furnace is more robust in design and is relatively insensitive to movement from lab-to-lab.

Tests ZLU\#93A and \#93B were conducted in sequence in EL-208. Two TCs were welded to the bare ZIRLO sample, which was heated to $985^{\circ} \mathrm{C}$ for a long enough hold time to grow $14-\mu \mathrm{m}$ oxide layers on the cladding inner and outer surfaces. The sample was cooled to $300^{\circ} \mathrm{C}$ and reheated to $1200^{\circ} \mathrm{C}$ to determine the effects of pre-oxide layers on heating ramp and hold temperature. There was an overshoot of $\approx 9^{\circ} \mathrm{C}$ in the hold temperature. Post-test calibration of the sample TCs to the NIST-calibrated TC at ANL resulted in an additional temperature correction of $3^{\circ} \mathrm{C}$. As a result, the furnace control parameters were modified to reduce the control TC temperature by $10^{\circ} \mathrm{C}$ and the sample temperature by $12^{\circ} \mathrm{C}$. The modified thermal history for the pre-oxidized ZIRLO sample is shown in Figure 166. The average temperature ramp rate from $1025-1175^{\circ} \mathrm{C}$ is $\approx 2.6^{\circ} \mathrm{C} / \mathrm{s}$. This ramp rate is particularly relevant to four of the six ZIRLO oxidation tests (see Table 72 in Section 5.2.3) as the maximum oxidation temperature for these tests was in this range.

The LOCA apparatus was moved into the IML, just outside IML Cell\#4; and electrical, hydraulic and gas lines were re-connected. Three benchmark tests were conducted out-of-cell. ZLU\#94 was run with a bare ZIRLO sample oxidized at $985^{\circ} \mathrm{C}$ to grow CP-predicted oxide layers of $14.5 \mu \mathrm{m}$. The measured weight gain was within $3 \%$ of the $\mathrm{CP}$-predicted weight gain, and the measured outer-surface oxide layer $(14 \pm 1 \mu \mathrm{m})$ was also in excellent agreement with the CP-predicted value. An additional weight-gain benchmark (ZLU\#97) was conducted at the target hold temperature of $1200^{\circ} \mathrm{C}$. The measured weight gain was within $8 \%$ of the CP-predicted value. Test ZLU\#98 was a thermal benchmark test conducted with bare ZIRLO (see Figure 166). 
Table 71. Data Summary for Out-of-cell and In-cell Benchmark Tests Conducted with the New LOCA Furnace in Laboratory EL-208 (Out-ofcell), in the Irradiated Materials Laboratory (IML, Out-of-cell) and in IML Cell \#4

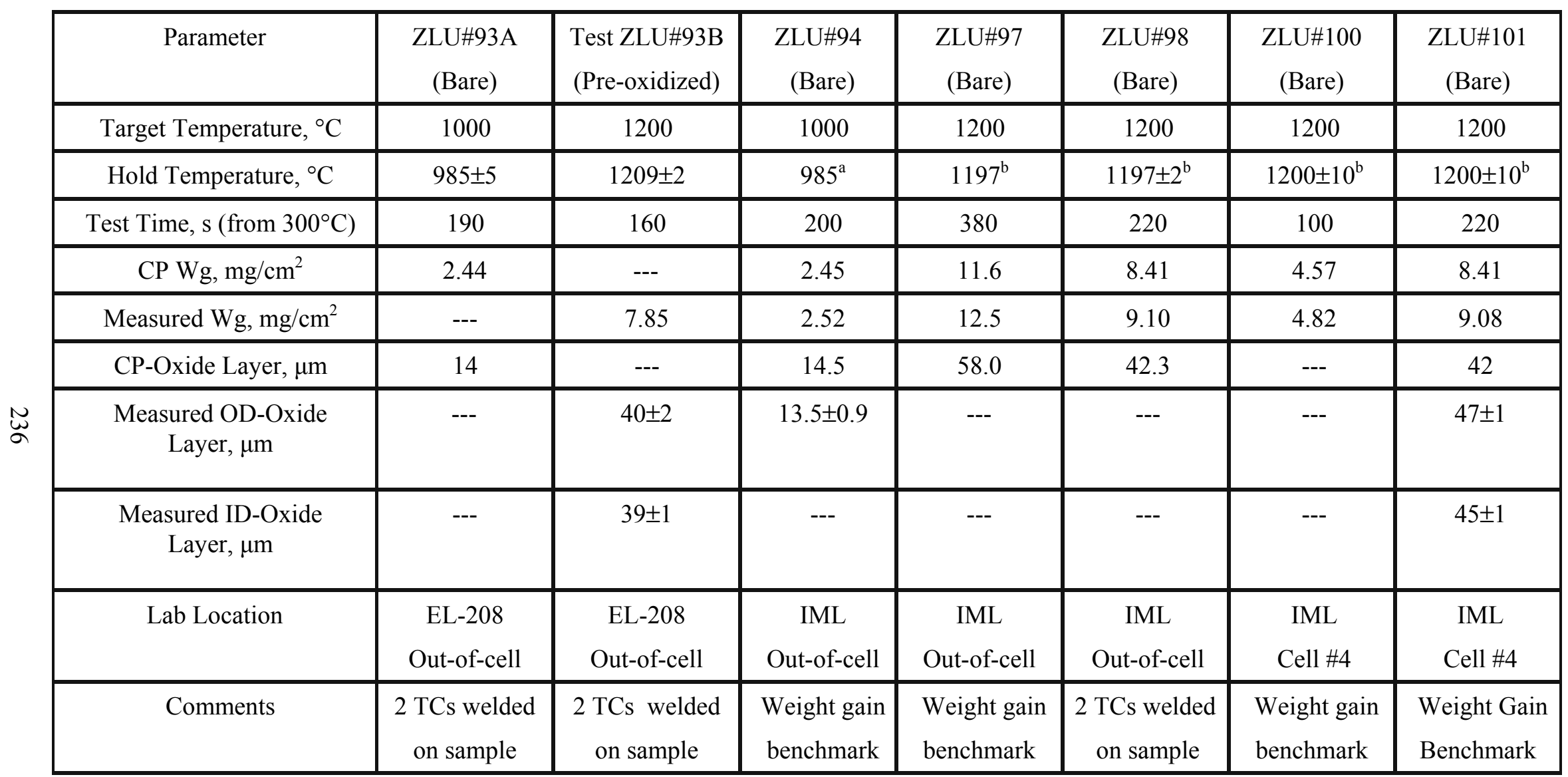

${ }^{\mathrm{a}}$ Furnace control parameters established for ZLU\#93A used for this test.

${ }^{b}$ Furnace control parameters for ZLU\#93B were modified to reduce steady temperature of holder TC by $10^{\circ} \mathrm{C}$. 


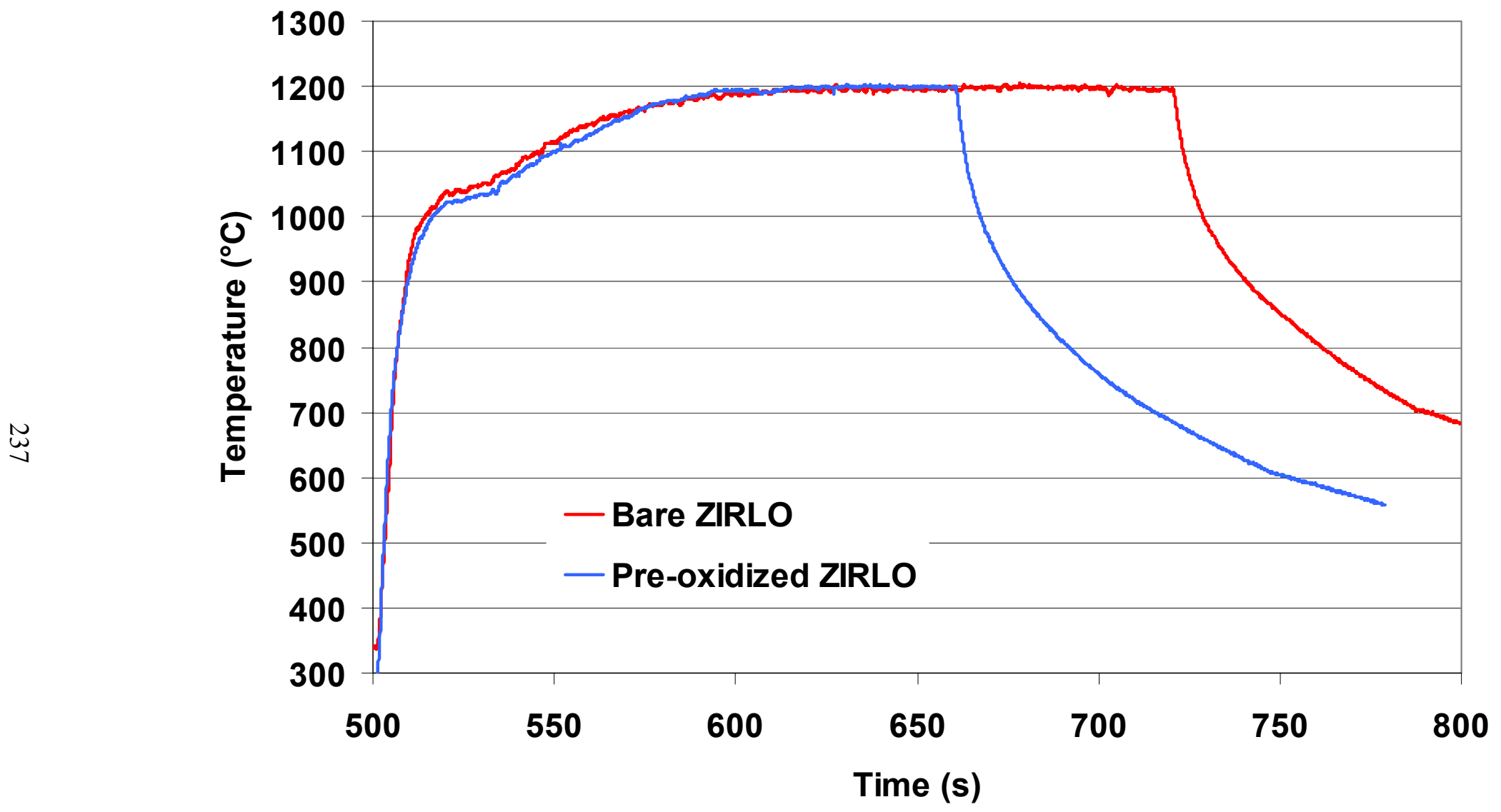

Figure 166. Comparison of thermal benchmark temperature histories for pre-oxidized ( $\approx 14-\mu \mathrm{m}$ OD and ID) ZIRLO (Test ZLU\#93B) and bare ZIRLO (Test ZLU\#98). ZLU\#93B temperatures were decreased by $12^{\circ} \mathrm{C}$ based on the decrease in holder temperature from the \#93B test to the \#98 test and the TC reading correction based on comparison to NIST-calibrated TC. 
The measured corrosion and bond layer thicknesses for these high-burnup ZIRLO specimens are 41-43 $\mu \mathrm{m}$ and $7 \mu \mathrm{m}$, respectively. Equivalent inner- and outer-surface pre-oxide layers are $12 \mu \mathrm{m}$. However, because of the low peak temperature $\left(\approx 1000^{\circ} \mathrm{C}\right)$ at the end of the rapid ramp and the slow heating from $1000^{\circ} \mathrm{C}$ to $1200^{\circ} \mathrm{C}$, these differences are not significant: the lower self-heating in preoxidized samples does not decrease the ramp temperatures from those recorded for bare ZIRLO.

It is clear from the thermal benchmark results that the performance of the new LOCA furnace is much less sensitive to physical movement than the performance of the old LOCA furnace. Also, the circumferential temperature variation appears to be less for the new furnace as compared to the old furnace. However, achieving such circumferentially uniform temperatures requires some adjustments and rather precise positioning of the sample within the furnace. In the first thermal benchmark test (ZLU\#96) conducted in the IML outside Cell\#4, the temperature variation in the circumferential direction was $18^{\circ} \mathrm{C}$ (i.e., $\pm 9^{\circ} \mathrm{C}$ deviation from the average of the two $\mathrm{TC}$ readings).

Although the temperature history for ZLU\#98 was measured for an initially bare ZIRLO sample, Figure 166 suggests that it is adequate for planning test times and interpreting data for high-burnup ZIRLO cladding samples. Given the temperature uncertainty associated with positioning the sample in the furnace, the test temperature is better represented by $1200 \pm 10^{\circ} \mathrm{C}$ than the benchmark value of $1197 \pm 2^{\circ} \mathrm{C}$. For in-cell tests, the technician must suit up in personal protective equipment (PPE) prior to entering the cell to position the quartz tube (containing the test train) within the furnace. The in-cell time must be limited with a high-burnup sample in the test train. Positioning within the furnace may not be as precise for in-cell tests as compared to out-of-cell tests.

After the LOCA apparatus was installed in IML Cell\#4, two thermal benchmarks were conducted: ZLU\#100 with a heating-phase test time of $100 \mathrm{~s}$ and ZLU\#101 with a heating-phase test time of $220 \mathrm{~s}$. The measured weight gain $\left(4.82 \mathrm{~g} / \mathrm{cm}^{2}\right)$ for the ZLU\#100 sample was only $\approx 5 \%$ higher than the CPpredicted value. The agreement is excellent considering that most of the oxidation occurred during the ramp. The 100-s heating-phase test corresponds to 7.4\% CP-ECR for high-burnup ZIRLO and is within the anticipated testing range of 3-10\% CP-ECR. For the 220-s heating-phase test (ZLU\#101), both the measured weight gain $\left(9.08 \mathrm{~g} / \mathrm{cm}^{2}\right)$ and the measured oxide-layer thicknesses $(47 \pm 1 \mu \mathrm{m}$ for OD and $45 \pm 1$ $\mu \mathrm{m}$ for ID) were in good agreement with CP-predicted values. The agreement between ID and OD oxide layer thicknesses indicates adequate steam flow inside the sample. The small circumferential variation in oxide layer thickness indicates adequate temperature uniformity in the circumferential direction.

Average cooling rates were determined from Figure 166 because of the possible sensitivity of postquench ductility to cooling rate. The overall average rate from $1200^{\circ} \mathrm{C}$ to the planned quench temperature of $800^{\circ} \mathrm{C}$ is $\approx 13^{\circ} \mathrm{C} / \mathrm{s}$ with rates of $29.4^{\circ} \mathrm{C} / \mathrm{s}$ from $1200^{\circ} \mathrm{C} \rightarrow 1000^{\circ} \mathrm{C}, 11.2^{\circ} \mathrm{C} / \mathrm{s}$ from $1000^{\circ} \mathrm{C} \rightarrow 900^{\circ} \mathrm{C}$, and $6.5^{\circ} \mathrm{C} / \mathrm{s}$ from $900^{\circ} \mathrm{C} \rightarrow 800^{\circ} \mathrm{C}$.

\subsubsection{Ductility results for high-burnup North Anna ZIRLO}

Six LOCA oxidation tests and 13 ring-compression ductility tests were conducted with defueled ZIRLO cladding from a high-burnup rod irradiated in one of the North Anna reactors. Cladding test samples were selected from three segments sectioned from Rod AM2-L17: one from a location $\approx 3.4 \mathrm{~m}$ (3320-3400 mm) above rod bottom, where local burnup was $\approx 60 \mathrm{GWd} / \mathrm{MTU}$; and two from $\approx 2.9 \mathrm{~m}$ (2800-2960 mm) above rod bottom, where local burnup was $76 \mathrm{GWd} / \mathrm{MTU}$. Rod-averaged burnup was $70 \mathrm{GWd} / \mathrm{MTU}$. Measured parameters of interest are: $43 \pm 2 \mu \mathrm{m}$ corrosion-layer thickness, $544 \pm 2 \mu \mathrm{m}$ $(\approx 0.54 \mathrm{~mm})$ cladding-wall thickness, $7 \pm 2 \mu \mathrm{m}$ fuel-cladding-bond thickness, and $9.50 \pm 0.02 \mathrm{~mm}$ cladding 
outer diameter, which is essentially the same as the nominal as-fabricated diameter. The cladding metal outer diameter used to normalize ring-compression displacements is in the range of 9.41-9.42 $\mathrm{mm}$.

Table 72 summarizes the oxidation test conditions, pre- and post-test hydrogen measurements, and ring-compression ductility results. Three samples were oxidized in steam at a hold temperature of $1200^{\circ} \mathrm{C}$ to CP-ECR values in the range of 6.3 to $10.2 \%$ and cooled without quench. The oxidation samples for these tests were cut from the same segment $(648 \mathrm{H}$ in Table 69$)$. Three tests were conducted with quench following oxidation to $4.0 \%, 5.1 \%$, and $6.3 \%$ CP-ECR. Based on previous experience, the $6.3 \% \mathrm{CP}$-ECR samples were expected to have negligible weight gain due to partial loss of corrosion layer offsetting oxygen pickup from steam. This was confirmed for the quenched sample oxidized to the same level. In general, post-test samples were sectioned to give two $\approx 8$-mm-long rings for compression testing, two $\approx 2$ $\mathrm{mm}$-long rings for hydrogen analysis, and one ring for metallographic imaging. Post-test hydrogen measurements are reported in Table 72. They are significantly lower than values measured for the pretest samples: $540 \pm 100$ vs. $670 \pm 40 \mathrm{wppm}, 510-540 \pm 100$ vs. $620 \pm 110 \mathrm{wppm}$, and $420 \pm 100 \mathrm{wppm}$ vs. $500 \pm 120 \mathrm{wppm}$. The results strongly suggest that about $100 \mathrm{wppm}$ of the measured pre-test hydrogen is in the corrosion layer. As such, post-test hydrogen data are used in the analysis of post-test ductility and embrittlement threshold.

Offset strains measured for high-burnup ZIRLO cladding are compared in Figure 167 to those measured for high-burnup Zry-4 cladding tested under similar conditions. Based on both offset and permanent strains, the ductile-to-brittle transition CP-ECR is 9\% for ZIRLO cooled without quench and $5 \%$ for ZIRLO cooled with quench at $800^{\circ} \mathrm{C}$. Quenching at $800^{\circ} \mathrm{C}$ following oxidation to $6.3 \%$ caused a significant reduction in offset and permanent strains, as well as embrittlement. However, both rings from the sample quenched at $800^{\circ} \mathrm{C}$ following oxidation to $4.0 \%$ were highly ductile. It should be noted that the $4.0 \%$ CP-ECR sample (ZLI\#5) reached a maximum temperature of only $1132^{\circ} \mathrm{C}$ during the ramp, while the $6.3 \% \mathrm{CP}$-ECR sample $(\mathrm{ZLI} \# 4)$ reached a maximum temperature of $1176^{\circ} \mathrm{C}$ prior to cooling. The results indicate a very strong sensitivity of post-quench ductility to maximum oxidation temperature and time at temperature.

Because of the dramatic decrease in ductility between $4.0 \%$ and $6.3 \%$ CP-ECR for quenched samples, a third test was run to 5.1\% CP-ECR (ZLI\#6) followed by quench. The results confirmed that post-quench ductility was maintained at about $5 \%$ CP-ECR with a maximum oxidation temperature of $1162^{\circ} \mathrm{C}$. However, the average hydrogen content of this sample was lower ( $\left.420 \mathrm{wppm}\right)$ than the previous two samples that were cooled with quench $(520 \mathrm{wppm})$. Two of the rings tested from this oxidationquench sample exhibited no through-wall failure up to the limits of displacement for the TC-instrumented ring. The third ring $-5.5-\mathrm{mm}$ long - failed with two through-wall cracks after an offset strain of $9.5 \%$. The results suggest that the ductility of high-burnup ZIRLO is very sensitive to peak oxidation temperature, test time above $1000^{\circ} \mathrm{C}$, and peak hydrogen content. For the ZLI\#6 ring that failed at 9.5\% offset strain, the hydrogen distribution in the circumferential direction was measured to determine if the failure locations corresponded to the local peaks in hydrogen concentration. The hydrogen content for the 0.6 -g ring was measured to be $414 \pm 115 \mathrm{wppm}$, and the local hydrogen content in the region of the two cracks was in the range of 500-600 wppm. At about $180^{\circ}$ from the crack location, the hydrogen content was only about 300 wppm. Combining these results with hydrogen data for two end samples $(\approx 1.5-\mathrm{mm}$ long), the post-test hydrogen is best represented by $420 \pm 100$ wppm for ZLI\#6 rings.

The post-quench ductility results for ZIRLO are subject to interpretation. Ductility is very high at $4.0 \%$ CP-ECR for rings with $540 \pm 100 \mathrm{wppm}$, while rings with $510 \pm 110 \mathrm{wppm}$ are brittle at $6.3 \% \mathrm{CP}$ ECR. The peak hydrogen contents of these rings are comparable. It is reasonable to conclude that the ductile-to-brittle transition oxidation level is $\approx 5 \%$ for $540 \pm 100$ wppm hydrogen in high-burnup ZIRLO. 
Table 72. Post-Test Ductility Results for High-Burnup North Anna ZIRLO Cladding Oxidized at $\leq 1200^{\circ} \mathrm{C}$, Cooled with (ZLI\#4-6) or without (ZLI\#1-3) Quench at $800^{\circ} \mathrm{C}$, and Ring-Compressed at $135^{\circ} \mathrm{C}$; $\mathrm{SC}=$ slow cooled without quench

\begin{tabular}{|c|c|c|c|c|c|c|c|}
\hline Test \# & \multicolumn{2}{|c|}{$\begin{array}{l}\text { Hydrogen Content, } \\
\text { wppm }\end{array}$} & $\begin{array}{c}\text { Test } \\
\text { Time, } \\
\text { s }\end{array}$ & $\begin{array}{c}\text { Peak } \\
\text { Temperature, } \\
{ }^{\circ} \mathrm{C}\end{array}$ & $\begin{array}{c}\text { CP-ECR, } \\
\%\end{array}$ & \multicolumn{2}{|c|}{$\begin{array}{l}\text { Strain, } \\
\quad \%\end{array}$} \\
\hline $\begin{array}{l}\text { ZLI\#2 } \\
\text { SC }\end{array}$ & $\begin{array}{c}670 \pm 40 \\
\text { for } 0.1-\mathrm{g} \\
\text { sample }\end{array}$ & $\begin{array}{c}540 \pm 100 \\
\text { for } 1-g \\
\text { sample } \\
\end{array}$ & 85 & 1176 & 6.3 & $\begin{array}{l}29 \\
9.5\end{array}$ & $\begin{array}{l}25 \\
6.5\end{array}$ \\
\hline $\begin{array}{l}\text { ZLI\#1 } \\
\text { SC }\end{array}$ & $\begin{array}{c}670 \pm 40 \\
\text { for } 0.1-g \\
\text { sample }\end{array}$ & $\begin{array}{c}510 \pm 100 \\
\text { for } 0.5-g \\
\text { sample }\end{array}$ & 110 & 1191 & 8.1 & $\begin{array}{l}5.0 \\
4.0\end{array}$ & $\begin{array}{l}-- \\
---\end{array}$ \\
\hline $\begin{array}{l}\text { ZLI\#3 } \\
\text { SC }\end{array}$ & $\begin{array}{c}670 \pm 40 \\
\text { for } 0.1-g \\
\text { sample }\end{array}$ & $\begin{array}{c}490 \pm 120 \\
0.34-\mathrm{g} \\
\text { sample }\end{array}$ & 145 & 1200 & 10.2 & $\begin{array}{l}1.0 \\
0.9\end{array}$ & --- \\
\hline $\begin{array}{c}\text { ZLI\#4 } \\
\text { Quench } \\
\text { at } 800^{\circ} \mathrm{C}\end{array}$ & $\begin{array}{c}620 \pm 140 \\
\text { for } 0.55-\mathrm{g} \\
\text { sample }\end{array}$ & $\begin{array}{c}510 \pm 110 \\
0.26-\mathrm{g} \\
\text { sample }^{\mathrm{b}}\end{array}$ & 85 & 1176 & 6.3 & $\begin{array}{l}1.1 \\
0.4\end{array}$ & 0.2 \\
\hline $\begin{array}{c}\text { ZLI\#6 } \\
\text { Quench } \\
\text { at } 800^{\circ} \mathrm{C}\end{array}$ & $\begin{array}{c}560 \pm 140 \\
\text { for } 0.55-g \\
\text { sample }\end{array}$ & $\begin{array}{c}420 \pm 100 \\
0.80-\mathrm{g} \\
\text { sample }^{\mathrm{b}}\end{array}$ & 70 & 1162 & 5.1 & $\begin{array}{c}>58 \\
49 \\
9.5\end{array}$ & $\begin{array}{c}>48 \\
--- \\
---\end{array}$ \\
\hline
\end{tabular}

${ }^{\mathrm{a}}$ From beginning of ramp at $300^{\circ} \mathrm{C}$ to end of heating phase.

${ }^{b}$ No weight gain; pre- and post-test sample weights were within $0.3 \%$.

${ }^{c}$ Hydrogen reading corrected for sample weight loss of $1 \%$. 


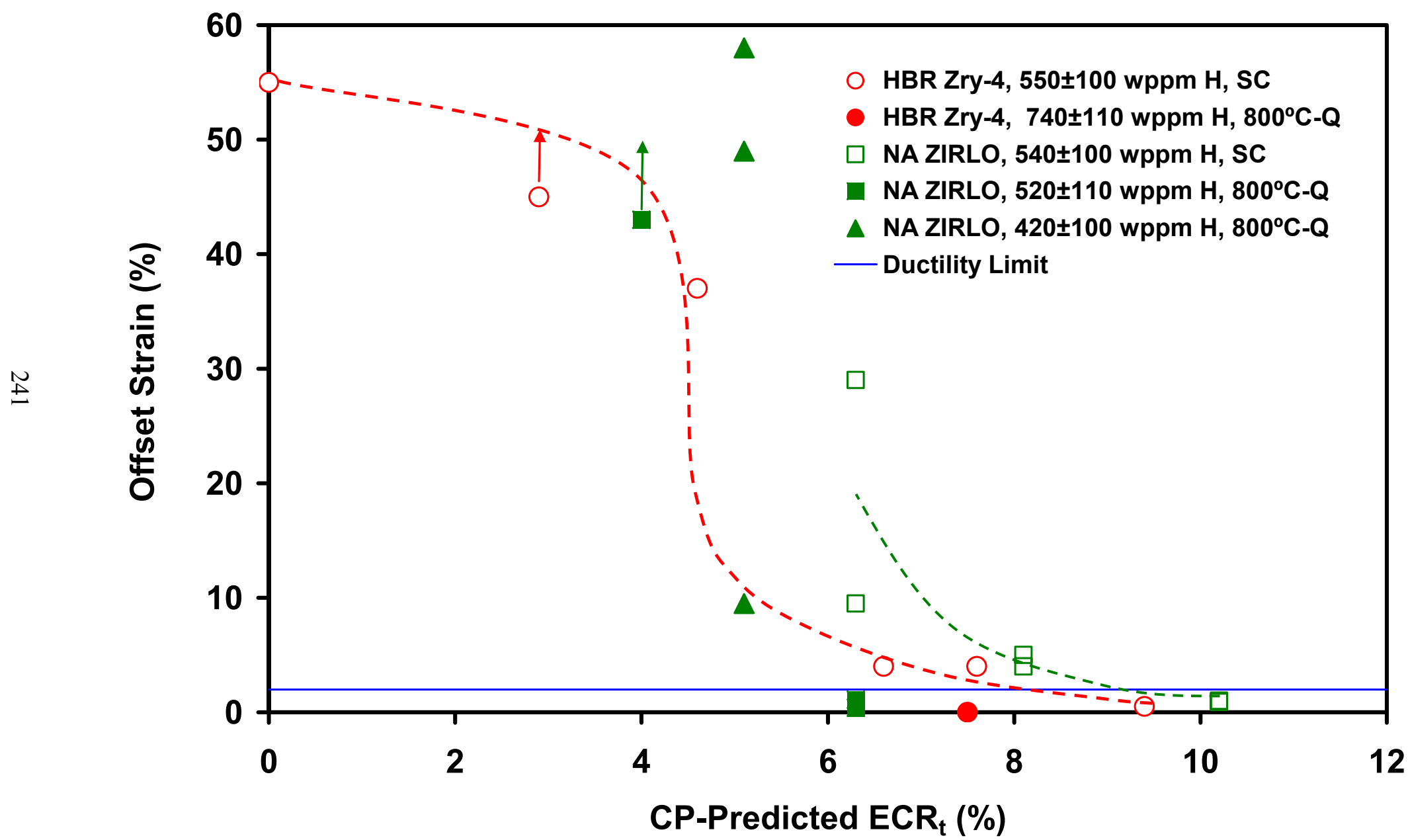

Figure 167. Comparison of post-test offset strains at $135^{\circ} \mathrm{C}$ for high-burnup North Anna ZIRLO and H.B. Robinson Zry-4 cladding, at $\leq 1200^{\circ} \mathrm{C}$ and cooled with or without quench at $800^{\circ} \mathrm{C}$. 
Load-displacement curves are shown in Figures 168-173 for rings cut from samples cooled without quench. For the ZIRLO sample oxidized to $6.3 \%$ CP-ECR, offset strains range from 9.5\% (Figure 169) to $29 \%$ (Figure 168). To determine if such variation was random or systematic, local hydrogen content was measured for these rings. The results are superimposed on the load-displacement curves. The high ductility ring had $\approx 630$-wppm hydrogen in the region of the side crack ( 3 o'clock position) perpendicular to the loading direction, while the ring at locations lining up with the loading direction had $\approx 500 \mathrm{wppm}$ hydrogen. For small ring displacements, the peak tensile bending stresses occur at the cladding inner surface under the loading platen and above the support platen (12 and 6 o'clock positions, respectively). As displacement and plastic strain increases, the peak tensile bending stress transitions to the cladding outer surface at the sides of the ring ( 3 and 6 o'clock positions). Contrast this hydrogen distribution to the one shown in Figure 169. The peak hydrogen content of $\approx 670 \mathrm{wppm}$ occurs at the low-displacement peak stress location. The results suggest that ductility differences between these two rings correlates with orientation of high local hydrogen content and peak tensile bending stress. As the hydrogen distribution is not known when the ring is positioned in the Instron, multiple oxidation tests $(\approx 3)$ would have to be conducted to generate multiple rings $(\approx 6)$ to determine the average and one-standard-deviation offset and permanent strains. As neither ring was brittle at 6.3\% CP-ECR and the ring orientation in Figure 169 gives the lower bound on ring ductility, multiple rings are not needed for this particular case. Also, notice that as ductility decreases with increasing CP-ECR, the strains from pairs of rings show little deviation ( $4 \%$ and 5\% offset for 8.1\% CP-ECR in Figures 170-171 and 1\% and $0.9 \%$ for $10.2 \%$ CP-ECR in Figures 172-173). For slow-cooled samples, it appears that circumferential variation of hydrogen does not affect the determination of transition CP-ECR to the nearest 1\% CP-ECR.

Load-displacement curves are shown in Figures 174-180 for rings cut from samples cooled with quench at $800^{\circ} \mathrm{C}$. At $6.3 \%$ CP-ECR (Figures 174-175), the rings were highly brittle following quench. Relative to the slow-cooled rings at $6.3 \% \mathrm{CP}$-ECR, the offset strain decreased from $\approx 20 \pm 10 \%$ to $<1 \%$, and the permanent strain decreased from $16 \pm 9 \%$ to essentially zero. Clearly, the ductility of post-LOCA high-burnup ZIRLO is highly sensitive to quench. In according with the testing plan, the oxidation level for the next test was lowered by about $2 \%$ to $4.0 \%$. Figures 176 and 177 show the dramatic increase in post-quench ductility for ZIRLO oxidized to only 4.0\% CP-ECR. Both rings deformed to within the limits imposed by the TCs and the ring geometry without cracking. Two factors should be considered in assessing these results: decrease in oxidation level from $6.3 \%$ to $4.0 \%$ and decrease in peak oxidation temperature from $1176^{\circ} \mathrm{C}$ to $1132^{\circ} \mathrm{C}$. As both oxidation tests were terminated during the heating ramp, the temperature ramp rate $\left(\approx 2.6^{\circ} \mathrm{C} / \mathrm{s}\right.$ from $1025^{\circ} \mathrm{C}$ to $\left.1175^{\circ} \mathrm{C}\right)$, as well as peak oxidation temperature, may be an important factor in determining transition oxidation levels for particular hydrogen contents: higher temperature ramp rates lead to longer time at high temperature and lower post-quench ductility for the same oxidation level.

A third test with quench was conducted to confirm the transition oxidation level of $5 \%$ determined from interpolation of the first two quench tests. The maximum oxidation temperature for this sample was $1162^{\circ} \mathrm{C}$. Two of the three rings sectioned from the $5.1 \% \mathrm{CP}$-ECR oxidation sample exhibited very high ductility (Figures 178-179). As shown in Figure 180, the third ring exhibited lower ductility $(\approx 10 \%$ offset strain). Based on post-test hydrogen analysis of small-mass end samples, the hydrogen content of the LOCA test sample was measured to be lower $(420 \pm 80 \mathrm{wppm})$ than for the previous two samples. As shown in Figure 180, the larger-mass ring-compression sample was found to have $414 \pm 115 \mathrm{wppm}$ hydrogen with local peaks as high as $600 \mathrm{wppm}$ near one of the two cracks that formed. 


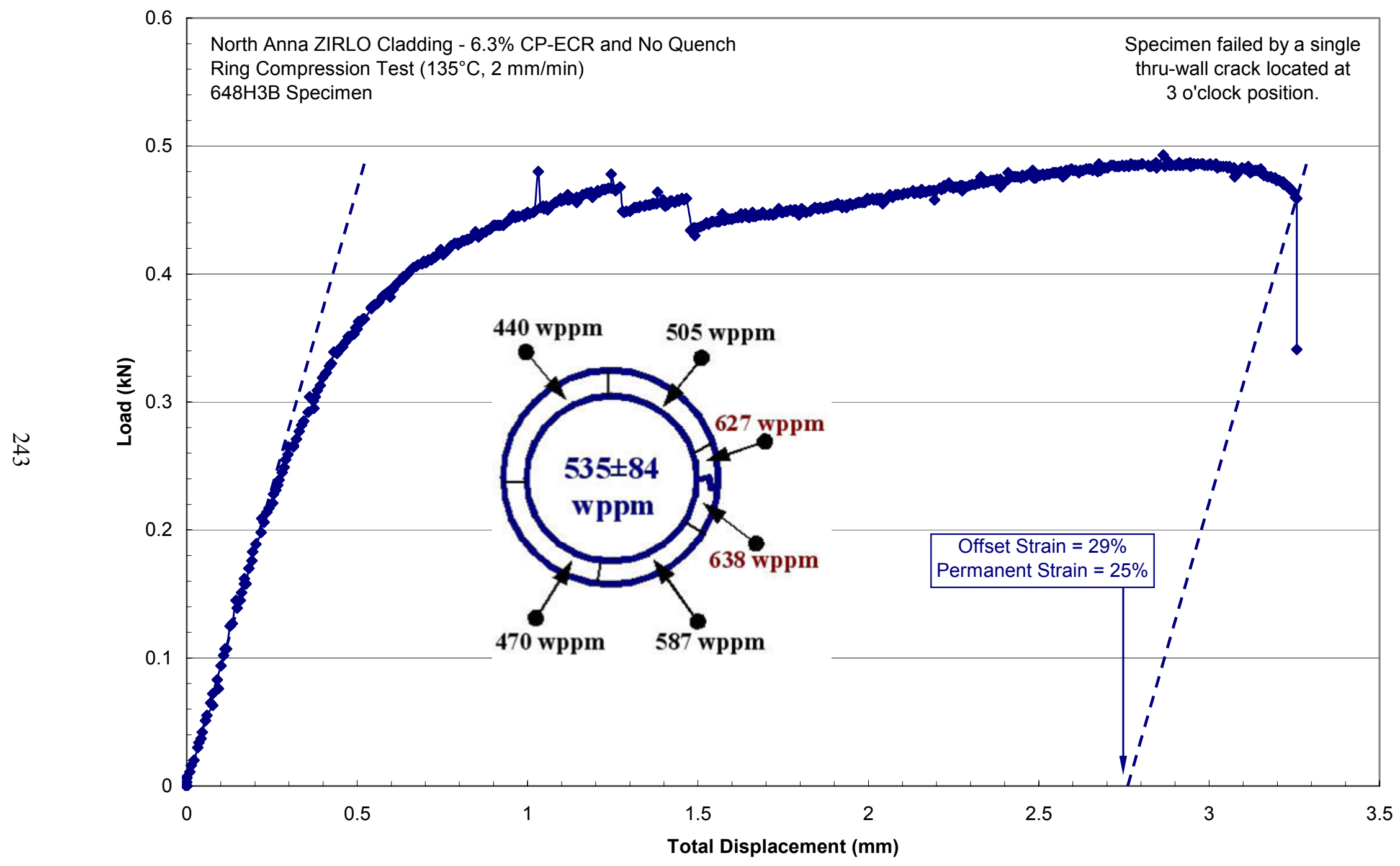

Figure 168. Load-displacement curve for high-burnup ZIRLO cladding oxidized to $6.3 \%$ CP-ECR and cooled without quench: Ring \#1. 


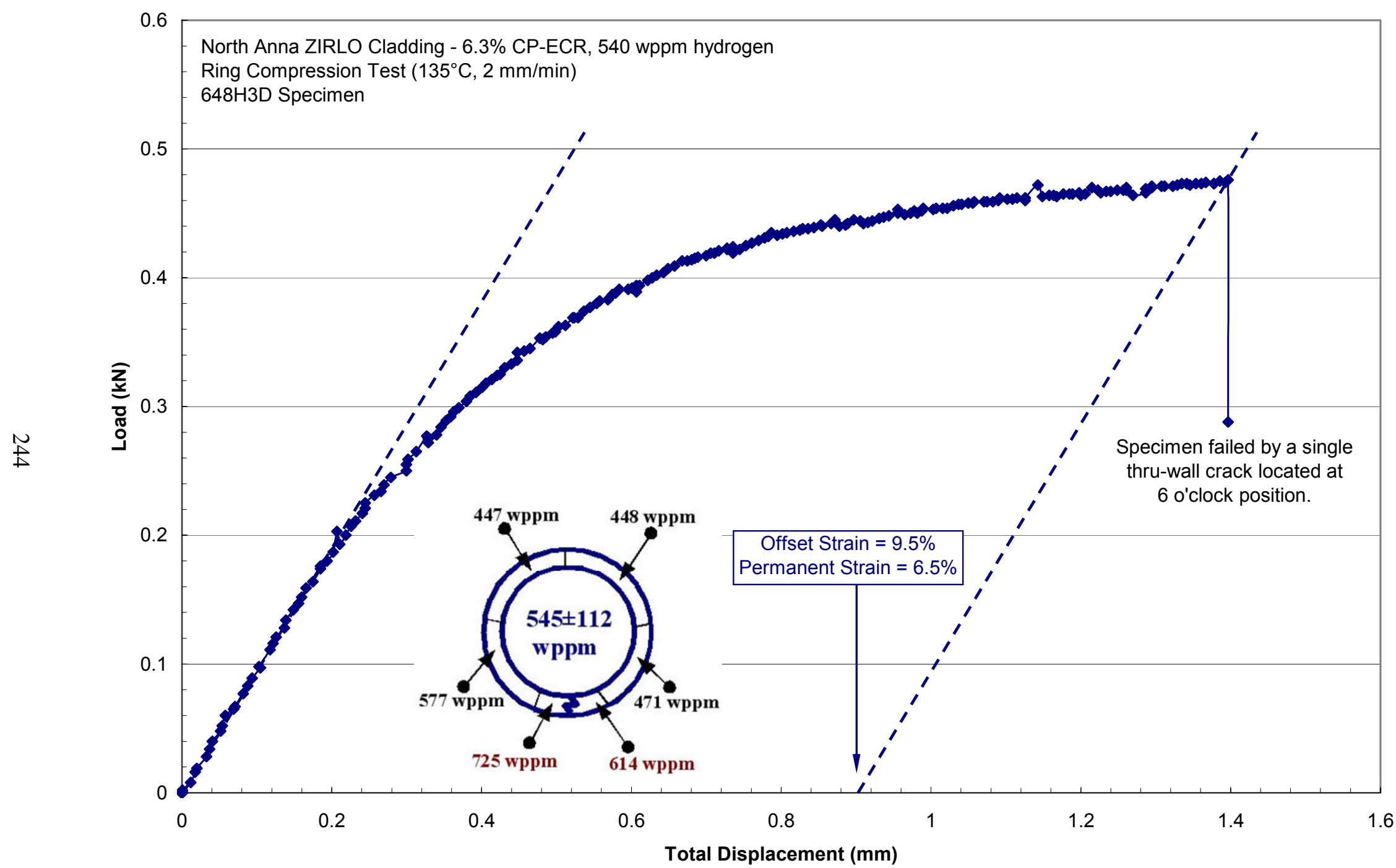

Figure 169. Load-displacement curve for high-burnup ZIRLO cladding oxidized to $6.3 \%$ CP-ECR and cooled without quench: Ring \#2. 


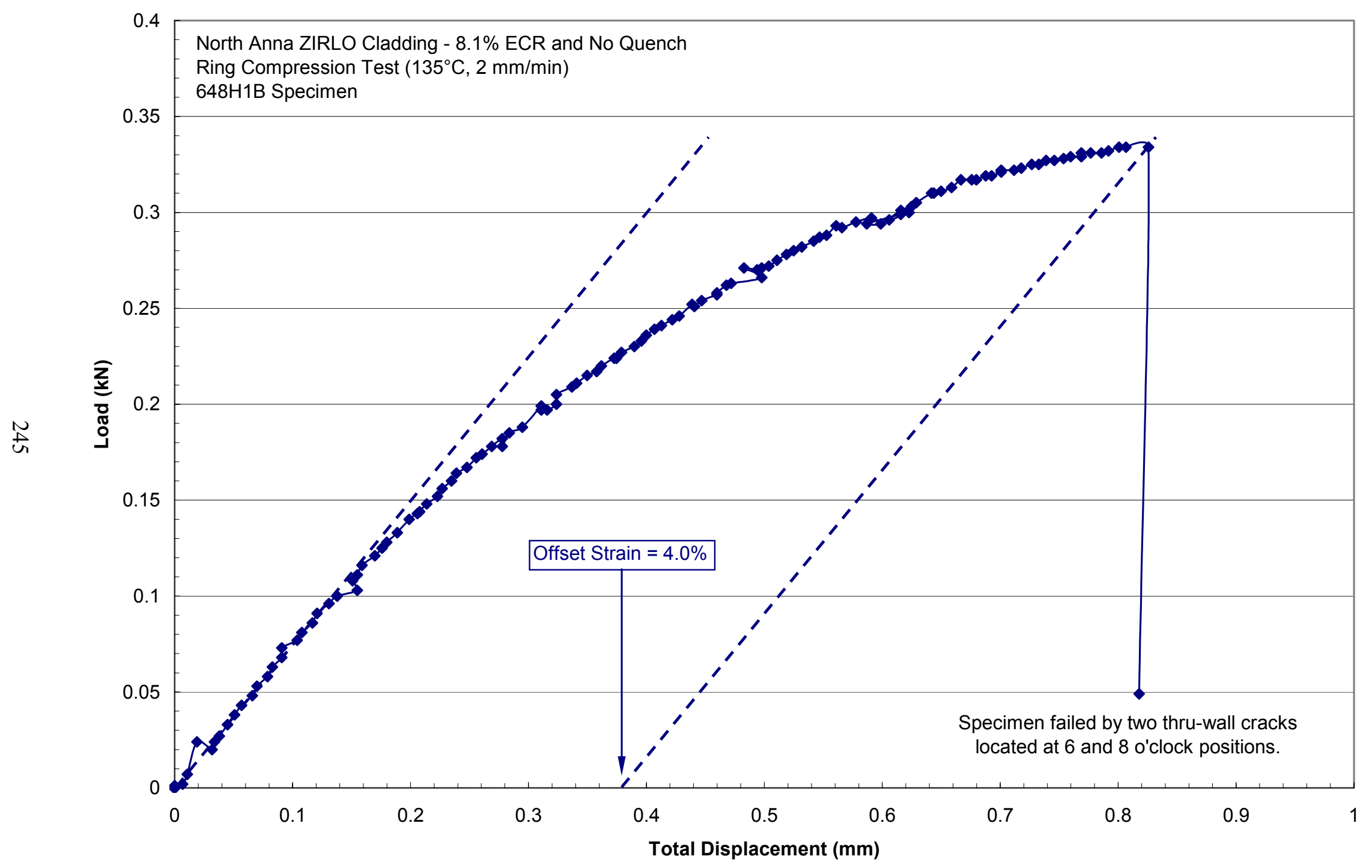

Figure 170. Load-displacement curve for high-burnup ZIRLO cladding oxidized to $8.1 \%$ CP-ECR and cooled without quench: Ring \#1. 


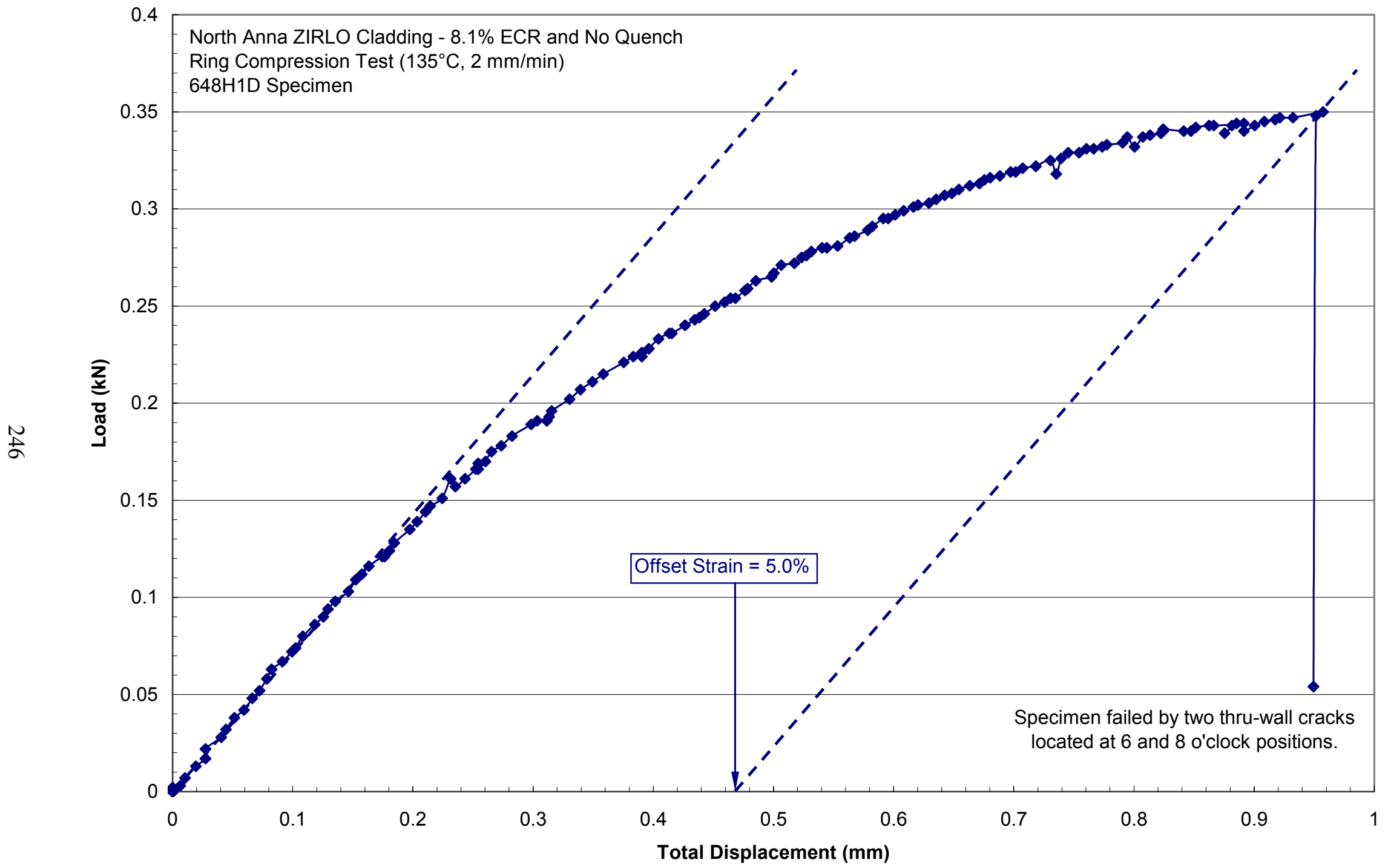

Figure 171. Load-displacement curve for high-burnup ZIRLO cladding oxidized to $8.1 \%$ CP-ECR and cooled without quench: Ring \#2. 


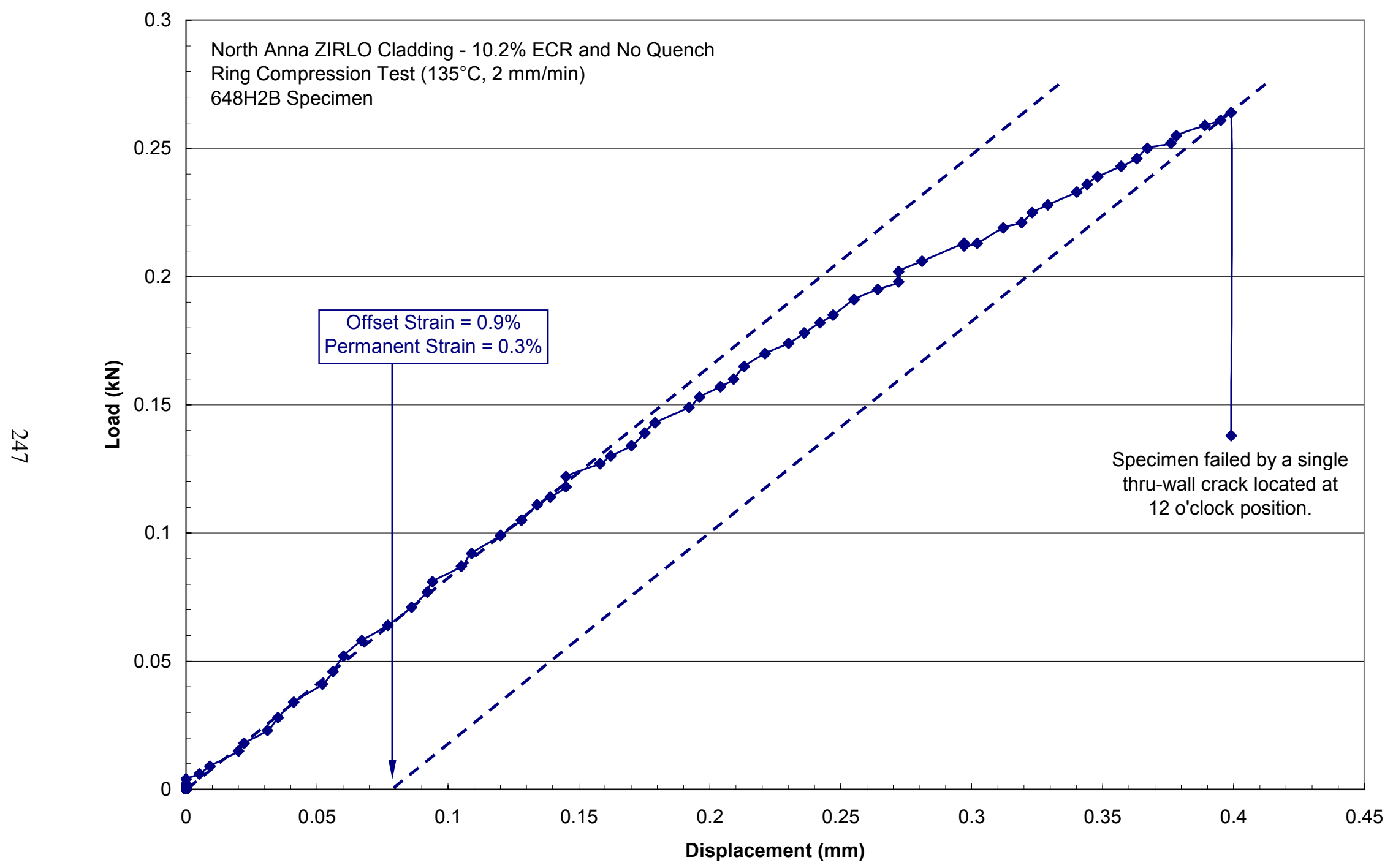

Figure 172. Load-displacement curve for high-burnup ZIRLO oxidized to $10.2 \%$ CP-ECR and cooled without quench: Ring \#1. 


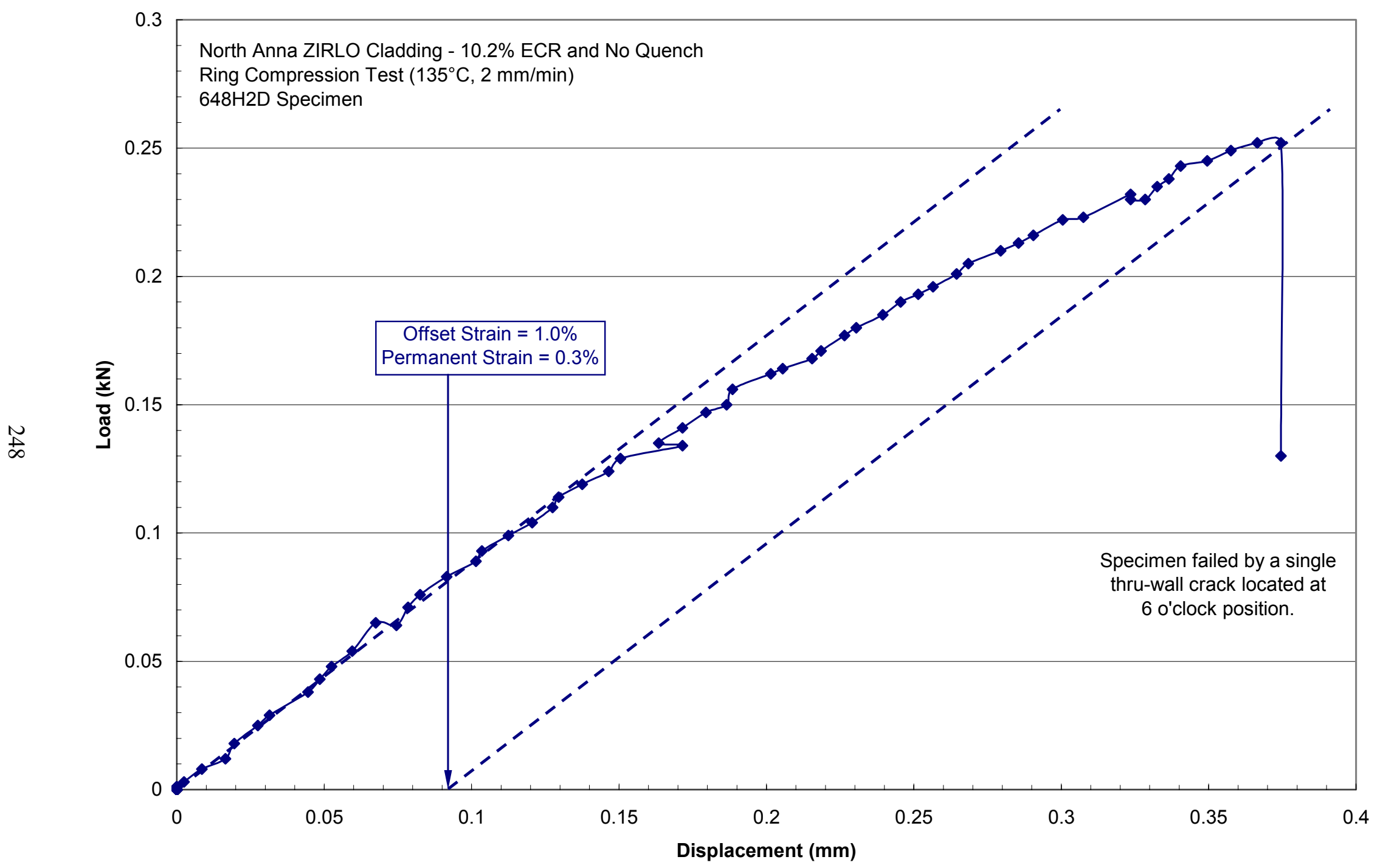

Figure 173. Load-displacement curve for high-burnup ZIRLO oxidized to 10.2\% CP-ECR and cooled without quench: Ring \#2. 


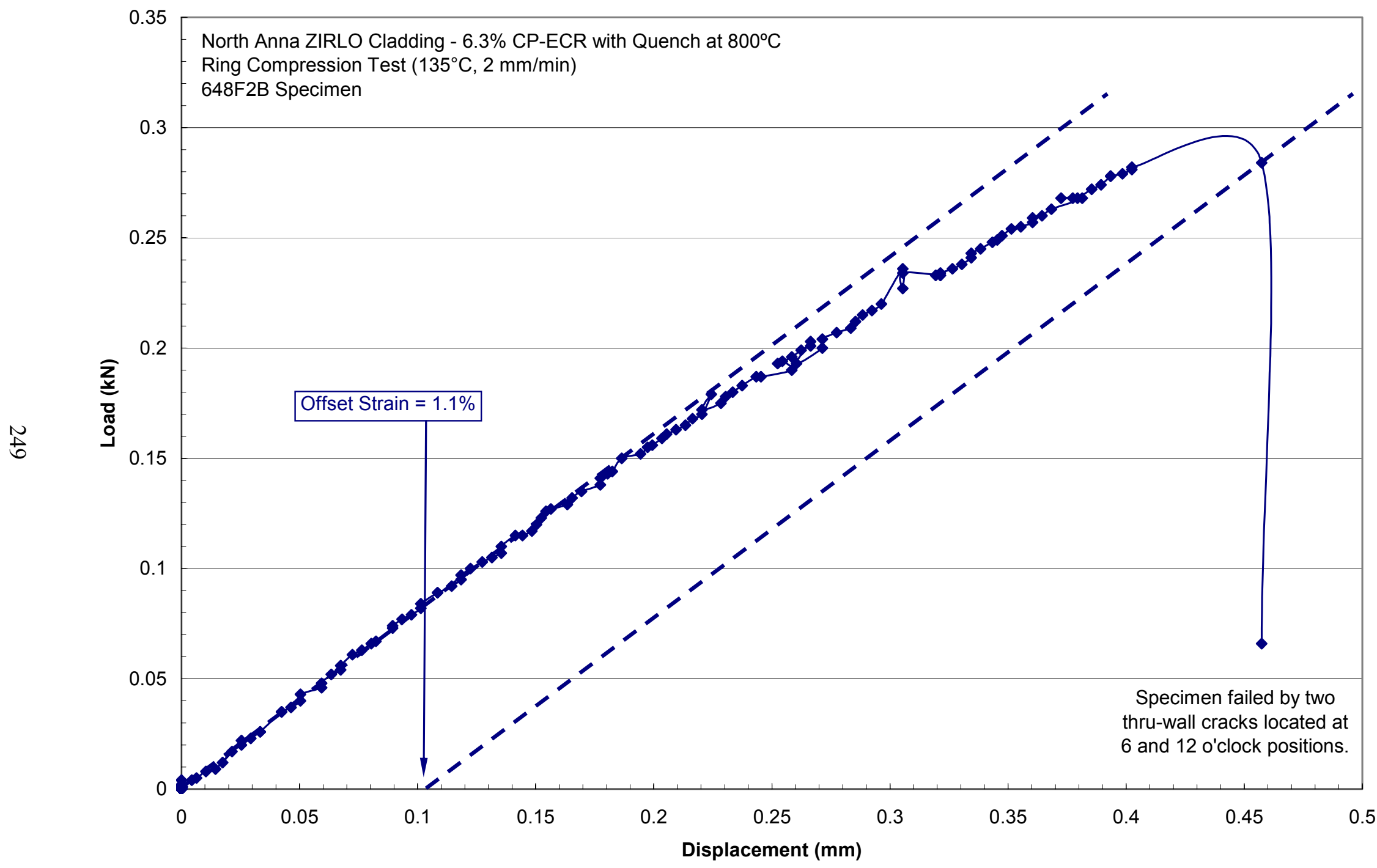

Figure 174. Load-displacement curve for high-burnup ZIRLO oxidized to $6.3 \%$ CP-ECR and cooled with quench at $800^{\circ} \mathrm{C}$ : Ring \#1. 


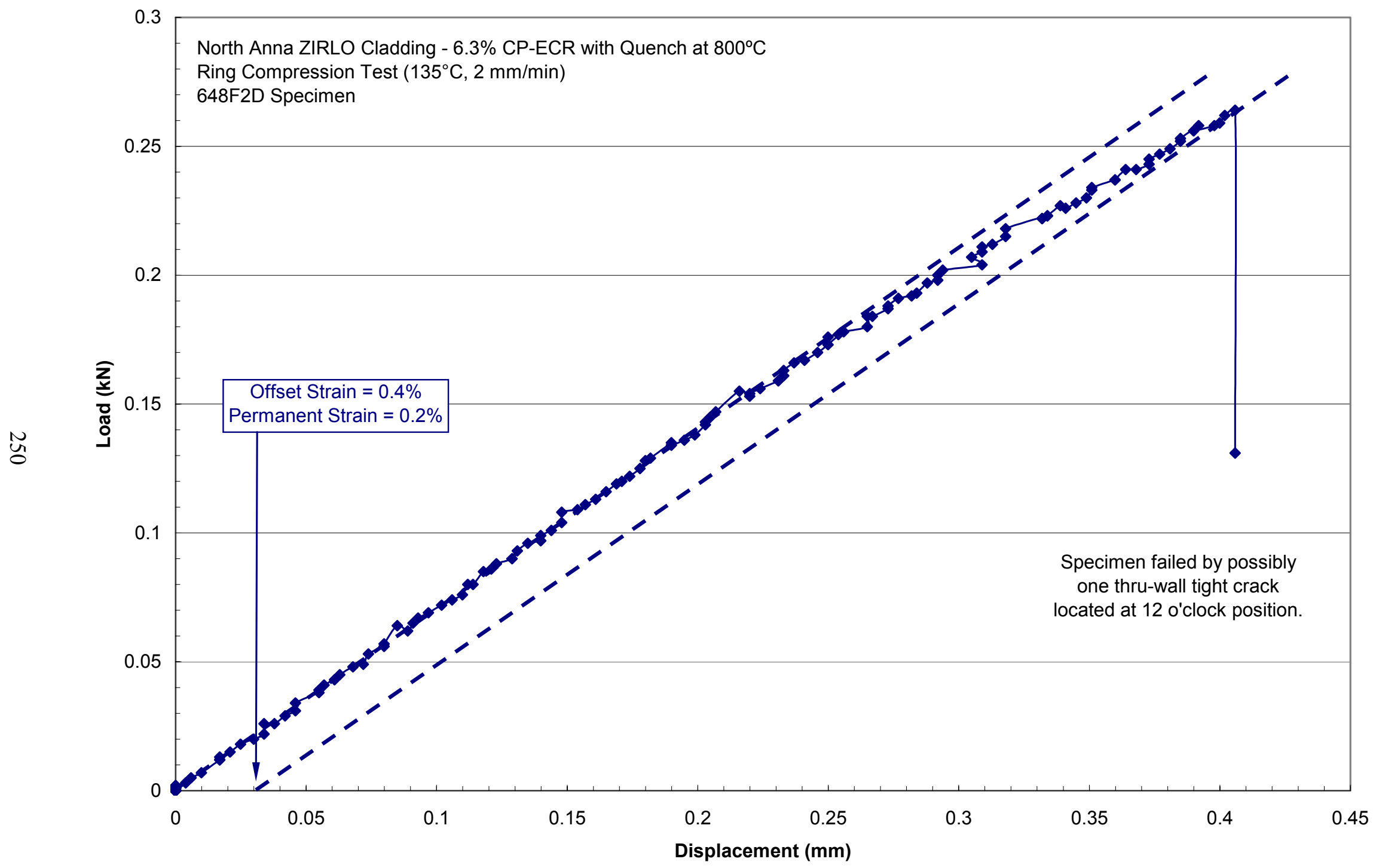

Figure 175. Load-displacement curve for high-burnup ZIRLO oxidized to $6.3 \%$ CP-ECR and cooled with quench at $800^{\circ} \mathrm{C}$ : Ring \#2. 


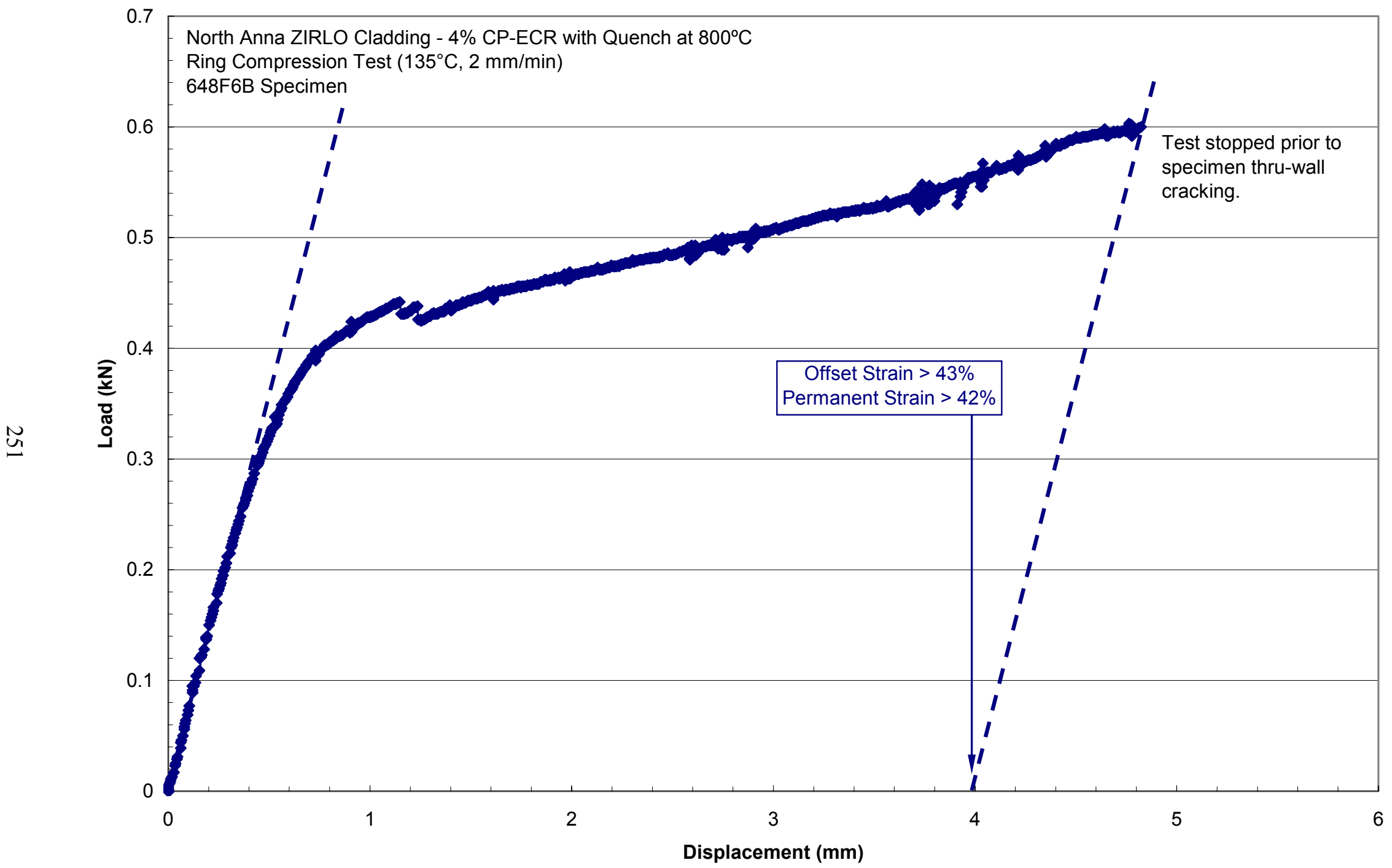

Figure 176. Load-displacement curve for high-burnup ZIRLO oxidized to $4.0 \%$ CP-ECR and cooled with quench at $800^{\circ} \mathrm{C}$ : Ring \#1. 


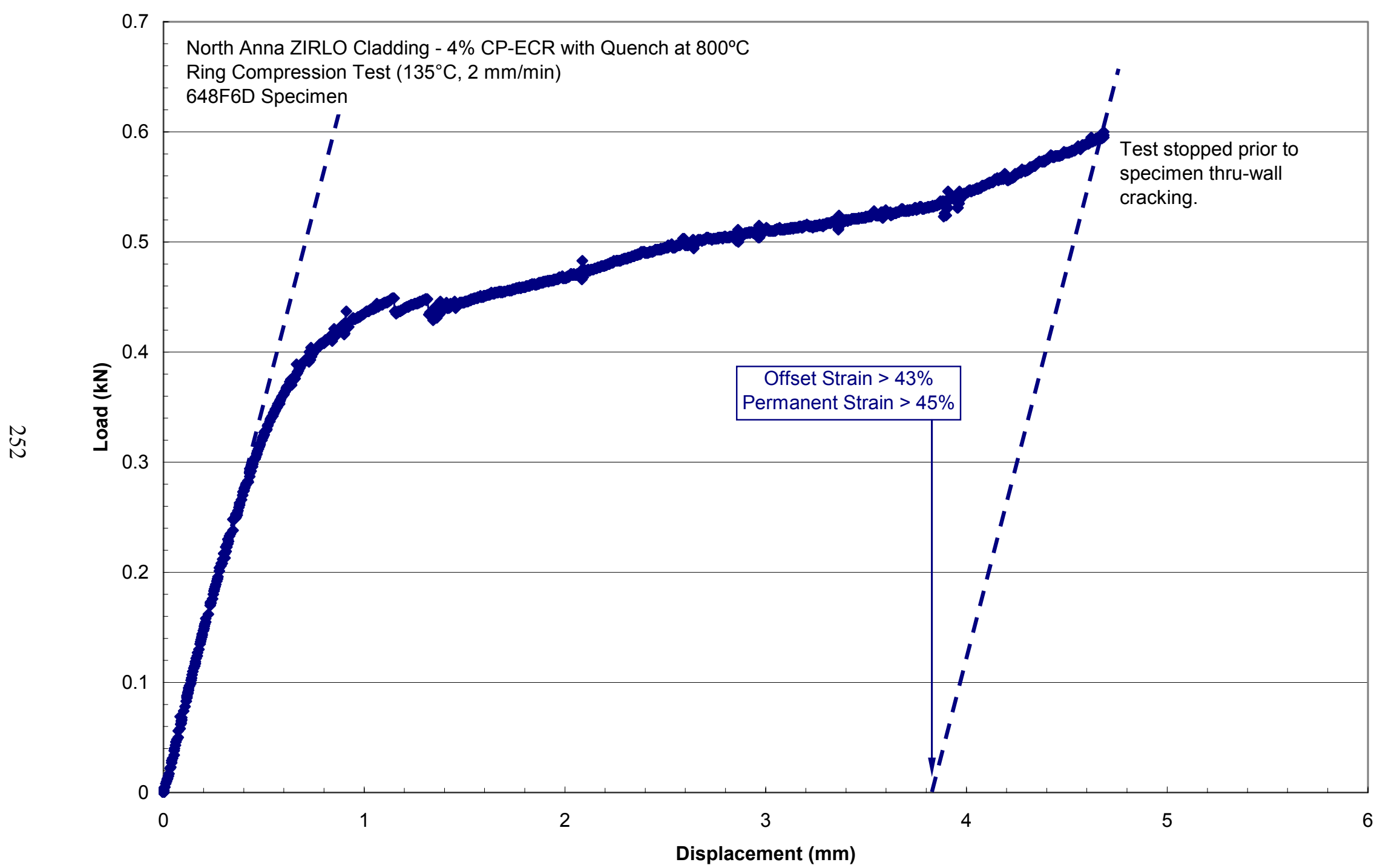

Figure 177. Load-displacement curve for high-burnup ZIRLO oxidized to 4.0\% CP-ECR and cooled with quench at $800^{\circ} \mathrm{C}$ : Ring \#2. 


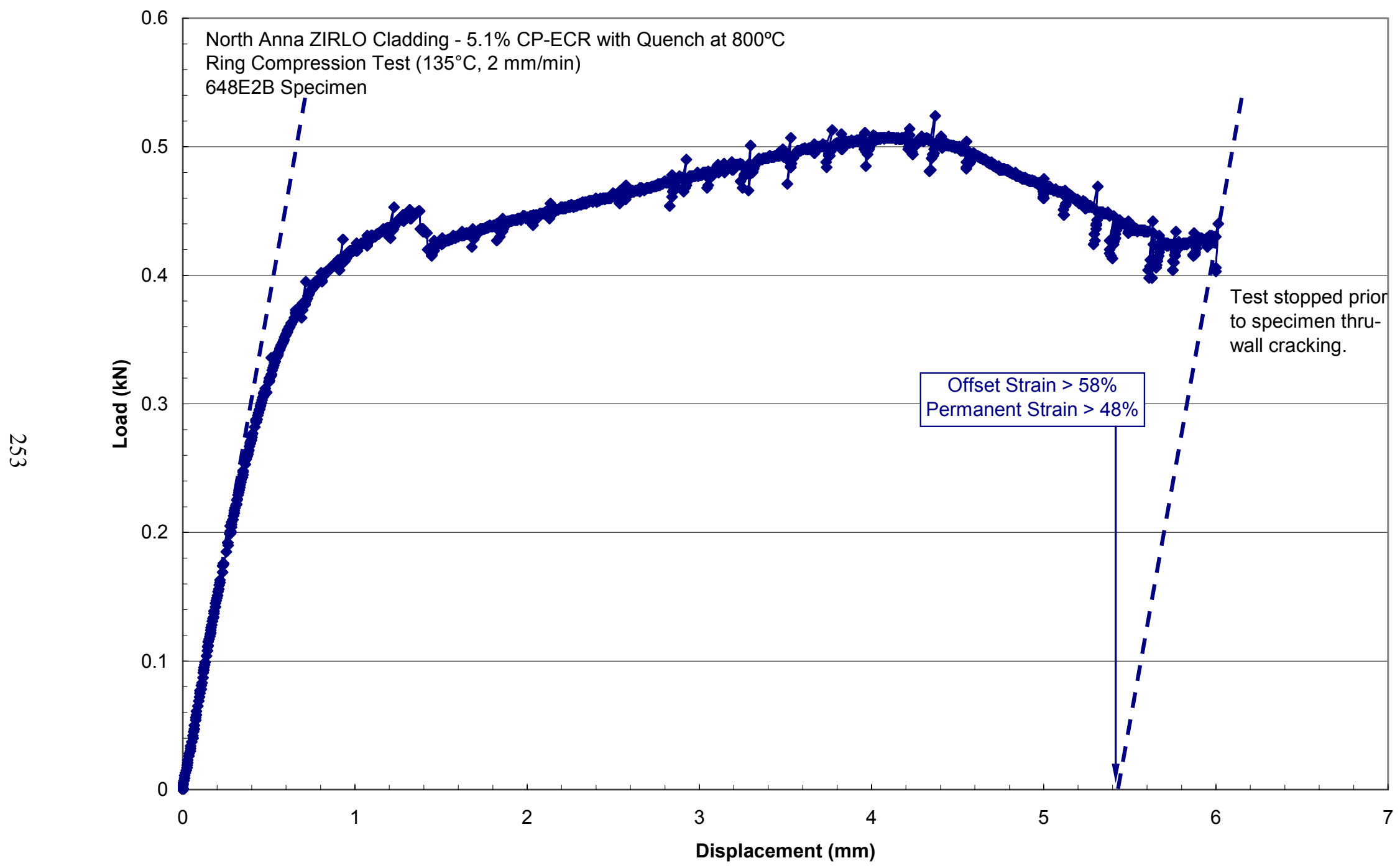

Figure 178. Load-displacement curve for high-burnup ZIRLO oxidized to $5.1 \%$ CP-ECR and cooled with quench at $800^{\circ} \mathrm{C}$ : Ring \#1 (7.4-mm long). The test was stopped due to displacement limitations prior to through-wall failure. 


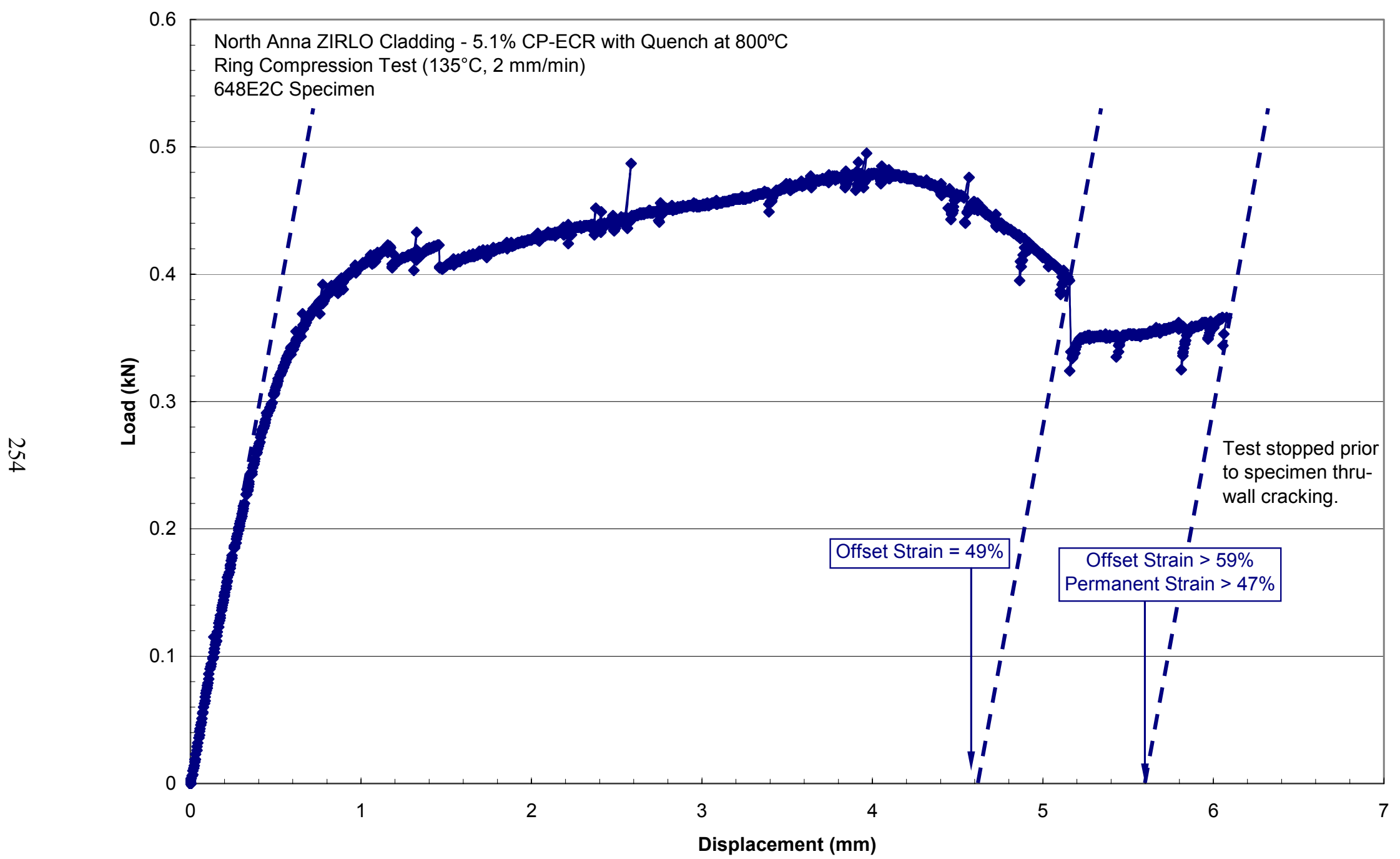

Figure 179. Load-displacement curve for high-burnup ZIRLO oxidized to $5.1 \% \mathrm{CP}$-ECR and cooled with quench at $800^{\circ} \mathrm{C}$ : Ring \#1 (7.2-mm-long center ring). Partial through-wall side crack ( $90^{\circ}$ from loading direction) observed at $49 \%$ offset strain. 


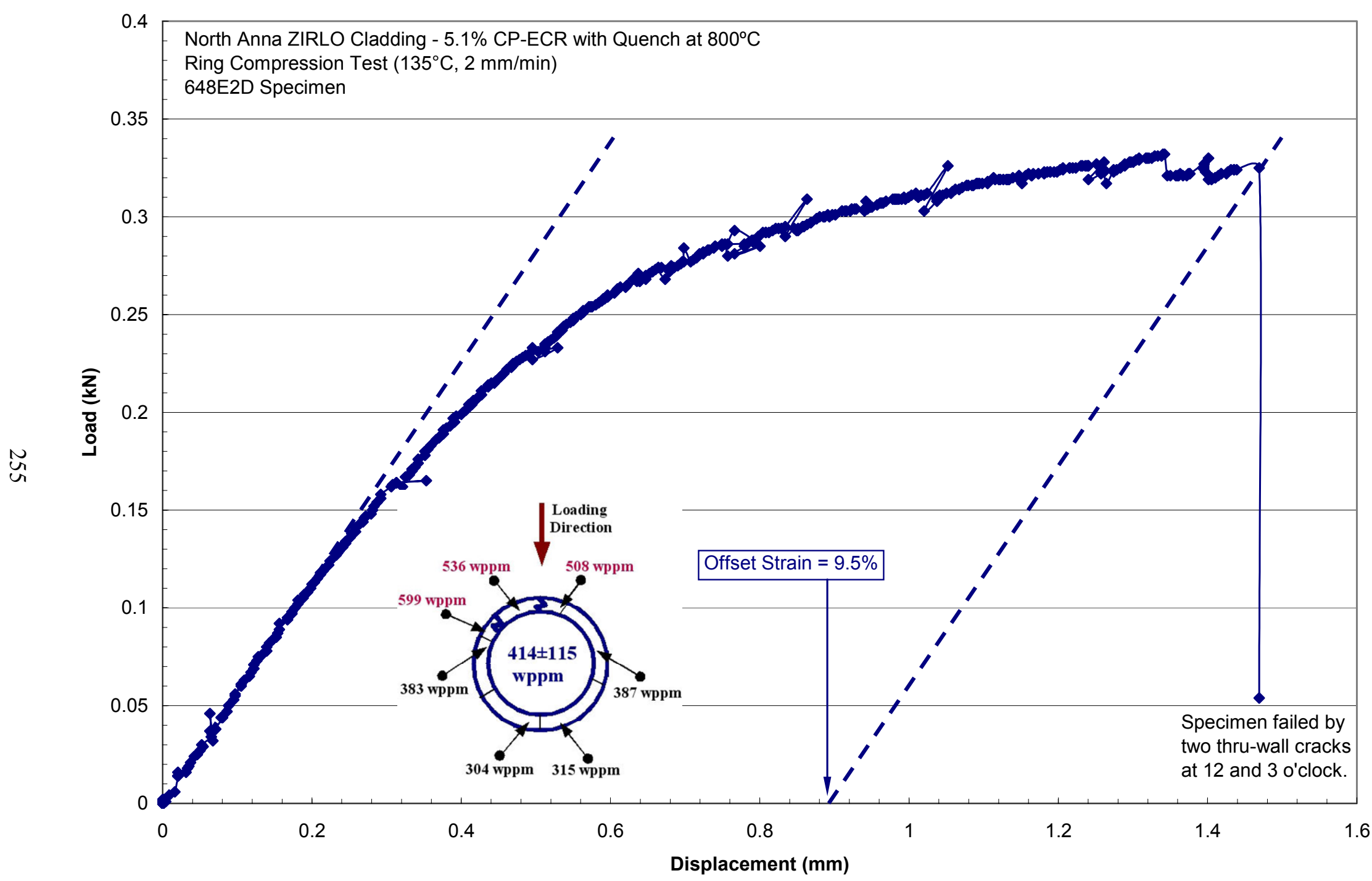

Figure 180. Load-displacement curve for high-burnup ZIRLO oxidized to 5.1\% CP-ECR and cooled with quench at $800^{\circ} \mathrm{C}$ : Ring \#1 (5.5-mm-long end ring). Through-wall cracks occurred at the 10 and 12 o'clock positions after $9.5 \%$ offset strain. 


\subsubsection{Discussion of high-burnup NA $17 \times 17$ ZIRLO test results}

Determination of the ductile-to-brittle transition CP-ECR (9\%) for high-burnup ZIRLO oxidized and cooled without quench was relatively straightforward. Two rings were sectioned from each of three LOCA tests samples for compression testing. Even though the large circumferential variation in hydrogen content had an effect on ductility in the highly ductile regime, it appeared to have little effect in the low ductility regime ( $8.1 \%$ CP-ECR) and the brittle regime (10.2\% CP-ECR). The post-test hydrogen content of these three samples was determined to be $540 \pm 100 \mathrm{wppm}$, while the pre-test hydrogen content for a low-mass end piece of the segment was $670 \pm 40 \mathrm{wppm}$. The results are comparable to the $8 \%$ transition CP-ECR determined for $15 \times 15$ HBR Zry-4, which had a lower transition CP-ECR (16\% vs. $19 \%$ for ZIRLO) in the as-fabricated condition. The results suggest that hydrogen at these levels dominates the embrittlement of these alloys during high-temperature steam oxidation. If one wanted to test prehydrided ZIRLO with uniform hydrogen distribution, tests could be conducted at several hydrogen concentrations: $550 \mathrm{wppm}, 600 \mathrm{wppm}$, and $650 \mathrm{wppm}$. After determination of the transition CP-ECR at these uniform hydrogen concentrations, tests would have to be conducted at this CP-ECR with prehydrided ZIRLO containing 550 $\pm 100 \mathrm{wppm}$ to determine if circumferential variations of this magnitude have a significant effect on the ductile-to-brittle transition CP-ECR. Based on results obtained for uniformly prehydrided Zry-4 and high-burnup Zry-4 with 550 $\pm 100 \mathrm{wppm}$, the circumferential variation in hydrogen content is expected to have a only a secondary effect on the ductile-to-brittle transition CP-ECR for samples cooled without quench.

Determination of the ductile-to-brittle transition CP-ECR (5\%) for high-burnup ZIRLO oxidized and quenched at $800^{\circ} \mathrm{C}$ was also straightforward, but data assessment was challenging because of the narrow range of oxidation levels $\left(4 \%\right.$ to $6 \%$ ) and peak temperatures (about $1130^{\circ} \mathrm{C}$ to $1180^{\circ} \mathrm{C}$ ) for transition from highly ductile to brittle. The few tests conducted with high-burnup ZIRLO, along with the results presented in Section 4 for prehydrided Zry-4, suggest that local axial and circumferential variations in hydrogen content and temperature ramp rate during the heating phase may affect the transition oxidation level. Repeating these tests with prehydrided ZIRLO would require a large test matrix. It is not clear whether uniformly prehydrided ZIRLO would be a good surrogate for high-burnup ZIRLO in terms of post-quench ductility and transition CP-ECR. A better comparison of results for prehydrided and high-burnup ZIRLO would be obtained at a lower oxidation temperature (e.g., 1000$1130^{\circ} \mathrm{C}$ ) at which embrittlement would occur during the hold time rather than during the temperature ramp.

\subsection{High-burnup Ringhals $17 \times 17$ M5}

\subsubsection{Characterization of high-burnup Ringhals M5 cladding}

Figure 181 shows the axial locations of Ringhals M5 Rod SUT3-00477 from which Studsvik sectioned and defueled four 80-mm-long cladding segments for ANL. Segment axial location relative to the bottom of the fuel rod was not maintained during defueling. Characterization results for LOCA pretest planning have been generated for samples sectioned from segments labeled by ANL as 645A, 645B, and $645 \mathrm{C}$ in Figure 181. Section 645D has been reserved for additional testing. The axial locations for these samples are about $3 \mathrm{~m}(2840-3160 \mathrm{~mm})$ from the bottom of the fuel rod. The rod-averaged burnup is $63 \mathrm{GWd} / \mathrm{MTU}$ based on vendor calculations ( $62 \mathrm{GWd} / \mathrm{MTU}$ based Cs-137 activity data). The corresponding peak burnup for the samples is $69 \mathrm{GWd} / \mathrm{MTU}(68 \mathrm{GWd} / \mathrm{MTU}$ based on Cs-137 activity data). Studsvik results based on non-destructive characterization give a cladding outer diameter of $9.48 \pm 0.01$ and a corrosion layer thickness of about $18 \pm 5 \mu \mathrm{m}$ (eddy current data). 


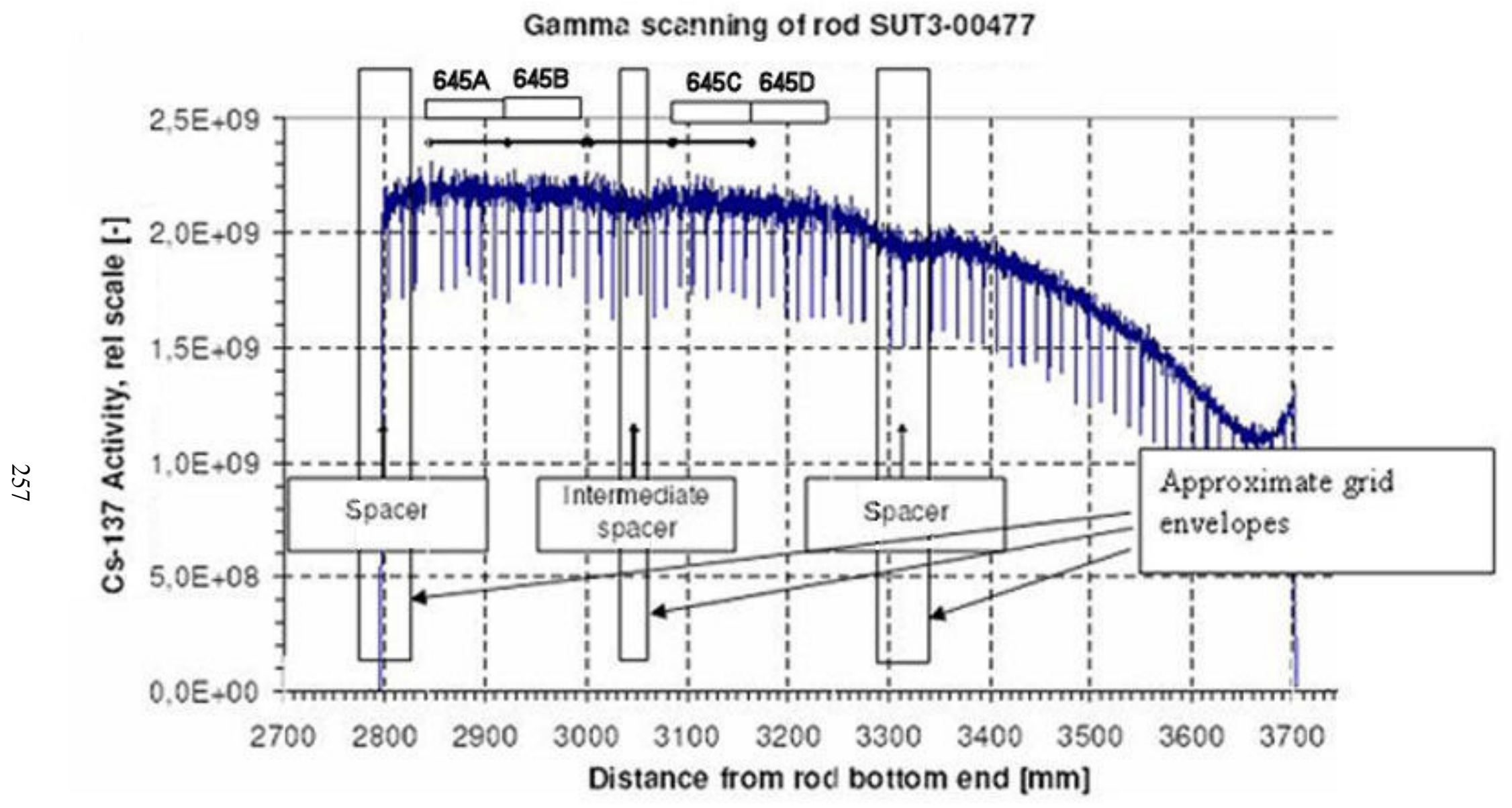

Figure 181. Sectioning diagram for Ringhals M5 defueled cladding segments sent to ANL from Studsvik. From left to right, the segments were labeled by ANL as 645A, 645B, 645C, and 645D. 
Table 73 summarizes the ANL characterization results for corrosion-layer thickness, fuel-claddingbond layer thickness, LECO-measured oxygen content, and LECO-measured hydrogen content. For LECO measurements, short cladding rings $(\approx 2$-mm-long) were sectioned and then snipped into four quarter rings. The hydrogen or oxygen content and mass were measured for each quarter ring. This mass included the masses of the corrosion layer, the cladding metal, and the fuel-cladding bond. The average hydrogen or oxygen content for a ring was determined from the total hydrogen or oxygen evolved from the four quarter rings normalized to the combined masses of the rings. Using a mass-average approach, the hydrogen content of the segments used for LOCA testing is $107 \pm 12$ wppm for a combined sample mass of $0.73 \mathrm{~g}$, with $75 \mathrm{wppm}$ as the lowest value and $123 \mathrm{wppm}$ as the highest value. As hydrogen measurements were performed at only four axial locations along the $240-\mathrm{mm}$ total cladding length, it is recommended that $110 \pm 20 \mathrm{wppm}$ be used to characterize the hydrogen content for LOCA samples. Eight metallographic images at one axial location were analyzed to determine the thicknesses of the corrosion layer $(12 \pm 1 \mu \mathrm{m})$, metal wall $(554 \pm 2 \mu \mathrm{m})$ and fuel-cladding bond $(8 \pm 3 \mu \mathrm{m})$. After sectioning 25 -mm-long LOCA samples, the outer diameter of five of these samples was determined by ANL to be 9.47-9.48 mm based on micrometer measurements.

Table 73. Ringhals M5 Characterization Results for Cladding Segments from Rod SUT3-00477

\begin{tabular}{|c|c|c|c|c|c|c|}
\hline $\begin{array}{c}\text { ANL } \\
\text { Sample } \\
\text { ID } \\
\end{array}$ & $\begin{array}{l}\text { Location } \\
\text { from } \\
\text { Bottom, } \\
\mathrm{mm} \\
\end{array}$ & $\begin{array}{l}\text { Corrosion } \\
\text { Layer from } \\
\text { Eddy Cur. } \\
\text { (EC), } \mu \mathrm{m}\end{array}$ & $\begin{array}{c}\text { Corrosion } \\
\text { Layer from } \\
\text { Metallography, } \\
\mu \mathrm{m}\end{array}$ & $\begin{array}{c}\text { Fuel-Clad } \\
\text { Bond Layer } \\
\text { from Met., } \\
\mu \mathrm{m}\end{array}$ & $\begin{array}{c}\text { LECO } \\
\text { Oxygen } \\
\text { Content, } \\
\text { wt. } \% \\
\end{array}$ & $\begin{array}{c}\text { LECO } \\
\text { Hydrogen } \\
\text { Content, } \\
\text { wppm } \\
\end{array}$ \\
\hline $648 \mathrm{~A}$ & $\begin{array}{l}2840- \\
2920\end{array}$ & $\approx 18 \pm 5$ & ב-- & "--- & "--- & $\begin{array}{c}101 \pm 21 \\
(0.10 \text {-g mass })\end{array}$ \\
\hline $645 B$ & $\begin{array}{c}2920- \\
3000\end{array}$ & $\approx 18 \pm 5$ & $\begin{aligned} & 12 \pm 1 @ \\
\approx & 2960 \mathrm{~mm}\end{aligned}$ & $\begin{array}{c}8 \pm 3 @ \\
\approx 2960 \mathrm{~mm}\end{array}$ & $1.01 \pm 0.13$ & $\begin{array}{c}103 \pm 5 \\
(0.22-\mathrm{g} \text { mass })\end{array}$ \\
\hline $645 \mathrm{C}$ & $\begin{array}{l}3080- \\
3160\end{array}$ & $\approx 18 \pm 5$ & --- & --- & --- & $\begin{array}{c}103 \pm 10 \\
(0.24-\mathrm{g} \text { mass }) \\
116 \pm 4 \\
(0.17-\mathrm{g} \text { mass })\end{array}$ \\
\hline
\end{tabular}

Figure 182 shows high-magnification micrographs of the corrosion layer at two circumferential locations at about $2960 \mathrm{~mm}$ from the rod bottom. The corrosion layer thickness was measured for eight such locations at this axial location. Figure 183 shows high-magnification images of the fuel-cladding bond layer at two circumferential locations. The bond-layer thickness was determined from the same circumferential locations (eight images) as the corrosion layer. Because of the highly non-uniform bondfuel interface, the reported bond thickness is that of an equivalent oxide bond with a smooth fuel interface. Figures 184 and 185 show two of eight images used to determine the cladding wall thickness. All three layers exhibit relatively uniform thickness in the circumferential direction. The images shown in Figures 182-185 are for an etched cross section of cladding. The etching solution and etching time 


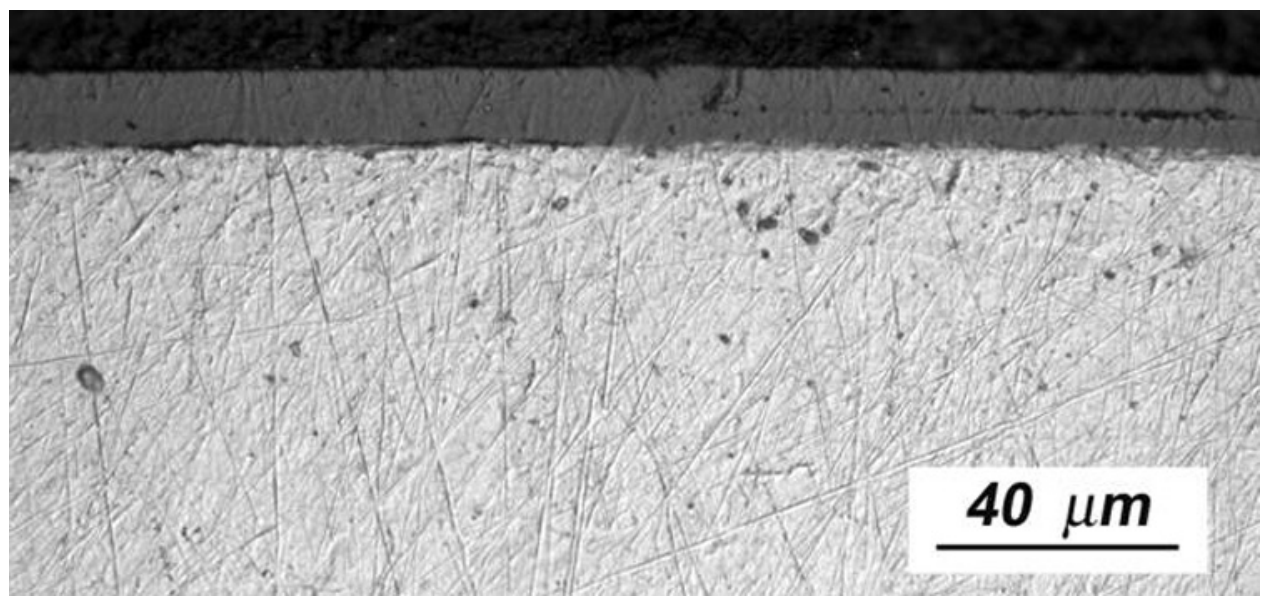

(a)

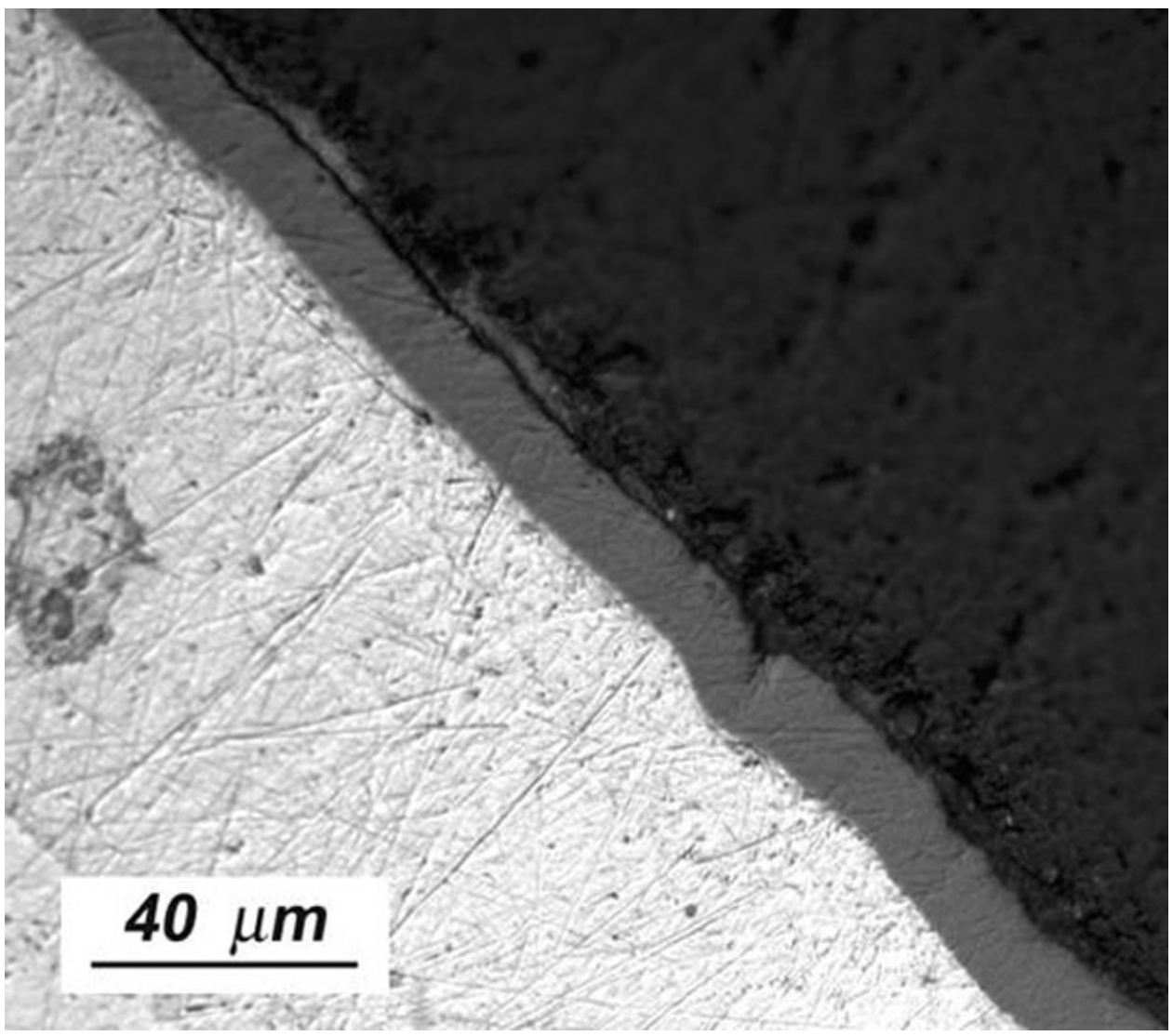

(b)

Figure 182. Micrographs of corrosion layer (dark gray) on M5 cladding (light gray) outer surface at $\approx 2960$ $\mathrm{mm}$ from bottom of high-burnup Ringhals Rod SUT3-00477. Based on images at eight circumferential locations, the corrosion layer thickness was determined to be $12 \pm 1 \mu \mathrm{m}$. 


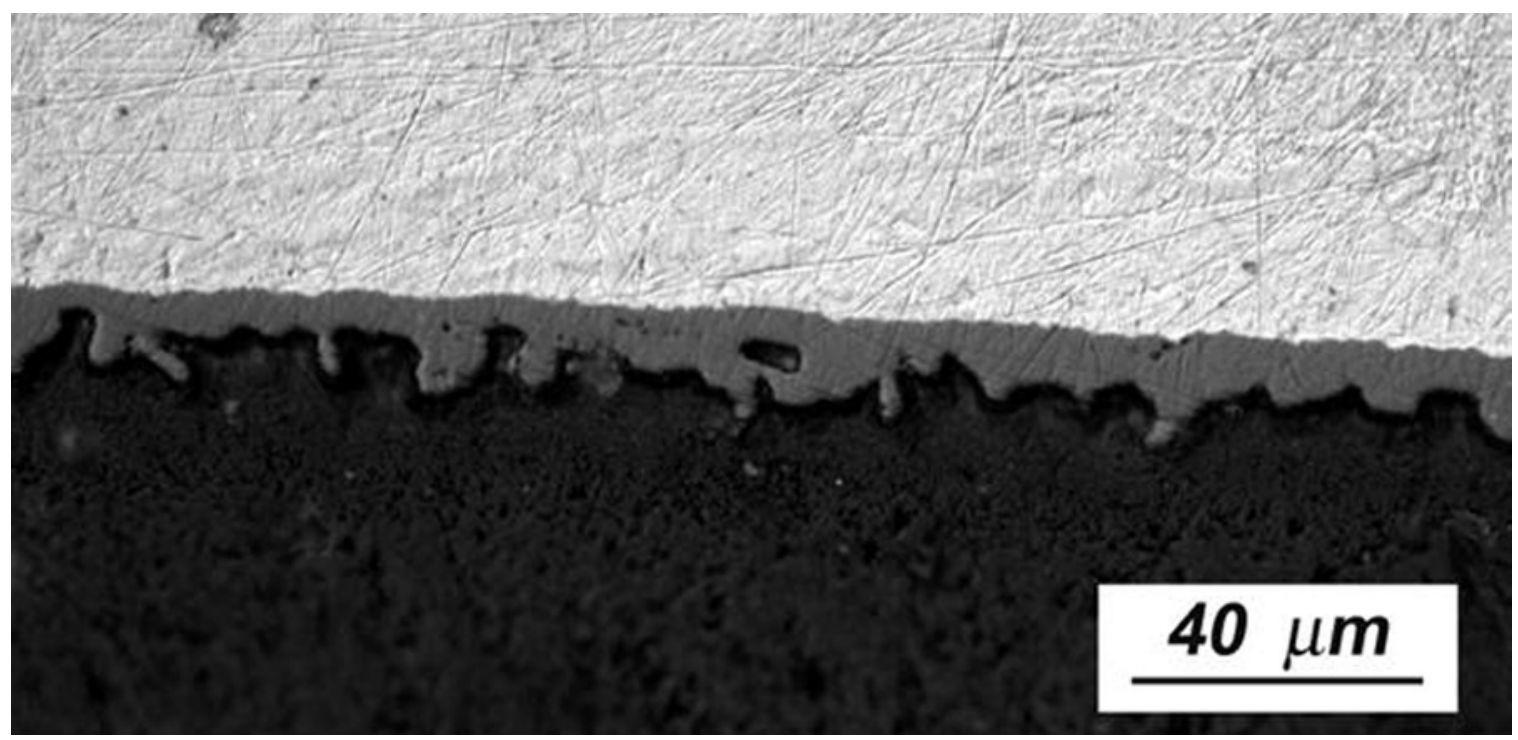

(a)

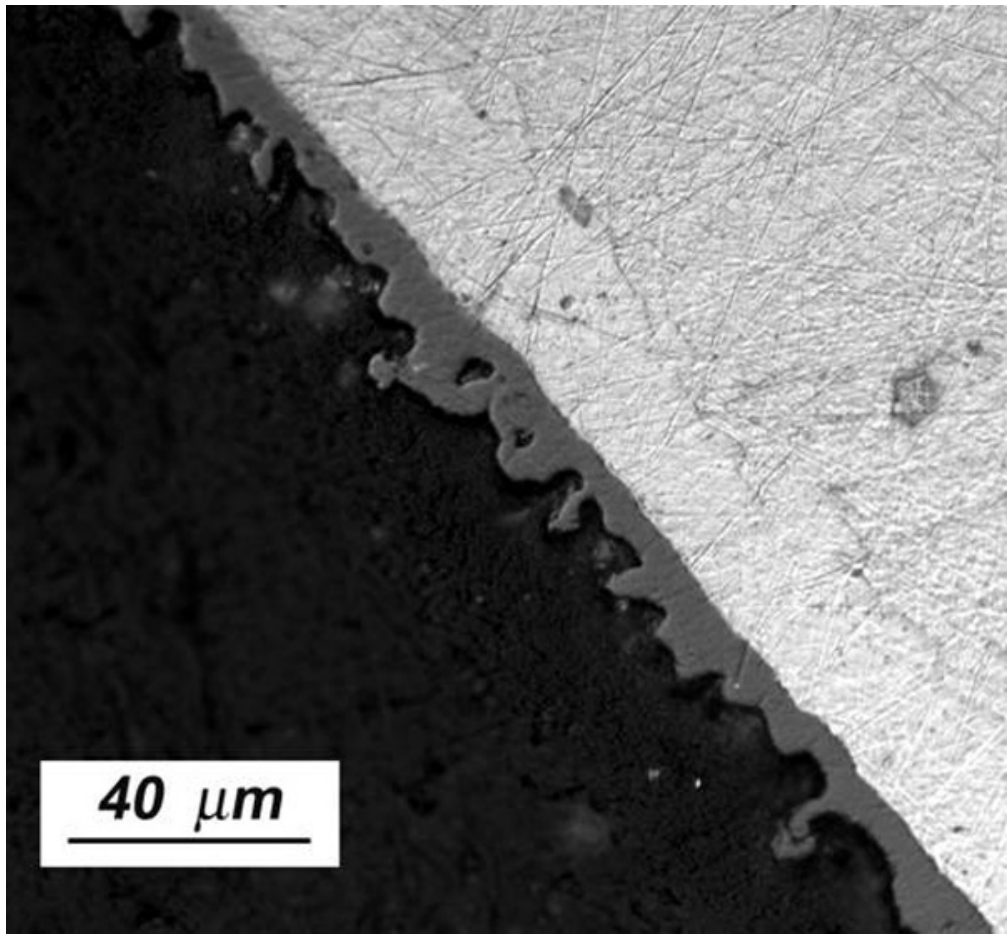

(b)

Figure 183. Micrographs of fuel-cladding-bond oxide layer (dark gray) on M5 cladding (light gray) inner surface at $\approx 2960 \mathrm{~mm}$ from bottom of Ringhals Rod SUT3-00477. Based on images at eight circumferential locations, the corrosion layer thickness was determined to be $8 \pm 3 \mu \mathrm{m}$. 


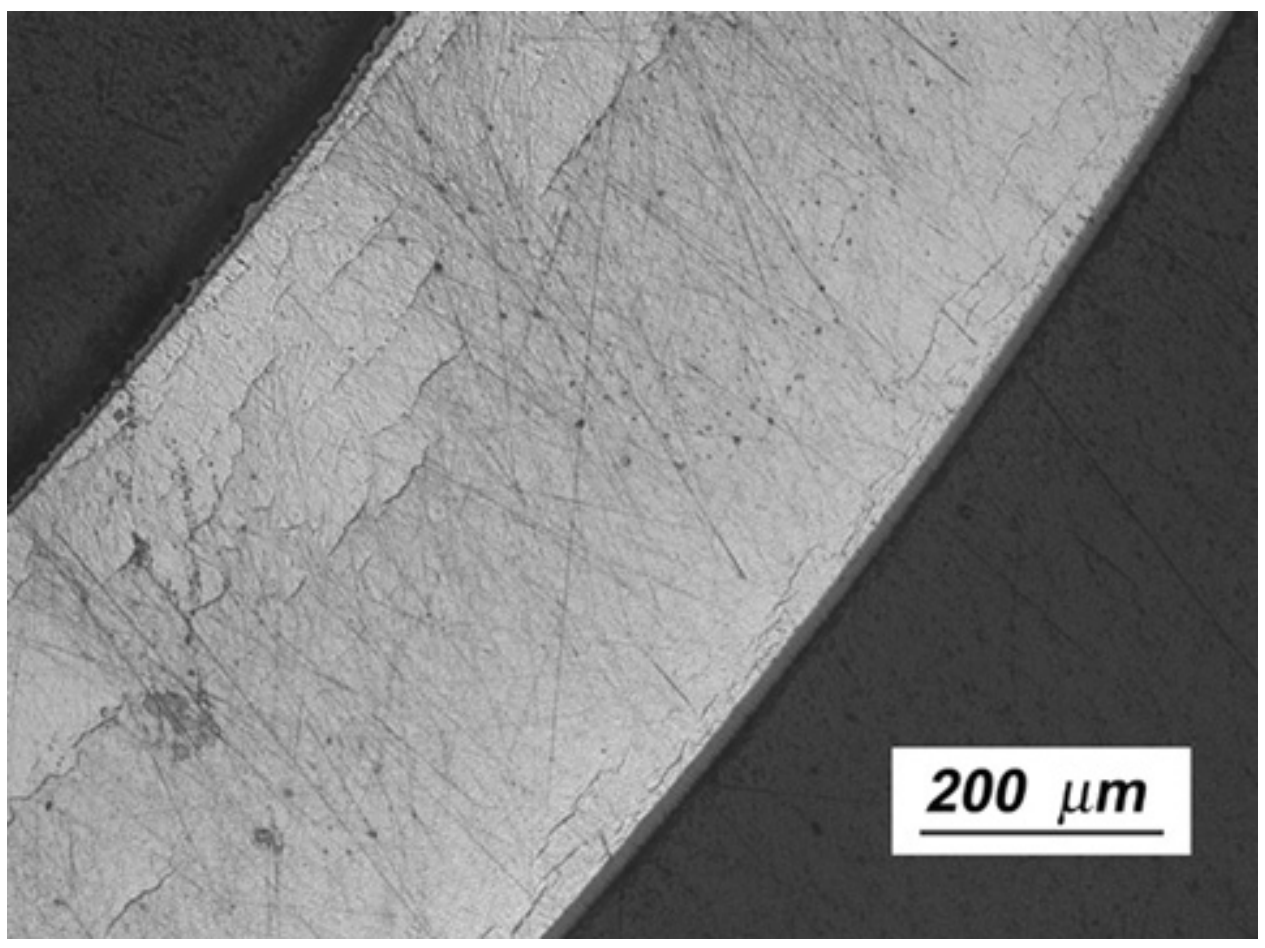

Figure 184. Metallographic image of high-burnup M5 cladding wall at one of eight circumferential locations. Based on data from all eight circumferential locations, the cladding wall thickness is $554 \pm 2 \mu \mathrm{m}$ $(\approx 0.55 \mathrm{~mm})$. Short circumferential hydrides are observed across the wall.

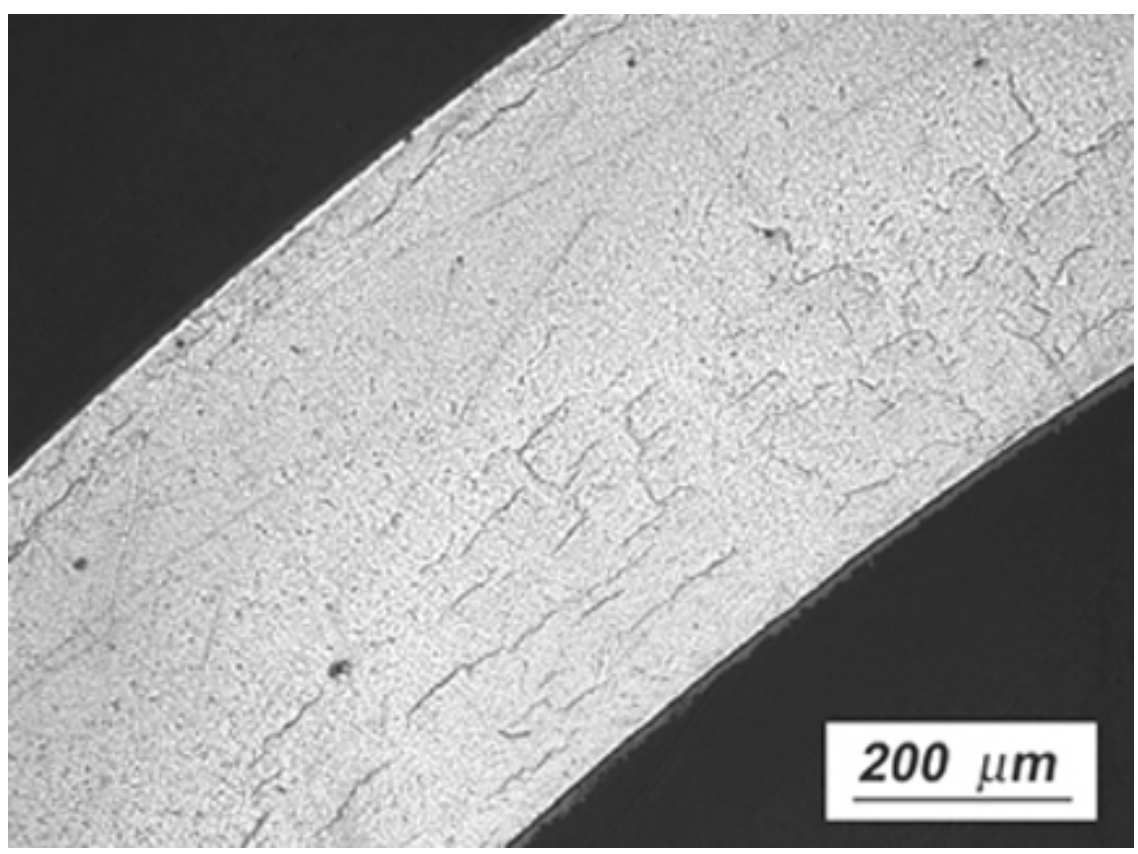

Figure 185. Metallographic image of high-burnup M5 cladding wall at a second circumferential location (same axial location as shown in Figure 184). Hydride morphology consists of short circumferential and radial hydrides. 
(120 s) used to generate the images in Figures 182-184 are the ones developed for Zry-4 and Zry-2 cladding materials. Short circumferential hydrides can be seen in Figure 184, but the contrast is poor compared to what was previously imaged for high-burnup Zry-2 with low ( $\approx 70$ wppm) hydrogen content. This hydride morphology is consistent with what was observed at seven of the circumferential locations. At one location (as shown in Figure 185), both radial and circumferential hydrides are evident. Lowdose-rate M5 guide tube material was used to optimize the etching time (210 s). The cladding surface was re-ground, re-polished, and re-etched for $210 \mathrm{~s}$ to image the hydrides in M5. However, contrast for highburnup M5 with $\approx 110$-wppm hydrogen was not as good as it was for "high-burnup" M5 guide tube material, $\approx 150$ wppm.

The metallographic images at the eight circumferential locations are consistent with the LECO hydrogen results: relatively uniform distribution of hydrogen concentration in the circumferential direction $-108 \pm 5 \mathrm{wppm}$ measured for a sample adjacent to the metallographic cross section imaged. The correction factor for hydrogen in the M5 metal, if all of it were in the metal, would be relatively small because of the thin corrosion and bond layers.

For high-burnup Zry-4 and ZIRLO, average and one-standard-deviation values were much higher than uncertainties in LECO measurements. Prior to, and after, LECO hydrogen measurement, the LECO is calibrated to several NIST-traceable Ti coupons with $220 \pm 3$ wppm hydrogen. ANL LECO data for these standards gives $218 \pm 10 \mathrm{wppm}$. Titanium coupons with $69 \pm 1 \mathrm{wppm}$ hydrogen were also analyzed with the ANL calibration factor for 220-wppm H. ANL LECO-measured values were $71 \pm 5$ wppm (for three coupons). The measurement uncertainty for M5 hydrogen is about 2-wppm on average and about \pm 7 wppm in standard deviation.

\subsubsection{LOCA apparatus thermal and metallurgical benchmark tests for M5}

The temperature history shown in Figure 166 was used for tests with high-burnup M5. Asfabricated dimensions of M5 and ZIRLO are the same. Also, heat capacity and heat of oxidation are about the same for the alloys during the ramp from $1000^{\circ} \mathrm{C}$ to $1200^{\circ} \mathrm{C}$ and hold time at $1200^{\circ} \mathrm{C}$.

\subsubsection{Ductility results for high-burnup Ringhals M5 cladding}

Seven LOCA oxidation tests and sixteen ring-compression ductility tests were conducted with defueled Ringhals M5 cladding. Cladding samples were selected from the uniform burnup $(\approx 69$ $\mathrm{GWd} / \mathrm{MTU})$ region about $3 \mathrm{~m}(2840-3240 \mathrm{~mm})$ from the bottom of rod SUT3-0047. Relevant parameters are: $12 \pm 1 \mu \mathrm{m}$ corrosion layer, $554 \pm 2 \mu \mathrm{m}(\approx 0.55 \mathrm{~mm})$ cladding wall, $8 \pm 3 \mu \mathrm{m}$ fuel-cladding bond, and $106 \pm 14$ wppm hydrogen content. The cladding outer diameter measured by ANL $(9.47-9.48 \mathrm{~mm})$ is consistent with Studsvik profilometry data and is close to the as-fabricated value $(9.50 \mathrm{~mm})$.

Table 74 summarizes oxidation test conditions, pre- and post-test hydrogen measurements, and ductility results. Measured sample weight gains increased from $4 \%$ at $13.4 \%$ CP-ECR to $6.7 \%$ at $18.1 \%$ CP-ECR and were below CP-predicted values (e.g., $\approx 15 \%$ lower at $13.4 \%$ CP-ECR), as expected. Posttest samples were sectioned to give two rings for compression testing, two short rings for hydrogen analysis, and either one short ring for metallographic imaging or a third ring for compression testing. Weight-gain-corrected hydrogen content varied from about 90 to $140 \mathrm{wppm}$. The weighted average of pre-test data is $\approx 110 \pm 15 \mathrm{wppm}$. With the $\pm 7 \mathrm{wppm}$ uncertainty in hydrogen measurements, $110 \pm 20$ wppm is recommended for the pre-test hydrogen content of the M5 samples used in LOCA oxidation tests. Differences between pre-test and corrected post-test hydrogen contents are attributed to differences in sample masses, in axial locations, and in possible hydrogen pickup during LOCA oxidation tests. 
Table 74. Post-Test Ductility Results for High-Burnup Ringhals M5 Cladding Oxidized at $1200^{\circ} \mathrm{C}$, Cooled with (800 $\left.{ }^{\circ} \mathrm{C}-\mathrm{Q}\right)$ or without Quench at $800^{\circ} \mathrm{C}$, and Ring-Compressed at $135^{\circ} \mathrm{C}$

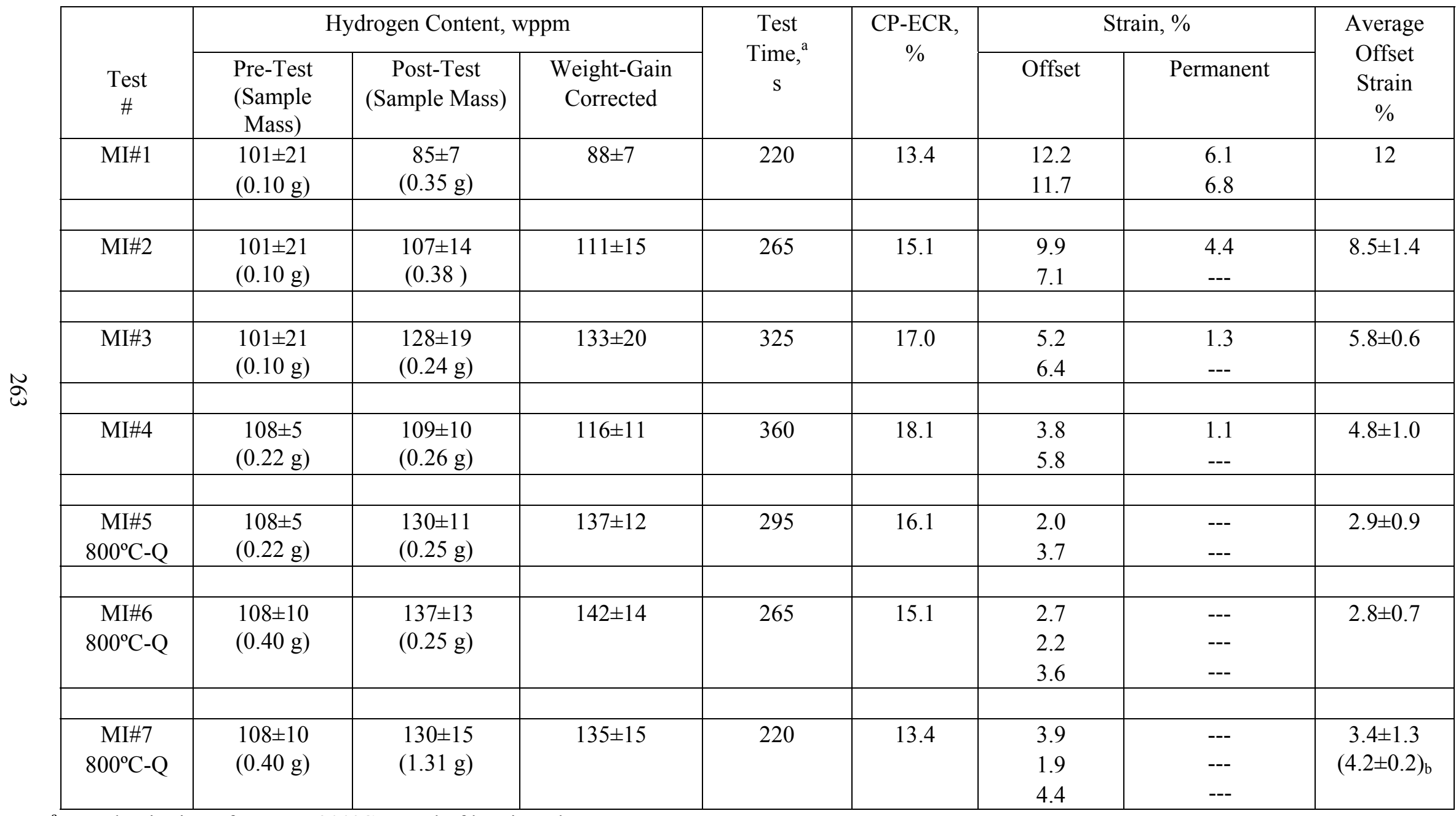

${ }^{\mathrm{a}}$ From beginning of ramp at $300^{\circ} \mathrm{C}$ to end of heating phase.

${ }^{\mathrm{b}}$ Average excluding $1.9 \%$ offset strain data point. 
Offset strains measured for high-burnup M5 cladding cooled with or without (i.e., slow cooled) quench at $800^{\circ} \mathrm{C}$ are compared in Figure 186 to those for fresh cladding oxidized and cooled under similar conditions. Based on offset strain, high-burnup operation (i.e., 110-wppm hydrogen) did not result in any significant decrease in M5 ductility for samples cooled without quench. Although many fresh and highburnup M5 rings failed with two cracks, enough rings failed with a single through-wall crack to allow determination of permanent strain vs. total CP-ECR (see Figure 187). Permanent strain is a more reliable metric than offset strain for determining ductile-to-brittle transition. For fresh cladding, the measured permanent strain is at the ductile-to-brittle transition limit (1\%) at 20\% CP-ECR. For high-burnup cladding cooled without quench, the permanent strain drops to $1.1 \%$ at about $18 \%$ CP-ECR. It is not clear from Figure 187 if there is a significant difference between results for high-burnup M5 cooled without quench and for fresh M5. However, the ductile-to-brittle transition CP-ECR is assessed at 18\% for high-burnup M5 cooled without quench.

The MI\#5 and MI\#6 samples were oxidized to $16.1 \%$ and $15.1 \%$ CP-ECR, respectively, and cooled with quench at $800^{\circ} \mathrm{C}$. Both rings sectioned from the $16.1 \%$-CP-ECR sample failed with through-wall cracks at the 12 and 6 o'clock positions. Offset strains were $2.0 \%$ and $3.7 \%$. Three rings (lengths of 7.7 $\mathrm{mm}, 7.4 \mathrm{~mm}$, and $6.1 \mathrm{~mm}$ ) were sectioned from the 15.1\% CP-ECR sample (MI\#6). All three rings failed with two through-wall cracks at offset strains of $2.7 \%, 2.2 \%$, and $3.6 \%$. Based on the $2 \%$ offset strain ductility criterion, all five rings would be classified as ductile and the embrittlement CP-ECR would be $16 \%$.

However, experience with as-fabricated and high-burnup M5 suggests that more than $2 \%$ offset strain is needed to get a permanent strain $\geq 1 \%$. At the ductile-to-brittle transition for as-fabricated M5 quenched at $800^{\circ} \mathrm{C}, 1 \%$ permanent strain corresponded to $\approx 3.5 \%$ offset strain. At the ductile-to-brittle transition for high-burnup M5 cooled without quench, 1.1\% permanent strain corresponded to $3.8 \%$ offset strain. It appears that $\approx 3.5 \%$ offset strain is required to ensure ductility for oxidized M5. In order to check the relationship between permanent and offset strain for high-burnup M5, the 6.1-mm-long ring sectioned from the MI\#6 sample (15.1\% CP-ECR) was loaded to a total displacement of $\approx 0.5 \mathrm{~mm}$ prior to interrupting the test. The permanent and offset strains for this intact ring were measured to be $0.5 \%$ and $2.3 \%$, respectively. The initial loading slope was used to mathematically unload the sample from maximum load to determine the $2.3 \%$ offset strain. The ring was then reloaded to failure. The reloading slope was $76 \%$ of the initial loading slope. Using this value for the unloading slope led to a decrease in offset strain from $2.3 \%$ to $1.1 \%$ after the first loading and from $3.6 \%$ to $2.2 \%$ after the second loading.

The CP-ECR was lowered to $13.4 \%$ for the MI\#7 test sample cooled with quench at $800^{\circ} \mathrm{C}$. It was anticipated that rings sectioned from this test sample would be clearly ductile. As shown in Table 74, two of the rings were ductile with about $4 \%$ offset strain. However, the middle ring exhibited only $1.9 \%$ offset strain, indicating brittle behavior. All three rings failed with two cracks, so it was not possible to measure reliable post-test diameters to determine permanent strains. Based on hydrogen-content measurement following ring compression tests, no difference could be found in local hydrogen content for the rings with $1.9 \%$ and $4.4 \%$ offset strains. The offset strain data for high-burnup M5 oxidized with and without quench are plotted in Figure 188, along with the recommended 3.5\% ductility limit for M5. Based on average offset strain values listed in Table 74, as well as Figure 188, the 13.4\% CP-ECR rings would be borderline ductile (3.4\% vs. $3.5 \%$ limit) if the low data point $(1.9 \%)$ were included and clearly ductile if the low offset strain value were excluded. From the perspective of the data trend (increasing ductility with decreasing (P-ECR), the $1.9 \%$ data point appears to be outlier. Although these results are subject to interpretation, the recommended transition oxidation level for high-burnup M5 oxidized at $1200^{\circ} \mathrm{C}$ and quenched at $800^{\circ} \mathrm{C}$ is $14 \pm 1 \%$. 


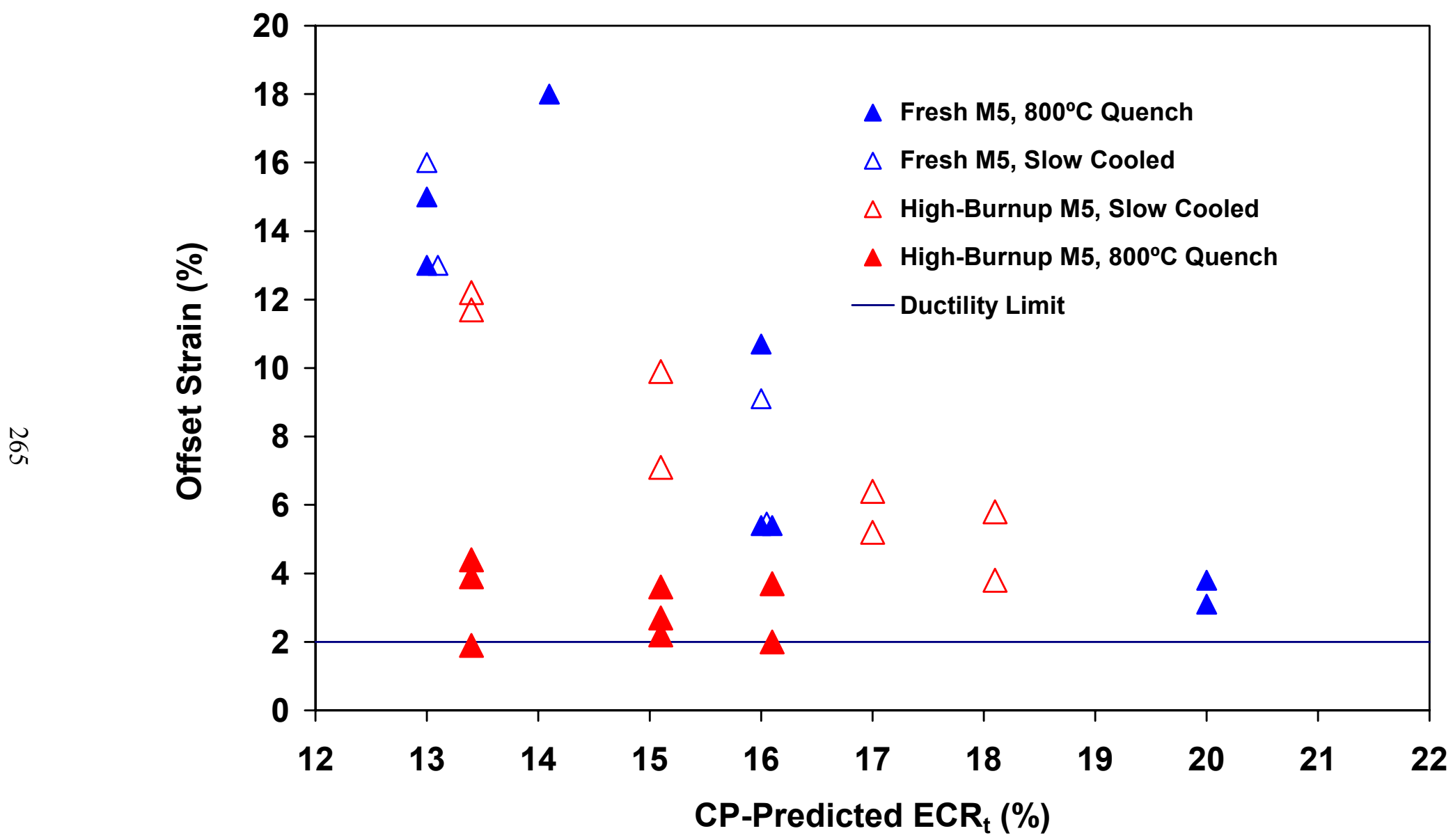

Figure 186. Comparison of post-test offset strains at $135^{\circ} \mathrm{C}$ for high-burnup $(110 \pm 20$ wppm hydrogen) Ringhals M5 cladding cooled with or without quench at $800^{\circ} \mathrm{C}$ and for fresh $\mathrm{M} 5$ cladding cooled without or without quench at $800^{\circ} \mathrm{C}$. All samples were oxidized at a hold temperature of $1200^{\circ} \mathrm{C}$. 


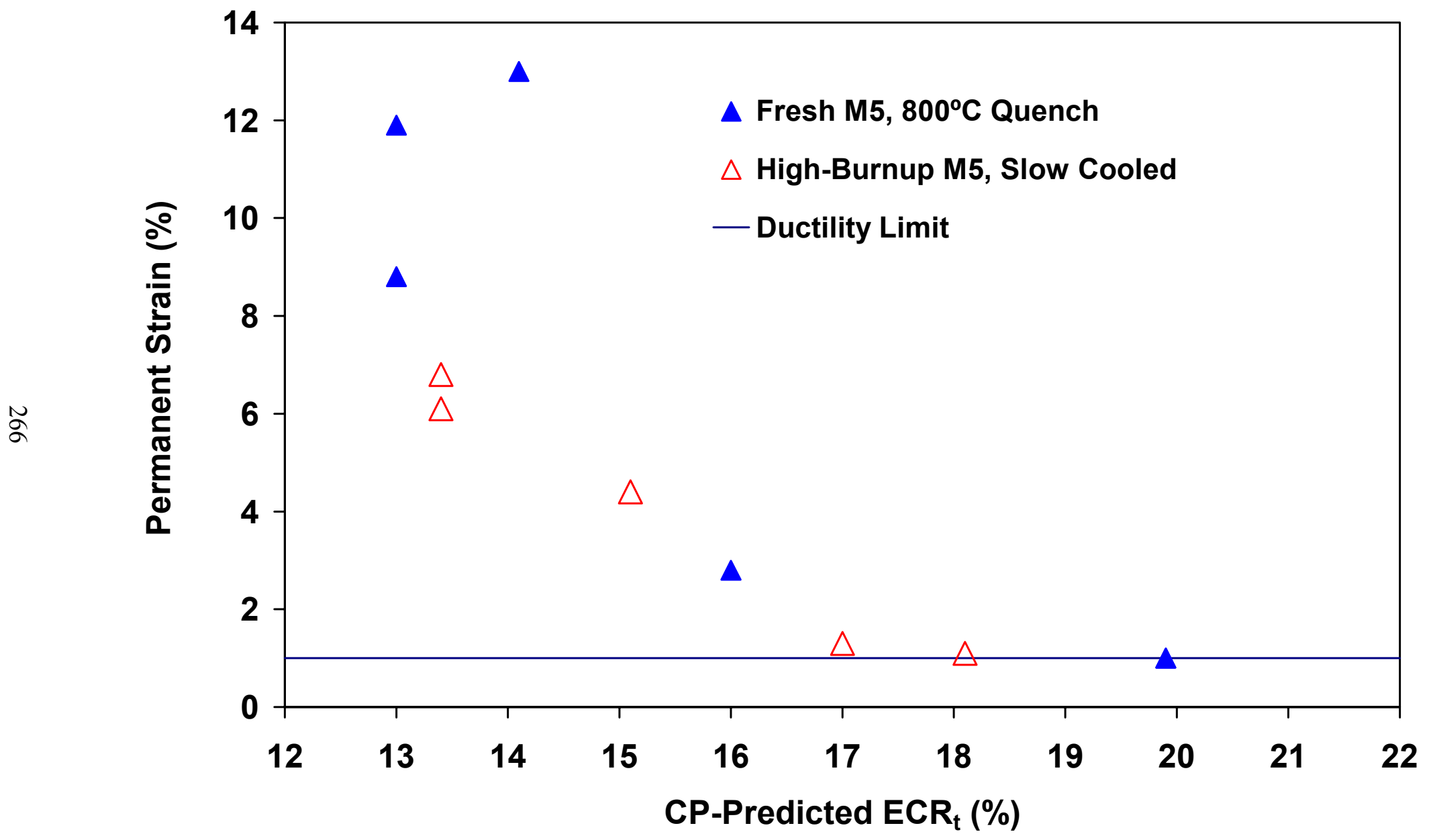

Figure 187. Comparison of post-test permanent strains at $135^{\circ} \mathrm{C}$ for high-burnup $(110 \pm 20$ wppm hydrogen) Ringhals M5 cladding cooled without quench and for fresh M5 cladding cooled with quench at $800^{\circ} \mathrm{C}$. All samples were oxidized at a hold temperature of $1200^{\circ} \mathrm{C}$. 


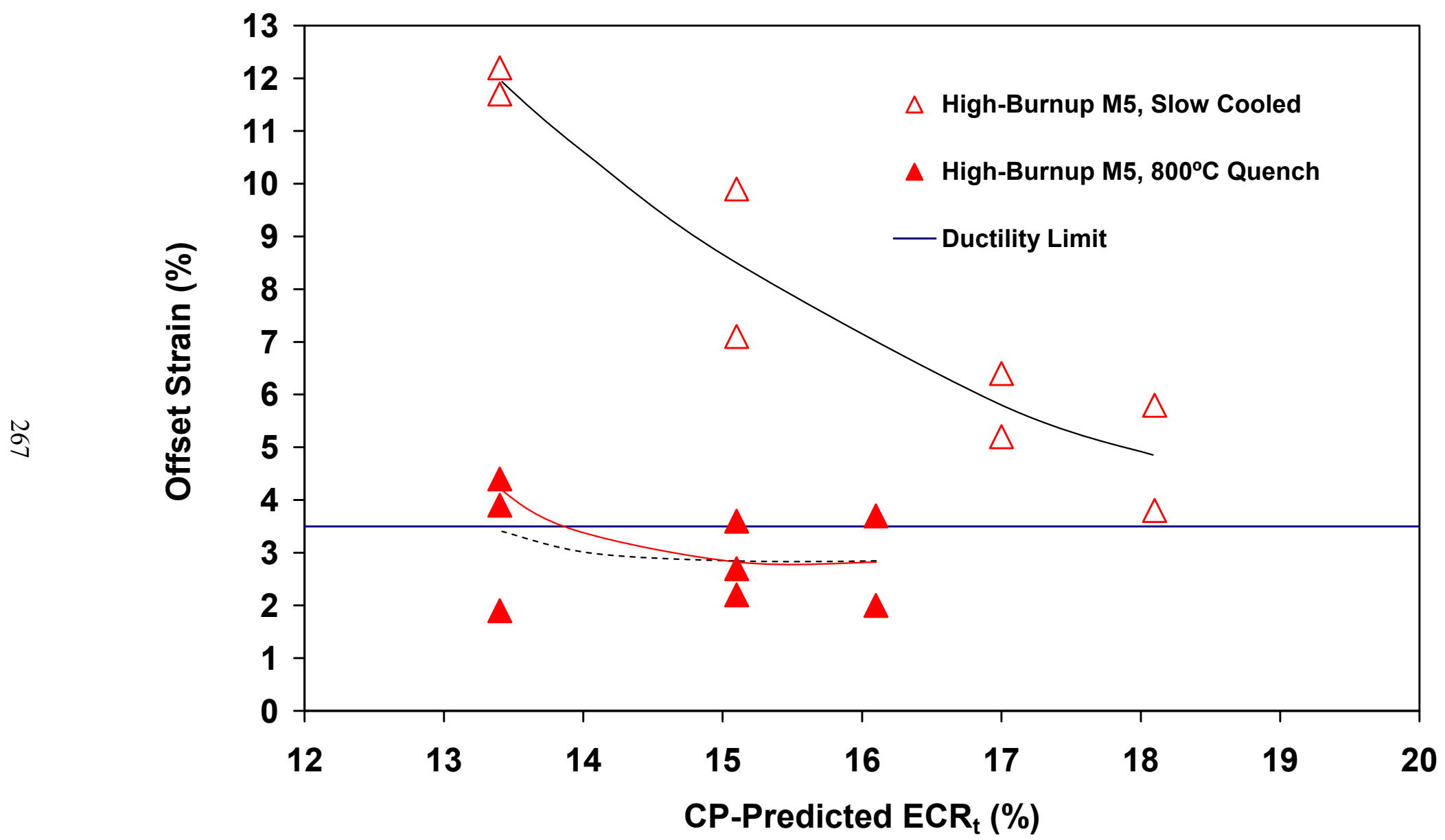

Figure 188. Post-test offset strains at $135^{\circ} \mathrm{C}$ for high-burnup ( $110 \pm 20 \mathrm{wppm}$ hydrogen) Ringhals $\mathrm{M} 5$ cladding cooled with or without quench. Ductility limit for offset strains has been reset to $3.5 \%$ for oxidized M5 cladding. Curved lines are fit to average offset strains for slow cooling, quench excluding $1.9 \%$ data point (red solid line) and quench including all strain data (dashed black line). 
Load-displacement curves are shown in Figures 189-196 for high-burnup M5 cladding samples cooled without quench. The determination of offset strain is shown in the load-displacement curves. Offset strain results for pairs of rings tested at each of the four CP-ECR values were very consistent. At least one of the two rings at each CP-ECR failed with a single crack, which enabled the determination of reliable permanent strains. These data were sufficient to determine the ductile-to-brittle transition CPECR (18\%) for samples cooled without quench.

Load-displacement curves are shown in Figures 197-204 for high-burnup M5 samples cooled with quench at $800^{\circ} \mathrm{C}$. For the range of oxidation levels (13.4-16.1\%), offset strains were relatively low. Also, permanent strains could not be measured because all eight rings failed with two cracks. To determine a relationship between offset and permanent strain, testing of one of the rings from the $15.1 \% \mathrm{CP}-\mathrm{ECR}$ sample was interrupted (by removing the load) prior to failure. As shown in Figure 201a, the offset and permanent strains for this intact sample were $2.3 \%$ and $0.5 \%$, respectively. This result confirmed previous results for oxidized as-fabricated and high-burnup rings sectioned from samples cooled without quench: $2 \%$ offset strain is insufficient to ensure ductility for M5; and 3.5\% offset strain should be used as the ductility criterion when permanent strains cannot be determined. The deformed ring was repositioned and re-loaded. Based on the initial loading slope (see Figure 201a), the offset strain at failure was calculated to be $3.6 \%$. The reloading slope (not shown) was $24 \%$ lower than the loading slope and should decrease as displacement increases. Using the lower slope to mathematically unload the ring gave $2.2 \%$ offset strain. This value represents an upper bound for the true offset strain.

Two of the rings from the sample oxidized to $13.4 \%$ CP-ECR and cooled with quench had high enough offset strains (3.9\% and 4.4\%) to be classified as ductile. The central ring had an offset strain of only $1.9 \%$, which implies embrittlement. Prior to conducting this test, the maximum load in the real-time load-displacement curve was set at $0.3 \mathrm{kN}$. As the load approached this level, the load axis was increased to $0.35 \mathrm{kN}$. Simultaneously with the change the sample failed. As there is no known feedback between output and control software, it is highly doubtful that changing the display load axis had any effect on sample loading. To further investigate possible reasons for the brittle behavior of the central ring, detailed post-test hydrogen measurements were taken for the brittle ring and the most ductile ring (4.4\% offset). The results are superimposed on the load-displacement curves in Figures 203 and 204. The brittle ring had a hydrogen content of $126 \pm 5 \mathrm{wppm}$ with a local peak of $\approx 130$ wppm near the crack at the 12 o'clock position. The ductile ring had slightly higher hydrogen content (136 $\pm 17 \mathrm{wppm})$ with a local peak of 156 wppm near the 12 o'clock crack. Thus, the difference in behavior of these two rings cannot be attributed to significant differences in average or peak hydrogen concentrations.

\subsubsection{Discussion of high-burnup Ringhals M5 results}

The ductile-to-brittle transition CP-ECR for high-burnup M5 samples oxidized at $1200^{\circ} \mathrm{C}$ and cooled without quench is $18 \%$ based on both offset and permanent strains. These samples had a pre-test hydrogen content of $110 \pm 20 \mathrm{wppm}$. Post-test hydrogen (corrected for weight gain) for the $17.0 \% \mathrm{CP}-$ ECR samples was higher $(133 \pm 20 \mathrm{wppm})$. This small difference can be attributed to hydrogen pickup during steam oxidation. The transition CP-ECR for high-burnup M5 samples oxidized at $1200^{\circ} \mathrm{C}$ and quenched at $800^{\circ} \mathrm{C}$ was assessed to be $14 \pm 1 \%$, based on the ductility ( $4 \%$ offset strain) of two rings sectioned from the 13.4\% CP-ECR sample and the data trend for all three tests cooled with quench. As the rings all failed with two cracks, permanent strains could not be measured. This led to uncertainty in determining the ductile-to-brittle transition oxidation level for high-burnup M5. Cooling with quench caused a significant reduction in M5 ductility compared to cooling without quench. Also, based on limited data (four points), the offset-strain ductility limit for $\mathrm{M} 5$ oxidized at $1200^{\circ} \mathrm{C}$ should be increased from $2 \%$ to $\approx 3.5 \%$. The $2 \%$ offset strain limit worked well for fresh $\mathrm{M} 5$ oxidized at $1000^{\circ} \mathrm{C}$ and $1100^{\circ} \mathrm{C}$. 


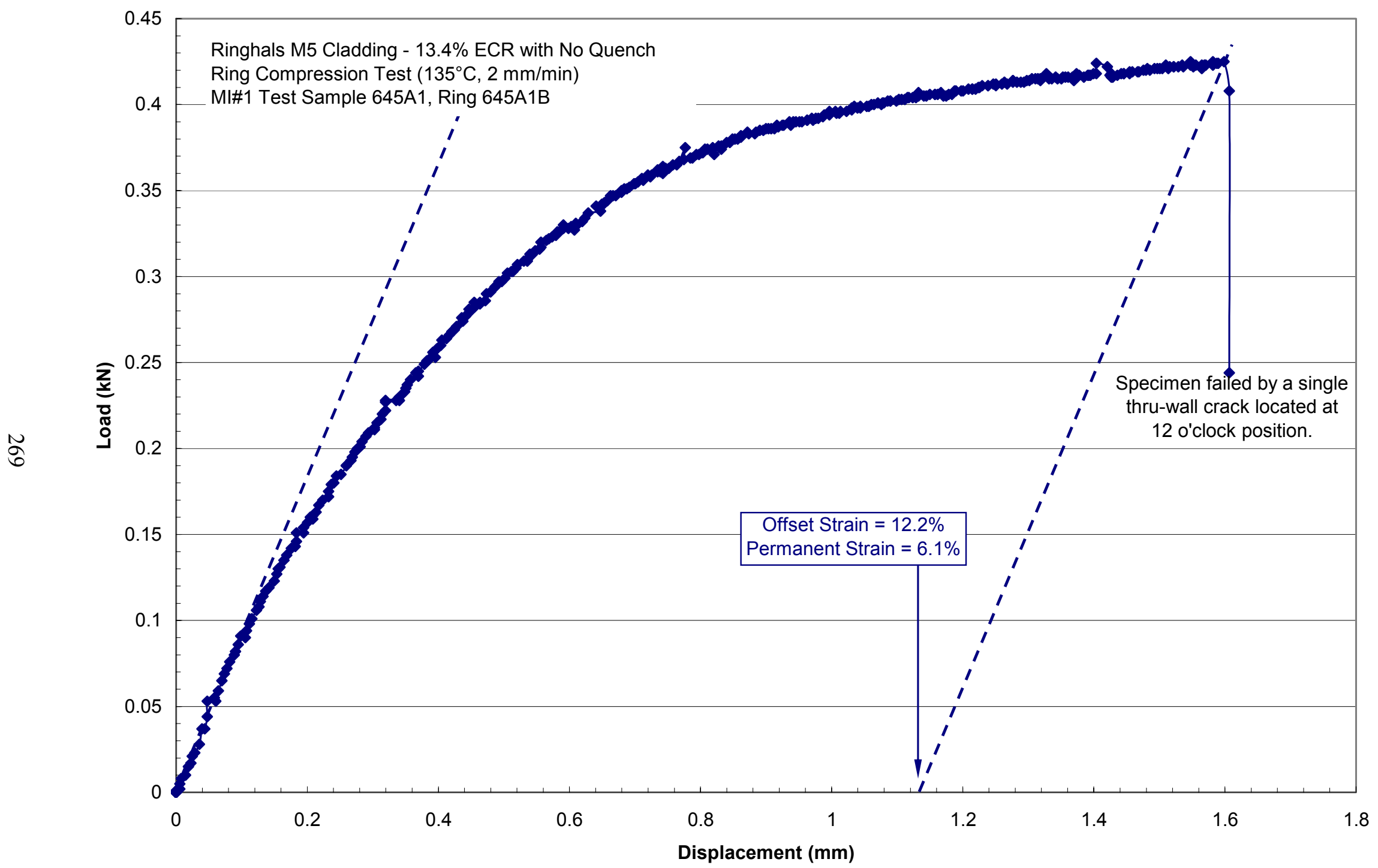

Figure 189. Load-displacement curve for high-burnup M5 cladding oxidized to $13.4 \%$ CP-ECR and cooled without quench: Ring \#1. 


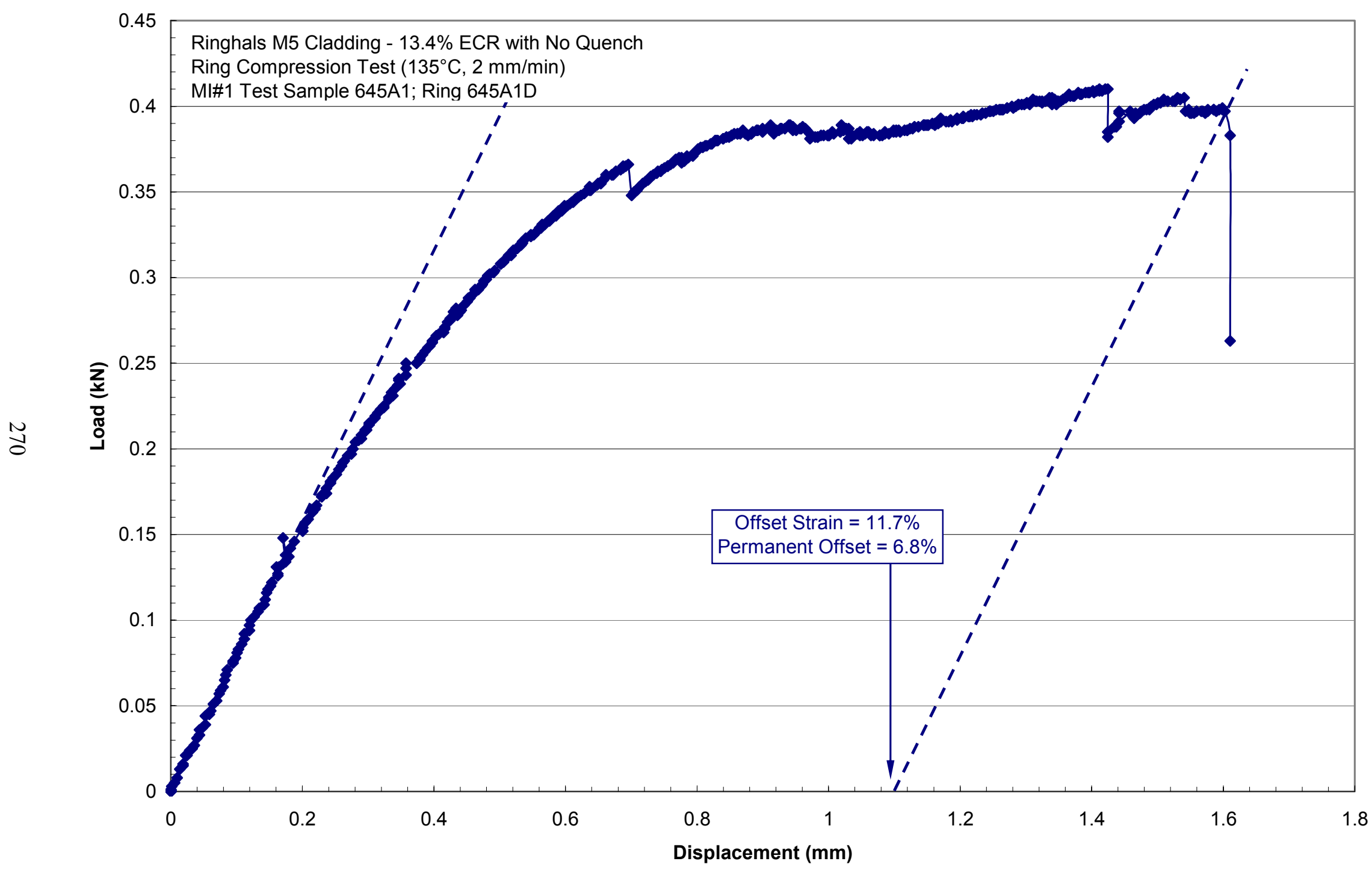

Figure 190. Load-displacement curve for high-burnup M5 cladding oxidized to 13.4\% CP-ECR and cooled without quench: Ring \#2. 


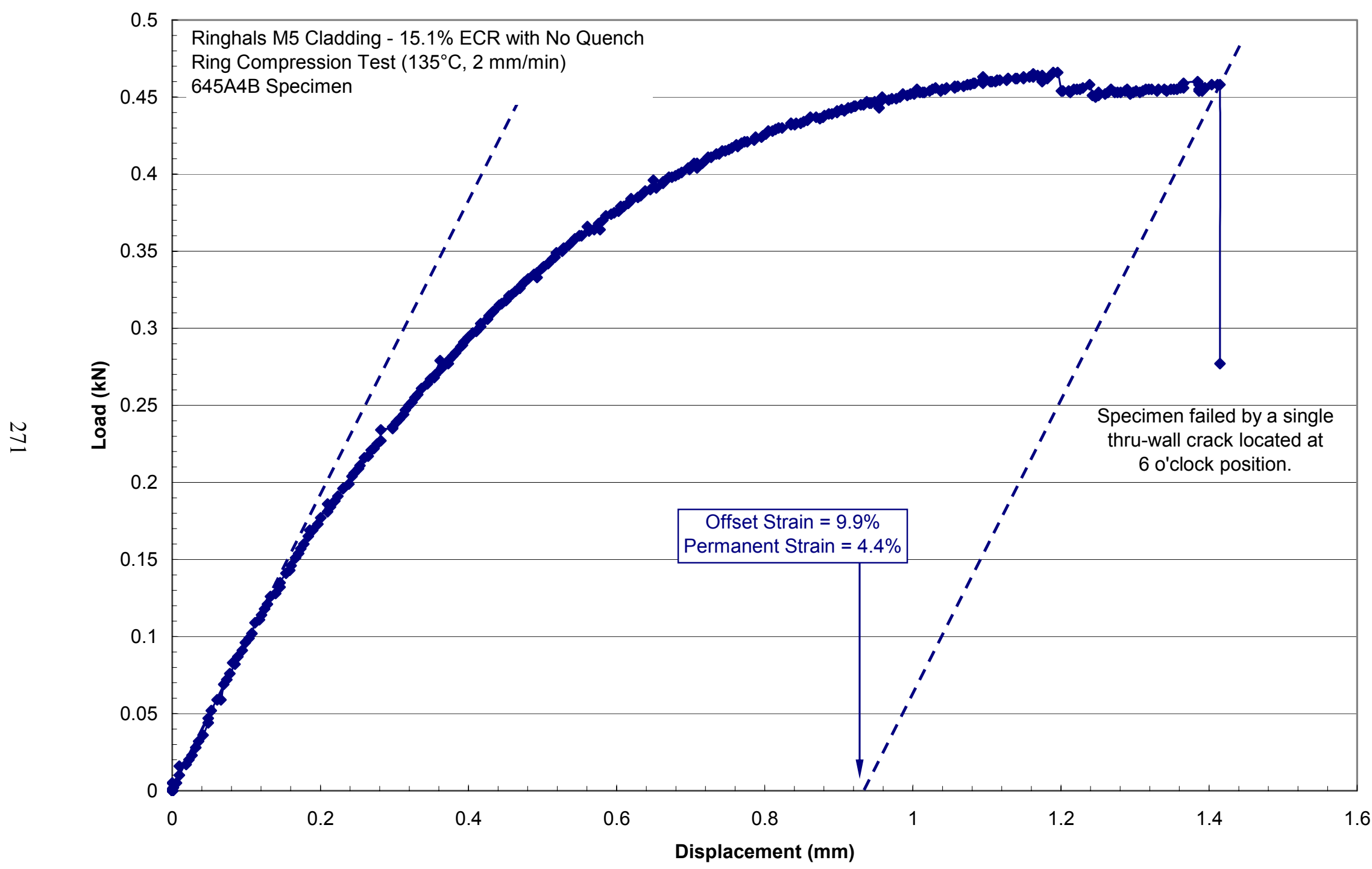

Figure 191. Load-displacement curve for high-burnup M5 cladding oxidized to 15.1\% CP-ECR and cooled without quench: Ring \#1. 


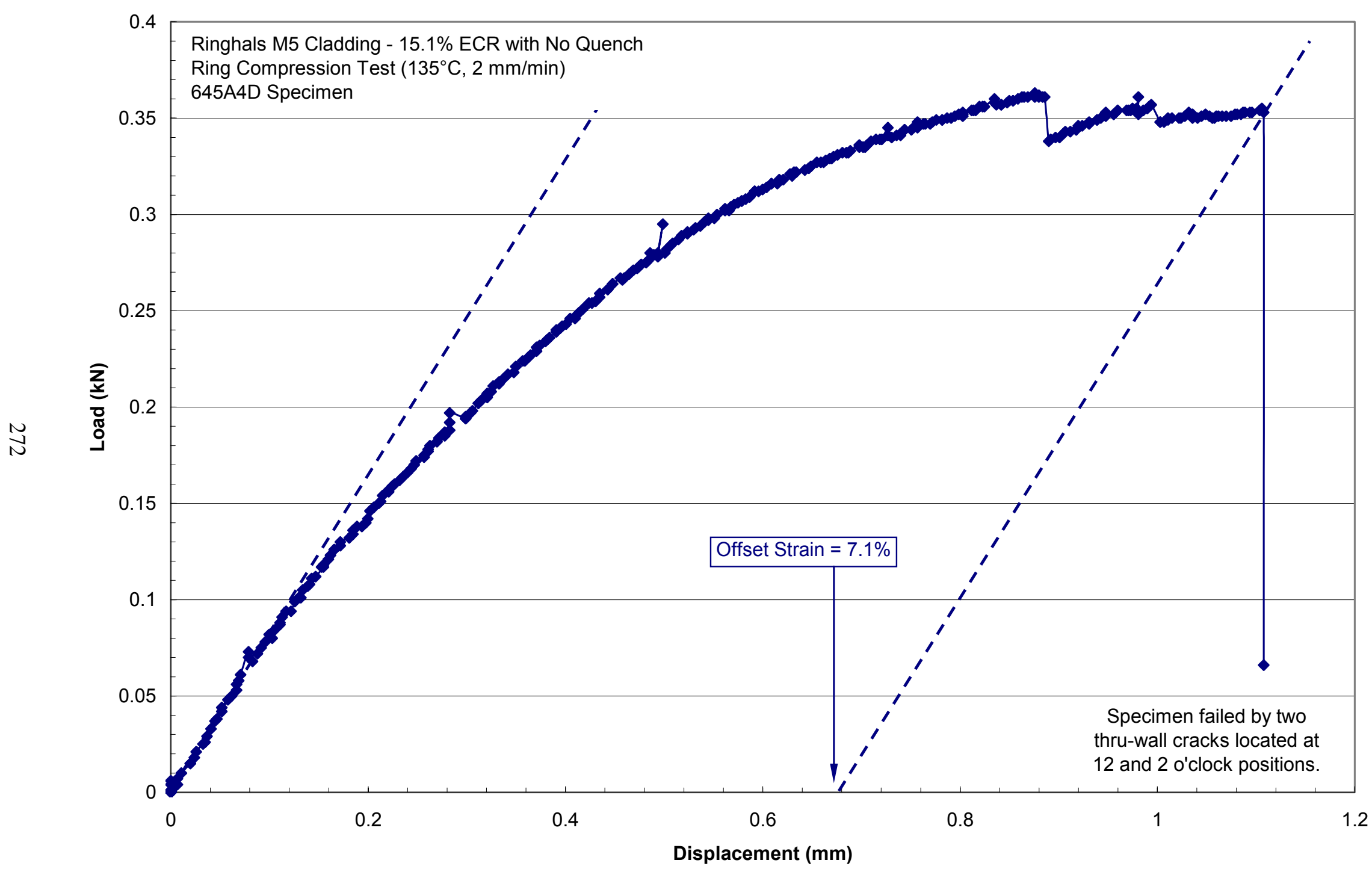

Figure 192. Load-displacement curve for high-burnup M5 cladding oxidized to 15.1\% CP-ECR and cooled without quench: Ring \#2. 


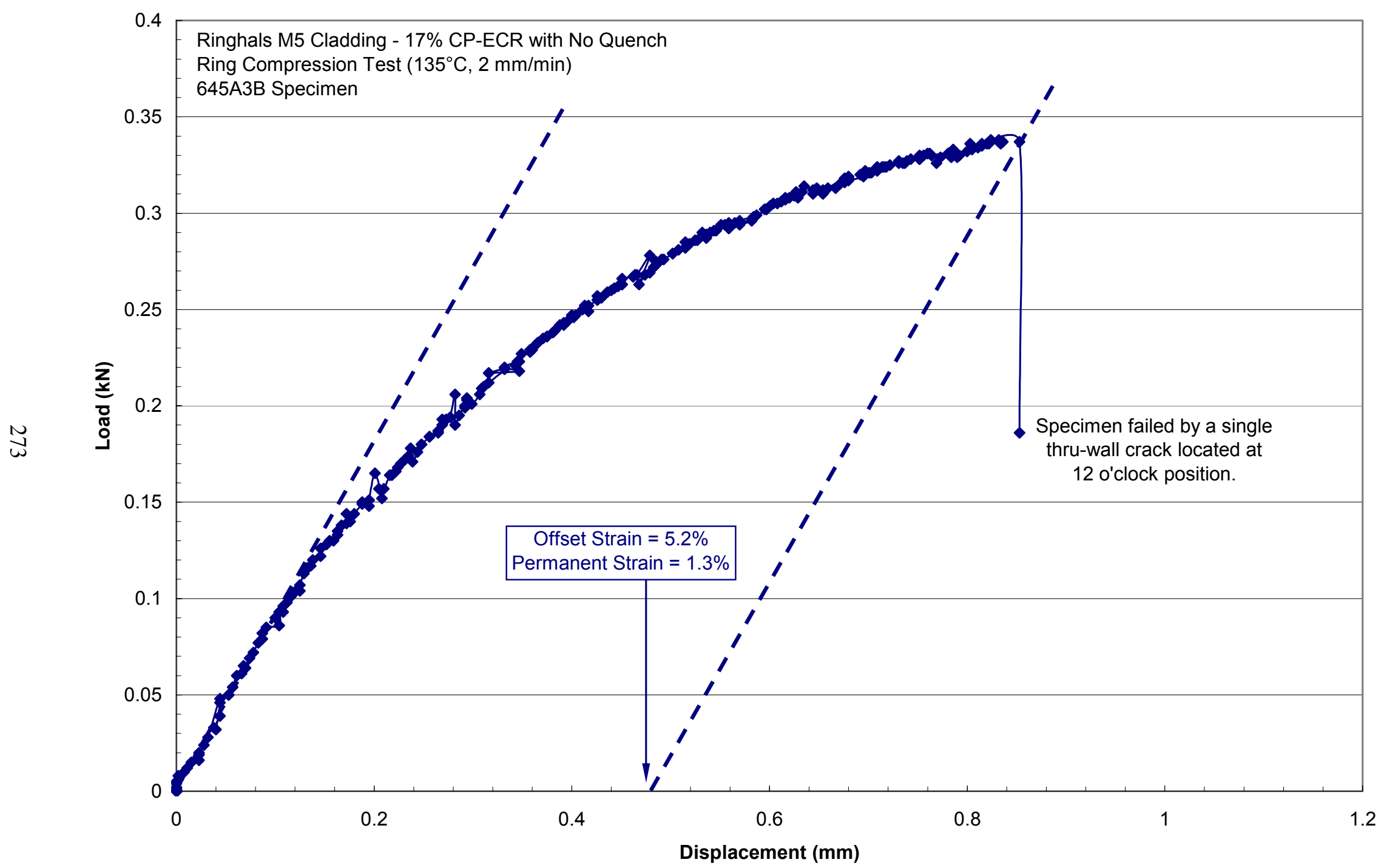

Figure 193. Load-displacement curve for high-burnup M5 cladding oxidized to $17.0 \%$ CP-ECR and cooled without quench: Ring \#1. 


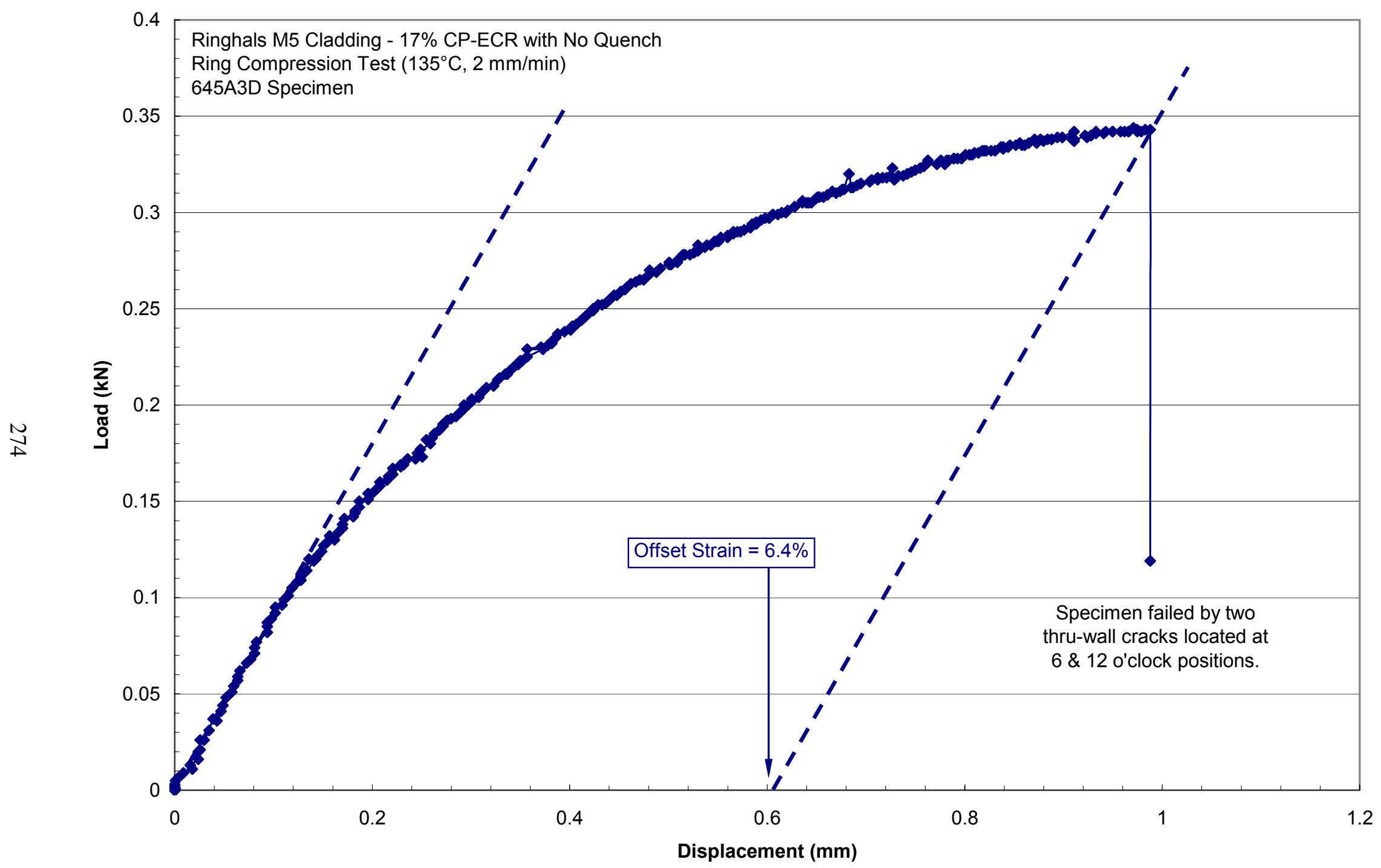

Figure 194. Load-displacement curve for high-burnup M5 cladding oxidized to 17.0\% CP-ECR and cooled without quench: Ring \#2. 


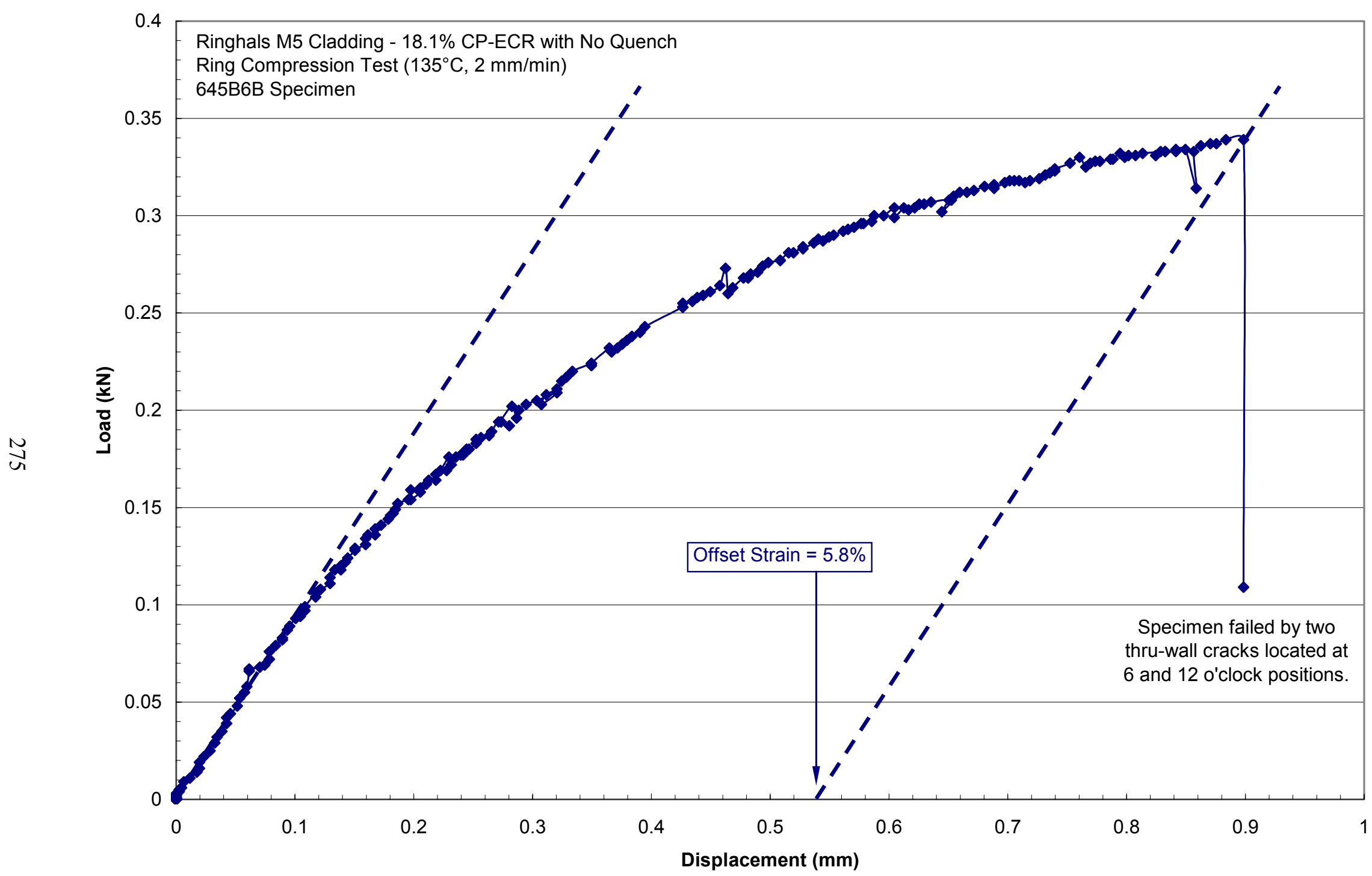

Figure 195. Load-displacement curve for high-burnup M5 cladding oxidized to 18.1\% CP-ECR and cooled without quench: Ring \#1. 


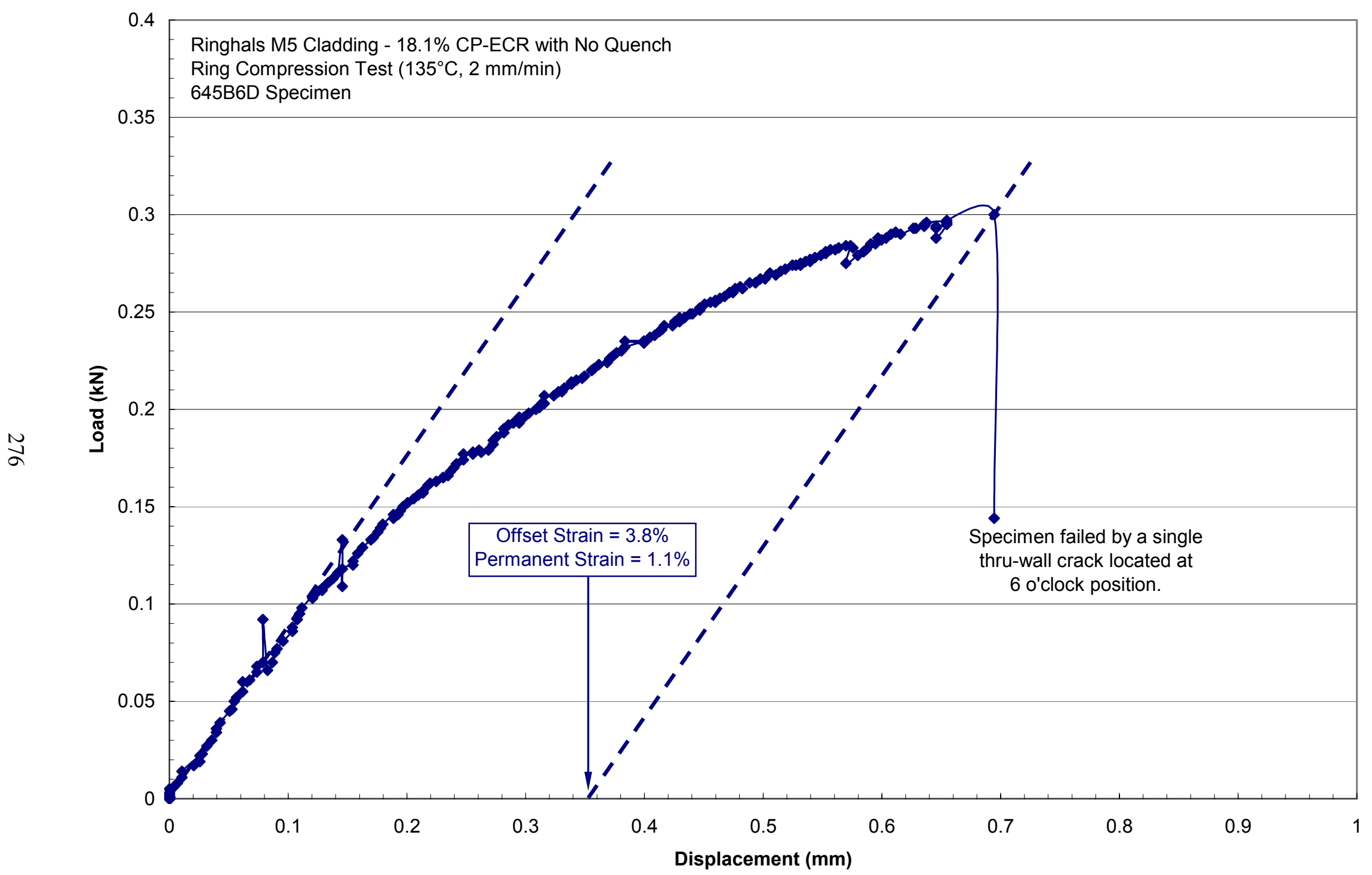

Figure 196. Load-displacement curve for high-burnup M5 cladding oxidized to 18.1\% CP-ECR and cooled without quench: Ring \#2. 


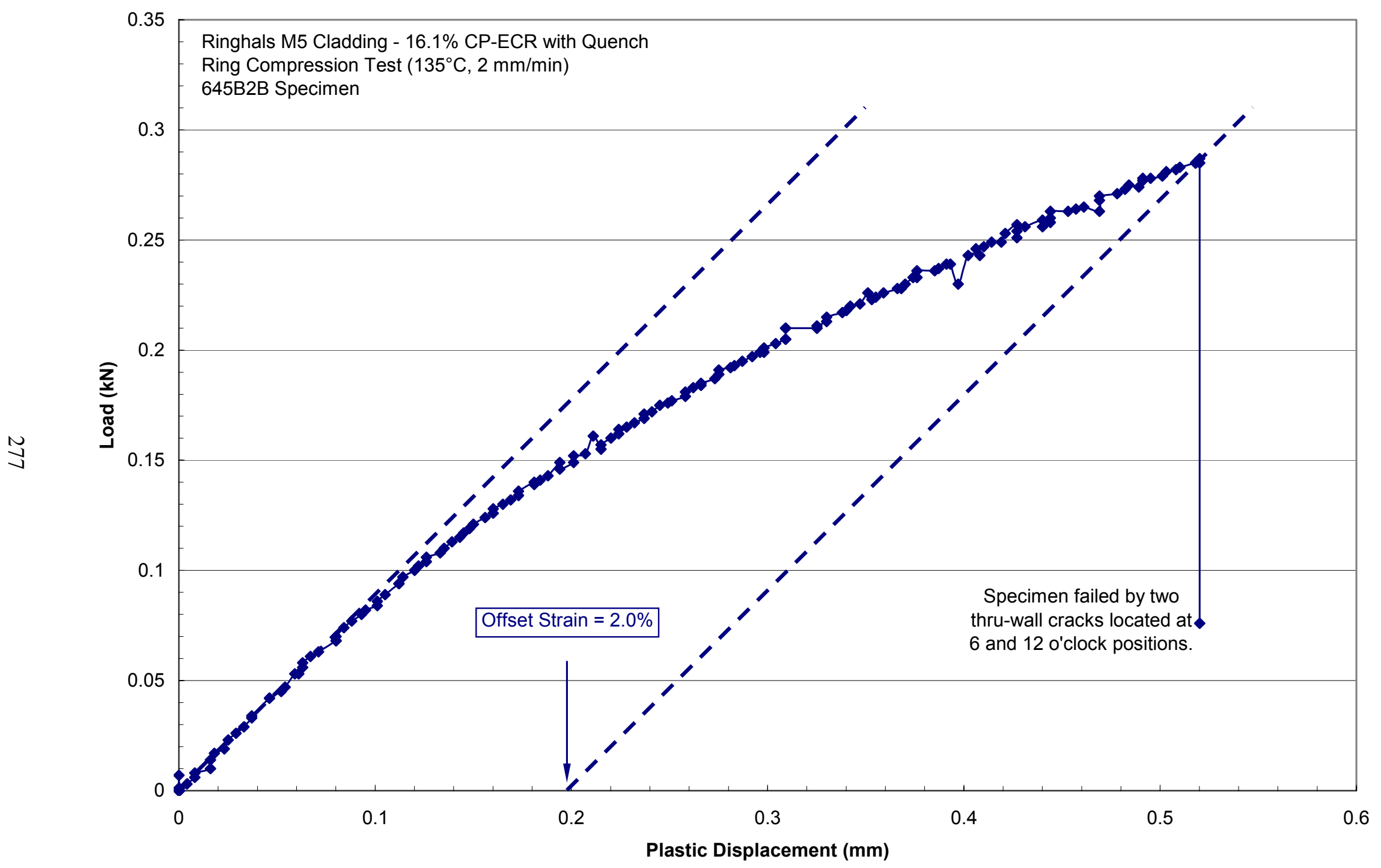

Figure 197. Load-displacement curve for high-burnup M5 cladding oxidized to $16.1 \%$ CP-ECR and cooled with quench: Ring \#1. 


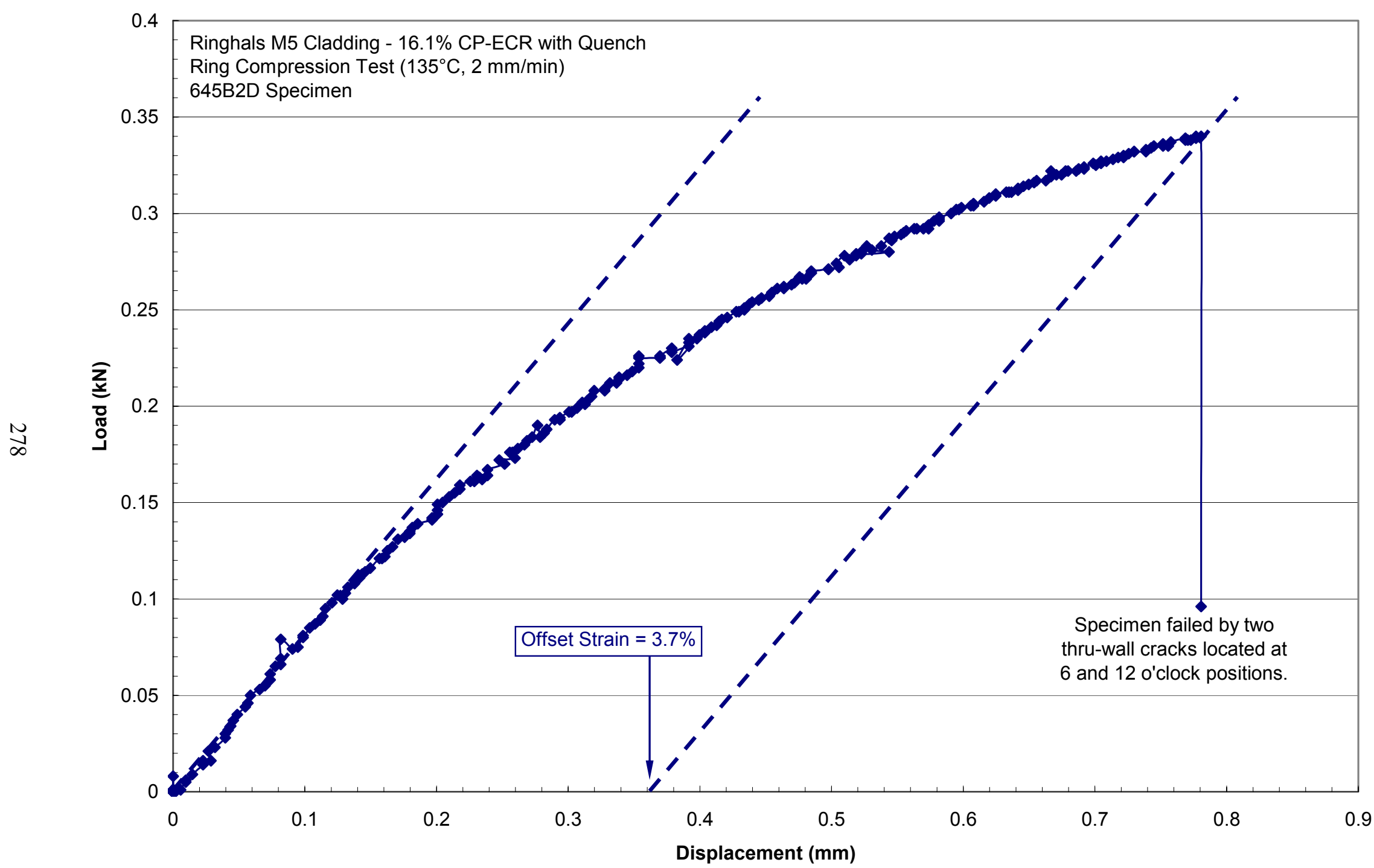

Figure 198. Load-displacement curve for high-burnup M5 cladding oxidized to 16.1\% CP-ECR and cooled with quench: Ring \#2. 


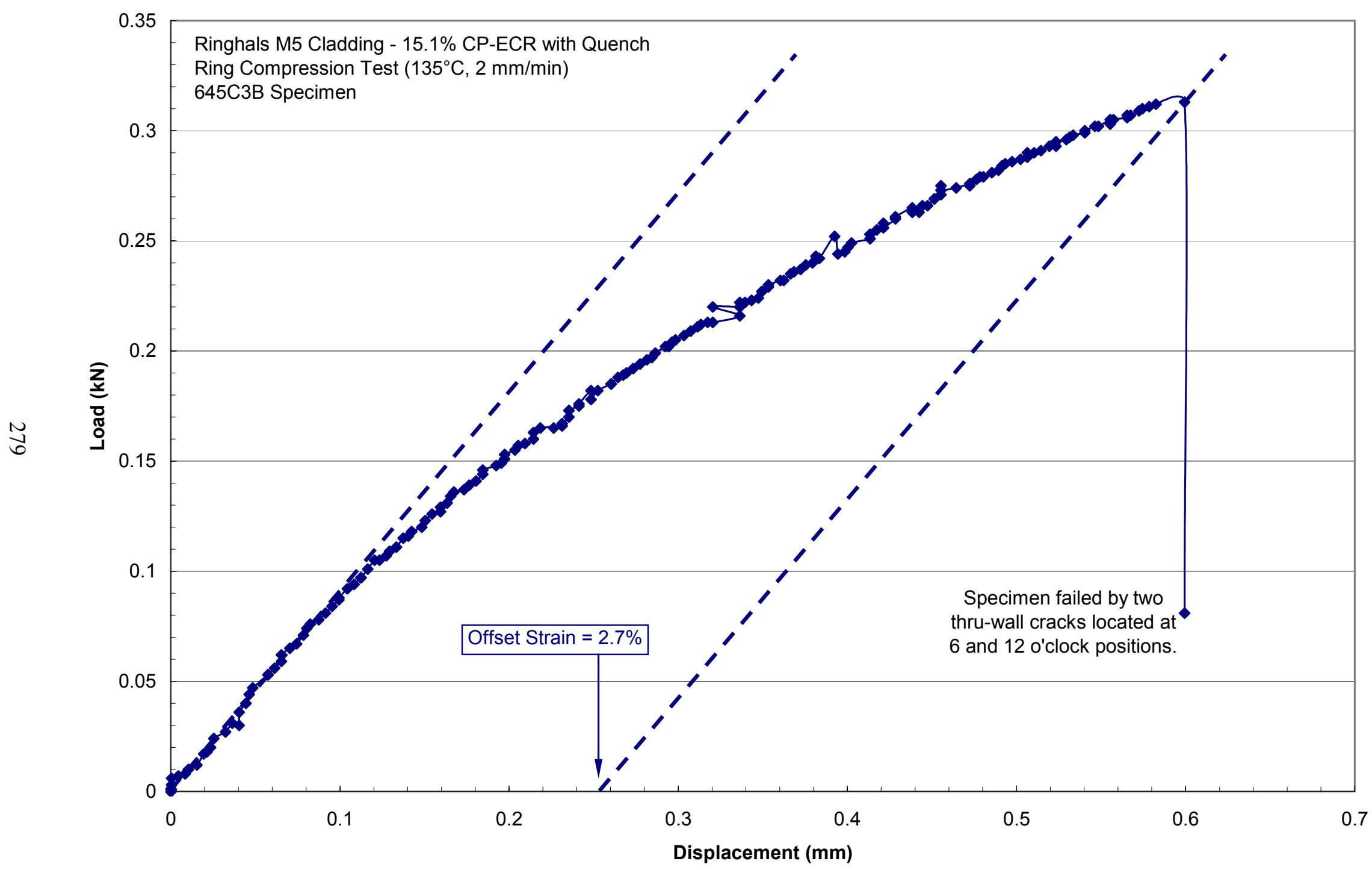

Figure 199. Load-displacement curve for high-burnup M5 cladding oxidized to 15.1\% CP-ECR and cooled with quench: Ring \#1. 


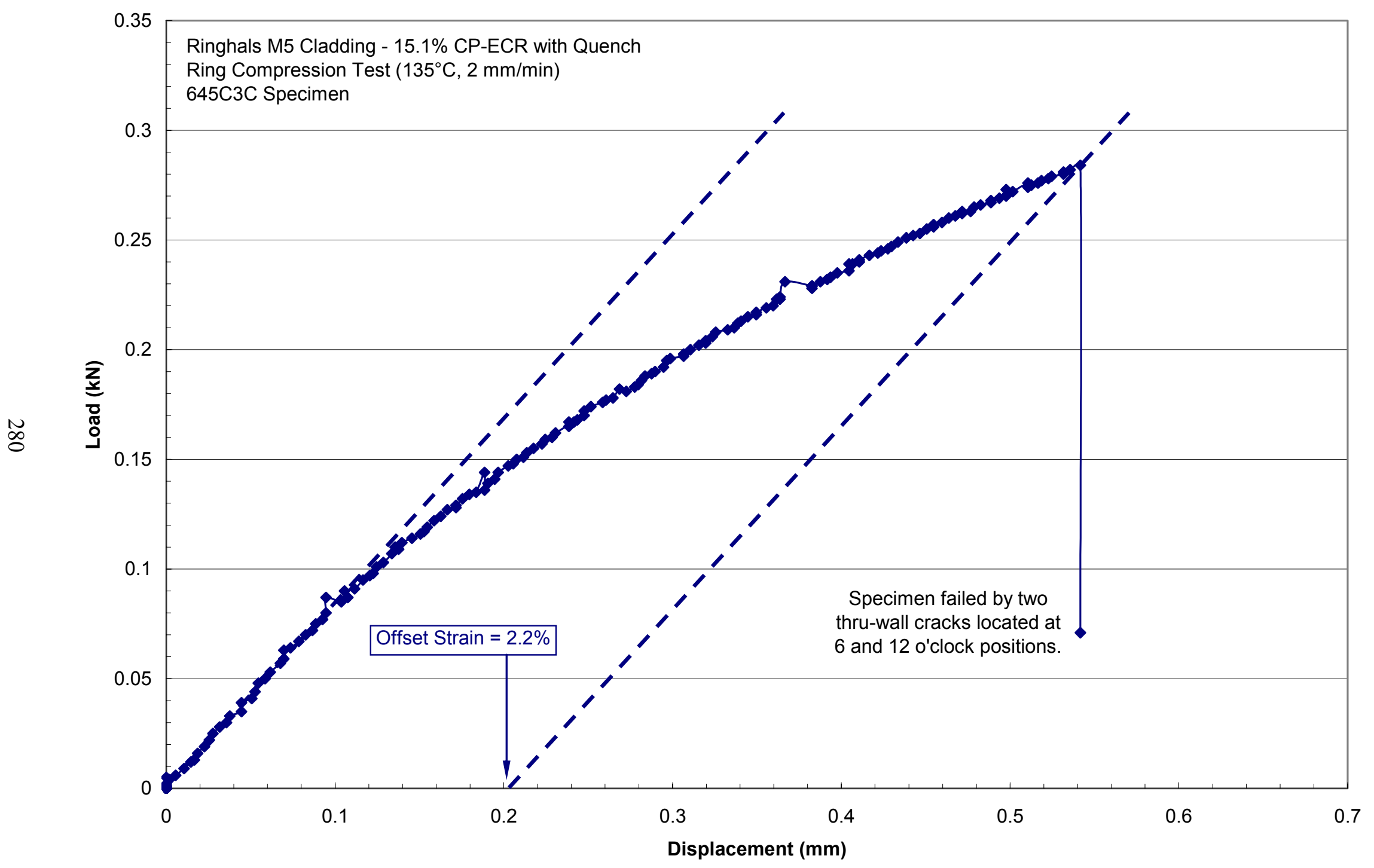

Figure 200. Load-displacement curve for high-burnup M5 cladding oxidized to 15.1\% CP-ECR and cooled with quench: Ring \#2. 


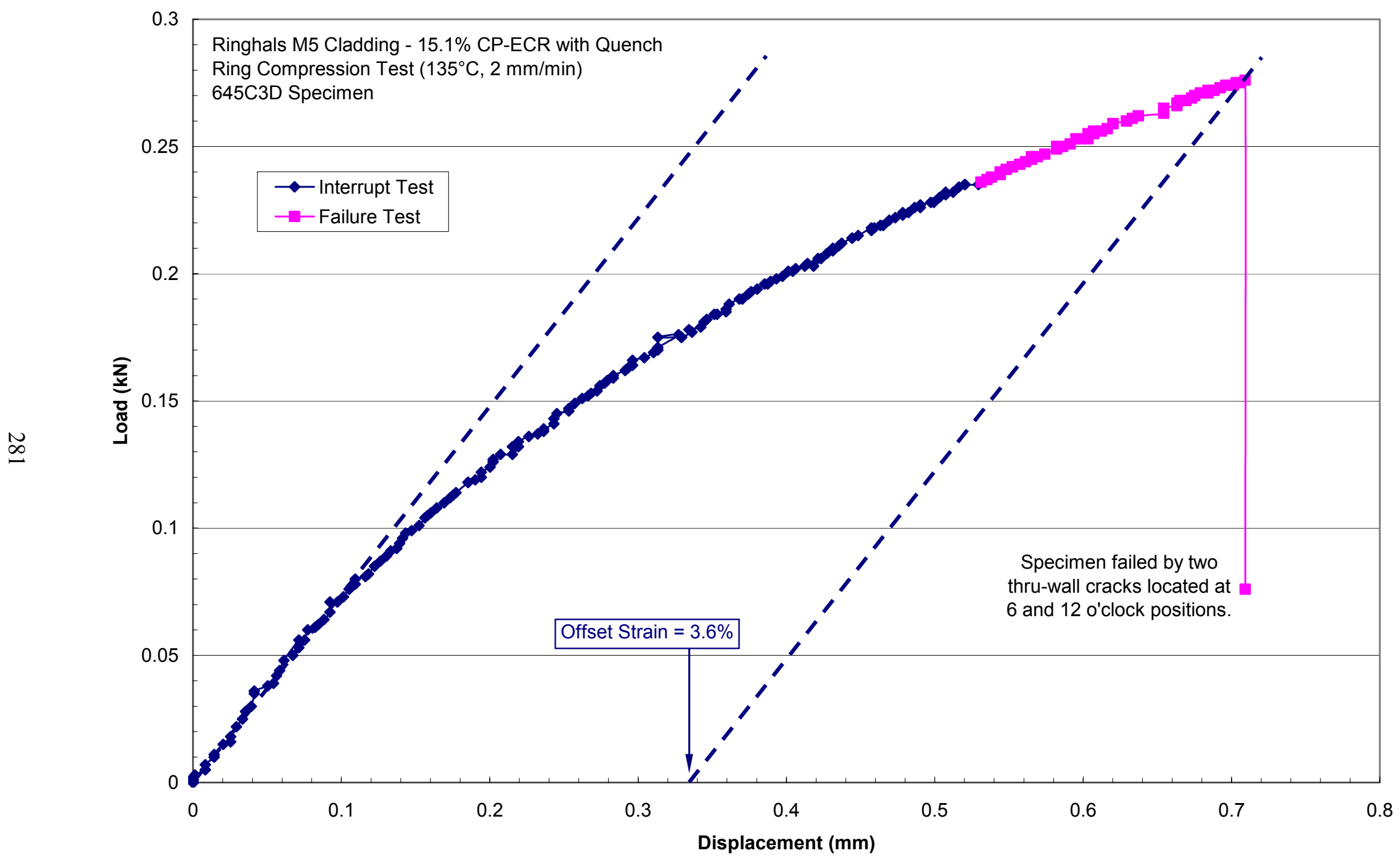

Figure 201a. Load-displacement curve for high-burnup M5 cladding oxidized to 15.1\% CP-ECR and cooled with quench: Ring \#3. Test was interrupted after a displacement of $\approx 0.5 \mathrm{~mm}$ to compare offset $(2.3 \%)$ to permanent strain $(0.5 \%)$ for an intact ring. Ring length was $6.1 \mathrm{~mm}$. 


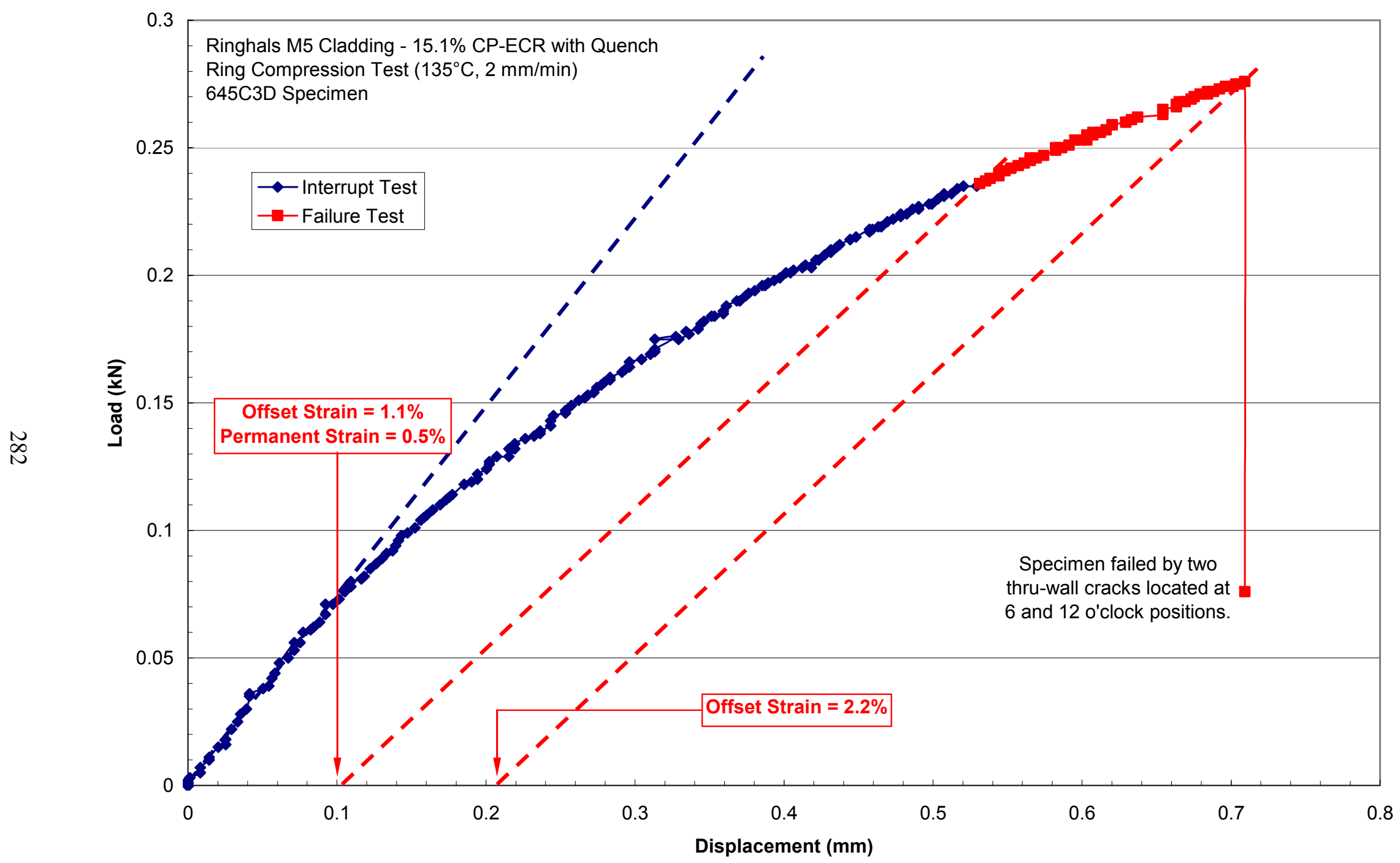

Figure 201b. Determination of offset strains using linearized loading slope from second loading of high-burnup M5 oxidized to $15.1 \%$ CPECR and cooled with quench: Ring \#3. Ring length was $6.1 \mathrm{~mm}$. 


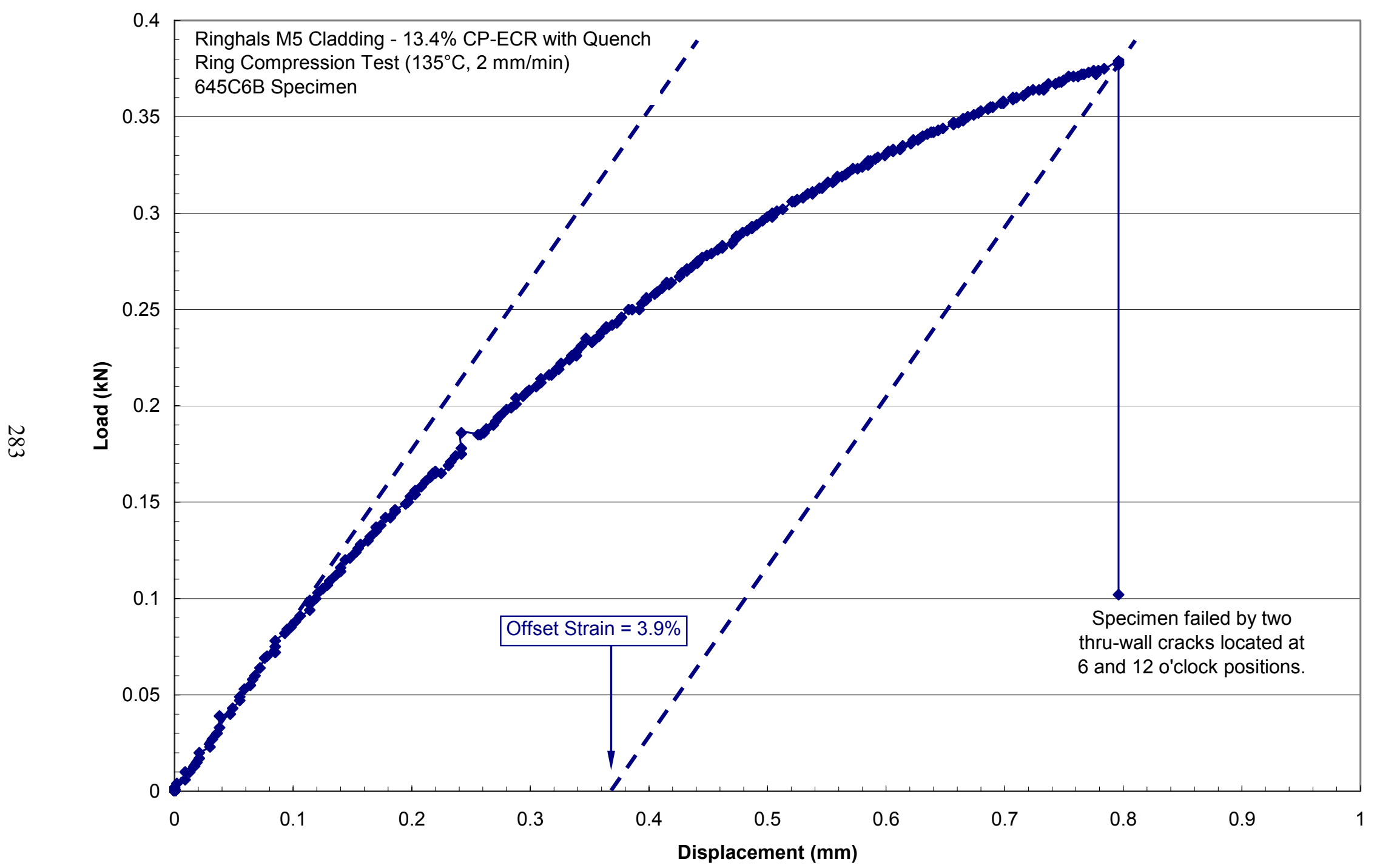

Figure 202. Load-displacement curve for high-burnup M5 cladding oxidized to $13.4 \%$ CP-ECR and cooled with quench: Ring \#1. 


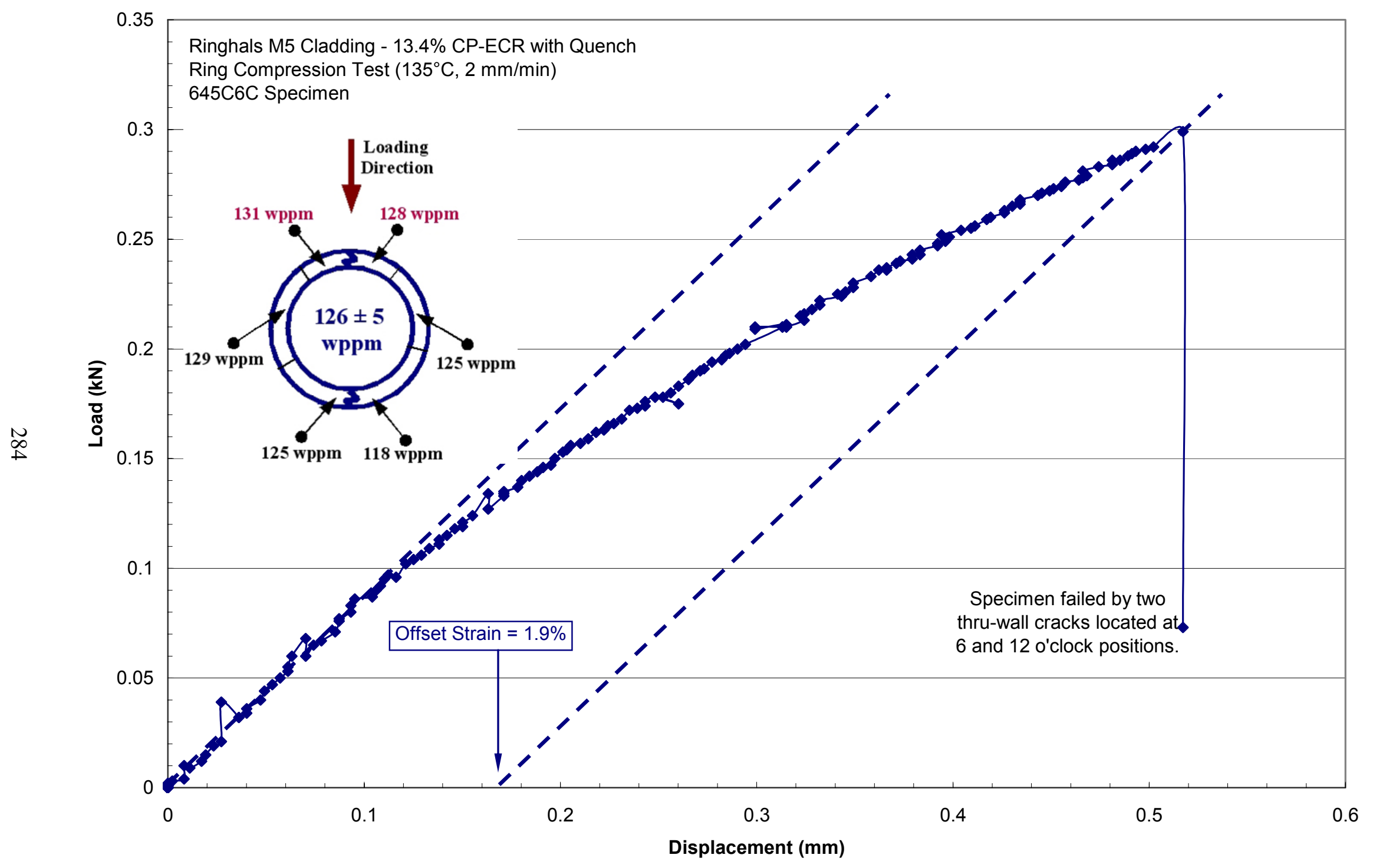

Figure 203. Load-displacement curve for high-burnup M5 cladding oxidized to $13.4 \%$ CP-ECR and cooled with quench: Ring \#2. 


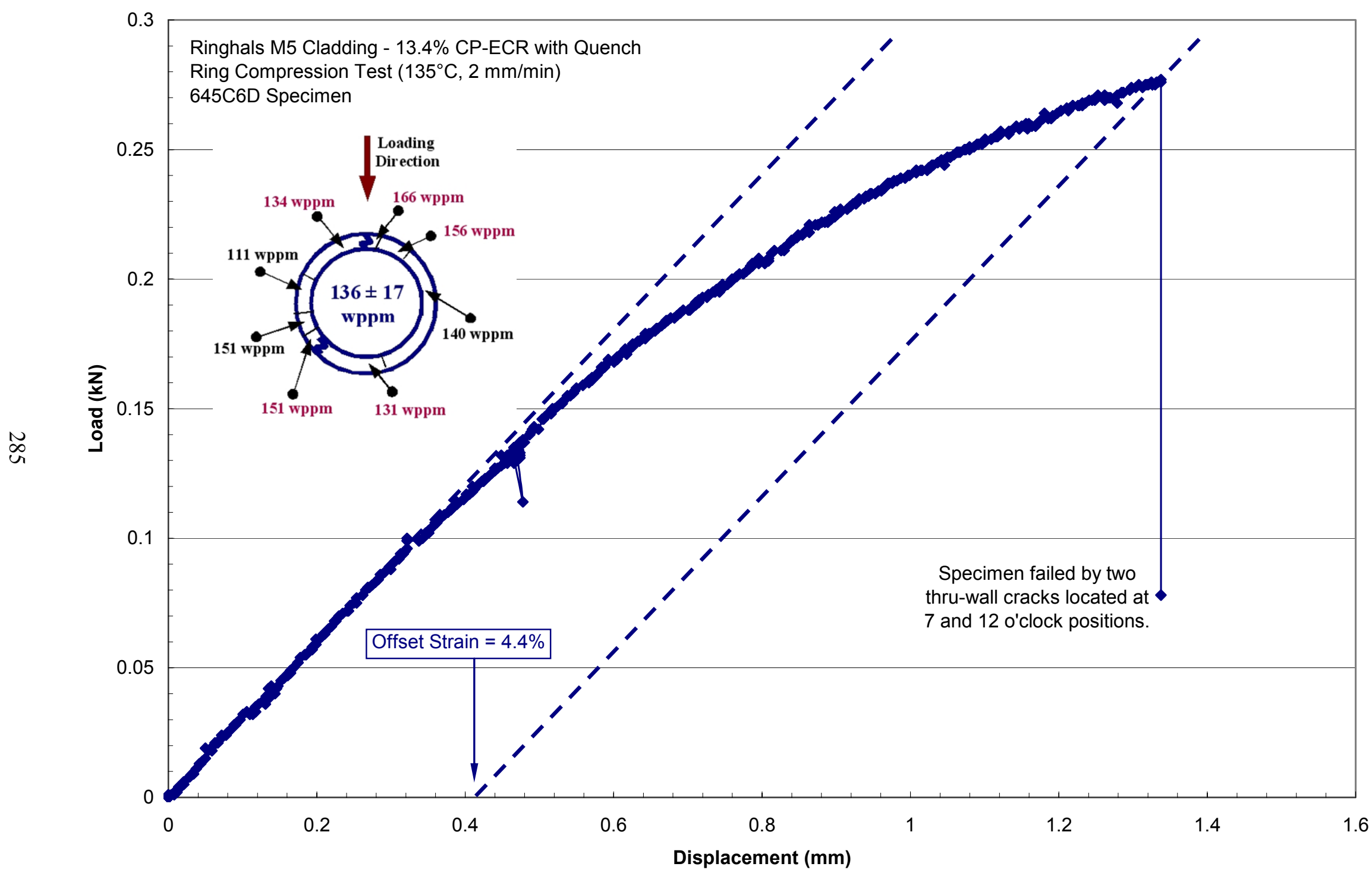

Figure 204. Load-displacement curve for high-burnup M5 cladding oxidized to $13.4 \%$ CP-ECR and cooled with quench: Ring \#3. 


\subsection{Summary of results for high-burnup cladding}

Oxidation tests were conducted at $\leq 1200^{\circ} \mathrm{C}$ with defueled Zry-4, ZIRLO, and M5 cladding samples sectioned from high-burnup fuel rods. The corresponding pre-test hydrogen levels for most of the samples were measured to be $550 \pm 100 \mathrm{wppm}, \approx 620 \pm 140 \mathrm{wppm}$, and $110 \pm 20 \mathrm{wppm}$ for Zry-4, ZIRLO, and M5, respectively. Post-test hydrogen measurements for ZIRLO were significantly lower $(540 \pm 100$ wppm), suggesting that some of the measured pre-test hydrogen was in the corrosion layer for these ZIRLO samples. For each alloy, a series of tests was conducted with samples cooled without quench to determine upper bound ductility values and ductile-to-brittle transition oxidation levels (CP-ECR). These were followed by oxidation tests with quench at $800^{\circ} \mathrm{C}$.

For each oxidation sample, two-to-three rings were sectioned for ring-compression ductility tests. Based on both offset and permanent strains, the transition CP-ECR values were determined to be $8 \%, 9 \%$, and $18 \%$ for high-burnup Zry-4, ZIRLO, and M5 samples, respectively. These values were determined to the nearest $1 \%$ CP-ECR based on the permanent strain criterion ( $\geq 1 \%$ for ductility).

Quenching at $800^{\circ} \mathrm{C}$ caused a significant reduction in ductility and transition CP-ECR for highburnup ZIRLO and M5 samples. Ductile-to-brittle transition CP-ECR values decreased from 9\% to 5\% for ZIRLO and from $18 \%$ to $14 \pm 1 \%$ for M5. A single quench test was conducted with a high-burnup Zry-4 sample containing higher hydrogen content $(740 \pm 100 \mathrm{wppm})$ following oxidation to $7.5 \% \mathrm{CP}-$ ECR. Rings sectioned from this sample were highly brittle. Based on the high ductility $(\approx 40 \%)$ of the slow-cooled sample oxidized to $4.5 \% \mathrm{CP}-\mathrm{ECR}$, as well as ductility reductions with quench for prehydrided Zry-4 and high-burnup ZIRLO, 5\% CP-ECR is recommended as the transition oxidation level of high-burnup Zry-4 with 550 \pm 100 wppm.

High-burnup M5 samples were exposed to steam oxidation at $1200^{\circ} \mathrm{C}$ for significant periods of time prior to cooling with or without quench. For high-burnup ZIRLO samples cooled with quench, the embrittlement threshold (5\%) occurred quickly after heating to only $1160^{\circ} \mathrm{C}$ prior to cooling. For highburnup Zry-4, 5\% post-quench embrittlement threshold corresponds to a peak oxidation temperature of $\approx 1180^{\circ} \mathrm{C}$. Experimental heating rates from $1025-1175^{\circ} \mathrm{C}$ were $\approx 2.0^{\circ} \mathrm{C} / \mathrm{s}$ for Zry- 4 and $2.6^{\circ} \mathrm{C} / \mathrm{s}$ for ZIRLO and M5.

Metallographic images of high-burnup Zry-4 and ZIRLO samples were consistent with the high circumferential variation in hydrogen content for these two alloys. In particular, the thickness of the dense hydride rim in the cladding metal near the corrosion-metal interface varied systematically around the circumference. Circumferential variations of about \pm 100 wppm appear to have only a secondary effect on the embrittlement threshold for oxidized, high-burnup ZIRLO cooled without quench. However, large circumferential variation in hydrogen content appears to have a significant effect on the ductility and embrittlement threshold for oxidized, high-burnup ZIRLO cooled with quench at $800^{\circ} \mathrm{C}$. The same observations were made for prehydrided Zry-4 in Section 4.

Embrittlement threshold levels (CP-ECR values) are plotted in Figure 205 as a function of hydrogen content for high-burnup Zry-4, ZIRLO, and M5. For high-burnup ZIRLO, post-test hydrogen content is used because it appears to be a more reliable indication of hydrogen content in the cladding metal. The embrittlement thresholds for high-burnup Zry-4 and ZIRLO are consistent with each other and appear to correlate quite well with the hydrogen content of these samples. Also shown in Figure 205 are the embrittlement thresholds determined for these cladding alloys in the as-fabricated condition. This figure clearly shows that hydrogen has a dominant effect on the embrittlement of high-burnup alloys. 


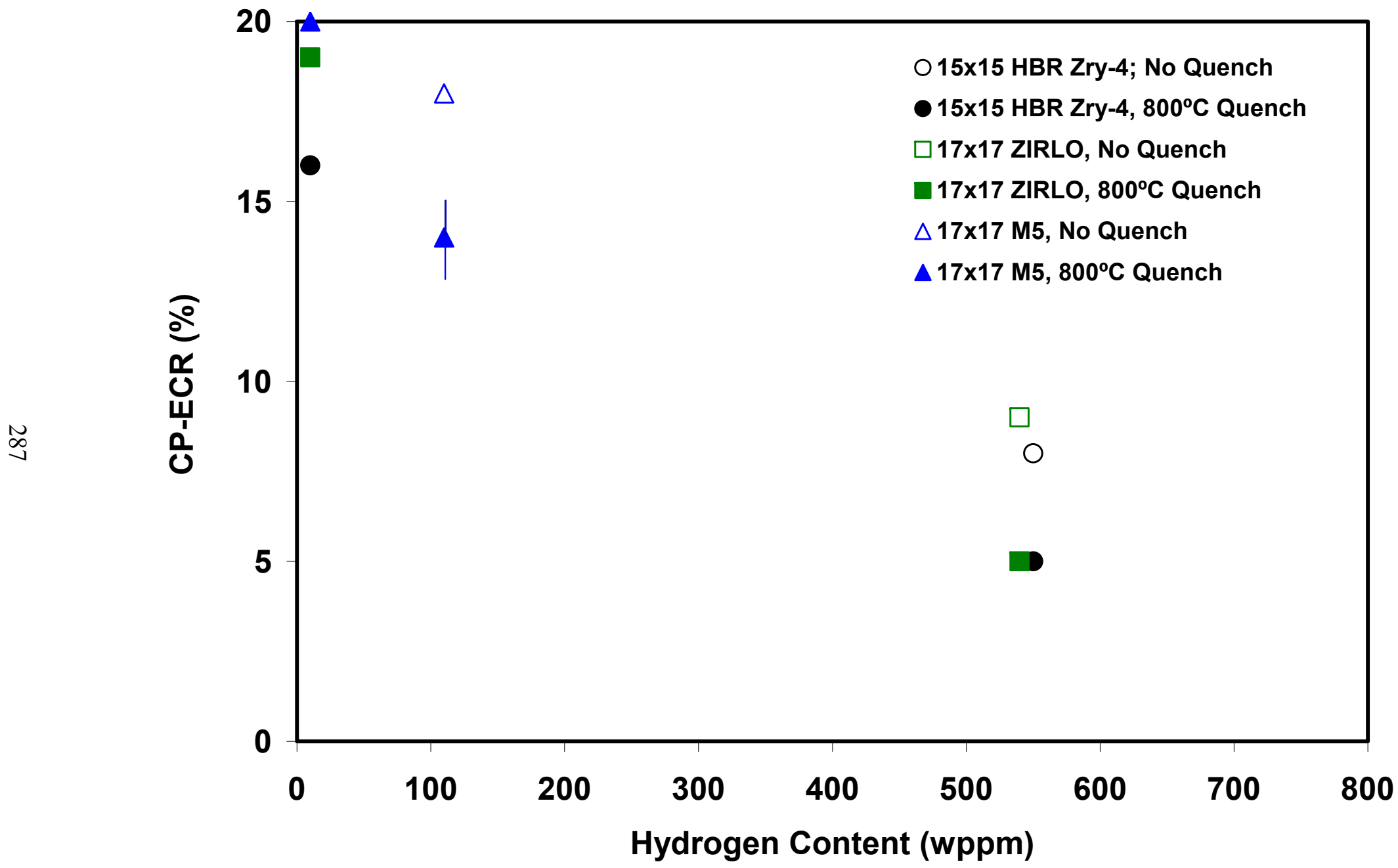

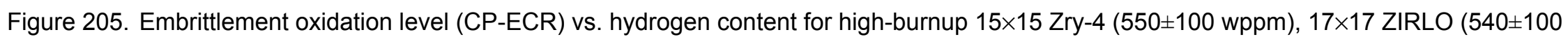
wppm) and $17 \times 17 \mathrm{M} 5(110 \pm 20 \mathrm{wppm})$ oxidized at $\leq 1200^{\circ} \mathrm{C}$, cooled at $11-13^{\circ} \mathrm{C} / \mathrm{s}$ to $800^{\circ} \mathrm{C}$, and either quenched or cooled without quench. 
This page is intentionally left blank. 


\section{$6 \quad$ LOCA Integral Test Results}

During the development and benchmarking of the LOCA integral test apparatus, numerous tests were conducted with as-fabricated $8 \times 8$ and $9 \times 9$ Zry-2 filled with zirconia pellets to simulate the heat capacity of the fuel. Four tests were then conducted with high-burnup fuel rod samples from Limerick fuel rods: ICL\#1 test was conducted in argon up through ballooning and burst to provide data on ballooning strain and minimum wall thickness; ICL\#2 was conducted in steam with a 300 -s hold time at $1204^{\circ} \mathrm{C}$, cooling at $3^{\circ} \mathrm{C} / \mathrm{s}$ to $800^{\circ} \mathrm{C}$, and slower cooling to RT; ICL\#3 was conducted under the same conditions as ICL\#2 through cooling to $800^{\circ} \mathrm{C}$, followed by quench and rapid cooling from $800^{\circ} \mathrm{C}$ to $460^{\circ} \mathrm{C}$; and ICL\#4 was conducted through the complete LOCA sequence with quench and rapid cooling from $800^{\circ} \mathrm{C}$ to $100^{\circ} \mathrm{C}$. The LOCA test apparatus is shown in Figures 6 (photograph) and 7 (schematic). The LOCA integral test sample, test train, and quartz tube chamber are shown in Figure 15. The LOCA test apparatus, pre-test sample characterization, post-test nondestructive examination results, and post-test destructive examination results are described in detail by Yan et al. [15, 22, 36, 37]. In this section, test results related to post-oxidation and post-quench ductility are emphasized. Some background information is also provided for the convenience of the reader.

\subsection{As-fabricated $9 \times 9$ Zry -2 oxidized at $1204^{\circ} \mathrm{C}$}

\subsubsection{Ballooning and burst}

In addition to numerous tests conducted during the developmental phase of the LOCA integral test apparatus, particular tests were conducted to provide baseline data for the in-cell tests. These out-of-cell tests with as-fabricated 9 $\times 9$ Limerick cladding (OCL series) parallel the thermal history of the in-cell tests with high-burnup 9×9 Limerick cladding (ICL series). The reference temperature histories for tests with slow-cooling from $800^{\circ} \mathrm{C}$ and rapid cooling (i.e., quench) from $800^{\circ} \mathrm{C}$ are shown schematically in Figure 16. Figure 206 shows reference internal-pressure and temperature histories for tests with quench at $800^{\circ} \mathrm{C}$. The reference hold time at $1204^{\circ} \mathrm{C}$ was $300 \mathrm{~s}$. Tests with as-fabricated Zry-2 were also conducted with hold times of $1 \mathrm{~s}$ and $120 \mathrm{~s}$, and ramp-to-burst tests were conducted in argon.

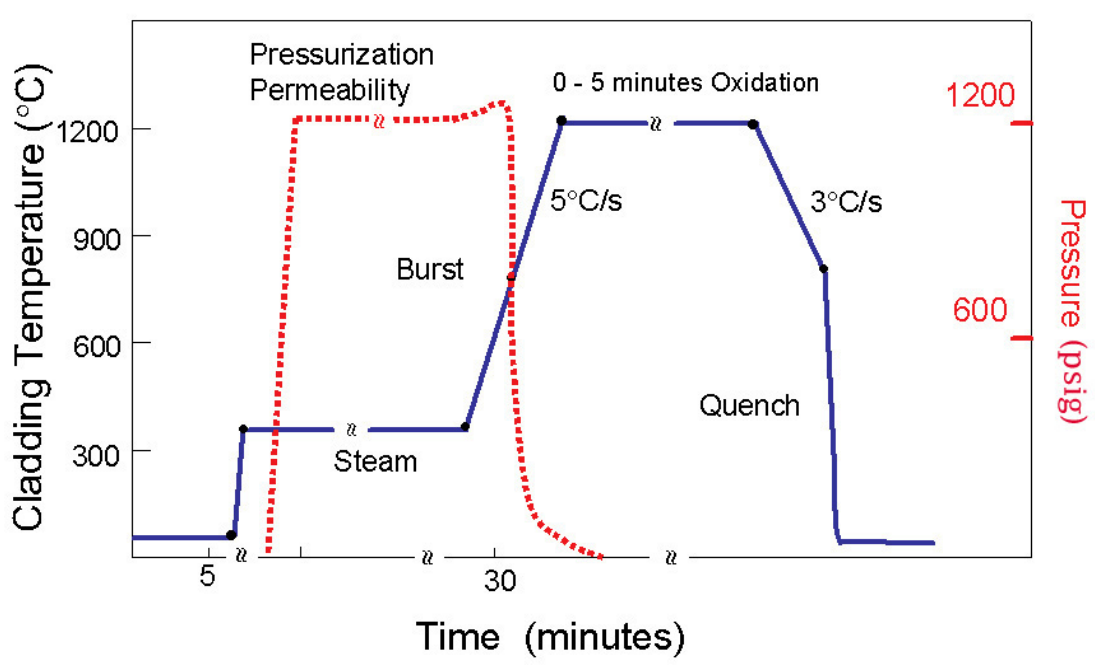

Figure 206. Temperature and pressure histories for full LOCA integral test sequence, including quench from $800^{\circ} \mathrm{C}$ to $100^{\circ} \mathrm{C}$. 
Table 75 summarizes the out-of-cell tests conducted to parallel the in-cell tests, as well the shorter hold-time tests used to characterize the increase in hydrogen content due to secondary hydriding from inner-surface oxidation. For ballooning and burst characterization, samples from tests such as OCL\#8 are the best to use because they capture images of the overall sample geometry, the ballooning diameter and axial extent, the burst length and opening, and the cross section at the midplane burst region where the reference thickness is determined for the ECR calculations. Time at temperature, oxidation, and quench all result in small changes in the burst opening due to loss of the thin, heavily oxidized region surrounding the burst opening. Figure 207 shows the following: (a) side view of the overall sample geometry, (b) enlarged side view of the ballooned-and-burst region, and (c) enlarged frontal view of the ballooned-and-burst region. Figure 207a shows the bending of the sample that occurred just prior to ballooning during anisotropic creep and plastic deformation of the alpha-phase cladding under internal pressure. Based on real-time videos, the ballooning follows very shortly after bending, and burst follows very shortly after ballooning begins. For all samples tested in the ANL LOCA integral apparatus, the maximum ballooning strain and burst occurred on the concave side of the bending curve. The local bending in the ballooned-and-burst region is imaged in Figure 207b. Figures such as 207c are used to determine the shape (dog bone), the axial length, and maximum opening of the burst.

Following imaging of the sample, outer-diameter measurements were performed for the reference $0^{\circ}$ orientation (burst side to $180^{\circ}$ from the burst side) and from a diameter orientation $90^{\circ}$ from the reference orientation. These measurements were made by using a micrometer at 20-30 axial locations to determine the maximum ballooning diameter and the axial profile for the two orientations. The differences $(\Delta d)$ between the measured diameters and the as-fabricated diameter $\left(D_{0}=11.18 \mathrm{~mm}, 0.440\right.$ in.) were used to determine the ballooning strain $\left(\Delta d / D_{0}\right)$. Figure 208 shows the $\Delta d / D_{0}$ axial profiles for the OCL\#8 test sample at the $0^{\circ}$ and $90^{\circ}$ orientations. The minimum wall thickness $\left(\mathrm{h}_{\min }\right)$ for ECR calculations (averaged over the burst cross section) can be estimated from these data by averaging the strains at the two orientations $([70 \%+50 \%] / 2$ at the burst midplane), selecting the maximum value (max $\left.\left\{\left(\Delta \mathrm{d} / \mathrm{D}_{\mathrm{o}}\right)_{\text {avg }}\right\}=\Delta \mathrm{D} / \mathrm{D}_{\mathrm{o}}=60 \%\right)$, and using the constant-volume plasticity relationship:

$$
\mathrm{h}_{\min }=\mathrm{h}_{\mathrm{o}} /\left(1+\Delta \mathrm{D} / \mathrm{D}_{\mathrm{o}}\right)
$$

where $\mathrm{h}_{\mathrm{o}}$ is the as-fabricated wall thickness $(0.71 \mathrm{~mm})$, and the plastic strain in the axial direction is assumed to be zero at the burst midplane. These assumptions were tested by sectioning the OCL\# 8 sample at the burst midplane and obtaining high magnification images from which the circumferential strain $\left(\Delta \mathrm{C} / \mathrm{C}_{\mathrm{o}}\right)$ could be measured directly, as well as the wall thickness. As shown in Figure 209 , the wall thickness is maximum at $\approx 180^{\circ}$ from the burst opening and minimum at the edges of the burst opening. The area-averaged wall thickness determined from Figure 209 was $0.434 \mathrm{~mm}$, the circumferential strain around the cladding mid-wall was $60 \%$, and the wall thickness determined from Equation 8 was $0.444 \mathrm{~mm}$. The difference between the precise measurement and the Equation- 8 calculation is only $2 \%$. Thus, Equation 10 is a practical algorithm for calculating the minimum wall thickness to be used in ECR calculations corresponding to the minimum wall thickness. The methodology has also been validated for oxidized ballooned-and-burst cladding. Figure 209 has also been used to gain a better appreciation for circumferential variation in cladding thickness, for the local effects of two-sided oxidation, and for interpretation of the effects of quench on burst opening. The thin cladding at the edges of the burst region experienced a high level of oxidation during a LOCA-type transient as compared to the thicker cladding $180^{\circ}$ from the burst region. Locally, this cladding will be highly brittle and the edges will most likely fragment during quench, resulting in a larger post-test burst width. Such behavior has no consequence relative to the current LOCA criteria, which apply to average rather than local behavior of the burst cross section. However, Figure 209 results are useful in order to rationalize observed changes to the burst region opening due to oxidation and quench. 
Table 75. Summary of LOCA Integral Test Results for Out-of-cell Tests with Near-archival As-fabricated (Unirradiated) 9×9 Zry-2 Samples Filled with Zirconia Pellets. Outer diameter and wall thickness of as-fabricated cladding are $11.18 \mathrm{~mm}$ and $0.71 \mathrm{~mm}$, respectively.

\begin{tabular}{|c|c|c|c|c|c|c|}
\hline Parameter & OCL\#5 & OCL\#8 & OCL\#22 & OCL\#17 & OCL\#11 & OCL\#13 \\
\hline Environment & Argon & Argon & Steam & Steam & Steam & Steam \\
\hline Hold Temperature, ${ }^{\circ} \mathrm{C}$ & --- & --- & 1204 & 1204 & 1204 & 1204 \\
\hline Hold Time, s & --- & --- & 1 & 120 & 300 & 300 \\
\hline Quench (Q) at $800^{\circ} \mathrm{C}$ or Slow Cooling (SC) & $\mathrm{SC}$ & $\mathrm{SC}$ & $\mathrm{Q}-800^{\circ} \mathrm{C}$ & $\mathrm{Q}-800^{\circ} \mathrm{C}$ & $\mathrm{SC}$ & $\mathrm{Q}-800^{\circ} \mathrm{C}$ \\
\hline$\left(\mathrm{P}_{\mathrm{g}}\right)_{\max }, \mathrm{MPa}$ & 8.96 & 8.62 & 8.87 & 9.10 & 8.61 & 9.09 \\
\hline $\mathrm{T}$ at $\left(\mathrm{P}_{\mathrm{g}}\right)_{\max },{ }^{\circ} \mathrm{C}$ & 660 & 687 & 690 & 6.83 & 680 & 676 \\
\hline Burst Pressure $\left(\mathrm{P}_{\mathrm{B}}\right), \mathrm{MPa}$ & 8.26 & 7.67 & 6.90 & 9.07 & 7.93 & 6.43 \\
\hline Burst Temperature $\left(\mathrm{T}_{\mathrm{B}}\right),{ }^{\circ} \mathrm{C}$ & $733 \pm 5$ & $766 \pm 17$ & $747 \pm 37$ & 750 & $753 \pm 22$ & $766 \pm 25$ \\
\hline $\begin{array}{l}\text { Burst Center Relative to Specimen Midplane, } \\
\qquad \mathrm{mm}\end{array}$ & +20 & -10 & +25 & -13 & +35 & 28 \\
\hline Burst Shape & Dog Bone & Dog Bone & Dog Bone & Dog Bone & Dog Bone & Dog Bone \\
\hline Burst Length, mm & 13 & 17 & 17 & 10 & 11 & 10 \\
\hline Max. Burst Width, mm & 2.5 & 2.5 & 1 & 0.8 & 1 & 1 \\
\hline Length of Balloon, mm & 100 & 140 & 140 & 145 & 140 & 150 \\
\hline$\left(\Delta \mathrm{D} / \mathrm{D}_{\mathrm{o}}\right)_{\max }{ }^{\mathrm{a}} \%$ & $44 \pm 10$ & $60 \pm 10$ & 54 & $49 \pm 11$ & $43 \pm 10$ & $43 \pm 8$ \\
\hline$\left(\Delta \mathrm{C} / \mathrm{C}_{\mathrm{m}}\right)_{\max ,}{ }^{\mathrm{b}} \%$ & --- & 60 & --- & --- & --- & --- \\
\hline $\begin{array}{l}\text { Reference Minimum Wall Thickness for ECR, } \\
\text { mm }\end{array}$ & $\approx 0.50$ & 0.434 & 0.46 & 0.48 & 0.50 & 0.50 \\
\hline Maximum CP-ECR, \% & 0 & 0 & 9 & 15 & 21 & 21 \\
\hline
\end{tabular}

${ }^{a}$ From profilometry at $0^{\circ}$ and $90^{\circ}$ relative to burst orientation.

${ }^{\mathrm{b}}$ Midwall circumferential strain determined from low-magnification photomicrographs. 


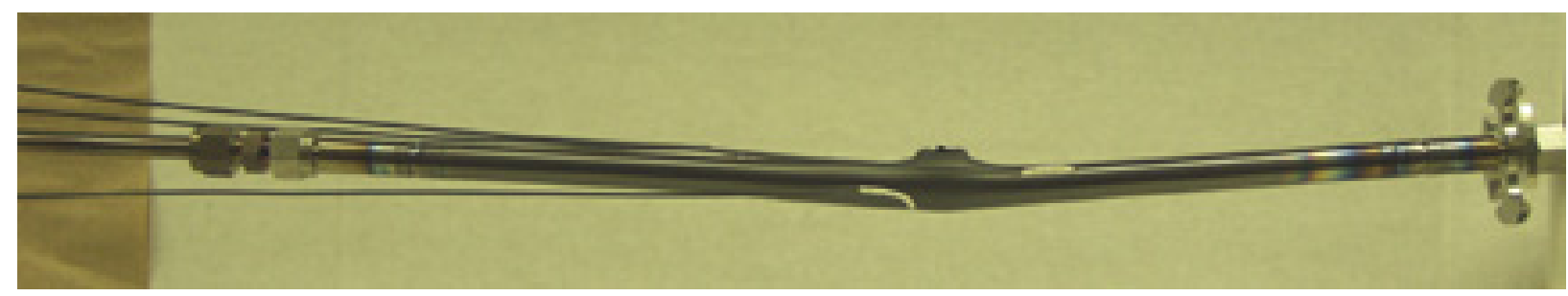

(a)

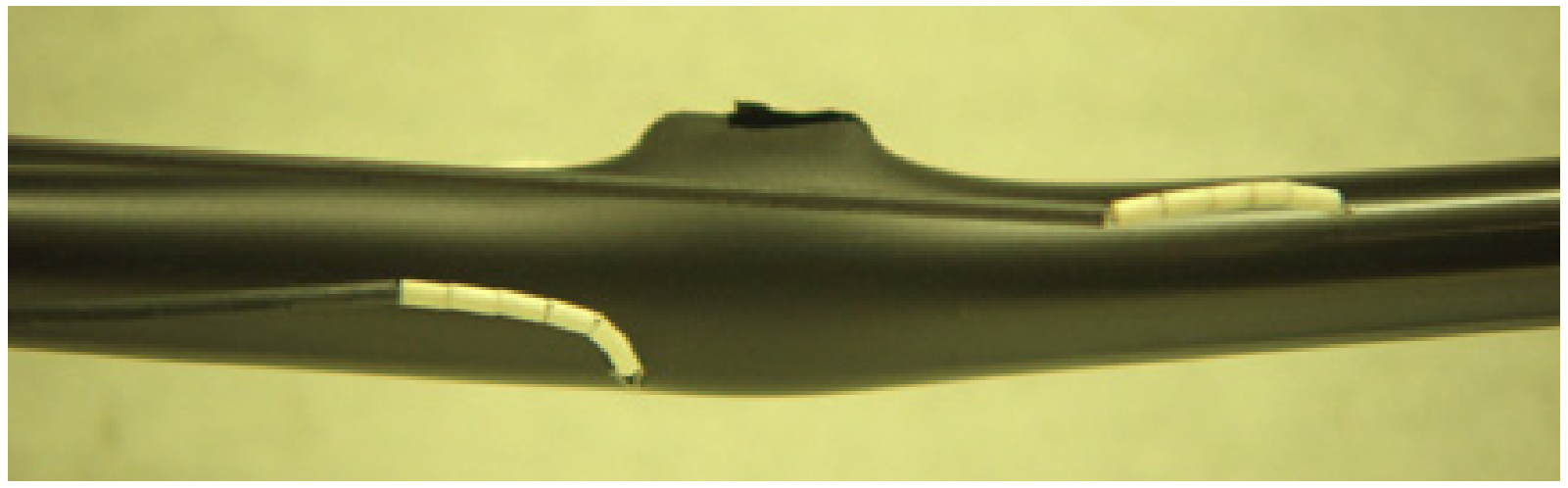

(b)

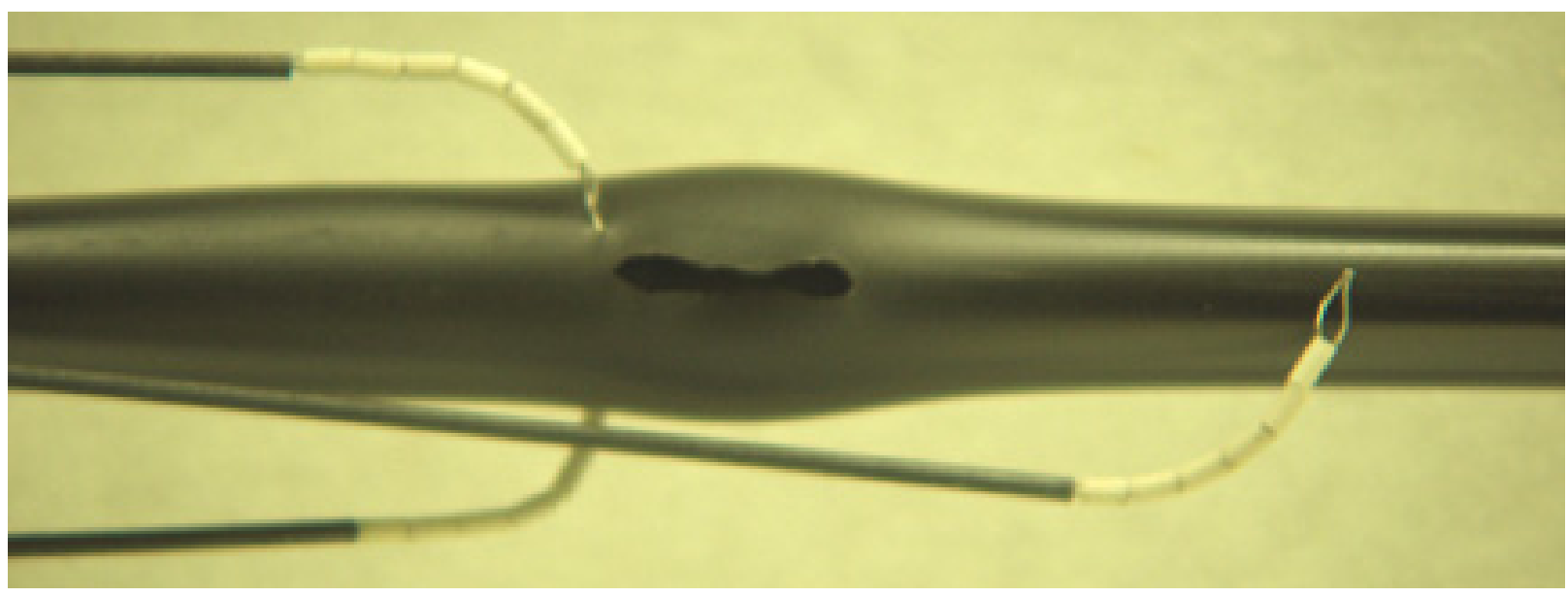

(c)

Figure 207. Images of the OCL\#8 test sample after heating in argon to burst at $\approx 770^{\circ} \mathrm{C}$ (due to a maximum internal pressure of $8.62 \mathrm{MPa}$ [gauge] and an estimated pressure of $\approx 7.7 \mathrm{MPa}$ just prior to burst) and slow cooling: (a) low magnification of side view of sample, (b) higher magnification of side view of ballooned-and-burst region, and (c) higher magnification of frontal view of burst opening. Top of the sample, from which the thermocouples were inserted prior to welding, is to the left in these photographs. 


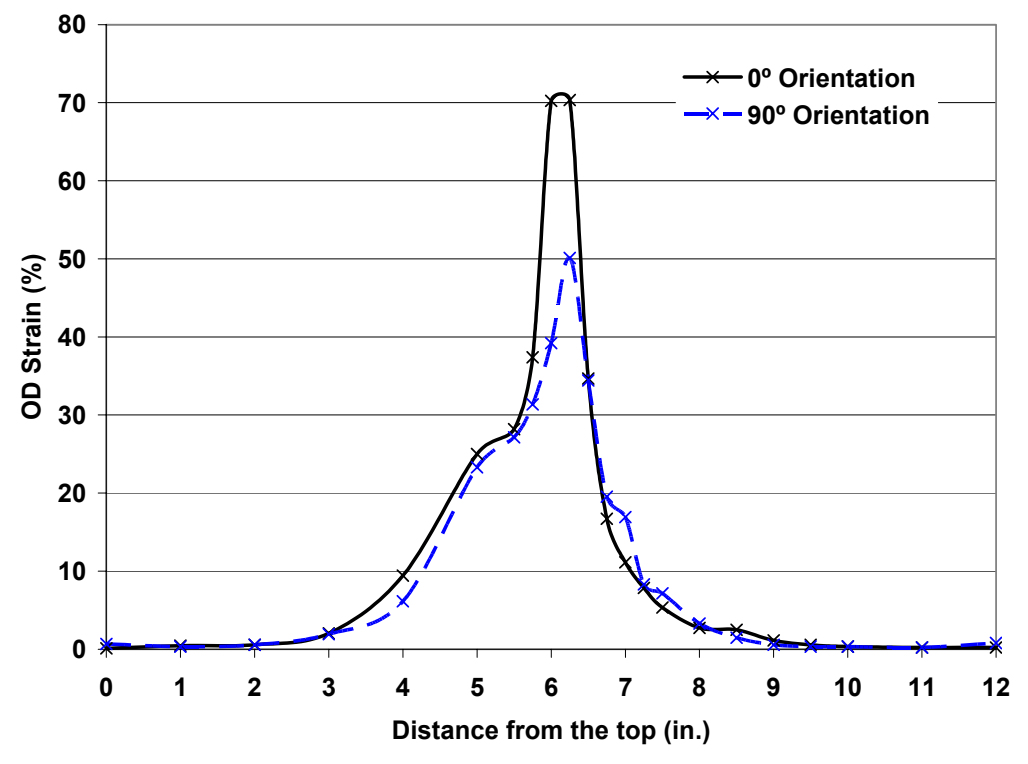

Figure 208. Axial profile of the diametral ballooning strain at $0^{\circ}$ and $90^{\circ}$ relative to the burst opening for test sample OCL\#8 heated under internal pressure in argon up to burst at $\approx 770^{\circ} \mathrm{C}$ and slow cooled to RT.

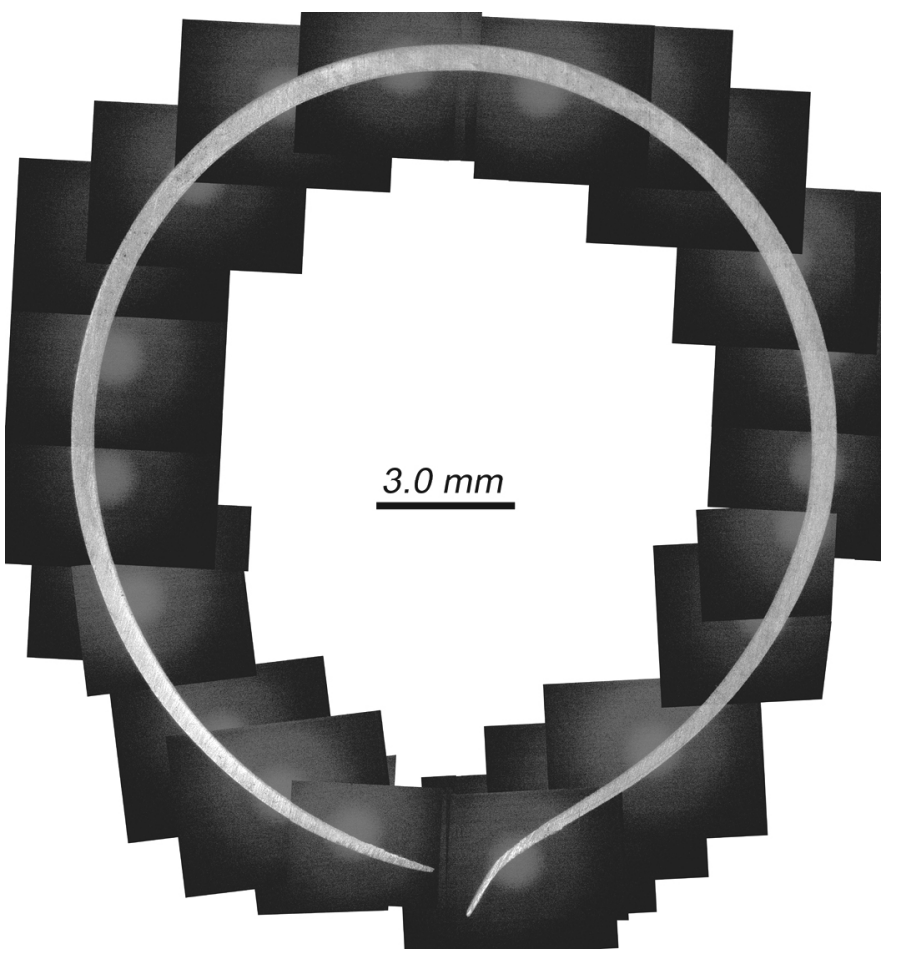

Figure 209. Cladding cross section at burst midplane for OCL\#8 sample (see Figure 208). 
The axial distribution of cladding strain shown in Figure 208 is typical of samples that developed a single balloon (e.g., OCL\#5 and OCL\#11). Ballooning and burst are instability phenomena. Differences were observed in maximum ballooning strain ( $\approx 40 \%$ to $60 \%$ ), axial extent of ballooning (100-150 mm), burst location relative to the sample midplane $(-13 \mathrm{~mm}$ to $+35 \mathrm{~mm})$, burst length $(11-17 \mathrm{~mm})$, and maximum burst opening $(0.8-2.5 \mathrm{~mm})$. These test-to-test result differences are to be expected for instabilities of this nature. However, later tests (e.g., OCL\#13, OCL\#17, and OCL\#22) exhibited a secondary balloon region in addition to the larger primary balloon region containing the burst opening. Diametral strain profiles for OCL\#5 and OCL\#6 are shown in Section 6.2 in comparison plots with results from corresponding high-burnup test-sample results (ICL\#1 and ICL\#2). Diametral profiles for three test samples with secondary balloon regions are shown in Figures 210-212. The secondary balloons have a maximum diametral strain of $15-30 \%$. However, these secondary balloons appear to have very little influence on the axial extent of ballooning. The ANL criterion for determining this axial extent is $\geq 2 \%$ strain, along with some judgment based on the intersection of the steeply decreasing part of the profile and the flat portion of the profile.

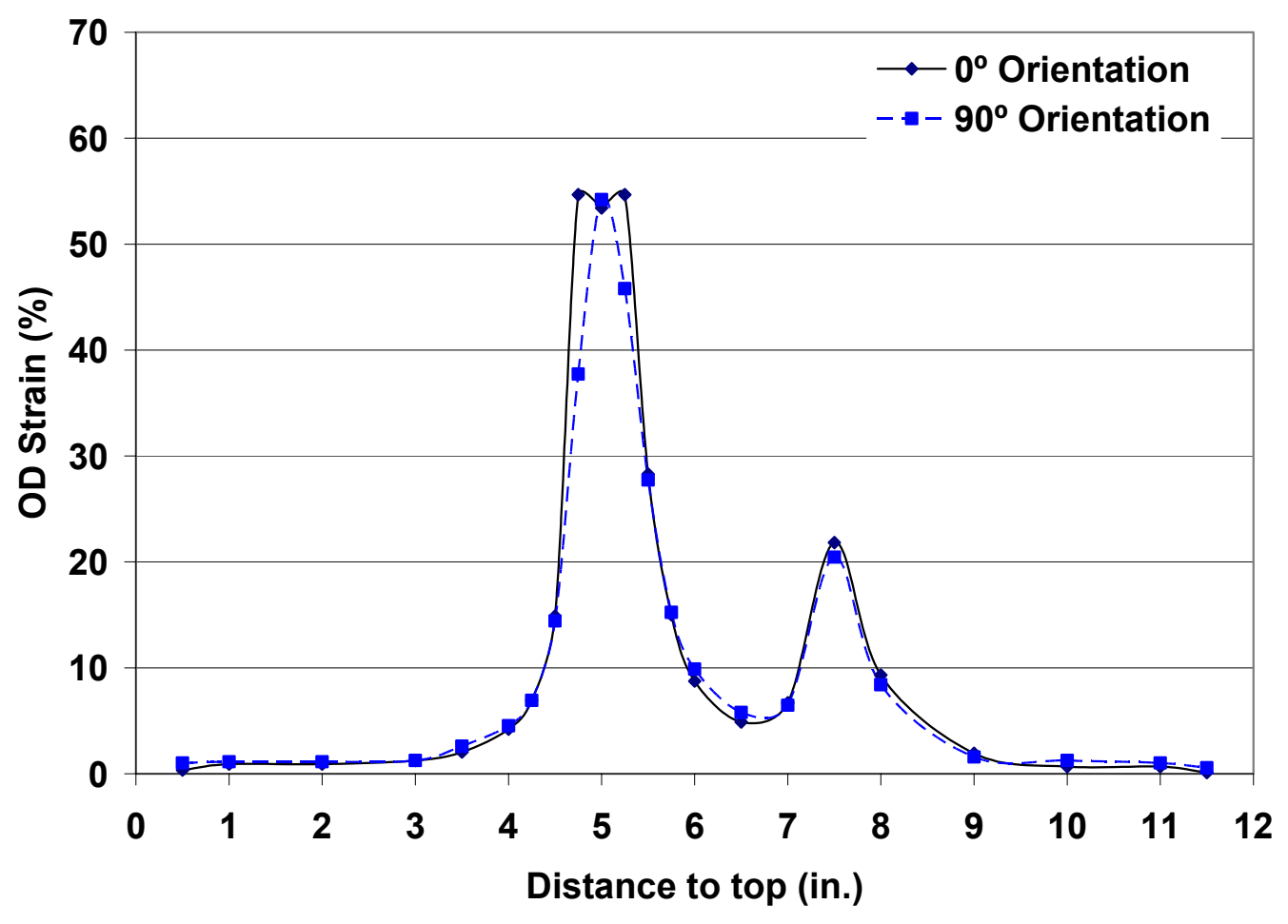

Figure 210. Ballooning strain profile for OCL\#22 test sample held for $1 \mathrm{~s}$ at $1204^{\circ} \mathrm{C}$, cooled to $800^{\circ} \mathrm{C}$, and quenched. 


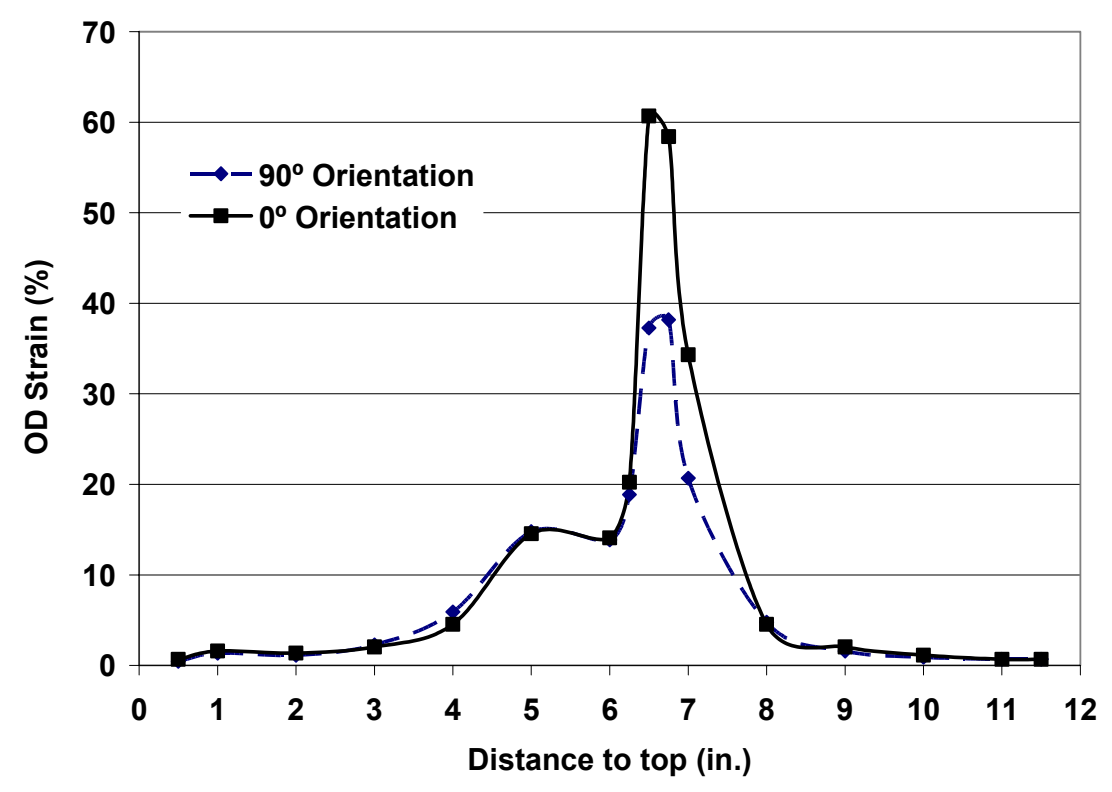

Figure 211 . Ballooning strain profile for OCL\#17 test sample held for $120 \mathrm{~s}$ at $1204^{\circ} \mathrm{C}$, cooled to $800^{\circ} \mathrm{C}$, and quenched.

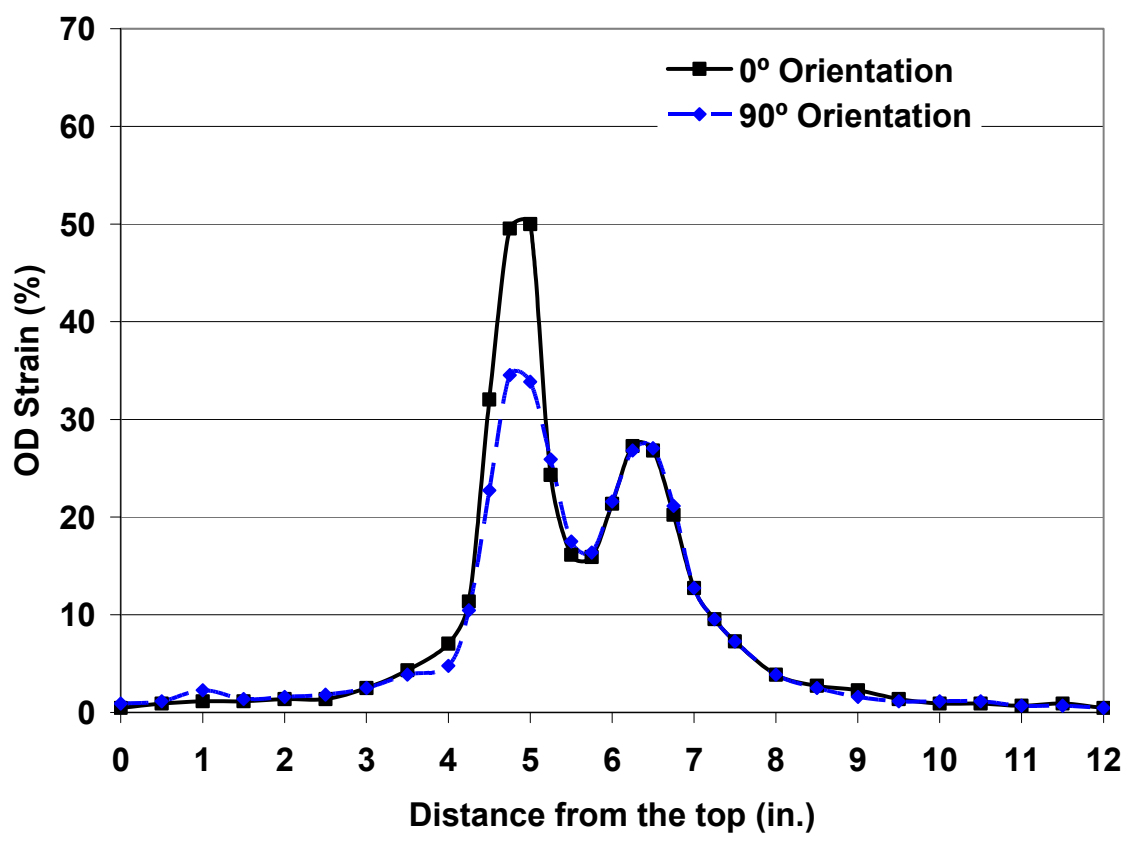

Figure 212. Ballooning strain profile for OCL\#13 test sample held for $300 \mathrm{~s}$ at $1204^{\circ} \mathrm{C}$, cooled to $800^{\circ} \mathrm{C}$, and quenched. 


\subsubsection{Oxidation and hydrogen pickup due to secondary hydriding}

Due to steam leakage through the burst opening, oxidation within the balloon region is expected to be two-sided. Such oxidation results in hydrogen release to the near-stagnant steam within the test sample. Unlike the outer surface exposed to flowing steam, a large fraction of the released hydrogen is trapped inside the sample and available for pickup by the inner-metal surface in and near the balloon region. Data from quantitative metallography and LECO oxygen-content measurements have been used to determine oxygen pickup $\left(\Delta \mathrm{C}_{\mathrm{O}}\right.$ in wt.\%) and corresponding ECR (in \%). To determine oxygen pickup from the LECO data, two sets of corrections must be made to the raw data. The first set involves renormalizing the LECO oxygen content in wt.\% to the weight of the metal prior to oxidation and subtracting the oxygen content in the as-fabricated cladding $\left(\mathrm{C}_{\mathrm{Oi}}=0.11 \mathrm{wt} . \%\right.$ for $\left.9 \times 9 \mathrm{Zry}-2\right)$. The second correction accounts for loss of brittle oxide during LECO sample preparation. Some oxide is lost during sectioning of 2-mm-long rings. More is lost during the "snipping" of four arc lengths from the ring. This sample subdivision is needed to prevent exceeding the oxygen-level limit of the LECO detector. In previous work, oxygen pickup has been determined by three means: sample weight gain, quantitative metallography, and refined LECO oxygen-content data. The oxygen content determined from the raw LECO data exhibited lower oxygen pickup than determined by means of sample weight gain and metallography. By multiplying the raw LECO data by a factor of 1.1, good agreement was obtained by all three techniques. The 1.1 factor is used to determine measured ECR. However, the correction factor is not needed to determine hydrogen pickup $\left(\Delta \mathrm{C}_{\mathrm{H}}\right)$. The equations used to convert the raw LECO oxygen ( $\mathrm{L}_{\mathrm{O}}$ in wt.\%) and hydrogen $\left(\mathrm{L}_{\mathrm{H}}\right.$ in wppm) data to ECR and hydrogen pickup are:

$$
\begin{aligned}
& \Delta \mathrm{C}_{\mathrm{O}}=\left(\mathrm{L}_{\mathrm{O}}-\mathrm{C}_{\mathrm{Oi}}\right) /\left(1-\mathrm{L}_{\mathrm{O}} / 100 \%\right), \text { wt. } \% \\
& \mathrm{ECR}=2.85\left(1.1 \times \mathrm{L}_{\mathrm{O}}-\mathrm{C}_{\mathrm{Oi}}\right) /\left(1-1.1 \times \mathrm{L}_{\mathrm{O}} / 100 \%\right), \% \\
& \Delta \mathrm{C}_{\mathrm{H}}=\left(1+\Delta \mathrm{C}_{\mathrm{O}} / 100 \%\right) \mathrm{L}_{\mathrm{H}}-\mathrm{C}_{\mathrm{Hi}}, \mathrm{wppm}
\end{aligned}
$$

where $\mathrm{C}_{\mathrm{Hi}}$ is the hydrogen content ( 5 wppm) of as-fabricated $9 \times 9$ Zry-2.

The LECO data for OCL\#22 (1-s hold time at $\left.1204^{\circ} \mathrm{C}\right)$ and OCL\#17 $\left(120\right.$-s hold time at $\left.1204^{\circ} \mathrm{C}\right)-$ both taken after bend-to-failure tests - are shown in Figures 213 and 214, respectively. For the OCL\#22 test sample, the maximum oxygen and hydrogen measurements were $3.95 \mathrm{wt} . \%$ and $2105 \mathrm{wppm}$, respectively. At the axial location where the maximum hydrogen reading was found, the LECO oxygencontent measurement was $2.33 \mathrm{wt} . \%$. Using Equations 11-13, the maximum ECR is calculated to be $11 \%$, and the maximum hydrogen pickup is calculated to be $2150 \mathrm{wppm}$. The $11 \%$ ECR value is higher than the 9\% CP-predicted value in Table 75 . If the 1.1 factor is not used for such a low-oxidation level sample (i.e., oxide loss during cutting and snipping is smaller than assumed), the measured ECR is reduced to $10 \%$. The maximum hydrogen content measured by LECO was 2700 wppm, where the oxygen pickup was $2.36 \mathrm{wt} \%$. The hydrogen pickup calculated by Equation 13 is $2760 \mathrm{wppm}$. The 
magnitude of the hydrogen pickup is quite large for such a short hold time at $1204^{\circ} \mathrm{C}$. The results suggest that significant hydrogen pickup occurs early in the LOCA transient. Enough hydrogen is released to the cladding interior due to inner-surface oxidation during the ramp to result in high hydrogen pickup.

The OCL\#17 LECO data shown in Figure 214 were taken from half of the sample. The maximum measured oxygen and hydrogen contents were $4.24 \mathrm{wt} . \%$ and $2936 \mathrm{wppm}$, respectively. The ECR determined from Equation 12 is 14\%, which agrees with the CP-predicted value. Using 2.39 wt.\% oxygen measured by LECO at the peak hydrogen location gives a hydrogen pickup of $3000 \mathrm{wppm}$. In terms of peak hydrogen content, relatively little is picked up during the 119-s additional hold time at $1204^{\circ} \mathrm{C}$.

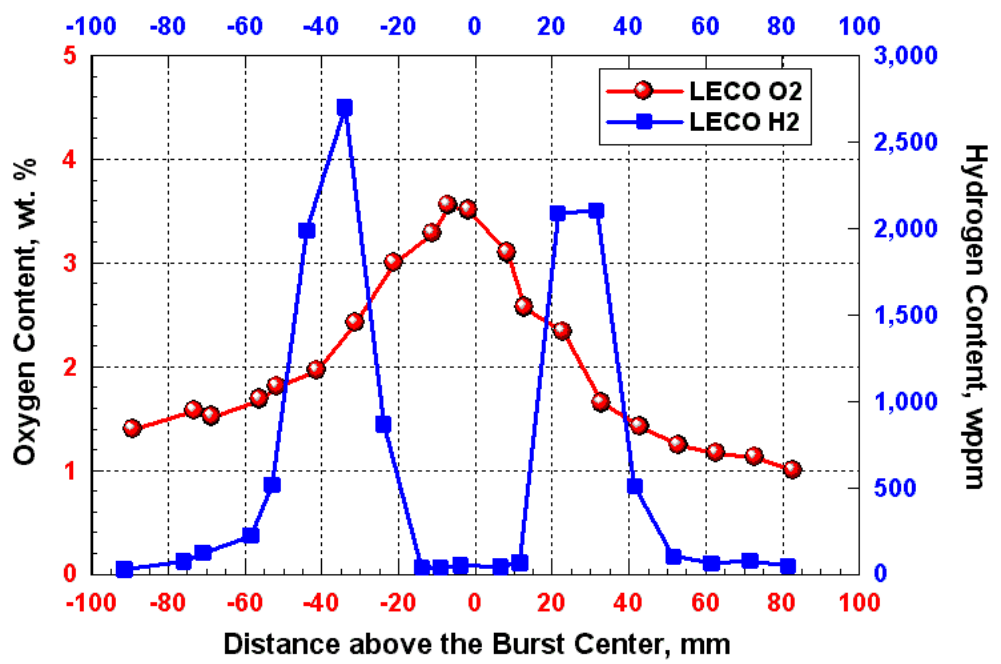

Figure 213. LECO oxygen and hydrogen content for OCL\#22 sample ramped in steam from $300^{\circ} \mathrm{C}$ to $1204^{\circ} \mathrm{C}$ at $5^{\circ} \mathrm{C} / \mathrm{s}$, held at $1204^{\circ} \mathrm{C}$ for $1 \mathrm{~s}$, cooled at $3^{\circ} \mathrm{C} / \mathrm{s}$ to $800^{\circ} \mathrm{C}$, and quenched.

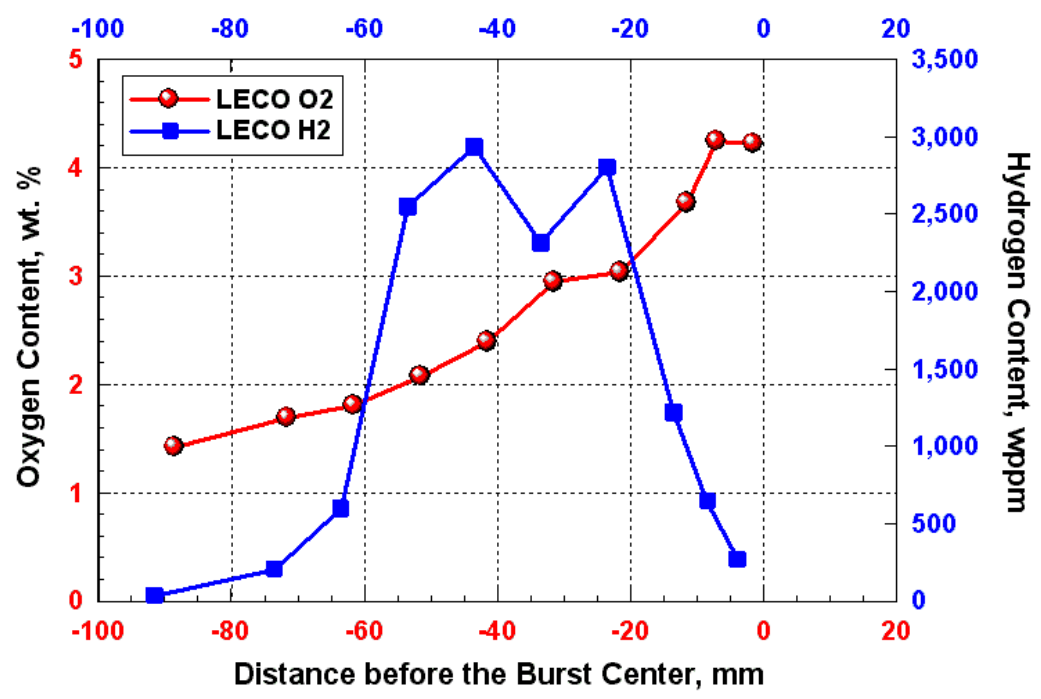

Figure 214. LECO oxygen and hydrogen content for OCL\#17 sample ramped in steam from $300^{\circ} \mathrm{C}$ to $1204^{\circ} \mathrm{C}$ at $5^{\circ} \mathrm{C} / \mathrm{s}$, held at $1204^{\circ} \mathrm{C}$ for $120 \mathrm{~s}$, cooled at $3^{\circ} \mathrm{C} / \mathrm{s}$ to $800^{\circ} \mathrm{C}$, and quenched. 
LECO data were also obtained for the OCL\#11 sample (300-s hold time at $\left.1204^{\circ} \mathrm{C}\right)$. Oxygen pickup from quantitative metallography was also determined. Figure 215 shows (a) the LECO data and (b) the converted data for ECR and hydrogen pickup. The quantitative metallography and LECO results are in excellent agreement. The maximum ECR determined from data is $18.5 \%$, as compared to $21 \%$ CP-predicted ECR in Table 75. The maximum hydrogen pickup was $3900 \mathrm{wppm}$. Thus, $>70 \%$ of the maximum hydrogen pickup occurs during the ramp to $1204^{\circ} \mathrm{C}$.

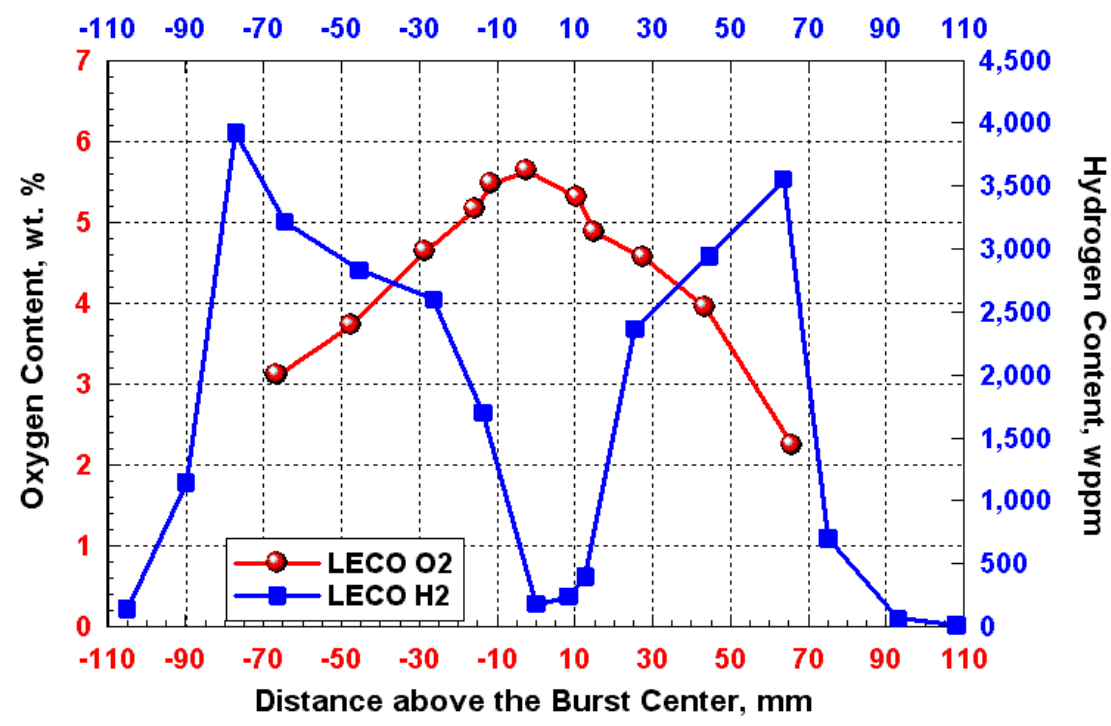

(a) LECO data

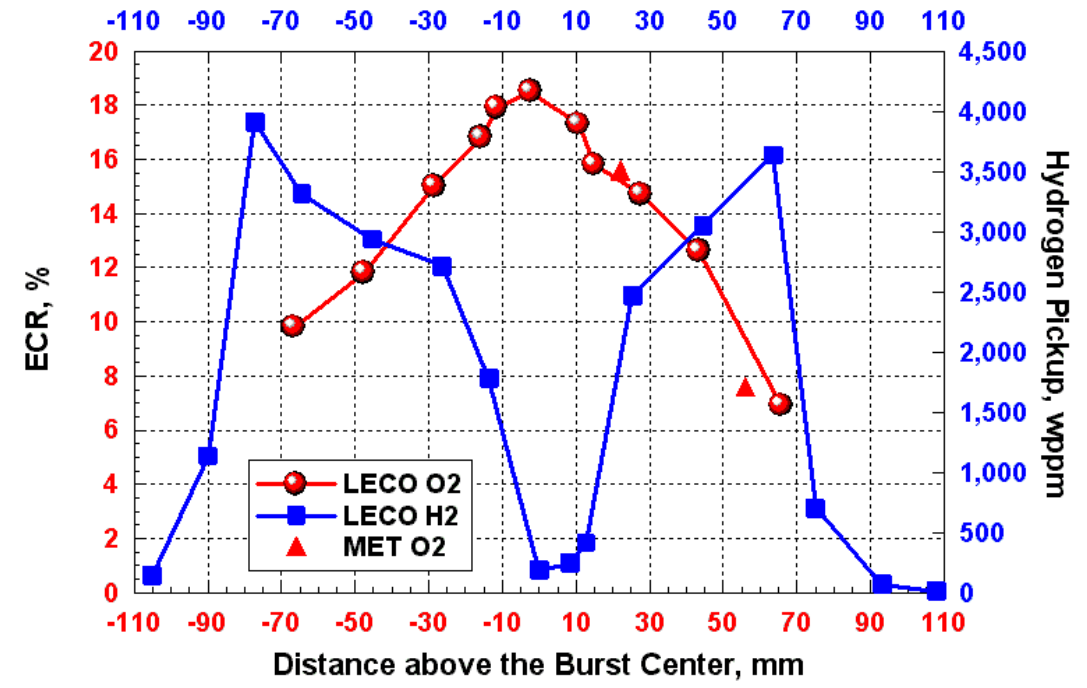

(b) Calculated from LECO data

Figure 215. Data for $\mathrm{OCL} \# 11$ sample ramped in steam from $300^{\circ} \mathrm{C}$ to $1204^{\circ} \mathrm{C}$ at $5^{\circ} \mathrm{C} / \mathrm{s}$, held at $1204^{\circ} \mathrm{C}$ for $300 \mathrm{~s}$, cooled at $3^{\circ} \mathrm{C} / \mathrm{s}$ to $800^{\circ} \mathrm{C}$, and slow cooled from $800^{\circ} \mathrm{C}$ to RT: (a) LECO oxygen and hydrogen content and (b) ECR derived from LECO and metallography data and hydrogen pickup derived from LECO data. 
Extensive metallographic characterization was performed for the OCL\#11 test sample. The results for the burst midplane are presented in Figure 216 because they lead to insights regarding the post-test strength and ductility corresponding to the maximum ECR. For the LOCA integral test samples, the fourpoint bend test was used to determine ductility. The four-point-bend fixture (see Section 6.1.3) has a 150$\mathrm{mm}$ span between loading points. Within this span, a uniform bending moment is applied to the sample. The span covers the ballooned region, along with some of the region outside the balloon. Figure 216 shows "local" ECR values determined from quantitative metallography. Although for licensing purposes the maximum ECR in the balloon region is defined in terms of the minimum cross-section-averaged wall thickness, there is considerable variation in percent oxidation and embrittlement around this cross section. The burst tips are highly oxidized and brittle. The oxidation level decreases from $>36 \%$ ECR at $0^{\circ}$ (relative to the burst opening), where the wall is thinnest, to $13 \%$ ECR at $180^{\circ}$, where the wall is thickest. In comparing Figure 216 to Figure 209, we concluded that the thin and highly oxidized cladding at the edges around the burst opening was probably lost during handling, cutting, and metallographic mount preparation. Based on Figure 216, if the four-point test is conducted in the traditional way with the flawed region (burst region) under axial tension during the bending test, then the crack will proceed rapidly through that region. Whether or not the sample has any bending ductility will depend on the whether or not the cladding near the back of the burst region (within $150^{\circ}$ to $210^{\circ}$ relative to the burst) will have sufficient ductility to blunt the crack propagating across the cladding section.

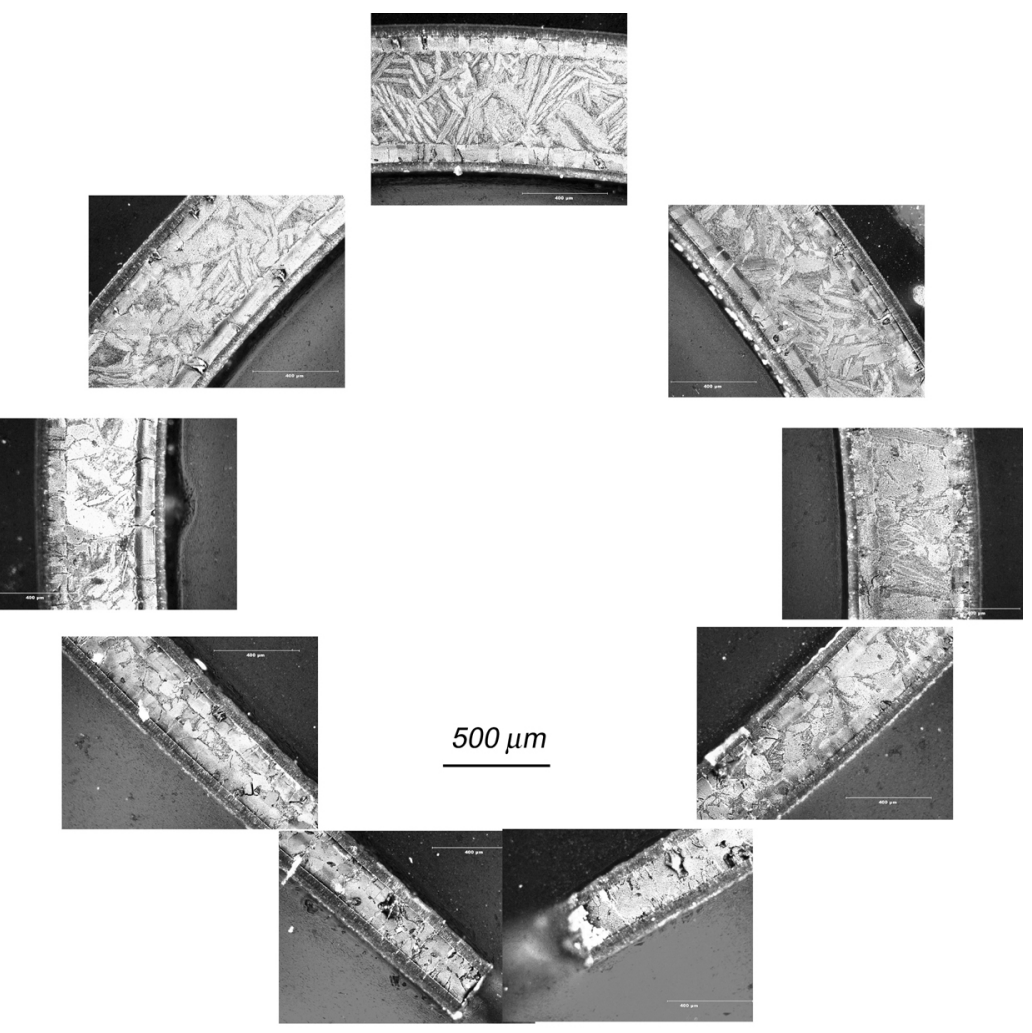

Figure 216. Metallographic images at nine locations around the cross section of the midplane of the burst region of the OCL\#11 test sample $\left(300 \mathrm{~s}\right.$ at $\left.1204^{\circ} \mathrm{C}\right)$. The cross-section-averaged ECR is $18.5 \%$. Locally, the oxidation level varies from $>36 \%$ to $13 \%$. 


\subsubsection{Post-quench ductility for unirradiated LOCA integral samples}

The Instron apparatus used to conduct the ring-compression tests was also used to conduct fourpoint bend tests. A special loading platen and fixture were designed to apply a uniform bending moment over $150 \mathrm{~mm}$ of the sample with the burst-region midplane located approximately at the center of the 150$\mathrm{mm}$ span. The test apparatus was benchmarked by comparing elastic bending results for as-fabricated HBR-type $15 \times 15$ cladding to the textbook solution for bending stiffness (force divided by displacement). The bending tests were conducted in the displacement-controlled mode. Measured displacement corresponds to the displacement at the loading points, $\pm 75 \mathrm{~mm}$ from the center of the as-fabricated cladding or $\pm 75 \mathrm{~mm}$ from the burst midplane location.

Several four-point-bend demonstrations were conducted with post-test samples with the same temperature history as the OCL\#13 test sample listed in Table 75. These samples were weak enough to be bent and broken by hand. With the burst area under bending tension, clean breaks occurred at the burst midplane under the uniform bending moment. With the burst area under compression, an axial crack formed at the burst tip, propagated into the high oxygen-hydrogen region between the burst midplane and the balloon neck, and caused cross-section failure due to bending in this region. Thus, while the burst region is structurally very weak, the thicker cladding region away from the burst is stronger in the unflawed condition, but is brittle enough to fail first in the flawed condition. This behavior illustrates the difficulties that arise from relying on the strength of brittle material. The strength, or resistance to load, decreases dramatically if a flaw is present.

The bending demonstrations were useful for planning purposes. However, four-point-bend tests were needed for quantitative data. Test samples OCL\#22 (1-s hold time at $\left.1204^{\circ} \mathrm{C}\right)$ and OCL\#17 (120-s hold time at $1204^{\circ} \mathrm{C}$ ) were subjected to four-point bending at RT. Figure 217 shows the pre- and post-test OCL\#22 sample, along with the Instron load-displacement curve. Most of the burst midplane cross section fails in a brittle mode, as indicated by the sharp load drop of $>70 \%$ at a bending moment of 21 $\mathrm{N} \cdot \mathrm{m}$. However, the local region $180^{\circ}$ from the burst opening is highly ductile. Within the deflection limits of the apparatus, this back ligament did not fail.

Figure 218 shows the four-point-bend results for the OCL\#17 sample, which was oxidized to a higher level than the OCL\#22 sample. This resulted in a lower maximum bending moment (12 vs. 21 $\mathrm{N} \cdot \mathrm{m}$ ) and brittle failure across the whole cross section. As predicted, by orienting the sample such that the burst region is in bending tension, failure occurs near the burst midplane cross section. Because of the bending orientation, the high-hydrogen cross section with the thicker wall and the lower level of oxidation did not fail even though it was probably more brittle than the weaker burst cross section.

Although additional Instron bending tests were not conducted at higher oxidation levels, samples oxidized to 20\% CP-ECR were subjected to "hand" bending and "hammer" crush impact loading. The trend is clear from these tests: as the oxidation level increases, the bending resistance of the burst region decreases (i.e., failure bending moment decreases), and the rest of the balloon region outside the burst area continues to embrittle as the oxygen and hydrogen content of this region increases.

From an embrittlement point of view, the hydrogen pickup due to oxidation inside the cladding increases so fast that it would be difficult to find an ECR low enough to guarantee ductility in the balloon region, even if ring-compression tests were performed at $135^{\circ} \mathrm{C}$ on rings cut away from the burst region. However, the strength or fracture toughness of the balloon region decreases as the oxidation level increases. The results suggest that some ECR limit would be needed in the balloon region to prevent 


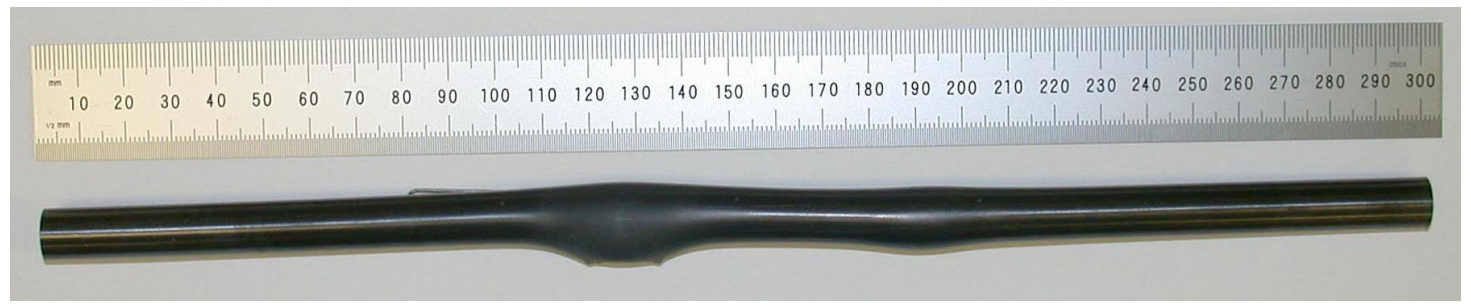

(a)

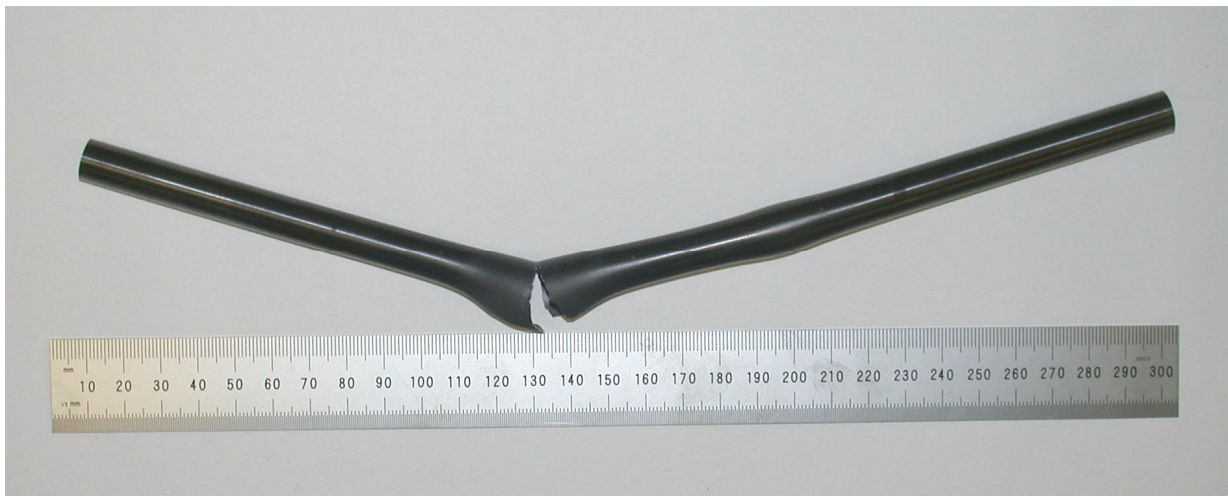

(b)

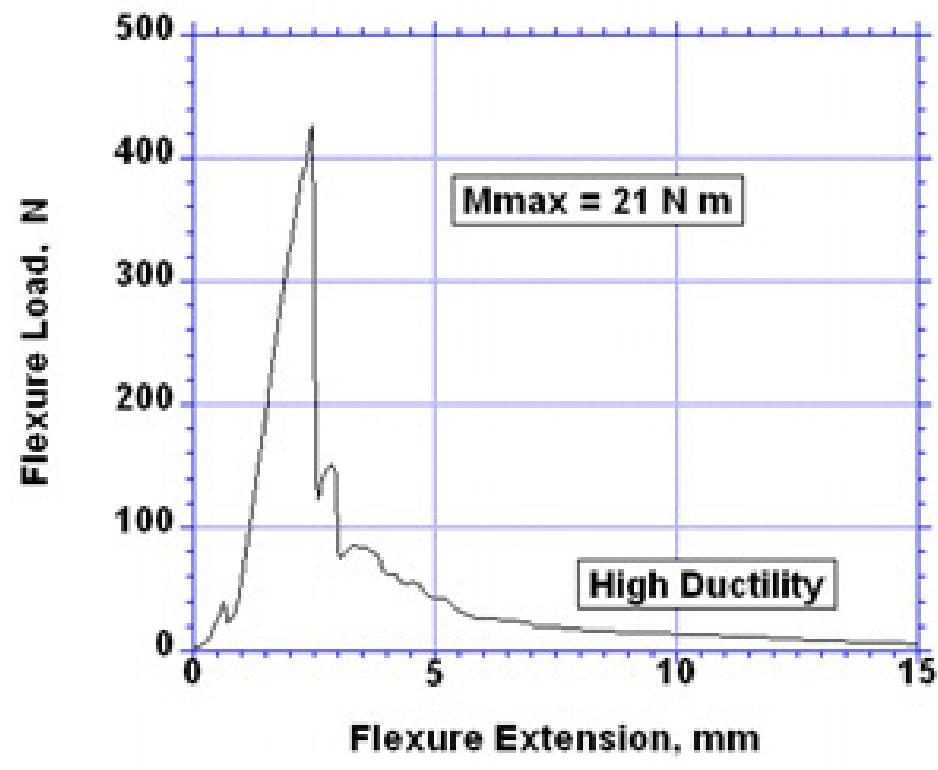

(c)

Figure 217. Bending test results for LOCA integral test sample OCL\#22: (a) pretest appearance with burst area on bottom, (b) post-test appearance with burst area on bottom, and (c) bending load vs. displacement (flexure extension) at the loading points. 


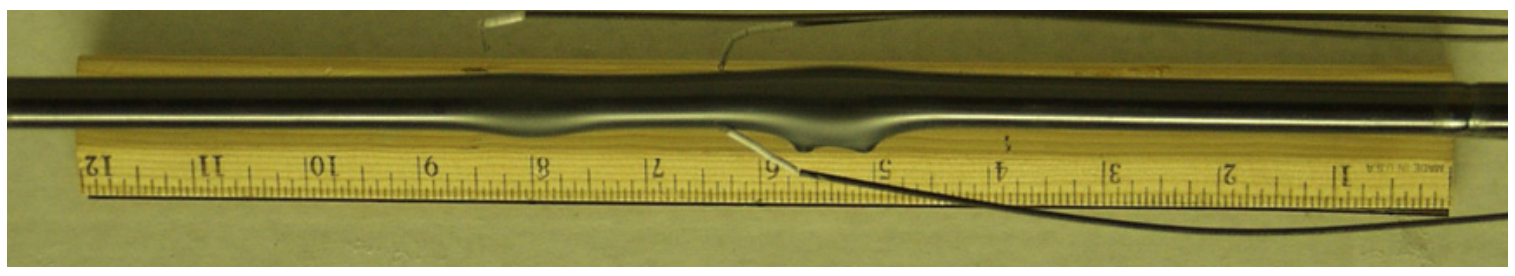

(a)

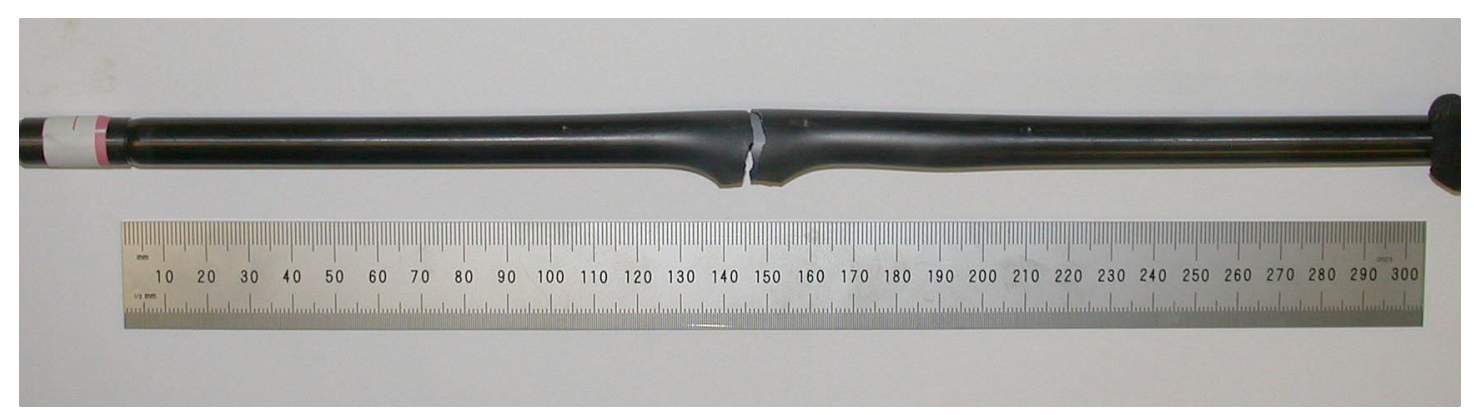

(b)

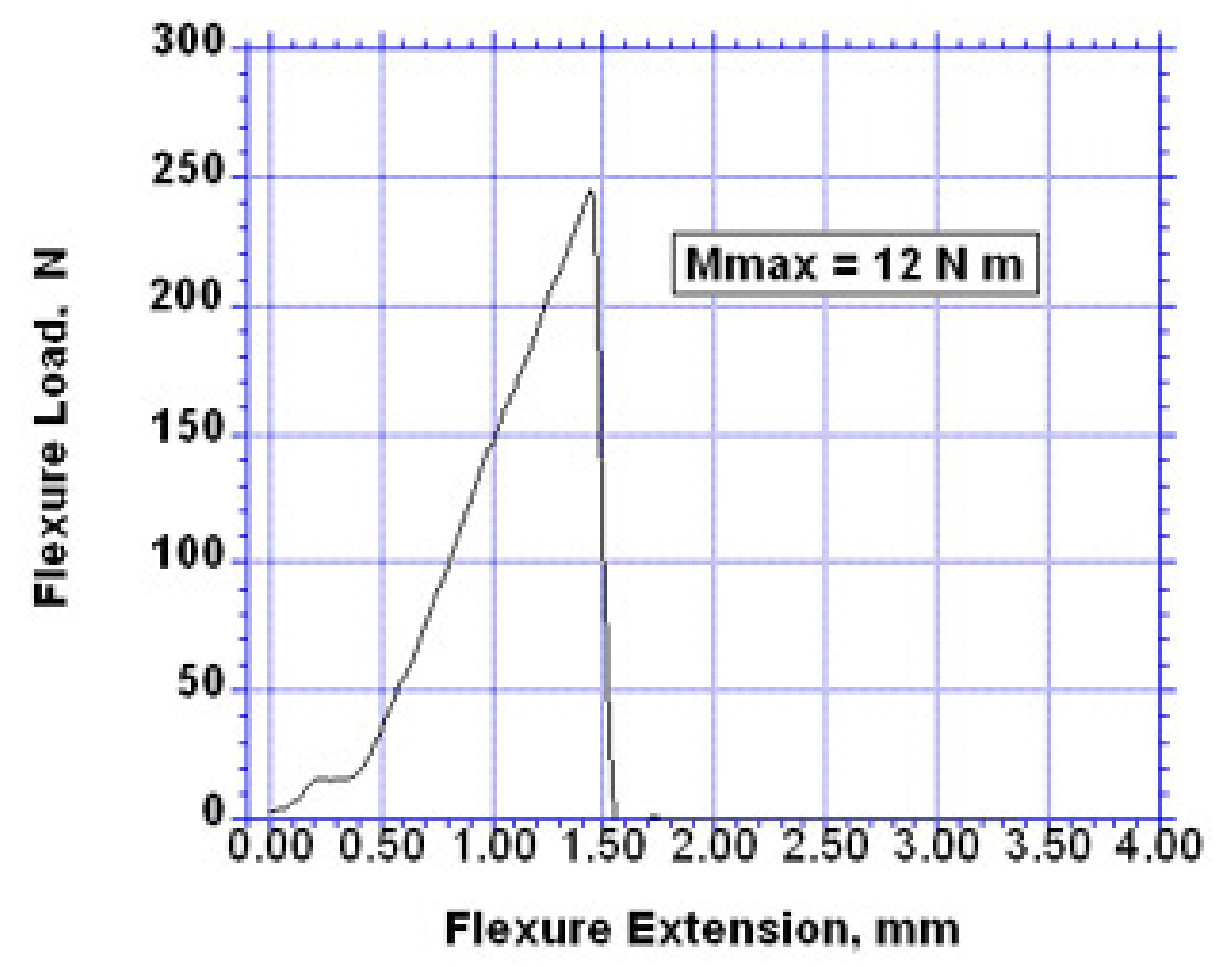

(c)

Figure 218. Bending test results for LOCA integral test sample OCL\#17: (a) pretest appearance with burst area on bottom, (b) post-test appearance with burst area on bottom, and (c) bending load vs. displacement (flexure extension) at the loading points. 
cross-wall failures from occurring due to thermal stresses during quench, side loads due to rod-to-rod impact, and dead-weight loading of the cladding. ANL samples oxidized to $15-20 \%$ CP-ECR had enough toughness to resist fragmentation, and they failed with clean cross-section breaks under bending. The current $17 \%$ limit should be sufficient to guarantee the toughness needed to resist fragmentation.

\subsection{High-burnup Limerick BWR 9×9 Zircaloy-2 oxidized at $1204^{\circ} \mathrm{C}$}

Based on characterization of as-irradiated, high-burnup Limerick cladding (rod F9) at the fuel midplane and at $0.7 \mathrm{~m}$ above the midplane, the corrosion layer thickness $(\approx 10 \mu \mathrm{m})$, the hydrogen content ( $\approx 70 \mathrm{wppm}$ ), and the fuel morphology were observed to be relatively constant for these axial locations. These values were assumed for the as-irradiated Limerick sections used for LOCA integral tests. Figures 219 and 220 show the locations of the ICL\#1-2 samples from rod F9 and the ICL\#3-4 samples from rod J4, respectively. The burnup of these rods was 56-57 GWd/MTU. Additional fuel characterization was performed within the region labeled "Practice Samples" in Figure 219. These samples were used to test the fuel removal device and to verify that removal of $13-25 \mathrm{~mm}$ of fuel from the ends of the LOCA sample by means of a hammer drill did not disturb the remaining fuel column.

In-cell LOCA integral tests were conducted with two thermal couples strapped to the outer surface of the cladding $50 \mathrm{~mm}$ above the sample centerline. One of these was used to control the furnace power to give a hold temperature of $1204^{\circ} \mathrm{C}$ at that location. The other thermocouple, located $180^{\circ}$ from the control thermocouple, was used to measure circumferential variation in cladding temperature. Based on benchmark tests (e.g., OCL\#14) with unirradiated Zry-2, the difference in output between a strapped and a welded thermocouple (TC) at the same axial elevation is $\approx 10^{\circ} \mathrm{C}$. Some of this difference may be due to circumferential temperature variation as the two TCs were not at the same circumferential location. Within the expected axial and circumferential variations in high-burnup cladding temperature during and following ballooning and burst, the difference between strapped and welded TC readings is not considered significant.

\subsubsection{Ballooning and burst of high-burnup samples}

Table 76 summarizes the results of the four in-cell tests with high-burnup fueled Limerick cladding (ICL series), along with companion out-of-cell tests OCL\#5 and OCL\#11. Both ICL\#1 and OCL\#5 were ramp-to-burst tests in argon. The burst temperatures, pressures, and maximum diametral strains are remarkably close for these two tests. In terms of these parameters, high-burnup operation had little effect on cladding burst conditions and strains. Hydrogen pickup during normal reactor operation would be expected to affect both the burst conditions and the burst strain. However, high-burnup Limerick cladding had low hydrogen content resulting from its thin corrosion layer.

The primary differences observed between the high-burnup cladding and the unirradiated cladding was in the pre-burst bending (less for high burnup), the axial extent of the balloon region (less for high burnup), and the shape of the burst region (oval for high burnup). Figure 221 shows a comparison of the ballooned-and-burst regions for the ramp-to-burst samples ICL\#1 and OCL\#5. Figure 222 shows a comparison in burst openings between the ICL\#2 and OCL\#11 test samples. The profiles of diametral strain for these companion tests are compared in Figures 223-224.

In Figure 225, the four in-cell test samples are shown. As expected, the partially quenched sample (ICL\#3) and the fully quenched sample (ICL\#4) have wider burst openings due to loss of thin, brittle cladding near the edges of the burst opening. 


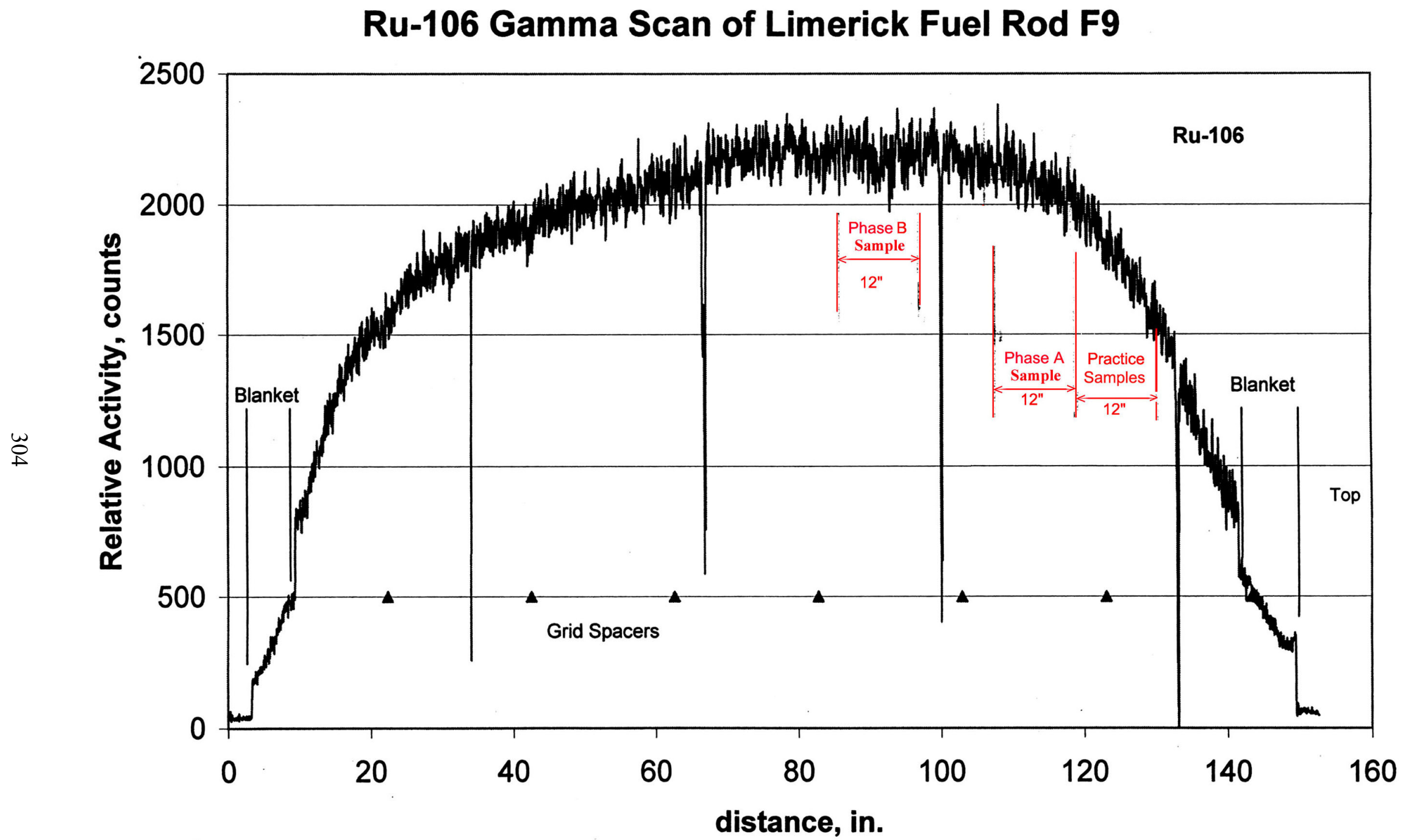

Figure 219. Gamma scan profile for high-burnup Limerick rod F9 showing locations of LOCA integral samples ICL\#1 (labeled Phase A) and ICL\#2 (labeled Phase B). Fuel and cladding characterization were performed at the fuel midplane, at $0.7 \mathrm{~m}$ above the midplane, and at $\approx 1.1 \mathrm{~m}$ above fuel midplane. 


\section{Gross Gamma Scan of Limerick Fuel Rod J4}

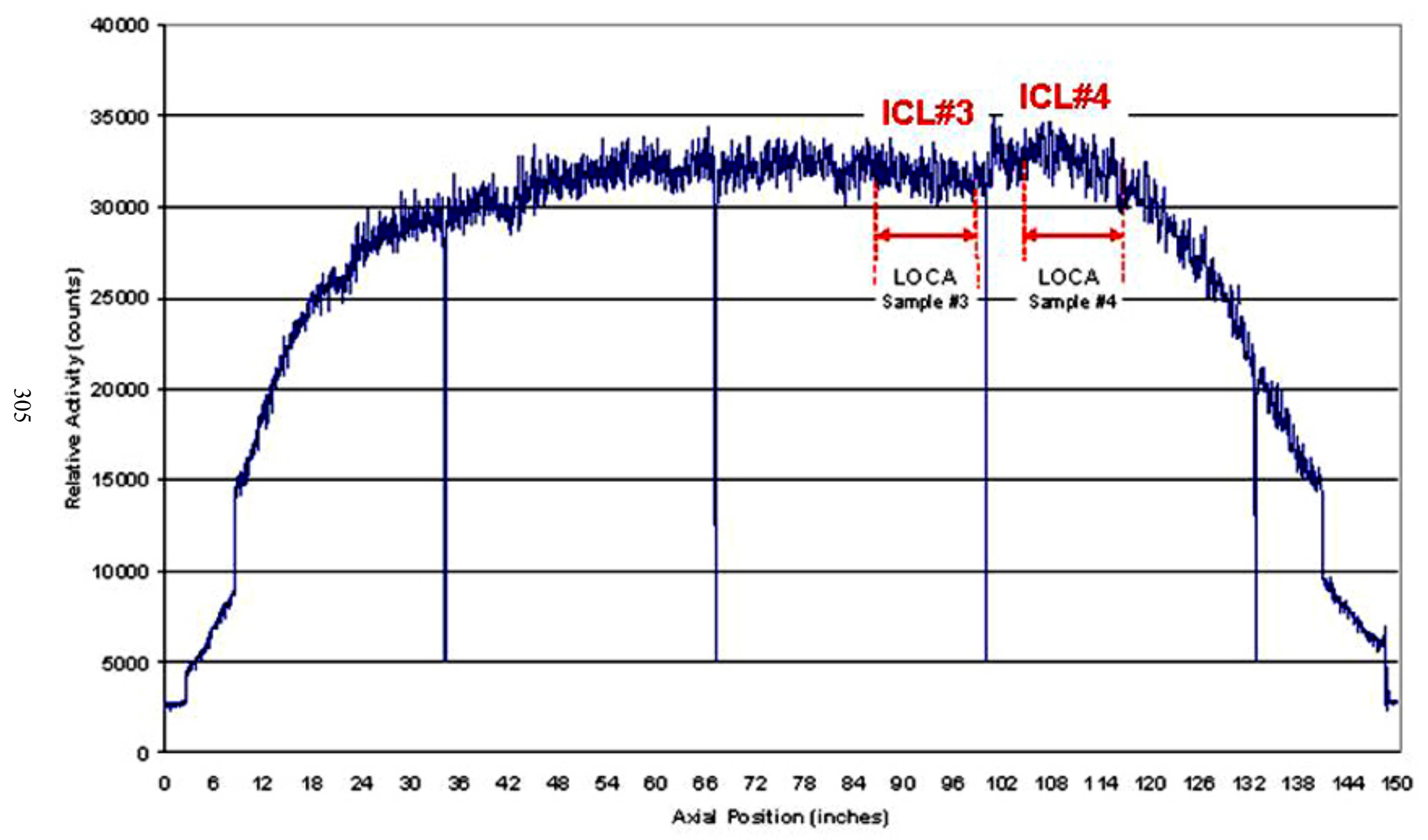

Figure 220. Gamma scan profile for high-burnup Limerick rod J4 showing axial locations of LOCA integral samples ICL\#3 and ICL\#4. 
Table 76. Summary of In-cell LOCA Integral Tests (ICL) with High-burnup Fueled Cladding Specimens from Limerick BWR. Also shown are the results of companion out-of-cell tests OCL\#5 and OCL\#11 with non-irradiated Zry-2 cladding.

\begin{tabular}{|c|c|c|c|c|c|c|}
\hline Parameter & ICL\#1 & OCL\#5 & ICL\#2 & OCL\#11 & ICL\#3 & ICL\#4 \\
\hline Environment & Argon & Argon & Steam & Steam & Steam & Steam \\
\hline Hold Temperature, ${ }^{\circ} \mathrm{C}$ & --- & --- & 1204 & 1204 & 1204 & 1204 \\
\hline Hold Time, s & 0 & 0 & 300 & 300 & 300 & 300 \\
\hline $\begin{array}{l}\text { Quench (Q) at } 800^{\circ} \mathrm{C} \\
\text { or Slow Cooled (SC) }\end{array}$ & $\mathrm{SC}$ & $\mathrm{SC}$ & $\mathrm{SC}$ & $\mathrm{SC}$ & $\begin{array}{l}\mathrm{Q}-800^{\circ} \mathrm{C} \\
\text { to } 460^{\circ} \mathrm{C}\end{array}$ & $\mathrm{Q}-800^{\circ} \mathrm{C}$ \\
\hline Max. Pressure, MPa & 8.96 & 8.96 & 8.87 & 8.61 & 9.00 & 8.86 \\
\hline Burst Pressure, MPa & 8.61 & 8.28 & 8.01 & 7.93 & 8.60 & 8.00 \\
\hline Burst Temperature, ${ }^{\circ} \mathrm{C}$ & $\approx 755$ & 733 & $\approx 750$ & 753 & $\approx 730$ & $\approx 790$ \\
\hline Burst Shape & Oval & Dog Bone & Oval & Dog Bone & Oval & Oval \\
\hline Burst Length, mm & 13 & 13 & 14 & 11 & 11 & 15 \\
\hline Max. Burst Width, mm & 3 & 2.5 & 3.5 & 1 & 4.6 & 5.1 \\
\hline Length of Balloon, mm & $\approx 70$ & 100 & $\approx 90$ & $\approx 140$ & $\approx 100$ & $\approx 80$ \\
\hline$\left(\Delta \mathrm{D} / \mathrm{D}_{\mathrm{o}}\right) \max , \%$ & $38 \pm 9$ & $44 \pm 10$ & $39 \pm 10$ & $43 \pm 10$ & $43 \pm 9$ & $36 \pm 9$ \\
\hline Max. Calculated ECR, \% & 0 & 0 & $\approx 20$ & $\approx 21$ & $\approx 21$ & $\approx 20$ \\
\hline
\end{tabular}




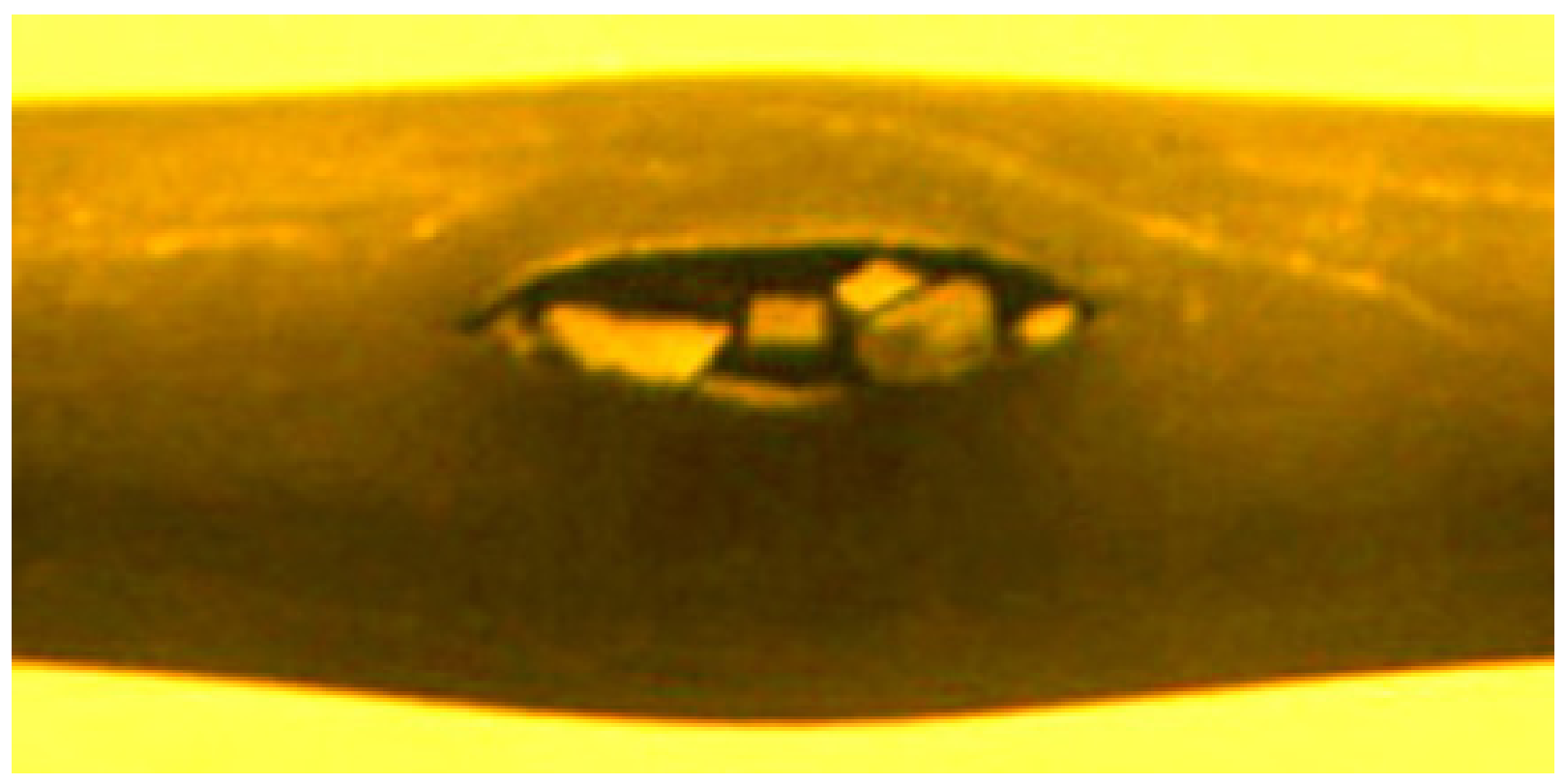

(a) ICL\#1

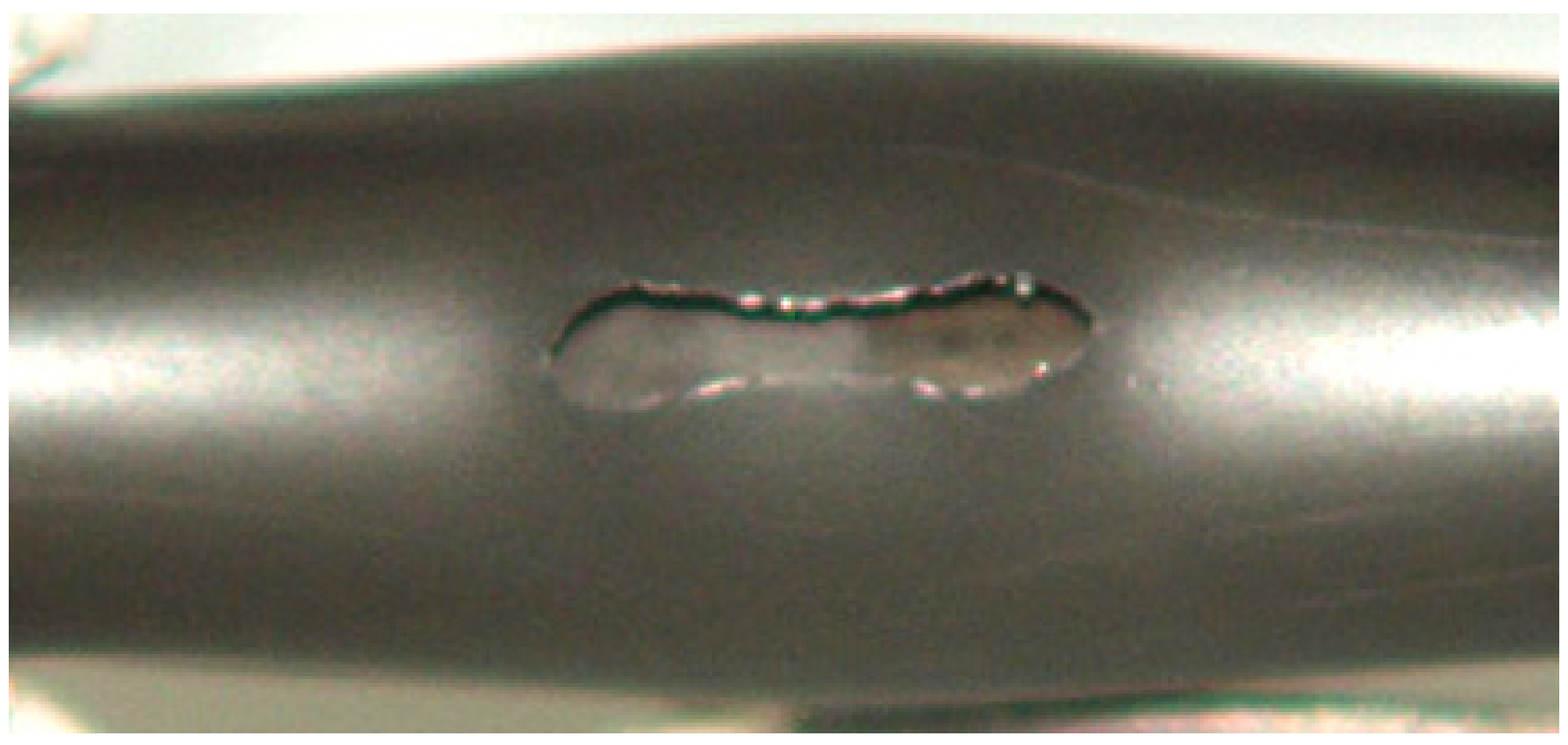

(b) OCL\#5

Figure 221. Comparison of burst openings for (a) in-cell LOCA integral test ICL\#1 specimen from highburnup Limerick rod F9 and (b) out-of-cell companion test OCL\#5 specimen from unirradiated Zry-2 cladding. Burst lengths are both $\approx 13$-mm long for these ramp-to-burst test samples. 


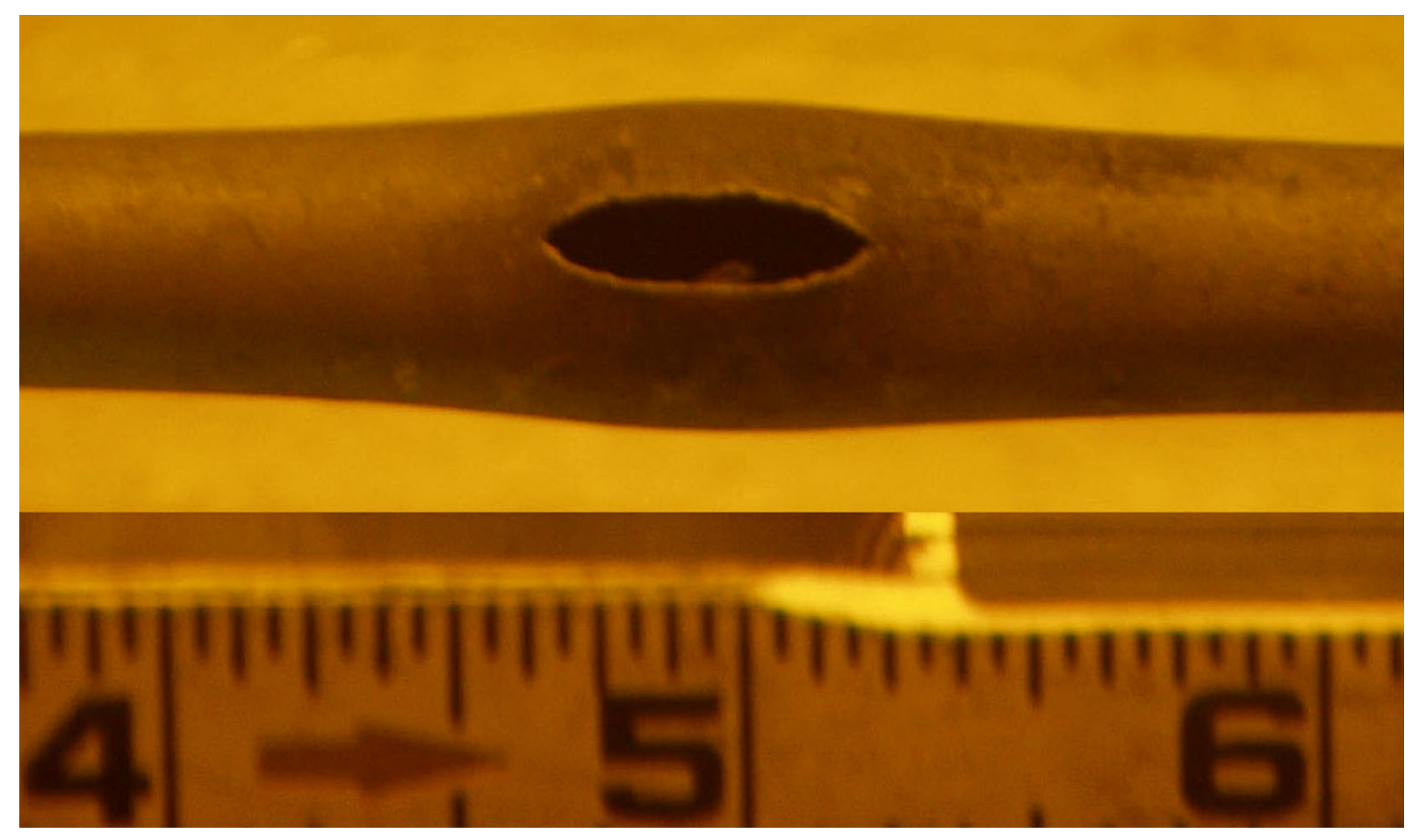

(a) ICL\#2

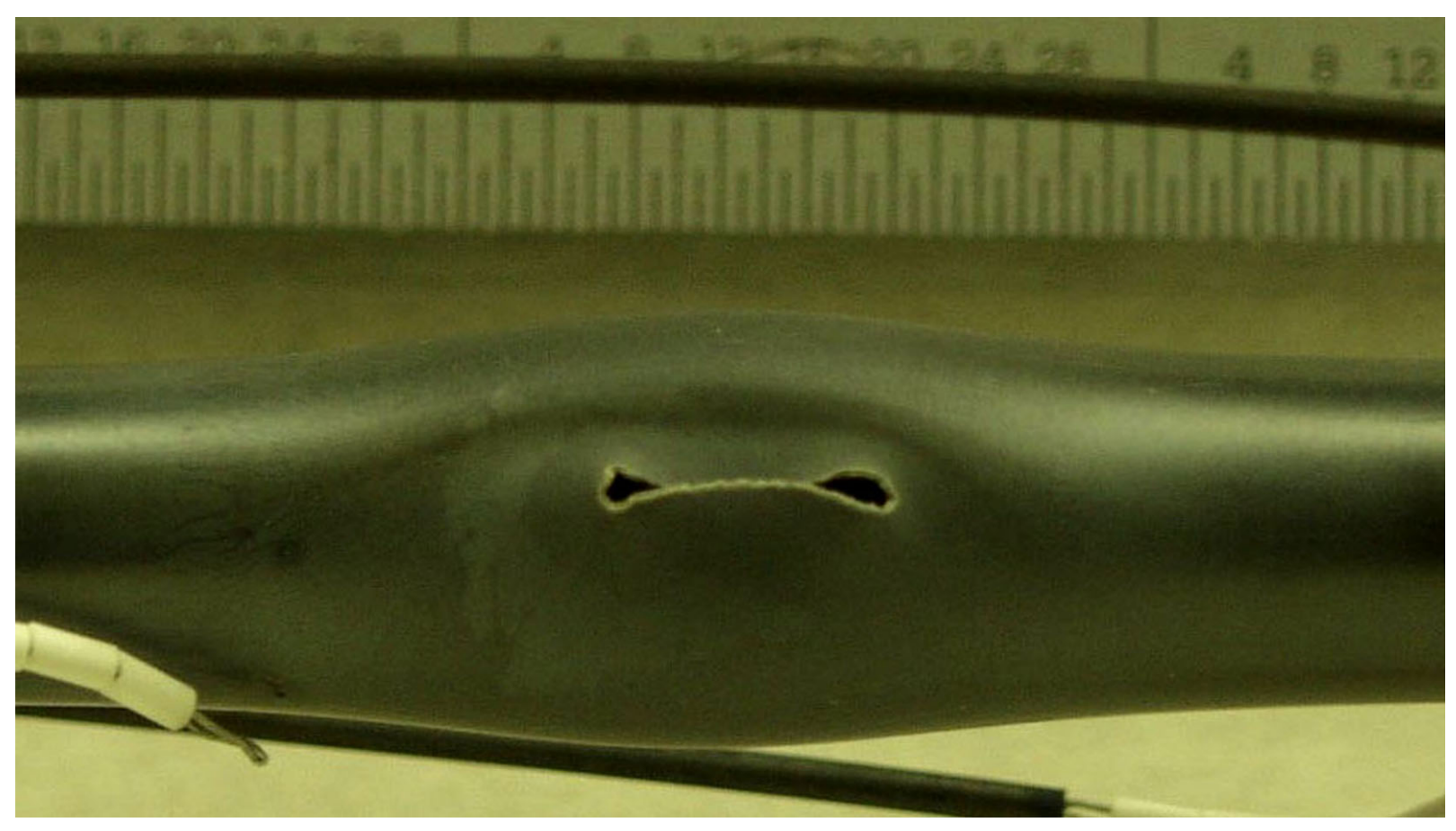

(b) OCL\#11

Figure 222. Comparison of burst openings for (a) high-burnup Limerick ICL\#2 specimen and (b) unirradiated OCL\#11 Zry-2 specimen after 300 -s exposure to steam at $1204^{\circ} \mathrm{C}$, followed by slow cooling to RT. 


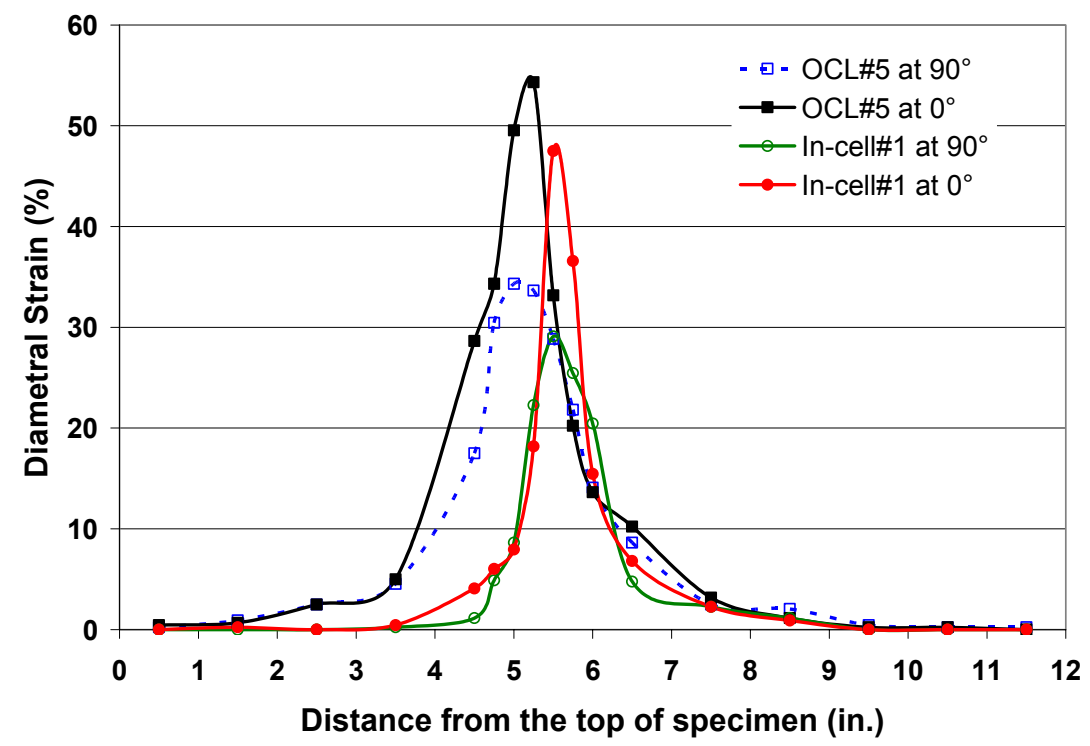

Figure 223. Outer-diameter strain for in-cell test ICL\#1 sample (high-burnup Limerick fueled Zry-2) and companion out-of-cell test OCL\#5 sample (unirradiated Zry-2 filled with zirconia pellets). Both tests were ramp-to-burst tests in argon, followed by slow cooling to RT.

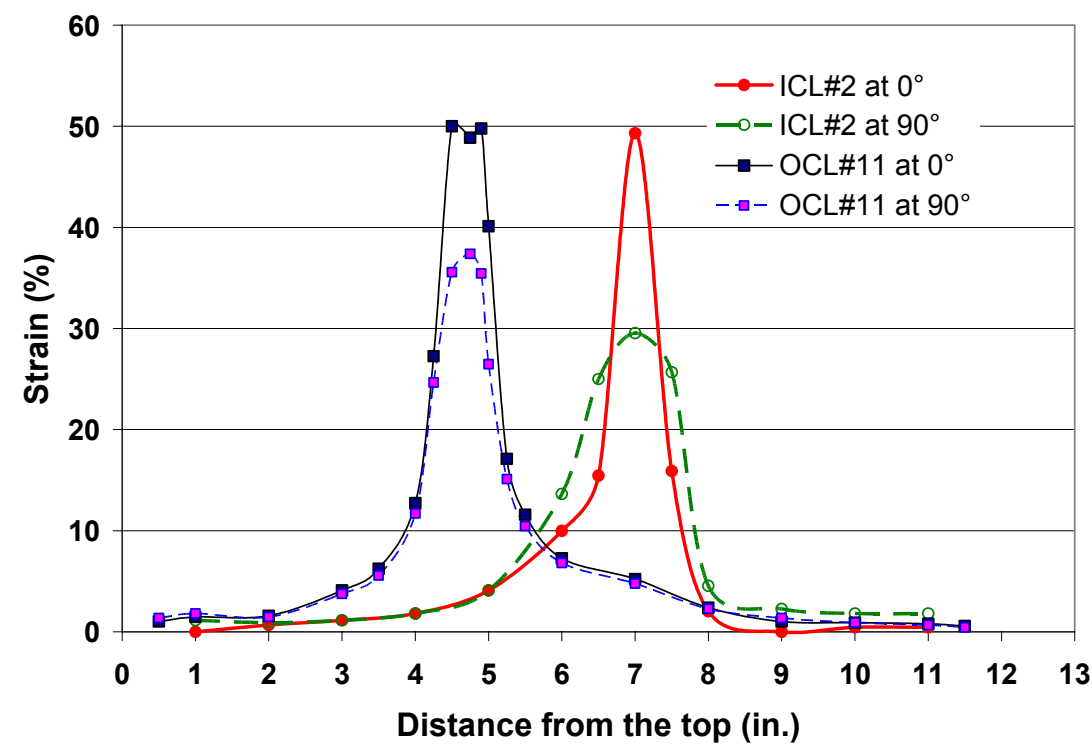

Figure 224. Outer-diameter strain for in-cell test ICL\#2 sample (high-burnup Limerick fueled Zry-2) and companion out-of-cell test OCL\#11 sample (unirradiated Zry-2 filled with zirconia pellets). Both samples were ramped to $1204^{\circ} \mathrm{C}$ in steam, held at $1204^{\circ} \mathrm{C}$ for $300 \mathrm{~s}$, and slow cooled to RT. 


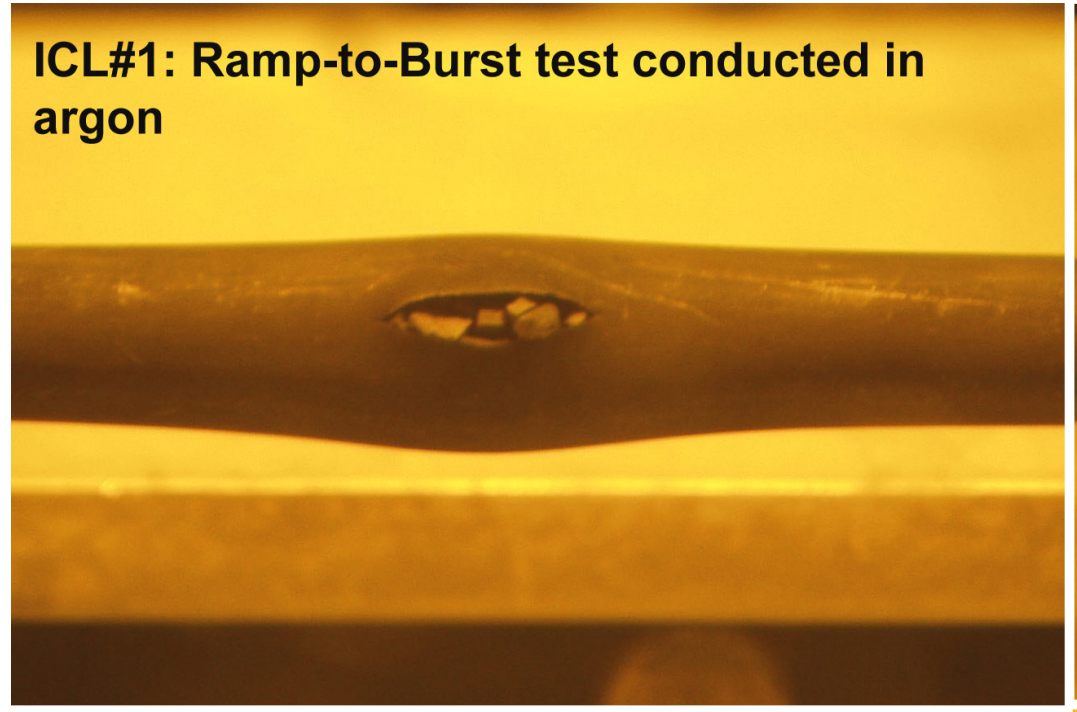

ICL\#2: LOCA sequence with 5-min. oxidation at $1204^{\circ} \mathrm{C}$ and slow-furnace cooling

ICL\#3: $5 \mathrm{~min}$-oxidation at $1204^{\circ} \mathrm{C}$ followed by quence at $800^{\circ} \mathrm{C}$ (quartz tube failed at $480^{\circ} \mathrm{C}$ )

ICL\#4: Full LOCA sequence (5-min. oxidation

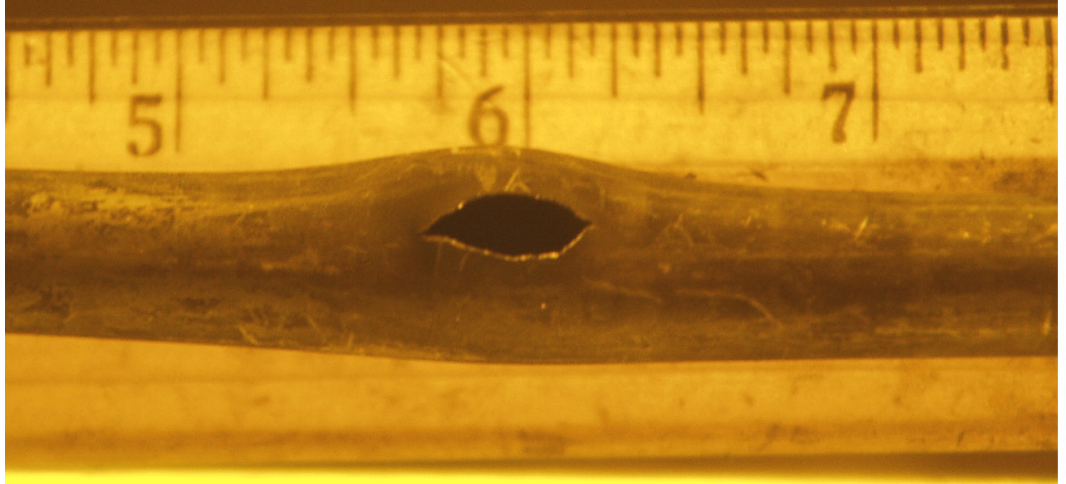
at $1204^{\circ} \mathrm{C}$ ) with quench at $800^{\circ} \mathrm{C}$

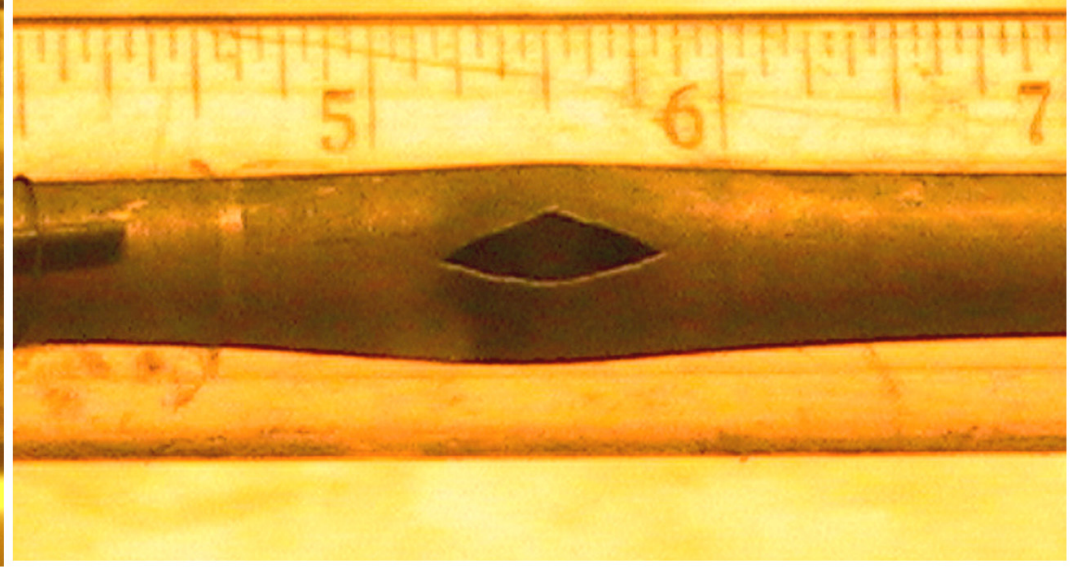

Figure 225. Comparison of ballooned-and-burst regions for four in-cell LOCA integral test samples. 


\subsubsection{Oxidation and hydrogen pickup due to secondary hydriding for high-burnup samples}

For ICL test samples \#2 and 3, extensive metallographic characterization and LECO measurements were performed within $\pm 50 \mathrm{~mm}$ of the burst midplane to determine the degree of steam oxidation (twosided vs. one-sided and OD vs. ID oxide-layer thickness within the balloon region), the axial profile of oxygen pickup determined by means of LECO and metallography, and the axial profile of hydrogen pickup. Low-magnification images were obtained for the fuel morphology within $\pm 50 \mathrm{~mm}$ and outside the balloon region (see Section 6.3).

For the ICL\#2 sample, whose burst opening had to be epoxied to prevent fuel falling out during movement of high-dose-rate samples (during for shield-window maintenance), LECO hydrogen and oxygen samples were limited to those away from the epoxied region (away from the burst opening and most of the balloon region). The sectioning diagram for ICL\#2 metallography is shown in Figure 226, along with a compressed view of the diametral strain profile to show the location of the burst midplane and the axial extent of the balloon region. LECO hydrogen and oxygen measurements were made at locations $\mathrm{H}_{1}$ and $\mathrm{H}_{2}$, both of which contained no epoxy.

The ICL\#3-sample sectioning diagram, along with the diametral strain profile, is shown in Figure 227. The sample fractured at three locations during handling: bending failure at $\mathrm{A}$, impact failure at $\mathrm{C}$, and failure (clean breaks) due to removal of tape from the burst opening region at $\mathrm{B}$. These locations were initially designated for metallography only. Following the handling failures, however, two of the surfaces were imaged by SEM for fractographic analysis. Not shown in the figure are the locations for LECO oxygen and hydrogen measurements.

Results from LECO hydrogen and oxygen measurements, for ECR determined from oxygen pickup from LECO and metallographic data, and for hydrogen pickup are emphasized because hydrogen and oxygen pickup have a significant influence on ductility. Figure 228 shows the LECO results for oxygen and hydrogen concentrations for the ICL\#2 and ICL\#3 test samples with axial locations referenced to the burst midplane. Equations 11-13 were used to convert the LECO data to oxygen pickup, ECR, and hydrogen pickup. The pre-test hydrogen and oxygen contents for high-burnup Limerick cladding (0.7wt.\% oxygen and 70-wppm hydrogen) were used in these calculations. The results are shown in Figure 229. The ECR values determined from LECO and metallographic data are reasonably close. Based on a reasonable extrapolation of these two off-center locations, the maximum ECR for the ICL\#3 sample is $\approx 18 \%$. This value is in good agreement with the $20 \%$ CP-ECR calculated for two-sided steam oxidation. The hydrogen pickup (maximum $>3000 \mathrm{wppm}$ ) is as high as the values measured for unirradiated cladding. The hydrogen peaks are closer to the center of the burst region, consistent with the shorter axial extent of ballooning for the high-burnup cladding. However, the hydrogen pickup near the burst midplane is significantly larger for high-burnup cladding than for unirradiated cladding. The combination of high-hydrogen and high-oxygen pickup in most of the balloon region $( \pm 40 \mathrm{~mm})$ suggests that the cladding should be quite brittle within this region. Recall that the unirradiated LOCA test samples had very low hydrogen pickup in the burst region. 


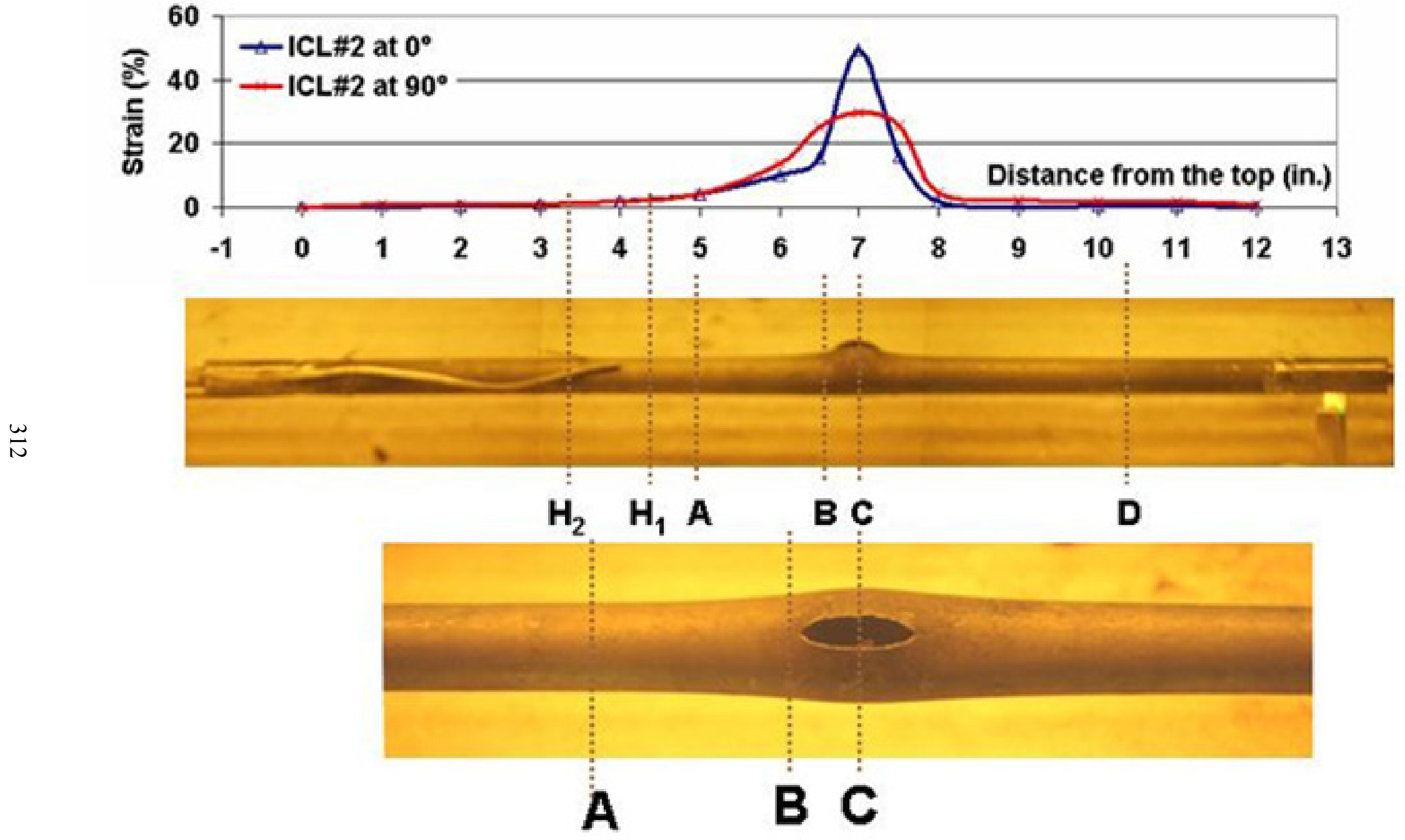

Figure 226. Sectioning diagram for ICL\#2 (300 s at $1204^{\circ} \mathrm{C}$, slow cooling to $\left.\mathrm{RT}\right)$ sample. Locations $\mathrm{A}$, $\mathrm{B}$, and $\mathrm{C}$ are metallography locations. $\mathrm{H}_{1}$ and $\mathrm{H}_{2}$ are locations for LECO hydrogen and oxygen measurements. 

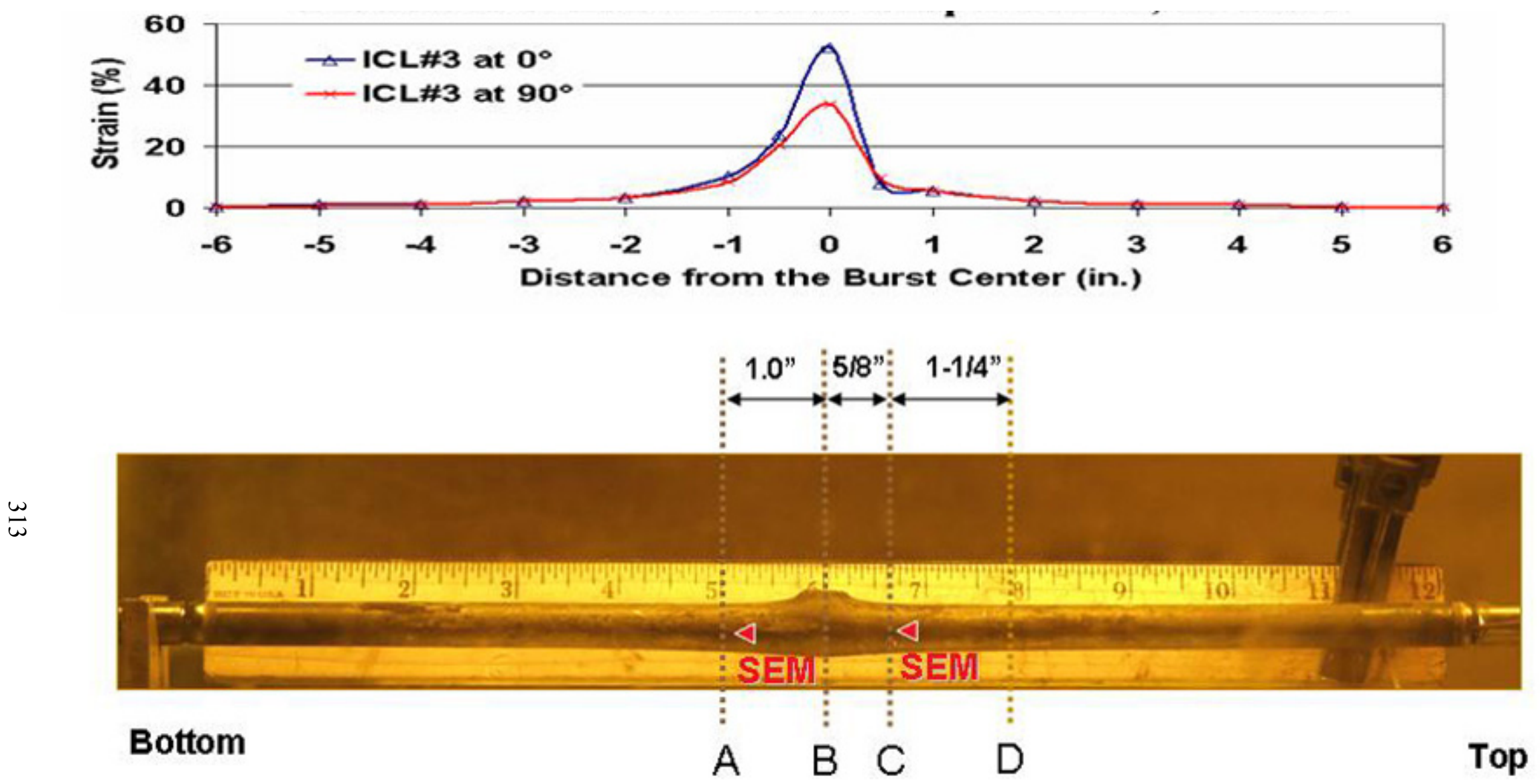

Figure 227. Sectioning diagram for ICL\#3 $\left(300 \mathrm{~s}\right.$ at $1204^{\circ} \mathrm{C}$, quench from $800^{\circ} \mathrm{C}$ to $460^{\circ} \mathrm{C}$, slow cooling to RT) sample. The sample fractured at locations $A, B$, and $C$ during handling prior to the sectioning at D. LECO hydrogen and oxygen sample locations are not shown. 


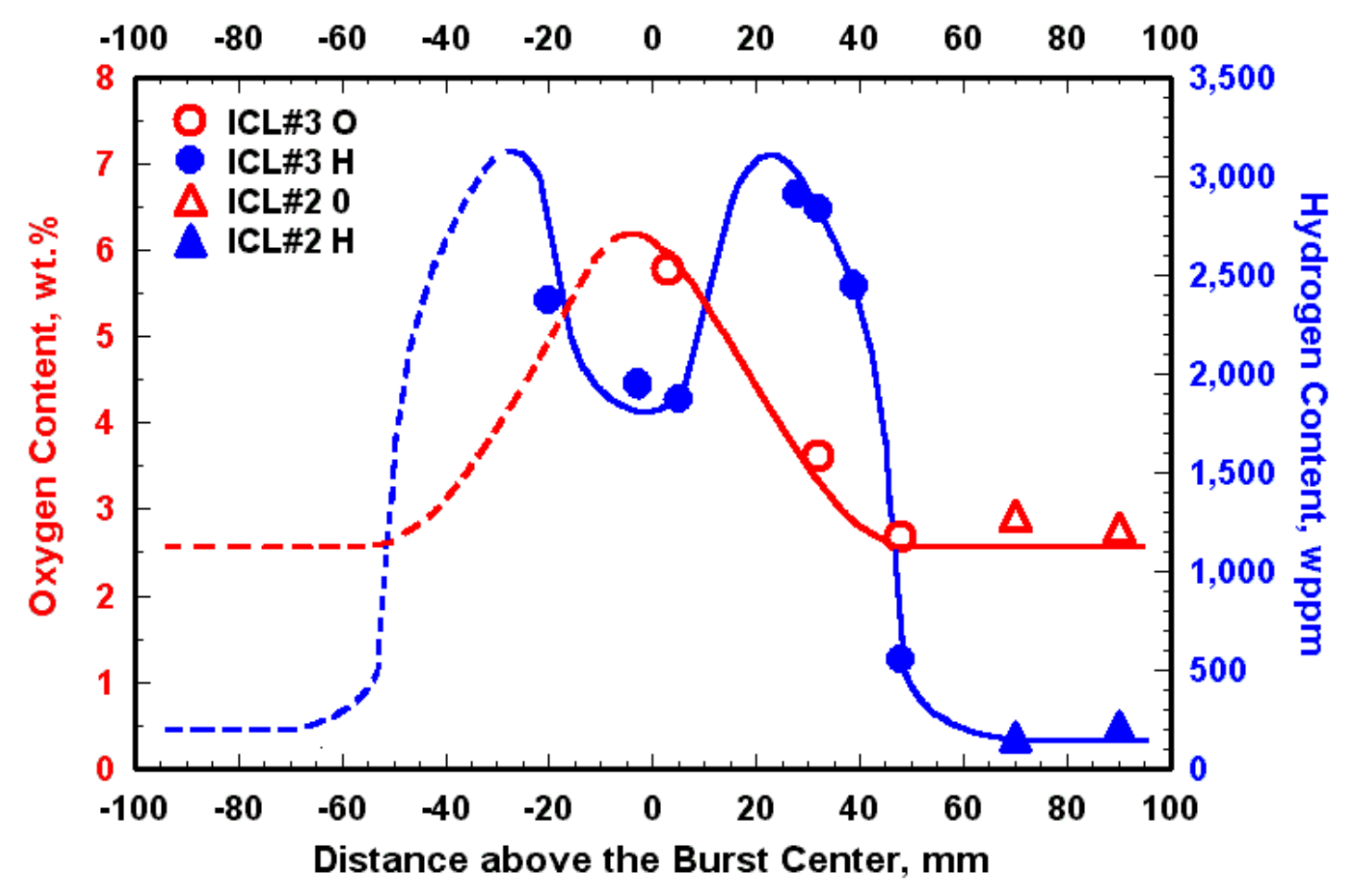

Figure 228. LECO oxygen-and hydrogen content for ICL\#2 and ICL\#3 test samples, both oxidized for 300 $s$ at $1204^{\circ} \mathrm{C}$. Concentrations are referenced to the weight of the oxidized samples.

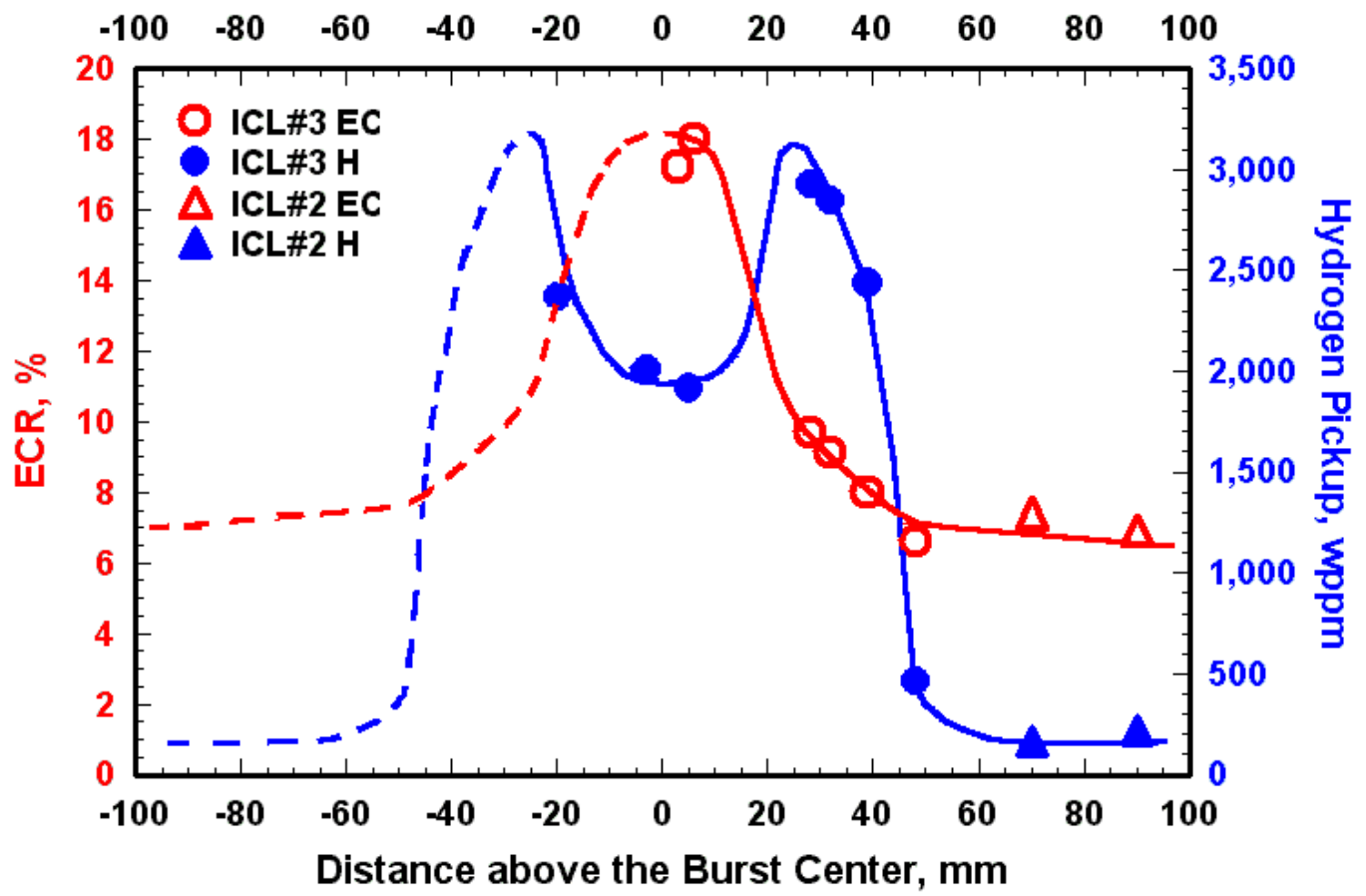

Figure 229. Axial distribution of ECR (based on LECO oxygen and metallographic data) and hydrogen pickup (based on LECO data in Figure 228) for ICL\#2 and ICL\#3 test samples. 


\subsubsection{Post-quench ductility of high-burnup samples}

The in-cell high-burnup LOCA test samples were not subjected to four-point-bend tests. However, based on optical microscopy and SEM imaging, along with hydrogen and oxygen pickup, embrittlement of these samples can be inferred. The SEM fractography was performed at two locations (A and C) of the ICL\#3 test sample that failed during handling. The results for location $\mathrm{C}(\approx 20 \mathrm{~mm}$ above the burst midplane) are shown in Figure 230. The morphology of the fracture surface suggests a brittle failure mode. Similar results were obtained at location A. Given the high combinations of ECR and hydrogen pickup at these locations $(\approx 25 \mathrm{~mm}$ below the burst midplane for $\mathrm{A})$, these locations would very likely have failed in a brittle mode even if they were tested at $135^{\circ} \mathrm{C}$.

It is encouraging that all four LOCA integral samples remained intact during and following quench. However, thermal stresses due to quench are relatively low. The samples were fixed at the top and free to expand and contract in the axial direction. If contraction during quench were partially constrained and/or if impact loads due to rod-to-rod contact during quench vibration were high enough to cause failure, then it is predicted that brittle failures would occur. It is also predicted that, based on ANL bend test results and JAEA axial constraint tests, such loading would result in a clean break across the cladding wall, rather than fragmentation. Except for the highly oxidized cladding at the edges of the burst region, the brittle cladding within the balloon region does not appear to be susceptible to fragmentation for maximum CP-ECR values $<20 \%$.

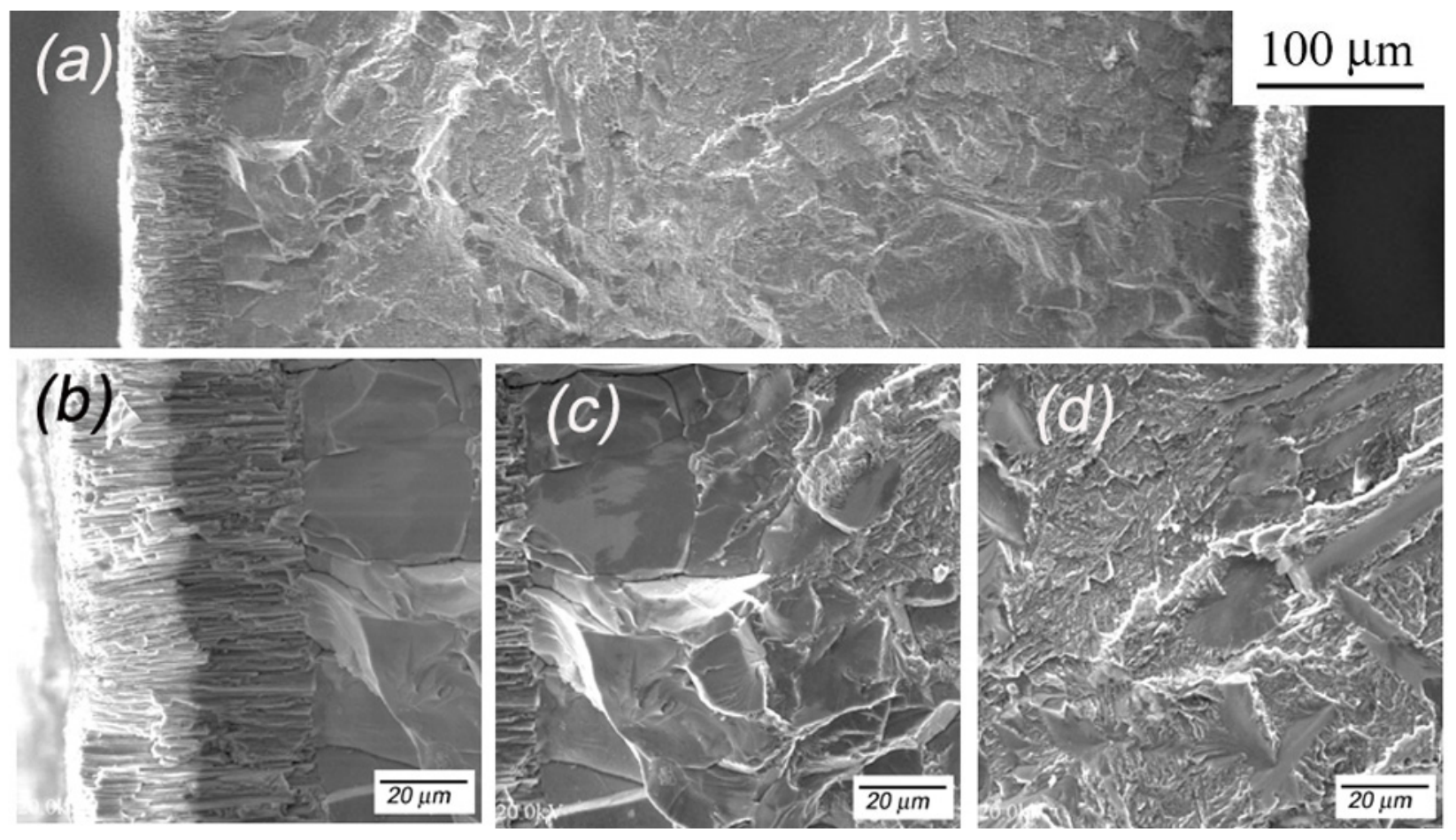

Figure 230. SEM fractography for ICL\#3 samples at axial location C in Figure 179 ( $20 \mathrm{~mm}$ above the burst midplane): (a) cladding cross section, (b) oxide layer, (c) oxygen-stabilized alpha layer, and (d) prior-beta layer. Interpolating from the results in Figure 229 , the estimated hydrogen pickup is $\approx 3000$ wppm, and the estimated measured ECR is $\approx 10 \%$ at this location. 


\subsection{Cladding inner-surface oxygen pickup from fuel-cladding bond and fuel}

As shown in Figure 128, high-burnup Limerick cladding has a fuel-cladding bond thickness of $10 \pm 5 \mu \mathrm{m}$. For this BWR fuel, the bond thickness is not uniform around the inner surface of the cladding. For the one-sided oxidation tests with defueled Limerick cladding, Figure $128 \mathrm{~b}$ shows that the bond layer remains after defueling in nitric acid. The minimum hold time at $1200^{\circ} \mathrm{C}$ for the Limerick one-side oxidized samples was $300 \mathrm{~s}$. Figure 231 shows one of eight micrographs taken at the midplane of the defueled, high-burnup Limerick sample oxidized for $300 \mathrm{~s}$ at $1200^{\circ} \mathrm{C}$. The post-test sample shows no indication of an inner-surface bond-oxide layer or of the oxygen-stabilized alpha layer that would have formed during reduction of the bond layer. Based on the estimate in Section 5 that such a bond layer would be reduced after $\approx 100 \mathrm{~s}$ during the ramp from $300^{\circ} \mathrm{C}$ to $1200 \mathrm{C}$, oxygen from the alpha layer would have continued to diffuse into the beta layer until its oxygen content were too low to stabilize the alpha phase at $1200^{\circ} \mathrm{C}$. These observations are not inconsistent with the results of the shorter-time (174-323 s) one-sided oxidation tests with high-burnup Zry-4 samples.

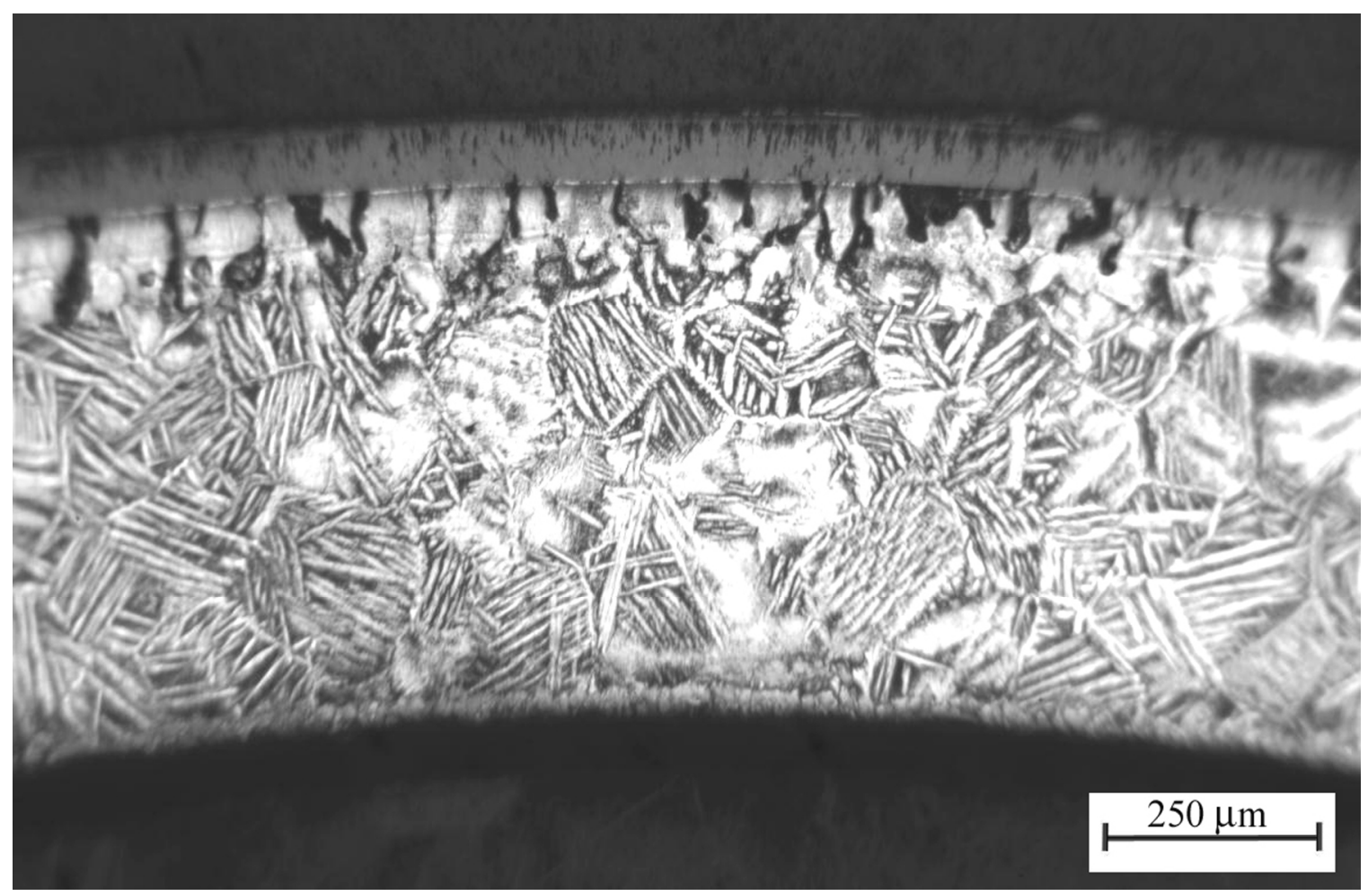

Figure 231. High-burnup Limerick oxidation sample following one-sided oxidation in steam at $1200^{\circ} \mathrm{C}$ for a 300 -s hold time. 
The degree to which the Zircaloy metal will pick up oxygen from the fuel depends on how much fuel remains attached to the bond during the outward expansion of the cladding. The fuel-to-bond strength is greater than the fuel strength; thus, some fuel will remain bonded as the cladding deforms outward. Figure 232 shows one circumferential location at the burst midplane for the ICL\#3 sample where there are chunks of fuel still bonded to the cladding. However, there is ample steam at this location to oxidize the cladding inner surface. The presence of this fuel does not appear to influence the growth of the high-temperature steam-oxide layer; the outer-surface oxide is about as thick as the inner-surface oxide.

The fuel morphology for the ICL\#2 sample at locations $180 \mathrm{~mm}$ below (b) and $50 \mathrm{~mm}$ above (c) the burst midplane is shown in Figure 233 and compared to the fuel morphology of the as-irradiated rod (a). The cladding strain at $180 \mathrm{~mm}$ below the burst is $<2 \%$, while the cladding strain at $50 \mathrm{~mm}$ above is $\approx 5 \%$. Most of the fuel appears to have pulled away from the cladding at $50 \mathrm{~mm}$ above the burst, while there is little change in fuel morphology at $180 \mathrm{~mm}$ below the burst region, which is outside the uniformly heated zone.
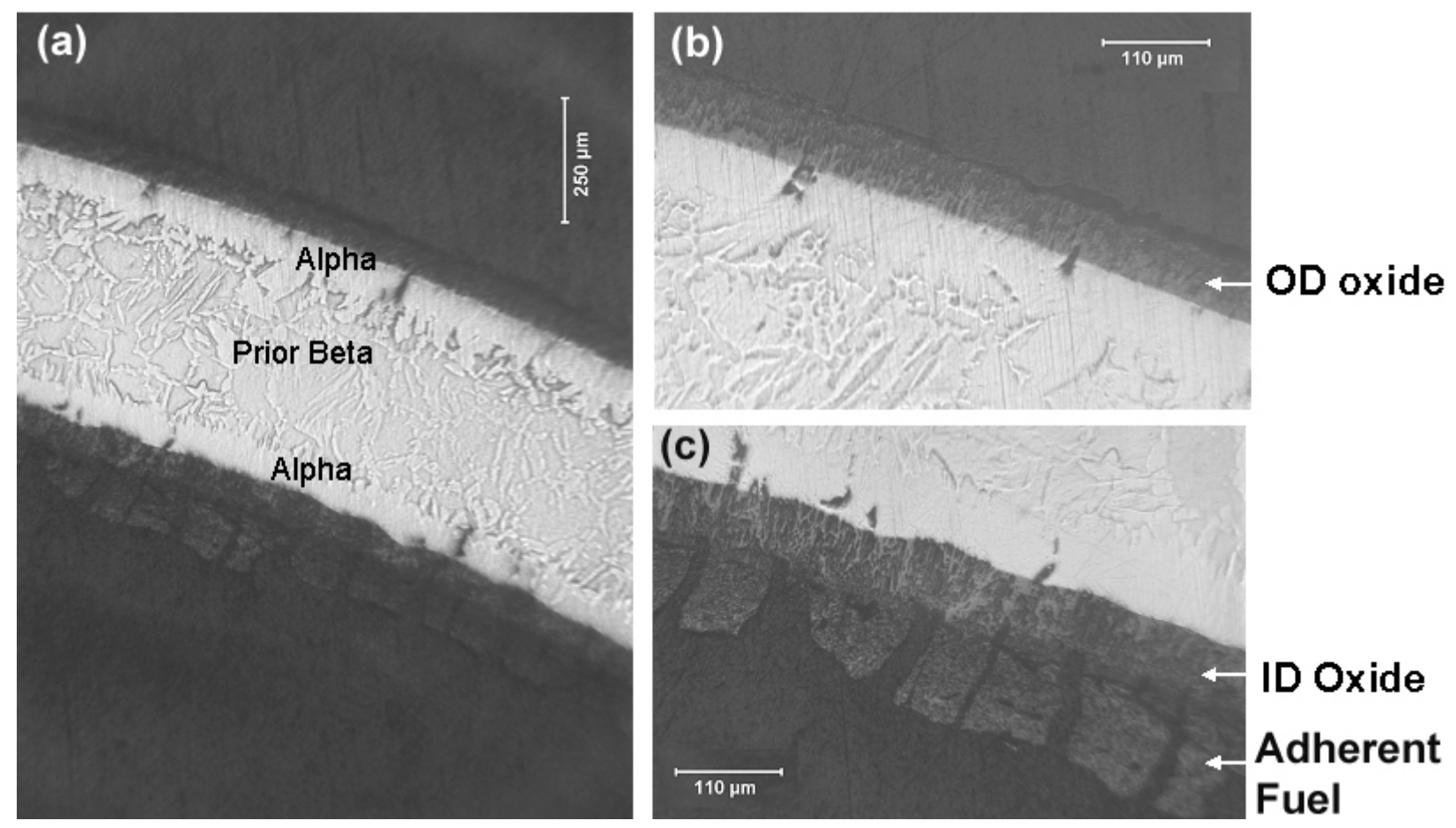

Figure 232. Metallographic results for a circumferential location at the burst midplane of the ICL\#3 sample, oxidized for $300 \mathrm{~s}$ at $1204^{\circ} \mathrm{C}$. Fuel particles adherent to the cladding inner surface are shown in (c). 


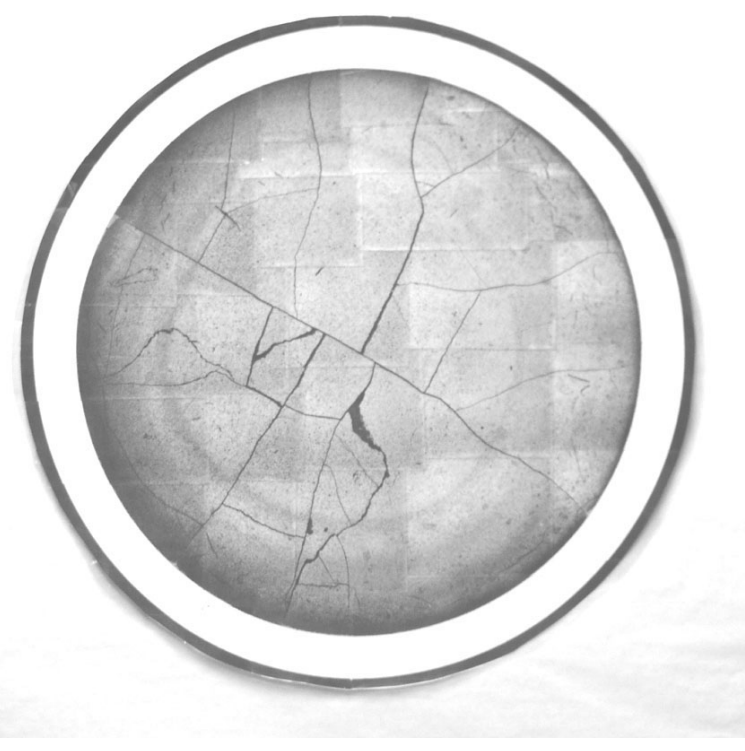

(a)

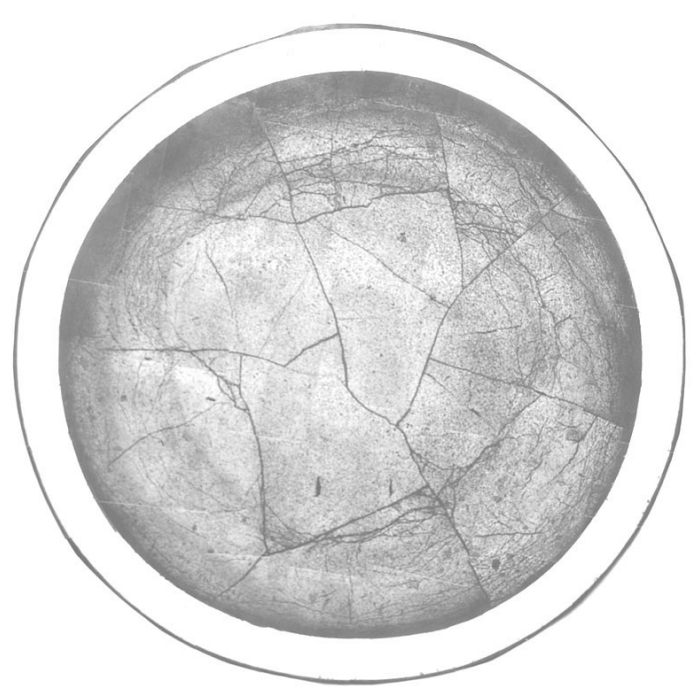

(b)

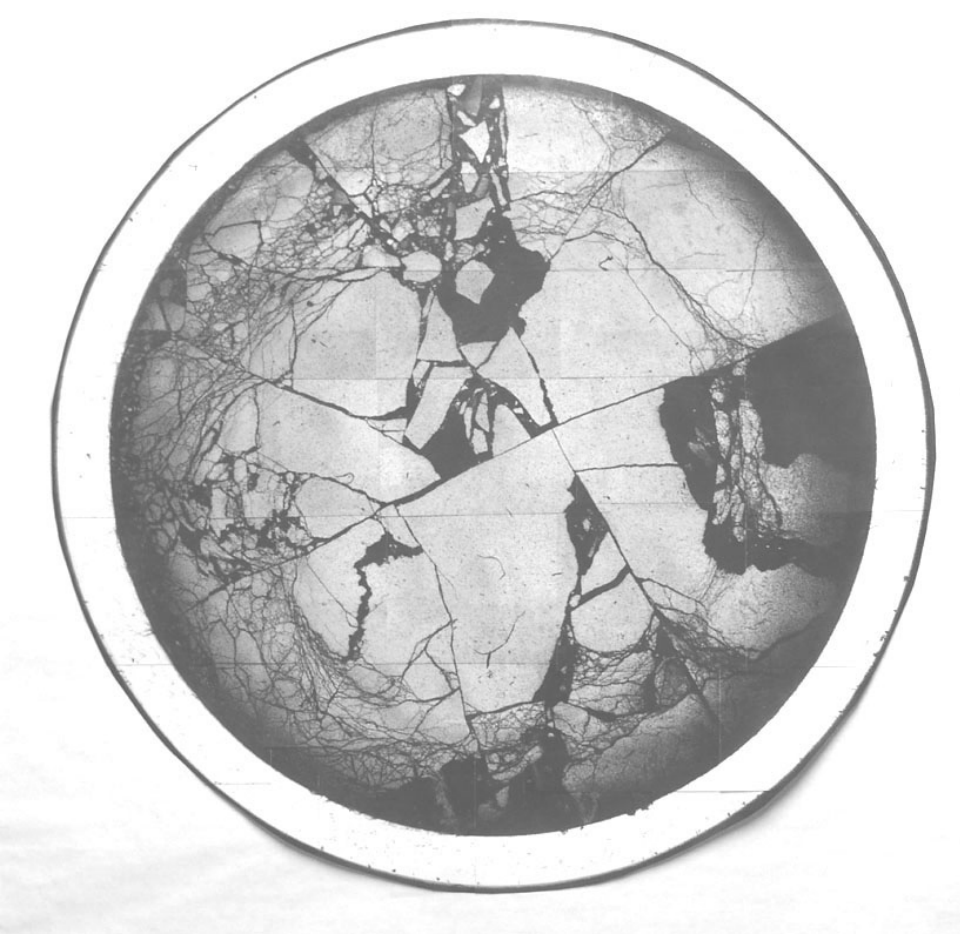

(c)

Figure 233. Fuel morphology for ICL\#2 LOCA sample: (a) as-irradiated, pre-test condition; (b) post-test condition $180 \mathrm{~mm}$ below burst midplane with <2\% creep strain; and (c) post-test condition at $50 \mathrm{~mm}$ above the burst midplane with $\approx 5 \%$ creep strain. 
Except for local regions on the inner surface of the ICL\#2 cladding, no oxygen-stabilized alpha layer is observed. This finding suggests that whatever oxygen has been picked up from the fuel-cladding bond layer and fuel particles or chunks adherent to the bond layer have been reduced after $300 \mathrm{~s}$ at $1200^{\circ} \mathrm{C}$ near the edges of the balloon. One local area of oxygen-stabilized alpha found at $50 \mathrm{~mm}$ above the burst midplane for the ICL\#2 sample (see Figure 233c for fuel morphology) is shown in Figure 234. Although this alpha layer could have been caused by local steam leakage, it is likely that it formed through oxygen pickup from the fuel.

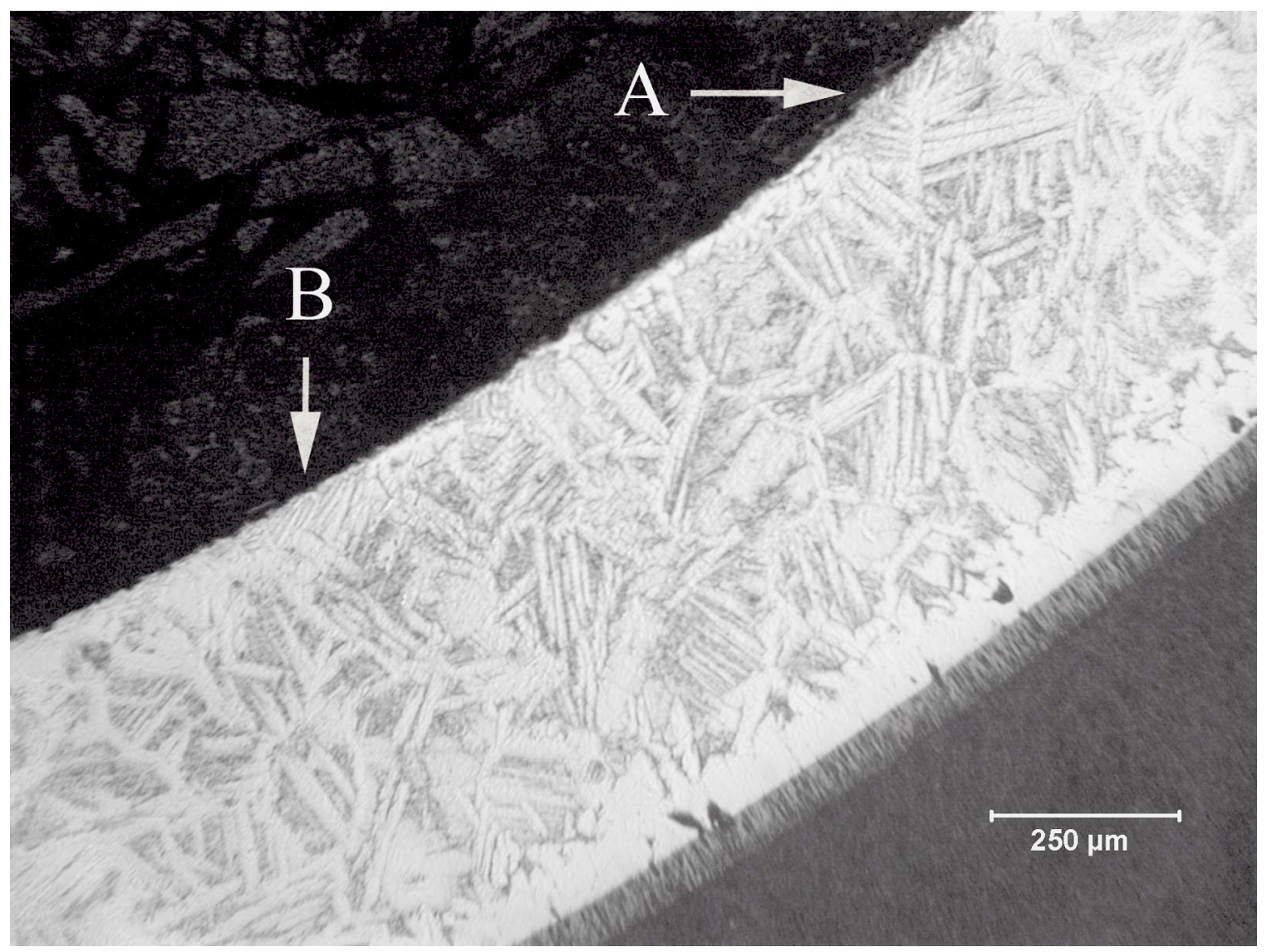

Figure 234. Evidence of local area on cladding inner surface of oxygen-stabilized alpha (left of B) for ICL\#2 sample at $50 \mathrm{~mm}$ above the burst midplane. The inner-surface region indicated by "A" does not have such an alpha layer and is more typical of what is observed for most of the inner surface at this axial location.

Although the observations from the LOCA integral test samples are not substantial, it is well known that $\mathrm{UO}_{2}$ fuel can be the source of oxygen for diffusion into the cladding metal. Hobbins and coworkers made such an observation in one of the Power-Coolant Mismatch tests in the Power Burst Facility [38]. In that test, in which the cladding collapsed onto the fuel, an ID alpha layer was observed. Hobbins et al. concluded that the thickness of the ID alpha layer was of comparable magnitude to the OD alpha layer that came from the reaction with steam. They also gave some evidence that this condition would only happen when hard contact exists between the cladding and the pellet. 
Two years later, Hofmann and Politis [14] confirmed Hobbins et al. observations. Hofmann and Politis put fresh $\mathrm{UO}_{2}$ pellets inside sealed unirradiated Zircaloy tubes and heated them in argon under various pressures. They found an ID alpha layer and also concluded that the uptake of oxygen due to the interaction with $\mathrm{UO}_{2}$ was approximately as high as that by the reaction with steam. These tests confirmed that solid contact was necessary and that the rate of oxygen transport via the gas phase is too low.

Taken together, these observations support the schematic in Figure 5. The fact that the alpha layers near the ID are always about the same thickness as those observed near the OD when an ID oxygen source is present suggests that oxygen diffusion in the cladding metal is the rate-limiting step - provided the oxygen source is in intimate contact with the surface of the metal.

Typical analyses show no hard contact between fuel pellets and cladding during a LOCA transient at very low burnups, so ID oxygen pickup would not be expected in low-burnup fuel. However, fuel bonding occurs at high burnups after the fuel-to-cladding gap has been closed for a long time, and bonding appears to provide the intimate contact that is needed.

Bonding occurs earlier in PWR fuel than in BWR fuel because the higher system pressure in PWRs results in more cladding creep-down. Bonding between the fuel and the cladding eventually occurs in BWRs as well. From ANL characterization work performed for Limerick BWR high-burnup (57 GWd/MTU) fuel, Surry low-burnup (36 GWd/MTU) fuel, TMI-1 PWR intermediate-burnup (48 GWd/MTU), and H. B. Robinson PWR high-burnup (63-67 GWd/MTU) fuel, bonding (and hence ID oxygen ingress during a LOCA) appear to begin at $\approx 30 \mathrm{GWd} / \mathrm{t}$ in PWR fuel and be complete around $\approx 50$ $\mathrm{GWd} / \mathrm{t}$, whereas it would not begin in BWRs until $\approx 40-50 \mathrm{GWd} / \mathrm{t}$.

\subsection{Summary of embrittlement implications of integral tests}

LOCA integral test results confirmed earlier observations of high hydrogen absorption in the vicinity of the balloons. Although some differences were observed in the distribution of hydrogen between fueled, irradiated samples and unirradiated samples filled with zirconia pellets, the hydrogen pickup due to oxidation inside the cladding increases so fast that it would be difficult to guarantee ductility in the balloon region with and ECR limit. Nevertheless, the results from bending tests suggest that some limit on oxidation would be needed to guarantee minimal toughness to prevent cross-section failure and possible fragmentation. In a pair of tests with unirradiated cladding, the failure bending moment decreased about $40 \%$ for a sample oxidized to $15 \%$ CP-ECR as compared to a sample oxidized to 9\% CP-ECR. The failures were relatively clean breaks across the samples. Also, relatively little fragmentation was observed during post-bending impact tests. These results, along with bending tests conducted with $20 \%$ CP-ECR samples, suggest that the current $17 \%$ ECR limit may be sufficient for retention of strength and toughness in the balloon region.

Based on earlier testing under somewhat different conditions, it was expected that oxygen might be picked up outside the balloon region on the cladding inner-surface from the fuel or fuel-cladding bonding layer. Although insufficient testing was done to be conclusive on this point, inner-surface alpha layers were observed in some locations, thus indicating oxygen pickup. During the reference 600 -s hold at $1200^{\circ} \mathrm{C}$, alpha layers that may have formed earlier in time due to oxygen pickup from the fuel-cladding bond would have disappeared at later times due to oxygen diffusion from the alpha layer to the beta layer. Recent tests at Halden are more conclusive and confirm inner-surface pickup of oxygen in high-burnup fuel [39]. 


\section{Conclusions and Recommendations}

Six mechanisms for cladding embrittlement during a LOCA are described in Section 1.4. Data relevant to these mechanisms are summarized and evaluated in this section.

\subsection{Beta-layer embrittlement of unirradiated cladding}

Because diffusion of oxygen into metal is much faster at high temperatures than at low temperatures, oxygen-induced embrittlement in the beta layer occurs in much shorter times at high temperatures. For as-fabricated cladding alloys, ductility and embrittlement threshold correlated better with oxidation levels calculated with the Cathcart-Pawel (CP) weight-gain correlation than with measured or best-estimate correlations for weight gain. This CP-predicted weight gain was converted to CP-ECR in percent using Equations 5 or 6 for one- and two-sided oxidation, respectively.

At oxidation temperatures of $1000^{\circ} \mathrm{C}$ and $1100^{\circ} \mathrm{C}$, the modern U.S. alloys tested did not experience embrittlement within the range of CP-ECR values $(\leq 20 \%)$ investigated, even when ring-compression tested at room temperature. The ANL criterion used to assess ductile vs. brittle behavior of samples oxidized at these temperatures is as follows: $\geq 2 \%$ offset strain (determined from ring-compression loaddisplacement curves) implies ductile behavior and $<2 \%$ offset strain implies brittle behavior. The $2 \%$ offset strain is based on the uncertainty determined both experimentally and analytically in the unloading slope just prior to failure (through-wall crack along the length of the $8 \pm 1 \mathrm{~mm}$ long ring).

As-fabricated cladding alloys do embrittle at $\leq 20 \%$ CP-ECR following oxidation at $1200^{\circ} \mathrm{C}$. Initially, these alloys were ring-compressed at room temperature, which is highly conservative relative to the calculated core temperature $\left(135^{\circ} \mathrm{C}\right.$ or $\left.275^{\circ} \mathrm{F}\right)$ following LOCA-quench cooling. These alloys oxidized at $1200^{\circ} \mathrm{C}$ were retested at $135^{\circ} \mathrm{C}$. Also, tests were interrupted following the first significant load drop ( $>30 \%)$ to allow a direct measurement of the diameter of the deformed sample in the loading direction. Based on the normalized diameter change, permanent strain could be measured directly for samples that failed with a single, tight through-wall crack. These permanent strains were always less than the offset strains within the ductile region. Based on an error analysis, rings exhibiting $\geq 1 \%$ permanent strain were characterized as ductile, and rings with $<1 \%$ permanent strain were classified as brittle. For load-displacement curves with a very rapid load drop of $80-100 \%$, the rings cracked into multiple pieces (usually two), and it was not possible to measure post-test diameter. Offset strains for these samples were used to establish trend curves for ductility vs. CP-ECR. However, permanent strains were used to determine the ductile-to-brittle transition CP-ECR.

Table 77 summarizes the results for embrittlement threshold for cladding alloys oxidized at $1200^{\circ} \mathrm{C}$, quenched at $800^{\circ} \mathrm{C}$, and ring-compressed at $135^{\circ} \mathrm{C}$. For three of these alloys $(17 \times 17$ Zry-4, ZIRLO, and M5), additional tests were conducted with samples cooled without quench. The results indicated that the embrittlement threshold for these alloys is not sensitive to quench temperatures $\leq 800^{\circ} \mathrm{C}$. Table 77 also indicates that different batches of one alloy (Zry-4) exhibited a range of embrittlement thresholds (1619\%), whereas some batches of four different alloys (Zry-2, Zry-4, ZIRLO, and M5) exhibited almost the same threshold (19-20\%). These results suggest that the embrittlement threshold is sensitive to manufacturing variables, but not to alloy constituents for the alloys tested in this program.

To generate the embrittlement threshold data in Table 77, numerous tests were conducted with each alloy. In general, alloys were oxidized at 5, 10,13, 17, and 20\% CP-ECR values. Additional 
Table 77. Embrittlement Threshold (CP-ECR) for As-fabricated Cladding Alloys Oxidized at $1200^{\circ} \mathrm{C}$, Cooled at $11-13^{\circ} \mathrm{C} / \mathrm{s}$ to $800^{\circ} \mathrm{C}$, Quenched at $800^{\circ} \mathrm{C}$ and Ring-compressed at $135^{\circ} \mathrm{C}$. For CPECR values $1 \%$ higher than the embrittlement threshold, the alloys are classified as brittle. Results are rounded off to the nearest whole-number percent.

\begin{tabular}{|c|c|c|c|c|}
\hline $\begin{array}{l}\text { Alloy and } \\
\text { Geometry }\end{array}$ & Manufacturer & Vintage & $\begin{array}{c}\text { Embrittlement } \\
\text { Threshold } \\
\text { CP-ECR, } \\
\%\end{array}$ & $\begin{array}{c}\text { Permanent } \\
\text { (Offset) } \\
\text { Strain, } \\
\%\end{array}$ \\
\hline $\begin{array}{c}\text { Zircaloy-4 } \\
15 \times 15\end{array}$ & Siemens & $\begin{array}{l}\text { Old, Low Tin } \\
\text { H.B. Robinson }\end{array}$ & 16 & $\begin{array}{c}1.1 \pm 0.4 \\
(2.9 \pm 0.6)\end{array}$ \\
\hline $\begin{array}{c}\text { Zircaloy-4 } \\
15 \times 15\end{array}$ & AREVA & $\begin{array}{l}\text { Current } \\
\text { Low Tin }\end{array}$ & 19 & $\begin{array}{c}1.5 \pm 0.3 \\
(3.3 \pm 0.6)\end{array}$ \\
\hline $\begin{array}{c}\text { Zircaloy-4 } \\
17 \times 17\end{array}$ & Westinghouse & $\begin{array}{l}\text { Current } \\
\text { Low Tin }\end{array}$ & 17 & $\begin{array}{c}1.1 \pm 0.4 \\
(2.5 \pm 0.5\end{array}$ \\
\hline $\begin{array}{c}\text { Zircaloy-2 } \\
10 \times 10\end{array}$ & $\begin{array}{c}\text { Global Nuclear } \\
\text { Fuel }\end{array}$ & $\begin{array}{c}\text { Current } \\
\text { ID Zr Liner }\end{array}$ & 19 & $\begin{array}{c}2.2 \\
(3.3 \pm 0.4)\end{array}$ \\
\hline $\begin{array}{c}\text { ZIRLO } \\
17 \times 17\end{array}$ & Westinghouse & $\begin{array}{c}\text { Current } \\
\text { Standard Tin }\end{array}$ & 19 & $\begin{array}{c}1.1 \pm 0.1 \\
(2.5 \pm 0.5)\end{array}$ \\
\hline $\begin{array}{c}\text { M5 } \\
17 \times 17\end{array}$ & AREVA & Current & 20 & $\begin{array}{c}1.0 \\
(3.5 \pm 0.4)\end{array}$ \\
\hline
\end{tabular}

tests were then conducted in the range of $13-20 \%$ CP-ECR to better determine the embrittlement threshold based both on the strain criteria and the shapes of the strain vs. CP-ECR curves.

For all but one of the alloys listed in Table 77, the embrittlement threshold was determined based on the results of two or three ring-compression samples sectioned from one or two oxidation-quench samples at a given CP-ECR level. This approach is adequate for evaluating the embrittlement threshold for a number of different alloys. For HBR-type Zry-4, this scoping approach led to the conclusion that the embrittlement oxidation threshold was about $14 \%$ (14.3\% based on interpolation of strain data at $13 \%$ and $15 \%$ CP-ECR). Additional tests were conducted with HBR-type Zry-4 samples oxidized at $1200^{\circ} \mathrm{C}$ to $13-16 \%$ CP-ECR. Based on six sets of strain data at 15.2\% CP-ECR and eight sets of strain data at $16.0 \%$ CP-ECR, embrittlement was found to occur at $15.6 \%$ CP-ECR based on interpolation. Thus, the more statistically significant database led to an increase of $1.3 \%$ in embrittlement CP-ECR. Based on this experience, the uncertainty in the threshold oxidation levels for the other alloys listed in Table 77 can be taken as $\pm 1 \%$. For more precise (e.g., $\pm 0.5 \%$ ) determination of embrittlement threshold, the approach used for HBR-type Zry-4 is recommended.

Although the range of embrittlement thresholds listed in Table 77 is relatively narrow $(17-20 \%$ for current alloys), the ductility vs. CP-ECR curves below the embrittlement threshold exhibited a wide spread from one cladding material to another. As shown in Figure 48, current $17 \times 17$ Zry- 4 showed a sharp decrease in ductility between 11 and $13 \%$ CP-ECR, while current $15 \times 15$ Zry-4 exhibited a sharp decrease in ductility between 13 and $15 \%$ CP-ECR. The $10 \times 10$ Zry-2 cladding exhibited a more gradual decrease in ductility with increasing CP-ECR up to the embrittlement threshold. 


\subsection{Beta-layer thinning of unirradiated cladding}

Embrittlement due to beta-layer thinning will not occur if the time at temperature is sufficiently limited. Within the test times used in this experimental work, beta-layer thinning was not a limiting phenomenon. At $1200^{\circ} \mathrm{C}$, the beta-layer thickness at the ductile-to-brittle-transition CP-ECR ranged from 0.2 to $0.4 \mathrm{~mm}$. Limiting the CP-ECR based on beta-layer embrittlement for oxidation at $1200^{\circ} \mathrm{C}$ is sufficient to preclude embrittlement due to beta-layer thinning. For test temperatures of $1000^{\circ} \mathrm{C}$ and $1100^{\circ} \mathrm{C}$, modern, belt-polished $17 \times 17$ alloys remained ductile at RT up to $20 \%$ CP-ECR with beta-layer thicknesses of $0.2-0.3 \mathrm{~mm}$. For $1000^{\circ} \mathrm{C}$, limiting the time based on breakaway oxidation is sufficient to preclude embrittlement due to beta-layer thinning. For $1100^{\circ} \mathrm{C}$, neither oxygen-induced embrittlement nor breakaway oxidation appears to be limiting. Beta-layer thinning is the most likely embrittlement mechanism at $1100^{\circ} \mathrm{C}$. However, for all as-fabricated alloys tested, this limit would occur at CP-ECR values $>20 \%$. Therefore, by limiting the CP-ECR based on ductility loss for $1200^{\circ} \mathrm{C}$ oxidation, betalayer thinning would not be a factor in cladding embrittlement. As pointed out in Ref. 1, beta-layer thinning does result in a decrease in strength and fracture toughness (as determined by impact tests). However, based on the results in the current study, post-quench ductility appears to be relatively insensitive to beta-layer thickness for $\geq 0.2$-mm-thick prior-beta layers.

\subsection{Localized embrittlement in a balloon}

Current industry practice uses the average of an enlarged cladding diameter and a corresponding reduced wall thickness in a balloon to calculate two-sided oxidation of the cladding (and two-sided oxygen pickup). The calculated CP-ECR is then compared with a limiting value. As shown in Section 6.2.2, this procedure does not guarantee ductility in a balloon. Hydrogen absorption at the cladding inner surface is so pronounced that we have not found a practical limit that could be used to ensure ductility. This was observed for both fresh and high-burnup cladding.

Nevertheless, the current practice $(\leq 17 \%$ ECR) does limit oxygen concentrations in the balloon wall and maintains material toughness, which was demonstrated by failure resistance to bending and crush-impact loads. When this practice is used, as was seen in Sections 6.1 and 6.2, the cladding survived quenching without fracture and retained a relatively high failure bending moment. Although this is a less conservative condition than retaining ductility, quench survival is an important step in maintaining a coolable geometry following a LOCA and is considered sufficient in licensing in some countries (e.g., Japan [40]).

\subsection{Hydrogen-enhanced beta-layer embrittlement}

Hydrogen, which enters the outer cladding surface during normal lifetime operation, increases oxygen solubility and pickup rate in the beta layer even at temperatures below $1200^{\circ} \mathrm{C}$. This reduces ductility compared with unirradiated cladding, as seen in Figure 235. For HBR-type Zry-4 oxidized at $1200^{\circ} \mathrm{C}$, about $550 \mathrm{wppm}$ of hydrogen in the cladding reduced the embrittlement threshold from $16 \%$ for fresh cladding to $8 \%$ for high-burnup cladding cooled without quench to $\approx 5 \%$ for high-burnup cladding quenched at $800^{\circ} \mathrm{C}$. The higher the hydrogen pickup during normal operation, the larger will be the decrease in embrittlement threshold. Embrittlement results for both prehydrided Zry-4 and high-burnup alloys (Zry-4, ZIRLO, and M5) are summarized in the following. 


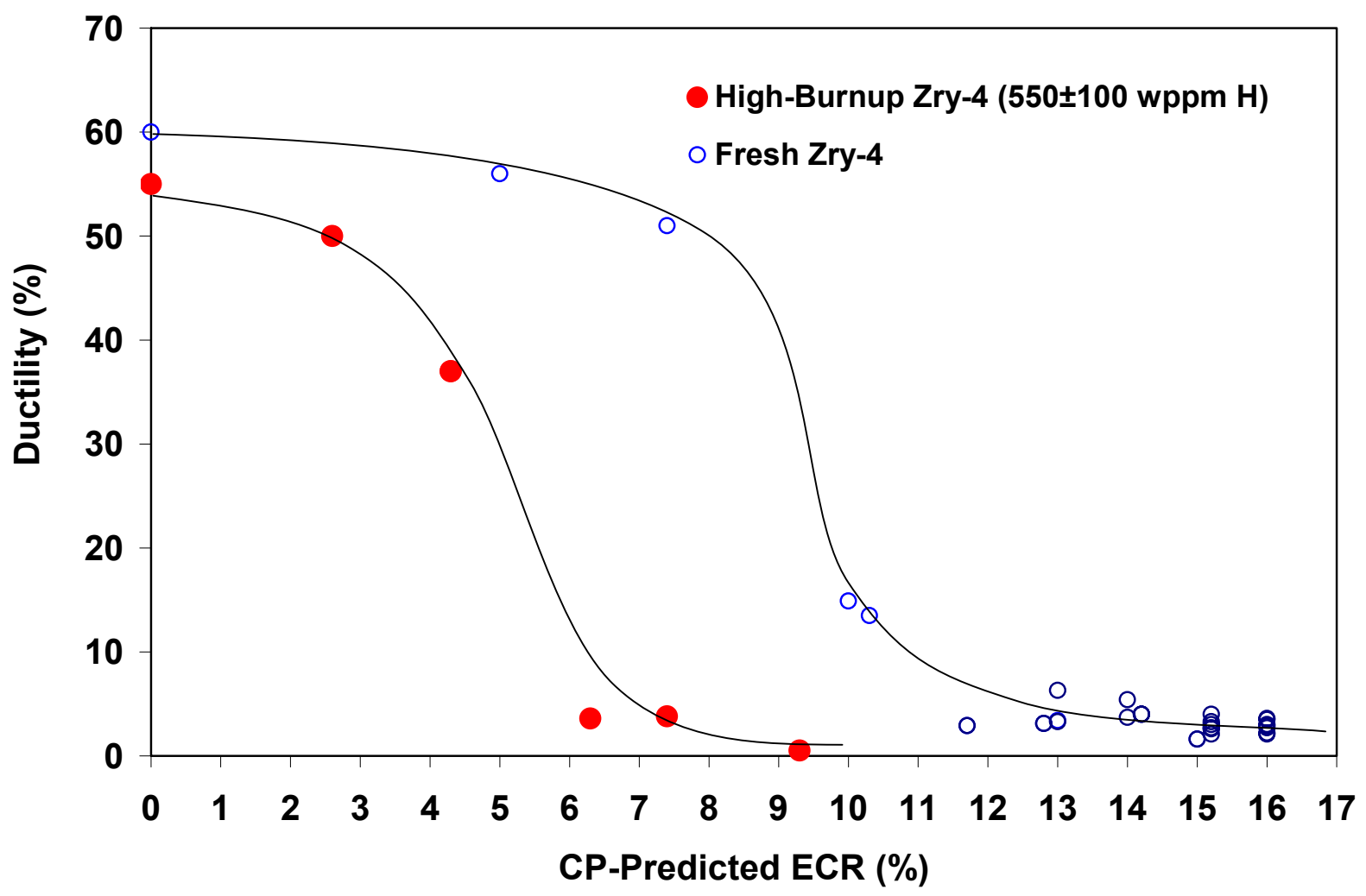

Figure 235. Offset strains for high-burnup Zry-4 (71-74 $\mu \mathrm{m}$ corrosion-layer thickness) and as-fabricated (fresh) HBR-type 15×15 Zry-4. Cladding samples were two-side oxidized at $\approx 1200^{\circ} \mathrm{C}$ and cooled at $\approx 11^{\circ} \mathrm{C} / \mathrm{s}$ to $800^{\circ} \mathrm{C}$. As-fabricated samples were quenched at $800^{\circ} \mathrm{C}$, while the highburnup samples were slow cooled from $800^{\circ} \mathrm{C}$ to $\mathrm{RT}$. 


\section{Hydrogen-enhanced embrittlement for prehydrided Zry-4}

Numerous LOCA embrittlement tests were conducted with prehydrided $17 \times 17$ Zry-4 and $15 \times 15$ HBR-type Zry-4 to map out regions of hydrogen concentration and oxidation levels resulting in embrittlement. Most of the tests were conducted using prehydrided HBR-type Zry-4. Ductility tests were performed for $1200^{\circ} \mathrm{C}$-oxidized samples, which were cooled at $\approx 11^{\circ} \mathrm{C} / \mathrm{s}$ to $800^{\circ} \mathrm{C}$ and either quenched at $800^{\circ} \mathrm{C}$, further cooled with quench at $700^{\circ} \mathrm{C}$ or $600^{\circ} \mathrm{C}$, or cooled from $800^{\circ} \mathrm{C}$ without quench. No ductility enhancement was observed by lowering the quench temperature from $800^{\circ} \mathrm{C}$ to $600^{\circ} \mathrm{C}$. A small, but significant, enhancement in ductility (1-2\%) was observed for samples cooled without quench. The increase in embrittlement threshold resulting from cooling without quench is shown in Figure 120 of Section 4 . The test samples used to generate the ductility and embrittlement data were prehydrided with relatively low circumferential variations (less than $\pm 30 \mathrm{wppm}$ ) in hydrogen concentration. A few tests were conducted with samples containing higher variation $( \pm 100 \mathrm{wppm})$ in hydrogen content in the circumferential direction. Based on average hydrogen content, it was anticipated that these samples would be ductile following quench at $800^{\circ} \mathrm{C}$. However, samples with $510 \pm 100$ and $610 \pm 100$ wppm hydrogen were brittle at 5.2\% and 4.7\% CP-ECR, respectively. A major finding in this work is that hydrogen (in the presence of oxygen) does not diffuse fast enough to homogenize in the circumferential and axial directions during short LOCA transients leading to embrittlement. More testing would be needed to determine the effects on embrittlement threshold of large variations - particularly in the circumferential direction - of hydrogen content.

\section{Hydrogen-enhanced embrittlement for high-burnup alloys}

Determining the embrittlement threshold vs. hydrogen content for high-burnup cladding is very challenging because the average hydrogen content varies with axial location over short distances, the circumferential variation in hydrogen can be as high as $\pm 100 \mathrm{wppm}$ (Zry-4 and ZIRLO), and the measured pre-test hydrogen can be 100 wppm higher (ZIRLO) than the post-test measured hydrogen. For practical reasons, testing of high-burnup cladding was initiated with a series of tests cooled without quench to map out the ductility vs. oxidation level. This approach allowed determination of the ductileto-brittle transition oxidation level for oxidation at $1200^{\circ} \mathrm{C}$ and cooling without quench. Based on the prehydrided Zry-4 results, this transition level should be higher than the transition level for samples quenched at $800^{\circ} \mathrm{C}$. The results helped to focus the tests with quench to within a narrow CP-ECR range. Table 78 and Figures 236 and 237 summarize the results of these studies.

For high-burnup (64 GWd/MTU) H. B. Robinson Zry-4, tests were conducted in the AGHCF. Based on tests conducted without quench, the transition CP-ECR oxidation level was determined to be $8 \%$ for samples with $550 \pm 100 \mathrm{wppm}$. Only one quench test was performed, but the hydrogen $(740 \pm 100$ wppm) and the oxidation (7.7\% CP-ECR) levels were above the embrittlement threshold. No additional quench tests were conducted with this alloy. However, based on the results for prehydrided HBR-type Zry-4 and high-burnup ZIRLO, the embrittlement threshold for high-burnup Zry-4 with 550-wppm hydrogen and cooled with quench at $800^{\circ} \mathrm{C}$ is assessed to be $\approx 5 \% \mathrm{CP}-\mathrm{ECR}$.

High-burnup ZIRLO (70 GWd/MTU) and M5 (63 GWd/MTU) cladding samples were tested in a beta-gamma cell in the Irradiated Materials Laboratory. Based on the results of three tests, the embrittlement threshold for high-burnup ZIRLO with $670 \pm 40$ wppm pretest hydrogen and $540 \pm 100$ wppm post-test hydrogen was determined to be $9 \%$ for cooling without quench. Based on three tests cooled with quench at $800^{\circ} \mathrm{C}$, the embrittlement threshold was determined to be $5 \%$ for samples with $620 \pm 100 \mathrm{wppm}$ pretest hydrogen and about $540 \pm 100 \mathrm{wppm}$ post-test hydrogen. For ZIRLO, it appears 
Table 78. Embrittlement Threshold (CP-ECR) for High-burnup Cladding Alloys Oxidized at $\leq 1200^{\circ} \mathrm{C}$, Cooled at $11-13^{\circ} \mathrm{C} / \mathrm{s}$ to $800^{\circ} \mathrm{C}$, and either Quenched (Q) at $800^{\circ} \mathrm{C}$ or Cooled without Quench. Ring-compression tests were performed at $135^{\circ} \mathrm{C}$. For CP-ECR values $1 \%$ higher than the embrittlement threshold, the alloys are brittle. Results are rounded off to the nearest wholenumber percent. SC = slow cooling without quench.

\begin{tabular}{|c|c|c|c|c|c|}
\hline \multirow{2}{*}{$\begin{array}{c}\text { High-Burnup } \\
\text { Alloy }\end{array}$} & \multicolumn{2}{|c|}{$\begin{array}{c}\text { Hydrogen } \\
\text { Content, wppm }\end{array}$} & \multirow{2}{*}{ Cooling } & $\begin{array}{c}\text { Maximum } \\
\text { Temperature } \\
{ }^{\circ} \mathbf{C}\end{array}$ & $\begin{array}{c}\text { PP-ECR, } \\
\mathbf{\%}\end{array}$ \\
\cline { 2 - 5 } & Pretest & Post-test & & 1200 & 8 \\
\hline H. B. Robinson & $550 \pm 100$ & --- & SC & 1180 & 5 \\
\hline $15 \times 15$ Zry-4 & & & Q & 1200 & 9 \\
\hline North Anna & $670 \pm 40$ & $540 \pm 100$ & SC & 1162 & 5 \\
$17 \times 17$ ZIRLO & $620 \pm 140$ & $540 \pm 100$ & Q & 1200 & 18 \\
\hline Ringhals & $110 \pm 10$ & $110 \pm 10$ & SC & 1200 & $14 \pm 1$ \\
\hline $17 \times 17$ M5 & $110 \pm 10$ & $140 \pm 15$ & Q & 1200 \\
\hline
\end{tabular}

that about 100 wppm of hydrogen may be in the corrosion layer (40-45 $\mu \mathrm{m}$ thick). Hydrogen in the corrosion layer would be released to the flowing steam during the LOCA transient, and it would not contribute to embrittlement. For this reason, results are given in terms of both pre-test (Figure 236) and post-test (Figure 237) hydrogen content for ZIRLO. For high-burnup M5 with $110 \pm 100$ wppm, the transition CP-ECR values were determined to be $18 \%$ without quench and $14 \pm 1 \%$ with quench.

The best-linear-fit lines drawn in Figures 236 and 237 are intended as a guide for the reader. More data at additional hydrogen levels would be needed to establish the shape of the embrittlement threshold vs. hydrogen curve.

\section{$\underline{\text { Prehydrided cladding vs. high-burnup cladding }}$}

The ductility and embrittlement data generated for prehydrided HBR-type Zry-4 were very useful in pretest planning and post-test analysis for LOCA testing of high-burnup HBR Zry-4. In Figure 148, it is demonstrated that the ductility of both materials is comparable for similar hydrogen concentrations and oxidation levels when both materials are cooled without quench. The embrittlement thresholds for prehydrided and high-burnup Zry-4 are also comparable for oxidation samples cooled without quench. This is shown in Figure 238. We are unable to make the same comparison for samples cooled with quench at $800^{\circ} \mathrm{C}$. The one high-burnup Zry-4 sample cooled with quench had a high hydrogen concentration (740 wppm) and a relatively high CP-ECR (7.5\%). The fact that the sample was brittle under these conditions is consistent with the data for prehydrided Zry-4. However, many more tests would be needed to assess the adequacy of using prehydrided cladding as a surrogate for high-burnup cladding. 


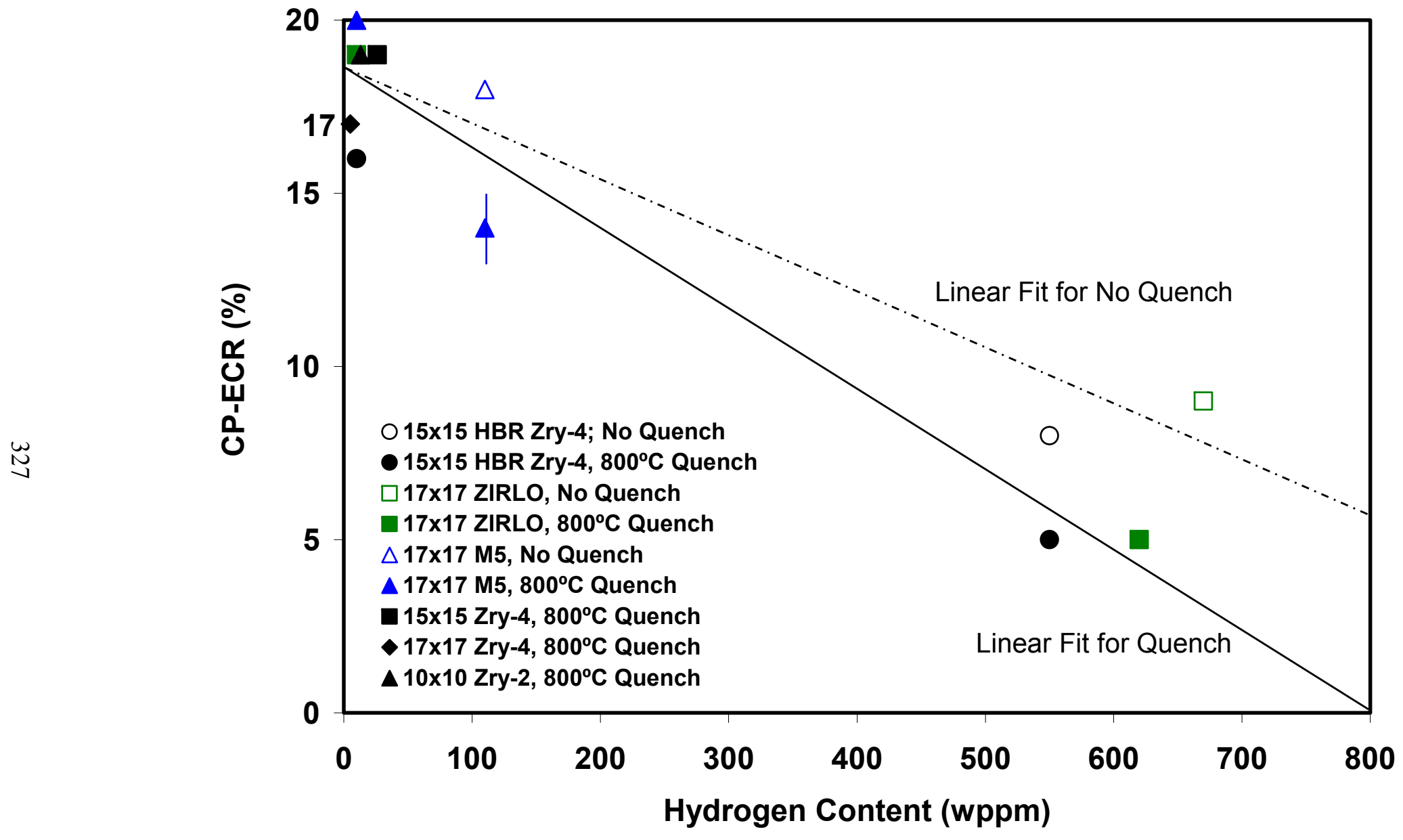

Figure 236. Embrittlement oxidation level (CP-ECR) vs. pre-test hydrogen content for high-burnup $15 \times 15 \mathrm{Zry}-4,17 \times 17 \mathrm{ZIRLO}$, and $17 \times 17 \mathrm{M} 5$ oxidized at $\leq 1200^{\circ} \mathrm{C}$, cooled at $11-13^{\circ} \mathrm{C} / \mathrm{s}$ to $800^{\circ} \mathrm{C}$, and either quenched or cooled without quench. 


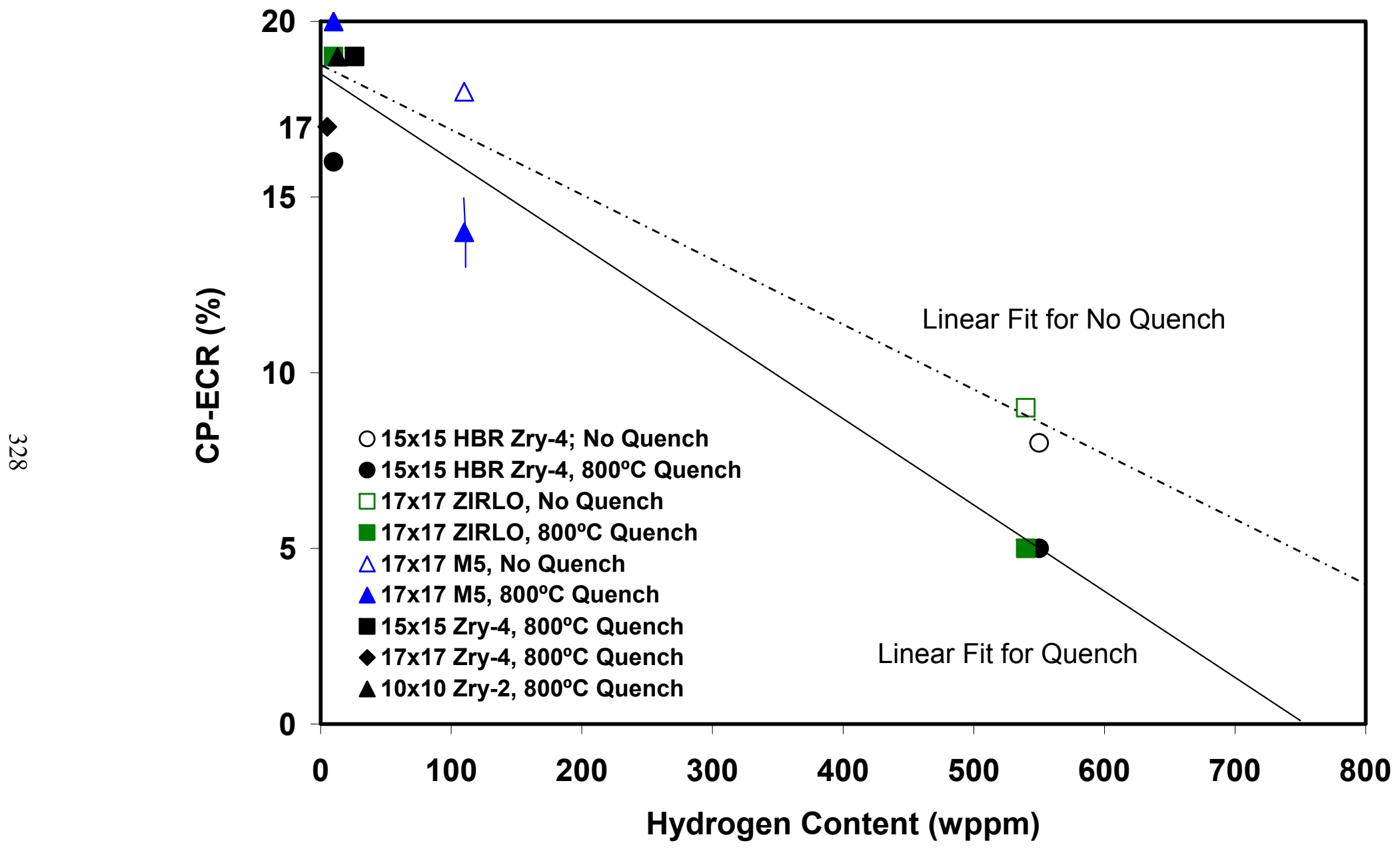

Figure 237. Embrittlement oxidation level (CP-ECR) vs. post-test hydrogen content for high-burnup $17 \times 17$ ZIRLO and pre-test hydrogen content for high-burnup $15 \times 15 \mathrm{Zry}-4$ and $17 \times 17 \mathrm{M} 5$ oxidized at $\leq 1200^{\circ} \mathrm{C}$, cooled at $11-13^{\circ} \mathrm{C} / \mathrm{s}$ to $800^{\circ} \mathrm{C}$, and either quenched or cooled without quench. 


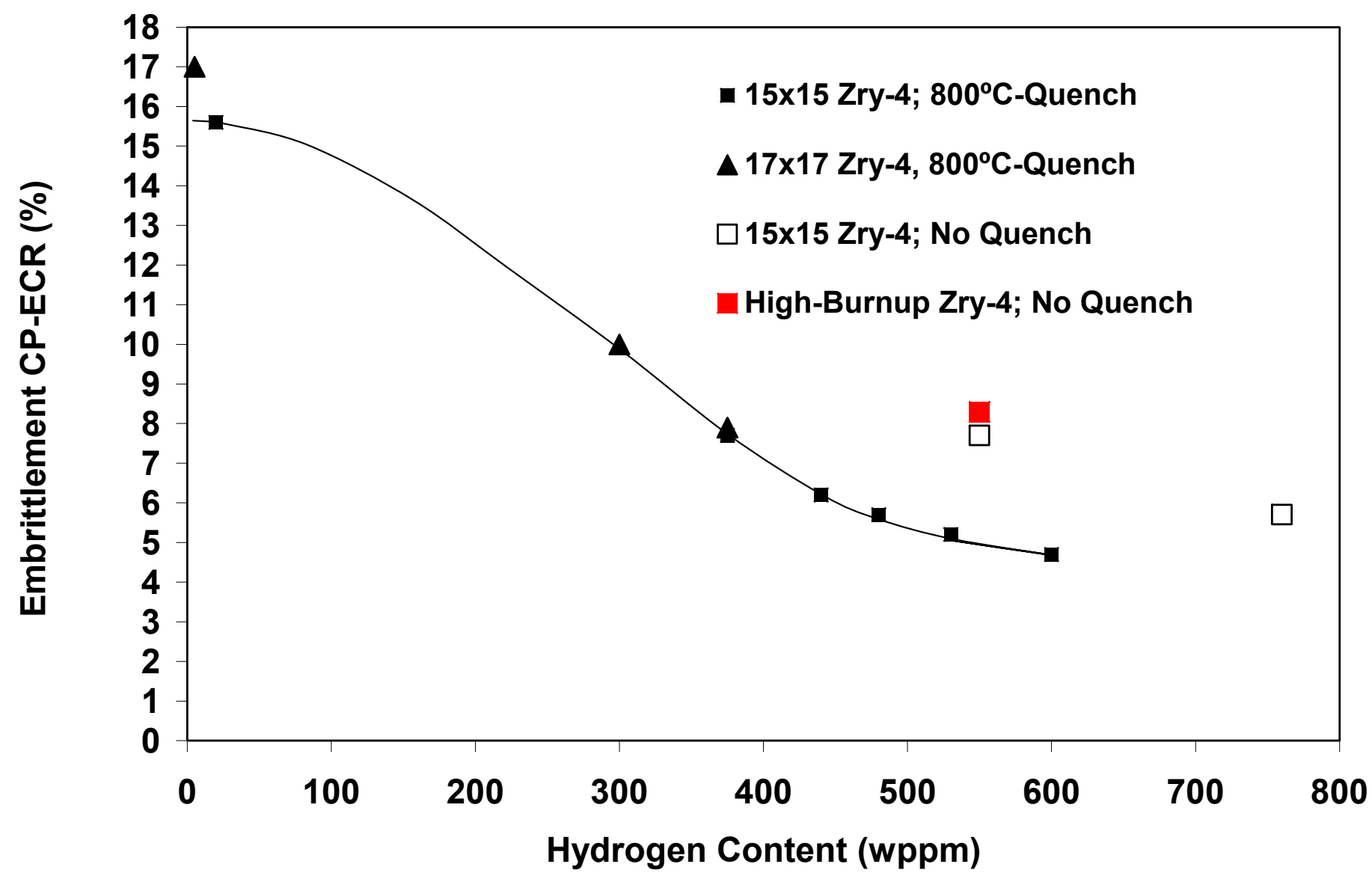

Figure 238. Embrittlement oxidation level (CP-ECR) vs. hydrogen content for high-burnup HBR Zry-4 and prehydrided $17 \times 17$ Zry-4 and $15 \times 15$ HBR-type Zry-4 oxidized at $\leq 1200^{\circ} \mathrm{C}$, cooled at $11-13^{\circ} \mathrm{C} / \mathrm{s}$ to $800^{\circ} \mathrm{C}$, and either quenched or cooled without quench. 


\subsection{Breakaway oxidation}

Figure 29 indicates that the minimum time for breakaway oxidation in Zircaloy-4 occurs around $1000^{\circ} \mathrm{C}$. The picture is about the same for other cladding alloys, but the minimum does not always occur exactly at $1000^{\circ} \mathrm{C}$. Nevertheless, the minimum can be found by searching in the neighborhood of $1000^{\circ} \mathrm{C}$, and the minimum time can be determined by using a hydrogen pickup concentration of $200 \mathrm{wppm}$ as the threshold for breakaway. There is another temperature range (around $775^{\circ} \mathrm{C}$ ) with relatively low breakaway times. However, oxidation is very slow at the lower temperatures, as is the hydrogen generation, and it takes a much longer time after breakaway oxidation to pick up 200 wppm of hydrogen. Although this lower temperature region should be characterized, the time for embrittlement at about $775^{\circ} \mathrm{C}$ would probably be much higher than the time to embrittle at $\approx 1000^{\circ} \mathrm{C}$.

Diffusion of oxygen in the metal is, of course, very slow at lower temperatures. Further, there will be no beta material in any of the zirconium-tin-niobium alloys at temperatures below about $650^{\circ} \mathrm{C}$ because that is the lowest phase transition temperature of the alloys. Hence, a relatively low concentration of oxygen will remain in solution in the alpha-phase metal below $650^{\circ} \mathrm{C}$, and the cladding will remain ductile. It should not be necessary to consider temperatures below the phase transition. Therefore, if the total time spent above $650^{\circ} \mathrm{C}$ is less than the measured breakaway time described above, breakaway should not occur.

Tables 20, 23, 29, and 36 in Section 3 indicate that the minimum breakaway times for belt-polished Zry-4, Zry-2, ZIRLO, and M5 are about 5000, >5000, 3000, and 6000 seconds, respectively. It is also seen from Table 18 that older rough-surface Zry-4 has a breakaway time of about 3800 seconds. On the other hand, the breakaway time for E1 10 can be seen in Figure 98 to be only about 500-700 seconds, which is much shorter than the anticipated duration of small-break LOCAs. Breakaway oxidation times may be important for some small-break LOCAs with lower oxidation temperatures and much longer oxidation times above $650^{\circ} \mathrm{C}$.

\subsection{Oxygen pickup from the cladding inside diameter (ID)}

The ID oxygen pickup can be accounted for in an analysis rather than with criteria per se. Because ID oxygen pickup is already accounted for within the ballooned region using the current industry practice, we need only modify the analysis for cladding locations away from a balloon to account for the more general ID oxygen pickup in high-burnup fuel.

For fresh cladding that experiences LOCA conditions, there is no oxygen pickup from the cladding ID away from the balloon, and Equation 5 for one-sided oxidation will give the appropriate CP-ECR. For moderate-to-high burnup fuel, however, oxygen pickup at the inner cladding surface will be bounded by the oxygen pickup due to steam oxidation. Thus, two-sided oxidation (Equation 6) will give a reasonable upper bound on the transient CP-ECR to be compared to the transient CP-ECR limit.

The exact burnup for a transition from Equation 5 to Equation 6 is not well defined. For burnups above $30 \mathrm{GWd} / \mathrm{MT}$ in PWRs and $40 \mathrm{GWd} / \mathrm{MT}$ in BWRs, there will be some fuel-to-cladding bonding, which indicates some ID oxygen pickup will occur during a LOCA. By $50 \mathrm{GWd} / \mathrm{MT}$ for PWRs $(60$ $\mathrm{GWd}$ /MT for BWRs), fuel bonding is likely to be well developed, and ID oxygen pickup from the bond and fuel may be as high as the OD oxygen pickup from flowing steam. 


\subsection{Recommendations}

During the course of these investigations, interesting phenomena were encountered that may be worth further investigation to thoroughly understand these phenomena and to determine their relevance to cladding behavior during and following LOCA-type transients, as well as embrittlement limits.

\subsubsection{Circumferential and axial variations in hydrogen content}

Variation of hydrogen content across the radius of the cladding (hydride rim effect) and over short axial distances (pellet-pellet interface effect) has been observed by many investigators. Studies using prehydrided Zry-4 with dense hydride rims [41] have demonstrated that the homogenization of hydrogen across the radius of the cladding is very rapid at $\geq 900^{\circ} \mathrm{C}$ due to the affinity of the beta phase for hydrogen, as well as the high solubility of hydrogen in this phase. However, most studies reported in the literature are for prehydrided cladding samples with relatively uniform hydrogen content in the circumferential and axial directions.

In the Argonne work, significant circumferential variation ( $\pm 100-140 \mathrm{wppm})$ in hydrogen content has been measured (by LECO vacuum fusion) and observed (by optical microscopy) for high-burnup Zry4 and ZIRLO. For oxidation test times at $1200^{\circ} \mathrm{C}$ up to the embrittlement CP-ECR level, no significant diffusion of hydrogen in the circumferential direction was observed. Hydrogen-concentration variations of 450 to $750 \mathrm{wppm}$ measured for cladding quarter segments prior to LOCA testing remained after LOCA testing. The same behavior was observed for prehydrided Zry-4 oxidized under similar LOCA conditions. In addition, axial variations of \pm 50 wppm within 25 -mm-long prehydrided LOCA samples were measured both before and after LOCA testing.

Additional testing could be performed to assess the effects on the embrittlement threshold of circumferential variation in hydrogen content.

\subsubsection{Embrittlement oxidation level as a function of hydrogen content for high-burnup cladding}

Additional tests could be performed to determine the embrittlement oxidation level vs. hydrogen content for a range of hydrogen contents. It is recommended that these tests be performed with highburnup ZIRLO cladding. Within the uniform-burnup region of high-burnup ZIRLO fuel rods, the corrosion layer varies from about $\approx 20-70 \mu \mathrm{m}$. The samples tested in this program had corrosion level thicknesses of about 40-45 $\mu \mathrm{m}$. Cladding samples with lower and higher corrosion levels should give a wide range of hydrogen contents. Testing of these samples would certainly add valuable embrittlement data points between $110 \mathrm{wppm}$ (M5) and $550 \mathrm{wppm}$ (in Zry-4 and ZIRLO metal), as well as possible data points above 550 wppm.

\subsubsection{Effects of cooling rate and quench temperature on post-quench ductility and embrittlement}

The cooling rate from the peak oxidation temperature to the quench temperature could have an effect on the embrittlement threshold. The quench temperature may also have a significant effect on the embrittlement threshold, as indicated by the differences between embrittlement thresholds for $800^{\circ} \mathrm{C}$ quenched high-burnup samples vs. samples cooled without quench. If one were to investigate these effects, it is recommended that tests be conducted with cooling rates of $1-5^{\circ} \mathrm{C} / \mathrm{s}$ and quench temperatures of $400-800^{\circ} \mathrm{C}$. These tests should be conducted with prehydrided cladding. 


\subsubsection{Assessment of prehydrided cladding as a surrogate for high-burnup cladding}

In parallel to the tests recommended in Sections 7.7.2 and 7.7.3, a series of tests could be performed using prehydrided ZIRLO with the same average hydrogen content as the high-burnup samples tested. The prehydriding can be performed to generate samples with relatively uniform hydrogen concentrations, as well as samples with large circumferential variations in hydrogen to address the recommendation in Section 7.7.1.

\subsubsection{Sensitivity of breakaway oxidation to sample preparation and test conditions}

Breakaway oxidation is an instability phenomenon that may be sensitive to differences in sample preparation method and test conditions. To standardize such testing, additional tests would be needed to determine the sensitivity of breakaway-oxidation time to sample length and cleaning, steam flow rate, heating ramp rate and method, and circumferential temperature variation. As shown in Table 19, breakaway oxidation was observed to occur for belt-polished $15 \times 15$ Zry- 4 after $5000 \mathrm{~s}$ at $985^{\circ} \mathrm{C}$ in the standard 686-mm-long quartz-tube test chamber used to test all cladding alloys in this program. However, when the same material was retested under these conditions in a shorter (610-mm-long) test chamber, no breakaway was observed at test times as high as $5400 \mathrm{~s}$. This result could mean that repeated tests (minimum of 5) may be needed and/or subtle differences in test conditions affect the results. Similar results were obtained with ZIRLO test samples, which exhibited breakaway oxidation after $3000 \mathrm{~s}$ at $970^{\circ} \mathrm{C}$ in the longer test train but exhibited no breakaway after $4000 \mathrm{~s}$ at $970^{\circ} \mathrm{C}$ in the shorter test train.

In addition, Westinghouse has an independent data set indicating that the ZIRLO breakaway oxidation time for $950-1000^{\circ} \mathrm{C}$ oxidation is $>4400 \mathrm{~s}$. Westinghouse and Argonne used different sample cleaning methods, different furnaces (resistance-heating vs. radiant-heating), and different temperature control and monitoring. It is recommended that these differences be evaluated before breakaway oxidation tests are standardized.

\subsubsection{Performance-based tests for new cladding alloys}

The tests performed in this research program for as-fabricated and prehydrided cladding alloys are recommended for evaluating the performance of new cladding alloys and the effects of manufacturing changes on LOCA embrittlement limits. The procedure for conducting high-temperature embrittlement tests and evaluating ductility by means of ring compression tests is straightforward. After standardization of the procedure for conducting breakaway oxidation tests, these would be very useful tests to evaluate the effects on LOCA embrittlement thresholds of alloy or manufacturing changes. Tests with prehydrided cladding are also recommended in relevant range of oxidation temperatures and hydrogen content. Heating rates, cooling rates, and wetting temperatures calculated for small-to-large break LOCAs could be used to determine relevant and reasonably bounding test conditions. 


\section{References}

1. G. Hache and H. M. Chung, "The History of LOCA Embrittlement Criteria," NUREG/CP-0172, May 2001, pp. 205-237.

2. L. Yegorova, K. Lioutov, N. Jouravkova, A. Konobeev, V. Smirnov, V. Chesanov, and A. Goryachev, "Experimental Study of Embrittlement of Zr-1\%Nb VVER Cladding under LOCARelevant Conditions," NUREG/IA-0211, Mar. 2005.

3. Annual Book of ASTM Standards, "Standard Specification for Wrought Zirconium Alloy Seamless Tubes for Nuclear Reactor Fuel Cladding," Vol. 02.04 (1997).

4. R. J. Comstock, G. Schoenberger, and G. P. Sabol, "Influence of Processing Variables and Alloy Chemistry on the Corrosion Behavior of ZIRLO Nuclear Fuel Cladding," Zirconium in the Nuclear Industry: Eleventh International Symposium, ASTM STP 1295, E. R. Bradley and G. P. Sabol, Eds., American Society for Testing and Materials, 1996, pp. 710-725.

5. W. J. Leech, "Ductility Testing of Zircaloy-4 and ZIRLO" Cladding after High Temperature Oxidation in Steam," NEA/CSNI/R(2001)18, Dec. 2001, pp. 135-143.

6. J.-P. Mardon, D. Charquet, and J. Senevat, "Influence of Composition and Fabrication Process on Out-of-Pile and In-Pile Properties of M5 Alloy," Zirconium in the Nuclear Industry: Twelfth International Symposium, ASTM STP 1354, G. P. Sabol and G. D. Moan, Eds., American Society for Testing and Materials, West Conshohocken, PA, 2000, pp. 505-524.

7. P. V. Shebaldov, M. M. Peregud, A. V. Nikulina, Y. K. Bibilashvilli, A. F. Lositski, N. V. Kuz'menko, V. I. Belov, and A. E. Novoselov, "E1110 Alloy Cladding Tube Properties and Their Interrelation with Alloy Structure-Phase Condition and Impurity Content," Zirconium in the Nuclear Industry: Twelfth International Symposium, ASTM STP 1354, G. P. Sabol and G. D. Moan, Eds., American Society for Testing and Materials, West Conshohocken, PA, 2000, pp. 545559.

8. O. Kubaschewski, Metallurgical Thermochemistry, Pergamon Press, Oxford, 1967.

9. James P. Coughlin, "Contributions to the Data on Theoretical Metallurgy," XII, Heats and Free Energies of Formation of Inorganic Oxides, U.S. Government Printing Office, 1954.

10. G. M. O'Donnell, H. H. Scott, and R. O. Meyer, "A New Comparative Analysis of LWR Fuel Designs," NUREG-1754, Nov. 2001.

11. L. Yegorova, K. Lioutov, N. Jouravkova, O. Nechaeva, A. Salatov, V. Smirnov, A. Goryachev, V. Ustinenko, and I. Smirnov, "Experimental Study of Narrow Pulse Effects on the Behavior of High Burnup Fuel Rods with Zr-1\%Nb Cladding and $\mathrm{UO}_{2}$ Fuel (VVER type) under ReactivityInitiated Accident Conditions: Program Approach and Analysis of Results," NUREG/IA-0213, Vol. 1, May 2006.

12. L. Baker and L. C. Just, "Studies of Metal-Water Reactions at High Temperatures; III. Experimental and Theoretical Studies of the Zirconium-Water Reaction," ANL-6548, May 1962. 
13. J. V. Cathcart, R. E. Pawel, R. A. McKee, R. E. Druscel, G. J. Yurek, J. J. Cambell, and S. H. Jury, "Zirconium Metal-Water Oxidation Kinetics IV. Reaction Rate Studies," ORNL/NUREG-17, Aug. 1977.

14. P. Hofmann and C. Politis, "Chemical Interaction Between Uranium Oxide and Zircaloy-4 in the Temperature Range Between 900 and $1500^{\circ} \mathrm{C}$," Zirconium in the Nuclear Industry (Fourth Conference), ASTM STP 681, American Society for Testing and Materials, West Conshohocken, PA, 1979, pp. 537-560.

15. Y. Yan, R. V. Strain, T. S. Bray, and M. C. Billone, "High Temperature Oxidation of Irradiated Limerick BWR Cladding,” NUREG/CP-0176, May 2002, pp. 353-372.

16. D. O. Hobson, "Ductile-Brittle Behavior of Zircaloy Fuel Cladding," Proc. ANS Topical Meeting on Water Reactor Safety, Salt Lake City, Mar. 26, 1973, pp. 274-288.

17. D. O. Hobson and P. L. Rittenhouse, "Embrittlement of Zircaloy-Clad Fuel Rods by Steam during LOCA Transients," ORNL-4758, Jan. 1972.

18. H. M. Chung and T. F. Kassner, "Pseudobinary Zircaloy-Oxygen Phase Diagram," J. Nucl. Matls. 84 (1979) 327-339.

19. S. Leistikow and G. Schanz, "The Oxidation Behavior of Zircaloy-4 in Steam between 600 and $1600^{\circ} \mathrm{C}$," Werkstoffe und Korrosion 36 (1985) 105-116.

20. S. Leistikow and G. Schanz, "Oxidation Kinetics and Related Phenomena of Zircaloy-4 Fuel Cladding Exposed to High Temperature Steam and Hydrogen-Steam Mixtures under PWR Accident Conditions," Nucl. Eng. and Des. 103 (1987) 65-84.

21. J. P. Mardon, J. C. Brachet, L. Portier, V. Maillot, T. Forgeron, A. Lesbros, and N. Waeckel, "Influence of Hydrogen Simulating Burn-Up Effects on the Metallurgical and Thermal-Mechanical Behavior of M5TM and Zircaloy-4 Alloys under LOCA Conditions," ICONE13-50457, $13^{\text {th }}$ Intl. Conf. on Nucl. Eng., Beijing, China, May 16-20, 2005, pp. 1-9.

22. Y. Yan, R. V. Strain, and M. C. Billone, "LOCA Research Results for High-Burnup BWR Fuel," NUREG/CP-0180, Mar. 2003, pp. 127-155.

23. B. Cheng and R. B. Adamson, "Mechanistic Studies of Zircaloy Nodular Corrosion," Zirconium in the Nuclear Industry: Seventh International Symposium, ASTM STP 939, R. B. Adamson and L. F. P. Van Swam, Eds., American Society for Testing and Materials, Philadelphia, 1987, pp. 387-416.

24. B. Cheng, H. A. Levin, R. B. Adamson, M. O. Marlowe, and V. L. Monroe, "Development of a Sensitive and Reproducible Steam Test for Zircaloy Nodular Corrosion," Zirconium in the Nuclear Industry: Seventh International Symposium, ASTM STP 939, R. B. Adamson and L. F. P. Van Swam, Eds., American Society for Testing and Materials, Philadelphia, 1987, pp. 257-283. 
25. J. A. Gresham, "Updated Westinghouse Breakaway Oxidation/Testing Behavior," letter report from Westinghouse to NRC, LTR-NRC-08-29, ADAMS ML081700587, June 12, 2008.

26. A. V. Nikulina, L. N. Andreeva-Andrievskaya, V. N. Shishov, and Yu. V. Pimenov, "Influence of Chemical Composition of $\mathrm{Nb}$ Containing Zr Alloy Cladding Tubes on Embrittlement under Conditions Simulating Design Basis LOCA," presentation at the $14^{\text {th }}$ Intl. Symp. on Zirconium in the Nuclear Industry, Stockholm, Sweden, June 13-17, 2004.

27. R. E. Pawel, R. A. Perkins, R. A. McKee, J. V. Cathcart, G. J. Yurek, and R. E. Druschel, "Diffusion of Oxygen in Beta-Zircaloy and the High Temperature Zircaloy-Steam Reaction," Zirconium in the Nuclear Industry, ASTM STP 633, A. L. Lowe, Jr. and G. W. Parry, Eds., American Society for Testing and Materials, 1977, pp. 119-133.

28. J. P. Mardon, "Impact of the LOCA Cooling Rates and Pre-corrosion Layer on the Cladding Residual Ductility: Main Learnings from the Recent CEA Experiments," presented at ACRS Reactor Fuels Subcommittee Meeting, Rockville, MD, July 27, 2005, ADAMS ML052230093.

29. J.-C. Brachet, V. Vandenberghe-Maillot, L. Portier, D. Gilbon, A. Lesbros, N. Waeckel, and J.-P. Mardon, "Hydrogen Content, Preoxidation, and Cooling Scenario Effects on Post-Quench Microstructure and Mechanical Properties of Zircaloy-4 and M5 ${ }^{\circledR}$ Alloys in LOCA Conditions," J. ASTM Intl., Vol. 5, No. 5 (2008). Available online as JAI101116 at www.astm.org.

30. J. C. Brachet, L. Portier, J. Hivroz, D. Hamon, T. Guilbert, T. Bredel, P. Yvon, J. P. Mardon, and P. Jacques, "Influence of Hydrogen Content on the $\alpha / \beta$ Phase Transformation Temperature and on the Thermal-Mechanical Behavior of $\mathrm{Zy}-4, \mathrm{M} 4(\mathrm{ZrSnFeV})$, and $\mathrm{M} 5^{\mathrm{TM}}$ (ZrNbO) Alloys During the First Phase of LOCA Transient," Zirconium in the Nuclear Industry, ASTM STP 1423, G. D. Moan and P. Rudling, Eds., American Society for Testing and Materials, 2002, pp. 673-701.

31. E. J. Ruzauskas and K. N. Fardell, "Design, Operation, and Performance Data for High Burnup PWR Fuel from the H. B. Robinson Plant for Use in the NRC Experimental Program at Argonne National Laboratory," 1001558, Electric Power Research Institute, Palo Alto, CA (2001).

32. L. F. Van Swam, G. M. Bain, W. C. Dey, D. D. Davis, and H. Heckermann, "BWR and PWR Fuel Performance at High Burnup," Proceedings of the 1997 Intl. Topical Meeting on LWR Fuel Performance, Portland, Oregon, March 2-6, 1997, pp. 455-462.

33. H. Tsai and M. C. Billone, "Characterization of High-Burnup PWR and BWR Rods, and PWR Rods after Extended Dry-Cask Storage,” NUREG/CP-0180, Mar. 2003, pp. 157-168.

34. L. F. Van Swam, A. A. Strasser, J. D. Cook, and J. M. Burger, "Behavior of Zircaloy-4 and Zirconium Liner Zircaloy-4 Cladding at High Burnup," Proceedings of the 1997 Intl. Topical Meeting on LWR Fuel Performance, Portland, OR, March 2-6, 1997, pp. 421-431.

35. K. Une, K. Nogita, S. Kashibe, T. Toyonaga, and M. Amaya, "Effect of Irradiation-Induced Microstructural Evolution on High Burnup Fuel Behavior," Proceedings of the 1997 International Topical Meeting on LWR Fuel Performance, Portland, OR, March 2-6, 1997, pp. 478-489.

36. Y. Yan, T. Burtseva, and M. C. Billone, "LOCA Results for Advanced-Alloy and High-Burnup Zircaloy Cladding," NUREG/CP-0185, June 2004, pp. 97-121. 
37. Yong Yan, Michael C. Billone, Tatiana A. Burtseva, and Hee M. Chung, "LOCA Integral Test Results for High-Burnup BWR Fuel,” NUREG/CP-0192, Oct. 2005, pp. 138-158.

38. R. R. Hobbins, G. R. Smolik, and G. W. Gibson, "Zircaloy Cladding Behavior during Irradiation Tests under Power-Cooling-Mismatch Conditions," Zirconium in the Nuclear Industry, ASTM STP 633, A. L. Lowe and G. W. Parry, Eds., American Society for Testing and Materials, 1977, pp. 182-208.

39. B. C. Oberlander, M. Espeland, and H. K. Jenssen, "LOCA testing of high burnup PWR fuel in the HBWR. Additional PIE on the cladding of the segment 650-5," IFE/KR/E-2008/004, ADAMS ML081750715, April 2008.

40. Fumihisa Nagase and Toyoshi Fuketa, "Results from Studies on High Burn-up Fuel Behavior under LOCA Conditions," NUREG/CP-0192, Oct. 2005, pp. 197-230.

41. F. Nagase and H. Uetsuka, "Hydride Morphology and Hydrogen Embrittlement of Zircaloy Fuel Cladding used in NSRR/HBO Experiment," Proc. 1997 International Topical Meeting on LWR Fuel Performance, Portland, OR, March 2-6, 1997, American Nuclear Society, pp. 677-684. 